\title{
Proceedings of the 2020 Society of Wood Science and Technology International Convention
}

\author{
"Renewable Resources for a Sustainable \\ and Healthy Future"
}

Edited by Susan LeVan-Green

https: //doi.org/10.22382/proc-2020-02

Overall General Chair: Andreja Kutnar,

InnoRenew COE and University of Primorska, Slovenia

2020 INTERNATIONAL CONVENTION, VIRTUAL CONFERENCE - (FORMERLY HOTEL

BERNARDIN), PORTOROŽ, SLOVENIA

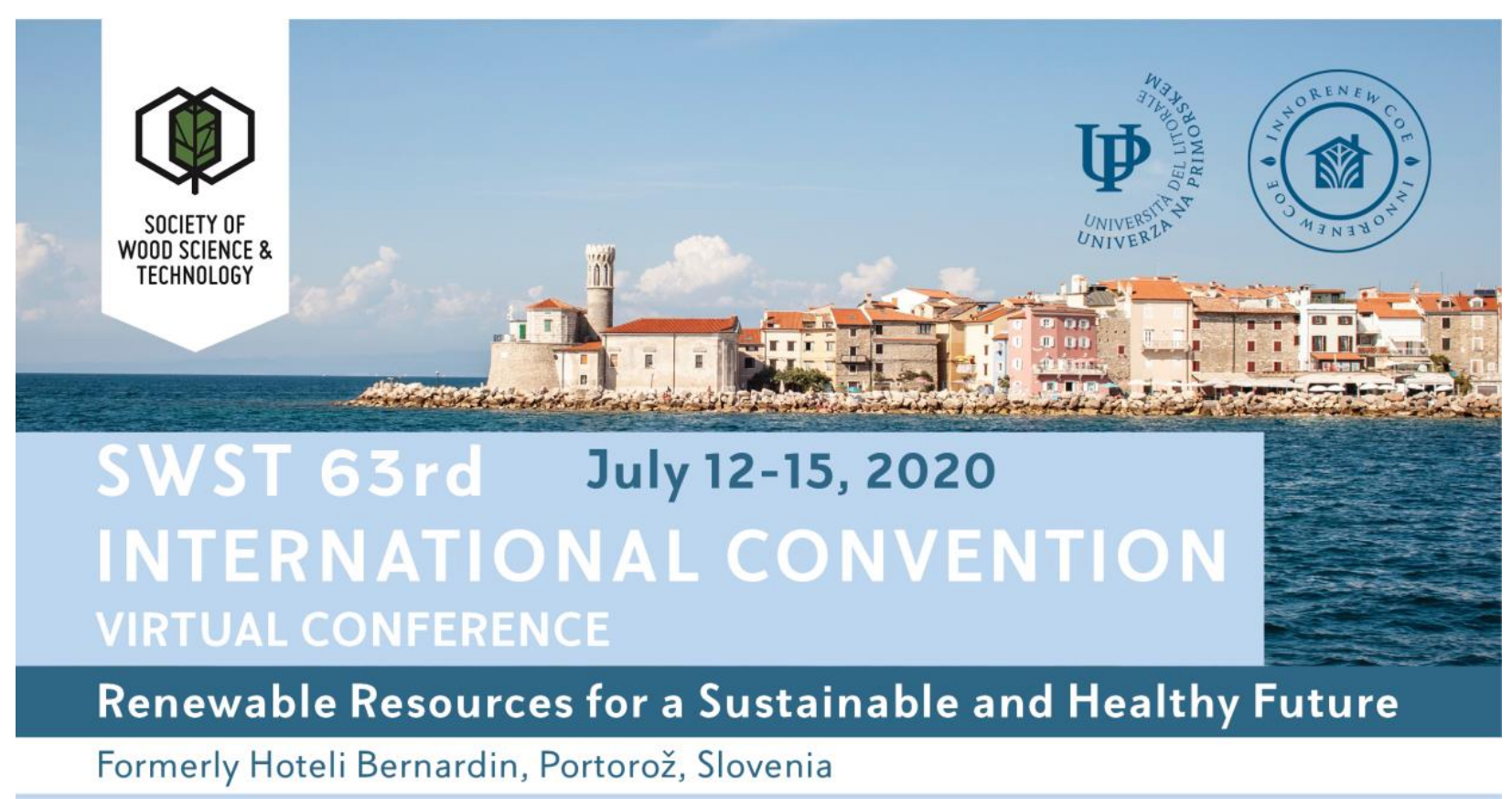




\section{TABLE OF CONTENT}

\section{MONDAY, JULY 13TH}

\section{Keynote:}

Wood Aging by Bohumil Kasal.

Early Stage Researchers: Chairs Benedikt Neyses, Luleå University of Sweden;

Martin Nopens, Universität Hamburg, Germany

Slovenian wood-based bioeconomy: present state and future perspectives

by Domen Arnič

Distributed Ledger Technology for Data Privacy and Traceability in Wood Supply Chain Environments by Sidra Aslam

Spatial Augmented Reality to Improve Manufacturing of Timber Frame Prefabricated Wall Elements by Birger Bartuska

Can Woody Biomass from Orchards Still Be Considered a Waste Material? By Maria Roberta Bruno

The differentiating Anatomical Features of Five Tree Species From East Seram, Indonesia by Tekat Dwi Cahyono

Evaluation Of The Seismic Behavior Of Hybrid Walls With Cross Laminated Timber For Building In Chile by Tulio Carrero

Water resistance of wood adhesives derived from cottonseed meal with all components utilization by Nairong Chen

Comparison of Devices for Acoustic Tomography of Tree and Material Properties of Degraded Wood by Valentino Cristini

Cascading Potential for Recovered Wood from Heavy Timber Frame Typology in Pre-Modern Dwelling Buildings in Madrid by Marina de Arana-Fernández

The Economic Balance of Obtaining the Raw Material for Briquettes and Pellets from Forest Sanitation by Molnar Gabor.

Determining the Aerodynamic Diameter of Various Wood Dust Types, to Better Assess Possible Health Risks by Maria Georgiades

Rapid determination of the quality of Spanish coniferous wood by models based on IR spectroscopy by René Herrera Díaz

Different types of coatings used for wooden shingles exposed to natural and artificial aging by Dominik Hess

Sustainable development - international framework - overview and analysis in the context of forests and forest products with competitiveness and new opportunities by Annika Hyytiä

Predictive Modeling and Optimisation of Alkaline Sulphite and Sodium Hydroxide Pretreatment of Maize (Zea mays) stalk fractions in the Production of Bioethanol by Tolulope Kolajo 
The effect of growing conditions on wood density by Luka Srajnc

Differences between hygroscopicity limit and cell wall saturation investigated by LF-NMR on thermally-modified and lignin-removed Southern pine (Pinus spp.) by Jingyu Li

Some mechanical properties of particleboards produced from four agro-forest residues using cassava starch and urea formaldehyde as adhesives by Prosper Mensah Spectroscopic characterisation of wood treated by different coatings after . weathering in subarctic conditions by Olena Myronycheva

Identification of wood vibro-acoustic parameters for musical instruments by Patrik Nop 72

Triboelectric activation of sawdust during cutting and sanding processes, a new approach to lower wood fine-dust contamination by Luca Nüssel....................... 73

ABES and DMA cure monitoring of tannin adhesive by Jaša Saražin

Characterization of raw materials and physical properties of particle board made from Douglas-fir bark by Mathias Schuh

Pulp and Paper Making Potential of Elephant and Thatching Grasses Growing in Zambia by Kennedy Sichamba 77

Numerical Study of Sorption Behavior of Piano Soundboard by Pavlina Suchomelova ... 83

Papermaking fines a potential wood-component for new materials outside the paper industry? by Armin Winter

Effect of lacquer decoration on VOCs and odor release from P.neurantha (Hemsl.) Gamble by Bin Zeng

Numerical Analysis of Tree Dynamic Response by Barbora Vojáčková

Assessment of European beech timber based on non-destructive measurement by Jan Zlámal

Timber Engineering: Chairs: Bohumil Kasal, Fraunhofer Institute for Wood Research, Germany; Mariapaola Riggio, Oregon State University, USA

Analysis of Half-Lap Joint of Full-Scale Unprotected CLT Floors and Walls During ASTM E119 Fire Tests by Seung Hyun Hong

Deconstructable Timber-concrete Composite connectors by Mohammad Derikvand .... 105

CLT panels from below-grade yellow-poplar sorted by non-destructive proof loading by Rafael Azambuja

Development of a Simplified Method for Prediction of Acoustic Behaviour of CLT with Facing Layers by Franz Dolezal

A Knowledge Management System to Support the US Cross Laminated Timber Industry by Omar Espinoza

Recovered Wood as Raw Material for Structural Timber Products. Characteristics, Situation and Study Cases: Ireland and Spain by Daniel Llana

Connection Ductility Demand for Different Ductility Levels in Capacity Design of Multi-Storey CLT Buildings by Igor Gavric 
Environmental Impacts and Carbon Offset of Mass Timber construction -

A Comparative Life Cycle Assessment Study by Marilia Hellmeister .

VoC-emission optimized Cross Laminated Timber by Marko Kovacevic

What is the best timber for construction? Available forest resources, mechanical efficiency, carbon storage by Jean-Michel Leban

Comparative assessment of energy efficiency and environmental impact between bamboo and polyvinyl chloride-based packing in cooling towers by Xinxin Ma

Monitoring Mass Timber Buildings: A Case Study of the InnoRenew CoE Building by Eva Prelovšek Niemelä

The case for mass timber tall buildings using a net zero carbon framework by Azzeddine Oudjehane

Regenerative wooden buildings in Europe: comparing Spain to other countries by Alberto Quintana Gallardo

ClickDesign project approach to model aesthetic performance of buildings by Jakub Sandak

Parameters to Minimize the Environmental Footprint of Wood and Engineered Wood Products by Erwin M. Schau

TallWood Design Institute: Latest Resilient Design and Seismic Engineering Research by Evan Schmidt

Are wood and sustainability-related terms emphasized more nowadays than 20 years ago? Corpora-based study in Czech and Slovenian languages by Vaclav Sebera

Options for climate change performance indicators for cross-laminated timber by Lars G.F. Tellnes

Business, Marketing, Digitalisation, and Regulations: Chairs Eric Hansen, Oregon State University, USA; Rob Kozak, University of British Columbia, Canada

Contribution and potential of the wood industry and its products to the circular economy: Case examples from the US and Central-Southeast Europe by Andreja Pirc Barcic..

Digitalization Rate of SMEs Involved in the Wood Fibres Value Chains in the Alpine Region by Tina Beranič

A Circular Economy for Wood under the European Green Deal by Michael Burnard ...... 180

Raising the bar: Women administrator leaders in top world forestry universities by Pipiet Larasatie

The Oil Palm Trunk: Opportunities and Challenges for the Malaysian Timber-Based Industries by Yueh Feng Loh

Moving past the traditional structure of academic publishing - re-aligning incentives with the goals of science by Benedikt Neyes

The Wood Science and Technology Program at West Virginia University: A Case Study by Gloria Oporto

Material Choice: A new frontier in corporate sustainability by Rajat Panwar 
Barriers and Drivers of thermally-modified wood: Perceptions of Architects in the US by Henry Quesada

Wood Waste, Source of Sustainable Livelihood for Women Group by Haruna Seidu ...

\section{TUESDAY JULY 14TH}

Composites and Adhesives: Chairs: David DeVallance, InnoRenew CoE \& University of Primorska, Slovenia; Douglas Gardner, University of Maine, USA

Learning about and from the functionality of primers in glulam bonding by Thomas Böger

Porous structures produced from different bark particles by mechanical foaming by Maria Busquets Ferrer

Influence of Atmospheric Air Plasma Pre-Treatment of Veneers on the Mechanical Properties and Stability of Beech Plywood by Sebastian Dahle

The Compatibility between Components of Wood-Plastic Composites using Chemical Force Microscopy by Bernard Effah

Innovative High-Feed Rate Additive Manufacturing Using Sustainable Nano- MicroCellulose-Reinforced Thermoplastic Composites by Doug Gardner

Green enzyme-based processes for value-added applications of lignin by Georg Guebitz 202

New Bio-Based Sandwich Panel with High Impact-Resistance, following Cradle-toCradle Design by Raphaela Hellmayr

Systematic evaluation of wheat flour, wheat starch and wheat protein in urea and phenol formaldehyde resins by Elfriede Hogger

Influences of various infill patterns on specific mechanical properties of 3D printed wood/Polylactic Acid (PLA) composites which were processed using Fused Deposition Modeling (FDM) by Stefan Kain

4D X-Ray CT Studies on Wood-based Panels at UGCT-Woodlab by Pierre Kibleur

Edge Banding Performance Analysis of Wood Based Material In The Furniture Industry by Kucuk Huseyin Koc

Highly efficient, stable, and recyclable hydrogen manganese oxide/cellulose film for the extraction of lithium from seawater by Daxin Liang

Agrocomposites for the reinforcement of concrete within light weight structures by Laetitia Marrot

Laboratory testing on the face bond durability of cross-laminated hardwoods by Munkaila Musah

Characterization of recycled wood plastic composites with added torrefied wood by Jaka Gašper Pečnik

Study on One-Shot Process for Wood-based Composites by Vicky Reichel 
Effect of Scavenger and Microwave Heating on Formaldehyde Emission from Particleboard by Anil Kumar Sethy

Biobased porous structures based on cellulosic materials by Axel Solt-Rindler

Wood species dependent performance of pMDI adhesion by Pia Solt

Highly Anisotropic Wood-Based Composite with Layered Structure for Thermal and Electrical Conduction by Hao Sun

Low Temperature Adhesive Bonding for Structural Wood Materials by Anita Tran ....

Development of a Concept for Electrically Conductive Furniture Panels by Christof Tschannen

Bonding Strength of Benuang and Duabanga Glulam Using Their Bark as Filler for Phenol Formaldehyde Resin by Imam Wahyudi

Preparation of Cellulose Acetate-Polyacrylonitrile Composite Nanofibers by Multi-fluid Mixing Electrospinning Method: Morphology, Wettability, and Mechanical Properties by Dong Wang

Characteristic properties of 3D-printed wood/Polylactic acid composites with different extrusion temperatures using fused deposition modeling by Chin-Hao Yeh ...

Wood-Metal Bonding Strength Improved Via Atmospheric Plasma Pre-Treatment by Jure Žigon

Wood Chemistry \& Cell Biology: Chair: Gloria Oporto, West Virginia University, USA

Simultaneous Chemical and Topographical Mapping of Wood Ultrastructures by Chemical Force Microscopy by Claudia Gusenbauer

Comparison of wood volumes and quality produced both by forestry and agroforest systems: the case of walnut (Juglans $\mathrm{x}$ Regia $\mathrm{x}$ Nigra by Lucie Heim

In situ synthesis of mesoporous carbon-encapsulated Iron nanoparticles derived from rattan for efficient adsorption by Lili Shang .....

The Visualization of Microstructure of Bamboo Nodes by High-resolution X-ray Microtomography (Micro-CT) by Shumin Yang

A direct bioautography as a screening-method for bioactive wood extracts against basidiomycetes, Regina Wanschura

\section{WEDNESDAY, JULY $15^{\text {TH }}$}

Wood in Health \& Wellbeing: Chairs: Mike Burnard, InnoRenew CoE \& University of Primorska, Slovenia; Eva Haviarova, Purdue University, USA

Building Wooden Hives for the Wellbeing of Honeybees, by Anna Dupleix

Human physiological responses during tactile and visual contact with densified and laminated wood by Dean Lipovac

Preparation of Kenaf based nanobiocomposite as sustainable adsorbent for the removal of organic and inorganic and pathogenic contaminants by Sujata Mandal 
Wood as a Building Material Affects the Indoor Environment Quality (IEQ) and Well-being of Occupants by Riina Muilu-Mäkelä

Demonstration of REED- Restorative Environmental and Ergonomic Design principles on InnoRenew CoE building architecture by Aarne Niemelä

Biodeterioration \& the Impact of Forest Disturbances: Chairs: Yusuf Sudo Hadi, Bogor Agricultural University (IPB), Indonesia; Francesco Negro, DISAFA, University of Torino, Italy

Population distribution and structure of Afzelia species in Southwestern Nigeria by Adejoke Akinyele

Termite Resistance of Stem and Branch Wood of Two Tropical Hardwood Species in Ghana by Kwaku Antwi

Accelerated Biodegradation of Kenaf Fiber/Soy Protein Composites Using Pectinase under Soil Burial Condition by Yu Fu

Impact of forest disturbances on wood quality: a review by Francesco Negro

Wood Modification \& Preservation: Chairs: Anna Sandak, InnoRenew CoE \& University of Primorska, Slovenia; Dick Sandberg, Luleå University of Technology, Sweden

Investigation on Thermo-Hydro Mechanical Treatments effects to densify Tasmanian planted and native timber species by Michelle Balasso

Prospects for powder coatings by Olha Baranova

Characterization of Spruce Log Soaking Water and their Antifungal and Wood Preserving Properties by Aitor Barbero-López

Integrated Flattening and Thermo-Hydro-Mechanical Modification of Bamboo Split by Changhua Fang

Manufacturing and Optimization of a Cellulose-Based "Green" High-Performance Materia by Matthias Jakob

Parameter Study on a Wood Impregnation Process by Mariana Frias

Inspired by nature: a novel impregnation process for wood preservation by Shujun Li ..

Microbial Dyeing - Infection Behavior and Influence of Lasiodiplodia theobromae in Poplar Veneer by Yuansong Liu

Effect of Moisture Content and Preservatives on Discoloration of Oil Palm Lumber by Prosper Mensah

Characterization of some properties of fast-growing Masson pine wood subjected to two-step freeze silicon oil treatment by Chukwuemeka Onyinyechi

An ionic-liquid based fire retardant for wood-based panels by Jussi Ruponen

Bioinspiration as a source for alternative wood modification, protection and functionalization by Anna Sandak

Hardness Determination in Surface-densified Wood: The Influence of the Hardness Test Method and the Density Profile by Alexander Scharf 
Coupling THM treatments with phenol-based resin for reduced set-recovery by Matthew Schwarzkopf

Wood Physics and Mechanics: Chairs: Ales Straze, University of Ljubljana, Slovenia; Mike Wolcott, Washington State University, USA

$\mathbf{X}$-ray computed tomography studies of moisture-content distribution in spruce boards exposed to liquid water by José Couceiro

Understanding the Energy Dissipation Process on Hardwoods and its Dependence on the Anatomical Structures by Júlio Amando de Barros

What Do We Know on Rosewoods Properties? A Wood Mechanics Update on the Endangered Pantropical Genus Dalbergia by Iris Brémaud

Hardwood cutting forces at different speeds up to $80 \mathrm{~m} / \mathrm{s}$ for an evaluated real chip thickness by Ondrej Dvoracek

Advanced X-ray CT Scanning: a Versatile Research Tool for Analyzing Cores of Living Trees by Tom De Mil

A sawmill simulation study of the volume yield changes when sawing with thinner kerfs by Magnus Fredriksson

Mechanical Properties versus Structure of Oil Palm Wood (Elaeis guineensis JACQ.) by Katja Fruehwald-Koenig

Color Change and Physical-Mechanical Properties of Four Furfurylated Fast-Growing Tropical Wood Species by Yusuf Sudo Hadi

Auto-ignition characteristics of wood by Christian Hansmann

Mechanical behavior of a painted wooden panel from the heritage subject to hygrothermal variations: role of the reinforcement by Delphine Jullien

Dynamic compensation of load cell response for cutting force measurements in wood machining by Daniel Lechowicz

Assessment of Energy-Saving by Using a Membrane-Based Thermal Energy Recovery System to Improve the Energy Efficiency of Kiln Drying Processes by Ling Li

The Steady-State Diffusion of Moisture in Southern Pine Lumber Guizhou Wang

Review of Physical and Structural Properties of Oak Wood from Historical Constructions by Alex Straze

Bark and wood as raw materials for high performance insulations, by Oliver Vay 


\section{POSTERS SESSION}

\section{STUDENT POSTERS:}

Understanding the Thermodiffusion Properties of Ionic Liquids in a Cellulosic Medium by Júlio Amando De Barros.

Intra-Tree and Inter-Tree Variations in the Wood of Breadfruit (Artocarpus altilis, Parkinson Ex. F.A Zorn) Fosberg by Olusola Samuel Areo

Investigation on Thermo-Hydro Mechanical Treatments Effects to Densify Tasmanian Planted and Native Timber Species by Michelle Balasso

Characterization of Spruce Log Soaking Water and their Antifungal and Wood Preserving Properties by Aitor Bargero-López

Porous structures produced from different bark particles by mechanical foaming by Maria Busquests Ferrer

Hardwood cutting forces at different speeds up to $80 \mathrm{~m} / \mathrm{s}$ for an evaluated real chip Thickness by Ondrej Dvoracek

Simultaneous Chemical and Topographical Mapping of Wood Ultrastructures by Chemical Force Microscopy by Claudia Gusenbauer

The importance of cold tack of urea formaldehyde in plywood production by Elfriede Hogger

Sustainable development - international framework - overview and analysis in the context of forests and forest products with competitiveness and new opportunities by Annika Hyytiä

Triboelectric Activation of Wood Surfaces by Mechanical Friction by Lena Maria Leiter

Structural, chemical, and multi-scale mechanical characterization of waste windmill palm fiber (trachycarpus fortunei) by Jing Li

Differences between hygroscopicity limit and cell wall saturation investigated by LF-NMR on thermally-modified and lignin-removed Southern pine (Pinus spp.) by Jingyu Li

Preparation of Kenaf based nanobiocomposite as sustainable adsorbent for the removal of organic and inorganic and pathogenic contaminants by Sujata Mandal.......

Bioinspired wood protection - evaluation of wood treated with biofinish by Faksawat Poohphajai ....

An ionic-liquid based fire retardant for wood-based panels by Jussi Ruponen

ABES and DMA Cure Monitoring of Tannin Adhesive by Jaša Saražin

Highly Anisotropic Wood-Based Composite with Layered Structure for Thermal and Electrical Conduction by Hao Sun ....

Low Temperature Adhesive Bonding for Structural Wood Materials by Anita Tran .......

The Vibrational Properties of Catalpa Ovata Wood for the Back Plate of the Guqin by Yi-Hsuan Tsai

Effects of Wood Decay on the Deformation Mechanism and Shear Performance of Screwed and Nailed Joints by Rintato Ueda 
Adding Value to Timber Components through Consideration of Demolition and Disassembly by St. John Walsh

Preparation of Cellulose Acetate-Polyacrylonitrile Composite Nanofibers by Multifluid Mixing Electrospinning Method: Morphology, Wettability, and Mechanical Properties by Dong Wang

Analysis of VOCs and odor-active compounds from veneered particleboard coated with water-based lacquer by Qifan Wang

Effect of lacquer decoration on VOCs and odor release from P.neurantha (Hemsl.) Gamble by Bin Zeng

\section{REGULAR POSTERS:}

Properties of Particleboard Made from Recycled Polystyrene and Cocos nucifera Stem Particles by Babatunde Ajayi

Heterospecific tree density and environmental factors affect Afzelia africana Sm. population structure in the Pendjari Biosphere Reserve, West Africa: Implications for Management and Restoration by Atanasso Akpovi Justin

Enhancing the fire resistance of cement-bonded particleboard made of Scots pine and Poplar by Tibor L. Alpár

Promotion of Eucalyptus Hybrid Species as Utility Poles for Electricity Transmission: The Mechanical Strength Properties of Eucalyptus urograndis Grown in Ghana by Emmanuel Appiah-Kubi

Increasing Cold Tack of pMDI resin with Partial Soy Flour Substitution by Osei Asafu-Adjaye

Adhesive Bonding of Planed and Sawn Jointed Sugar Maple Lumber: Bending Strength of Glued Joints by Mohammadali Azadfar

The Influence of Oil Uptake on Moisture Excluding Efficiency in Thermally Treated Wood by Jan Baar

Non-linear Material Model of Mechanical Behaviour of Oak Wood Exposed to Different Relative Humidity Conditions by Martin Brabec

Building Your Social Media Presence by Candra Burns

Development of technology for one-sided surface carbonization of wood by Petr Cermak

Surface free energy of ten tropical woods species and their acrylic and alkyd varnishes wettability by Wayan Darmawan

Bond Strength of Wood Adhesives: The Sensitivity of Standard Test Methods to Imperfections by Mohammad Derikvand

Bagasse xylan nanocomposite films with high transparency, barrier properties and enhanced mechanical strength characteristics by Seyedrahman Djafaripetroudy

Experimental analysis of mass loss kinetics during heat treatment of wood by Jakub Dömény 
Smart Thumper ${ }^{\mathrm{TM}}$, a Non Destructive Lumber Evaluation Phone Application by Frederico José Nistal França.....

Building a portable offline bark identification system through training:

A MobileNet-V2 by Knowledge Distilling and Network Pruning by Rado Gazo

Assessing success of sustainability curriculum development efforts: evidence from a US higher education institution by Rado Gazo

Circular Economy Principles for Furniture Industry by Eva Haviarova

Natural insulating material in the form of burning by Michaela Horváthová

Low temperature potassium hydroxide pulping of straw by Md Sarwar Jahan

535

Objective and Subjective Detection of Wood Defects by Branimir Jambreković

536

Dynamic Properties of Traditional Timber Building by Gi Young Jeong

Cellulose Nanofiber Effect on Bonding Strength of PUR and PVAc Glued Wood Joint in Shear Loading by Gourav Kamboj

Digital Solutions in Architecture and Timber Construction by Manja Kitek Kuzman .......

Investigations of the Strength and Resistance of Glued Pine Wood from Tuchola

Region by Tomasz Krystofiak

540

Variations of earlywood vessel diameter of Quercus petraea Liebl according to tree size and altitude by Jean-Michel Leban

Comparative study on moso bamboo shear strength in four test methods by Huanrong Liu

Development of Palm Oil-based Resins for Natural Fiber Composites by Wendi Liu ......

Anatomical features and growth ring width correlation of Catalpa bungei by Yamei Liu

Structural Reliability Analysis of Cross Laminated Timber Plates submitted to Bending

Test by Nilson Mascia

Physical Properties of Particleboard Produced from Residues of Musa paradisiaca pseudostem, Theobroma cacao and Ceiba pentandra by Prosper Mensah

Characterization of Particleboard Produced from Residues of Musa Paradisiaca Pseudostem, Theobroma Cacao Pod, Theobroma Cacao Stem and Ceiba Pentandra by Stephen Mitchual

Global CLT industry in 2020: Growth beyond the Alpine Region by Lech Muszynski

How Megaplatypus mutatus behaves inside a trunk? Studying its galleries via Computerized Axial Tomography and Digital Images Processing by Esteban Ceriani Nakamurakare

Introducing the SWST Wood Technology Student Chapter at DISAFA, University of Torino, Italy by Francesco Negro

Investigation of the damping behaviour of beech material by Gábor Németh

Measuring the heat of interaction between lignocellulosic materials and water by Martin Nopens

Combined FTIR spectroscopy and rheology for investigating the influence of different wood extracts on adhesive curing by Merve Özparpucu 
An anionic polyelectrolyte hybrid for wood-polyethylene composites with high strength and fire safety via self-assembly by Mingzhu Pan

Dynamic behavior of phenol-formaldehyde modified wood under cyclic loading by Jaka Gašper Pečnik

The way of using logging waste in wood-based panels production by Olena

Pinchevska ...

Utilization of Juniper residues for strandboard manufacturing by Tomas Pipiska

594

Surface Modification of Bamboo Fibers for Reinforcing Cement-based Composites by Renhui Qiu

Mapping of moisture on wood surface with hyperspectral imaging by Jakub Sandak .... 596

Reduction of Phenol Formaldehyde Resin Content in Dry-Processed Fibreboards by

Adding Hydrolysis Lignin by Viktor Savov

Life cycle assessment of the new InnoRenew CoE research building - hot spots and the effects of methodological differences on the results for a wooden frame building by Erwin M. Schau

Adhesives Based on Lignin, Tannin and Liquefied Wood by Milan Sernek

Structural joints of furniture made of cardboard and plywood by Alena Sobotkova

Paper and plastic waste composite boards for furniture by Alena Sobotkova

Attracting children to wood science and renewable material professions by Vesna

Starman

Effect of Moderate Thermal Treatment on Properties of Resonance Spruce for Piano

Soundboard by Jan Tippner

Effect of Cutting Parameters on Dust Emission and Surface Roughness during Helical Planing Sucupira Wood by Bruna Ugulino

Effects of Radial Growth Rate on Wood Quality Parameters of Superior Teakwood from Muna Island, Indonesia by Imam Wahyudi

Modeling of Thermal Performance of Cellulose Insulation Imbedded with Phase Change Material by Xun Wang

Segmentation of Knot Defects on Coniferous Lumber Surface Using Deep Neural Network by Hwanmyeong Yeo

Classification of Heat Treatment Degree of Wood Components Using Near-infrared Spectroscopy by Hwanmyeong Yeo

Enhancing particleboard panels' performance properties by nanocellulose and boric acid reinforcement by Mert Yildirim

Development of low formaldehyde-emitting furniture components by nanocellulose and boric acid reinforcement by Mert Yildirim

Improving the Mould and Blue-stain resistance of Bamboo through Acidic Hydrolysis By Zixuan Yu

Physical and mechanical properties of flatten bamboo panel and bonding performance in different bonding surface by Xiubiao Zhang 
Proceedings of the $\mathbf{2 0 2 0}$ Society of Wood Science and Technology International Convention

Biographies and Photos

630

Sponsors

816 


\title{
Monday, July 13
}

\section{Keynote:}

\section{Ageing of wood in structures: does it really happen?}

\author{
Bohumil Kasal, \\ Czech Technical University in Prague, Czech Republic and Professor at the \\ University of Primorska, Slovenia.
}

\begin{abstract}
Ageing in general is a process or permanent, irreversible change of relevant properties with time. This definition is applicable to many scenarios and the term relevant properties is of the key importance. To study the ageing (or causes of ageing) is practically impossible in the context of structural materials that are intended to be used sometimes for centuries. Accelerated methods are often used to predict the change of materials properties with time and often, extrapolation is used to do so. Direct validation of accelerated methods to simulate processes of ageing is virtually impossible. This presentation will attempt to shed the light onto the mystery of ageing of wood.
\end{abstract}

\author{
Early Stage Researcher \\ Chairs: \\ Benedikt Neyses, Lulea University of Technology, Sweden \\ Martin Nopens, Universität Hamburg, Germany
}

\section{Slovenian wood-based bioeconomy: present state and future perspectives}

\author{
Domen Arnic, Slovenian Forestry Institute \\ domen.arnic@gozdis.si \\ Peter Prisian, Slovenian Forestry Institute \\ Peter.prislan@gozdis.si \\ Luka Juvancic, Dept of Animal Science, Biotechnical Faculty, University of Ljubljana, \\ Slovenia \\ Luka.juvancic@bf.uni-lj.si
}

\begin{abstract}
The availability of fossil fuels, overexploitation of natural resources and climate change are implying a more sustainable use of raw materials. Bioeconomy is an economic paradigm, with the main idea to minimize the energy and material consumption and to maximize the share of renewable resources (Winkel, 2017). Expanding the bioeconomy has been identified as a strategic aim of the EU. Forestry and wood-based bioeconomy represent an important part of the overall bioeconomy (Hagemann et al., 2016). Paper and wood manufacturing, as well as forestry, represent $9 \%, 8 \%$ and $2 \%$ of the EU's bioeconomy turnover respectively (ElChichakli et al., 2016).
\end{abstract}

Forest are covering almost $60 \%$ of the total surface in Slovenia, representing a source of wood-based raw materials for a sustainable bioeconomy. We assessed the current state of bioeconomy in Slovenia based on four indicators suggested by Hagemann et al. (2016) and Jasinevičius et al. (2017): (I) availability of wood biomass, (II) wood biomass market, (III) policy and social context and (IV) added value within bioeconomy (Arnič et al., 2019). 


\section{Proceedings of the 2020 Society of Wood Science and Technology International Convention}

In 2017, annual available wood biomass on the market was 5.01 million m3; $53 \%$ was exported and $47 \%$ was used in the domestic wood processing industry. In the same year, a Slovenian forest- and wood-based bioeconomy employed around 19.000 workers and created more than 770 million euros of gross value added, which represents one-third of gross added value of Slovenian bioeconomy (the highest economic result in last two decades). Compared to other countries (i.e. Austria, Germany, and Finland) Slovenia still lags in development of a wood-based bioeconomy, due to the low percentage of harvested forest growth and in a higher share of exported wood.

Further development of wood-based bioeconomy in Slovenia may be performed at two levels. Firstly, by improving the efficiency of forest management and optimizing and upgrading existing timber-processing technologies. Secondly, with the development and establishment of novel technologies that enable more efficient use of lower quality wood, wood residues and by-products of the wood processing and paper industry according to the principles of circular bioeconomy (Hurmekoski et al., 2018).

\section{References:}

Arnič D., Prislan P., Juvančič L. 2019. Raba lesa v slovenskem biogospodarstvu. Gozdarski vestnik, 10, 77: $375-393$.

El-Chichakli B., von Braun J., et al. 2016. Five cornerstones of a global bioeconomy. Nature, 535, 7611: 221.

Hagemann N., Gawel E., et al. 2016. Possible Futures towards a Wood-Based Bioeconomy: A Scenario Analysis for Germany. Sustainability, 8, 1: 98 .

Hurmekoski E., Jonsson R., et al. 2018. Diversification of the forest industries: role of new wood-based products. Canadian Journal of Forest Research, 48, 12: 1417-1432.

Jasinevičius G., Lindner M., Verkerk P., Aleinikovas M. 2017. Assessing Impacts of Wood Utilisation Scenarios for a Lithuanian Bioeconomy: Impacts on Carbon in Forests and Harvested Wood Products and on the Socio-Economic Performance of the Forest-Based Sector. Forests, 8, 4: 133.

Winkel G. 2017. Towards a Sustainable European Forest-based Bioeconomy: Assessment and the Way Forward. European Forest Institute (EFI) pp.

\section{Biography}




\title{
Privacy-aware Distributed Ledger for Product Traceability in Supply Chain Environments
}

\author{
Sidra Aslam ${ }^{1,2 *}$ - Michael Mrissa ${ }^{1,2}$ \\ ${ }^{1}$ InnoRenew CoE, Livade 6, 6310 Izola, Slovenia \\ *\{firstname.surname\}@innorenew.eu
}

${ }^{2}$ University of Primorska, Faculty of Mathematics, Natural Sciences and
Information Technology, Glagoljaška ulica 8, 6000 Koper, Slovenia

\begin{abstract}
Wood supply chain stakeholders need traceability of individual products as well as protection from disclosure of their global activity (e.g. operation volumes), thus making data privacy a major concern. However, typical solutions to manage privacysensitive data are centralized and rely on third parties. Therefore, they suffer from single point of failure, trust and performance issues. Distributed ledger technology ensures data replication, immutability and availability, however, privacy-sensitive data remains publicly available. In this paper, we propose a framework design that combines distributed ledger technology with ring signature, mix networks and distributed hash table to manage data privacy. We illustrate the applicability of our solution with a product traceability scenario for the wood supply chain.
\end{abstract}

Keywords: distributed ledger, wood supply chain, privacy, security 


\section{Introduction}

Supply chain management (SCM) has gained massive attention for both industry and academia [6]. Through the SCM process, all the stakeholders (producers, transporters, suppliers, customers, etc.) communicate with each other to trace products and increase overall quality. However, they generally have challenging requirements, as they need traceability and at the same time they need protection against information disclosure about their activity. Typical centralized solutions for product traceability are subject to the single point of failure problem that makes them vulnerable to attacks $[6,15,16]$ and creates bottleneck that hinders scalability. Therefore, privacy-aware, decentralized solutions for product traceability are highly needed.

In this paper, we propose a framework based on Distributed Ledger Technology (DLT) to manage privacy-sensitive information for the Wood Supply Chain (WSC). DLT - and its most famous implementation, blockchain - mitigates the above issues by providing immutable decentralized storage to ensure data transparency and availability over the network [15]. DLT usage relates to a large number of application domains such as smart home, internet of things, supply chain, and finance, etc. It eliminates the need of a third party to establish trust as it records data in a data structure that is replicated on distributed nodes and where data fragments are related to each other with cryptographic techniques (hash functions) to guarantee integrity and immutability. Using DLT requires carefully looking at privacy concerns because all data and privacy-sensitive information over the network is publicly accessible, as proven by the amount of existing research papers $[13,4]$ and notes ${ }^{1}$.

This paper is structured as follows: Section 2 highlights the need for a privacy solution to protect data along the wood production chain. Section 3 presents our contribution to support privacy aware distributed information management along the wood production chain. Section 4 reviews most relevant work in the area and shows how wood production chain currently lacks distributed privacyaware solutions. The paper is concluded in Section 5.

\section{Motivating Scenario and Research Problem}

In this section, we introduce a simple furniture production scenario that motivates the need for DLT and highlights our research challenges. As presented in Fig. 1, we have identified 6 actors that participate to a WSC. 1) Wood cutting company identifies and cuts specific trees. 2) Transport company drives wood logs to storage warehouse. 3) Storage warehouse company sorts, processes and stores logs. 4) Furniture assembly company cuts logs and assembles furniture. 5) Furniture shop company stores and exposes assembled furniture for sale. 6) Customer buys wooden furniture and verifies product origin.

This scenario highlights the need for traceability, trust and anonymity in the supply chain. Indeed, all the actors of the chain want to provide full product traceability to the customers. A typical solution to this issue consists in inserting RFID chips in the trees and logs produced. RFID chips are detected at every stage of the WSC to provide stakeholders with required traceability. At this stage, typical third-party centralized solutions to store RFID data form a Single Point Of Failure (SPOF), thus motivating research towards decentralized solutions. In particular, blockchain is a

\footnotetext{
${ }^{1}$ https://pdfs.semanticscholar.org/549e/7f042fe0aa979d95348f0e04939b2b451f18.pdf
} 


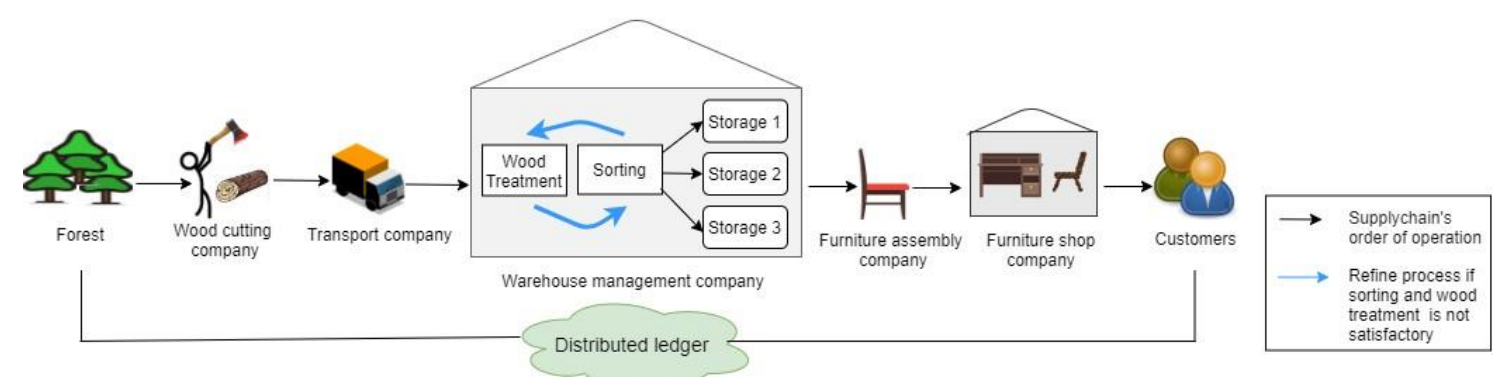

Figure 1: Workflow of wood supply chain system

type of DLT where transactions between users are stored in blocks and replicated on all participating nodes, thus avoiding SPOF. Typically, users generate public and private keys and use public keys as addresses to identify themselves in transactions. Miners use techniques such as proof of work or proof of stake [11] to add and validate blocks. In order to prevent modification of recorded transactions, blocks are linked to each others. Each block contains a hash of the previous block (except the first block in a chain called "genesis") [9].

However, our scenario also highlights that, although the actors of the WSC are willing to provide individual customers with traceability, they also do not wish to have their production information publicly accessible. There is a need to develop solutions that guarantee that it is not possible to access all product data and, for instance, draw statistics from it. Therefore, based on this scenario, our solution must provide 1) confidentiality to protect data from unauthorized access, 2) integrity to verify the originality of content, 3) availability to make sure that data should be always accessible upon request, 4) anonymity to protect the relationship between user identity and data content (unauthorized users must be unable to link data with their owner) and 5) scalability (the proposed solution must manage large number of users and transaction data with reasonable performance).

Such requirements highlight our motivation to combine blockchain with other solutions to provide anonymity and unlinkability of data on decentralized storage and at the same time enable traceability for customers over specific data items. In the following, we formulate a list of scientific locks (SL) that rise from this scenario and the requirements of the actors described above:

- SL1: Unlinkability between data and user's identity. In our context, protecting privacy means SL1a) protecting access to users' identities available in transactions, and SL1b) preventing disclosure of users' identities that could be found out by exploiting temporal dependencies between transactions. The difficulty is to find a solution that integrates smoothly with blockchain and does not affect its original operation.

- SL2: Management of data updates. In our motivating scenario, actors need to update information at each point of the chain (for example product location). The difficulty is to find a way to circumvent original blockchain design to allow data updates.

- SL3: Data security and fine-grained user access. Data stored on DL must be protected from unauthorized access with encryption mechanisms and users' actions on data must be 
managed through access control models. The difficulty is to provide decentralized solutions that integrate smoothly with blockchain.

- SL4: Acceptable usability and response time. System design need to be usable with low response time. However, high response time is a major issue for blockchain. Answering previous scientific locks will increase the system complexity, the difficulty is to integrate solutions while maintaining low computational cost.

To answer these scientific locks, we present in the following a solution that integrates relevant technologies in a single framework. We show how the framework integrates those different aspects to answer the aforementioned scientific locks and we provide insight on the relevance of our framework with the help of our motivating scenario.

\section{Conceptual Framework}

In this paper, we propose a privacy-aware decentralized information management framework to support WSCs (or any distributed information system). This framework combines blockchain technology with ring signature, mix network and distributed hash table as shown in Fig. 2.

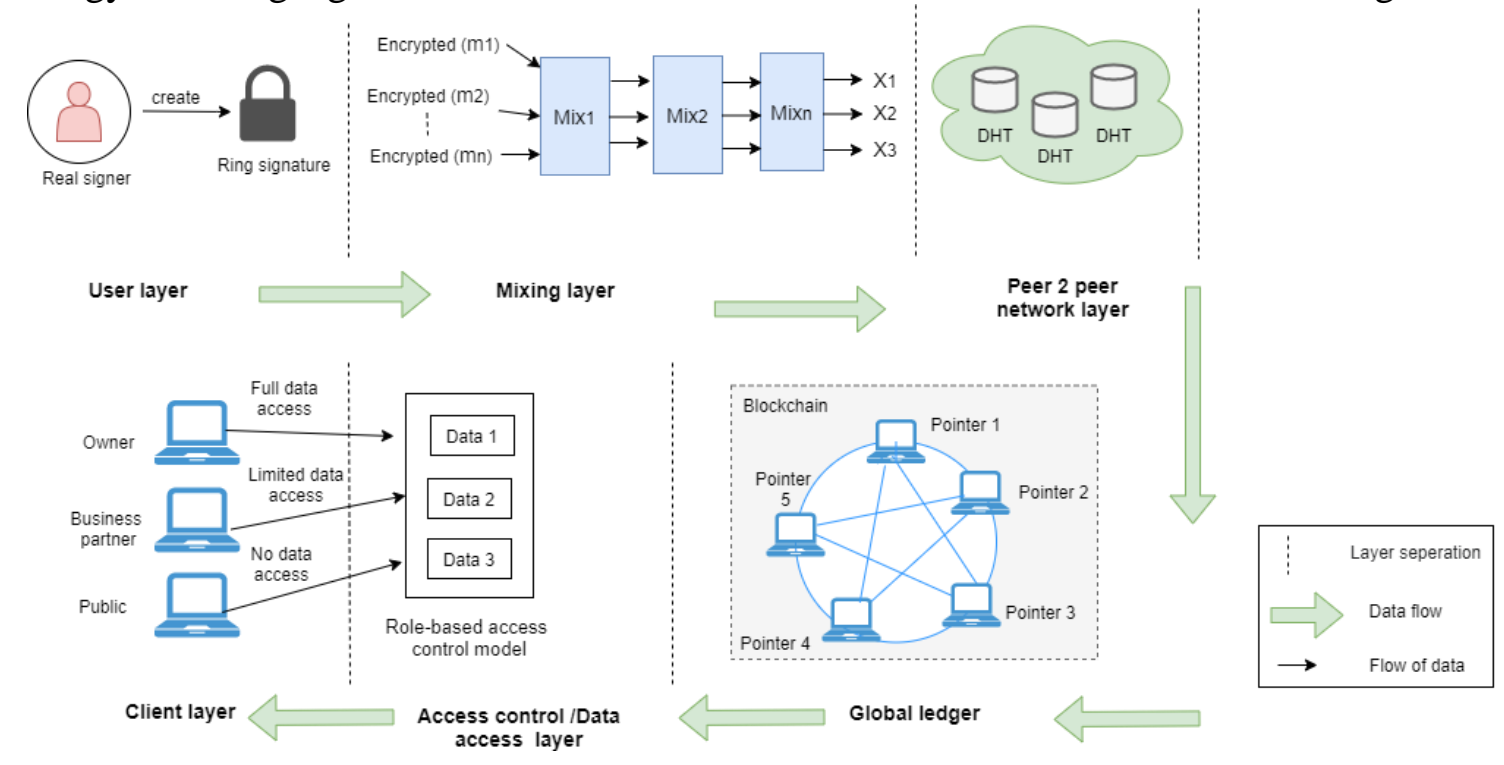

Figure 2: Overview of our conceptual framework

First, our framework answers SL1a using ring signature, that allows a group of several actors equipped with public/private keys (called a ring) to jointly sign a message. Messages going out of a ring can be verified to prove they have been emitted within the ring and at the same time guarantee anonymity of the emitter's identity.

Second, our framework makes use of mix network to prevent user' identity disclosure through temporal dependency obfuscation, thus answering SL1b. Indeed, mix networks randomize temporal relationships between messages, thus making it impossible to observe time dependency between messages and draw conclusion on the identity of message emitter. 
Third, we address SL2 by jointly using blockchain and DHT. Due to its design, DHT addresses performance and data update issues related to blockchain. Therefore, we use DHT to store actual data, and blockchain to store pointers to the data in the DHT. This solution offers both the benefits of blockchain immutability and DHT performance and possibility for update. Indeed, data can be modified in the DHT but pointers cannot be deleted or modified because of blockchain immutability.

SL3 is resolved using role-based access control. In order to preserve the decentralized nature of our framework we adopt Decentralized Public Key Infrastructure (DPKI) [1] to enable role-based access control.

Fourth, we address SL4 by using DHT to store and manage data. Combining DHT with blockchain greatly improves performance as demonstrated in [10].

In our WSC scenario, actors such as the wood cutting company will store data through ring signature, then mix network, so that we will not be able to identify who put the information into the DHT and pointers to it in the blockchain. The rules for role-based access control will be recorded so that different levels of access are granted to different actors.

In our example, general access is not possible, however, business partners can access limited data (such as knowledge of what kind of tree species was cut) and data owner (company employees) have full access. Location data can be updated as the wood follows its progress in the supply chain.

\section{Related Work}

In this section, we review the most relevant existing research on privacy management for blockchain. In [12], the authors present a blockchain-based distributed platform for anonymized trading of datasets. The work is decentralized except a third party to deal with privacy policy management. An dynamic identity management system based on the bitcoin blockchain is proposed in [2] that also relies on third party. It ensures users' data confidentiality and allows a user to control their identities over public networks. In [5] identity management in blockchain is addressed using zero knowledge protocol and smart contracts. However, the work cannot handle malicious verifiers and thus other cryptographic schemes need to be combined with it to achieve better security.

In [8] privacy issues in blockchain-based IoT are explored. Ring signature is used to provide anonymity on the healthcare blockchain. However, DoS and modification attack is still possible because an attacker can make services unavailable for a user and inject falsified transactions in a network. In 2015, [17] presented a personal data management system using blockchain technology that combines blockchain and off-blockchain storage to provide privacy and allow users to control their data. However, it is not efficient to manage and query large volume of data.

In 2018, [7] described identity management on the blockchain by using Sovrin, uPort, and ShoCard. It allows users to control their transactions and enhance the data's transparency due to storage of data on distributed nodes. The authors in [3] propose blockchain-based medical data management system that allows patients to access their medical data across different providers and patient databases. This system is helpful to manage authentication, confidentiality, and data sharing. In paper [15] authors discussed blockchain technology in a supply chain system. Smart contracts are used to secure transactions between parties and remove the middle party. The major drawback of the proposed scheme is scalability. A decentralized supply chain system using smart contract is presented in [16]. The proposed system is useful to trace goods and recipe ingredients through supply chain system. Moreover, it is unable to trace damaged or loss goods during supply chain process. In [14], authors provided a survey of cryptographic techniques to resolve immutability 
issue of blockchain. Similarly, they discussed advantages and limitations of these techniques when used in either public or private blockchain.

Table 1 summarizes advantages and limitations of existing work and relates to our identified scientific locks. We summarize which aspects are addressed in Table 2.

Table 1: Summary of related work analysis

\begin{tabular}{|c|c|c|c|c|}
\hline Ref.No & Challenge Addressed & Approach & Advantages & Limitations \\
\hline$[12]$ & $\begin{array}{l}\text { Anonymized } \\
\text { dataset (SL1b) }\end{array}$ & $\begin{array}{l}\text { Blockchain based } \\
\text { distribution scheme }\end{array}$ & $\begin{array}{l}\text { Decentralization; Data } \\
\text { owner can trace their } \\
\text { data }\end{array}$ & $\begin{array}{l}\text { Need third party to } \\
\text { manage privacy } \\
\text { policy; Privacy } \\
\text { risk remain }\end{array}$ \\
\hline$[2]$ & $\begin{array}{l}\text { Ensure identity in } \\
\text { bitcoin blockchain } \\
\text { (SL1a) }\end{array}$ & $\begin{array}{l}\text { Zero-knowledge } \\
\text { proofs }\end{array}$ & $\begin{array}{l}\text { Dynamic update of } \\
\text { identities }\end{array}$ & Need third party \\
\hline$[5]$ & $\begin{array}{l}\text { Anonymity of } \\
\text { user data over } \\
\text { blockchain } \\
\text { (SL1b) }\end{array}$ & $\begin{array}{l}\text { Zero-knowledge } \\
\text { protocol and } \\
\text { Smart contract }\end{array}$ & $\begin{array}{l}\text { Provide data privacy; } \\
\text { Eliminate need of } \\
\text { third party }\end{array}$ & $\begin{array}{l}\text { Require more } \\
\text { security schemes; } \\
\text { Unable to work } \\
\text { when verifier is } \\
\text { malicious }\end{array}$ \\
\hline$[8]$ & $\begin{array}{l}\text { Secure management } \\
\text { of healthcare data on } \\
\text { blockchain (SL1a) } \\
\text { (SL1b) (SL3) }\end{array}$ & $\begin{array}{l}\text { Ring signature, } \\
\text { Smart contract, } \\
\text { and Cryptographic } \\
\text { techniques }\end{array}$ & $\begin{array}{l}\text { Decrease blockchain } \\
\text { bandwidth and } \\
\text { computational power }\end{array}$ & $\begin{array}{l}\text { DOS attack is } \\
\text { possible; Scalability }\end{array}$ \\
\hline$[17]$ & $\begin{array}{l}\text { Decentralized user } \\
\text { private data } \\
\text { management (SL3) } \\
\text { (SL4) }\end{array}$ & $\begin{array}{l}\text { Fine-grained access } \\
\text { control, Encryption, } \\
\text { and Decryption } \\
\text { schemes }\end{array}$ & $\begin{array}{l}\text { Remove third party; } \\
\text { User has control } \\
\text { over their personal } \\
\text { data }\end{array}$ & $\begin{array}{l}\text { Framework cannot } \\
\text { manage large } \\
\text { volume of data }\end{array}$ \\
\hline$[7]$ & $\begin{array}{l}\text { Digital Identity } \\
\text { management on the } \\
\text { blockchain (SL1a) }\end{array}$ & $\begin{array}{l}\text { Sovrin, Uport and } \\
\text { ShoCard }\end{array}$ & $\begin{array}{l}\text { Completely decentralized } \\
\text { transparency; User can } \\
\text { control data transactions }\end{array}$ & $\begin{array}{l}\text { Lack of usability to } \\
\text { manage } \\
\text { cryptographic keys; } \\
\text { Unable to cope with } \\
\text { data transparency }\end{array}$ \\
\hline$[3]$ & $\begin{array}{l}\text { Blockchain based } \\
\text { medical data } \\
\text { management } \\
\text { system (SL3) }\end{array}$ & $\begin{array}{l}\text { Smart contract, Proof } \\
\text { of work, and Syncing } \\
\text { algorithm }\end{array}$ & $\begin{array}{l}\text { Patients can access } \\
\text { their medical record; } \\
\text { Authentication, Avoid } \\
\text { single point of failure }\end{array}$ & $\begin{array}{l}\text { Cannot maintain } \\
\text { large volume of data; } \\
\text { centralized security }\end{array}$ \\
\hline
\end{tabular}

\section{Conclusion}

In this paper, we illustrate the need for privacy-aware product traceability in wood supply chains with a scenario that shows the challenges of this specific application domain, before identifying related scientific locks. We then propose a framework that relies on a combination of ring signature, mix network, blockchain and DHT to provide adapted measures that allow traceability for authorized users without disclosing all the business information of the different actors.

Further work includes exploring different options for decentralized authentication, assessing the solution performance in real or simulated environment, and deploying a proof-of-concept prototype in collaboration with an existing company. 
Proceedings of the 2020 Society of Wood Science and Technology International Convention

Table 2: Comparative analysis of our proposed framework

\begin{tabular}{|l|l|l|l|l|}
\hline \multirow{2}{*}{ Ref. no/Year } & \multicolumn{2}{|c|}{ Privacy features } & $\begin{array}{l}\text { Security } \\
\text { properties }\end{array}$ & Traceability \\
\cline { 2 - 5 } & $\begin{array}{l}\text { Identity } \\
\text { protection }\end{array}$ & $\begin{array}{l}\text { Transaction data } \\
\text { protection }\end{array}$ & Confidentiality & No \\
\hline$[1,2017]$ & Yes & No & Confidentiality & No \\
\hline$[2,2016]$ & Yes & Yes & Confidentiality & No \\
\hline$[5,2019]$ & Yes & No & Integrity & No \\
\hline$[7,2018]$ & Yes & Yes & $\begin{array}{l}\text { Confidentiality; } \\
\text { Integrity; } \\
\text { Availability }\end{array}$ & No \\
\hline$[8,2018]$ & Yes & No & $\begin{array}{l}\text { Confidentiality; } \\
\text { Integrity; }\end{array}$ & Yes \\
\hline$[9,2019]$ & Yes & Yes & No & Yes \\
\hline$[14,2019]$ & No & No & No & Yes \\
\hline$[15,2018]$ & No & No & Availability & No \\
\hline$[16,2015]$ & Yes & Yes & $\begin{array}{l}\text { Confidentiality; } \\
\text { Integrity; } \\
\text { Availability }\end{array}$ & Yes \\
\hline Our framework & Yes & Yes & & \\
\hline
\end{tabular}

\section{References}

[1] Karl Aberer, Anwitaman Datta, and Manfred Hauswirth. A decentralized public key infrastructure for customer-to-customer e-commerce. International Journal of Business Process Integration and Management, 1(ARTICLE):26-33, 2005.

[2] Daniel Augot, Hervé Chabanne, Olivier Clémot, and William George. Transforming facetoface identity proofing into anonymous digital identity using the bitcoin blockchain. In 2017 15th Annual Conference on Privacy, Security and Trust (PST), pages 25-2509. IEEE, 2017.

[3] Asaph Azaria, Ariel Ekblaw, Thiago Vieira, and Andrew Lippman. Medrec: Using blockchain for medical data access and permission management. In 2016 2nd International Conference on Open and Big Data (OBD), pages 25-30. IEEE, 2016.

[4] Alex Biryukov, Dmitry Khovratovich, and Ivan Pustogarov. Deanonymisation of clients in bitcoin p2p network. In Proceedings of the 2014 ACM SIGSAC Conference on Computer and Communications Security, pages 15-29, 2014.

[5] Yogita Borse, Anushka Chawathe, Deepti Patole, and Purnima Ahirao. Anonymity: A secure identity management using smart contracts. Available at SSRN 3352370, 2019. 
Proceedings of the 2020 Society of Wood Science and Technology International Convention

[6] Fang Dong, Pengcheng Zhou, Zijian Liu, Dian Shen, Zhuqing Xu, and Junzhou Luo. Towards a fast and secure design for enterprise-oriented cloud storage systems. Concurrency and Computation: Practice and Experience, 29(19):e4177, 2017.

[7] Paul Dunphy and Fabien AP Petitcolas. A first look at identity management schemes on the blockchain. IEEE Security \& Privacy, 16(4):20-29, 2018.

[8] Ashutosh Dhar Dwivedi, Gautam Srivastava, Shalini Dhar, and Rajani Singh. A decentralized privacy-preserving healthcare blockchain for iot. Sensors, 19(2):326, 2019.

[9] Kristoffer Francisco and David Swanson. The supply chain has no clothes: Technology adoption of blockchain for supply chain transparency. Logistics, 2(1):2, 2018.

[10] Yahya Hassanzadeh-Nazarabadi, Alptekin Küpçü, and Öznur Özkasap. Lightchain: A dhtbased blockchain for resource constrained environments. CoRR, abs/1904.00375, 2019.

[11] Sungmin Kim and Joongheon Kim. Poster: Mining with proof-of-probability in blockchain. In Proceedings of the 2018 on Asia Conference on Computer and Communications Security, pages $841-843,2018$.

[12] Shinsaku Kiyomoto, Mohammad Shahriar Rahman, and Anirban Basu. On blockchainbased anonymized dataset distribution platform. In 2017 IEEE 15th International Conference on Software Engineering Research, Management and Applications (SERA), pages 85-92. IEEE, 2017.

[13] Malte Moser. Anonymity of bitcoin transactions, 2013.

[14] Eugenia Politou, Fran Casino, Efthymios Alepis, and Constantinos Patsakis. Blockchain mutability: Challenges and proposed solutions. IEEE Transactions on Emerging Topics in Computing, 2019.

[15] Sara Saberi, Mahtab Kouhizadeh, Joseph Sarkis, and Lejia Shen. Blockchain technology and its relationships to sustainable supply chain management. International Journal of Production Research, 57(7):2117-2135, 2019.

[16] Martin Westerkamp, Friedhelm Victor, and Axel Küpper. Blockchain-based supply chain traceability: Token recipes model manufacturing processes. In 2018 IEEE International Conference on Internet of Things (iThings) and IEEE Green Computing and Communications (GreenCom) and IEEE Cyber, Physical and Social Computing (CPSCom) and IEEE Smart Data (SmartData), pages 1595-1602. IEEE, 2018.

[17] Guy Zyskind, Oz Nathan, et al. Decentralizing privacy: Using blockchain to protect personal data. In 2015 IEEE Security and Privacy Workshops, pages 180-184. IEEE, 2015. 


\title{
Spatial Augmented Reality to Improve Manufacturing of Timber Frame Prefabricated Wall Elements
}

\author{
Birger Bartuska1 \\ b.bartuska@wood-kplus.at \\ Alfred Tesichinger2 \\ Alfred.teischinger@boku.ac.at \\ Martin Riegler 1 \\ m.riegler@wood-kplus.at \\ 1 Wood K Plus, Austria \\ 2 Institute of Wood Technology and Renewable Materials, Department \\ of Material Sciences and Process Engineering, BOKU - University of \\ Natural Resources and Life Sciences
}

\begin{abstract}
Industry 4.0 the so called 4th industrial revolution is a concept that includes many different approaches that could lead to a highly efficient and flexible (manufacturing) industry. A main goal of Industry 4.0 is to be able to achieve mass customization with the same cost as mass production. In several branches of the wood industry for example kitchen- or prefabricated housing production it is already state of the art to produce in lot size 1 . Often this is only possible with a lot of manual labor which increases the price of the manufactured products significantly.

Production of complex products like prefabricated timber wall elements in lot size 1 requires numerous work instructions that are different for every single part that is produced. These instructions need to be understood and carried out with as few errors as possible and as fast as possible to keep rework and cycle times to a minimum. Therefore, flexibility in production is a key element because of the large variety of the produced elements.

Spatial augmented reality makes it possible to integrate information directly into a work environment by projecting it on workbenches or even work pieces themselves. Because spatial augmented reality does not require a headgear or goggles to be worn it can in many cases be implemented in production processes quite easily without restricting workers in their movement or field of view.

In this research we evaluate a self-developed projector based spatial augmented reality application for the manufacturing of timber frame prefabricated wall elements and compare it to existing production processes that are well established in the industry. The completion time and the error rates are measured during selected production steps performed under laboratory conditions.
\end{abstract}

\section{Biography}




\title{
Can Woody Biomass from Orchards Still Be Considered a Waste Material?
}

\author{
Maria Roberta Bruno ${ }^{1 *}$, Valentina Lo Giudice ${ }^{1}$,Paola Cetera ${ }^{2}$, Luigi Todaro ${ }^{3}$. \\ ${ }^{1}$ PhD Student,School of Agricultural, Forestry, Food and Environmental Sciences, University of \\ Basilicata. V.le dell'Ateneo Lucano 10, 85100 Potenza, Italy, *Corresponding author \\ mariaroberta.bruno@unibas.it; \\ valentina.logiudice@unibas.it \\ ${ }^{2} \mathrm{PhD}$, Council for Agricultural Research and Economics -Research Centre for Engineering and \\ Agro-Food Processing (CREA-IT), Via dellaPascolare, 16 - 00015 Monterotondo (Roma), Italy \\ paola.cetera@crea.gov.it \\ 3Professor, School of Agricultural, Forestry, Food and Environmental Sciences, University of \\ Basilicata. V.ledell'AteneoLucano 10, 85100 Potenza, Italy, \\ luigi.todaro@unibas.it
}

\begin{abstract}
In Europe (EU-27) orchards occupy 5,947,860.54 ha (Eurostat, 2017). The main permanent crops are represented by olive trees, orange trees, vineyards and different crops belonging to the Rosaceae family (i.e. apricot, peach, cherry, pear and apple trees). Their management produces a large amount of biomass. According to Pari et al., (2018), in Europe more than 13 million tons of pruning biomass (over dry basis) are available from the main orchards each year, in Italy around 6 million tons are produced yearly (including uprooted biomass). This biomass is mostly burned either sometimes chopped and left on the soil to maintain the organic carbon levels or to prevent soil erosion. The interest in finding sustainable solutions related to the wood residues management has led to focus the attention on the extraction of secondary metabolites from pruning residues, also called "extractives". The aim of this study is to enhance the wood biomass coming from apricot (Prunus Armeniaca L.), olive (Olea Europaea L.) and orange trees (Citrus sinensis L.). The experimental material was collected in Basilicata region in May 2018. The biomass includes pruning residues (branches) and trunk residues obtained after the cultivations explant. In all samples the bark was separated from the wood. In the case of orange and apricot samples, the sapwood and the heartwood within the trunk were considered separately. These samples first were cut into small pieces, then ground to obtain sawdust. Extraction of sawdust was performed using an Accelerated Solvent Extractor with three types of solvents: ethanol/ water $(50: 50 \mathrm{v} / \mathrm{v})$, only ethanol and only water, at $120^{\circ} \mathrm{C}$. After extraction, organic solvents were evaporated under vacuum using a rotary evaporator at $37^{\circ} \mathrm{C}$, while water was freeze-dried for 48h. The chemical analyses of the extracts were performed using an LC-MS. The results showed the extractive yields and the secondary metabolites present in each sample. Secondary
\end{abstract}




\section{Proceedings of the 2020 Society of Wood Science and Technology International Convention}

metabolites are chemical compounds produced by several plant tissues (e.g. leaves, bark, roots, buds, wood). They provide different medicinal applications, due to the antioxidant, anticancer, anti-inflammatory, antifungal and other properties. The investigation of the natural compounds is not an easy procedure but interesting natural compounds as catechine and oleuropein were found in the samples. These types of natural compounds may be applied in the cosmetic sectors in order to create new value-added products, opening a perspective for the use of orchard biomass as new raw material.

Key words: biomass, agricultural, waste, chemical analysis, metabolites secondary, antioxidant compounds, reuse.

\section{Introduction}

In Europe (EU-27) the orchards occupy 5,947,860.54 ha (Eurostat, 2017). Italy with its 1,389,829.43 ha (Eurostat, 2017) is in Europe (EU-28) the second Country after Spain, with the largest number of orchards. In the Italian regions, the orchards that cover the largest areas are olive trees equal to $51 \%$ of the entire surface, followed by vineyards with $31 \%$, orange trees with $6 \%$ and tree crops belonging to the rosaceae family (peach, apricot, apple, pear, cherry) which occupy about $9 \%$ (Istat, 2018). The orchards produce a large quantitative of biomass coming from pruning and trees explantation. This biomass from pruning and explants is mostly burned, sometimes chopped and left on the soil to maintain the organic carbon levels, rarely it is added to produce the farm organic compost. The main reason why this biomass is burned, reflects the fact that it doesn't produce sufficient profit. Therefore, the European strategy have created the basis for enhancing the natural resources as well as for a sustainable economic growth. Starting to the European line guides, the aim of this study is the valorisation of biomass from orchards, in particular from apricot tree (Prunus Armeniaca L.) olive tree (Olea Europaea L.) and orange tree (Citrus Sinensis L.), through the analyses of the secondary metabolites present in the extractives from pruning and trunk biomass of these plants. Both in the pruning and in the trunks were separated the bark from the wood, in add in the trunk (except for the olive tree) the wood is divided in heartwood and sapwood. In all these plants parts there were determined: $i$ ) their most frequent molecular compounds, ii) their chemical composition using liquid chromatography (LC-MS). The investigation of the natural compounds is not an easy procedure but interesting natural compounds as catechine and oleuropein was found in the samples. 
Proceedings of the $\mathbf{2 0 2 0}$ Society of Wood Science and Technology International Convention

\section{Materials \& Methods}

\section{ORCHARDS BIOMASS EXTRACTIVES}

The biomass from Apricot trees (Prunus Armeniaca L. var. Pisana), olive trees (Olea Europaea L. var. Coratina) and orange trees (Citrus Sinensis L. var. Navellina) formed by pruning residues and trunk uproot were gathered in May 2018 in different orchards within Policoro-Metaponto area (Basilicata Region). The samples were pounded through a Fritsch grinder ring to obtain the powder (Vibrating Mill Pulverisette Cup 9, 3 times 40 seconds at 1000 RPM) with the grinding set $\mathrm{N}^{\circ} 484125$. Extraction of sawdust was performed using an Accelerated Solvent Extractor (Dionex ASE 200, Voisins Le Bretonneux, France). Extraction was performed in $33 \mathrm{~mL}$ cell size on $5 \mathrm{~g}$ of sawdust at $120^{\circ} \mathrm{C}$ under a pressure of 100 bars ( 3 static cycles of 5 minutes each) using ethanol, water and a mixture of ethanol:water (50:50 v/V). After extraction, organic solvents were evaporated under vacuum using a rotaryevaporator (Rotary evaporator BuchiRotavapor $\mathrm{R}-300)$ at $37^{\circ} \mathrm{C}$.

\section{LC-MS ANALYSIS}

U-HPLC analysis of extracts was carried out using an LC-MS-8030Shimadzu apparatus equipped with a Diode array detector SPDM20A.The separation was carried out in thermostatic conditions at $40{ }^{\circ} \mathrm{C}$ with a reversed-phase column (Phenomenex ${ }^{\circledR}$ Luna $3 \mu \mathrm{m} \mathrm{C18).} \mathrm{The} \mathrm{detection}$ was carried out with an UV detector set atthe wavelength of $280 \mathrm{~nm}$ and under selected ion monitoring by negative and positive mode ESI-MS. The operating parameters for MS detection were as follows: nebulizing gas $\left(\mathrm{N}_{2}\right)$, flow $3.0 \mathrm{~L} / \mathrm{min}$, drying gas flow $15 \mathrm{~L} / \mathrm{min}$, interface voltage $4.5 \mathrm{kV}$, gas pressure $230 \mathrm{kPa}$, DL temperature: $250{ }^{\circ} \mathrm{C}$, block heater temperature $400{ }^{\circ} \mathrm{C}$.

\section{STATISTICAL ANALYSIS}

The most frequency molecular compounds and PCA were computed using the R statistical software environment (http://www.r-project.org).

\section{Results and Discussion}

The LC-MS analyses are still being worked on but the first results showed that the most frequent compounds, in the samples of apricot tree, olive tree and orange tree, are interesting molecular compounds. In the apricot tree samples (fig.1) was detected these phenolic compounds as m/z 289 [Catechine $+\mathrm{H}$ ], m/z 575 [ProcydinDimer $+\mathrm{H}$ ], m/z 433 [Naringenin $+\mathrm{H}$ ], m/z 559 m/z [Phenolic Glycoside+H], m/z 271 [Phlorentin+H]. According to Rice-Evans et al., 1997 , the phenolic compounds have an high antioxidant activity and several proprieties as against cancer, cardiovascular diseases.

In the Fig. 2 are reported the most frequency compounds analysed in the different part of the olive tree samples. The compounds as m/z 539 [Oleuropeina+H], m/z 523 [Ligstroside+H], have 
according to Cardoso et al., 2011antioxidant, anti-inflammatory, antimicrobial, cardioprotective, hypoglycemic and anticarcinogenic. The orange tree samples (fig.3) showed that among the most frequent compounds there is $\mathrm{m} / \mathrm{z} 179$ [CaffeicAcid $+\mathrm{H}$ ] that exhibits a significant potential as an antidiabetic agent by suppressing a progression of type 2 diabetic states that is suggested by an attenuation of hepatic glucose output and enhancement of adipocyte glucose uptake, insulin secretion, and antioxidant capacity (Un et al., 2006).

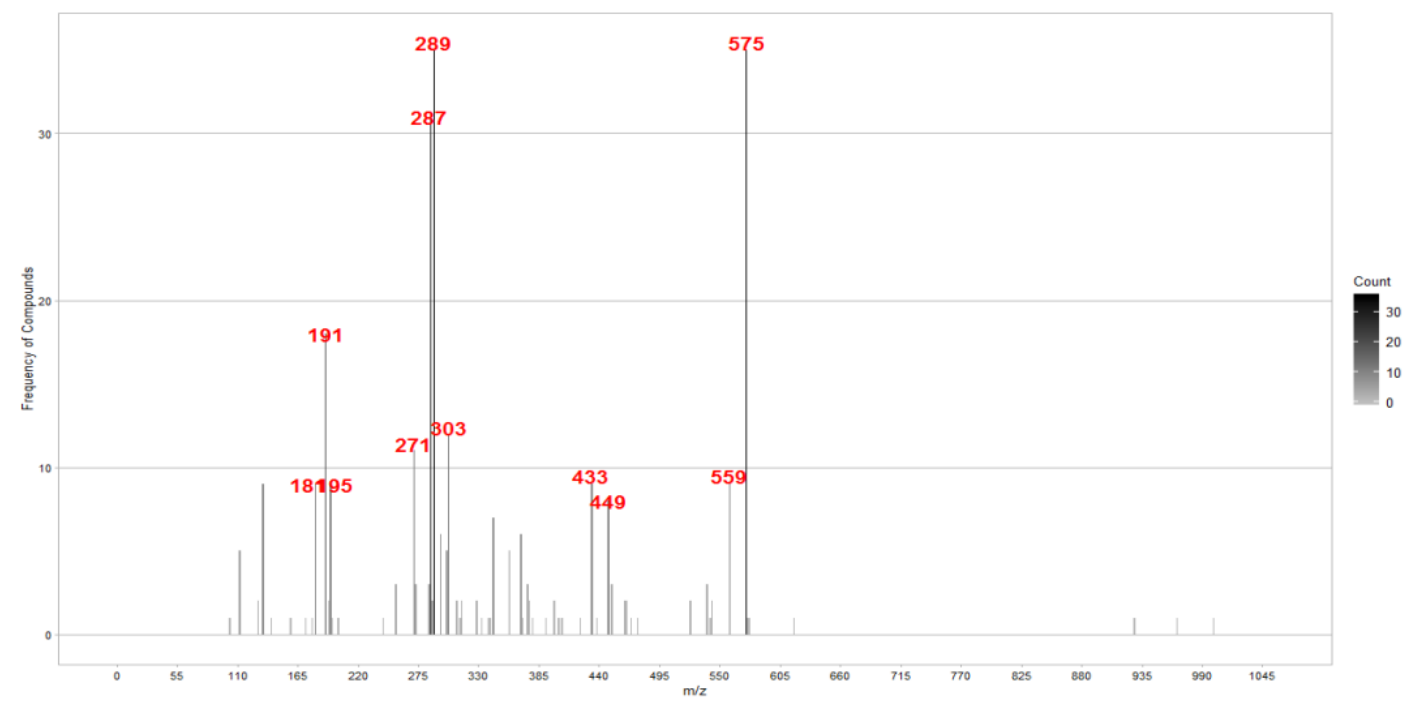

Figure 1: Most frequent compounds in the Apricot tree samples

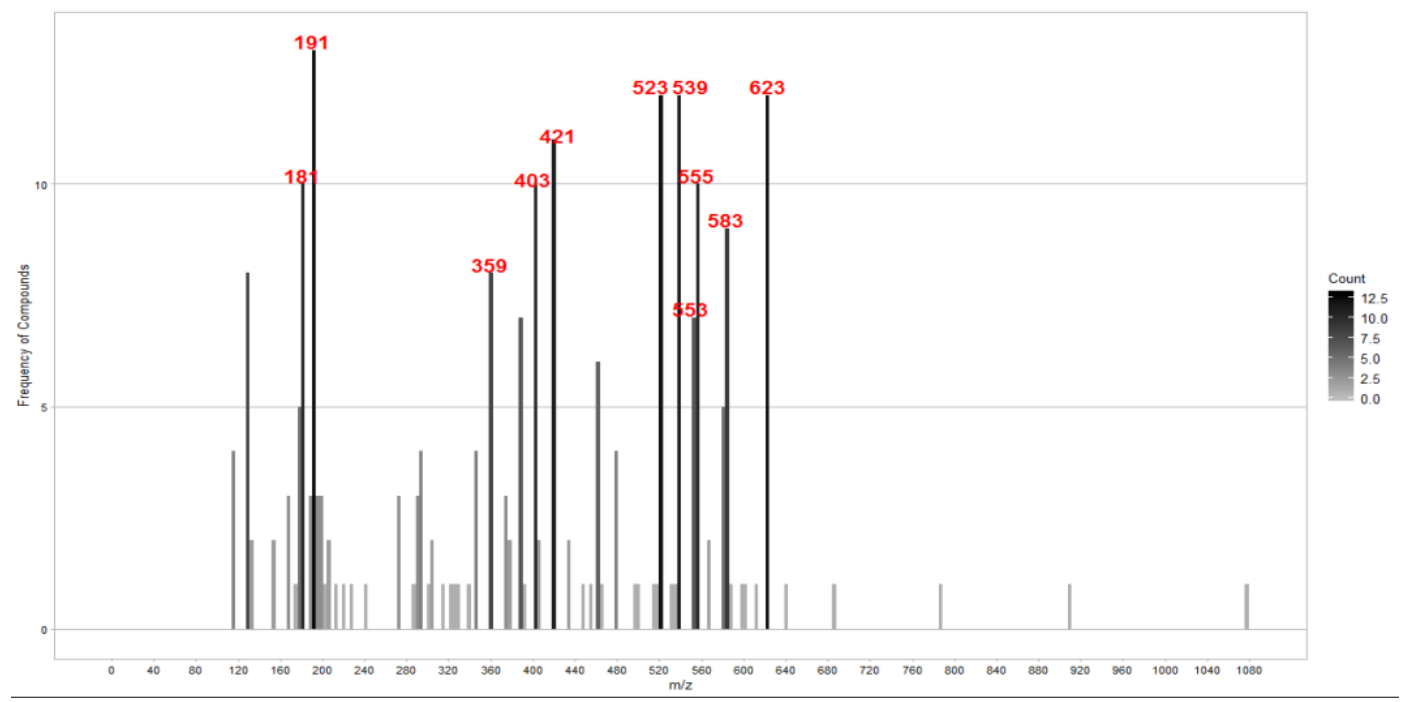

Figure 2: Most frequent compounds in the Olive tree samples 


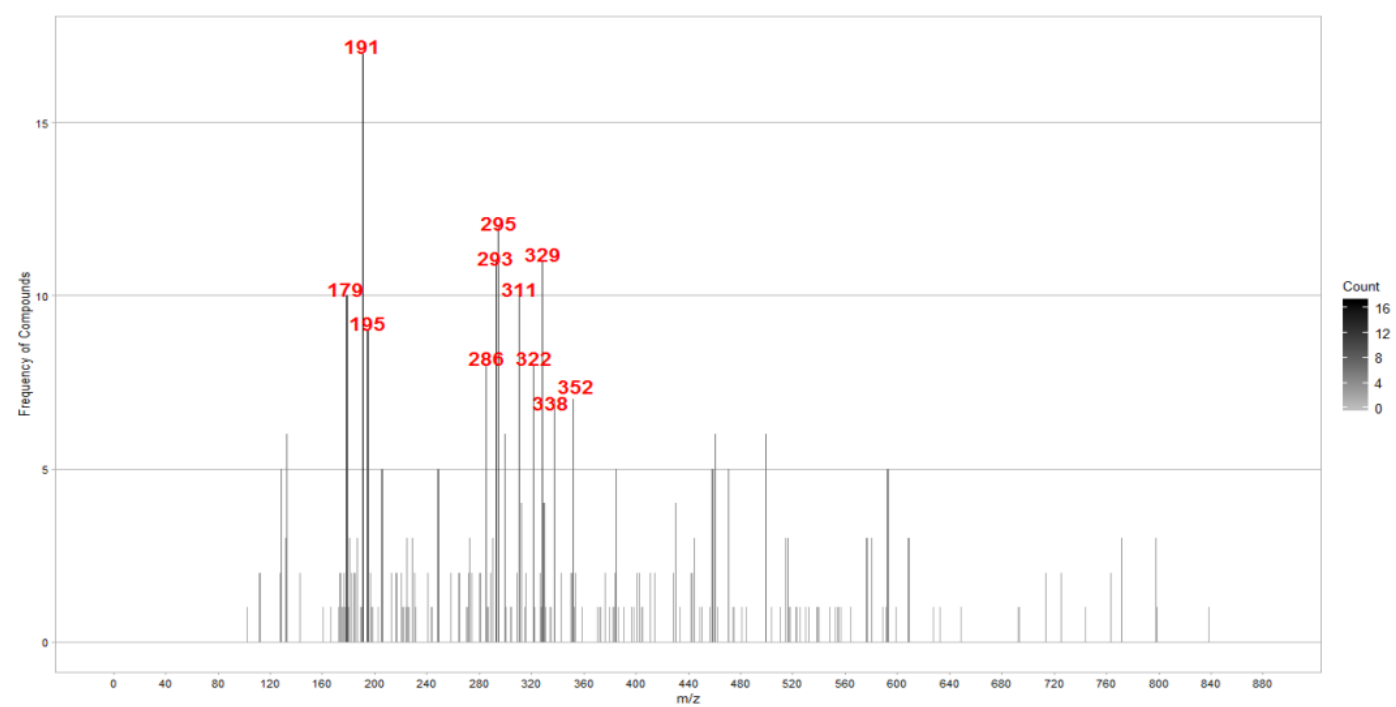

Figure 3: Most frequent compounds in the Orange tree samples

\section{Summary and Conclusions}

The agricultural biomass coming from pruning and uproot tree of tree different orchards species apricot tree, olive tree and orange tree have several proprieties as reported in the analyses of this study. This agricultural biomass, considered waste material, contains different antioxidant compound with useful properties for the human health. Our research will proceed by applying these agricultural wood extractives as a raw material in an industrial product.

\section{Acknowledgements}

The Ph.D. programme in Agricultural, Forest and Environmental Sciences is coordinated by F. Napolitano, at the University of Basilicata, supported by Maria Roberta Bruno.

\section{References}

Eurostat - Data Explorer, 2017: https://appsso.eurostat.ec.europa.eu

Statistics Istat, 2018: http://dati-censimentoagricoltura.istat.it

Cardoso, S.M., Falcão, S.I., Peres, A.M., Domingues, M.R.M., (2011) Oleuropein/ligstroside isomers and their derivatives in Portuguese olive mill wastewaters. Food Chem. 129, 291-296.

Rice-Evans, C.A., Miller, N.J., Paganga, G., (1997) Antioxidant properties of phenolic compounds. Trends Plant Sci. 
Proceedings of the 2020 Society of Wood Science and Technology International Convention

Un, J.J., Lee, M.K., Yong, B.P., Jeon, S.M., Choi, M.S., (2006)Antihyperglycemic and antioxidant properties of caffeic acid in db/db mice. J. Pharmacol. Exp. Ther. 318, 476-483

Biography 
Proceedings of the 2020 Society of Wood Science and Technology International Convention

\title{
The Differentiating Anatomical Features of Five Tree Species from East Seram, Indonesia
}

\author{
Tekat Dwi Cahyono, University of Darussalam Ambon, Indonesia \\ tekadwicahyono@gmail.com \\ Atmawi Darwis, Institut Teknologi Bandung, Indonesia \\ atmawiidarwis@gmail.com
}

\begin{abstract}
This research was aimed to determine the differentiating anatomical features of tree species naturally grow in East Seram, Indonesia. The selected tree species were Ficus virgata, Duabanga moluccana, Terminalia catappa, Octomeles sumatrana, and Hernandia nymphaeifolia. The differentiating features of those tree species shown as the druses were found only in the axial parenchyma of $T$. catappa.

Furthermore, F. variegata had the axial parenchyma in the form of wide-band and latex canal in ray parenchyma. The storied fibers were only found in O. sumatrana. The smallest vessel pit diameter and traumatic canal were found in $H$. nymphaeifolia. Meanwhile, those in D. moluccana may be differentiated with the other tree species by paying more attention to the short and narrow rays. Prismatic crystals of $D$. moluccana often present in non-chambered axial parenchyma cells, where usually a few large crystals and many minute crystals are present in the same cell.

Biography
\end{abstract}




\title{
Evaluation of the Seismic Behavior of Hybrid Walls with Cross Laminated Timber for Building in Chile
}

\author{
Tulio Carrero, \\ tecarrero@uc.cl \\ Pablo Guindos, \\ pguindos@ing.puc.cl \\ Hernán Santa María, \\ hsm@ing.puc.cl \\ Jairo Montano \\ jamontano@uc.cl
}

UC Timber Innovation Center, Pontifical Catholic University of Chile, Chile

\begin{abstract}
It has been proven, both experimentally and numerically, that CLT walls are structural systems of high rigidity and strength. Through the use of hybrid light-frame-type (Light Frame Building, LFTB) type walls, obtained by combining frames of different materials (wood, steel, concrete) with CLT stiffener plate, it is estimated that its optimized their seismic behavior.
\end{abstract}

It is essential to advance the reproduction of results for the use of the material (CLT) as a structural alternative while using ductile connection systems with the support of other materials. On the other hand, if the benefit of the increased ductility of the wall connections is taken into account, this system could compete internationally against the wall system in CLT.

A structural configuration of wooden walls has been invented that allows doubling capacity and stiffness, in addition to significantly increasing ductility with respect to conventional walls made of equivalent wood. The conventional composition of this type of wall consists of a CLT panel, one or more hold-down anchors and one or several cutting angles. The deformation under the action of a lateral load, such as an earthquake, shows a clear dominance of the movement of a rigid tipping and sliding body. The capacity, rigidity and ductility with aspect ratios close to $1: 1$ is governed by the lifting force concentrated in the hold-down anchor.

Unlike the conventional wall, the invented composition consists of:

- A labeled frame composed of rigid elements of steel tubes, post-tensioned reinforced concrete or high-strength wood compounds such as micro-laminated wood or laminated wood chips.

- Two CLT panels arranged externally with respect to the rigid frame and forming a sandwich panel as a whole.

- Self-drilling screws or pins that connect the CLT panels to the rigid frame.

- Steel cables that hold the wall axially preventing the movement of rigid body by overturning. 


\section{Proceedings of the 2020 Society of Wood Science and Technology International Convention}

The general objective of this research is to increase the technical and economic feasibility of mediumsized wooden buildings in Chile through hybrid structures with CLT as a resistant system. To achieve this objective, the following methodology will be used: (i) both the CLT connections with the framework and the real-scale hybrid walls will be studied experimentally; (ii) finite element numerical models will be calibrated (using MCASHEW and RFEM TIMBER) based on the experimental results.

This current doctoral research has already obtained promising experimental results when evaluating a proof of concept for a combination of wood and steel (system connections and walls), showing much potential to explore in this construction system in structural terms, as will be seen later. Among the important advantages achieved with the proposed system, there is a reduction in the amount of structural walls required in the projects. Structural designs of a private housing building with the proposed wall system were made, the results indicated that the walls meet the requirements of the national standard for seismic building design (NCh433) for 6 and 10 floors.

KEYWORDS: Connection, CLT, hybrid connections, cyclic behavior, steel, concrete, Seismic design, wooden laminate walls, hybrid structures, ductility, rigidity.

Biography 
Proceedings of the 2020 Society of Wood Science and Technology International Convention

\title{
Water Resistance of Wood Adhesives Derived from Cottonseed Meal with All Components Utilization
}

\author{
Nairong Chen, Fujian Agriculture and Forestry University, China \\ fafucnr@163.com
}

\begin{abstract}
Development of eco-friendly adhesives from renewable biomass, as a promising replacement for petro-derived formaldehyde adhesives for woody composites, have attracted considerable attention due to the rising environment, health, and resource concerns. Here, the cottonseed meal, a non-food biomass, which was modified by Sodium Dodecyl Sulfonate (SDS), urea, hydroxyl sodium, or polyquaternary ammonium salt (PAS) to prepare an eco-friendly wood adhesive, and its performance was evaluated by water absorption, insoluble content, and shear strength of Eucalyptus plywood.

Results showed that cottonseed meal with particle sizes higher than 140 mesh is suitable for adhesive application. After curing, the SDS or PAS modified adhesive showed light color compared to other two adhesives formulation. When soaking into water, the PAS modified adhesive had the lowest water absorption and the highest insoluble content. Whereas, the SDS modified adhesive showed the best wet shear strength. Both water absorption, insoluble content and shear strength had positive correlation in each modifier pretreatment adhesive, but the properties correlation in different modifiers treated adhesive was ambiguous. We reasoned that modifiers can unfold the globular of protein to liner structure, and then entangled together with enhancement water resistance during the curing process of adhesive.

Biography
\end{abstract}




\title{
Comparison of Devices for Acoustic Tomography of Tree and Material Properties of Degraded Wood
}

\author{
Valentino Cristini, \\ Valentine.cristini@gmail.com \\ Jan Tippner \\ Jan.tippner@mendelu.cz
Department of Wood Science and Technology, Faculty of Forestry and Wood Technology, Mendel University in Brno, Czech Republic

\begin{abstract}
With street and park trees, unlike forests, the risk of damage to property and health is significantly higher, therefore trees growing on such sites need to be regularly checked.

Some damages or rots adversely affecting the stability of trees are simply not detectable by visual assessment. Though so, the use of acoustic tree tomography is in such a case necessarily, which consists in measuring defects in radial cross-sections of a stem by the velocity of sound waves propagation.

This study compares the results of the three most used devices for acoustic tomography of standing trees (ARBOTOM ${ }_{\circledast}$, ARBORSONIC $_{\circledast}$ a PICUS ${ }_{\circledast}$ ) on selected individuals of hardwood species in Brno (Czech Republic) and the acoustic (sound velocity, dynamic elastic modulus, acoustic constant), physical (moisture content and density) and mechanical ( elastic modulus and compressive strength) properties of wood degraded by white-rot fungi measured in laboratory environment.

According to an analysis of variance, there is a significant statistical difference between the values measured by the PICUS ${ }_{\circledast}$ acoustic tomograph and the values measured by ARBOTOM $_{\circledast}$ and ARBORSONIC ${ }_{\circledast}$ tomographs.

Based on the measured data, it can be stated that PICUS ${ }_{\circledast}$ measured velocities are considerably lower than those recorded by the other acoustic tomographs (ARBOTOM ${ }_{\circledast}$ and ARBORSONIC $_{\circledast}$ ). Image reconstructions (tomograms) from the three acoustic tomographs differ significantly from each other. Measured material properties of degraded wood will be applied in the interpretation of non-destructive test results used for tree stability assessment and to understand the correlation between fungal species and the level of wood degradation.
\end{abstract}

Keywords: sound propagation, tomograph, wood-decay fungi, material properties, tree stability, biological degradation

Biography 


\title{
Cascading Potential for Recovered Wood from Heavy Timber Frame Typologies in Pre-Modern Dwelling Buildings in Madrid
}

\author{
Marina de Arana-Fernández ${ }^{1^{*}}-$ Daniel F. Llana ${ }^{1,2}$ - Bahareh Nasiri $i^{3}$ - Guillermo \\ Íñiguez-González ${ }^{1,2}$ \\ ${ }^{1}$ Department of Foresty and Enviromental Engineering and Management, \\ MONTES (School of Forest Engineering and Natural Resources), Universidad \\ Politécnica de Madrid, Madrid, Spain \\ m.aranafer@gmail.com* \\ danielfllana@gmail.com \\ guillermo.iniguez@upm.es \\ ${ }^{2}$ Timber Construction Research Group, Universidad Politécnica de Madrid, \\ Madrid, Spain \\ ${ }^{3}$ Department of Bioproducts and Biosystems, Aalto University, Espoo, Finland \\ bahareh.nasiri@aalto.fi
}

\begin{abstract}
Wood is one of the premodern materials par excellence. It lost presence due to the appearance of steel and concrete in construction, however, now it is regaining importance for its structural performance, its capacity to fixate $\mathrm{CO}_{2}$ and its low energy demand during manufacturing process. In our current climate emergency, rethinking how resources are treated has become a need, and wood can be in the centre of the debate. The use of recovered timber in construction could be an important measure to widen the lifespan of this material. Cascading could help in the development of new economic models and potentiate environmental-friendly others like circular economy.

Premodern buildings could be a great source for reclaimed timber because the presence of timber in them is almost inevitable. A quantification of amount of recoverable timber that can be obtained from them is interesting in order to potentiate the reuse of the material.
\end{abstract}

Key words: Cascading, circular economy, corrala, dwelling typologies, Madrid cultural heritage, reclaimed timber, timber reuse 


\section{Proceedings of the 2020 Society of Wood Science and Technology International Convention}

\section{Introduction and state of the art}

Timber has been used in construction since the ancient times. It is a highly versatile material, workable and resistant. It has gone through difficult times due to the appearance of modern materials such as steel and concrete, but nowadays it is regaining its former importance thanks to the evolution of timber engineering products, the prefabrication and for its great performing characteristics, resistance and sustainability.

In the present times, due to the climate change emergency that we are enduring where our ecosystems and resources are being affected (Lindner et al., 2010; Schröter et al., 2005), material reuse and recovery are necessary to achieve a sustainable and responsible economy and way of life. Timber presents itself as one possible solution, being the only construction material to fixate $\mathrm{CO}_{2}$ (Wood, 1991) and it can be adapted to new needs without the use of large amounts of energy in the transformation process (Peck, 2001).

Circular economy is a key principle for reaching sustainable development goals (Sachs et al., 2019). This concept has highlighted sustainable use of resources, materials and energy due to increasing dependency on resources and increasing resource consumption (de Wit et al., 2018). Remarkably, around $40 \%$ of the resource consumption has been used in building and construction industry on a yearly basis (Bringezu et al., 2017). Thus, it is necessary to enhance the resource efficiency of materials in buildings through cascading concept, reusing the same piece or unit several times (Sirkin \& Houten, 1994). Timber is the perfect example for it as it could help to achieve this compromise with the planet thanks to its renewability and reusability.

The spread of the use of recovered timber could be one of the challenges of this century. Studies are being held in order to determine the potential for cascading of timber and how can it be obtained from building demolitions (Fraanje, 1997; Höglmeier et al., 2013; Sakaguchi et al., 2016, 2017). As a result of those studies, cascading wood from buildings is a possible and influential course of action, though several choices, such as ecological taxation of resources, prohibition to dumping waste wood on site, regulation enabling the use of recovered wood in buildings and reliable data, showing the quantity and quality of available recovered wood, need to favour cascading.

Although there is currently an abundance of forests, the resources of the planet are finite, and it is our duty to rethink how we use them in a more efficient, responsible and circular way.

Re-examining how we have built our cities, the constructive systems and the pre-modern materials used, could be a good start to understand the cascading potential for recovered wood.

Firstly, cities are fundamentally made of anonymous constructions, which are the true originators of a good urban tissue, and their use is mainly dwelling. These buildings are rarely the most notorious constructions of a city, but they are the most common, the less protected by cultural heritage laws and the most likely to suffer a change of use or rehabilitation. 


\section{Proceedings of the 2020 Society of Wood Science and Technology International Convention}

Secondly, studying the pre-existent constructive systems and typologies could deepen the understanding of the aforementioned buildings. A very common dwelling typology in Mediterranean cultures is the house with a courtyard. This typology has evolved since the ancient Mesopotamians, the Greeks and the Romans to our days, and it has been progressively adapted to the times, the culture and the urban tissue. There is an endemic type of courtyard house in Madrid mainly built between the $16^{\text {th }}$ and $19^{\text {th }}$ centuries that is very present in the city centre, called "corrala" (Santa Cruz Astorqui, 2012).

Finally, vernacular residential constructions are linked to a city's DNA and it is important to maintain them in order to keep the essence of our cities. As the pre-modern buildings that they are, all of them have timber in its structure. The quantification of these structures, determining the species used and the general amount of timber saved, could lead to a change of paradigm and foster new behaviours towards rehabilitation, construction and reuse of materials.

\section{Traditional typologies and timber constructive systems in residential buildings in Spain}

In Spain, as well as in many other countries, timber constructive systems have evolved from the primigenial log shelters, to more intricated systems as heavy timber frames and light timber frames. Recently, due to the appearance of new timber-derived products, an important development in new constructive systems has taken place. The recent appearance of these new ways of construction has changed the paradigm for timber buildings.

In Spain, as it happened in other countries, the appearance of new materials such as concrete and steel has put timber in a second place, and almost since the beginning of the $20^{\text {th }}$ century timber construction began to lose presence in the Spanish construction paradigm.

The Spanish Civil War (1936-1939) supposed a turning point in the industrial use of timber (Zapata Blanco, 1998). Timber's use in construction was relegated to the countryside and northern areas of the country, where forests are more present. Thus, the main "source" of recoverable structural timber is premodern architecture; considering premodern constructions those buildings that were built with neither concrete nor steel in their structures.

The main timber constructive system in Spain before the Civil War is heavy timber frame. Timber is present in the horizontal and roofing structures and, in some typologies, in the vertical structure too, either laced in the walls or as isolated supports.

In the following scheme (Fig. 01), the main dwelling typologies, materials and constructive systems have been studied to define the most common residential timber buildings and main examples of premodern architecture with timber structures. 


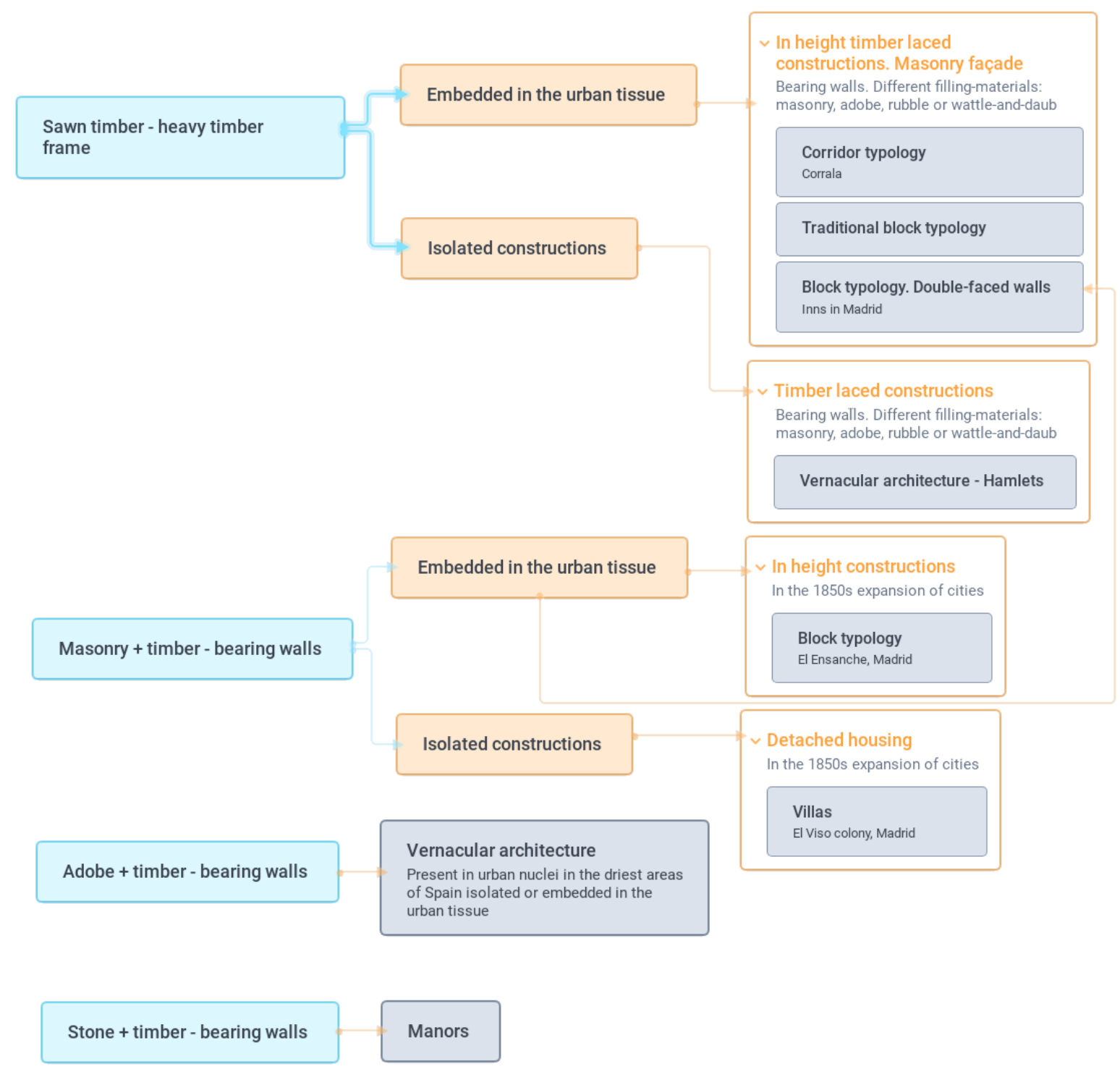

Fig. 01. Traditional typologies scheme.

Recovered timber has an enormous potential as constructive material, either as sawn timber or transformed into a timber-derived product. Analysing the state of the built heritage, a deeper understanding of the existing structures could be achieved. It could lead, for instance, to more curated demolition practices that could benefit both the conservation of built heritage and the reuse of the timber obtained from it (Nunes et al., 2019). If the obtained pieces are in good conditions (not damaged by water or attacked by termites or fungi), they could be placed into similar buildings that use pieces of approximately the same dimensions.

In this process of reusing the timber obtained from existing buildings, a new category has been stablished. Depending on the amount and quality of the material (i.e. dimension of the cross- 


\section{Proceedings of the 2020 Society of Wood Science and Technology International Convention}

section, length, species and condition of the pieces) that can be obtained from the existing timber buildings, they will be considered as either "sources" or "drainers" of timber. The sources will be those buildings from which reusable timber can be obtained, and drainers will be those in which timber is needed in order to be rehabilitated.

Again, demolition practices are of vital importance because with more curated systems (e.g. manual demolition), more material may be recovered for potential reuse. With better demolition practices, all buildings are potential sources for recovered wood, excepting the ones protected by cultural heritage laws.

For the present study, a vernacular dwelling typology has been chosen; the Madrilenian "corrala". It has been selected in order to analyse the potential of an existent building to be source of recoverable timber. The state of the timber of demolished buildings is interesting to be defined to determine its potential for cascading (Sakaguchi et al., 2016) and to quantify the amount of timber in the built heritage of Spain.

\section{Pre-modern Madrid. The "corrala"}

The "corrala" belongs to the corridor typology. It is a common type of building in Madrid's centre because it was an abundant typology and many of those buildings have arrived at our days mainly untouched. In Madrid's Centro district, there are 3,221 dwelling buildings built prior to 1900 (EMVS - Empresa Municipal de Vivienda y Suelo), 286 of which are "corralas" (Santa Cruz Astorqui, 2012). They represent the clearest example of vernacular residential architecture in the city.

This typology has been in use since the $16^{\text {th }}$ century until the first decades of the $20^{\text {th }}$ century, and in the meantime has not substantially evolved. Originally, it was a simple house and when the city began to grow and the need of dwelling was a pressing matter, these houses began to suffer transformations to lodge all the people coming to the city. They began to grow in height and depth, inhabiting the spaces that were previously destined for the courtyards, and ended by tilting the urban tissue (Fig. 02). Most of them have arrived to our days as 4-storey buildings. The expansive use of the typology took place between the $17^{\text {th }}$ and $19^{\text {th }}$ centuries. 


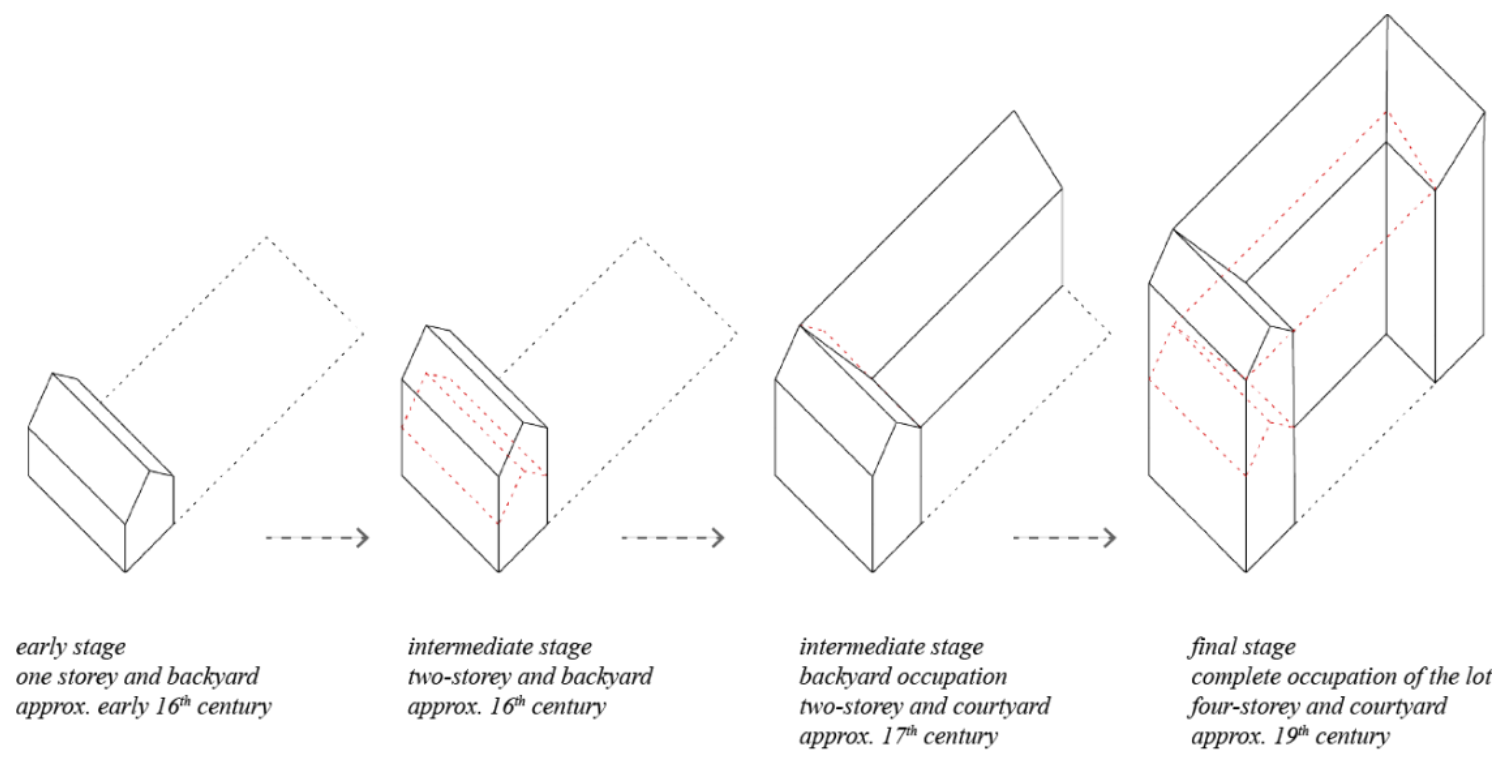

Fig. 02. Development of a "corrala" from the beginning to the complete occupation of the urban lot.

The constructive system, heavy timber frame with timber-laced walls, remained the same during all the years that the typology was in use. All the supporting structure is timber made with pieces of different cross-sections depending on the part of the building that they are placed. The crosssections were defined by the urbanistic laws of the moment, "Ordenanzas de Madrid" by Ardemans (1719), and were anthropomorphic measurements (e.g. elbows, hands, feet, fingers) (Fig. 03).
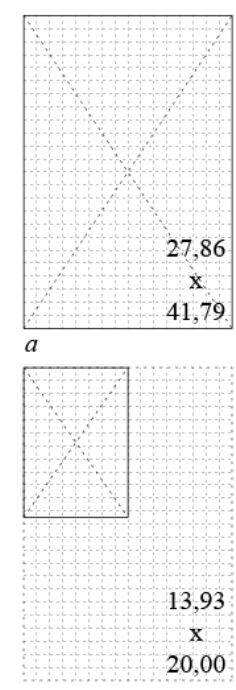

$e$
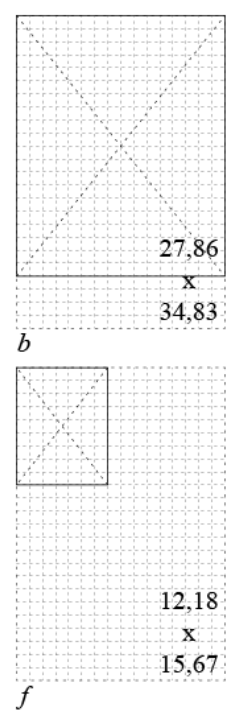
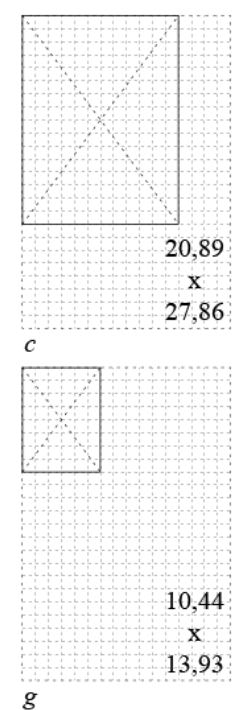
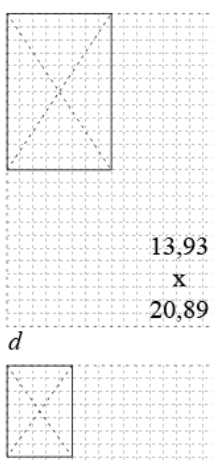

8,70

$\mathrm{x}$

12,18

all in $\mathrm{cm}$ a. "Elbow beam" of undetermined length b. "Foot-and-quarter beam" of undetermined length

c. "Foot beam" of undetermined length d. "Hand beam" of lengths varying from 6,50 to $3,34 \mathrm{~m}$.

e. "Eleven-and-a-halffinger joist" of lengths varying from 5,00 to $2,78 \mathrm{~m}$.

f. "Nine-finger joist" of length of $4,45 \mathrm{~m}$ g. "Half-a-foot joist" of undetermined length h. "Seven-finger joist" of lengths varving from

Fig. 03. Cross-sections established by Teodoro de Ardemans, 1719. 
As a vernacular typology being built in the urban tissue, the building adapted itself to the space available, not following any particular urban guidelines. The typical "corrala" has generally one facade front and is developed in depth. It is built between party walls and has the courtyard as common feature, although it can vary in extension and position within the lot. The surface considered for the archetypical "corrala" illustrated in Fig. 04, is of 260 sqm. per storey, and fourstorey height.

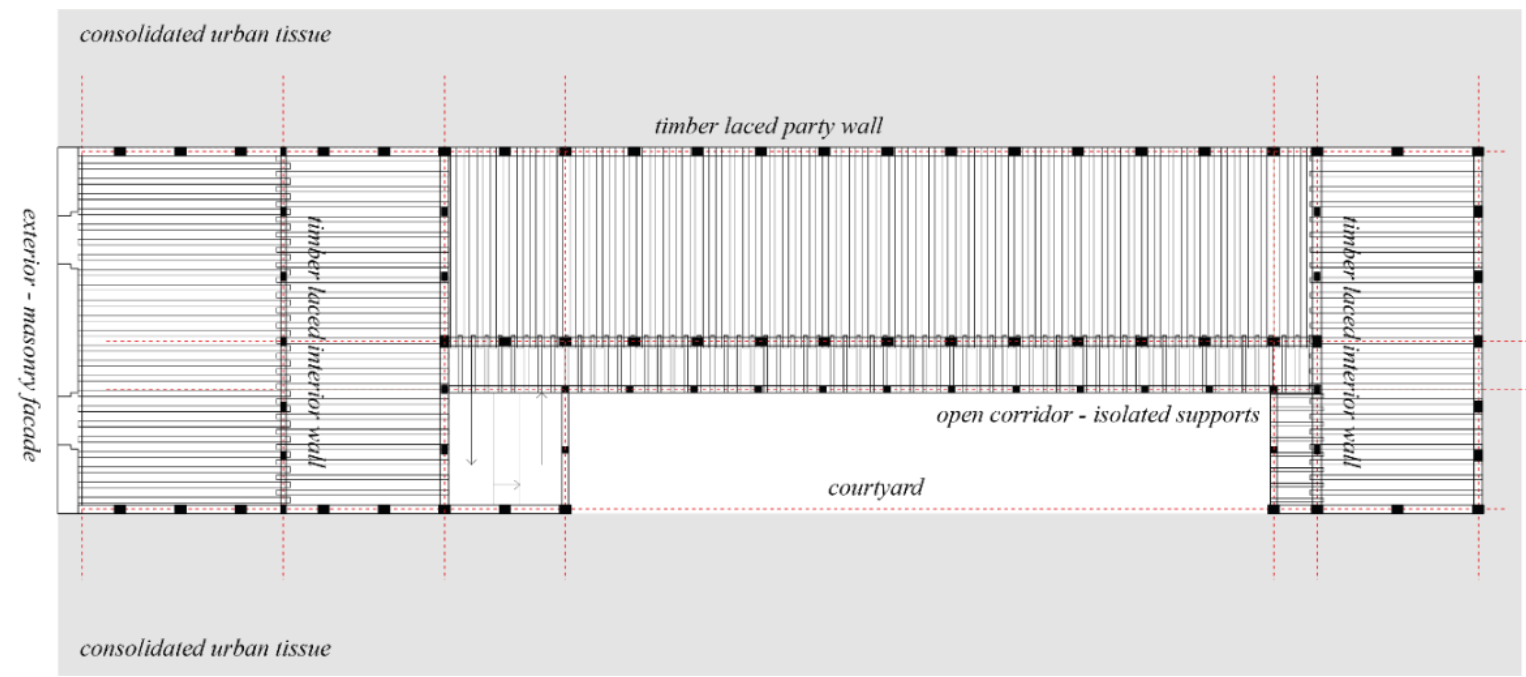

Fig. 04. Plan of an archetypical "corrala".

Until the $19^{\text {th }}$ century, the totality of the supporting structure of the dwelling buildings was timber made. After the $19^{\text {th }}$ century, facades begun to be masonry-made instead of timber laced and the corridor supports could be made of cast iron.

The vertical structure, with exceptions in the facade (those built after the $18^{\text {th }}$ century), is composed by timber-laced walls (Aroca Hemández-Ros \& González-Redondo, 2000). Timber laced structures are mentioned in texts from the $12^{\text {th }}$ century (Langenbach, 2009), and its use is spread around the globe. The laced wall is composed by vertical and horizontal timber elements that support the upper floors (Fig. 05). 


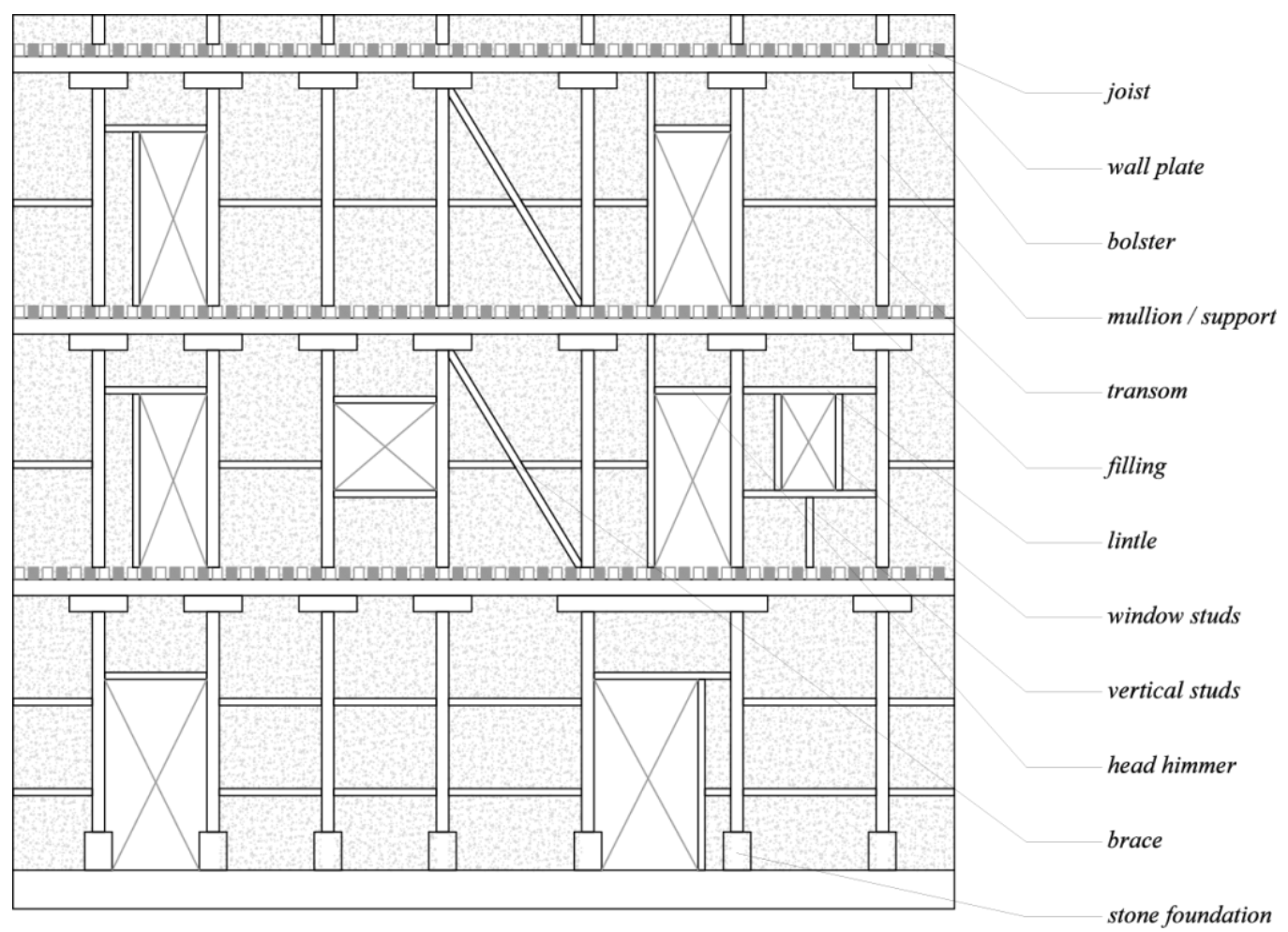

Fig. 05. Composition of a laced wall in a "corrala".

The filling between the supports could be either masonry, adobe or wattle-and-daub. For the "corralas" built after the fire of the Main Square in Madrid in 1790, masonry filling began to be the most used because it avoided the spread of the potential fires (Villanueva, 1790).

In the "corrala" the horizontal structure, composed by beams and joists, is also timber-made. Being the constructive system the heavy timber frame, the joints between pieces are usually mortise and tenon, and no steel is present.

The roofing structure is usually composed by ridgepole trusses with a simple design. Due to the lack of high loadings and the cheap construction, they usually lack the bottom chord (Fig. 06). 


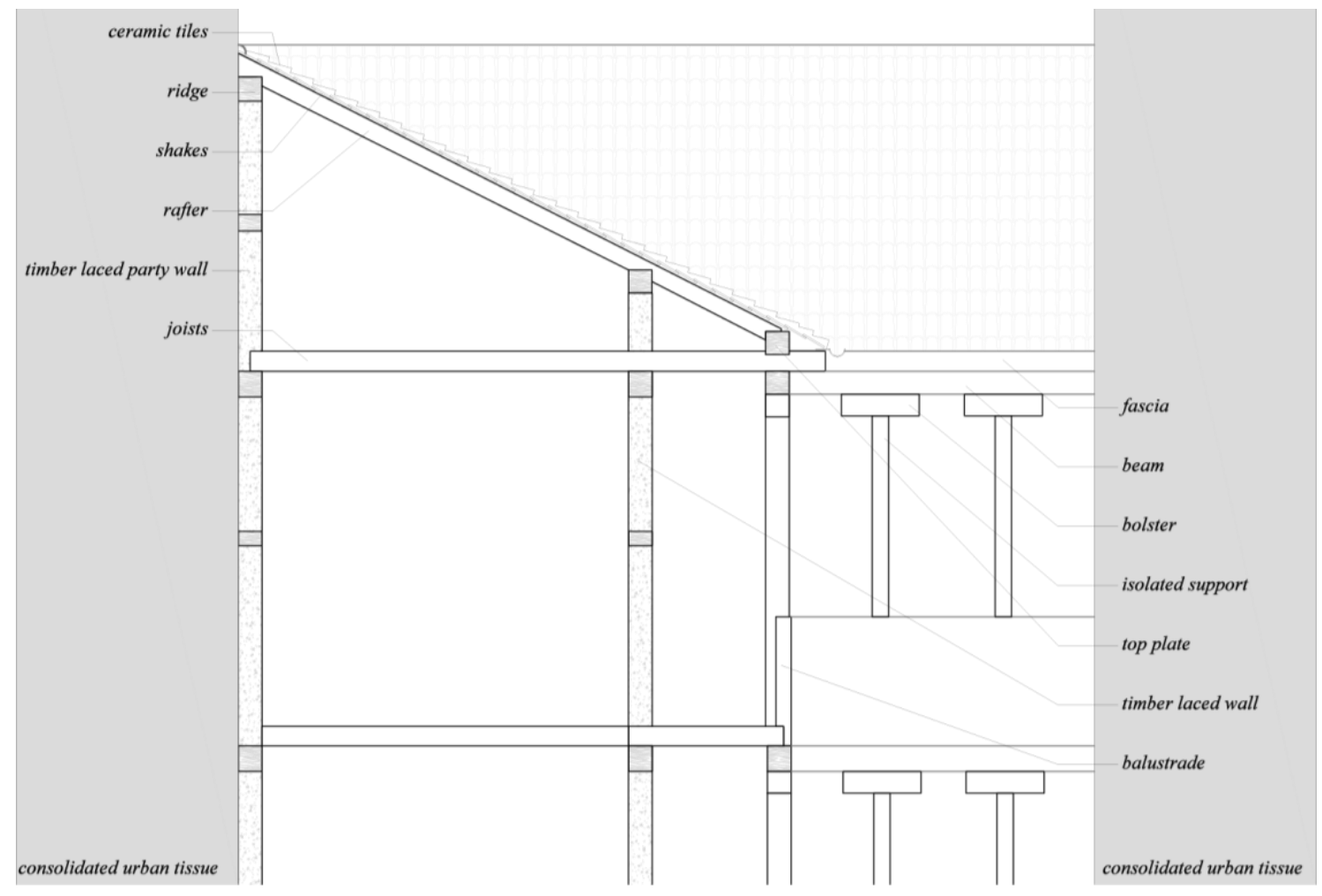

Fig. 06. Transverse section.

The species used for this type of building are mainly Scots Pine (Pinus Sylvesris L.) (Santa Cruz Astorqui, 2012) and European Black Pine (Pinus nigra A.) because they are the most common and accessible species of timber due to the proximity of the forests to the city.

The interest of the present work is to analyse the volumes of timber that could be recovered from the pre-existing buildings. The data obtained from this analysis would help to determine the cascading potential that these buildings, and in particular the "corrala", have for the timber in their structures.

In order to achieve this, and with the description and characterisation of the archetypical "corrala", the general volume calculations have been made dividing the structure in: vertical structure, horizontal structure, roofing and shakes (Table 01). 
Proceedings of the $\mathbf{2 0 2 0}$ Society of Wood Science and Technology International Convention

Table 01. Volumes and sections of the timber structures present in the "corrala"

\begin{tabular}{|l|l|l|}
\hline Location in the building & Volume of timber in $\mathrm{m}^{3}$ & \multicolumn{1}{|c|}{ Average section of the pieces in } \\
\hline Vertical structure & 38.00 & $20.89 \times 27.86$ \\
\hline Horizontal structure & 102.00 & $13.93 \times 20.00$ \\
\hline Roofing & 15.40 & $13.93 \times 20.89$ \\
\hline Shakes (roof + flooring) & 17.80 & Thickness $=2.00$ \\
\hline Total (without shakes) & 155.40 & - \\
\hline
\end{tabular}

The laced walls (mullions, wall plates) and isolated supports were considered in the calculations of the vertical structure. In the horizontal structure, joists and bolsters. In the roofing, the trusses. The shakes were not considered in the general figure due to the fact that they are not structural pieces and the possibilities to reuse them are lower than with the structural pieces because of its use and location in the building.

Previous studies consider that the amount of recovered wood from buildings that could be reused as bearing structures is a $26 \%$. If the timber could be transformed into other pieces, the reusable amount would be a $45 \%$ (Höglmeier et al., 2013). If the results obtained from the "corrala" are merged with this data, from the raw $155.40 \mathrm{~m}^{3}, 40.40 \mathrm{~m}^{3}$ would be reusable as supporting structures and $69.90 \mathrm{~m}^{3}$, would be the total of timber reusable to be transformed into other products.

As it has been described, there is timber in all the parts of the structure. The geometry of the pieces, their lengths, sections and timber quality, makes them an interesting source for recovered timber.

\section{Conclusions: the potentials for cascading}

Timber is present in all the elements of the structure of the "corrala" with different sections and lengths. The reusability of the timber is very high because the joinery between the pieces is mainly steel-free; the pieces are usually joint by tight ropes and mortise and tenon. The fact that almost all the elements of the structure can be reused allows the categorization of these buildings as "sources" of recoverable timber.

The potential of timber to be transformed and reused into other structures is immense. Those pieces could be either used to rehabilitate similar buildings protected by heritage laws that need the same kind of timber or transformed into new timber products that would also have great performance although they were made with recovered timber. 


\section{Proceedings of the 2020 Society of Wood Science and Technology International Convention}

Cascading should be put into practice with the timber recovered from constructions by transforming high quality timber into smaller pieces such as joists. After its service life it could be transformed into boards, then into chips, and so on until it is no longer reusable.

These results should encourage on the one hand, a revision and completion of the current regulation of reclaimed timber to establish the parameters in which timber is reclaimed and further uses of it. On the other hand, the deconstruction of buildings instead of the demolition in order to enhance the possibilities for timber to be reused once the life of the building has come to an end.

\section{Acknowledgements}

Project InFutUReWood is funded in Spain by the Ministerio de Ciencia, Innovación y Universidades (MICIU). Project reference PCI2019-103544. Diseño innovador para el futuro uso y reutilización de componentes de edificación de madera.

Project InFutUReWood is supported under the umbrella of ERA-NET Cofund ForestValue by Vinnova - Sweden's Innovation Agency, Formas - Swedish Research Council for Sustainable Development, Swedish Energy Agency, the Forestry Commissioners for the UK, the Department of Agriculture, Food and the Marine for Ireland, the Ministry of the Environment for Finland, the Federal Ministry of Food and Agriculture through the Agency for Renewable Resources for Germany, the Ministry of Science, Innovation and Universities for Spain, the Ministry of Education, Science and Sport for Slovenia. ForestValue has received funding from the European Union's Horizon 2020 research and innovation programme under grant agreement $\mathrm{N}^{\circ} 773324$.

\section{References}

Ardemans, T. (1719). Ordenanzas de Madrid, y otras diferentes que se practican en las ciudades de Toledo y Sevilla, con algunas advertencias á los alarifes y particulares, y otros capítulos añadidos á la perfecta inteligencia de la materia, que en todo se cifra en el gobierno. Imprenta de Don Joseph Doblado.

Aroca Hemández-Ros, R., \& González-Redondo, E. (2000). Tipificación de las soluciones constructivas de la edificación doméstica madrileña de los siglos XVIII y XIX. In A. Graciani, S. Huerta, E. Rabasa, M. Tabales, I. J. de Herrera, SEdHC, U. Sevilla, J. Andalucía, \& C. Granada (Eds.), Actas del Tercer Congreso Nacional de Historia de la Construcción (pp. 2628).

Bringezu, S., Ramaswami, A., Schandl, H., O’Brien, M., Pelton, R., Acquatella, J., Ayuk, E. T., Chiu, A. S. F., Flanegin, R., Fry, J., Giljum, S., Hashimoto, S., Hellweg, S., Hosking, K., Hu, Y., Lenzen, M., Lieber, M., Lutter, S., Miatto, A., Zivy, R. (2017). Assessing global resource use. A system approach to resource efficiency and pollution reduction. In International Resource Panel of the United Nations Environmental Programme. UNESCO (ed.). de Wit, M., Hoogzaad, J., Ramkumar, S., Harald, F., \& Douma, A. (2018). The Circularity Gap 
Proceedings of the 2020 Society of Wood Science and Technology International Convention

Report. An analysis of the circular state of the global economy. In Circle Economy (Issue January).

Fraanje, P. J. (1997). Cascading of pine wood. Resour. Conserv. Recy., 19(1), 21-28.

Höglmeier, K., Weber-Blaschke, G., \& Richter, K. (2013). Potentials for cascading of recovered wood from building deconstruction - A case study for south-east Germany. Resour. Conserv. Recy., 78, 81-91.

Langenbach, R. (2009). Don't tear it down! : preserving the earthquake resistant vernacular architecture of Kashmir. UNESCO (ed.).

Lindner, M., Maroschek, M., Netherer, S., Kremer, A., Barbati, A., Garcia-Gonzalo, J., Seidl, R., Delzon, S., Corona, P., Kolström, M., Lexer, M. J., \& Marchetti, M. (2010). Climate change impacts, adaptive capacity, and vulnerability of European forest ecosystems. Forest Ecol. Manag., 259(4), 698-709.

Nunes, A., Palmeri, J., \& Love, S. (2019). Deconstruction vs. Demolition: An evaluation of carbon and energy impacts from deconstructed homes in the City of Portland (Issue March).

Peck, T. (2001). The International Timber Trade (Woodhead Publishing Limited (ed.)). Woodhead Publishing Limited.

Sachs, J. D., Schmidt-Traub, G., Mazzucato, M., Messner, D., Nakicenovic, N., \& Rockström, J. (2019). Six Transformations to achieve the Sustainable Development Goals. Nat. Sustain., 2(9), 805-814.

Sakaguchi, D., Takano, A., \& Hughes, M. (2016). The potential for cascading wood from demolished buildings: the condition of recovered wood through a case study in Finland. Int. Wood Prod. J., 7(3), 137-143.

Sakaguchi, D., Takano, A., \& Hughes, M. (2017). The potential for cascading wood from demolished buildings: potential flows and possible applications through a case study in Finland. Int. Wood Prod. J., 8(4).

Santa Cruz Astorqui, J. (2012). Estudio tipológico, constructivo y estructural de las casas de corredor en Madrid. Universidad Politécnica de Madrid.

Schröter, D., Cramer, W., Leemans, R., Prentice, I. C., Araújo, M. B., Arnell, N. W., Bondeau, A., Bugmann, H., Carter, T. R., Gracia, C. A., De La Vega-Leinert, A. C., Erhard, M., Ewert, F., Glendining, M., House, J. I., Kankaanpää, S., Klein, R. J. T., Lavorel, S., Lindner, M., Zierl, B. (2005). Ecology: Ecosystem service supply and vulnerability to global change in Europe. Science, 310(5752), 1333-1337.

Sirkin, T., \& Houten, M. ten. (1994). The cascade chain. A theory and tool for achieving resource sustainability with applications for product design. Resour. Conserv. Recy., 10(3), 213-276.

Villanueva, J. de. (1790). Ordenanzas que se incluyen en el Informe enviado el 1 de octubre de 1790 al Ayto. de Madrid.

Wood, H. G. (1991). Life with $\mathrm{CO}$ or $\mathrm{CO}_{2}$ and $\mathrm{H}_{2}$ as a source of carbon and energy . FASEB J., 5(2), 156-163.

Zapata Blanco, S. (1998). Historia económica de la madera en España, desde mediados del siglo XIX a 1936. Un primer esbozo. (Vol. 9).

\section{Biography}




\title{
The Economic Balance of Obtaining the Raw Material for Briquettes and Pellets from Forest Sanitation
}

\author{
MOLNÁR Gábor * \\ dr.eng. - Transilvania University in Brasov \\ Address: Str. Universitatii nr. 1, 500068 Brasov, Romania \\ E-mail:molgabor@yahoo.com \\ Loredana Anne-Marie RĂDULESCU \\ Prof.dr.eng. - Transilvania University in Brasov \\ Address: Str. Universitatii nr. 1, 500068 Brasov, Romania \\ E-mail: loredana@unitbv.ro
}

\begin{abstract}
In Romania, there are several tests for the use of wood biomass resulting from the exploitation and cleaning of forests, respectively of pastures and woodlands, in order to obtain energy. For this purpose the collected wood biomass is chopped, crushed when the chipping is obtained, by the process of transforming the wood and wood residues into technological chips with dimensions of $10-35 \mathrm{~mm}$.

Chopping is the raw material for obtaining industrial products, plates, cellulose, or which can be used as fuel, briquettes, pellets.

In order to make a calculation to justify the use of the ax in order to obtain the energy, we start from calculating the possible area of collection of the remains needed for the ax. For example the forested area + pastures + meadows in Harghita county according to I.N.S1.: $264.113+153.385+162.739$ hectares. So 580.237 hectares.

Through this paper I have proposed to bring to your attention a very topical theme, with pronounced practical valences, namely the superior use of wood material from forest sanitation.
\end{abstract}

Key words: spruce; biomass; forest sanitation.

\section{INTRODUCTION}

Analyzing the quantity of firewood needed for heating at the country level we can see that the market for briquettes is huge and by using for heating the briquettes by the inhabitants, especially in the rural area, the cost is reduced by up to $50 \%$ compared to the use of fire wood. Thus, we can speak of an efficiency resulting from the difference in density and calorific power between firewood and briquettes (680$740 \mathrm{~kg} / \mathrm{m}_{3}$ dry firewood, $900 \mathrm{~kg} / \mathrm{m}_{3}$ in briquettes). At the same time, the burning mode differs, the briquettes burn for a longer period of time, increasing the energy efficiency of the stoves compared to the dry firewood that burns with open fire and in a short time (Coşereanu et al. 2015).

For example, the volume of wood mass from these surfaces, exploited in the period 2008-2017 is of, according to I.N.S: $10,644,600 \mathrm{~m}_{3}$. From the biometrics, the percentage of cracks (Melles 2007) is calculated $319,338 \mathrm{~m}_{3}$ and of bark $851,568 \mathrm{~m}_{3}$, so in total 1,170,996 $\mathrm{m}_{3}$ of unused wood mass.

Figure 1 shows a depot of wood residues from Harghita County.

\section{OBJECTIVE}

The objectives of the research consist in the study of the woody material from the hygiene of the forests, taking into account the cost of harvesting, production and the resulting profit, taking into account the previous studies, completed by the researches carried out by the author.

\section{MATERIAL, METHOD, EQUIPMENT}

* Corresponding author

${ }^{1}$ I.N.S. - Institutul Naţional de Statistică - National Institute of Statistics 


\section{Proceedings of the 2020 Society of Wood Science and Technology International Convention}

The collection of biomass needed for energy use from the forests of Romania began with the technology that allows the application of the method of wood chopping, using:

1. cutting the debris of the operating debris and of the small trees, with mobile shredders, of small size;

2. chopping in the primary platform of the wood in the form of trees or parts of trees.

The study of the collection of the thin wood, of the wood from the hygiene of the forests and of the remains of the forest was carried out in the field, using specific questionnaires at the same time by collecting the data from the National Forest Registry.

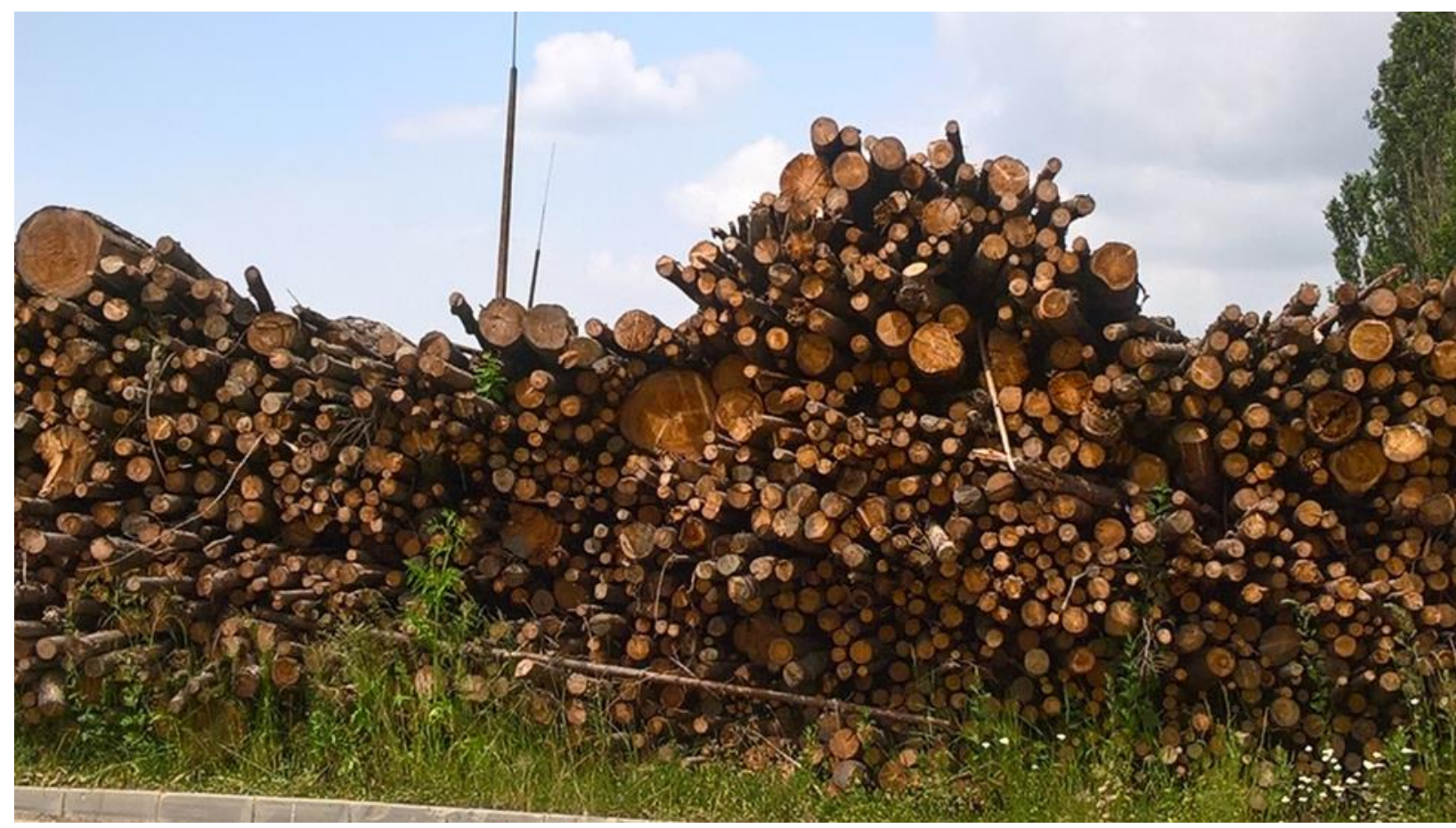

Fig. 1

Wooden warehouse for chopping in Harghita County (photo G. Molnár)

With table and graphs we try to study the cost of collection, production and capitalization.

The collection of the thin wood, of the wood from the hygiene of the forests and of the remains of the forest can be done with trailers, carts, forestry tractors respectively universal and at an approximate price of (information collected from the commonages representants):

- in case of using the forestry tractor for the collection of the thin wood, the price is of 38 - 55 lei per $\mathrm{m}_{3}$ wood material exploited and transported on the forest road, namely 38 lei per $\mathrm{m}_{3}$ is the cost for felling and gathering (28 lei per $\mathrm{m}_{3}$ ) plus cleaning of cribs (10 lei per $\mathrm{m}_{3}$ ) and transported maximum $500 \mathrm{~m}$, respectively 55 lei per $m_{3}$ is the cost for demolition and gathering (45 lei per $\mathrm{m}_{3}$ ) plus cleaning of cribs (10 lei per $\mathrm{m}_{3}$ ) and transported maximum $4500 \mathrm{~m}$.

- in the case of the use of slags for the collection of the thin wood, the price is $62-82$ lei per m3 wood material exploited and transported on the forest road, namely 62 lei per $m_{3}$ is the cost for felling, cleaning cracks and collecting (40 lei per $\left.\mathrm{m}_{3}\right)$ plus the cost of binding ( 7 lei per $\mathrm{m}_{3}$ ) plus the proximity with the forestry tractor ( 15 lei per $\mathrm{m}_{3}$ ) and transported maximum $500 \mathrm{~m}$, respectively 82 lei per $\mathrm{m}_{3}$ is the cost for felling, cleaning pots and collecting (60 lei per $\left.\mathrm{m}_{3}\right)$ plus the cost of binding ( 7 lei per $\mathrm{m}_{3}$ ) plus the nearest one with the forestry tractor (15 lei per $\mathrm{m}_{3}$ ) and transported maximum $4500 \mathrm{~m}$.

- collection, transport of cakes, scraps and debris are not for a fee (Commonages).

Determining the price of a m3 of chop depends on: 


\section{Proceedings of the 2020 Society of Wood Science and Technology International Convention}
A. The price of wood per foot
B. Cost of machine operating time and productivity over 8 hours
C. Different, unpredictable (5\%)

A. The price of wood per foot

For future calculations we will use the following transformations:

$0.7 \mathrm{~m}_{3}=1 \mathrm{~m}$ ster,

$1 \mathrm{~m}$ ster chisel $=0.67 \mathrm{~m} 3 \mathrm{nc}$ (non-compact cubic meter) (Gaber et al. 2014) biomass is:

From the information collected from D. S2., 2019, we know that the price of one $\mathrm{m}_{3}$ of wood for

- thin wood, weeding I, 50 - 75 lei / m3 (Sandominic commonages),

- thin wood, cracking II, 95 lei / m3 (Sandominic commonages),

- thin wood, weeding, 42 - 70 lei / m3 (D. S. Harghita),

- wood from hygiene, 260 lei / m3 (D. S. Suceava), commonages).

- jars and other debris, free of charge in the amount of collection and transport (the Sandominic

At the same time $0.4 \mathrm{~m}_{3}$ of wood is equal to $1 \mathrm{~m}_{3} \mathrm{nc}$ of chopping (Gaber et al. 2014). If for one $\mathrm{m}_{3}$ of thin wood the price offered in 2019 is on average 68.5 lei, the price $1 \mathrm{~m} 3 \mathrm{nc}$ of chopping is 30.2 lei.

B. The cost of the machine operating time and the productivity for 8 hours consists of the cost-hourmachine cost (CTOM) of the following phases of work, respectively the quantity of wood processed per hour:

a. Shaping of small wood

b. The collection of the thin wood, wood from hygienic and the resulting wood residues

c. Transport of thin wood and wood waste to the primary platform

d. Wood chipping in the primary platform

e. Transport to the combustion boiler or briquetting / pellet press

a. Forming small wood, according to symbol D62c5 $\left(^{* \star \star *} 1997\right)$ we know that the production of a working group with two workers is $40.37 \mathrm{~m}_{3}$ in 8 hours per worker. The cost of the labor for the 8 hours and 2 workers is: 8 hours $\times 2$ workers $\times 14.55$ Lei / $\mathrm{h}=232.8$ lei, which can be transformed into a cost related to $1 \mathrm{~m}_{3} \mathrm{nc}$ of chopping, which is $6.54 \mathrm{Lei} / \mathrm{m}_{3} \mathrm{nc}$ of cut $\left(232.8 \mathrm{Lei} /\left(\left(2{ }^{*} 40.37^{*} 0.7{ }^{*} 0.67\right)=35.60 \mathrm{~m} 3 \mathrm{nc}\right)\right.$ of cut realized).

The cost-hour-machine cost, CTOM, that is the cost of the small wood shaping machine, mechanical saw:

The purchase price of the machine is 2000 lei,

Amortization period 5 years,

Number of hours of use per year 1600 hours

$10 \%$ interest

Fixed expenses

Amortization: $2000 /(5 * 1600)=0.25$ lei / h

Interest: $(2000 * 0.1 * 6) /(2 * 5 * 1600)=0.075$ lei $/ \mathrm{h}$

Variable expenses, that is

Maintenance - repairs and others 0.075 lei / $\mathrm{h}$

The total cost of the small woodworking equipment:

$0.25+0.075+0.075=0.40$ lei / $\mathrm{h}$ which represents a cost of $(8 * 0.4) / 35.6=0.089$ lei $/ \mathrm{m} 3 \mathrm{nc}$.

Productivity is the ratio between the production achieved and the total consumption of time without delay, namely $80.74 \mathrm{~m}_{3}$ respectively $35.60 \mathrm{~m} 3 \mathrm{nc}$ in 8 hours, so $4.45 \mathrm{~m} 3 \mathrm{nc}$ in one hour.

\footnotetext{
${ }^{2}$ D.S. Direcția silvică, Forestry Direction
} 


\section{Proceedings of the 2020 Society of Wood Science and Technology International Convention}

$=201.16$ lei

Total processing cost, $\mathrm{Ct}=(\mathrm{CTOM} * 8$ hours $)+\mathrm{CMat}=0.089 * 8+6.54 * 30.65=0.712+200.45$

b. The collection of wood materials with harness, in 8 hours:

Minimum workmanship depending on the distance to be assembled, max. $100 \mathrm{~m}$, according to symbol J2la ( $\left.{ }^{* * *} 1997\right)$ is: $8 \times 13.7^{*} 0.63$ lei / hour $=8 * 8.63=69.04$ lei for $12.7 \mathrm{~m} 3$ in 8 hours, so 5.43 lei per m3.

The work according to the gathering distance, between 101 and $200 \mathrm{~m}$, according to symbol J2la $\left.{ }^{* * * *} 1997\right)$ is: $8 \times 13.7{ }^{*} 0.78$ lei / hour $=8 * 10.68=85.64$ lei for $10.19 \mathrm{~m}_{3}$ in 8 hours, so 8.38 lei per m3.

The work according to the gathering distance, between 201 and $300 \mathrm{~m}$, according to symbol J2la $\left.{ }^{* * \star *} 1997\right)$ is: $8 \times 13.7^{*} 0.94$ lei / hour $=8^{*} 12.87=103.02$ lei for $8,59 \mathrm{~m}_{3}$ in 8 hours, so 11.99 lei per m3.

The work according to the gathering distance, between 301 and $400 \mathrm{~m}$, according to symbol J2la $\left.{ }^{* * * *} 1997\right)$ is: $8 \times 13.7^{*} 1.1$ lei $/$ hour $=8^{*} 15.07=120.56$ lei for $7,3 \mathrm{~m}_{3}$ in 8 hours, so 16.51 lei per m3.

The work according to the gathering distance, between 401 and $500 \mathrm{~m}$, according to symbol J2la $\left.{ }^{* * * *} 1997\right)$ is: $8 \times 13.7^{*} 1.25$ lei $/$ hour $=8 * 17.12=137$ lei for $6.4 \mathrm{~m}_{3}$ in 8 hours, so 21.4 lei per m3.

The work according to the gathering distance, between 501 and $600 \mathrm{~m}$, according to symbol J2la $\left.{ }^{* * * *} 1997\right)$ is: $8 \times 13.7^{*} 1.41$ lei $/$ hour $=8^{*} 19.31=154.53$ lei for $5,69 \mathrm{~m}_{3}$ in 8 hours, so 27.15 lei per $\mathrm{m}_{3}$.

The work according to the gathering distance, between 601 and $700 \mathrm{~m}$, according to symbol J2la $\left.{ }^{* * * *} 1997\right)$ is: $8 \times 13.7^{*} 1.56$ lei $/$ hour $=8{ }^{*} 21.37=170.97$ lei for $5.13 \mathrm{~m}_{3}$ in 8 hours, so 33.32 lei per $\mathrm{m}_{3}$

The maximum work according to the distance to be assembled, between 701-1000 $\mathrm{m}$, according to symbol J2la $\left(^{* * * *} 1997\right)$ is: $8 \times 13.7^{*} 2.02$ lei / hour $=8 * 27.67=221.39$ lei for $3,95 \mathrm{~m}_{3}$ in 8 hours, so 56.04 lei per $\mathrm{m}_{3}$.

The thin wood gathering with the arms, in 8 hours:

The work according to symbol J4I $\left.{ }^{* * * *} 1997\right)$ is: $8 \times 13.32 * 1.27$ lei $/$ hour $=8{ }^{*} 16.91=135.35$ lei for $6.30 \mathrm{~m}_{3}$ in 8 hours, so 21.48 lei per $\mathrm{m}_{3}$.

The small wood gathering with arms, in 8 hours:

The work according to symbol J5 $\left({ }^{* * * *} 1997\right)$ is: $8 \times 13.32 * 1.57$ lei / hour $=8 * 20.91=167.29$ lei for $5.1 \mathrm{~ms}$ steri, that is $7.28 \mathrm{~m} 3$ in 8 hours, so 22.97 lei per $\mathrm{m}_{3}$.

Gather woody materials with tassel, in 8 hours:

Minimum workmanship depending on the distance to be assembled, max. $50 \mathrm{~m}$, according to symbol J3la $\left(^{* * *} 1997\right)$ is: $8 \times 13.7^{*} 1.5$ lei $/$ hour $=8^{*} 20.25=162.00$ lei for $5.32 \mathrm{~m}_{3}$ in 8 hours, so 30.45 lei per $\mathrm{m}_{3}$.

The maximum manpower according to the distance to gather, over $400 \mathrm{~m}$, according to symbol J3lf $\left.{ }^{* * * *} 1997\right)$ is: $8 \times 13.7{ }^{*} 3.98$ lei / hour $=8^{*} 54.52=436.2$ lei for $2,09 \mathrm{~m} 3$ in 8 hours, so 208.71 lei per m3.

Gather wood material with universal tractors, in 8 hours:

Minimum workmanship depending on the distance to be assembled, max. $15 \mathrm{~m}$, according to symbol J9a ( $\left.{ }^{* * *} 1997\right)$ is: $8 \times 14.03^{*} 0.2$ lei / hour $=8^{*} 2.80=22.45$ lei for $78.2 \mathrm{~m} 3$ in 8 hours, so 0.28 lei perm3.

The work according to the gathering distance, between $16-50 \mathrm{~m}$, according to symbol $\mathrm{J9b}$ (**** 1997 ) is: $8 \times 14.03{ }^{*} 0,22$ lei / hour $=8{ }^{*} 3.08=24.68$ lei for $71,38 \mathrm{~m} 3$ in 8 hours, so 0.345 lei per m3.

The maximum work depending on the distance to be assembled, over $50 \mathrm{~m}$, according to symbol J9c $\left({ }^{* * * *} 1997\right)$ is: $8 \times 14.03{ }^{*} 0.28$ lei $/$ hour $=8{ }^{*} 3.92=31.42$ lei for $57,28 \mathrm{~m}_{3}$ in 8 hours, so 0.54 lei per $\mathrm{m} 3$.

The cost of the cost-car-hour, CTOM, namely the cost of the harness:

The purchase price of the harness is 10,000 lei,

The purchase price of horses, $2 \times 10,000=20,000$ lei,

Amortization period 5 years,

The number of hours of use per year is 200 days with 8 working hours, namely 1,600 hours, 


\section{Proceedings of the 2020 Society of Wood Science and Technology International Convention}

The insurance premium is 1000 lei / year, Interest calculated by the bank is $10 \%$ per annum.

In the process of working with the harness we must distinguish two types of expenses:

Fixed expenses, that is:

Amortization: $10,000 /(5 * 1600)=1.25$ lei / h,

Interest: $(10,000 * 0.1 * 6) /(2 * 5 * 1600)=0.37$ lei $/ \mathrm{h}$,

Insurance: $1000 / 1600=0.62$ lei $/ \mathrm{h}$.

Variable expenses, that is:

Horse provisions, 20,000 lei per year $=12.5$ lei $/ \mathrm{h}$,

Tires: 5,000 lei / 1,600 $\mathrm{h}=3,125$ lei / $\mathrm{h}$

Repairs, oil and other expenses, $3000 / 1600=1.87$ lei $/ \mathrm{h}$.

The total hourly labor cost of the harness is: $1.25+0.37+0.62+12.5+3.12+1.87=19.73$ lei / $\mathrm{h}$.

The cost of the harness for the activity of collecting the remains, namely the cost per m3 nc produced, is made up of the actual working time plus the standing time ie:

Effective working time:

Collection and transport of wood waste to the primary platform, 8 hours,

Chopping wood, 8 hours,

Transport to the combustion boiler or to the briquetting / pelletized press, 8 hours,

TOTAL $24 \mathrm{~h}$

Stationary time $10 \%$ of the actual working time, namely $2.4 \mathrm{~h}$.

TOTAL $26.4 \mathrm{~h}$

Therefore, the cost of the harness, related to $\mathrm{m}_{3} \mathrm{nc}$ of waste produced, is thus: $19.73{ }^{*} 26.4$ / $35.6=14.63$ lei / m3 nc.

Productivity according to the gathering distance, max. $100 \mathrm{~m}$, namely $12.7 \mathrm{~m} 3$ in 8 hours, respectively 1.58 $\mathrm{m}_{3}$ in one hour.

Productivity according to the distance to be collected, between $101-200 \mathrm{~m}$, namely $10.19 \mathrm{~m} 3$ in 8 hours, respectively $1.27 \mathrm{~m}_{3}$ in one hour.

Productivity according to the distance to be collected, between 201-300 m, namely $8.51 \mathrm{~m} 3$ in 8 hours, respectively $1.06 \mathrm{~m}_{3}$ in one hour.

Productivity according to the distance to be collected, between $301-400 \mathrm{~m}$, namely $7.30 \mathrm{~m} 3$ in 8 hours, respectively $0.91 \mathrm{~m}_{3}$ in one hour.

Productivity according to the distance to be collected, between $401-500 \mathrm{~m}$, namely $6.40 \mathrm{~m} 3$ in 8 hours, respectively $0.80 \mathrm{~m}_{3}$ in one hour.

Productivity according to the distance to be collected, between 501-600 m, namely $5.69 \mathrm{~m} 3$ in 8 hours, respectively $0.71 \mathrm{~m}_{3}$ in one hour.

Productivity according to the distance to be collected, between $601-700 \mathrm{~m}$, namely $5.13 \mathrm{~m} 3$ in 8 hours, respectively $0.64 \mathrm{~m}_{3}$ in one hour.

Productivity according to the distance to be collected, between $701-1000 \mathrm{~m}$, namely $3.95 \mathrm{~m} 3$ in 8 hours, respectively $0.49 \mathrm{~m}_{3}$ in one hour.

Figure 2 shows the relationship between the collection distance and productivity characterized by the polynomial regression equation. 


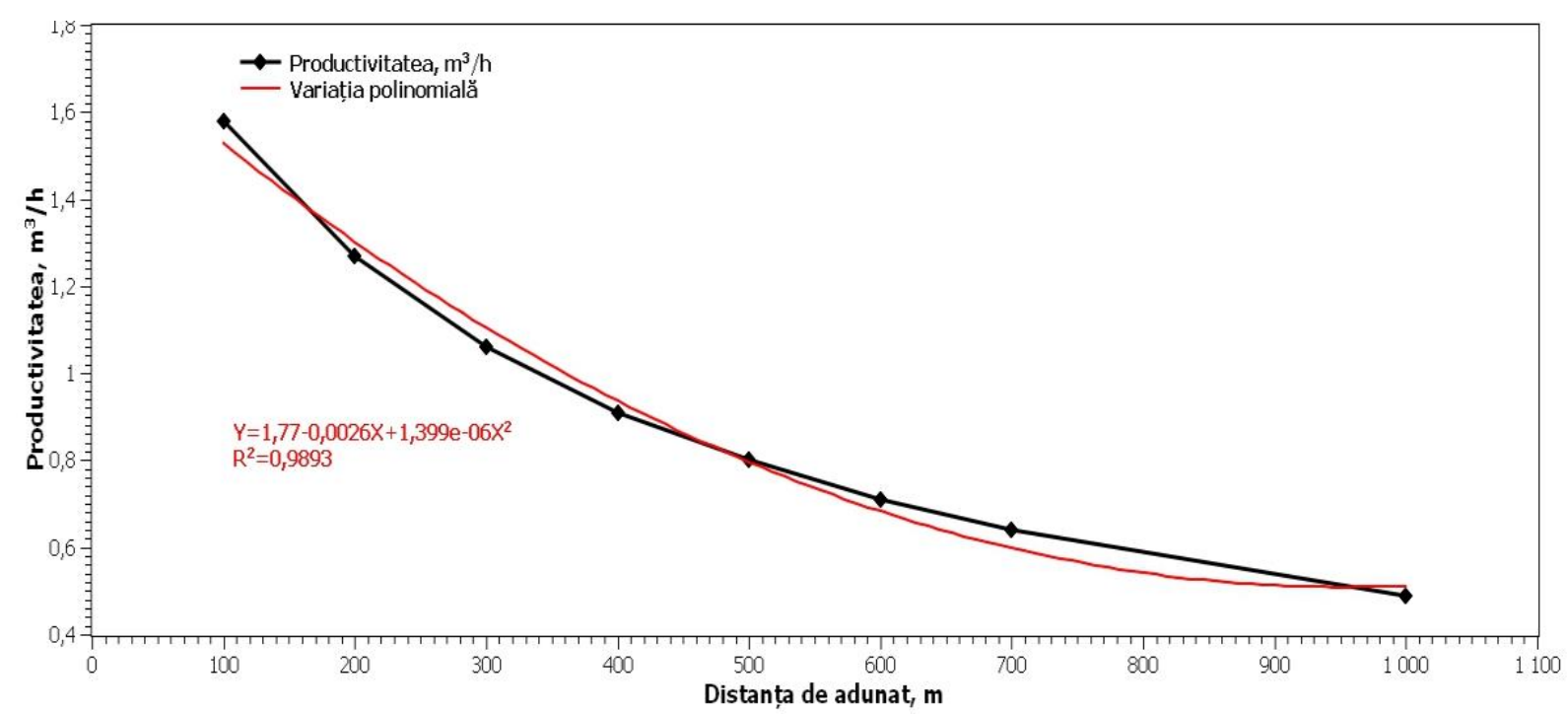

Fig. 2

Increasing the collection distance correlated with productivity

The total processing cost, $\mathrm{Ct}=\left(\mathrm{CTOM}^{*} 8\right.$ hours $)+$ CMat $=14.63 * 8+69.04=186.08$ lei, in case when the distance to gather is max. $100 \mathrm{~m}$.

The total cost of processing, $\mathrm{Ct}=(\mathrm{CTOM} * 8$ hours $)+\mathrm{CMat}=14.63 * 8+221.39=338.4$ lei, if the distance to gather is between 701-1000 m.

The cost-hour-machine cost, CTOM, namely the cost of the universal tractor:

The purchase price of the tractor is 40,000 lei,

Amortization period 5 years,

The number of hours of use per year is 200 days with 8 working hours, namely 1,600 hours,

The insurance premium is 3200 lei / year,

Interest calculated by the bank is $10 \%$ per annum.

In the process of working with the universal tractor we have to distinguish two types of expenses:

Fixed expenses, that is:

Amortization: $40,000 /(5 * 1600)=5$ lei $/ \mathrm{h}$,

Interest: $(40,000 * 0.1 * 6) /(2 * 5 * 1600)=1.5$ lei $/ \mathrm{h}$,

Insurance: $3,200 / 1600=2$ lei $/ \mathrm{h}$.

Variable expenses, that is:

Fuel (9l to 5.62 lei): 50.58 lei / h,

Oils and lubricants (estimated at $20 \%$ of fuel cost): $50.58 * 0.2=10.1$ lei / $\mathrm{h}$,

Tires: 10,000 lei / 1,600 $\mathrm{h}=6.25$ lei $/ \mathrm{h}$

Repairs expenses (estimated at minimum $30 \%$ of depreciation): $5^{*} 0.3=1.5$ lei $/ \mathrm{h}$.

The hourly labor cost, namely the cost-hour-machine cost, CTOM of the universal tractor is: $5+1,5+2+$ $50,58+10,1+6,25+1,5=76,93$ lei $/ \mathrm{h}$.

The cost of the universal tractor for the activity of collecting the remains, namely the cost per m3 nc produced, is made up of the actual working time plus the parking time namely:

Effective working time:

Collection and transport of wood waste to the primary platform, 8 hours,

Chopping wood, 8 hours,

Transport to the combustion boiler or briquetting / pelletizing press, 8 hours, TOTAL $24 \mathrm{~h}$ 


\section{Proceedings of the 2020 Society of Wood Science and Technology International Convention}

Stationary time $10 \%$ of the actual working time, namely $2.4 \mathrm{~h}$.

TOTAL $26.4 \mathrm{~h}$

So the cost of the tractor compared to $\mathrm{m}_{3}$ of waste produced is therefore: $76.93{ }^{*} 26.4 / 35.6=$ 57.00 lei / m3 nc.

Productivity according to the gathering distance, max. $15 \mathrm{~m}$, namely $78.2 \mathrm{~m} 3$ in 8 hours, respectively $9.775 \mathrm{~m}_{3}$ in one hour.

Productivity depending on the distance to be collected, between $16-50 \mathrm{~m}$, namely $71.38 \mathrm{~m}_{3}$ in 8 hours, respectively $8.92 \mathrm{~m}_{3}$ in one hour.

Productivity according to the distance to gather, over $50 \mathrm{~m}$, namely $57.28 \mathrm{~m}_{3}$ in 8 hours, respectively $7.16 \mathrm{~m}_{3}$ in one hour.

The total cost of processing, $\mathrm{Ct}=(\mathrm{CTOM} * 8$ hours $)+\mathrm{CMat}=57{ }^{*} 8+22.45=478.45$ lei, if the distance to gather is max. $15 \mathrm{~m}$.

The total cost of processing, $\mathrm{Ct}=(\mathrm{CTOM} * 8$ hours $)+\mathrm{CMat}=57 * 8+31.42,=487.42$ lei, if the distance to gather is over $50 \mathrm{~m}$.

The cost-hour-car cost, CTOM, namely the cost of the cart (Brad 2010):

The purchase price of the cart is 15,000 lei,

The purchase price of horses, $2 \times 10,000=20,000$ lei,

Amortization period 5 years,

The number of hours of use per year is 200 days with 8 working hours, namely 1,600 hours,

The insurance premium is 1000 lei / year,

Interest calculated by the bank is $10 \%$ per annum.

In the process of working with the cart we have to distinguish two types of expenses:

Fixed expenses, that is:

Amortization: $15,000 /(5 * 1600)=1.87$ lei / h,

Interest: $(15,000 * 0.1 * 6) /(2 * 5 * 1600)=0.56$ lei / h,

Insurance: $1000 / 1600=0.62$ lei $/ \mathrm{h}$.

Variable expenses, that is:

Horse provisions, 20,000 lei per year $=12.5$ lei $/ \mathrm{h}$,

Tires: 5,000 lei / 1,600 $\mathrm{h}=3,125$ lei / $\mathrm{h}$

Repairs, oil and other expenses, $3000 / 1600=1.87$ lei $/ \mathrm{h}$.

The total hourly labor cost of the cart is: $1.87+0.56+0.62+12.5+3.12+1.87=20.54$ lei $/ \mathrm{h}$.

The cost of the cart for the activity of collecting the remains, namely the cost per m3 nc produced, is made up of the actual working time plus the parking time namely:

Effective working time:

Collection and transport of wood waste to the primary platform, 8 hours,

Chopping wood, 8 hours,

Transport to the combustion boiler or to the briquetting / pelletized press, 8 hours,

TOTAL $24 \mathrm{~h}$

Stationary time $10 \%$ of the actual working time, namely $2.4 \mathrm{~h}$.

TOTAL $26.4 \mathrm{~h}$

So the cost of the cart compared to $\mathrm{m}_{3}$ of waste produced is therefore: $20.54{ }^{*} 26.4$ / $35.6=15.23$ lei / m3 nc.

Productivity according to the mode of gathering, with the arms thin wood, namely $6.30 \mathrm{~m}_{3}$ in 8 hours, respectively $0.787 \mathrm{~m}_{3}$ in one hour.

Productivity according to the mode of gathering, with the arms small wood, namely $7.28 \mathrm{~m}_{3}$ in 8 hours, respectively $0.91 \mathrm{~m}_{3}$ in one hour.

The total cost of processing, $\mathrm{Ct}=(\mathrm{CTOM} * 8$ hours $)+\mathrm{CMat}=15.23 * 8+135.35=257.19$ lei, if the way of gathering is with the arms, thin wood.

The total cost of processing, $\mathrm{Ct}=\left(\mathrm{CTOM}^{*} 8\right.$ hours $)+\mathrm{CMat}=15.23 * 8+167.29,=289.13$ lei, if the way of gathering is with the arms, small wood. 


\section{Proceedings of the 2020 Society of Wood Science and Technology International Convention}

c. Transport of thin wood and wood waste to the primary platform consists of:

- loaded thin round wood with Ifron, in 8 hours,

The minimum manpower depending on the distance, between 10-15 m, according to symbol J12a

$\left.{ }^{* * * *} 1997\right)$ is: $8 \times 14.25 * 0.09$ lei / hour $=8 * 1.28=10.24$ lei for $89 \mathrm{~m} 3$ in 8 hours, so 0.11 lei per m3.

The maximum manpower depending on the distance, between 75.1-100 $\mathrm{m}$, according to symbol J12b $\left.{ }^{* * * *} 1997\right)$ is: $8 \times 14.25 * 0.186$ lei $/$ hour $=8 * 2.65=21.20$ lei for $43 \mathrm{~m}_{3}$ in 8 hours, so 0.49 lei per $\mathrm{m}$.

- loaded steri wood with Ifron, in 8 hours

The minimum manpower depending on the distance, between $10-15 \mathrm{~m}$, according to symbol $\mathrm{J} 13$ $\left({ }^{* \star * *} 1997\right)$ is: $8 \times 13.72{ }^{*} 0.111$ lei $/$ hour $=8 * 1.52=12.18$ lei for 72 meters steri equal with $50.4 \mathrm{~m}_{3}$ in 8 hours, so 0.24 lei per $\mathrm{m}_{3}$.

The maximum manpower depending on the distance, between 75.1-100 $\mathrm{m}$, according to symbol $\mathrm{J} 13\left({ }^{* * \star *} 1997\right)$ is: $8 \times 13.72{ }^{*} 0.211$ lei $/$ hour $=8{ }^{*} 2.89=23.15$ lei for 38 meters steri equal to $26.6 \mathrm{~m}_{3}$ in 8 hours, so 0.87 lei per $\mathrm{m}_{3}$.

- the transport of wood to the primary platform costs us 20 lei per m3,

- unloaded thin round wood with Ifron, in 8 hours

The minimum manpower depending on the distance, between 10-15 m, according to symbol $\mathrm{J} 14 \mathrm{a}$ $\left({ }^{* * *} 1997\right)$ is: $8 \times 14.75{ }^{*} 0.026$ lei / hour $=8{ }^{*} 0.38=3.06$ lei for $307 \mathrm{~m}_{3}$ in 8 hours so 0.009 lei per m3.

The maximum manpower depending on the distance, between 75.1-100 m, according to symbol J14b $\left(^{* * *} 1997\right)$ is: $8 \times 14.75 * 0.02$ lei $/$ hour $=8{ }^{*} 0.29=2.36$ lei for $163 \mathrm{~m}_{3}$ in 8 hours, so 0.014 lei per m3.

At short distances, the most economical mode of transport is for the operating residues to be transported in a natural state to the chopping center (Brad 2010)

On longer distances the operating residues (Brad 2010) are baled in bales bound $70 \mathrm{~cm}$ in diameter and 3.2 meters long, bearing the names of logs of composite residues or composite residue logs (CRL). Such a bundle of green debris weighs $500 \mathrm{~kg}$ and is packed and transported to the road by conventional forwarders and then to the chopping station using log carriers.

The cost-hour-machine cost, CTOM, of the light wood transport equipment, cracks.

The purchase price of the machine is 61,000 lei,

Amortization period 10 years,

Number of hours of use per year 1600 hours

$10 \%$ interest

Fixed expenses Amortization: $61,000 /(10 * 1600)=3.81$ lei $/ \mathrm{h}$. Interest: $(61,000 * 0.1 * 6) /(2 * 10 * 1600)=1.14$ lei $/ \mathrm{h}$

Variable expenses, that is Maintenance - repairs and others 2.7 lei / $\mathrm{h}$

The total cost of the transport equipment of thin wood, jacks:

$3.81+1.14+2.7=7.65 \mathrm{lei} / \mathrm{h}$ which represents a cost of $(8 * 7.65) / 35.6=1.72$ lei $/ \mathrm{m} 3 \mathrm{nc}$.

d. Chopping of thin wood and wood waste in the primary platform, in 8 hours

Labor: 8 * 14.5 lei $/$ hour $=116$ lei

The labor per $\mathrm{m}_{3} \mathrm{nc}$ of chop is 116 lei / $35.6 \mathrm{~m} 3 \mathrm{nc}$ of chop $=3.26$ lei / $\mathrm{m}_{3} \mathrm{nc}$.

Wood chopping in the primary platform is done using a chopper operated by a tractor (in the case of small quantities), or a larger chopper mounted on a truck (in the case of many scrap operations).

The cost-hour-machine cost, CTOM, namely the cost of the chopper:

The purchase price of the chopper is 43,800 lei,

Amortization period 10 years,

Number of hours of use per year 500 hours

$10 \%$ interest 


\section{Proceedings of the 2020 Society of Wood Science and Technology International Convention}

Fixed expenses

Amortization: $43,800 /(10 * 500)=8.76$ lei $/ \mathrm{h}$

Interest: $(43,800 * 0.1 * 6) /(2 * 10 * 500)=2.63$ lei $/ \mathrm{h}$

Variable expenses, that is

Maintenance - repairs and others 5.7 lei / $\mathrm{h}$

Total cost of the chopper

$8.76+2.63+5.7=17.1$ lei $/ \mathrm{h}$ which represents a cost of $\left(8^{*} 17.1\right) / 35.6=3.84$ lei $/ \mathrm{m} 3 \mathrm{nc}$.

The productivity of the chopper is $35.6 \mathrm{~m} 3 \mathrm{nc}$ in 8 hours, respectively $4.45 \mathrm{~m}_{3} \mathrm{nc}$ in one hour.

The total processing cost, $\mathrm{Ct}=\left(\mathrm{CTOM}^{*} 8\right.$ hours $)+\mathrm{CMat}=3.84 * 8+116=146.72$ lei.

e. Transport to the combustion boiler or to the briquetting / pelletized press,

Time required: 8 hours for $40.37 \mathrm{~m}_{3}$ of small wood, that is $5.04 \mathrm{~m}_{3}$ of small wood per hour.

Labor: 8 * 14.5 lei / hour $=116.0$ lei

The labor per $\mathrm{m}_{3} \mathrm{nc}$ of chop is 116 lei / $35.6 \mathrm{~m} 3 \mathrm{nc}$ of chop $=3.25$ lei / m3 nc.

The transport is done by pickup trucks.

The cost-hour-machine cost, CTOM, of the chip transporter:

The purchase price of the machine is 61,000 lei,

Amortization period 10 years,

Number of hours of use per year 1600 hours

$10 \%$ interest

Fixed expenses

Amortization: $61,000 /(10 * 1600)=3.81$ lei $/ \mathrm{h}$.

Interest: $(61,000 * 0.1 * 6) /(2 * 10 * 1600)=1.14$ lei $/ \mathrm{h}$

Variable expenses, that is

Maintenance - repairs and others 2.7 lei / $\mathrm{h}$

The total cost of the chip transport equipment: $3.81+1.14+2.7=7.65$ lei / $\mathrm{h}$ which represents a cost of $(8$

* 7.65$) / 35.6=1.72$ lei / m3 nc.

The productivity of the chip transporter means $35.6 \mathrm{~m} 3 \mathrm{nc}$ in 8 hours, respectively $4.45 \mathrm{~m}_{3} \mathrm{nc}$ in one hour.

Total processing cost, $\mathrm{Ct}=(\mathrm{CTOM} * 8$ hours $)+\mathrm{CMat}=1.72 * 8+116=129.76$ lei.

\section{RESULTS AND DISCUSSION}

So the cost of operating the machine is the cost-hour-machine (CTOM) sum of the following phases of work:

a. Shaping of small wood

b. The collection of the thin wood and the resulting wood residues

c. Transport of thin wood and wood waste to the primary platform

d. Wood chipping in the primary platform

e. Transport to the combustion boiler or briquetting / pellet press

That is, it consists of the following:

The total cost of the small woodworking equipment, 0.089 lei / $\mathrm{m}_{3} \mathrm{nc}$.

The cost of the tractor or harness or cart, namely 57 lei / m3 nc or 14.63 lei / m3 nc or 15.23 lei / m3

$\mathrm{nc}$,

The cost of the transport equipment for thin wood, namely 1.72 lei / m3 nc.

The cost of the mincer namely 3.84 lei / $\mathrm{m}_{3} \mathrm{nc}$,

The cost of the chip transport equipment namely 1.72 lei / m3 nc. 


\section{Proceedings of the 2020 Society of Wood Science and Technology International Convention}

Total $\operatorname{Tr}$ (Tractor) $=64.37$ lei $/ \mathrm{m}_{3} \mathrm{nc}$.

Total At (Harness) $=21.99$ lei $/ \mathrm{m} 3 \mathrm{nc}$.

Total Cr (Cart) $=22.59$ lei $/ \mathrm{m} 3 \mathrm{nc}$.

The determination of the price of one $\mathrm{m}_{3} \mathrm{nc}$, non-compact cubic meter, of the resulting chips is established as follows:

A. The price of wood per foot, namely 30.2 lei / m3 nc,

B. Cost of machine operating time,

C. Different, unpredictable (5\%).

$\operatorname{Tr} .(A+B) * 1.05=99.30$ lei $/ m_{3} n c$,

At. $(A+B) * 1.05=54.79$ lei $/ \mathrm{m}_{3} \mathrm{nc}$,

Cr. $(A+B) * 1.05=55.42$ lei $/ \mathrm{m}_{3} \mathrm{nc}$.

The average weight of one $\mathrm{m}_{3} \mathrm{nc}$ (non-compact cubic meter) of chips is on average $320 \mathrm{~kg}$ (Brad 2010), so the average price calculated per ton is, depending on the equipment used for collection:

Tr. 310.31 lei / ton,

At. 171.21 lei / ton,

Cr. 173.21 lei / ton.

Average: 218.24 lei / ton.

So as a conclusion we can say that from the wood waste, which otherwise we would not use, we can obtain, with an average production price of 218.24 lei / tonne, chop, raw material for pellets that have a sale price of 870 lei / tonne, respectively raw material for briquettes with an average selling price of 666 lei / tonne.

\section{REFERENCES}

Brad, M., L. (2010).Cercetări privind valorificarea superioară a lemnului de mici dimensiuni, Teză de doctorat, Braşov

Coşereanu, C., Lica, D., Lunguleasa, A. (2015). Investigation on the quality of briquettes made from rarely used wood species, agro-wastes and forest biomass. PRO LIGNO, 11(1):32-39.

Grabner, M., Cherubini, P., Rozenberg, P., Hannrup, B. (2006). Summer drought and low earlywood density induce intra-annual radial cracks in conifers. Scandinavian Journal of Forest Research, 21: 151-157.

Grîu, B., T. (2014). Evaluarea şi mărirea puterii calorice a biomasei lemnoase, Teză de doctorat, Braşov.

Melles, E. (2007). Cercetări privind recoltarea şi valorificarea produselor lemnoase din pădurile montane din zona Harghita, Universitatea Transilvania, Teză de doctorat, Braşov.

**** 1997. Norme de timp și producție unificate pentru lucrări din silvicultură, R.N.P.

Biography 


\title{
Determining the Aerodynamic Diameter of Various Wood Dust Types, to Better Assess Possible Health Risks
}

\author{
Maria Georgiades 1 \\ maria.georgiades@students.boku.ac.at \\ Roman Mynaz \\ Roman.myna@boku.ac.at \\ Raphaela Hellmayr 1 \\ Raphaela.hellmayr@boku.ac.at \\ Stephan Frömel-Frybort2 \\ s.froemel-frybort@wood-kplus.at \\ Rupert Wimmer 1 \\ Rupert.wimmer@boku.ac.at

\begin{abstract}
${ }_{1}$ University of Natural Resources and Life Sciences, Vienna, Austria 2Wood K plus - Competence Centre for Wood Composites and Wood Chemistry, Austria
\end{abstract}

\begin{abstract}
During wood processing such as sawing, cutting, routing, turning and sanding, particulate matter as particles, fibers or wood flour are produced, which are posing risks to the workers' health. The breathing in dust is the most common type of exposure, and the question is, to what extent particles of different sizes remain airborne, before they get deposited on the ground? It is known that the upper respiratory system is able to filter out larger particles, while smaller particles can go deep into the lungs causing damage and scarring to the lung tissue. Deposition rates of wood particles have certainly a linkage to the particles diameter, however, it is also possible that bigger particles coming from e.g. solid wood might stay airborne as long as smaller particles coming from other wood materials (e.g. particleboards). To better assess possible health risks of wood dust particles, we have developed a new approach to rapidly determine the aerodynamic diameter of wood dust particles. In general, the aerodynamic diameter of a particle is defined as that of a sphere, whose density is $1 \mathrm{~g} /$ $\mathrm{cm}_{3}$ (density of water), which is settling in still air at the same velocity as the particle in question. We built a closed chamber deposition apparatus, and measured deposition times of various wood dust fractions and types. The measured deposition times of the differently-sized wood particles allowed an improved classification of wood particles in terms of potential health risks. It is now possible to better characterize wood particles in terms of particle matter sizes as well as their effective airbornebehavior.
\end{abstract}

Key words: aerodynamic diameter, airborne dust, wood dust particles, wood processing, deposition time, respiratory system

Biography 
Proceedings of the 2020 Society of Wood Science and Technology International Convention

\title{
Rapid Determination of the Quality of Spanish Coniferous Wood by Models Based on IR Spectroscopy
}

\author{
René Herrera Díaz, University of the Basque Country, Spain \\ reneherdiaz@gmail.com \\ Juan Ignacio Fernández-Golfin Seco, Spanish Center of Forest Research (CIFOR)- \\ INIA \\ golfin@inia.es
}

\section{Abstract}

The preliminary detection of changes in the wood matrix by using non-destructive methods is a research area under continuous exploration, and it is of great interest to different industries and forest managers due to the generalized way that forest management is practiced. Therefore, the information on the proportion of juvenile wood produced in a given plantation area is highly interesting. The Infrared techniques are associated with multivariate statistical methods such as principal components analysis (PCA), principal components regression (PCR) and partial least squares regression (PLS-R), in order to extract information about the material tested. Thus, the original variables are converted into a set of uncorrelated linear combinations of the original variables containing most of the variability of the dataset, to use finally for the calculation of prediction models. The objective of this study is to find fast and highly reliable methods for distinguishing different species of coniferous wood existing in Spain and in each of them, differentiate their qualities. For this, profiles of radiata pine, maritime pine, Scots pine, and Austrian pine were used. Each profile was measured from the juvenile zone to the limit with the bark $(65 \% \mathrm{RH}$ and $25 \stackrel{\circ}{\circ}$ ), performing at least 30 individual measurements in transmittance mode. The pre-processing of the signals included the calculation of the derivatives, the smoothing, and trimming of the noise and the lengths that do not discriminate the samples, in addition to the normalization of the vector. The derived models were calculated according to the Savitzky-Golay algorithm. For the mathematical transformation of the spectra, PCA, parallel factor analysis, regression modeling and classification (SIMCA, PLS), cluster analysis (CA), identity test ( IT) and partial least squares (PLS) methods were applied. The preliminary results showed predictions with high correlations ( $\geq 98 \%)$ regarding the differentiation of the coniferous wood studied, being a relatively fast and economical methodology. The second goal was to differentiate the wood quality in each sample. The results showed a qualitative classification of the wood samples, separating each sample in three regions (juvenile, transition, and adult) and with correlations higher than $81 \%$. These are promising techniques from the economic and scientific point of view since it does not involve the destruction of the material nor require long measuring times.IR techniques associated with chemometrics showed adequate results for the discrimination of the samples, but the application in the wood-industry is required more calibrations and validation models in order to avoid false positives.

\section{Biography}




\title{
Different types of coatings used for wooden shingles exposed to natural and artificial aging
}

\author{
Authors: Dominik Hess *, Jan Baar, Jan Tippner \\ Department of Wood Science and Technology, Faculty of Forestry and Wood \\ Technology, Mendel University in Brno, Zemědělská 3, 61300 Brno, Czech \\ Republic; office phone: +420545134550; e-mail: hessdominikcloud.com; \\ *corresponding author
}

The present study aims to perform a chemical analysis of the surface of wooden shingle exposed to natural and artificial aging, which were treated with various types of protective coatings. The specimens were made by Spruce wood (Picea abies L.). The dimension of the specimens were $(18 \pm 1) \times(74 \pm 1) \times(150 \pm 2) \mathrm{mm}(\mathrm{R} \times \mathrm{T} \times \mathrm{L})$. The faces of all specimens were covered by epoxy resin to prevent water absorption in the longitudinal direction. Three coatings were used for surface treatment: wood tar (high temperature decomposition without oxygen), and carbolineum (distillation residues of benzoic acid). The coatings were applicated by brush. After application of the coatings, the specimens were air-conditioned at the relative humidity of $65 \%$ and the temperature of $20^{\circ} \mathrm{C}$. Before artificial and natural aging, initial FTIR analysis of the Spruce wood surface were performed on a Nicolet iS 10 (Thermo Scientific) instrument with ATR-FTIR full reflection attenuation technique. The natural aging specimens were exposed on the outdoor racks. The artificial aging was carried out in the Q-SUN XE-1 XENON TEST chamber. Artificial exposure conditions were stated according to ASTM G155. In the infrared spectra of control specimens surfaces there were vibrations of bonds and parts of molecules of all wood components: celluloses, lignin, hemicelluloses and extractive substances. Absorption bands can be identified in two basic areas - the characteristic group vibration area (3700-3000 cm-1) and the 'fingerprint' area (1800-650 cm-1). In the infrared spectra of the treated specimens by wood tar, in addition to the individual wood components, vibrations of parts of the molecules of the chemical components of wood tar were also reflected. The vibrations of the $-\mathrm{CH} 2$ and $-\mathrm{CH} 3$ groups were most pronounced. The components of the wood tar preparation contain various $\mathrm{C}=\mathrm{O}$ carbonyl groups, the most intense vibrations of which were at 1736 and $1708 \mathrm{~cm}-1$. By comparing the infrared spectra of treated specimens by carbolineum and untreated specimens, the presence of the carbonyl group $\mathrm{C}=\mathrm{O}$ (aldehydes or esters) as well as the hydrocarbon chains in carbolineum can be established. The components of wood tar contained longer hydrocarbon chains, i.e. with a higher number of (CH2) - groups than the components of carbolineum. Differences can also be observed in the wavelength range $1800-1620 \mathrm{~cm}-1$, where vibrations of the carbonyl groups occur. The first measurements of the surface of spruce specimens treated by wood tar and carbolineum were performed. Tests for artificial and natural aging are still ongoing. After the tests, further FTIR measurements will be made and the results will be compared and properly described.

Key words: wooden shingle; spruce; wood tar; carbolineum; artificial aging; natural aging; FTIR Biography 


\title{
Sustainable Development - International Framework - Overview and Analysis in the Context of Forests and Forest Products with Competitiveness and New Opportunities
}

\author{
Ms. Annika Hyytia, Finland \\ Annika.hyytia@helsinki.fi
}

\begin{abstract}
The forest sector is in a remarkable role providing significant new sustainable opportunities globally. Innovations have an important role in the sustainable development, business and competitiveness. Quality is part of competitiveness. Quality is important for competitiveness. Customers' role is important. This is a qualitative research based on literature. It is based on research articles and literature and organizational literature including several academic sources, for example Proquest, Academic Search Complete (EBSCO), Agris, CAB Abstracts, SCOPUS (Elsevier), Web of Science (ISI) and Google Scholar and Internet sites.
\end{abstract}

Biography 


\title{
Predictive Modeling and Optimization of Alkaline Sulphite and Sodium Hyrodroxide Pretreatments of Maize (Zea Mays) Stalk Fractions in the Production of Bio-ethanol. Kolajo, Tolulope E. Department of Wood Products Engineering, University of Ibadan \\ *Corresponding Author: tolukolajo@yahoo.com
}

\begin{abstract}
Chemical pretreatment of lignocellulosic biomass is usually under high temperatures and are preferential for lignin condensation, especially in an heterogenic structured biomass such as maize stalk. A low temperature pretreatment of maize whole stalk (WS) and fiber-rich Rind Fractions (RF) was achieved using Alkaline sulphite (AS) and $\mathrm{NaOH}$. Pretreatment was done in a chemical reactor at $120{ }_{0} \mathrm{C}$, with 14,16 and $18 \% \mathrm{w} / \mathrm{v}$ active alkali charges for 60,90 and 180 minutes, resulting in a first order $3^{2} 2$ full factorial experiment. Regression models were developed to predict cellulose yield (CY) and Residual Klason Lignin (RKL) through the interaction of independent variables. Optimization was achieved using Response Surface Methodology. The highest CY for both pretreatments was at 14\%, 60 minutes. Difference in CY between WS and RF was not statistically significant at $\alpha_{0.05}$. The models developed have high $\mathrm{R}_{2}$ values $(0.758$ - 0.954 for $\mathrm{CY}, 0.767$ - 0.963 for RKL) in both pretreatments, with no significant difference between actual and predicted values. Optimized schedules were 18\%,120 minutes and 16\%,60 minutes; for WS and RF, and 14\%,120 minutes and $18 \% 60$ minutes for $\mathrm{AS}$ and $\mathrm{NaOH}$ respectively. The models developed adequately predicted CY and RKL with reasonable agreement between adjusted and predicted $\mathrm{R}_{2}$ values.

Keywords: Pretreatment, Cellulose Yield, Residual Klason Lignin, Optimization, Rind fraction INTRODUCTION

Bio-ethanol is the most common alternate fuel and can be produced via fermentation of lignocellulosic biomass (Achinas et al., 2016; Park et al., 2019). Cellulosic ethanol is a type of biofuels produced from agricultural residues, wood, grasses, or some parts of plants, otherwise referred to as biomass. Biomass is present in different forms such as agricultural crops ad residues, grasses and all green plants, some mill wastes such as bagasse, and these can be found all over the world (Sun and Cheng, 2002). The conversion of Cellulose-derived sugars into ethanol and other biofuels have been established, and this is through chemical and biochemical technologies (Binder and Raines1, 2010). Lignocelluloses however, have recalcitrance, a resistance to degradation which is attributable to its composition, stability and the robustness to the cell walls of the biomass, and to
\end{abstract}




\section{Proceedings of the 2020 Society of Wood Science and Technology International Convention}

the cross-linking between the cellulose, hemicellulose and the lignin through ester and ether linkages (Zhu and Pan, 2010). Therefore, in order to extract carbohydrates from plant cell walls, there is need to disconnect the cellulose fibers from the binder-lignin, and then hydrolyze the celluloses fibers. These are broken down into simple monosaccharides which are then available for a myriad of uses such as fermenting to ethanol. The recalcitrance of lignocelluloses has been the major constraint in a number of applications, such as bio-ethanol production (Bloomberg, 2013; Zhao et al., 2018). Several pretreatment methods have been explored, which includes: Dilute acid pretreatment (Li et al., 2016; Thomas et al, 2017; Liu et al., 2018), Organosolv pretreatment (ethanol, tetrahydrofuran and $\gamma$-valerolactone) (Nguyen et al., 2015; Thomas et al., 2017; Li et al., 2018), Ionic liquids (Liu et al., 2016; Raj et al., 2018), Wet Oxidation (Qiang and Thomsen, 2012), Sulfite pretreatment to remove recalcitrance of lignocellulose (Zhu et al., 2009a), Fiber Steam explosion (Guerrero et al., 2017; Liyakathali et al., 2017), Liquid water pretreatment (Hongdan et al., 2013), Ultrasound pretreatment (Ivetic et al., 2017; He et al., 2017; Luzzi et al., 2017), Extrusion pretreatment (Heredia-Olea et al., 2015) Biological pretreatment using enzymes (Janusz et al., 2017; Houtman et al., 2018) amongst others. An effective pretreatment is expected to overcome biomass recalcitrance, deconstruct the biomass into the three dimensional structure of a ligno-cellulose, break cellulose crystallinity, avoid degradation of carbohydrates, avoid the formation of inhibitory byproducts and allow lignin recovery (Alvira et al., 2010). Alkaline sulphite is a mild pretreatment method which has been used for the maize stalk fractions (Marzieh et al., 2014; Kim et al., 2016) and meets the requirements stated above. It achieves delignification by increasing the internal surface swelling, decreasing polymerization and cellulose crystallinity, and breaking of links between lignin and other carbohydrates (Badiei et al., 2014).

The optimization of the most suitable pretreatment methods is specific for a particular biomass type, and is a function of both the pretreatment variables applied and some inbuilt characteristics of the plant biomass such as age, structure and composition (Zabed et al., 2017). A pretreatment schedule is defined by a combination of process factors such as chemical charge, time, pressure, solid to liquid ratio, temperature and the presence/absence of catalysts (Jonsson et al., 2013). The Response Surface Methodology (RSM) uses statistical and mathematical techniques to investigate and optimize the combined effects of input variables influencing responses with the main aim of optimizing this response (Montgomery, 2005). In this case, the process factors are limited to 
chemical concentration and preteratment time while the responses are cellulose yield and the residual lignin in the pretreated hydrolysates. RSM has been used in the design, formulation, development, and analysis of new scientific studies, using a reduced number of experimental runs and simultaneously varying the process factors. Oehlert (2000) describes RSM as a suitable tool in describing a response and in optimisation using continuous treatments on the input variables. When there is more than one response then it is important to find the compromise optimum that takes all the variables into consideration.

A factorial design combines levels of the independent variables and dependent variables through models generated by multiple linear regressions and a set of predefined experiments. These models produce response surface graphs that describe the behaviour of the system all over the experimental range, and can be extrapolated to cover areas where experiments were not performed. A full factorial experiment is one that considers all possible combinations of the two or three factors involved in the experimental design, across all levels (Box et al., 2005; Rabelo et al., 2014). Such an experiment allows the study of the effect of every single factor being considered on the response variable. It also determines the effects of interactions between the input factors on the response variable. In this study, the full factorial experiment was used to obtain the actual value of the responses.

Maize cultivation is predominant in South West Nigeria, producing abundant residue after its harvest. Maize stover is a morphologically diverse biomass containing cobs, leaves, husks and stalks in ration 15:22:14:50 per kg of dry matter of maize grain while the stalk is an heterogeneous mix of pith and rind fractions, also having different morphologies (Li et al., 2011; Takada et al., 2018; Djatkov et al., 2018, Dawid et al., 2020). The fractions of the maize stalk having different characteristics might have varying reactions to similar delignification schedules (Jiang et al., 2015; Kolajo and Onilude, 2019). This study optimizes the low temperature chemical pretreatment of maize whole stalk (WS) and fiber-rich Rind Fractions (RF) using AS and $\mathrm{NaOH}$.

\section{MATERIALS AND METHODS}

\section{Sample Collection and Preparation}

The maize stalks were of the 3-months maturation DMR-LSR-W (Streak and Downy mildew resistant) variety from the Institute of Agricultural Research and Training (IAR\&T), Ibadan, Nigeria. The stalks were reduced into chips $(25 \mathrm{~mm})$ and some of the chips were further separated 
into pith and rind fractions; the rind is the hard outer part while the pith is the soft inner core. These were air dried until a constant mass was obtained prior tests and pretreatment.

\section{Pretreatment Schedule}

Pretreatment variables were alkali charges of 14,16 and $18 \%$ for a pretreatment time of 60, 90 and 120 minutes for the whole maize stalk and the rind fraction, making it a $3^{2} 2$ full factorial experimental. Each schedule was pulped in three replicates. The cellulose yield (CY) was obtained as a percentage of the input raw biomass while residual lignin (RKL) in the pulp lap was analyzed using TAPPI T236 standards.

\section{Modeling and Optimisation}

Linear models, two factorial interaction, quadratic models and cubic models were used to interpret the response of cellulose yield and RKL to changes in concentration and pretreatment times for each of the biomass fractions. The models were obtained using Design Expert software 6.0 (Statease, USA, MN) and the appropriate equation was selected from the highest order polynomial where there is insignificant lack of fit, the model was not aliased and there is maximization of the $R_{2}$ value with close relationship between Adjusted $R_{2}$ and the Predicted $R_{2}$ values.

The general form of the quadratic equation chosen was:

$$
Y=a_{0}+\sum_{i=1}^{k} a_{i} x_{i}+\sum_{i=1}^{k} a_{i i} x_{i}^{2}+\sum_{i=1}^{k} \sum_{i \neq j=1}^{k} a_{i j} x_{i} x_{j}+\varepsilon
$$

Where,

$x_{i}, x_{j}$ are the input variables,

ao is the intercept,

$a_{i}, a_{i i}, a_{i j}$ are the first order, quadratic and interaction coefficients respectively

$i, j$ are the index numbers of the factors

$\varepsilon$ is the residual error

$Y$ is the response function

The adequacy of the model was proven by the coefficient of determination $R 2$ and adequate precision values. Quadratic model was chosen based on high $R_{2}$ value and low deviation from the mean. Validation of the model developed was achieved by comparing the empirical data with those predicted by the models. A Chi-square test was also used to test the validity of the model. Chisquare is expressed as $X_{2}$.

$$
X^{2}=\sum \frac{(\text { Exp-Pred })^{2}}{(\text { Pred })}
$$

Where, 


$$
\begin{array}{ll}
X_{2} & =\text { Chi-square } \\
\text { Exp } & =\text { Experimental/Actual/Empirical values } \\
\text { Pred } & =\text { Predicted values }
\end{array}
$$

Optimization was achieved using Response Surface Methodology. Results from pretreatment were optimized using the Historical data package of Design Expert® software, using the criteria of highest CY and lowest RKL for each level of variation.

\section{Statistical Analysis}

Values obtained for CY and RKL were expressed as mean \pm standard deviation. The difference between the means was obtained by one-way analysis of variance (ANOVA) at $\alpha_{0.05}$.

\section{RESULTS}

The effects of the variables' individual and second order interactions on the response surface of the independent variables were analyzed. The experimental design, with each corresponding pretreatment yield and RKL are presented in Supplementary Tables S1 to S4.

\section{Modeling}

The experimental data for the CY and RKL from WS (Table S1) and RF (Table S2) using AS pretreatment were approximated by a quadratic function, after which the efficiency of the models for prediction of $\mathrm{CY}$ and RKL was estimated based on the error parameters and correlation coefficients (Kasote et al., 2013; Ogunsina et al., 2014). A reduced polynomial model was obtained by excluding the insignificant terms from the quadratic models. The terms $x_{1}$ and $x_{2}$ are alkali charges and pretreatment time respectively.

AS pretreatment

The final equations for AS pretreatment estimating CY and RKL are for WS are given by equations 3 and 4 respectively:

$$
C Y(\%)=40.68-1.5 x_{1}-2.43 x_{2}+1.33 x_{2}^{2}+1.2 x_{1} x_{2} \quad \ldots
$$

$\left(\right.$ Std Dev $=1.63$, Mean $=41.79$, Adj $R^{2}=0.7006$, Pred $\left.R^{2}=0.6157, R^{2}=0.758\right)$

$$
R K L(\%)=5.14-0.80 x_{1}-0.46 x_{2}+0.5 x_{1}^{2}-0.19 x_{2}^{2}-0.25 x_{1} x_{2} \quad \ldots
$$

$\left(\operatorname{Std}\right.$ Dev $=0.20$, Mean $=5.35$, Adj R $=0.9438$, Pred $\left.R^{2}=0.9277, R^{2}=0.9546\right)$

In the same way, the final equations for AS pretreatment for RF are as given in equations 5 and 6:

$$
C Y(\%)=45.56-2.98 x_{1}-1.17 x_{2}+0.4 x_{1} x_{2}
$$


$\left(\right.$ Std Dev $=0.79$, Mean $=45.54$, Adj R $=0.9190$, Pred R2 $\left.=0.8896, R^{2}=0.935\right)$

$$
R K L(\%)=4.99-0.59 x_{1}-0.23 x_{2}+0.54 x_{1}^{2}+0.2 x_{1} x_{2}
$$

$\left(\right.$ Std Dev $=0.13$, Mean $=5.32$, Adj R2 $=0.9547$, Pred $\left.R^{2}=0.9421, R^{2}=0.963\right)$

Equations 3 and 5 reproduced CY and showed that there are significant interactions between pulping time and liquor concentration. There was high regression coefficient $\left(\mathrm{R}_{2}=0.758\right.$, 0.935) while the Adjusted $\mathrm{R}_{2}$ is in agreement with the Predicted $\mathrm{R}_{2}$ for WS $(0.7006,0.6157)$ and RF $(0.9190,0.8896)$ respectively. This trend is also true for RKL (Equations 4 and 6) with $\mathrm{R}_{2}$ of $0.9546,0.963$ and the Adjusted $\mathrm{R}_{2}(0.9438,0.9547)$ and Predicted $\mathrm{R}_{2}(0.9277$, $0.9421)$ in close agreement. The pure errors obtained for CY was less than 5\% (0.01 - 4.38\%; $0.01-1.66 \%)$ and less than $1 \%(0.01-0.27 \% ; 0.01-0.36 \%)$ for RKL and Chi-square values are insignificant at $95 \%$ confidence level. Analysis of Variance shows a low lack of fit which indicates that the model represents the actual relationship of input factors and responses. The model is therefore adequate to navigate the design space.

\section{$\mathrm{NaOH}$ pretreatment}

The reduced mathematical equations to predict CY and RKL for WS are given by equations 7 and 8 respectively.

$$
C Y(\%)=43.96-3.7 x_{1}-1.17 x_{2}-1.43 x_{1}^{2}-0.55 x_{1} x_{2} \quad \ldots
$$

$\left(\right.$ Std Dev $=0.81$, Mean $=42.64$, Adj $\mathrm{R}^{2}=0.9429$, Pred $\left.\mathrm{R}^{2}=0.9218, \mathrm{R}^{2}=0.954\right)$

$$
R K L(\%)=5.28-0.17 x_{1}-0.33 x_{2}-0.17 x_{1}^{2}-0.13 x_{2}^{2} \quad \ldots
$$

$\left(\right.$ Std Dev $=0.12$, Mean $=5.08$, Adj R $R^{2}=0.8854$, Pred $\left.R^{2}=0.8424, R^{2}=0.907\right)$

Thr final equations for RF are given as:

$$
C Y(\%)=42.29-0.95 x_{1}-1.78 x_{2}-0.38 x_{1}^{2}+0.42 x_{2}^{2}
$$

$\left(\right.$ Std Dev $=0.61$, Mean $=42.31$, Adj R $\mathrm{R}^{2}=0.8836$, Pred $\left.^{2}=0.8473, \mathrm{R}^{2}=0.906\right)$

$$
R K L(\%)=5.22-0.38 x_{1}-0.65 x_{2}+0.15 x_{1} x_{2}
$$

$$
\left(\text { Std Dev }=0.40, \text { Mean }=5.01, \text { Adj R }=0.7112, \text { Pred } R^{2}=0.6212, R^{2}=0.767\right)
$$

The R2 values are high for CY (0.954 and 0.906 for WS and RF respectively) and RKL (0.907 and 0.767). The closeness of the values of Adjusted $R_{2}$ and Predicted $R_{2}$ for both WS $(0.8836$ and $0.8473)$ and RKL (0.7112 and 0.6212) confirms the suitability of the model to navigate the design 
space. The residuals obtained were less than $2 \%(0.01-1.24 \%)$ and less than $1 \%(0.01-0.62 \%)$ for RKL. Values obtained from Chi-square test shows that the difference is not significant at $\alpha_{0.05 .}$ Effect of alkali charge and pretreatment time on $C Y$

The highest CY obtained from AS pretreatment was $46.8 \pm 2.9 \%$ at $14 \%$ concentration and 60 minutes for WS, and 50.0 $0.2 \%$ at $14 \%$ concentration and 60 minutes for RF. NaOH pretreatment has the highest CY at $14 \%$ alkali charge and 60 minutes for both WS $(46.4 \pm 0.5 \%)$ and RF $(45.0 \pm 0.5 \%)$. There is a gradual decline in the yield as pulping time increased from 60 minutes, to 90 minutes and 120 minutes at all the concentrations of $14 \%, 16 \%$ and $18 \%$. The difference between cellulose yields for whole and rind fraction is significant at $\alpha 0.05$

Effect of alkali charge and pretreatment time on RKL

The lowest RKL was $4.0 \pm 0.01 \%$ for WS and $4.7 \pm 0.01 \%$ for RF using AS at $18 \% 120$ minutes. $\mathrm{NaOH}$ pretreatment records the lowest RKL at $4.5 \pm 0.02 \%$ for whole stalk and $3.6 \pm 0.16 \%$ at the same schedule. This translates to an average of over $70 \%$ lignin removal, which is slightly lower than $82 \%$ recorded by Liu et al., (2016).

Optimized schedule

The schedule with run order with 120 minutes and $18 \%$ concentration was selected for AS pulping of WS, with a desirability index of 0.583 . The schedule $16 \%$ alkali charge, 60 minutes, was selected for RF with an average desirability of 0.652 . For $\mathrm{NaOH}$ pulping, $14 \%$ concentration at 120 minutes at 0.652 desirability was selected for WS while $18 \%$ concentration at 60 minutes at 0.549 desirability was selected as the optimized pre-treatment schedule for RF. The response surface plots for these optimised schedules are seen in Figures 1 and 2. 
Proceedings of the $\mathbf{2 0 2 0}$ Society of Wood Science and Technology International Convention
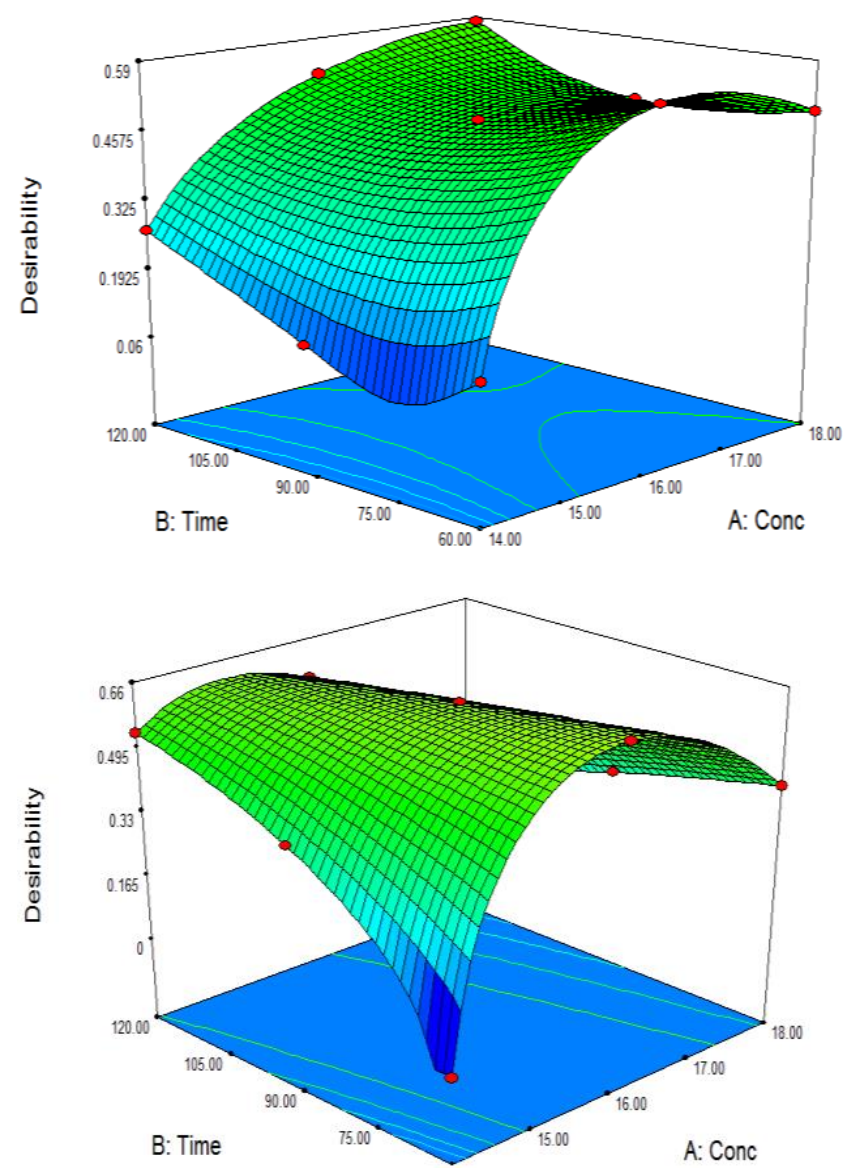

(a)

(b)

Figure 1: Response Surface Plots for optimised Alkaline sulphite pretreatment schedule for (a) WS (b) RF. 

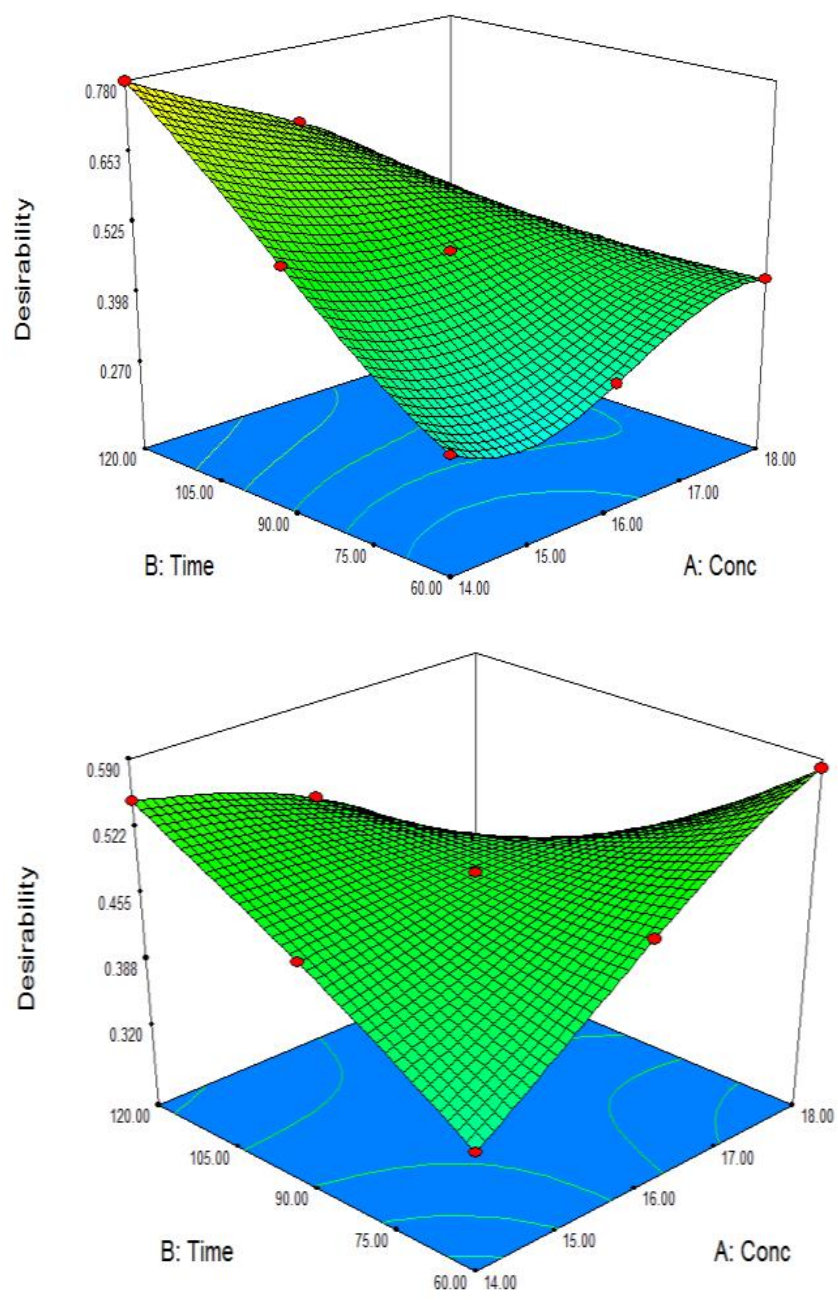

(a)

(b)

Figure 2: Response Surface Plots for optimised $\mathrm{NaOH}$ pretreatment schedule for (a) WS (b) RF.

\section{CONCLUSION}

The results presented have contributed to the development of more suitable pretreatments which saves energy, cost and time in the production of cellulosic ethanol from biomass. The different process factors in AS and $\mathrm{NaOH}$ pretreatments of maize stalk fractions have been examined and their relationships established; when time and alkali charge are increased, there is a corresponding decrease in the RKL of the biomass. The difference between the cellulose yield and RKL of whole stalk and the rind fraction was statistically significant. The results of the pulping experiments which were modeled into quadratic polynomial equations showed that the model fitted well as the residuals generated between actual and predicted values were not significant. From optimization results, the residuals follow the normal distribution with very minimal deviations. The model 
obtained from the pretreatment experiment may be used to predict cellulose yield and residual klason lignin for other biomass with similar physical and chemical morphology.

\section{ACKNOWLEDGEMENT}

This work was supported by the Petroleum Technology Development Fund of the Federal Republic of Nigeria and The Postgraduate College, University of Ibadan, Nigeria.

\section{REFERENCES}

Achinas, S., \& Euverink, G. J. W. (2016). Consolidated briefing of biochemical ethanol production from lignocellulosic biomass. Electronic Journal of Biotechnology, 23, 44-53. doi:10.1016/j.ejbt.2016.07.006

Alvira, P., Tomás-Pejó, E., Ballesteros, M., \& Negro, M. J. (2010). Pretreatment technologies for an efficient bioethanol production process based on enzymatic hydrolysis: A review. Bioresource Technology, 101(13), 48514861. doi:10.1016/j.biortech.2009.11.093

Badiei M, Asim N, Jahim JM, Sopian K (2014) Comparison of chemical pretreatment methods for cellulosic biomass. Procedia Soc Behav Sci 9:170-174. doi:10.1016/j.apcbee.2014.01.030

Binder, J.B. and R.T. Rainesl. (2010). Fermentable sugars by chemical hydrolysis of biomass. PNAS 2010;107(10):4516e21.

Bloomberg (2013). "Chevron defies California on carbon emissions" An article published by Bloomberg LP, USA. Accessed from https://www.bloomberg.com/ news/articles/2013-04-18/ chevron-defies-california-on-carbonemissions

Box, G. E.; W.G. Hunter and J.S. Hunter. (2005). Statistics for Experimenters. Design, Innovation, and Discovery (2nd ed.). Wiley. ISBN 0-471-71813-0.

Dawid W., Jacek P., Izabela R., PiotrG., Damian J., Gieszka W, Kinga S. and Magdalena w. (2020). Chemical composition of maize stove fractions versus methane yield and energy value in fermentation process. Energy 198 (2020).https://doi.org/10.10.16/j.energy.2020.117258

Djatkov D, Martinova M, Kaltschmittb M. Influencing parameters onmechanicalephysical properties of pellet fuel made from corn harvest resi-dues. Biomass Bioenergy 2018;119:418e28.https://doi.org/10.1016/j.biombioe.2018.10.009

Guerrero, A. B., Ballesteros, I., and Ballesteros, M. (2017). Optimal conditions of acid-catalysed steam explosion pretreatment of banana lignocellulosic biomass for fermentable sugar production. J. Chem. Technol. Biotechnol. 92, 2351-2359. doi: $10.1002 /$ jctb.5239

He, Z., Wang, Z., Zhao, Z., Yi, S., Mu, J., and Wang, X. (2017). Influence of ultrasound pretreatment on wood physiochemical structure. Ultrason. Sonochem. 34, 136-141. doi: 10.1016/j.ultsonch.2016.05.035

Heredia-Olea, E., Pérez-Carrillo, E., Montoya-Chiw, M., and Serna-Saldívar, S. O. (2015). Effects of extrusion pretreatment parameters on sweet sorghum bagasse enzymatic hydrolysis and its subsequent conversion into bioethanol. Biomed Res Int. 2015:325905. doi: 10.1155/2015/325905

Hongdan, Z., Shaohua, X., and Shubin, W. (2013). Enhancement of enzymatic saccharification of sugarcane bagasse by liquid hot water pretreatment. Bioresour. Technol. 143, 391-396. doi: 10.1016/j.biortech.2013.05.103

Houtman, C. J., Maligaspe, E., Hunt, C. G., Fernández-Fueyo, E., Martínez, A. T., and Hammel, K. E. (2018). Fungal lignin peroxidase does not produce the veratryl alcohol cation radical as a diffusible ligninolytic oxidant. J. Biolog. Chem. 293, 4702- 4712. doi: 10.1074/jbc.RA117.001153

Ivetić, D. Ž., Omorjan, R. P., ordevi,ć, T. R., and Antov, M. G. (2017). The impact of ultrasound pretreatment on the enzymatic hydrolysis of cellulose from sugar beet shreds: modeling of the experimental results. Environ. Prog. Sustain Energy. 36, 1164-1172. doi: 10.1002/ep.12544.

Janusz, G., Pawlik, A., Sulej, J., Urszula, S., Anna, S. B., Andrzej, J. W., et al. (2017). Lignin degradation: microorganisms, enzymes involved, genomes analysis and evolution. FEMS Microbiol. Rev. 41, 941-962. doi: 10.1093/femsre/fux049

Jiang, W., Chang, S., Li, H., Oleskowicz-Popiel, P., Xu, J., (2015). Liquid hot water pretreatment on different parts of cotton stalk to facilitate ethanol production. Bioresour. Technol. 176, 175-180. 


\section{Proceedings of the 2020 Society of Wood Science and Technology International Convention}

Jönsson L.J., Alriksson B, Nilvebrant NO. Bioconversion of lignocellulose: inhibitors and detoxification. Biotechnol Biofuels. 2013;6:16.

Kasote, D.M., Y.S. Badhe and M.V. Hegde. (2013). Effect of mechanical press oil extraction processing on quality of linseed oil. Industrial Crops and Products. 42:10-13.

Kim, J. S., Lee, Y. Y., and Kim, T. H. (2016). A review on alkaline pretreatment technology for bioconversion of lignocellulosic biomass. Bioresour. Technol. 199, 42-48. doi: 10.1016/j.biortech.2015.08.085

Kolajo T.E. and Onilude, M.A. 2019. Physical and Chemical Assays of Maize stalk fractions for Ethanol Production. Energy, Ecology and Environment. ISSN 2363-7692. DOI 10.1007/s40974-00110-z

Li Z, Zhai H, Zhang Y, Yu L. 2011.Cell morphology and chemical characteristics of corn stover fractions. Ind Crop Prod 2012;37:130e6.https://doi:10.1016/j.indcrop.2011.11.025.

Li, H., Qu, Y., Yang, Y., Chang, S., and Xu, J. (2016). Microwave irradiation-A green and efficient way to pretreat biomass. Bioresour. Technol. 199, 34-41. doi: 10.1016/j.biortech.2015.08.099

Li, J., Shi, S., Tu, M., Via, B., Sun, F. F., and Adhikari, S. (2018). Detoxification of Organosolv-Pretreated Pine Prehydrolysates with Anion Resin and Cysteine for Butanol Fermentation. Appl. Biochem. Biotechnol. 1-19. doi: 10.1007/s12010-018-2769-4

Liu, Y. R., Thomsen, K., Nie, Y., Zhang, S. J., and Meyer, A. S. (2016). Predictive screening of ionic liquids for dissolving cellulose and experimental verification. Green Chem. 18, 6246-6254. doi: 10.1039/C6GC01827K

Liu, Y., Sun, B., Zheng, X., Yu, L., and Li, J. (2018). Integrated microwave and alkaline treatment for the separation between hemicelluloses and cellulose from cellulosic fibers. Bioresour. Technol. 247, 859-863. doi: 10.1016/j.biortech.2017.08.059

Liyakathali, N. A. M., Muley, P. D., Aita, G., and Boldor, D. (2016). Effect of frequency and reaction time in focused ultrasonic pretreatment of energy cane bagasse for bioethanol production. Bioresour. Technol. 200, 262-271. doi: 10.1016/j.biortech.2015.10.028

Luzzi, S. C., Artifon, W., Piovesan, B., Tozetto, E., Mulinari, J., Kuhn, G. D. O., et al. (2017). Pretreatment of lignocellulosic biomass using ultrasound aiming at obtaining fermentable sugar. Biocatal. Biotransform. 35, 161-167. doi:10.1080/10242422.2017.1310206

Marzieh B., N. Asim, J.M. Jahim and K. Sopian (2013). Comparison of Chemical Pretreatment Methods for Cellulosic Biomass. APCBEE Procedia, 9, 170-174. doi:10.1016/j.apcbee.2014.01.030.

Montgomery, D.C. (2005). Design and Analysis of Experiments: Response surface method and designs. New Jersey: John Wiley and Sons, Inc.

Nguyen T.Y., Cai C.M., Kumar R, Wyman C.E. 2015. Co-solvent pretreatment reduces costly enzyme requirements for high sugar and ethanol yields from lignocellulosic biomass. Chemsuschem. 2015;8:1716-25.

Oehlert, G. W. 2000. Design and analysis of experiments: Response surface design. NewYork: W.H. Freeman and Company'

Ogunsina, B.S., G.A. Olatunde and O. Adeleye. (2014) Effect of pre-treatments on mechanical oil expression from Dika Kernels. Effect of pre-treatments on mechanical oil expression from Dika Kernels. Journal of Agricultural Technology. 10(2):309-319.

Park, J.H.; Jin, M.H.; Lee, Y.J.; Song, G.S.; Choi, J.W.; Lee, D.W.; Kim, J.G. Two-in-one fuel synthetic bioethanollignin from lignocellulose with sewage sludge and its air pollutants reduction effects. Energies 2019, 12, 3072.

Qiang Z and Thomsen B. (2012). Effect o different wet oxidation pretreatment conditions on ethanol fermentation from corn Stover. Information technology \& Agricultural Eng.; 134 : 953-958.

Rabelo SC, Andrade RR, Maciel Filho R, Costa AC. Alkaline hydrogen peroxide pretreatment, enzymatic hydrolysis and fermentation of sugarcane bagasse to ethanol. Fuel. 2014;136:349-57.

Raj, T., Gaur, R., Lamba, B. Y., Singh, N., Gupta, R. P., Kumar, R., et al. (2018). Characterization of ionic liquid pretreated plant cell wall for improved enzymatic digestibility. Bioresour. Technol. 249, 139-145. doi: 10.1016/j.biortech.2017.09.202

Takada M, Niu R, Minami E, Saka S. Characterization of three tissue fractions incorn (Zea mays) cob. Biomass Bioenergy 2018;115:130e5.https://doi.org/10.1016/j.biombioe.2018.04.023

Thomas VA, Donohoe BS, Li M, Pu Y, Ragauskas AJ, Kumar R, Nguyen TY, Cai CM, Wyman CE. Adding tetrahydrofuran to dilute acid pretreatment provides new insights into substrate changes that greatly enhance biomass deconstruction by Clostridium thermocellum and fungal enzymes. Biotechnol Biofuels. 2017;10:252.

Zabed H, Sahu JN, Suely A, Boyce AN, Faruq G. Bioethanol production from renewable sources: current perspectives and technological progress. Renew Sust Energ Rev. 2017;71:475-501. 
Zhao, X., Luo, K., Zhang, Y., Zheng, Z., Cai, Y., Wen, B., Cui, Z., Wang, X., 2018. Improving the methane yield of maize straw: Focus on the effects of pretreatment with fungi and their secreted enzymes combined with sodium hydroxide. Bioresour. Technol. 250, 204-213.

Zhu, J.Y. and X.J. Pan. (2010). Woody biomass pre-treatment for cellulosic ethanol production: Technology and energy consumption evaluation. Bio-resource Technology 101 (2010) 4992-5002

Zhu, J.Y., X.J. Pan, G.S. Wang and R. Gleisner. (2009a). Sulfite pre-treatment for robust enzymatic saccharification of spruce and red pine. Bio-resource Technology 100, 2411-2418.

Biography 


\title{
The Effect of Growing Conditions on Wood Density
}

\author{
Luka Krajnc \\ Luka.krajnc@gozdis.si \\ Polona Hafner \\ Polona.hafner@gozdis.si \\ JOŽICA GRIČAR \\ Jozica.gricar@gozdis.si
}

\section{Slovenian Forestry Institute, Slovenia}

\begin{abstract}
European forests overall are currently a net carbon sink, however, this is likely to change in the coming decade. It is therefore important to optimize the relationship between maintaining forest carbon stock and producing an annual yield of higher-quality timber, which will remain in use longer and will more likely be recycled. Wood density is one of the most important indicators of wood quality overall, as it is closely related to other important mechanical properties (elastic modulus, bending strength). Together they form the grade-determining properties, which are used for classifying structural timber into strength classes. Presented study has investigated how different environmental factors affect wood density of the most commonly grown tree species in Slovenia. Standing trees were sampled in various forest stands using a Resistograph, a high-resolution resistance drilling device. Sampled tree species were European beech (Fagus sylvatica), Norway spruce (Picea abies) and silver fir (Abies alba). Factors like soil bedrock, elevation and others affecting wood density were studied, quantified and compared between sampled species. The preliminary results indicate that wood density varies significantly between trees of different species growing under the same conditions and that elevation has a tangible positive effect on wood density overall. The results currently indicate that an approximately $10 \%$ increase in wood density of Norway spruce trees can be detected between trees from $700 \mathrm{~m}$ and trees from 1500 meters above the sea level. The identified magnitude of differences between trees is likely associated with shortening of the growing season with altitude, which affect basic relations between wood anatomy, tree-ring width and wood density.
\end{abstract}

Biography 


\title{
Proceedings of the 2020 Society of Wood Science and Technology International Convention
}

\section{Differences between Hygroscopicity Limit and Cell Wall Saturation Investigated by LF-NMR on Thermally-Modified and Lignin-Removed Southern Pine (Pinus spp.)}

\author{
Ms Jingyu Li, Beijing Forestry University, China \\ ljyemma@163.com
}

\begin{abstract}
Low-field nuclear magnetic resonance (LF-NMR) was used to clarify the difference between the fiber saturation point (FSP) determined at the hygroscopicity limit (HL) versus cell wall saturation (CWS) of untreated, thermally-modified (TM), and lignin-removed (DL) Southern pine (Pinus spp.). The thermal treatment was conducted at $225^{\circ} \mathrm{C}$ for 4 hours, and the delignified treatment was done by a mixture of $967 \mathrm{~mL}$ distilled water, $20 \mathrm{~g}$ sodium chlorite ( $\mathrm{NaClO} 2)$, and $13 \mathrm{~mL}$ acetic acid $(\mathrm{CH} 3 \mathrm{COOH})$ at $40^{\circ} \mathrm{C}$ in a water bath for $40 \mathrm{~h}$. The HL samples was attained by conditioning in $100 \%$ relative humidity (RH) while CWS samples were fully saturated with distilled water. Cell wall water of CWS samples was determined at $-3^{\circ} \mathrm{C}$ with LFNMR. The moisture content (MC) of the HL samples was found to decrease after thermal treatment, while increase after lignin removal. The tendency remain to be same for cell wall water of CWS samples. At $25^{\circ} \mathrm{C}$, the $\mathrm{HL}$ state of the treated samples contained 2 peaks, representing bound water and part of water constrained in pits, respectively; The samples included 34 peaks in CWS state, corresponding to bound water, water in pits or smaller pores, and free water in the cell lumena (usually Peak 3 and Peak4). When comparing the cell wall water difference for $\mathrm{HL}$ and CWS samples, an increase by $5.58 \%$ was shown for untreated samples. A possible explanation may be the cell wall was further swollen under liquid saturation. This difference was found to increase for DL samples by $8.58 \%$, while TM samples shows negligible difference. The results suggest that the number of sorption sites in the cell wall decreased after heat treatment, and the swelling behavior was weakened. But for delingnified treatment, more soption sites may be exposed, and the cell wall was more resilient towards water swelling.

Moreover, the increase in water content located in the cell wall was determined using freezing point depression. For untreated samples, about $11 \%$ of the MC was found in cell wall nanopores with sizes ranging from $1.73 \mathrm{~nm}$ to $13.80 \mathrm{~nm}$. The discrepancy between the $\mathrm{HL}$ and CWS values of the samples was attributed to freezable water in the nanopores of the matrix components and inter-microfibrils.
\end{abstract}

Biography 


\title{
Some Mechanical Properties of Particleboards Produced from Four Agro- forest Residues Using Cassava Starch and Urea Formaldehyde as Adhesives
}

\author{
Mr. Prosper Mensah, CSIR Forestry Research Institute, Ghana \\ pmensah@csir-forig.org.gh
}

\begin{abstract}
The increase in demand of particleboards for furniture and other applications has prompted a largescale research into the suitability of various types of lignocellulosic materials for its manufacture. For the appropriate use of particleboards produced from such materials their properties need to be established. This paper evaluated some mechanical properties of particleboards produced from four agro-forest residues using cassava starch and urea formaldehyde as adhesives. One layer homogenous particleboards of sizes $20 \mathrm{~mm} \times 300 \mathrm{~mm} \times 300 \mathrm{~mm}$ were manufactured from the agroforest residues. The boards which were produced at a targeted density of $600 \mathrm{~kg} / \mathrm{m} 3$ with adhesive content of $12 \%$ (based on the oven-dry weight) were pressed at $170^{\circ} \mathrm{C}$ for 480 seconds using compacting pressure of 3.5 $\mathrm{MPa}$. The modulus of elasticity, modulus of rupture and hardness were determined in according with the American National Standard Institute A208.1-2009. With the cassava starch (CS) blend, MoR was in a range of 4.95-12.93 MPa and urea formaldehyde (UF) blend the MoR was in the range of 6.89-16.54 MPa. The MoE for the CS blend ranged from 1030.50-2173.00 MPa and that of UF blend were in the range of 1390.68-2412.68 MPa. CS blend recorded 2.49-6.79 MPa for its hardness and UF blend hardness was in the range of 3.63-8.78 $\mathrm{MPa}$. The uniform distribution of the respective biomass particles and the flowability of the adhesives in the microstructure of the manufactured particleboards is the major factor responsible for the improvement in the mechanical properties tested. It was concluded that with the exception of particleboards manufactured from Theobroma cacao pod using CS and UF all other selected biomass made an acceptable particleboards with optimum performance, minimum weight, and possible cost effective for interior application, fitments and other furniture to be used in dry conditions.
\end{abstract}

Keywords: Agro-forest residue; Cassava starch, Mechanical properties; Particleboard, Urea formaldehyde

Biography 


\title{
SPECTROSCOPIC CHARACTERISATION OF WOOD TREATED BY DIFFERENT COATINGS AFTER WEATHERING IN SUBARCTIC CONDITIONS
}

\author{
Olena Myronycheva1, Alona Sekan1, Injeong Kim1, Olov Karlsson1, Peter Jacobsson2, Margot \\ Sehlstedt-Persson1, Dick Sandberg1
}

1 Wood Science and Engineering, Luleå University of Technology, Skellefteå, Sweden 2 Martinsons Byggsystem AB, Skelleftea, Sweden

\begin{abstract}
Weathering of wood is a complex natural phenomenon that is influenced by factors both in macroand micro-scale. The degradation by weathering constitutes of complex physical-chemical changes influenced by environmental factors such as moisture, sunlight, temperature, chemical compounds, wind, and biological organisms and their related agents. The aim of our study was the evaluation of MIR and NIR spectroscopic technique for characterisation of wood treated by commercial coatings contained different biocidal treatments after weathering in subarctic conditions.

Tangential and radial surfaces of the Scots pine and Norway spruce were treated with coatings containing various biocides. Treatment was in the form of fairly transparent wood oil (T), while the two others were coatings that had more of a non-transparent character $(\mathrm{H}$ and $\mathrm{P})$. Treated specimens and control were placed in various directions on racks outdoor for natural weathering. The measurement of the NIR spectra of specimens that were not exposed, after weathering and dried after weathering, was done by the point-based microNIR portable sensor. Multivariate statistical analysis (MSA) showed that data from types of exposure contributed less compared to surface treatments in the 3D principal component analysis model (PCA). Grouping pattern around treatments $\mathrm{H}$ and $\mathrm{P}$ could be obtained as the two individual groups more or less fully separated. From the treatment $\mathrm{T}$ and non-treated specimens, no individual grouping behaviour could be observed, however, more intense exposed seemed to be clustered in a different way than mildly exposed ones. A more extensive weather exposure gave also a more degraded surface for T-treated specimens. The NIR portable spectrometer may be used for assessment of the extent of weathering, but the treatment $\mathrm{P}$ followed by treatment $\mathrm{H}$ had minimal changes. Coefficients Plot in the PLSDA model for different types of exposure for those treatments showed the influence of the NIR wavelengths in classes related to exposure type. The changes caused by weathering phenomenon was evaluated by using multivariate methods in which resulting multivariate model parameters for prediction of the changes were determined. Analysis of the chemical structure of coatings after weathering analysed by mid-infrared spectroscopy gave support to the lower stability of $\mathrm{T}$ treatment during weathering.
\end{abstract}

Keywords: wood, treatment, natural weathering, infrared, near-infrared, spectroscopy

\section{INTRODUCTION}

The measurement by electromagnetic radiation such as mid-infrared (MIR) and near-infrared spectroscopy (NIR) is non-destructive analytical techniques providing an individual chemical fingerprint of the sample. The non-destructive nature of the technique made it quite popular in 
material science and widely applied to the wood (Sandak, Sandak, and Meder 2016). Industrial digitalisation and movement towards the Industry 4.0 revolution opened new applications to spectroscopic techniques in environmental chemistry. However, the semi-quantitative approach and heterogeneity of wooden material limit its application in the material involved in environmental analysis such as weathering. Weathering of wood is a complex, natural phenomenon that is influenced by factors both in macro- and micro-scale. The surface degradation by weathering evolves complex physical-chemical-biological changes caused by environmental factors such as moisture, sunlight, temperature, chemical compounds, wind, and biological organisms.

Therefore, the aim of our study was the evaluation of field NIR spectroscopic technique for characterisation of wooden material treated by commercial coatings of three different types, in outdoor applications in subarctic conditions.

\section{MATERIAL AND METHODS}

Kiln-dried Scots pine sapwood boards were cut into specimens with a dimension of $15 \times 12 \times 2 \mathrm{~cm}$ (TxWxL). Kiln-dried Norway spruce boards were cut to specimens with a dimension of $15 \times 8 \times 1.5$ $\mathrm{cm}$. The end-grain surfaces of each specimen were sealed with a SikaFlex, Switzerland. The total non-sealed surface area of the specimens was $420 \mathrm{~cm} 2$ and $300 \mathrm{~cm} 2$ for Scots pine and Norway spruce, respectively. Three surface treatments with different biocidal composition and an uncoated control group were evaluated, and variables in the experimental design of the current study presented in Table 1.

Table 1. Experimental design.

\begin{tabular}{|c|c|c|c|}
\hline Variables & Code & Description of Variables & No. of replicates \\
\hline \multirow[t]{4}{*}{ Treatment } & $\mathrm{H}$ & $\begin{array}{l}\text { Waterborne Pigmented Primer with two } \\
\text { biocides and alkyd binder }\end{array}$ & 18 \\
\hline & $\mathrm{T}$ & Waterborne wood oil with a single biocide & 18 \\
\hline & $\mathrm{P}$ & $\begin{array}{l}\text { Waterborne paint for indoor use with four } \\
\text { biocides and acrylate binder }\end{array}$ & 18 \\
\hline & $\mathrm{C}$ & No treatment & 18 \\
\hline \multirow[t]{2}{*}{ Wood specie } & & Scots pine & 36 \\
\hline & & Norway spruce & 36 \\
\hline Angle of & & 0 & 24 \\
\hline \multirow{3}{*}{ exposure } & & 45 (south) & 24 \\
\hline & & 90 (north) & 24 \\
\hline & & No exposed & 20 \\
\hline $\begin{array}{l}\text { Type of } \\
\text { exposure }\end{array}$ & & $\begin{array}{l}\text { No exposed/After exposure for } 115 / \text { Dried } \\
\text { after exposure for } 115 \text { days }\end{array}$ & 20/72/72 \\
\hline
\end{tabular}

The amount of applied treatment coating on each specimen was $100 \pm 10 \mathrm{~g} / \mathrm{m} 2$. The specimens were placed on the exposure site (in Skellefteå latitude: 64.744453, longitude: 20.955569) at June 5th, and removed September 27 th with a total exposure time 115 days. The specimens were inclined to the south with an angle of $45^{\circ}$, and to the north by an inclination angle of $90^{\circ}$ against the horizontal plane as well as in the horizontal position.

The moisture content of the specimens before and after outdoor exposure was measured gravimetrically by heating in an oven at $103^{\circ} \mathrm{C}$ until constant weight. 
The NIR spectra were collected by portable microNIR OnSite Spectrometer (VIAVI Solutions Inc., San Jose, CA, USA) with NIR wavelengths from 908 to $1676 \mathrm{~nm}$ with step $6 \mathrm{~nm}$, every week during the observation period. NIR spectral data collected in five replicates and dataset contained 1166 observations in total used for the prediction model. The analysis was performed using variables Treatment, Wood Specie, Day and Angel of Exposure. The FTIR spectra in the MIR range 4000-400 cm-1 were collected from dried specimens (MC in Table 2) isolated by scraping surface material from the treated wood after weathering of specimens in ATR mode and transformed to the absorbance mode by FT-IR Frontier Spectrometer, PerkinElmer. The comparison of unexposed treatment and treatments at different directions of exposure was made for chemical changes detection. Data analysis was performed with MS Excel 2016, IBM SPSS, USA and SIMCA14, Umetrics AB, Sweden (Eriksson et al. 2013).

\section{RESULTS AND DISCUSSION.}

In Figure 1, the multivariate modelling of the NIR spectra of the grouping of all specimens in the study is presented. This is shown as a three-dimensional plot of principal component analysis (PCA). In this way clear grouping pattern by treatments that are coloured differently could be seen: treatment with P-product (red) and H-products (blue) dots where separated quite well from the other groups whereas untreated (yellow) and treated with T-treated (green) were mixed (Figure 1a).

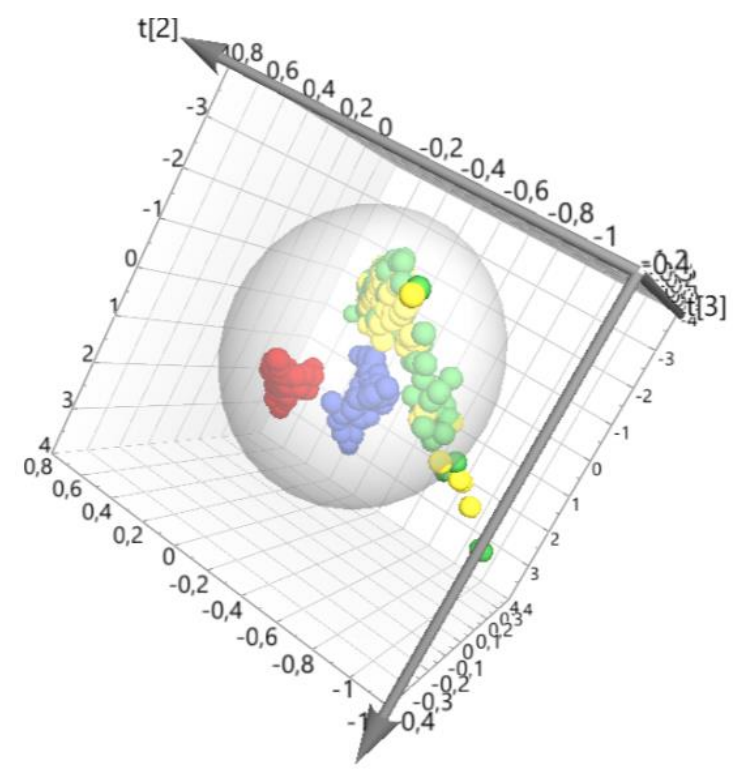

a)

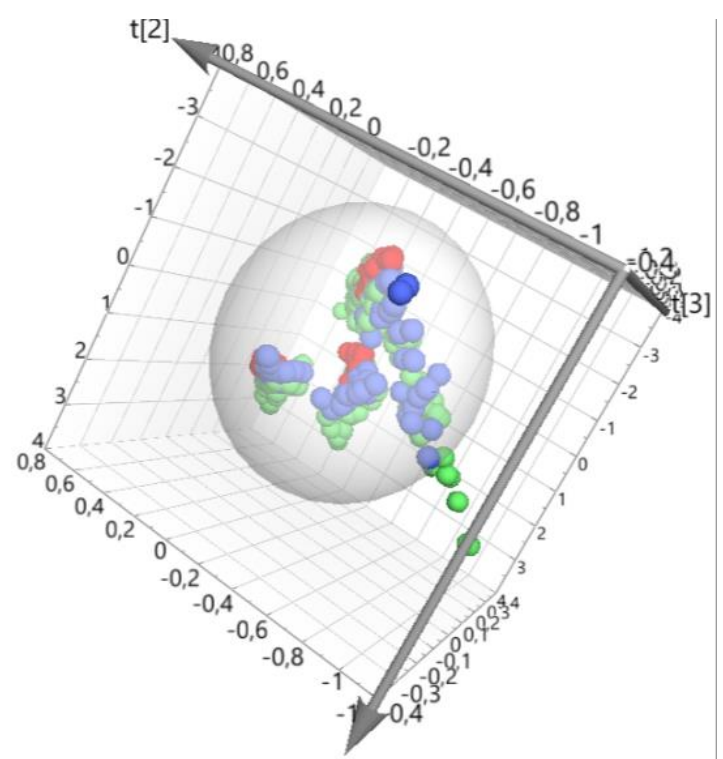

After exposure Dried after exposur€ b) 


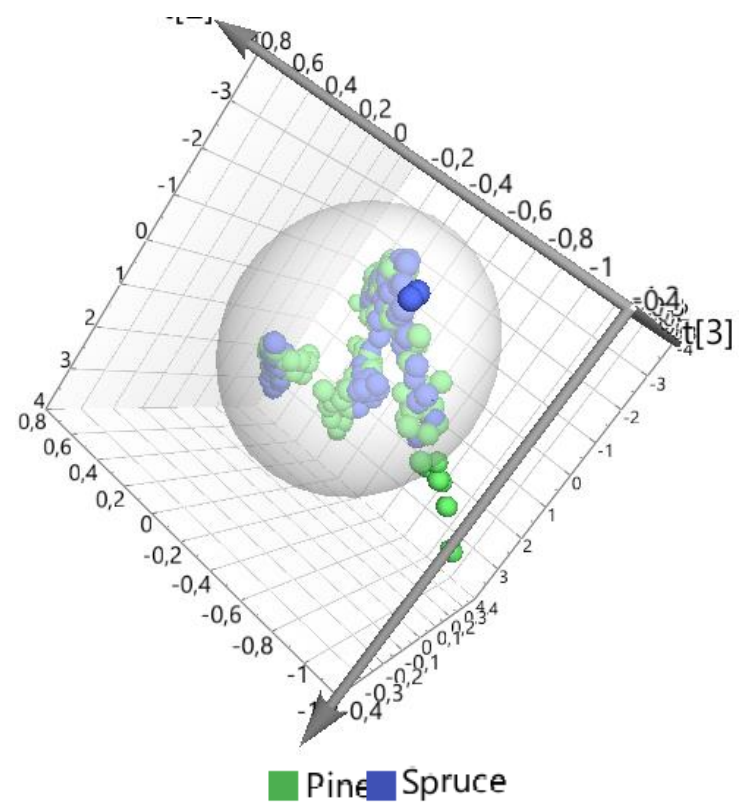

c)

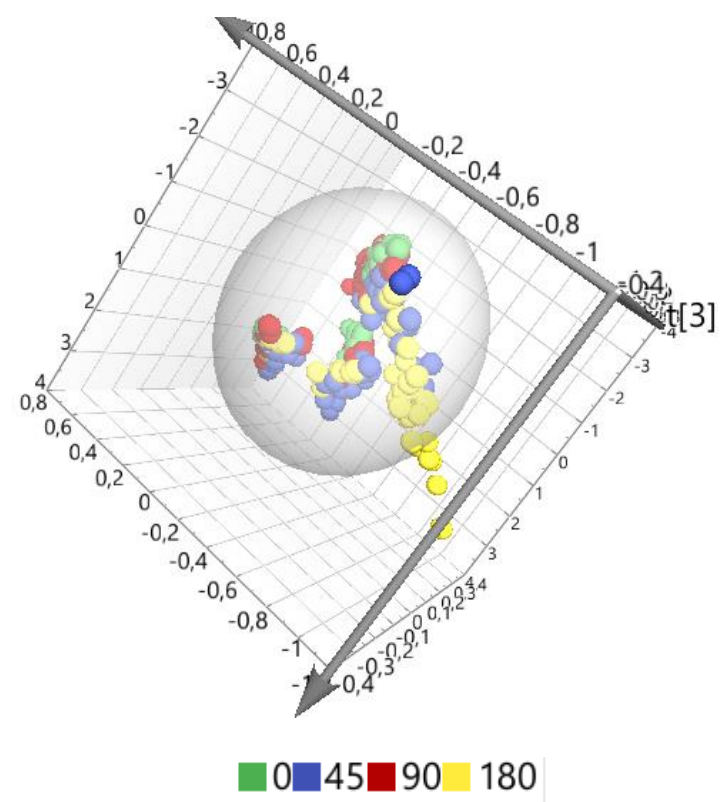

d)

Figure 1. The 3D PCA model of NIR spectra overview with legends coloured by: a) coating treatment, b) type of exposure, c) wood species, $d)$ angle of exposure $(0$ - non exposure specimens)

Already in the non-exposed specimens (red dots in Figure 1b), such separation between treatment $\mathrm{H}$ and $\mathrm{P}$ was seen whereas for T-treatment mixing with uncoated specimens were obvious. Also, after the weathering exposure, such separation of specimens related to the various treatments could be observed (green dots in Figure 1b). Furthermore, the weathered specimens in treatment $\mathrm{H}$ and $\mathrm{P}$ (green dots in Figure 1b) were clustered at somewhat different position in the plot than the corresponding non-exposed specimens (red dots in Figure 1b). Moisture is a frequent contributor in NIR spectra, and H- and P-dried weathered specimens (green dots in Figure 1b) were also clustered at somewhat different positions than the dried weathered specimens (blue dots in Figure 1b). This indicated that also, other factors than moisture contributes to the separations of groups in the PCA-plot as the treatment itself played a dominant role in the separation in the multivariate plot of weathered specimens.

From visual inspection, T treatment was found to be more vulnerable to weathering conditions than treatment $\mathrm{H}$ and especially treatment $\mathrm{P}$ (Table 2).

Table 2. The final pictures of the treated Scots pine boards after 115 days of exposure before drying

\begin{tabular}{|l|l|l|l|l|}
\hline Angle & H & T & P & C \\
\hline
\end{tabular}




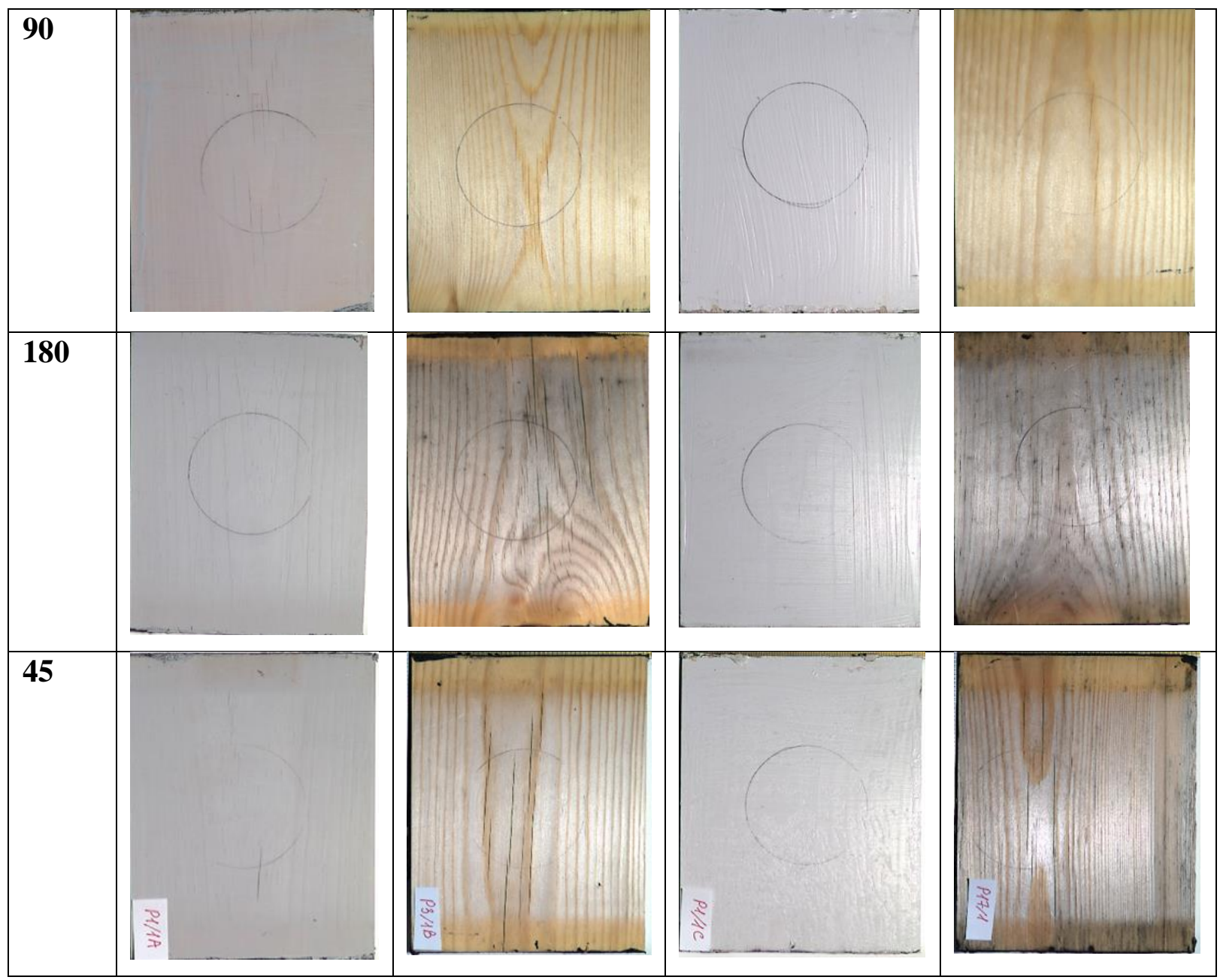

Furthermore, moisture content in the specimens varied depending on the exposure position as shown in Table 3. In Figure 1d influence of exposure position on the modelled NIR-data is presented; specimens from T-treated and uncoated ones that were more exposed (180 degree) were clustered more or less at other position than the mildly exposed (90 degree), while a similar trend was more difficult to observe for $\mathrm{H}$ - and $\mathrm{P}$-treatments.

Table 3. Moisture content of weather exposed specimen

\begin{tabular}{|l|c|c|c|}
\hline Treatment & Angle of & \multicolumn{2}{|c|}{ Wood Specie } \\
\cline { 3 - 4 } & Exposure & Pine & Spruce \\
\hline $\mathrm{H}$ & 45 (south) & $16.77 \pm 0.16$ & $15.03 \pm 0.13$ \\
& 0 & $19.75 \pm 0.56$ & $17.70 \pm 0.02$ \\
& 90 (north) & $16.38 \pm 1.25$ & $16.59 \pm 0.32$ \\
\hline $\mathrm{T}$ & 45 (south) & $16.78 \pm 0.31$ & $17.04 \pm 0.46$ \\
& 0 & $17.75 \pm 0.34$ & $18.42 \pm 0.26$ \\
& 90 (north) & $17.78 \pm 0.13$ & $16.54 \pm 0.75$ \\
\hline $\mathrm{P}$ & 45 (south) & $16.84 \pm 0.48$ & $15.42 \pm 0.70$ \\
& 0 & $18.79 \pm 2.36$ & $18.81 \pm 0.11$ \\
& 90 (north) & $17.20 \pm 1.06$ & $17.01 \pm 2.83$ \\
\hline
\end{tabular}




\begin{tabular}{|l|c|c|r|}
\hline C & 45 (south) & $15.99 \pm 0.13$ & $16.97 \pm 2.62$ \\
& 0 & $18.07 \pm 0.30$ & $18.32 \pm 0.15$ \\
& 90 (north) & $16.75 \pm 0.36$ & $16.99 \pm 0.62$ \\
\hline
\end{tabular}

Alkyd and acrylate binder were the dominant organic components in $\mathrm{H}$ - and $\mathrm{P}$-coating treatment and biocides contributed only to low extent. Functional groups in these two binders also contributed to absorptions when analysing the surface materials using FTIR in which carbonyl absorptions at $1720 \mathrm{~cm}-1$ was found to be fairly stable towards weathering, while changes in hydrocarbon absorptions were more difficult to evaluate. Preliminary data for T-treatment indicated changes in the carbonyl absorptions that might reflect its less stable appearance. Thus, the importance of degradation of coating in the clustering within each coating is still difficult to verify and needs further studies.

\section{Validation of multivariate models}

The PCA model of NIR spectra which provided the data for the presentations in Figure 1 gave a description of data (R2) $99.9 \%$ and prediction (Q2) $99.9 \%$ that is quite good for NIR spectra (Table 4). The partial least squares regression (PLS) model with Y variables (Treatment, Wood Specie, Day, Angel of Exposure, Type of Exposure) contained 21 principal components and less prediction value (Q2 in Table 4) was used to find the best-modelled variable. The variable Type of Exposure contributed mostly to the models' performance compared to other variables after the diagnostic of the PLS model (data not shown here). Therefore, that variable (Type of Exposure) was used as a response in the PLS-DA model since that model provides maximum separation between such amounts of classes (Eriksson et al. 2013). The parameters of all models developed are described in Table 4.

Table 4. The multivariate models' parameters

\begin{tabular}{|l|l|c|c|c|c|c|}
\hline № & Name & Component & Observations & R2X(cum) & R2Y(cum) & Q2(cum) \\
\hline 1 & PCA & 3 & 1166 & 0.999 & & 0.999 \\
\hline 2 & PLS & 21 & 1166 & 1 & 0.799 & 0.788 \\
\hline 3 & PLS-DA & 8 & 1166 & 1 & 0.845 & 0.844 \\
\hline
\end{tabular}

The Coefficients plot in Figure 2, displays regression coefficients correlated to scaled and centred $\mathrm{X}$-variables (NIR-spectra) from all specimens in class After exposure. As the model is based on all samples and their composition varies this means that correlations could not be related to a specific treatments structure. However, some general conclusions can be drawn. Negative and positive correlations were found indicating decreases and increases in presence of absorptions upon weathering exposure, respectively. The negative high coefficients at the beginning of the NIR spectra (lower wavelength) could be related to the VIS region and visible changes of colour on the surface (Schwanninger et al. 2011). Although moisture was found in the specimen (Table 3), typical strong water signal (around $1450 \mathrm{~nm}$ ) have not been generated.

The observation of Coefficients plot for all classes in the PLS-DA model showed the strongest correlation for wavelength around $1620 \mathrm{~nm}$ which may be related to $\mathrm{C}-\mathrm{H}$ hydrocarbon chains possibly in alkene groups (Workman and Weyer 2012; 2008). Class Dried after exposure had the strongest positive correlation around wavelength $1403 \mathrm{~nm}$ that is close to absorptions originated from methyl $\mathrm{C}-\mathrm{H}$ absorptions associated with branched aliphatic hydrocarbon (Workman and Weyer 2012; 2008). 


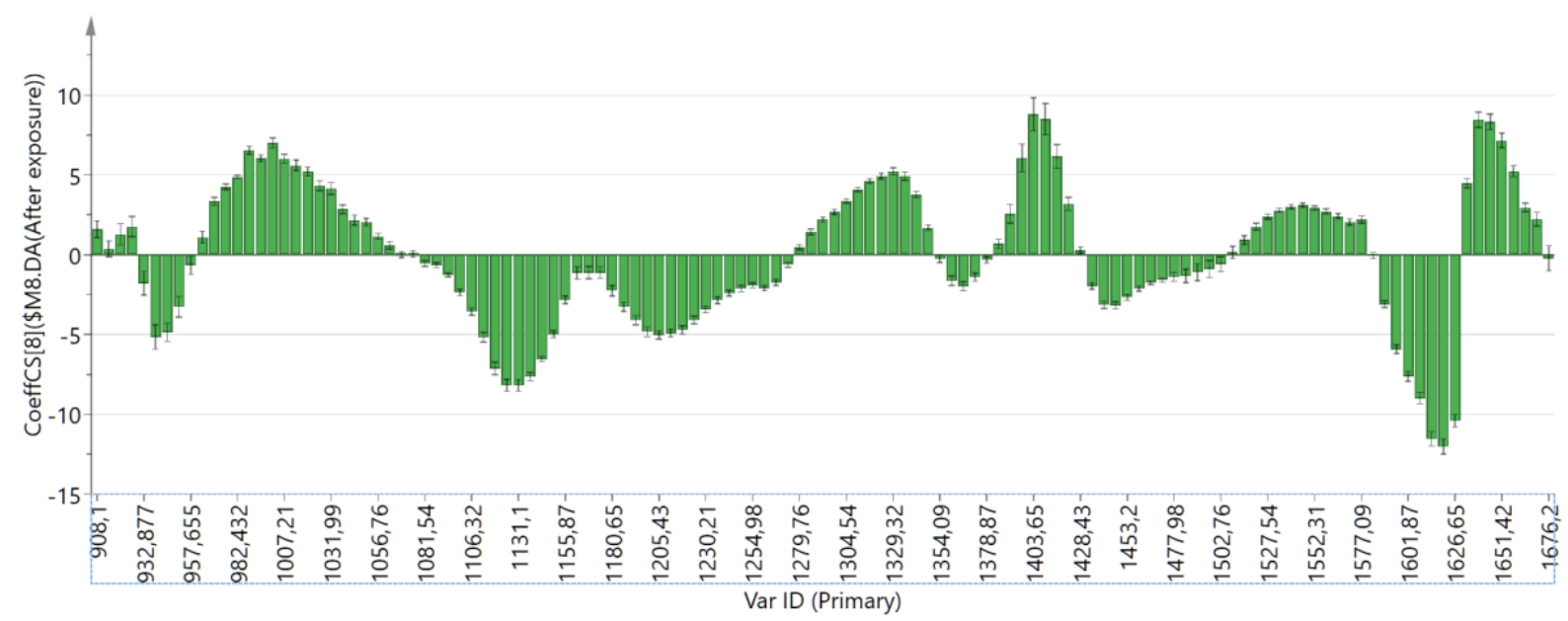

Figure 2. The Coefficients plot of PLS-DA model from all specimens.

The misclassification table in the PLS-DA model shows the proportion of correctly classified observations in the prediction set. The NIR spectra in different treatments could be predicted to the extent of around $80 \%$ in total, as presented in Table 4.

Table 4. Misclassification table PLS-DA (green - correct prediction, yellow -misclassification)

\begin{tabular}{|l|c|c|c|c|c|c|}
\hline Variable & Number & Correct & $\begin{array}{c}\text { After } \\
\text { exposure }\end{array}$ & $\begin{array}{c}\text { Dried } \\
\text { after } \\
\text { exposure }\end{array}$ & $\begin{array}{c}\text { No } \\
\text { exposure }\end{array}$ & $\begin{array}{c}\text { No class } \\
\text { (YPred } \leq)\end{array}$ \\
\hline After exposure & 599 & $100 \%$ & 599 & 0 & 0 & 0 \\
\hline Dried after exposure & 367 & $95.91 \%$ & 0 & 352 & 15 & 0 \\
\hline Non exposure & 200 & $100 \%$ & 0 & 0 & 200 & 0 \\
\hline No class & 0 & & 0 & 0 & 0 & 0 \\
\hline Total & 1166 & $98.71 \%$ & 599 & 352 & 215 & 0 \\
\hline
\end{tabular}

The classes represented types of exposure regarding no exposure and after exposure could be predicted with $100 \%$. When in dried after exposure type 15 specimens were misclassified. The explanation of such consequences could be due to the nature of the treatment $\mathrm{P}$ that was less degraded during exposure than other treatments-product and homogeneity of the weathered and the non-weathered wood

\section{CONCLUSION}

The evaluation of three commercial wood coating by spectroscopic techniques revealed that NIR spectra might be used for the detection of weathered or non-weathered specimens. From our data from NIR and MIR, the most variability in the model was probably from changes in hydrocarbons as well as carbonyl compounds related to the chemical composition of the treatment $\mathrm{T}$. Despite complicated for interpretation spectra and step $6 \mathrm{~nm}$ in the portable microNIR spectrometer, the PLS-DA model gave almost $99 \%$ of the prediction. That indicates portable microNIR as a promising technique for the assessment of the weathered coated wood in outdoor exposure. 


\section{ACKNOWLEDGEMENT}

The acknowledgement by authors provided to the Swedish Research Council for the Environment Agricultural Sciences and Spatial Planning, FORMAS (project number 419, 2017) and IPOS DP2 Vinnova for funding our research. Kempe foundation is gratefully acknowledged for financial support.

\section{REFERENCE}

Eriksson, L, T Byrne, E Johansson, J Trygg, and C Vikström. 2013. Multi-and Megavariate Data Analysis: Basic Principles and Applications.

Sandak, Anna, Jakub Sandak, and Roger Meder. 2016. 'Tutorial: Assessing Trees, Wood and Derived Products with near Infrared Spectroscopy: Hints and Tips'. Journal of Near Infrared Spectroscopy 24 (6): 485. https://doi.org/10.1255/jnirs.1255.

Schwanninger, Manfrred, Jos\&\#x00E9 Rodrigues, Carlos, and Karin Fackler. 2011. 'A Review of Band Assignments in near Infrared Spectra of Wood and Wood Components'. Journal of Near Infrared Spectroscopy 19 (5): 287-308. https://doi.org/10.1255/jnirs.955.

Workman, Jerry, and Lois Weyer. 2008. Practical Guide to Interpretive Near-Infrared Spectroscopy. Boca Raton: Taylor \& Francis.

- 2012. Practical Guide and Spectral Atlas for Interpretive Near-Infrared Spectroscopy.

2nd ed. Boca Raton; London: CRC Press.

Biography 
Proceedings of the $\mathbf{2 0 2 0}$ Society of Wood Science and Technology International Convention

\title{
Identification of Wood Vibro-acoustic Parameters for Musical Instruments
}

\author{
Patrik Nop, \\ Department of Wood Science and Technology, \\ Faculty of Forestry and Wood Technology, Mendel University in Brno, Czech \\ Republic \\ xnop@mendelu.cz
}

\begin{abstract}
Wood is one of the most interesting materials in terms of studying acoustic properties. For its unique character has always been the most used material for the production of quality musical instruments, loudspeakers, architecture acoustic elements etc. The treatment of composites or wood modifications can significantly improve properties to meet the highest standarts of products. Consequently, advanced vibro-acoustic analysis of material is necessary to identify main characteristics determining wood quality in terms of acoustics and asses its suitability for acoustic related applications.

The three methods are used for determination of acoustic properties of materials - resonance frequency method by microphone, modal analysis using microaccelerometers or laser vibrometers, direct measurement of speed of sound transmission through the material by piezoelectric probes. Acoustic parameters of the material are derived from the physical properties measured by these metods (density, speed of sound propagation, dynamic modulus of elasticity). Acoustic constant and sound impedance calculated from these properties, the loss coefficient or logarithmic decrement of damping and finally acoustical conversion efficiency (ACE) and relative acoustical conversion efficiency (RACE) combining mentioned material parameters should be indicative of the acoustic quality of wood. The subject of the presented study is a combination of measuring methods and modal analysis with focus on relationships of common vibro-acoustic parameters and the connection of required tonal intervals in the timbre of musical instruments and the natural frequency intervals of specimens made from individual wood species. The goal is to find a more reliable correlation of parameters for a more complex vibro-acoustic wood analysis, which helps in selecting suitable wood for the production of musical instruments and determine the key parameters for evaluation of wood modifications aiming to improving of acoustic properties.
\end{abstract}

Key worlds: Vibro-Acoustic Study, Acoustic Properties, Modal Analysis, Frequency Spectrum

Biography 


\title{
Triboelectric Activation of Sawdust During Cutting and Sanding Processes, A New Approach to Lower Wood Fine-Dust Contamination
}

\author{
Luca Nüssel 1 \\ nuluca@yahoo.de \\ Lisa Doni 1 \\ Lisa.doni@gmx.net \\ Roman Myna2 \\ Roman.myna@boku.ac.at \\ Stephan Frömel-Frybort2 \\ Stephan.frybort@boku.ac.at \\ Rupert Wimmer 1 \\ Rupert.wimmer@boku.ac.at
}

1 Institute of Wood Technology and Renewable Materials, Department of Material Sciences and Process Engineering, BOKU - University of Natural Resources and Life Sciences

2 Wood K plus - Competence Centre for Wood Composites and Wood Chemistry

\section{Abstract}

We have recently shown that triboelectric charging of wood particles occurs during collision and separation of such particles, which is leading to either positive or negative particle charges. In this research we particularly focused on the triboelectric activation of wood particles that occurs during circular saw cutting and sanding, with the purpose of developing approaches that lower wood fine-dust contamination. Wood samples from spruce, beech, as well as from particleboards and medium density fiberboards were processed at various conditions. For the sawing we varied cutting depth, feeding speed and the number of saw blade teeth. For the sanding we varied grain size and abrasion depth. The interactions between wood species, wood density, the aforementioned cutting and sanding parameters, and the triboelectric charge of the obtained wood particles were investigated. Data show that medium-density fiberboard particles received the highest triboelectric activation, while spruce obtained the lowest. The different electrical activations (charges) of wood particles can be explained by the wood density, and the resin content. We have shown that different particle sizes emerge during cutting and sanding, which is a major reason for extent of triboelectric activation. With the collected data it was possible to expand the triboelectric series with spruce, beech, particleboards and mediumdensity fiberboards. A well-directed triboelectric activation of wood particles during sawing and sanding will greatly improve the efficiency of wood dust collection systems. Improved dust collection reduces health risks at the workspace, lowering the workers exposure to wood fine-dust particles. Keywords:

triboelectric charge, triboelectric series, sawdust, spruce, beech, particleboard, medium-density fiberboard, wood machining

Biography 
Proceedings of the 2020 Society of Wood Science and Technology International Convention

\title{
ABES and DMA Cure Monitoring of Tannin Adhesive
}

\author{
Jasa Sarazin 1 \\ jasa.sarazin@bf.uni-lj.si \\ Milan Sernek1 \\ milan.sernek@bf.uni-lj.si \\ Antonio PIzzi2 \\ antonio.pizzi@univ-lorraine.fr
}

\author{
${ }_{1}$ University of Ljubljana, Biotechnical Faculty, Slovenia \\ 2 Universite de Lorraine LERMAB-ENSTIB, Nancy, France
}

\begin{abstract}
Determination of optimal pressing time and temperature is essential for economical production of wood-based composites. Two useful and fast, laboratory-scale methods for determination of these parameters are Dynamic Mechanical Analysis (DMA) using oscillatory test on rheometer and real time shear test conducted on Automated bonding evaluation system (ABES).

The objective of this preliminary study was to examine curing process of pine tannin-hexamine adhesive, which is one of the wood bio-based adhesives studied in the ongoing project WooBAdh. Bond strength development of the bio-based adhesive was determined on rheometer and ABES at five different press temperatures. Oscillatory test on rheometer was conducted using two aluminum discs in parallel plate geometry, whereas ABES was using beech (Fagus sylvatica L) cut veneer for formation of lap shear bonds.

It was found out that curing process of the tannin adhesive determined by rheometer resulted in significantly longer pressing times compare to pressing times derived from ABES. This was ascribed mainly to bigger amount of adhesive tested by rheometer (gap was $0.5 \mathrm{~mm}$ ), absence of the pressure and presence of aluminum discs instead of wood, which would absorb the water from the adhesive during curing process.

Biography
\end{abstract}




\title{
Proceedings of the 2020 Society of Wood Science and Technology International Convention
}

\section{Characterization of Raw Materials and Physical Properties of Particleboard Made from Douglas fir Bark}

\author{
Mathias Schuh 1 \\ schuh@hfm.tum.de \\ Philipp Hüser2 \\ philipp.hueser@student.hswt.de \\ Simon Redel 2 \\ simon.redel@student.hswt.de \\ Klaus Richter3 \\ richter@hfm.tum.de
}

\author{
1 Technical University of Munich, Holzforschung München, Germany \\ 2 Hochschule Weihenstephan-Triesdorf, Germany \\ 3 Technical University of Munich, School of Life Sciences Weihenstephan, Wood \\ Research Munic, Germany
}

\begin{abstract}
The objective of this research was to investigate the suitability of Douglas-fir (Pseudotsuga menziesii) bark as a raw material for particle board production. A high percentage of the bark is used for energy production. The material was chosen because of its availability and to achieve a higher added value. Bark was obtained from two sawmills in south Germany, which used different debarking processes. One sawmill used a router head debarker and the other a rotor debarker. A screening process was carried out to characterize the particle size distribution of the raw material. Also, the mass percentage of wood was measured. The debarking method significantly influences the particle size distribution and the content of wood in the raw material. The bark was crushed in a wet state in a hammer mill to reduce the number of fine particles $(<1 \mathrm{~mm})$. The particles were kiln-dried at $70{ }^{\circ} \mathrm{C}$. To separate the roundish bark from the longish wood particles double layer sieves with perforated plates were developed. The particles were separated in two fractions. In average the mass percentage of wood in the raw material was $13 \%$. After separation the low wood fraction contained around $3 \%$ of wood and the high wood fraction around $21 \%$. Particles smaller than $1 \mathrm{~mm}$ were rejected. The boards were manufactured with three layers. The fraction with the high wood content was used in the core layer and the fraction with the low wood content was used in the surface layers for aesthetic reasons.

The study was designed to investigate the influence of three factors: adhesive type, adhesive amount and board density. A commercial urea formaldehyde (UF) and a melamine urea formaldehyde (MUF) adhesive was used in different concentration of 5, 8, 11, 14 and $17 \%$ in the core layer. The boards bonded with UF were produced with a target density of 650,800 and $950 \mathrm{~kg} / \mathrm{m}^{3}$, MUF bonded boards only with a target density of $800 \mathrm{~kg} / \mathrm{m}^{3}$. The amount of adhesive in the surface layers was always $3 \%$ higher than in the core layer. In total 60 boards of $380 \times 340 \times 14 \mathrm{~mm}$ were made with a laboratory hot press at $200^{\circ} \mathrm{C}$ with a pressing time of 610 seconds. For the testing process all boards were sanded to an equal thickness of $12 \mathrm{~mm}$ with a wide belt sander at grid 100 . The evaluated physical properties were modulus of rupture (MOR), modulus of elasticity (MOE), transverse tensile strength, thickness swelling, indentation hardness (Brinell), abrasion resistance and thermal conductivity. The results show that the requirements for particle boards for indoor use according to the standard DIN EN
\end{abstract}


Proceedings of the 2020 Society of Wood Science and Technology International Convention

312 type P2 are met, when the adhesive content in the core layer is above $11 \%$. The boards bonded with the MUF adhesive showed lower thickness swelling and higher transverse tensile strength after immersion for 24 hours in water at $20^{\circ} \mathrm{C}$. Producing boards with a density of $950 \mathrm{~kg} / \mathrm{m}^{3}$ was not possible due to steam burst.

Biography 


\title{
Pulp and Paper Making Potential of Elephant and Thatching Grasses Growing in Zambia
}

\author{
Kennedy Sichamba ${ }^{1^{*}}$ and Vanessa Chanda ${ }^{2}$ \\ ${ }^{1}$ Lecturer, Copperbelt University, School of Natural Resources, Kitwe, Zambia. \\ *Corresponding author \\ kennedysichamba@gmail.com \\ ${ }^{2}$ Former student, Copperbelt University, School of Natural Resources, Kitwe, \\ Zambia \\ nessachandacmv@gmail.com
}

\begin{abstract}
Elephant grass (Pennisetum purpureum) and thatching grass (Hyparhenia rufa) are common grass species in Zambia. Elephant grass is a perennial plant, growing in uncultivated wetlands and is mainly used for making mats and baskets, while thatching grass grows in open woodlands, and used for thatching houses in rural communities or burned out as a weed. Chemical composition, kraft pulp yield, and burst strength of paper handsheets of the grasses were determined in order to evaluate their suitability for pulp and paper making. The grasses were first air dried for a week and then cut in $2 \mathrm{~cm}$ pieces before analysis. Determination of chemical composition was conducted following the standard ASTM procedures with minor modifications. Kraft pulp was produced by cooking air dried grass material in $18 \%$ alkali solution containing sodium hydroxide and sodium sulfide, with $25 \%$ sulfidity. Pulp yield was expressed as percentage of the ratio of dry pulp to dry grass material. The pulp was bleached using hydrogen peroxide, sodium hypochlorite and sodium hydroxide to improve its brightness. The Bursting strength of paper handsheets was determined following the standard TAPPI T403 procedure. The cellulose, hemicelluloses, acid insoluble lignin and ash content of elephant grass and thatching grass were, respectively, $64.8 \%, 19.8 \%, 8.3 \%, 3.5 \%$ and $54.5 \%, 33.1 \%, 7.8,2.9 \%$. The high holloceluloses and relatively lower lignin content suggest that both grasses can easily be pulped. The Pulp yields ( $51 \%$ and $65 \%$,) were comparable to commercial pulp species such as switch grass and wood. The burst strength values were lower than other species previously studied. The handsheets were able to hold ink and glue quiet well. The results of this study suggest that both elephant and thatching grasses could be an alternative raw material for making pulp, paper and paper products, though addition research would be required to determine the optimal pulping conditions, to validate the findings of this study, and to investigate other pulp and paper properties. Paper from these grasses could be used to fabricate paper shopping bags to replace or reduce the use of environmentally harmful plastic bags in the country.
\end{abstract}


Key words: elephant grass, thatching grass, chemical composition, kraft pulp, handsheets Introduction

Paper consists of a web of fibers obtained from plants, bonded together primarily by hydrogen bonds. Any plant material can be used to make paper provided that it is readily available and produces high amount of fibers which are conformable and able develop strong hydrogen bonds (Smook 2002). Chemical content (cellulose, hemicelluloses, lignin and ash) is also an important yardstick of plant materials' suitability for pulping and paper making. Usually, the higher the amounts of celluloses and hemicelluloses in a plant material, the more the pulp yield and the better the quality of fibers (Khali 2006). In addition, lower lignin content indicates that fibers can be extracted from the plant material more easily. Wood from trees is the principle raw material used in pulp and paper making since it is readily available and produces good quality fibers. However, using trees has a lot of challenges. Because of its' complex structure, wood requires a lot of chemicals to process; trees take long to mature; high deforestation rate is threatening the future of wood raw materials; and wood faces competition from other uses such as energy and construction. Because of these factors, recent research has focused on identifying alternative non-wood raw materials for paper making.

Because of their availability, several grass species have been investigated for their potential for pulp and paper making, and the results are promising. Work on suitability of elephant grass for paper making in South Africa showed that is it suitable for making paper, because both the pulp yield and paper strength properties were comparable to commercial plant species (Madakadze et al. 2010). To extract the fibers, the grass materials were cooked in $14 \%$ alkali solution containing sodium hydroxide and sodium sulfide at $160^{\circ} \mathrm{C}$ for two hours. The pulp yield was $50 \%$ (compared to $48 \%$ for switch grass, a commercial species), while the burst index was above $5.85 \mathrm{KPa} \cdot \mathrm{m}^{-2} \mathrm{~g}^{-1}$, suggesting that the grass was suitable for making high strength paper. Similar results were obtained from elephant grass growing in India (Reddy et.al. 2014). The pulp yield was $58 \%$ while the burst index was $4.98 \mathrm{KPa} \mathrm{m}^{2} \mathrm{~g}^{-1}$. An earlier study by Madakadze et al. (1999) also found several warm seasonal grasses (switch grasses, big bluestem, cord grass, and sand reed) in Canada to be suitable raw materials for paper making. The pulp yield ranged from $44 \%$ - 51\%, and the burst index was above 5.0. KPa.m-2g-1 for all species. Jahan (2016) also found that umbrella palm grass (cyperus flabettiformic) is suitable for paper making. Both the pulp yield $(55 \%)$ and the burst index $\left(4.4 \mathrm{kPa} . \mathrm{m}^{2} / \mathrm{g}\right)$ were similar to other grass species, although the $\alpha$-cellulose content (32.2\%) was lower, and the lignin content (24.0\%) was higher than most grasses.

The aim of this study was to evaluate the pulp and paper making properties of elephant grass (Pennisetum purpureum) and thatching grass (Hyparhenia Rufa) growing in Zambia. The grasses are readily available in the country. Elephant grass is a perennial plant, grows in uncultivated wetlands and is sometimes used for making mats and baskets. Thatching grass on the other hand grows in open woodlands, and it is also a common feature on roadsides in peri urban roads in the country. It is mainly used for thatching houses in rural communities or burned out as a weed. To our knowledge, no study has been done on the suitability of these grasses for pulp and paper making. 


\section{Chemical Composition}

\section{Materials \& Methods}

Subsamples of the raw materials were analyzed for ash, lignin, hemicelluloses and $\alpha$-cellulose. The air-dried grass materials were first grinded to pass through a 40-mesh screen according to TAPPI T 257 ("Sampling and Preparing Wood for Analysis"). The Ash content was determined according to ASTM D-1102 "Standard test method for ash content in wood and wood-based materials" (ASTM International, 1984), while the acid insoluble lignin content was analyzed according to ASTM D-1106 "Standard test method for lignin in wood" (ASTM International, 1984). Alpha cellulose and Hemicelluloses content were determined following the procedure by Rowel (2005).

\section{Pulping Procedure}

To extract fibers, the grass materials were cooked in $18 \%$ alkali solution containing sodium hydroxide and sodium sulfide at $25 \%$ sulphidity, with an initial liquid to material ratio of five. About $180 \mathrm{~g}$ ( $7.7 \%$ moisture content) of the grass material was weighed in a beaker, to which $25.3 \mathrm{~g}$ of $\mathrm{NaOH}, 8.4 \mathrm{~g}$ of $\mathrm{Na}_{2} \mathrm{~S}$ and $937 \mathrm{ml}$ of water were added. The material was cooked for 8 hours at about $100^{\circ} \mathrm{C}$ while stirring with a glass rod. Additional water was added as required. After cooking, the fibers were thoroughly washed with water to remove the excess chemicals and then refined using a domestic blender for about five minutes. Refining collapses the fibers to improve their conformability. Refined pulp was then screened to remove uncooked materials. The fibers were then bleached to improve their brightness, by cooking in hydrogen peroxide, sodium hypochlorite and sodium hydroxide in series. Bleaching conditions used for each chemical followed those recommended by Biermann (1996), and are shown in table 1 below.

Table 1. Bleaching Conditions

$\begin{array}{llll}\text { Conditions } & \text { Sodium Hypochlorite } & \text { Hydrogen Peroxide } & \text { Sodium hydroxide } \\ \text { Chemical addition } & 2 \% & 2 \% & 2 \% \\ \text { Consistency } & 5 \% & 10 \% & 10 \% \\ \text { Temperature } & 35^{\circ} \mathrm{C} & 75^{\circ} \mathrm{C} & 95^{\circ} \mathrm{C} \\ \text { Time } & 1.5 \text { hours } & 2 \text { hours } & 1.5 \text { hours } \\ \mathrm{Ph} & 10 & 10 & 12\end{array}$

\section{Hand sheet Making and Strength Test}

To make paper handsheets, about 3.5g of air-dried pulp was thoroughly mixed with 1 liter of water in a blender to make pulp slurry. To form the mat, the slurry was poured on a mould which was placed in water and thereafter raised to allow the pulp settle on the mould as the water drains. The mat was then consolidated by gently pressing it between a cloth. The mat was then hot pressed under a cotton cloth using a hot-pressing iron to form the paper. Paper hand sheets were then prepared for determination of burst strength. Bursting strength test was performed using a Bursting tester (Mullen tester) according to TAPPI T403"Bursting Strength of Paper" (Tappi International, 1997). Greeting cards, business cards, envelopes and miniature 


\section{Proceedings of the 2020 Society of Wood Science and Technology International Convention}

bags were then made from the handsheets to demonstrate the ink and glue holding capabilities of the paper.

\section{Results and Discussion}

\section{Chemical Composition}

Cellulose, hemicelluloses, acid insoluble lignin and ash content of elephant and thatching grasses are shown in the table 2 below. The cellulose content of elephant grass (64.8\%) was higher than that of thatching grass (54.5\%), but the cellulose composition of both grasses were however higher than that of most hardwoods and softwoods, which range from $45 \%$ to $50 \%$ (Smook 2002), as well as that of switchgrass (41.2\%), a commercial specie used for pulp production, (Madakadze et al. 2010). Cellulose content of elephant grass observed in this study was significantly higher than that of elephant grass growing in South Africa (45.6\%) reported by Madakadze et al. (2010). The difference could be explained by differences in species, age and the harvesting season, as well as the extraction methods. The high cellulose content of the grasses was consistent with the lower lignin content $(7.8-8.3 \%)$, and it suggests that the grasses can produce good quality pulp. The lignin content of the grasses was much lower than that of both softwoods and hardwoods (20-35\%) as well as switch grass (23.89\%) as reported by Madakadze et al. (2010). The low lignin content shows that fibers can be extracted from the grass using less delignification chemicals with mild conditions. The average ash content was lower than most grasses, suggesting that the grass could also be processed commercially with less difficult. These figures suggest that elephant grass and thatching glass could potentially be used for producing good quality pulp, but further research work is necessary to verify these findings.

Table 2. Chemical Composition of elephant grass and thatching grass ( $\% \pm$ SD)

$\begin{array}{lll} & \text { Elephant grass } & \text { Thatching gras } \\ \text { Cellulose } & 64.8 \pm 0.75 & 54.5 \pm 0.50 \\ \text { Hemicellulose } & 19.8 \pm 0.79 & 33.1 \pm 0.83 \\ \text { Holocellulose } & 84.6 \pm 0.577 & 87.6 \pm 0.58 \\ \text { Acid insoluble lignin } & 8.3 \pm 0.045 & 7.8 \pm 0.15 \\ \text { Ash } & 3.52 \pm 0.03 & 2.96 \pm 0.05\end{array}$

\section{Pulp Yield}

Pulp yield of elephant grass (51\%) was lower than that of thatching grass (65\%). Elephant pulp yield was comparable to the yield of most of softwoods and hardwoods (45-50\%), and other grasses previously studied such as elephant grass (50\%) and switchgrass (48\%) as reported by Madakadze et al. (2010). But Reddy et al. (2014) reported elephant grass pulp yield of 58\%, slightly higher than the yield obtained from the current study. The difference was probably due to species, age, and difference pulping methods used. Kraft pulping was used in the current study while soda pulping was applied in the latter study. The pulp yield of elephant grass was also comparable to other grasses like umbrella palm grass from Bangladesh (55.0\%) as reported by Jahana (2016). The higher yield observed for thatching grass in the current study might be 
attributed to incomplete extraction and screening. Open air cooking was used to extract the fibers, at much lower temperatures (below $110^{\circ} \mathrm{C}$ ), and the pulp was not thoroughly screened to remove uncooked materials due to limited equipment. However, the higher pulp yield was consistent with high cellulose and hemicelluloses content of the grasses. Species chemical composition is one of the principal factors that affect the chemical pulp yield. Results of this study suggest that both elephant grass and thatching grass could potentially be used to produce pulp. However, follow-up work should be done to extract fibers at optimum conditions, followed by sufficient screening to verify these results. Further work should also be done on several other species of elephant and thatching grasses growing in Zambia.

\section{Burst strength}

Paper hand sheets of elephant grass had an average burst index of $1.96 \mathrm{kPa} \cdot \mathrm{m}^{2} \cdot \mathrm{g}^{-1}$ while that of thatching grass had an average burst index of $1.94 . \mathrm{kPa} \cdot \mathrm{m}^{2} \cdot \mathrm{g}^{-1}$. Both were much lower than other grasses studied previously like elephant grass growing in Southern Africa (over 5.85 $\mathrm{kPa} \cdot \mathrm{m}^{2} \cdot \mathrm{g}^{-1}$ ) (Madakadze et. al (2010), elephant grass growing in India (4.98 $\mathrm{kPam}^{2} \cdot \mathrm{g}^{-1}$ ) (Reddy et al. (2014) and switchgrass (Madakadze et al.2010). Incomplete defibration and screening leading to weaker interbiber bonding due to uncooked materials in pulp, might have contributed to the lower bursting strength of paper observed in this study. Bleaching improved the paper brightness (Figure 1a), and elephant grass pulp was brighter than thatching grass pulp, probably due to higher cellulose content of elephant grass. The paper was able to hold ink and glue reasonably well, as seen from the products - shopping bags and envelope - which were crafted (figure 1b), suggesting that paper from thatching grass could be used to manufacture products like paper shopping bags and envelopes, where glue is applied.

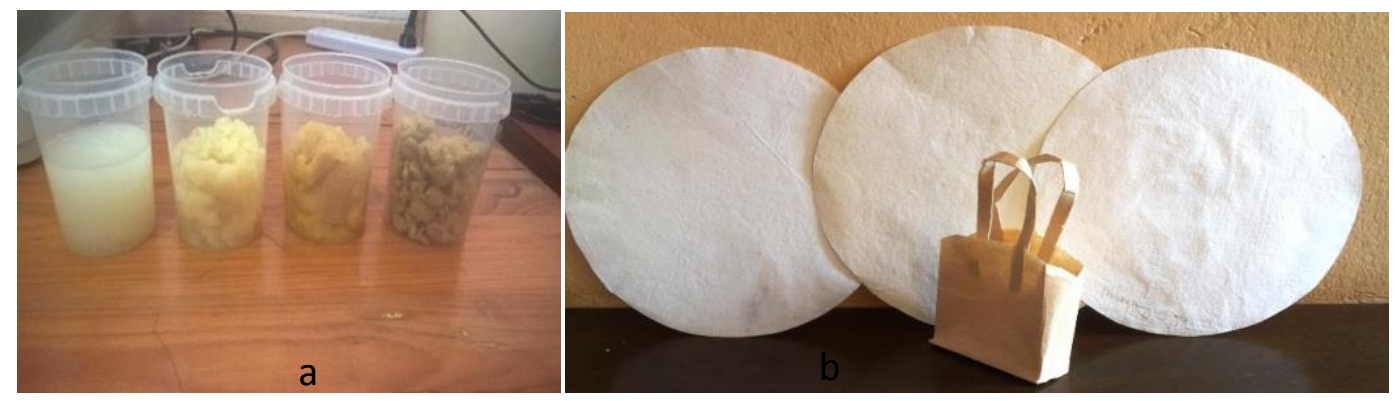

Figure 1. (a) Brightness changes during bleaching, (b) Paper hand sheets fabricated from thatching grass fibers, and a shopping bag.

\section{Summary and Conclusions}

Results of this preliminary study suggest that elephant grass and thatching grass could potentially be used for producing pulp and paper. The holocellulose content was high while lignin content was relatively lower. The pulp yield was comparable to some of the species used commercially. The low bursting strength could be improved by adding chemical additives. Additional work would be needed to determine the optimal pulping conditions, and to test the physical, mechanical and chemical properties of both pulp and paper from these grasses. The abundance and fast growth are additional advantages these plant materials possess as 


\section{Proceedings of the 2020 Society of Wood Science and Technology International Convention}

alternative raw materials for making paper. Paper produced from the resources could be used to make paper shopping bags (as illustrated in this study) or other fiber-based products.

\section{References}

ASTM International, 1984. ASTM Standards D 1106, "Standard test method for lignin in wood". ASTM International, 1984. ASTM Standards D 1102, "Standard test method for ash in wood and wood based materials".

Biermann,J.C (1996) Handbook of Pulping and Paper Making. Second eddition. Academic Press, California, USA.

Enayati A. M (2009) Papermaking potential of Conola stalks. BioResources, 1(4), pp. 245-256. Jahan S.M, Uddin N.M, Rahman A, Rahman M. M , and Amin, N.M (2016). Soda Pulping of Umbrella Palm Grass (cyperus flabettiformic). Journal of Bioresources and Bioproducts (2016) 1 (2):85-91.

Khali A.O (2006) Chemical composition, anatomy,lignin distribution and cell wall structure of Malaysia plant waste fibers. BioResources, 1(2), pp. 220-232.

Madakadze I. C, Masamvu T. M, Radiotis T et al. (201). Evaluation of pulp and paper making characteristics of elephant grass (Pennisetum purpureum Schum) and switchgrass (Panicum virgatum L.). African Journal of Environmental Science and Technology Vol. 4(7), pp. 465-470.

Madakadze I.C, Radiotis T, Li J. et al. (1999). Kraft pulping characteristics and pulp properties of warm season grasses. Bioresource Technology 69 (1999) 75-85.

Reddy O.K, Maheswari U.C, Shukla M. et al. (2014). Preparation, Chemical Composition, Characterization, and Properties of Napier Grass Paper Sheets. Separation Science and Technology, Volume 49, pp. 1527-1534.

Rowell R. M (2005). Handbook of Wood Chemistry and Wood Composites. CRC Press, New York, USA.

Smook G.A (2002). Handbook for pulp and paper technologists, 3rd ed., Vancouver, Canada, Angus Wilde Publications.

TAPPI International, 1997. Tappi Standard T403. "Bursting Strength of Paper".

TAPPI International. Tappi Standard T264. "Prepareation of Wood for Chemical Analysis"

TAPPI International. Tappi Standard T 257. "Sampling and Preparing Wood for Analysis".

\section{Biography}




\title{
Proceedings of the 2020 Society of Wood Science and Technology International Convention
}

\section{Numerical Study of Sorption Behavior of Piano Soundboard}

\author{
Pavlina Suchomelova1 \\ pavlina.suchomelova@mendelu.cz \\ Jakub Dömény 1 \\ jakub.domeny@mendelu.cz \\ Tadeáš Doskočil2 \\ doskocil@petrof.com \\ Petr Zatloukal \\ xzatlou6@node.mendelu.cz \\ Jan Tippner 1 \\ jan.tippner@mendelu.cz
}

1 Department of Wood Science and Technology, Faculty of Forestry and Wood Technology, Mendel University in Brno, Czech Republic 2 PETROF, spol. s r. o., Czech Republic

\begin{abstract}
Wooden musical instruments are strongly influenced by moisture content. Moisture induce the changes of tuning, defects and resonance properties of pianos. Minimization of wood hygroscopicity ensures the shape stability and stable acoustic properties of the soundboard during the changes of ambient climatic conditions (relative air humidity, temperature). Complex physical model of piano soundboard provides a reliable tool to describe the sorption properties of piano soundboard and possibilities to improve the resistance to moisture influence by thermal modification of wood. The main goal of modelling is shortening the development of the appropriate modification process.

The numerical model of thermally treated and untreated wood was designed, implemented into the FEM based computational software and validated on small samples ( $44 \times 450 \times 12 \mathrm{~mm})$. The sorption properties of treated and untreated resonance spruce wood (Picea abies (L.) Karst) were experimentally evaluated. All the samples were conditioned in the laboratory chamber to 7 states of the equilibrium moisture content (EMC). The duration of attaining the EMC (sorption dynamics), dimensional changes and the weight changes (density) were recorded and used for the validation of numerical model.

The model of moisture diffusion is based on the partial differential equation which stems from the transient form of Fick's law. No significant influences of the temperature field on the diffusion were found, so all the tasks were solved isothermally. Validated numerical model was applied on the geometries of real piano soundboards with respect to the wood fiber deflection. The longitudinal, radial and tangential diffusion coefficients were considered as a function of actual moisture content. The results show that the thermally modified soundboard reaches the EMC 3 times slower than untreated soundboard, what is caused mainly by the change of the diffusion coefficients. The influences of the moisture transfer coefficient value were also investigated to detect the influence of the surface layer varnishing. Its influence was found to be very significant - by reducing the coefficient in one order of magnitude (from $1 \mathrm{E}-7$ to $1 \mathrm{E}-8 \mathrm{~m} \cdot \mathrm{s}-1$ ), the time of reaching the $\mathrm{EMC}$ is 3 times longer. The numerical evaluation of piano soundboard showed the influence of individual parameters on its sorption behavior
\end{abstract}


Proceedings of the 2020 Society of Wood Science and Technology International Convention

and helped to reveal the key factors that need to be addressed during the development of thermally modified soundboards.

Biography 
Proceedings of the 2020 Society of Wood Science and Technology International Convention

\title{
Papermaking Fines a Potential Wood-component for New Materials Outside the Paper Industry
}

\author{
Armin Winter, University of Life Science, Vienna, Austria \\ armin.winter@boku.ac.at
}

\begin{abstract}
In times of climate change and the development of country-specific bio-economy strategies, the demand for wood-based raw materials will rise. This research project aims to increase the utilization of the individual wood components. For example, the paper industry produces different types of paper fibres with different mechanical and chemical properties during the production process. Depending on the paper product, different fibre fractions can have both positive and negative effects. One of these fractions are the so-called primary fines and these fines have a great impact on the behaviour of pulp, on its processing, and on the characteristics of the resulting products. This fraction is produced during pulp digestion and is characterised by a short fibre length and a high lignin content. According to the standard, these are fibres that can be separated through a 200 mesh screen (76 $\mu \mathrm{m}$ plate). In order to make the subsequent bleaching process more efficient and cost-effective, this fraction should be separated and used for products outside the paper industry. Here, alternative ways of utilization are shown, such as oil-absorbing sponges, reinforcing fibers for biopolymers, high-density products for boards and additionally as starting material for nanocellulose. In order to put the potential of the primary fines into context, the resulting products will be compared with common reinforcing fibers such as microfibrillated cellulose fibres (MFC). Can the primary fines bring the same improvements as MFC fibers? In general, the energy consumption for fractionation is considerably lower compared to mechanical defibrillation. Additionally, the major challenge of establishing alternative utilization methods is shown, which is related to the processing properties of the resulting primary fines fraction.

Biography
\end{abstract}




\title{
Effect of lacquer decoration on VOCs and odor release from P.neurantha (Hemsl.) Gamble
}

\author{
Bin Zeng ${ }^{1}-$ Jun She ${ }^{2, *}-$ Qifan Wang ${ }^{3}$ \\ ${ }^{1}$ Master student, Northeast Forestry University, Harbin, Heilongjiang, China \\ 1433016521@qq.com \\ ${ }^{2}$ Prof., Northeast Forestry University, Harbin, Heilongjiang, China ${ }^{*}$ Corresponding \\ author \\ shenjunr@126.com \\ ${ }^{3}$ Ph.D. candidates, Northeast Forestry University, Harbin, Heilongjiang, China \\ wangqifan66@163.com
}

\begin{abstract}
With the widespread use of lacquered solid wood materials in the interior, the problem of "odor" caused by solid wood and its lacquer finish is becoming more and more serious. Studying the VOCs and odor characteristic compounds released from lacquer wood can improve the environmental protection level of products and help to solve the odor problem of furniture. The VOCs and odor-active substances released from three kinds of lacquer-coated P.neurantha (Hemsl.) Gamble were analyzed by gas chromatography-mass spectrometry /olfactometry (GC$\mathrm{MS} / \mathrm{O})$. It was found that the three kinds of lacquers had strong inhibitory effects on the release of olefins from P.neurantha (Hemsl.) Gamble, which could reduce the release of olefins by more than 90\%, however, the TVOC release of the Painted Panel increased. Among them, Polyurethane lacquer (PU) could lead to a large number of ester compounds released, and the same time lead to a significant increase in the release of aromatic hydrocarbons. Waterborne lacquer also released a large number of esters and lead to a sharp increase in the release of alcohol compounds. UV curable lacquer had the best inhibition effect on olefins, alcohols, aldehydes, ketones and other compounds in P.neurantha (Hemsl.) Gamble, and does not release esters or other compounds, but the release of toluene will increase sharply. Benzaldehyde, Toluene, and 1,3-dimethyl-Benzene were identified as key odor characteristic compounds of P.neurantha (Hemsl.) Gamble. PU lacquer has a completely closed effect on Benzaldehyde, but the 1,3dimethyl-Benzene odor strength is significantly enhanced. Waterborne lacquer had a good inhibitory effect on 1,3-dimethyl-Benzene, but the VOCs released by waterborne lacquer can enhance the odor intensity of Benzaldehyde. UV lacquer has good sealing effect on key odor characteristic compounds released by P.neurantha (Hemsl.) Gamble except Toluene. Aromatic and fruity are the main odor characteristics of P.neurantha (Hemsl.) Gamble and three kinds of lacquer-decorated P.neurantha (Hemsl.) Gamble. The amount of TVOC released and the overall odor strength of the P.neurantha (Hemsl.) Gamble will be increased by coating treatment, especially PU lacquer. The overall odor intensity of UV lacquer is the lowest among the three panels, but the toluene concentration released by UV lacquer itself is higher, which has certain
\end{abstract}




\section{Proceedings of the 2020 Society of Wood Science and Technology International Convention}

side effects on indoor environment. Therefore, it is suggested to control toluene. Considering the VOCs release level and the overall odor intensity, the waterborne lacquer is still the best one in the three panels.

Key words: GC-MS/O; P.neurantha (Hemsl.) Gamble; VOCs; Odor characteristics

\section{Introduction}

With the pursuit of high-quality life, the interior decoration industry has developed rapidly in recent years. However, at the same time, the problem of indoor air pollution is also aggravated. Indoor air quality (IAQ) is closely related to human health (Klepeis et al. 2001). Furniture products as one of the main sources of indoor household pollution (Liu et al. 2017), the harmfulness of furniture releasing substances to human living environment has been plaguing consumers and production enterprises, and its impact mainly comes from the odor and harmful compounds released by board and various decorative materials (Shen et al. 2018). Among many furniture, solid wood furniture is popular because of its unique texture and comfortable texture. However, it is unavoidable that furniture materials need to be coated with various coatings in order to decorate and protect the wooden board. Painting can not only give wood color, improve gloss and smoothness, but also enhance the three-dimensional and touch sense of wood texture. At the same time, the properties of coated wood such as moisture resistance, water resistance and oil resistance will also be improved to varying degrees.

At present, the odor of woods has been well investigated, but research is still not extensive. Yang et al. (2017) proposed two feasible odor detection schemes for solid wood furniture, such as sampling and tracking the production process of odor furniture on the spot according to consumer complaints. At the same time, the composition of odor emitted from solid wood bedside cabinet was studied (Yang et al. 2018). It was found that benzene series and a few low molecular lipids, such as ortho-p-xylene, n-butyl acetate and sec-butyl acetate, were the main components of odors. Liu et al. (2018) found that Ethanol-Toluene solution extraction could reduce the intensity of some odors of poplar (Populus cathayana Rehd.) and rubber (Hevea brasiliensis), but residual benzene was produced during extraction, which led to the increase of benzene odor. Wang et al. (2017) studied the odor compounds released from poplar (Populus $L$. spp.), pine (Pinus L. spp.) and linden (Tilia L. spp.), the key odorants were identified by GC-MS/O. Schreiner et al (2018) studied odor-active compounds released from Pinus sylvestris $L$. in Germany by gas chromatography-olfactometry (GC-O) and aromatic extract dilution analysis (AEDA), 44 kind of odorous compounds were identified. Ghadiriasli et al. (2018) found that the odor of oak wood mainly came from fatty acid degradation products, terpenoids and lignin degradation based on gas chromatography-olfactometry (GC-O) and odor extraction dilution analysis (OEDA) technology. It was found that most of the odor components of oak were composed of a series of terpenoids, mainly monoterpenes and sesquiterpenes, aldehydes, acids and lactones, and some polyphenols containing phenolic core components. 


\section{Proceedings of the 2020 Society of Wood Science and Technology International Convention}

However, in practical application, wood is mostly used indoors with lacquer decoration, but there is few report on this aspects. Wang et al. (2018a, 2018b) investigated the effects of environmental factors on particleboard with different lacquers, and found the temperature, relative humidity and the ratio of the air exchange rate to the loading factor have different influence to the lacquer boards during the release process, but the difference between particleboard with different lacquers was not showed. There is also few report about the odor emission from solid wood with lacquer.

In this study, the odor-active substances released from P.neurantha (Hemsl.) Gamble, which is widely used in the field of furniture material for the character of strong corrosion resistance, compact wood, small size affected by external environment, and not easy to deform (Qi et al. 2015) were analyzed by GC-O technology. Also, the odor and volatile organic compounds (VOCs) of P.neurantha (Hemsl.) Gamble with different commonly used lacquers, namely, polyurethane coatings (PU), waterborne coatings, and UV curable coatings (UV) were investigated and compared. P.neurantha (Hemsl.) Gamble will release volatile organic compounds (VOCs) and odors to the surrounding environment during production, display and use, which will affect indoor air quality. P.neurantha (Hemsl.) Gamble itself can release its unique aroma, so it has the function of preventing insects and dispersing mosquitoes. However, the odor released by the boards will change after lacquer decorations. Because the odor released from wood and surface coating will have different interaction. Therefore, in order to better understand the odor release from the coated P.neurantha (Hemsl.) Gamble in real life, it is necessary to study the P.neurantha (Hemsl.) Gamble with different lacquers.

\section{Materials \& Methods}

\section{Material}

P.neurantha (Hemsl.) Gamble, produced in GuangYun Forest Farm of Guilin City, Guangxi, was selected as the test material. The diameter of the disc was $60 \mathrm{~mm}$, and the moisture content was $12 \%$. The test base material was coated uniformly with lacquers of Polyurethane coatings (PU), waterborne coatings and UV curable coatings (UV). Specific finishing parameters were showed as follows: Polyurethane coatings (Huarun-transparent primer/semi-clear finish, main agent: curing agent: diluent $=2: 1: 1)$. Paint two primers $\left(10 \mathrm{~m}^{2} / \mathrm{kg} /\right.$ time $)$ and two topcoats $(10$ $\mathrm{m}^{2} / \mathrm{kg} /$ time), each paint 12 hours apart; Water-borne acrylic paint (Sankeshu 360 water-borne wood paint- transparent primer / varnish, main agent: water $=10: 1)$. Paint two primers (10 $\mathrm{m}^{2} / \mathrm{kg} /$ time) and two topcoats (10 $\mathrm{m}^{2} / \mathrm{kg} /$ time), each paint 12 hours apart; Ultraviolet curing coatings (plain chemical-LED UV curing varnish, cleaning spray gun cleaning product surface spraying UV coating 55 leveling for 3-10 minutes UV curing), a total of two coatings, 10 $\mathrm{m}^{2} / \mathrm{kg} /$ time. Construction environment conditions: indoor temperature $23 \pm 2{ }^{\circ} \mathrm{C}$ and relative humidity $40 \pm 10 \%$. The room is in a continuous ventilation state. The surface of solid wood is polished with 150 mesh sandpaper, and 180 mesh sandpaper is used between the two paints. After finishing the coating, the sample was cut into a circle with the diameter of $60 \mathrm{~mm}$. The edge of the sample is sealed with aluminum tape along the thickness direction to prevent high release 
from the edge of the material. After edge sealing, the material is vacuum sealed, label paper is affixed, and stored in the refrigerator at $-30^{\circ} \mathrm{Cfor}$ reserve.

\section{Equipment}

\section{Sampling equipment}

Micro chamber Thermal Extractor Markes's M-CTE250 model was used as the microchamber thermal extractor which was produced by Markes International Company of UK. The nitrogen was used as carrier gas, and the temperature could be adjusted in the range of $0-250^{\circ} \mathrm{C}$.

Tenax-TA adsorption tube Tenax-TA tubes were produced by Markes International Company of UK. The length is $89 \mathrm{~mm}$, the outer diameter is $6.4 \mathrm{~mm}$, and it contains 2,6 diphenylfuran porous polymer resin filler. The two ends are equipped with copper caps, which can effectively adsorb VOCs volatilized from wood-based panels and store them in tubes.

\section{Analysis and detection equipment}

Thermal desorption instrument Thermal desorption instrument was produced by Markes International Company of UK, the model is Unity. The cold trap adsorption temperature is $-15^{\circ} \mathrm{C}$, the carrier gas is helium, the carrier gas flow rate is $30 \mathrm{ml} / \mathrm{min}$, the analytical temperature is $300^{\circ} \mathrm{C}$, the pipeline temperature is $180^{\circ} \mathrm{C}$, the thermal desorption desorption sample is $10 \mathrm{~min}$, the pre-purging time is $1 \mathrm{~min}$.

Gas chromatography-mass spectrometry (GC-MS) DSQ single four-stage Gas chromatographymass spectrometry was produced by Thermo Company of USA. The instrument chromatographic column type was DB-5, specifications of $3000 \mathrm{~mm} \times 0.26 \mathrm{~mm} \times 0.25$ um quartz capillary column; GC inlet temperature $250^{\circ} \mathrm{C}$; carrier gas flow rate $1.0 \mathrm{ml} / \mathrm{min}$ (constant current); non-shunt injection; heating procedure: start temperature $40^{\circ} \mathrm{C}$, keep $2{ }^{\circ} \mathrm{C} / \mathrm{min}$, rise to $50{ }^{\circ} \mathrm{C}$, keep $4 \mathrm{~min}$, and then rise to $150{ }^{\circ} \mathrm{C} / \mathrm{min}$ The temperature was kept for 4 minutes, and finally increased to $250{ }^{\circ} \mathrm{C}$ for 8 minutes at $10{ }^{\circ} \mathrm{C} / \mathrm{min}$. Ionization mode is the ionization source (EI) with $70 \mathrm{eV}$ energy, $230^{\circ} \mathrm{C}$ ion source temperature, $250{ }^{\circ} \mathrm{C}$ transmission line temperature, 50-450 amu scanning mode, 280 interface temperature and $150{ }^{\circ} \mathrm{C}$ four-stage rod temperature.

Olfactory Detector Sniffer 9100 Olfactory Detector came from Brechbühler AG (Echallens, Switzerland). The transmission line temperature was $150^{\circ} \mathrm{C}$, and nitrogen was used as the carrier gas through a purge valve. Moist air was added to prevent dehydration of the nasal mucosa of the odor assessors. Direct intensity methods were chosen for analysis of the compounds.

Thermal desorptioner TP-5000 universal thermal desorptioner was produced by Beifen Tianpu Instrument Technology Co., Ltd. in Beijing. It can desorb and remove the residues in the tube of Tenax after sample analysis.

\section{Method}

\section{Sampling}


Before the experiment, the micro-chamber/thermal extractor was cleaned once with deionized water and once with methanol. The samples were put in the micro-chamber extractor under the specific sampling condition. Area of exposure was $5.65 \times 10^{-3} \mathrm{~m}^{3}$, the cell volume was $1.35 \times 10^{-4}$ $\mathrm{m}^{3}$, and the loading rate was $41.85 \mathrm{~m}^{2} \cdot \mathrm{m}^{-3}$. Four specimens were made for an identity condition during a sampling cycle of $8 \mathrm{~h}$. The environment condition was as follows: temperature $23 \pm 5^{\circ} \mathrm{C}$, relative humidity $30 \pm 10 \%$, the ratio of the air exchange rate to the loading factor $0.5 \mathrm{~m}^{3} \cdot \mathrm{m}^{-2} \cdot \mathrm{h}^{-1}$ ). 2 liter VOCs was collected by micro-chamber/thermal extractor. The adsorption tubes that collected the samples were covered with copper caps, wrapped in PTFE plastic bags, labeled, and stored in a freezer at $-30^{\circ} \mathrm{C}$. Four samples were made for a kind of board (three repetitions were performed for each measurement).

\section{GC-MS analysis method}

External standard method was used in this experiment, and the data processing is completed by Xcalibur software system. Qualitative volatile compounds were identified by NIST (08 standard library) and Wiley library. and only the positive and negative matching degree was more than 750 (the maximum value was 1000). Through Excel data processing system, the relative percentage content of each chemical component in wood odor substances was obtained by area normalization method.

\section{GC-O analysis method}

GC-O analysis uses the time-intensity method (Sun et al. 2018). After the peak of the detected substance determines the composition and concentration of the compound, the odor characteristics and intensity of the odor emitted from the chromatographic column are recorded by the evaluator's sniffing. Five grades of odor intensity were set, which ranged from 0 to 4: 0 to denote no odor, 1 to denote weak odor, 2 to denote moderate odor intensity, 3 to denote strong odor intensity, and 4 to denote the strongest odor intensity (Hou et al. 2018). Four smellers aged between 20 and 30 years old, with good olfactory perception, smokeless and heavy-flavor cosmetics, non-allergic constitution and chronic rhinitis were selected to carry out the experiment. After screening and training, they were familiar with various odor compounds in wood, including understanding the odor characteristics and odor of wood. Intensity evaluation methods, while accumulating commonly used odor description vocabulary. Before the experiment, all the olfactors were trained in smelling fragrance. The olfactory discrimination test shall be conducted in a room with good ventilation conditions, temperature of $20-25{ }^{\circ} \mathrm{C}$ and relative humidity of $40 \%$. It is required that there is no peculiar smell in the room. Each sample was sniffed twice by the evaluator. When the test results were collated and recorded, the same odor characteristics descriptions obtained by at least two olfactors at the same time were recorded in the results. The average odor intensity results of four olfactors were taken as the intensity values. The compounds were identified by aroma odor recognition and odor description.

\section{Results and Discussion}




\section{Analysis of TVOC and VOCs Components from P.neurantha (Hemsl.) Gamble with different decorative materials}

In this study, the release of VOCs from P.neurantha (Hemsl.) Gamble and three types of lacquers board was analyzed. The TVOC emission of P.neurantha (Hemsl.) Gamble increased after decorating with three kinds of lacquers (Fig. 1). The major constituents of P.neurantha (Hemsl.) Gamble were aromatics and olefins, a few alkanes, alcohols, aldehydes and other compounds were also found, the esters compounds were not detected. After decoration, the release of TVOC and VOCs components from solid wood changed a lot. Aromatic hydrocarbons and esters were the mainly constituents of PU lacquered P.neurantha (Hemsl.) Gamble, compared to the primary compounds of esters from water-borne lacquer P.neurantha (Hemsl.) Gamble, and main components of aromatic hydrocarbons (accounting for $87.7 \%$ of TVOC) from UV lacquered P.neurantha (Hemsl.) Gamble. It was remarkable that the VOCs concentration increased greatly after the PU lacquer decoration, the TVOC emission increased by about $227.9 \%$. Wang et al. (2009) also came to the similar conclusion indirectly. They studied the volatile organic compounds in the air of polyurethane synthetic leather factory using adsorption tube and secondary thermal desorption GC-MSD, and found the PU would release a great quantity VOCs.

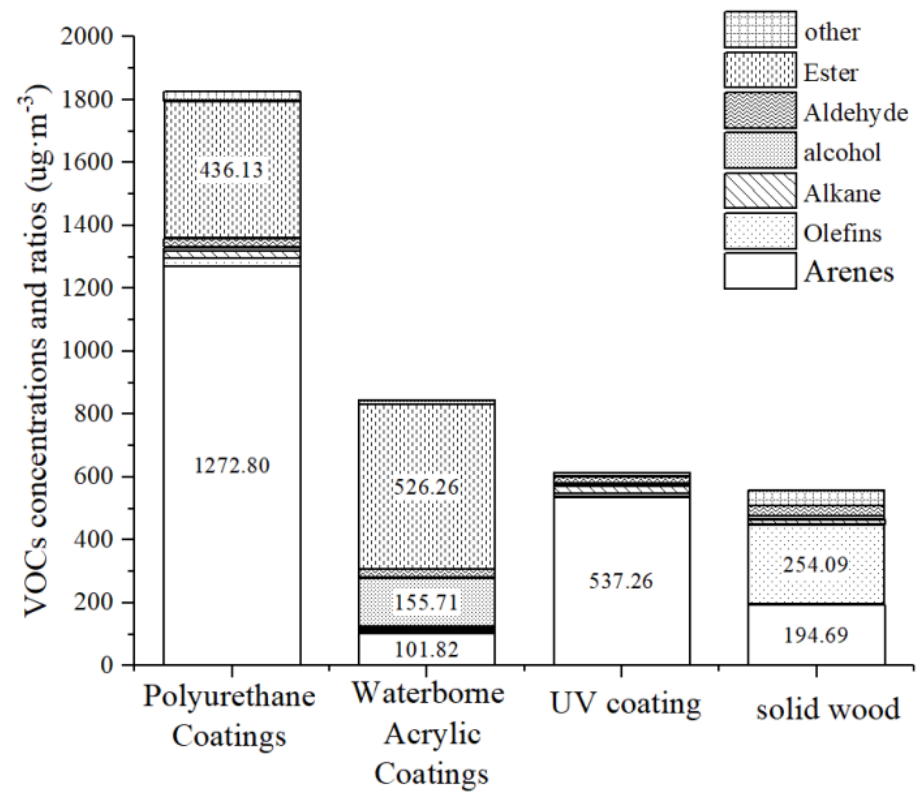

Figure 1: VOCs concentration and ratios from P.neurantha (Hemsl.) Gamble with three lacquer decorations

After being decorated with three different lacquer, the release of volatile organic compounds (VOCs) from the solid wood could be inhibited by the surface coating, however, the lacquer material would release some other compounds at the same time. The inhibitory effects on VOCs components released from P.neurantha (Hemsl.) Gamble varied between different lacquer decorations. Table 1 showed the increase rate of TVOC and VOCs of P.neurantha (Hemsl.) Gamble with three kinds of lacquer decorations. Research showed the olefins from P.neurantha (Hemsl.) Gamble were well inhibited by these three kinds of lacquers (the inhibition rate was more than $90 \%)$. 
PU lacquer could inhibit aldehydes, ketones and other compounds, but the release of aromatic hydrocarbons increased sharply with an increase rate of $553.74 \%, 436.13 \mathrm{ug} \cdot \mathrm{m}^{-3}$ esters was found from the PU lacquer. Among them, 1,3-dimethylbenzene, o-xylene and butyl acetate increased most significantly, the concentration reached $633.85 \mathrm{ug} \cdot \mathrm{m}^{-3}, 240.12 \mathrm{ug} \cdot \mathrm{m}^{-3}$ and $273.71 \mathrm{ug} \cdot \mathrm{m}^{-3}$, respectively. These 3 kinds of compounds had different effects on human beings. The correlation research indicated, 1,3-dimethylbenzene would be irritative to human eyes and the upper respiratory tract, it also had anesthetic effect on central nervous system at high concentration. The lowest toxic concentration of 1,3-dimethylbenzene (TCLO) inhaled in rats was $3000 \mathrm{mg} \cdot \mathrm{m}^{-3}$ (24h) (AIHA. 1962), which was much higher than the release amount in this experiment. For residue and accumulation of this compounds were not serious, and the photolysis might happen when it transferred to atmosphere (Archives of Toxicology. 1985), it belongs to slight toxicity, however, long-term exposure would lead to neurasthenia syndrome, kin dry, chapped, dermatitis., etc. As a low toxic compound, o-xylene could stimulate the skin and mucosa and anesthetize the central nervous system. The lowest toxic concentration (TDLO) of inhalation in rats was $1500 \mathrm{mg} \cdot \mathrm{m}^{-3}$. Although the release detected in this experiment was far less than the toxicity value, long-term exposure still would affect the function of liver and kidney, and severe patients might even have hallucinations and unconsciousness (Archives of Andrology. 1983). Butyl acetate belongs to slight toxicity, (Wang et al. 2005), but it could stimulate the eyes and upper respiratory tract. Long-term inhalation of butyl acetate with high concentration might lead to tear, sore throat, cough, chest tightness, shortness of breath and other symptoms. Serious cases could cause conjunctivitis, keratitis, and skin contact can cause dry skin (Zhu et al. 2010).

Among these three lacquers, the TVOC released from P.neurantha (Hemsl.) Gamble varnished with UV was the least (only increased about $10 \%$ ). It had the best inhibitory effect on olefins, alcohols, aldehydes and ketones, and did not release esters or other compounds. However, the release of toluene from P.neurantha (Hemsl.) Gamble varnished with UV increased sharply, reaching $403.36 \mathrm{ug} \cdot \mathrm{m}^{-3}$, nearly 33.5 times that of unpainted P.neurantha (Hemsl.) Gamble. According to the relevant data, toluene was highly toxicity (Shen et al. 2013). At a certain concentration, it can stimulate human skin and mucosa, and had anesthetic effect on human central nervous system. Therefore, toluene should be the key limiting substance in VOCs released from indoor wooden furniture. In China, the concentration limit of toluene released from woodbased panels and their products for interior decoration was less than $100 \mathrm{ug} \cdot \mathrm{m}^{-3}$. The US BIFMA stipulated that the toluene released from seats should not higher than $250 \mathrm{ug} \cdot \mathrm{m}^{-3}$. Japanese industrial standards also set the limited that the toluene in indoor air should less than $260 \mathrm{ug} \cdot \mathrm{m}^{-}$ 3. In this study, the mass concentration of toluene had exceeded the standard, therefore, although UV paint has a good inhibitory effect on VOCs release, the concentration of toluene released by itself is high, which would influence the indoor environment. Therefore, in order to control the emission of VOCs more comprehensively, it is suggested to control the emission of toluene in UV paint. Compared to UV, the concentration of waterborne lacquered board was $233.16 \mathrm{ug} \cdot \mathrm{m}^{-3}$ higher than UV. It could inhibit the release of aromatic hydrocarbons, olefins, alkanes, aldehydes and ketones, but the release of alcohols increased by 12.5 times, and it also released $526.25 \mathrm{ug} \cdot \mathrm{m}^{-3}$ esters. Among them, 2,2'-oxybis-1-propanol, 3,3'-oxybis-1-propanol and 2-methyl-Propanoic acid-1-(1,1-dimethylethyl)-2-methyl-1,3-propanediyl ester increased most 
significantly, which had little impact on human beings. Above all, compared to PU and UV, waterborne lacquer board was less harmful to human.

Table 1 The Release Increase Rate of TVOC and Components

\begin{tabular}{cccccccc}
\hline \multicolumn{7}{c}{ The Release Increase Rate of TVOC and Components under Different Paints } \\
\hline Types of Paints & $\begin{array}{c}\text { TVOC/ } \\
\%\end{array}$ & $\begin{array}{c}\text { Aromatic } \\
\text { /\% }\end{array}$ & $\begin{array}{c}\text { Olefins/ } \\
\%\end{array}$ & $\begin{array}{c}\text { Alkanes/ } \\
\%\end{array}$ & $\begin{array}{c}\text { alcohols/ } \\
\%\end{array}$ & $\begin{array}{c}\text { Aldehydes/ } \\
\%\end{array}$ & $\begin{array}{c}\text { others/ } \\
\%\end{array}$ \\
\hline $\begin{array}{c}\text { Polyurethane } \\
\text { Coatings }\end{array}$ & 227.9 & 553.74 & -90.59 & 41.13 & 1.45 & -7.79 & -37.52 \\
$\begin{array}{c}\text { Waterborne Acrylic } \\
\quad \text { Coatings }\end{array}$ & 51.78 & -47.7 & -95.63 & -42.75 & 1251.71 & -9.88 & -72.26 \\
$\quad$ UV coating & 9.95 & 175.95 & -95.53 & 37.1 & -39.28 & -26.49 & -76.52 \\
\hline
\end{tabular}

Characterization of odor-active compounds of P.neurantha (Hemsl.) Gamble with different lacquers

Based on GC-MS library search, GC-O olfaction and retention index analysis, totally 19 kinds of odor-active compounds were identified from four kinds of samples and were classified as alcohols ( 2 substances), aromatic hydrocarbons ( 6 substances), aldehydes ( 5 substances), esters (6 substances). The specific odor characteristic compounds were shown in Table 2.

Table 2 Characteristic odor Compounds and Concentrations Released from Four Plates

Mass Concentration of Odorant Compounds Released from Three Paint Finishes and solid wood

\begin{tabular}{|c|c|c|c|c|c|c|c|}
\hline \multirow[b]{2}{*}{ Serial } & \multirow[b]{2}{*}{$\begin{array}{c}\text { Molecular } \\
\text { Formula }\end{array}$} & \multirow[b]{2}{*}{ Compound Name } & \multirow[b]{2}{*}{$\begin{array}{c}\text { Odor } \\
\text { Characteristics }\end{array}$} & \multicolumn{4}{|c|}{ Mass Concentration /ug $\cdot \mathrm{m}^{-3}$} \\
\hline & & & & $\begin{array}{c}\text { Polyurethane } \\
\text { Coatings }\end{array}$ & $\begin{array}{c}\text { Waterborne } \\
\text { Acrylic Coatings }\end{array}$ & $\begin{array}{c}\text { UV } \\
\text { coating }\end{array}$ & $\begin{array}{l}\text { solid } \\
\text { wood }\end{array}$ \\
\hline 1 & $\mathrm{C}_{6} \mathrm{H}_{6}$ & benzene & Aromatic & - & 18.29 & 23.2 & 12.82 \\
\hline 2 & $\mathrm{C}_{7} \mathrm{H}_{8}$ & toluene & $\begin{array}{c}\text { Aromatic, } \\
\text { sweety }\end{array}$ & 16.32 & 12.34 & 403.36 & 11.68 \\
\hline 3 & $\mathrm{C}_{8} \mathrm{H}_{10}$ & ethylbenzene & $\begin{array}{c}\text { Aromatic, } \\
\text { sweety }\end{array}$ & 176.57 & 16.54 & 26.56 & 25.38 \\
\hline 4 & $\mathrm{C}_{8} \mathrm{H}_{10}$ & $\begin{array}{l}\text { 1,3-dimethyl- } \\
\text { benzene }\end{array}$ & Aromatic & 633.85 & 49.65 & 74.61 & 93.34 \\
\hline 5 & $\mathrm{C}_{8} \mathrm{H}_{10}$ & o-xylene & Aromatic & 240.12 & - & - & - \\
\hline 6 & $\mathrm{C}_{9} \mathrm{H}_{12}$ & $\begin{array}{l}\text { 1,2,3-trimethyl- } \\
\text { benzene }\end{array}$ & Aromatic & 73.07 & - & - & - \\
\hline 7 & $\mathrm{C}_{6} \mathrm{H}_{12} \mathrm{O}$ & $\begin{array}{c}\text { 2-ethyl- } \\
\text { cyclobutanol }\end{array}$ & Cheese flavor & 5.72 & - & - & - \\
\hline 8 & $\mathrm{C}_{6} \mathrm{H}_{12} \mathrm{O}_{2}$ & $\begin{array}{c}\text { acetic acid, butyl } \\
\text { ester }\end{array}$ & Fruity & 273.71 & & & \\
\hline 9 & $\mathrm{C}_{6} \mathrm{H}_{12} \mathrm{O}$ & hexanal & $\begin{array}{c}\text { Green grass } \\
\text { scent }\end{array}$ & 6.64 & - & - & 9.23 \\
\hline 10 & $\mathrm{C}_{7} \mathrm{H}_{6} \mathrm{O}$ & benzaldehyde & Almond & - & 5.16 & - & 4.93 \\
\hline 11 & $\mathrm{C}_{8} \mathrm{H}_{16} \mathrm{O}$ & octanal & $\begin{array}{c}\text { Fruity sweet and } \\
\text { sour }\end{array}$ & 5.25 & 5.67 & 5.45 & 4.52 \\
\hline 12 & $\mathrm{C}_{8} \mathrm{H}_{18} \mathrm{O}$ & 2-ethyl-1-hexanol, & Sweet flower & 5.97 & 8.75 & 6.99 & 11.52 \\
\hline 13 & $\mathrm{C}_{9} \mathrm{H}_{18} \mathrm{O}$ & nonanal & Fruity & 9.09 & 8.67 & 5.93 & 6.24 \\
\hline 14 & $\mathrm{C}_{10} \mathrm{H}_{20} \mathrm{O}$ & decanal & Citrus smell & 7.38 & 8.2 & 5.44 & 5.83 \\
\hline
\end{tabular}




\section{Proceedings of the 2020 Society of Wood Science and Technology International Convention}

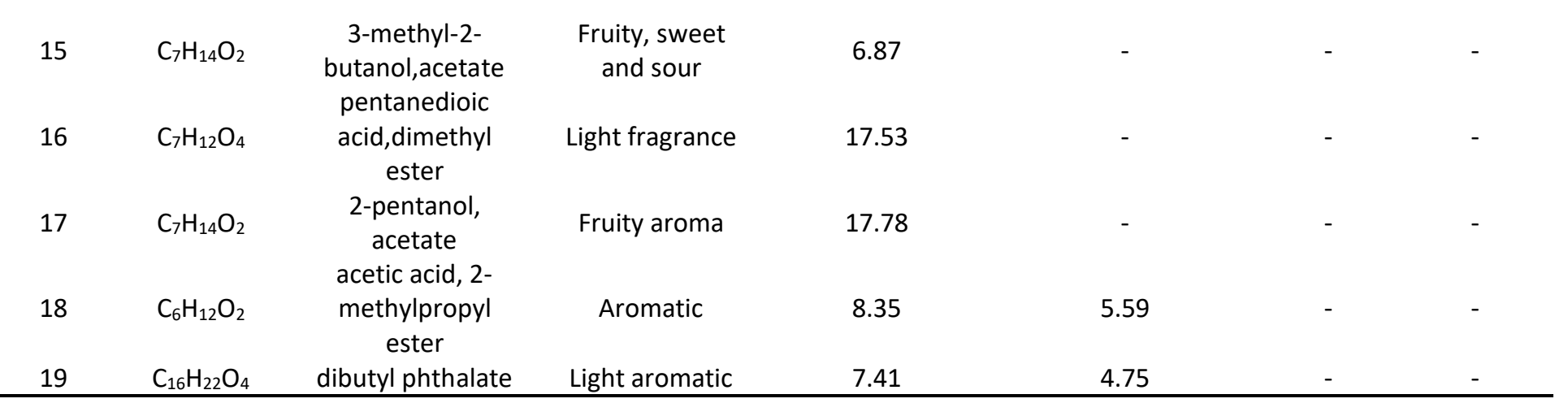

Aromatic hydrocarbons and aldehydes were the main characteristic odor compounds of P.neurantha (Hemsl.) Gamble, while aromatic was the main odor character according to the results of olfactory identification, which played a major role in the overall odor formation of P.neurantha (Hemsl.) Gamble. The odor characteristics of P.neurantha (Hemsl.) Gamble were identified as follows: benzene was reported as aromatic, same to the finding of aromatic odor by the U.S. National Institute for Occupational Safety and Health (NIOSH, 2010a). Sax (1984) also found its gasoline-like and rather pleasant aromatic odor in their research, and the burnt character was reported by Wang et al (2019). Toluene was found to have aromatic and sweety character, while the characteristic of sweet and pungent was reported by NIOSH (2010b). Our testing found ethylbenzene to have sweet and pungent odor, similar to the sweet and gasolinelike odor by NOAA (2016) and the pungent character by Infante et al. (2012). It was also found to be aromatic odor by Larranaga et al. (2017). The hexanal detected in this experiment had a green grass characteristic, same to the detection of Furia (1980), whereas its odor was also described as fruity in Burdock (2010), sharp, aldehyde odor in Lewis (2007). The benzaldehyde in this experiment was reported to have almond character, which could also be found in the research of O'Neil (2013) and Larranaga et al (2016). In this experiment, octanal was reported to have fruity sweet and sour smell, similar to the fruity odor by Larranaga et al (2016). Other researchers found it to present a fatty, citrus and honey odor (Burdock, 2010) and a pungent odor (Panten et al, 2018). The nonanal was found to be fruity in this research, which was also be found orangerose odor by Lewis (2007), and floral, waxy and green character by Nishimura (1995). Decanal was reported as citrus smell in this study, similar with the orange peel of Kohlpaintner et al (2013), whereas Lewis (2007) reported a slight Floral-fatty odor. The odor character of 2-ethyl-1-hexanol (sweet flower) and 1,3-dimethyl-benzene (aromatic) were reported for the first time.

After varnished with PU lacquer, the odorous compounds increased to 14 species, including 9 kinds of new odor compounds. The odor compounds released from PU lacquer-coated P.neurantha (Hemsl.) Gamble were the most species among these 3 kinds of lacquers, the concentration of odor compounds was also significantly higher than other boards. Among them, 2-ethyl-Cyclobutanol (cheese flavor), butyl acetate Acetic acid (fruit flavor), 3-methyl-2-Butanolacetate (sweet and sour fruit flavor), 2- pentanol-acetate (fruit flavor), 1,2,3-methyl-Benzene (aromatic) had an important contribution to the overall odor formation of board. Therefore, compared to P.neurantha (Hemsl.) Gamble, the overall odor characteristics of PU lacquer-coated board were significantly different. The odor intensity of PU lacquer-coated P.neurantha (Hemsl.) Gamble was stronger than uncoated board. The odor compounds of waterborne lacquer-coated 
P.neurantha (Hemsl.) Gamble were mostly similar to unpainted P.neurantha (Hemsl.) Gamble, only 1 kind of odorant (dibutyl phthalate, light aromatic) was added, and its odor intensity was less than 1.5, which contributed little to the overall odor formation. UV lacquer-coated P.neurantha (Hemsl.) Gamble released the least odor compounds. After coated with UV paint, the concentration of most of compounds decreased, except for benzene and toluene. The concentration of these two compounds increased $10.38 \mathrm{ug} \cdot \mathrm{m}^{-3}$ and $391.68 \mathrm{ug} \cdot \mathrm{m}^{-3}$, respectively. As the main odor contributor, toluene increased most significantly, which greatly affect to the formation of the overall odor. The odorous compounds of hexanal and benzaldehyde from P.neurantha (Hemsl.) Gamble disappeared after painting with UV.

\section{Effect of different lacquer decorations on the odor of P.neurantha (Hemsl.) Gamble}

To explore the effect of three kinds of lacquer decorations on the overall odor of P.neurantha (Hemsl.) Gamble, the characteristic odors were divided into four categories: aromatic, fruity, sweety, others. Considering the complex interaction among various odorant compounds, the effect of fusion on the total odor intensity was chosen for this experiment. The total relative intensity of each type was calculated by adding the intensities of different odorants with similar characters together. The changes of odor after lacquer decoration was analyzed in Fig. 2. Aromatic was the dominant odor impression of P.neurantha (Hemsl.) Gamble, with a rating of 7.6, followed by fruity (6.1). The attributes others (2.0) sweety (1.8) were rated with low intensities. The total intensity of P.neurantha (Hemsl.) Gamble was 17.5.

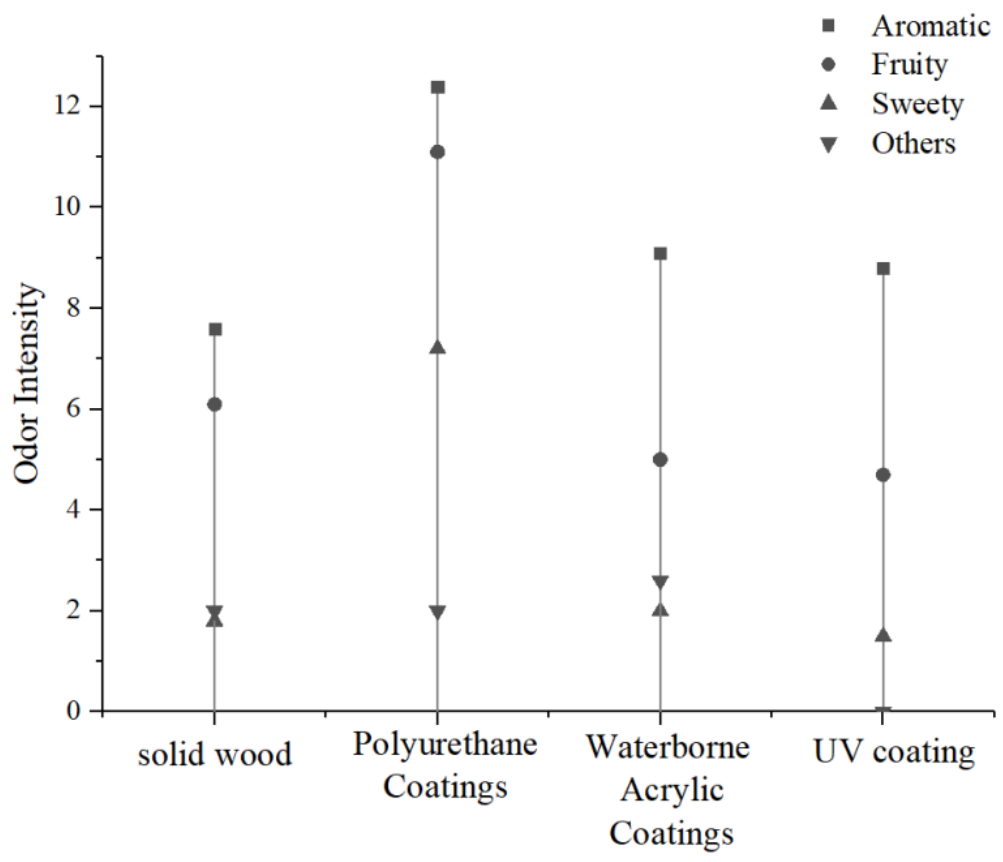

Figure 2 Relation diagram of odor concentration and odor intensity of four boards

The overall odor intensity of PU lacquered P.neurantha (Hemsl.) Gamble was the highest among these three lacquered boards, with the total intensity of 32.7. Aromatic (12.4) and fruity (11.1) was the main flavor. The intensity of sweety was 7.2, while the others was 2.0. Compared with unpainted P.neurantha (Hemsl.) Gamble, the intensity of aromatic and fruity increased nearly 5, 


\section{Proceedings of the 2020 Society of Wood Science and Technology International Convention}

which became the decisive odor of the overall odor formation, while the intensity of sweety also increased 5.4, and played an important role in modifying the overall odor. The overall odor intensity of board was significantly enhanced after with PU lacquer decoration, and the overall odor characteristics of PU lacquered P.neurantha (Hemsl.) Gamble were also significantly different.

The main character of waterborne lacquered P.neurantha (Hemsl.) Gamble was aromatic with the intensity was 9.1, the attributes of fruity, others and sweety were 5.0, 2.6 and 2.0, respectively. Compared with unpainted P.neurantha (Hemsl.) Gamble, the overall odor intensity increased slightly. Among them, the intensity of aromatic odor increased by 1.5 , becoming the main contributor to the overall odor. The intensity of fruity flavor decreased after decoration, but it still played an important role in modifying the formation of the overall flavor. Sweety flavor and other flavors increased, but the intensity of fruity flavor was still weak, which had little effect on the overall flavor. The waterborne lacquer had little influence on the overall odor characteristics of P.neurantha (Hemsl.) Gamble, but the overall odor intensity was enhanced slightly (18.7).

The aromatic was the key characteristic odor of the whole odor of P.neurantha (Hemsl.) Gamble varnished by UV lacquer. Compared with unpainted P.neurantha (Hemsl.) Gamble, the intensity of the other three types of odor characteristics decreased except for aromatic. Among them, the other types of odor intensity had been reduced to 0 , and the total sweety flavor intensity had been reduced to 1.5, while the fruity flavor intensity still had some modification effect on the overall odor. Among them, toluene was the main odor contributing compound. UV paint would have a good effect on TVOC and odor inhibition when the release of toluene was reduced.

To further explore the effects of three kinds of lacquer on the odor compounds of P.neurantha (Hemsl.) Gamble, The odor intensities of 10 odor compounds released by P.neurantha (Hemsl.) Gamble before and after painting were compared (Fig. 3), and the effects of different kinds of lacquer on specific odor compounds were analyzed. 


\section{Proceedings of the 2020 Society of Wood Science and Technology International Convention}
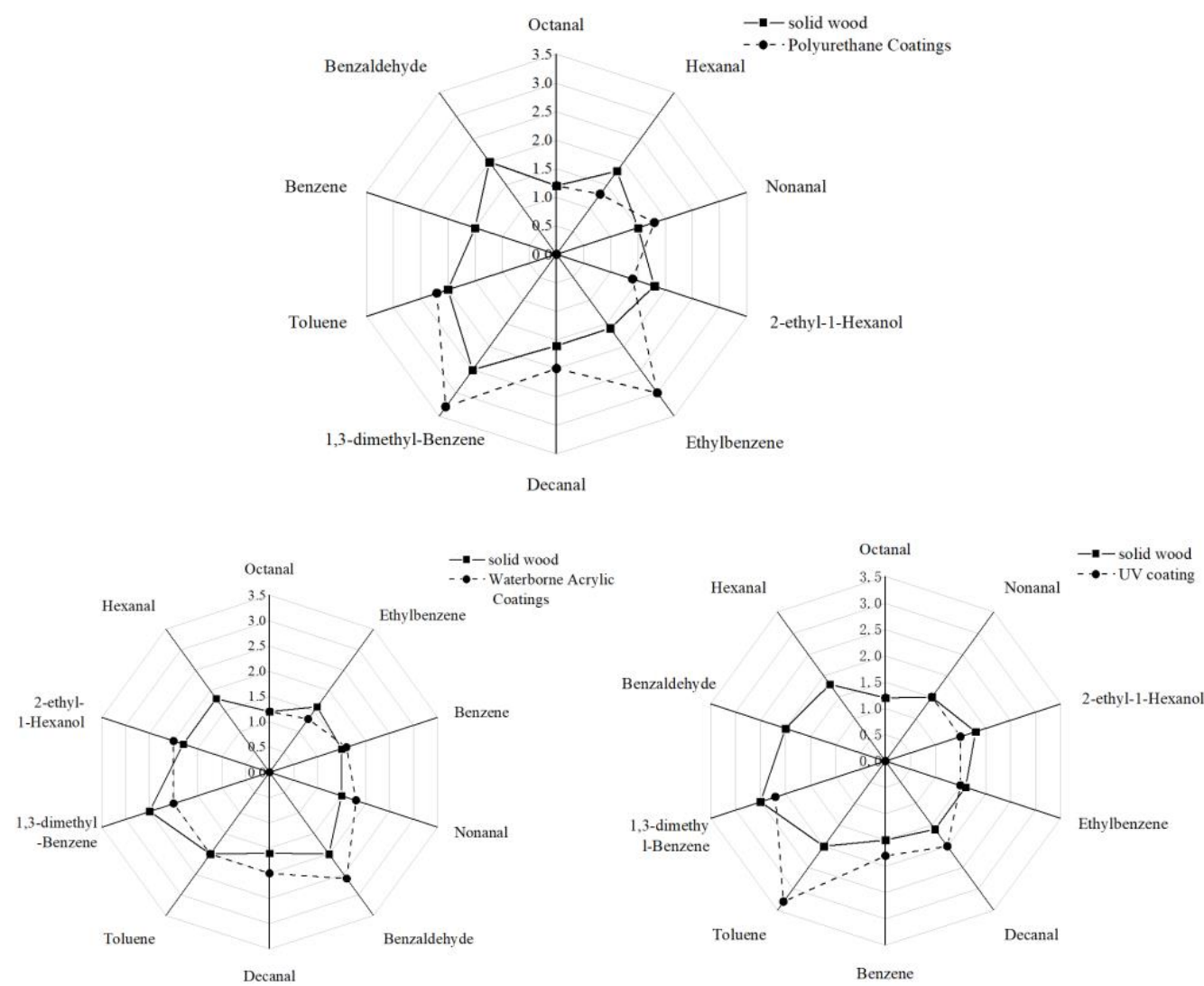

Figure 3: Contrast of odor profile from P.neurantha (Hemsl.) Gamble with three lacquer decorations

Benzaldehyde, toluene and 1,3-dimethyl-benzene had higher odor intensity among the odorcontributing compounds of unpainted P.neurantha (Hemsl.) Gamble, which played a decisive role in the formation of overall odor. Benzene and benzaldehyde had not been detected in the compounds from P.neurantha (Hemsl.) Gamble decorated with PU lacquer, indicating PU lacquer had a good sealing effect on these two odors compounds. In addition, the emission of hexanal and 2-ethyl-1-hexanol decreased to less than 1.5 compared with other odor compounds, these two odor compounds had little effect on the formation of overall odor. In addition to these four odor compounds, the odor intensity of other compounds has been strengthened. Among them, the odor intensity of ethylbenzene and 1,3-dimethyl-Benzene was no less than 3, which played a key role in the formation of overall odor. And, it also released many special odor compounds with high odor intensity. As a result, the overall characteristic odor and odor intensity of P.neurantha (Hemsl.) Gamble decorated with PU lacquer would change significantly. Hexanal, the odor characteristic compound of P.neurantha (Hemsl.) Gamble, was not detected after it was decorated with waterborne lacquer. And the odor intensity of 1,3-dimethyl-benzene and ethylbenzene decreased. Therefore, waterborne lacquer has a good inhibitory effect on the release of these three odor characteristic compounds. However, the VOCs released by waterborne lacquer will increase the concentration of benzene, benzaldehyde, 2-ethyl-1hexanol, decanal and nonanal, likewise the odor intensity would also increase. Therefore, the overall odor intensity of P.neurantha (Hemsl.) Gamble after waterborne lacquer decoration would be enhanced to some extent, but the overall odor characteristics showed little difference. 


\section{Proceedings of the 2020 Society of Wood Science and Technology International Convention}

UV lacquer had a certain inhibitory effect on the odor release of P.neurantha (Hemsl.) Gamble, in addition UV lacquer itself did not release other types of odor compounds. After being decorated with UV lacquer, Hexanal and benzaldehyde can no longer be detected. The odor intensity of 1,3-dimethyl-benzene, 2-ethyl-1-hexanol and ethylbenzene also decreased. Decanal and benzene had slightly increased odor intensity, while toluene's odor intensity increased significantly, reaching 3.3, which became the main contributor to the overall odor formation. From the point of view of overall odor formation, the overall odor characteristics of UV lacquer tend to be aromatic, and the overall odor intensity changes slightly, and the main odor characteristics and overall odor intensity were caused by the high concentration of toluene.

\section{Summary and Conclusions}

After being decorated with three different lacquer, the release of volatile organic compounds (VOCs) from the solid wood could be inhibited by the surface lacquer, however, the lacquer material would release some other compounds at the same time. The TVOC release of P.neurantha (Hemsl.) Gamble increased after three kinds of lacquer decoration, and the increase of P.neurantha (Hemsl.) Gamble with PU lacquer decoration was the most significant. The VOCs released from unpainted P.neurantha (Hemsl.) Gamble mainly consist of aromatic hydrocarbons and olefins. Aromatic hydrocarbons and esters were the main components of PU lacquer-coated P.neurantha (Hemsl.) Gamble. Esters are the main components of Waterborne lacquer-coated P.neurantha (Hemsl.) Gamble. The aromatic hydrocarbons are the main components of P.neurantha (Hemsl.) Gamble decorated with UV lacquer.

The three kinds of lacquers have strong inhibitory effects on the release of olefins from P.neurantha (Hemsl.) Gamble, which can reduce the olefins by more than $90 \%$. PU lacquer can release a large number of esters and aromatic hydrocarbons, but it can inhibit aldehydes and ketones. Waterborne lacquer itself also releases a large number of esters, resulting in a sharp increase in the release of alcohols after lacquered. However, the aromatic hydrocarbons, olefins, alkanes, aldehydes and ketones released by P.neurantha (Hemsl.) Gamble were inhibited to some extent. UV lacquer has the best inhibition effect on olefins, alcohols, aldehydes, ketones and other compounds in P.neurantha (Hemsl.) Gamble and does not release esters or other compounds, but its toluene release will increase sharply.

Ten characteristic odor compounds were released from unpainted P.neurantha (Hemsl.) Gamble, among which Benzaldehyde, Toluene and 1,3-dimethyl-Benzene played a decisive role in overall odor formation. PU lacquer had a completely closed effect on Benzene and Benzaldehyde, but enhanced the odor intensity of Ethylbenzene and 1,3-dimethyl-Benzene significantly. Waterborne lacquer has a good inhibitory effect on Hexanal, 1,3-dimethyl-Benzene and Ethylbenzene. But the VOCs released by itself will enhance the odor intensity of Benzene, Benzaldehyde, 2-ethyl-1-Hexanol, Decanal and Nonanal. UV lacquer has good sealing effect on odor compounds except decanal, benzene and toluene.

The overall odor composition of unpainted P.neurantha (Hemsl.) Gamble was mainly aromatic. After finishing with PU lacquer, the overall odor intensity of P.neurantha (Hemsl.) Gamble was 


\section{Proceedings of the 2020 Society of Wood Science and Technology International Convention}

significantly enhanced, and the overall odor was mainly fruity and aromatic. The types of odor compounds released by waterborne lacquer-coated P.neurantha (Hemsl.) Gamble are similar to those of unpainted P.neurantha (Hemsl.) Gamble. The overall odor characteristics are still mainly aromatic, but the overall odor intensity is slightly enhanced. The overall odor of P.neurantha (Hemsl.) Gamble with UV lacquer is basically aromatic.

\section{Acknowledgements}

This research was funded by the "Project of National Natural Science Foundation of China" (grant no. 31971582).

\section{References}

American Industrial Hygiene Association Journal (1962) (AlHA, 475 Wolf Ledges Pkwy., Akron, OH 44311) V.19- 1958- : 23,95.

Archives of Toxicology (1985) (Springer-Verlag, Heidelberger PI. 3, D-1000 Berlin 33, Fed. Rep. Ger.) V.32- 1974- : 58,106.

Archives of Andrology (1983) (Elsevier Science Pub. Co., Inc., 52 Vanderbilt Ave., New York, NY 10017) V.1- 1978- : 11,233.

Burdock GA, et al (2010) Fenaroli's Handbook of Flavor Ingredients. 6th ed., Boca Raton, FL: CRC Press p. 828.

Burdock GA, et al (2010) Fenaroli's Handbook of Flavor Ingredients. 6th ed.Boca Raton, FL 2010, p. 1520

Furia TE, et al (1980) CRC Handbook of Food Additives. 2nd ed. Volume 2. Boca Raton, Florida: CRC Press, Inc. p. 276.

Ghadiriasli R, Wagenstaller M, Buettner A (2018) Identification of odorous compounds in oak wood using odor extract dilution analysis and two-dimensional gas chromatographymass spectrometry/olfactometry. Anal. Bioanal. Chem. 410, 6595-6607.

Hou L J, Yan C, Zhao H et al (2018) Headspace Solid Phase Microextraction-Gas Chromatography-Mass Spectrometry-Sniffing Technique Analysis of the Main Aroma Components of Jujube Brandy. Chinese Journal of Food Science, 18(08): 232-238.

Kohlpaintner C et al (2013) Aldehydes, Alphatic. Ullmann's Encyclopedia of Industrial Chemistry. 7th ed. (1999-2015). New York, NY: John Wiley \& Sons.

Klepeis NE, Nelson WC, Ott WR et al (2001) The National Human Activity Pattern Survey(NHAPS): a resource for assessing exposure to environmental pollutants. Journal of Exposure Analysis and Environmental Epidemiology 11(3): 231-252.

Larranaga MD, Lewis RJ, Sr, Lewis, RA (2016) Hawley's Condensed Chemical Dictionary 16th Edition. John Wiley \& Sons, Inc. Hoboken, p. 150.

Larranaga MD, Lewis RJ, Sr, Lewis, R.A (2016) Hawley's Condensed Chemical Dictionary 16th Edition. John Wiley \& Sons, Inc. Hoboken, p. 1002.

Liu R, Wang C, Huang A (2018) Characterization of odors of wood by gas chromatographyolfactometry with removal of extractives as attempt to control indoor air quality. Molecules 23(1): 203.

Lewis RJ (2007) Hawley's Condensed Chemical Dictionary 15th Edition. John Wiley \& Sons, Inc. New York, NY, p. 647. 


\section{Proceedings of the 2020 Society of Wood Science and Technology International Convention}

Lewis RJ (2007) Hawley's Condensed Chemical Dictionary 15th Edition. John Wiley \& Sons, Inc. New York, NY, p. 904.

Lewis RJ (2007) Hawley's Condensed Chemical Dictionary 15th Edition. John Wiley \& Sons, Inc. New York, NY, p. 371

Liu WJ, Shen J, Wang QF (2017) Design of DL-SW microchip and rapid detection of wood-based panel VOCs . Journal of Forestry Engineering 2 (04): 40-45.

Nishimura O (1995) Agric Food Chem 43: 2941-45.

NOAA; CAMEO Chemicals (2016) Database of Hazardous Materials. Ethylbenzene (100-41-4). Natl Ocean Atmos Admin, Off Resp Rest; NOAA Ocean Serv. Available from, as of June 14.

NIOSH. NIOSH Pocket Guide to Chemical Hazards. (2010a) Department of Health \& Human Services, Centers for Disease Control \& Prevention. National Institute for Occupational Safety \& Health. DHHS (NIOSH) Publication No. 168.

NIOSH. NIOSH Pocket Guide to Chemical Hazards. (2010b) Department of Health \& Human Services, Centers for Disease Control \& Prevention. National Institute for Occupational Safety \& Health. DHHS (NIOSH) Publication No. 168.

O'Neil MJ (2013) The Merck Index - An Encyclopedia of Chemicals, Drugs, and Biologicals. Cambridge, UK: Royal Society of Chemistry, , p. 186.

Panten J, Surburg H (2015) Flavors and Fragrances, 2. Aliphatic Compounds. Ullmann's Encyclopedia of Industrial Chemistry. 7th ed. (1999- 2018). New York, NY: John Wiley \& Sons.

Qi YQ, Li XJ, Huang QG (2015) VOC emission control in wood furniture nitrolacquer painting workshop . Journal of Forestry Engineering 29 (04): 11-16.

Sax, N.I. (1984) Dangerous Properties of Industrial Materials. 6th ed. New York, NY: Van Nostrand Reinhold, p. 152.

Schreiner L, Bauer P, Buettner A (2018) Resolving the smell of wood Identification of odouractive compounds in Scots pine (Pinus sylvestris L.). Sci. Rep. 8, 1-9.

Sun ZB, Yan XJ, Lin B et al (2018) GC-O sniffing analysis based on direct intensity method for different vinegar-age Zhenjiang vinegar aroma active ingredients. Chinese Journal of Food Science, 18(03): 227-234.

Shen J, Jiang LQ (2018) Progress in VOCs release from wood-based panels. Journal of Forestry Engineering, 3(06): 1-10.

Shen J, Liu Y, Zhang WC et al (2013) Study on particleboard VOCs release. Beijing: Science Press , 2013.

Wang QF, Shao YL, Cao TY et al (2017) Identification of key odor compounds from three kinds of wood species. 2017 International conference on Environmental Science and Sustainable Energy, ESSE139, Suzhou, China.

Wang QH, Tian SL, Xie WM et al (2005) Treatment of volatile mixed waste gas containing butyl acetate, $\mathrm{n}$-butanol and phenylacetic acid in pharmaceutical plants by bio trickling filter [J]. Environmental science, (02): 55-59.

Yang R, Xu W, Liang XY et al (2017) Exploration and analysis of VOC and odor detection technology for solid wood furniture. Furniture 38 (05): 99-103.

Yang R, Xu W, Liang XY et al (2018) Component Analysis of VOC and Odor Gas Release in Solid Wood Bedside Cabinet. Furniture 39 (02): 24-27. 
Zhu WG, Luo H (2010) Organic Chemistry Experiments: Xiangtan University Press:196.

Wang BG, Feng ZC, Zhou Y, Liu HX (2019) Composition spectrum of volatile organic compounds in the air of polyurethane synthetic leather factory. China Environmental Science, 29 (09): 914-918.

Wang Q, Shen J, Shao Y, Dong H, Li Z, Shen X. Volatile organic compounds and odor emissions from veneered particleboards coated with water-based lacquer detected by gas chromatography-mass spectrometry/olfactometry. European Journal of Wood and Wood Products. doi:10.1007/s00107-019-01427-6

Wang QF, Shen J, Du JH, Cao TY, Shen XW. (2018a) Characterization of Odorants in Particleboard Coated with Nitrocellulose Lacquer under Different Environment Conditions. FOREST PRODUCTS JOURNAL. 68(3):272-280

Wang QF, Shen J, Shen XW, Du JH (2018b) Volatile Organic Compounds and Odor Emissions from Alkyd Resin Enamel-coated Particleboard. BioResources 13(3): 6837-6849.

\section{Biography}


Proceedings of the 2020 Society of Wood Science and Technology International Convention

\title{
Numerical Analysis of Tree Dynamic Response
}

\author{
Barbora Vojáčková \\ bara.vojackova@gmail.com \\ Jan Tippner \\ jan.tippner@mendelu.cz \\ Department of Wood Science and Technology, Faculty of Forestry and Wood \\ Technology, Mendel University in Brno, Czech Republic
}

\begin{abstract}
The methods of tree stability assessment in practice mostly rely upon static testing, when the description of the mechanical response to loading is based on observation of strain along the stem, root-plate inclination and change of stem deflection. Trees have evolved, live and fail in a dynamic environment and current research of tree biomechanics is more and more based on the description of dynamic mechanical response to loading. In general, the change of dynamic response (leading to defect observation) can be influenced by the change of geometry, material stiffness, mass and damping distribution. Theoretical and experimental dynamic analyses provide us mainly the frequencies, modes of vibrations or development of amplitudes of the tree in time. The fundamental goal is to analyse the possibility of use of outputs in the frequency domain or time domain as a suitable tool for observation of tree defects.

Modal, harmonic and transient finite-element analyses of tree response were carried out using ANSYS Mechanical APDL software to describe the natural frequencies, mode shapes and development of amplitudes in frequency and time domain. The parametric segmented finite-element model of the tree (simplified root plate, trunk with crown effect) with orthotropic material was developed. The model was experimentally validated based on static response: tilt and deformation were compared with field experiments. The parametric definition of the model enabled "what-if" analyses with the change of geometry and material constants simulating different defects and trees state. The correlation between the dynamic response of model and internal tree defects (stem, root plate) were found to be significant, which provide the possibility of application in non-destructive tree assessment.
\end{abstract}

Biography 


\title{
Proceedings of the 2020 Society of Wood Science and Technology International Convention
}

\section{Assessment of European Beech Timber Based on Non-destructive Measurement}

\author{
Jan Zlámal \\ xzlamal4@mendelu.cz \\ Jan Tippner \\ jan.tippner@mendelu.cz
}

\author{
Department of Wood Science and Technology, Faculty of Forestry and Wood \\ Technology, Mendel University in Brno, Czech Republic
}

\begin{abstract}
Grading stands at the beginning of the entire chain of wood processing. Although there are many techniques used for wood selection, this study is focused on the grading of wood directly in the forest on the standing trees and timber after logging. The main aim is to verify the accuracy of wood properties assessment based on measurements by common devices for non-destructive (NDT) or semi-destructive (SDT) testing methods. Three types of NDT and SDT were used on European beech (Fagus sylvatica, L.). This species was selected as most planted hardwood in the Czech Republic with great potential for use. The standing trees without signs of damage or rot were measured by device for NDT and SDT. Then the examine trees were felled down and processed to logs with constant length, which were measured by the same devices as the standing trees. The frequency-resonant methods were also used for assessment of logs. Immediately after logs measurement, cross-sections from every tree were cut off for laboratory testing.

The main evaluated properties were wood density, sound velocity, dynamic modulus of elasticity, micro-drilling and indentation resistance, damping. Variability of values and relationships between parameters from each method and forest stands were analyzed. These analyses were carried out to find simple principles for determining production parameters assessment directly in the forest stand. Significant relationships from this study will be used as a background for developing methods for individual timber grading in forestry practice.

Keywords: European beech, Grading, Standing trees, Logging, Non-destructive testing methods Biography
\end{abstract}




\title{
Monday, July 13
}

\author{
Timber Engineering, Mass Timber \& Sustainable Architecture \\ Chairs: \\ Bohumil Kasal, Farunhofer Institute for Wood Research, German \\ Mariapaola Riggio, Oregon State University, USA
}

\section{Analysis of Half-Lap Joint of Full-Scale Unprotected CLT Floors and Walls during ASTM E119 Fire Tests}

\author{
Seung Hyun Hong, Oregon State University, USA \\ hongseu@oregonstate.edu
}

\begin{abstract}
The half-lap joint is one of the easiest and most convenient ways for in-plane assembly of CLT panels in the construction field. However, in case of fire, it can become a channel for the flow of heated air from the fire exposed side towards the unexposed side and spread the fire outside the burning compartment. Therefore, the objective of this study was to determine the fire-resistance of the halflap joint of full-scale unprotected CLT. The independent variables in the experiment were two positions of floors and walls (vertical and horizontal), two species groups (SPF and DF-L), and two adhesive systems (PUR and MUF). The thickness of the CLT assemblies was $175 \mathrm{~mm}$, and each layer was 35 $\mathrm{mm}$. The temperature was measured using thermocouples at 3 locations along the half-lap joint, and 9 locations of each bonding lines in the CLT. All assemblies were tested following ASTM E119 in a loaded condition. In the late stage of the ASTM E119 fire test, the formation of visible gaps at the halflap joints was observed and monitored in CLT walls. After the fire tests, panels were cut into 1 squarefoot blocks, on which the residual depth was measured in 8 perimeter locations. In addition, the blocks including the half-lap joint were cut along the joint groove line to measure charring inside the gap. The residual CLT depth along the half-lap joint were then compared with the average residual depth in other locations of the panels. Data from TCs aligned along the joints were also analysed and compared to TC data from other parts of the panels. Finally, the calculated char rates for material along the joint were compared to these for the rest of the solid panels. The results will be available at the time of presentation.
\end{abstract}

Biography 


\title{
Deconstructable Timber-Concrete Composite Connectors
}

\author{
Mohammad Derikvand ${ }^{*}$ - Gerhard Fink2 \\ 1 Postdoctoral Researcher, Department of Civil Engineering, Aalto University, \\ 02150 Espoo, Finland* Corresponding author \\ Mohammad.derikvand@aalto.fi \\ 2 Assistant Professor, Department of Civil Engineering, Aalto University, 02150 \\ Espoo, Finland \\ Gerhard.fink@aalto.fi
}

\begin{abstract}
The application of deconstructable connectors in timber-concrete composite (TCC) floors enables the possibility of disassembly and reuse of timber materials at the end of building's life. This paper introduces the initial concept of a deconstructable TCC connector comprised of a selftapping screw embedded in a plug made of rigid polyvinyl chloride and a level adjuster made of silicone rubber. This connection system is versatile and can be applied for prefabrication and insitu concrete casting of TCC floors in both wet-dry and dry-dry systems. The paper presents the results of preliminary tests on the shear performance of four different configurations of the connector system in T-section glulam-concrete composites. The shear performance is compared to that of a permanent connector made with the same type of self-tapping screw. The failure modes observed are also analyzed to provide technical information for further optimization of the connector in the future.
\end{abstract}

Key words: deconstructable connector, timber-concrete composite, push-out test, shear strength, slip modulus, failure mode.

\section{Introduction}

Timber-concrete composite (TCC) floors can be described as a slab-type engineered wood product or a number of individual timber beams connected to a (thin) concrete slab through shear 
connectors. The concrete slab, placed on top of the timber component, predominantly resists compression in the composite system, the timber component predominantly resists tension, and the connectors transfer shear loads between the two components. When designed properly, TCC floors can benefit from the high compressive strength of concrete and the high tensile strength of timber (Dias et al. 2018). In previous research works, TCC floors have most commonly been constructed using permanent connectors. Although structurally effective, the application of permanent connectors in the construction of TCC floors can represent challenges for the sustainability and disposal of such structures and result in waste management problems at the end of building's life (Khorsandnia et al. 2018). This is because most of the timber materials used could not be easily recycled or reused due to the permanent connections between the timber elements and the concrete slab. This problem can be addressed when a design for disassembly approach is considered by making use of deconstructable connectors. The use of deconstructable connectors can facilitate the process of dismantling and recycling of TCC structures (Khorsandnia et al. 2016). However, while the structural capacities of various types of permanent connectors have been investigated in numerous studies over the past two decades, little effort has been put into developing and evaluating the performance of deconstructable connectors for TCC floors.

With a focus on design for disassembly and reuse of timber materials at the end of building's life, the goal of this research is to develop a deconstructable connector that can be used for both on-site concrete casting and offsite prefabrication of TCC floors in wet-dry and dry-dry systems. The results of a series of preliminary tests on the shear performance and failures modes of the initial prototype of the deconstructable connector are reported in this paper. The prototype of this connector is comprised of a self-tapping screw embedded in a plug made of rigid polyvinyl chloride (PVC) and a lid and a level adjuster made of silicone rubber. The preliminary tests were performed on five T-section glulam-concrete connections made with four different types of the connector and a permanent screw connector of the same configuration under monotonic shear loads.

\section{Specification of the deconstructable connector and preliminary tests}

The concept of the presented approach is that the self-tapping screw itself can directly be used as a deconstructable connector. For this purpose, a solution is required that can prevent the screw from coming into direct contact with the fresh concrete during the construction process. One of the main challenges here, however, is to make sure that the structural properties of the resulting deconstructable connection will be comparable to that of an equivalent permanent connection of the same configuration. Another aim of this research project is that the connector can be used in various construction procedures (i.e., wet-dry and dry-dry systems) and floor configurations. This might be achievable by adding an extra protective layer to the screw itself instead of producing a connector separately. 

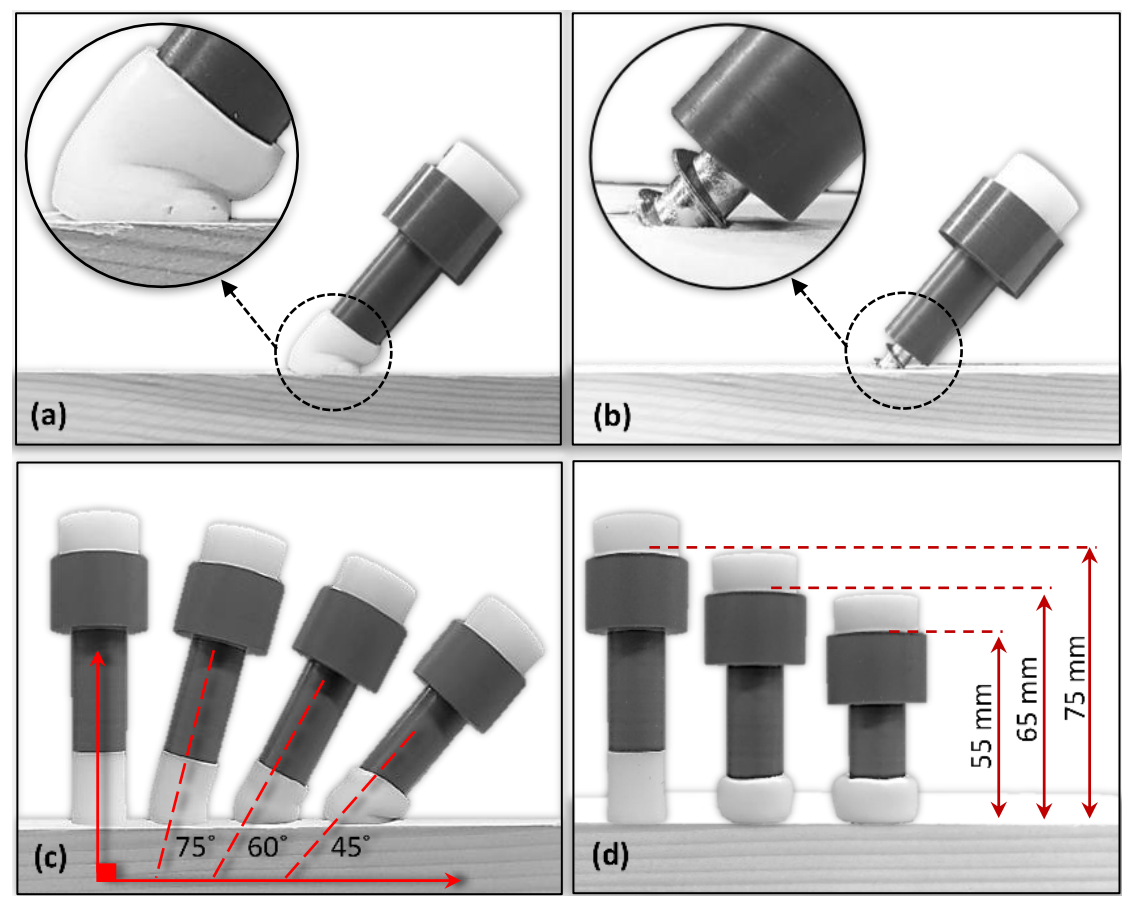

Figure 1. Illustration of the connector (a) with level adjuster, (b) without level adjuster, (c) inserted at different angles, and (c) inserted at different heights by compressing the level adjuster.

The extra protective layer could be in the form of a pipe or an internally threaded plug that can fully cover the portion of the screw that is exposed to the fresh concrete. The resulting connector will be a single deconstructable screw that can directly be driven into the timber component without the need for any additional element or process. Based on this idea, a fully threaded selftapping screw is inserted into a plug made of rigid PVC. In addition, the connector had a lid and a level adjuster made of silicone rubber. The level adjuster can easily deform and be compressed while the connector is being inserted into the timber component. This enables the possibility of using the same connector with the same dimensions at different insertion angles and concrete slab heights without exposing any part of the screw to the fresh concrete (Fig. 1). The presence of a level adjuster, however, may result in reduced shear performance as well. This effect was studied as a variable during the preliminary tests. For this purpose, per each deconstructable connector tested with level adjuster an equivalent of the same connector was also manufactured and tested without level adjuster. Another important parameter that was considered for the preliminary testing was the configuration of the inner side of the PVC plug. Two types of PVC plugs with and without internal threads were tested for this purpose (Fig. 2). It was assumed that the connector with internal threads would lead to a better shear behaviour as there will be no gap between the screw and the PVC plug in such configuration resulting in a tight fit between the two elements. The diameter of the hole inside the PVC plug with internal threads was equal to the shank diameter of the screw. In the PVC plug without internal threads, however, the diameter of the hole inside the plug was equal to the thread diameter of the screw. This resulted in some unfilled gaps between the inner sides of the hole in the plug and the shank of the screw. 

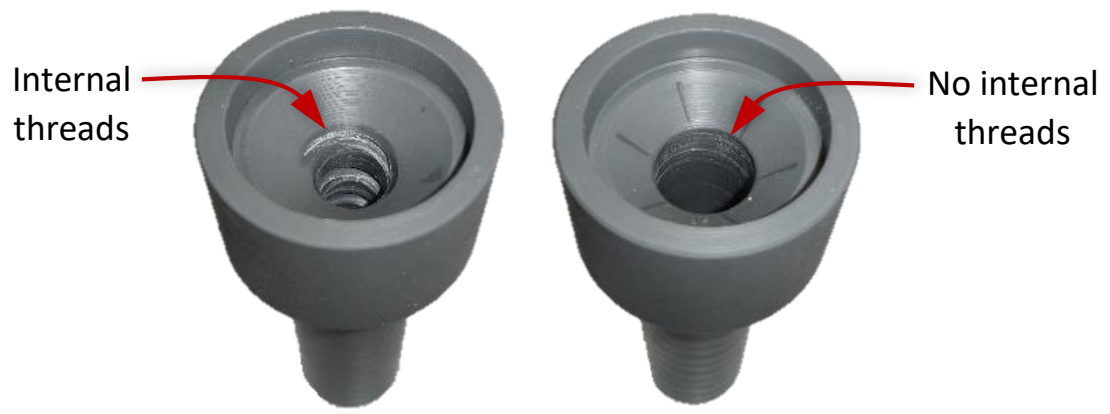

Figure 2. PVC plugs with internal threads (left) and without internal threads (right).

Table 1: Compilation of the experimental tests.

\begin{tabular}{|c|c|c|c|c|c|c|}
\hline \multirow{2}{*}{$\begin{array}{l}\text { Connector } \\
\text { Symbol }\end{array}$} & \multicolumn{3}{|c|}{ Test variables } & \multirow{2}{*}{$\begin{array}{l}\text { Level adjuster } \\
\text { height (mm) }\end{array}$} & \multirow{2}{*}{$\begin{array}{l}\text { Insertion } \\
\text { angle }\left({ }^{\circ}\right)\end{array}$} & \multirow{2}{*}{$\begin{array}{l}\text { Embedment } \\
\text { depth (mm) }\end{array}$} \\
\hline & Connector type & $\begin{array}{l}\text { Internal } \\
\text { threads }\end{array}$ & $\begin{array}{c}\text { Level } \\
\text { adjuster }\end{array}$ & & & \\
\hline $\mathrm{P}$ & Permanent & - & & & 90 & 80 \\
\hline DTL & Deconstructable & Yes & Yes & 20 & 90 & 80 \\
\hline DTN & Deconstructable & Yes & No & 20 & 90 & 80 \\
\hline DNL & Deconstructable & No & Yes & 20 & 90 & 80 \\
\hline DNN & Deconstructable & No & No & 20 & 90 & 80 \\
\hline
\end{tabular}

In total, four groups of deconstructable connectors and a permanent screw connector with the same configuration were constructed as given in Table 1. The permanent screw connector served as a control specimen. The fully threaded self-tapping screw was made of high resistance galvanized carbon steel with a length of $150 \mathrm{~mm}$, a shank diameter of $6.6 \mathrm{~mm}$, and a thread diameter of $11 \mathrm{~mm}$. The timber component in the T-section connection specimens in this study were cut from a 5-layer glulam beam (Nordic whitewood) with $b \times h \times l=90 \times 200 \times 300 \mathrm{~mm} 3$. A low-shrinking concrete with a maximum aggregate size of $16 \mathrm{~mm}$ was used for preparing the specimens. The density and compressive strength of the concrete used were $2388 \mathrm{~kg} / \mathrm{m} 3$ and 55.3 $\mathrm{MPa}$, respectively. The concrete properties were measured by testing six cubic specimens with the dimensions of $b \times h \times l=100 \times 100 \times 100 \mathrm{~mm} 3$.

To prepare the glulam-concrete connection specimens for the preliminary testing, the connectors were driven into the glulam component to a penetration depth of $80 \mathrm{~mm}$. Before casting the concrete, the top surface of the glulam in each specimen was covered by a layer of waterproof paint to prevent the glulam from absorbing moisture from the wet concrete. A plywood formwork was then fixed around the specimens and a steel reinforcement wire mesh was installed to maintain the integrity of the concrete and minimize any crack development (Fig. 3). The concrete was then poured onto the formwork to a height of $75 \mathrm{~mm}$. The test specimens were left to cure for 28 days. The formwork was removed prior to testing. 

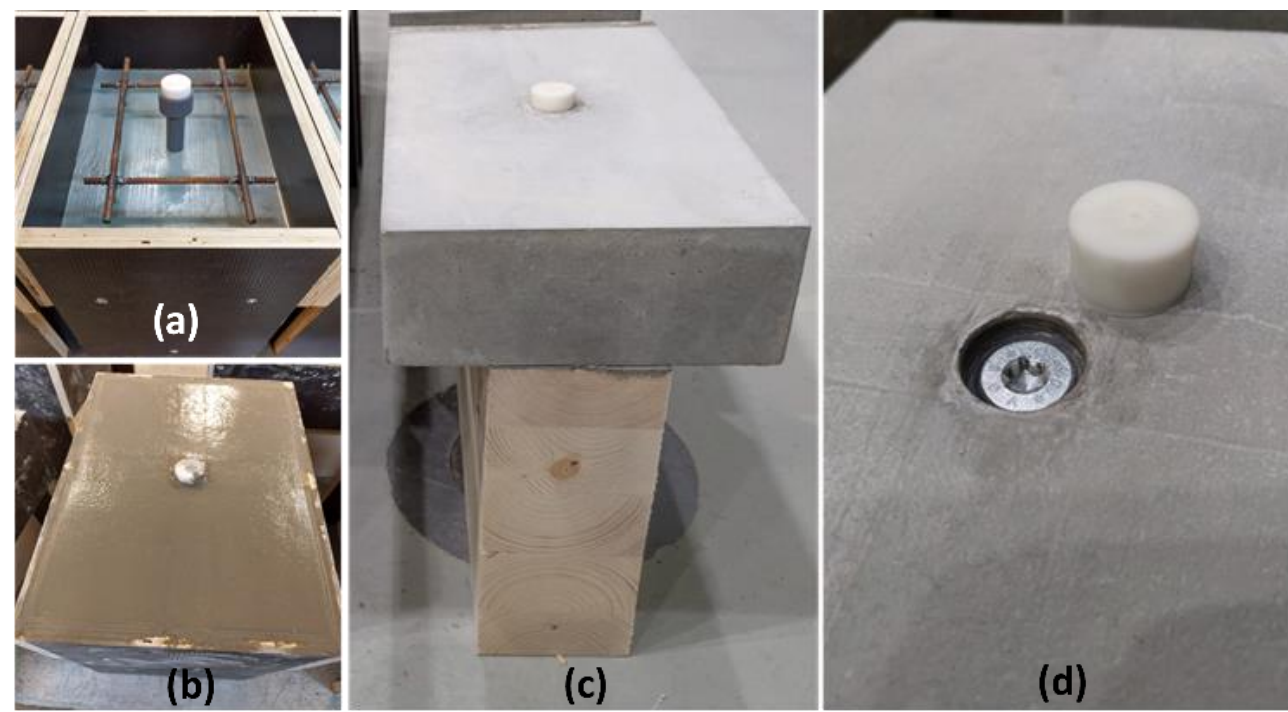

Figure 3. A T-section glulam-concrete deconstructable connection. (a): the prepared formwork, (b): concrete cast onto the formwork, (c): the resulting T-section connection, and (d): the screw head inside the connector after removing the rubber lid.
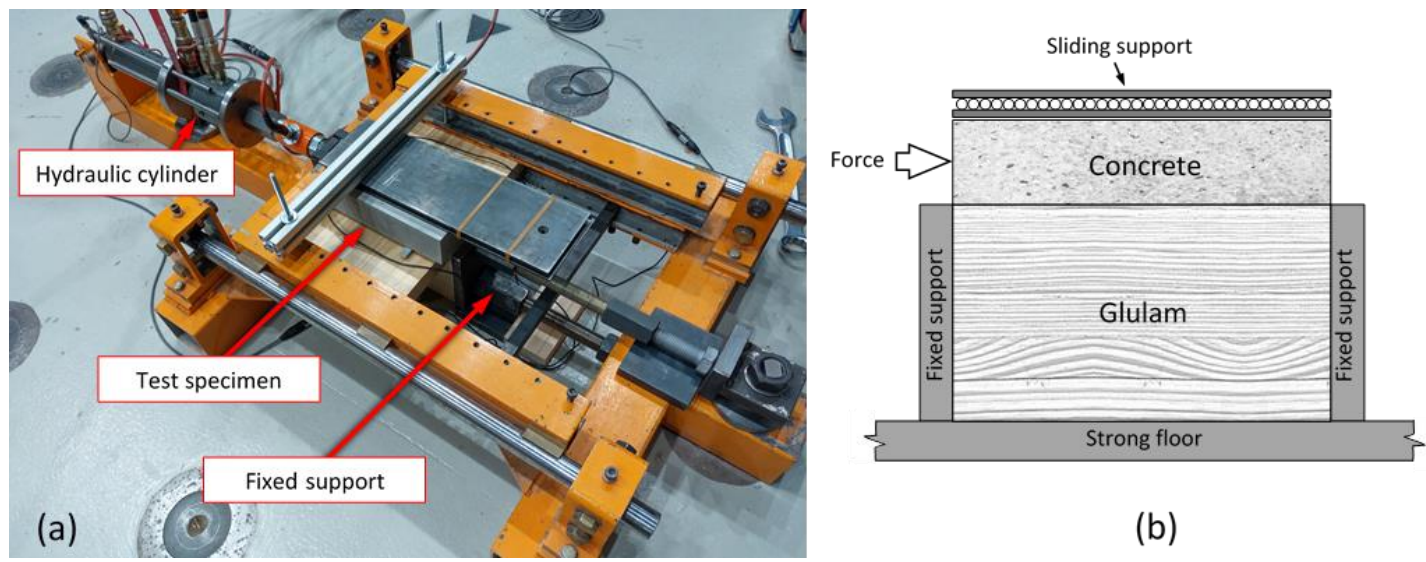

(b)

Figure 4. (a) The push-out test set-up used and (b) the side-view of a specimen under loading.

The specimens were tested under monotonic shear load in accordance with the procedures described in EN 26891 (1991) using the test set-up depicted in Figure 4. The slip between the concrete and glulam components was recorded from both sides of the test specimens using two linear variable differential transformers (LVDT). The shear strength of the connections was quantified as the peak load $\left(F_{\max }\right)$ obtained at $\mathrm{u}=15 \mathrm{~mm}$ slip. The stiffness of the permanent connector was quantified by calculating the slip modulus $\left(K_{s}\right)$ of the connector at $40 \%$ of its estimated peak load $\left(F_{\text {est }}\right)$. An accurate $F_{\text {est }}$ is vital for a realistic slip modulus calculation of connectors (Dias 2012). However, in the absence of a reliable $F_{\text {est }}$ for the deconstructable connectors in this study, the slip modulus of these connectors was calculated based on their individual $F_{\max }$. The $F_{\max }$ values will then be used as $F_{\text {est }}$ for the subsequent experiments on these connectors in the future. 


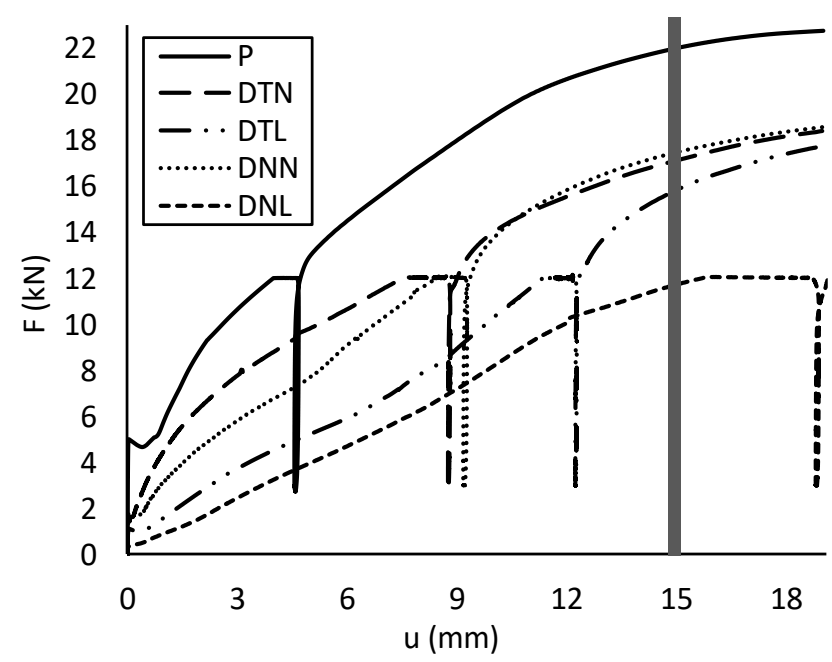

Figure 5. The load-slip curves of the connections. The vertical bar indicates the point where $F_{\text {est }}$ is taken for the subsequent testing.

Table 2: $F_{\max }$ and $K_{s}$ of the connectors.

\begin{tabular}{ccc}
\hline Connector symbol & $F_{\max }(\mathrm{kN})$ & $K_{s}(\mathrm{kN} / \mathrm{mm})$ \\
\hline P & 22.0 & 6.00 \\
DTN & 17.1 & 4.30 \\
DTL & 15.8 & 1.53 \\
DNN & 17.4 & 2.21 \\
DNL & 11.7 & 1.39 \\
\hline
\end{tabular}

\section{Results}

The load-slip curves of the test connectors are illustrated in Figure 5. As expected, the permanent screw connector exhibited higher $F_{\max }$ and $K_{s}$ under loading than the deconstructable ones (Table 2). In the group of deconstructable connectors, the two connectors with internal threads in the PVC plug (DTN and DTL) showed a higher $K_{s}$ value than the identical connectors without internal threads (DNN and DNL). The existence of the level adjuster also appeared to negatively influence both $F_{\max }$ and $K_{s}$ of the deconstructable connectors.

The failure modes of the connectors can be seen in Figure 6. In all the test connectors, some slight crushing of the concrete was observed at the interface of the slab and glulam.

Despite this, the concrete section in the permanent connector exhibited a rigid behavior and all the deformation took place in the glulam and the screw itself. The plastic hinge was observed in the timber concrete interface. The DTN and DNN connectors also showed a failure mode almost similar to that observed in the permanent connector together with some plastic deformation at the bottom of the PVC plug. For the DTL and DNL connectors, plastic hinge was above the timber concrete interface due to the level adjuster. 

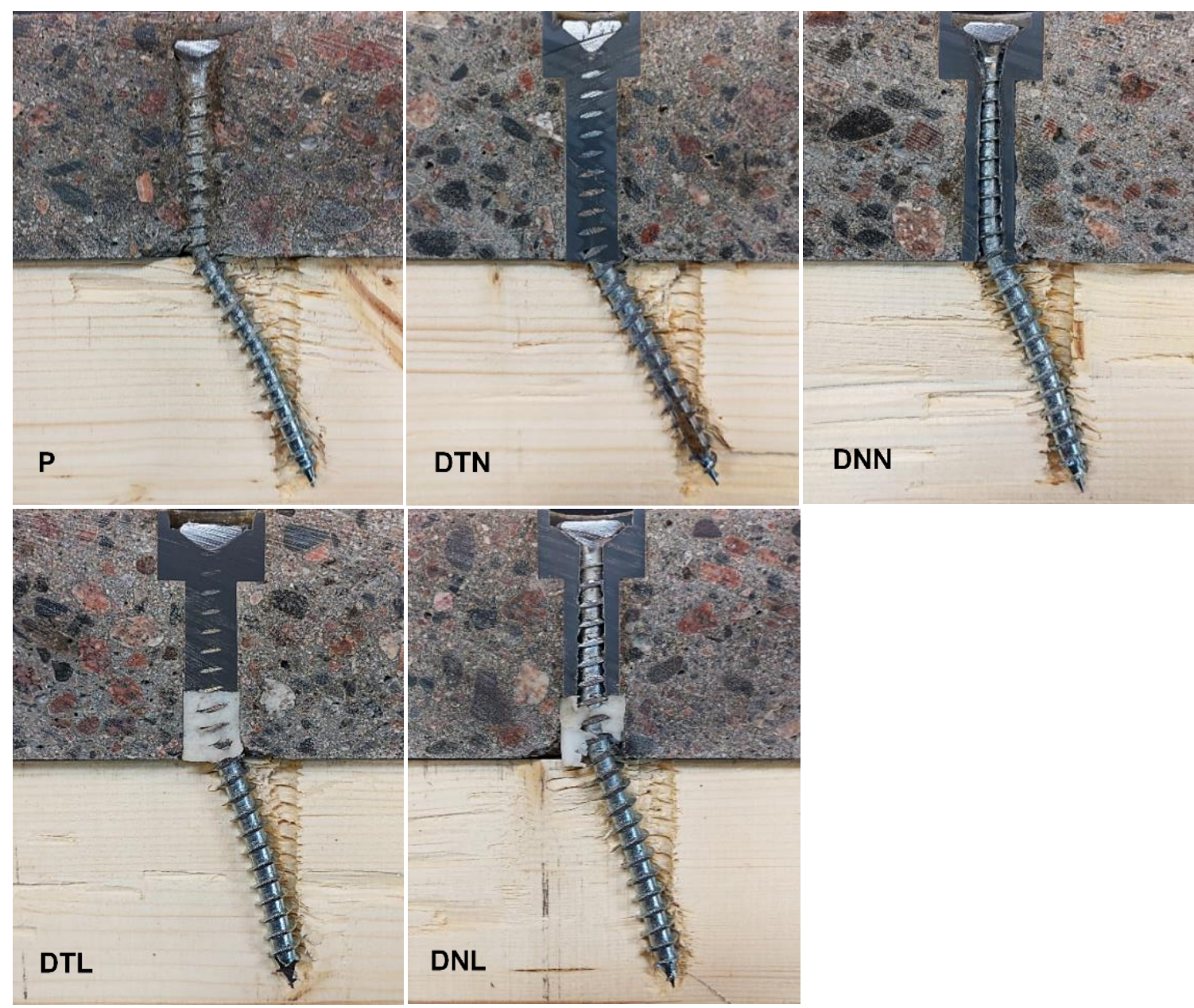

Figure 6. Failure modes of the test connections.

From the failure modes of the test connectors, it can be seen that the deformation and crushing of the glulam occurred all the way through the length of the self-tapping screw in the glulam section. However, in all cases almost only one major plastic hinge was formed in the screw itself. This might suggest that the $80 \mathrm{~mm}$ embedment depth of the self-tapping screw should be larger for alpha $=90^{\circ}$. Nevertheless, in the present study the focus lies on the behavior near the timberconcrete interface.

\section{Conclusions and Outlook}

In this paper, the initial concept of a deconstructable connector for TCC floors was introduced. The results of some preliminary tests on the shear behaviour of five glulam-concrete connections were presented and compared. Four different configurations of the deconstructable connector were examined: with or without the presence of a level adjuster and with or without internal threads in the connector plug. The relevant failure modes under monotonic load exposure were analyzed. In all samples the screws were inserted at $90^{\circ}$ angle, and accordingly the slip modulus and load-carrying capacity were low. Even though the number of tests was limited, some differences were observed between the slip modulus and load-carrying capacity of the 
deconstructable connectors and those of the permanent screw connector of the same configuration.

Based on the results of this preliminary project, ongoing research is underway in order to optimize and characterize the properties of deconstructable connector systems under different insertion angles and connection arrangements. The subsequent experimental steps also include some modification on the geometry and material type of the protective layer around the selftapping screw in order to replace PVC with a more sophisticated material. Some structural and practical aspects of the deconstructable connector introduced in this paper will also be addressed in the future experiments that have been planned for this research.

\section{References}

Dias A, Fragiacomo M, Gramatikov K, Kreis B, Kupferle F, Monteiro S, Sandanus J, Schänzlin J, Schober K, Sebastian W (2018) Design of timber-concrete composite structures. A State-of-the-Art Report by COST Action FP1402/WG, 4.

Dias A.M.P.G (2012) Analysis of the nonlinear behavior of timber-concrete connections. Journal of structural engineering 138(9): 1128-1137.

EN 26891 (1991) Timber structures - Joints made with mechanical fasteners - General principles for the determination of strength and deformation characteristic. European Committee for Standardization, Brussels, Belgium.

Khorsandnia N, Valipour H, Bradford M (2018) Deconstructable timber-concrete composite beams with panelised slabs: Finite element analysis. Construction and Building Materials 163: 798-811.

Khorsandnia N, Valipour H, Schänzlin J, Crews K (2016) Experimental investigations of deconstructable timber-concrete composite beams. Journal of Structural Engineering 142(12): 04016130.

Biography 


\title{
Proceedings of the 2020 Society of Wood Science and Technology International Convention
}

\section{CLT Panels from Below-Grade Yellow-Poplar Sorted by Nondestructive Proof Loading}

\author{
Rafael Azambuja1 \\ rdazambuja@mix.wvu.edu \\ David Devallancez \\ devallance@innorenew.eu \\ Joseph McNeel1 \\ jmcneel@wvu.edu \\ Curt Hassler 1 \\ chasslerwv@gmail.com \\ Gregory Dahle1 \\ chasslerwv@gmail.com

\section{${ }_{1}$ West Virginia University, USA 2Innorenew CoE, Slovenia}

\section{Abstract}

To manufacture and market a uniform and consistent quality product, the US lumber industry developed grading rules to classify the produced lumber. Given most hardwood lumber in the US is used in appearance applications, a common practice is to grade them following National Hardwood Lumber Association (NHLA) visual grading rules that are based on clear of defect area. However, this kind of visual grading evaluation does not effectively reflect the modulus of elasticity in the flatwise orientation which can be quickly determined using non-destructive testing methods (e.g., proof loading or stress wave evaluation). Additionally, when lumber is purposed for producing composites, such as cross-laminated timber panels, there is potential to use lower grades that do not meet visual structural grades, as these grades are based largely on lumber used alone and in a edgewise bending orientations (e.g., in a floor joist application). Given the potential of using lower grade lumber, the objective of this research was to mechanically evaluate CLT panels produced from yellow-poplar (Liriodendron tulipifera) lumber that did not achieve structural grades (i.e., below-grade) as determined by NELMA rules. To achieve an optimized layout for the panel, the population distribution of MOE was assessed and divided into subgroups. To maximize the CLT panel resistance the layout consisted of boards with MOE values equal or above $1.65 \times 106$ psi in external layers. Inner layers (at or near the neutral axis) consisted of MOE values between $1.2 \times 10_{6}$ psi and $1.65 \times 10_{6}$ psi. The MOE of $1.65 \times 106$ psi and higher represent the top $40 \%$ of the population, so it was chosen for use in external layers of a 5-layer panel ( 2 layers out of 5 ). In total, ten panels were produced that had dimensions of $3.75^{\prime \prime}$ thick $\times 18^{\prime \prime}$ wide $\times 120$ " long. To evaluate the adhesion between layers in the panel, bond quality was evaluated using shear block and cyclic delamination tests in accordance to ANSI A190.1 (2017). These evaluations were performed as recommended in PRG 320 (2018) in three positions of within the panel, at both ends and at the central region. The different positions for evaluation was to insure homogeneity throughout the panel. Flatwise bending in accordance to ANSI/PRG 320 (2018) was used to evaluate the CLT panel modulus of rupture (MOR) and MOE. Also, strain patterns during bending tests was collected by a digital image correlation (DIC) system. The DIC system was also used to provide information on failure development patterns within the specimens. Results from the bond quality and mechanical testing will be presented to provide information regarding the potential for 
Proceedings of the 2020 Society of Wood Science and Technology International Convention

using visually graded, below-grade yellow-poplar lumber to produce CLT panels. Additional information will be presented on the correlation between NDE values and placement within the panels to the resulting CLT panels' mechanical properties.

Biography 


\title{
Development of a Simplified Method for Prediction of Acoustic Behaviour of CLT with Facing Layers
}

\author{
Franz Dolezal ${ }_{*}^{*}$-Niko Kumer 2 -Alexander Baranyai 1 -Armin Wilfling 3
}

1 Key Researcher, Research Assistent, IBO - Austrian Institute for Building and Ecology GmbH, Vienna, Austria *Corresponding author franz.dolezal@ibo.at,alexander.baranyai@ibo.at

2 Research Manager, Stora Enso Wood Products, Bad St. Leonhard, Austria

niko.kumer@storaenso.com

3 Audio Engineer, Vienna, Austria

armin.wilfling@chello.at

\begin{abstract}
Since there is no standardised prediction method for acoustic behaviour of Cross Laminated Timber (CLT) building elements with facing layers, evidence that they fulfil certain properties have to be verified by acoustic measurements in laboratories instead of simple calculations. This leads to higher expenses for this building material compared to concrete or bricks and related disadvantages concerning competitiveness. The aim of this project is, inter alia, to develop a simple method to predict the weighted sound reduction index of CLT with facing layers with satisfying accuracy, in the early design stage of the building, by using as little input parameters as possible.

In a first step small test specimen are developed to analyse the resonant behaviour of CLT in combination with different facing layers by means of vibration measurements. These investigations are carried out at small concrete slabs with the mass equivalent of CLT and the facing layer as well as with different suspending bracket types. Further on, a mock up made of CLT with suspending brackets and varying types of gypsum plasterboards in plasterboard panel size, is analyzed by use of conventional vibration measurement technique as well as a selfdeveloped digital method with MEMs (surface micromachined capacitive accelerometers) and subsequent data processing over the relevant frequency spectrum from $20 \mathrm{~Hz}$ to at least $2000 \mathrm{~Hz}$. Finally sound pressure level measurements of whole walls are carried out in an accredited test facility to verify the results of the small specimen and the simplified model. Standardized 1/3 octave frequency band measurements and time signal recording with subsequent FFT analysis enable precise definition of the resonant frequency of the vibrant system. Results of the resonant frequency, gathered from mentioned vibration measurements are the basis for the simplified model to calculate the weighted sound reduction index.
\end{abstract}

Key words: CLT, sound insulation, facing layers, vibration, resonance frequency Introduction 
Several types of facing layers are applied, already for decades, to improve minor sound insulation of building components like walls or floors. Accordingly, reliable and precise prediction methods for enhanced components have been developed and even standardized in EN ISO 12354-1. These standardized methods, unfortunately, are limited to heavy, homogeneous basic structural elements. In general, improvement of sound reduction index $(\Delta R)$, caused by the facing layer, is added to the sound reduction index $(R)$ of the basic element. But, this depends on the acoustic behavior of the basic element as well, and this leads to the need of more information of the interrelation between facing layers and Cross Laminated Timber (CLT) slabs since CLT can neither be assigned as heavy nor as a homogenous element. The essential parameter, but not the only one, to define acoustic behavior and sound insulation of a combined element, is its resonant frequency $f_{R}$, defined by the dynamic stiffness $\mathrm{s}^{\prime}$ and the area related masses $\mathrm{m}^{\prime}$ of the involved materials. Though, dynamic stiffness of a facing layer not only depends on the properties of the gap (filled with air or insulation material) but also on the dynamic stiffness of the hangers or bearing structure of the facing layer in general. Considering the different types of facing layer designs and materials (flexible, fixed, wood, metal, damping profiles, detached, etc.), it does not seem to be appropriate, only to take the dynamic stiffness of the gap (filled with air or damping material) into account.

\section{Materials \& Methods}

In this research project the focus is on the improvement of CLT walls with facing layers made of plasterboard by using hangers (with and without resilient material), as shown in Figure 1, and wooden slats $(60 \mathrm{~mm} \times 40 \mathrm{~mm})$ which are screwed into the hangers and serve as the supporting structure of the plasterboard.
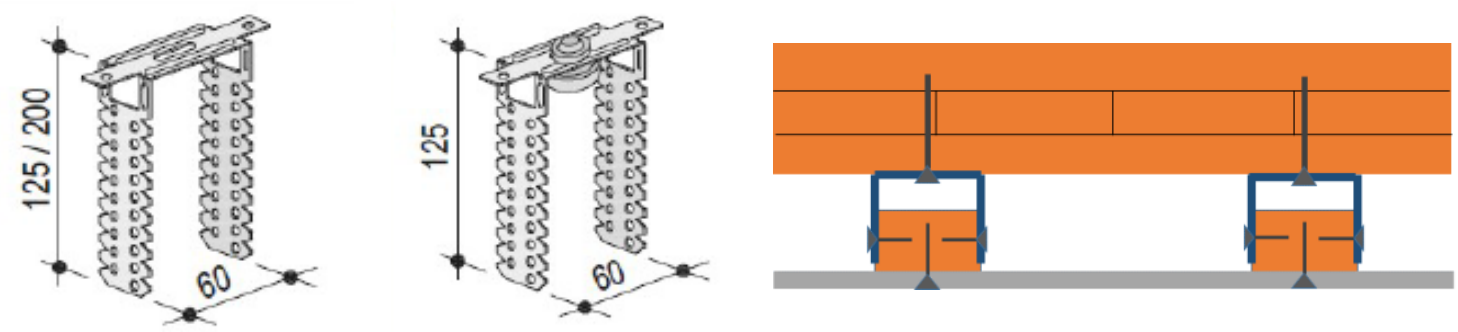

Figure 1. Hangers for wall (and ceiling) mounting of wooden slats with and without resilient layers under the mounting screw and a schematic view of the investigated building element made of CLT slab with hangers, wooden slats and plasterboard.

The acoustic improvement of the sound reduction index $\Delta \mathrm{R}$ of a facing layer is defined according to EN ISO 12354-1 as the difference between the sound reduction index R of the building element with and without facing layer.

In general, $\Delta \mathrm{R}$ can be determined easily by sound measurement in a test facility. It can also be calculated according to EN ISO 12354-1 as well, as far as the base structure is a homogeneous mineral structure, based on the resonant frequency of the mass-spring system, taking the sound reduction index of the basic element into account. This simple mass-spring-mass system is calculated according to Equation 1, when the insulation layer is fixed directly on the basic construction. 


$$
f_{R}=\frac{1}{2 \pi} \sqrt{s^{\prime}\left(\frac{1}{m^{\prime}}+\frac{1}{m^{\prime \prime}}\right)}
$$

For lightweight structures, when the mass difference is small (like usually for CLT with facing layers) Equation 1 has to be applied as well, where m' and m'" are the coupled masses of CLT and the plasterboard(s). Therefore, it is not only necessary to know both involved masses, but the dynamic stiffness of the coupling hangers as well. Furthermore, s' is not only defined by the hangers, it is a combination of the elastic property of the hangers (most likely also depending on the mass of the carrying plasterboard(s)) and the air or insulation material in the gap between the wooden slats (Rabold 2019).

This combined dynamic stiffness is the sum of the one from the air ( $\mathrm{s}^{\prime}$ air) between the masses (with or without insulation material) and the one of the hangers (s'hanger), according to Equation 2. This is the reason why s' is hard to define and usually not known for wooden lightweight structures. Therefore, sound insulation and improvement of sound reduction index of (wooden) lightweight and mass timber structures with facing layers, usually are measured in laboratories in transmission suites.

$$
s^{\prime}=s^{\prime}{ }_{\text {air }}+s^{\prime}{ }_{\text {hanger }}
$$

\section{From Small to Large Scale Measurement Setups}

With the final goal to avoid large scale test situations, two small scale test specimen have been developed with the aim to verify their comparability with the laboratory test results. At the following test settings, measurements are carried out:

1) Vibration measurements on mass-equivalent, cheap concrete paving slabs

2) Vibration measurements on a 1:1 scale mock up in the size of a standard gypsum plasterboard (1250 x $2000 \mathrm{~mm})$

3) Sound pressure measurements with subsequent FFT (1 Hz steps) in the laboratory

4) Vibration measurements on the specimen used in the laboratory

5) Standardized one third octave band sound pressure measurement in an accredited laboratory

The purpose of these five different experimental settings is to compare the results and find the easiest way with the lowest efforts and investments to generate satisfying results of the acoustic behaviour of CLT with different facing layers.

In general, vibration measurements are carried out with a two channel analyser and piezo accelerometers with shaker excitation of the specimen. In Hopkins (2007), it is advised to prefer the measurement of the phase of the driving point mobility, since it is more accurate to identify the resonance frequency in high damped systems where it can be difficult to discern the peak. Unfortunately, the available equipment does not include neither phase nor force measurement. Thus, as a compromise, frequency spectra of the accelerations are measured and peaks in the magnitudes evaluated by comparing characteristics on sending and receiving side. Hereinafter, test settings 1 to 3 are described, results are given for setting 1 and 3 .

\section{Vibration measurements on mass-equivalent, cheap concrete paving slabs}


The idea of the first setting is to connect mass-equivalent concrete slabs with hangers and excite with the hammer and with a shaker with white noise in order to find the resonant frequency of this reverberant system representing CLT and plasterboard connected with the hangers. So Masses where created with paving slabs 400 x 400 x $40 \mathrm{~mm}$ with a mass of $15 \mathrm{~kg}$ each and connected with 4 hangers and wooden slats. On the sending side, 1 to 3 and on the receiving side 1 to 6 slabs are varied. So mass combinations in $15 \mathrm{~kg}$ steps from 15 to $15 \mathrm{~kg}$ until 30 to $90 \mathrm{~kg}$ can be investigated by varying concrete slabs on both sides as shown in Figure 2.
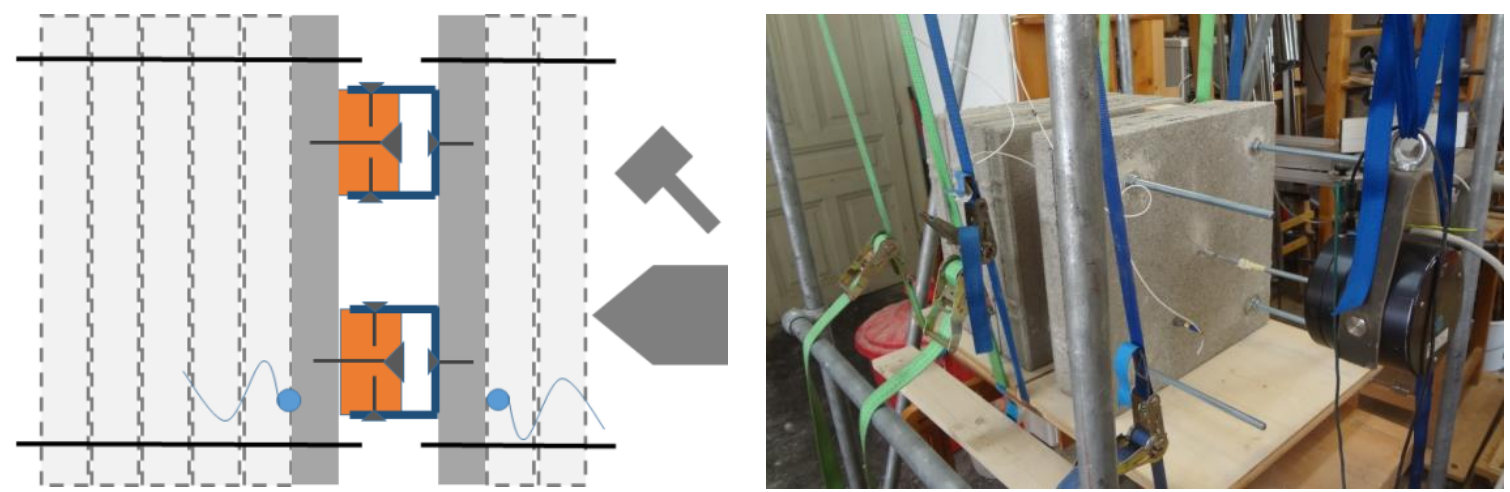

Figure 2. Schematic view of the measurement setup (left) and real picture from the workshop with accelerometer and shaker for excitation.

In this setting, several vibration measurements are carried out. Transient excitation with a hammer is applied, as well as stationary excitation with white noise and sinus sweep by using a shaker, which is connected to the concrete slab with a stinger made of a threaded rod. The whole setting is partly following EN 29052-1 for the determination of the dynamic stiffness s' of materials below floating floors. Calibration is realised by exciting with several pure sine wave signals. The time signals of the acceleration of the receiving and the sending side are taken to a dual channel FFT analyser to calculate the frequency response function.

\section{Vibration measurements on a 1:1 scale mock up in gypsum plasterboard size}

In the second setting, a $2000 \times 1250 \times 100 \mathrm{~mm}$ 3-layer CLT slab is the basic structure to sustain the plasterboard(s) via the same type of hangers (distance horizontally $625 \mathrm{~mm}$ and $1500 \mathrm{~mm}$ vertically) and wooden slats (Fig. 3). The entire multi-layer wall element is assembled in a workshop, placed on resilient interlayers to decouple the wall from the floor, and since there are no transmission suits available, vibration measurements have to be carried out. In order to gain as much information as possible, several parts of the assembly are varied during measurement: hangers with and without resilient layers, distance $d$ between CLT and plasterboard (50, 75 and $100 \mathrm{~mm}$ ), 1 or 2 layers of plasterboards, different types of plasterboards with different mass and bending stiffness. Additionally, each measurement is carried out with and without $50 \mathrm{~mm}$ mineral wool in the cavities. A cross section of the assembly is shown in Figure 3 and real pictures in Figure 4. 


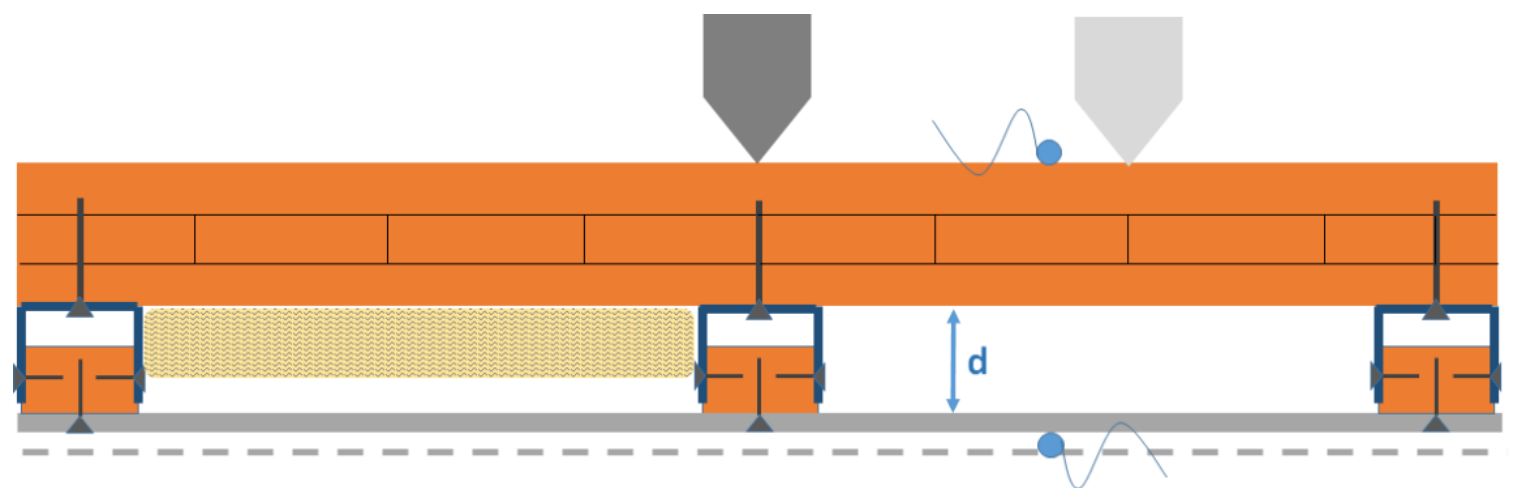

Figure 3. Schematic mock up wall element with $100 \mathrm{~mm}$ CLT slab and variation of 1 or 2 plasterboards, type of plasterboard, type of hanger, cavity filling and distance d between the coupled masses.

Excitation is conducted with white noise by the use of a shaker on two positions (in the centre on a slat - and between two slats in the cavity). At each excitation position, four accelerometer positions are measured on the CLT slab (sending side) and on the same position on the opposite plasterboard (receiving side) in the frequency range from 0 to $20.000 \mathrm{~Hz}$. Base measurement was the plain CLT slab with 2 excitation points and 10 sensor points each.
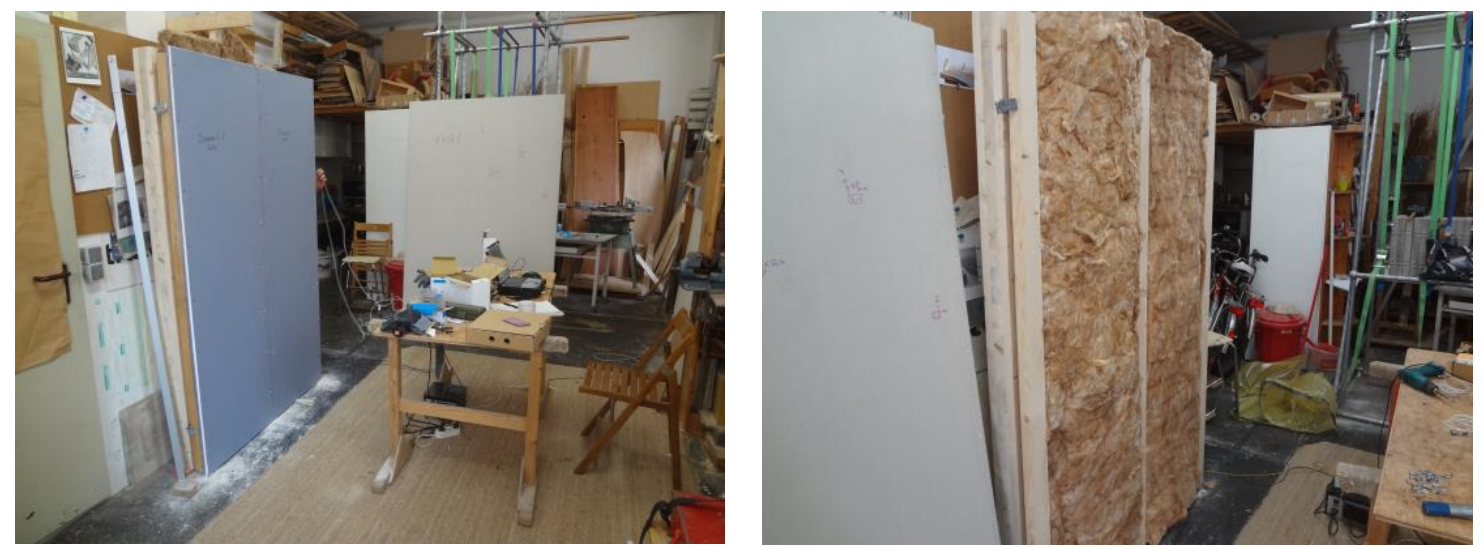

Figure 4. Test setting CLT and plasterboard on resilient layer with plasterboard (left) and without plasterboard (right). The shaker is hidden behind the structure and excites the CLT slab.

\section{Sound pressure measurements with subsequent FFT (1 Hz steps) in the lab}

Sound pressure measurements in an accredited test facility are carried out in order to get data for the sound reduction index R of CLT with facing layers. The size of the opening between the reverberation chambers is $4000 \times 2700 \mathrm{~mm}$, so the CLT slab is slightly smaller to fit into the concrete frame and is sealed afterwards. On one hand standardised 1/3 octave band measurements were carried out, on the other hand, time signal is recorded by use of a rotating microphone and converted into the frequency spectrum by FFT analyses. Calculation of sound insulation requires the reverberation time $\mathrm{T}$ as well, but there is no method for measuring $\mathrm{T}$ in 1 $\mathrm{Hz}$ steps. Thus, calculation is approximated by using the $1 / 3$ octave band results for the reverberation time according to Equation 3 . $\mathrm{R} 1 \mathrm{~Hz}$ is the sound reduction index in $1 \mathrm{~Hz}$ steps, Ls is the sum of the sound pressure levels in the sending room, $L_{R}$ is the sum of the sound pressure levels in the receiving room. Furthermore, $\mathrm{S}$ is the surface area of the wall and $\mathrm{T}$ the reverberation time measured in $1 / 3$ octave bands. 


$$
R_{1 H z}=L_{S}-L_{R}+10 * \lg \left(\frac{S * T}{0,16 * V}\right)
$$

\section{Results and Discussion}

Data from all above mentioned test settings already has been gathered, but still has to be analysed and needs to be interpreted and integrated into the whole picture. So in the following only results from settings 1 (small) and 3 (transmission suite) are discussed.

\section{Vibration measurements on mass equivalent, cheap concrete paving slabs}

Mass-equivalent vibration measurement with concrete paving slabs, carried out with transient and stationary excitation led to already expected results: the higher the resonant masses, the lower the resonance frequency. Furthermore, it could be shown, that with a resilient layer, resonance frequency decreases significantly (Fig. 5).
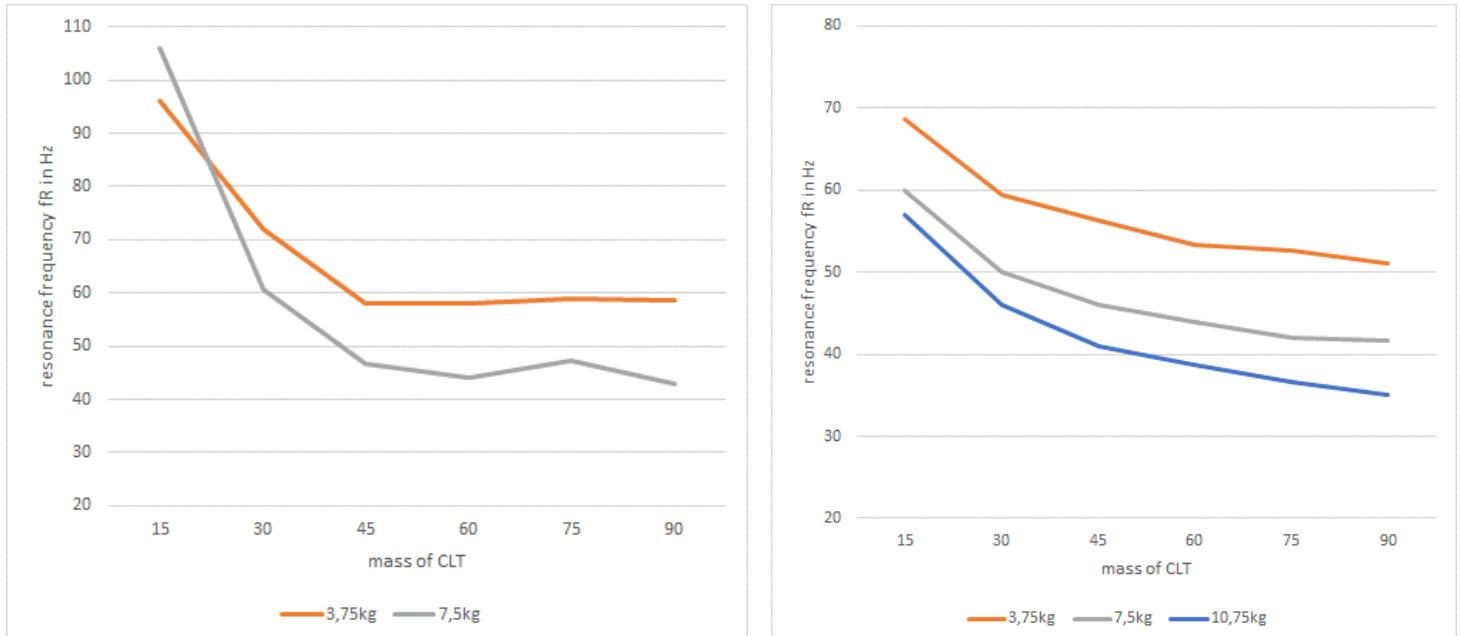

Figure 5. fR of concrete representing the mass of different plasterboards connected with CLT $100 \mathrm{~mm}$ with vertical distance of hangers of $800 \mathrm{~mm}$ and hangers without resilient layer (left). Hangers with resilient layer (right).

The $10 \mathrm{~kg}$ situation without resilient layer (2 concrete paving slabs on the sending side) seems to be an outlier. This can be originated in a mistake in the test setting. Therefore, it does not appear in the left hand chart of Figure 5.

\section{Sound pressure measurements with subsequent FFT (1 Hz steps) in the lab}

The resulting time signal from the sound pressure measurements is converted into the frequency spectrum by FFT analyses. Results are gathered from the same extensive variation of materials as in the 1:1 mock up. Only a small extract can be shown and discussed in this paper. Figure 6 shows exemplarily results for the situation with $50 \mathrm{~mm}$ plasterboard and the one with $100 \mathrm{~mm}$ gap between CLT and plasterboard and double layer plasterboard as well as the plain CLT slab. It is always indicated the $1 / 3$ octave band result, starting from $50 \mathrm{~Hz}$, and the one in $1 \mathrm{~Hz}$ steps, starting from $20 \mathrm{~Hz}$. 
The three, for the low frequency range relevant modes at 68,136 and $200 \mathrm{~Hz}$ are marked in Figure 6 with "M" as well as the resonance frequencies, indicated with arrows. These modes can be detected in the results of the structural reverberation time of the CLT slab, installed into the concrete frame of the transmission suite, as well. Measurements in $1 \mathrm{~Hz}$ steps reveal that these modes of the CLT slab and their insufficient covering by the facing layers seem to be reliable for the minor sound insulation in the lower frequency range as well as the position of the resonance frequency.

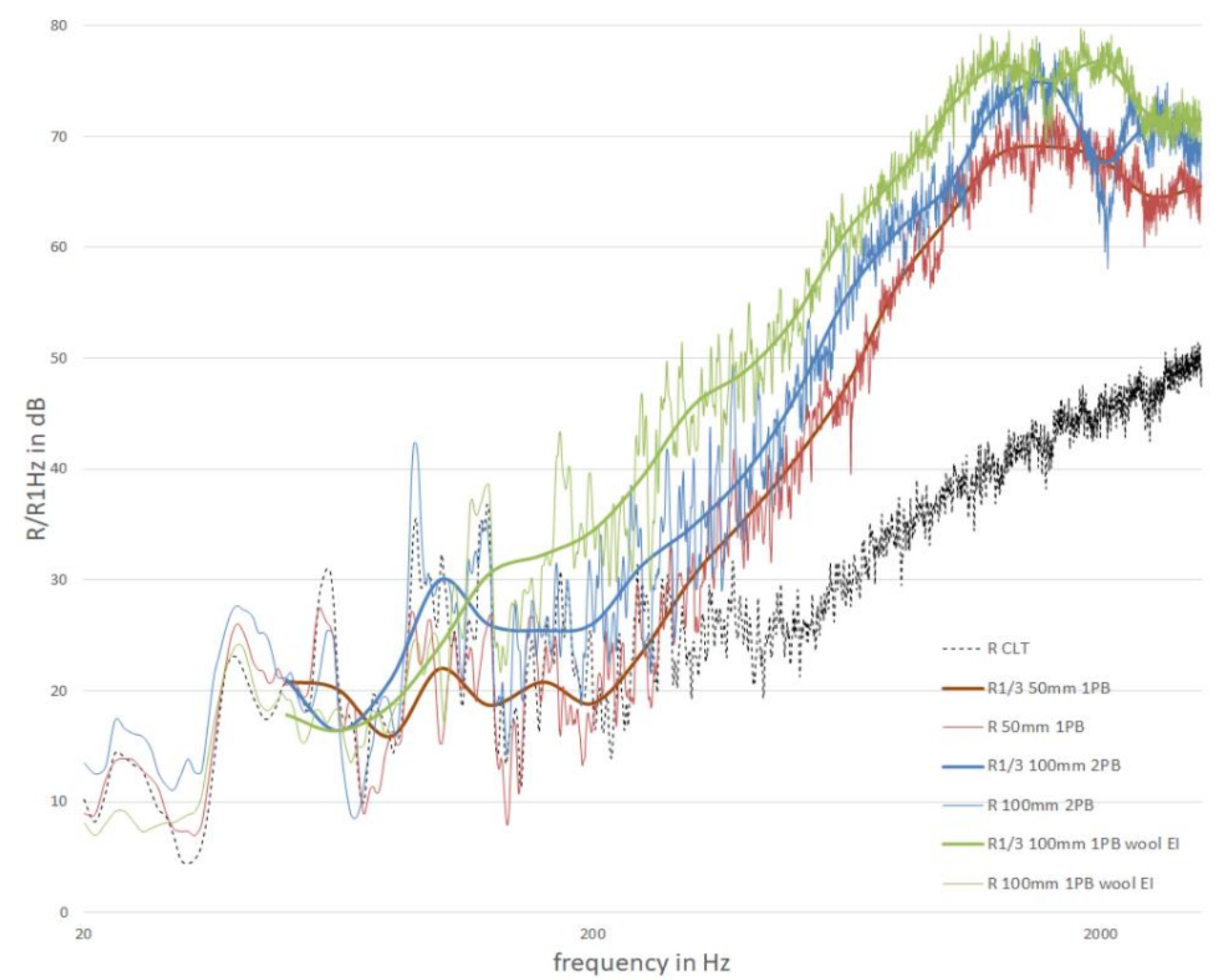

Figure 6. Sound reduction index R and R1Hz for CLT (black) and CLT + plasterboard (PB) - $50 \mathrm{~mm}$ gap in red, 100 $\mathrm{mm}$ and $2 \mathrm{~PB}$ in blue and in green results for CLT $+1 \mathrm{~PB}$ with hangers with resilient material (EI) and mineral wool (wool). Resonance frequencies are indicated with arrows and eigenmodes of the CLT slab with "M".

\section{Summary and Conclusions}

It seems to be obvious that the usually applied facing layers do not cover the resonant modes of the CLT slab. At least in these two modes, the plasterboard oscillates jointly, instead. This effect has already been described by Josse (1964) who states that, below the resonance frequency, the two layers of a double wall oscillate as a single plate with the mass of both layers. Dependent on the size of the gap and the decoupling with or without resonant material, higher modes can be concerned as well. This decoupling begins with the frequency of the kink, when the $18 \mathrm{~dB}$ increase, as stated in Sharp (1978) and indicated as resonance frequency, starts. This confirms also the finding of Rabold (2010) that the $18 \mathrm{~dB}$ increase is only developed, if the first eigenmode of the CLT slab is below the resonance frequency.

This leads to the conclusion that for an efficient sound insulation in the low building acoustic frequency range, the system has to be detuned in a more intense way with higher differences of the oscillating masses or a spring with minor stiffness properties. 
Data from the other test setups already has been generated, but still has to be analysed and needs to be interpreted and integrated into the whole picture.

Furthermore, already promising results have been generated from the self developed digital method with MEMs (surface micromachined capacitive accelerometers), but repeatability of the measurements still is not satisfying, so work still has to continue.

\section{Acknowledgements}

The author gratefully acknowledge Stora Enso Wood Products Austria and Knauf GmbH for financing and supporting the project with knowledge, material and equipment. Furthermore sincere thanks to the TGM acoustic measurement team who carried out the sound measurements in their transmission suite at Akustik Center Austria in the usual comprehensive way.

\section{References}

Rabold A, Schödel B, Schanda U (2019) Schalltechnische Optimierung von Unterdeckenabhängern. Proceedings DAGA, Rostock

Hopkins C (2007) Sound Insulation. Elsevier Ltd.

Josse R, Lamure J (1964) Transmission du son par une paroi simple. Acustica 14: 266-280.

Sharp B H (1978) Prediction methods for the sound transmission of building elements. Noise control Engineering Journal 11: 53-63.

Rabold A, Wissel C, Schanda U, Hessinger J (2010) Prognose der Schalldämmung von leichten Trennwänden. Proceedings DAGA, Berlin

Biography 


\title{
A Knowledge Management System to Support the US Cross Laminated Timber Industry
}

\author{
Omar Espinoza, University of Minnesota, USA \\ espinoza@umn.edu. \\ Ed Thomas. US Forest Service, USA \\ ed.thomas2@usda.gov \\ Urs Buehlmann, Virginia Tech, USA \\ buehlmann@gmail.com \\ Rahul Bora, Dell, USA \\ rahul.bora@dell.com
}

\begin{abstract}
Cross Laminated Timber (CLT) is a product that offers numerous benefits, including a lighter environmental footprint, structural simplicity, and design versatility. Due to these advantages, the CLT industry is growing rapidly. However, CLT also faces challenges such as, for example, low levels of awareness among construction professionals or difficulties with building code compliance. To overcome such challenges, the number of research projects concerning the use of CLT as a building material has increased dramatically during the last few year and with it the number of people involved in CLT production, use and research. For the market success of CLT, a product in the early stages of market adoption, it is critically important for stakeholders (i.e., researchers, manufacturers, design/construction professionals, developers, government agencies, and the public in general) to have access to knowledge about past, present, and future research pertaining to CLT in the U.S. and the world. The ultimate goal of this project is to help sustain and improve the health of U.S. forests while supporting the forest products industry. The main objective of this research was to build and maintain a self-updating and user-focused Knowledge Management System (KMS) for research and market information for Cross Laminated Timber (CLT). Currently, the resulting CLT KMS has over 2,800 records with more added continuously - including peer-reviewed journal articles, conference papers, reports, theses and dissertations, news and magazine articles, and others. The information is categorized into 20 topics, including seismic, mechanical, and fire, performance, tall buildings, and others. The creation of an easily accessible, free knowledge database fosters collaboration between parties, prevents duplication of efforts, raises awareness, and reassures investors and construction professionals about the merits of CLT-based construction projects.
\end{abstract}

Biography 


\title{
Recovered Wood as Raw Material for Structural Timber Products. Characteristics, Situation and Study Cases: Ireland and Spain
}

\author{
Daniel F. Llana1,2*-Guillermo Íñiguez-González1,2-Marina de Arana-Fernándezı \\ -Caitríona Uí Chúláinz-Annette M. Hartez
}

1 Department of Foresty and Enviromental Engineering and Management, MONTES (School of Forest Engineering and Natural Resources), Universidad

Politécnica de Madrid, Madrid, Spain

danielfllana@gmail.com*

guillermo.iniguez@upm.es

m.aranafer@gmail.com

2Timber Construction Research Group, Universidad Politécnica de Madrid, Madrid, Spain

3College of Science and Engineering, National University of Ireland Galway,

Galway, Ireland

caitriona.uichulain@nuigalway.ie

annette.harte@nuigalway.ie

\begin{abstract}
The circular economy is an efficient system to reuse materials reducing the amount of waste generated. In order to implement it in the timber sector, the InFutUReWood (Innovative Design for the Future - Use and Reuse of Wood (Building) Components) is a European project studying the possibilities for reuse and recycling of timber from demolition for structural applications. Nowadays in Ireland and Spain, most of the wood waste is reduced to chips. In Ireland, chips are mainly used for energy production, pallet blocks, and composting, while in Spain are used for energy production and particleboard manufacture.

Possible structural applications depend on the amount, dimensions, and condition of recovered timber. Most of the recovered timber in Ireland has medium size cross-sections, while in Spain it is mainly large cross-section. Cross laminated timber (CLT) is a good option for reuse and experimental tests are ongoing in Ireland on CLT manufactured from old timber trusses. However, for large cross-sections, direct reuse for rehabilitation works will be a more efficient use of the material.
\end{abstract}

Key words: Circular economy, classification system, construction and demolition waste, mass timber products, timber recycling, reclaimed wood, wood waste management 


\section{Introduction}

The circular economy is a sustainable system to reduce the amount of waste by reusing it as a new resource with the consequent environmental and value-added benefits. Ever increasing timber demand for construction purposes in Europe will lead to a deficiency of new timber resources in the future. Therefore, the implementation of a circular economy system in the timber sector is strongly recommended. InFutUReWood (Innovative Design for the Future - Use and Reuse of Wood (Building) Components) is a 3-year European project that focuses on the reuse and recycling of current reclaimed wood in the circular economy as structural material (InFutUReWood 2020).The National University of Ireland Galway (NUIG) from Ireland and the Universidad Politécnica de Madrid (UPM) from Spain are two of the eight European institutional partners of the project.

The Construction and Demolition (C\&D) sector creates a large amount of wood waste, generally now used for energy recovery and wood panel production (Irle et al. 2015). Much of that wood could be salvaged to be reused or recycled for structural purposes. Potential end-use structural applications include high quality Engineered Wood Products (EWP) such as Glue-laminated (Glulam) timber, solid wood panels and Cross Laminated Timber (CLT) (Hafner et al. 2014). Previous tests on CLT from recovered timber showed higher stiffness capacity and lower strength than CLT from new sawn timber (Rose et al. 2018). However, this was a small scale study and it doesn't appear to taken into account the natural variability of timber quality. The CaReWood project studied the possibilities to recycle recovered wood in laminated products (Irle et al. 2019).

In the present work, the term "recovered timber" includes structural and sawn timber from demolition, while "recovered wood" includes recovered timber, plus doors, windows, door and window frames, furniture, pallets, and packaging. Finally, "wood" also includes carpentry waste, forest pruning and thinning.

The main objective of this paper is to show the particularities of the current situation of recovered wood in Ireland and Spain and to explore structural applications for recovered timber.

\section{Current situation of recovered wood in Ireland and Spain}

The information presented from Ireland and Spain was mainly obtained by surveys, interviews and technical visits to demolition companies and wood waste management facilities.

Most recovered timber in Ireland comprises medium size cross-section timber (Fig. 1a) including joists and roof rafters from buildings from the 1960s-70s. The timber is usually sourced from the roof structure. Building typologies at that time were mainly composed of concrete structures with roof timber trusses. 


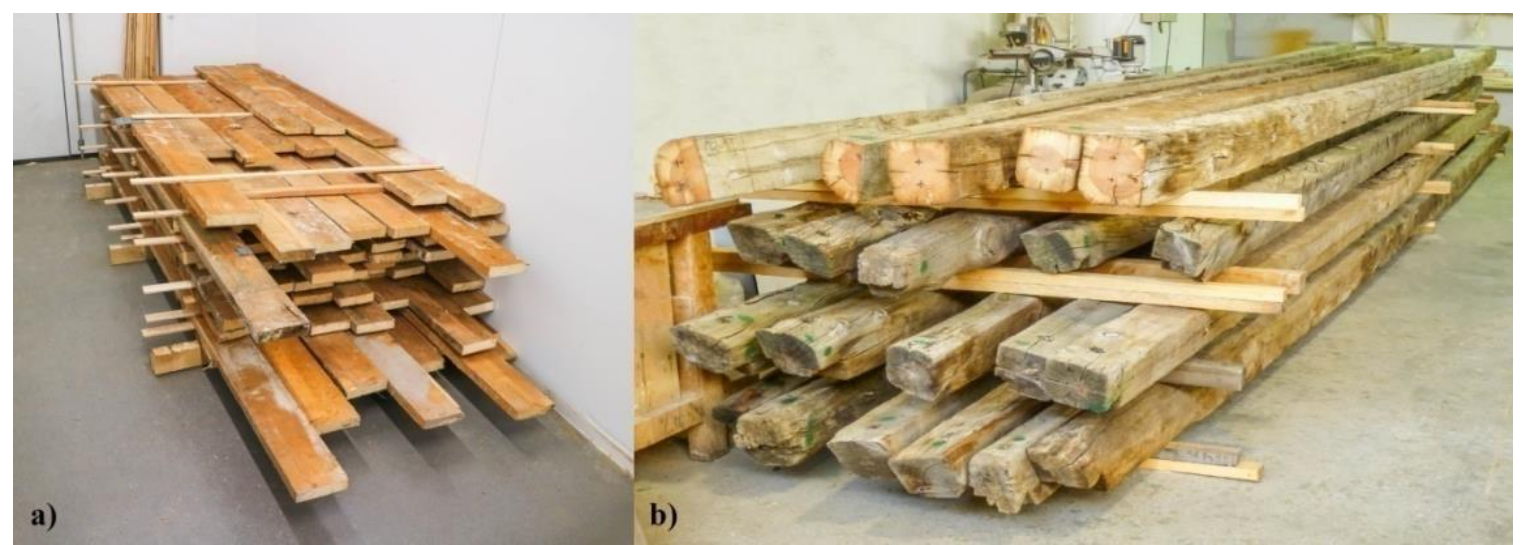

Figure 1. Recovered timber a) from Ireland, b) from Spain

Irish demolition companies remove timber in the easiest and cheapest way as there is not an established market in Ireland for long and good quality recovered timber pieces. Some companies segregate the timber in-situ in order to reduce skip cost, but most of the recovered timber arrives in the waste management facilities mixed with other materials. A very small amount of wood waste goes to landfill.

Recovered wood is managed in wood waste facilities where it is segregated and reduced to chips, $60 \mathrm{~mm}$ size or smaller. This includes timber from demolition, furniture, broken pallets, and packaging. The end-uses for the chips include energy production (exported to the UK), the manufacture of pallet blocks, composting, animal bedding, garden mulch, and playground surfacing. A preliminary study estimates slightly more than 100,000 t per year of wood waste is processed into chips. Furthermore, some companies use wood waste as boiler fuel.

The classification system for wood waste used in Ireland is dependent on whether it is to be exported or used locally. If the wood waste is to be exported to the UK, a classification system developed by Wood Recyclers' Association in 2009 and published as an informative annex in PAS 111 (2012) is used (Table 1). However, if the final use is in Ireland, the European classification system (OJEU 2018), implemented by the Irish Environmental Protection Agency (EPA 2018), is used (Table 2).

Table 1: UK wood waste classification system according to annex A of PAS 111 (2012)

\begin{tabular}{|l|l|}
\hline Grade & \multicolumn{1}{c|}{ Materials } \\
\hline A & $\begin{array}{l}\text { Solid wood, pallets, packing cases and cable drums } \\
\text { Untreated }\end{array}$ \\
\hline B & $\begin{array}{l}\text { Grade A plus building and demolition materials and furniture made from solid wood } \\
\text { Limits on treated and coated materials }\end{array}$ \\
\hline C & $\begin{array}{l}\text { Grades A and B plus panel products (chipboard, MDF, plywood, OSB and fiberboard) } \\
\text { Mix wood including painted timber and glues. Coated and treated timber }\end{array}$ \\
\hline D* & $\begin{array}{l}\text { Hazardous material (fencing, transmission poles, railway sleepers, cooling towers) } \\
\text { Treated with Copper/Chrome/Arsenic (CCA) and creosote }\end{array}$ \\
\hline $\begin{array}{l}* \text { The European Commission is concerned about the UK classification system because the amount of wood } \\
\text { waste classified as "D" hazardous is around 0.5\% of the total wood waste, while in other European countries } \\
\text { like Germany is around 15\% (Perchard 2017) }\end{array}$ \\
\hline
\end{tabular}


Table 2: European waste classification system according to OJEU (2018)

\begin{tabular}{|l|l|}
\hline $\begin{array}{c}\text { Most common } \\
\text { used codes }\end{array}$ & \multicolumn{1}{c|}{ Materials } \\
\hline 170201 & $\begin{array}{l}\text { Wood non-hazardous } \\
\text { (when wood waste is segregated in-situ, skips containing only wood) }\end{array}$ \\
\hline 170903 & $\begin{array}{l}\text { C\&D wastes containing hazardous substances } \\
\text { (mixed or segregated wood waste in the skips) }\end{array}$ \\
\hline 170904 & $\begin{array}{l}\text { Mixed C\&D wastes non-hazardous } \\
\text { (when wood waste is mixed in the skips with other materials) }\end{array}$ \\
\hline 191206 & Wood containing hazardous substances \\
\hline 191207 & $\begin{array}{l}\text { Wood other than that mentioned in 191206 } \\
\text { (this code is assigned to 170201 skips arriving at waste management facilities } \\
\text { or is assigned to wood from 170904 skips after it is segregated from other } \\
\text { materials in the facilities) }\end{array}$ \\
\hline $\begin{array}{l}\text { Codes starting with 17 are assigned by C\&D companies when skips are filled in-situ } \\
\text { Codes starting with 19 are assigned by waste management facilities for wood waste processing }\end{array}$ \\
\hline
\end{tabular}

In the case of Spain, most of the recovered timber from demolition comprises large cross-sections (Fig. 1b) from buildings over 100 years old. This is due to a scarcity of timber construction after the Spanish Civil War (1936-1939).

In general, big C\&D companies do not care about recovering timber from demolition, because there is not a consolidated recovered timber market. However, there are small C\&D companies deconstructing small buildings and also purchasing timber from big demolitions sites. These small companies reuse it for their own refurnishing works or sell it for restoration purposes. Typical markets include refurbishment of heritage buildings, carpentries for vintage furniture, and private domestic construction. The market price of large cross-section 5-meter length recovered timber from pine is approximately double the equivalent new sawn timber, because of the great amount of labour needed during deconstruction, removing nails and cleaning pieces, and the perception that old timber is of better quality than new timber due to different forest management.

A significant amount of wood is reduced to chips in wood waste management facilities for two final end-uses: energy production and particleboards. Not all processed wood is recovered wood. In the case of energy production, most of it is from pruning, thinning, or undermanaged forest. For particleboards, recovered timber, furniture from demolition, broken pallets, and carpentry waste are processed together. A small amount of demolition timber processed in the north of Spain comes from France, while the final uses are always in Spain. Furthermore, there is a well-established network to collect furniture from individual owners and packaging and this recovered wood is used in the manufacture of particleboards.

There is no national classification system for wood waste or recovered timber in Spain. Wood waste management facilities usually classify it according to the European List of Waste (OJEU 2018) (Table 2).

\section{Possible structural applications for recovered timber}

The main issue for reuse or recycling of recovered timber is its separation from other materials during demolition or in the wood waste management facility. The newer the demolished building 
the more difficult it is to segregate different materials. Buildings that are more than 100-year old have mainly large cross-section timber (heavy beams, joist, rafters...), which is easy to segregate. Modern buildings (from the 1950s) have a lot of nails and glue in the timber members.

Important also is the quantity of recovered timber, its dimensions and condition. As a preliminary estimation from a 5-storey building in an Irish urban area from the 1960s (timber mainly in the roof), around $30 \mathrm{t}$ of wood were recovered (including furniture and doors). In the case of Spain, a 5 -storey building in an urban area from the 1890s (large cross-section timber) around 120t of timber were recovered (only sawn timber).

The end-uses of reclaimed structural timber are determined by the timber length and the crosssection of the recovered timber together with the structural capacity.

Medium size cross-section timber is suitable for EWP manufacturing. Timber trusses (commonly available in Ireland) provide similar cross-sections to boards used for CLT panels and the amount of waste generated during manufacturing will be minimum. In this case, medium length pieces (circa $2 \mathrm{~m}$ ) are suitable as finger joints can be used. A testing program of CLT panels from recovered timber is currently ongoing in the NUIG laboratories (Fig. 2).

Large cross-section timber (commonly available in Spain) can be also used for CLT panels, however, a reduction of the section to CLT board dimensions implies a significant amount of wood waste and energy consumption and restricts a possible further life of the timber following the cascading principle of sequential reuse (Sirkin and Houten 1994). Therefore, it is deemed better to reuse it in restoration works on heritage buildings where long recovered timber pieces are available (more than $5 \mathrm{~m}$ length).

Furthermore, in renovation works, mainly due to energy efficiency regulations, roof decking boards are usually removed. Sometimes, floor boards are also removed. The common thickness of these planks is $25 \mathrm{~mm}$, so, this recovered timber could be suitable for EWP.

Demolition techniques should be adapted in order to maximize the yield of good condition and length of recovered timber for the potential uses described above. Furthermore, the development of a classification system that combines non-destructive testing and visual grading for recovered wood is necessary. 


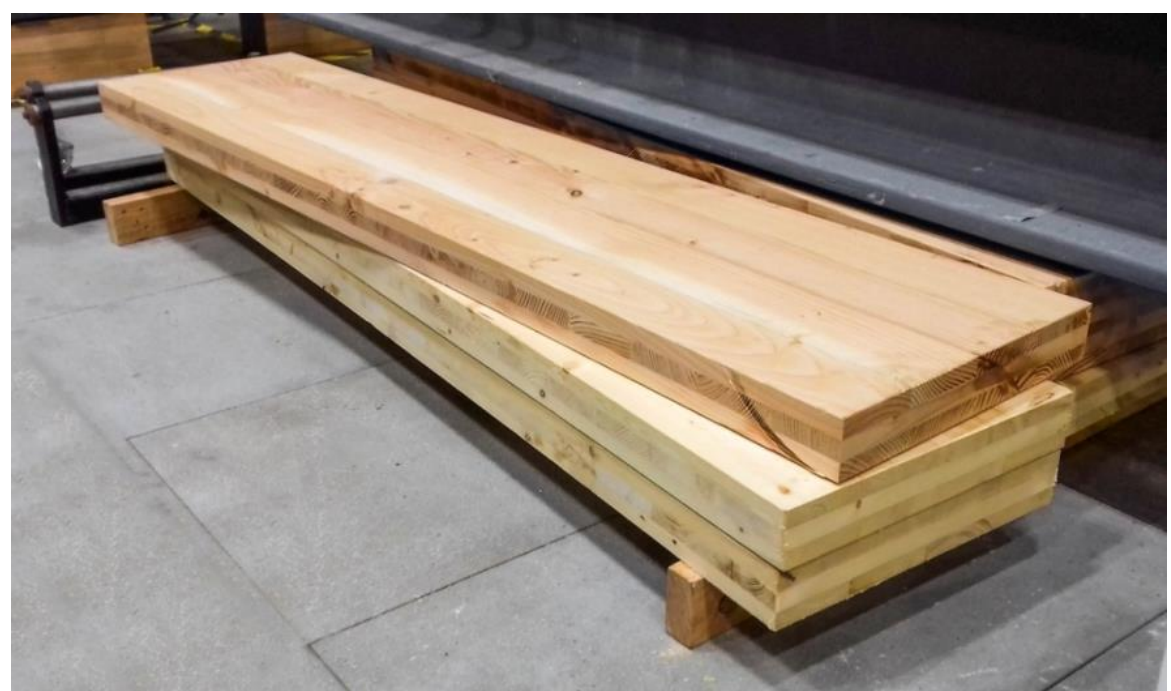

Figure 2. CLT panels from recovered timber in the NUIG laboratory

\section{Summary and Conclusions}

Circular economy implementation in the timber sector is necessary. InFutUReWood, including institutional partners from Ireland and Spain, is a European project that focuses on the reuse and recycling of current reclaimed wood as structural material.

In Ireland, most of the recovered timber has medium size cross-section from buildings from the 1960s-70s. At present, all timber is reduced to chips mainly for use in energy production, pallet blocks manufacturing, and composting.

In Spain, most of the recovered timber has large cross-sections from structural elements salvaged from buildings more than 100 years old. Currently, a small amount is reused in construction while most of it is reduced to chips for energy production and particleboards.

The potential use of recovered timber is influenced by several factors: the segregation of timber from other materials, the amount of timber recovered, its condition and dimensions. Medium size cross-sections are suitable for CLT manufacturing, while large cross-sections are better suited for reuse in restoration and renovation works. CLT panels manufactured from recovered and new timber have been manufactured in Ireland and are soon to be tested in the NUIG laboratories.

\section{Acknowledgements}

ProjectInFutUReWood is funded in Spain by the Ministerio de Ciencia, Innovación y Universidades (MICIU). Project reference PCI2019-103544. Diseño innovador para el futuro - uso y reutilización de componentes de edificación de madera.

Project InFutUReWood is funded in Ireland by the Department of Agriculture, Food and the Marine under the DAFM research funding program. Project reference 18CENForestValue1. 
Proceedings of the 2020 Society of Wood Science and Technology International Convention

Project InFutUReWood is supported under the umbrella of ERA-NET Cofund Forest Value by Vinnova Sweden's Innovation Agency, Formas- Swedish Research Council for Sustainable Development, Swedish Energy Agency, the Forestry Commissioners for the UK, the Department of Agriculture, Food and the Marine for Ireland, the Ministry of the Environment for Finland, the Federal Ministry of Food and Agriculture through the Agency for Renewable Resources for Germany, the Ministry of Science, Innovation and Universities for Spain, the Ministry of Education, Science and Sport for Slovenia. Forest Value has received funding from the European Union's Horizon 2020 research and innovation programme under grant agreement $\mathrm{N}^{\circ} 773324$.

The authors would like to thank Mr. Paul Hogan from Hegarty Demolition (InFutUReWood Irish industrial partner), and demolition and waste management companies from Ireland and Spain for kindly supplying information.

\section{References}

EPA (2018) Waste Classification. List of Waste \& Determining if Waste is Hazardous or Non-hazardous. Environmental Protection Agency. 52 p.https://www.epa.ie/pubs/reports/waste/stats/wasteclassification/ (Accessed 17.03.2020)

Hafner A, Ott S, Winter S (2014) Recycling and End-of-Life Scenarios for Timber Structures. In the book: Materials and Joints in Timber Structures, RILEM Bookseries 9, 89-98

InFutUReWood European Project website https://www.infuturewood.info/(Accessed 15.05.2020)

Irle M, Privat F, Deroubaix G, Belloncle C (2015) Intelligent recycling of solid wood. Pro Ligno 11(4):14-20

Irle M, Privat F, Couret L, Deroubaix G, Belloncle C, Déroubaix G, Bonnin E, Cathala B (2019) Advanced recycling of post-consumer solid wood and MDF, Wood Mater SciEng 14(1):1923

Official Journal of the European Union (2018) Commission notice on technical guidance on the classification of waste 2018/C 124/01. Published 9.4.2018. $134 \mathrm{p}$.

PAS 111 (2012) Specifications for the requirements and test methods for processing waste wood (BSI). $32 \mathrm{p}$.

Perchard E (2017) Waste wood classification change could be "catastrophic" for UK recycling. https://resource.co/article/waste-wood-classification-change-could-be-catastrophic-uk-recycling12072 (Accessed 17.03.2020)

Rose CM, Bergsagel D, Dufresne T, Unubreme E, Lyu T, Duffour P, Stegemann JA (2018) CrossLaminated Secondary Timber: Experimental testing and modelling the effect of defects and reduced feedstock properties. Suistanability 10(11):4118

Sirkin T, Houten M ten (1994) The cascade chain. A theory and tool for achieving resource sustainability with applications for product design. Resour Conserv Recy 10(3):213-276

\section{Biography}




\title{
Connection Ductility Demand for Different Ductility Levels in Capacity Design of Multi-Storey CLT Buildings
}

\author{
Igor Gavric1* - Iztok Sustersic2 - Mislav Stepinac3
}

\author{
1 InnoRenew CoE and University of Primorska, Slovenia * Corresponding author; \\ igor.gavric@innorenew.eu \\ 2 InnoRenew $\mathrm{CoE}$ and University of Primorska, Slovenia \\ iztok.sustersic@innorenew.eu \\ 3 University of Zagreb, Croatia \\ mislav.stepinac@grad.unizg.hr
}

\begin{abstract}
Key words: cross-laminated timber, ductility, capacity design, shear walls, seismic design

Current European building codes Eurocode 8 provide no information on the ductile behaviour and failure mechanisms of cross-laminated timber (CLT) structures. Structural ductility is a key property to ensure good seismic behavior of buildings, as it allows yielding of dissipative zones along the building height which consequently reduces the seismic actions in comparison to a case of a brittle non-dissipative structure where little or no reduction of seismic actions is present. The development of a ductile global failure mechanism must be ensured by identifying the ductile connections in a suitable location within the structure and designing all the remaining connections and structural elements with sufficient overstrength in order to achieve plasticization in the ductile elements.

This study investigates the ductility demand for CLT connections in capacity design of multistorey CLT buildings for different ductility levels. To make the capacity design fully applicable for a new structural system, information and understanding of ductile failure mechanisms of this system is necessary along with the values of overstrength factors and a suitable calculation procedure which considers the capacity design principles.

Non-linear static (pushover) analyses are performed on CLT walls numerical models, with prior application of capacity design method, calibrated based on experimental data on CLT metal connections (hold-downs, angle brackets) and CLT screwed connections. To ensure sufficient deformation capacity of ductile components, variables that influence CLT walls stiffness, strength and ductility are considered in parametric analyses: wall geometry (aspect ratio), monolithic walls vs. segmented (coupled) walls, position of connections, type and number of connections, vertical load on CLT wall panels. Failure mechanisms are studied together with global ductility levels based on different local ductility levels of dissipative connections.
\end{abstract}

Biography 


\title{
Environmental Impacts and Carbon Offset of Mass Timber Construction - A Comparative Life Cycle Assessment Study
}

\author{
Marilia Hellmeister 1 \\ marilia.hellmeister@maine.edu \\ Stephen Shaler \\ shaler@maine.edu \\ Hongmei Gu2 \\ hongmeigu@usda.gov \\ Shaobo Liang2 \\ sshliang@gmail.com \\ 1 University of Maine, USA \\ 2USDA, Forest Service, Forest Products Laboratory, USA

\section{Abstract}

Anthropic actions greatly increased the normal levels of carbon in the atmosphere which had never been higher since the industrial revolution (Joshi et al. 2011). High levels of carbon dioxide in the atmosphere produce impacts such as greenhouse effect, land surface air temperature increase, biodiversity loss and food security (IPCC 2019). To maintain and adapt to the current and foreseeable climate changes, it is necessary to identify the responsible sectors to prepare and address mitigation measures in order to reduce carbon emission levels.

According to the Global Alliances for Buildings and Construction 2018 report, buildings construction and operations are accounted for over a third of the global final energy use and almost $40 \%$ of energy-related carbon emissions. It is important to state that we are considering "carbon emission" as all global warming responsible gases, and not only carbon dioxide. Being the largest contributor to the shares of energy and emissions, the building sector has the potential to lead the transition towards a more sustainable future. Choosing wood as the primary structural material over the conventional steel and concrete system conceptualizes the so-called mass timber construction process (Kremer \& Symmons 2015). Wood buildings are the best option to substitute fossil fuel-dependent materials because it is a renewable-based material, it does not only sequester carbon while growing, it also stores the sequestered carbon for the whole life cycle of the building and in the case of repurposing or reusing a wood product warrants longer life spam, storing the carbon for more years ahead.

A study by Colorado School of Mines have found evidence that CLT buildings can be more energy efficient in regions where more heating is required for user comfort, therefore the U.S northeast region presents a great potential to lead the demand for new mass timber buildings in the nation(Khavari et al. 2016). In addition to the climate advantage, the region is also favored regarding its proximity to large urban and industrial centers due to the geographical position and logistic flow modalities (Duveneck et al. 2017, Thompson et al. 2013) and has great forest regeneration potential especially in the "New England" region, composed by the six following states: Connecticut, Maine, Massachusetts, New Hampshire, Rhode Island, and Vermont.

The goal of the present report is to determine if mass timber buildings can reduce carbon emissions over their entire life cycle when compared with steel and concrete structural system. The impacts will be measured in terms of embodied carbon quantified as Global Warming Potential [kg CO2 eq] using the Life Cycle Assessment open-source software ATHENA® Impact Estimator for Buildings (IE4B). This project it provides scientific data to support the choice of sustainable and renewable building materials that can reduce carbon emissions, operational energy expenditure and consequently mitigate climate change. The increasing use of mass timber buildings will result in a growing demand for timber products, fostering the growth of regional markets and consequently promoting economic, social and environmental development, when responsibly managed.

Biography 


\title{
Proceedings of the 2020 Society of Wood Science and Technology International Convention
}

\section{VOC Emission Optimized Cross Laminated Timber}

\author{
Marko Kovacevic, Wood K Plus, Austria \\ m.kovacevic@wood-kplus.at
}

\begin{abstract}
Cross laminated timber (CLT) is one of the most popular engineered wood products. The main species used for this product is spruce. To respond to the strongly increasing demand of CLT, it will become necessary to also investigate additional raw material resources for its production. Pine - having in mind its availability, mechanical properties and ability to grow even in regions with poor growth conditions - could offer a high potential to serve as a new material for CLT in the future.

The first phase of the study comprises the characterization and quantitative evaluation of VOC emissions from spruce and pine in order to draw conclusions about the variability of VOC emissions. A comparison of kiln-dried and green wood provided a sound basis for further investigations.

Furthermore, different CLT variants were tested in order to compare their emission levels.

The second phase covers the optimization of the CLT manufacturing process regarding VOC emissions. Based on findings from the first phase, process parameters such as drying and gluing, as well as storage time were modified.

In the final project phase, long-term tests in model rooms constructed of different types of CLT are being carried out, enabling evaluate the influence of various building materials regarding indoor air quality in reality-close scenarios.

Results showed a significant influence of drying temperature and drying time on VOC-emission from pine. Additionally, the gluing step in CLT production as well as a combination of wood species (pine, spruce) used, resulted in a considerable VOC-reduction in the final product.

Biography
\end{abstract}




\title{
What is the Best Timber for Construction? Available Forest Resources, Mechanical Efficiency, Carbon Storage
}

\author{
Jean-Michel Leban, INRAE, France \\ jean-michel.leban@inra.fr \\ Gilles Duchanois, Ecole Nationale Supérieure d'Architecture de Nancy, France \\ gilles.duchanois@archi.nancy.fr \\ Jean-Denis Lanvin, FCBA, France \\ jean-denis.lanvin@fcba.fr
}

\begin{abstract}
The wooden products are used since centuries by human being for construction purposes. During the last decades grading rules have been established in order to sort the timber on the basis of estimates of its structural properties such as the modulus of rupture and the modulus of elasticity. For softwoods that are commonly used for construction, these estimates or proxies are the wood density, the knot size and the ring width. The timber structural properties are known to vary with these proxies. For instance, the modulus of elasticity of Norway spruce wood can vary from 4000 Mpa until 20000 Mpa when wood density varies from $300 \mathrm{~kg} / \mathrm{m} 3$ up to $550 \mathrm{~kg} / \mathrm{m} 3$. Similar ratio of variation can be observed for the modulus of rupture.

Therefore, when architects and engineers are dimensioning wooden structures they need to define the geometry of the wooden structure, identify the levels of loads to be supported and, given a grading class of wood properties, they compute the sections of the different timber sections to be used for building the wooden structure. More recently there is an increasing interest of both (i) increasing the use of wood in the construction sector and (ii) maximize the amount of carbon stored in the wooden buildings, knowing that the carbon content of wood is $50 \%$ of the dry mass. In this context the question that arises is: what are the timber mechanical properties that (i) minimizes the amount of carbon removed from the forests stands when harvesting the trees for producing timber, (ii) maximize the amount of carbon stored into a wooden structure, and of course (iii) fulfils the mechanical constructions codes.
\end{abstract}

For answering these questions we will consider wooden roof trusses built with Norway spruce by comparing two contrasted solutions, the first being the use of fast growing trees with low wood density and low mechanical properties, i.e. with higher timber sections (trees from plantations with rotation age of 30 years), the second being the use of high wood density timber from slow growing trees and high mechanical properties, i.e. with lower timber sections (trees from plantations with rotation age of 60 years). Considering the whole forestry wood chain by the mean of models from the tree growth until the wooden roof trusses will permit to better quantify the best mechanical range of properties that minimize the amount of carbon removed from the forests and maximize the carbon storage in the construction sector.

References

Leban, J. M., \& Haines, D. W. (1999). The modulus of elasticity of hybrid larch predicted by density, rings per centimeter, and age. Wood and Fiber Science, 31, 394-402.

Ramage, M. H., Burridge, H., Busse-wicher, M., Fereday, G., Reynolds, T., Shah, D. U., Scherman, O. (2017). The wood from the trees : The use of timber in construction. Renewable and Sustainable Energy Reviews, 68(October 2016), 333-359.

https://doi.org/10.1016/j.rser.2016.09.107

\section{Biography}




\title{
Comparative Assessment of Energy Efficiency and Environmental Impact between Bamboo and Polyvinyl Chloride-based Packing in Cooling Towers
}

\author{
Xinxin $\mathrm{Ma}$ \\ Dept of Biomaterials, International Center for Bamboo and Rattan China \\ maxx@icbr.ac.cn
}

\begin{abstract}
Bamboo can be used to perfectly replace for many traditional construction materials owning to its numerous physical, mechanical and environmental advantages. The increased environmental concerns in the world has caused high demand for different bamboo products. In this study, the bamboo-based packing were utilized to replace traditional polyvinyl chloride (PVC)-based packing in cooling towers. The cooling capacity, energy efficiency and environmental impact of bamboo packing were evaluated. The energy efficiency and environmental impact of bamboo packing were studied and compared with the PVC packing through life cycle assessment (LCA) in terms of the cumulative energy demand (CED) and the technology of Building for Environmental and Economic Sustainability (BEES). The results showed that the thermal performance of the PVC packing was better than that of the bamboo grid packing. The resistance characteristic of the bamboo grid packing was better than that of the PVC packing. In a real thermal power generation practice (Dongfeng Motor Thermal Power Plant in Hubei, China), the total saving of standard coal was about 540t in six months after using the bamboo grid packing. The LCA results indicated that the utilization of bamboo-based packing to replace PVC packing in cooling towers reduced total CED from $3420 \mathrm{MJ}$ to $561 \mathrm{MJ}$ per functional unit, counting a reduction of 6.10 times. The major environmental impacts (BEES indices), i.e., the total Global warming potential, Acidification, $\mathrm{HH}$-cancer, $\mathrm{HH}$-noncancer, $\mathrm{HH}$ criteria air pollutants, Eutrophication and Smog, were reduced by 1.48-10.52 times.
\end{abstract}

Biography 


\title{
Monitoring Mass Timber Buildings: A Case Study of the InnoRenew CoE Building
}

\author{
Eva Prelovšek Niemelä ${ }^{1}$ \\ eva.prelovsek@innorenew.eu AArne N \\ Aarne Niemelä ${ }^{1}$ \\ aarne.niemela@innorenew.eu \\ Andreja Kutnar2 \\ andreja.kutnar@innorenew.eu \\ Anna Sandak2 \\ anna.sandak@innorenew.eu \\ Jan Vcelak3 \\ jan.vcelak@cvut.cz \\ Jakub Sandak2 \\ jakub.sandak@innorenew.eu \\ Iztok Sustersic2 \\ iztok.sustersic@innorenew.eu \\ 1 Innorenew CoE \\ 2 InnoRenew CoE \& University of Primorska \\ 3 Innorenew CoE \& Czech Technical University in Prague, UCEEB
}

\begin{abstract}
The increased demand for mass timber and the increased use of timber in facades has led to new innovative solutions and applications in architecture. The new InnoRenew CoE building applies some of these innovations. To verify how timber structures and exposed timber surfaces behave in the long term, it is necessary to collect long-term data in-situ. The institute's buildings $(8,200 \mathrm{~m} 2)$ that are currently under construction in Izola, Slovenia, will consist of a hybrid of timber, concrete, and steel structure. The upper part of the complex (1st-3rd floors) will be completely made of mass timber, mainly Cross Laminated Timber (CLT). The building will be equipped with an expansive monitoring system during and after construction. The main goal of monitoring is to provide insight into timber performance and ageing in the long term. This will allow comparing the actual behaviour to mathematical models and will facilitate improved construction with wood in the future.

The building is designed with different materials on each façade (stone, plaster, wooden ventilated façade, wooden lamellas), and with various separated volumes and architectural shapes (arcades, covered balconies, small atriums) that will create diverse microclimatic conditions. The diversity of architecture makes it possible to assess a wide range of parameters that influence the long-term appearance and performance of the measured façades. These parameters are temperature, relative humidity, illumination, wind speed, and dust (particulate matter). Additional monitored parameters include the hygrothermal attributes of several façade layers (stone and wooden façade) on mass timber walls and of roof layers (balconies, green roof) on mass timber roof structures.

A prototype sensor for determining the ageing dynamics of a building's exterior elements and its facade will be installed in various locations. The sensor allows detailed monitoring microclimate affecting materials in different positions on and in the building, including all exposure sides and different shading configurations. The collected data will be used to improve dose-response models for
\end{abstract}




\section{Proceedings of the 2020 Society of Wood Science and Technology International Convention}

the determination of appearance changes along the building's service-life. The same data will be used to validate Finite Element (FE) simulation tools used for the building's design. The appearance of the building will be continuously monitored by high-resolution colour and thermal vision cameras installed in selected spots around the building.

Structural monitoring of the building will be performed with accelerometers at the roof level, in the middle of the largest plate spans, with LVDTs at the corner and middle of selected CLT walls and at selected support points. Global and local vibrations of the building will be evaluated in terms of seismic safety and the wind serviceability evaluation of mass timber buildings.

Keywords: sustainable architecture, mass timber buildings, CLT, structural monitoring, hygrothermal monitoring, timber façade, microclimate

\section{Acknowledgements}

The authors acknowledge the European Commission for funding InnoRenew CoE (grant agreement \# 739574), under the H2020 Widespread-Teaming programme and Republic of Slovenia (investment funding of the Republic of Slovenia and the European Union's European Regional Development Fund).

\section{Biography}




\title{
The case for mass timber tall buildings using a net zero carbon framework
}

\author{
Azzeddine Oudjehane \\ SAIT - Southern Alberta Institute of Technology \\ Azzeddine.oudjehane@sait.ca
}

\begin{abstract}
The recent introduction of CLT - cross laminated timber in North America has been followed by a surge in projects for tall wood mass buildings. Hence, wood mass timber construction in North America is expected to grow with the recent surge in the manufacturing of Cross Laminated Timber (CLT) accompanied with changes to the International Building Code.

In North America, the use of wood products has up until recently been limited to midrise residential construction using wood frame construction. Mass timber on the other hand has the potential to become the core structure for almost every type of building, across all industry segments commercial buildings in particular.

This presentation will focus on a construction project management approach to using CLT. A 10 storey building design is considered and a 3D model is designed with two alternatives for the superstructure: reinforced concrete and CLT. Several impact analyses for energy consumption, cost, life cycle analysis and carbon impact of both alternatives are developed, and a value management approach is used to benchmark the two designs. The following learning objectives will be addressed Identify the trends for global mass timber construction

- Define the net zero carbon framework

- Review the construction methodology for tall wood mass buildings

- Identify the energy, cost and environmental impacts for a 10 storey mass timber building
\end{abstract}

\section{Introduction}

As climate change continues to grow in prominence, the carbon impact of buildings is increasingly becoming part of a global strategy to reduce the overall GHG emissions from the built environment. Indeed, emissions from buildings account for 30 to 40 percent of global carbon and GHG emissions.

Whilst much of the focus has primarily been around operational energy in the built environment, there is a growing emphasis on the significant impacts of embodied carbon - the emissions associated with earlier building life cycle stages, such as manufacturing and construction.

Hence, increasing numbers of countries, cities and organizations committing to carbon neutrality by mid-century, zero carbon buildings are finally getting the attention they deserve as a critical solution to climate change. From an innovation in construction perspective, the Zero-carbon building (ZCB) framework is also regarded as an 
innovative and important approach to reducing both carbon emissions and energy consumption.

Another trendy innovative construction approach has encompassed an increasing interest for modular construction of tall buildings using mass timber.

Hence, the past 10 years have seen numerous construction projects use mass timber engineered wood products to erect tall buildings 10 storey and up. Modern tall wood buildings are the result of the convergence of three key drivers:

- Environmental pressure to use sustainable building materials

- Tight tolerance, high-quality, low site-impact construction

- Prefabrication and short duration construction cycles

In Canada, several provinces have moved to allow for mass timber high rises up to 12 storeys. The up coming national building code changes that will come into effect in 2020, allowing for the construction of taller wood buildings up to 12 storeys an increase from the current height limit across Canada for wood buildings to 6 storeys.

Market expansion for the use of CLT in the construction of high rises, i.e. 10 storey and higher, is also dependant on changes to building regulations, standards and codes. However, most studies concur that the concern and issue revolved less about CLT's structural performance and more about its perceived flammability. Hence, to set fire safety requirements and allowable heights, areas and number of stroreys for tall mass timber buildings, the newly proposed building code to be included in the 2021 edition of the International Building Code identified three new types of construction (Wood Business 2018)

- Type IV-A: Maximum 18 stories, with gypsum wallboard on all mass timber elements.

- Type IV-B: Maximum 12 stories, with a limited area of exposed mass timber walls and ceilings allowed.

- Type IV-C: Maximum nine stories, with all exposed mass timber designed for two- hour fire resistance.

All of the above building types of construction are essentially driven by ensuring the fire rating of the building is maintained, despite the fact that CLT has a strong fire resistance through charring. Indeed pending on the panel thickness, CLT can be manufactured with fire resistance up to 90 minutes (GreenSpec.com 2018) whilst the race to build wood mass buildings taller continues as Norway hosts the tallest 18-storey wood mass building in the world at 85.4 meters (Construction Canada 2019).

To use a value engineering process for the design and construction of any project, the consideration of alternatives often compares wood and concrete for the building materials.

A case study (Mallo 2016) evaluated the economic performance of various construction systems, for a 40,000 square feet performing arts building. The study illustrated that in terms of cost of material, labour and speed of construction, a CLT walls and roof with glulam beams and wood frame system would cost up to $20 \%$ less per square foot when compared to the building system option of concrete walls, roof and light steel frame steel. Construction time for CLT systems was also estimated to last up 4 months shorter.

As mass timber is found to nearly offset all upfront embodied carbon in the building, making the case for mass timber tall buildings with a zero carbon framework as outlined 
in this shirt paper subscribes to the foundations of value analysis principles without the function analysis of a 10-storey building. A benchmark comparison of the alternative designs for a 10-storey building with concrete and a full CLT is conducted in order to evaluate the benefits of CLT from the perspective of construction project management.

\section{What is Zero Carbon Building?}

The Canada Green Building Council CaGBC defines a zero-carbon building as: "a highly energy efficient building that produces onsite, or procures, carbon-free renewable energy or high-quality carbon offsets to offset the annual carbon emissions associated with building materials and operations." Zero carbon buildings represent the industry's best opportunity for cost-effective emissions reductions that spur innovation in design, building materials and technology, creating jobs and business opportunities." From a global perspective, the International Organization for Standardisation "(ISO) 16745 framework provides a set of methods to calculate, report, communicate and verify carbon metrics for emissions arising from the measured energy use during the activity of an existing building. The simplicity of its approach means it is applicable at all scales, from cities and building portfolios to individual buildings".

Within the ZCB (zero carbon building) framework, the measurement of the building's actual impact is measured by 3 factors related to $\mathrm{CO}$ emissions: embodied carbon, operation carbon and offset carbon.

Hence:

- Embodied carbon of buildings refers to the GHG emissions associated with the manufacturing, maintenance, and decommissioning of a structure. It is directly associated with the building materials.

- Operational carbon of buildings is the carbon load created by the use of energy to heat, cool and power a building

- Offset carbon is a reduction in emissions of carbon dioxide or other greenhouse gases made in order to compensate for emissions made elsewhere

The first component of the Zero Carbon Balance is the quantification of the embodied carbon, which is the emissions from the manufacturing, transport, installation, use, and end of life of building materials.

Embodied carbon emissions represent approximately 11 per cent of all energy-related carbon emissions globally. Furthermore, emissions that occur during the production and construction phases, referred to as upfront carbon, are already released into the atmosphere before the building is operational or the retrofit is complete. Given the timeframe for meaningful climate action is shrinking, there is a growing awareness of the critical importance of addressing embodied carbon.

To account for emissions through the life cycle of building materials, embodies carbon is measured using LCA - life cycle assessments. The figure below illustrates the energy levels required for the manufacturing of various building materials including CLT. 


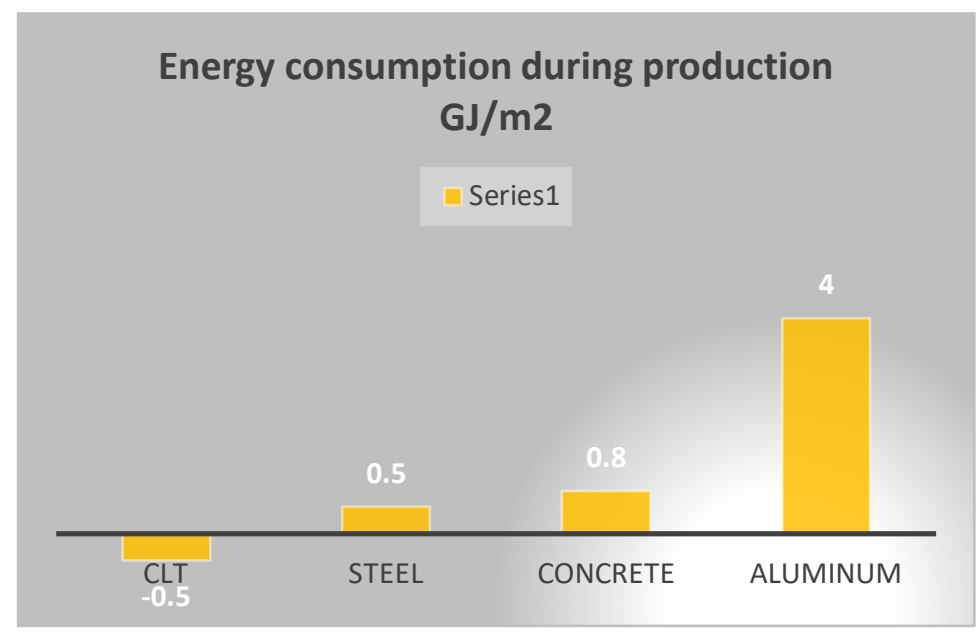

Figure. 1. Energy consumption during production in $\mathrm{GJ} / \mathrm{m} 2$

Operational carbon emissions are associated with energy use and releases of refrigerants during regular building operations. One simple method to assess the operational impact of a design would consider the energy model of the building. The first element of consideration to make the case for mass timber tall buildings in this paper will be made using a 10-storey structure for which 2 alternatives will be considered: traditional concrete with steel and a mass timber construction system using CLT

\section{The Construction of mass timber tall buildings}

There is currently a widespread enthusiasm for mass timber as a building material. Around the world, designers are leveraging the strength, stability, and design flexibility of engineered products (EWPs) such as cross-laminated timber (CLT) and glue laminated timber to push beyond wood's perceived boundaries, achieving building heights and spans that would have once required concrete, steel, or masonry for structural support.

In North America, the residential market for structural framing and sheathing is mainly dominated by wood products such as dimensional lumber, plywood, OSB, defining light wood frame construction. In Canada, up until 2015, light frame construction was limited to mid rise buildings up to 6 storey.

Mass timber construction systems on the other hand are a complement to light woodframe and post-and-beam construction. As shown in Fig.2, MTC - mass timber construction framing systems use solid wood panels as wall, floor and roof elements. 


\section{LIGHT WOOD-FRAME POST + BEAM}

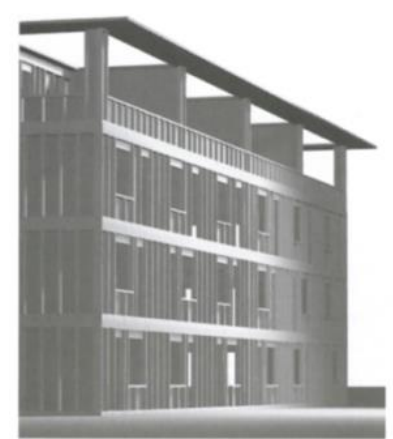

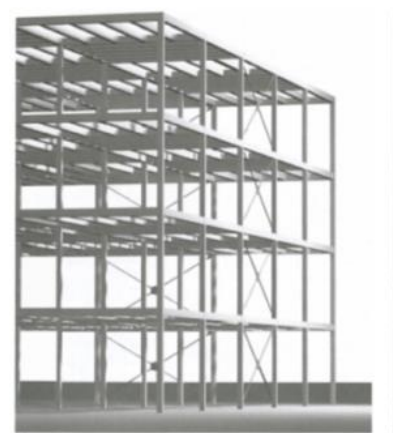

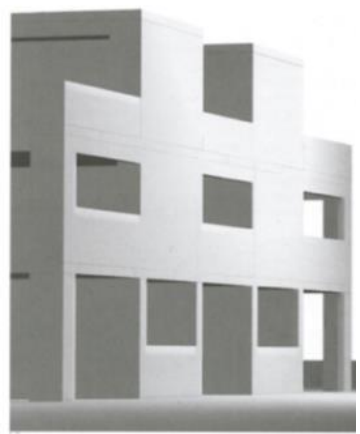

Figure. 2. Three wood building construction systems (WW-WSP 12)

Amongst the wood products used for MTC systems, Cross laminated timber CLT is the most recent engineered wood product to enter the construction market in Canada and the US. Up until the construction of what was the tallest wood mass building in the world, Brock Commons building at the University of BC (NaturallyWood 2017), CLT applications in Canada were limited to heavy duty platform oil rigs and some showcase demo buildings. (NRCan 2019). According to the definition by the American Panel Association - APA: "A CLT panel consists of several layers of kiln- dried lumber boards stacked in alternating directions, bonded with structural adhesives, and pressed to form a solid, straight, rectangular panel.

CLT panels consist of an odd number of layers (usually, three to seven,) and may be sanded before shipping. While at the mill, CLT panels are cut to size, including door and window openings, with state-of- the art CNC (Computer Numerical Controlled) routers, capable of making complex cuts with high precision. Finished CLT pan el s are exceptionally stiff, strong, and stable, handling load transfer on all sides."(APA 2016). CLT panels be produced in large sizes (up to 0.5 metres (18") thick, 4 metres (12') wide and 24 metres (72') long) into which door, window and service openings can be machined. An odd number of layers is normally used (to decrease warping), and nails or screws may be used for added strength. Alternatives to CLT include a variety of other panels such as NLT - Nail laminated timber or DLT - dowel laminated timber.

Because of its strength and dimensional stability, mass timber offers a low-carbon alternative to steel, concrete, and masonry for many applications. With a very high strength to weight ratio particularly compared to concrete, MTC can be used in conjunction with other wood systems such as post-and- beam, or in hybrid structures with steel or concrete. On the other hand, mass timber is not necessarily a good alternative to light wood-frame construction systems because dimension lumber framing provides a compelling combination of performance and cost where permitted by code. In fact, building types where traditionally designers typically default to forms of construction other than light wood-frame, including offices, public/institutional buildings, schools, and taller mixed-use occupancies, may offer greater appeal and suitability for 
mass timber than low- rise commercial or residential building. This paper however will only address the case of a 10-storey residential building.

\section{The 10-storey building framework}

For the purpose of this case study, the following performance properties were used (StructurLam 2017)

- CLT Wall panels

- Density: $485 \mathrm{~kg} / \mathrm{m3}(\mathrm{SPF})$

- SpecificHeat Capacity: $1.6 \mathrm{~kJ} / \mathrm{kg} \mathrm{K}$ (dependent on moisture content)

o Thermal Conductivity: RSI Value: 0.84 per $100 \mathrm{~mm}(\mathrm{~K} \cdot \mathrm{m} 2 / \mathrm{W})$,

$\circ \quad \mathrm{R}$ Value: 1.2 per inch $\left(\mathrm{h} \cdot \mathrm{ft} 2 \cdot{ }^{\circ} \mathrm{F} / \mathrm{Btu}\right)$

To convert from $\left(B T U^{*}\right.$ in $) /\left(\mathrm{hr}^{*} \mathrm{ft} 2{ }^{*} \mathrm{~F}\right)$ to $\mathrm{W} /\left(\mathrm{m}^{*} \mathrm{~K}\right)$ value must divide by $6.933 \mathrm{o}(1.2 / 6.933)$ $=0.17307$ per inch of thickness

$\circ$ Exterior wall thermal conductivity $=0.17307^{\star} 18=3.115 \mathrm{~W} /\left(\mathrm{m}^{\star} \mathrm{K}\right)$

$\circ$ Interior wall thermal conductivity $=0.17307^{*} 6=1.0384$

- CLT Floors panels

- Same thickness acting as two way systems.

- Deflection integrated in long term creep factors associated with wood

- design in Canadian design standards.

The 3D design for the 10-storey building is shown below with the 2 alternatives for the super- structure consisting of either reinforced concrete or CLT floors and walls raised over foundations.
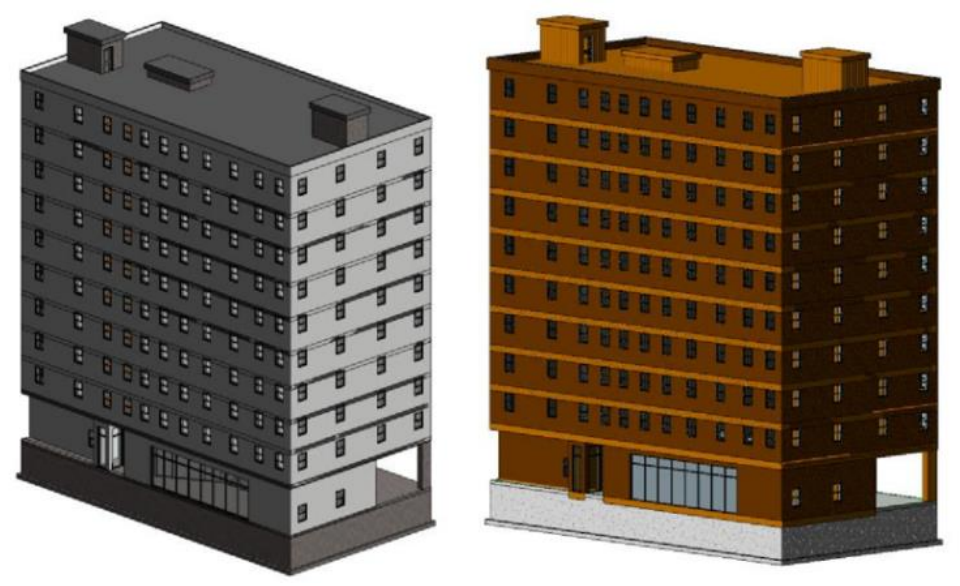

Figure 3. Two alternatives for design: Concrete (left) and CLT (right).

In order to undertake a benchmark study, an old existing low income housing 10-storey building was used for this case study. One basic design was made on Autodesk REVIT and the instance properties for materials were then altered afterwards. This allowed for an identical building to be analyzed using the different alternatives of building materials. Below is some basic information about which building material is used for each specific model. Given the emphasis on the superstructure, the building envelope, cladding, the accessories and glazing in this building were identical. Figure 3 illustrates the 2 main alternatives discussed in this paper: one using concrete and steel frame walls; one 
using CLT over concrete foundation.In this paper, two types of superstructures of the 10-storey building will be emphasized: full CLT and concrete with steel frame interior walls.

\section{Cost and Energy performance comparison}

Cost performance of each building alternative was estimated on the basis of quantity take-off obtained from the REVIT 3D models.. For most material prices, an average unit price of the material was used. Labour costs were normalized to Alberta's average labor rates assuming the mobilization of just 1 crane and a crew of 10 specialized trades for CLT assembly. As a result, and despite the high premium cost of the CLT panels in addition to transportation from the closest plant, the unit price construction costs for a

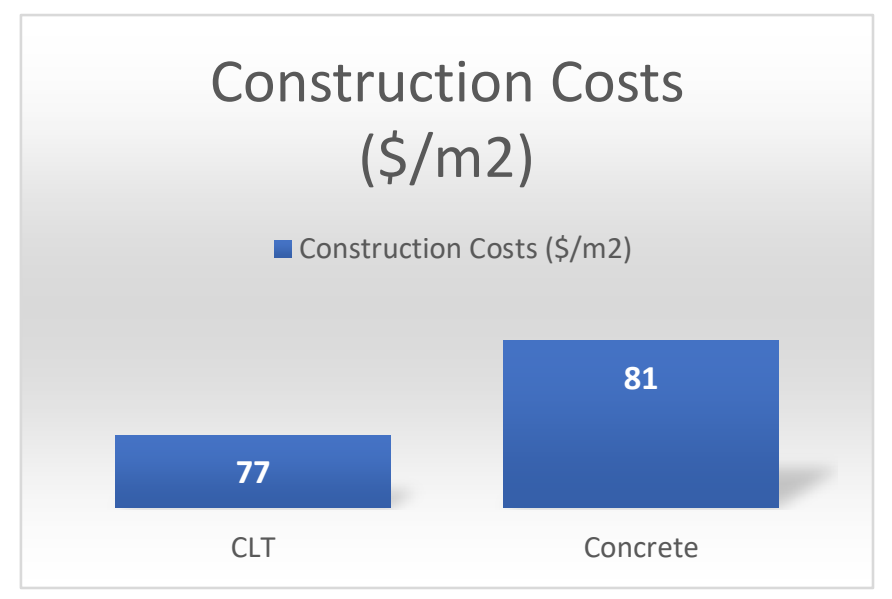

10-storey CLT building were 5\% lower

Figure 4. Unit price construction costs for a 10-storey building CLT vs. Concrete

Costs for the concrete building primarily because the CLT alternative did not include drywall to increase the fire rating. The charts below illustrated the cost breakdown estimated on the basis of material takeooff and associated labor costs.
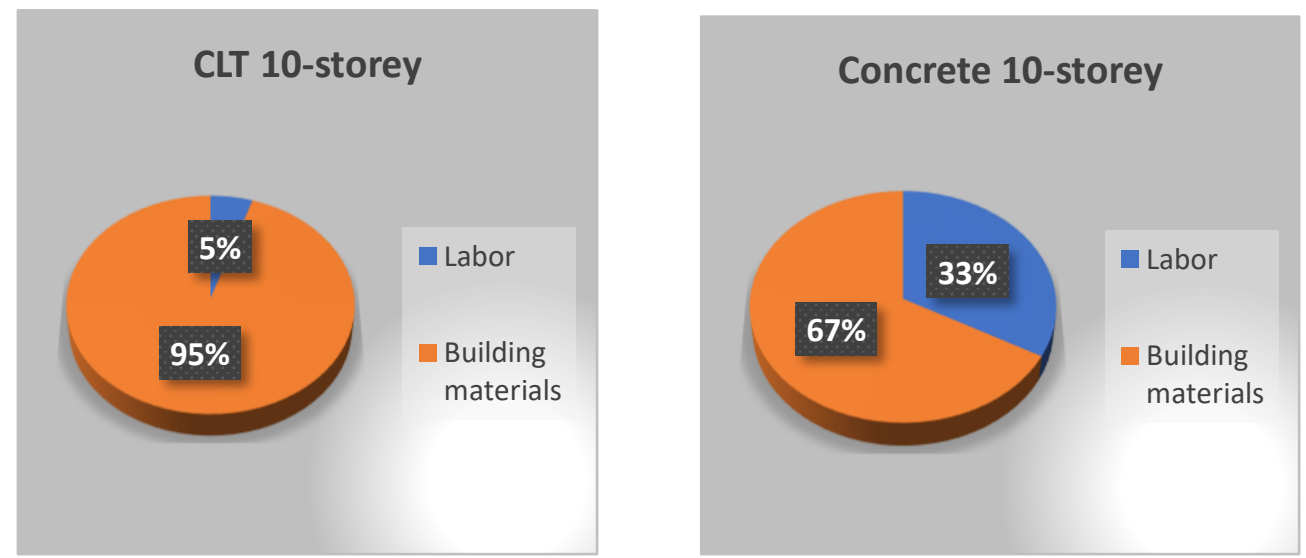

Figure 5. construction costs breakdown for a 10-storey building CLT vs. Concrete 
Given the zero carbon framework considerations, a tabulation of operational energy requirements was simulated directly from the outputs of the 3D model. An energy analysis was first performed based on the industry standards of each materials. It is based on the quantity and area of material as estimated from the quantity take-off. The BTU, electrical kWh, and natural gas GJ energy equivalent were calculated to illustrate two energy sources such as gas and natural gas. Overall energy costs could also be considered using average constant rates of $0.11 \$ / \mathrm{kWh}$ and $6.00 \$ / \mathrm{GJ}$ (ATCO 2019) to conduct a full life cycle cost analysis. The results of the energy performance are listed below.

$\begin{array}{lcrr}\text { Building Type } & \begin{array}{c}\text { BTU Require Per } \\ \text { Hour }\end{array} & \text { Energy in kWh } & \text { Energy in } \\ \text { Concrete } & 2,067,167.49 & 605.85 & 2.19 \\ \text { Full CLT } & 1,269,818.21 & 372.16 & 1.35\end{array}$

Table 1. Energy performance comparison.

Energy performance was analyzed using the heating degree day (HDD) method where the demand for energy needed to heat a building incorporates the heating degree days, based on Calgary data, the seasonal efficiency of the fuel, heat combustion value and approximate cost of the energy.

In addition to the above calculation solely based on material performances, an energy model of the building design of the 2 alternatives was performed against a NetZero energy benchmarking. The results are shown below. It is to be noted however, that the building design did not include any electrical and mechanical systems. The 2 alternatives used the same type of building envelope and exterior cladding and the EUI is simulated for heating and cooling the building for a Calgary based location.

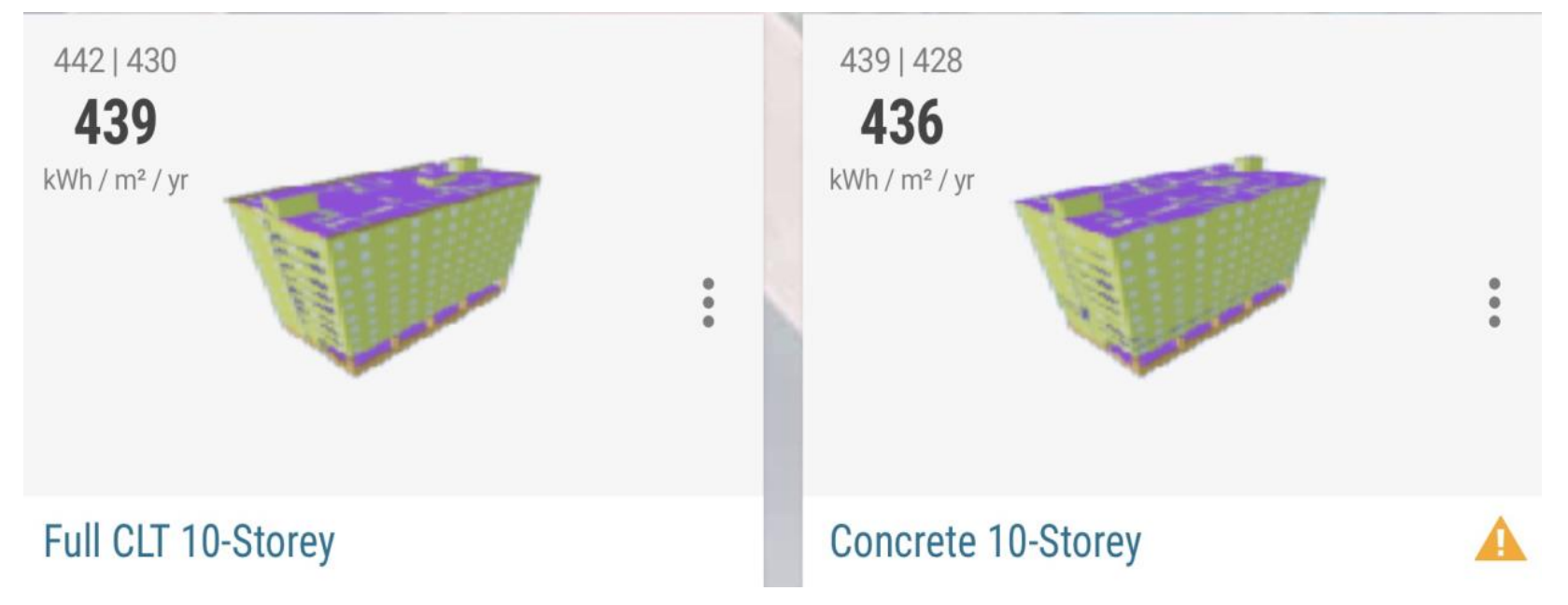

Figure 6. Energy use intensity simulation of the 2 alternatives of the 10-storey building

The benchmark comparison of two alternatives for a 10-storey building using concrete and CLT has indicated limited differences in terms of impacts of cost and energy performances. Nevertheless, we believe that CLT provides slightly more flexibility in terms or energy requirements and thereby a lesser carbon footprint when it comes down to construction. 


\section{Conclusion}

Despite some limitations, the case study presented in this paper may indicates the followings:

- The construction of a 10-storey tall wood mass building using CLT is more economical than a traditional concrete with steel construction method of construction

- The EUI of the superstructure of a CLT 10-storey building for a northern hemisphere climate zone such as Calgary Alberta on average indicate a similar energy performance to concrete 10 storey building. However, the heating degree day HDD Method clearly favours CLT as a building material with nearly $50 \%$ lower energy requirements.

From a Construction Project Management perspective and a value analysis requirement for decision making, a life cycle analysis for embodied energy as well as a life cycle cost analysis may differentiate more the 2 alternatives.

Within the ZCB framework towards environmental impacts, operation carbon that would result from the EUI would indicate the same carbon impact for both alternatives to the 10 -storey building. In addition to converting the EUI into carbon impacts, a building LCA life cycle analysis to measure the embodied carbon would make the case for using CLT and MTC as a carbin sink.

\section{Acknowledgments}

This project has been supported by an Applied Research Fund grant -ARF 2017-03, from Applied Research Industry Services at the Southern Alberta Institute of Technology.

This study is now part of an ERASMU KnoWood project on "mass timber sustainable design and construction".

\section{References}

APA, 2016, CLT Form No S500, retrieved February 282019 from from https://www.apawood.org/cross-laminated-timber

ATCO Energy 2019, Fuel comparison fact card, retrieved from http://www.atcoenergysense.com/Documents/Fuel_Comparison_Fact_Card_2015_web final.pdf

Barnes. S, 2019, Code Changes Pave Way for CLT in Tall Buildings and Spark Flammability Debate, in CE Construction Executive, March 4 2019,

Construction Canada, 2019, B.C. first to allow 12-storey tall wood buildings, retrieved from https://www.constructioncanada.net/b-c-first-to-allow-12-storey-tall-wood-buildings/ 
Proceedings of the $\mathbf{2 0 2 0}$ Society of Wood Science and Technology International Convention

Churkina G, et al, 2020, Buildings as a carbon sink, in Nature Sustainability, 3, pages 269-276 (2020)

Dezeen, 2019; Mijostarnet becomes world's tallest timber toeer, retrieved from https://www.dezeen.com/2019/03/19/mjostarne-worlds-tallest-timber-tower-vollarkitekter-norway/

GreenSpec.com, 2018, Crosslam timber / CLT- Fire resistance and rating, retrieved from http://www.greenspec.co.uk/building-design/crosslam-timber-fire-resistance-andrating/

Ibn- Mohammed, et al., 2013,, Operational vs. embodied emissions in buildings-A review of current trends, in Energyand Buildings Volume 66, November 2013, Pages 232-245

Mallo M and Espinoza O, 2016, Cross Laminated Timber VS. Concrete/Steel: Cost comparison using a case study, WCTE 2016, World Conference on Timber Engineering, August 2016 Vienna,

Naturally Wood 2017, Brock commons Time lapse, UBC Tall wood building, retrieved from https://youtu.be/GHtdnY_gnmE

Natural Resources Canada 2019, Cross-Laminated Timber, retrieved from https://www.nrcan.gc.ca/forests/industry/products-applications/15829

StructurLam 2017, CLT Design guide, retrieved from http://www.structurlam.com/wpcontent/uploads/2017/04/CLT-US-Design-Guide-Sept-2015.pdf

The B1M, 2019, The world's tallest timber buildings, retrieved from https://youtu.be/v3JqSsc8ZKk

Tranchard S., 2017, Measuring the carbon footprint of buildings in a simple way, ISO.org

Wei Pan and Nin Y., 2015, A socio-technical framework of zero-carbon building policies, in Building Research, Volume 43, 2015 - Issue 1: Net-zero and net-positive design

WoodBusiness 2018, Tall mass timber code change approved, retrieved from https://www.woodbusiness.ca/tall-mass-timber-code-changes-approved-5408/

WW-WSP-12 , 2019, Tall Wood Buildings and the 2021 IBC: Up to 18 Stories of Mass Timber (C) 2019 WoodWorks

Biography 
Proceedings of the $\mathbf{2 0 2 0}$ Society of Wood Science and Technology International Convention

\section{Regenerative wooden buildings in Europe: comparing Spain to other countries}

A. Quintana1, Erwin M. Schau2, Eva Prelovšek Niemelä2, Michael D. Burnard2,3

${ }_{1}$ Center for Physics Technologies (CTFAMA), Universitat Politècnica de València, Spain

2 InnoRenew CoE, Livade 6, 6310-Izola, Slovenia

3 University of Primorska, Andrej Marušič Institute, Muzejski trg 2, 6000-Koper, Slovenia

Abstract

Climate change is currently one of the biggest threats to humanity. Buildings generate around $40 \%$ of the total carbon emissions in the world, considering contributions from the production process of the materials, the construction of the building, and its operational phase. Besides carbon emissions, the building sector is also responsible for many other environmental impacts such as land transformation and waste generation. It is therefore urgent to carefully analyze those impacts, to determine how to optimize them while considering the local situation of the building. For this study, a wooden singlefamily model house was compared in different locations in Europe using Life Cycle Assessment. The main purpose is to analyze how the impacts over the entire life cycle of the house vary depending on the location. Initial results indicated that heating was the major impact source (air, water) in cool climates, as expected. In warmer climates, heating water was the most significant impact. Based on these initial findings, additional steps to reduce the buildings impacts were considered and compared using local alternative renewable materials in Valencia, Spain and Portorož, Slovenia as they have reasonably comparable climates. For the Spanish context, a compressed rice-straw and wood structural panel system was considered as an alternative to light wood framing, and in Slovenia, the rock-wool insulation materials were exchanged for wood-fiber insulation, while the light wood frame was kept. The results demonstrate the advantages of optimization with local materials but highlight the difficulties of using limited resources as a widespread solution. Nonetheless, local alternative materials often have other environmental impacts and support a more circular economy.

\section{Acknowledgements}

Authors EMS, EPN, and MDB gratefully acknowledge the European Commission for funding InnoRenew CoE (grant agreement \#739574), under the H2020 Widespread-Teaming programme and Republic of Slovenia (investment funding of the Republic of Slovenia and the European Union's European Regional Development Fund). Author AQG was supported in part by a STSM grant from COST Action CA16114 RESTORE.

Biography 


\title{
Proceedings of the 2020 Society of Wood Science and Technology International Convention
}

\section{ClickDesign project approach to model aesthetic performance of buildings}

\author{
Jakub Sandak1 \\ jakub.sandak@innorenew.eu \\ Anna Sandak 1 \\ anna.sandak@innorenew.eu \\ Lone ross Gobakken2 \\ lone.ross.gobakken@nibio.no
}

1 InnoRenew CoE \& University of Primorska, Slovenia

2 Norwegian Institute of Bioeconomy Research, Norway

\section{Abstract}

Today's bio-based building materials, even if well-characterized from the technical point of view, are often lacking reliable models describing their aesthetical performance during service life. Appearance changes of materials are related to several deterioration processes, caused by biotic and abiotic factors. The kinetic and/or intensity of such changes is varying due to structure, location, microclimate, architectural design and the materials used for construction. The goal of this research is to characterize and model selected aesthetical aspects of building materials, combined with a numerical simulation of its visual changes as a function of deterioration processes. A novel method for fusion of multi-sensor data (including color, texture, gloss, roughness) into a single indicator expressing "satisfaction with appearance" or customer perception is recently tested in a frame of CLICKdesign (Delivering fingertip knowledge to enable service life performance specification of wood) project. It will allow the design of procedures for the definition of the limit states (aesthetical and functional), as well as optimal scheduling of maintenance and/or replacement actions. The tool, dedicated to investors, architects, construction engineers, professional builders, suppliers and other relevant parties, including final customers will be validated and integrated with BIM software.

Acknowledgments: Project CLICKdesign is supported under the umbrella of ERA-NET Cofund ForestValue by the Ministry of Education, Science and Sport (MIZS) - Slovenia; The Ministry of the Environment (YM) - Finland; The Forestry Commissioners (FC) - UK; Research Council of Norway (RCN) -Norway; The French Environment \& Energy Management Agency (ADEME) and The French National Research Agency (ANR) - France; The Swedish Research Council for Environment, Agricultural Sciences and Spatial Planning (FORMAS), Swedish Energy Agency (SWEA), Swedish Governmental Agency for Innovation Systems (Vinnova) - Sweden; Federal Ministry of Food and Agriculture (BMEL) and Agency for Renewable Resources (FNR) - Germany. ForestValue has received funding from the European Union's Horizon 2020 research and innovation programme under grant agreement $N^{\circ} 773324$.

The authors gratefully acknowledge the European Commission for funding the InnoRenew project [Grant Agreement \# 739574] under the Horizon 2020 Widespread-Teaming program and the Republic of Slovenia (investment funding of the Republic of Slovenia and the

\section{Biography}




\title{
PARAMETERS TO MINIMIZE THE ENVIRONMENTAL FOOTPRINT OF WOOD AND ENGINEERED WOOD PRODUCTS
}

\author{
Erwin M. Schau* \\ Researcher $(\mathrm{PhD})$ \\ InnoRenew Centre of Excellence (CoE), Izola - Isola (Slovenia) \\ * Corresponding author: erwin.schau@innorenew.eu
}

\begin{abstract}
Reducing the environmental impacts of products and activities becomes more and more important as the world's population grows and limits of the earth's carrying capacity are closing in or already exceeded. Wood and engineered wood products, coming from a natural source, are generally seen as more environmentally sound than alternative products and materials. However, to keep up with the general development of environmental efficiency (i.e., less environmental impact per produced unit), wood and engineered wood products should also improve their environmental footprint. In this contribution, the standardized method of life cycle assessment is used to investigate a range of wood and wood products with a focus on building materials, like glued-laminated timber (glulam) and oriented strand boards. Where data permits, the Environmental Footprint indicators as recommended by the European Union, are applied. The results are used to highlight fields of improvement and strategies for an even lower environmental profile for wood materials and products and could be of interest for producers as well as purchasers and users of materials and products based on wood materials. By combining all strategies, a reduction of the overall environmental footprint by up to ca $60 \%$ was achieved.
\end{abstract}

Key words: environmental impact, engineered wood products, optimization, oriented strand board (OSB), glued-laminated timber (glulam)

\section{Introduction}

Wood products have been used for centuries, have a natural origin and are generally seen as an environmentally sound material (Obućina et al, 2017). However, as the world's population grows (United Nations, 2019), so does also the use of materials and products and their accompanying environmental impact (Crippa, 2019). The carrying capacity of our one and only world is limited; therefore, environmental efficiency (i.e., less environmental impact per produced unit) strategies are needed to cope with larger demand from a growing world population. This is also valid for wood products, especially in the building sector where engineered wood products could play a significant role as the core for high rise mass timbered buildings (Ramage et al. 2017). As competing products to wood, like concrete, steel and glass, are not sleeping but working to 
continuously improve the environmental footprint of their product, so should the wood industry in order to not be left behind.

This contribution applies the standardized method of life cycle assessment (LCA) (ISO14040/44 (2012), cradle-to-gate, to investigate a range of wood and wood products with a focus on building materials like glued-laminated timber (gluelam) and oriented strand boards (OSB). Where data permits, 13 different Environmental Footprint (EF) indicators, as recommended by the European Union (2020), are applied. The results are used to highlight fields of improvement and strategies for an even lower environmental profile for wood materials and products that could be of interest for producers as well as purchasers and users of materials and products based on wood materials.

\section{Materials and Methods}

EcoInvent database v 3.5 (Ecoinvent, 2018), as implemented in the LCA software SimaPro v 9.0 (Pré Consultants 2019), is used for this analysis. This database includes a range of different life cycle inventories for building materials and wood products. The cut-off system modelling and global (or rest of the world) geographical data has been used as a reference. The cradle-to-gate system boundary, including forestry operations, transport and manufacturing, has been chosen. For the life cycle impact assessment, the EU Environmental Footprint indicators are applied, except the toxicology impact categories, which are replaced by newer ones not yet implemented in the software used.

The starting point for different strategies (or parameters) of influence has been chosen with the background that the production itself is to a large extent already optimized. This might be more or less the case. Then, environmental impact reducing potential also outside the direct control of the producing company, but still under some control (for example, buying decisions), has been investigated. Seven strategies to reduce the environmental footprint of OSB and glulam products are investigated. These are presented in Table 1.

Table 1: $\quad$ Description of strategies reported

$\begin{array}{ll}\begin{array}{l}\text { Strategy } \\ \text { No. }\end{array} & \begin{array}{l}\text { Name } \\ 1\end{array} \\ \begin{array}{l}\text { Reduce the amount of glue } \\ \text { (low glue) }\end{array} \\ 2 & \text { Modal shift to train } \\ 3 & \begin{array}{l}\text { Local supply of wood raw } \\ \text { material }\end{array} \\ 4 & \text { Clean electricity }\end{array}$

Description

Resins are reduced by $20 \%$ (amount, but similar effect if the environmental impact of the resin is reduced by $20 \%$ )

Transport by ship and heavy-duty vehicle is performed by train $(200 \mathrm{~km})$ instead The production site is located near the wood source, such that local sourcing $(50 \mathrm{~km}$ lorry) is possible All electricity is coming from renewable sources (100\% waterpower from river) 
Proceedings of the $\mathbf{2 0 2 0}$ Society of Wood Science and Technology International Convention

$5 \quad$ Biomass heat only

$6 \quad$ Reduced wood input

$7 \quad$ Combined (not glulam) Fossil energy sources (natural gas and oil) for heat production is replaced with biomass (wood chips)

Wood need is reduced by $10 \%$ (amount, but same effect if the environmental impact of the wood raw material is reduced by $10 \%$ ) Combination of several strategies (see above; Glulam: no. 1,3,4 and 6; OSB: no. $1,3-6)$

No. 5, Biomass heat only, is applied only in the OSB case, as heat from biomass is already implemented in glulam reference production. The different strategies are combined in no. 7, with the exception of no. 2, Modal shift to train, as this is not realistic for local $(50 \mathrm{~km})$ supply of wood (where no. 3 is applied to reduce the impact from transport of raw materials).

\section{Results and Discussion}

Results are presented in Figure 1 (glulam) and Figure 2 (OSB) and show the reduction for each strategy adjusted for each of the investigated environmental footprint impact categories (measured in percentage). The characterized results are reported in Annex I and II for better transparency. The results show that the combined strategy, as expected, leads to the highest reduction, up to 60 $\%$ for climate change (glulam). Clean electricity is a very promising single strategy for both glulam and OSB. 


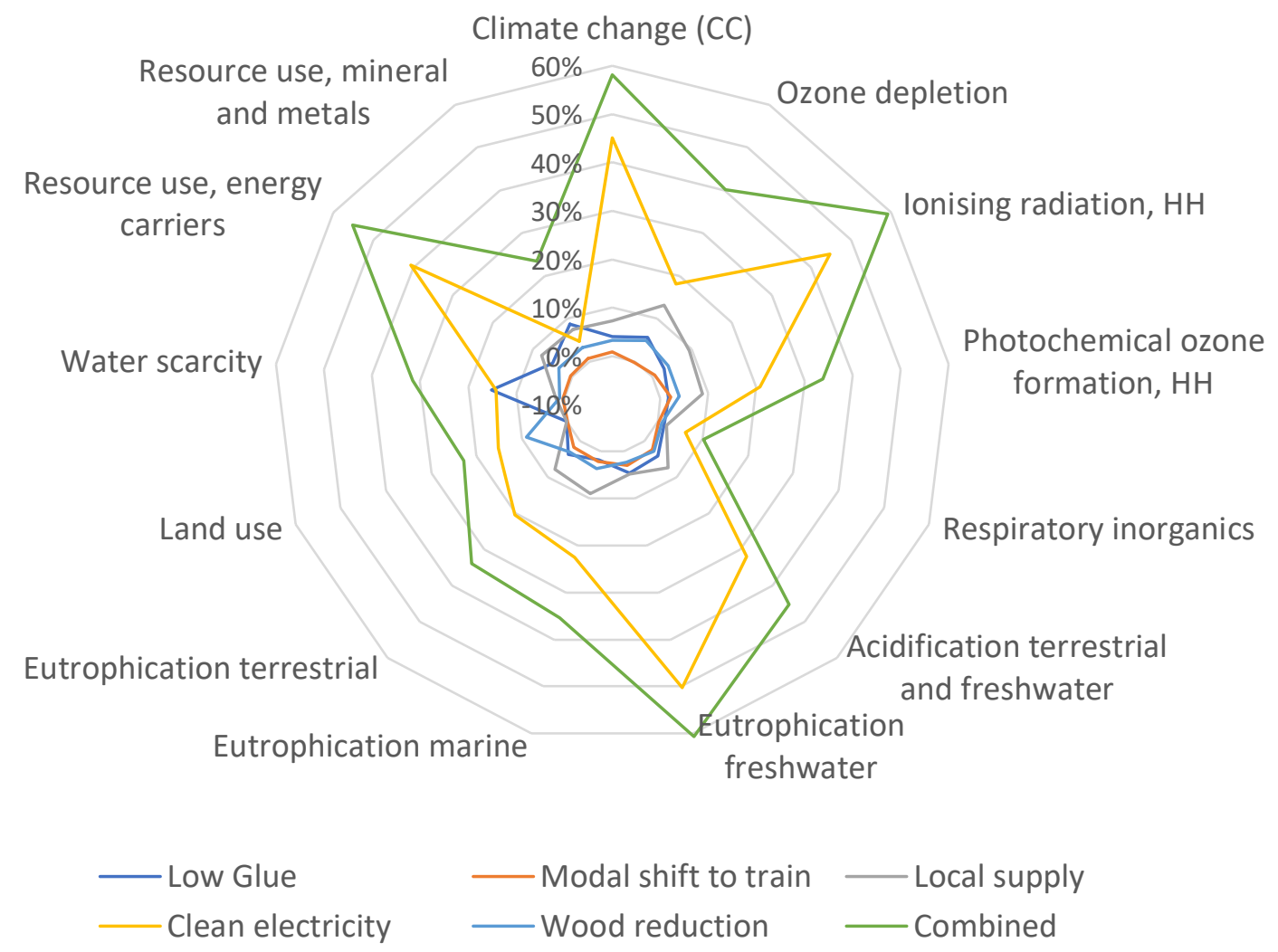

Figure 1. Reduction potentials for different strategies in relation to no action-reference for glued-laminated timber (glulam), depicted for different environmental impacts.

Investigated strategies optimization for glulam lead to a reduction of $0 \%$ for low glue in the land use impact indicator and up to $50 \%$ for clean electricity in the eutrophication freshwater impact category, followed by $45 \%$ in climate change and ionizing radiation impact categories. The respiratory inorganics impact category is difficult to reduce; in total for the combined strategy, only $10 \%$ reduction is achieved. 


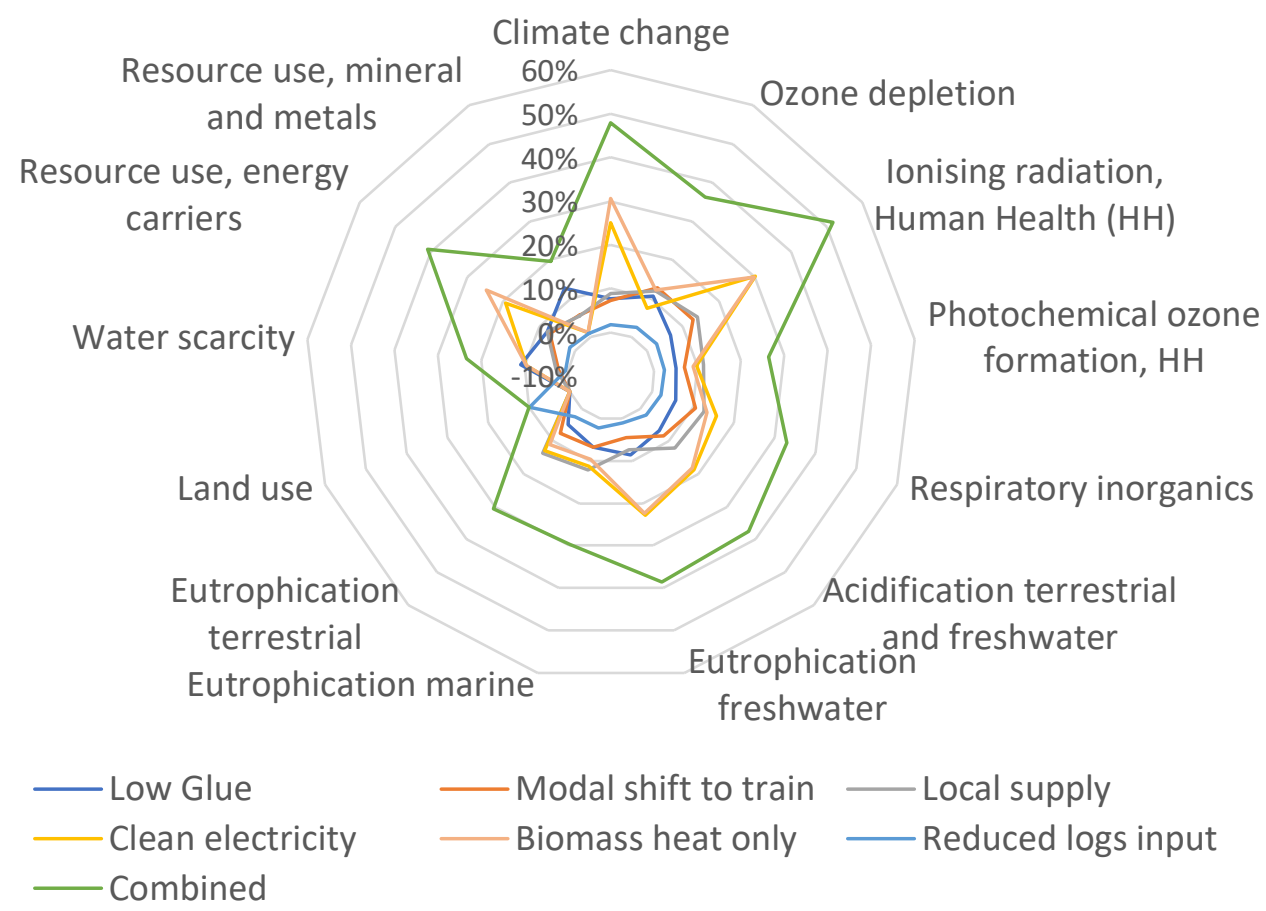

Figure 2. Reduction potentials for different strategies in relation to no action-reference for oriented strand board (OSB), depicted for different environmental impacts.

The results for OSB show that, overall, even with also targeting heat supply, the reduction in environmental impact was not as large as with glulam. The exception was in the category of respiratory inorganics, where OSB had a satisfactory reduction of $33 \%$ for the combination strategy, while glulam had only a $10 \%$ reduction. The most promising strategy for OSB was a shift to clean energy, both electricity (from waterpower) and heat (from biomass).

Strategy no. 1 Reduce the amount of glue (low glue) leads to a larger reduction of environmental impact for OSB than for glulam. The reason for this can partially be explained by OSB's use of much more glue than glulam per $\mathrm{m} 3$, such that a $20 \%$ reduction leads to $3.6 \mathrm{~kg}$ reduction in glue for OSB but "only" $2.3 \mathrm{~kg}$ of glue for glulam.

No. 2, modal shift from heavy-duty vehicle to train, makes sense only for land transport and long distances. A further reduction of the modal shift to train might be reached if all train transport is electrified. This scenario applies the same ratio of diesel train to electric train (ca 50/50) as in the reference situation.

Other strategies to further reduce the environmental impact of OSB and glulam are upstream in forestry, where the building of forest roads and use of wood harvesting machines are believed to have potential. However, this is left for future research.

Even though the percentage reduction is not directly transferable, as the amount of glue, transport length and mode, energy source and wood by-products (cutoffs) are different, the results for OSB 
and glulam are believed to point in the same direction for other similar engineered products, like particleboard and cross laminated timber.

Downstream, in the production of buildings and furniture, to optimize the use and reuse of materials (minimize waste), material recycling and energy recovery strategies at end of life are believed to be of importance for the life cycle environmental impact of engineered wood products.

The economical cost of different strategies investigated are believed to be responsible; some could even bring a higher profit or cost savings as more environmentally sound wood products goes hand in hand with more efficient transport and production processes and might even be higher priced in the market. However, a financial cost analysis has not been part of this study.

\section{Summary and Conclusions}

Different strategies were applied and adjusted in order to improve the environmental profile of engineered wood products, specifically glulam and OSB. With relatively small (e.g., $10 \%$ reduction of wood in production) adjustment, considerable reduction of the environmental impacts of wood products are possible, especially if several strategies are applied and adjusted in combination.

Shifting to clean energy (electricity for glulam and both heat and electricity for OSB) could considerably lower environmental impacts. By combining different strategies, a total reduction of $10-61 \%$ for glulam and $10-52 \%$ for OSB was achieved. This shows that producers of engineered wood products have a range of strategies available to easily further reduce the life cycle environmental impact of their products. This should be pursued by the wood industry to ease competition with other materials.

Similar research could be done on products from specific geographical regions, as these can be quite different from the global reference made in this contribution. Also, further up in the value chain (e.g. forestry) and further down the life cycle to end of life should be investigated to find further strategies (or parameters) to optimize with the aim of reducing the overall environmental footprint of engineered wood components and their final products.

The results presented here will be used to optimize wooden buildings, for example, to make an environmentally optimized single-family house and compare it to the average European nearly zero-energy building (nZEB) (Schau et al 2019).

\section{Acknowledgements}

The author gratefully acknowledges the European Commission for funding InnoRenew CoE (grant agreement \#739574), under the H2020 Widespread-Teaming programme, and Republic of Slovenia (investment funding of the Republic of Slovenia and the European Union's European Regional Development Fund). 


\section{References}

Crippa, M., Oreggioni, G., Guizzardi, D., Muntean, M., Schaaf, E., Lo Vullo, E., Solazzo, E., Monforti-Ferrario, F., Olivier, J.G.J., Vignati, E., Fossil $\mathrm{CO}_{2}$ and GHG emissions of all world countries - 2019 Report Publications Office of the European Union, Luxembourg, 2019, ISBN 978-92-76-11100-9, doi:10.2760/687800, JRC117610.

Ecoinvent Centre, 2018, Ecoinvent Life Cycle Inventory Database, v 3.5

European Union (2020) European platform on LCA; Retrieved 27 April 2020 from https://eplca.jrc.ec.europa.eu/

ISO 14040. (2006). Environmental management - Life cycle assessment - Principles and framework. Geneva: International Organization for Standardization.

ISO 14044. (2006). Environmental management - Life cycle assessment - Requirements and guidelines. Geneva: International Organization for Standardization.

Obućina, M., Kitek Kuzman, M., \& Sandbeg, D. (2017). Use of sustainable wood building materials in Bosnia and Herzegovina, Slovenia and Sweden. Retrieved 29 May 2020 from http://ltu.diva-portal.org/smash/get/diva2:1140697/FULLTEXT01.pdf

Pré Consultants, 2019, SimaPro Analyst, v. 9.0

Ramage, M. H., Burridge, H., Busse-Wicher, M., Fereday, G., Reynolds, T., et al. (2017). The wood from the trees: The use of timber in construction. Renewable and Sustainable Energy Reviews, 68(Oct. 2015), 333-359. Doi:10.1016/j.rser.2016.09.107

Schau EM, Prelovšek Niemelä E, Niemelä AJ, Alencar Gavric TA and Iztok Šušteršič I (2019) Life cycle assessment benchmark for wooden buildings in Europe: Single family house - nearly zero-energy building ( $n Z E B$ ) in The 9th International Conference on Life Cycle Management (LCM2019). Poznan 1-4 Sep 2019 (platform presentation)

United Nations, Department of Economic and Social Affairs, Population Division (2019): World Population Prospect: The 2019 Revision. New York: United Nations. 
Annex 1: Characterized results for glued-laminated timber (glulam)

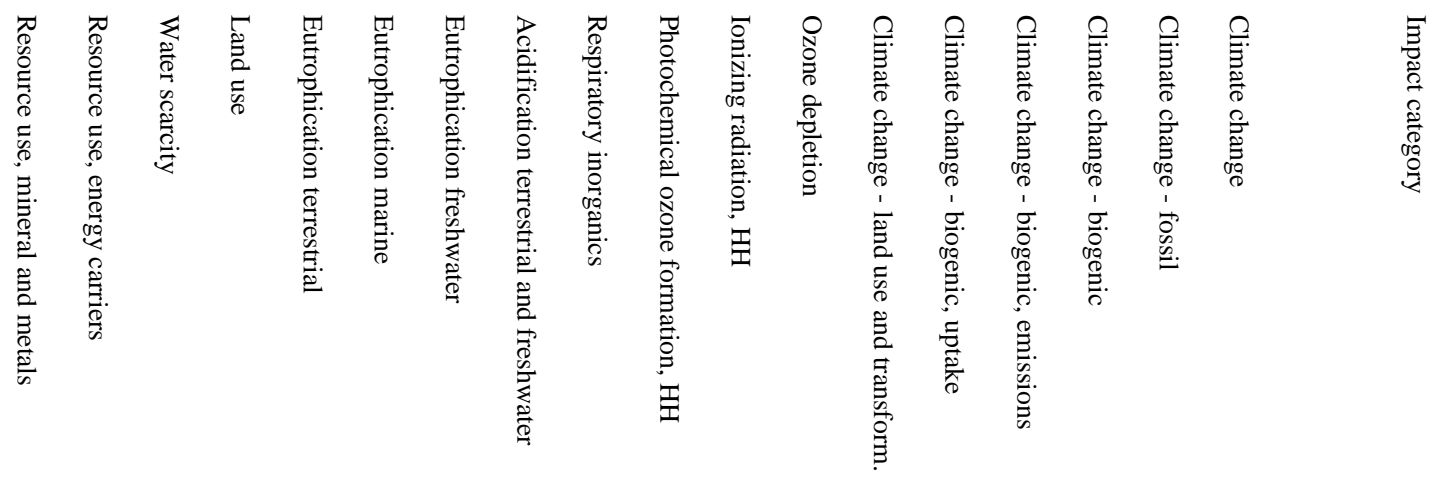

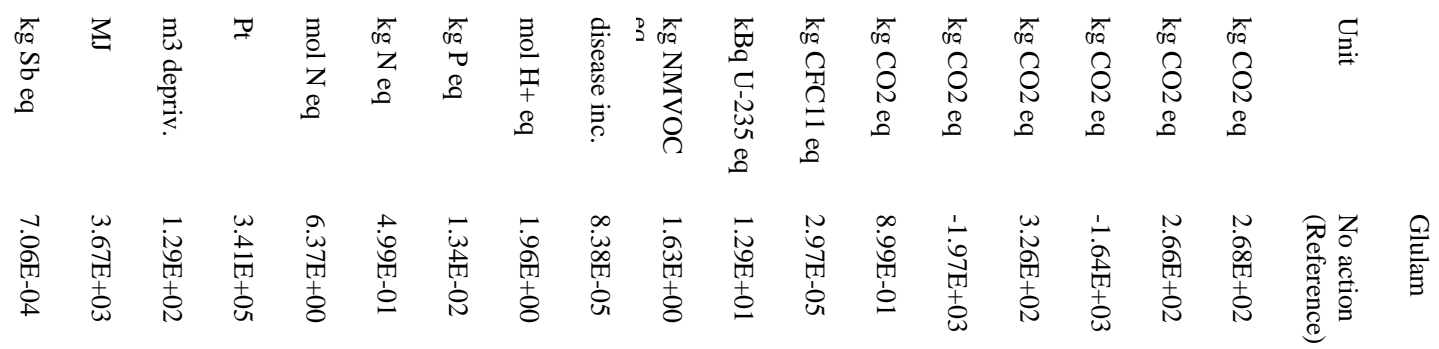

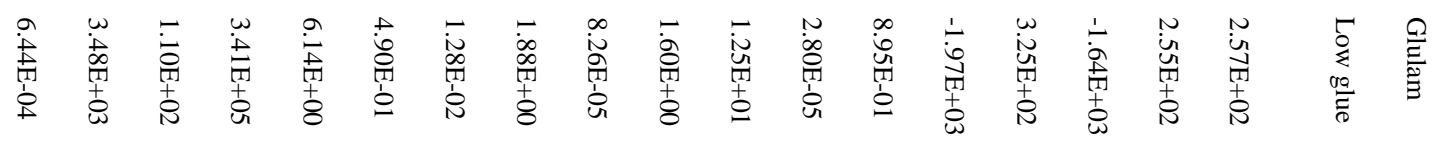

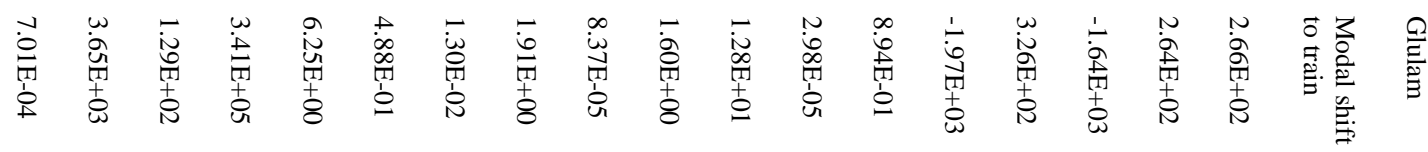

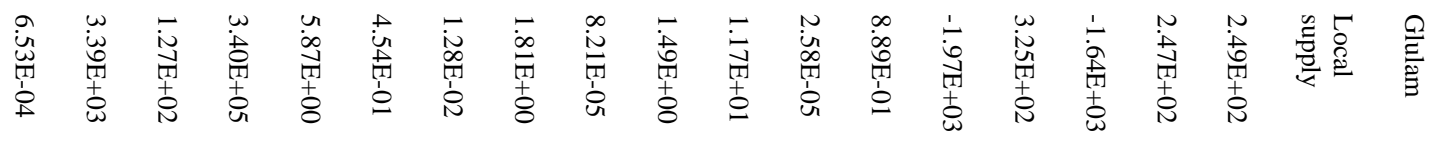

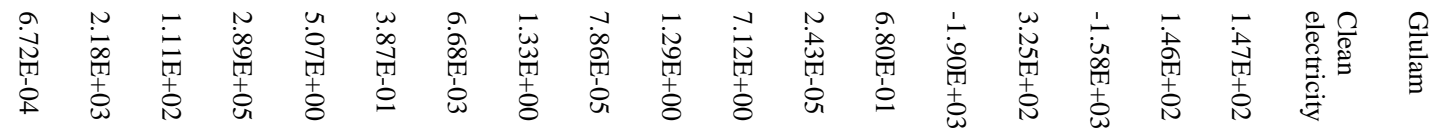

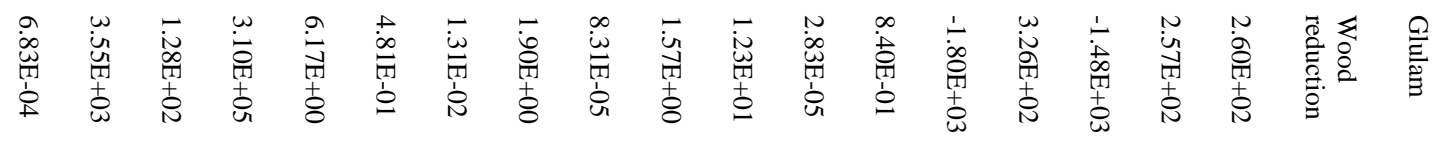

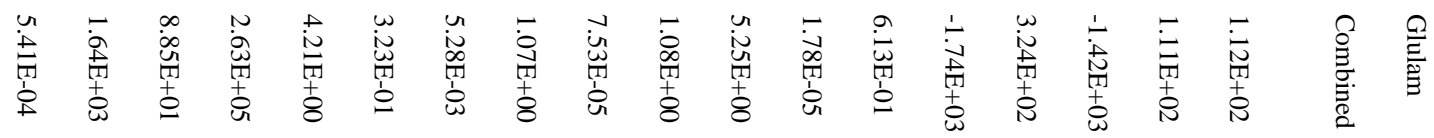


Annex 2: Characterized results for oriented strand board (OSB)

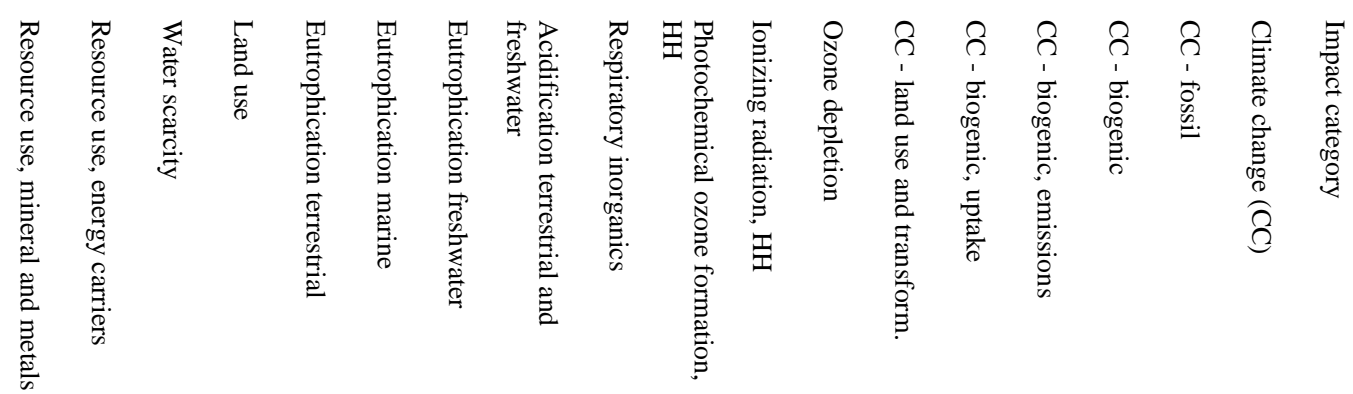

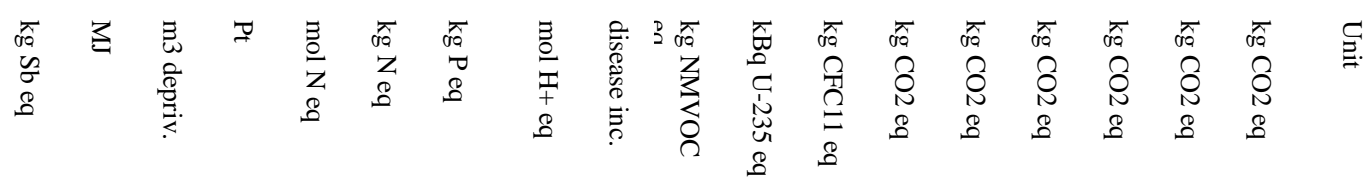

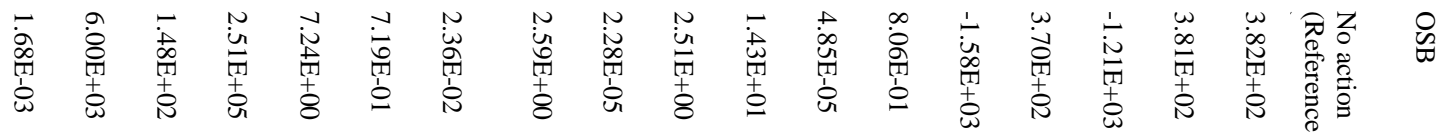

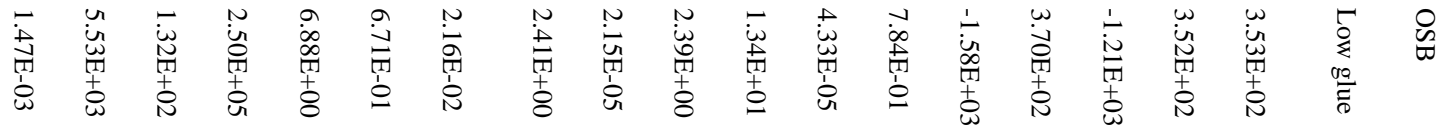

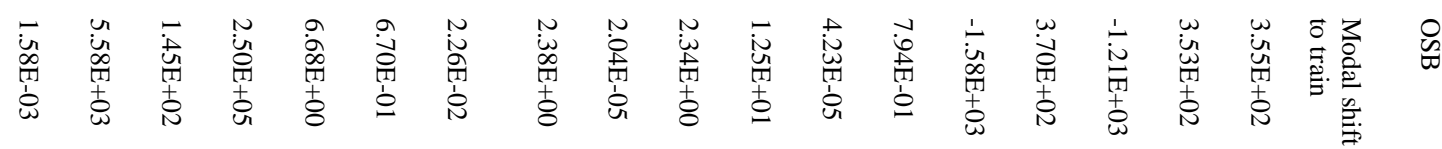

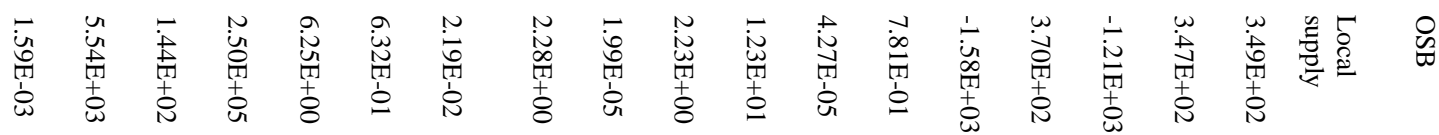

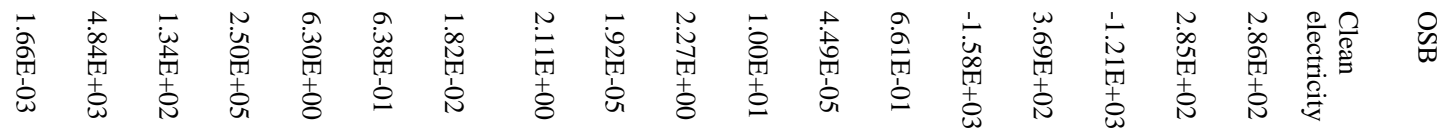

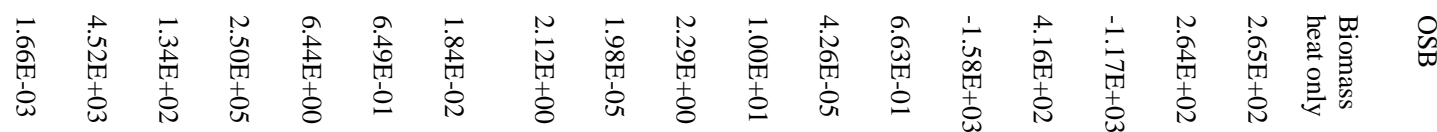

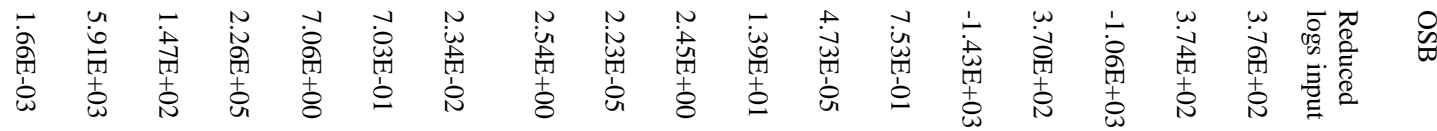

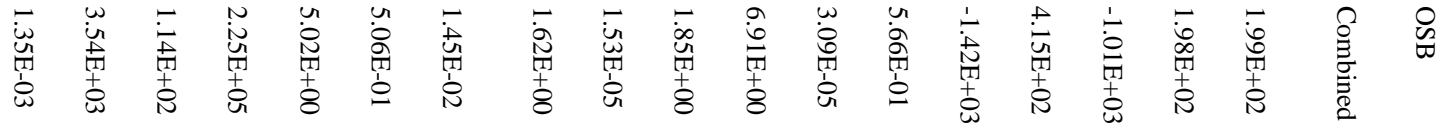

Biography 


\title{
Proceedings of the 2020 Society of Wood Science and Technology International Convention
}

\author{
TallWood Design Institute: \\ Latest Resilient Design and Seismic Engineering Research
}

\author{
Evan Schmidt, TallWood Design Institute, USA
}

\begin{abstract}
TallWood Design Institute (TDI) represents an interdisciplinary collaboration between three colleges at two US universities and is tasked with overseeing a program of applied research aiming to characterize and improve advanced timber products and building systems for adoption in US construction.

Research is carried out by a network of affiliated faculty members and industry partners in the architecture, engineering and construction communities. Areas of investigation range from seismic/structural performance to moisture/durability, acoustic, fire, manufacturing and human/environmental health.

In addition to highlighting key aspects of TDI's applied research program and industry testing consortium, this presentation will outline two new interdisciplinary projects of particular interest in the realm of resilient timber design for seismically active regions.

The first project, "Design, Construction and Maintenance of Mass Timber Post-Tensioned Shear Walls" will characterize and validate the long-term performance of cross-laminated timber (CLT) and veneerbased (LVL and mass plywood) post-tensioned rocking shear wall systems, in terms of anchorage detailing, and system response to climate, moisture, dimension changes and tension loss. Additionally, a related project engaged in construction and post-occupancy monitoring of the Oregon Forest Science Center will be discussed in context.

The second project, "Innovative Lateral Systems for Mass Timber," will generate benchmark data characterizing the performance of multiple innovative mass-timber shear wall systems from the scale of connectors to full-scale building systems up to three stories tall. This work is intended to lay groundwork for upcoming full-scale NHERI shake table tests that are part of a multi-organization research initiative looking at seismic performance of mass timber building systems.
\end{abstract}

Biography 


\title{
Are wood and sustainability-related terms emphasized more nowadays than $\mathbf{2 0}$ years ago? Corpora-based study in Czech and Slovenian languages
}

\author{
Vaclav Sebera, Innorenew CoE, Slovenia \\ vaclav.sebera@innorenew.eu \\ Julija Ursic, Innorenew CoE, Slovenia \\ julija.ursic@innorenew.eu
}

\begin{abstract}
It is well known that wood, despite its morphological and property complexity, is a material that makes a great sense to be used in constructions for many reasons such as thermal and structural benefits and sustainable aspects. If we acknowledge these facts, then one would expect that "wood" has been pronounced (i.e. it was written and spoken about wood) with an increasing trend in last two decades during which a call for sustainability and sustainable materials has been increasing in our society. But is it really truth, do we really promote, speak, write and publish about wood more now than 20 years ago? This work would like to try to answer such questions by language analysis using linguistic tool such as Czech National Corpus that comprises about 4.5 billions of words, and Slovenian corpus Gigafida that has about 1.8 billions of words, both containing data for nearly two last decades. The further research questions were: who pronounce wood more, women or men?; what degree of education is the most frequent for people who speak about wood?; what are the most frequent collocations to word "wood"?; what kind of material people pronounce the most? In conclusion, we would like to outline whether statistical analysis of the language can help us to understand whether people have changed their approach to sustainability, wood and related terms in last two decades.
\end{abstract}

Biography 


\title{
Options for Climate Change Performance Indicators for Cross-laminated Timber
}

\author{
Lars G.F. Tellnes, Ostfold Research , Norway \\ lars@ostfoldforskning.no \\ Kristine Nore, Splitkon AS, Norway \\ kristine.nore@splitkon.no \\ Anne R. Ronning, Ostfold Research, Norway \\ anne@ostfoldforskning.no
}

\begin{abstract}
Cross-laminated timber is a structural building material increasingly used in larger buildings substituting concrete and steel materials. Often, climate change mitigation is a motivation and wood products have benefits from typically lower fossil fuel use, carbon sink in the material and potential for secondary use with reuse, recycling or energy recovery. The standard EN 15804 is commonly applied to document the environmental impacts of individual materials, but some aspects such as carbon storage and benefits beyond life cycle often left out when comparing to other materials in practice. There has been a wide focus on such issues in research, but the implementation of these aspects in environmental criteria applied in procurement and buildings design guidelines are more limited. The objective of the paper is to assess different approaches to a more holistic modelling of the climate change mitigation potential of wood products and how the aspects can be applied in industry used criteria for materials in sustainable constructions. The study focusses on practice in Norway, while the research is linked to the international agenda.

From research, how to deal with temporary carbon storage has had a large focus within life cycle assessment (LCA) in the last 10 years. Most studies assume zero contribution as it is assumed that the carbon sequestration is equalled by the carbon released at end-of-life. However, there has been several methods developed for time-adjusting of biogenic carbon in LCA, but these have not been included in standards so far and seems too complicated for industrial widespread use. Outside the LCA framework, carbon storage in products has also been increasingly focused in the national greenhouse gas inventories where it is called "Harvested wood products" (HWP). Besides, carbon storage, wood products has the benefit after end use in potential for secondary use. In many LCA these benefits are left out to avoid double counting, but increased focus on consequential LCA has challenged this practice.
\end{abstract}

To make more holistic approaches to climate change mitigation potential to be applied by decisions for material choice in buildings, there is a need for common frameworks, but there is also a potential by individual organisation to set more specific requirements. In Norway, there has been developed a standard for greenhouse gas calculation of buildings (NS3720), so this should be used as a framework, but there would be a need for further specification when used in green public procurement or other green building classification schemes such as BREEAM-NOR. In public procurement, there is also possible for projects to apply environmental cost of carbon emissions to weight the reduced climate change impact to an increased cost. These many approaches can give quite different results, but it can be challenging to defines on approach as the right. Further research and development should therefore focus on how these approaches can be applied in practice and facilitate the use through guidelines and best practice case studies.

Biography 


\title{
Monday, July 13
}

\author{
Business, Marketing, Digitalization, and Regulations \\ Chairs: \\ Eric Hansen, Oregon State University, USA \\ Rob Kozak, University of British Columbia, Canada
}

\section{CONTRIBUTION AND POTENTIAL OF THE WOOD INDUSTRY AND ITS PRODUCTS TO THE CIRCULAR ECONOMY: CASE EXAMPLES FROM THE US AND CENTRAL-SOUTHEAST EUROPE}

\author{
Andreja Pirc Barčić $1 *$ - Eric Hansen2 \\ 1Assistant professor, University of Zagreb, Faculty of Forestry, CROATIA \\ apirc@sumfak.hr;andreja.pirc.pirc@sumfak.hr \\ 2Professor Oregon State University, College of Forestry, Oregon, USAh Scientist, \\ USDA Forest Service Northern Research Station, Princeton, WV, USA \\ eric.hansen@oregonstate.edu
}

\begin{abstract}
Sharing and collaborative value-delivery models are aspects of the circular economy. Currently, renew and repair schemes for durable, wood-based (bio-based) products, such as furniture, are still rare. A combination of shifting consumer behaviour and rapidly-evolving digital technologies is disrupting long-established business models across many industries and putting increasing pressure on traditional growth models. For example, sharing and collaborative principles applied to products and/or services will give the potential to increase product longevity, reusability and the sharing of materials. Product sharing can also facilitate the sharing of overcapacity or underutilization, improving the efficiency of resource use. Given that the level of wood used in residential and public construction, interior design, and outdoor design continues to expand, results and information conducted during this work can help in the process of implementing sharing and collaborative economy principles in the wood-based sector. Perhaps the hardest part will be convincing consumers/customers, but also other stakeholders to change their use/behavior and way of thinking. An improved understanding of the sharing and collaborative economies is therefore needed to inspire more thoughtful and appropriate responses to these variegated realities, in terms of policy, regulation and institutional support. However, there hasn't been an opportunity thus far to consolidate this body of work for wood sector communities and to collaboratively shape a future agenda on the topic. The aim of this work is to present a contribution of the wood-based industry to the concepts of sharing and collaborative economies as components of the circular economy based the U.S. and Central-South-Eastern European countries.
\end{abstract}

Key words: circular economy, sharing and collaborative models; wood-based products 


\section{A THEORETICAL BACKGROUND OF THE SHARING \& COLLABORATIVE CONCEPTS AS ASPECTS OF THE CIRCULAR ECONOMY}

Bioeconomy and circular economy (CE) are concepts which complement each other. Furthermore, the wood-based sector together with forest sector play a central role in a bioeconomy, because they provide material, bioenergy and a wealth. More precisely, bio-based industries have a long history of discussing and partly realizing cascade use of wood. On the other hand, the circular and sharing economy concepts are related. Sharing and collaborative models are aspects of the circular economy. Currently, renew and repair schemes for durable, wood-based (bio-based) products, such as furniture, are rare. Their effect on material demand will in any case largely depend on consumer response and rebound effects. One example that highlights sharing and collaborative economy principles in the field of wood furniture comes from IKEA. IKEA has been piloting various initiatives across its European stores to see how they can build circularity into their offer to customers with an aim to support customers to care and repair, rent, share, bring back and resell their IKEA products to prolong product life.

Accoridng to Sposato et al. (2017) the development of a sharing economy can bring new opportunities in economic terms, but sharing models also are able to bring interesting environmental advantages in terms of resource savings and avoided waste. For this reason, the sharing economy within the wood-based sector can be considered connected to circular economy issues. Circular economy is a term to define an economic system that foresees restorative and regenerative mechanisms (Ellen MacArthur Foundation, 2012). It is representative of a broad number of interpretations that have in common an increased efficiency of resources by minimizing waste and resource extraction (Chertow, 2000). Its main objective is to oppose the linear economy by closing the loops in terms of resources and materials (Sposato et. al. 2017). As the European communication "Towards a circular economy: A zero waste programme for Europe" (COM/2014/0398 final/2) states: "These are based on experience of successful initiatives that could be scaled up and applied more widely, and include among others, in the consumption phase, collaborative consumption models based on lending, swapping, bartering and renting products, and product service systems to get more value out of underutilized assets or resources (e.g., cars, tools, lodging)" (European Commission (EC), 2015a). What do cars, printers, clothing, and furniture have in common? Or perhaps better, what will they have in common. Some expect that in the future many of these products will no longer be owned. Instead, consumers will access them via some form of renting. Sposato et al. (2017) noted results from the French Agency for Environment and Energy Management (2014) that one third of domestic waste may turn into potential sharing goods and the $33 \%$ of the total environmental impacts can be avoided through collaborative economy models. A report of the study office of the European Parliament (2016) concludes (according to results from Italian Statsitical Yearbook 2015) that more than $46 \%$ of domestic consumption in Italy is recoverable/reusable through sharing economy models.

In the past ten years, technology has dramatically changed our lives and social media have revolutionized the way we communicate and collaborate with each other in ways that weren't earlier possible (Smith et al. 2015). Nesta (2014) observed that the sharing economy has become a popular term to describe a range of various business models, activities and organizations in order to get a new perspective on the social, environmental, and economic value that can be created from a number of assets and skills, in innovative ways. According to Codagnone and Martens (2016) there is no 'shared' consensus on what activities comprise the 'sharing economy'. Furthermore, the activities and organizations that are today commonly referred to as the 'sharing economy' have also been labelled as 'collaborative consumption' (Botsman, 2013; Botsman and Rogers, 2010a; 
Botsman and Rogers, 2010b). The sharing economy represents a fundamental shift in how consumers value products. In the current commercial economy, consumers value ownership which contributes to conspicuous consumption and waste resulting in artificially high demand for natural resources. Collaborative consumption can mitigate these negative effects, but poor communication and small social networks constrain the concept (Smith et al. 2015). According to Coyle (2016) the sharing economy offers a quick and cheap way of matching supply with demand for goods and services. The main innovation in the business model of the sharing economy lies in the technological platforms and mobile apps which bring demand and supply together and group them in a way which was not possible before (quicker, cheaper and on a larger scale), including in geographical areas or services sectors where the concentration of players is lower and where new commercial opportunities are now arising (Basselier 2018). Veleva and Bodkin (2018) noted that according to World Economic Forum (2016) it is estimated that the circular economy will provide an economic opportunity of over $\$ 1$ trillion as well as significant social and environmental benefits. On the other hand, according to a European Commission Report (2018a) on the collaborative economy, the overall size of the collaborative economy in the EU-28 in 2016 is estimated to be EUR 26.5 billion. Additionally, the collaborative economy offers about 394,000 jobs across the EU, representing about $0.15 \%$ of total EU-28 employment. The largest markets for the collaborative economy can be found in France (25\% from total collaborative EU-28 market), UK (17\%), Poland (10\%) and Spain (10\%). These top four countries also offered the most jobs in the collaborative economy (approx. 74,600, 69,400, 65,400 and 39,700, respectively) in 2016. In general, the seven largest collaborative economy markets in the EU (France, UK, Poland, Spain, Germany, Italy and Denmark) represent about $80 \%$ of total collaborative revenues in the EU-28 in 2016.

Developments around the sharing economy are also taking place in North America. Many platforms started originally in the United States and are beginning to have a significant impact in many European countries. While these platforms have the technical capacity to work globally, they often need to be adapted to local contexts and their usage differs across regions in line with local customs and regulations. Remarkably little research has been done using a side-by-side comparison of types of platforms (monetary, non-monetary) for different purposes (labour, spaces, goods). From lighting-as-a-service to the rise of clothing rental, more companies are beginning to catch on to the potential of providing products-as-a-service (PaaS) through rental, pay-per-use and pay-per-service models for items that traditionally have been purchased outright (and usually landfilled when no longer needed). In February 2019, the Swedish furniture company IKEA announced a furniture leasing trial to explore "scalable subscription services" for everything from couches to kitchens. Yet while some already have dubbed IKEA's pilot, which will roll out only in Sweden for now, the "Netflix of furniture," the details of access over ownership become increasingly more complicated with physical things than with digital. Many more companies-not just social enterprises - are including matters of sustainability in their strategic decision-making and choose to include circular economy practices in their business models. However, many circular economy-minded businesses have a narrow definition of what it means. For example, the report, called Opportunity and Disruption: How Circular Thinking Could Change U.S. Business Models, surveyed 300 U.S. based executives in companies of various sizes across four sectorsautomotive, consumer electronics/telecoms, food/agriculture and healthcare showed some interesting figures about the circular economy. The report looked at whether U.S. companies were including sustainability issues in their growth strategies and, as part of that, what role circular economy goals were playing in those considerations. The study showed that managing ongoing 
product maintenance, adapting sales and distribution models and rethinking product pricing were the three most challenging changes a company would have to make. The report also found that $62 \%$ of American companies are planning to move toward circularity and that almost twice as many U.S. firms are embedding sustainability in strategic decision-making compared to the year before (from 48\% to 85\%). In the February 2019 issie of Forbes, Van Rial notes that that there is still work to be done to get the full benefits out of circular economic thinking, it's all about a comprehensive approach to transforming a company's business model with the goal of creating and retaining value across all processes in their organizations. That means rethinking everything from product design to financing to recycling.

According Codagnone et al. (2016) regarding sharing there are different new business models that are being developed: (1) P2P (Peer-to-Peer) where the exchange happens among individuals intended as "private"; (2) B2P (Business-to-Peer), where the change happens among companies and single consumers and consumers become now individuals linked in virtual communities; (3) P2B (Peer-to-Business) among single consumer to companies; and (4)- B2B (Business-to-Business) among companies themselves. Additionally, according to the EC (2016a), there are three categories of collaborative actors: service suppliers that share goods, resources, time and/or competencies; the users of these services; and the mediators that act through collaborative platforms. Vaughan and Hawksworth (2014) interpret that 'sharing economy' concepts are seen as closely related to the 'circular economy' and/or the 'collaborative economy', but with no clear distinction between consumption and production activities. Several core elements of the sharing economy, such as promoting access over ownership, enabling peer-to-peer connections, and accelerating the use of digital platforms, have the potential to foster greater inclusivity. According to the study regarding sharing economy and business opportunities conducted by Pluess et al. (2016), maximizing the potential of the sharing economy will depend not only on innovation by individual businesses, but also on collaboration among companies, policymakers, and civil society organizations;

Sharing economy platforms have experienced a meteoric rise in recent years, and are projected to grow rapidly in the near future. The rapid growth of some of these platforms has stirred considerable debate over application of state and local regulations to these platforms and the suppliers who use them. For example, the Internet and social media are enabling individuals to more easily connect and share ideas. The maker economy is creating the possibilities to create new streams of income, both for individual artisan sellers as well as for local family-based makers (European Commission 2015a). Digital platforms generally placed under the 'sharing economy' and various other labels match different groups of users and providers and increase the scale and speed of traditional transactions such as selling, renting, lending, labor trade, and provision of services. In many cases, these platform-mediated activities involve peer-to-peer or peer-tobusiness transactions that occur in a regulatory vacuum.

\section{Documents supporting sharing \& collaborative economy}

The labels 'sharing economy' and 'collaborative economy' are used in official documents of the European Commission (EC, 2015b); the European Economic and Social Committee (EESC, 2014); the European Parliament (European Parliament, 2014); and the US Federal Trade Commission (FTC 2015). 
European identity is strongly characterized by inclusivity and social solidarity, thus the collaborative economy represents an opportunity for social innovation in these terms. In recent years, a European network has focused on articulating a European perspective and an appropriate research agenda to study the realities of the collaborative economy. There has been a series of EUsupported initiatives aimed at examining new social and economic models for achieving sustainable growth. For example, the EU Innovate project investigates the creative, innovative and entrepreneurial roles of users in developing sustainable novel products, services and systems (http://www.euinnovate.com/en/sustainable-enterprises). National initiatives have also emerged and innovation and growth value of the collaborative economy has also been recognized widely outside of Europe. The collaborative economy offers greater choice to consumers and new opportunities to entrepreneurs, but citizens and businesses must be aware of existing rules and obligations. In its Communication on "A European Agenda for Collaborative Economy", issued in June 2016, the European Commission announced that it would continuously review developments in the European collaborative economy. According to the communication, the EU provides clarity on applicable EU rules and policy recommendations to help citizens, businesses and EU countries fully benefit from new business models and promote the balanced development of the collaborative economy. In October 2018, the Commission organized the high-level conference, 'Collaborative economy: opportunities, challenges, policies' in Brussels to take stock of policy, regulatory and market developments since the adoption of the Communication on the collaborative economy in June 2016. During the conference the Commission published the results of research about the use of the collaborative economy. The results indicated that one in four EU citizens have used services offered via collaborative platforms and one in five say they either have offered such services or can imagine doing so (European Commission, 2018b). According to the EC (2016), the role of the platforms is essential because they link suppliers with users and allow transactions among them and have grown rapidly thanks to digital progress like internet, applications, and social networks.

To better understand the economic activity generated and issues raised by emerging internet peer-to-peer platforms, the US Federal Trade Commission held a workshop in June 2015 entitled The "Sharing" Economy which has brought together economic, legal, stakeholders, and business experts with an aim to examine competition, consumer protection, and economic issues arising from sharing economy activity. Workshop results show some of the factors underlying the growth of the sharing economy such as how platforms can facilitate entry by small suppliers by providing them with the means to efficiently reach customers on a large scale; and how small suppliers can offer goods and services at attractive prices because they can employ underutilized assets (FTC 2015).

The global economy is rapidly becoming digital and ICT is no longer a specific sector but the foundation of all modern innovative economic systems. The Internet and digital technologies are transforming the lives we lead, the way we work - as individuals, in business, and in our communities as they become more integrated across all sectors of our economy and society. According to a Digital Single Market Strategy for Europe (European Commission, 2015b), a digital single market is one in which the free movement of goods, persons, services and capital is ensured and where individuals and businesses can seamlessly access and exercise online activities under conditions of fair competition, and a high level of consumer and personal data protection, irrespective of their nationality or place of residence. The same document states that, platforms generate, accumulate and control an enormous amount of data about their customers and use algorithms to turn this into usable information. The growth of such data is exponential - $90 \%$ of 
all data circulating on the Internet were created less than 2 years ago. Moreover, platforms have proven to be innovators in the digital economy, helping smaller businesses to move online and reach new markets. New platforms in mobility services, tourism, music, audiovisual, education, finance, accommodation and recruitment have rapidly and profoundly challenged traditional business models and have grown exponentially. The rise of the sharing economy also offers opportunities for increased efficiency, growth and jobs, through improved consumer choice, but also potentially raises new regulatory questions.

\section{Case examples from the US and Central-Southeast Europe}

\section{Business-to-business and business-to-peer connections - Example of IKEA}

IKEA recently launched a furniture rental offering as part of it shift towards the circular economy. The world's largest furniture retailer has unveiled plans to rent its products to consumers for the first time, as it strives to become a 'net-positive' business by 2030. The launch of the scheme came after IKEA UK's sustainability manager Hege Sæbjørnsen said that building a circular economy into IKEA's business model developing a closed-loop solution will be "fundamental" to the retailer's ability to grow and remain relevant with customers in the future (https://www.dezeen.com/2019/02/20/ikea-rental-furniture-circular-economy-design, 2018). The company's 2017 sustainability report (Ingka holding B.V. and its controlled entities, 2017) highlighted that these processes were delivering tangible results. The report outlined a 5.8\% increase in total sales for the financial year. Globally, IKEA has already trebled the sales from its 'sustainable life at home' products. According to Torbjourn Loof, IKEA's chief executive, IKEA is working towards an ongoing target of becoming "a truly circular retailer" trialing furniture leasing across its Swedish stores firstly focusing on office furniture for business owners. Under the proposed scheme, businesses will rent their furniture for a set period before it is taken back by IKEA for either refurbishment, upcycling, resale or recycling. In that way they will prolong the furniture lifecycle. If the proposed business concept trial is successful, IKEA may roll the concept out across other markets and to add kitchens for the consumer market. The most important thing is that if the proposed business concept will be successful it will be fundamental to the company's ability to grow, remain relevant with customers, and survive long-term. In 2017, IKEA last launched its first kitchen incorporating $100 \%$ post-consumer recycled (PCR) plastics and PCR wood. All products are now being designed using its 'democratic design' principles, which are founded on circular values and focused on making products accessible to all (IKEA Sustainability Report, 2018).

Business-to-peer \& busines-to-business sharing

More than 40 years ago, CORT (Chantilly, VA, US) began with a single goal in mind: to deliver unparalleled customer service to people and businesses. They began with residential furniture rental in five regions across the United States and have grown to become the nation's leading provider of transition services, including furniture rental for home and office, event furnishings, students and the military communities, and other services. In addition to their 100+ offices, showrooms and clearance centers across the United States, it has operations in the United 
Proceedings of the 2020 Society of Wood Science and Technology International Convention

Kingdom and partners in more than 80 countries around the globe.'We believe that our customers, colleagues and partners deserve great. And we believe that great things come from an authentic commitment to delivering our very best, every time, everywhere' - Jeff Pederson, President and CEO.

The company SOFRINNOV (Ramonville-Saint-Agne, France) is involved with the construction of shelters that can be used in emergency situations (e.g., refugee camps) and in construction of bungalows and houses compliant with high level thermal needs and low carbon emissions. Both products are developed by recycling woods pallets and using them as building blocks. By creating a piece of wood that acts as a cement between the pallets, they can be assembled as needed. As an example, construction time for a $25 \mathrm{~m} 2$ space takes one day for one person and everything can be assembled by hand without power tools.

The company Feather (New York, San Francisco, Los Angeles, US) believes that furniture ownership is a thing of the past. Through their circular model, they allow members to use the furniture items they need today and when their life or tastes change, they pick it up and give them a second (and third and fourth) life. Furthermore, the company points out that being a flexible subscription service is what makes it possible for their customers to live more conveniently. That's why Feather offers furniture changes to all subscribers. A furniture change is any trip that Feather team makes to someone's home. During these trips consumers may swap items for different ones and/or return items to the Feather ecosystem if they don't want or need them anymore. Members qualify for one free change every year; all other furniture changes are flat-rate and cost $\$ 99$ regardless of the number of items being swapped, picked up, or added. Delivery and assembly are included in this price. Most of the items have been previously used by another Feather subscriber. After each deployment, every Feather item undergoes a quality check and extensive sanitation process before it arrives to be assembled in new consumer home. We believe that when life changes, your things should be able to change with you - without spending a fortune or hurting the planet in the process!

Since 1935 more than one and a half million Aalto stools have been sold. In 2006, Artek (Helsinki, Finland) began collecting used Aalto furniture, searching them out from flea markets and old factories, schools and shipyards. This led to the founding of the Artek 2nd Cycle initiative, which offers these re-discovered pieces for sale, beginning a second cycle in their lives. Artek 2nd Cycle not only showcases the longevity of Artek furniture, it also promotes conscious consumption - the idea that what we buy should be carefully chosen, cherished rather than disposed - and seeks to honour the natural materials that have gone into producing these enduring designs. Gaining character and beauty through everyday use, each Artek 2nd Cycle piece of furniture ages with grace, becoming unique with time. "Nothing is ever reborn, but neither does it totally disappear. And that which has once been, will always reappear in a new form." Circular thinking?

The Dutch wood working company Herso (Loosbroek, the Netherlands) uses reclaimed wood to make new products, from furniture to floors. Herso uses wood from old floors, furniture, cut offs from carpenters and of course their own. They select good pieces of wood, even small ones, to use in their designs. Iron pieces, such as nails, are also reused, while sawdust is use to make bio-alcohol, cat litter, and compost. In the rare case they need to use new wood, it is always FSC certified. Rather than just selling their products, Herso has a sort of deposit money arrangement. In essence, you rent the products. During its use, the product keeps a value that is determined beforehand. At the end of use the product can be handed in, so that Herso can use it again to make new furniture and floors. All Herso's tables are solid and made by hand. They only 
use biodegradable glue. The company also takes on various projects, such as the no-waste floor of Circl, a circular pavilion in the Netherlands. The floor is the size of a football field and made from wood from all sorts of sources, such as a villa from the 50s, old furniture, a hardwood terras, window frames, and an old door. All this waste wood is turned into a beautiful wooden floor. And Herso promises that when the pavilion is deconstructed in 25 years, that they will make new products from the floor.

For Nnof (Vilvoorde, Belgium), office furniture that needs replacing is no longer simply waste. It provides the raw material for Nnof interior designers to design new furnishings which dovetail perfectly with trendy new office design concepts. This design service fits in seamlessly with the principle of the circular economy. Instead of simply dumping existing office furniture, Nnof creates a new cycle that gives it a second or even third life. Nnof stands for 'nearly new office facilities': office furniture that is almost new. The Vilvoorde company designs offices with mostly recycled material, which usually comes from the customer's previous interior. Chairs are reupholstered, tables are given a new top layer, cupboards are disassembled and transformed into new furniture. The end result does not look like a thrift store, but simply as a new interior. In the last two years they have committed the company to re-working, e.g., they use tablets from old tables to make seating furniture, or they design a rack system made from used table bases. If customers leave them somewhat free in their ideas, they can reuse a very large part of their interior. How did they get there? "Around the turn of the century I started to read a lot about climate change, our handling of raw materials and all the problems that awaited us", managing director Didier Pierre. 'That was not fun!

\section{Summary}

A combination of shifting consumer behaviour and rapidly-evolving digital technologies is disrupting long-established business models across many industries and putting increasing pressure on traditional growth models. For example, sharing and collaborative principles applied to products and/or services will give the potential to increase product longevity, reusability and the sharing of materials. Product sharing can also facilitate the sharing of overcapacity or underutilization, improving the efficiency of resource use.

In this study, scientific papers, professional study documents, and policies regarding the sharing and collaborative economies in the U.S. and Europe (economy in general, but also within the wood-based sector) were reviewed and summarized, all relative to sharing and collaborative models as aspects of the circular economy. A theoretical background of the circular economy and sharing and collabrative models as aspects of the circulary economy were developed with an example of IKEA, one of the best-known examples of sharing economy in the wood-based sector. Also, documents and policies supporting sharing and collaborative principles related to the U.S. and European markets were examined. Based primarily on the work of Codagnone and Martens (2016), Botsman (2013), Botsman and Rogers (2010a); Botsman and Rogers (2010b); and Codagnone et al. (2016) examples of the sharing economy and/or collaborative economies related to the U.S. and Central-Southeastern European market were traced. Examples were categorized based on different business models - P2P (Peer-to-Peer); B2P (Business-to-Peer), P2B (Peer-toBusiness); B2B (Business-to-Business). Further, data analysis about perceptions of the sharing and collaborative economies within the wood-based sector was conducted using data from a survey of the Slovenian wood-based sector stakeholders. Given that the level of wood used in residential and public construction, interior design, and outdoor design continues to expand, results and information conducted during this work can help in the process of implementing sharing and 
collaborative economy principles in the the wood-based sector. Perhaps the hardest part will be convincing consumers/customers, but also other stakeholders to change their consumption behavior and way of thinking. An improved understanding of the sharing and collaborative economies is therefore needed to inspire more thoughtful and appropriate responses to these variegated realities, in terms of policy, regulation and institutional support. However, there has not been an opportunity thus far to consolidate this body of work for wood sector communities and to collaboratively shape a future agenda on the topic. Also, we hope that this study will bring a definite value to European and US initiatives on business innovation within the wood-based industry. The information and knowledge from this study will also be valuable for other researchers and scholars examining the collaborative economy in the wood-based sector.

More importantly, this study is giving wood industry stakeholders information and extends knowledge regarding the circular economy and sharing economy which should be used in the development of the actions needed for the cascade use of wood, wood products and utilization of wood following 'circular', 'sharing', and/or 'caring' principles in the wood-based sector. Cascading use of wood is the smart way to use a natural resource - putting it to good use before it is reused, recycled and finally burnt for energy. It strongly overlaps with circular economy ideas. Acknowledgement: The authors would like to thank the Socoety of Wood Science and Technology for Short Term Scientific Mission Scholarship support for Andreja Pirc Barčić .

\section{References}

Basselier R, Langenus G Walravens R (2018) The Rise of the Sgaring Economy. NBB Economic Review 57-78. https://www.nbb.be/doc/ts/publications/economicreview/2018/ecoreviii 2018_h3.pdf

Botsman R (2013) The Sharing Economy Lacks A Shared Definition Fast Company. Retrieved.https://www.fastcompany.com/3022028/the-sharing-economy-lacks-a-shareddefinition

Botsman R, Rogers R (2010a) Beyond zip car: Collaborative consumption. Harvard Business Review, 88(8) 30.

Botsman R, Rogers R (2010b) What's mine is yours: The rise of collaborative consumption. New York: Harper Collins.

Chertow M R (2000) Industrial symbiosis: literature and taxonomy. Annual Review of Energy and the Environment, 25, 313-337.

Codagnone C, Biagi F, Abadie F (2016) The Passions and the Interests: Unpacking the 'Sharing Economy' (2016) Institute for Prospective Technological Studies, JRC Science for Policy Report. Available at SSRN: https://ssrn.com/abstract=2793901 or http://dx.doi.org/10.2139/ssrn.2793901 Codagnone C, Martens B (2016) Scoping the Sharing Economy: Origins, Definitions, Impact and Regulatory Issues. European Commission. JRC Technical Reports. Institute for perspective technological studies, Digital Economy, Working paper 2016/01.

Coyle D (2016) The Sharing Economy in the UK. http://www.sharingeconomyuk.com/perch/resources/210116thesharingeconomyintheuktpdc.docx 1111.d ocx-2.pdf

Ellen MacArthur Foundation (2015) Growth Within: a Circular Economy Vision for a Competitive Europe, SUN, McKinsey Center for Business and Environment, On line at: 
https://www.ellenmacarthurfoundation.org/assets/dow nloads/publications/EllenMacArthurFoundation_Grow th-Within_July15.pdf

European Commission (2015a) Communication from the Commission to the European Parliament, the Council, the European Economic and Social Committee and the Committee of the Regions, Towards a Circular Economy: a Zero Waste Programme for Europe, COM/2014/0398 final/2. http://eurlex.europa.eu/resource.html?uri=cellar:50edd1fd-01ec-11e4-831f-

01aa75ed71a1.0001.01/DOC_1\&format=PDF.

European Commission (2015b) A Digital Single Market Strategy for Europe. COM(2015) 192 final, Brussels: European Commission.

European Commission (2016) Online Platforms Accompanying the document Communication Online Platforms and the Digital Single Market \{COM(2016) 288 final $\}$

European Commission (2018a) Study to Monitor the Economic Development of the Collaborative Economy in the EU. Final Report, part A.

European Commission (2018b) The use of the collaborative economy. file:///C:/Users/Andrea/Downloads/fl_467_sum_en\%20(2).pdf

European Economic and Social Committee (EESC) (2014) Opinion of the European Economic and Social Committee on Collaborative or participatory consumption, a sustainability model for the 21st century. European Economic and Social Committee (EESC), INT/686.

European Parliament (2014) New Trends and Key Challenges in the Area of Consumer Protection. Brussels: European Parliament, Directorate-General for Internal Policies.

European Parliament (2016) Report on a longer lifetime for products: benefits for consumers and companies, (2016/2272(INI)), Committee on the Internal Market and Consumer Protection, Pascal Durand, Rapporteur, On line at: http://www.europarl.europa.eu/sides/getDoc.do?pubR ef=//EP//NONSGML+REPORT+A8-2017- 0214+0+DOC+PDF+V0//EN.

Federal Trade Commission (FTC) (2015) FTC The "Sharing" Economy Workshop transcript $\begin{array}{llllll}\text { segment } & 3 & - & \text { June } & 9, & 2015 .\end{array}$ D.C.https://www.ftc.gov/system/files/documents/videos/sharing-economy-workshop part2/ftc_sharing_economy_workshop__transcript_segment_3.pdf

IKEA (2018) IKEA Sustainability Report. https://preview.thenewsmarket.com/Previews/IKEA/DocumentAssets/535135.pdf

ING (2018) Opportunity and disruption: How circular thinking could change US business models A circular economy survey.https://www.ingwb.com/media/2692501/ing_us-circular-economysurvey-05-02-2019.pdf (Accesed 11/12/19)

Smith J D, Morgan D, Howell B (2015) The Sharing Economy and Design. International conference of engineering and product design education, 3-4 September, 2015. Loughbourgh University, Design School, Loughbourgh, UK.

Sposato P, Preka R, Cappellaro F, Cutaira L, (2017) SHARING ECONOMY AND CIRCULAR ECONOMY. HOW TECHNOLOGY AND COLLABORATIVE CONSUMPTION INNOVATIONS BOOST CLOSING THE LOOP STRATEGIES. Environmental Engineering \& Management Journal (EEMJ). Vol. 16 Issue 8, p1797-1806. 10p.

Vaughan R, Hawksworth J (2014) The sharing economy: how will it disrupt your business? Megatrends: the collisions. PriceWaterhouse\&Cooper, London, UK.

VelevaV, Bodkin G (2018) Corporate-entrepreneur collaborations to advance a circular economy. Journal of Cleaner Production, 188: 20-37.

World Economic Forum, 2016 Circular Economy. https:/www.weforum.org/globalchallenges/ projects/circular-economy (Accessed 05/07/2019) 
Proceedings of the 2020 Society of Wood Science and Technology International Convention

****: https://www.grupposaviola.com/en/eco-ethical

****:https://www.forbes.com/sites/annefield/2019/02/26/circular-economy-support-among-uscompanies-kind-of/\#da8630179c84,

****: https://solarimpulse.com/efficient-solutions/sylcat

****: https://www.livefeather.com/how-it-works

****: https://www.artek.fi/2ndcycle/en/about

Biography 


\title{
Digitalization Rate of SMEs Involved in the Wood Fibers Value Chains in the Alpine Region
}

\author{
Tina Beranič $1 *$-Martina Šestak 1 - Katja Kerman 1 - Špela Pečnik 1 -Aida \\ Kamišalić 1
}

\author{
1 Faculty of Electrical Engineering and Computer Science, University of Maribor, \\ Slovenia \\ * Corresponding author \\ tina.beranic@um.si,martina.sestak@um.si,katja.kerman1@um.si, \\ spela.pecnik@um.si,aida.kamisalic@um.si
}

\begin{abstract}
Digitalization is an increasingly important topic in various business domains, regardless of its size. Despite all the benefits that digitalization brings, the introduction and use of digital technologies in business processes could bring certain challenges and obstacles, especially in subsectors with a low digitalization level. In European countries, the rate of digitalization is measured with a plurality of indicators, among which is also the Digital Economy and Society Index (DESI). In 2019, Slovenia was ranked as 16th among 28-member states, while other Alpine region countries, i.e., Austria, Italy, and Germany, were ranked on the 13th, 24th, and 12th places, respectively. Although available digitalization measures cover a large spectrum of domains and views, the analysis revealing the digitalization level of the Small and Medium-sized Enterprises (SMEs), limited only to the natural fiber domain, cannot be detected. In order to overcome the identified gap, analysis was made measuring the current digitalization level of SMEs operating in the wood fiber value chains. The paper presents the preliminary results of the gathered data, acquired using a survey questionnaire gathering the information from the identified SMEs from Slovenia and Italy. As the results indicate, the level of digitalization in the respondent SMEs is rather low. Although digitalized areas and departments can be detected, a lot of space for possible improvements is still open, allowing multiple possibilities for digitalization development.
\end{abstract}

Keywords: SMEs, digitalization, tools, wood fiber, Alpine Region, Slovenia, Italy, obstacles

\section{Introduction}

Technological development is becoming an indispensable constant, regardless of the business domain in which companies operate. Daily, we are witnessing the technological changes, making the work easier, processes more straightforward and faster, and providing support for different business tasks. Nowadays, digitalization also penetrates extensively into the domains whose primary orientation is not related to IT. According to the definition, digitalization is the use and integration of digital technologies aiming to change the business model, reorganize the work within an organization and upgrade processes within a company [1], [2]. The European Union supports digitalization strongly, to the extent that increasing the usage of ICT technologies and their potential for economic growth is one of the main pillars of the Europe 2020 Strategy and the Industry 4.0 revolution [3], [4]. Regardless of all the benefits that digitalization brings, the process 
can be very challenging for SMEs. According to the European Commission, SMEs are companies with less than 250 employees and less than a 50 million EUR turnover or 43 million EUR Balance Sheet in total [5]. According to the 2018/2019 Annual Report on European SMEs published by the European Commission [6], over 25 million SMEs were registered in the European Union (EU28 ) in 2018, which made up $99.8 \%$ of all EU-28 enterprises operating in the non-financial business sector.

In recent years, a lot of attention has been paid to the introduction of digitalization into SMEs in different business domains. The current state can be seen within the available indexes and measures of digitalization. One of the most known is the Digital Economy and Society Index (DESI) [7], measured by the European Commission. It is used for measuring the level of digitization in EU countries with the use of six areas: connectivity, human capital/digital skills, use of internet services by citizens, integration of digital technology by business, digital public services, and research and development of ICT [7]. Another one is the Digital Transformation Scoreboard (DTS) [8] as part of the Digital Transformation Monitor (DTM) [9] which was launched in 2016 by the European Commission. Its primary purpose is to monitor the transformation of existing industries and businesses. DTS consist of several dimensions, and each is divided into two categories called enablers and outputs. Enablers are again divided into several categories, including digital infrastructure, investments and access to finance, supply and demand of digital skills, e-leadership, and entrepreneurial culture [10]. On the other hand, OECD in the context of the Going Digital project [11], among others, reveals digitalization indicators specifically for the SMEs`subdomain. Many country-level metrics can also be detected. In the Trentino region in Italy, research was done for assessing the level of digitalization of enterprises and evaluating possible strategies to optimize its internal processes with Industry 4.0 technologies [12]. In Germany, in Baden-Württemberg, the "Digital Economic Index" was measured based on 1,124 interviews with companies. The index measured the degree of digitalization of business processes, internal company procedures, and workflows, as well as the intensity of the use of new digital technologies and services. Another study, the "Digitization Index for Small and Mediumsized Enterprises 2019/2020", in which 2,095 SMEs took part, shows that German SMEs are working on their digital transformation continuously [13].

The available information reveals great insight, also into the digitalization level of the SMEs. But still, they do not provide an insight into the digitalization level and tools used within SMEs divided by various domains, for example, the natural fibers domain, e.g. SMEs in wood fiber value chains. The manufacturing of wood and wood-based products takes an important place in the European industry ecosystem, with the highest number of registered enterprises, i.e. around 160,000 in 2017 [14]. SMEs operating in the manufacturing of wood and wood products contribute to this industry by producing a 60-80\% share of added value [6]. For example, Slovenia, the second most forested country in Europe, has $85 \% 1$ of SMEs registered in the fiber-based sectors, which also includes the wood fiber sector [15]. Another example is the Italian Trentino region. In 2019, about 41,583 $\mathrm{m} 3$ of wood was sold, where approx. 39,000 m3 came from spruce wood, $220 \mathrm{~m} 3$ from larch and $900 \mathrm{~m} 3$ from pine [16]. Despite the industry prevalence, the manufacturing industry of wood and wood products is, in general, characterized by a low number of investments in research and

1 Estimation based on the number of members (SMEs) of Strategic research and innovation partnership for Sustainable food production, Circular Economy and Wood Industry Cluster Slovenia. 
development (R\&D) initiatives, and it is categorized as a "low-tech" industry [6], affecting its current digitalization level.

The paper aims to present the preliminary results of the analysis of the digitalization level of SMEs included in different wood fibers value chains, like the eco-construction value chain in Slovenia, or the recycled wood value chain in Italy. The study was performed within the EU-project Smart SME's, which is co-financed by the European Parliament through the Alpine Region Preparatory Action Fund II (ARPAF II). The data were acquired with a survey questionnaire gathering the information from the Slovenian and Italian (Trentino region) SMEs identified in different wood fiber value chains.

The structure of the paper is as follows. The next Section presents the implemented survey, covering the questionnaire structure and gathered results, presented in a structured form also as a comparison between Slovenian and Italian SMEs. Among other information, obstacles are presented for the expansion of the digitalization detected by SMEs. The last Section sums up the results, providing final comments and remarks on the gathered information.

\section{Digitalization rate of wood fiber value chains}

The data within the implemented analysis were gathered using a structured questionnaire, which was divided into different parts, combining content-related questions. The first part of the questionnaire covered company information, the second part covered the current state of integration of digitalization in the company, in the third part companies were asked why and in what way they are willing to invest in digitization, and in the last, fourth part, the questions looked into any targeted external support gathered from companies' regions used for adaptation of new digitalization technologies. To achieve the highest possible response rate, the questionnaires were translated into the language of the country in which the company was located, i.e. Slovenian and Italian. The questionnaires in Slovenia were distributed as an online questionnaire, while also sent to the respondents in paper form.

\section{Surveyed SMEs and their digitalization level}

Sixteen SMEs from the Alpine region responded to the survey, 12 from Slovenia and four from Italy, specifically from the Trentino region. 56.3\% of surveyed SMEs came from the production sector, $37.5 \%$ process wood, while only a few SMEs operate in the wood procurement or construction sectors, $12.5 \%$ and $18.8 \%$, respectively. Most surveyed SMEs had a low to moderate level of digitalization. In Italy, only $50 \%$ of SMEs provided an answer to this item, indicating that they rarely use digitalization tools. On the other hand, half of the surveyed SMEs in Slovenia use digitalization tools in approximately $50 \%$ of their work, approximately one third uses it rarely or never, and only $8.3 \%$ use it in all processes.

Table 1 - Frequencies and percentages for processes where digitalization already takes place in surveyed SMEs.

\begin{tabular}{|c|c|c|c|c|c|c|}
\hline \multirow{2}{*}{} & \multicolumn{2}{|c|}{ Slovenia } & \multicolumn{2}{|c|}{ Italy } & \multicolumn{2}{|c|}{ Total } \\
\cline { 2 - 7 } & $f$ & $\%$ & $f$ & $\%$ & $f$ & $\%$ \\
\hline
\end{tabular}


Proceedings of the $\mathbf{2 0 2 0}$ Society of Wood Science and Technology International Convention

\begin{tabular}{|l|c|c|c|c|c|c|}
\hline Purchasing & 7 & 58.3 & 1 & 25.0 & 8 & 50.0 \\
\hline Production & 9 & 75.0 & 2 & 50.0 & 11 & 68.8 \\
\hline Packaging & 3 & 25.0 & 0 & 0.0 & 3 & 18.8 \\
\hline Logistics & 5 & 41.7 & 1 & 25.0 & 6 & 37.5 \\
\hline Sales & 8 & 66.7 & 3 & 75.0 & 11 & 68.8 \\
\hline General management & 9 & 75.0 & 3 & 75.0 & 12 & 75.0 \\
\hline Other & 3 & 25.0 & 0 & 0.0 & 3 & 18.8 \\
\hline
\end{tabular}

Table 1 lists the most common processes or departments within respondent SMEs, where digitalization is already a common practice. The digitalization is most commonly used in the general management department, followed by the sales, production and logistics departments. In Slovenian SMEs, packaging is the process with the lowest digitalization, and in Italian SMEs, logistics, purchasing, and packaging are among the processes with the lowest levels of digitalization.

\section{The use of ICT tools for communication within the surveyed SMEs}

Communication, either with clients or partners or within the company, is a promising area, allowing numerous digitalization options. Different communication options within Slovenian and Italian SMEs are presented in Figure 1. The most commonly used ICT tool for the communication with partners and clients in Slovenian SMEs is email, and in Italian SMEs their websites. When it comes to the phone and email, both options are the second most used within Italian SMEs, followed by different messaging applications. In contrast, in Slovenian SMEs, email is followed by phone and the company website. Online sharing platforms or messaging applications are used less commonly, followed by fax and external services for distance meetings.

Communication with employees in Slovenian SMEs is most often done via phone and email, and less frequently via other tools. External services for distance meetings are used as un(commonly) as a fax. Communication with employees within the Italian SMEs is performed by phone and email. Fax or external services for distance meetings are not used at all.

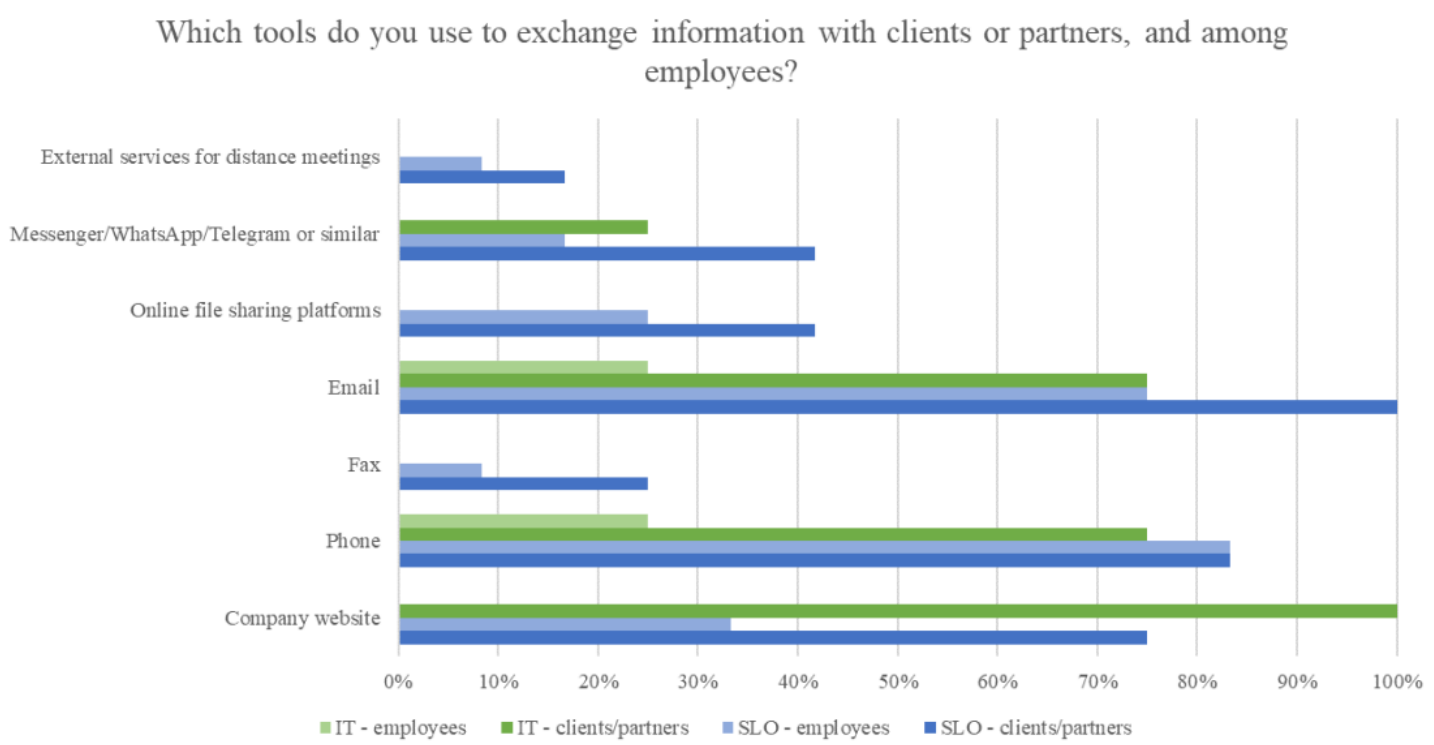


Proceedings of the 2020 Society of Wood Science and Technology International Convention

Figure 1 - Survey results considering exchanging information with clients, partners and among employees.

\section{Digitalization goals and present or future digitalization investments}

In order to invest in digitalization, companies must see a clear goal and advantage. Therefore, the surveyed SMEs were asked which goals they associate with digitalization. Slovenian SMEs stated innovations and productivity as the most frequent answer, $58.3 \%$, followed by cost-saving, 50\%, and new clients or markets, $41.7 \%$. When it comes to the surveyed SMEs from Italy, new clients and markets were most commonly associated with digitalization, at $75 \%$, followed by innovations, $50 \%$. However, none of the Italian SMEs associated digitalization with productivity or cost-saving.

Some of the surveyed SMEs had already taken, or were willing to take some measures and actions towards digitalization. Among Italian SMEs, the most common option was investment into the development of the company's website and e-recruitment on social media, followed by online advertisements and promotion. Only 25\% of SMEs (would) invest in the acquisition of novel or significantly improved hardware and/or software and in the introduction of new IT security concepts and applications, while none (would) invest in the reorganization of the workflow for integration of new digital work steps. On the other hand, three-quarters of Slovenian SMEs (would) invest in the acquisition of novel hardware and/or software. Around half (would) invest in the website development, in the development of new concepts for marketing or sales via the Internet, and e-recruitment in social networks. Investing in the introduction of new IT security concepts and applications, and reorganization of the workflow for integration of new digital work steps to increase the level of digitalization is less frequent among Slovenian SMEs.

\section{Perceived digitalization obstacles}

Although digitalization is an emerging topic in almost every business domain, different obstacles are perceived, especially among small and medium companies whose primary domain is not related to IT. Regarding the digitalization obstacles SMEs are facing, a similar trend can be observed in both countries. Very commonly, lack of financial resources is exposed, stated by at least half of the respondents within Italian and Slovenian SMEs. It was followed by a lack of qualified personnel, as well as difficulties with reorganizations. The more technologically oriented obstacle, i.e. lack of data protection and security is the least commonly experienced challenge in both countries.

The most commonly exposed obstacle, lack of financial resources, is a known problem, which countries try to address by using different kinds of targeted support. Since the support is available in Slovenia and Italy, the survey looked at whether the surveyed SMEs are receiving any external targeted support related to digitalization. As the results indicate, only one Italian SME is receiving funding aimed as an investment in production processes. The number is similar within the Slovenian SMEs. Two of them responded that they are currently in the application process for targeted external support, while one of them will invest the funding in purchasing processes. 


\section{Conclusions}

The results of the preliminary analysis researching the state of digitalization in Slovenian and Italian SMEs included in the wood fiber value chain are presented. The results reveal a relatively low level of digitalization for both Slovenian and Italian SMEs. Only a minority of the SMEs' departments and processes are digitalized, offering a lot of space for further development and implementation. However, it can be observed that SMEs are faced with several challenges and obstacles when it comes to digitalization, with lack of financial resources being the most predominant one. As the financial aspect is a known obstacle, not only for SMEs, countries are addressing the challenges with different kinds of targeted external support. But, as indicated by our results, only a few of the surveyed SMEs are receiving external funds to increase their level of digitalization. Since the survey covered only a small sample of Slovenian and Italian SMEs, the results could not be generalized, and have to be interpreted with caution. Nevertheless, they still offer a great insight into the current digitalization rate of SMEs embedded in wood fiber values chains.

\section{Acknowledgements}

The content of this paper was developed within the Smart SME's Project, co-financed by the European Parliament through the Alpine Region Preparatory Action Fund (ARPAF II) (20192021). The authors would like to express their appreciation to the project partners (Schweizerische Arbeitsgemeinschaft für die Berggebiete (SAB), BIOPRO Baden-Württemberg GmbH, Department for Economic Development, Research and Labour of the Autonomous Province of Trento, Hub Innovazione Trentino, ecoplus. The Business Agency of Lower Austria and Anteja ECG) for their valuable contribution and all the survey's respondents for their insight into the researched topic.

\section{References}

[1] Gartner Inc., "Digitalization,” Gartner Glossary, 2020. .

[2] IGI Global, "What is Digitalization," 2020. [Online]. Available: https://www.igiglobal.com/dictionary/it-strategy-follows-digitalization/7748. [Accessed: 05-May-2020].

[3] B. Rivza, M. Kruzmetra, I. Gudele, and D. Foris, "Digitalization as an essential growth factor contributing in SME development (experience of Latvia and Romania)," Agron. Res., vol. 17, no. 1, 2019.

[4] C. Santos, A. Mehrsai, A. C. Barros, M. Araújo, and E. Ares, "Towards Industry 4.0: an overview of European strategic roadmaps," Procedia Manuf., vol. 13, pp. 972-979, 2017.

[5] European Commission, "What is an SME?," Internal Market, Industry, Entrepreneurship and SMEs, 2020. [Online]. Available: https://ec.europa.eu/growth/smes/business-friendlyenvironment/sme-definition_en. [Accessed: 04-May-2020].

[6] European Commission, "Annual Report on European SMEs - 2018/2019," 2019.

[7] European Commission, "The Digital Economy and Society Index (DESI)," 2019. [Online]. Available: https://ec.europa.eu/digital-single-market/en/desi. [Accessed: 05May-2020].

[8] European Commission, "Digital Transformation Scoreboard," 2018. [Online]. Available: https://ec.europa.eu/growth/tools-databases/dem/monitor/scoreboard. [Accessed: 04-May- 
2020].

[9] European Commission, "Digital Transformation Monitor," 2018. [Online]. Available: https://ec.europa.eu/growth/tools-databases/dem/monitor/. [Accessed: 04-May-2020].

[10] J. Erjavec, A. Manfreda, J. Jaklič, and M. I. Štemberger, "Stanje in trendi digitalne preobrazbe v Sloveniji," Econ. Bus. Rev., vol. 20, pp. 109-128, 2018.

[11] OECD, Going Digital: Shaping Policies, Improving Lives. 2019.

[12] Politecnico di Milano - Manufacturing Group - School of Management, "Industria 4.0 verso la digitalizzazione," 2017. [Online]. Available: https://www.testindustria4-0.com/. [Accessed: 04-May-2020].

[13] Deutsche Telekom AG Corporate Communications, "The digital status quo of German small and medium-sized enterprises," 2019.

[14] Eurostat, "Manufacturing statistics - NACE Rev. 2," 2020. [Online]. Available: https://ec.europa.eu/eurostat/statistics-explained/index.php/Manufacturing_statistics__NACE_Rev._2\#Sectoral_analysis. [Accessed: 15-May-2020].

[15] A. Kamišalić and D. Osvald, "Regional Status Analysis Slovenia (Smart SME's - WP2 Mapping of actual state of play and needs)," 2019.

[16] BIOPRO Baden-Württemberg GmbH, "Mapping of actual state of play and needs Synthesis report (Smart SME's - WP2),” 2020.

Biography 


\title{
Proceedings of the 2020 Society of Wood Science and Technology International Convention
}

\section{A Circular Economy for Wood under the European Green Deal}

\author{
Michael Burnard 1 \\ mike.burnard@innorenew.eu \\ Uwe Kies2 \\ uwe.kies@innovawood.eu \\ Kim Turk Mehes1 \\ kim.turk@innorenew.eu \\ 1 InnoRenew CoE \& University of Primorska, Slovenia \\ 2InnovaWood, Belgium
}

\begin{abstract}
The Circular Economy (CE) has become a prevalent topic in policy and research in Europe during the last years. In 2015, the EU Circular Economy Package was adopted which defined priority areas relevant to the forest-based sector and wood use. The most important of these were Construction \& Demolition and Biomass and bio-based products. With this new focus, the EU shifted its narrative focus from becoming a recycling society and using waste as a resource to extending the life and value of products, materials, and resources in the economy as long as possible. This latter narrative continues in the European Green Deal (EDG) was accepted by the European Commission in December 2019. Plans are under way to implement broad national policy support for it throughout the EU. The EDG sets the goal of driving Europe to become the first climate-neutral continent, highlighting several priority areas for policy development. The main opportunities for Wood under the EDG seem to lie under the building and renovation and sustainable industry policy areas. However, construction related topics here are primarily related to energy efficiency and material minimization through renovation. Several construction materials are specifically mentioned, but wood is not (in contrast to cement and steel, sand, and gravel). Moreover, the value of steel, chemicals, and cement is highlighted as indispensable to Europe's economy, targeting a zero-carbon steel making process by 2030 . Forests are addressed extensively in the EDG, with the emphasis on reducing de-forestation and increasing afforestation to increase the absorption for $\mathrm{CO}_{2}$. While promoting a circular bioeconomy is mentioned as part of plans for forest policy, it remains difficult to see the same support for wood value chains as for steel and cement related value chains. At this stage the lack of specific mention of wood or wood value chains implies several things for the future of wood in Europe's plans for the circular economy: First, as researchers and practitioners, we must shape product development with environmental and social impacts in mind; second, developing materials, products, and processes that align with key activities in the EDG such as renovation, material reduction, digitization; and, third, be active in developing policy at the regional, state, and international levels that support the role of wood in the circular economy. The H2020-funded WoodCircus project addresses each of these items, including research and policy recommendations for strengthening the role of the forest sector in the CE.
\end{abstract}

The authors gratefully acknowledge funding support from the EC for the WoodCircus H2020 project (GA\# 820892). Authors MB and KTM gratefully acknowledge the EC for funding support from the InnoRenew CoE H2020 project (GA\# 739574).

\section{Biography}


Proceedings of the $\mathbf{2 0 2 0}$ Society of Wood Science and Technology International Convention

\title{
Raising the Bar: Women Administrator Leaders in Top World Forestry Universities
}

\author{
Pipiet Larasatie \\ pipiet.larasatie@oregonstate.edu \\ Taylor Barnett \\ barnettt@oregonstate.edu \\ Eric Hansen \\ eric.hansen@oregonstate.edu \\ Oregon State University, USA
}

\begin{abstract}
The forest sector has been historically acknowledged as a male-oriented and male-dominated workplace. Due to this image, women were reported less likely to choose a career in the forest sector. As a part of the first author's PhD dissertation, this study utilizes interviews to explore the perceptions of women leaders on the role of universities in diversifying the forest sector. Our respondents are women administrator leaders (e.g., dean, vice dean, department head) in the top four forestry universities in the world based on The Center for World University Rankings: Swedish University of Agricultural Sciences (SLU) in Sweden, Oregon State University (OSU) in USA, University of British Columbia (UBC) in Canada, and University of Helsinki (UH) in Finland. Most of our respondents agree that there is today, better gender diversity in their institutions due to university and college/faculty efforts. However, a leader mentioned that there has been a heavy burden on early women faculty member entrants to the field. These few individuals carry a disproportionate service workload representing diverse perspectives on committees and in other university work. This takes time away from primary job requirements such as research, at times resulting in poor performance reviews and at other times resulting in exhaustion.
\end{abstract}

Biography 


\title{
Proceedings of the 2020 Society of Wood Science and Technology International Convention
}

\section{The Oil Palm Trunk: Opportunities and Challenges for the Malaysian Timber-Based Industries}

\author{
Yueh Feng Loh, Malaysian Timber Board, Malaysia \\ loh@mtib.gov.my
}

\section{Abstract}

The Malaysian timber industry is an important income generator for the Malaysian's economy. In 2019, the export revenue of timber and timber products was valued an excess of RM22 billion. The supply of raw material is central in order to further develop this thriving industry towards continuous growth. With natural forests being kept safe via sustainable forest management practices and with heightened awareness in conservation and green practices, the timber industry is looking at alternative raw material. There are 5.7 million hectares of oil palm plantations in Malaysia. After 25 years, the oil palm trees will begin yielding less fruit and need to give way for replanting of new young trees. This presents a boon to the timber industry as the felled oil palm trunk (OPT) is a renewable source of alternative raw material. It is expected close to 11 million OPT logs will be felled to make way for replanting every year. This alternative material has come at the right time for timber industry. With tough competition in the global marketplace, rising costs and tight supply of timber, the timber industry has been looking for a revival. The solution appears to be in OPT which is able to be processed into plywood and timber. Initiative that carried out by Malaysian Timber Industry Board (MTIB) and the timber industry, both in the past and present, has enabled OPT to become a new and an important source of raw material for conversion into veneer, plywood and other timber products. To date, MTIB has encouraged and promoted a number of activities particularly in the processing of OPT into value-added downstream products for further utilization in both construction and furniture industries. There are fundamental differences between OPT and natural forest logs in the area of density, moisture content and mechanical properties. These attributes require modified equipment and processing methods for peeling, sawing, drying, chemical treatment, gluing and finishing. These differences pose challenges to the existing plywood and timber factories that have to research and identify the best operational techniques to process OPT. There are many challenges in processing OPT. More research work would be needed especially in the process of transforming OPT into plywood and other timber products. Good quality products can be made, however the ultimate test is how well the market can accept them. The emergence of plywood and sawn timber made from OPT should present an attractive proposition to importing countries as it is environmentally friendly and sustainable. This is also in line with rising demands for environmentally friendly and sustainably managed timber products in the developed countries. With this in mind, many initiatives have to be undertaken to introduce these timber products to the global market.

Biography 


\title{
Moving Past the Traditional Structure of Academic Publishing - Realigning Incentives with the Goals of Science
}

\author{
Benedikt Neyses, Luleå University of Technology, Sweden \\ benedikt.neyses@ltu.se
}

\section{Abstract}

Academic publishing is dominated by an oligopoly of a small number of large publishers, with Elsevier, Sage, Springer, Taylor \& Francis and Wiley accounting for more than $50 \%$ of all articles within scientific, technical and medical (STM) publishing. Between 1986 and 2005, serial expenditures for the member libraries of the Association of Research Libraries have increased by $302 \%$, while the number of serial items purchased over the same period has increased by only $45 \%$. In 2014, STM publishers generated a revenue of several billion dollars, and as these publishers obtain the content they are selling free of charge, their average profit margin reaches the extraordinary value of $37 \%$.

Simply put, within the current structure of academic publishing, the large publishers generate high profits while only contributing marginal value to the system. In the realm of social sciences and economics, such behavior is known as "free-riding", a type of market failure. Usually, this leads to under-production of the goods or services affected and the system eventually breaks down. However, in the case of academic publishing under-production is avoided because the content creating institutions, i.e. the universities have an apparent dependence on the publishers, which further amplifies the publisher's status as free-riders.

The current situation has caused an incentive structure that encourages a publication bias towards positive results, "salamipublishing" of marginal scientific findings, and an exponentially increasing number of peer-reviewed publications, even though, historically, actual scientific progress has only been linear.

One solution to these problems would be to report scientific studies without using the traditional publishing companies as middlemen, by creating a community-based and non-profit publishing platform, but this has not happened, yet. From a gametheory perspective, the current situation is similar to a so-called "stag hunt" game that has developed towards a risk-dominant Nash equilibrium. This means that for any one actor within the system it is safer to avoid risk and instead maintain the status quo, even though all actors would be better off if they would cooperate and move towards a pay-off dominant strategy.

Historical analyses of other stag hunt-like situations have shown that moving from the risk-dominant equilibrium towards the pay-off dominant equilibrium is difficult because most actors predominantly act out of self-interest. A possible approach to solve this dilemma could be to re-align the incentive structure within academic publishing in a way that the self-interest of individual actors aligns with the larger goal of science, which is the establishment of increasingly accurate descriptions of the natural world. Hence, my objective is to gauge the interest for this topic within the wood science community, and to start a discussion about which steps need to be taken in order to put such a re-alignment of incentives into practice.

\section{Biography}


Proceedings of the 2020 Society of Wood Science and Technology International Convention

\title{
The Wood Science and Technology Program at West Virginia University: A Case Study
}

\author{
Gloria Oporto, West Virginia University, USA \\ gloria.oporto@mail.wvu.edu \\ Joseph McNeel, West Virginia University, USA \\ jmcneel@mail.wvu.edu
}

\begin{abstract}
Over the past decade, an education in Wood Science has continued to attract fewer students as a career option at universities across the US. For example, at one land grant university in the Appalachian region, the wildlife and fisheries management program attracts 70 to 80 new students every fall. In contrast, the wood science program in that same university draws fewer than 10 students every fall. But in terms of potential employment after graduation and the earning potential of graduates from these two programs, a wood science graduate is highly marketable and will generally earn more than a graduate from a wildlife and fisheries program. Graduates from a wood science program will typically receive two or even three employment offers with an average starting salary ranging as much as $\$ 50$ to $\$ 70 \mathrm{~K}$ annually, depending on his/her specific responsibilities. The wood science program at West Virginia University (WVU) continues to struggle with low enrollment and scrutiny from University administrators hoping to expand programs. This paper focuses on the efforts of the Wood Science Program at WVU over the last ten years, from the successful re-accreditation review in 2010 to the last re-accreditation review in 2020. We will focus on how undergraduate education has evolved over this time, as well as the impact of changing enrollment goals on the program and its sustainability over time. Topics such as sustainability, green building, carbon footprint, and circular economy have driven educational changes at many institutions of higher learning and many academic administrators believe that students entering university demand an education that incorporates these terms into the curriculum. This program, undergoing to challenges and opportunities, is also moving in that direction and it is performing aggressive recruiting activities in conjunction with the University Forest Resource Management Program and several wood-related companies to promote, attract, recruit and retain students in both, Forestry and Wood Science and Technology fields.
\end{abstract}

\section{Biography}


Proceedings of the 2020 Society of Wood Science and Technology International Convention

\title{
Material Choice: A New Frontier in Corporate Sustainability
}

\author{
Rajat Panwar, Appalachian State University, USA \\ panwarr@appstate.edu \\ Eric Hansen, Oregon State University, USA \\ eric.hansen@oregonstate.edu
}

\begin{abstract}
Corporate involvement in achieving environmental sustainability has been proliferating during the last four decades, but it is generally restricted to the choices firms implement to make their production processes environmentally friendlier. As a result, while there is a significant body of literature that seeks to discern between green firms and non-green firms within an industry, such juxtapositions at an industry level are rather scant. This is striking, particularly because the environmental impacts of a firm are intrinsically and inherently tied to the nature of the basic raw material that passes through its value chain. Competing raw materials may lead to significantly different end-of-product life cycle environmental impacts, even between firms with the same level of commitment to greenness in their production processes. This understanding, while common among LCA scholars, is not fully integrated in corporate sustainability literature. Our primary purpose in this presentation is to explore the role of material choice in corporate sustainability. Specifically, we address how material choice imposes fundamental restrictions on a firm's ability to mitigate its environmental impacts. Overall, we propose that corporate sustainability discourse ought to shift its focus away from firm level initiatives to focus on industry characteristics. We argue that the keystone choice in sustainability decisions is about materials. The process choice is a secondary, though important, matter.
\end{abstract}

Biography 
Proceedings of the 2020 Society of Wood Science and Technology International Convention

\title{
Barriers and Drivers of Thermally-Modified Wood: Perceptions of Architects in the USA
}

\author{
Henry Quesada, Virginia Tech, USA \\ quesada@vt.edu
}

\begin{abstract}
Thermal modification is a relatively new wood modification process in the United States (US). The production of thermally-modified wood (TMW) in the US is estimated in 100,000 cubic meters per year and hardwood species commonly known as yellow poplar (tulip wood) and ash are the most common treated species in this industry. In this project over 1000 architects were surveyed to ask their knowledge on TMW. Only 15\% of the respondents indicated they have worked with TMW in some capacity, indicating that there is still little awareness of TMW in the architectural community. The most common perceived advantage of TMW by architects is dimensional stability while there is little knowledge by the respondents on pricing and availability of TMW.
\end{abstract}

Biography 
Proceedings of the 2020 Society of Wood Science and Technology International Convention

\title{
Wood Waste, Source of Sustainable Livelihood for Women Group
}

\author{
Haruna Seidu \\ hseidu@csir-forig.org.gh \\ James Korang \\ jkorang@csir-forig.org.gh \\ Safia Ibrahim \\ isafia19@gmail.com \\ CSIR - Forestry Research Institute of Ghana, Ghana
}

\begin{abstract}
Ghana has made significant headway toward poverty reduction over the past few decades. However, Poverty is pervasive in rural areas and in recent times, in the regional cities across the length of the country. In Kumasi, the Ashanti region of Ghana, is situated the country's biggest wood processing and furniture production hub. The Sokoban Wood Village (SWV) employs over 12,000 direct and indirect jobs. A study was conducted to assess how this men dominated trading community is helping women in poverty alleviation in fulfilment of the Sustainable development Goal One (SGD1). The survey revealed an interesting trade, emerging at the Sokoban Wood Village where women are using wood waste from the processing of wood to produce charcoal. This is done by heaping scrap wood covered with sawdust for carbonization without cutting trees in the forest. Over 70 women are involved in this business, each making approximately USD 90 a week from the production of $7.2 \mathrm{~m} 30$ f charcoal for both local food vendors and domestic use. The charred sawdust is used as soil conditioners for local vegetable producers within the Kumasi metropolis. Despite the tedious nature of the carbonization process, it is a real livelihood for their families. In conclusion, the activities of these women is saving the cutting down of trees by charcoal producers leading to sustainable forest management.
\end{abstract}

Key Words: Women group, livelihood, Charcoal, sustainable forest management, Scrap wood

\section{Biography}




\title{
Tuesday, July 14
}

\section{Composites and Adhesives}

Chairs:

David DeVallance, InnoRenew CoE \& University of Primorska, Slovenia

Douglas Gardner, University of Maine, USA

\section{Learning About and From the Functionality of Primers in Glulam Bonding}

\author{
Thomas Böger 1 \\ boeger@hfm.tum.de \\ Klaus Richter2 \\ richter@hfm.tum.de

\begin{abstract}
1Technical University of Munich, Holzforschung München, Germany Research Munich, Germany
\end{abstract} \\ 2Technical University of Munich, School of Life Sciences Weihenstephan, Wood
}

\section{Abstract}

In the past decades, glulam has been produced almost exclusively from spruce due to its broad availability and easy machinability [1]. However, nowadays silviculture changes and the availability of other species, e.g., beech, birch, larch and Douglas fir, will increase [2]. Some of those species offer new opportunities for glulam due to their higher durability or higher mechanical properties. On the other hand, production processes have to adapt to those species and still be profitable, as well as fulfilling standards for quality and safety.

An adhesive type often used in glulam production is the one component polyurethane (1C-PUR) because of its high throughput in the production due to short processing times. However, in combination with the earlier mentioned species, 1C-PUR struggles to gain technical approval. This is due to too high delamination rates and too little wood failure. Nevertheless, when applying a primer onto the wood prior to the adhesive, 1C-PUR complies with regulations. Since the primer is an additional step in the production, it hinders an adaptation in the industrial-scale manufactory. Therefore, a deeper understanding of the primers' functions would set the first step to integrating it into the adhesive formulation.

In this study, we investigated the effect of a hydrophobic resorcinol-based primer and a commercial hydrophilic primer on beech, birch, larch and Douglas fir bonded with 1C-PUR. Thus, two sets of experiments were conducted, where untreated wood was compared with primer-treated wood. First, the influence of the primers on the bond quality in the glulam was assessed by European standards for mechanical testing. Also the progressive method of digital image correlation (DIC) is applied to gain a deeper understanding of changes in the stress distribution in and around the bondline. Secondly, the primers' influence on the hydrologic processes near the surface of the wood was evaluated by means of an automated dynamic vapor sorption device (DVS), vapor flow rate, contact angle and its swelling behavior.

Mechanical tests reviled a significant improvement in the tensile shear strength and wood failure percentage, especially when tested on wet wood. In addition, changes in wettability and sorption behavior of the wood were observed, even though the samples differ between the primers. However, no significant changes in the vapor flow rate, as well as the swelling and shrinkage, were perceived.

Based on the currently available results, we conclude that i) the hydrophobic primer supports the wood structure, which leads to a change in stress distribution near the bondline, whereas ii) the hydrophilic primer changes the water transport near the bondline at high humidity values and in the wet stage of the wood. 
Proceedings of the 2020 Society of Wood Science and Technology International Convention

[1] D. Ohnesorge, M. Henning, and G. Becker, "Bedeutung von Laubholz bei der Brettschichtholzherstellung: Befragung unter BSH-Produzenten in Deutschland, Österreich und der Schweiz," (in German), Holztechnologie, 2009.

[2] FAO, "Global Forest Resources Assessment 2015, Country Reports," ed. Rome: Food and Agriculture Organization of the United Nations, 2014.

Biography 


\title{
Porous Structures Produced from Different Bark Particles by Mechanical Foaming
}

\author{
Maria Busquets Ferrer1 \\ m.busquetsferrer@wood-kplus.at \\ Axel Solt-Rindler 1 \\ a.rindler@wood-kplus.at \\ Oliver Vay 1 \\ o.vay@wood-kplus.at \\ Christian Hansmann2 \\ c.hansmann@wood-kplus.at \\ Wolfgang Gindl-Altmutter2 \\ wolfgang.gindl-altmutter@boku.ac.at

\begin{abstract}
${ }_{1}$ Wood K plus - Competence Centre for Wood Composites and Wood Chemistry Area Wood Materials Technologies, Resources and Life Sciences, Vienna
\end{abstract} \\ 2Institute of Wood Technology and Renewable Materials, BOKU-University of Natural
}

\begin{abstract}
Bark is the outer layer of trees and therefore protects the inner structures from environmental impact. Currently its potential is not exploited, as bark is mainly used as fuel in the sawmills. This implies that a high amount of potential raw material is wasted, since bark is an interesting material to obtain value added products. Moreover, and due to an increasing demand of energy there is also an increase interest in developing efficient insulation materials from renewable resources, and bark could be one of the possible options. The purpose of this study was to use spruce bark as a raw material to produce porous structures that could be implemented as insulation materials, since spruce is commonly use in the wood industry, and the amount of its bark available is higher than other species. Thus, wet spruce bark was obtained directly after debarking and disintegrated into different particle sizes by different chippers and mills. Furthermore, bark fibres were successfully produced by means of a laboratory refiner. Consequently, particles and fibres with different morphological properties were obtained and characterized by incident light microscopy and particle size distribution. In order to obtain a porous material different bio-based and non-biobased binders such as cationic starch, wheat gluten, bone glue and polyvinyl acetate (PVAc D3) were investigated. The foams could be produced by mechanically introducing air inclusions with low water contents and hardened to stable structures by conventional hot air drying.

The porous structures were finally characterized in terms of density, morphology, thermal conductivity and mechanical properties. The results reveal comparable properties to conventional bio-based insulation materials. Thus this study draws possible pathways to utilize bark as insulation material, without complex material pre-treatment.
\end{abstract}

Biography 


\title{
Proceedings of the 2020 Society of Wood Science and Technology International Convention
}

\section{Influence of Atmospheric Air Plasma Pre-Treatment of Veneers on the Mechanical Properties and Stability of Beech Plywood}

\author{
Sebastian Dahle 1 \\ sebastian.dahle@bf.uni-lj.si \\ Irena Uranjek2 \\ irena@rogacplus.si \\ Jure Zigon 1 \\ jure.zigon@bf.uni-lj.si \\ Sergej Medved 1 \\ sergej.medved@bf.uni-lj.si
}
1 University of Ljubljana, Biotechnical Faculty, Department of Wood Science and Technology, Slovenia
2Rogač Plus d.o.o., Slovenia

\begin{abstract}
Wood-based sheet materials such as plywood, fiberboard, particleboard, and oriented strain board find applications in civil engineering, building technology, furniture manufacturing and many more. All these materials rely strongly on an effective bond formation between the resin and the wood base material, which gives rise to their mechanical performance and stability, as well as their resistance to moisture and liquids. In our study, we present the use of the PlasmaTreat Openair $\subsetneq$ commercial atmospheric air plasma system, which we employed for the pretreatment of veneers of common beach (Fagus sylvatica L.) wood before formation of plywood boards. Plasma treatment parameters were optimized following the change in water contact angle. Two different stacking patterns were used for plasma-treated veneers. The time stability of the plasma modification was investigated by forming a second set of plywood boards 70 hours after plasma treatment of the respective veneers. The influence of the plasma treatment on mechanical properties was studied via bending and shear strength of the four sets of plasma-treated boards in comparison to a plywood out of the same veneer without plasma treatment. Water and moisture resistance were tested through water immersion and surface water resistance tests. Further, confocal laser scanning microscopy was used to determine changes of the surfaces' morphologies.
\end{abstract}

Biography 


\title{
The Compatibility between Components of Wood-Plastic Composites using Chemical Force Microscopy
}

\author{
Bernard Effah1* - Martina Meincken2 \\ 1Dept. of Interior Design \& Materials Technology, Kumasi Technical University, \\ Ghana \\ bernard.effah@kstu.edu.gh / bernardeffah@gmail.com \\ ${ }_{2}$ Department of Forest and Wood Science, Stellenbosch University, South Africa \\ mmein@sun.ac.za
}

\begin{abstract}
Chemical Force Microscopy (CFM) was used to quantify the adhesive forces between functionalised tips and model substrates through adhesive force measurements to understand how well the main components of wood-plastic composites adhere to each other.

Films of $\alpha$-cellulose, lignin alkali, softwood and hardwood extractives, polyethylene-graft-maleic anhydride (PE-g-MA), ethylene-co-vinyl alcohol (EVOH), low-density polyethylene (LDPE) and Polypropylene (PP) were prepared. Silicon force modulation cantilevers were modified with carboxylic acid $(\mathrm{COOH})$, methyl $\left(\mathrm{CH}_{3}\right)$ and the compounds typically used as compatibiliser, namely PE-g-MA and EVOH, for force-distance measurements. The films were characterized using Fourier Transform Infrared (FTIR) spectroscopy to confirm the presence of functional groups. From the force-distance curves the average adhesive force between the substrates and the coated tips was determined and principal component analysis (PCA) was conducted to ascertain the total variance.

Strong adhesive forces can be expected between similar chemical groups and accordingly strong adhesive interactions were found between the $-\mathrm{COOH}$ coated tip and cellulose and extractives films. Similarly, the $-\mathrm{CH}_{3}$ coated tip exhibited stronger interaction on the lignin film. The interaction between the compatibiliser coated tips and model $\alpha$-cellulose, lignin alkali, softwood and hardwood extractives components showed varied sensitivity and affinity.

CFM allows the analysis of the interaction of individual components contained in WPCs and allows a better understanding of the bonding nature of WPC components.
\end{abstract}

Keywords: Atomic force microscopy, chemical force microscopy, adhesive force, wood-plastic composites, surface analysis. 


\section{Introduction}

Over the last few decades there has been a continuing interest in the development of composite materials of plastic reinforced with natural fibers. Among the many reasons for such interest is the possibility of formulating materials for use as primary and secondary structures that, on the basis of weight and strength, are stronger and more rigid than conventional individual materials of construction and to achieve specific performance requirements (Stokke, Wu and Han 2013, Wegener and Windeisen 2016).

In wood-plastic composites (WPCs), wood is combined with a polymer and other additives to produce a material with improved properties, while making more efficient use of the wood resource. The heterogeneity of the individual WPC components, however, makes its adhesion mechanisms complex and difficult to predict and the adhesion phenomena in WPCs are not entirely understood (Kim and Pal 2010). To describe the adhesion in WPCs well one needs to understand how the major components forming the bulk of the composite interact with each other. Thus to improve the adhesion potential of the composite, the properties of the substrate and binder that can enhance, hinder or complicate the development of optimum adhesion should be known (Orue, Eceiza and Arbelaiz 2018).

It is of interest to note that with recent advanced surface characterization techniques, the understanding of material surfaces has been significantly improved, making it possible to control and tailor surface characteristics for specific applications, from a micrometer down to the nanometer scale. One of these techniques is the atomic force microscope (AFM), which is a valuable tool used to examine surfaces with high resolution and can image the topography, as well as the chemical composition on the surface and mechanical properties (Gardner, Oporto and Tze 2016).

Typically AFM measurements are conducted with unmodified silicon probes to obtain topographical images and in this case the tip-sample adhesion corresponds to van der Waals interactions between the tip and sample surface, which does not provide information about the chemical properties of the material being analyzed. However, specific chemical interactions can be determined with chemically functionalised AFM probes to help identify specific binding interactions (Berquand and Ohler 2010, Deda et al. 2012). The chemical functionalization of the tip results in increased sensitivity to selected functional groups, which is termed Chemical Force Microscopy (CFM) (Duwez et al. 2001). With CFM it is possible to investigate molecular interaction of interest, while all other interactions are repressed (Le Moigne et al. 2018).

A good understanding of the surface characteristics and the adhesion properties of the major components forming WPCs would help to optimize the design of WPC products. This study sought to provide some insight on the adhesion between WPC components through CFM analysis to create high resolution images of the surface morphology, as well as the distribution of functional groups and to quantify the interactions between coated AFM tips and substrate films at the molecular level. 


\section{Materials and methods}

Low-density polyethylene (LDPE, Sasol Polymers) with a MFI value of $65 \mathrm{~g} / 10 \mathrm{~min}$ and polypropylene (Sigma-Aldrich, Isotactic, average Mw-12,000, and Mn-5,000) were used to make films for AFM and FTIR analysis. The polymers used as compatibilizers were poly ethylene-covinyl alcohol (EVOH, Sigma-Aldrich, 44 mole \% ethylene, $\mathrm{Tm}=165{ }^{\circ} \mathrm{C}$, glass transition temperature $\mathrm{Tg}=55^{\circ} \mathrm{C}$ ) and oplyethylene-graft-maleic anhydride (PE-g-MA, Sigma-Aldrich, viscosity $1,700-4,500 \mathrm{cP} 140^{\circ} \mathrm{C}$ ). $\alpha$-cellulose and lignin alkali were obtained from Sigma-Aldrich and extractives of pine (softwood) and eucalyptus (hardwood) were supplied by the Department of Forest and Wood Science at University of Stellenbosch.

Films of $\alpha$-cellulose, lignin alkali, softwood and hardwood extractives, as well as PE-g-MA, EVOH, LDPE and PP were prepared from solution and pellets by direct deposition and film casting.

FTIR spectroscopy analysis was carried out using a Nicolet Is 10 FTIR spectrophotometer operated in the absorption mode, in the wavenumber range of 4000-400 cm-1. The spectra were obtained with a resolution of $4 \mathrm{~cm}-1$ and averaged over 32 scans.

Silicon force modulation cantilevers from Nanosensors (Switzerland) with a spring constant of 2 $\mathrm{N} / \mathrm{m}$ were coated by Novascan Technologies (Ames, IA USA) with $\mathrm{COOH}$ and $\mathrm{CH}_{3}$ groups, and tips were functionalised according to Bastidas et al. (2005) and Klash (2010) with EVOH and PEg-MA. For the CFM measurements and analysis, an Easy Scan 2 AFM from Nanosurf (Switzerland) was used in the force modulation imaging and spectroscopy modes.Force-distance curves were obtained with all coated tips on the various substrate films and the adhesive forces were determined.

\section{Results and Discussion}

Figure 1 shows the interaction between $-\mathrm{COOH}$ and $-\mathrm{CH}_{3}$ coated tips and the major components found in wood: cellulose, lignin and extractives. As expected, strong adhesive forces were determined between similar chemical groups. The force distance curves showed a high adhesive force between the $-\mathrm{COOH}$ tip and cellulose, which contains hydroxyls groups $(-\mathrm{OH})$, followed by extractives and a relative low reactivity on lignin. The $-\mathrm{CH}_{3}$ coated tip, on the other hand, showed a higher sensitivity towards lignin than to cellulose and extractives confirming similar studies by Basson (2013). 


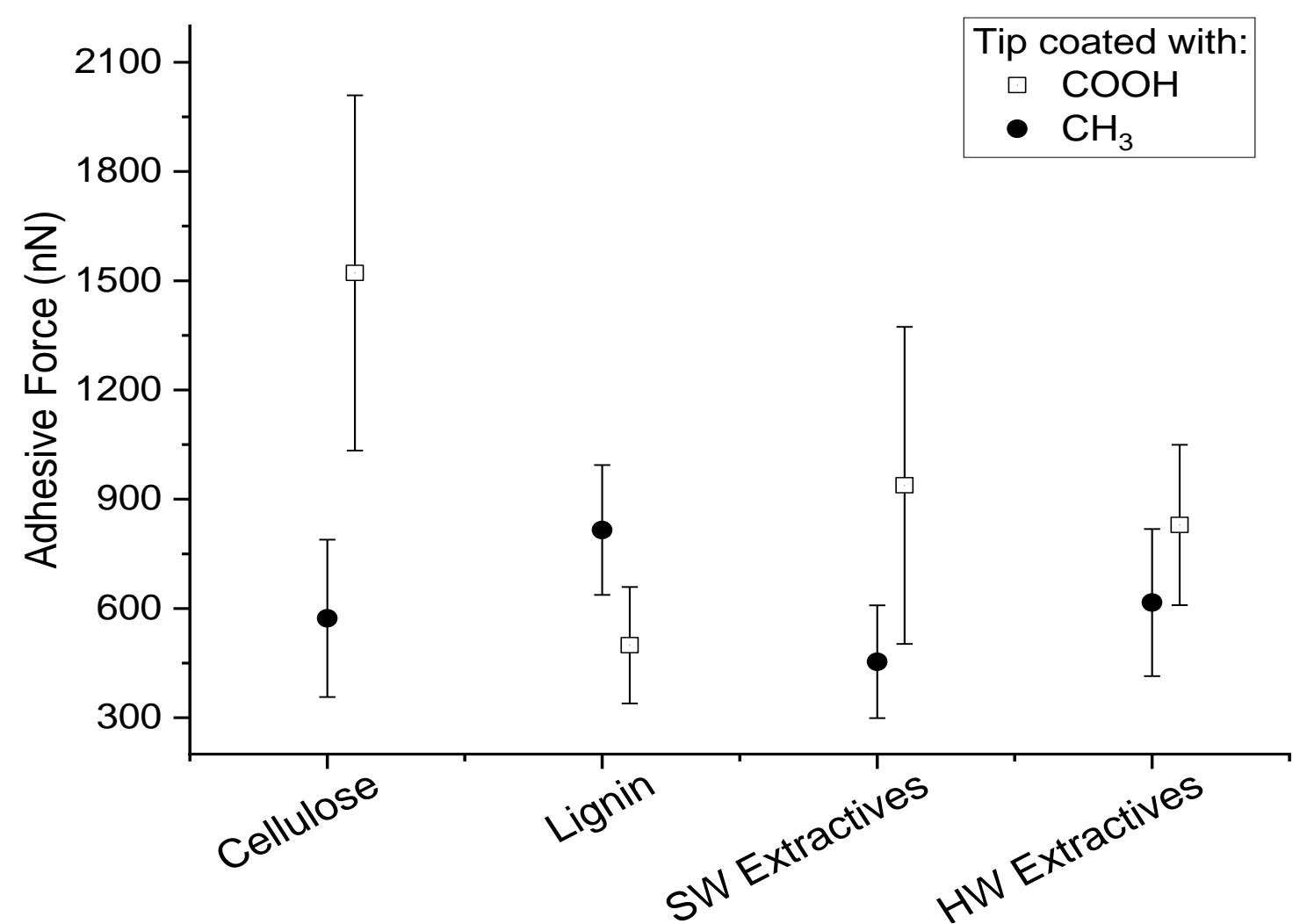

Figure 1: Adhesive force between $\mathrm{COOH}$ and $\mathrm{CH}_{3}$ functionalized tips and model wood components

The interaction between the EVOH coated tip and the major wood components (Fig. 2) showed the same trend as the $\mathrm{COOH}$ tip. A strong adhesive force of about $800 \mathrm{nN}$ was determined on cellulose and softwood extractives, somewhat less on hardwood extractives and only about $250 \mathrm{nN}$ on lignin. The PE-g-MA coated tip showed a fairly consistent sensitivity towards all components with adhesive forces around 200nN. Overall, EVOH showed a larger sensitivity towards the wood components than PE-g-MA, which might make it sensitive to different wood species with varying chemical composition. 


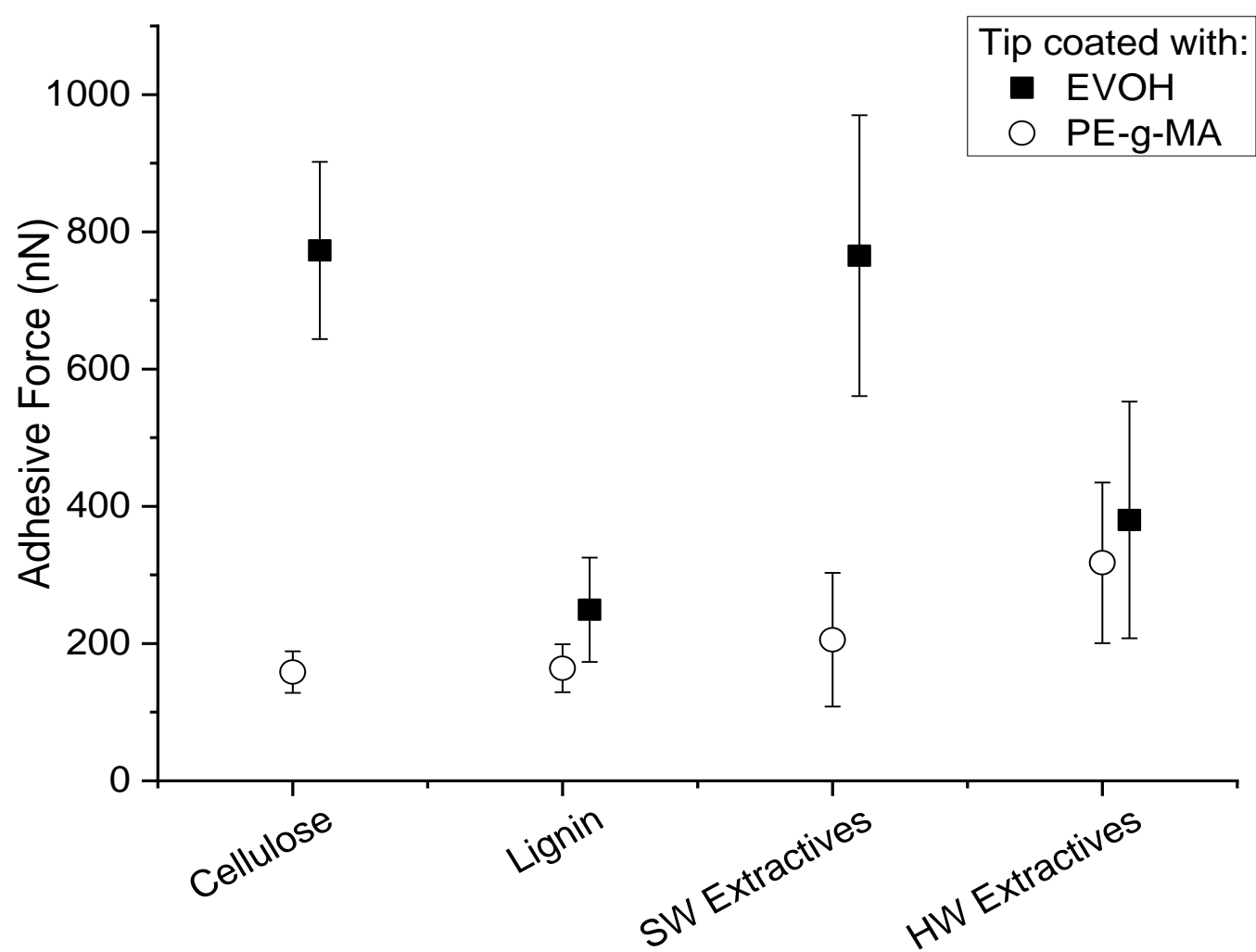

Figure 2: Adhesive force between compatibiliser functionalized tips and model wood components

Figure 2 shows that EVOH exhibits a higher adhesive force on all the components and can therefore be expected to have good interaction with all the components of a WPC. However, the different sensitivity to the wood components could result in different compatibilising results for different wood species. PE-g-MA showed a fairly consistent interaction to all the components, which might be beneficial when working with different wood species.

Comparison of adhesive forces between the $-\mathrm{COOH}$ and $-\mathrm{CH}_{3}$ coated tips and LDPE and PP films are shown in Figure 3. A stronger adhesive force was observed with the $-\mathrm{CH}_{3}$ tip on LDPE than PP. This was expected as the polymer surfaces are hydrophobic and as such responded better to a hydrophobic tip. However, it is worth noting that although there was a quantitative difference between the average responses of the two tips, they were not statistically significant different. The $-\mathrm{COOH}$ coated tip showed more consistent adhesive forces on LDPE and PP, while the - $\mathrm{CH}_{3}$ tip responded better to LDPE than PP. This may be due to the presence of methyl groups in the branch structure of LDPE and PP. Quantitatively, the COOH tip showed week adhesive force on both polymers.

The adhesive forces between different coated tips and polymer is also shown in Figure 3 . The $\mathrm{COOH}$ coated tip exhibited strong interactions on all the compatibilisers. The adhesive interaction between the - $\mathrm{COOH}$ coated tip and PE-g-MA is larger due to the maleic anhydride groups present in the PE-g-MA. 


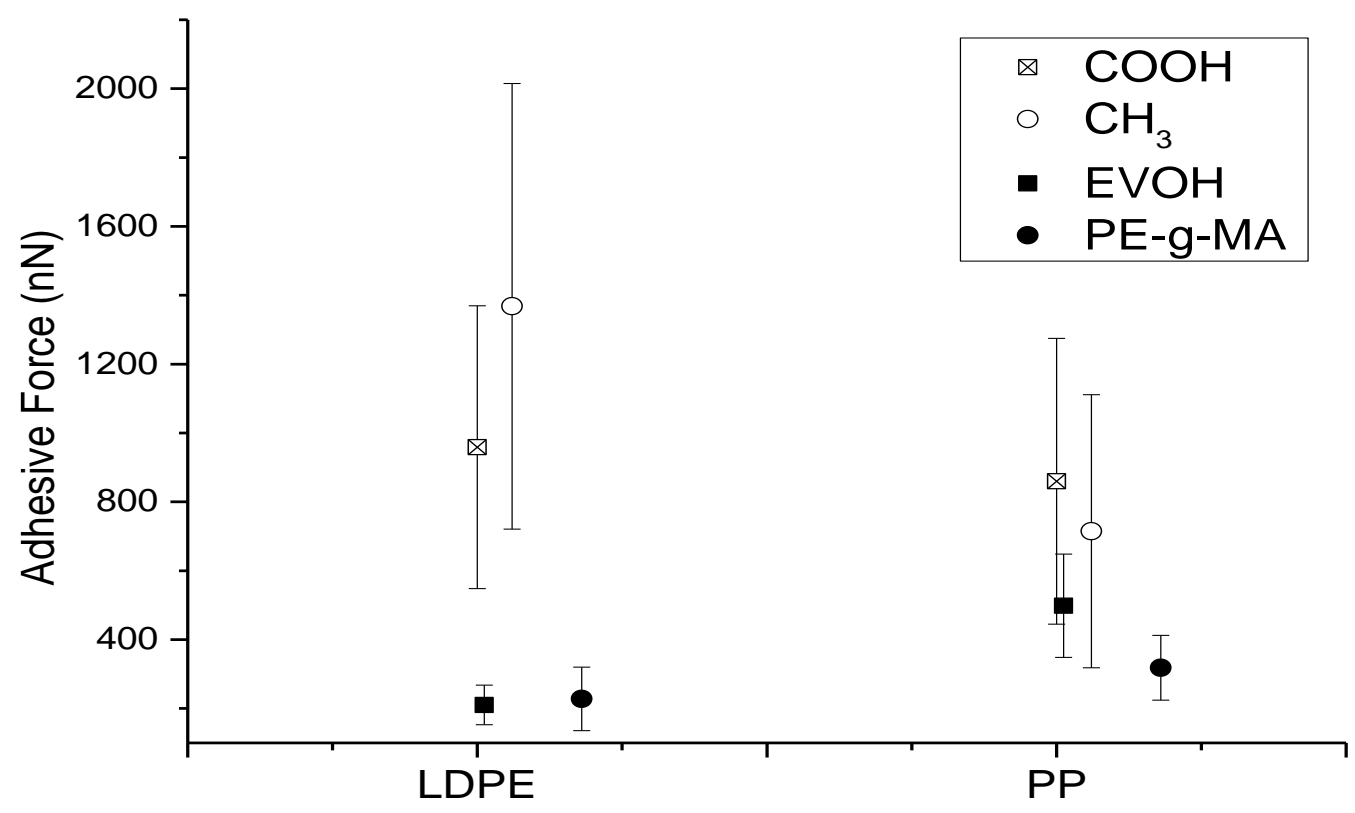

Figure 3: Adhesive force between different functionalized tips and model wood components

Tips coated with EVOH compatibiliser showed a strong adhesive force on PP and a weak interaction on LDPE and a similar trend is seen in the with PE-g-MA coated tip (Figure 3). This could be due to the composition of the compatibilisers with more emphasis on the use of PP for WPCs and the presence as well as aliphatic hydroxyl group in EVOH which have the potential for forming miscible blends with a variety of polymers containing complementary functional groups such as esters, (meth)acrylates, acetoxys, pyridines and others (Le Moigne et al. 2018).

Figure 4 shows a PCA biplot for the WPC model substrates and different modified AFM tips. PCA reduced the multiple observed variables to three components, which measured the sensitivity of the coated tips to the substrates. The covariance was positive for- $\mathrm{COOH}$, maleic anhydride groups in PE-g-MA and ethylene-co-vinyl alcohol (EVOH) groups. However, it was negative for $-\mathrm{CH}_{3}$ groups. From Figure 4, -COOH and PE-g-MA coated tips show good sensitivity to EVOH and PEg-MA substrates. The EVOH coated tip shows a high affinity to cellulose and softwood extractives. On the other hand the $-\mathrm{CH}_{3}$ coated tip was sensitivity towards the LDPE substrate. The variable sensitivity of all the coated tips towards PP, lignin and hardwood extractive substrates can clearly be observed from the PCA Biplot. 


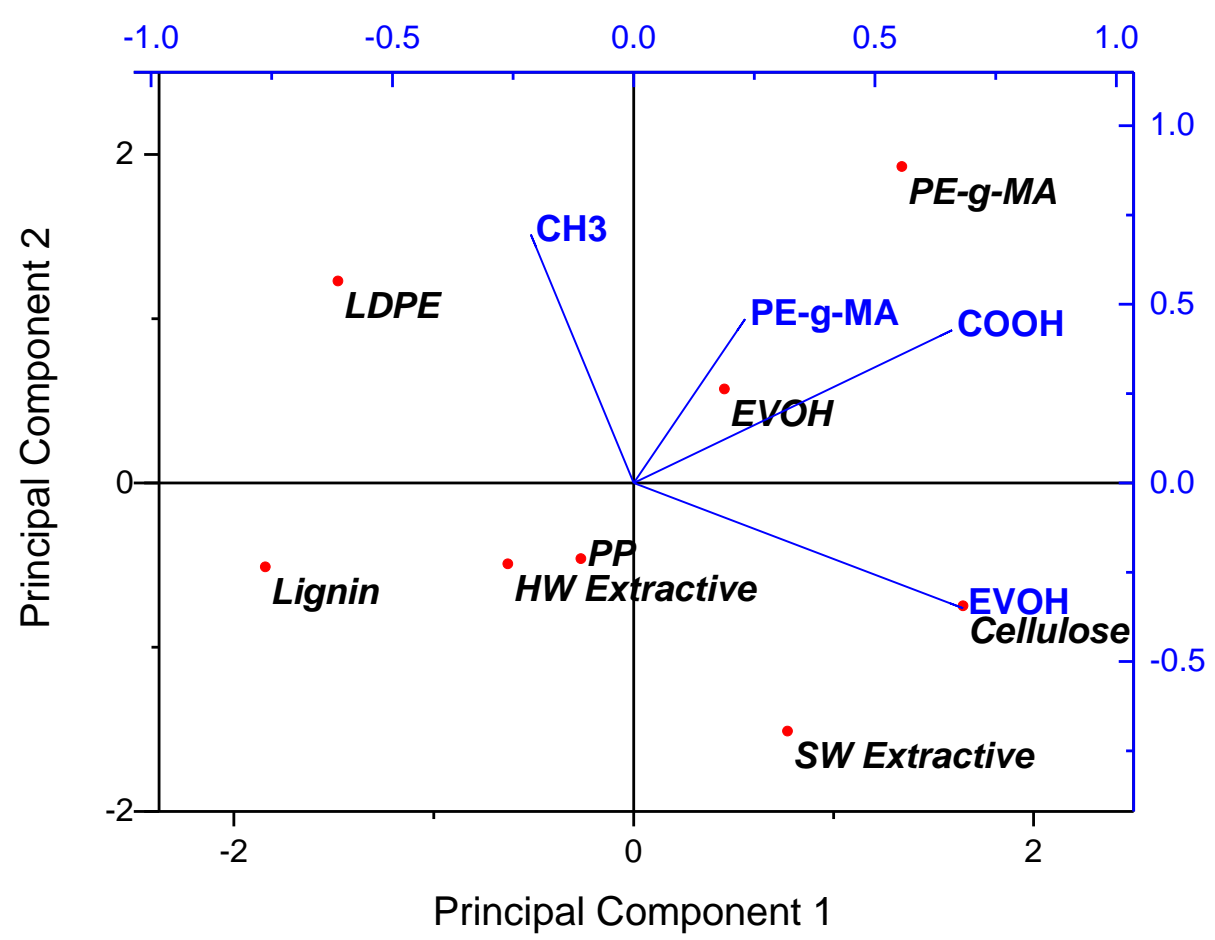

Figure 4: PCA biplot of WPC model substrates and different coated AFM tips

\section{Conclusion}

In CFM, the tip is chemically modified to detect special functional groups and their distribution on the surface of a sample by means of adhesive force measurements. In this study, tips modified with methyl $\left(-\mathrm{CH}_{3}\right)$ and carboxylic acid $(-\mathrm{COOH})$ functional groups and WPC compatibiliser compounds of EVOH and PE-g-MA were used to mimic their interactions on model components of wood (cellulose, lignin and extractives), polyolefins and WPC compatibilisers. The -COOH coated tip showed strong adhesive interactions on cellulose and the extractives and the - $\mathrm{CH}_{3}$ coated tip exhibited strong interaction on lignin. Even though lignin contains some hydroxyl and acid functional groups, it is mostly hydrophobic and a weak interaction between lignin and the carboxylic tip was expected, while a strong interaction was expected with the $-\mathrm{CH}_{3}$ tip. With regards to the extractives, the - $\mathrm{COOH}$ coated tip showed strong interactions on both hardwood and softwood extractives, as opposed to the $-\mathrm{CH}_{3}$ coated tip, which had weak interactions on the same substrates. The $-\mathrm{COOH}$ coated tip exhibited strong interactions on all the compatibilisers. The compatibiliser EVOH coated tip showed strong adhesive force on PP and a weak interaction on LDPE. A strong adhesive force was achieved between the PE-g-MA coated tip and PP and weak adhesive force on LDPE.

From our study, the surface chemistry of model WPC components was assessed with CFM and adhesive forces determined between wood components, polymers and compatibilisers at the molecular level. 


\section{References}

Agyeman S, Obeng-Ahenkora N K, Assiamah S, Twumasi G (2019) Exploiting recycled plastic waste as an alternative binder for paving blocks production. Case Studies in Construction Materials, 11, e00246.

Basson N C (2013) The effect of molecular composition on the properties of polyolefin-wood composites (Doctoral dissertation, Stellenbosch: Stellenbosch University).

Bastidas J C, Venditti R, Pawlak J, Gilbert R, Zauscher S, Kadla J F (2005) Chemical force microscopy of cellulosic fibers. Carbohydrate polymers, 62(4), 369-378.

Berquand A, Ohler B (2010) Common Approaches to Tip Functionalization for AFM-base Molecular Recognition Measurements. Bruker Application Note.

Deda D K, Bueno C D C, Ribeiro G A, Moraes A D S, Garcia P S, Brito B, Leite F D L (2012) Atomic force microscopy-based molecular recognition: A promising alternative to environmental contaminants detection.Current microscopy contributions to advances in science and technology, $5,1-30$.

Duwez A S, Poleunis C, Bertrand P, Nysten B (2001) Chemical recognition of antioxidants and UV-light stabilizers at the surface of polypropylene: atomic force microscopy with chemically modified tips. Langmuir, 17(20), 6351-6357.

Gardner D, Oporto G, Tze W T Y (2016) Wood and Fiber-Based Composites: Surface Properties and Adhesion. In Lignocellulosic Fibers and Wood Handbook: Renewable Materials for Today's Environment (pp. 345-383). Wiley Blackwell.

Godfrey L (2019) Waste plastic, the challenge facing developing countries-Ban it, change it, collect it?. Recycling, 4(1), 3.

Kim J K, Pal K (2010) Recent advances in the processing of wood-plastic composites; 32. Springer Science \& Business Media.

Kumi-Larbi Jnr A, Yunana D, Kamsouloum P, Webster M, Wilson D C, Cheeseman C (2018) Recycling waste plastics in developing countries: Use of low-density polyethylene water sachets to form plastic bonded sand blocks. Waste management, 80, 112-118.

Le Moigne N, Otazaghine B, Corn S, Angellier-Coussy H, Bergeret A (2018) Surfaces and Interfaces in Natural Fibre Reinforced Composites: Fundamentals, Modifications and Characterization. Springer. 
Orue A, Eceiza A, Arbelaiz A (2018) Pretreatments of Natural Fibers for Polymer Composite Materials. In Lignocellulosic Composite Materials. Springer, Cham: 137-175.

Stokke D D, Wu Q, Han G (2013) Introduction to wood and natural fiber composites; John Wiley \& Sons.

Wegener G, Windeisen E (2016) Chemically-Based Modern Wood Composites. Lignocellulosic Fibers and Wood Handbook: Renewable Materials for Today's Environment: 305-311.

Biography 
Proceedings of the 2020 Society of Wood Science and Technology International Convention

\author{
Innovative High-Feed Rate Additive Manufacturing Using Sustainable \\ Nano- Micro- Cellulose-Reinforced Thermoplastic Composites \\ Douglas Gardner, University of Maine, USA \\ douglasg@maine.edu
}

\begin{abstract}
The University of Maine and Oakridge National Laboratory are collaborating on a research program to explore Innovative High-Feed Rate Additive Manufacturing Using Sustainable Nano- Micro- CelluloseReinforced Thermoplastic Composites. The research will focus on developing and evaluating low-cost nano-cellulose- and micro cellulose-reinforced thermoplastic formulations for use in composites manufacturing. The project will produce cellulose fibers using various type of lignocellulosic feedstocks at different fibrillation levels, develop surface treatment approaches and efficient drying techniques. The project will also involve innovative composite preparation and adaptation to large scale additive manufacturing. The project will include material and process characterization at different stages of the project and techno-economic analysis of different processes. We will also evaluate surface finishing methods to produce a suitable tooling surface. In parallel, the project will also perform modeling studies to predict temperature distribution and thermal distortion during 3D printing as well as toolpath optimization. Finally, the developed materials will be demonstrated in the use phase for different applications.
\end{abstract}

Biography 


\title{
Proceedings of the 2020 Society of Wood Science and Technology International Convention
}

\section{Green enzyme-based processes for value-added applications of lignin}

\author{
Georg Gebitz \\ guebitz@boku.ac.at \\ Gibson Nyanhongo \\ g.nyanhongo@boku.ac.at
}

BOKU-University of Natural Resources and Life Sciences, Vienna, Austria

\begin{abstract}
Lignin accounts for around $30 \%$ of all non-fossil-based carbon sources while only about $3 \%$ of the lignin resulting from pulp and paper production is currently used for value-added applications. Controlled modification of lignosulfonates (LS) with laccase-enzymes opens up a number of sustainable applications which are presented here. Modified LS were used to substitute fossil-based styrene-butadiene latex as binder in coating formulations for graphic paper. Laccase oxidation resulted in improved printing properties (reduced picking), reduced penetration according to sectional fluorescence microscopy while Abo Akademi gravimetric water retention properties were comparable to those obtained with reference latex. Slow-release fertilizer granules were developed from laccase polymerized LS and alginate which prolonged the release of fertilizer from 5 to 25 days. Hydrogels and films were enzymatically synthesized from LS and fibres (e.g. cellulose) for reinforcement. In these materials, the laccase remained active and completely reduced oxygen to water in a closed system, making it suitable for application as oxygen barrier system. Finally, laccase functionalized LS have a potential as biobased glues for various applications. In addition to up-grading of LS, laccases have likewise great potential to covalently functionalize (e.g. hydrophobization, antimicrobial) lignocellulose materials. Thereby, functional molecules like fatty acid esters, alkylamines, aromatic amines, fluorophenols or tannins were enzymatically coupled to lignin moieties. Covalent binding was proven by using lignin model molecules like syringylglycerol $\beta$-guaiacyl, guaiacylglycerol $\beta$-guaiacylether and dibenzodioxocin together with LC-MS, XPS and NMR analysis. Overall, this demonstrates the potential of enzyme-based processes for up-grading lignin and lignocellulosic materials.
\end{abstract}

\section{Biography}




\title{
Proceedings of the 2020 Society of Wood Science and Technology International Convention
}

\section{New Bio-Based Sandwich Panel with High Impact-Resistance, following Cradle-to-Cradle Design}

\author{
Raphaela Hellmayr 1 \\ raphaela.hellmayr@boku.ac.at \\ Mathias Deutz1 \\ mathias.deutz@students.boku.ac.at \\ Roman Mynaz \\ roman.myna@boku.ac.at \\ Rupert Wimmer 1 \\ rupert.wimmer@boku.ac.at

\begin{abstract}
1 University of Natural Resources and Life Sciences, Vienna, Austria 2Wood K plus - Competence Centre for Wood Composites and Wood Chemistry, Austria
\end{abstract}

\begin{abstract}
Wood is a bio-based and renewable material with superior properties, however, dimensional constraints or limitations in specific properties exist. During the past century different engineered wood products have been developed to overcome these limits. Most developments are combining wood particles, wood veneer sheets, or solid wood lamella, all glued with adhesives to materials such as particleboards, plywood or cross laminated timber. Formaldehyde-reacting adhesives are currently used in the wood industry. Existing regulations are limiting formaldehyde emissions, but the bio-based resource wood is still combined with a petrochemical component, with a separation of these components at the end of the product life-cycle being impossible. The aim of this research is to develop sustainable products without any toxic chemicals, which enables value creation within a natural cycle. The cradle-to-cradle design principle is adopted, as proposed in the 1990s by Braungart and McDonough, which defines products optimized for a biological cycle, a technical cycle, or the combination of both. To apply this for engineered wood products, two possibilities exist: (1) separate material components at the end of life, or (2) use only non-toxic and biodegradable materials. Within that frame a novel sandwich panel was developed. The panel has two wooden surface layers, made from plywood, and a core layer made from a non-woven hemp mat. A novel adhesive with a lignin-base was used to assemble core and face layers. The panel is lightweight and demonstrates a good thermal performance. Due to the flexible non-woven core, the new panel type is also elastic and impact-resistant. This property profile makes the panel interesting for indoor facings, claddings or partition walls in sports halls and gyms.
\end{abstract}

Key words: cradle to cradle, wood, hemp, lignin, bio-based, adhesive, sandwich panel, non-woven, lightweight

\section{Biography}




\title{
Proceedings of the 2020 Society of Wood Science and Technology International Convention
}

\section{Systematic evaluation of wheat flour, wheat starch and wheat protein in urea and phenol formaldehyde resins}

\author{
Elfriede Hogger 1 \\ e.hogger@kplus-wood.at \\ Hendrikus W.G. Van Herwijen1 \\ e.herwijnen@wood-kplus.at \\ Wolfgang Kanter2 \\ wolfgang.kantner@metadynea.com \\ Johannes Konnerth 3 \\ johannes.konnerth@boku.ac.at
}

\author{
1Wood K plus, Kompetenzzentrum Holz Gmbh, Austria \\ 2Metadynea Austria GmbH \\ 3Department of Material Sciences and Process Engineering, BOKU - University of \\ Natural Resources and Life Sciences
}

\begin{abstract}
The continuous demand of plywood underlines that it is one of the important products in the wood panel industry. Plywood can be used for many applications, a basic distinction is made between interior and exterior use. The resins generally used in European plywood production are urea (UF) and phenol formaldehyde (PF). Both resin systems have advantages and disadvantages. UF resins are both inexpensive and widely used, but respond sensitively to the effects of moisture and water and release formaldehyde during hydrolysis (Dunky 1998). Due to their chemical stability in cured state, PF resins are resistant to moisture and weathering and have few to hardly any formaldehyde emissions, but are more expensive than UF resins (Dunky \& Niemz 2002).
\end{abstract}

A common practice to reduce the disadvantages during processing of these resins is the addition of additives. Among other benefits, additives can reduce the consumption of raw material and thus lower the price of the adhesive, or improve processing parameters. There are two main categories of additives: extenders and fillers, while the first one has adhesive properties itself (EN 923-15). Among other extenders available, wheat flour is used most commonly. However, the quantities of wheat flour added to the resins are usually based on operational experience. There are rarely systematic scientific studies in literature on the effects of the addition of wheat flour and its main ingredients to resins. Wheat flour generally consists of $67-70 \%$ starch and $12-18 \%$ protein (Lindhauer 2010).

In this project, wheat flour and its main components were systematically studied in various quantities as an addition to either UF or PF resins. To identify the influence of the flour and its components on the resins, the physico-chemical and mechanical properties of the adhesives and the plywood panels thereof were investigated. Possible limitations, also with regard to the quantities added, were evaluated.

The aim was to add quantities of up to $100 \%$ extender, based on solid content of the resins. The addition of protein to the two resin systems was limited to a maximum of $30 \%$ due to its strong 


\section{Proceedings of the 2020 Society of Wood Science and Technology International Convention}

influence on the viscosity. Although the extenders behaved differently with respect to viscosity of the resins and in terms of buffer capacity, no effect on curing behavior could be observed with either UF or PF resins.

The influence of extenders on wet shear strength of plywood panels was investigated according to EN 314-1. Panels with UF-based blends were pre-treated according to the criteria for interior use and panels with PF-based blends according to the criteria for exterior use. The treatments considered most critical for each area of use were applied.

For all UF-based panels wet shear strength was tested and results met the requirements of EN 314-2, while for PF-based panels satisfactory results were obtained only when small amounts of wheat flour or starch were added. For the case of PF, protein could be added up to $30 \%$ still meeting the requirements of EN 314-2.

Keywords: UF, PF, wheat extenders, viscosity, ABES, plywood, wet shear strength

Biography 


\title{
Influences of various infill orientations on specific mechanical properties of 3D printed wood/Polylactic Acid (PLA) composites which were processed using Fused Deposition Modeling (FDM)
}

\author{
S. $\mathrm{KAIN}_{1} *-$ M. $\mathrm{MUSSO}_{2}-$ A. PETUTSCHNIGG 1
}

1 Research Scientist, University of Applied Sciences Salzburg, Department of Forest Products Technology and Timber Construction, Kuchl, Austria, A.P.: alexander.petutschnigg@fh-salzburg.ac.at * Corresponding author: stefan.kain@fh-salzburg.ac.at

2 Research Scientist, University of Salzburg, Department of Chemistry and Physics of Materials, Salzburg, Austria, M.M.: maurizio.musso@sbg.ac.at

\begin{abstract}
The production of components using Additive Manufacturing (AM), in particular Fused Deposition Modeling (FDM), has increased significantly in recent years. Not only the process technology itself has steadily developed, also the product range of materials for FDM has continuously grown.

In addition to many commonly utilized thermoplastic polymers which are suitable for conventional FDM - such as Polylactic Acid (PLA) or Acrylonitrile-Butadiene-Styrene (ABS) some very special materials, including wood/PLA composites (wood filaments), have also been successfully used for FDM. Basically, wood filaments are composite materials made of the thermoplastic polymer PLA, in which wood fibers are embedded. Such compounds provide several benefits in connection with specific mechanical properties, while having a positive environmental footprint.
\end{abstract}

In this paper, possible effects of different infill patterns (infill orientations) on selected mechanical characteristics - in particular tensile strength, compressive strength as well as charpy impact strength - of FDM 3D printed specimens are analyzed. The specimens were produced using two specially made wood/PLA composites - consisting of one specific PLA polymer (Ingeотм 3251D) which was blended with two various contents of wood fibers (ARBOCEL® C100). In connection with the wood fiber content, one wood/PLA composite was made of 15 wt. \% wood fibers and the other was made of 25 wt. \% wood fibers. A commercially available Ultimaker $2+$ from Ultimaker B.V. equipped with an unmodified $0.6 \mathrm{~mm}$ nozzle was used for processing the non-abrasive wood/PLA composites. After several preliminary tests, the printing speed was finally set to $22.5 \mathrm{~mm} \bullet \mathrm{sec}-1$, to ensure the best possible printing quality.

The FDM 3D printed test specimens were tested as a function of the infill orientations (infill patterns) applied as well as the wood fiber content used. In the context of the infill patterns, the influence factors of seven different orientations - in particular $0^{\circ}, 15^{\circ}$ crossed, $30^{\circ}$ crossed, 
$45^{\circ}$ crossed, $60^{\circ}$ crossed, $75^{\circ}$ crossed and $90^{\circ}-$ on selected mechanical material properties have been investigated.

It can be shown that there is in some ways a direct correlation between the applied infill pattern (infill orientation) and the measured mechanical characteristic. In addition, it can also be demonstrated that a higher wood fiber content in the wood/PLA composite leads to significantly higher mechanical properties.

A further development of conventional FDM 3D printing is the so-called 4D printing. In this case, a moisture-induced shape transformation of the FDM 3D printed object is caused over time.

Key words: Fused Deposition Modeling; FDM; Wood filaments; Mechanical performance; Tensile strength; Compressive strength; Charpy impact strength; Infill orientations; Infill patterns 


\section{Introduction}

In recent years, a lot has happened in 3D printing using FDM methodology. A large variety of new materials with interesting properties became available for 3D printing - including wood filaments - at the same time the process technology being steadily adapted. Especially for new materials, it is essential to know exactly specific material characteristics, as these significantly affect the final performance of the 3D printed object. In addition, when using 3D printing, the internal structure (infill) of the object can be influenced, which in turn can affect specific mechanical properties.

Basically, all thermoplastic materials can be utilized for manufacturing physical threedimensional objects with the aid of FDM 3D printing. This manufacturing method builds a layerby-layer model by depositing the melted thermoplastic material until the three-dimensional object is finished (Gebhardt, 2011).

As a result of sustainability concerns as well as environmental concerns, companies worldwide are trying to substitute petrochemical-based products by using innovative materials made of biopolymers which are reinforced with natural fibers, so-called bio-composites (Mohanty et al. 2002; Faruk et al. 2012).

Researchers around the world have already reported the successful utilization of wood fillers. In general, fillers made of wood are preferred due to the low price - compared to the more expansive synthetic filler materials - and the unlimited availability (English and Falk 1996; Osswald 1999; Williams and Wool 2000; Bledzki and Faruk 2003; Peltola et al. 2014). In addition, filler materials made of natural resources have a low density (Holbery and Houston 2006), which leads to a noticeable light-weight structure in comparison to synthetic fibrous fillers, such as glass fibers (Summerscales et al. 2010).

\section{Materials \& Methods}

\section{Formulations and fabrication of specially made wood/PLA composites}

The PLA granulate (Ingeoтm 3251D) supplied by NatureWorks LLC (Minnetonka; USA) and the wood fibers/particles (ARBOCEL® ${ }^{\circ}$ 100) provided by JRS J. Rettenmaier \& Söhne GmbH + Co KG (Baden-Württemberg; Germany) was compounded using a twin-screw compounder, without adding any additives like colorants or coupling agents during the compounding process. As soon as the wood/PLA composite was compounded, it was shredded and compounded again to ensure a more homogeneous distribution of the wood fibers/particles in the polymer matrix. In total, two different wood/PLA recipes were applied for fabricating the wood filaments, which were then used for manufacturing the test specimens. In general, the components of the wood filaments are the same, they only varied regarding the wood fiber content (composite \#1: $15 \mathrm{wt} . \%$ and composite \#2: $25 \mathrm{wt}$. \%). Both wood filaments had a diameter of $1.75 \mathrm{~mm}$, respectively. Table 1 shows the various wood/PLA recipes of the two specially made wood filaments. 
Table 1: Comparison of the two specially made wood filaments in terms of composition.

\begin{tabular}{|c|c|c|}
\hline \multirow{2}{*}{ ID } & \multicolumn{2}{|c|}{ Recipe of the wood/PLA composites used } \\
\cline { 2 - 3 } & $\begin{array}{c}\text { PLA (IngeoTm 3251D) } \\
{[\mathrm{wt} . \%]}\end{array}$ & $\begin{array}{c}\text { Wood fibers (ARBOCEL® C100) } \\
\text { [wt. \%] }\end{array}$ \\
\hline Composite \#1 & 85 & 15 \\
\hline Composite \#2 & 75 & 25 \\
\hline
\end{tabular}

\section{Test specimens production}

An Ultimaker 2+ from the Dutch company Ultimaker B.V. (Geldermalsen; Netherland) was utilized for fabricating the different specimens for testing the mechanical performance of the two specially made wood/PLA composites. The FDM 3D printer was equipped with a standard $0.6 \mathrm{~mm}$ nozzle for processing the wood filaments. In addition, specific printer settings were adjusted, in order to produce test specimens having the best possible quality. The print speed was decreased to about $22.5 \mathrm{~mm} \bullet \mathrm{sec}-1$, while the infill speed was set to about $13.5 \mathrm{~mm} \bullet \mathrm{sec}-1$. Default settings were applied for the nozzle temperature as well as the build plate temperature, the nozzle temperature being maintained at $210^{\circ} \mathrm{C}$, while the build plate temperature being set to $60^{\circ} \mathrm{C}$. The slicing software Cura (v 3.2.1) from Ultimaker B.V. was utilized for the slicing procedure as well as for adjusting the process parameters - including the varying infill orientations (infill patterns) applied - for producing the test specimens.

\section{Infill orientation (infill pattern)}

In order to identify a possible influence of various infill patterns (infill orientations) on specific mechanical properties - such as tensile strength, compressive strength as well as charpy impact strength - seven different infill orientations were selected and applied for fabricating all test specimens. The infill patterns (infill orientations) are depicted in figure 1.
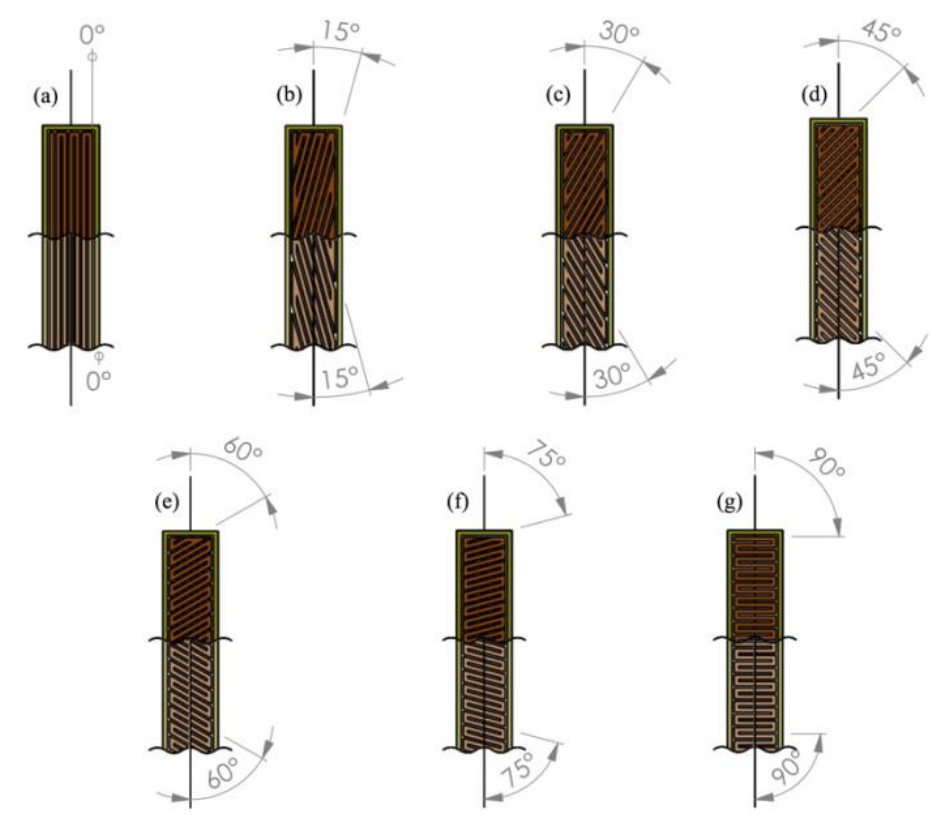
Figure 1: All seven infill patterns applied for fabricating the test specimens $\mid$ (a) $0^{\circ} \mid$ (b) $15^{\circ}$ crossed $\mid$ (c) $30^{\circ}$ crossed | (d) $45^{\circ}$ crossed $\mid$ (e) $60^{\circ}$ crossed | (f) $75^{\circ}$ crossed | (g) $90^{\circ}$

\section{Impact strength (unnotched specimens)}

A pendulum impact tester CEAST 9050 Pendelschlagwerk from Instron GmbH (Darmstadt; Germany) was utilized, in order to investigate the charpy impact strength of the FDM 3D printed test specimens. In addition, the testing machine was equipped with a hammer which is capable to apply an impact energy of $0.5 \mathrm{~J}$, and all measurements were conducted according to the standard DIN EN ISO 179-1 (2010).

\section{Tensile strength}

A Zwick/Roell Z250 - universal material testing machine - from the Zwick Roell Group (Ulm; Germany) equipped with an add-on device for testing the tensile strength and a $20 \mathrm{kN}$ load cell was utilized for the investigations. The cross-head speed during testing was set to about $10 \mathrm{~mm} \cdot \mathrm{min}-1$, while the initial distance between the lower and upper grip was about $115 \mathrm{~mm}$, meaning a resulting clamping length of about $17.5 \mathrm{~mm}$. All measurements were implemented according to the standard ÖNORM EN ISO 527-4 (1997).

\section{Compressive strength}

For testing the compressive strength of the FDM 3D printed test specimens, the same universal testing machine was utilized which was used for measuring the tensile strength. In this case, the testing machine was equipped with a $250 \mathrm{kN}$ load cell as well as an add-on device for testing the compressive strength. The cross-head speed during testing was also set to $10 \mathrm{~mm} \cdot \mathrm{min}-1$. All measurements were conducted according to the standard ÖNORM EN ISO 604 (2003).

\section{Results and Discussion}

The following results come from the previously published publication (Kain et al. 2020).

Furthermore, additional investigation results regarding special mechanical properties can be also found in this publication.

\section{Impact strength (unnotched specimens)}

An analysis of the impact strength (unnotched specimens) illustrates that FDM 3D printed specimens having an infill orientation of $0^{\circ}$ provided by far the highest measured characteristic values, as it can be seen in figure 2. Basically, the more the infill pattern (infill orientation) shifts towards $90^{\circ}$, meaning the infill orientation being equal to the testing direction, the more the resulting impact strength decreases. In general, the adhesion of two adjacent filament strands is not that good, for that reason the FDM 3D printed structure can only slightly withstand the impact of the hammer. 


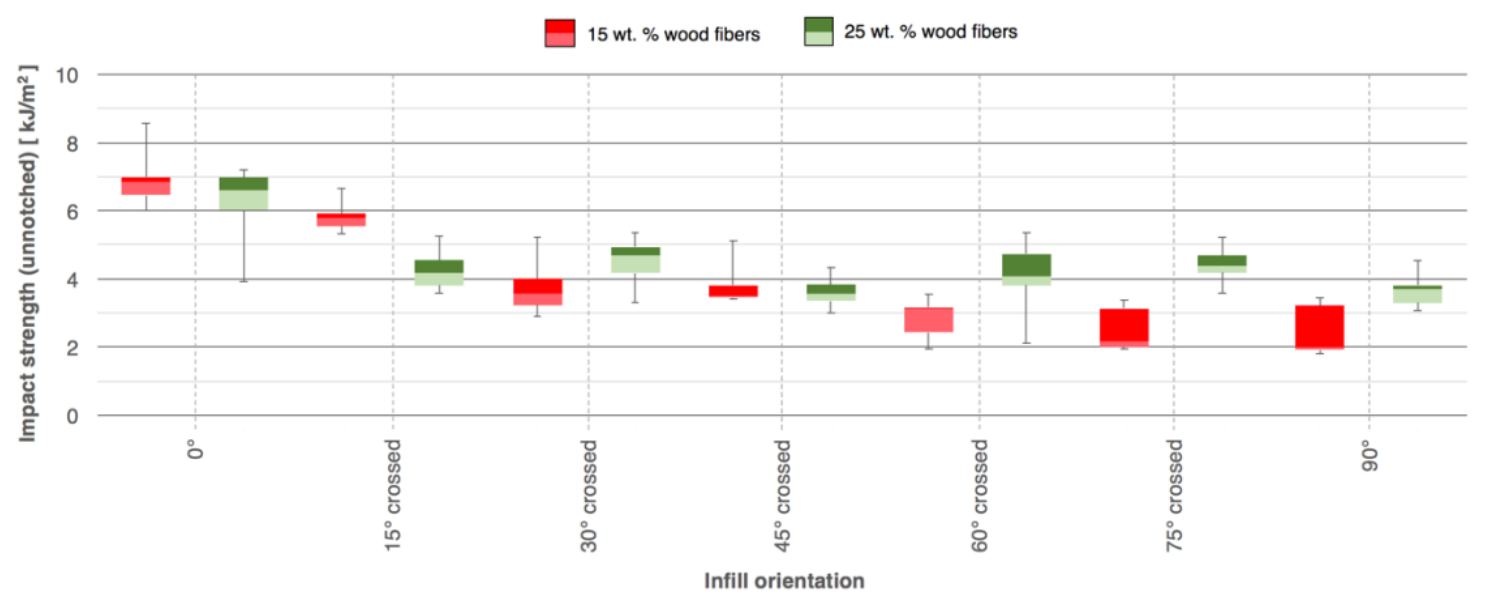

Figure 2: The behavior of the impact strength (unnotched specimens) depending on the infill orientation applied as well as the wood/PLA composite used (composite \#1 or composite \#2).

\section{Tensile strength}

Figure 3 illustrates an analysis of the ultimate tensile strength of the FDM 3D printed test specimens as a function of the infill orientation applied and the wood fiber content within the wood filaments used (composite \#1 or composite \#2). The box plots show that the highest possible tensile strength can be measured when an infill orientation of $15^{\circ}$ crossed or $30^{\circ}$ crossed is applied, depending on the wood/PLA composite used. Additionally, it is also assumed that the behavior of the ultimate tensile strength - as it can be seen in figure 3 - directly correlates with the printing path (infill orientation) followed by the print head to create the three-dimensional object. As outlined in relevant literature (Stark and Rowlands 2003; Peltola et al. 2014), a higher content of wood fibers in the specimen leads to higher mechanical characteristics (compressive strength, tensile modulus, compressive modulus, tensile strength, etc.). Due to that reason, test specimens made of the wood/PLA composite having a higher share of fibers, generally lead to a higher mechanical performance.

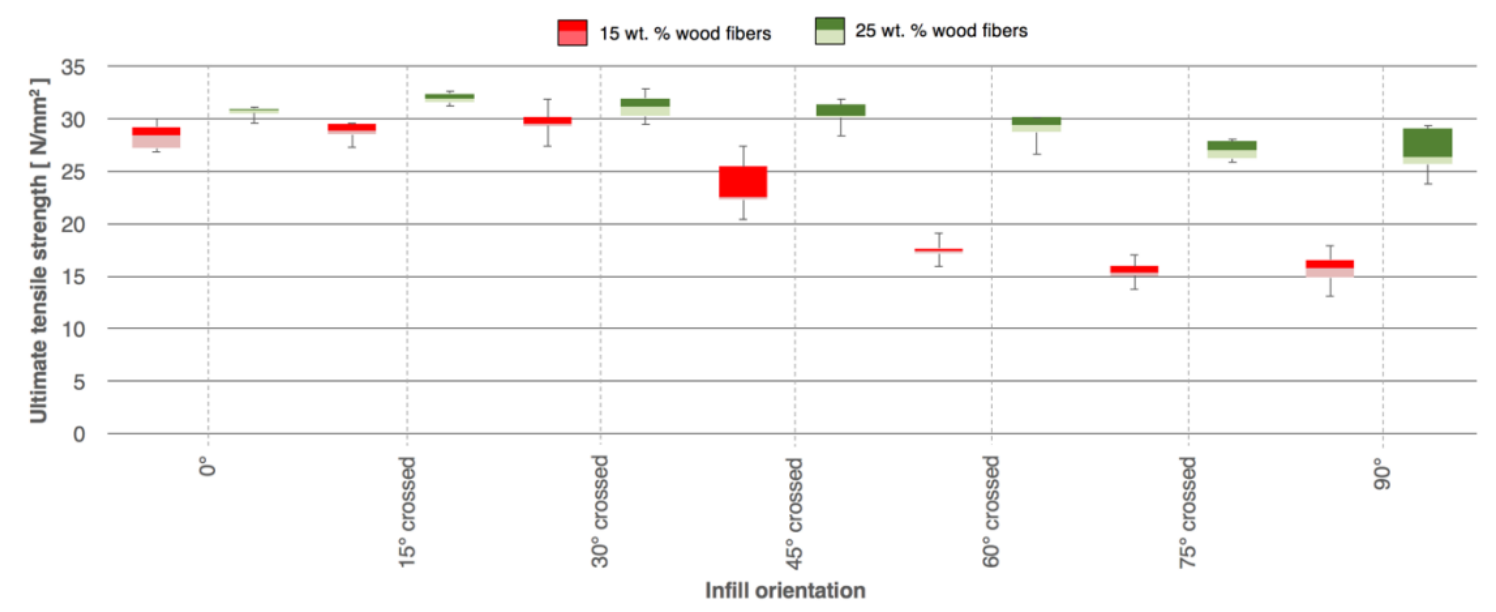

Figure 3: The behavior of the ultimate tensile strength as a function of the wood/PLA composite (composite \#1 or composite \#2) used and the infill orientation applied. 


\section{Compressive strength}

Figure 4 shows the evaluation of the compressive strength $\sigma 0,2$ of the FDM 3D printed test specimens, depending on the fiber content of the wood/PLA composite used and the infill orientation (infill pattern) applied. Basically, the behavior of the compressive strength is related to the tensile strength behavior (as it can be seen in figure 3), but not being that pronounced. The highest possible material characteristic denoting the compressive strength can be measured when the infill pattern (infill orientation) is set to $0^{\circ}$ or $15^{\circ}$ crossed. This means, the infill orientation is parallel or almost parallel to the loading direction, which leads to an optimal flow of forces.

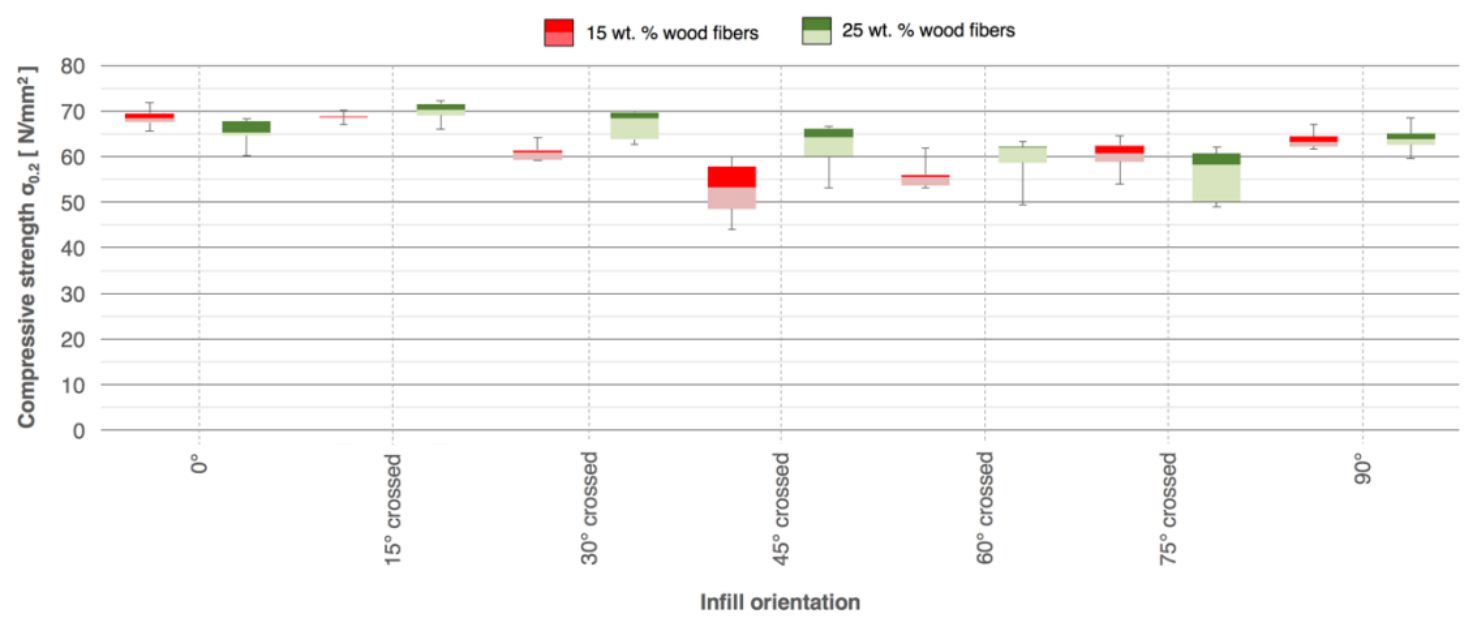

Figure 4: The behavior of the compressive strength $\sigma_{0,2}$ depending on the infill orientation (infill pattern) applied and the fiber content (composite \#1 or composite \#2) in the wood/PLA composite.

\section{Summary and Conclusions}

It can be shown that there is a direct correlation between the infill orientation (infill pattern) applied and the mechanical performance (tensile strength as well as compressive strength) of the FDM 3D printed test specimens. The behavior of both mechanical properties is not exclusively directly correlated, as it can be seen in figure 3 as well as in figure 4 .

For the impact strength it can be claimed, that FDM 3D printed specimens with an infill orientation (infill pattern) of $0^{\circ}$ show the best possible impact strength. The further the infill pattern (infill orientation) shifts towards $90^{\circ}$ (the testing direction corresponding to the infill orientation), the worse the resulting mechanical properties become.

In addition, it can be demonstrated that the wood fiber content of the wood/PLA composites (composite \#1 or composite \#2) has an influence on the mechanical performance of the FDM 3D printed test specimens. Basically, it can be shown that a higher fiber content tends to result in higher mechanical characteristics of the FDM 3D printed biocomposites. At least up to a wood fiber content of $25 \mathrm{wt}$ \% , a noticeable improvement in mechanical characteristics can be observed. 
Proceedings of the 2020 Society of Wood Science and Technology International Convention

Taking into account all the results obtained, it is strongly recommended to carefully select the infill pattern (infill orientation) - especially for load bearing components - in order to obtain the best possible performance for the FDM 3D printed objects.

\section{Acknowledgements}

All investigations are implemented within the project Interreg Austria-Bavaria AB 97 TFP HyMat. One major objective of this joint venture is to successfully implement a research platform for producing and processing hybrid materials, such as 3D printable wood fiber reinforced biocomposites.

\section{References}

Bledzki AK and Faruk O (2003) Wood fibre reinforced polypropylene composites: Effect of fibre geometry and coupling agent on physico-mechanical properties. Applied Composite Materials 10(6): 365-79.

DIN EN ISO 179-1 (2010) Plastics-determination of charpy impact properties: part 1: noninstrumented impact test (ISO 179-1:2010)

English BW and Falk RH (1996) Factors that Affect the Application of Woodfiber-Plastic Composites. In: Proceedings (Forest Products Society) no. 7293: 189-194.

Faruk O, Bledzki AK, Fink H-P and Sain M (2012) Biocomposites reinforced with natural fibers: 2000-2010. Progress in Polymer Science 37: 1552-1596.

Holbery J and Houston D (2006) Natural-fiber-reinforced polymer composites in automotive applications | Overview: Low-cost composites in vehicle manufacture. JOM 58(11): 80-86.

Kain S, Ecker JV, Haider A, Musso M, Petutschnigg A (2020) Effects of the infill pattern on mechanical properties of fused layer modeling (FLM) 3D printed wood/polylactic acid (PLA) composites. European Journal of Wood and Wood Products 78 (1): 65-74.

Mohanty AK, Misra M and Drzal LT (2002) Sustainable Bio-Composites from renewable resources: Opportunities and challenges in the green materials world. Journal of Polymers and the Environment 10: 19-26

Osswald TA (1999) Fundamental principles of polymer composites: processing and design. Madison, Wisconsin.

ÖNORM EN ISO 527-4 (1997) Plastics-determination of tensile properties: part 4: test conditions for isotropic and orthotropic fibre-reinforced plastic composites (ISO 527-4:1997)

ÖNORM EN ISO 604 (2003) Plastics-determination of compressive properties (ISO 604:2002)

Peltola H, Päkkönen E, Jetsu P and Heinemann S (2014) Wood based PLA and PP composites:

Effect of fibre type and matrix polymer on fibre morphology, dispersion and composite properties. Composites: Part A vol. 61: 13-22.

Stark NM and Rowlands RE (2003) Effects of wood fiber characteristics on mechanical properties of wood/polypropylene composites. Wood and Fiber Science vol. 35: 167-174.

Summerscales J, Dissanayake NPJ, Virk AS and Hall W (2010) A review of bast fibres and their composites | Part 1 - Fibres as reinforcements. Composites: Part A vol. 41: 1329-1335.

Williams GI and Wool RP (2000) Composites from natural fibers and soy oil resins. Applied Composite Materials 7: 421-432.

Biography 


\title{
Proceedings of the 2020 Society of Wood Science and Technology International Convention
}

\section{D X-Ray CT Studies on Wood-based Panels at UGCT-Woodlab}

\author{
Pieerre Kibleur 1 \\ pierre.kibleur@ugent.be \\ Wanzhao $\mathrm{Li}_{2}$ \\ liwanzhao1103@126.com \\ Jan Van den Bulcke 1 \\ jan.vandenbulcke@ugent.be \\ Joris Van Acker 1 \\ joris.vanacker@ugent.be \\ ${ }_{1}$ UGCT - UGent-Woodlab, Department of Environment, Faculty of Bioscience \\ Engineering, Ghent University, Belgium \\ 2College of Materials Science and Engineering, Nanjing Forestry University, China
}

\begin{abstract}
In the decade since the building of Nanowood in 2009, the University of Ghent's Center for X-ray Tomography (UGCT) has deepened its expertise, and its portfolio of techniques to investigate materials. Nanowood is an X-ray CT scanner specifically designed for high-resolution investigation of wood and wood-based materials. It is capable of reaching resolutions down to $400 \mathrm{~nm}$, and possesses an ingenuous modular system (two X-ray sources and two detectors), to provide the most adequate setup for the study of a given wood-based sample (Dierick et al., 2014).

Specifically, when studying the interaction of wood with water, the contrast between these two phases can be particularly low, due to the similarity in density and elementary composition. However, the study of this interaction is particularly relevant not only for wood, but also for engineered-wood, such as wood-based panels. Indeed, their behavior remains largely un-characterized, while their use worldwide continues to grow.

To study this interaction, we are able at UGCT to use a hygroscopy setup. Coupled to a generator of moist air (GenRH, System Measurements Systems Ltd., UK), an indigenous climate chamber allows to visualize in-situ a sample swelling under the effect of water absorption (Patera et al., 2017). The most recent use cases involved medium-density fiberboard (MDF), and advanced reconstruction algorithms to compensate for the motion artefacts inherent to the acquisition of tomograms on a non-stable sample. Eventually, the results revealed the three-dimensional deformation field, in a representative sample, during swelling at $95 \%$ relative humidity (Kibleur et al., in preparation).

Furthermore, aside from the interaction with water, the pure mechanics of wood-based panels present exceptional complexity. Moreover, although macroscopic tests may dynamically characterize the material, the true nature of the deformations down to the level of the constituent (e.g. wood fibers, wood flakes, etc...) is unknown. However, we are able to use a dynamic load cell (Deben Ltd., UK), for use in combination with CT. This cell can apply a load of up to $5 \mathrm{kN}$, in compression or in tension. In the latest works, this enabled us to visualize, at different compression steps, the evolution of the microstructure in laminated veneer lumber (LVL) and oriented strain board (OSB). The results confirmed the impact of the glue on the local stiffness, but also revealed the importance of highdensity intrusions protecting the microstructure (Li et al., in review).
\end{abstract}


Proceedings of the 2020 Society of Wood Science and Technology International Convention

Overall, time-resolved X-ray CT, often referred to as 4D CT, presents growing opportunities for advanced material characterization. Our research group combines expertise and innovativeness, on hardware and software alike. The present work highlights such innovations, specific to wood-based materials.

Biography 


\title{
Edge Banding Performance Analysis of Wood Based Material in The Furniture Industry
}

\author{
Kucuk Huseyin Koc1*-Ender Hazir2 - Sedanur Seker3 \\ 1 Prof., Istanbul University-Cerrahpasa, Istanbul, Turkey \\ * Corresponding author \\ hkoc@istanbul.edu.tr \\ $2 \mathrm{PhD}$., Istanbul University-Cerrahpasa, Istanbul, Turkey \\ ender.hazir@istanbul.edu.tr \\ 3 Msc., Istanbul University-Cerrahpasa, Istanbul, Turkey \\ sedanur.seker@istanbul.edu.tr
}

\begin{abstract}
Edge banding applications have an intensive use in the furniture industry due to the visuality, added value and protective properties it provides. In addition, the edge banding process is an important step in the production process. In this study, the results of PVC based edge banding application applied to the $18 \mathrm{~mm}$ MDF (Medium Density Fiberboard) and PB (Particle Board) slide edges are evaluated. Samples were taken from an industrial process by sampling method. In the application, a computer controlled computer edge banding machine was used. In the edge banding machine parameters such as speed glue temperature, speed and pressure were kept constant. Dependant variable was edge banding performance while independent variable was selected as material type. Edgebandign performance was analyzed with ANOVA and probability plot.

According to results, material type was found as significant factor. MDF and PB for edge banding performance values were found as 0.049 and $0.051 \mathrm{~N} / \mathrm{mm} 2$, respectively.
\end{abstract}

Key words: Furniture, edge banding, adhesion resistance, edge banding performance, quality control

\section{Introduction}

One of the most common processes seen in almost all modern furniture products is edge banding application. This process, which seems simple in practice, actually has a complex process detail with at least 5-6 parameters taken into account. For this reason, edge banding machines working with traditional managements have quickly been replaced by computer controlled smart edge banding machines all over the world. However, it is not possible to say that the problem has been solved optimally even if the widespread use of computer controlled machines provides an increase in quality and efficiency in edge banding. Because one of the important problems that arise in the life cycle of products such as furniture and doors is that the edge bands are opened to the process of use or deformed at various levels causes the function of the product to weaken. 
Edge Band applications have an intensive use in the furniture industry due to the visuality, added value and protective properties it provides. However, edgebanding applications are an important cost item in the process. The edgeband cost accounts for $3 \%$ of the cost of particle board and coated particle board [1-3].

The first time woodworking appeared most commonly dates back to the medieval period. In this period, massive trees were used as raw materials in furniture and threaded bushings were used as joining technique. In this style, drawer, chest, carved door wings were made, and over time, mosque and church furniture were transferred. Box furniture constructions were obtained by adding narrow solid woods side by side [4]. Nowadays, with the rapidly developing technology, important changes have occurred in the furniture sector, but the use of wood and wood composites, which are wood-based wood composites, has become widespread due to the limited demand for wood and the increasing demand for furniture [5-7].

Wood-based boards are produced in a way that their surface areas are homogeneous but their crosssectional areas cannot be aesthetically pleased due to their production technologies. For this reason, it was necessary to perform a complementary aesthetic application on the sectional part of the plate, which has been applied any surface treatment. While the edge massif application was widely used in the past, today this application has been replaced by the combined materials under the name of edge band produced from various raw materials. Since the edgebands require a second process to cover the edges after the surface treatment of the boards is completed, the furniture industry has developed production techniques in accordance with this production technique [8].

PVC Edge Band emerges as a product with thermoplastic feature, which is the most common use area. The fact that it has been used for many years has led to the fact that the production technology of this material has advanced and its usage area has been expanded further. The most important feature of the glued edge bands is that they are produced in accordance with the coated plate surfaces used in furniture manufacturing under today's conditions. By using quality raw materials, it can be ensured to obtain high standard products. The fact that it is very suitable for furniture production processes and offers a wide range of options for color matching with other materials has made PVC edgebands the most used type of edgebanding.

Wooden edge bands are wooden strips obtained by cutting the coatings obtained from solid trees by peeling or cutting management in the longitudinal direction and by cutting them in special dimensions to the place of use. Although wood products are not alternative for those who cannot give up their natural appearance, using wood edgebanding that is fully compatible with this wood look is undoubtedly an important place in furniture production. When choosing wood belts to be used, it will be very accurate to choose quality wood [9-11]. Saçl1 [12]; investigated the effects of application time, edge band type and edge band thickness on adhesion performance in edge band application in melamine coated particle boards. As a result of the study, it was revealed that the factors determined had an impact on adhesion performance. In the study of Lyu et al. [13], they applied PVC edgebanding to fiber board based materials in the edgebanding process. In evaluating adhesion performance, they made performance evaluation based on glue amount, temperature and application speed parameters. As a result of the study, the maximum performance was reached at $140-150{ }^{\circ} \mathrm{C}$, the amount of glue 363-379 $\mathrm{gr} / \mathrm{m}^{2}$ and the application speed at the factor levels of $13-15 \mathrm{~m} / \mathrm{min}$. In the study of Sedlecky and Gasparik [14], they conducted researches in terms of 
processing and energy consumption of wood-based materials with edge banding applied. As a result of the study, it was concluded that the energy consumption increased in the drilling process for the materials with edge banding. Yapıc1 et al. [15] investigated the effects of edgeband thickness on performance on solid edgebanding applications. As a result of the study, they stated that $5 \mathrm{~mm}$ thickness gives better results in MDF applications. Sacli and Neseli [16] Using the Taguchi experiment design, melamine-coated particle boards studied the performance evaluation of the edgeband thickness at the end of the aging period. It is concluded that the aging period and edgeband thickness are important on performance.

The experimental design approach is a method used in planning the experiments and evaluating the data obtained as a result of the application in an objective way [17-19]. By using the experimental design in evaluating a process or developing a new product, information about the process can be gathered, effective parameters and interactions between the parameters can be monitored, and it is based on investigating optimum levels by type of quality characteristic. One of the most important experimental design techniques used for the development of products and processes, reaching a structure required by certain standards, meeting customer requests, is the response surface method. This method can be used in the development and improvement of new processes as well as the improvement of existing systems. In cases where a specified quality characteristic (response) is affected by different parameters and levels, it is a method aimed at optimizing this quality characteristic by using mathematical and statistical methods to make modeling and analysis. Response surface method; reveals the relationship between the variables and the response or responses in line with the application of regression analysis using experimental data that emerged in accordance with the design using experiment design, regression analysis and optimization techniques.

Considering real life problems, it is aimed to be able to produce by finding cheaper and more effective ways without compromising product quality. To achieve this goal, the response surface method can use both statistical and mathematical models together [19-25].

For the improvement of edge banding, at least three groups should be taken into consideration together with the basic parameters. The first of these are the parameters that depend on the edgeband structure (type, quality, dimensions). The second is the adhesive properties used and the third is the process-dependent (speed, pressure, temperature, etc.) parameters. In addition, materialing of the application is another important parameter group in the edge banding process. In this study, it is revealed the factors affecting the edge band adhesion resistance in the edge band application, which has an intensive use in the furniture industry. And by optimizing factor levels, it is aimed to discuss factors affecting adhesion resistance and improvement conditions.

\section{Materials \& Methods}

Medium Density Fibreboard (MDF) and Particle Board (PB) were selected as test material in order to determine the edge banding performance. Density levels of PB and MDF samples were measured using randomly cut specimens with $50 \mathrm{~mm}$ by $50 \mathrm{~mm}$ squares. Each sample was weighed and its dimensions were measured at an accuracy level of $0.1 \mathrm{~g}$ and $0.01 \mathrm{~mm}$, respectively. Average density of particleboard was determined as $0.56 \mathrm{~g} / \mathrm{cm} 3$ while this value was $0.68 \mathrm{~g} / \mathrm{cm} 3$ for MDF samples. 
The edge banding has a widespread use due to its visually and protection against external influences. At the same time, it creates added value in wooden furniture due to its different colour options, different thicknesses and different types. In this study, PVC edge banding with a thickness of $3 \mathrm{~mm}$ is used. The PVC edge banding applied to the samples was carried out on the CNCcontrolled edge banding machine. The speed of the machine is determined as $10 \mathrm{~m} / \mathrm{min}$, and the glue temperature is set to $190^{\circ} \mathrm{C}$.

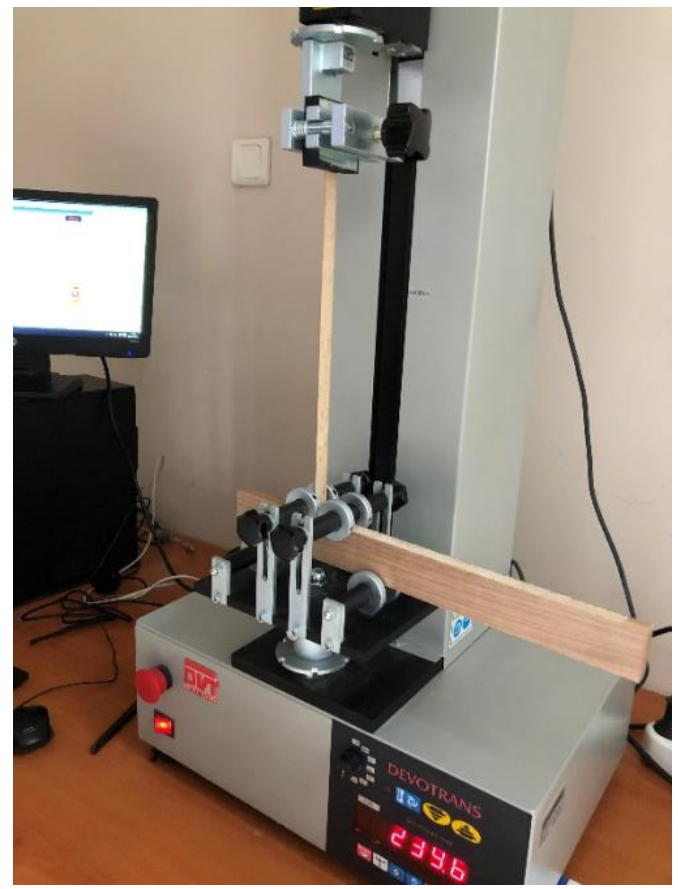

Figure 1.a. MDF edge banding test started

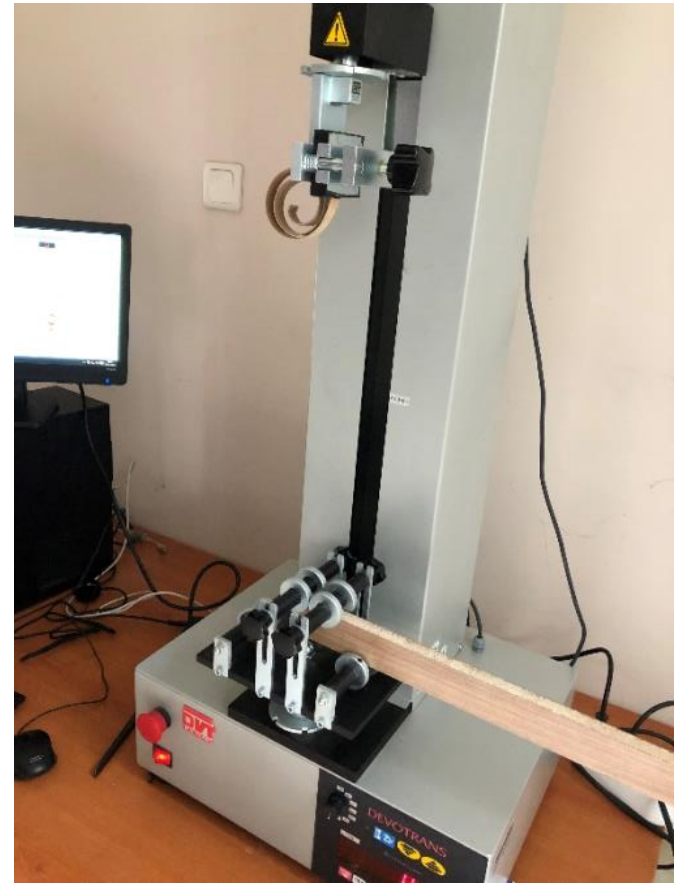

Figure 1.b. MDF after the test. 


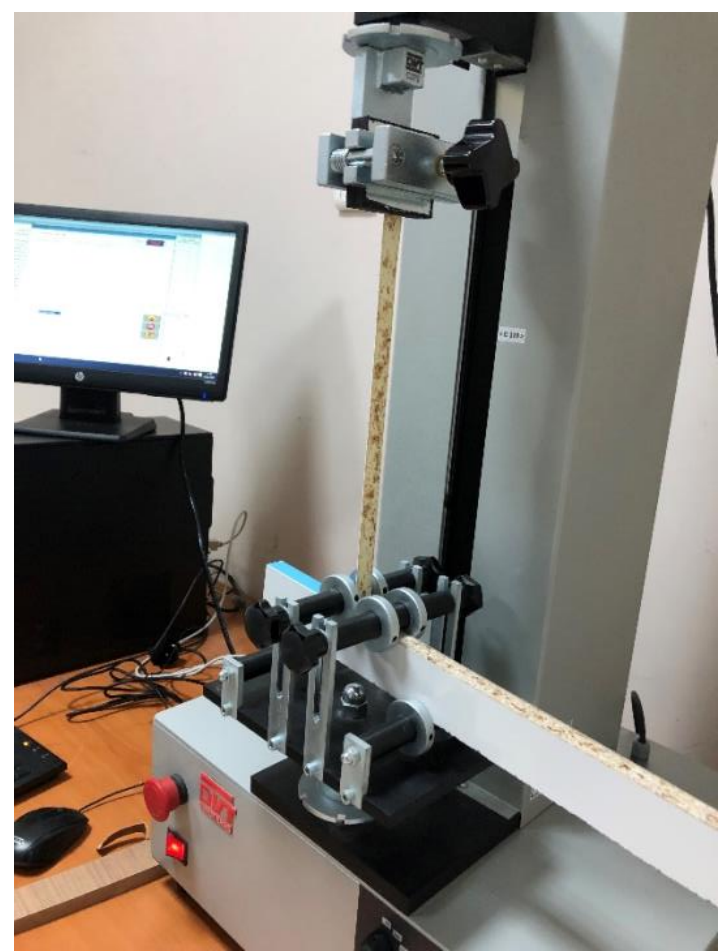

Figure 2.a. PB edge banding test started

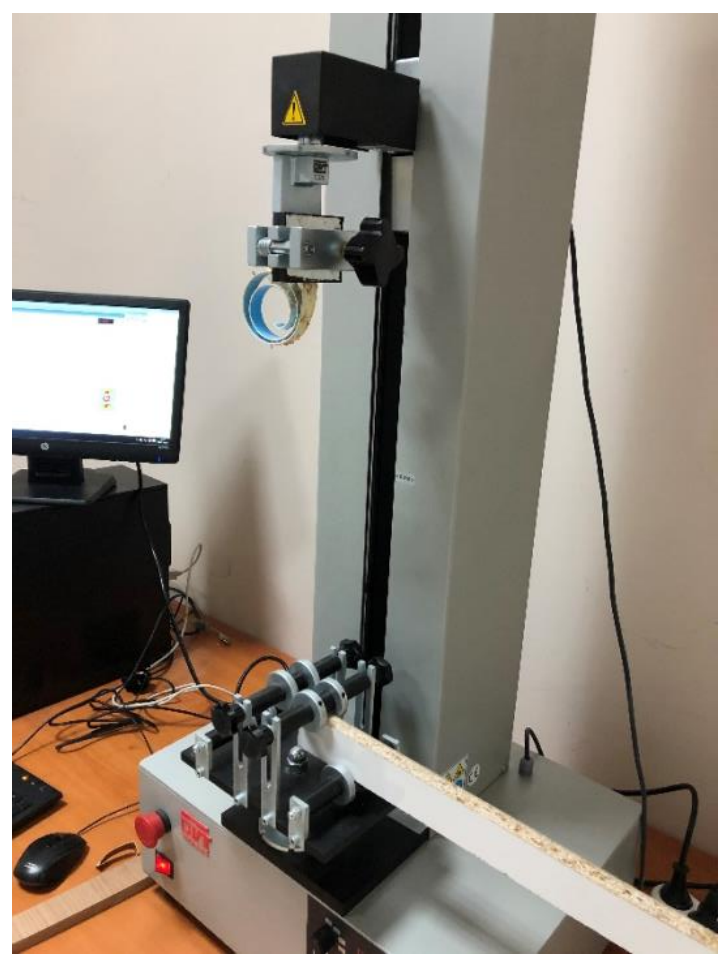

Figure 2.b. PB after the test.

These samples were measured by using universal testing machine which is showing Figure $\mathbf{3}$ and loading rate was selected as $5 \mathrm{~mm} / \mathrm{min}$. For each sample, the maximum edge bending strength was determined as the force applied to each experimental sample at the time of failure. The results for each of the specimen was illustrated by using edge banding performance software. Application images of edge banding performance for MDF are given in Figure 1.a and 1.b. Application images of edge banding performance for PB are given in Figure 2.a and 2.b. 

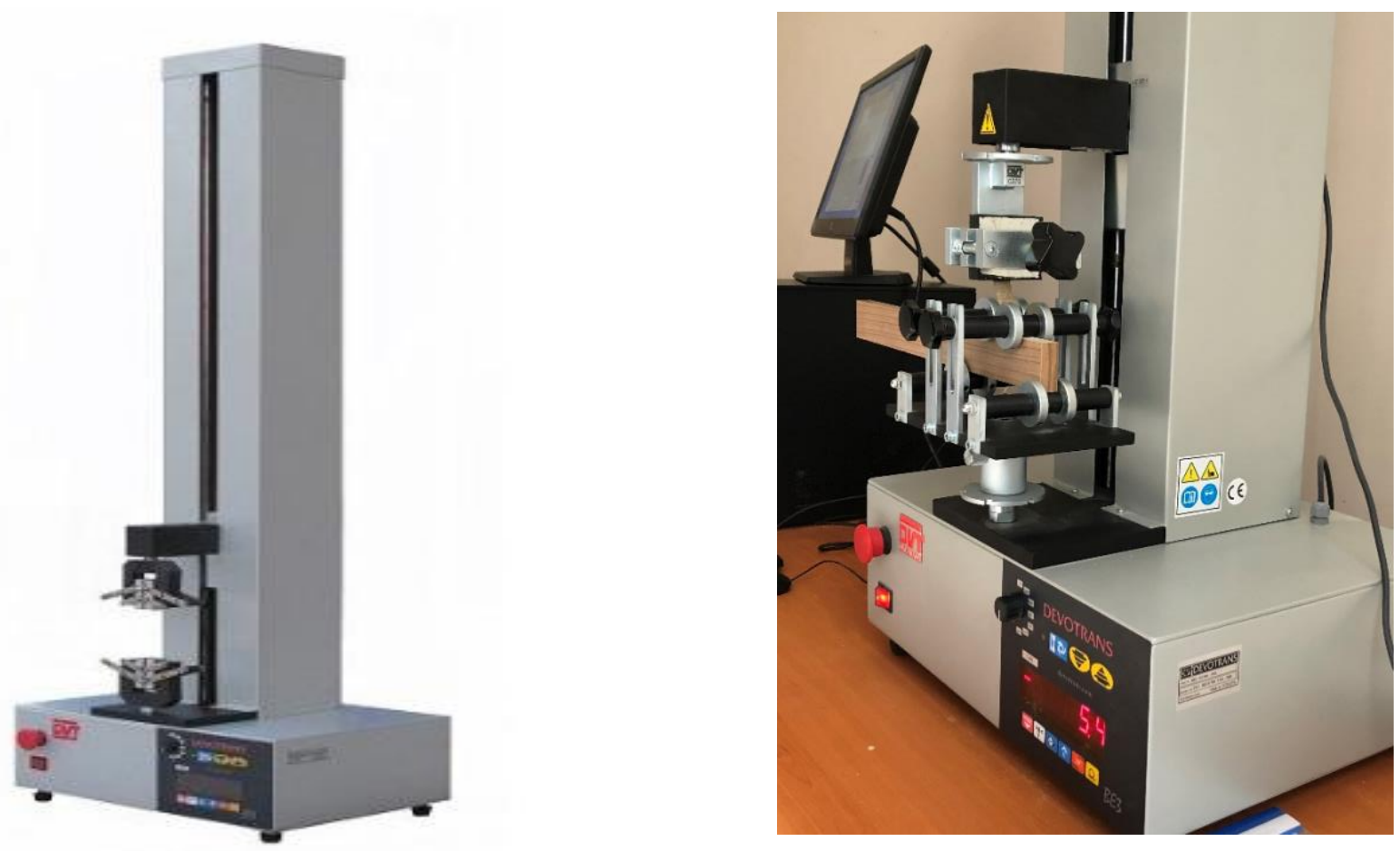

Figure 3. Universal testing machine

\section{Results and Discussion}

In this study, PVC edgebanding performance for different material types such as MDF and PB was determined. Edgebandign performance was analyzed with ANOVA and probability plot.

Probability plot of edge banding performance values of MDF and PB is displayed in Figure 4. This plot was presented with results of mean, standard deviation (StDev), sample size (N), Andersen darling test (AD) and P-critical values. According to the results of 95\% confidence level, P-values were high than 0.05 showing the model the observations have a normal distribution. MDF and PB for edge banding performance values were found as 0.049 and $0.051 \mathrm{~N} / \mathrm{mm} 2$, respectively. 


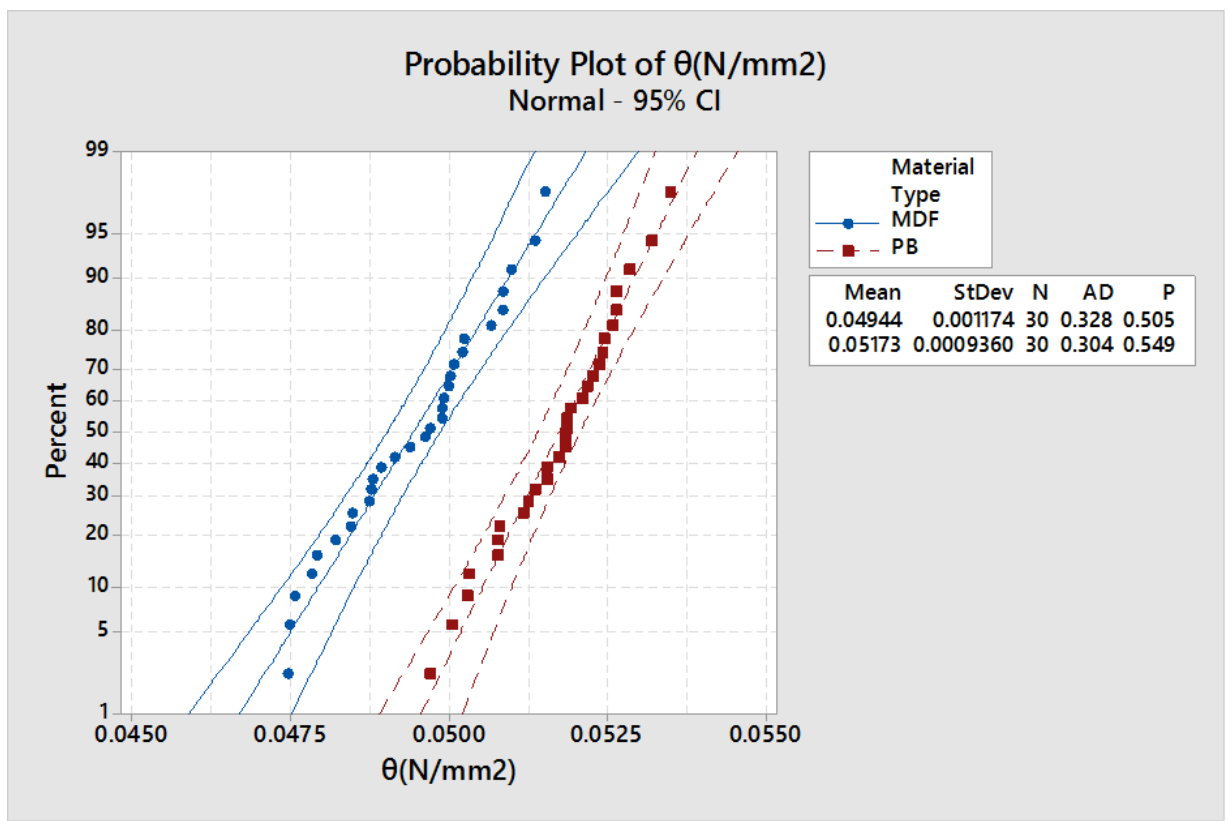

Fig. 4. Probability plot result of Edge banding for MDF and PB

For each type of material types, $30 \times 2$ arrays were measured and these results were evaluated with One-Way-ANOVA analysis. According to results, material type was found as significant factor. ANOVA result for edge banding of MDF and PB was given in Table 1.

Table 1 ANOVA Results for Edge banding of MDF and PB

\begin{tabular}{llllll}
\hline Source & DF & Adj SS & Adj-MS & F-Value & P-Value \\
\hline Material Type & 1 & 0.000079 & 0.000079 & 69.96 & 0.000 \\
Error & 58 & 0.000065 & 0.000001 & & \\
Total & 59 & 0.000144 & & & \\
\hline
\end{tabular}

\section{Conclusions}

The aim of this study, PVC edgebanding performance for different material types such as MDF and $\mathrm{PB}$ was determined. The data collected to evaluate the performance of the edgebanding was evaluated using the Pobability plot and Anderson darling test. ANOVA was applied to determine the effective factor. According to the results of $95 \%$ confidence level, $P$-values were high than 0.05 showing the model the observations have a normal distribution. Material type was found as significant factor. MDF and PB for edge banding performance values were found as 0.049 and $0.051 \mathrm{~N} / \mathrm{mm} 2$, respectively.

\section{Acknowledgements}




\section{Proceedings of the 2020 Society of Wood Science and Technology International Convention}

"This work was supported by Scientific Research Projects Coordination Unit of Istanbul University-Cerrahpasa. Project number:FBA-2019-33685.”

\section{References}

[1]Sakarya, S., Doğan, Ö., Mobilya Sektör Raporu 2016, Orta Anadolu İhracatçı Birlikleri Genel Sekreterliği ,Ankara, 2016.

[2] Usta İ., Güray A., Ankaradaki Küçük Ölçekli Mob. Firmalarının Yapısı ve Ürün Türlerinin Yöresel Taleple İlişkisi, I. Uluslararası Mobilya Kongresi, 14-17 Ekim, İstanbul, Türkiye,.1999.

[3] Anonim, Ülkeler Bazında Dünya Mobilya Ticareti Değerleri 2018, www.trademap.org. (Nisan 2018).

[4] Hüseyin, H., Kodal, S., Altinok, M., Kaplamalı Orta Yoğunluklu Lif Levhada (MDF) Köşe Birleştirme Tipinin ve Tutkal Çeşidinin Diyagonal Basma ve Çekme Direncine Etkisi, Yapı Teknolojileri Elektronik Dergisi 1, 7-14, 2007.

[5] Sözen, E., Kabin Tipi Mobilyalarda Düz Köşe Birleştirmelerinde Kullanılan Kenar Bandı Kalınlığının ve Türünün Birleştirme Direnci Üzerindeki Etkisinin Belirlenmesi, Yüksek Lisans Tezi, Zonguldak Karaelmas Universitesi, 2008.

[6] Akkök, A., Demonte Mobilya Üretiminde Kenar Bantlama İşleminin, Birleştirme Elemanlarının Mekanik Performansı Üzerine Etkileri, Kahramanmaraş Sütçü İmam Üniversitesi, 2016.

[7] Anonim, PVC ve ABS bazlı kenar bantlarının benzerlik ve farklılıkları https://www.romaplastik.com/kenarbandidokt

[8] Stark, N., M., Cai, Z., Carll, C., 2010, Wood Handbook, Wood as an engineering material, Centennial, Particleboard, General Technical Report FPL-GTR-190.

[9] Yılmaz, B.M., 2018, Mobilya endüstrisinde kullanılan pvc kenar bantları için değerlendirme kriterlerinin belirlenmesi ve test metodlarının geliştirilmesi, Yükseklisans tezi, Hacettepe Üniversitesi, Ankara.

[10] Sözen, E., 2008, Kabin Tipi Mobilyalarda Düz Köşe Birleştirmelerinde Kullanılan Kenar Bandı Kalınlığının ve Türünün Birleştirme Direnci Üzerindeki Etkisinin Belirlenmesi, Yüksek Lisans Tezi, Zonguldak Karaelmas Universitesi.

[11] Akkök, A., 2016, Demonte Mobilya Üretiminde Kenar Bantlama İşleminin, Birleştirme Elemanlarının Mekanik Performansı Üzerine Etkileri, Yükseklisans tezi, Kahramanmaraş Sütçü İmam Üniversitesi, 2016.

[12] Sacl1, C., 2015, The effect of time and edhe danding type and thickness on the bending and tensile strength of melamine coated particleboard, Proceeding of 27 International conferance, 213-219.

[13] Lyu, J., Jiang, L., Chen, M., 2017, Influence of temperature of applying glue, glue dosage and feed rate on Peel strength of edge band from curved edge part, IOP conf. Series:Material Science and Engineering 274: 1321-1332.

[14] Sedlecky M., Gasparik, M., 2017, Power consumption during edge milling process of medium density fiberboard and edge-glued panel, BioResources 12(4): 7413-7426. 
[15] Yapıc1, F., Likos, E., Esen, R., 2012, The effect of edge banding thickness of some trees on withdrawal strength of beech dowels pins in composite material, Wood research, 5(4):610612.

[16]Sacl, C., Neseli, S., 2016, Determination of the effect of edge banding thickness and aging period on the mor and moe of melamine coated particle board using Taguchi method, Tehnicki vyesnik, 23 (4): 1059-1065.

[17] Montgomery, D.C., 2005, Design and Analysis of Experiments, 5th ed. John Wiley \& Sons, Inc. Arizona, ISBN: 978-1-118-14692-7.

[18] Dellino, G., Kleijnen, J.P.C. and Meloni, C., 2010, Robust optimization in simulation: Taguchi and Response Surface Methodology, Int. J. Production Economics, 125, 52-59.

[19]Miro-Quesada, G. and Del Castillo, E., 2004, Two approaches for improving the dual response method in robust parameter design, Journal of Quality Technology, 36 (2), 154-168.

[20] Dvorak, T.M., 2001, Response surface optimization techniques for multiple objective and randomly valued independent variable problems, Phd. Thesis, University of Central Florida.

[21] Montgomery, D.C. and Runger, G.C., 2011, Applied statistics and probability for engineers, John Wiley \& Sons, United States of America, ISBN: 0-471-20454-4.

[22]Lin, D.K.J., and Tu, W., 1995, Dual response surface optimization, Journal of Quality Technology, 27(1), 34-39.

[23] Wang, B. P., 2004, Parameter optimization in multiquadric response surface approximations, Structural and Multidisciplinary Optimization, 26, 219-223.

[24] Chen, H.-W., Wong, W. K. and Xu, H., 2012, An augmented approach to the desirability function, Journal of Applied Statistics, 39 (3), 599-613.

[25] Asiltürk, İ. and Neşeli, S., 2012, Multi response optimisation of CNC turning parameter via Taguchi method-based response surface analysis, Measurement, 45, 785-794.

Biography 


\title{
Proceedings of the 2020 Society of Wood Science and Technology International Convention
}

\author{
Highly efficient, stable, and recyclable hydrogen manganese \\ oxide/cellulose film for the extraction of lithium from seawater
}

\author{
Daxin Liang, Northeast Forestry University, China \\ liangdaxin@yahoo.com
}

\begin{abstract}
The extraction of lithium from seawater has attracted much interest as a means to meet increasing demand for lithium with the rapid expansion of the electric vehicle and electronics markets. Herein, a renewable and recyclable hydrogen manganese oxide (HMO)-modified cellulose film was developed and investigated toward the extraction of lithium from lithium-containing aqueous solutions. The porous film was characterized and its extraction efficacy and selectivity toward lithium from an aqueous solution (ppm level) and seawater (ppb level) were investigated. The HMO/cellulose film exhibited a higher $\mathrm{Li}+$ adsorption capacity (21.6 mg g-1 HMO) than HMO/polymer (e.g., polyvinyl chloride or polyvinylidene fluoride) films, which have been examined in the literature for lithium extraction, owing to its multi-dimensional porosity and hydrophilicity. The kinetics analysis based on a pseudo-second-order model indicated that the $\mathrm{Li}+$ extraction rate of the $\mathrm{HMO} /$ cellulose film was three times higher than that achieved by the HMO powder alone (i.e., $0.075 \mathrm{cf} 0.023 \mathrm{~g} \mathrm{mg-1} \mathrm{h-1).}$

Furthermore, the $\mathrm{HMO} / c e l l u l o s e$ film displayed high selectivity for $\mathrm{Li}+$ when exposed to seawater-the extraction of $\mathrm{Li}+$ reached $99 \%$, whereas that of the other ions present in seawater (i.e., $\mathrm{Sr}_{2+}, \mathrm{K}+$, Ca2+) was less than 4\%. In addition, the adsorption capacity and mechanical strength of the HMO/cellulose film remained stable even after eight adsorption-desorption cycles. The present findings demonstrate the potential of the present $\mathrm{HMO} /$ cellulose film for the recovery of $\mathrm{Li}+$ from seawater or waste water.
\end{abstract}

\section{Biography}




\title{
Proceedings of the 2020 Society of Wood Science and Technology International Convention
}

\section{Agrocomposites for the reinforcement of concrete within light weight structures}

\author{
Laetitia Marrot 1 \\ laetitia.marrot@innorenew.eu \\ Jana Winkelmann2 \\ jana.winkelmann@wki.fraunhofer.de \\ Natalie Vellguth2 \\ natalie.vellguth@wki.fraunhofer.de \\ Jan Binde2 \\ jan.binde@wki.fraunhofer.de \\ Marco Wolf2 \\ marco.wolf@wki.fraunhofer.de \\ 1 InnoRenew CoE \& University of Primorska, Slovenia \\ 2 Fraunhofer WKI, Germany
}

\section{Abstract}

Concrete performs well in compression but has low tensile performance. To improve properties of concrete under tensile loading conditions (e.g., bending) requires a complementary supporting material to absorb excessive tensile forces. For this purpose, steel is a common solution to reinforce concrete. Steel reinforcement is though susceptible to corrosion due to the alkaline environment within concrete.

To reduce corrosion problems, another approach for concrete reinforcement is the complete substitution of the steel with a textile reinforcement made of glass, carbon and/or plastic fibers. Textile fabrics can be customized thanks to their thread systems (warp thread in the machine direction and weft threads across the machine direction). The type of crossing of warp and weft threads is referred to as weave. The weave influences properties such as mechanical resistance, dimensional stability and drapability. While effective, synthetic fibres, however, come from petroleum-based resources and their production is energy-intensive.

Cellulosic fibres are widely available in most countries and provide a cost-effective, low density reinforcement material. In addition, cellulose fibres are biodegradable, renewable, non-hazardous and non-abrasive. Their specific mechanical properties (i.e. specific strength and modulus) are comparable to those of synthetic fibres (e.g. E-glass) when used as reinforcement materials. These advantages make cellulosic fibres a convenient material for the reinforcement of cement-based materials. As well as for synthetic fibres, an alkaline environment can weaken cellulosic fibres, therefore a coating is required to protect them. This study aims at assessing available flax fabrics for the reinforcement of concrete. Several weaving types will be considered and mechanically characterized with textile standards. Their resistance to an alkaline environment will be tested, and different coating formulations will be investigated to enhance the flax fabrics performances. The selection of a suitable polymer coating focuses on compatibility with the reinforcing fibres, processing and usage properties such as viscosity, drip time, biobased content, and chemical and temperature resistance.

Biography 


\title{
Proceedings of the 2020 Society of Wood Science and Technology International Convention
}

\section{Laboratory testing on the face bond durability of cross-laminated hardwoods}

\author{
Munkaila Musah \\ mmusah@mtu.edu \\ Xinfeng Xie \\ xinfengx@mtu.edu
}

Michigan Technological University, USA

\begin{abstract}
The study investigated the durability of the face bond in cross-laminated layups using 7 hardwood and 2 softwood species from the forests of the Great Lakes region. The layups were glued using resorcinoland melamine-based structural wood adhesives. A total of 720 combinations of the cross-laminated wood species and adhesives were tested for delamination by exposing the samples to cyclic wet-dry conditions. Distribution of the adhesive at the bond lines was studied as well, to understand the effect of adhesive penetration on the bond durability. The results indicated that mix hardwood species generally produced good bonds than single species cross lamination and the hybrid cross lamination (Softwood and hardwood) had better bond durability in wet-dry conditions. Also, both melamine and resorcinol based adhesives could be used to manufacture cross-laminated timber since softwood species cross lamination, hybrid cross lamination, and mix hardwood cross lamination met the requirements of the AITC Test T110-2007 (>8\%) in dry and wet cycles. High failure rate ( $\geq 50 \%)$ was produced in aspen, white ash and white pine for melamine glue and yellow birch for resorcinol adhesive in the single species combination. Similarly, in the mix species cross lamination, red mapleaspen, red maple-white ash, and red oak-hard maple in melamine, as well as aspen-hard maple, aspen-yellow birch, red maple-hard maple and red oak-white ash cross lamination in the resorcinol adhesive, recorded $\geq 50 \%$ rate of delamination which raises caution in their use in CLT manufacturing. Anatomical features and specific gravity were related to delamination of both single species cross lamination and mix species cross lamination. The abrupt and gradual transition in softwood recorded no delamination with all adhesives except in melamine gradual transition that failed to meet the requirement of the AITC 110-2007 (> 8\%). In addition, the viscosity of the adhesive influences the maximum depth of penetration, which intends to affects face bond performance and durability in an environmental condition (delamination percentage).
\end{abstract}

\section{Biography}




\title{
Proceedings of the 2020 Society of Wood Science and Technology International Convention
}

\section{Characterization of recycled wood plastic composites with added torrefied wood}

\author{
Davide DeVallance \\ devallance@innorenew.eu \\ Jaka Gašper Pečnik \\ jaka.pecnik@innorenew.eu \\ Matthew Schwarzkopf \\ matthew.schwarzkopf@innorenew.eu
}

InnoRenew CoE, Slovenia

\section{Abstract}

Torrefaction is a thermochemical process carried out at elevated temperatures between $200{ }^{\circ} \mathrm{C}$ and $300{ }^{\circ} \mathrm{C}$. This process leads to decomposition of material, change in structure, mass loss and volatiles release. Torrefied wood (TW) shows improved energy density, grindability and exhibits lower mass and water absorption. Today, this process is predominantly used in energy applications. In our study, manufactured wood plastic composites (WPC) were evaluated for mechanical, thermal and water absorption properties for repeated cycles of regrinding and remolding the composites. This process was performed to evaluate the potential of these materials to be recycled and determine if WPCs with torrefied materials improved recyclability of the WPCs. Wood species type, filler ratios of TW and torrefication temperature were also varied between WPCs. The project focused on selected short rotation crops, as they are a commonly used source for energy purposes and, therefore, underestimated for more advanced materials. In the study, three willow varieties (Millbrook, Fabius and Fish Creek) were torrefied using a tube furnace at both $225^{\circ} \mathrm{C}$ and $300{ }^{\circ} \mathrm{C}$ in a 30-minute process. Different mixtures of torrefied wood $(0,5,15,25$ and $40 \%)$ and un-torrrefied wood were mixed with a constant amount of polypropylene and lubricant for pellet production using a Thermo 16TE twin-screw extruder. Test specimens were manufactured using a hydraulic hot press at $200{ }^{\circ} \mathrm{C}$ to meet standardized tensile (ASTM D638) and flexural (ASTM D790) standards. After the first cycle (Run 1) of testing was completed, the samples were reground using a Pulversette mill with a $3 \mathrm{~mm}$ screen to match the pellet material size in Run 1 . The regrinding and new sample preparation was continued until statistically significantly differences in material properties were found. Results from mechanical properties of Millbrook indicated significant reduction in modulus of elasticity of selected mixtures compared to control group using untorrefied wood only. More evident decrease in flexural properties was observed with higher torrefication temperature. This was also confirmed for flexural strength. Elastic modulus in tension was improved with increasing torrefication temperature. However, tensile strength was found to be lower in comparison with the reference group (un-torrefied wood only WPCs). Additionally, water absorption decreased with higher percentages of added TW and temperature of torrefication. Research of ongoing cycle testing will be presented and used to evaluate the viability of reuse for WPC tailored with TW from different short rotation willow species.

\section{Biography}




\title{
Study on one-shot process for wood-based composites
}

\author{
Vicky Reichel ${ }^{*}$ - Werner Berlin1-Felix Rothe 1 - \\ Jan Beuscherı - Klaus Dröder 1
}

\begin{abstract}
1 Research Assistant, Research Assistant, Research Assistant, Head of Department, Head of Chair and Professor, Institute of Machine Tools and Production

Technology, Technische Universität Braunschweig,

Department: Manufacturing of Hybrid Components

@ Open Hybrid LabFactory e.V, Wolfsburg, Germany

*Correspondingauthorv.reichel@tu-braunschweig.de,w.berlin@tu-

braunschweig.de, f.rothe@tu-braunschweig.de; j.beuscher@tu-braunschweig.de;

k.droeder@tu-braunschweig.de
\end{abstract}

\begin{abstract}
Environmental changes force industries to use renewable and degradable materials for lightweight solutions to solve weight and therefore $\mathrm{CO} 2$. One highly prioritized topic is the combination of wood materials with biodegradable plastics. Especially when processing these materials, it is essential to develop efficient processes to reduce obstacles and enable the application in serial use. To take advantage of the mechanical behaviour of the wood structure it is necessary to investigate the combination of thin solid wood with plastic. Regarding large-scale production, an injection moulding process is addressed in this study. When processing raw material cutting operations are used. To use the shear cutting process has several advantages: it is a cost effective process with short cycle times. Also no thermal influence or water immersion occur on the working material (like in laser beam or water jet methods), so material sensitive on this can be worked by shearing. But as a disadvantage a working force is applied. This work aims to show the findings this working fore on $5 \mathrm{~mm}$ wood solids and the influence of the created surface on the bonding between plastic and wood cutting edge. The process connections and dependencies of shear cutting and injection moulding are investigated. Different wood materials were used to analyse the effects of cutting and material parameters (e.g. moisture, forces) on the cutting edge quality (e.g. structural damage). To detect the effect of different cutting edge qualities on the joint between wood and plastic component tensile specimen were tested.
\end{abstract}

Key words: Wood-Plastic-Composite, Cutting Edge, Injection Moulding Process

\section{Introduction}

When using wood materials in combination with polymer materials the structure of wood often is subordinately and wood is used as flour filling in polymers $[1,2]$. This is related to its low density as well to the special ability of wood to bind $\mathrm{CO}_{2}$ while growing. Therefore, wood has a low environmental footprint compared to other filling and reinforcement materials e. g. based on glass or carbon. Using wood fibres in polymers addresses the reinforcement of the compound but is often related to difficult processing by means of thermal damage of the fibres [2]. Another way is to use solid wood plates. The advantage is the natural composite structure of wood base 
element: celluloses as fibres and lignin as matrix. For this no extra processing of the raw material is necessary and the cost to performance ratio becomes economically relevant for a wood-plastic application.

\section{Manufacturing of Wood-Polymer composites}

When using wood as flour filling in polymers the wood raw material (flour, shavings, chips, fibres) is just mixed into the polymer granules. Typical methods to produce wood-plasticcomposites (WPC) parts are the direct extrusion of profiles (US market: 98\% [3]), injection moulding or pressing techniques [3].

The usage of solid wood like wood veneer in combination with polymers requires the adaption of existing processing methods. Taking the mechanical characteristic of the wood veneer into count pressing techniques become more relevant $[4,5]$. The veneer and polymer films can be stacked alternately and pressed while increased temperature melts the polymer. The cured veneerpolymer-compound can be processed further.

For decorative parts thin veneer is processed in injection moulding and overmoulded as well as back-injected with rips and other supporting structures. Since this process is widely used there is a number of findings available for the process parameters and resulting (bonding) strength [6$11]$.

The investigation shown in this paper aims to determine influences and parameter relations of bond strength between solid wood and polymer material based on a varying bonding agent ratio and wood surface characteristic. For this firstly the bonding strength between wood veneer and polymer using a bonding agent are analysed. After determining the optimal processing parameters for this, the influence of a shear cutting surface on the bonding strength is evaluated. The results of all the experiments are shown and discussed below.

\subsection{Shear cutting of wood materials}

In this section the shear cutting process and the resulting characteristics on wood cutting edge surface topology is described.

The shear cutting process is described based on DIN 8865 shown in Figure 1. A punch is moved against the die with a specific die clearance. This clearance influences the resulting cutting force, the wear of the tool and the workpiece edge cutting quality. Additionally, a blank holder can be used when materials tend to move or bend when processed.

Advantages of the process are the short cycle times and the overall low cost. A major disadvantage is mainly the tool based method which includes wear and therefore maintenance intervals.

The shear cutting of wood is not highly investigated yet due to the process is not typically used for wood materials as Wagenführ et al. [12] and Kollmann [13] said.

Defining the forces and the resulting surface geometry the process can be adapted for the following injection moulding for wood-polymer parts. To show basic findings is targeted by the experiments presented in this paper. 


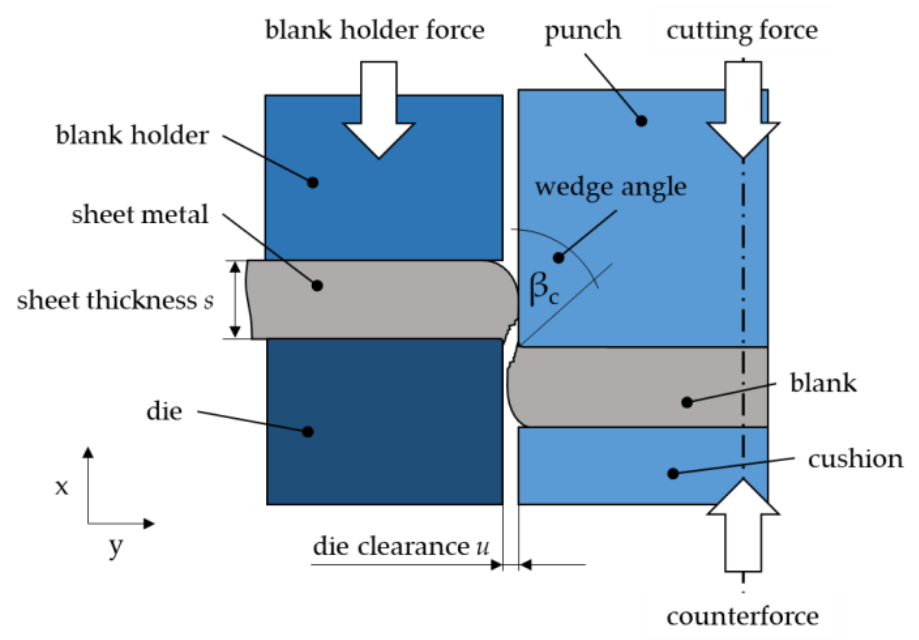

Figure 1 Basic terms of shear cutting process

Wood has low density due its capillary and therefore hollow structure. When cutting, the force is applied orthogonal to this tubes and the structure is compressed and damaged. In comparison to metal material the mirco sectional analysis shows significant fractures at the cutting edge (see Figure 2).

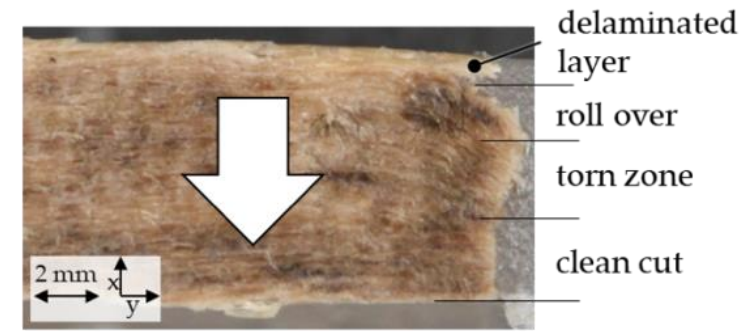

Figure 2 Cutting edge geometry of solid wood in the shear cutting process

The cutting edge geometry shows different sections. A delamination in the first millimetres can be detected. The fibres in this section spring back when the load maximum is exceeded and tearing appears. This effect leads to a delamination between the fibres torned and the fibres expanded and bended. It is observed that the torn zone where fibres tear apart is situated behind the roll over zone where fibres are bend. A clean cut appears at the lower cutting section. It is assumed that the fibres are first compressed and stretched to their maximum followed by a clear cut.

\subsection{Influence of bonding agent}

Combining the two different material categories of wood and polymers the bonding strength can be increased by using bonding agents. There are findings available for maleic anhydride grafted polypropylene (MAHg-PP) especially when using polypropylene (PP) material $[3,14,15]$. This thermoplastic polymer type is often used in polymer parts due to its specific mechanical characteristics [16]. Polypropylene belongs to the group of polyolefins and is partially crystalline and non-polar [17]. To react with a joining partner, the accessible active molecular groups are required. Such groups are not available in untreated polypropylene. When using maleic 
anhydride grafted polypropylene (MAHg-PP) as a bonding agent a chemical connection can be achieved [18].

The achievable strength of polymer and wood are influenced by the wood quality, surface structure, material parameters like moisture content, etc. Therefore, we decided to evaluate the optimal bonding strength on the wood veneer and polymer used specifically in this study.

\subsubsection{Experiments on bonding strength depending on the bonding agent}

The polypropylene type BJ356O manufactured by Borealis ${ }^{\circledR}$ and ExxonMobile ${ }^{\circledR}$ 's bonding agent ExxelorTM PO 1020 containing approximately 1 wt.-\% of maleic acid [19] were used for investigations.

The bonding strength was determined as shear strength in 3-point-bending specimen (see Figure 3 ). The specimen geometry offers a large connection area which suitable to test thin veneer coated with polymer.

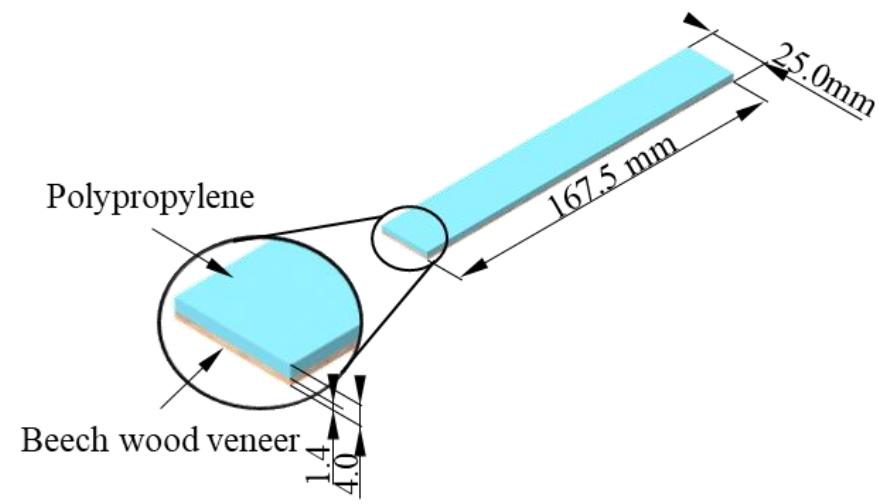

Figure 3 Polypropylene-wood veneer bending specimen

The aim of the experiment was to achieve the optimal bonding agent content and melt temperature of the plastic melt by varying the values in three steps according to Table 1 .

Table 1 Variation of the adhesion promoter content and the melt temperature for the initial tests

\begin{tabular}{|l|c|c|}
\hline & $\begin{array}{c}\text { Melt temperature } \\
\mathbf{T} \text { in }\left[{ }^{\circ} \mathbf{C}\right]\end{array}$ & $\begin{array}{c}\text { Bonding agent content } \\
\mathbf{m} \text { in [wt.- } \% \text { ] }\end{array}$ \\
\hline Lower level & 190 & 5 \\
\hline Basic level & 200 & 10 \\
\hline Higher level & 210 & 20 \\
\hline
\end{tabular}

Figure 4Error! Reference source not found. shows the influence on the bending strength of the variation of melt temperature and bonding agent content. It can be assumed that the bond strength decreases with increasing temperature. This can be explained by the convergence of the melt temperature to the temperature of maximum reaction between beech wood and oxygen at $210{ }^{\circ} \mathrm{C}$ which leads to higher depolymerization of cellulose [2]. This means that fewer free hydroxyl groups are available with which the bonding agent can react. 


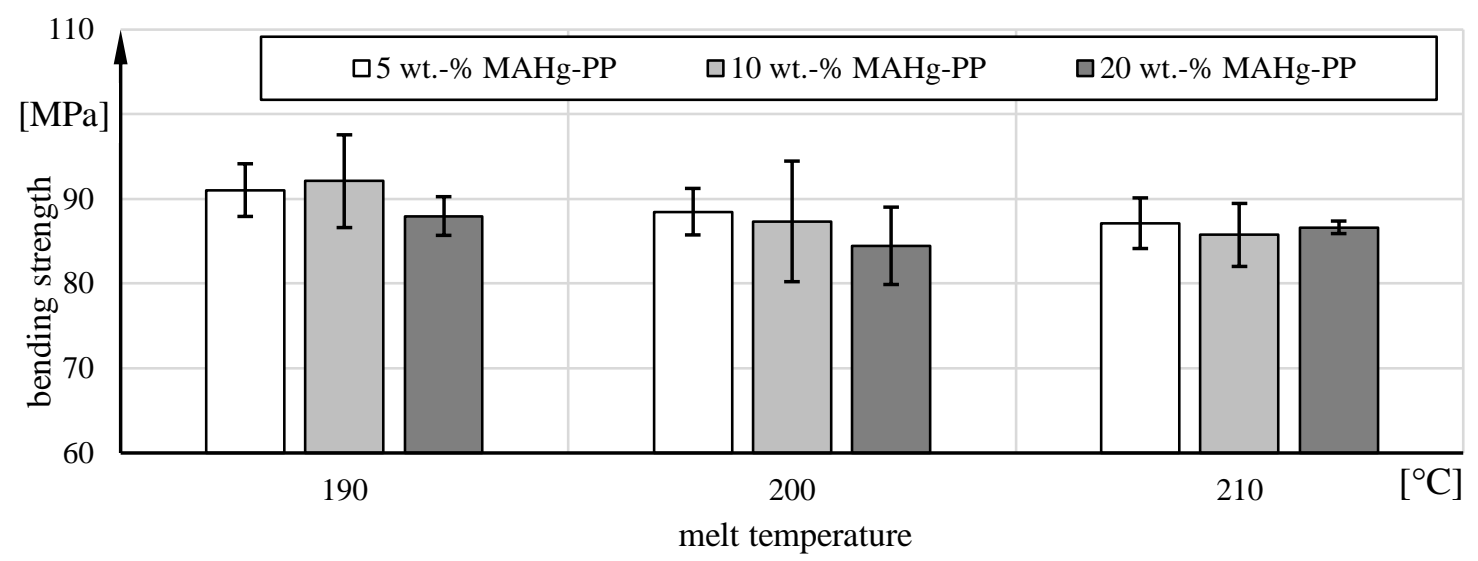

Figure 4 Dependence of bending strength on melt temperature and bonding agent content

At adhesion promoter contents of 5 and $10 \mathrm{wt} .-\%$, the strength is approximately the same. It decreases at the highest adhesion promoter content. This indicates a saturation already reached at $5 \mathrm{wt} .-\%$ adhesion promoter content. A further increase even has a strength-reducing effect.

For the following investigations an adhesion promoter content of 5 wt.-\% and a melt temperature of $190^{\circ} \mathrm{C}$ is used.

\subsection{Influence of shear cutting surface characteristic on bond strength in tensile specimen}

To determine the influence of the shear cutting surface characteristic different material and tool parameters in the shear cutting process are used. The influence of two different wood types beech and oak are addressed due to their different structure and therefore expected varying behavior when cut.

Secondly the determination of the bond strength values is addressed in this study. For this purpose, the cut edge of the wood material was butt-moulded. For the achievement of a composite strength, possible interlocking effects between polymer and cutting edge of the wood material are to be used. The preceding shear cutting process is used to display different cut edge characteristics of the wood material. The quantification of this influence is determined by means of tensile test force.

For this two-step process the specimen dimensions are shown in Figure 5. A thickness of 5mm solid wood material was choosen to enlarge the bonding surface. When manufacture the woodpolymer specimen the dimension ratio of both components is nearly the same. This is important for tensile testing to force the bonding area to fail rather than the material. 


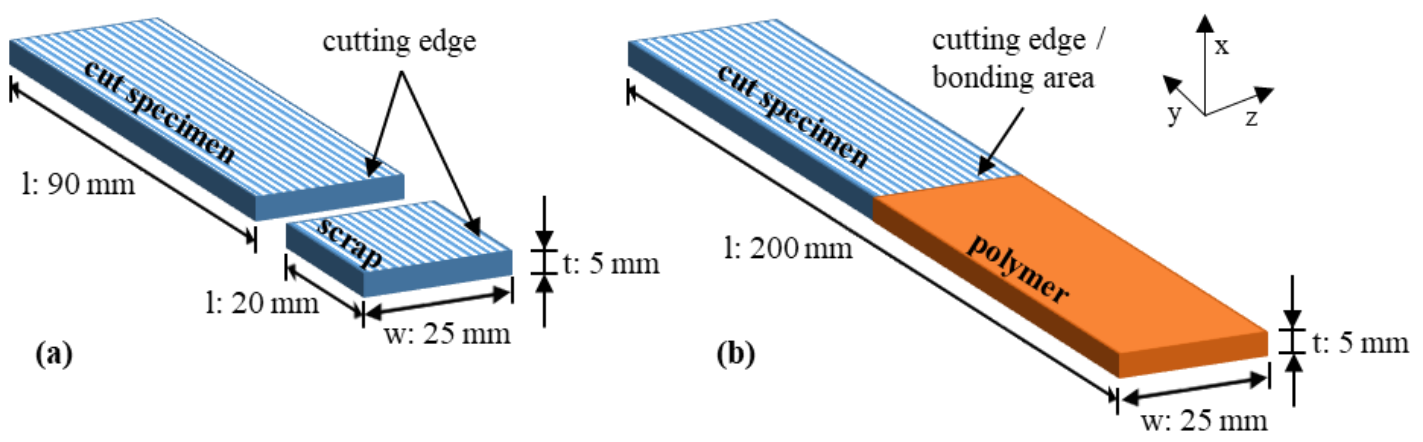

Figure 5 Shear cutting (a) and injection moulding (b) specimen

The process parameters are shown in Table 2. Depending on the experiment different parameters are listed and varied.

Table 2. Processing parameters for shear cutting and injection moulding process

\begin{tabular}{|c|c|c|}
\hline Process parameter & Symbol \& Units & Value \\
\hline \multicolumn{3}{|c|}{ I. Shear cutting process } \\
\hline Wood specimen dimensions & $\mathrm{w} \times 1 \times \mathrm{t}$ in $\mathrm{mm}$ & $25 \times 110 \times 5$ \\
\hline Shear gap & $\mathrm{u}$ in $\mathrm{mm}$ & $0.016(\mathrm{u} / \mathrm{t}: 8 \%)$ \\
\hline Cutting speed & $\mathrm{Vc}$ in $\mathrm{mm} / \mathrm{min}$ & 500 \\
\hline Cutting condition & $\mathrm{T}_{\mathrm{t}}$ in ${ }^{\circ} \mathrm{C}$ & $23^{\circ} \mathrm{C}$ at $65 \% \mathrm{rH}$ \\
\hline Grain orientation & $\gamma_{\mathrm{c}}$ in $^{\circ}$ & 90 \\
\hline Wood type & - & beech $(\mathrm{BE}) ;$ oak $(\mathrm{OA})$ \\
\hline $\begin{array}{c}\text { Preconditioning } \\
\text { (according to EN 13483-1) }\end{array}$ & $\omega$ in $\%$ & $9 ; 15$ \\
\hline Tool shape/cutting angle & $\alpha_{\mathrm{c}}$ in $^{\circ}$ & straight: 0 ; angled: 20 \\
\hline Quantity of specimen per series & - & 10 \\
\hline
\end{tabular}

II. Injection molding process

\begin{tabular}{|c|c|c|}
\hline $\begin{array}{c}\text { Injection molding specimen } \\
\text { dimensions }\end{array}$ & $\mathrm{w} \times 1 \times \mathrm{t}$ in $\mathrm{mm}$ & $25 \times 200 \times 5$ \\
\hline Melt temperature & $\mathrm{T}$ in ${ }^{\circ} \mathrm{C}$ & 190 \\
\hline Max. pressure & $\mathrm{bar}$ & 760 \\
\hline Holding pressure & $\mathrm{t}$ in s & $\begin{array}{c}19 \mathrm{~s} \text { at } 760 \mathrm{bar} ; \\
6 \mathrm{~s} \text { at } 0 \text { bar }\end{array}$ \\
\hline Mold temperature & $\mathrm{T}$ in ${ }^{\circ} \mathrm{C}$ & 60 \\
\hline Cooling time & $\mathrm{t}$ in $\mathrm{s}$ & 60 \\
\hline Bonding agent ratio & $\mathrm{m}$ in wt.- $\%$ & 10 \\
\hline Quantity of specimen per series & - & \\
\hline
\end{tabular}

\subsubsection{Shear cutting properties of wood specimen}

The shear cutting process was realized on a self-constructed shear cutting tool. The tool was mounted on a press which enabled the movement of the punch while recording the target value of the cutting force. To determine material related dependencies the wood type and the wood moisture were varied in two different values. Using different wood types show the influence of 
specific wood structures. By varying the moisture of the wood specimen the cutting force is influenced directly. In shear cutting process basic parameters like the shear cutting gap and cutting velocity were held constant while the shear tool geometry was varied from straight to angled. The different tool shapes lead to different cutting edge geometries and therefore high influence on the bonding strength was expected.

The values reached for oak and birch are constantly on the same force level when using the same process parameters. A comparison of values for the two different cutting tools shows that using a drawing cut is a reliable method to reduce cutting forces around $-19 \%$ for both wood types. This is related to the cutting mechanism: the straight cut (pushing cut) applies forces over the whole cutting edge at the same time. A force peak is therefore generated. The angled cut (drawing cut) conversely applies forces per section which is lower. Also it can be detected that the deviation of the overall values can be reduced for angled cuts.

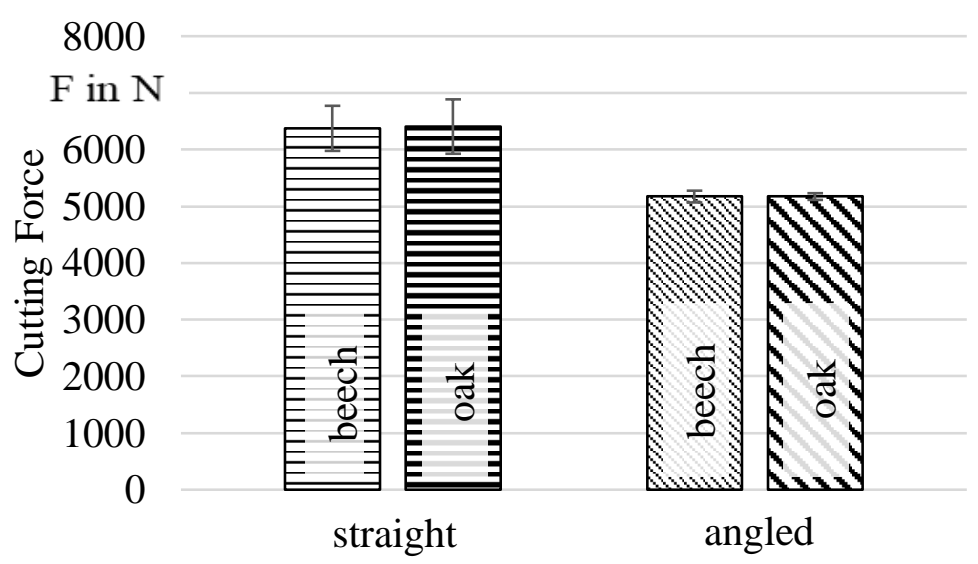

Figure 6 Influence of tool geometry on cutting force

\begin{tabular}{|c|}
\hline Tool geometry \\
\hline straight, angled \\
\hline Specimen thickness \\
\hline $5.0 \mathrm{~mm}$ \\
\hline Testing temperature \\
\hline $23^{\circ} \mathrm{C}$ \\
\hline Cutting speed \\
\hline $500 \mathrm{~mm} / \mathrm{min}$ \\
\hline Shear gap \\
\hline 0.016 mm \\
\hline Wood type \\
\hline beech, oak \\
\hline Preconditioning \\
\hline moisture $\omega: 9 \%$ \\
\hline
\end{tabular}

The analysed cutting force values for different wood moistures showed no significant difference. This could be related to weak conditioning. The moisture content of $9 \%$ and $15 \%$ were chosen to show a high difference in mechanical behaviour. Usually this difference is adequate to modify the strength properties of wood material. The specimen geometry could have an influence on the fibre saturation. Moisture is transported longitudinal to fibre direction which is a long distance in the used specimen. The moisture can differ therefore in different positions of the specimen.

Table 3 shows section views of the cutting surface and cutting edge on different specimen. As described in 2.1 the upward specimen side shows a thin delaminated layer followed by a bend torn zone and a compressed clean cut section. The height of the torn zone is larger when an angled cut is used. This is related to the cutting mechanism: while a straight cut applies forces over the whole cutting edge, the angled cut only applies force to a punctual point of the specimen. The force is therefore higher for the individual section and the torn zone enlarges. The angled cut shows therefore higher material damage by fibre bending.

Table 3 Cutting edge and surface characteristics for beech and oak ( $\omega: 9 \%)$

beech

oak 


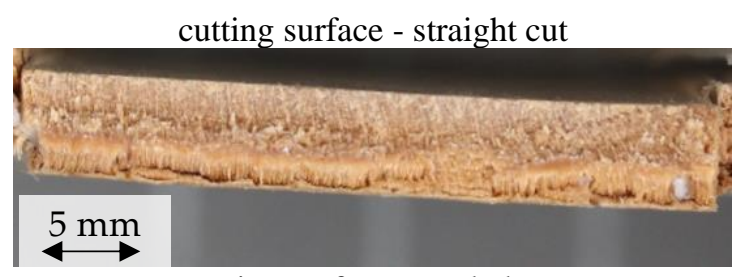

cutting surface - angled cut

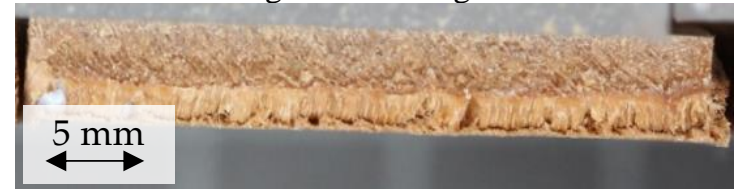

cutting edge - both cutting shapes

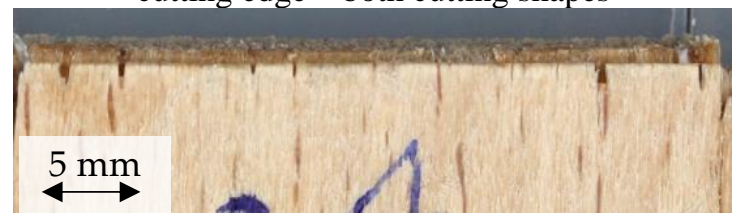

cutting surface - straight cut

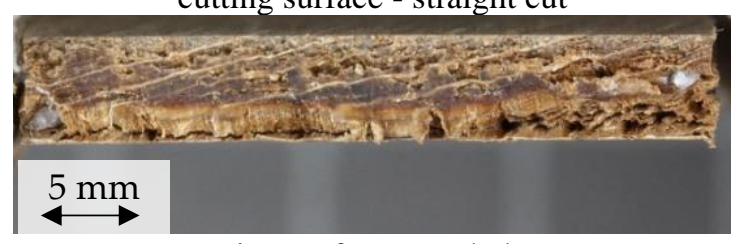

cutting surface - angled cut

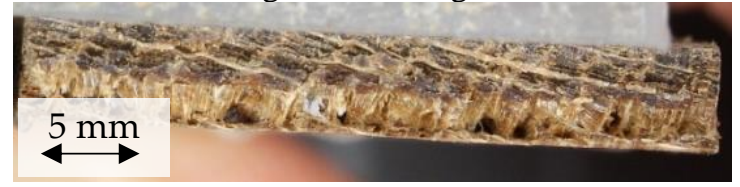

cutting edge - both cutting shapes

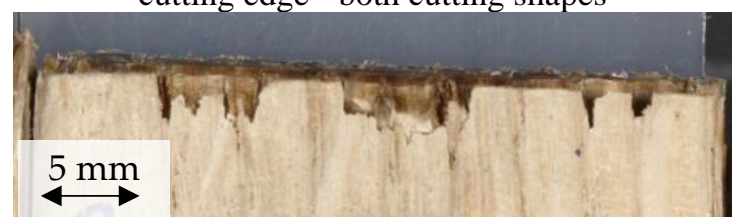

The cutting edge of beech shows a lower amount fibre breakage and fringe sections. For both tool geometries the cutting edges of both materials showed no clear difference.

Comparing the micro sectional views, it turned out that the reproducibility of the cutting edge is low. The individual wood types show specific breakage behavior but no identical cutting edge and surface. This is related to the natural origin of wood as well as to the fibre structure. The structure of the single specimen differs slightly so the cutting edge is differently pronounced depending on the ratio of hard and soft proportion (early/latewood).

\subsubsection{Bonding strength of wood-polymer tensile specimen}

To show dependencies of the bonding strength the cut wood specimen where moulded with MAHg-PP in a tensile test form. The target value was the bonding strength $\mathrm{F}$ in $\mathrm{N} / \mathrm{mm}^{2}$.

To analyse the bonding area microsections were made shown in Figure 7. It turned out that the cutting edge of oak material tend to close fully by the injected polymer material. Therefore, no interlocking effects by undercuts occur.

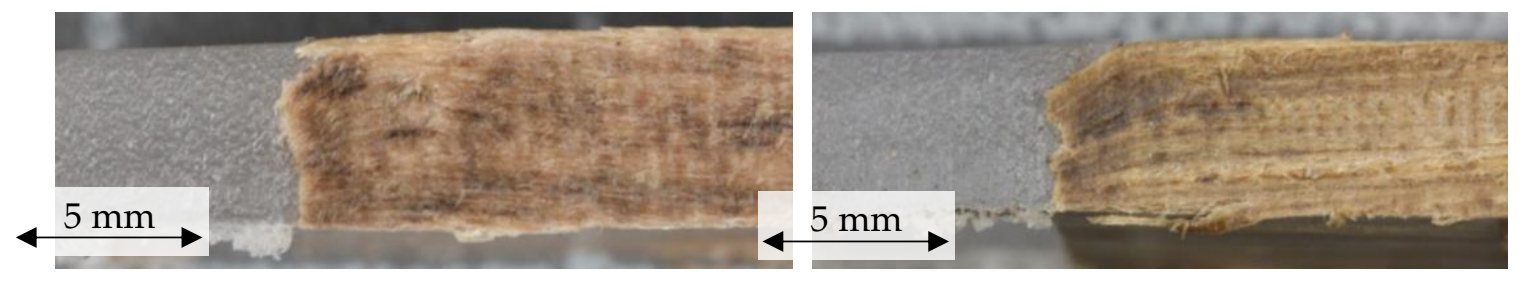

Figure 7 Microsectional view of beech (1.) and oak (r.) plastic specimen

The results can be seen in Figure 8. Firstly, the high deviation of values needs to be mentioned. Therefore, no significant factors and values could be detected. But as a trend it can be said that oak showed slightly lower values. It cannot make any statement about the dependencies of the tool and surface geometry of the wood on the bonding strength in combination with plastic polymer. 


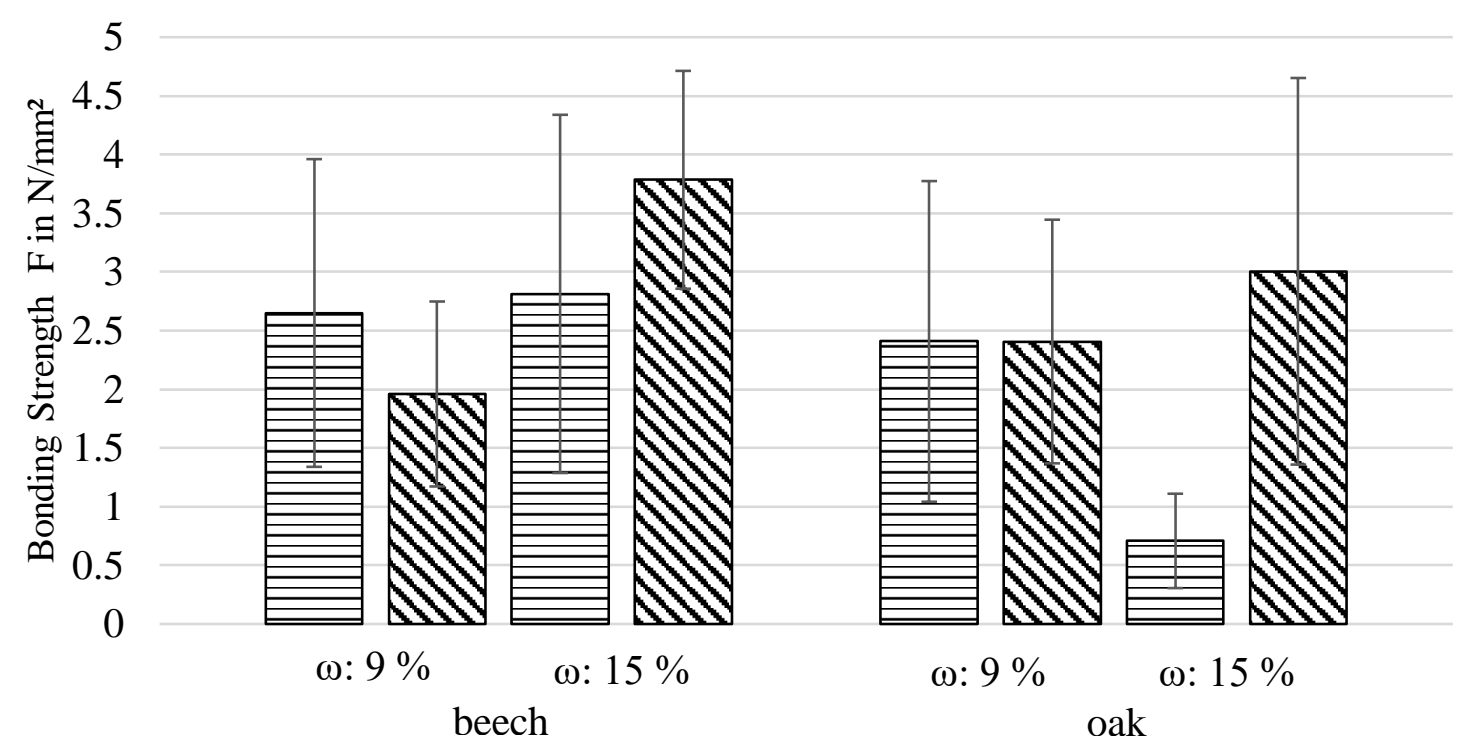

Figure 8 Tensile force of wood-plastic joint

The overall values are low in comparison to the strength in the individual materials. The chemical bonding seems to be low. When manufacture the specimen it could be detected that the ejectors of the injection moulding mould are positioned on each material side of the specimen. Therefore, in the demoulding process a bending force in the joint area was applied. The specimens were pre-damaged by this process.

\section{Conclusion}

There were results shown for the shear cutting of $5 \mathrm{~mm}$ solid wood specimen and the resulting bonding strength in wood-plastic-composites.

For the shear cutting process it can be said that lower cutting forces appear for drawing cuts but higher material deformation and damage occur. The influence of wood moisture content could not be examined. There is no difference in the forces for beech and oak wood material. The analysis of the surface topology needs to be extended e.g. by roughness values. By doing so the possible interlocking effects could be predicted.

In the further investigation on the bonding strength the values showed extremely high deviations so no significant parameters could be found. The original question of the influence of the shear cutting edge geometry on the bonding strength could not be answered.

The investigation showed that the specimen geometry used was not expedient. In future investigations it is planned to use a combination of a higher bonding surface area and tensile specimen. This can be reached by enlarge specimen size but also by overmould the wood specimen not only by a butt-joint but from both sides. This also allows a better resistance against bending forces which may be applied in demoulding processes.

\section{References}

[1] Kim, J.-K.; Pal, K. (2010): Recent advances in the processing of wood-plastic composites, 1. Aufl.: Springer. Berlin, Heidelberg, New York. ISBN: 364214876X. 
[2] Rowell, R. M. (2012): Handbook of wood chemistry and wood composites, 2nd ed.: CRC Press. Boca Raton. ISBN: 9781439853818.

[3] Dipl.-Geogr. Dominik Vogt, Dipl.-Phys. Michael Karus, Dipl.-Ök. Sven Ortmann, Dipl.Ing. Christin Schmidt, Dipl.-Gwl. Christian Gahle (2006): Studie Wood-Plastic-Composites (WPC) Holz-Kunststoff-Verbundwerkstoffe. Märkte in Nordamerika, Japan und Europa mit Schwerpunkt auf Deutschland Technische Eigenschaften - Anwendungsgebiete Preise Märkte - Akteure.

[4] Buchelt, B.; Siegel, C.; Wagenführ, A.; Nendel, W. (2015): Veneer prepreg - biobased prepregs for thermoplastic processing methods. In: Journal of Plastics Technology 11 6, p. 356-74.

[5] Ouali, A. A.; Rinberg, R.; Nendel, W.; Kroll, L.; Richter, A.; Spange, S.; Siegel, C.; Buchelt, B.; Wagenführ, A. (2015): New Biocomposites for Lightweight Structures and their Processes. In: Materials Science Forum 825-826, p. 1055-62.

[6] Dietzel, A.; Raßbach, H.; Krichenbauer, R. (2016): Material Testing of decorative veneers and different approaches for structural-mechanical modelling. In: BioResources 11 3, p. 7431-50.

[7] Makenji, K.; Goodship, V.; Buckley, S.; Evered, C. (2006): A New In-Mould Decoration Process using Real Wood Veneer. In: Progress in Rubber, Plastics and Recycling Technology 22 4, p. 225-42.

[8] Makenji, K.; Goodship, V.; Fanning, R.; Buckley, S. (2007): Analysis of Back Injecting Real Wood Veneers using Engineering Polymers in an Injection Moulding Process. In: Progress in Rubber, Plastics and Recycling Technology 23 2, p. 83-95.

[9] Makenji, K.; Cherrington, R. (2015): Plastic Trim. In: Crolla, D.; Foster, D. E.; Kobayashi, T.; Vaughan, N. D. (Hrsg.): Encyclopedia of automotive engineering. Chichester, West Sussex, United Kingdom. ISBN: 9781118354179.

[10] Barth, S.; Hartmann, M.; Rudolph, M.; Karlinger, P.; Michanickl, A.; Schemme, M. (2016): Zusammen Massnehmen - Verfahrensenticklung zum Hinterspritzen von Holzfurnieren am Beispiel eines Zillstocks. In: Kunststoffe 7. URL: www.kunststoffe.de/1396574.

[11] Müller, N.; Haart, C.; Sauer, M. : Lenkraddekorschalen und interieurzierelemente sowie verfahren zu deren Herstellung DE 102004062646 B4.

[12] Wagenführ, A.; Scholz, F. (Hrsg.) (2018): Taschenbuch der Holztechnik. München. ISBN: 978-3-446-45440-8.

[13] Kollmann, F. F. P. (1975): Principles of Wood Science and Technology. II wood based materials: Springer Berlin Heidelberg. Berlin, Heidelberg. ISBN: 978-3-642-87931-9.

[14] Endres, H.-J.; Hausmann, K.; Helmke, P. (2006): Untersuchung des Einflusses unterschiedlicher Haftvermittler und Haftvermittlergehalte auf PP-Holzmehl-Compounds. In: KGK - Kautschuk Gummi Kunststoffe, S.399 - 404. URL: http://www.pharmafood.de/ai/resources/59566227820.pdf.

[15] Maier, R. D.; Schiller, M. (2016): Handbuch Kunststoff-Additive, 4., vollständig neu bearbeitete Auflage: Hanser. München. ISBN: 9783446432918.

[16] PlasticsEurope Deutschland e.V.; Conversio Market \& Strategy GmbH : Plastics demand by resin types 2018. Distribution of European (EU28+NO/CH) plastics converters demand by resin type in 2018. Frankfurt am Main.

[17] Whiteley, K. S.; Heggs, T. G.; Koch, H.; Mawer, R. L.; Immel, W. (2010): Ullmann's encyclopedia of industrial chemistry: Wiley. Chichester. ISBN: 9783527306732. 
[18] Takase, S.; Shiraishi, N. (1989): Studies on composites from wood and polypropylenes. II. In: Journal of Applied Polymer Science 37 3, p. 645-59.

[19] Erdmann, M. (2009): Entwicklung innovativer Compatibilizer-Systeme für PolypropylenNanocomposites auf der Basis organophiler Schichtsilikate: Logos-Verl. Berlin. ISBN: 9783-8325-2319-0.

Biography 


\title{
Proceedings of the 2020 Society of Wood Science and Technology International Convention
}

\section{Long Fiber Wood Compounds}

\author{
Thomas Schmid \\ thomas.schmid@th-rosenheim.de \\ Mara Schumacher \\ mara.schumacher@th-rosenheim.de
}

Rosenheim Technical University of Applied Sciences, Germany

\begin{abstract}
Compounds made from wood and plastic, commonly known as WPCs, are established and used around the globe. The objective of this particular project is to develop a new compound by embedding long TMP wood fibers in a polymer matrix. Substituting glass or carbon fibers with long wood fibers presumably leads to a reduction of weight due to the fact that wood fibers have a much lower density than glass or carbon fibers. It also leads to a reduction in cost.

The mechanical properties of the new compound should be better than commercial WPC and comparable to CRP or GRP. Boundary conditions for a successful outcome of the project is that all the processing (metering, melting, compounding) is to be done in an injection molding machine. After a functional processing procedure is established, first results have been obtained using standard polymers, such as PE or PP. Further research activities will be the utilization of bio-based polymers that will lead to a completely bio-based fiber enhanced plastic. To ensure consistent wood fiber dimensions the fibers are processed with the university's laboratory scale refinerplant and subsequently analyzed using different fiber analysis methods. So far, several test specimen have been produced and tested concerning tensile stress. The results are indicating that in comparison with a standard WPC the wood fiber enhanced material shows a higher tensile strength. Furthermore, the compound will be directly injected on- and into a non-woven material. This is made of wood-and polymer-fibers. The aim at this part of the project is to produce thermoplastic hybrid composites reinforced with wood fibers by using Compression Hybrid Molding, which combines the advantages of injection molding and compression molding. A possible application for this kind of combination can be the processing of components for the automotive industry, as for example casing doors.

Key words: wood fiber, TMP-Fiber, wood-plastic-compounds, fiber-reinforced plastic, bio-economy, injection molding
\end{abstract}

\section{Biography}




\title{
Proceedings of the 2020 Society of Wood Science and Technology International Convention
}

\section{Effect of Scavenger and Microwave Heating on Formaldehyde Emission from Particleboard}

\author{
Anil Kumar Sethy ${ }^{1,2}$ \\ sethyanil@gmail.com \\ Beena Babu1 \\ beenababu68@gmail.com \\ Vipin Kumar Chawlas \\ vipinfri@gmail.com
}

\begin{abstract}
1 Institute of Wood Science and Technology, Bangalore;India 2 Czech University of Life Science, Prague, Czech Republic

3 Indian Plywood Industries Research and Training Institute
\end{abstract}

\begin{abstract}
Formaldehyde based resins are most economic and widely used resin in panel industries. Among these, urea formaldehyde (UF) resin is the most commonly used resin because of its low cost and good bonding strength. However, formaldehyde emission from UF bonded boards is quite substantial and pose health concern. Higher formaldehyde to urea (F/U) molar ratio yields better resin in terms of bond strength, however, it is also the cause for excessive formaldehyde emission. While, one of the most effective ways to reduce formaldehyde emission is to reduce the F/U molar ratio, lower molar ratio also adversely affects the bond strength and thickness swelling of the boards. The present study was aimed to use chemical scavengers (ammonium bicarbonate and sodium metabisulfite) in the resin and microwave irradiation of the pressed boards to reduce formaldehyde emission from particleboard. Urea formaldehyde resin was prepared in the laboratory using F/U molar ratio of $1: 1.6$. This ratio was selected as most of the industries in India use F/U moral ratio between 1:1.5 to 1:1.8. Particleboards were prepared using $10 \%$ resin (solid content based on the oven dry weight of wood) without the addition of sizing material. Ammonium chloride ( $0.5 \%$ based on the solid content of the resin) was used as catalyst. Scavengers were added to the resin just before blending with wood particles. Boards were pressed at a temperature of $120^{\circ} \mathrm{C}$ and specific pressure of $15 \mathrm{~kg} / \mathrm{cm}_{2}$ for a compression cycle of 16 minute for $13 \mathrm{~mm}$ boards. Microwave heating was carried out in a domestic microwave oven operating at a frequency of $2.45 \mathrm{GHz}$. Microwaving was carried out at a power level of 160 watt. Temperature at the core of the sample was measured with the help of thermocouple in pre-drilled holes. Irradiation time was optimized to maintain core temperature at about $50^{\circ} \mathrm{C}$. Formaldehyde from the board samples (control, scavenger treated, microwave heated) was extracted by perforator method and estimated using UV spectroscopy. Internal bond strength as well as thickness swelling of samples were also assessed.

Both the scavengers were found very effective in reducing formaldehyde content in the boards to meet E1 class requirement ( $\leq 8 \mathrm{mg} / 100 \mathrm{~g}$ oven dry board). Sodium metabisulfite was found more effective even at lower concentration as compared to ammonium bicarbonate. Addition of scavengers with UF resin improved the internal bond strength, however, thickness swelling also increased by 2$6 \%$ with increasing scavenger concentration. Microwave heating, as a post treatment method,
\end{abstract}




\section{Proceedings of the 2020 Society of Wood Science and Technology International Convention}

accelerated removal of unreacted formaldehyde from the boards thereby reduced the formaldehyde content in the irradiated boards. The average formaldehyde content reduced from $19.27 \mathrm{mg}$ to 5.69 $\mathrm{mg}$ per $100 \mathrm{~g}$ oven dry board with a microwaving time of 5 minutes. Assessment of board properties indicated no detrimental effect of microwave heating on the internal bond strength and thickness swelling. The results suggest that, formaldehyde emission from particleboard prepared with high F/U molar ratio UF resin can be controlled to E1 class requirement either by using scavengers or by microwave irradiation.

Keywords: Formaldehyde emission, Scavenger, Microwave heating, Internal bond strength, Thickness swelling

\section{Biography}




\title{
Proceedings of the 2020 Society of Wood Science and Technology International Convention
}

\section{Biobased porous structures based on cellulosic materials}

\author{
Axel Solt-Rindler 1 \\ a.solt-rindler@wood-kplus.at \\ Stefan Veigel2 \\ stefan.veigel@boku.ac.at \\ Christian Hansmann 1 \\ c.hansmann@wood-kplus.at \\ Wolfgang Gindl-Almutter3 \\ wolfgang.gindl-altmutter@boku.ac.at
}

\begin{abstract}
1 Wood K plus - Competence Centre for Wood Composites and Wood Chemistry, Austria 2 University of Natural Resources, BOKU, Austria 3 Institute of Wood Technology and Renewable Materials, BOKU-University of Natural Resources and Life Sciences, Vienna, Austria
\end{abstract}

\section{Abstract}

The demand for biobased products is increasing as new sustainable materials are required in terms of climate change and increasing environmental pollution mainly induced by non-sustainable fossil-based waste material. However, also the demand of functionalized materials that perform e.g. as packaging materials or thermal insulation materials on porous structures is constantly increasing, as biodegradable materials or energy-saving installations are gaining more relevance. That is why investigations on the proper utilization of biobased and re-growing materials towards bio-based materials with advanced properties are inevitable to acquire the demanded material properties. One straightforward pathway is to up-grade residues from existing production processes of materials that are on a sustainable basis. By-products from wood processing like sawdust, but also agricultural residues e.g. wheat bran are potentially interesting, as no supply chain must be established, and the raw material is available worldwide in enormous amounts. Thus, hardwood and softwood sawdust were obtained directly from sawmills and commercially available wheat bran was used for the investigations. As the raw materials differ significantly in their primer morphology different disintegration processes (ultra-fine friction grinder, ultra-centrifugal mill and laboratory refiner) were applied and a variety of particle and fiber evaluation methods (incident light microscopy, cam sizer, particle size distribution) were conducted to observe the material. Different biobased (cationic starch, wheat gluten) and non-biobased binders (urea-formaldehyde, polyvinyl acetate, potassium water glass) were investigated in terms of bonding to the particles and their ability to form stable porous material structures. Different foaming procedures were tested under different aspects as e.g. vapor expansion, chemically induced carbon dioxide inclusions and mechanically introduced air inclusions. To achieve a stable dry structure different dewatering and drying procedures were applied. Stable and dry porous structures were subsequently characterized by means of scattering electron microscopy (SEM), thermal conductivity measurements and mechanical testing. The results reveal comparable 
Proceedings of the 2020 Society of Wood Science and Technology International Convention

properties to conventional bio-based insulation materials and packaging material. Therefore, the findings of this study draw pathways for utilizing former residues towards new functionalized biobased porous structures potentially relevant for future applications.

Key words: biobased porous structures, residue utilizing, wheat bran, insulation, packaging material;

Biography 


\title{
Proceedings of the 2020 Society of Wood Science and Technology International Convention
}

\section{Wood species dependent performance of pMDI adhesion}

\author{
Pia Solt 1 \\ p.solt@wood-kplus.at \\ Hendrikus W.G. Van Herwijnen 1 \\ e.herwijnen@wood-kplus.at \\ Roland Mitter2 \\ roland.mitter@egger.com \\ Johannes Konnerth \\ johannes.konnerth@boku.ac.at
}

1 Wood K plus - Competence Center of Wood Composites and Wood Chemistry, Kompetenzzentrum Holz GmbH, Austria

2 Fritz Egger GmbH \& Co. OG, Austria

3 Institute of Wood Technology and Renewable Materials, Department of Material Sciences and Process Engineering, BOKU - University of Natural Resources and Life Sciences, Austria

\begin{abstract}
Particleboards are high volume commodity materials typically processed by the furniture industry. Due to their high reactivity, chemical versatility and economic competitiveness formaldehyde-based polycondensation adhesives are used in huge amounts in the particleboard industry. Considering the world production volume of particleboards of approx. 84 mio. $\mathrm{m}^{3}$ (2015) (FAOSTAT 2017), the resin consumption of standard adhesive is assumed to 5-7 million tons per year. Owing to the reclassification of formaldehyde as a Carcinogen Category 1B compound and in view of potential and highly probable even stronger future restrictions of formaldehyde use, the industry is constrained to actively searching for appropriate alternatives. Currently, pMDI may be regarded as the most relevant formaldehyde free adhesive candidate. This conclusion is supported by the fact that this system is already in industrial use not only for OSB production but also in the particleboard industry, albeit in comparably small amounts.

Having a look at the curing mechanism of pMDI resin, the isocyanate groups $\mathrm{R}-\mathrm{N}=\mathrm{C}=\mathrm{O}$ in $\mathrm{pMDI}$ are highly reactive to all nucleophilic compounds. A possible reaction is for example the reaction of the isocyanate group with a hydroxyl group, which leads to the formation of urethane. Such a reaction can theoretically take place between isocyanate groups and hydroxyl groups of cellulose or lignin, while forming covalent bonds with the wood adhesive. Research regarding the effect of moisture on the curing reactions of pMDI has been studied extensively with many techniques such as different spectroscopy methods, or thermal analysis. The results have shown that moisture in the wood has a significant effect on the chemical reaction mechanism, curing products and curing kinetics. With regard to the effect of moisture content on mechanical properties of bonds, is has been found that a high amount of moisture is also necessary to obtain relevant lap-shear strength. Beside the effect of moisture, pMDI adhesive performance with wood is dependent on many other variables. Some of these include bonding conditions (pressure, temperature, rate, etc.), but also particle geometry
\end{abstract}




\section{Proceedings of the 2020 Society of Wood Science and Technology International Convention}

(planer shavings, flakes, fibers, etc.) and wood species. However, only limited research is available on the influence of wood species.

Goal of this work is to further advance our understanding of pMDI/wood adhesion and its wood species dependence in correlation with moisture content. Therefore, four European wood species - beech, birch, spruce and pine - were selected for this investigation. Methods of analysis include production and testing of particleboards using industrial pressing parameters and development of tensile shear strength of single lap-joints. Furthermore, the novel results are supported by various other experiments. This study found a significant difference in the strength development and other mechanical properties of pMDI using different wood species, with one conspicuous species - the pine.

Keywords: pMDI, isocyanate adhesives, wood species, moisture content, adhesive curing, particle boards, bonding strength, bond line

\section{Biography}




\title{
Highly Anisotropic Wood-Based Composite with Layered Structure for Thermal Insulation and Electrical Conductivity
}

\author{
Hao Sun 1-Min Xu 1* \\ 1 Graduate Student, Professor, Northeast Forestry University, Harbin, \\ Heilongjiang, China \\ qdshenyue@163.com,*Corresponding author \\ donglinxumin@163.com
}

\begin{abstract}
Composite materials have attracted tremendous attention because of their excellent properties and unique functionalization. Generally, the conventional composites composed of substrate and functional fillers are fabricated by melt mixing, solution mixing, and mechanical mixing, which leads to a random and isotropic structure. To improve its performance, the high volume of the fillers is mixed into the composite, which caused high cost, aggregation of fillers, and even destroyed the structure of composites. By designing an anisotropic and ordered structure, the high performance of composites with a low volume of fillers can be achieved. Trees are the most abundant biomass on the planet and natural wood can transport water and nutrients by aligned microchannels. Hardwood is mainly composed of wood fibers, vessels, wood rays, and parenchyma. Intercross axial wood fibers and radial wood rays partially reflect the anisotropy of wood, which forms a natural hierarchical structure. Presently, natural wood with anisotropic structures has attracted much attention for optical, water filtration, and ion transportation. Here, we propose a fabrication method for making a lightweight, anisotropic, and compressible wood scaffold with aligned layered structure by a simple chemical treatment. The wood scaffold exhibits a low density of $32.18 \mathrm{mg} / \mathrm{cm} 3$ and a high specific surface area of $31.68 \mathrm{~m} 2 / \mathrm{g}$. Moreover, the wood scaffold presents an anisotropic thermal conductivity. The thermal conductivity perpendicular to the fiber direction and along the fiber direction were $0.033 \mathrm{~W} / \mathrm{mK}$ and $0.11 \mathrm{~W} / \mathrm{mK}$, respectively. The wood-based electrically conductive film is prepared by directly immersing the wood scaffold into a carboxylic multi-wall carbon nanotubes suspension, followed by densification. The MWCNTs are transported and anchored on the surface of fibers driven by capillary force through aligned nanochannels, a large amount of mesoporous, and hydroxyl groups. The electrically conductive film presents an anisotropic conductivity, excellent flexibility, a high tensile strength of $93.00 \mathrm{MPa}$ and a Young's modules of $2.40 \mathrm{GPa}$. The electrical conductivity along the fiber direction and perpendicular to the fiber direction were $42.19 \mathrm{~S} / \mathrm{m}$ and $1.31 \mathrm{~S} / \mathrm{m}$, respectively.
\end{abstract}

Key words: Wood-based composite; Layered structure; Anisotropic; Thermal insulation; Electrical conductivity

Biography 


\title{
Proceedings of the 2020 Society of Wood Science and Technology International Convention
}

\section{Low Temperature Adhesive Bonding for Structural Wood Materials}

\author{
Anita Tran \\ anita.tran@boku.ac.at \\ Melanie Mayr \\ melanie.mayr@boku.ac.at \\ Johannes Konnerth \\ johannes.konnerth@boku.ac.at \\ Wolfgang Gindl-Altmutter \\ wolfgang.gindl-altmutter@boku.ac.at
}

\section{Institute of Wood Technology and Renewable Materials, Department of Material Sciences and Process Engineering, BOKU - University of Natural Resources and Life Sciences Vienna, Austria}

\section{Abstract}

Reliable and securely bonded joints are mandatory for structural timber products, consequently the manufacture is strictly regulated. In the case of finger jointed solid timber, according to EN 15497, the wood temperature specification is at minimum 18 ${ }^{\circ} \mathrm{C}$ for adhesive application. In the present study, we examine adhesive bonding at distinctly lower substrate temperatures, providing enough time for cure in order to ascertain whether sufficient bond strength can be achieved under conditions currently not foreseen by the relevant standard.

Scarf joints from spruce, imitating finger joint angles of $7.5^{\circ}$, were produced at different temperatures. A two-component adhesive composed of melamine-urea-formaldehyde (MUF) resin and hardener was applied separately. Adhesive strength was verified by macroscopic, microscopic and micromechanical testing to further understand the influence of pressing and postcuring temperature. Resulting tensile shear strength varied marginally for different temperatures even after water immersion. Penetration of the adhesive into the wood in fiber direction was deeper on hardener than on resin application side due to differences in viscosity with no dependency on temperature. Nanoindentation visualized the penetration of the adhesive into the cell wall with increased hardness and reduced modulus of elasticity from unfilled cells to adhesive filled cells independent of the temperature. Equally indents directly into adhesive showed hardness values with no significant difference temperature wise.

Our results show that the temperature of the substrate at the time of adhesive application has no influence on macro- and microscopic level hence adhesive bonding at low temperatures is feasible, given that enough time for cure at sufficient temperature is allowed. Deep penetration in to the fiber cavities and the cell wall itself proves similar adhesive strength even at 0 ${ }^{\circ} \mathrm{C}$ cold bonding.

Key words: adhesive bonding, cold temperature cure/hardening, low temperature, melamine-urea-formaldehyde resin, nanoindentation, penetration depth, wood adhesion

\section{Biography}




\title{
Development of a Concept for Electrically Conductive Furniture Panels
}

\author{
Christof Tschannen1-Heiko Thoemen2* \\ 1 Junior Scientist, Bern University of Applied Sciences, Biel, Switzerland \\ christof.tschannen@bfh.ch \\ 2 Head of Research Unit Composite Materials and Furniture Development, Bern \\ University of Applied Sciences, Biel, Switzerland *Corresponding author \\ heiko.thoemen@bfh.ch
}

\begin{abstract}
The wood industry, in particular, the interior and building sector are affected by the digital transformation. As a result, furniture is required to additionally inhere special functions like integrated illumination while being flexible in positioning and re-arrangements.

The focus of this paper is the development of a concept for a conductive furniture panel including the cable-free conduction of electricity and illumination using LED. Two types of panels were investigated for this study. Single-layer particle boards for resistance measurements and three-layer particle boards for conceptual testing were produced using hot-pressing. The samples were analyzed for their electrical properties with resistance measurements.

The results for the conductive panels were promising and reached resistivities of $4.8 * 10_{-3} \Omega \mathrm{m}$. Highly flexible positioning of a LED was possible, using the panels in combination with the LED fixation pin.

Further research is still required to finalize the concept as the material showed inhomogeneous blending and poor processability of the conductive panels. But the panels provide a feasible concept for a conductive furniture panel.
\end{abstract}

Key words: wood-based panel, conductive wood-based panels, electrical conductivity, carbon fibers, furniture, interior lighting 


\section{Introduction}

The integration of electronic components is now an integral part of many products. Accordingly, hardware manufacturers and furniture producers are also working on solutions for the increasing demand for wiring in furniture. In a concept study, it has now been demonstrated that wiring can be completely omitted if furniture panels are designed accordingly. The newly developed approach makes use of a characteristic feature of wood-based particleboard: Such boards typically have a three-layer structure. If appropriately designed, the top layers can serve as conductors of electricity, with the middle layer serving as an insulator. When using such functionalized boards, LED lights and, if necessary, other electrical components can be placed in the furniture in a highly flexible, wireless and thus cost-effective manner.

\section{Literature Review}

Electrical properties of an element or a material is given by the atomic shell and the number of free electrons in the outer atomic structure respectively. This applies for wood as well as for synthetic polymers that are normally not considered as conductive materials (Leute 2015, Niemz and Sonderegger 2017). Therefore, every material including wood has its own specific electrical resistance depending on the atomic density and the number of free electrons. Nevertheless, the conductivity of wood is poor compared to copper due to the limitations of the free electrons to move. Furthermore, the electrical properties of wood are limited as the orthotropy of wood didacts a dependency in direction and is additionally influenced by the density and the extractives which varies from one species to the other. One of the most significant factors on the resistance of wood is the moisture content. Consequently, it is no surprise that the moisture content of wood can be measured over the electrical resistance. This is true for almost dry wood up to the fiber saturation point (FSP) with a strong correlation between resistance and moisture content. In wood-based panels there are even more influence factors. Some adhesives, catalysts and additives may reduce the resistance even further. (Niemz and Sonderegger 2017) Medium density fiberboards (MDF) fabricated with phenolic or pMDI (polymeric methylene diphenyl diisocyanate) have a higher conductivity than a MDF board manufactured with a melamine-urea-formaldehyde adhesive (Prieto and Kiene 2007). Ugolev (1986) in Niemz and Sonderegger (2017) measured the electric resistance and resistivity on different wood species parallel and perpendicular to the fiber direction. The species with the lowest resistance parallel and perpendicular to the fiber direction is Oak (Quercus robur L.) with 2.0*1010 $\Omega$ parallel and $5.5^{*} 1010 \Omega$ perpendicular to the fiber direction. The species with the highest resistance parallel to the fiber direction is Birch (Betula B.) with 4.0*1011 $\Omega$ and Pine (Pinus sylvestris L.) with $7.9 * 1011 \Omega$ perpendicular to the fiber direction. As mentioned above the extractives in wood may affect the electrical resistance which explains the low resistance of Oak. Oak is one of the species with a very high content, up to $12 \%$, of extractives in the core besides tropical wood (Lohmann 2010). The electrical resistance of wood is therefore between $1.7 * 10_{7} \Omega \mathrm{m}$ to $8.6^{*} 19_{9}$ $\Omega \mathrm{m}$ and can be considered as an electrical insulator as in the definition of Kuchling (2011).

Enhancing the electrical properties of wood and wood-based products was investigated frequently in the past. The recent study of Guo et al. (2018) showed the application of a copper nanowire on the surface of wood and creating a conductive surface coating. The resistivity of that nanowire was measured at $2.6^{*} 10_{-7} \Omega \mathrm{m}$ which is relatively close to the resistivity of copper itself $(1.71 * 10-8 \Omega \mathrm{m})$. The sheet resistance was significantly higher with 0.34 to $9.53 \Omega \mathrm{m}$ depending on the copper nanowire suspension applied and furthermore the structure of the wood 
specially in perpendicular direction lead to an almost electrically insulated surface. In another study Agarwal et al. (2006) described a method for a layer by layer nanocoating of individual cellulose fibers for papermaking, creating electrically conductive fibers. Adding these conductive fibers to the cellulose fibers for paper results in resistivities of $1 * 10-3$ to $10 \Omega \mathrm{m}$, depending on the amount added to the paper. In the field of wood-based panels some examples are described as well. In the study of Zauscher (1992) the alignment of fibers of MDF boards using magnetic fields is investigated to enhance the panel properties. In order to align the fibers with a magnetic field, the fibers were previously coated with an acrylic powder loaded with nickel. Although, not having the conductive properties as goal, a wood fiber susceptible for a magnetic field is most likely also electrically conductive. Many patents show the addition of carbon fibers and other conductive materials to wood-based panels as a protection against electromagnetic radiation (Fu et al. 2001, 2014; Qian et al. 2015; Zhang 2016). Furthermore, Könekamp (2017) describes a device for the production of a wood-based panel using fiber shaped additives or fillers on an industrial production machine. Of all wood-based panels, particle boards (chip boards) represent $50 \%$ of the manufactured panels on the European market (EUWID 2019).

Synthetic polymers are considered as insulator materials and are like wood without free electrons on the outer atomic shell. In this field however, a lot of research was concluded to enhance the electrical properties. One method to enhance the electrical properties is the addition of conductive filler material. Leute (2015) provides an overview of the different conductive fillers and the theory of it. Typical conductive fillers are carbon black, carbon fibers, graphite, carbon nanotubes or metallic fibers or particles. The idea is to add enough conductive material to enhance the formation of a conductive network but keep the properties of the polymer in the desired range. This point where enough conductive filler is applied is called the percolation threshold $\left(\mathrm{K}_{\mathrm{c}}\right)$ as in Figure 9. Once the conductive network is formed, additional conductive filler material does not enhance the conductivity any further or only in a non-significant range.

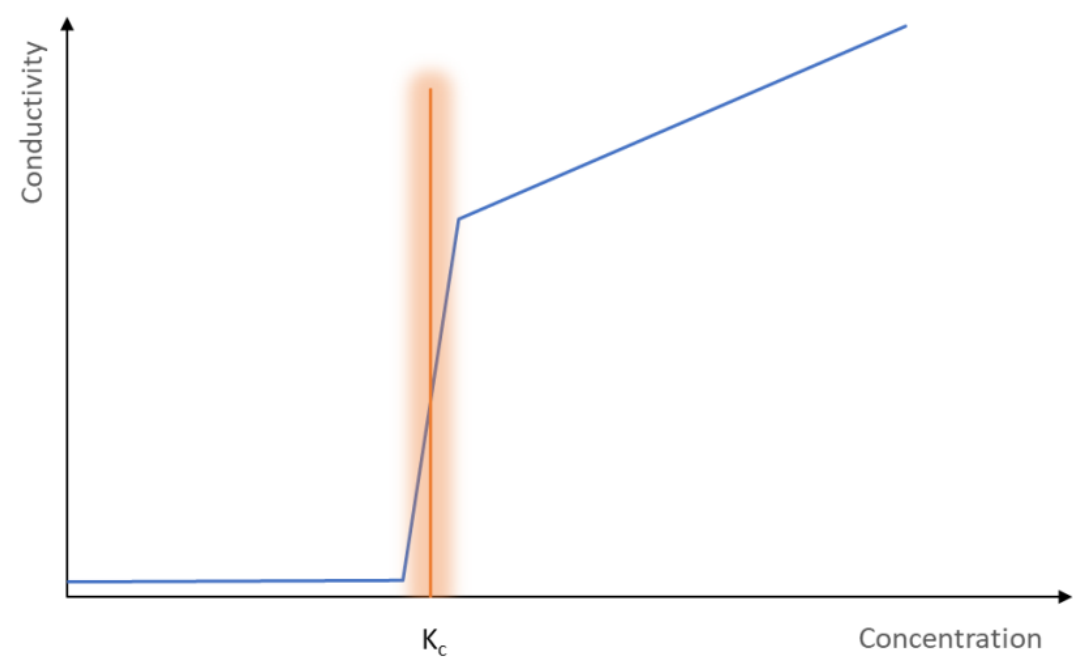

Figure 9: The conductivity as a function of the additive concentration with $\mathrm{K}_{\mathrm{c}}$ as the percolation threshold, modified from Leute (2015)

In the manifold of investigations concluded in this field it was discovered that long particles with small diameters in random alignment achieve the best results at lowest concentration, whereas 
ball shaped particles need the highest concentration to form a conductive network (Pike and Seager 1974; Bigg 1977; Hu et al. 2008).

A similar application is known from the field of adhesives. Conductive adhesives based on the addition of carbon based fillers is described in different studies. (Brischke 2007; Brischke et al. 2008; Wehnert et al. 2012).

Carbon fibers are due to their aspect ratio (length divided by diameter) best suited as a conductive filler. The fibers are mostly based on polyacrylonitrile (PAN) as precursor with a common diameter of $7 \mu \mathrm{m}$ (Whelan 1995). Carbon fibers are relatively expensive. The latest forecast by Rao et al. (2018) for 2020 expects an average price of $10 \$ / \mathrm{kg}$.

\section{Materials}

\section{Materials \& Methods}

\section{Conductive fibers}

Two different carbon fibers types (CF1 and CF2), SFC 3/EPB $3 \mathrm{~mm}$ and SCS CarbonKurzschnitt $220 \mu \mathrm{m}$ (Sutter-Kunststoffe AG, Fraubrunnen, Switzerland), were used in this study to manufacture the conductive particle boards. CF1 has an average fiber length of $3 \mathrm{~mm}$ and a density of $1800 \mathrm{~kg} / \mathrm{m}_{3}$ and CF2 $220 \mu \mathrm{m}$ and $1700-2000 \mathrm{~kg} / \mathrm{m} 3$ respectively. Both fiber types contained up to $10 \mathrm{wt}$ \% oligomeric epoxy resin as facing.

\section{Wood material}

Wood particles (Swiss Krono AG, Menznau, Switzerland) consisting of deciduous trees mainly beech (Fagus sylvatica) and coniferous trees mainly spruce (Picea abies) were used in this study. Two qualities of particles were used. They complied with the industry grade for surface layer and core layer material. The moisture content of the particle material was around $3 \%$ in average and a packaging density around $300 \mathrm{~kg} / \mathrm{m} 3$.

\section{Adhesive}

The adhesive used in this study was a urea formaldehyde with the trade name Kaurit 350 (BASF SE, Ludwigshafen, Germany) and an average solid content of $66.5 \%$. A solution of ammonium sulphate (purity $\geq 99 \%$ ) with a concentration of $40 \mathrm{wt} . \%$ was used as a catalyst (hardener) to accelerate the reaction of the adhesive.

\section{Copper tape}

A conductive copper tape 3M 1181 with a width of $19.1 \mathrm{~mm}$ and $0.07 \mathrm{~mm}$ thickness was used as an interface to the particle board for measuring the resistance of the board. The resistance of the conductive adhesive on the tape is described with $0.005 \Omega$ by the producer. The application of the copper tape differs to the standard application and the contact interface with the conductive adhesive of the tape was not used, therefore, the resistivity of copper can be used as characterization e.g. $1.71 * 10_{-8} \Omega \mathrm{m}$.

\section{Connection pin}

A connection pin to connect a LED (light emitting diode) to the conductive particle board was developed at Bern University of Applied Sciences (BUAS, Biel, Switzerland). The pin consists of two aluminium discs and a polyethylene disk stacked on each other with the polyethylene disk in between. The pin has two drill holes, one reaching the first aluminium disc whereas the second drill hole reaches all the way through the first aluminium disc and the polyethylene disc into the 
second aluminium disc with an expanded drill hole diameter in the first aluminium disc. An LED can be plugged into this pin by inserting the cathode into the first drill hole and the anode into the second drill hole. The pin has a diameter of $10 \mathrm{~mm}$ and has a screw thread at the outer surface to easily turn it into a pre-drilled hole in the particle board. 


\section{Experimental}

\section{Manufacturing of conductive particle boards}

Two types of panels were produced in this study. P1 a one-layer particle board with the dimensions $250 \mathrm{~mm} \times 250 \mathrm{~mm} \times 8 \mathrm{~mm}$ and a target density of $650 \mathrm{~kg} / \mathrm{m} 3$. UF resin was applied with $10 \mathrm{wt} . \%$ solids based on the dry mass wood and $3 \mathrm{wt} . \%$ ammonium sulphate in solution based on solids adhesive. The carbon fibers were added as a substitute of wood in weight percent. $\mathrm{P} 2$ is a 3-layer particleboard with a thickness of $16 \mathrm{~mm}$ and a ratio of surface layer to core layer of 50/50, i.e. the surface layers with a thickness of $4 \mathrm{~mm}$ each and the core layer with a thickness of $8 \mathrm{~mm}$. The addition of conductive fibers was only done in the surface layer material.

The carbon fibers substitution was 3 wt. $\%, 4$ wt. $\%, 5$ wt. $\%, 10$ wt. $\%, 20$ wt. $\%$ and 30 wt. $\%$ for $\mathrm{P} 1$ and $10 \mathrm{wt} . \%$ for P2, see Table 4. The carbon fibers and the wood particles were mixed together prior to the application of the adhesive for both panel types.

The highest carbon fiber substitution of $30 \mathrm{wt}$.\% with both carbon fiber types CF1 and CF2 was tested first to asses weather the content could be lowered or must be increased. The content of carbon fibers was then lowered to a minimal value of $3 \mathrm{wt}$.\% only using CF1.

Table 4: Overview of conductive particle boards manufactured.

\begin{tabular}{|l|l|l|l|}
\hline Panel nr. & Panel type & $\begin{array}{l}\text { Carbon fiber content } \\
(\text { wt.\% })\end{array}$ & Carbon fiber type \\
\hline 1 & P1 & 30 & CF2 \\
\hline 2 & P1 & 30 & CF1 \\
\hline 3 & P1 & 20 & CF1 \\
\hline 4 & P1 & 10 & CF1 \\
\hline 5 & P1 & 5 & CF1 \\
\hline 6 & P1 & 4 & CF1 \\
\hline 7 & P1 & 3 & CF1 \\
\hline 8 & P2 & 10 & CF1 \\
\hline
\end{tabular}

After the blending of the material in a mixer, half of a panel was formed for P1. Two stripes of the conductive copper tape were placed on top of the half-formed panel parallel to each other circa 2 centimeters from each side with the copper conductive tape sticking out at one side roughly 5 centimeters. Then the second half of the panel was formed on top of the conductive tape enclosing the copper tape in the core of the panel. For P2 the procedure was similar, the first surface layer was formed using the wood-carbon fiber mixture. Then the entire core-layer material was formed on top of it and finally covered again with a surface layer consisting of the wood-carbon fiber mixture. No copper adhesive tape was used for P2.

Both panel types were then pressed using a Höfer laboratory press (HLOP 210, Höfer Presstechnik GmbH, Taiskirchen, Austria) and a press factor of $15 \mathrm{~s} / \mathrm{mm}$ at a press platen temperature of $180{ }^{\circ} \mathrm{C}$. The press program followed three steps, closing, holding and opening with a very slow opening rate of $1 \mathrm{~mm}$ in 10 seconds for one millimeter.

\section{Methods}

\section{Resistance measurements}

Electrical resistance measurements were done using a multimeter Agilent U1241B (Keysight Technologies, California, USA). The multimeter was connected to the two copper adhesive stripes sticking out of the conductive particle board. The detection range of the multimeter is 
possible up to $100 * 106 \Omega$. The distance between the parallel copper adhesive tape was $0.2 \mathrm{~m}$. The principle of this test is that the board itself closes the electric circuit when connected in this way with the assumption that the resistance of the copper tape is significantly lower than the resistance of the particle board. Therefore, the measured resistance belongs to the conductive particle board. This test was only performed on the panels of type P1. From the measured resistance (R) and the known cross-section (A) and length (l), the resistivity ( $\rho$ ) was calculated using (1. The length was assumed to be the distance between the parallel copper adhesive tapes, i.e. $0.2 \mathrm{~m}$.

$$
\rho=\frac{R * A}{l}
$$

\section{Conceptual testing}

The panel of type $\mathrm{P} 2$ was prepared by drilling $10 \mathrm{~mm}$ diameter holes at random spots. Additionally, on all edges a hole of $2 \mathrm{~mm}$ diameter was drilled into the cross-section of each surface layer approximately in the middle of the board. A 9volt battery was prepared with two cables and an additional resistor of $200 \Omega$. The connection pin with an LED was placed in one of the pre-drilled $10 \mathrm{~mm}$ holes and the cables of the battery were plugged into the small diameter holes at the edges of the board as shown in Figure 10. This test was repeated several times with all the possibilities of plugging the pin as well as the cables to prove the concept.

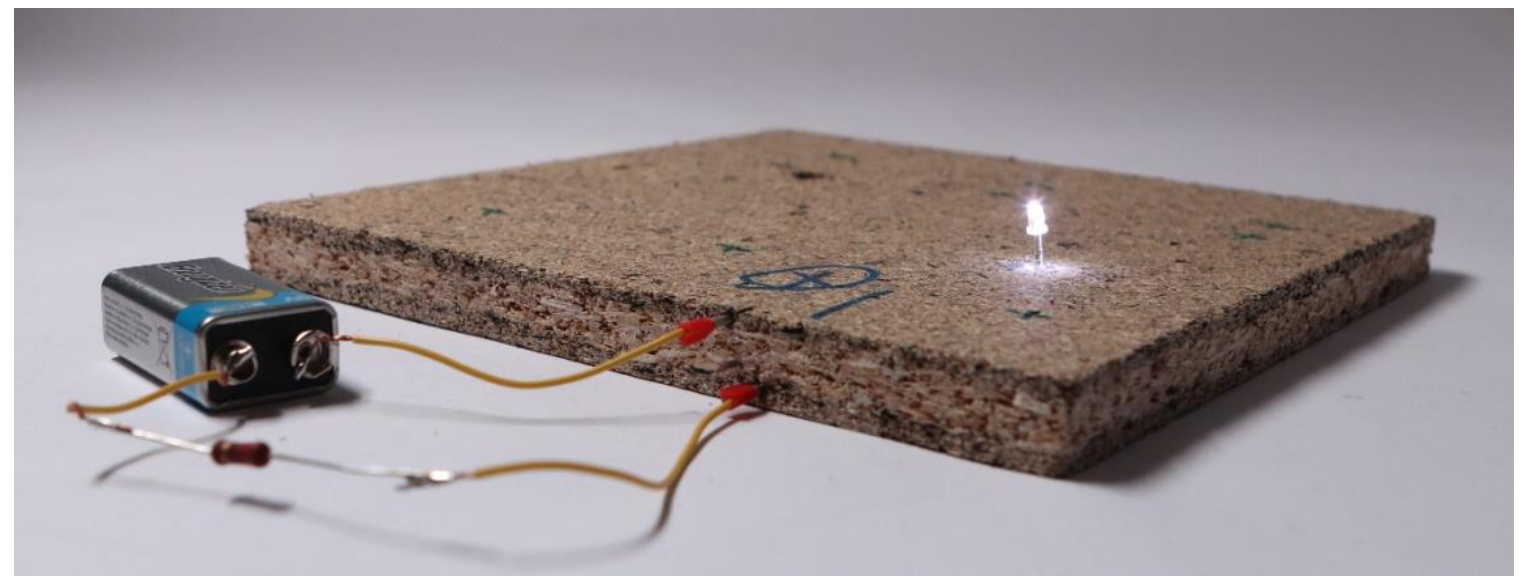

Figure 10: Conceptual testing of the conductive particle board connected to the pin with an LED and a battery. 


\section{Results and Discussion}

All panels of type P1 were found to be conductive after manufacturing with the process described before. The measured resistance and calculated resistivity are shown in Table 5

Table 5: Resistance and resistivity of P1 panels.

\begin{tabular}{|l|l|l|}
\hline Panel nr. & Resistance in $\Omega$ & Resistivity in $\Omega \mathrm{m}$ \\
\hline 1 & 20 & 0.192 \\
\hline 2 & 0.5 & 0.005 \\
\hline 3 & 1 & 0.01 \\
\hline 4 & 1.7 & 0.016 \\
\hline 5 & 11.9 & 0.115 \\
\hline 6 & 15.2 & 0.146 \\
\hline 7 & 19.4 & 0.186 \\
\hline
\end{tabular}

The panel with $30 \mathrm{wt} . \%$ of CF2, panel nr. 1 resulted in very high resistivity and could not compete with the panels manufactured with CF1 as conductive filler. This follows findings of Bigg (1977) and Hu et al. (2008) about conductive polymers where a higher aspect ratio of the carbon fibers provide better results with a percolation at lower concentration. The aspect ratio of the $220 \mu \mathrm{m}$ fibers is $31.4: 1$ whilst the aspect ratio of the $3 \mathrm{~mm}$ fibers is $429: 1$. Furthermore, the panel nr. 7 with only 3 wt. $\%$ of CF1 achieved better resistivity than panel nr. 1 . The resulting panel had a very poor appearance, nonetheless. It was very brittle, and the surface showed very inhomogeneous material mixtures. After manufacturing panel nr. 1 and 2 it was decided to follow the research plan including CF1 as only conductive filler as CF2 showed to be unsuited.

In Figure 11 the results are shown graphically with the addition of a linear regression line based on the data of panel nr. 2 to 4 and 5 to 7 respectively. The intercept does not show the percolation threshold necessarily as the data was very small for these experiments. But following the theory as described by Leute (2015) this may indicate that the theory of synthetic polymers might be applicable to the conductive panels as well.

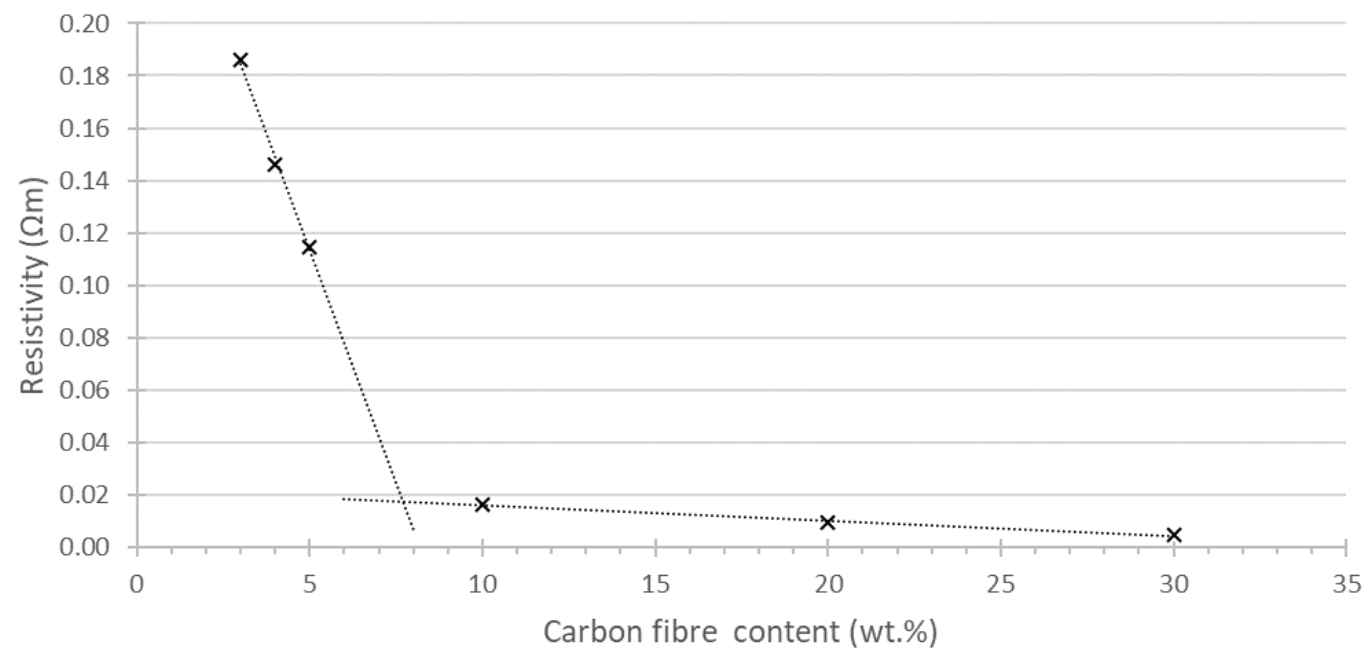

Figure 11: P1 - resistivity over carbon fibre content of panel nr. 2 to 7 manufactured with CF1.

However, it is possible to state that conductivity is achieved even with a relative low percentage of carbon fibers. The conceptual test using the 3-layer panel and the pin showed that the concept 
works. Using a 3-layer panel (P2) allows to use the two surface layers as positive and negative phase of the electric circuit. The boards were found to be conductive as the functionality was given independent from the place where the pin was plugged in. The only drawback of the pin was that it had naturally some loose connections due to its prototype state. However, the test performed with the P1 panels resulted only in the best-case resistance as the resistance was measured between the two parallel copper tapes, whereas with the conceptual testing the applicability was proved.

The characterization of the conductive particle boards in terms of resistivity is shown in Figure 12 , showing materials in the range of conductors - semiconductors - and insulators and typical resistivity values for wood. Nevertheless, the conductive panels are not competitive with standard conductive materials as copper. A reduction in resistivity compared to wood was achieved by over 10 orders of magnitude.

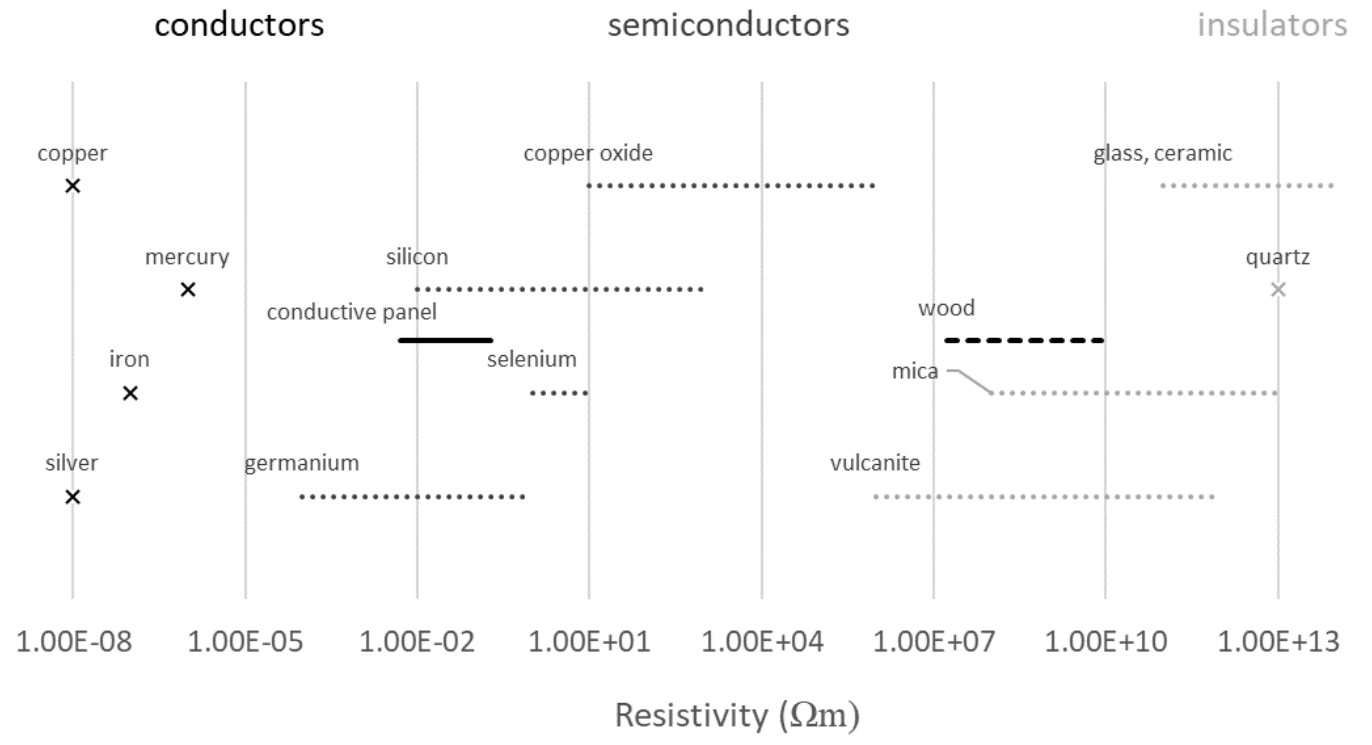

Figure 12: Overview of resistivity from different materials. Figure modified from Kuchling (2011). Resistivity values for wood according to Ugolev (1986) in Niemz and Sonderegger (2017). Own experimental panels are labelled as conductive panel.

\section{Summary and Conclusions}

Manufacturing a conductive particle board mainly based on the non-conductive material wood was successfully demonstrated in this study. The literature study showed on the example of synthetic polymers how a non-conductive material can turn into a conductive one by adding conductive filler materials. Carbon fibers were found to be well suited for this application. Two types of panels were produced in this study. A one-layer panel P1 with two copper adhesive tapes as interface for resistance measurements and three-layer panels P2 with conductive filler material in the surface layers. Using the P1 panels for characterization and measurement of resistance and $\mathrm{P} 2$ as conceptual testing proved the conductivity of the panel and the concept to work. The development of the connection pin, although not covered in this paper, supported the overall concept for an electrically conductive furniture panel (a patent application was placed for the conductive panels and the connection pin by BUAS in the meantime). Some testing, outside the description of this paper, showed the connection of two conductive panels type P2 to work 


\section{Proceedings of the 2020 Society of Wood Science and Technology International Convention}

with a simple butt-joint, whilst the second panel is integrated in the electric circuit without special connectors to ensure the conductivity.

Acceptable resistivity is given at $10 \mathrm{wt}$ \% carbon fiber content, however, compared to copper relatively high. Further improvement of resistivity by optimization of the process and material parameters is most likely possible but will never be as good as a standard conductor material itself. Adding more carbon fibers to further enhance the conductivity properties will not improve the conductivity in a decisive matter following the theory of Leute (2015). The input of more expensive material for a disproportionate gain in conductivity will not be justifiable. For the application in a conductive panel any grade of carbon fibers with good electrical properties may be used. For the ease of access an industry grade material was used for this study but carbon fibers originating of renewable resources are imaginable for this application too. This benefits in two ways. Carbon fibers based on renewable resources can be less expensive than standard fibers for heavy duty application and are sustainable compared to an oil-based fiber.

Another fact that was not discussed so far is the effect of the relative high resistivity of the panels and the consequences for the power consumption. All tests were conducted on relatively small samples with a resistivity of $0.01 \Omega \mathrm{m}$ for a $10 \mathrm{wt} . \%$ panel. Using this number to calculate the resistance of a $2 \mathrm{~m}$ long and $0.5 \mathrm{~m}$ width panel with an average surface layer thickness of $4 \mathrm{~mm}$ and the assumption the power passes through both surface layers results in an overall resistance of $32 \Omega$ for one panel. This is a very optimistic calculation and $32 \Omega$ is quite a high resistance compared to a standard conductor material for the same application. However, the conductive panels have another benefit that is difficult to express in numbers and comes at a cost on behalf of the energy efficiency. The overall conductivity of the panels allows for a flexible solution in furniture without the need of an extra electrical installation and are highly innovative. The conductive panels offer new possibilities for design pieces and furniture for the mass market. Further work is required to polish the concept to a state where products for the market can be developed. But this was a first big success for a conductive furniture panel.

\section{References}

Agarwal M, Lvov Y, Varahramyan K (2006) Conductive wood microfibres for smart paper through layer-by-layer nanocoating. Nanotechnology 17:5319-5325. doi: 10.1088/09574484/17/21/006

Bigg DM (1977) Conductive Polymeric Compositions. Polym Eng Sci 17:842-847

Brischke C (2007) Untersuchung abbaubestimmender Faktoren zur Vorhersage der Gebrauchsdauer feuchtebeanspruchter Holzbauteile. E-Dissertationen der Univ Hambg 321

Brischke C, Rapp AO, Bayerbach R (2008) Measurement system for long-term recording of wood moisture content with internal conductively glued electrodes. Build Environ 43:15661574. doi: 10.1016/j.buildenv.2007.10.002

EUWID (2019) EUWID Special : Wood-Based Panels. EUWID Wood Prod Panels 76

Fu F, Hua Y, Lu B (2001) Manufacture of composite wood board with conducting function. Patent CN1294959 (A)

Fu F, Lu K, Hou J (2014) Fiberboard with electromagnetic shielding function and preparation method thereof. Patent CN104175381BB

Guo H, Büchel M, Li X, et al (2018) Dictating anisotropic electric conductivity of a transparent 
copper nanowire coating by the surface structure of wood. J R Soc interface 15:. doi: 10.1098/rsif.2017.0864

Hu N, Masuda Z, Yan C, et al (2008) The electrical properties of polymer nanocomposites with carbon nanotube fillers. Nanotechnology 19:. doi: 10.1088/0957-4484/19/21/215701

Könekamp M (2017) Method and device for producing wood-based material panels, and woodbased material panels. Patent WO2017207451 (A1)

Kuchling H (2011) Taschenbuch der Physik, 20th edn. Fachbuchverlag Leipzig im Carl Hanser Verlag, München

Leute U (2015) Elektrisch leitfähige Polymerwerkstoffe - Ein Überblick für Studierende und Praktiker. Springer Fachmedien, Wiesbaden

Lohmann U (2010) Holzlexikon, 4th edn. Genehmigte Lizenzausgabe für Nikol Verlag, Hamburg

Niemz P, Sonderegger W (2017) Holzphysik. Fachbuchverlag Leipzig im Carl Hanser Verlag, München

Pike GE, Seager CH (1974) PHYSICAL REVIEW B Percolation and conductivity: A computer study. P. Phys Rev B 10:1421-1434

Prieto J, Kiene J (2007) Holzbeschichtung: Chemie und Praxis. Vincentz network, Hannover

Qian J, Gao W, Li L, Lu J (2015) Fiber wood with electromagnetic shielding function and preparation method thereof. Patent CN104985668 (A)

Rao S, Simha TGA, Rao KP, Ravikumar GV V. (2018) Carbon Composites Are Becoming Competitive And Cost Effective. Infosys Report. Bengaluru

Ugolev BN (1986) Holzkunde und Grundlagen der Holzwarenkunde. Lesn. Prom., Moskau

Wehnert F, Heinrich J, Jansen I (2012) Multifunctional adhesives by integration of Carbon Nanotubes. In: 9th European Adhesion Conference (EURADH), Friedrichshafen. Fraunenhofer IWS, Dresden

Whelan A (1995) Reinforcement of Mouldings. In: Simpson WG (ed) Plastics and Resin Compositions. The Royal Society of Chemistry, Cambridge, pp 26-53

Zauscher S (1992) Orienting Lignocellulosic Fibers by Means of a Magnetic Field. Oregon State University

Zhang F (2016) Manufacturing method for environment-friendly and energy-saving decoration board resisting fire, electromagnetic radiation and static. Patent CN105328760 (A)

Biography 
Proceedings of the 2020 Society of Wood Science and Technology International Convention

\title{
Bonding Strength of Benuang and Duabanga Glulam Using Their Bark as Filler for Phenol Formaldehyde Resin
}

\author{
Sari Delviana Marbun \\ sari.delvianamarbun@gmail.com \\ Imam Wahyudi \\ imyudarw16@yahoo.com \\ Jajang Suryana \\ jayana58@gmail.com \\ Deded Sarip Nawawi \\ dnawawi66@yahoo.com \\ IPB University, Indonesia
}

\begin{abstract}
In line with environmental issues and forest sustainability, the bark of two tree species from tropical rain forests of Indonesia i.e. benuang (Octomeles sumatrana/BN) and duabanga (Duabanga moluccana/DB) were used as filler for phenol formaldehyde resin (PF-filler). Effect of each bark as PF-filler on bonding strength of BN and DB glulam produced was analyzed. Four glue mixture compositions with ratio of PF, technical filler, and bark i.e. A $(10: 0: 0)$, B (10:1.5:0.5), C (10: $1.25: 0.75)$, and D (10: $1: 1)$ were prepared. Characteristics of each bark and glue mixture were also investigated. Glulam parameters being studied, namely moisture content, density, delamination, bonding strength, wood failure, and formaldehyde emission were determined following JAS 1152. Results showed that bonding strength was influenced by bark species and glue mixture composition. The B composition -the lowest portion of bark- was the best for BN glulam, while for DB glulam D composition -the highest portion of bark- was the best. Generally, utilization of bark as filler improves the bonding strength. Without the bark, the failure occurred on the glue line. DB's bark is more potential to be utilized as PF-filler as compared to BN's bark.
\end{abstract}

Keywords: bonding strength, D. moluccana, filler, glulam, O. sumatrana, bark

Biography 
Proceedings of the 2020 Society of Wood Science and Technology International Convention

\title{
Preparation of Cellulose Acetate-Polyacrylonitrile Composite Nanofibers by Multi-fluid Mixing Electrospinning Method: Morphology, Wettability, and Mechanical Properties
}

\author{
Dong Wang \\ sdzcwangdong@nefu.edu.cn \\ Wanli Cheng \\ nefucwl@nefu.edu.cn \\ Qingxiang Wang \\ wqx18846834061@nefu.edu.cn \\ Guangping Han \\ guangping.han@nefu.edu.cn
}

\author{
Northeast Forestry University, China
}

\begin{abstract}
Electrospun cellulose acetate-polyacrylonitrile (CA-PAN) nanofibrous membranes with controllable spatial structure were fabricated by a multi-fluid mixing electrospinning process. SEM showed that morphologies of membranes transformed from smooth to rough surface upon changing the weight ratios of CA to PAN, whereas their average diameters increased from 303 to $502 \mathrm{~nm}$. The static contact angle value of membranes increased from 86 to $131^{\circ}$ with increase in CA content. The hydrophilic-hydrophobic properties were affected by the Mixture Rule of surface microstructure and spatial structure. The PAN nanofibers had higher elongation at break ( $\varepsilon b$ ), however their yield strengths were lower, while CA fibers exhibited poor mechanical properties. After introduction of CA fibers into CAPAN membranes, the mechanical properties were improved significantly. The 33\%CA(67PAN) nanofibers showed highest tensile strengths ( $\left.\delta_{\max }, 5.0 \mathrm{MPa}\right)$ and $\varepsilon_{\mathrm{b}}(29.2 \%)$ values. Moreover, the composition, roughness and thermal stabilities of nanofibers were also analyzed. The structure-property relationship was clarified.
\end{abstract}

Keywords: electrospinning; CA-PAN nanofibrous membranes; hydrophobicity; structure-property relationship

Biography 


\title{
Proceedings of the 2020 Society of Wood Science and Technology International Convention
}

\section{Characteristic properties of 3D-printed wood/Polylactic acid composites with different extrusion temperatures using fused deposition modeling}

\author{
Chin-Hao Yeh \\ harrison19960219@gmail.com \\ Teng-Chun Yang \\ tcyang.04@nchu.edu.tw
}

National Chung Hsing University, Taiwan

\section{Abstract}

This work aimed at determining the effects of different extrusion temperatures on the wood fiber-reinforced polylactic acid (PLA) composite (WFRPC) components manufactured by fused deposition modeling (FDM). The physicalmechanical properties of the WFRPC components printed at different extrusion temperatures (200, 210, 220, and $230 \_\mathrm{C}$ ) were determined. The results showed that most of the physical properties were not significantly affected by different extrusion temperatures. However, the color difference and density of the FDM-printed WFRPC components increased as the extrusion temperature increased. As the extrusion temperature increased over 200 。C, the tensile and flexural properties of the WFRPC components decreased. Additionally, when the extrusion temperature increased from 200 to $230 \circ \mathrm{C}$, the compression strength and the internal bond strength increased by $15.1 \%$ and $24.3 \%$, respectively. Furthermore, using scanning electronic microscopy (SEM), the fracture surface of the tensile component printed at high extrusion temperature exhibited better adhesion between the extruded filament segments. The results showed that different extrusion temperatures of the FDM printing process have an effect on the color, density, and mechanical properties on the FDM-printed WFRPC component.

Keywords: wood fiber; polylactic acid (PLA); fused deposition modeling (FDM); extrusion temperature; physicomechanical properties

Biography 


\title{
Proceedings of the 2020 Society of Wood Science and Technology International Convention
}

\section{Wood-Metal Bonding Strength Improved Via Atmospheric Plasma Pre- Treatment}

\author{
Jure Zigon \\ jure.zigon@bf.uni-lj.si \\ Sebastian Dahle \\ sebastian.dahle@bf.uni-lj.si
}

\begin{abstract}
Hybrid composites of wood and metals present an interesting material for different building and construction purposes. Joints between the elements in this kind of composites can be formed with different types of adhesives, however, the compatibility between adhesives used and different materials is often challenging. A proper surface treatment is a crucial step before bonding process. In the present study, an atmospheric plasma discharge, generated in air at atmospheric pressure, was employed to enhance the adhesion strength of joints between common beach (Fagus sylvatica L.) wood and two different types of metals (steel and aluminum alloy), using four different types of adhesives. Firstly, the optical properties of plasma discharges and its influence on treated substrates' surface morphology were studied. X-ray photoelectron spectroscopy revealed chemical changes with the surface oxidation of all the materials after treatment with plasma. Improved wettability properties of substrates due to plasma treatment were confirmed with calculated surface free energies. Finally, adhesion properties of bonds were investigated with measurements of tensile shear strength of singlelap joints between wood and metals. Atmospheric plasma treatment technology showed a great potential for enhancement of adhesives strength of joints combining wooden and metal elements. Additionally, it was shown that better bonding performances of more cost-affordable adhesives can be reached, if the treatment with plasma discharge is applied on the bonded materials prior to bonding process.
\end{abstract}

\section{Biography}




\title{
Proceedings of the 2020 Society of Wood Science and Technology International Convention
}

\section{Wood Chemistry and Cell Biology}

Chair:

Gloria Oporto, West Virginia University, USA

\section{Simultaneous Chemical and Topographical Mapping of Wood Ultrastructures by Chemical Force Microscopy}

\author{
Claudia Gusenbauer1 \\ claudia.gusenbauer@boku.ac.at \\ Etienne Cabane2 \\ cabanee@ethz.ch \\ Tiina Nypelö3 \\ tiina.nypelo@chalmers.se \\ Johannes Konnerth 1 \\ johannes.konnerth@boku.ac.at
}

1 Institute of Wood Technology and Renewable Materials, Department of Material

Sciences and Process Engineering, BOKU - University of Natural Resources and Life Sciences, Austria

2 Institute for Building Materials, Wood Materials Science, ETH Zürich

3 Dep. of Chemistry and Chemical Engineering, Applied Chemistry, Chalmers Universit of Technology, Sweden

\begin{abstract}
Atomic force microscopy (AFM) represents a nanotechnology method capable of visualizing the ultrastructure of wood cell walls up to the nanometer range. The centerpiece of this method is a $<100$ $\mathrm{nm}$ radius tip which is scanning the surface of the sample. By tracing the movement of the tip, the topography of the specimen is visualized. Functionalization protocols of the AFM tip enable additional simultaneous mapping of chemical surface properties, called Chemical Force Microscopy (CFM)1. In this further development, force-distance measurements are performed in varying liquids in which the adhesion force between a chemically modified tip (e.g. hydrophilic or hydrophobic) and functional groups of a material reveals chemical surface variations with high spatial resolution.

We perform CFM experiments on native and functionalized wood structures to gain novel insights into the surface characteristics of ultra-microtomed lignocellulosic scaffolds2. In detail, we show a close-up look of chemical surface properties of different cell wall layers and chemically treated wood ultrastructures and present the required sample preparation, challenging scanning conditions and the gained insights into bio-based materials. This approach aims at confirming the presence of functional groups with high spatial resolution, targeting functionalization procedures of wood cell walls and shall support the extending of current wood applications through better understanding of the inherent wood properties.
\end{abstract}

Keywords: wood cell wall, adhesion, atomic force microscopy, chemical force microscopy, functionalized tip 
Proceedings of the 2020 Society of Wood Science and Technology International Convention

\section{Literature:}

1) Frisbie, C.D., et al., Functional group imaging by chemical force microscopy. Science, 1994. 265(5181): p. 2071.

2) Gusenbauer, C., et al., Visualization of the Stimuli-responsive Surface Behavior of Functionalized Wood Material by Chemical Force Microscopy. Scientific Reports, 2019. 9(1): p. 18569.

Biography 


\title{
Comparison of wood volumes and quality produced both by forestry and agroforest systems: the case of walnut (Juglans $x$ Regia $x$ Nigra)
}

Lucie Heimı, Kevin Candelier2,3, Eric Badel4, Louis Denaud, Lydie Dufours, Rémy Marchall

$1 \mathrm{PhD}$ student, Arts et Metiers Institute of Technology, LABOMAP, HESAM

Université, F-71250 Cluny, France, lucie.heim@ensam.eu

2CIRAD, UPR BioWooEB, F-34398 Montpellier, France.

з BioWooEB, Univ. Montpellier, CIRAD, Montpellier, France.

4INRAE - UCA, UMR 0547 PIAF Physique et physiologie Intégratives de l'Arbre en environnement Fluctuant. Centre de recherche Auvergne-Rhône-Alpes, Clermont-Ferrand, France

5INRAE - CIRAD - Montpellier SupAgro - CIHEAM, UMR 1230 SYSTEM, Montpellier, France

\begin{abstract}
Agroforestry trees grow in very different conditions than forestry trees systems mainly because of their higher exposure to wind and light, strong interactions with annual crops, numerous human operations on branches (pruning) and root systems.

Until now, agroforestry woods have not been studied a lot for their quality. Our research aims to understand how those particular growing conditions affect the development of trees - especially primary and secondary growths - and wood quality.

In a first stage, we have focused on hybrid walnut (Juglans x Regia x Nigra) located into the Restinclières Agroforestry Platform (RAP), near Montpellier, France, managed by lab System INRAE (https://umr-system.cirad.fr/en/the-unit/research-and-training-platform-inpartnership/restinclieres-agroforestery-platform-rap). We have performed dendrometric measurements and take wood samples both in agroforestry plot (AF) and in a forest control plot (FC). The trees were all 25 years old.

Agroforestry walnut are spaced 4,8,12 or $16 \mathrm{~m}$ on a same planting line and the density in the plot is 100 trees/ha. Between each line, cereal crops are cultivated. In FC plot, the walnut tree density is almost 200 trees/ha and are mixed with other trees, i.e. alder (Alnus spp) and ash trees (Fraxinus excelsior). Both plots are north-south oriented.

Concerning wood production, the DBH measurements of the trees performed since 2002 allow a comparative assessment of secondary growth. It shows that radial growth in AF plot is on average $50 \%$ greater than in FC plot.
\end{abstract}


Concerning wood quality, we have first considered duraminisation process because the color associated to this phenomenon is the main quality criteria for walnut wood industry and end-users. The study of duraminisation was made on $5 \mathrm{~mm}$ radial increment cores (2 per tree) and on disk from 5 trees harvested in each plot. The first results did not show any significant difference between AF and FC only considering the color but biochemical and MFA measurements are currently in progress in order to confirm this result.

Key words: Agroforestry, walnut, wood quality, density, growth

\section{Introduction}

Trees had in the past an important place in agricultural landscapes but the emergence of the intensive agriculture, at the middle of 20th century, has largely contributed to the decline of the tree in the agricultural environment. Indeed, the intensification of agricultural practices and the 
evolution of technical facilities have led to a decrease in the quantity of trees present in cultivated areas. But since 70's, these modern agricultural models presented economic, environmental and social weaknesses (Nair, 1993), leading scientists to define and implement alternative agricultural models integrating environmental and social issues into economic development (MEA, 2005). This agro-ecological evolution of agriculture has contributed to the emergence of agroforestry systems.

Agroforestry encompasses a set of land use practices which aim to realize the benefits from growing woody and herbaceous species together, commonly by the addition of trees to land already being used for pasture or for growing annual crops (Anderson, 1993).

At first, agroforestry practices were only focused on the food production and the trees were of secondary importance but were very profitable in the quality and quantity of food production. Nowadays, trees can represent a long-term investment for the farmer, providing a significant additional income when they are mature enough to be felled, harvested and resold as timber.

Agroforestry trees grow in very different conditions than those from forestry systems, mainly because of their high exposure to wind and light, strong interactions with annual crops, numerous human operations on branches (pruning) and root systems. However, contrary to the trees from forestry systems, agroforestry woods have not been studied a lot for their growing, qualities and properties.

This study is part of a more general thesis work seeking to compare the growing conditions and the quality of agroforestry wood with the similar wood species from conventional forest stands.

Three elements are studie: Firstly, the primary and secondary growth of agroforestry trees are analyzing in three species: Juglans, Poplar and Robinia. The duraminisation phenomenon is studying in walnut (Juglans $x$ Regia $x$ Nigra), and finally, the mechanical aspect athwart the study of Poplar.

The aim of this article is to present the first results from this $\mathrm{PhD}$ thesis work. The present study is focused only on the wood production and on the wood quality of agroforestry walnut trees.

Common walnut (Juglans regia L.), black walnut (Juglans nigra L.) native to North America, and their interspecific hybrids (Juglans nigra $\mathrm{x}$ Juglans regia) produce high quality lumber. It is a tree that normally does not grow in the forest and that is considered like one of the "flagship" species used in the French agroforestry systems.

The uses of high-quality walnut wood are mainly veneer and cabinet-making, but also nuts production. Currently, the high value of walnut wood is mainly related to its aesthetic characteristics, i.e its brown color or color contrasts and patterns marked by grain.

As the environmental growth conditions are different, we will focused first trees productivity considering primary and secondary growths both on an agroforestry plot compared to trees from a control plot (conventional stand). Then, as the main quality criteria for this wood is its color, we will considered duraminisation process because of the color associated to this phenomenon.

\section{Materials \& Methods}

The agroforestry system of Restinclières was created in 1995 by INRAE. It is located near Montpellier, in South of France and is one of the bigger agroforestry systems in France. The system is composed by 45 ha of plantations, with forest plots, agroforestry plots and crop fields. In this 
way, it allows comparison of production and growth of agroforestry plots with those of forest plots or crops.

Our studies focus on two walnut trees plots: one is an agroforestry (AF), the other is a forest (FC) one. Both are north-south oriented lines. Agroforestry walnut are spaced 4, 8, 12 or $16 \mathrm{~m}$ on a same planting line and the density in the plot is 100 trees/ha. Between each line, cereal crops are cultivated every years. In FC plot, the wa lnut tree density is almost 200 trees/ha and are mixed with other trees, i.e. alder (Alnus spp) and ash trees (Fraxinus excelsior) (Figure 1).

Figure 1. Agroforestry plot (left) and Forest control plot (right)
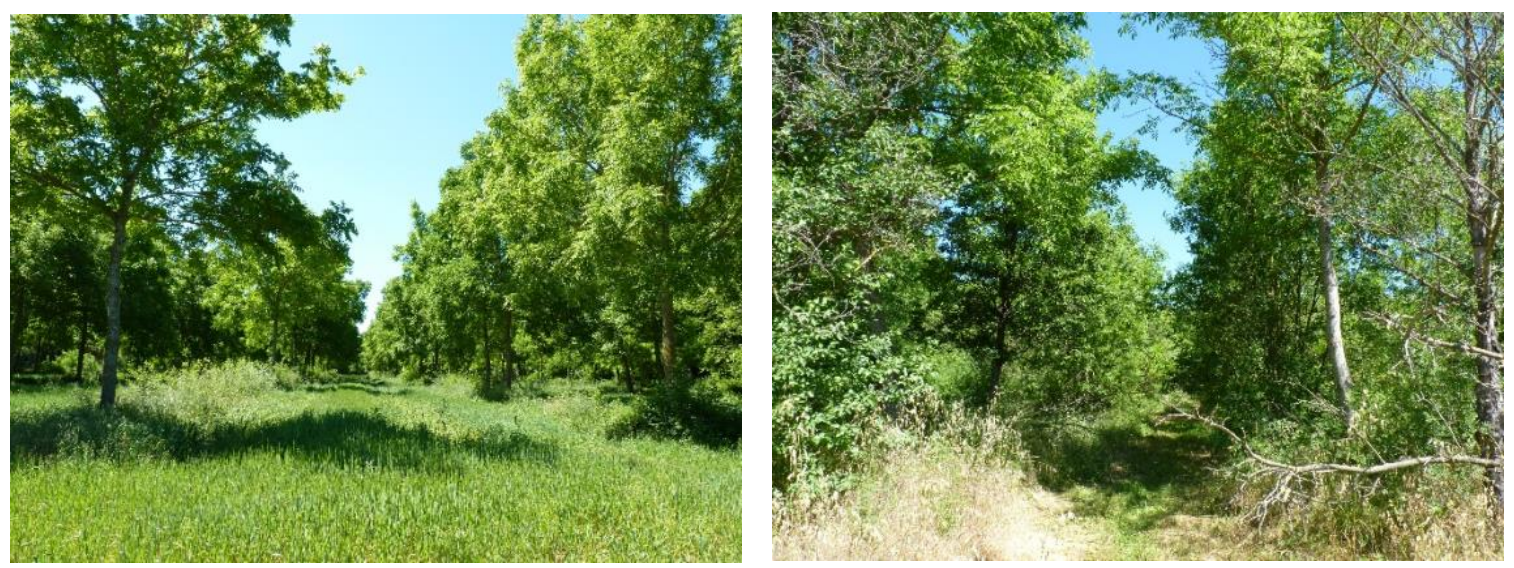

A

growth monitoring carried out since since 2002 with an annual DBH measurement. It allowed to determine the primary growth and the radial growth of the agroforestry (AF) walnut trees compare to those from the forest system (FC).

The studies of specific gravity and of duraminisation were made on radial increment cores with a diameter of $5 \mathrm{~mm}$ and on disks. Two cores were made on 6 trees in each plot. One core was made in the north-south orientation and the other in the east-west one.

Then the cores were divided on small pieces of $1 \mathrm{~cm}$ length. After an oven-drying step performed at $103^{\circ} \mathrm{C}$ until their mass stabilization, all samples were weighed, and their volume was determined to define their infradensity.

\section{Results and Discussion}

Annual monitoring of walnut tress growth showed that radial growth in AF plot is on average $50 \%$
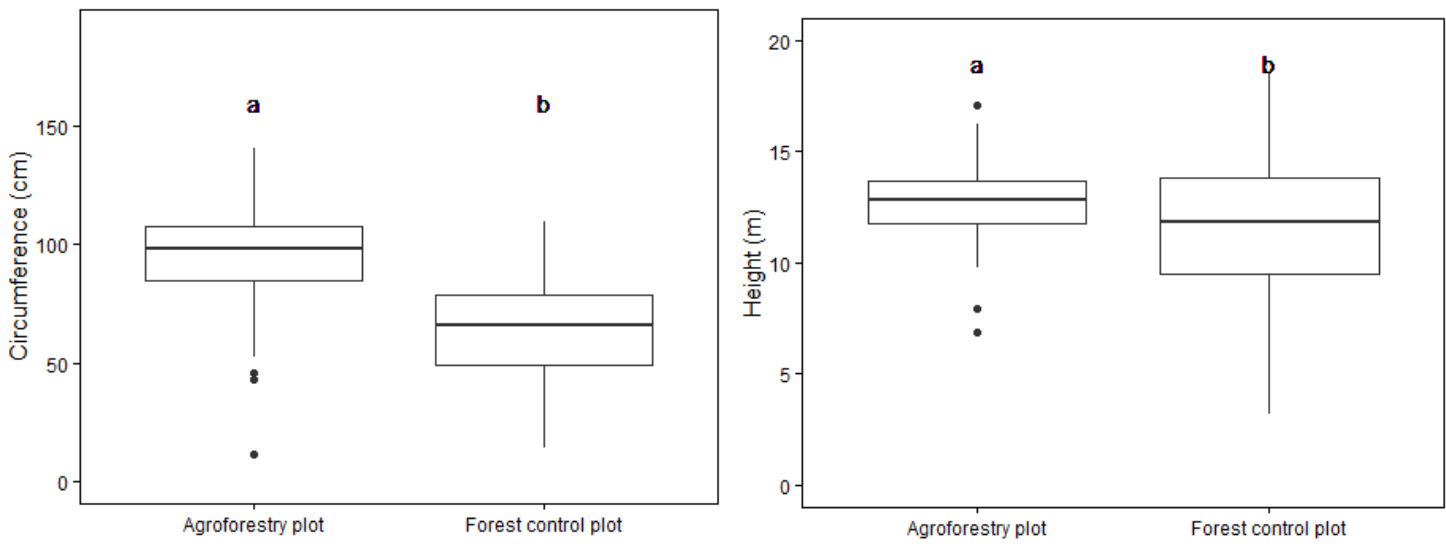

greater than those in FC plot, with mean values of 
circumference of $66 \mathrm{~cm}$ and $52 \mathrm{~cm}$, respectively (figure 2a). The height of walnut trees in AF plot is also more important than those of trees from FC plot with average values of $12.8 \mathrm{~m}$ and $11.5 \mathrm{~m}$ high, respectively (figure $2 b$ ).

Figure 2. (a) Circumference at 1,30 height of AF walnuts and FC walnuts / (b) Height of AF walnuts and FC walnuts (2017)

Concerning radial growth, our results are in agreement with observations made on the impact of stand density on growth. In forest stands, density had significant effects on tree radial growth and crown size, and the lowest stand density produced trees with the largest stem diameter (Jiang et al., 2007). Moreover, Cabanettes et al (2004) showed that in agroforestry system, the spacing of the trees favored radial growth.

Concerning axial growth, it can be observed that agroforestry walnut trees are taller than those of forest control walnuts. These results are not conform to the observations from other studies indicating that agroforestry trees are usually smaller than forest trees (Cabanettes et al., 2004).

Moreover, a study conducted on young poplars stimulated by periodic controlled bending showed that axial growth is reduced by mechanical stimulations and hydric stress while radial growth was strongly increased by the periodic stem bending (Niez et al., 2019). With a lower stand density compared to conventional forest, agroforestry systems increase the exposition of the trees to wind and thus to mechanical stress, inducing a lower axial growth. However, Cabanettes et al (2004) showed that agroforestry trees with shelter are taller than agroforestry trees without shelter. The plots used in this study are surrounded by large hedges that can reduce the effect of the wind on the growth of the trees. This could explain why the agroforestry walnut trees are not smaller than the walnut trees from the control forest plot.

Concerning specific density, our first results show that there is no statistically significant difference between the infradensities of agroforestry wood trunk and those of forest trees (figure 3).

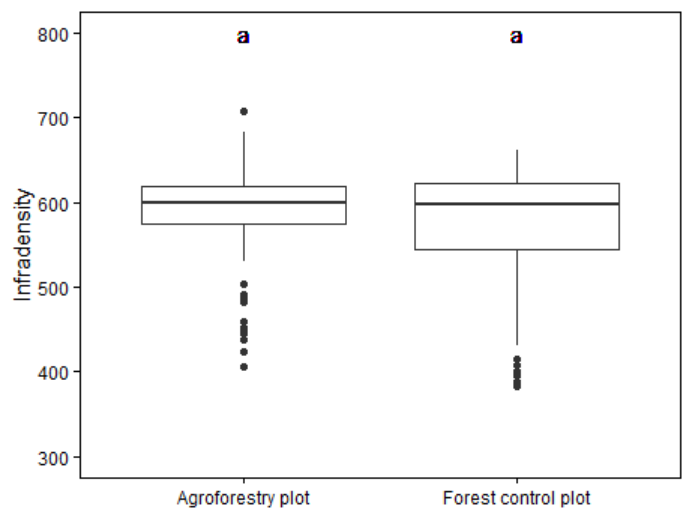

Figure 3. Infradensity of AF walnut trunks and FC walnut trunks

Juglans sp belongs to the semi-porous hardwood group. In hardwoods, particularly those with porous initial zones, an increase in growth rate leads to an increase in wood density, due to a higher proportion of the final wood. However, in hardwoods such as walnut, where the distribution of 
vessels is more homogeneous, specific gravity is little affected by the increase in the width of the rings and therefore by the increase in the speed of growth (Trouy, 2015). This may explain why, although the growth in agroforestry walnut trees is higher, their infradensity is not significantly different from that of walnut trees in the FC plot.

The analysis of radial variation of infradensity did not show significant differences along the trunk (from the bark to the cord) and this for both plots (AF and FC). Yet the density in Juglans nigra is usually higher in the duramen than in sapwood (Rink, Phelps, 2007).

In the same time, the study of duraminisation made on $5 \mathrm{~mm}$ radial increment cores did not show any significant difference between AF and FC only considering the color with visual appreciate. This result can be related to the previous one: the process of duraminisation seems to have started only slightly in the two plots.

\section{Summary and Conclusions}

The study of the growth of agroforestry walnut trees compared to walnut trees from a control forest stand clearly indicated that agroforestry trees have a greater growth rate in height and width. Therefore, agroforestry walnuts produced more biomass than walnut from conventional plot at the same age. This result is potentially interesting for the wood industrial sector but also for the farmers; their walnut trees can be a significant source of additional income at the farm level.

This study of growth and thigmomorphogenesis in an agroforestry environment is followed in parallel within an agroforestry system of Robinia pseudoaccacia. The study is also done by comparing agroforestry individuals with individuals from control forest plots.

Some trees will be staked and others not, in order to study the impact of wind on the radial and apical growth of agroforestry trees.

Thereby, walnut trees produce more wood in agroforestry system than in forest system, but the wood density is quite the same in both systems. Before concluding on the similarity of the woods, we have made colorimetric and biochemical measurements. These trials are currently in progress. The color and extractives content for each plot are characterized along radial axis and the values will be compared between AF plot and FC plot. The colorimetric tests are performed before and after a treatment of the wood surfaces with a starch indicator, using a Colorimeter based on the CieLab system. To quantify the total amount of extractives two successive solvents-extraction process will be used. All these results will allow us to better know the quality of agroforestry walnut wood.

\section{Acknowledgements}

The authors thank INRAE System Lab, especially Jean-François Bourdoncle, Alain Sellier and Christian Dupraz for for their technical contributions in our work. They also thank the Hérault department (Sophie Marco, Hélène Sosa and Vincent Sablain) and all those who accompany them in this PhD work. 


\section{References}

ANDERSON, L. S. and Sinclair, 1993. Ecological interactions in agroforestry systems. In : [en ligne]. 1993. Disponible à l'adresse : https://agris.fao.org/agrissearch/search.do?recordID=GB2012107229.

CABANETTES, Alain, AUCLAIR, D. et IMAM, W., 2004. Diameter and height growth curves for widely-spaced trees in European agroforestry. In : Agroforestry Systems. 2004. DOI 10.1023/A:1026440329824.

JIANG, Ze-Hui, WANG, Xiao-Qing, FEI, Ben-Hua, REN, Hai-Qing et LIU, Xing-E., 2007. Effect of stand and tree attributes on growth and wood quality characteristics from a spacing trial with Populus xiaohei. In : Annals of Forest Science. 1 janvier 2007. Vol. 64, n 8, p. 807-814. DOI 10.1051/forest:2007063.

MEA (éd.), 2005. Ecosystems and human well-being: synthesis. Washington, DC : Island Press. ISBN 978-1-59726-040-4. GF50 .E269 2005

NAIR, P. K. R., 1993. An Introduction to Agroforestry. S.1. : Springer Science \& Business Media. ISBN 978-0-7923-2135-4.

NIEZ, Benjamin, DLOUHA, Jana, MOULIA, Bruno et BADEL, Eric, 2019. Water-stressed or not, the mechanical acclimation is a priority requirement for trees. In : Trees - Structure and Function. 2019. Vol. 33, n 1, p. 279-291. DOI 10.1007/s00468-018-1776-y.

RINK, George et PHELPS, John E., 2007. Variation in Heartwood and Sapwood Properties Among 10-Year-old Black Walnut Trees. In : Wood and Fiber Science. 22 juin 2007. Vol. 21, $\mathrm{n}^{\circ} 2$, p. $177-182$.

TROUY, Marie-Christine, 2015. Anatomie du bois - Formation, fonctions et identification. In : Librairie Quae [en ligne]. 2015. Disponible à l'adresse : https://www.quae.com/produit/1310/9782759223510/anatomie-du-bois.

Biography 


\title{
Proceedings of the 2020 Society of Wood Science and Technology International Convention
}

\section{In situ synthesis of mesoporous carbon-encapsulated Iron nanoparticles derived from rattan for efficient adsorption}

\author{
Lili Shang, International Center for Bamboo and Rattan, China \\ shangll@icbr.ac.cn
}

\begin{abstract}
Rattan, a tropical climbing palm that exhibits no branches or seasonal rings is characterized by a homogeneous parenchyma and vascular bundle distribution in contrast to wood. The stem has vascular features which are functional in water transport that are unusual compared with those in arborescent. Besides, rattans do have wide and long vessels, which can be as big as $3 \mathrm{~m}$ long and 532 $\mu \mathrm{m}$ in diameter, with uniformly and continuously pitted walls, and it is notable that the amount of stem occupied by vessels may be as much as $30 \%$ total stem volume. Such considerable vessels imply rapid water transport efficiency in the long stems. Furthermore, the honeycomb like microstructures of parenchyma cells with wide pits may well be used for infiltration of liquid. In conclusion, the inherently open pores from the natural anatomy of the rattan structures are more beneficial to the metal solution infiltration. Carbon-encapsulated iron nanoparticles (CEINPs) were synthesized by one step pyrolysis from rattan cane. The nanoparticles were characterized for physicochemical properties by SEM, TEM, XRD, Raman, and FTIR methods. The morphologic results showed that the nanoparticles had coreshell structures with a-Fe in situ encapsulated within 10-30 layer graphitic shell. The $\mathrm{N}_{2}$ adsorption results showed their specific surface area was $135.29 \mathrm{~m} 2 \mathrm{~g}-1$ with $3.07 \mathrm{~nm}$ average pore size. Methylene blue (MB) as a typical kind of cation dye was chosen to investigate the adsorption performance of the CEINPs samples. The adsorption results exhibited that CEINPs were effective to adsorb MB. The adsorption capacity increased with an increase of the iron contents from 5 to $15 \%$. The maximum value was $186.22 \mathrm{mg} \mathrm{g}-1$ at $10 \mathrm{wt}$ \% iron content. The synthesized CEINPs derived from rattan would open a new path to develop a dyes removal product for wastewater treatment.
\end{abstract}

Keywords: Rattan, Vessels, Carbon-encapsulated iron nanoparticles, Methylene blue, Adsorption

\section{Biography}




\title{
Proceedings of the 2020 Society of Wood Science and Technology International Convention
}

\section{The Visualization of Microstructure of Bamboo Nodes by High-resolution X- ray Microtomography (Micro-CT)}

\author{
Shumin Yang \\ yangsm@icbr.ac.cn \\ Elin Xiang \\ xiangelin@163.com \\ Lili Shang \\ shangll@icbr.ac.cn
}

\author{
International Center for Bamboo and Rattan, China
}

\begin{abstract}
Bamboo plant is one of the most important non-wood resources with excellent mechanical properties. The characteristics properties of bamboo are determined to a large extent by its structure. The anatomical structure of the culms consists of parenchyma cells, with embedded vascular bundles composed of metaxylem vessels, sieve tubes with companion cells, and fibers. the fibre characteristics of internodes such as micro and ultrastructure have been reported more. Little is known about the structure of bamboo nodes due to its rigidity and difficulty in slicing. In this study, high resolution X-ray computed microtomography (Micro-CT) was applied to efficient and non-invasive determination of the microstructure of bamboo nodes. This research could provide a basis for deeper understanding of growth mechanism and realizing resource efficient utilization of bamboo.

The distribution of vascular bundle of bamboo nodes was similar to that of internodes, which were gradually sparse from the outer to the inner, while the parenchyma gradually increases. However, there were significant differences in the shape and arrangement of vascular bundle. All cells are strictly axially arranged within the internodes of culm, and when the vascular bundle passes through the node, it will have different degree of bending, branching and thickening. There are no ray cells for radial transportation in nodes similar to that in internode, but the vascular bundle branched into diaphragm as as a supplement. In addition, the bamboo nodes does not have a typical vascular bundle similar to that of internodes, and the lateral fiber cap is often absent or only weakly developed. The bamboo diaphragm is composed of transverse conduction tissue and parenchyma cells, formed a complex reticular structure. Furthermore, the microstructure of bamboo nodes with different numbers of branches is readily imaged through Micro-CT, and it is clearly visible that many criss-crossed conduction tissues are connected between the culm and the branches.

The morphological dimensions of vascular bundles, parenchyma and vessel obtained by Micro-CT scan are agreement with those by optical microscope and field emission scanning electron microscopy. There were obvious heterogeneity of the pits distribution in different types of cell walls. The number of pits in the vessel cell wall is much higher than that of parenchyma and fibre cells, and pits in the metaxylem vessel is densely distributed in the center of the vascular bundle.

the unique microstructure of bamboo nodes and internodes is the result of adapting to environment optimization. Micro-CT technology is a fast and non-destructive imaging characterization method of bamboo science, which can obtain high resolution 2-D and 3-D images, and quantitative analysis of morphological size. The method can make up the defects of the traditional method, which is not timeconsuming and can obtain three-dimensional structure.
\end{abstract}

Key words : Micro-CT; microstructure; internodes; nodes; nondestructive testing

\section{Biography}




\title{
A Direct Bioautography as a Screening Method for Bioactive Wood Extracts Against Basidiomycetes
}

\author{
Regina Wanschura ${ }^{*}$-Elisabeth Windeisen $1-J$. Philipp Benz 2 - Klaus Richter 1 \\ 1 Technical University of Munich, Chair of Wood Science, Winzererstr. 45, D- \\ 80797 Munich \\ *wanschura@hfm.tum.de \\ windeisen@hfm.tum.de \\ richter@hfm.tum.de
}

\author{
2 Technical University of Munich, TUM School of Life Sciences Weihenstephan, \\ Wood Bioprocesses, Hans-Carl-von-Carlowitz-Platz 2, D-85354 Freising \\ benz@hfm.tum.de
}

\begin{abstract}
Many (tropical) wood species contain biochemically interesting and partly unknown substances. As these extractives consist of a great variety of components differing in quantity and composition, the analysis is often time-consuming and sophisticated, especially for very polar and/or high molecular compounds. Bioassay-guided fractionation is helpful to focus on the key bioactive substances, however the established bioassay methods cannot be readily adapted to basidiomycete fungi that are commonly used for the respective durability tests. They do not sporulate easily in laboratory settings and working with hyphae is still common in many laboratories. To overcome this restriction, a direct bioautography using homogenized hyphae from basidiomycetes was developed. Four tropical wood species regarding their potential bioactivity on two selected basidiomycete fungi were analyzed. The extract constituents were resolved by a two-dimensional planar chromatography and the metabolites were located by characteristic zones of fungal growth inhibition, which was accentuated by a color reaction using a dye reagent: 3-(4,5-dimethyldiazol2-yl)-2,5diphenyltetrazolium bromide (MTT) which is mixed directly into the hyphae agar. This technique can be used as a rapid "pre-selection" of noticeable (bioactive) extracts and therefore the analysis becomes more efficient. In the present study, tropical hardwoods are extracted with organic solvents and are screened against Rhodonia placenta and Trametes versicolor. Both fungi show positive reaction to the MTT-test and some of the separated bioactive compounds are detected on the hyphae-agar overlaid TLC which were then analyzed by gas chromatography/ mass spectrometry (GC/MS). Potentially responsible compounds could be identified, such as the alkaloid bicuculline from Mezilaurus itauba, which has not been described in this species yet.
\end{abstract}

Keywords: basidiomycetes, bioassay, GC/MS, heartwood extracts, hyphae agar

\section{Introduction}

Many tropical timbers stand out due to their high durability against wood-degrading fungi (Schwager und Lange 1998) which is determined by exposing wood samples to certain fungal 
species and measuring the loss of mass (Råberg et al. 2005, EN 113, EN 350-1). However, the mechanism behind this high durability has not been fully understood yet. The high content and the composition of extractives in tropical wood compared to species from colder climates might be one reason (Schultz and Nicholas 2000) and it is an accepted fact that the extractives contribute to the natural durability of wood to a considerable extent (Rutiaga-Quinones 2001, Kirker et al. 2013). Natural extracts were already utilized in ancient times, and in recent years, the chemistry of extractives has retrieved growing interest due to ecological concerns of synthetic substances (Singh $\mathrm{T}$ and Sing 2012; Snow et al. 2019) and basically the working principles of nature might open totally new bioactive structures. Applications to pharmaceutics and food and for the production of platform chemicals are partly implemented (Willför et al. 2003, 2005; Smeds et al. 2012) but many potentially bioactive wood extractives (e.g. polyphenols, stilbenes, lignans) remain unused so far (Yang 2009), which might be useful, i.e. as wood protection agents.

Planar chromatography combined with a microbial detection method, termed bioautography, is considered an efficient assay for the detection of antimicrobial compounds (Dewanjee et al. 2015). It allows for the localization of the activity even in a complex matrix and therefore permits a targetguided isolation of the active components (Rahalison et al. 1991). These conventional bioautography test-methods are mostly designed for spore-producing fungi (Favre-Godal et al. 2013) which are easily harvestable and inoculated on agar. However, these standard antifungal assays cannot be readily adapted to basidiomycetes, like, in particular $T$. versicolor and $R$. placenta. The production of basidiospores in vitro was subject of several studies in the past (Croan and Highley 1991), and even if it was improved over the last few years (Choi et al. 2001, 2002; Stirling et al. 2016), the work with hyphae is still standard in many laboratories (Deklerck et al. 2017).

The main objective of the study was to develop a direct bioautography using homogenized hyphae from these two basidiomycetes. Both fungi have already been used in earlier studies testing the activity of the tropical wood species Tectona grandis and Dipteryx odorata (Wanschura et al. 2016) as well as Handroanthus spp. (formerly Tabebuia spp.), Mezilaurus itauba and Manilkara bidentata (Wanschura et al. 2017).

It was investigated whether the bioautographic agar overlay method (Rahalison et al. 1991) and the hyphae agar (Kawamura et al. 2004) can be combined. Combining the two techniques should provide a possibility to benefit from the advantages of a direct bioautography (rapid, easy to implement) while testing wood extractives against commonly used basidiomycetes, which do not readily sporulate.

Separating the compounds thoroughly should be achieved by performing the thin-layer chromatography as a twodimensional development (2D-TLC) as suggested by Wedge and Nagle (2000). Furthermore, the vitality of the mixed hyphae should be determined by using the viability stain 3-(4,5-dimethylthiazol-2-yl)-2,5-diphenyltetrazolium bromide (MTT). By indicating the vitality of the mixed hyphae through a stain, the judgment of whether a compound (-mixture) causes fungal inhibition or not should be improved.

Consequently, the presented technique should provide a rapid method to evaluate bioactive components in complex extract mixtures, but also applicable to fractions of them or single extractives, to focus the analytical efforts on the possibly causative key compounds, trying to better understand the increased durability of the tested tropical wood species.

\section{Materials \& Methods}


Wood samples and test organisms. The tropical wood species used were Astronium graveolens, Intsia spp., Shorea laevis and M. itauba that come from South and Central America. The boards used to cut the specimens were purchased from local lumberyards. Wood blocks of $1 \mathrm{~cm} 3$ were sawn out of the heartwood, milled in a cross hammer mill (Retsch) together with dry ice and sieved with a mesh size of $0.315-0.05 \mathrm{~mm}$. The sample moisture content was determined via oven drying at $105^{\circ} \mathrm{C}$ (double determination) and the sample weight is referred to as absolutely dry.

The white-rot fungus $T$. versicolor BAM 116 (CTB $863 \mathrm{~A}$ ) and the brown-rot fungus $R$. placenta BAM 113 (FPRL 280) were chosen as test organisms (according to EN 113), in order to detect a possible bioactivity of the wood extractives in the four species.

Solvent extraction: Determination of the extract content in organic solvents was done in a Soxhlet extractor using petroleum ether, acetone and methanol (all supplied by Merck, Darmstadt, Germany, SupraSolv quality) successively for $6 \mathrm{~h}(5 \mathrm{~g}$ of wood flour extracted with $170 \mathrm{ml}$ of the respective organic solvent; double determination; determined gravimetrically) with a relative deviation of less than $10 \%$.

Thin-layer chromatography (TLC). A two dimensional chromatography (2D-TLC) was performed on preparative glass plates (stationary phase: silica $60 ; 2 \mathrm{~mm} ; 20 \times 20 \mathrm{~cm}$; Merck, Darmstadt, Germany) without a fluorescence indicator for bioautography and for gas chromatography/mass spectrometry (GC/MS) analysis. For a proper detection of the substance spots, the separation was also performed on analytical aluminum TLC plates (stationary phase: silica $60 ; 2 \mathrm{~mm} ; 20 \times 20 \mathrm{~cm})$ as well. The plates were subjected to derivatization by dipping the plates for $10 \mathrm{~s}$ in a mixture of $\left(\mathrm{NH}_{4}\right)_{6} \mathrm{Mo}_{7} \mathrm{O}_{24}(5 \%)$ and $\mathrm{Ce}\left(\mathrm{SO}_{4}\right)_{2}(0.2 \%)$ in a $5 \%$ sulfuric acid solution.

For the bioassays (performed as duplicates), $30 \mu \mathrm{l}$ of extract solution with a concentration of 100 g 1-1 (resp. $3 \mathrm{mg}$ ) was applied onto the plates. The solvents used for the mobile phase $(300 \mathrm{ml}$ solvent mixture) were used for both, the acetone and the methanol extracts.

For the separation of $S$. laevis mixtures of butanone:methanol: $\mathrm{dH}_{2} \mathrm{O}(20: 3: 4)+10$ drops of formic acid (for D1) and butanone:propanol: $\mathrm{dH}_{2} \mathrm{O}(6.5: 2.5: 1)+10$ drops of formic acid (for D2), for $M$. itauba mixtures of cyclohexane:ethyl acetate:ethanol $(1: 1: 19.5)+10$ drops of $\mathrm{NH} 3$ (for D1) and chloroform:methanol: $\mathrm{dH}_{2} \mathrm{O}(35: 18: 1)+15$ drops of $\mathrm{NH}_{3}$ (for D2) and for Intsia spp. and $A$. graveolens mixtures of cyclohexane:acetone:ethanol (3:6:1) + 10 drops of formic acid (for D1) and chloroform:acetone:methanol $(1: 2: 2)+10$ drops of formic acid (for D2) were used. The plates were left to dry overnight at $60^{\circ} \mathrm{C}$ to completely remove the organic solvents. One TLC plate per fungi and wood species was performed without extractives as a reference. Furthermore, one TLC plate per extract and wood species was prepared for the following GC/MS analysis.

Hyphae agar. As described in Wanschura et al. (2020) and Wanschura (2020) the homogenized

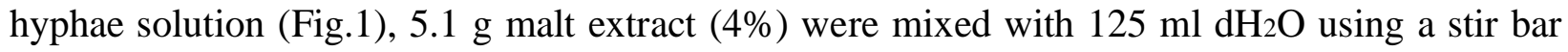
(Kawamura et al. 2004), the bouillon was poured into Erlenmeyer flasks and autoclaved (sterilization temperature $121^{\circ} \mathrm{C}$ for $20 \mathrm{~min}$; autoclave: HMC Europe, Tüßling, Germany). Three inoculation blocks $(0.5 \times 0.5 \mathrm{~cm})$ were cut from the fungal film of an agar plate of either $R$. placenta or T. versicolor and were put into the malt extract medium. After the liquid cultures were incubated in an incubator (Memmert) for 10 to 14 days at $22^{\circ} \mathrm{C}, 70 \%$ relative humidity, the malt extract medium was decanted from the liquid cultures of $R$. placenta $(19000 \mathrm{rpm})$ or $T$. versicolor (10 $750 \mathrm{rpm}$ ) and the hyphae were homogenized using a homogenizer (VWR, Ismaning, Germany). Then, the suspension was centrifuged (4 min), the supernatant was discarded and the hyphae were washed with $10 \mathrm{ml}$ of sterile $0.9 \%$ sodium chloride solution. Five milliliters of hyphae 
solution (formerly suspended in $2.5 \mathrm{ml}$ of $0.9 \%$ sodium chloride) was added to $250 \mathrm{ml}$ potato dextrose agar $\left(9.75 \mathrm{~g}\right.$ PDA) of with a temperature of $>50^{\circ} \mathrm{C}$ (hyphae concentration of approximately 2\%). $1 \mathrm{ml}$ of an aqueous MTT solution was mixed directly into the agar with a concentration of $10 \mathrm{mg} \mathrm{ml-1}$ (Rahalison et al. 1991; Osmonova 2011).

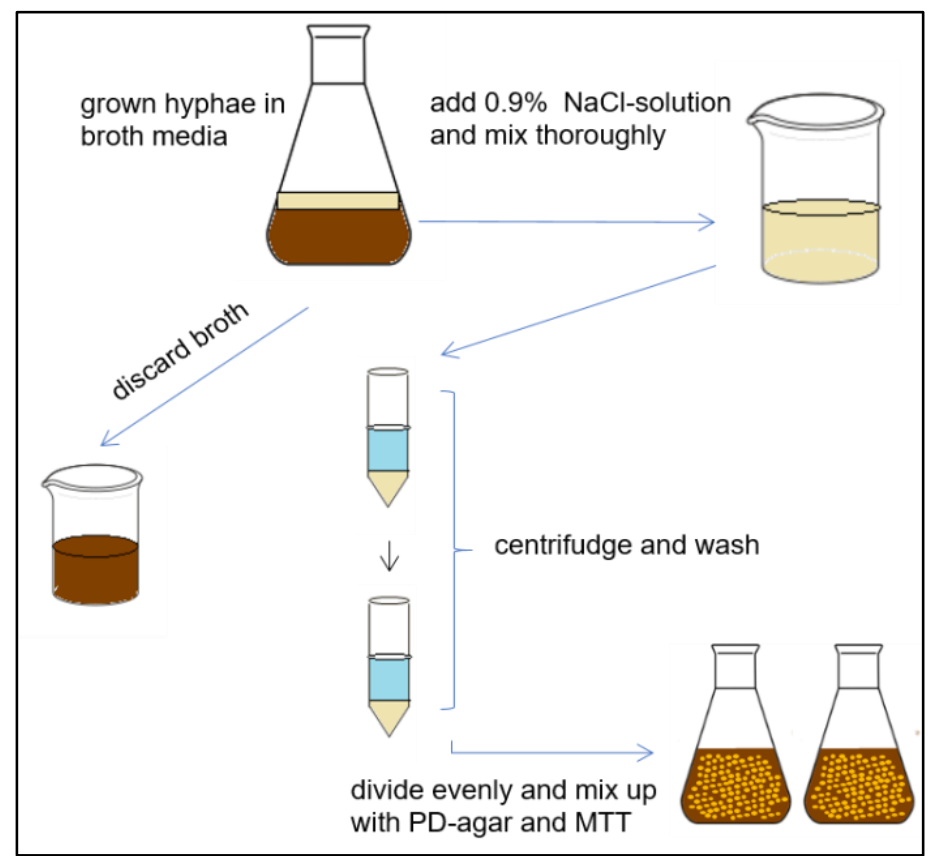

Fig1: Flowchart of the production of hyphae agar (Wanschura 2020)

Bioassay. The TLC plate was locked into a template and overlaid with $120 \mathrm{ml}$ of the hot hyphae agar-MTT mixture to generate 1-mm-thick agar layer (Fi.XX). After drying (for 1-2 min), the plate was disassembled from the template form, stored in a bioassay dish $(245 \times 245 \times 25 \mathrm{~mm}$, Corning Life Science, Lowell, MA, USA) and incubated in an incubator at $22^{\circ} \mathrm{C}$ and $70 \%$ relative humidity.

To determine the location of the compounds on the TLC designated for GC/MS analysis, the bioassay plates were photographed after incubation. On each photo, the inhibition zones were marked. Together with the detection of the substance spots by ultraviolet (UV) light, these pictures were used as an overlay to mark the corresponding spots on the "GC/MS-plate", which were then scratched from the plate. Furthermore, the TLC plates were compared with a respective chromatogram developed under identical conditions, which was revealed with the oxidative dying reagent (see Coloring of the hyphae through the vital stain MTT). This compound visualization provided helpful information about their localization in the plate (Wanschura et al. 2020). 


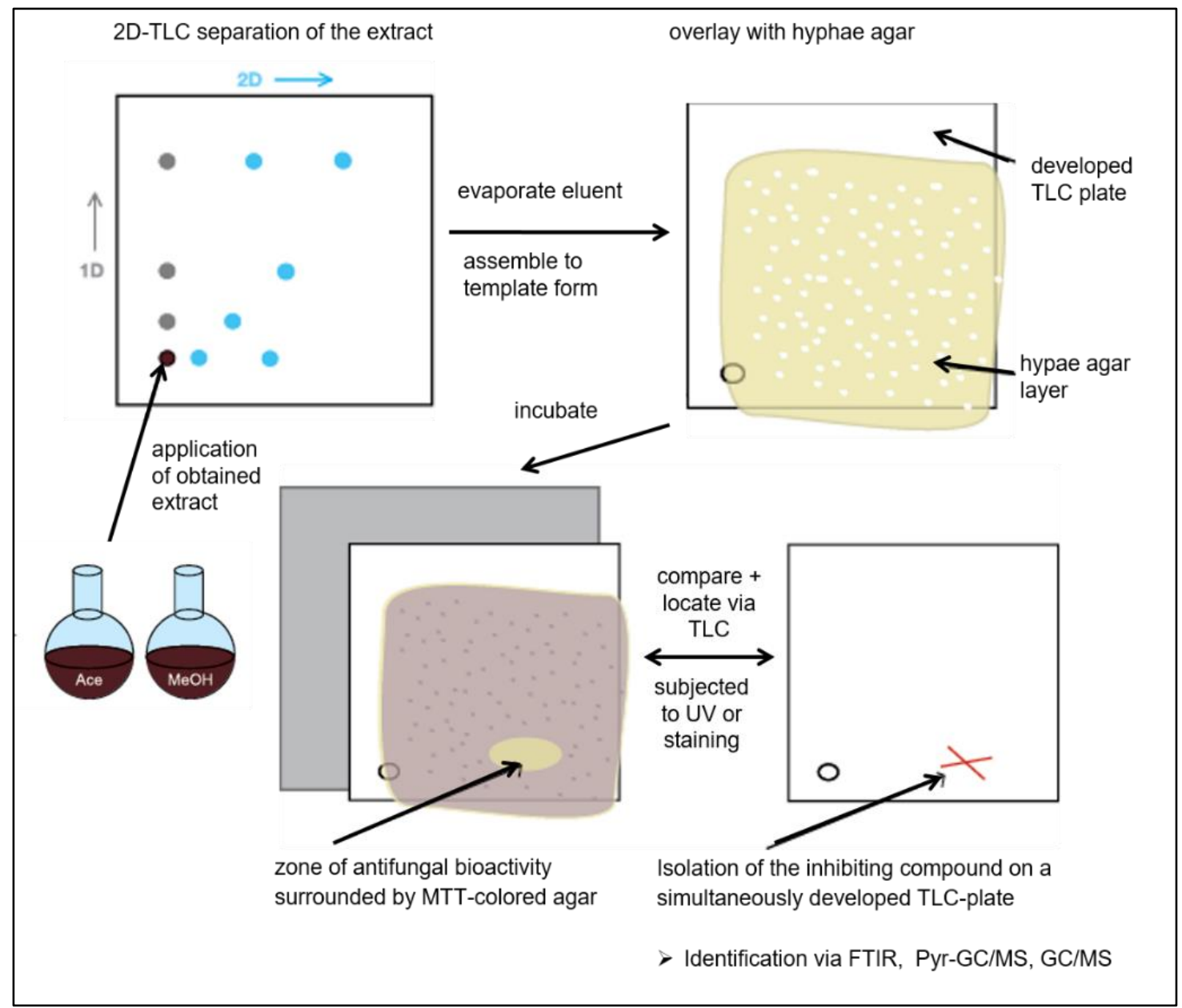

Fig.2 Overview over the Hyphae-agar assay overlay method (Wanschura 2020)

GC/MS: The substance spots were scratched from the TLC plates, dissolved in $5 \mathrm{ml}$ methanol, micro filtrated and after evaporating the solvent, the residue was dissolved in $100 \mu l$

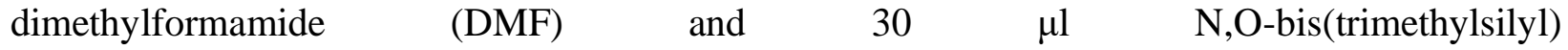
trifluoroacetamide/chlorotrimethylsilane (BSTFA/TMCS; SigmaAldrich) $\left(80^{\circ} \mathrm{C}\right.$ for $\left.1 \mathrm{~h}\right)$. Heating program GC: $10^{\circ} \mathrm{C}$ min-1 from $100^{\circ} \mathrm{C}$ to $320^{\circ} \mathrm{C}$ (held isothermally for $15 \mathrm{~min}$ ); injector temperature: $300^{\circ} \mathrm{C}$; split: $30: 1$ (39 ml min-1), carrier gas: helium; column: SGE-BPX 5 (15 $\mathrm{m} \times 0.25 \mathrm{~mm} ; 0.25 \mu \mathrm{m}$ film); MS ionization: $-70 \mathrm{eV}$; detector temperature: $150^{\circ} \mathrm{C}$; MS source: $230^{\circ} \mathrm{C}$; recorded mass range: 40 to $800 \mathrm{amu}$.

\section{Results and Discussion}

Coloring of the hyphae. Based on the reduction of the yellow tetrazolium salt, actively growing cells produce a blue/purple, insoluble formazan product (Mosmann 1983). MTT has already been utilized successfully to quantify the effects of antifungal agents on cell viability or as a method of colorimetric determination of fungal cell densities on a number of fugal species (Hidore et al. 1991; Meshulam et al. 1995; Freimoser et al. 1999; Etexeberria et al. 2011; Patel et al. 2013; Stockert et al. 2018). Best conditions were evaluated for the tests using $\beta$-thujaplicin (Rennerfelt 1948) in a disk diffusion assay. The solution used had a concentration of $40 \mu \mathrm{g} \mathrm{ml}-1 \mathrm{MTT}$. The 
best optical results were achieved at a concentration of $0.2 \mathrm{~g} \mathrm{l}-1$ producing clear zones of fungal inhibition (Wanschura et al. 2020)

\section{Determination of antifungal activity of the extract fractions}

Extract content of the tested species. The extracts of the wood species were obtained through successive extraction with three solvents (Fig.3). As the lipid factions of the extracts showed no bioactivity in preliminary carried out agar dilution tests these parts were not further tested, although they contributed considerably to the extract amounts (M. itauba: $4.1 \%$ ).

Fig 3: Extract contents from the tested species in percentage of dry weight [\%] (Wanschura et al. 2020).

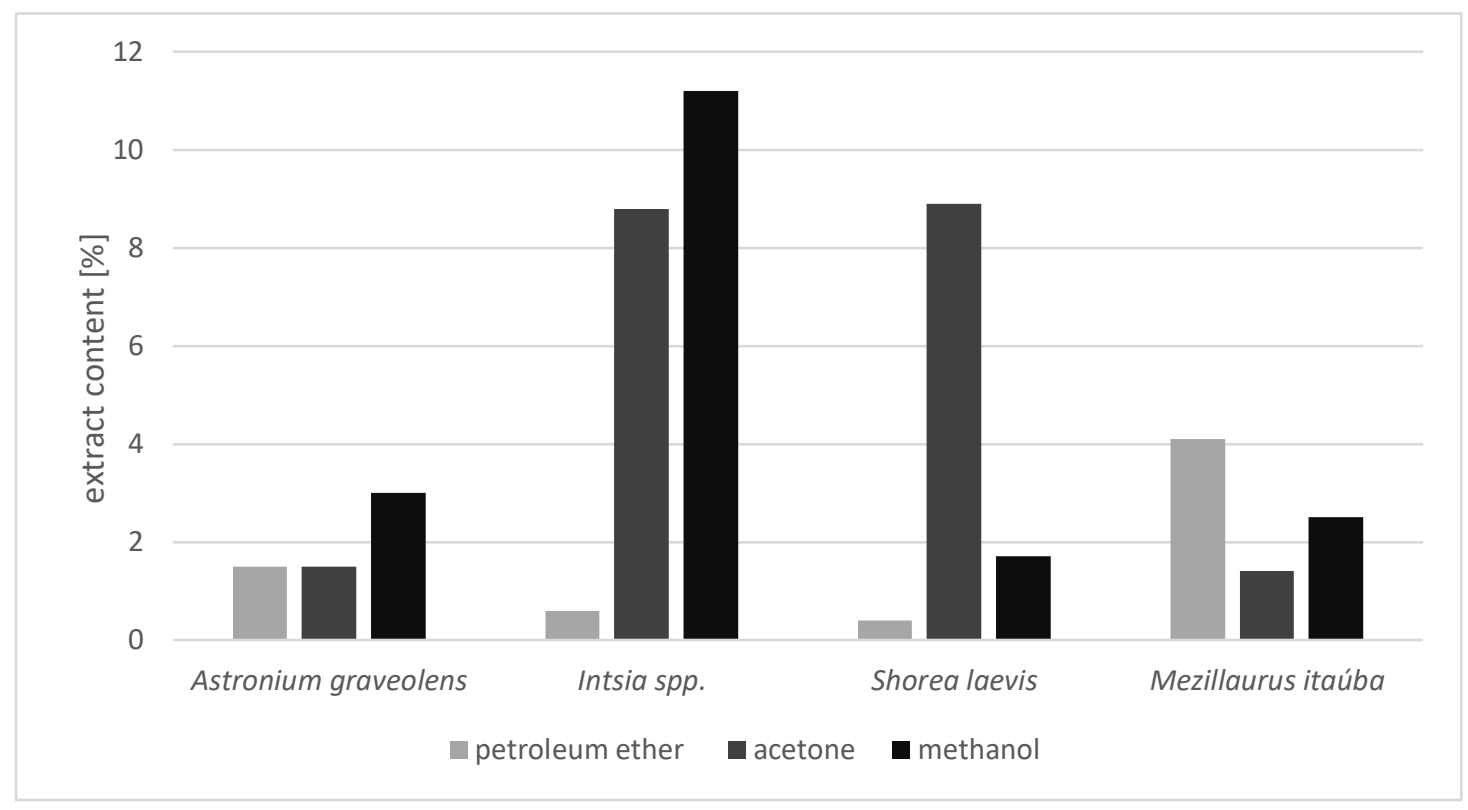


2D-TLC Bioassay. Figure 4 (I-IV) shows the bioassay results from Shorea laevis acetone and methanol extracts tested against $T$. versicolor and $R$. placenta. The absence of fungal growth indicates the inhibition due to the present extract compound. Unless the agar is not colored by the extract compound (marked with an arrow), these zones show a bright beige coloring of the agar. Fungal activity can clearly be seen by the blue color of the agar induced by the MTT reaction. For a better visualization of the bioactive zones on the photos shown in Figure 2 (IIV), the zones were marked by a circle. Inside the circles, the partitioned antifungal constituents of the extract can be found.

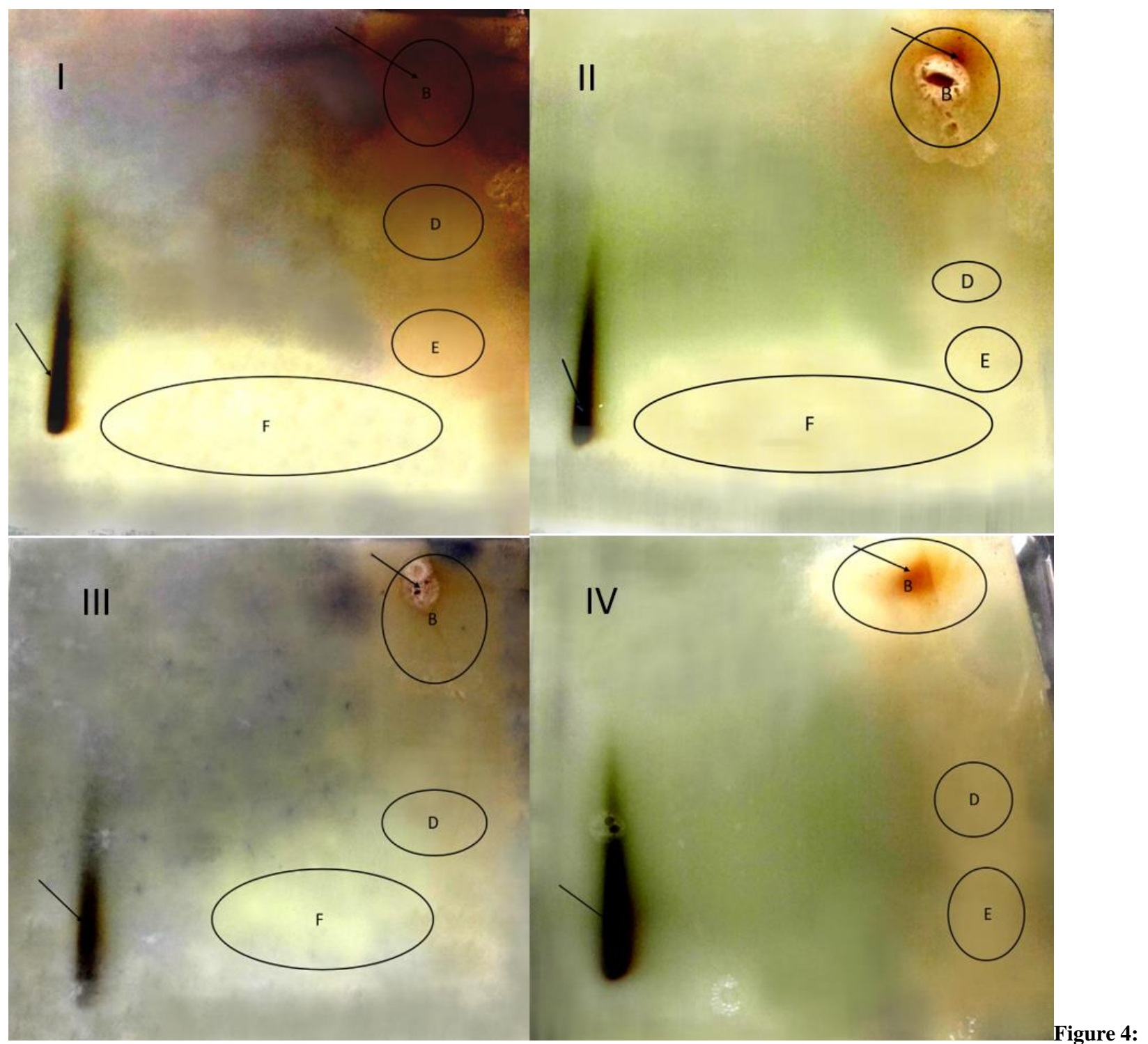

2D-TLC direct bioautography of Shorea laevis acetone (I/II) and methanol (III/IV) extract: bioactivity response from T.versicolor and Postia placenta

The reaction time until the blue coloring of the MTT appeared was varying from 3 to 8 days, whereby the response time for $R$. placenta cultures was longer. Even though the intensity of the blue coloring varies (probably due to unequally distributed hyphae), the optical determination of 
the bioactive zones is highly improved. As a completely homogeneous dispersion of the hyphae is difficult, the optical determination of the bioactive zones was much more exact using the MTT vitality stain than an evaluation by judging the hyphal growth alone. It could be observed that both fungi are not able to distinguish between compounds that are located very close together on the TLC. Instead, they formed inhibition zones with no or less fungal activity. On the one hand, this could be due to the fungal sensitivity, but more on the other hand, the substances very close together are more likely to get mixed during the diffusion process from the silica phase into the agar overlay, although the agar layer is very thin. Therefore, the detected fractions are aggregated to zones of fungal growth inhibition (Wanschura et al.2020).

Compounds detected in the inhibition zones of Astronium graveolens. Five zones with bioactivity against both fungi were detected (Tab.1): D, E, G, H, and $\mathrm{K}$ while fraction A only inhibited the growth of $R$. placenta. Compared to compounds in the other active zones, the compound(s) in zone A may have a smaller microbiologically effective spectrum. It is known that Astronium species contain different hydrolyzable tannins like gallotannins and ellagitannins together with different phenolic derivates (Da Silva et al. 2011). Other already known components found in Astronium species are gallic acid, caffeic acid, chlorogenic acid, china acid, quercetin and rutin (Imai et al. 2008; Brito Pereira Bezerra Martins et al. 2018). In zone E and in the methanol zones $\mathrm{H}$ and $\mathrm{K}$, an unidentified flavonoid ( $\left.\mathrm{R}_{\mathrm{t}} 19.86\right)$ and gallic acid ( $\left.\mathrm{R}_{\mathrm{t}} 12.63\right)$ were detected, as well as two triterpenes ( $R_{t} 22.74$ and $\left.R_{t} 22.69\right)$ in methanol zone $G$. The bioactive potential of the acetone zones $\mathrm{G}$ and $\mathrm{H}$ cannot be explained sufficiently at this moment (Wanschura et al. 2020).

Tab. 1: Compounds detected on the TLC from Astronium graveolens extracts that were developed similar to the bioassay plates (Wanschura et al. 2020).

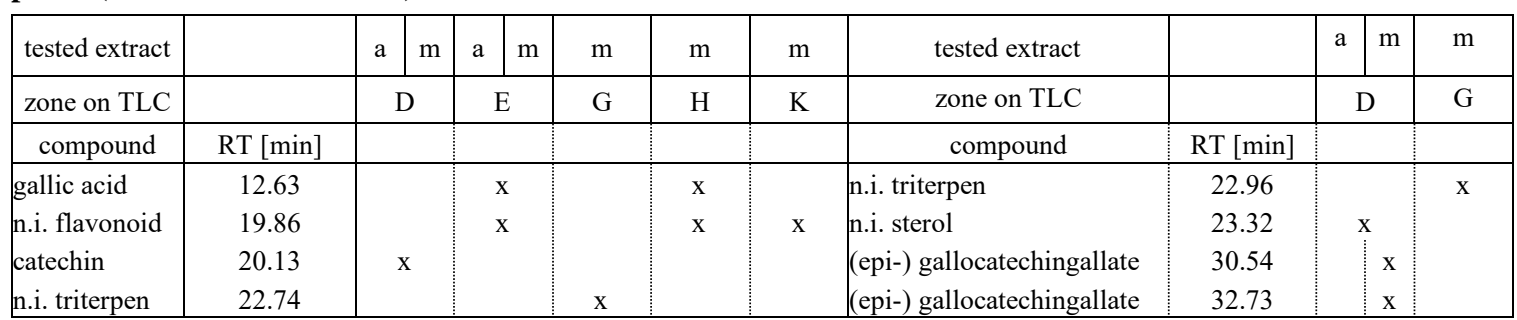

Compounds detected in the inhibition zones of Intsia spp. Catechin isomers like robinetinidol or fisitinidol and some more flavonoids were detected in 3 bioactive zones (Wanschura et al. 2020). Furthermore, the reduced hyphal growth in another zone could be explained by a higher content of gallic acid. Gallic acid has already been detected in an Intsia species by Kilic and Niemz (2012). Robinetin was reported as the main flavonoid in Intsia bijuga. Further constituents mentioned in this study were dihydromyricetin, myricetin, naringenin and leucocyanidin (Hillis and Yazaki 1973).

Tab. 2: Compounds detected on the TLC from Intsia spp. extracts that were developed similar to the bioassay plates (Wanschura et al. 2020).

\begin{tabular}{|c|c|c|c|c|c|c|c|c|c|c|c|c|}
\hline tested extract & & $\mathrm{a}$ & $\mathrm{m}$ & $\mathrm{a}$ & $\mathrm{a}$ & & & $\mathrm{a}$ & $\mathrm{m}$ & $\mathrm{a}$ & $\mathrm{m}$ & $\mathrm{m}$ \\
\hline zone on TLC & & & & $\mathrm{F}$ & $\mathrm{H}$ & zone on TLC & & & & & & $\mathrm{E}$ \\
\hline compound & $\mathrm{RT}[\mathrm{min}]$ & & & & & compound & $\mathrm{RT}$ [min] & & & & & \\
\hline n.i. compound & 12.40 & & & $\mathrm{x}$ & & catechin isomer & 19.18 & & $\mathrm{x}$ & $\mathrm{x}$ & & $\mathrm{x}$ \\
\hline gallic acid & 12.63 & & & & $\mathrm{x}$ & catechin isomer & 19.33 & & & $\mathrm{x}$ & & \\
\hline dehydroabietic acid & 16.80 & & $\mathrm{x}$ & & & catechin isomer & 19.34 & & & & $\mathrm{x}$ & $\mathrm{x}$ \\
\hline
\end{tabular}

Compounds detected in the inhibition zones of Shorea laevis. In the two detected bioactive zones, some fungicidal triterpenes were detected and additionally resveratrol in one of them 
(Wanschura et al. 2020). Hadi (2009) identified hopeaphenol, a resveratrol tetramer, in Shorea ovalis. Bisset et al. (1971) detected triterpenes like ursolic aldehyde, dipterocarpol, shoreic acid and dammarenolic acid in Shorea roxburghii. The bioactivity of zones E and F might be related to a diterpenic compound, which has a fragment pattern that indicates the occurrence of dehydroabietic acid. Dehydroabietic acid has a well-studied bioactivity profile, including antiviral, antibiotic and antifungal activity (Helfenstein et al. 2017). Even though dehydroabietic acid, as a resin acid, is usually found in conifers like Pinus spp., it is known that Shorea species form resin ducts (Wagenführ and Scheiber 1974).

Tab. 3: Compounds detected on the TLC from Intsia spp. extracts that were developed similar to the bioassay plates (Wanschura et al. 2020).

\begin{tabular}{|c|c|c|c|c|c|c|c|c|c|c|}
\hline tested extract & & $\mathrm{m}$ & a & $\mathrm{m}$ & $\mathrm{a}$ & & & $\mathrm{a}$ & $\mathrm{m}$ & \\
\hline zone on TLC & & $\mathrm{D}$ & \multicolumn{2}{|c|}{$\mathrm{E}$} & $\mathrm{F}$ & zone on TLC & & \multicolumn{2}{|c|}{ B } & $\mathrm{D}$ \\
\hline compound & $\mathrm{RT}$ [min] & & \multirow{4}{*}{$\mathrm{x}$} & \multirow{4}{*}{$\mathrm{x}$} & \multirow{4}{*}{$\mathrm{x}$} & compound & $\mathrm{RT}$ [min] & \multirow{4}{*}{\multicolumn{2}{|c|}{$\mathrm{x}$}} & \\
\hline dehydroabietic acid & 16.80 & & & & & n.i. triterpen & 25.27 & & & $\mathrm{x}$ \\
\hline resveratrol & 19.15 & $\mathrm{x}$ & & & & n.i. triterpen & 26.98 & & & $\mathrm{x}$ \\
\hline & & & & & & n.i. triterpen & 27.21 & & & $\mathrm{x}$ \\
\hline
\end{tabular}

Some more compounds, already isolated from the heartwood of Shorea spp., such as the tanninrelated compounds like gallic acid, flavogallonic acid dilactone, valoneic acid dilactone, ellagic acid and catechin (Schwager and Lange 1998; Hirano et al. 2003) were not detected on the TLC. One reason might be the relatively low concentration of some compounds on the TLC, which could therefore not be isolated properly. To address the concentration problems that do not allow correct identification of probably bioactive compounds, further preparative chromatography methods could provide higher amounts of the pure compounds, which would allow for additional analysis methods, such as nuclear magnetic resonance (NMR).

Compounds detected in the inhibition zones of Mezilaurus itauba. Like many Lauraceae species, M. itauba contains a portfolio of alkaloids (Gottlieb 1972). Already identified alkaloids from Mezilaurus synandra are coclaurine and corytuberine as well as some lactones (Silva et al. 1983) and neolignans from M. itauba (Yanez et al. 1988).

Tab. 4: Compounds detected on the TLC from Intsia spp. extracts that were developed similar to the bioassay plates (Wanschura et al. 2020).

\begin{tabular}{|c|c|c|c|c|c|c|c|c|c|c|c|}
\hline tested extract & & $\mathrm{m}$ & $\mathrm{a}$ & $\mathrm{m}$ & $\mathrm{a}$ & $\mathrm{m}$ & & & \begin{tabular}{l|l}
$\mathrm{a}$ & $\mathrm{m}$ \\
\end{tabular} & \begin{tabular}{l|l}
$\mathrm{a}$ & $\mathrm{m}$ \\
\end{tabular} & $\mathrm{m}$ \\
\hline zone on TLC & & $\mathrm{E}$ & $\mathrm{F}$ & & $\mathrm{G}$ & $\mathrm{K}$ & zone on TLC & & $\mathrm{F}$ & $\mathrm{G}$ & $\mathrm{K}$ \\
\hline compound & $\mathrm{RT}$ [min] & & & & & & compound & RT [min] & & & \\
\hline bicuculline & 18.61 & $\mathrm{x}$ & $\mathrm{x}$ & & & & boldine & 20.71 & $\mathrm{x}$ & & \\
\hline methylcoclaurine & 18.73 & & & & $\mathrm{x}$ & & boldine-isomer & 20.83 & $\mathrm{x}$ & & \\
\hline laurotetanine & 18.93 & & & $\mathrm{x}$ & & & boldine-derivate & 20.99 & & $\mathrm{x}$ & \\
\hline n.i. alkaloid & 19.22 & & & & $\mathrm{x}$ & & boldine-isomer & 21.22 & & $\mathrm{x}$ & $\mathrm{x}$ \\
\hline coclaurine & 19.30 & $\mathrm{x}$ & $\mathrm{x}$ & & $\mathrm{x}$ & $\mathrm{x}$ & n.i. triterpen & 21.50 & $\mathrm{x}$ & & \\
\hline reticuline & 19.40 & & & & $\mathrm{x}$ & & n.i. triterpen & 21.53 & & & $\mathrm{x}$ \\
\hline norbicuculline & 19.48 & $\mathrm{x}$ & $\mathrm{x}$ & & $\mathrm{x}$ & & n.i. alkaloid & 22.49 & & $\mathrm{x}$ & \\
\hline n.i. alkaloid & 19.58 & & & & & $\mathrm{x}$ & n.i. alkaloid & 22.63 & $\mathrm{x}$ & & $\mathrm{x}$ \\
\hline n.i. alkaloid & 19.63 & & & & $\mathrm{x}$ & & isoboldine & 22.66 & & $\mathrm{x}$ & \\
\hline n.i. alkaloid & 20.14 & & & & & $\mathrm{x}$ & n.i. triterpen & 24.84 & & $\mathrm{x}$ & \\
\hline
\end{tabular}

While the benzyltetraisochinoline coclaurine $\left(R_{t} 19.30\right)$ was present in all bioactive zones $(\mathrm{E}, \mathrm{F}$, $\mathrm{G}, \mathrm{K}$ ), reticuline ( $\mathrm{R}_{\mathrm{t}}$ 19.40) and methylcoclaurine ( $\mathrm{R}_{\mathrm{t}} 18.73$ ) could only be detected in zone $\mathrm{G}$. With the exception of zone E, all zones contained aporphines like boldine ( $\left.\mathrm{R}_{\mathrm{t}} 20.71\right)$ or one of its isomers isoboldine and corytuberine ( $\left.R_{t} 20.83, R_{t} 21.22\right)$. Furthermore, its derivates laurotetanine 
( $\mathrm{R}_{\mathrm{t}}$ 18.93) and methyllaurotetanine or its isomer isocorydine ( $\left.\mathrm{R}_{\mathrm{t}} 20.99\right)$ could be identified (Wanschura et al. 2020). Benzyltetraisochinolines as well as aporphines belong to the most frequently detected alkaloids in the family Lauraceae (Custódio and da Veiga Junior 2014).

In the zones E, F and K, two compounds were detected, which have not been described in Mezilaurus species yet: norbicuculline and bicuculline (Fig.6), of which the latter is known as a GABA ( 4-aminobutanoic acid) receptor antagonist (Starke 2013), the chief inhibitory neurotransmitter in the central nervous system (Watanabe et al. 2002). Furthermore, a triterpene was found in zone $\mathrm{G}\left(\mathrm{R}_{\mathrm{t}}=24.84\right)$. As the results show, a part of the natural durability of the tested tropical wood species can certainly be attributed to the detected substances causing the inhibition zones on the TLC plates. Because this inhibition is also dependent on the substance concentrations, the minimal inhibitory concentrations should be determined in a next step. Furthermore, these concentrations must then be related to the concentrations that prevail in the wood. Some of the compounds may meet the requirements in potency and concentration to play an outstanding role for natural durability. Nevertheless, consideration should be given to the entire extractive mixture of the wood species. Some of them play a role as an elicitor, regulator or water repellent and may have important influence on the natural durability (Wanschura et al. 2020).

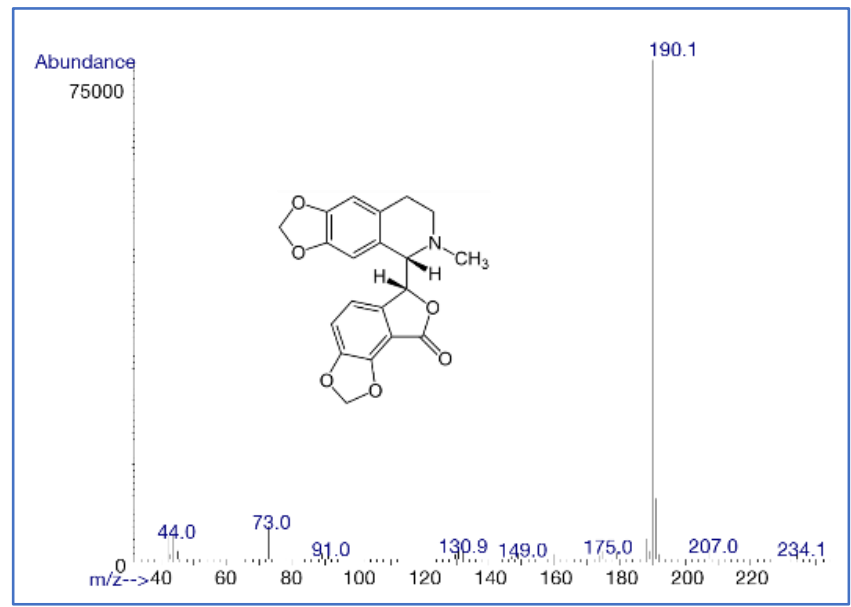

Fig. 6: Fragment pattern of bicuculline at $R_{\mathbf{t}} \mathbf{1 8 . 6 1}$ from Zone E (Mezillaurus itaúba)

\section{Summary and Conclusions}

The combination of the bioautographic agar overlay method and the hyphae agar method was found to provide a possibility to benefit from the advantages of a direct bioautography (rapid, easy to implement), while testing wood extractives against commonly used basidiomycetes, which are not readily sporulating. It provides a possibility to examine the direct fungicidal activity and was successfully implemented for basidiomycete fungi using $R$. placenta and $T$. versicolor, which recovered rapidly from the treatment. The added vital stain contributed to the visible assignment of the inhibition zones, containing antifungal agents in a rapid and clear way. The chemically complex mixtures of semipolar and polar tropical wood extracts from A. graveolens, Intsia spp., $S$. laevis and $M$. itauba were resolved by 2D-TLC and analyzed by GC/ MS. In most of the bioactive zones, major substance classes including several known fungicidal compounds could be identified. It was shown that the method represents a straightforward analysis tool to test extracts 
from wood for bioactive substances even in complex mixtures. The hyphae-agar bioassay provides a more rapid method for the investigation of bioactive wood extracts, enabling isolation and identification of possible key substances. This might accelerate the elucidation of potential structures, for example for biocidal, pharmaceutical or chemical uses. Furthermore, the isoquinoline alkaloids bicuculline and norbicuculline were detected, which have not been described in $M$. itauba yet.

\section{Acknowledgments}

The authors would like to thank Mathias Baumgartner, Claudia U. Lindner, Valerija Erceg, Selina Götz and Martina Schwarzmüller for their valuable contribution by performing parts of the analysis.

\section{References}

Bisset, N.G., Wolff, R.E., Chavanel, V., Lantz, J.P. (1971) Constitutants Sesquiterpenique et Triterpeniques des resins du genre Shorea. Phytochemistry 10:2451-2463.

Brito Pereira Bezerra Martins, A.O., Albuquerque Siebra, A.L., de Morais Oliveira, C.D., Leite, G.O., Melo Coutinho, H.D., Athayde, M.L., Bolignon, A.A., Andrade, J.C., Oliveira, L.R., Kerntopf, M.R., Barbose, R., Alves Santana Cesário, F.R., Coutinho, T.S., Quintans-Júnior, L.J., Alencar de Menezes, I.R. (2018) Antimicrobial gastroprotective and healing effect of the hydroalcoholic extract of Astronium fraxinifolium. Lett. Drug Des. Discov. 15:325-334.

Croan, S.C., Highley, T.L. (1991) Conditions for carpogenesis and basidiosporogenesis by brown rot fungi basidiomycete Gloeophyllum trabeum. Mater. Org. 27:1-9.

Custódio, D.L., da Veiga Junior, V.F. (2014) Lauraceae alkaloids. RSC Adv. 4:21864-21890.

Da Silva, V.C., Napolitano, A., Eletto, D., Rodrigues, C.M., Pizza, C., Vilegas, W. (2011) Characterization of gallotannins from Astronium species by flow injection analysis-electrospray ionizationion trap-tandem mass spectrometry and matrix assisted laser desorption/ionization time-of-flight mass spectrometry. Eur. J Mass Spectrom. $17: 365-375$.

Deklerck, V., De Windt, I., Defoirdt, N., Van den Bulcke, J., Beeckman, H., Espinoza, E., Van Acker, J. (2017) Assessing the natural durability for different tropical timber species using the miniblock test. Proceedings IRG Annual Meeting. Ghent, Belgium. Document No. IRG/WP 17-10886.

Deutsches Institut für Normung e.V. (1994) EN 350-1: Natürliche Dauerhaftigkeit von Vollholz. Teil 1: Grundsätze für die Prüfung und Klassifikation der natürlichen Dauerhaftigkeit von Holz. Berlin, Beuth 1994-10.

Deutsches Institut für Normung e.V. (1996) EN 113: Prüfverfahren zur Bestimmung der vorbeugenden Wirksamkeit gegen holzzerstörende Basidiomyceten. Bestimmung der Grenze der Wirksamkeit. Berlin, Beuth 1996-11.

Dewanjee, S., Gangopadhyay, M., Bhattacharya, N., Khanra, R., Dua,T.K. (2015) Bioautography and its scope in the field of natural product chemistry. Pharm. Biomed. Anal. 5:75-84.

Etxeberria, A., Mendarte, S., Larregla, S. (2011) Determination of viability of Phytophthora capsici oospores with the tetrazolium bromide staining test versus a plasmolysis method. Rev. Iberoam. Micol. 28:43-49.

Favre-Godal, Q, Queiroz, E.F., Wolfender, J.L. (2013) Latest developments in assessing antifungal activity using TLC-bioautography: a review. J. AOAC Int. 96:1175-1188. 


\section{Proceedings of the 2020 Society of Wood Science and Technology International Convention}

Freimoser, F.M., Jakob, C.A., Aebi, M., Tuor, U. (1999) The MTT [3-(4,5-dimethylthiazol-2-yl)-2,5diphenyltetrazolium bromide] assay is a fast and reliable method for colorimetric determination of fungal cell densities. Appl. Environ. Microbiol. 65:3727-3729.

Gottlieb, O.R. (1972) Review article: Chemosystenmatics of the Lauraceae. Phytochemistry 11:1537-1570.

Hadi, S. (2009) The isolation of hopeaphenol, a tetramer stilbene, from Shorea ovalis Blume. Adv. Nat. Appl. Sci. 3:107-113.

Helfenstein, A., Vahermo, M., Nawrot, D., Demirci, F., Iscan, G., Krogerus, S., Yli-Kauhaluoma, J., Moreira, V.M., Tammela, P. (2017) Antibacterial profiling of abietane-type diterpenoids. Bioorg. Med. Chem. 25:132-137.

Hidore, M.R., Nabavi, N., Sonleitner, F., Murphy, J.W. (1991) Murine natural killer cells are fungicidal to Cryptococcus neoformans. Infect. Immun. 59:1747-1754.

Hillis, W.E., Yazaki, Y. (1973) Polyphenols of Intsia heartwoods. Phytochemistry 12:2491-2495.

Hirano, Y., Kondo, R., Sakai, K. (2003) Novel stilbenoids isolated from the heartwood of Shorea laeviforia. J. Wood. Sci. 49:339-343.

Imai, T., Inoue, S., Matsushita, N.O.Y., Suzuki, R., Sakurai, M., de Jesus, J.M.H., Finger, S.K.O.Z., Fukushima, K. (2008) Heartwood extractives from the Amazonian trees Dipteryx odorata, Hymenaea courbaril, and Astronium lecointei and their antioxidant activities. J. Wood Sci. 54:470-475.

Kawamura, F., Ohara, S., Nishida, A. (2004) Antifungal activity of constituents from the heartwood of Gmelina arborea: part 1. Sensitive antifungal assay against Basidiomycetes. Holzforschung 58:189-192.

Kilic, A., Niemz, P. (2012) Extractives in some tropical woods. Eur. J. Wood Wood Prod. 70:79-83.

Kirker, G.T., Blodgett, A.B., Arango, R.A., Lebow, P.K., Clausen, C.A. (2013) The role of extractives in naturally durable wood species. Int. Biodeterior. Biodegradation. 82:53-58.

Meshulam, T., Levitz, S.M., Christin, L., Diamond, R.D. (1995) A simplified new assay for assessment of fungal cell damage with the tetrazolium dye, (2,3)-bis-(2-methoxy-4-nitro- 5-sulphenyl)-2H)-tetrazolium-5-carboxanilide (XTT). J. Infect. Dis. 172:1153-1156.

Mosmann, T. (1983) Rapid colorimetric assay for cellular growth and survival: application to proliferation and cytotoxicity assays. J. Immunol. Methods 65:55-63.

Osmonova, N. (2011) Screening of antimicrobial effects of selected fungi and studies on antibiotic constituents of Bulgaria inquinans (Pers.) Fr. (Bulgariaceae) and Meripilus giganteus (Pers.:Fr.)P.Karst. (Meripilaceae). Dissertation. University of Hamburg.

Patel, N., Oudemans, P.V., Hillman, B., Kobayashi, D.Y. (2013) Use of the tetrazolium salt MTT to measure cell viability effects of the bacterial antagonist Lysobacter enzymogenes on the filamentous fungus Cryphonectria parasitica. Antonie van Leeuwenhoek 103:1271-1280.

Råberg, U., Edlund, M.L., Terziev, N., Land, C.J. (2005) Testing and evaluation of natural durability of wood in above ground conditions in Europe - an overview. J. Wood Sci. 51:429-440.

Rahalison, L.M., Hamburger, M., Hostettmann, K. (1991) A bioautographic agar overlay method for the detection of antifungal compounds from higher plants. Phytochem. Anal. 2:199-203.

Rennerfelt, E. (1948) Thujaplicin, a fungicidal substance in the heartwood of Thujja plicata. Physiol. Plant. 1:245254. 


\section{Proceedings of the 2020 Society of Wood Science and Technology International Convention}

Rutiaga-Quinones, J.G. (2001) Chemische und biologische Untersuchungen zum Verhalten dauerhafter Holzarten und ihrer Extrakte gegenüber holzabbauenden Pilzen. Dissertation. Technische Universität München.

Schultz, T.P., Nicholas, D.D. (2000) Naturally durable heartwood: evidence for a proposed dual defensive function of the extractives. Phytochemistry 54:47-52.

Schwager und Lange (1998) Biologischer Holzschutz. Literaturstudie über akzessorische Bestandteile dauerhafter Holzarten mit resistenzwirksamer Aktivität. Münster. Landwirschaftsverlag. Schriftenreihe Nachwachsende Rohstoffe.

Silva, R., Nagheim, T.J., Mesquita, A.A.L., Gottlieb, O. (1983) y-Lactones from Mezillaurus synandra. Phytochemistry 22:772-773.

Singh, T., Sing, A.P. (2012) A review on natural products as wood protectant. Wood Sci. Technol. 46:851-870.

Smeds, A.I., Eklund, P.C., Monogioudi, E., Willför, S.M. (2012) Chemical characterization of polymerized products formed in the reactions of matairesinol and pinoresinol with the stable radical 2,2,diphenyl-1-picrylhydrazyl. Holzforschung 66:283-294.

Starke, K. (2013) Grundlagen der Pharmakologie des Nervensystems. In: Allgemeine und spezielle Pharmakologie und Toxikologie. 11. Auflage. Hrsg. Aktories, K., Förstermann, U., Hofmann F und Starke, K. München, Elsevier GmbH. pp. 115-116.

Stirling, R., Kus, S., Uzunovic, A. (2016) Inhibition of basidiospores germination by western red cedar heartwood extractives. Int. Biodeterior. Biodegradation. 114:145-149.

Stockert, J.C., Horobin, R.W., Colombo, L.L., and Blázquez-Castro, A. (2018) Tetrazolium salts and formazan products in cell biology: viability assessment, fluorescence imaging, and labeling perspectives. Acta Histochem. 120:159-167.

Wagenführ, R., Scheiber, C. (1974) Holzatlas, 3.Auflage. VEB Fachbuchverlag Leibzig, Germany 1989:311-315.

Wanschura, R., Windeisen, E., Richter, K. (2016) Screening of bioactive extracts of a tropical hardwood species and identification of key substances. Proceedings of the 14th EWLP and IUFRO scientific workshop on Biorefinery, Autrans.

Wanschura, R., Windeisen, E., Richter, K. (2017) Establishing a screening method for bioactive extractives of wood species against basidiomycetes. IUFRO Division 5 Conference and 60th SWST Convention Proceedings, Vancouver.

Wanschura, R., Baumgartner, M., Linder, C.U., Windeisen, E., Benz, J.P., Richter, K. (2020) Direct bioautography for the screening of selected tropical wood extracts against basidiomycetes. Holzforschung, published online, https://doi.org/10.1515/hf-2019-0153.

Wanschura R (2020) Isolation, Separation and Bioactivity of Wood Extracts. Submitted for dissertation. Technical University of Munich

Watanabe, M., Maemura, K., Kanbara, K., Tamayama, T., Hayasaki, H. (2002) GABA and GABA receptors in the central nervous system and other organs. Int. Rev. Cytol. 213:1-47.

Wedge, D., Nagle, D.G. (2000) A New 2D-TLC Bioautography method for the discovery of novel antifungal agents to control plant patogens. J. Nat. Prod. 63:1050-1054.

Willför, S., Hemming, J., Reunanen, M., Holmbom, B. (2003) Phenolic and lipophilic extractives in Scots pine knots and stemwood. Holzforschung 57:359-372. 
Proceedings of the 2020 Society of Wood Science and Technology International Convention

Willför, S., Eklund, P., Sjöholm, R., Reunanaen, M., Sillanpää, R., von Schoultz, S., Hemming, J., Nisula, L., Holmbom, B. (2005) Bioactive phenolic substances in industrially important tree species. Part 4: identification of two new 7-hydroxy divanillyl butyrolactol lignans in some spruce, fir, and pine species. Holzforschung 59: 413-417.

Yanez, Y., Aura, M.P., Pedro, P., Duz, D. (1988) Neolignans from Mezillaurus itaúba. Phytochemistry 25:1953-1956.

Yang, D.Q. (2009) Potential utilization of plant and fungal extracts for wood protection. Forest Prod. J. 59:97-103.

Biography 


\title{
Wednesday, July 15
}

\author{
Wood in Health and Well Being \\ Chairs: \\ Mike Burnard, InnoRenew CoE \& University of Primorska, Slovenia \\ Eva Haviarova, Purdue University, USA
}

\section{Building Wooden Hives for the Wellbeing of Honeybees}

\author{
Anna Dupleix 1 \\ anna.dupleix@umontpellier.fr \\ Delphine Jullien 1 \\ delphine.jullien@umontpellier.fr \\ Emmanuel Ruffio2 \\ emmanuel.ruffio@gmail.com \\ Bertrand Schatzz \\ bertrand.schatz@cefe.cnrs.fr \\ Pascale Moity-Maizi4 \\ pascale.maizi@supagro.fr \\ 1 LMGC, Univ. Montpellier, CNRS, Montpellier, France \\ 2 TREFLE, I2M, France \\ 3 CEFE, France \\ 4GRED, France
}

\section{Abstract}

Life sciences have proven that the honey bee (Apis mellifera) is an animal species presently threatened by human activity. The human-bee relationship involves a third part, the beehive, which concentrates local traditional knowledge, conditions beekeeping practices and defines the living environment closest to the bees. Historically, the first hives were shaped during the Middle Ages in Western Europe from a variety of locally available materials (wood of different species, trunks, cork bark, straw, basketry, ceramics and stones) in the form of small cavities to imitate the "ideal nest" found by wild colonies in the wild: crevices in cliffs, walls, hollow tree trunks. This diversity was gradually reduced during the $19_{\text {th }}$ century with the invention of mobile frames, which allowed a tenfold increase in honey production. To meet the constraints of human exploitation, the hive was then designed after the Second World War in rectangular shape with wooden planks of light and inexpensive species (e.g. maritime pine) that were summarily assembled (nailed), but not manufactured according to a know-how integrating wood species chosen for their quality or to meet the needs of the bees.

However, recent discoveries in anthropology reveal a category of beekeepers ("beekeepermanufacturers") who design hive models on their farms that imitate living things. At the source of their innovative approach lies the observation that "the box hive is unsuited to the biology and ecology of bees". Already denounced from the end of the 19th century, this statement was relayed by ethnoecological surveys which revealed a better vitality of colonies reared in chestnut trunk hives.

The research work presented here questions the direct (chemical action) and indirect (facilitated hygrothermal regulation) properties and mechanisms that are brought into play by wood material when it 
Proceedings of the $\mathbf{2 0 2 0}$ Society of Wood Science and Technology International Convention

is used to build hive and which make it possible to promote the well-being and biological development of the bees living in. The first results show that: (i) the volatile chemical substances of chestnut wood have a repellent effect on Varroa destructor (parasitic bee mite), (ii) wood hygroscopicity and thermal properties quantitatively regulates the temperature and humidity, facilitating the regulating activity of the bees on the in-hive climate.

Biography 


\title{
Proceedings of the 2020 Society of Wood Science and Technology International Convention
}

\section{Human physiological responses during tactile and visual contact with densified and laminated wood}

\author{
Dean Lipovac \\ dean.lipovac@innorenew.eu \\ Jure Zitnik \\ jure.zitnik@innorenew.eu \\ Michael Burnard \\ mike.burnard@innorenew.eu
}

InnoRenew CoE \& University of Primorska, Slovenia

\begin{abstract}
Tactile and visual contact with different materials can lead to diverse physiological responses in people. It has been shown that touching untreated solid wood is associated with decreased physiological arousal, when compared to other common materials (i.e., marble, tile, and stainless steel) (Ikei et al 2017b). These results indicate that people tend to be in a more relaxed state during contact with wood. Recently, wood modification has gained interest due to its improved properties (Sandberg et al 2017). Compression is a modification method that creates a densified material with altered properties, including surface properties. Differences in surface properties can influence human physiological response to wood. For example, lower physiological arousal was observed after tactile contact with untreated wood than after coated wood (Ikei et al 2017a). However, we are not aware of any existing study that investigated physiological responses to laminated and densified wood in comparison to untreated solid wood.

Our objective was to compare human physiological responses to wooden materials with different surface characteristics. We prepared six samples approximately $30 \mathrm{~cm} \times 20 \mathrm{~cm}$ in size. Three of those were made of solid poplar wood, and were either untreated, densified, or resin-impregnated and densified. The other two wooden samples were made of particleboard that was either veneered with poplar or laminated with a wood imitation covering. Finally, we included a sample made of mineral filled thermoplastic composite (Kerrock $\left.{ }^{\circledR}\right)$, to serve as a reference material.

We conducted a pilot study where 20 participants sat on a chair with their dominant hand resting on one of the materials, while their heart rate, heart rate variability, blood pressure, and electrodermal activity were measured. Each participant spent five minutes with their hand touching each material and was tested at all six materials in a single session, with one-minute breaks between the materials. Afterwards, the participants rated their tactile and visual preference of the presented materials on a Likert-type scale. Finally, they ranked the presented materials from most to least preferred for everyday use as a desk top material.

The presented results will show how modified and laminated wood samples compare against untreated wood and mineral filled thermoplastic composite in terms of human physiological responses. In
\end{abstract}


Proceedings of the 2020 Society of Wood Science and Technology International Convention

addition, we will present associations between preference ratings and rankings with physiological data.

\section{References}

Ikei H, Song C, Miyazaki Y (2017a) Physiological effects of touching coated wood. Int J Env Res Pub He 14(7):773.

Ikei H, Song C, Miyazaki Y (2017b) Physiological effects of touching wood. Int J Env Res Pub He 14(7):801.

Sandberg D, Kutnar A, Mantanis G (2017) Wood modification technologies - A review. Iforest 10:895908.

Biography 


\title{
Proceedings of the 2020 Society of Wood Science and Technology International Convention
}

\section{Preparation of Kenaf based nanobiocomposite as sustainable adsorbent for the removal of organic and inorganic and pathogenic contaminants}

\author{
Sujata Mandal \\ sujatamandal@my.unt.edu \\ Sheldon Shi \\ sheldon.shi@unt.edu \\ Sreekar Marpu \\ sreekarbabu.marpu@unt.edu \\ University of North Texas, USA
}

\begin{abstract}
Water contamination due to rapid industrialization and increased population by multiple pollutants ranging from pathogens, organic and inorganic chemicals impose a major threat to human health and the environment. This study focuses on the potential use of nanotechnology to reduce cost and improve efficiency in pollution control and water treatment. Kenaf promises ecofriendly diverse pollutant remediation and in this research, kenaf based activated carbon will be first prepared by the self - activation process. The activated carbon will be then used as a bio adsorbent for the removal of congo red ( $\mathrm{CR}$ ), an anionic dye and divalent metal lead (Pb) from aqueous solution. The bio adsorbent will be impregnated with nanosilver and antibacterial efficacy will also be explored. Adsorption study of lead will be carried out and quantified using atomic absorption spectroscopy (AAS). Surface morphology of the activated carbon before and after adsorption of lead and congo red to be investigated using a scanning electron microscope (SEM). Experimental equilibrium data will be fitted to Langmuir and Freundlich adsorption isotherm and values of the parameters of the isotherm will be reported. The optical and chemical properties of nanocomposite will be characterized extensively using UV Vis and Fourier Transform Infrared (FTIR) Spectroscopy. Effect of contact time, pH and initial pollutant concentration on adsorption will also be investigated.
\end{abstract}

Keywords: human health, contamination, pathogens, toxic metal, congo red, nanocomposite

\section{Biography}




\title{
Proceedings of the 2020 Society of Wood Science and Technology International Convention
}

\section{Wood as a Building Material Affects the Indoor Environment Quality (IEQ) and Well-being of Occupants}

\author{
Riina Muilu-Mäkelä1 \\ riina.muilu-makela@luke.fi \\ Ann Ojala 1 \\ ann.ojala@luke.fi \\ Martin Ohlmeyer2 \\ martin.ohlmeyer@thuenen.de \\ Tytti Sarjala 1 \\ tytti.sarjala@luke.fi
}

\section{Natural Resources Institute Finland 2 Thunen Institute Germany}

\begin{abstract}
Wood as a building material has good acoustic, hygroscopic and antibacterial properties that affect the quality of indoor environments. The odour of wood is typically well accepted, positively evaluated, and wood reflects warm wavelengths, which also creates a pleasant atmosphere. These multisensory perceptions potentially mean that wood has positive effects on mood. Accordingly, in previous studies, wood has been shown to affect the activity of the human autonomic nervous system and to relieve stress. Especially after working, people have been shown to have more positive feelings in wooden than in non-wooden environments. However, more investigations are needed to enhance the effects of materials, especially wood on human well-being, which has an economic value too.

As a hygroscopic material, wood absorbs and releases moisture and stabilizes room humidity. Primarily, wood and wood-based panels emit volatile extractives (primary emissions) that affect the odour of indoor space. In the present study the effect of the wooden materials, like wooden floor, wall panels and furniture's on indoor environment quality (IEQ) was evaluated in two different working environments. The fluctuation of the room humidity and temperature were continuously measured and VOC contents and acoustics of the environments analysed. Furthermore, the IEQ parameters were linked with the psychological analyses from experiences that occupants had in the particular test environments.

Moreover, VOC profiles vary, depending on the wood species and process conditions. Thus, in the present study soft wood specific volatile terpenes were measured from Norway spruce and Scots pine blocks and the effects of time and moisture level on evaporated terpene contents were analysed. Health effective properties of main terpenes were tested in an eye epithelium cell model system and by antioxidativity tests. Commercially important soft wood species Pine wood was used in interior of the working environment and as such the role of terpenes in IEQ was specifically evaluated.

The results indicated that some individual terpenes can be harmful in very high contents, but such an amount of terpenes is hardly evaporated from the wood constructions. Instead, some antioxdative effects were detected, indicating that some terpenes have protective effects against free radicals that are released in cells especially under stress. The highest and lowest peaks in moisture contents measured from the test environments were cut down faster in the room with wood than in the room
\end{abstract}


Proceedings of the 2020 Society of Wood Science and Technology International Convention

with synthetic materials. Volatile terpenes gave a specific odour to the wooden room which was easily recognised by the occupants. The fragrant was well-liked.

The present study is part of the ongoing research project (Wood for Good, W4G) where the aim is to evaluate the role of wood on human well-being by psychological and physiological analyses. During a test series modelling multitasking computer work stress the effect of indoor wood material on physiological stress levels and on attentional functioning are investigated. The beneficial effects of wood for individual health and a healthier society will be formed into economical values and taken into consideration in designing, consuming and decision-making.

\section{Biography}




\title{
Proceedings of the 2020 Society of Wood Science and Technology International Convention
}

\section{Demonstration of REED- Restorative Environmental and Ergonomic Design principles on InnoRenew CoE building architecture}

\author{
Aarne Niemelä 1 \\ aarne.niemela@innorenew.eu \\ Eva Prelovšek Niemelä1 \\ eva.prelovsek@innorenew.eu \\ Michael Burnard2 \\ mike.burnard@innorenew.eu \\ 1InnoRenew CoE, Slovenia \\ 2InnoRenew CoE and University of Primorska, Slovenia
}

\section{Abstract}

Restorative Environmental and Ergonomic Design (REED) is a building design paradigm that can provide guidance for architectural design focused on multiple aspects of sustainability: environmental, social, individual wellbeing, and economic. Individual wellbeing is enhanced through the restorative capacity of the building and ergonomic interventions to support safety and activity. One of the key elements of restorative living and working environments is wood as a basic design element. Restoration is increasing in importance, since urban lifestyle is increasingly concentrated indoors; we spend up to $90 \%$ of our time indoors. While clinical practice focuses on treating illness, newest research suggests that, the indoor environmental quality has an important role to play in sustaining human wellbeing. Studies have demonstrated that wooden surfaces in human spaces have a calming effect, helping to reduce stress. Wood may indirectly help to improve occupant health through by improving air quality, visual comfort, olfactory aspects of the environment, and through the connection to nature it triggers in occupants.

To demonstrate and further refine the REED paradigm, we designed a mass timber building that is currently under construction in town of Izola, Slovenia. The building $(8,200 \mathrm{~m} 2)$ consists of office, meeting space, and laboratory facilities. The principles of using natural materials, particularly massive wood, natural light, quality of air, heating and ventilation, acoustic elements, open spaces of social interaction and physical movement, views through the building interior zones and to outdoors, outdoor areas with particular microclimatic zones, green roofs, terraces and park design are demonstrated in the InnoRenew CoE building's complex design. Users are motivated to use sustainable and healthy means of transportation through urban design of the building complex and its environment. This represents a shift in building design (and urban neighbourhood/community design) from minimizing environmental harm towards creating positive impacts for the natural environment, building users, and society in general. The presentation will include an overview of the REED design elements in the building and how their effect on occupants will be tested.

Keywords: sustainable architecture, mass timber buildings, restorative environment, connection to nature, wellbeing 
Proceedings of the $\mathbf{2 0 2 0}$ Society of Wood Science and Technology International Convention

Acknowledgement:

Authors gratefully acknowledge the European Commission for funding InnoRenew CoE (grant agreement \# 739574), under the H2020 Widespread-Teaming programme and Republic of Slovenia (investment funding of the Republic of Slovenia and the European Union's European Regional Development Fund).

Biography 


\title{
Biodegradation and the Impact of Forest Disturbances
}

Chairs:

Yusuf Sudo Hadi, Bogor Agricultural University (IPB), Indonesia

Francesco Negro, DISAFA, University of Torino, Italy

\section{Population distribution and structure of Afzelia species in Southwestern Nigeria}

\author{
Adejoke Akinyele 1*-Akintunde Solomon 2
}

1 Senior Lecturer, Department of Forest Production and Products, Faculty of Renewable Natural Resources, University of Ibadan, Ibadan, Oyo State, Nigeria * Corresponding author akinyelejo@yahoo.co.uk

2 Department of Forest Production and Products, Faculty of Renewable Natural Resources, University of Ibadan, Ibadan, Oyo State, Nigeria solomonakintunde@yahoo.co.uk

\begin{abstract}
Afzelia species are among the threatened multipurpose tree species in Africa because they have socio-economic importance. There are loss and fragmentation of the species due to different forms of disturbances. These species undergo increasing human pressure and are threatened because of their overexploitation or by the lack of natural regeneration by seedling, or just simply as a result of the loss of their ecological environments. Therefore, investigation was conducted to assess the population distribution and structure of Afzelia species in three forest reserves of Southwestern Nigeria namely Omo Biosphere Reserve, Gambari Forest Reserve and Akure Forest Reserve. Systematic sampling method was used with $10 \%$ sampling intensity on a straight line alternating transect line in the study areas. Adult trees $(\mathrm{dbh} \geq 10 \mathrm{~cm})$ were measured within square plots of $2500 \mathrm{~m} 2$ sizes $(50 \times 50)$ in 125 plots in the three forest reserves. Nest transects of $50 \times 0.5 \mathrm{~m} 2$ was laid within each plot for total enumeration of the species at sapling stage $(\mathrm{dbh} \geq 5<10 \mathrm{~cm})$. Another nest transects of $10 \times 10 \mathrm{~m} 2$ were established at the four corners of the $50 \times 50 \mathrm{~m}_{2}$ plots to enumerate seedlings $(\mathrm{dbh}<5 \mathrm{~cm})$. Collected data were sorted to generate diameter size classes. ANOVA was used to show differences in tree dbh and variation in the number of individual trees in each study area. Tree variables such as Blackman and Green indices, basal area, average diameter, height of Lorey and density were calculated and interpreted.

Density $(0.06)$, diameter $(0.01 \mathrm{~cm})$, basal surface area $(0.01 \mathrm{~cm})$, Lorey height $(0.07 \mathrm{~m})$ and Green index (0.03) were significant across locations. Density (0.23), stand /hectare and stand diameter $(\mathrm{cm})(0.01)$ were significant for regeneration status while basal surface area $(\mathrm{cm} 2)(0.00)$ was not significant for saplings. Seedlings had significant diameter /hectare (0.01) and basal surface area (cm2) (0.23) while stand density /hectare (0.01) was not. Akure Forest Reserve had highest Shannon index (1.54), Simpson index (0.82), and Shannon Maximum diversity index (2.89) while
\end{abstract}




\section{Proceedings of the 2020 Society of Wood Science and Technology International Convention}

Gambari Forest Reserve had the least (0.80 and 0.45, respectively). However, Gambari Forest Reserve had the highest value for species evenness (0.28).

The high diversity in Afzelia population observed in Akure Forest Reserve could be as a result of low disturbance of the reserve since its management under the Forestry Research Institute of Nigeria (FRIN) offer more security against illegal activities.

Key words: Population distribution, Population structure, Afzelia species, Southwestern Nigeria

\section{Introduction}

Afzelia species are one of the highly demanded multipurpose tree species in Africa that are under threat due to its importance as a socio-economic tree species (Traoré et al., 2011). It is highly valuable for fodder and medicine (Nacoulma et al., 2011) as the leaves are fed to animals during the dry season and the barks used for the treatment of some human diseases (Arbonnier, 2002; Assogbadjo et al., 2010). Afzelia species rejuvenation has been adversely affected by human disturbances and environment pejoration (Ouédraogo and Thiombiano, 2012). The greatest threats to plant diversity include the loss and fragmentation of tropical forests (du Toit et al., 2004) and the tropical rainforests are especially vulnerable to deforestation and degradation (Lafrankie et al., 2006). In Nigeria, population growth and high demand on land have led to excessive logging and overexploitation and most forest reserves have been converted to farmland of arable and cash crops or other land uses. Due to the lucrative nature of timber trade, unceasing lumber harvesting in both the restricted woodland and the unrestricted areas has been instigated. According to Adekunle $e t$ al. (2010), 111,377 lumber stem, from 62 different aboriginal hardwood species of humid tropical forest, from 16 families, were exploited from Ondo State woodland bionetwork between 2003 and 2005. Despite the importance of Afzelia species to the rural population, the information on Afzelia species and scientific data on its ecological distribution, regeneration potential, and its conservation are scarce.

According to Olajuyigbe et al. (2013), although all tree species in every region are threatened due to climate change, some are more vulnerable than others. The strong anthropogenic weight as a result of slash-and-burn practiced by about $70 \%$ of the agrarian inhabitants of Nigeria and uncultivated (FAO, 2003) phases progressively disturb the population structure of Afzelia species. This is further compounded by the fact that the species occurs in natural stands, with no planning or reinforcement study, therefore, the structure, regeneration, and the possible danger of the loss of the species in Nigeria are still less considered (Bonou et al., 2009).

Therefore, this study assessed the population distribution and structure of Afzelia species in three forest reserves in Southwestern Nigeria. 


\section{Materials \& Methods}

\section{Study Area}

The study was conducted in Omo biosphere reserve, Ogun state, Gambari Forest reserve, Ibadan, Oyo State and Akure forest reserve, Ondo State (Figure 1).

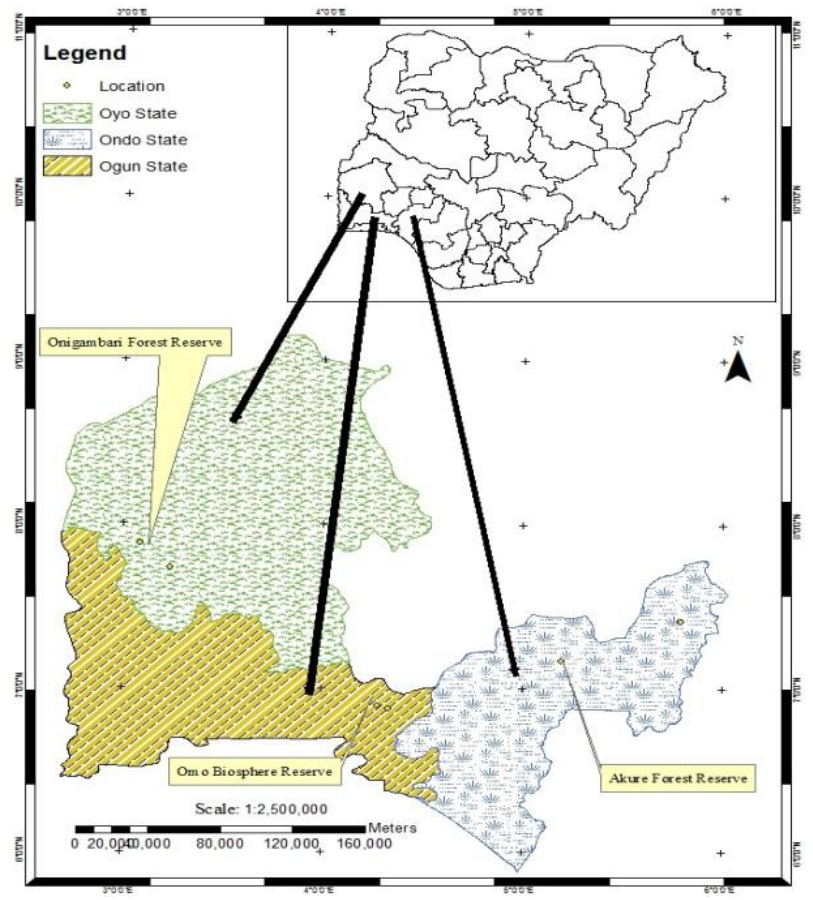

Figure 1: Map of Nigeria showing the locations of the study

\section{Omo Biosphere Reserve (OBR)}

Omo Biosphere Reserve is locally called Igbo iyalode by the rural dwellers in Omo forest reserve, Ogun state. The biosphere lies approximately between latitude $6^{\circ} 55^{\prime} 12^{\prime \prime}$ to $7^{\circ} 10^{\prime} 12^{\prime \prime} \mathrm{N}$ and longitude $4^{\circ} 13^{\prime} 12^{\prime \prime}$ to $4^{\circ} 24^{\prime} 0^{\prime \prime} \mathrm{E}$ in the high forest zone of southwestern Nigeria. Omo Biosphere Reserve has 460 ha core area and 14,200 ha buffer zone and was constituted a Strict Nature Reserve in 1949 and Biosphere Reserve in 1977 (Onyekwelu et al., 2008). The climate of the area is humid tropical and it exhibits two distinct seasons: rainy and dry seasons as obtained in the rainforest ecological zone of Nigeria. The wet (rainy) season commences in March and ends in November while dry season extends from December to February. Annual rainfall is from 1700 to $2200 \mathrm{~mm}$ while annual temperature and average daily relative humidity are $26^{\circ} \mathrm{C}$ and $80 \%$, respectively. Rainfall distribution in Omo Biosphere Reserve is bi-modal with a marked decline in August and the peaks in July and September. According to Onyekwelu et al. (2008), the average elevation is 
about 123 meters. Nwachokor and Uzu (2008) reported the soils as being predominantly ferruginous tropical, which is the typical variety found in intensively weathered areas of basement complex formations in the rainforest zone of southwestern Nigeria. The upper parts of the soil layer are well-drained, mature, red, stony, and gravely (Onyekwelu et al., 2008).

\section{Gambari Forest Reserve}

Gambari Forest Reserve is located on latitude $7^{\circ} 25^{\prime}$ and $7^{\circ} 55^{\prime} \mathrm{N}$ and longitude $3^{\circ} 53^{\prime}$ and $3^{\circ} 9^{\prime} \mathrm{E}$ in the low land semi-deciduous forest belt of Nigeria. The total land area of the reserve is $17,984 \mathrm{ha}$ which is divided into two- natural and plantation forests. The natural forest consists of indigenous species such as Terminalia spp, Triplochiton scleroxylon, Irvingia garbonensis, Treculia africana, among others, while exotic species such as Gmelina arborea and Tectona grandis made up the plantation forest. The topography of Gambari Forest Reserve is generally undulating, with an altitude between $90 \mathrm{~m}$ and $140 \mathrm{~m}$ above sea level. The annual rainfall is between $1200 \mathrm{~mm}$ to $1300 \mathrm{~mm}$, and it extends from March to November. The dry season is severe with low relative humidity and an average annual temperature of $26.4^{\circ} \mathrm{C}$ (Larinde and Olasupo, 2011).

\section{Akure Forest Reserve}

The Strict Nature Reserve (SNR) within Akure Forest Reserve, Ondo State, Nigeria was used for the study. It was carved out and designated as a Strict Nature Reserve in 1954 by the Forestry Research Institute of Nigeria (FRIN). It covers an area of $69.93 \mathrm{~km} 2$ and is situated on latitude $5^{\circ} 45^{\prime}$ and $8^{\circ} 15^{\prime} \mathrm{N}$ and longitude $4^{\circ} 30^{\prime}$ and $6^{\circ} \mathrm{E}$. The area has a humid sub-tropical climate, indicating that it is within the tropical rainforest ecological zone which is dominated by broadleaved hardwood trees that form dense, layered stands. The mean annual temperature is between $19^{\circ} \mathrm{C}$ and $34^{\circ} \mathrm{C}$ while the monthly mean temperature is about $27^{\circ} \mathrm{C}$, making it conducive to the growth and development of tropical rain forest (Adeduntan, 2009). The rainy season is usually between March and November (about $2500 \mathrm{~mm}$ with bimodal rainfall pattern), lasting for 9 months annually, while the dry seasons usually last for 3 months, between December and February (Ola-Adams and Hall, 1987). Plantations of indigenous and exotic tree species were established at the boundaries and buffer zone of the reserve. The SNR is bounded on one side by a river making accessibility to the forest very difficult. Several rural communities around the reserve are involved in its management and protection. Anthropogenic activities, such as organized 
taungya farming, collection of firewood, and gathering of other non-timber forest products (NTFPs), were restricted to the buffer zone.

\section{Methodology \\ Sampling techniques and data collection}

Systematic sampling method was used with $10 \%$ sampling intensity on a straight line alternating transect line in the study areas. Adults trees $(\mathrm{dbh} \geq 10 \mathrm{~cm})$ were measured within square plots of 2500m2 sizes (50x50), a total of one hundred and twenty five (125) plots were laid and sampled in the three forest reserves. Variables measured on sampled trees are diameter at breast height (dbh $\geq 10 \mathrm{~cm})$, the total and bole height.

Nest transects of $50 \times 0.5 \mathrm{~m} 2$ were laid within each plot for enumeration and measurement of saplings. All stems belonging to the genus were identified and enumerated. All stems with girth greater than $5.0 \mathrm{~cm}$ but less than $10 \mathrm{~cm}$ at $1.30 \mathrm{~m}$ above the ground with a height greater than 1.5 $\mathrm{m}$ were measured and enumerated for total height.

Nest Transects of $10 \times 10 \mathrm{~m} 2$ were established at the four corners of the $50 \times 50 \mathrm{~m} 2$ plots for enumeration and measurement of seedlings. Also, nest transects of $10 \times 0.2 \mathrm{~m} 2$ were established within the quadrats. All seedlings stems from each transect were identified and enumerated. For each species, seedlings with a diameter less than $5.0 \mathrm{~cm}$ were identified, counted and its collar diameter measured at ground level for each plant stem with the aid of cloth tape. The height was measured with meter rule.

\section{Data analysis}

Data were sorted to generate diameter size classes and the density in each class was computed. Pattern of species population structure was established based on the density of species in the different dbh classes and interpreted as an indication of variations in population dynamics. Oneway Analysis of Variance was used to show differences in tree dbh and variation in the number of individual trees in each study area.

Species characteristics (number of stems, basal area, and total height) were calculated separately for each diameter class within the same plot. Simpson evenness and Shannon index were used to quantify the structural diversity of the Afzelia species in the study areas, based on different structural attributes. The diversity index was calculated for diameter distribution. 
Stand Density (stand/hectare)

Medium basal surface area $\left(\mathrm{cm}_{2}\right)$

Lorey height of individuals (m)

Diameter of tree with medium basal

surface area $(\mathrm{cm})$

Blackman index

Green index

$$
\begin{aligned}
& D g=\sqrt{1} / n \sum_{i=1}^{n} d i^{2} \ldots \ldots \ldots \ldots \ldots . .1 \\
& \mathrm{G}=\pi / 40000 \mathrm{~s} \sum_{\mathrm{i}=1}^{\mathrm{n}} \mathrm{di}^{2} \ldots \ldots \ldots \ldots . .2 \\
& H_{L}=\sum_{i=1}^{n} g i h i / \sum_{i=1}^{n} g i \ldots \ldots \ldots . . . .3 \\
& D g=\sqrt{1 / n \sum_{i=1}^{n} d i^{2}} \ldots \ldots \ldots \ldots \ldots .4
\end{aligned}
$$

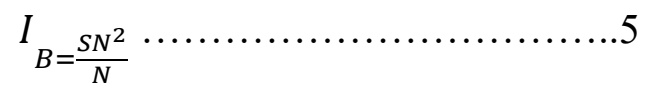

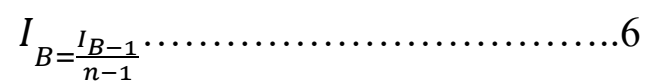
population trees; $N$, mean of population trees.

Basal area $\left(\mathrm{cm}_{2}\right)$ in each study area was calculated using the formula:

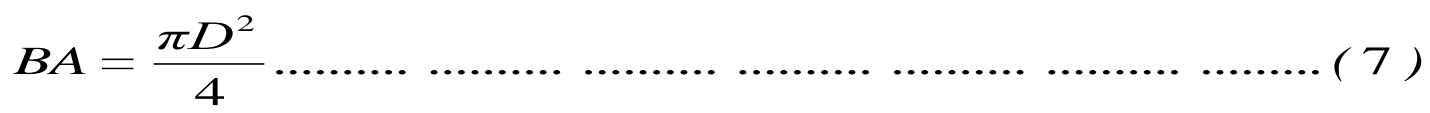

\section{Tree Species Classification and Biodiversity Indices}

(i) Relative density was computed as:

$$
R D=\frac{n_{i}}{N} \times 100
$$

Where:

$$
\begin{aligned}
& \mathrm{RD}=\text { species relative density } \\
& \mathrm{n}_{\mathrm{i}}=\text { number of individual of species } \mathrm{i} \\
& \mathrm{N}=\text { total number of all tree species in the entire community. }
\end{aligned}
$$

(ii) Species relative dominance (RDo $(\%)$ ) was computed using the equation:

$$
R D_{O}=\frac{\sum B a_{i} \times 100}{\sum B a_{n}}
$$

Where:

$$
\begin{aligned}
& \mathrm{Bai}=\text { basal area of individual tree belonging to species } \mathrm{i} \\
& \mathrm{Ban}=\text { stand basal area }
\end{aligned}
$$


(iii) Species diversity index was calculated using the Shannon-Weiner diversity index (Kent and Coker, 1992):

$$
H^{\prime}=-\sum_{i=1}^{S} p_{i} \ln \left(p_{i}\right.
$$

Where:

$$
\begin{aligned}
& H^{\prime}=\text { Shannon-Weiner diversity index } \\
& \mathrm{S}=\text { Total number of species in the community } \\
& \mathrm{P}_{\mathrm{i}}=\text { Proportion of } \mathrm{S} \text { made up of the } \mathrm{ith} \text { species } \\
& \ln =\text { natural logarithm }
\end{aligned}
$$

(iv) Shannon's maximum diversity index was calculated using the relationship:

$\mathrm{H}_{\max }=\ln (\mathrm{S})$

Where:

$\mathrm{H}_{\max }=$ Shannon's maximum diversity

$\mathrm{S}=$ Total number of species in the community

(v) Species evenness in each community was determined using Shannon's equitability (EH):

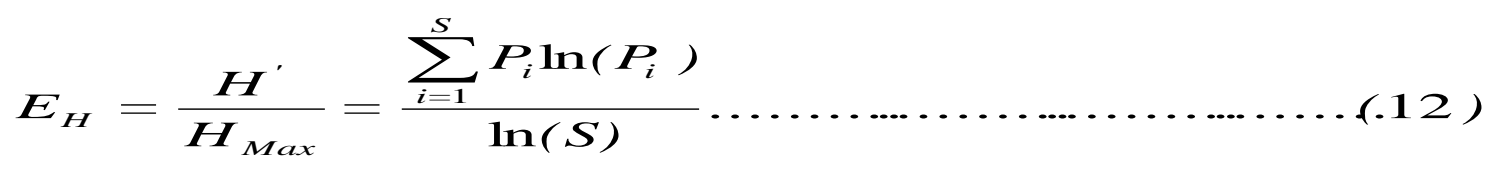

(vi) Simpson's index

$$
D=1-\sum\left(\frac{n_{i}}{N}\right)^{2}
$$

Where:

$\mathrm{D}=$ Simpson's index

$\mathrm{n}_{\mathrm{i}}=$ number of individual of species $\mathrm{i}$

$\mathrm{N}=$ total number of all tree species in the entire community

\section{Results}




\section{Dendrometric Parameters}

Table 1 showed the dendrometric characteristics of Afzelia species populations at all population levels according to locations. There were significant differences in the density, diameter, basal surface area and Lorey height in the three forest reserves. The diameter, basal surface area, and Lorey height of Afzelia species populations ranged from 63 to $172 \mathrm{~cm}, 1$ to $3 \mathrm{~m} 2 / \mathrm{ha}$, and 21 to $38 \mathrm{~m}$, respectively. High values of diameters, basal surface areas and height were observed in Ondo State (Akure Forest Reserve).

\section{Enumeration of Sapling}

The natural regeneration of the Afzelia Species populations was recorded in the three Forest Reserves (Table 2). Sapling density ( $n=8)$ was high in Akure Forest Reserve when compared with the other two Forest reserve having 1 sapling stand of Afzelia species per hectare. There was a significant difference in mean density and mean diameter $(P<0.01)$ but there was no significant difference in the mean basal surface area. Of the three forest reserves, Omo biosphere Reserve had the highest sapling mean diameter and mean basal surface area. There were no significant differences in the diameter class distribution in the three Forest Reserves.

Table 1: Tree Growth Variables of Afzelia species according to Forest Reserves in Southwestern Nigeria

\begin{tabular}{lllllll}
\hline $\begin{array}{l}\text { Parameter } \\
\text { Trees }\end{array}$ & $\begin{array}{l}\text { Omo } \\
\text { Biosphere } \\
\text { Reserve }\end{array}$ & $\begin{array}{l}\text { Gambari } \\
\text { Forest } \\
\text { Reserve }\end{array}$ & $\begin{array}{l}\text { Akure } \\
\text { Forest } \\
\text { Reserve }\end{array}$ & $\begin{array}{l}\text { Std. } \\
\text { Deviation }\end{array}$ & $\begin{array}{l}\text { Std. Error } \\
\text { Mean }\end{array}$ & P-Value \\
\hline $\begin{array}{l}\text { Density } \\
\text { (stand/hect.) }\end{array}$ & 1 & 1 & 7 & 0.58 & 0.33 & $0.057^{*}$ \\
$\begin{array}{l}\text { Diameter } \\
\text { (cm) }\end{array}$ & 132.38 & 63.41 & 171.95 & 0.82 & 0.33 & $0.01^{*}$ \\
$\begin{array}{l}\text { Basal } \\
\begin{array}{l}\text { Surface area } \\
\text { (cm2) }\end{array}\end{array}$ & 1.71 & 0.91 & 2.91 & 0.82 & 0.29 & $0.01^{*}$ \\
$\begin{array}{l}\text { Lorey } \\
\text { Height (m) }\end{array}$ & 30.36 & 20.57 & 37.65 & 1.00 & 0.58 & $0.074^{*}$ \\
$\begin{array}{l}\text { Medium } \\
\text { Basal Area } \\
\text { (cm2) }\end{array}$ & $3.33 \times 10-3$ & $4.78 \times 10-5$ & $2.04 \times 10-3$ & 0.82 & 0.33 & $0.001 \mathrm{~ns}$ \\
$\begin{array}{l}\text { Blackman } \\
\text { index }\end{array}$ & 10.62 & 0.60 & 1.40 & 0.82 & 0.33 & $0.001 \mathrm{~ns}$ \\
\hline
\end{tabular}




\begin{tabular}{lllllll} 
Green Index & 0.57 & 0.067 & 0.067 & 0.45 & 0.2 & $0.033^{*}$ \\
\hline
\end{tabular}

*significant at $\mathrm{P}<0.01$

Table 2: Density, Diameter and Basal surface area of Afzelia saplings in the study areas

\begin{tabular}{lllllll}
\hline $\begin{array}{l}\text { Sapling } \\
\text { Variables }\end{array}$ & $\begin{array}{l}\text { Omo } \\
\text { Biosphere } \\
\text { Reserve }\end{array}$ & $\begin{array}{l}\text { Gambari } \\
\text { Forest } \\
\text { Reserve }\end{array}$ & $\begin{array}{l}\text { Akure } \\
\text { Forest } \\
\text { Reserve }\end{array}$ & $\begin{array}{l}\text { Std. } \\
\text { Deviation }\end{array}$ & $\begin{array}{l}\text { Std. } \\
\text { Error }\end{array}$ & P-Value \\
\hline $\begin{array}{l}\text { Density } \\
\text { (stand/hect.) }\end{array}$ & 1 & 1 & 8 & 1.154 & 0.67 & $0.225^{*}$ \\
$\begin{array}{l}\text { Dbh }(\mathrm{cm}) \\
\begin{array}{l}\text { Basal Surface } \\
\text { Area }(\mathrm{cm} 2)\end{array}\end{array}$ & 0.073 & 0.072 & 0.067 & 0.817 & 0.33 & $0.01^{*}$ \\
\hline
\end{tabular}

*significant at $\mathrm{P}>0.01$

\section{Enumeration of Seedlings}

There were significant differences in the diameter and basal surface area $(P>0.01)$ in the three forest reserves (Table 3). Omo Biosphere Reserve had the highest basal surface area, $5.9 \times 10-6 \mathrm{~cm} 2$ while seedling density was highest in Akure Forest Reserve (18 seedlings/ha) followed by Omo Biosphere Reserve (6 seedlings/ hectare) and Gambari Forest Reserve (3 seedlings /hectare).

Table 3: Density, Diameter and Basal surface area of Afzelia seedlings in the study areas

\begin{tabular}{lllllll}
\hline $\begin{array}{l}\text { Seedlings } \\
\text { Variables }\end{array}$ & $\begin{array}{l}\text { Omo } \\
\text { Biosphere } \\
\text { Reserve }\end{array}$ & $\begin{array}{l}\text { Gambari } \\
\text { Forest } \\
\text { Reserve }\end{array}$ & $\begin{array}{l}\text { Akure } \\
\text { Forest } \\
\text { Reserve }\end{array}$ & $\begin{array}{l}\text { Std. } \\
\text { Deviation }\end{array}$ & $\begin{array}{l}\text { Std. } \\
\text { Error }\end{array}$ & P-Value \\
\hline $\begin{array}{l}\text { Seedling Density } \\
\text { (stand/hect.) }\end{array}$ & 6 & 3 & 18 & 0.82 & 0.33 & $0.001 \mathrm{~ns}$ \\
$\begin{array}{l}\text { Dbh }(\mathrm{cm}) \\
\text { Basal Surface }\end{array}$ & 0.015 & 0.022 & 0.008 & 1.00 & 0.5774 & $0.01^{*}$ \\
Area $(\mathrm{cm} 2)$ & $5.9 \times 10-6$ & $5.57 \times$ & $9.66 \times$ & 1.00 & 0.5773 & $0.225^{*}$ \\
& & $10-8$ & $10-8$ & & & \\
\hline
\end{tabular}

*significant at $\mathrm{P}>0.01$

Height distribution of saplings in Omo Biosphere Reserve, Gambari Forest Reserve and Akure Forest Reserve, showed that most of the stems were within the range of 5.0-6.5 cm (figure 2) while most diameter class distribution of seedlings in the three reserves was within the range of 0.51-1.0 cm (Figure 3). 


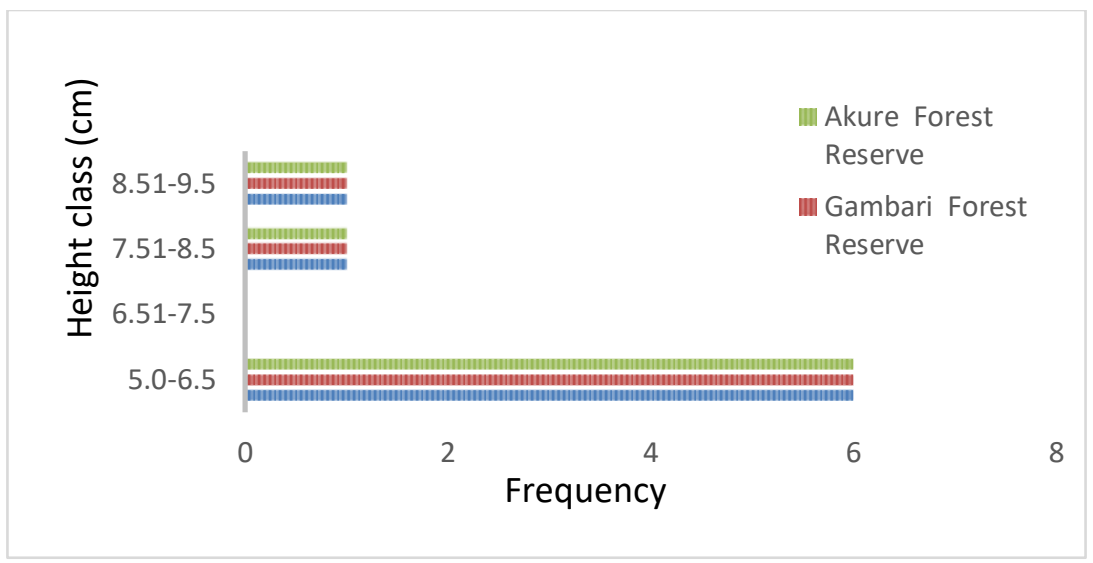

Figure 2: Height distribution of Saplings in Omo, Gambari and Akure forest reserves (stem/ha)

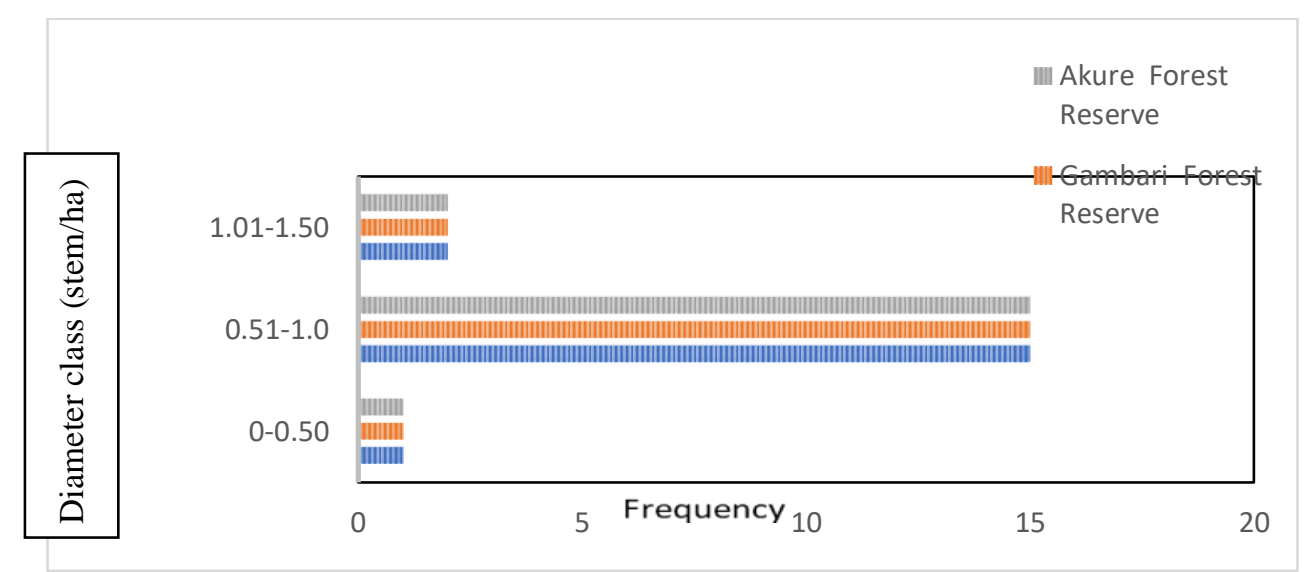

Figure 3: Diameter class distribution of seedlings in Omo, Gambari and Akure forest reserves (stem/ha)

\section{Structure of Afzelia tree species in the study areas}

The diameter distribution of tree stems in Omo Biosphere Reserve showed that most of the stems were within the range of 91-130cm (Figure 4), in Gambari Forest reserve were within the range of $10-50 \mathrm{~cm}$ while the diameter distribution of stems in Akure Forest Reserve showed that most of the stems fell within the range of $\geq 211$.

Height distribution of the trees in Omo Biosphere Reserve showed that height range from 10 and $35 \mathrm{~m}$ as shown in figure 5 . Height class $30-35 \mathrm{~m}$ had the highest number of stands ( 8 stands). Trees are mainly within 15-20m height class in Gambari Forest Reserve had the highest number of stems, while in Akure Forest reserve, height class 26-30m and 36 to 40m had 2 stands/ ha each. 


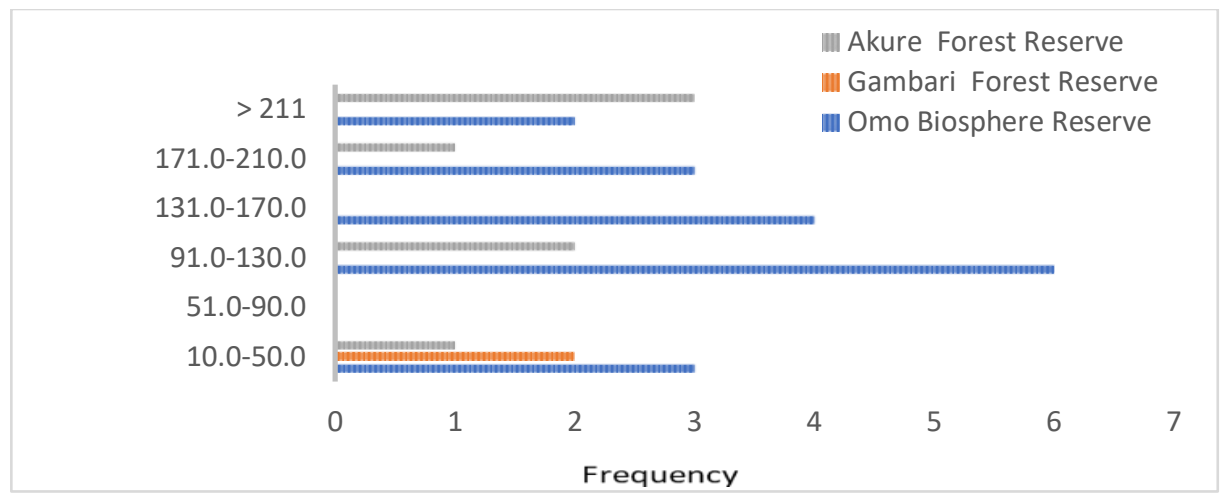

Figure 4: Diameter distribution of tree stems in Omo, Gambari and Akure Forest Reserves (stem/ha)

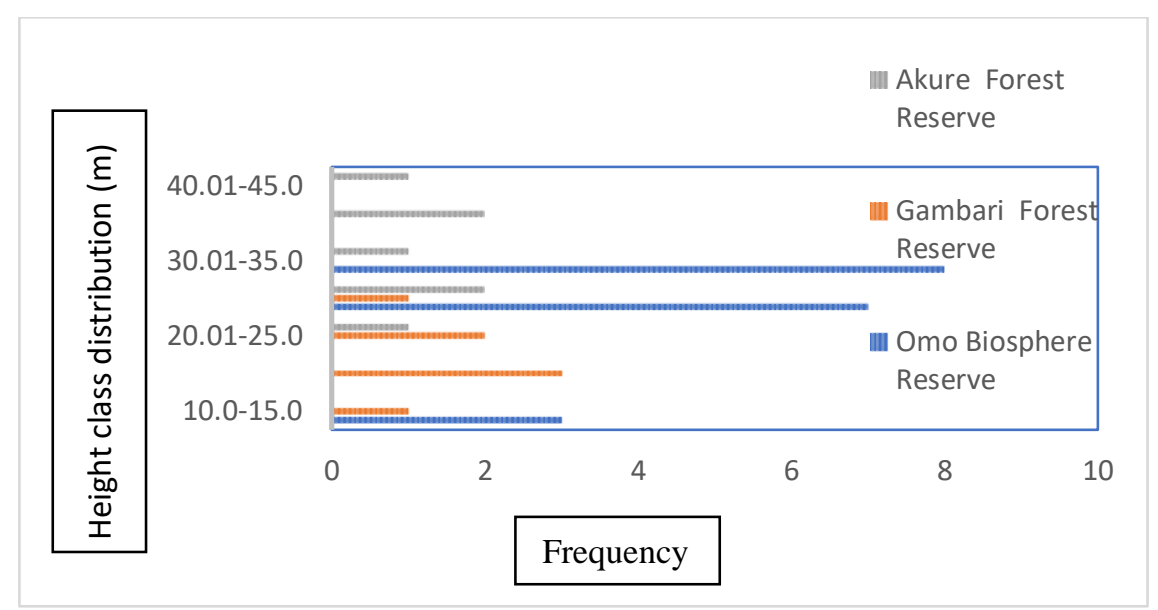

Figure 5: Height class distribution of tree stems in Omo Gambari and Akure Forest Reserve (stem/m)

Table 5 showed the diversity obtained for Omo Biosphere Reserve for each diameter class. The results showed that the Relative density (RD) in the diameter class of Afzelia species ranged from 0.00 to $33.33 \%$ in the Biosphere Reserve. Diameter with the highest relative density was obtained in height class $91-130 \mathrm{~m}$, while the least was observed to be between classes 51 to $90 \mathrm{~m}$. The Relative dominance ranged from $0.00-28.50 \%$. Height class from $211 \mathrm{~m}$ and above had the highest relative dominance followed by height class $171-210 \mathrm{~m}$ with relative dominance of $27.5 \%$. The Shannon-weinner diversity index $\left(\mathrm{H}^{\prime}\right)$ and Simpson's index (D) obtained for this Forest Reserve were 1.5417 and 0.8161 respectively. The Shannon maximum diversity was 2.8904 , while Simpson evenness was obtained as 0.0636

Table 6 showed the diversity obtained for Gambari Forest Reserve for the diameter class. The results showed that the Relative density (RD) in the diameter class of Afzelia species in the forest reserve to varied from 0.00 to $71.43 \%$. Diameter class with the highest relative density was found in height class $10-50 \mathrm{~m}$, while the least was observed to be between diameter class 51 to $90 \mathrm{~m}, 91$ - 
$130 \mathrm{~m}$ and height above $210 \mathrm{~m}$. Relative dominance ranged from $0.00-40.93 \%$. Height class from $171-210 \mathrm{~m}$ had the highest relative dominance followed by height class $10-50 \mathrm{~m}$ with relative dominance of $36.24 \%$. Shannon-weinner diversity index $\left(\mathrm{H}^{\prime}\right)$ and Simpson's index (D) obtained for this forest reserve were 0.7964 and 0.4490 respectively. Shannon maximum diversity was 1.9459, while Simpson evenness was obtained as 0.2832.

Table 7 showed the diversity obtained for Akure Forest Reserve for the diameter class. The results showed that the Relative density (RD) in the diameter class of Afzelia species in the strict nature reserve to varied from 0.00 to $42.86 \%$. Diameter class with the highest relative density was found in height class height above $20 \mathrm{~mm}$, while the least was observed to be between diameter classes 51- 90m, and 91-130m. Relative dominance ranged from $0.00-78.25 \%$. Height class from $211 \mathrm{~m}$ and above had the highest relative dominance followed by, height class $171-210 \mathrm{~m}$ with relative dominance of $13.35 \%$. Shannon-weinner diversity index (H') and Simpson's index (D) obtained for this forest reserve were 1.18 and 0.69 respectively. Shannon maximum diversity was 1.96 , while Simpson evenness was obtained as 0.16 .

Table 5: Afzelia Species Richness and Diversity Indices in Omo Biosphere Reserve

\begin{tabular}{lllllllll}
\hline $\begin{array}{l}\text { Dbh } \\
\begin{array}{l}\text { Class } \\
(\mathrm{cm})\end{array}\end{array}$ & $\begin{array}{l}\text { Freq. } \\
(\mathrm{stem} / \\
\text { ha })\end{array}$ & $\begin{array}{l}\text { Basal Area } \\
(\mathrm{m})\end{array}$ & $\begin{array}{l}\text { Total } \\
\text { Height } \\
(\mathrm{m})\end{array}$ & $\begin{array}{l}\text { Relative } \\
\text { Density } \\
(\%)\end{array}$ & $\begin{array}{l}\text { Relative } \\
\text { Dominance } \\
(\%)\end{array}$ & $\begin{array}{l}\mathrm{H} \\
-(\mathrm{Pi} \\
\mathrm{In}(\mathrm{Pi})\end{array}$ & $\mathrm{D}$ & $\begin{array}{l}\text { Simpson } \\
\text { Evenness }\end{array}$ \\
\hline $10-50$ & 3 & 0.0306 & 29.4 & 16.67 & 0.10 & 0.2987 & 0.0278 & 0.0096 \\
$51-90$ & 0 & 0.0000 & 0.00 & 0.00 & 0.00 & 0.0000 & 0.0000 & 0.0000 \\
$91-130$ & 6 & 6.5800 & 174.41 & 33.33 & 21.41 & 0.3660 & 0.1111 & 0.0384 \\
$131-170$ & 4 & 6.8300 & 127.41 & 22.22 & 22.22 & 0.3342 & 0.0049 & 0.0017 \\
$171-210$ & 3 & 8.5300 & 88.37 & 16.67 & 27.75 & 0.2987 & 0.0278 & 0.0096 \\
$\geq 211$ & 2 & 8.7700 & 63.55 & 11.11 & 28.50 & 0.2441 & 0.0123 & 0.0043 \\
Total & 18 & 30.74 & 483.14 & 100 & 100.00 & 1.5417 & 0.1839 & 0.0636 \\
\hline
\end{tabular}

Table 6: Afzelia Species Richness and Diversity Indices in Gambari Forest Reserve

\begin{tabular}{lllllllll}
\hline $\begin{array}{l}\text { Dbh } \\
\begin{array}{l}\text { Class } \\
(\mathrm{cm})\end{array}\end{array}$ & $\begin{array}{l}\text { Freq. } \\
(\mathrm{stem} /\end{array}$ & $\begin{array}{l}\text { Basal Area } \\
(\mathrm{m})\end{array}$ & $\begin{array}{l}\text { Total } \\
\text { Height } \\
(\mathrm{m})\end{array}$ & $\begin{array}{l}\text { Relative } \\
\text { Density } \\
(\%)\end{array}$ & $\begin{array}{l}\text { Relative } \\
\text { Dominance } \\
(\%)\end{array}$ & $\begin{array}{l}\mathrm{H} \\
-(\mathrm{Pi} \\
\mathrm{In}(\mathrm{Pi})\end{array}$ & $\mathrm{D}$ & $\begin{array}{l}\text { Simpson } \\
\text { Evenness }\end{array}$ \\
\hline $10-50$ & 5 & 2.3020 & 85.17 & 71.43 & 36.24 & 0.2404 & 0.5102 & 0.2622 \\
\hline
\end{tabular}


Proceedings of the $\mathbf{2 0 2 0}$ Society of Wood Science and Technology International Convention

\begin{tabular}{lllllllll}
\hline $51-90$ & 0 & 0.0000 & 0.00 & 0.00 & 0.00 & 0.0000 & 0.0000 & 0.0000 \\
$91-130$ & 0 & 0.0000 & 0.00 & 0.00 & 0.00 & 0.0000 & 0.0000 & 0.0000 \\
$131-170$ & 1 & 1.4500 & 22.8 & 14.29 & 22.83 & 0.2780 & 0.0204 & 0.0105 \\
$171-210$ & 1 & 2.6000 & 24.71 & 14.29 & 40.93 & 0.2780 & 0.0204 & 0.0105 \\
$\geq 211$ & 0 & 0.0000 & 0.00 & 0.00 & 0.00 & 0.0000 & 0.0000 & 0.0000 \\
Total & 7 & 6.3520 & 132.70 & 100.01 & 100 & 0.7964 & 0.5510 & 0.2832 \\
\hline
\end{tabular}

Table 7: Afzelia Species Richness and Diversity Indices in Akure Forest Reserve

\begin{tabular}{lllllllll}
\hline $\begin{array}{l}\text { Dbh } \\
\begin{array}{l}\text { Class } \\
(\mathrm{cm})\end{array}\end{array}$ & $\begin{array}{l}\text { Freq. } \\
\text { (stems }\end{array}$ & $\begin{array}{l}\text { Basal Area } \\
(\mathrm{m})\end{array}$ & $\begin{array}{l}\text { Total } \\
\text { Height } \\
(\mathrm{m})\end{array}$ & $\begin{array}{l}\text { Relative } \\
\text { Density } \\
(\%)\end{array}$ & $\begin{array}{l}\text { Relative } \\
\text { Dominance } \\
(\%)\end{array}$ & $\begin{array}{l}\mathrm{H} \\
-(\mathrm{Pi} \\
\mathrm{In}(\mathrm{Pi})\end{array}$ & $\mathrm{D}$ & $\begin{array}{l}\text { Simpson } \\
\text { Evenness }\end{array}$ \\
\hline $10-50$ & 1 & 0.0940 & 22.8 & 14.29 & 0.46 & 0.2780 & 0.0204 & 0.0105 \\
$51-90$ & 0 & 0.0000 & 0.00 & 0.00 & 0.00 & 0.0000 & 0.0000 & 0.0000 \\
$91-130$ & 0 & 0.0000 & 0.00 & 0.00 & 0.00 & 0.0000 & 0.0000 & 0.0000 \\
$131-170$ & 2 & 1.6200 & 58.60 & 28.57 & 7.95 & 0.2579 & 0.0816 & 0.0419 \\
$171-210$ & 1 & 2.7200 & 32.80 & 14.29 & 13.35 & 0.2780 & 0.0204 & 0.0105 \\
$\geq 211$ & 3 & 15.9400 & 118.7 & 42.86 & 78.25 & 0.3631 & 0.1837 & 0.0944 \\
Total & 7 & 20.37 & 232.90 & 100.01 & 100.01 & 1.18 & 0.31 & 0.16 \\
\hline
\end{tabular}

Omo Biosphere reserve had the highest frequency of Afzelia species 18 stand/ha among the three study areas, while the other two had equal frequencies of 7 stems each. Omo Biosphere Reserve had the highest value for both the basal area and total height of tree stems (30.74 and 483.14, respectively) within the three study areas. Shannon diversity index showed that Omo Biosphere Reserve (1.54) was more diverse than the other two study areas. Afzelia species were evenly distributed in Omo Biosphere Reserves when compared with the other two study areas.

Table 8 showed that Akure Forest Reserve had the highest density of saplings per hectares i.e. 8 stem/ stand while Omo Biosphere Reserve had the highest basal area /ha. As for the Shannon diversity index, the table revealed that Omo Biosphere Reserve had the highest value (1.37) followed by Gambari Forest Reserve (1.18) while Akure Forest Reserve had the least value (0.74). Gambari Forest Reserve had the highest value for Simpson index (0.69) followed by Omo Biosphere Reserve (0.68) while Akure Forest Reserve had the least (0.41). For species evenness, 
Omo Biosphere Reserve had the highest value (0.52) followed by Gambari Forest Reserve (0.45) while SNR 2, Akure Forest Reserve had the least value (0.36). Also, both Omo Biosphere Reserve and Gambari Forest Reserve had the highest value (2.64) for Shannon maximum diversity while Akure Forest Reserve had the least value (2.08).

Table 9 showed that Akure Forest Reserve had the highest density of saplings per hectares i.e. 18 stands/ stand followed by Omo Biosphere reserve (6 stands/ha) and Gambari Forest Reserve had the least ( 3 stands /ha). Omo Biosphere Reserve had the highest basal area /ha. As for the Shannon diversity index, the table revealed that Gambari Forest Reserve had the highest value (1.54) followed by Omo Biosphere Reserve (0.79) while Akure Forest Reserve had the least value (0.56). Omo Biosphere Reserve had the highest value for Simpson index (0.58) followed by Gambari Forest Reserve (0.31) while Akure Forest Reserve had the least (0.29). For species evenness, Akure Forest Reserve had the highest value (0.19) followed by Gambari Forest Reserve (0.005) while Omo Biosphere Reserve had the least value (0.004). Omo Biosphere Reserve had the highest value (4.65) for Shannon maximum diversity followed by Gambari Forest Reserve (3.5) while Akure Forest Reserve had the least value (2.89).

Table 8: Sapling Species Richness and Diversity Indices of Afzelia spp in the Forest Reserves

\begin{tabular}{lccc}
\hline Diversity Indices & $\begin{array}{c}\text { Omo Biosphere } \\
\text { Reserve }\end{array}$ & $\begin{array}{c}\text { Gambari } \\
\text { Forest Reserve }\end{array}$ & $\begin{array}{c}\text { Akure Forest } \\
\text { Reserve }\end{array}$ \\
\hline Density (Stem/ha) & 1 & 1 & 8 \\
Basal Area(m) & 0.06 & 0.057 & 0.028 \\
Total Height (m) & 145.57 & 116.66 & 65.93 \\
Relative Density \% & 100.01 & 100.01 & 100 \\
Relative Dominance \% & 100 & 100 & 100 \\
Shannon Index & 1.37 & 1.18 & 0.74 \\
Simpson Index & 0.68 & 0.69 & 0.41 \\
Species Evenness & 0.52 & 0.45 & 0.35 \\
Shannon Maximum & 2.64 & 2.64 & 2.079 \\
Diversity & & & \\
\hline
\end{tabular}


Proceedings of the 2020 Society of Wood Science and Technology International Convention

Table 9: Seedlings Species Richness and Diversity Indices of Afzelia species in the Forest Reserves

\begin{tabular}{llll}
\hline Diversity Indices & $\begin{array}{l}\text { Omo Biosphere } \\
\text { Reserve }\end{array}$ & $\begin{array}{l}\text { Gambari Forest } \\
\text { Reserve }\end{array}$ & $\begin{array}{l}\text { Akure Forest } \\
\text { Reserve }\end{array}$ \\
\hline Density (Stands/ha) & 6 & 3 & 18 \\
Basal Area(m) & 0.02 & 0.012 & 0.001 \\
Total Height (m) & 57.12 & 40.53 & 2.14 \\
Relative Density \% & 100 & 100 & 100 \\
Relative Dominance \% & 100 & 100 & 100 \\
Shannon Index & 0.79 & 1.54 & 0.57 \\
Simpson Index & 0.58 & 0.31 & 0.29 \\
Species Evenness & 0.004 & 0.005 & 0.19 \\
Shannon Maximum & 4.65 & 3.5 & 2.9 \\
Diversity & & & \\
\hline
\end{tabular}

\section{Discussion and Conclusions}

Tree growth variables such as tree height, bole height and diameter at breast height are important tools used in forestry. The average diameter of a tree has been a useful parameter of interest which is often recommended in forestry (Sokpon and Biaou, 2002). In this study Afzelia species had a curve for its diameter size-class distribution. The height distributions of Afzelia trees in Omo Biosphere Reserve showed an inverse J-shaped distribution which showed that the height class is increasing steadily. However, height distribution in Gambari Forest Reserve showed a J-shaped distribution which implied that the trees were under serious threat in the reserve either by man or anthropogenic factors hampering the growth and development of Afzelia species in the forest reserve. This is in agreement with the findings of Salami et al. (2016) and Salami and Akinyele (2017) who further established the degraded nature of the reserve and its poor regeneration potential. In Akure Forest Reserve, the height distribution had an inverse J-shaped distribution. Though there were fluctuations between diameter class $10-50 \mathrm{~cm}$ and $91-130 \mathrm{~cm}$ having a zigzag in the graph which could mean that the population of the species has been hampered with in the past either by man or by anthropogenic factors.

Paradise and Houngnon (1997) and Sokpon and Biaou (2002) observed the same distribution in Lama Reserve, Benin and Bassila Forest Reserve, Benin, respectively. According to Cunningham (2001), the curve could be indicating the need for more light or competition-intolerant species as 
well as an unusual reproductive strategy leading to low numbers of seeds. Afzelia species are known as shade-intolerant species and the absence of individuals with larger diameters especially in Gambari Forest Reserve and Akure Forest Reserve could be as a result of extensive logging activities where the trees are under severe pressure or anthropogenic factors such as windthrow, fire, which could lead to the local extinction of the population of the species. Large-diameter trees are usually the best seed-bearers of the population, as they ensure the production of seeds, thereby supporting the regeneration of the species implying that the low density of large-diameter trees may hamper the regeneration of the population. The density of Afzelia species indicated that the study areas were sparingly populated especially Omo Biosphere Reserve and Gambari Forest Reserve. Indeed, Salami and Akinyele (2018) recorded 405 Nigerian tropical timber species in Omo Biosphere Reserve but Afzelia was only 2 stands/ ha. This could be as a result of the dense canopy cover in the three study areas and Afzelia being a light-demanding tree species cannot survive under canopies of other tree species. This could also be accounted for by the increase in rainfall and relative humidity in the three study areas as Afzelia species do not thrive well in areas with high relative humidity and high rainfall. Afzelia species are known to thrive well in the savanna regions where the relative humidity is low and with a little amount of rainfall but if found in the rain forest, they tend to occupy the drier part of the forest reserve and mountain top or hilly part of a rainforest. Assogbadjo et al. (2010) in Wari- Maro forest reserve showed that dendrometric features have implications for Anogeissus leiocarpa stands under low pressure. Kiki (2008) and Fandohan et al. (2010). In their studies on Vitex doniana and Tamarindus indica, respectively reported that human pressures have negative effects on dendrometric parameters such as density and regeneration on adult density but a positive effect on the mean diameter. Bello and Akinyele (2018), in their study on population distribution and diversity of Pycnanthus angolensis in Southwest, Nigeria also reported that there has been heavy exploitation of the species and habitat loss due to deforestation and land encroachment which has resulted in the sparse population of mature trees in some of their study areas, but and juvenile trees in Osun State, Nigeria.

The existence of species in a community especially under varied environmental conditions relies solely on the regeneration process. According to Khumbongmayum et al. (2005), regeneration is an important aspect of forest management, as it ensures the desired species composition and stocking after various disturbances. The future composition of forests within a stand in space and time is depicted by the potential regenerative status of tree species (Henle et al., 2004). The 


\section{Proceedings of the 2020 Society of Wood Science and Technology International Convention}

reproductive status of the population is determined by the ratio of various age groups which indicates its future course (Odum, 1971). The proportion of seedlings, saplings and trees of different species could be used to predict any possible change in forest composition (Zubair and Bhatt, 2016). The observed low number of saplings and seedlings in Omo Biosphere Reserve and Gambari Forest Reserve could be due to anthropogenic factors, trampling by wild animals and man, other biotic and abiotic stresses (Bognounou et al., 2009), such as shade unlike Akure Forest Reserve with high numbers of seedlings and saplings. This emphasizes the partial positive effect of protected areas in conserving highly valued plant species (Fandohan et al., 2010a). Also, the differences in sapling and seedling heights in the three study areas could be explained by the high intra- and inter-specific competitions (Shackleton, 2002) for light.

The reduced canopy cover has a direct effect on seed production, but it may also indirectly affect regeneration through changes in the understory vegetation and soil properties (Vetaas, 2000).

\section{Acknowledgments}

The authors gratefully acknowledge the support of Forestry Research Institute of Nigeria, and the Department of Forest Production and Products, University of Ibadan, Nigeria.

\section{References}

Adeduntan, S. A. (2009). Influence of Human Activities on Diversity and Abundance of Insects in Akure Forest Reserve, Ondo State Nigeria. International Journal of Biological and Chemical Sciences. 3(9):1320-1335.

Adekunle, V. A. J., A. O. Olagoke and L. F. Ogundare (2010). Rate of timber production in a tropical rainforest ecosystem of southwest Nigeria and its implications on sustainable forest management. Journal of Forestry Research 21:225-230.

Arbonnier, M. (2002). Trees, shrubs and lianas of dryland West Africa. CRAD-MNHNIUCN, Paris, France. Pp541-550

Assogbadjo A.E; R. L. G. Kaka“1, B. Sinsin, and D. Pelz, (2010). Structure of Anogeissus leiocarpa Guill., Perr. Natural stands in relation to anthropogenic pressure within 
Wari-Maro Forest Reserve in Benin. African Journal of Ecology, vol. 48(3):644-653.

Bello O. A. and Akinyele A.O. (2018). Population Distribution and Diversity of Pycnanthus angolensis in Southwest, Nigeria. Journal of Natural Sciences, Engineering and Technology (Formerly ASSET Journal series B). Vol. 17: 21-27.

Bognounou, F, Thiombiano, A, Savadogo, P, Boussim, I. J, Odén, P. C, Guinko, S. (2009). Woody vegetation structure and composition at four sites along a latitudinal gradient in Western Burkina Faso. Wood Tropical Forestry, 300: 29-45.

Bonou, W. R. Gl'el'e Kaka"1, A. E. Assogbadjo, H. N. Fonton, and B. Sinsin, (2009). Characterisation of Afzelia africana Sm. habitat in the Lama forest reserve of Benin. Forest Ecology and Management, vol. 258, no. 7, pp. 1084-1092.

Cunningham, A. B. (2001). People, Wild Plant Use and Conservation. People and Plants Conservation Manuals. Journal of Applied Ethnobotany. Earthscan Publications Ltd, London, $300 \mathrm{pp}$.

Du Toit, J. T., B .H. Walker, and B. M. Campbell. (2004). Conserving tropical nature: current challenges for ecologists. Trends in Ecology and Evolution 19, no. 1: 12-17.

Fandohan, A. B; A. E. Assogbadjo, R. L. G. Kaka"1, B. Sinsin, and P. van Damme, (2010). Impact of habitat type on the conservation status of tamarind (Tamarindus indica L.) populations in the W National Park of Benin," Fruits, 65():11-19.

Food and Agriculture Organization (2003). State of the World's Forests, 2003. Food and Agriculture Organization of the United Nations, Rome. Pp 151

Henle, K., S. Saree and K. Wiegand. (2004). The role of density regulation in extinction processes and population viability analysis. Journal of Biological Conservation 13: 9-52.

Kent, M, Coker P. (1992). Vegetation description and analysis. London, UK: Belhaven Press. Pp363

Kiki, M. (2008). Structure and regeneration of natural populations of Tamarindus indica L. and from Vitex doniana Sw. to Reign her eserve of Biosphere Transfrontali'ere of W / BENIN: Case of la Commune of Banikoara, emoire Me to Ingest 2008 enieur of jobs, $\mathrm{EPAC} / \mathrm{UAC}$. 


\section{Proceedings of the 2020 Society of Wood Science and Technology International Convention}

Khumbongmayum, A. D., M. L. Khan and R. S. Tripathi (2005). Survival and growth of seedlings of a few tree species in the four sacred groves of Manipur, Northeast India. Current Science 88:1781-1788.

Lafrankie, J. V., P. S. Ashton, G. B. Chuyong, L. Co, R. Condit, S. J. Davies, R. Foster, S. P. Hubbell, D. Kenfack, D. Lagunzad, E. C. Losos, N. S. M. Nor, S. Tan, D. W. Thomas, R. Valencia \& G. Villa. (2006). Contrasting structure and composition of the understory in species-rich tropical rainforests. Ecology 87: 2298-2305.

Larinde, S. L., and Olasupo, O. O. (2011). Socio-Economic Importance of Fuelwood Production in Gambari Forest Reserve Area, Oyo State, Nigeria. Journal of Agriculture and Social Research.11(1)201-210.

Nacoulma, B. M. I., Traoré, S., Hahn, K., Thiombiano, A. (2011). Impact of land use types on population structure and extent of bark and foliage harvest of Afzelia africana and Pterocarpus erinaceus in Eastern Burkina Faso. International Journal of Biodiversity and Conservation 3, 62-72.

Nwachokor, M. A. and Uzu, F. O., (2008). Updated Classification of Some Soil Series in Southwestern Nigeria._Journal of Agronomy. 7 (1): 76-81.

Odum, E. P. (1971). Fundamentals of Ecology. (3rd Edition)Saunders Company, Philadelphia, USA. 546p

Ola-Adams B. A. and Hall J. B. (1987). Tree population changes in treated rainforest at Omo Forest Reserve. Journal of Ecology 3(4): 291-313.

Olajuyigbe, S. O., A. O. Akinyele, S. O. Jimoh and A. O. Adegeye. (2013). Tree species Diversity in the Department of Forest Resources Management, University of Ibadan, Nigeria. African Journal of Sustainable Development. Volume 3(1):124-135.

Onyekwelu, J. C., Mosandl, R. and Stimm, B., (2008). Tree species diversity and soil status of primary and degraded tropical rainforest ecosystems in south-western Nigeria. Journal of Tropical Forest Science Vol. 20, No. , pp. 193-204

Ouédraogo, A., Thiombiano, A., (2012). Regeneration pattern of four threatened tree species in Sudanian savannas of Burkina Faso. Agroforestry Systems 86, 35-48.

Paradise, G. and Houngnon P. (1997). The vegetation of the aerie class of Lama in the mosa whom forest savanna of Sud-Benin (ex-South Dahomey). 34-47. 
Salami K. D., Akinyele A. O., Adekola P. J. and Odewale M. A. (2016). Tree Species Composition and Regeneration Potential of Onigambari Forest Reserve, Oyo State. Direct Research Journal of Agriculture and Food Science Volume 4 (3): 39-47

Salami K. D. and Akinyele A. O. (2017). Tree Species Diversity and Abundance in Degraded Gambari Forest Reserve, SouthWest Nigeria. In: Ojurongbe O. (ed.), Translating Research Findings into Policy in developing countries. Contributions from Humboldt Kolleg, Oshogbo-2017. LAP Lambert Academic Publishing, Germany. Pp 276287.

Salami K. D. and Akinyele A. O. (2018). Floristic Composition, Structure and Diversity Distribution in Omo Biosphere Reserve, Ogun State, Nigeria. Ife Journal of Science Vol. 20(3):639-648.

Shackleton C. (2002). Nearest-neighbour analysis and the prevelance of woody plant competition in South African savannas. Plant Ecology, 158: 65-76.

Sokpon N. and Biaou H. S. (2002). The use of diameter distribution in sustained-use management of remnant forests in Benin: case of Bassila forest reserve in North Benin. Forest Ecology and Management 161: 13-25.

Traoré S; Blandine M. I. N , Karen H. and Adjima T. (2011). Impact of land use types on population structure and extent of bark and foliage harvest of Afzelia africana and Pterocarpus erinaceus in Eastern Burkina Faso. International Journal of Biodiversity and Conservation Vol. 3(3), pp. 62-72,

Vetaas, O. R. (2000). The effect of environmental factors on the regeneration of Quercus semecarpifolia Sm. in Central Himalaya, Nepal. Plant Ecology 146: 137-144.

Zubair, A. M. and A. B. Bhatt (2016). Regeneration status of tree species and survival of their seedlings in Kedarnath Wildlife Sanctuary and its adjoining areas in Western Himalaya, India. Tropical Ecology 57(4): 677-690.

Biograpahy 


\title{
Termite Resistance of Stem and Branch Wood of Two Tropical Hardwood Species in Ghana
}

\author{
Antwi Kwaku1, 2, Cremer Tobias 3, Amoah Martin1, and Frimpong-Mensah \\ Kwasi 1,4 \\ 1Department of Construction and Wood Technology Education, University of \\ Education - Winneba, Kumasi - campus, Kumasi-Ashanti, Ghana \\ 2Department of Wood Technology, Tamale Technical University, Tamale - \\ Northern, Ghana \\ 3Eberswalde University for Sustainable Development, Schicklerstr.5, 16225 \\ Eberswalde, Germany \\ 4Department of Wood Science and Technology, Kwame Nkrumah University of \\ Science and Technology, Kumasi-Ashanti, Ghana \\ (antwikwaku10@gmail.com,Tobias.Cremer@hnee.de, \\ akwasiamponsah07@gmail.com,.and frimpongmensahk@yahoo.com)
}

\begin{abstract}
An in-ground resistance of Nesogordonia papaverifera and Hollarhena floribunda stem and branch wood to termite attack was evaluated to determine its service life and branch acceptance. Five matured trees each with similar diameter at breast height were selected within the middle belt of Ghana. The European Standard EN 252, 1989 and EN 350-1 1994 were used for the standard test of natural durability (grave-yard test) for a period of 12 months on termite prone site. All samples were tested at air-dried moisture content of $14 \pm 2 \%$ as specified in the standard. Stem and branch woods of $N$. papaverifera are very durable. However, stem and branch woods of $H$. floribunda are both non-durable and may need treatments with preservatives to improve their service life, if it becomes necessary to use them for ground applications. The heartwood portions could be more useful for structural applications when untreated than the sapwood portions (used as control). However, the sapwood when treated with preservatives could be used for similar structural applications. Branchwood of both N. papaverifera and $H$. floribunda performed well as compared to the stemwood and could consequently be utilized in addition to their stemwood for non-structural applications to increase the raw material base of the wood industry in Ghana.
\end{abstract}

KEY WORDS: Termite resistance, natural durability, stem and branchwood, Nesogordonia papaverifera, Hollarhena floribunda, and Ghana. 


\section{INTRODUCTION}

The depletion rate of Ghana's forest has become one major challenge facing the wood-related industries, foresters and environmentalists. This is because, depletion of forest and wood lands do not only affect industrial and economic growth negatively, but also disturb the whole forest ecosystem (Dadzie, P. K 2013). In Ghana, the depletion trend has been attributed to demand for wood, inefficient logging and processing practices, and misuse of wood secondary resources like branches (Ayarkwa, J., Hirashima, Y., \& Sasaki, Y., 2000). Increasing market demand, both locally and internationally, has resulted in the overexploitation of these 'traditional' market species, rendering some of them endangered (like odum, sapele, mahogany, etc.) (Poku, K., Wu, Q. \& Vlosky, R., 2001).

As prices of these traditional timber increase, and quality and quantities decline, manufacturers and producers have little option other than to pay attention to the branch wood, root wood, bark and other lesser-known species that were previously ignored if they were to remain in business (Boampong, E., Effah, B., Antwi, K., Boadi Asante, A., Nti A. J., 2015). One of the crucial questions in tropical forest management is the future of branch wood, root wood, bark and lesserknown timber species. Hundreds of potentially valuable trees are being left behind, often simply to be burnt in forest clearing operations (Effah, B., Osei, J. K., \& Antwi, K.,2013).

Branch is an important wood resource with many applications, it represents $25-32 \%$ of the total wood volume and is a secondary resource with a potential for high-value applications that has been inadequately explored (Hilton, M. 2001). In Ghana, H. floribunda is used mostly for carving traditional stool for Kings, Queen mothers, Fetish priest and other prominent persons in the society and considered to be the best white wood available for these purposes (Abbiw, D. K. 1990). N. papaverifera is mostly used in furniture production and other structural purposes.

Natural durability of timber may be defined as resistance of timber to attack by wood deterioration agents such as wood decaying fungi and wood destroying insects. It is interesting to know from literature that, not much has been studied in respect to investigate the natural durability of $N$. papaverifera and $H$. floribunda stem and branch wood in spite of their important contribution to wood resource. The aims of this research are to determine the natural durability of these wood species and assess performance of naturally durable wood species in above ground test for ground application. The natural durability (percentage mass loss and visual durability ratings) of the species tissues (heartwood) and sapwood as control and axial positions (base, middle and top for stem) of the tree component (stemwood) and branchwood for $N$.

papaverifera and $H$. floribunda were determined and their results analyzed.

\section{Area of Study}

\section{MATERIALS AND METHODS}

Five matured trees of $N$. papaverifera and $H$. floribunda were acquired from New Koforidua, in the Ejisu - Juaben Municipality, in the central part of Ashanti region within the middle belt of Ghana to provide wood for characterization of the species. The trees were obtained from a cocoa farm in the same locality within the open forest of the area, which lies within Latitudes 1 o $15^{\prime} \mathrm{N}$ and $1_{\circ} 45^{\prime} \mathrm{N}$ and Longitude 6o 15' $\mathrm{W}$ and 7o $00 \mathrm{~W}$. It occupies a land area of $637.2 \mathrm{~km} 2$ (EJMA, 2015). The Municipal Assembly has bi-modal rainfall pattern. The major rainfall period begins from March to July peaking in July. The average annual rainfall for the major season is about 
$1200-1500 \mathrm{~mm}$ per year. The minor rainfall period begins in September and tapers off in November with an average minor annual rainfall of $900-1120 \mathrm{~mm}$ per year. December to February is usually dry, hot and dusty. Mean annual temperatures in the Municipal area are lowest around $25{ }_{\circ} \mathrm{C}$ in August and highest around $32{ }_{\circ} \mathrm{C}$ in March. Relative humidity is moderate but quite high in during the rainy season. The topography of the municipality area is generally undulating, dissected by plains and slopes with heights ranging between 240 - 300 meters above sea level (EJMA, 2015).

\section{Research Design and Data Collection}

In this study, the sampling approach by Bao, F. C., Jiang, Z. H., Jiang, X. M., Lu, X. X., Luo, X. Q. \& Zhang, S. Y. (2001) was adopted. Trees of similar diameters at breast height were selected for harvesting for both $N$. papaverifera and $H$. floribunda species. The trees were first identified by a technical officer from the Forestry Commission, Juaso District who worked on the identification of most less utilized species with the Forestry Research Institute of Ghana. Fresh dry leaves and seeds from the trees were collected and sent to the laboratory in Forest Research Institute of Ghana for the confirmation of the field identification using the field guide to the forest trees of Ghana by Hawthorne, W. \& Gyakari, N (2006).

The natural durability classification referred only on the heartwood of timber species as sapwood of almost all timbers is susceptible to wood deterioration agents as a result makes the sapwood non-durable. However, in this study, the sapwood portions of stem and branch wood of both species were used as control, to determine the extent and the rate of attack by termites as compared to their heartwood portions. The research compared the natural durability of stemwood of $N$. papaverifera (danta) and H. floribunda (sese) to their branchwood by applying soil block (graveyard) test for a period of 12 months based on European standard EN 252, (1989). Quartey A. G. (2009) and Dadzie, P. K., \& Amoah, M., (2015) have acceptably evaluated the natural durability of some lesser known Ghanaian hardwood species within 6 months and 12 months based on this standard EN 252 (1989) and EN 350-1 (1994) respectively.

Moisture contents were measured with a moisture meter (MO210 designed to measure wood moisture content up to $44 \%$, as specified by the manufacturers) which was found to have accuracy of $\pm 2 \%$ upon validation with sampled oven-dry method using 40 samples drawn from stem and branch wood of the species (10 stem samples +10 branchwood samples each species). Ayarkwa, J., Hirashima, Y., \& Sasaki, Y., (2000), Amoah, M., Appiah-Yeboah, J., \& Okai, R. (2012) and Dadzie, P. K., \& Amoah, M., (2015) have also acceptably used moisture meters in wood property studies. Mass loss was quantitatively measured on a 4-point percentage scale as: 0-5 \% loss Very durable; 6-10 \% loss Durable; 11-40 \% loss Moderately durable; and 40-100 \% loss Non-durable (Eaton and Hale 1993). The extent of attack was however, quantitatively measured on 5-point visual rating scale based on EN 252 (1989) and EN 350-1 (1994) as: 0, No attack; 1, Slight attack; 2, Moderate attack; 3, Severe attack; and 4, Failure.

The test site was located at the South - West physiological region of the Kwame Nkrumah University of Science and Technology, Kumasi. The field has medium to fine texture soil with pores spaces varying from 40 to $60 \%$ and it is a domain to many of termite mounds (KumiWoode, B. G 1996). The test field has temperature range of $20{ }^{\circ} \mathrm{C}$ minimum to a maximum of 34 ${ }^{\circ} \mathrm{C}$, and average humidity of $60 \%$ at $1500 \mathrm{GMT}$ and $80 \%$ at $0900 \mathrm{GMT}$. There is also a 
double maximum rainfall pattern $(214.3 \mathrm{~mm}$ in June and $165.2 \mathrm{~mm}$ in September) which has direct effect on the environment, including soil organisms' activities and agriculture. As a result, it is reported that the site is generally a very high decay hazard zone that has high decay index (Ministry of Food and Agriculture 2013; Kumi-Woode, B. G 1996).

The trees for the study were selected based on their availability in the farmland, a diameter at breast (dbh) height greater than $45 \mathrm{~cm}$ and the overall straightness of the trunk. The average diameters of the trees at 1.3 meter above ground (dbh) were $64.4 \mathrm{~cm}$ for $N$. papaverifera and 53 $\mathrm{cm}$ for $H$. floribunda. The selected trees were harvested using chain-saw. The average length of the clear bole between where the first branch begins and the terminal point of buttresses of each species were measured and recorded. The recorded average lengths were $1809 \mathrm{~cm}$ and $1468 \mathrm{~cm}$ for $N$. papaverifera and $H$. floribunda. The full lengths of the trees were divided into three equal parts and demarcated with permanent makers and $50 \mathrm{~cm}$ from the knot, a branch bole of $1.5-2$ $\mathrm{m}$ were extracted from the first and second branches of each tree to obtain varied diameters of branch wood for the study.

This criterion was adopted to ensure straightness of branch disc and possibly avoid the inclusion of obvious tension wood. In all, 50 branch boles (i.e. 5 branches $\times 5$ trees for each species) with diameters ranging from $260-560 \mathrm{~mm}$. Stemwood samples were also obtained from a total of 30 stem boles (i.e. 5 bottom +5 middle +5 top for each species). All stem and branch wood samples were conveyed from the farmland to Boadu Wood Mill for processing. Both quarter and through-and-through sawn methods were used for the conversion of the logs to lumber using band saw.

All samples were conditioned in an air-drying shed of Fabi Timbers to an average moisture content of $14 \pm 2 \%$ at same temperature and relative humidity as used by the company to air-dry wood. After drying, both branch and stem boards were re-sawn into strips and crosscut to the

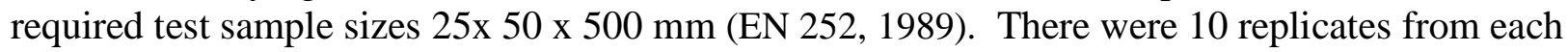
billet division ( 5 heartwood samples and 5 sapwood samples), totaling 360 samples for the test. Clear heart and sap wood samples were critically examined to ensure that they are free from both natural and artificial defects (i.e. samples free of knots, fuzzy and woolly surfaces which are evidence of reaction wood and any other visible defects) All samples were randomly selected and carefully inserted at a leveled and well drained test field $(60 \times 60 \mathrm{~m})$ such that two-thirds of their lengths were above the ground on the demarcated termite prone site as shown in "Figure land 2". The plot was demarcated into six equal blocks. Each block contains 60 samples.

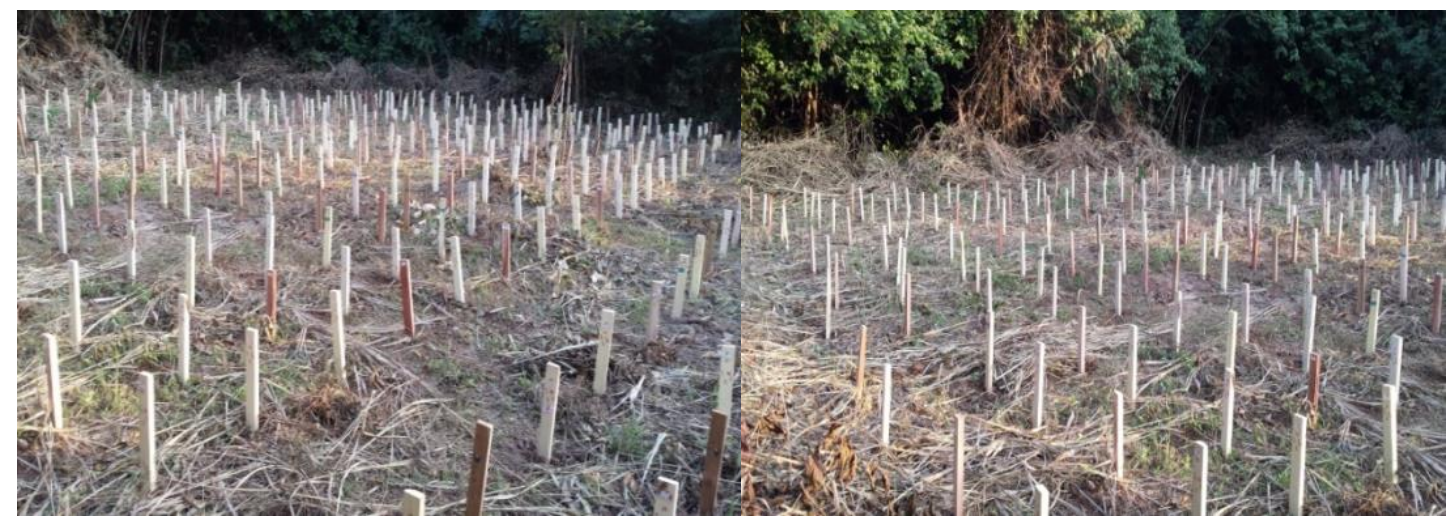


Figure 1: Stakes planted on the field (Source: Field photograph)


Figure 2: Samples after 2 weeks of planting; A (N. papaverifera heart), B (N. papaverifera sap), C (H .floribunda) and D, E and F Samples after 3months of planting (Source: Field photograph)

\section{RESULTS AND DISCUSSIONS}

Mass loss and visual rating for stemwood and branchwood of $N$. papaverifera and $H$. floribunda

The percentage mass loss between the stemwood and branchwood of $N$. papaverifera was 4.18 $\%$ and $6.30 \%$ respectively. Percentage mass loss is marginally higher in branchwood than in stemwood making the stemwood more durable than the branchwood "Table 1". Contrary, $H$. floribunda stemwood recorded $43.09 \%$ higher than the branchwood $42.34 \%$.

However, both stem and branchwood is rated non-durable "Figure 3". And for species tissues, the percentage mass loss along the stem heartwood portions of $N$. papaverifera was 2.82 (0.76) and the branch was $4.70(0.71)$. Statistically there is a significant difference between 
the stem heart and the branch heart $(\mathrm{P}<0.05)$. However, both stem and branch heart values falls within one classification. This could be ascribing to a greater total extractives and lignin content recorded in earlier study of these species (Antwi, K., 2018). Similar observations were reported by Eaton, R. A., \& Hale, M. D. C., (1993), Quartey A. G. (2009) and Antwi-Boasiako, C., \& Damoah, A., (2010) that durability of individual wood species depend on the amount of the extractives and lignin content as well as some physical properties. Similarly, the sapwood portions also recorded a percentage mass loss of 7.89 (1.11) for the branch and $5.54(0.73)$ for the stem "Table 1". The heartwood portions of the stem and branch were however rated very durable while its sapwood portions used as control rated durable after 12 months of field exposure according to durability classifications by Eaton, R. A., \& Hale, M. D. C., (1993).

The percentage mass loss along the heartwood portions of $H$. floribunda branch recorded a value of 20.40 (1.63) and the stem also recorded a value of 20.55 (1.66). Statistically, there is no significant difference between the branch heart and the stem heart $(\mathrm{P}<0.05)$. Similarly, the sapwood portions also recorded a percentage mass loss of 64.28 (9.50) for the branch and 65.63 (9.40) for the stems which shows no significant difference at 5\% level of probability between the branch and stem "Table 1". The heartwood portions of both stem and branch were rated moderately durable while its sapwood used as control was rated nondurable "Figure 4".

A visual durability rating shows the heartwood from the stem and branch of $N$. papaverifera slight attack by termites "Figures 5a and b" after 12 months of field exposure. However, sapwood used as control, from the stem and branch of $N$. papaverifera were moderately attacked by termites "Figures $5 \mathrm{c}$ and d". For H. floribunda, the heartwood portions of both stems and branch division were moderately attacked by termites "Figures 5 e and f". However, the sapwood portions used as control from both stem and branch were severely attacked "Figures $5 \mathrm{~g}$ and h". In both species, the sapwood portion used as control had a greater termite attack than the heartwood portions. The heartwood from the bottom of the $N$. papaverifera and $H$. floribunda stem were most resistant to attack by termites than the top and the branch divisions of the trees "Table 1". Similar to earlier research by DeBell, J., Morrell, L. L., \& Gartner, B. L., (1999) that the most durable heartwood is often present at the heartwood of the base of the stem, since it has the highest concentrations of extractives.

Table 1: Mean percentage mass loss and durability ratings along the stem and branch of $N$. papaverifera and $\boldsymbol{H}$. floribunda after 12 months of field exposure (\%)

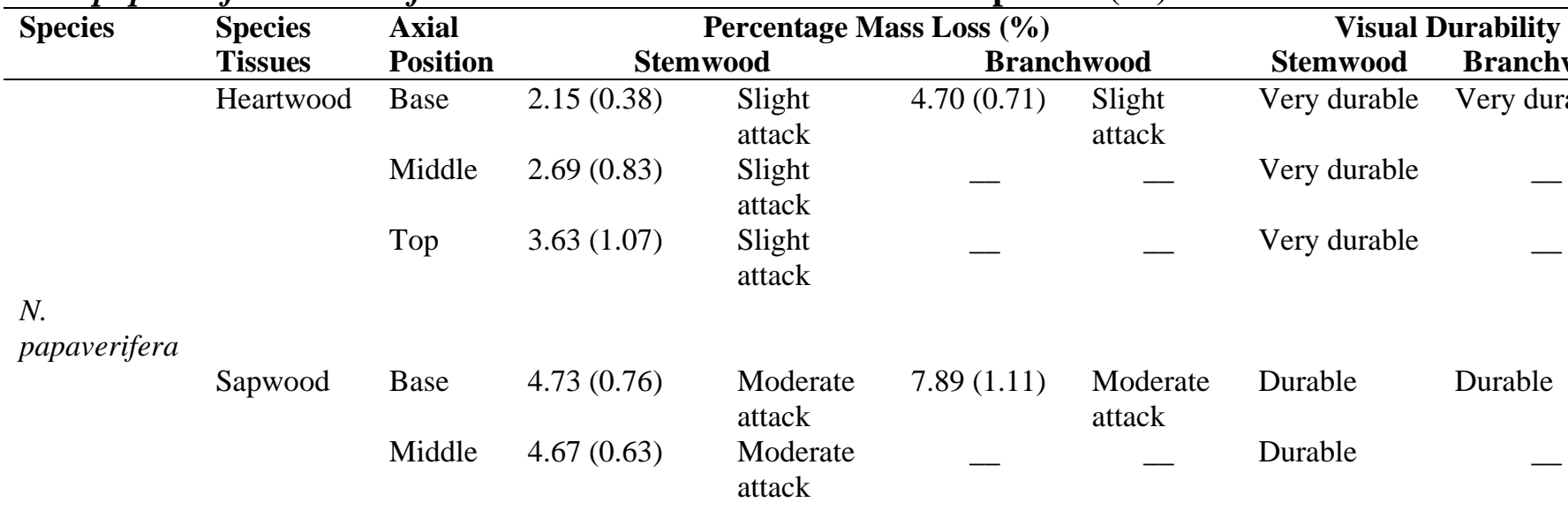


Proceedings of the $\mathbf{2 0 2 0}$ Society of Wood Science and Technology International Convention

\begin{tabular}{|c|c|c|c|c|c|c|c|}
\hline & Top & $7.22(0.81)$ & $\begin{array}{l}\text { Moderate } \\
\text { attack }\end{array}$ & - & - & Durable & - \\
\hline \multirow[t]{3}{*}{ Heartwood } & Base & $20.40(1.56)$ & $\begin{array}{l}\text { Moderate } \\
\text { attack }\end{array}$ & $\begin{array}{l}20.40 \\
(1.63)\end{array}$ & $\begin{array}{l}\text { Moderate } \\
\text { attack }\end{array}$ & $\begin{array}{l}\text { Moderately } \\
\text { durable }\end{array}$ & $\begin{array}{l}\text { Moderately } \\
\text { durable }\end{array}$ \\
\hline & Middle & 20.58 (1.55) & $\begin{array}{l}\text { Moderate } \\
\text { attack }\end{array}$ & - & - & $\begin{array}{l}\text { Moderately } \\
\text { durable }\end{array}$ & - \\
\hline & Top & 20.69 (1.87) & $\begin{array}{l}\text { Moderate } \\
\text { attack }\end{array}$ & - & - & $\begin{array}{l}\text { Moderately } \\
\text { durable }\end{array}$ & - \\
\hline \multirow[t]{3}{*}{ Sapwood } & Base & $64.99(8.61)$ & $\begin{array}{l}\text { Severe } \\
\text { attack }\end{array}$ & $\begin{array}{l}64.28 \\
(9.50)\end{array}$ & $\begin{array}{l}\text { Severe } \\
\text { attack }\end{array}$ & Non-durable & Non-durable \\
\hline & Middle & $65.93(11.33)$ & $\begin{array}{l}\text { Severe } \\
\text { attack }\end{array}$ & - & - & Non-durable & - \\
\hline & Top & $65.97(8.25)$ & $\begin{array}{l}\text { Severe } \\
\text { attack }\end{array}$ & - & - & Non-durable & - \\
\hline
\end{tabular}

$\sim$ Standard deviations in parentheses (Source: Field experimental results)

\section{floribunda}

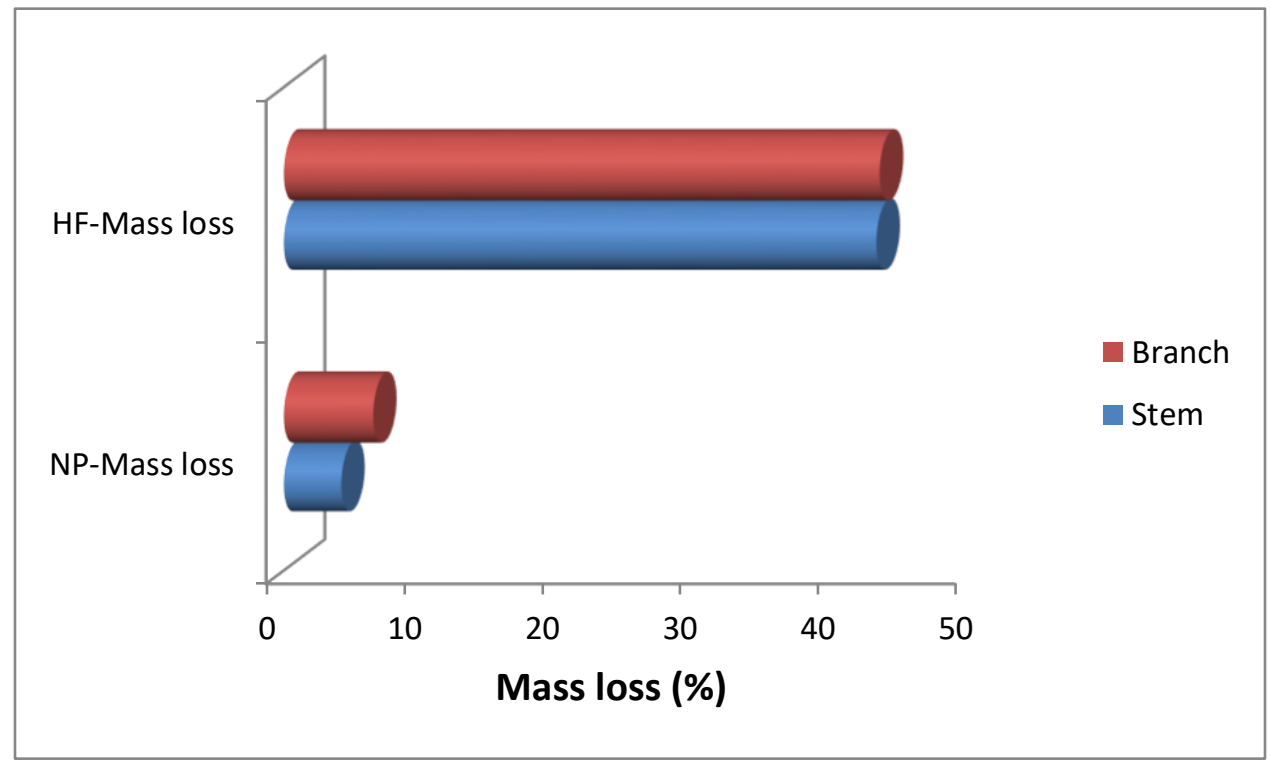

Figure 3: Tree components (stem and branch) of $N$. papaverifera \& $\mathrm{H}$. floribunda 
Proceedings of the $\mathbf{2 0 2 0}$ Society of Wood Science and Technology International Convention

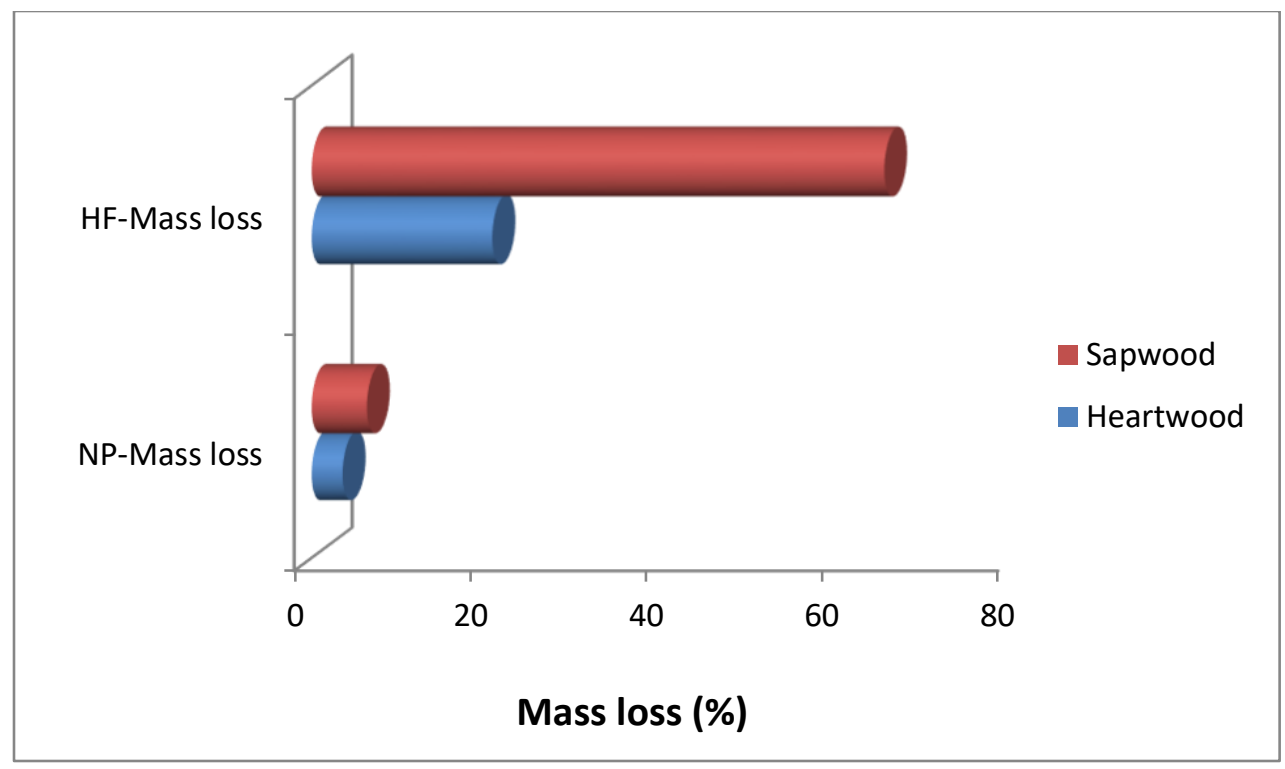

Figure 4: Tree tissues (heart and sap) of $N$. papaverifera \& $H$. floribunda 
Proceedings of the $\mathbf{2 0 2 0}$ Society of Wood Science and Technology International Convention
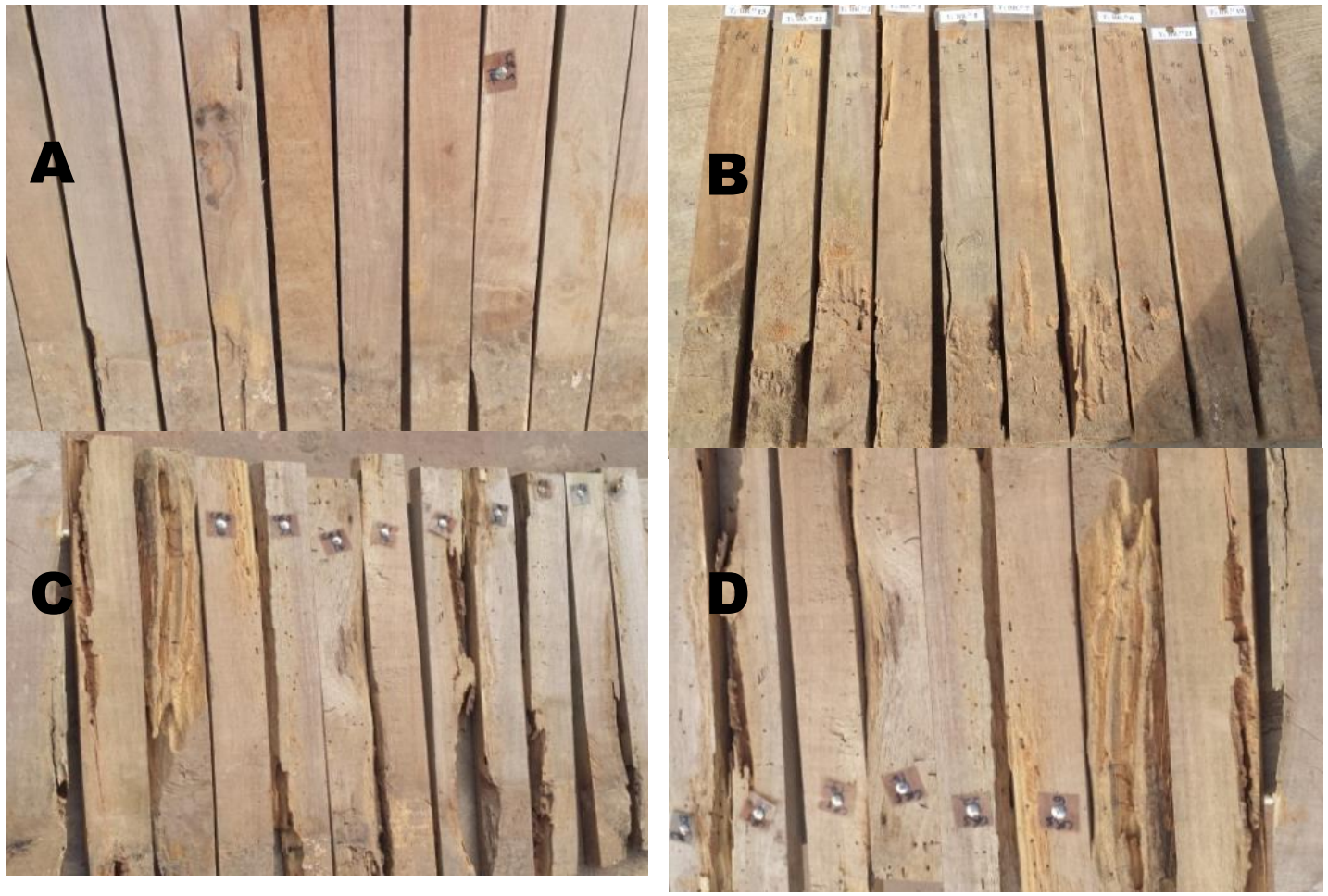

Figure 5: N. papaverifera stem heart (A) and branch heart (B) and $N$. papaverifera stem sap (C) and branch sap (D) samples after 12 months field exposure (Source: Field photograph)
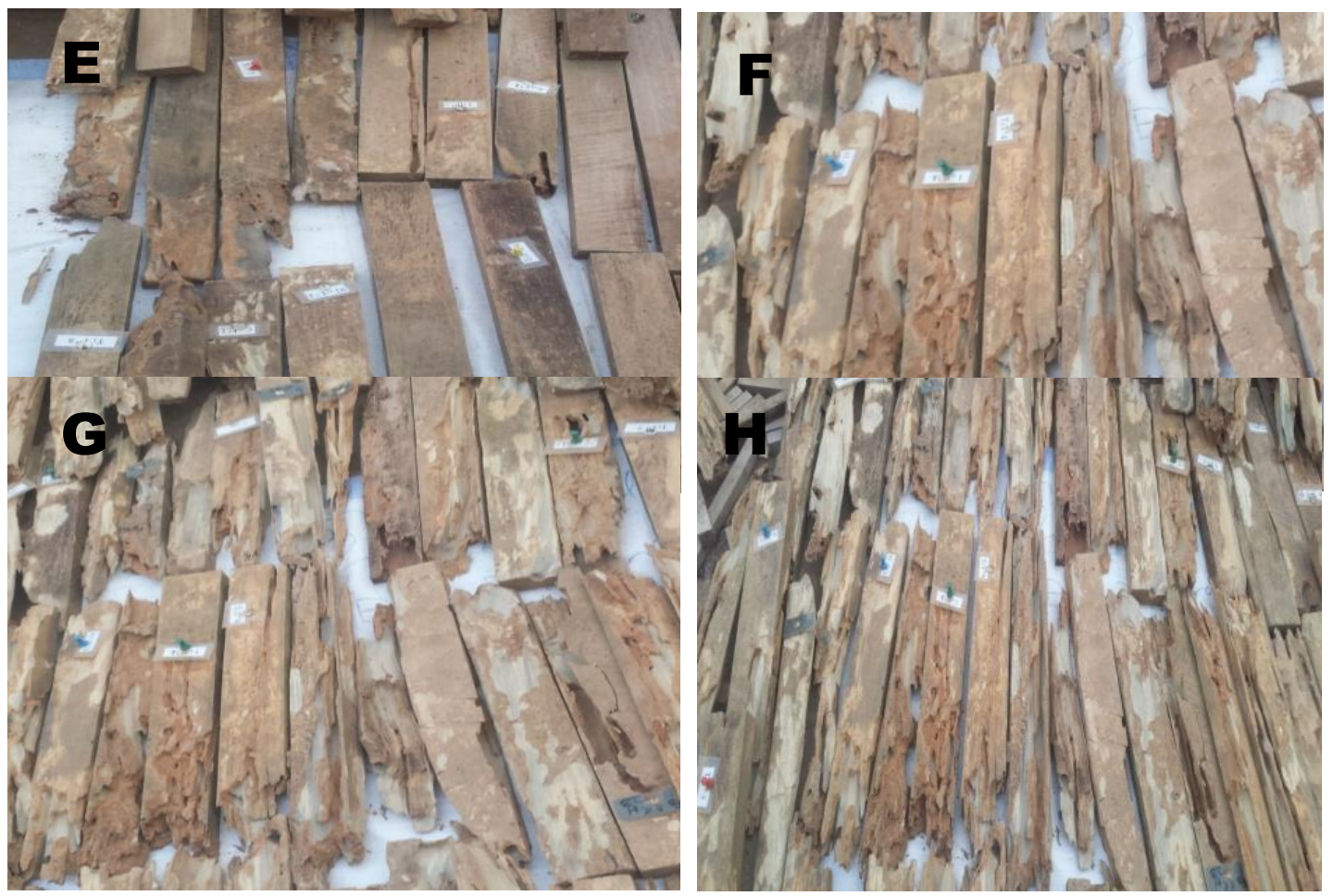

Figure 6: H. floribunda stem heart (E) and branch heart (F) and H. floribunda stem sap (G) and branch sap (H) samples after 12 months field exposure (Source: Field photograph) 


\section{CONCLUSIONS}

The heartwood of $N$. papaverifera stem and branch resisted most attack by termites and could be more useful for structural applications when untreated. However, the sap when treated could be used for similar structural applications. Stem and branch wood of $H$. floribunda, may need treatments with preservatives to improve their service live, if it becomes necessary to use them for ground applications. Branchwood of both $N$. papaverifera and $H$. floribunda could consequently be utilized in addition to their stemwood to increase the raw material base of the wood industry.

\section{ACKNOWLEDGEMENTS}

Authors wish to thank Mr James Boakye Acheampong and Ohene Micheal for their assistance during field test.

\section{REFERENCES}

Abbiw, D. K. (1990) Useful plants of Ghana: West African uses of wild and cultivated plants. Intermediate Technology Publications. The Royal Botanic Gardens, Kew, Richmond, UK.

Amoah, M., Appiah-Yeboah, J., \& Okai, R. (2012). Characterization of physical and mechanical properties of branch, stem and root wood of iroko and emire tropical trees. Research Journal of Applied Sciences, Engineering and Technology, 4(12), 1754-1760.

Anon, (2015) Town and Country Planning Department, Ejisu-Juaben Municipal in the Regional Context

Antwi, K. (2018) Characterisation of stem and branch wood of Nesogordonia papaverifera and Holarrhena floribunda species for structural and non-structural applications. Thesis in the Department of Construction and Wood Technology Education, Faculty of Technical Education, submitted to the School of Research and Graduate Studies, University of Education, Winneba, in partial fulfilment of the requirements for award of the Doctor of Philosophy (Wood Science and Technology) degree

Antwi-Boasiako, C., \& Damoah, A., (2010). Investigation of synergistic effects of extracts from Erythrophleum sauveolens, Azadirachta indica, and Chromolaena odorata on the durability of Antiaris toxicaria. Department of Wood Science and Technology, Faculty of Renewable Natural Resources, Kwame Nkrumah University of Science and Technology, Kumasi, Ghana. International Biodeterioration \& Biodegradation (Impact Factor: 2.24). 64(2):97-103.

Ayarkwa, J., Hirashima, Y., \& Sasaki, Y., (2000). Potential Contribution of Branchwood Quantity Left after Logging Operations, Towards Reducing Depletion Rate and Preserving Ghana's Forest Ecosystem. American Journal of Agriculture and Forestry. 1(2), 32-39.

Bao, F. C., Jiang, Z. H., Jiang, X. M., Lu, X. X., Luo, X. Q. \& Zhang, S. Y. (2001). Differences in wood properties between juvenile wood and mature wood in 10 species grown in China. Wood Science and Technology 35(2001)363-375. Springer.

Boampong, E., Effah, B., Antwi, K., Boadi Asante, A., Nti A. J., (2015). Factors Influencing the Choice of Timber for Furniture and Joinery Production in Ghana. European Journal of Engineering and Technology, 3(5), 12-16 
Dadzie, P. K. (2013). Potential Contribution of Branchwood Quantity Left after Logging Operations, Towards Reducing Depletion Rate and Preserving Ghana's Forest Ecosystem. American Journal of Agriculture and Forestry. 1 (2), 32-39.

Dadzie, P. K., \& Amoah, M. (2015). Density, some anatomical properties and natural durability of stem and branch wood of two tropical hardwood species for ground applications. European Journal of Wood and Wood products. Springer-veklag Berlin Heidelberg.

DeBell, J., Morrell, L. L., \& Gartner, B. L., (1999). Within-stem variation in tropolone content and decay resistance of second-growth western red cedar. Forest Science. 45 (2): 101107.

Eaton, R. A., \& Hale, M. D. C., (1993). Wood decay, pests and protection, 546. Cambridge: Chapman and Hall, University Printing house.

Effah, B., Osei, J. K., \& Antwi, K., (2013). Examining the physical properties and within tree variability in the physical properties of two lesser-known timber species in Ghana. International Journal of Science and Technology, 3 (8): 328-332.

EN 252 (1989) Field test method for determining the relative protective effectiveness of a wood preservative in ground contact. European Committee for Standardization.

EN 350-1 (1994) Durability of wood and wood based products-Natural Durability of solid woodPart 1: Guide to the principles of testing and classification of the natural durability of wood. European Committee for Standardization.

Hawthorne, W. \& Gyakari, N. (2006). Photo guide for the forest trees of Ghana: tree spotters guide for identifying the largest trees, Oxford Forestry Institute, UK.

Hilton, M. (2001) In Dadzie, P. K. (2013). Potential Contribution of Branchwood Quantity Left after Logging Operations, Towards Reducing Depletion Rate and Preserving Ghana's Forest Ecosystem. American Journal of Agriculture and Forestry. 1 (2), 32-39.

Kumi-Woode, B. G. (1996). Natural decay resistance of some Ghanaian timbers and wood decay hazard potential for Ghana, 98. Msc. Thesis. Faculty of Forestry. Lakehead University Thunder bay, Ontario: Canada.

Ministry of Food and Agriculture (2013) Ashanti Region, Kumasi metropolitan, background and location, ministry of food and agriculture, Republic of Ghana. Retrieved from https://mofa.gov.gh/site/?page_id=818. Accessed 11th October, 2018.

Poku, K., Wu, Q. \& Vlosky, R., (2001). Wood properties and their variations within the tree stem of lesser-used species of tropical hardwood from Ghana. Wood and Fiber Science 33 (2): 284-291.

Quartey A. G. (2009). Doctoral Thesis: Relationships between some anatomical, physical and durability properties of the wood of some lesser utilised Ghanaian hardwoods. Faculty of Renewable Natural Resources, Kwame Nkrumah University of Science and Technology library, Kumasi

Biography 


\title{
Accelerated Biodegradation of Kenaf Fiber/Soy Protein Composites Using Pectinase under Soil Burial Condition
}

\author{
Yu Fu \\ yufu@my.unt.edu \\ Sheldon Shi \\ sheldon.shi@unt.edu \\ Liping Cai \\ liping.cai@unt.edu \\ University of North Texas, USA
}

\begin{abstract}
Kenaf bast is one kind of popular natural fibers used as reinforcement of composites. Compared to synthetic or petroleum-based fibers, it is biodegradable and environmentally friendly. However, the biodegradation time of kenaf fiber composites can be long according to the environmental condition. In many cases, it would be important that the degradation time could be controllable. Pectinase is an enzyme that catalyzes the degradation of pectin. This study investigates the biodegradation behavior of kenaf fiber and soy-based composite (KSC) under soil burial conditions with and without pectinase. The specimens were buried in soil and kept at constant temperature and humidity. The thermal, mechanical, morphological properties and weight loss of composites were evaluated as a function of time. The results indicated that the pectinase enzyme could be used to accelerate the degradation process of KSC significantly.
\end{abstract}

Biography 


\title{
Proceedings of the 2020 Society of Wood Science and Technology International Convention
}

\section{Impact of forest disturbances on wood quality: a review}

\author{
Francesco Negro \\ francesco.negro@unito.it \\ Davide Ascoli \\ d.ascoli@unito.it \\ Matteo Garbarino \\ matteo.garbarino@unito.it \\ Raffaella Marzano \\ raffaella.marzano@unito.it \\ DISAFA, University of Torino, Italy
}

\section{Abstract}

Climate and land use changes are triggering an increase in frequency and severity of natural disturbances in forest ecosystems (fire, wind and ice storms, insect and fungi outbreaks, avalanches, floods and droughts). These events can strongly affect the quality of wood coming from disturbed sites, where quality is intended as its capability to meet the requirements of specific products and end uses.

The presentation illustrates how the scientific literature of the last 20 years has been studying the impacts of forest disturbances on different aspects related to wood quality (e.g. density, mechanical properties, storage methods, etc.). To this purpose, a bibliographic search was run on the Scopus database by matching different terms related to forest disturbances and wood quality. Based on the consistency with the topic, 37 documents were extracted, of which $30 \%$ published in the past five years. Wildfires and droughts resulted the most studied disturbances. Three main fields of research, evidently interconnected, can be identified: (I) impacts on wood quality, e.g. physico-mechanical properties of wood exposed to disturbances; (ii) changes in the anatomical features of wood, e.g. vessels size and density change depending on environmental stresses; (iii) effects on the timber market, e.g. relation between delay in salvage and timber costs. Severe disturbances can restrict the use of wood to the less value added applications, up to limiting it to the energy uses only as time passes since disturbance.

Overall, the outcome indicates that various aspects have been addressed, but several knowledge-gaps remain to be investigated. In the coming years this could represent a relevant field of research in the forest-wood sector.

Keywords: climate change, forest disturbances, research, wood quality

Biography 
Proceedings of the $\mathbf{2 0 2 0}$ Society of Wood Science and Technology International Convention

\author{
Wood Modification and Preservation \\ Chairs: \\ Anna Sandak, InnoRenew CoE and University of Primorska, Slovenia \\ Dick Sandberg, Luleå University of Technology, Sweden
}

\title{
Investigation on Thermo-Hydro Mechanical Treatments effects to densify Tasmanian planted and native timber species
}

\author{
Michelle Balasso 1 \\ michelle.balasso@utas.edu.au \\ Andreja Kutnar2 \\ andreja.kutnar@innorenew.eu \\ Eva Prelovšek Niemeläs \\ eva.prelovsek@innorenew.eu \\ Marcia Mikuljan3 \\ marica.mikuljan@innorenew.eu \\ Gregory Nolan \\ gregory.nolan@utas.edu.au \\ Nathan Kotlarewskis \\ nathan.kotlarewski@utas.edu.au \\ Julianne O'Reilly5 \\ julianne.oreilly@utas.edu.au
}

${ }_{1}$ School of Natural Sciences, ARC Training Centre for Forest Value, University of

Tasmania, Australia

2InnoRenew CoE \& University of Primorska, Slovenia

3InnoRenew CoE, Slovenia

4 School of Technology, Environments and Design, University of Tasmania,

Launceston, Tasmania, Australia, Centre for Sustainable Architecture with Wood, University of Tasmania, Australia

5 School of Technology, Environments and Design, University of Tasmania, Launceston, Tasmania, Australia ARC Training Centre for Forest Value, University of Tasmania, Hobart, Tasmania, Australia

\section{Abstract}

Young and fast grown plantation timbers differ in quality and product performances due to the higher amount of juvenile wood and the presence of features, which are deemed to decrease the overall wood density and structural performances, hindering their adoption and use in structural applications.

Wood modification treatments as densification have been developed to address the major issues related to wood properties such as density, durability, insulation capacities and workability, as well as overall inplace performances. In particular Thermo-Hydro-Mechanical treatments (THM) have been the innovation for wood densification, as the combined use of pressure and high temperatures in a steamed 


\section{Proceedings of the 2020 Society of Wood Science and Technology International Convention}

environment has shown great advantages in lowering the damages to the timber while maintaining the shape effect of the treatments.

In this study, three Australian timbers were used to test the effects of THM treatments and their potential to densify fibre-grown plantation hardwood and softwood (Eucalyptus nitensH. Deane \& Maiden and Pinus radiata D. Don) as well as native Tasmanian eucalypts, commercially known as Tas Oak (a mixture of E. regnans F. Muell, E. obliqua L'Hér and E. delegatiensis L'Hér). Samples with a thickness of $8 \mathrm{~mm}$ were densified under THM treatments to a final thickness of $5 \mathrm{~mm}$, and the effects of the densification were studied through the evaluation of Post-THM density, densification ratio, mass loss, spring-back, set recovery after a cycle of water soaking and drying, dimensional change and water absorption rate.

Marked differences were observed for the three species, which compressed at different degrees; the treatments remarkably increased the densities of the timbers, with $E$. nitensobtaining the highest degree of densification $(+153 \%)$ and the lowest mass loss $(2.42 \%)$. Similar results were found for the other fastgrown species, $P$. radiata, while the native specimens achieved, on average, the lowest degree of densification and the highest mass loss (4.13\%). The evaluation of the shape recovery after water soaking revealed the strong reaction of the softwood species, which achieved the highest set recovery $(75 \%)$ due to the extremely high water-absorption rate. E. nitens and Tas Oak specimens showed higher performances in maintaining the final thickness, with both presenting less than $30 \%$ of set-recovery.

This first investigation of effects of THM treatments on Tasmanian timber species, especially fibre-grown plantation wood, has shown the opportunity to achieve satisfactory outcomes to ameliorate the timber properties through densification and the main areas where further investigation is needed. These results open to future structural properties investigation for a full characterisation of the quality of modified timber and additional studies on possible uses of densified plantation timbers for Engineered wood applications, such as high-quality floorings.

The authors acknowledge the Society for Wood Science and Technology which funded the Short-Term Scientific Mission in which the project was developed.

\section{Biography}




\title{
Prospects for powder coatings
}

\author{
Olha Baranova 1 \\ olhabaranovaa@gmail.com \\ Olena Pinchevska 1 \\ olenapinchevska@nubip.edu.ua \\ Kravchenko Olga2 \\ kravchenko@uhl-mash.com.ua \\ Valentyn Sviderskiyз \\ xtkm@kpi.ua \\ Denis Zavialov1 \\ lazarovuch@ukr.net
}

\begin{abstract}
1 National University of Life and Environmental Sciences of Ukraine, Ukraine 2 LLC "UHL-MASH", Ukraine

з National Technical University of Ukraine "Igor Sikorsky Kyiv Polytechnic Institute, Ukraine
\end{abstract}

\section{Abstract}

Modern methods of creating protective and decorative coatings make it possible to produce high-quality, resistant and durable films. There is a wide range of choice of protective and decorative coatings for wood and wood materials. Painting material is chosen depending on the conditions of product material. Today paints and varnishes, which consist high-quality films with decorative and performance indicators, and also satisfy environmental indicators - complex multicomponent systems. Some of them have a number of mandatory components that cause a negative impact on the environment. Today, there is great potential for powder coatings for MDF wood-based panels, which due to their homogeneous structure. It is important to select the necessary material, as well as the corresponding technological process, which will provide the necessary quality indicators of the coating and their low costs, in particular, the finishing of profile surfaces.

Biography 


\title{
CHARACTERIZATION OF SPRUCE LOG SOAKING WATER AND ITS ANTIFUNGAL AND WOOD PRESERVING PROPERTIES
}

Aitor Barbero-Lópezı, Viljem Vek3, Virpi Virjamoı,2, Ida Poljanšek3, Miha Humar3, Primož Oven, Antti Haapala1.

1 School of Forest Sciences, University of Eastern Finland, Joensuu, FI-80101,

Finland * Corresponding author aitorb@uef.fi,Antti.haapala@uef.fi

2 Department of Environmental and Biological Sciences, University of Eastern Finland, Joensuu, FI-80101, Finland virpi.virjamo@uef.fi

3 Department of Wood Science and Technology, University of Ljubljana, Ljubljana, 1000, Slovenia viljem.vek@bf.uni-lj.si,ida.poljansek@bf.uni-lj.si,miha.humar@bf.uni-lj.si, primoz.oven@bf.uni-lj.si

\begin{abstract}
In this experiment, spruce log soaking liquid that is a residue from veneer manufacturing was characterized. Its antioxidant activity, antifungal activity against Gloeophyllum trabeum and Trametes versicolor, and its wood preserving potential when exposed to $T$. versicolor were evaluated. The results showed that spruce log soaking liquid contains several phenolic compounds, including tannins, that are known to inhibit fungal growth. The industrial specimen tested did not inhibit the fungal growth nor protect wood from decay. The presence of sugars is suggested as a reason of the inefficiency against the fungi in parallel to the structure of the phenols. It is concluded that the chemicals dissolved in spruce bark soaking liquids are not useful ingredients for wood preservative formulations against wood-decaying fungi, but further tests are warranted as several chemicals found on this side-stream are known inhibitors of fungi in more purified form.
\end{abstract}

Key words: log soaking extracts; wood degradation; wood decay; biorefining 


\section{INTRODUCTION}

Log soaking is a standard pre-treatment before debarking and lathing of logs when making veneer, and plywood thereof. During this process, the logs are submerged in pits with warm water-different wood species will require different water temperature (Rohumaa et al. 2016) - for several hours or days until the bark and wood is softened and logs can be processed further. In Nordic countries, such as Finland, the temperatures used for the water are between $20^{\circ} \mathrm{C}$ and $70^{\circ} \mathrm{C}$, but they depend a lot on the outdoor conditions (Rohumaa et al. 2016) and the company specific practices in manufacturing the veneer (Dupleix et al. 2013). The water used in log softening turns into yellowish to brown, depending on the process and wood species, indicating the dissolution of some constituents of the bark and wood during the process. During the year, considerable concentration of chemical compounds enrich in log soaking waters as the bark residues are seldom cleared and water is replaced either very gradually or only a few times each year.

Wood industry is looking for green antifungal compounds to be used in wood preservatives due to increased public awareness and legislative issues. Many of the traditional chemicals are under pressure from European and national environmental agencies to have limitations related to chemical legislation as with the case of chromated copper arsenate in 1990s (Liu et al. 2018), especially in Europe and North America. Wood-derived chemicals are considered as an interesting alternative to traditional wood preservatives because some have demonstrated antifungal properties, such as tannins (Anttila et al. 2013), beech wound-wood methanolic extracts (Vek et al. 2013) and pyrolysis distillates (Barbero-López et al. 2019). The extractives used for wood preservative formulations should ideally come from industrial residues to reduce the costs and promote the material efficiency highlighted as a goal of i.e. bio- and circular economy initiatives. Thus, characterizing wood industry side-streams, such as the pit water is a key step in valorizing the thus far unused chemical streams of wood processing.

The aim of this study is to characterize the spruce log soaking pit water (SPW), to test its fungicidal properties against wood-decaying fungi and the effects on wood decay if the condensed pit water is used to impregnate wood.

\section{METHODOLOGY}

The specimen of $100 \mathrm{~L}$ of soaking water was obtained from a plywood mill site. The total amount of dry extracts in SPW was determined gravimetically. The sucrose, D-fructose and D-glucose was analyzed from filtered (Whatmann 42 ashless) liquid samples with K-SUFRG enzymatic assay kit (Megazyme, Ireland) according to the manufacturer's protocol. The concentration of small molecular weight phenolics was done using a High Performance Liquid Chromatography 
(HPLC) and compared to commercial standards for quantification following the same method as in Barbero-López et al. (2020). Condensed tannins (i.e. proanthocyanidins) were analyzed from HPLC-samples with acid-butanol assay and UV-Vis colorometry according to Hagerman (2011). Purified Picea abies bark tannins (Hagerman 2011) were used as a standard for quantification of tannins in SPW.

The antioxidant activity of the SPW was evaluated by measuring its DPPH radical scavenging activity (Brand-Williams et al. 1995; Mensor et al. 2001). An agar diffusion test was performed in petri dish (Humar and Pohleven 2007; Vek et al. 2013) to test the antifungal activity of the log soaking water and Silvanolin-a commercial reference-against Gloeophyllum trabeum and Trametes versicolor. Lastly, Scots pine sapwood (Pinus sylvestris) and European beech (Fagus sylvatica) wood was impregnated with a dilution of SPW containing $1 \%$ of dissolved solids and exposed to the white rot fungus $T$. versicolor during 16 weeks, according to mini block procedure explained in Lu et al. (2016), to determine fungicidal properties of treated wood. 


\section{RESULTS AND DISCUSSION}

The total dissolved material concentration in the SPW was $1.3 \%$. None of the tested samples gave sufficiently high composition for quantitative analyses of sucrose, D-fructose and D-glucose. However, other sugars that were not tested may be present in the spruce log soaking liquids. The HPLC results showed that lignans were the most common phenolic compounds in SPW, but procyanidins, flavonoids, stilbenes and phenolic acids were also present at low concentrations. The results of the acid-butanol assay showed a concentration of condensed tannins of 372.3 $\mathrm{mg} / \mathrm{L}$.

The DPPH radical scavenging activity of the SPW was lower than with the reference antioxidant; butylated hydroxyanilsole, ascorbic acid and gallic acid at concentrations of $500 \mathrm{mg} / \mathrm{L}$, or lower. However, at a concentration of $1000 \mathrm{mg} / \mathrm{L}$, SPW's antioxidant activity was $77 \%$, similar to tested references, between $84 \%$ and $88 \%$.

The SPW had no antifungal activity against the tested wood-decaying fungi while the commercial reference sylvanolin was able to inhibit both fungi (Table 1). Additionally, the SPW solids at higher concentration caused a little promotion of the fungal growth in both fungi species. Similar results were found in the miniblock test, where the European beech wood blocks mass loss was $41 \pm 3 \%$ when impregnated with distilled water (controls) and $40 \pm 3 \%$ when impregnated with $1 \%$ SPW dissolved solids. In the case of Scots pine sapwood, distilled water impregnated wood lost $33 \pm 5 \%$ mass, very similar to the $26 \pm 2 \%$ mass loss that happened in the SPW impregnated wood.

Table 1: Antifungal activity of the spruce log soaking liquid (SPW) against Gloeophyllum trabeum and Trametes versicolor. The values are given in mean inhibition $\% \pm$ standard error, calculated from a total of 6-9 replicates, depending on the fungus and treatment.

\begin{tabular}{lcc}
\hline & \multicolumn{2}{c}{ Inhibition $(\% \pm$ S.E. $)$} \\
& G. trabeum & T. versicolor \\
\hline SPW 5\% & $-8 \pm 3$ & $-8 \pm 4$ \\
SPW 1\% & $3 \pm 2$ & $9 \pm 5$ \\
Sylvanolin 5\% & $47 \pm 1$ & $73 \pm 2$ \\
Sylvanolin 1\% & $33 \pm 3$ & $49 \pm 7$ \\
\hline
\end{tabular}


The results of this study indicate that the SPW are rich in chemicals with known antifungal activity, such as tannins and have antioxidant activity. However, these liquids did not inhibit the wood-decaying fungi tested neither in the diffusion nor in miniblock test, and their antifungal activity decreased when their concentration was increased. This may indicate that other chemicals that can promote fungal growth, such as sugars, might be present and hinder their effects, as previously found and discussed in other bio-based extracts (Barbero-López et al. 2018, Barbero-López 2020). In addition, some fungi has developed the ability to tolerate some of the phenolic compounds, predominately the ones similar to the structure of lignin.

Thus, further tests are needed to identify the presence of other constituents in soaking liquids, as well as testing their properties and antifungal efficiency after being purified.

\section{REFERENCES}

Anttila A-K, Pirttilä AM, Häggman H, Harju A, Venäläinen M, Haapala A, Holmbom B, Julkunen-Tiitto R (2013) Condensed conifer tannins as antifungal agents in liquid culture. Holzforschung 67: 825-832.

Barbero-López A (2020) Antifungal activity of several vegetable origin household waste extracts against wood-decaying fungi in vitro. Waste Biomass Valorization.

Barbero-López A, Chibily S, Tomppo L, Salami A, Ancin-Murguzur FJ, Venäläinen M, Lappalainen R, Haapala A (2019) Pyrolysis distillates from tree bark and fibre hemp against wood-decaying fungi. Ind Crops Prod 129: 604-610.

Barbero-López A, Monzó-Beltrán J, Virjamo V, Akkanen J, Haapala A (2020) Revalorization of coffee silverskin as a potential feedstock for antifungal chemicals in wood preservation. Int Biodeterior Biodegradation.

Barbero-López A, Ochoa-Retamero A, López-Gómez Y, Vilppo T, Venäläinen M, Lavola A, Julkunen-Tiitto R, Haapala A (2018) Activity of spent coffee ground cinnamates against wood-decaying Fungi in vitro. BioResources 13: 6555-6564.

Brand-Williams W, Cuvelier ME, Berset C (1995) Use of a free radical method to evaluate antioxidant activity. LWT - Food Science and Technology 28: 25-30.

Dupleix A, Denaud L-E, Bleron L, Marchal R, Hughes M (2013) The effect of log heating temperature on the peeling process and veneer quality: beech, birch, and spruce case studies. Eur J Wood Prod 71: 163-171. 
Hagerman AE (2011) Tannin Handbook. Department of Chemistry \& Biochemistry, Miami University, Oxford, $\mathrm{OH}$.

http://www.users.muohio.edu/hagermae/tannin.pdf

Humar M, Pohleven F (2007) Experiences with non-standard test methods for estimation of fungicidal properties and mode of fungicidal action Pro Ligno 3: 1725 .

Liu M, Zhong H, Ma E, Liu R (2018) Resistance to fungal decay of paraffin wax emulsion/copper azole compound system treated wood. Int Biodeterior Biodegradation 129: 61-66.

Lu J, Venäläinen M, Julkunen-Tiitto R, Harju AM (2016) Stilbene impregnation retards brown-rot decay of Scots pine sapwood. Holzforschung 70: 261-266.

Mensor LL, Menezes FS, Leitão GG, Reis AS, dos Santos TC, Coube CS, Leitão SG (2001) Screening of Brazilian Plant Extracts for Antioxidant Activity by the Use of DPPH Free Radical Method. Phytother Res. 15: 127-130.

Rohumaa A, Yamamoto A, Hunt CG, Frihart CR, Hughes M, Kers J (2016) Effect of Log Soaking and the Temperature of Peeling on the Properties of Rotary-Cut Birch (Betula pendula Roth) Veneer Bonded with Phenol-Formaldehyde Adhesive. BioResources 11: 5829-5838.

Vek V, Oven P, Humar M (2013) Phenolic extractives of wound-associated wood of beech and their fungicidal effect. Int Biodeterior Biodegradation 77: 91-97.

Biography 


\title{
Proceedings of the 2020 Society of Wood Science and Technology International Convention
}

\section{Integrated Flattening and Thermo-Hydro-Mechanical Modification of Bamboo Split}

\author{
Yu Luan \\ luanyu19951125@163.com \\ Changhua Fang \\ fang1979@gmail.com
}

\section{International Center for Bamboo and Ratten, China}

\begin{abstract}
Bamboo is an abundant, sustainable resource in the tropics and subtropics. Owing to faster growth, shorter rotation and higher mechanical strength compared with other species, bamboo, as a supplement to timber, has gained increasing attention for its economic and environmental values over the last three decades. One of the most used engineered bamboo products is laminated bamboo board made of bamboo splits. However, due to the arc shape, bamboo splits have to be planed on four sides to get uniform and rectangular strips before assembling and gluing. During the four-side planing process, a large part (more than 60\%) is removed and wasted. On the other hand, the non-uniform distribution of vascular bundles embedded in the matrix makes bamboo non-homogeneous along radial direction of bamboo culm wall with decreased density and mechanical strength from outer to inner portion. In order to increase bamboo split utilization rate and homogeneity, this study explored an integrated treatment of flattening and thermo-hydro-mechanical (THM) densification on arc-shaped bamboo splits. Green bamboo splits with high moisture content were compressed at $170^{\circ} \mathrm{C}$ and $190^{\circ} \mathrm{C}$ with a special vapor releaser for 20 minutes. After treatment, arc-shaped bamboo splits were flattened. The compression ratio was around $44 \%$. The average density increased from $0.7 \mathrm{~g} / \mathrm{m} 3$ for control samples to 1.15 and $1.16 \mathrm{~g} / \mathrm{m}_{3}$ for treated samples at $170^{\circ} \mathrm{C}$ and $190^{\circ} \mathrm{C}$, respectively. The density and mechanical strength increased significantly with much less differences along the radial direction of bamboo culm wall. The hygroscopicity decreased significantly with much lower moisture adsorption rate after treatment. The compress set recoveries of samples treated at $170^{\circ} \mathrm{C}$ and $190^{\circ} \mathrm{C}$ were $4.2 \%$ and $2.5 \%$, respectively, which are very low.
\end{abstract}

\section{Biography}




\title{
Proceedings of the 2020 Society of Wood Science and Technology International Convention
}

\section{Manufacturing and Optimization of a Cellulose-Based "Green" High- Performance Material}

\author{
Matthias Jakob \\ matthias.jakob@boku.ac.at \\ Ivana Czabany \\ ivana.czabany@boku.ac.at \\ Johannes Konnerth \\ johannes.konnerth@boku.ac.at \\ Wolfgang Gindl-Altmutter \\ wolfgang.gindl-altmutter@boku.ac.at
}

Institute of Wood Technology and Renewable Materials, BOKU-University of Natural Resources and Life Sciences, Vienna, Austria

\begin{abstract}
Although wood and natural fibers exhibit an advantageous combination of good mechanics at comparably low density, they are clearly inferior to well-established structural materials such as metals or polymer composites in terms of absolute strength and stiffness.

Densification is a well-known strategy to enhance the mechanical properties and the homogeneity of wood-based materials and has been known for decades. The transverse compression of wood is the most prominent method. The main challenges using this process are the avoidance of cell wall damages and set-recovery due to heat and moisture. One successful way to compress wood without cell wall damages is a partially delignification of wood to create a more flexible cell wall.

Veneers from different wood species, delignified by two different delignification procedures (organosolv and alkali), were compared to each other before and after delignification and compression procedure. Tensile and bending tests showed that these mechanical properties could be improved.

Lap joint shear test results showed no increase in bonding performance compared to native wood veneers. The characterization of the densified surfaces will be an essential step forward improving bonding performance and thus enable the manufacturing of "green" high-performance materials.
\end{abstract}

Keywords: alkali treatment, delignification, mechanical properties, organosolv treatment, veneers, wood densification, wood modification

Biography 
Proceedings of the $\mathbf{2 0 2 0}$ Society of Wood Science and Technology International Convention

\title{
Parameter Study on a Wood Impregnation Process
}

\author{
Mariana Frias \\ mariana.frias-de-albuquerque.1@ulaval.ca \\ Pierre Blanchet \\ pierre.blanchet@sbf.ulaval.ca \\ André Bégin-Drolet \\ andre.begin-drolet@gmc.ulaval.ca \\ Véronica Landry \\ veronic.landry@sbf.ulaval.ca \\ Laval University, Canada
}

\section{Abstract}

Wood is a renewable resource that has been used as material in interior design products for years. Despite its superior mechanical resistance, different modification processes were developed in order to enhance wood's hardness and make it an even more durable material. Impregnating wood pores with a monomer solution is a common method for that purpose. However, most implemented impregnation processes can be considered wasteful both on used materials and process duration. The comprehension of the parameters that influence monomer penetration through wood may enable an optimization of the process and the chemical impregnation in a specific location of interest in wood instead of the entire piece. For this study, monomer solutions were disposed on the surface of thin samples of hardwood species under different conditions. The analyzed parameters were the pore pattern of each species, the level of vacuum applied in the process and the viscosity of the monomer solution. After the impregnation process, the weight gain of the samples was calculated, and the penetration depth of the fluid was evaluated through density profiles and micro X-ray tomography imaging. Results showed that surface density of wood was increased after the monomer impregnation for all conditions and that the introduction of a level of vacuum for a short period of time already enhanced the penetration depth. Samples imaging and 3D digital reconstruction allowed the comprehension of the process allied to the anatomy of wood. It made it possible to observe that the preferred path of a fluid in wood is through the longitudinal direction but that it can also permeate through the vessel's pits and flow into deeper vessels only with surface impregnation as opposed to industrial's current method of submerging wood pieces into chemicals. An improved impregnation process would make the use of wood products an even smarter and more sustainable choice.

Biography 
Proceedings of the $\mathbf{2 0 2 0}$ Society of Wood Science and Technology International Convention

Inspired by nature: a novel impregnation process for wood preservation

\author{
Shujun Li \\ lishujun_1999@126.com \\ Xiongfei Luo \\ Ixf@nefu.edu.cn \\ Ben Dang \\ Ixf@nefu.edu.cn \\ Zhhijun Chen \\ chenzhijun@nefu.edu.cn \\ Northeast Foresty University, Harbin,China
}

\begin{abstract}
Conventional wood impregnation processes adopt the full cell method, which requires vacuum and press combined treatment to push preservatives into the wood. In this work, a novel impregnation process is proposed. Plant transpiration can generate pull power, which has been used for the researches on stumpage modification of wood, usually with borehole infusion method or tree sap replacement method. Bionic tree transpiration device makes the novel impregnation more suitable for wood preservation with water-borne preservatives.

Biography
\end{abstract}




\title{
Microbial Dyeing - Infection Behavior and Influence of Lasiodiplodia theobromae in Poplar Veneer
}

Yuansong Liu1, Zhiming Yu1,*, Yang Zhang ${ }_{1, *}$, Chusheng Qi1, Ruilin Tang1, Boshi Zhao1, Haowei Wang1, Yiyun Han 1

1College of Materials Science and Technology, Beijing Forestry University, Beijing, 100083, China *Corresponding author: yuzhiming@bjfu.edu.cn (Z. Yu), bjfuzhangyang@bjfu.edu.cn (Y. Zhang)

\begin{abstract}
To seek a greener and more environmentally friendly wood dyeing method, this paper conducted a 35 days microbial dyeing test on bleached poplar by reversely utilizing the blue-strain fungus lasiodiplodia theobromae in poplar. The effects of microbial dyeing on the color properties, chemical composition, micromorphology, and surface properties of poplar veneers were studied. The brightness value and the reflectivity of bleached poplar gradually decreased with the dyeing time, the reflectivity of the front of the veneer was generally maintained at about $5 \%$ after more than 14 days dyeing time, and the $\mathrm{K} / \mathrm{S}$ values gradually increased in the range of $400-700 \mathrm{~cm}-1$, which were all greater than four. After 35 days of biological staining, the hypha of lasiodiplodia theobromae has generally penetrated the poplar veneer with a thickness of about $0.5 \mathrm{~mm}$ through the transverse structure (wood ray, vessel) but showed little effect on the chemical composition of poplar. The subtle difference of the chromatic aberration between the light and water wash could be observed after the dyeing time exceeded 14 days, and the chromatic aberration after illumination and washing was below 3NBS and 1NBS, respectively. In addition, the wettability and tensile modulus of veneer after dyeing showed minor changes.
\end{abstract}

Key words: Microbial dyeing; poplar; stain fungi; lasiodiplodia theobromae

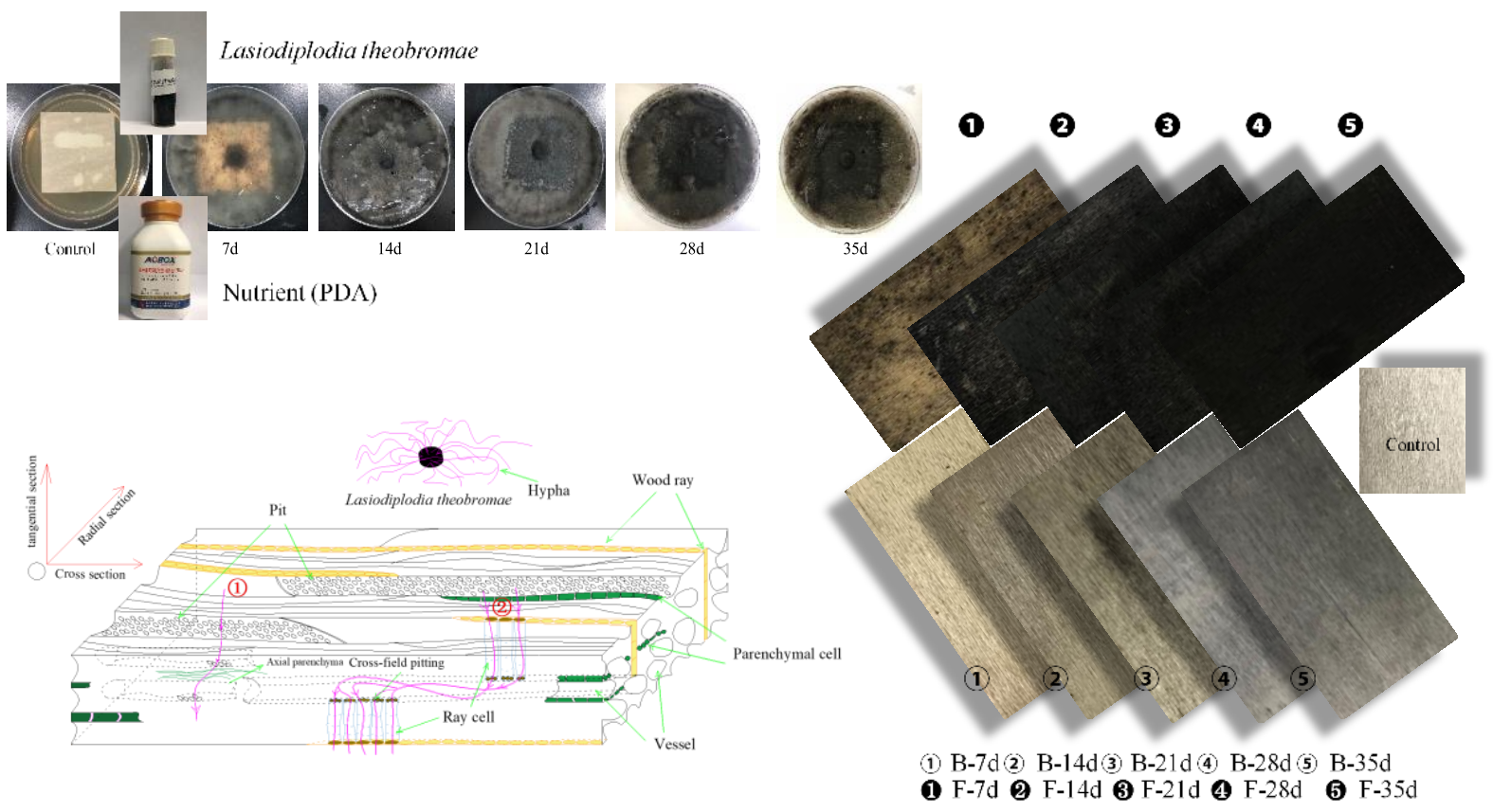

Fig. Diagram of poplar veneer infected by lasiodiplodia theobromae.

Biography 


\title{
Proceedings of the 2020 Society of Wood Science and Technology International Convention
}

\section{Effect of Moisture Content and Preservatives on Discoloration of Oil Palm Lumber}

\author{
Prosper Mensah \\ pmensah@csir-forig.org.gh \\ CSIR-Forestry Research Institute of Ghana, Ghana
}

\section{Abstract}

The subject of deforestation and degradation of tropical forests has attracted a lot of attention in the last two decades culminating in the 1992 Rio Declaration of Forest and Environment. Considering the current rate of expansion of lumber processing industries in Ghana, the current Annual Allowable Cut (AAC) of one million cubic meters of round logs is considered to be insufficient to satisfy the increasing demand of timber industries. one major area which has been highlighted in the forest policy is the introduction of lesser-used species to widen the natural resource base of the forest and to address the imbalance between supply and demand for the resources. in other to properly promote a particular lesser-used species (LUS), it is necessary among other properties to establish their chemical characteristics or behavior, which is making the industry very often shun their use. As a contribution to addressing these problem, oil palm lumber a lesser used species was subjected to different moisture content variation to find out its behavior with respect to discoloration. Samples of oil palm trunk were extracted at Norpalm Oil Mill in the Western Region and Juabeng Oil Palm in Ashanti region. Wood samples of oil palm were condition in a kiln to a moisture content of $15 \%, 20 \%, 25 \%$, $30 \%, 40 \%$ and $50 \%$, while other samples were condition to serve as control. The results obtained cover discoloration, mildew, surface checks, end checks and splits. the effect of the extractives on the discoloration of oil palm lumber was also investigated by means of immersing some samples of oil palm lumber into sea water and clear water for 48 hours respectively. Though, Dusban 4E is a widely used preservative in the timber industry, oil palm lumber samples of $40 \mathrm{~mm}$ thick immersed in Dusban 4E for 48 hours and conditioned in a kiln to a moisture content of $30 \%$ discolored from week 2. However, oil palm lumber samples of $40 \mathrm{~mm}$ thick immersed in clear water for 48 hours and thereafter immersed in Dusban $4 \mathrm{E}$ for another 48 hours and kiln dried to a moisture content of $15 \%$, $20 \%, 25 \%$ and $30 \%$ did not show any discoloration from week 2 to week 18 . It was discovered that in the utilization of oil palm lumber, it should be immersed in clear water for 48 hours before any chemical treatment is given and thereafter kiln drying. From the general results, the species has proved to be good substitute for some of the 'noble' species that are getting extinct from the forest of Ghana.

Keywords: Clear water, Discoloration, Dusban 4E, Elaeis guineensis, Moisture Content, Se

\section{Biography}




\title{
Characterization of some properties of fast-growing Masson pine wood subjected to two-step freeze-silicone oil treatments
}

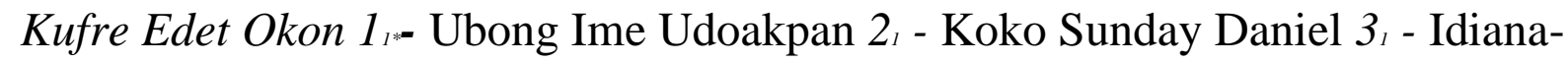
Abasi Kufre Okon4 $4_{2}$ Chukwuemeka Onyinyechi Daphne $5_{3}$

1Lecturer,Forest Superintendent, Lecturer, Department of Forestry and Natural Environmental Management, University of Uyo, Uyo, Akwa Ibom State, Nigeria* kufreokon@uniuyo.edu.ng, ubongudoakpan@gmail.com,kokodaniel@uniuyo.edu.ng,chukwuemeka.onyinyechi @mouau.edu.ng

2Graduate Student and Mrs., Department of Geography and Regional Planning, University of Uyo, Uyo, Akwa Ibom State, Nigeria

udomidiana@gmail.com

\begin{abstract}
This study investigate the properties variations of Masson pine wood undergoing two-step freezesilicone oil treatments. Seven treatments were performed and compared to control: Freezetreatment (FT), freezing followed by silicone oil treatment at 150, 180 and $200{ }_{\circ} \mathrm{C}$ (FTST150, FTST180 and FTST210) and silicone oil treatment at 150180 and 200。 (ST150, ST180 and ST200). The effect of the treatments on the dimensional stability, chemical structure, thermal degradation and wettability were evaluated. Results indicated that the freeze-silicone oil treatments improved the dimensional stability and decreased the hygroscopicity relative to those of the control wood. Freeze-silicone oil treatments also changed the chemical structure by degrading the wood components. The treatments significantly influenced the thermal degradations of the wood as freeze-silicone oil treated samples at 150,180 and $210{ }_{\circ} \mathrm{C}$ presented sharp peaks. The wettability of the treated wood increased, thus preventing the spread of water onthe wood surface.
\end{abstract}

Key words: Thermal modification, contact angle, crystallinity, masson pine

\section{Introduction}




\section{Proceedings of the 2020 Society of Wood Science and Technology International Convention}

The hygroscopicity of wood is responsible for many constraints of utilizing wood for various outdoor applications. This is because, as a natural material containing cellulose, hemicellulose and lignin, wood is susceptible tohygro-expansion and anisotropy (Rostand et al. 2013). Wood modification by two-step freeze-silicone oil treatments is among the various techniques used to improve the quality and serve life of wood.

Thermal modification of wood is the most suitable commercial process for improving wood quality by reducing the affinity of wood to water uptake. The dimensional stability of wood and other characteristics of wood can be improved because wood components undergo degradation under high-temperature treatments (Cui et al. 2017). Although, the techniques of thermal modification is well developed, there is the need to explore other wood modification process in combination with thermal treatment.

Freeze treatment in combination with thermal treatment is a woodmodification technique which has been used recently in the treatment of different species of wood (Missio et al. 2015a, Missio et al. 2016, Okon and Okon 2018). Freeze treatment of wood increases wood permeability (Hur and Kang 1997), reduces shrinkage, collapse and checking in wood (Ilic 1995). According to Awoyemi et al. (2010), during freeze treatment there is the movement of moisture from the cell wall to the lumen water resulting in the expansion of liquid water in the lumen with consequent compressive stress to the cell wall, increase rigidity of the wall and reduction in shrinkage The aim of this study is to investigate the properties variations of wood undergoing two-step freeze-silicone oil treatments. Familiarity with physiochemical properties of modified wood is important because they can significantly influence the performance and broaden the used of the wood in structural application.

\section{Materials \& Methods}

Masson Pine (Pinus massoniana (Lamb.) Hook), a fast-growing wood species was used for this research. Samples were obtained from Fuzhou, Fujian Province, China. The dimension of the samples was $20 \mathrm{~mm}$ (radial) $\times 20 \mathrm{~mm}$ (tangential) $\times 50 \mathrm{~mm} 3$ (longitudinal) made up of straight grain and cut from the heartwood.

Two-step freeze-silicone oil treatments

Freeze Treatment $(F T)$ : Freeze treatment was carried out according to the method described by (Okon and Okon 2018, Missio et al. 2015) with slide modification. Freeze treatment of the samples was performed in refrigerator. 140 samples were frozen from room temperature $(21.5 \mathrm{o})$ to $-22{ }_{\circ} \mathrm{C}$ with an average cooling rate of $0.07 \mathrm{oC}$ min-1. The freezing rate ranged from the temperature of freezing water $(\sim 3 \mathrm{oC})$ to the final freezing temperature $\left(\sim 22{ }_{\circ} \mathrm{C}\right)$. The treatment time was 7 -days, measured after temperature was stabilized at $-22 \mathrm{oC}$. All freeze treated samples were allowed to defrost, then oven-dried at $60 \mathrm{oC}$ to $\sim 12 \%$ moisture content.

Silicone oil Treatment (ST): Parameters of silicone oil treatments performed in this research were defined based on a pilot experiment and previous scientific works (Okon et. al 2017, Okon and Okon 2018).

Two-step freeze-silicone oil treatment (FTST) was performed considering the same parameters described above for the freeze and silicone oil treatments. Seven treatments was performed and compared with the control (Table 1). 


\section{Proceedings of the 2020 Society of Wood Science and Technology International Convention}

Table 1: Experimental procedure for two-step freeze-silicone oil treatment of masson pine wood

\begin{tabular}{|c|c|c|c|c|c|c|}
\hline \multirow[b]{2}{*}{ Treatments } & \multicolumn{3}{|c|}{ Freeze treatment step } & \multicolumn{3}{|l|}{ Silicone oil treatment step } \\
\hline & Condition & Temperature $(\mathrm{o} C)$ & Time $(\mathrm{h})$ & Condition & $\begin{array}{c}\text { Temperature } \\
\left({ }_{\mathrm{o}} \mathrm{C}\right)\end{array}$ & $\begin{array}{l}\text { Time } \\
\text { (h) }\end{array}$ \\
\hline Control & - & - & - & - & - & - \\
\hline FT & Wet & -22 & 168 & - & - & - \\
\hline FTST150 & Wet & -22 & 168 & Climate chamber $(20 \mathrm{oC}$ and $65 \%)$ & 150 & 4 \\
\hline FTST 180 & Wet & -22 & 168 & Climate chamber $(20 \mathrm{oC}$ and $65 \%)$ & 180 & 4 \\
\hline FTST 210 & Wet & -22 & 168 & Climate chamber $(20 \mathrm{oC}$ and $65 \%)$ & 210 & 4 \\
\hline ST150 & - & - & - & Climate chamber $(20 \mathrm{oC}$ and $65 \%)$ & 150 & 4 \\
\hline ST 180 & - & - & - & Climate chamber $(20 \mathrm{oC}$ and $65 \%)$ & 180 & 4 \\
\hline ST 210 & - & - & - & Climate chamber $(20 \mathrm{oC}$ and $65 \%)$ & 210 & 4 \\
\hline
\end{tabular}

FT: freeze treatment, FTST: two-step freeze-silicone oil treatment, ST: silicone oil treatment

Dimensional stability: Anti-swelling efficiency (ASE) and swelling for the control and treated samples were determined according to ASTM-1037 (1999). Water repellent efficiency (WRE) and water absorption (WA) were determine according to Okon and Udoakpan (2018). The thermal stability of the control and treated samples were determined using thermogravimetric analyzer (NETZSCH 44, Germany) under nitrogen atmosphere. The X-ray diffraction (XRD) of the control and treated samples were obtained using (Rigaku Ultima IV, Japan) X-ray diffractometer. Fourier Transform Infrared Spectroscopy (FTIR) of the control and silicone oil treated wood were obtain using Nicolet 6700 infrared spectrophotometer equipped with an ATR accessory with scanning range of 4000-650 cm-1 at the $4 \mathrm{~cm}-1$ resolution for 32 scans.Contact angle of control and treated wood was measured using Drop Shape Analyzer DSA100.Swelling, water repellant efficiency and water absorption data were analyzedusing Analysis of Variance (ANOVA).

\section{Results and Discussion}

Dimensional stability: The results indicated that the dimensional stability of the treated samples improved significantly (Table 2) and enhanced dimensional stability than the control samples. FTST 210 and ST210 treatments presented the highest dimensional stability (swelling and antiswelling shrinkage). Swelling varied from $10.00 \%$ to $3.34 \%$, reflecting a reduction of $66.60 \%$. Anti-swelling shrinkage presented the highest value $(66.86 \%)$ at ST200 treatment (Table 1). Treatments with a heating step (FTST and ST) were more efficient than the freeze treatment (FT) to modifying swelling and anti-swelling shrinkage parameters, this is in line with the report by(Missio et al. 2015). FTST210 and ST210 treatments presented the highest decrease in swelling (3.71\% and 3.34\%) compared to the control, indicating a reduction of $63.23 \%$ and $66.90 \%$ respectively (Table 2). Freeze - silicone oil treatment reduced the swelling of the wood, thus increasing its dimensional stability. This is due to the elimination of the $\mathrm{OH}$ groups of hemicelluloses of the wood caused by degradation as a result of the heat applied in the treatments. 

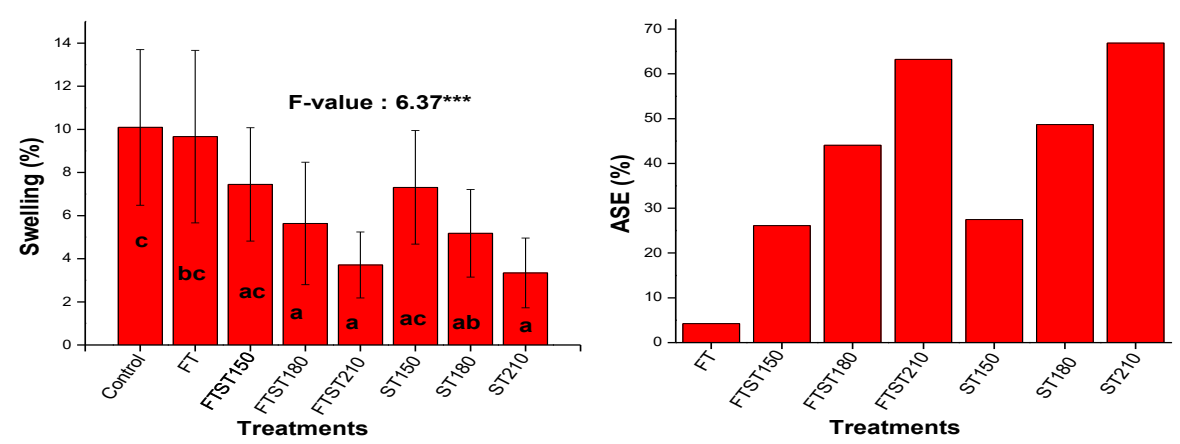

Figure 1: Swelling and anti-swelling efficiency of control and two-step freeze-silicone oil treated Mason Pine wood

Water repellent efficiency and water absorption of control and treated Masson pine wood are present in Figure 1, providing information on the dimensional stability of the wood. WRE values increased marginally with the highest values obtained at FTST210 and ST210. Water absorptionvalues decreased with increase in treatments temperature recording the highest value at ST210.Treatments with a heating step (FTSTand ST) were more efficient than the freeze treatment (FT) to modify WRE and water absorption. This is in line with the investigation by Missio et al. (2016).Based on these results, it is evident thattwo-step freeze-silicone oil treatments applied in this study affectedthe WRE and water absorption of the wood. The loss of methyl radicals of some guaiacyl and syringic units as well as increase in phenolic groups was responsible for the increase in the dimensional stability of wood(Tjeerdsma et al. 1998).
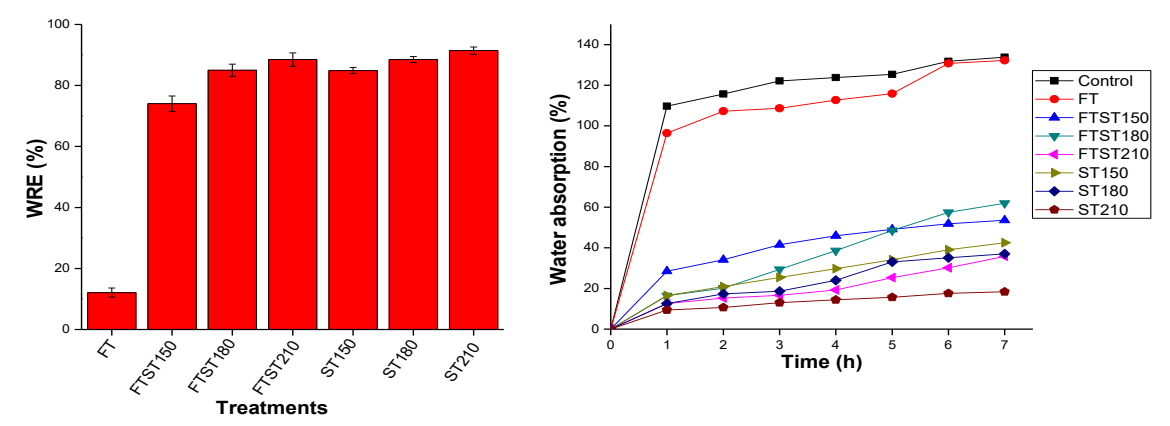

Figure 2: Water repellent efficiency and water absorption of control and treated Mason Pine wood.

X-ray diffraction (XRD) spectra of the control and treated Masson pine wood are presented in Figure 3. Relative significant modification between the spectra of control and treated samples were observed. The diffraction peaks at $2 \theta$ in the XRD patterns were observed at $12.38 \mathrm{o}, 15.72 \mathrm{o}, 22.22 \mathrm{o}$, 35.28 corresponding to (1-10), (110), (200) and (040) of the crystallographic plane of cellulose with regards to the characteristic diffraction peaks of cellulose I $\beta$ while definite peak occurred at the maximum of $22.2^{\circ}$. The intensity of diffraction peaks at 35.28 o were stable, this is because the glucan chains of cellulose were not destroyed. The treatments of wood does not alter cellulose crystallinity or cellulose crystallinestructure, but could affects the size of microfibril bundles and the accessibility of cellulose to water(Sik et al. 2010). 


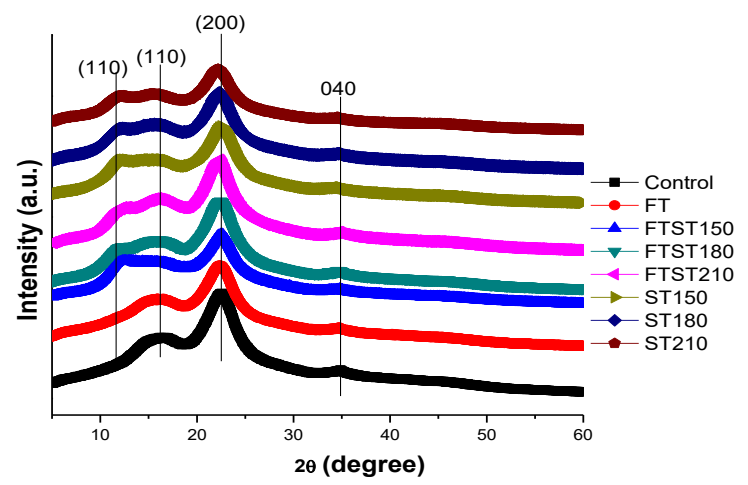

Figure 3: X-ray diffraction pattern of control and treated Masson Pine wood using two-step freeze-silicone oil treatment.

The thermogravimetric analysis (TGA) curves are presented in Figure 5. Weight loss was observed from the TGA curves, in the first stage (dehydration stage) ranging from 27 to $124 \mathrm{oC}$, relating to the evaporation of water in the wood. In the second stage, ranging from $124{ }_{\circ} \mathrm{C}$ to $282{ }_{\circ} \mathrm{C}$ some wood components have degraded,followed by the breakdown of bonds of some complex structures. Thermal degradation of wood was highest in the third stage, between temperatures 282 to $367 \mathrm{oC}$. The wood mass reduction was higher in control and FT samples compared to the treated wood. In the fourth stage, TGA curves werenearly characterized by a flat region and approach zero (gradual mass loss), implying that lignin is almost completely depleted(Lin et al. 2018).

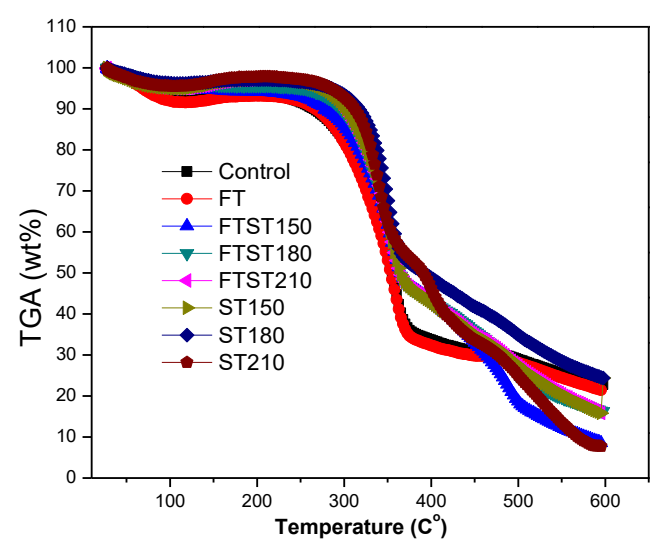

Figure 5: TGA curves of control and two-step freeze-silicone treated Masson Pine wood.

Figure 5shows the FTIR spectra of control and treated Masson pine wood.The absorption bands at $2912 \mathrm{~cm}-1$ and $2950 \mathrm{~cm}-1$ are attributed to $\mathrm{C}-\mathrm{H}$ and $\mathrm{CH} 3$ stretching (Popescu et al. 2013). The absorption band of treated samples increased remarkably at $1253 \mathrm{~cm}$-1corresponding to Si$\mathrm{CH} 3$ stretching in silicone oil. The band at $895 \mathrm{~cm}-1$ in the fingerprint region showed reduction in intensity due to treatmentsand is assigned to $\mathrm{C}-\mathrm{H}$ out-of-plane bending vibration in lignin, cellulose and hemicelluloses (Zheng et al. 2015) as well as Si-C, Si-O and Si-O$\mathrm{CH}_{3}$ groups(Selamoglu et al. 1989). Therefore silicone oil was absorbed by wood, decreasing the hydrophilicity and enhancing the dimensional stability of wood. 


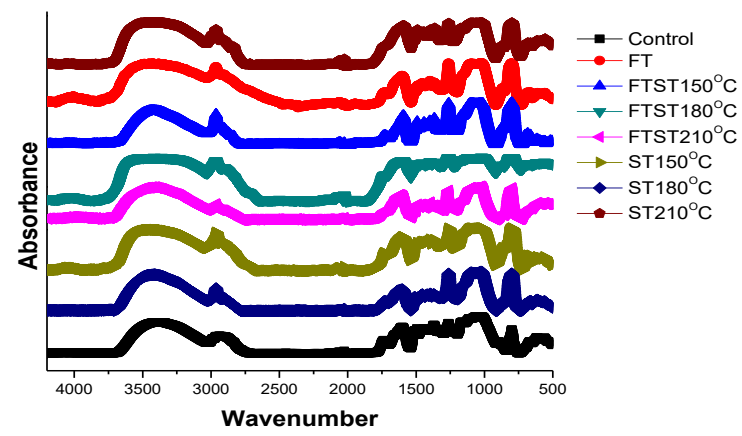

Figure 6: FTIR spectra of control and two-step freeze-silicone oil treated masson Pine wood.

The contact angle of the control and two-step freeze-silicone oil treated masson pine wood is presented in Figure 7, to evaluate the wettability of the wood after treatments. The two-step freezesilicone oil treated samples presented significantly higher contact $(>90 \mathrm{oC})$, compared to less than 90o obtain in control and FT treatments. The freeze treatment step showed low contact angle (Missio et al. 2015a) while the control and FT treatments presented spreading droplet with contact angle $(<90 \mathrm{oC})$ i.e high hydrophilic surface. This indicates that the two-step freeze-silicone oil treatments has an excellent effect on enhancing the surface hydrophobicity of the treated wood. High contact angle $>90^{\circ}$ obtained in FTST150 -FTST210 and ST150 - ST210 treatments implied that the surface of the treated wood becamehighly hydrophobicwith high water repellency.The differences between the contact angles in radial and tangential directions are not significant, however the contact of FT on the radial direction was greater compared to that of the tangential surface.
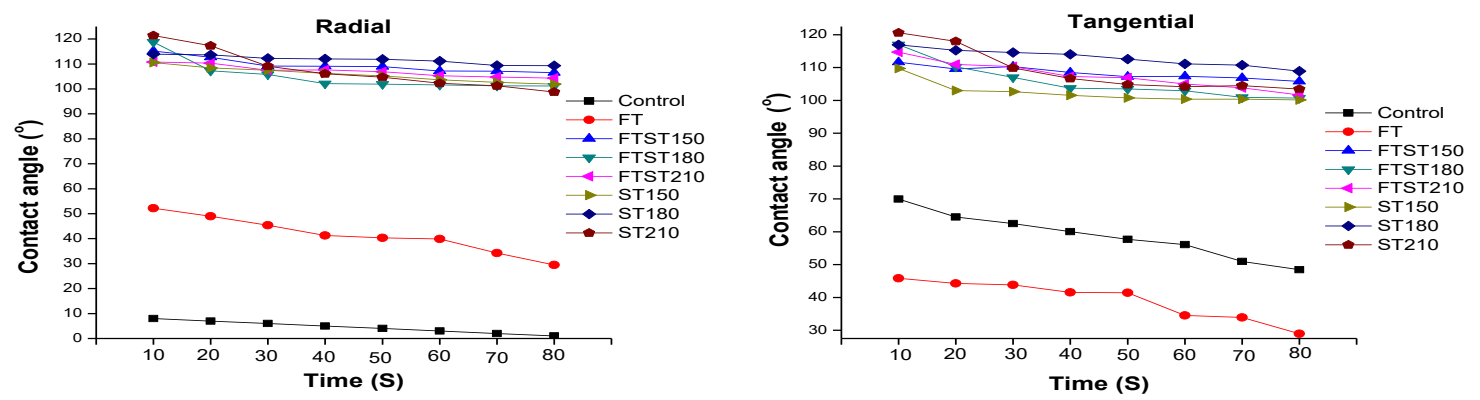

Figure 7: Contact angle of control and two-step freeze-silicone oil treated Masson Pine wood in the radial and tangential sections.

\section{Summary and Conclusions}

Two-step freeze-silicone oil treatments significantly modified the physical and chemical properties of Masson pine wood. The modification pattern of the physical properties were similar in the combined treatments. The treatments enhanced the dimensional stability of the wood by reducing the swelling and water absorption and increased the anti-swelling efficiency and water repellence efficiency of the wood. The relative crystallinity of the wood was increased as a result of the effect of the combined freeze-silicone oil treatment. The TGA curves clearly showed the major 


\section{Proceedings of the 2020 Society of Wood Science and Technology International Convention}

components of the wood were degradation in the control and the treated wood.A significant changes were observed in the FTIR spectra of the treated wood compared to control indicating modification of the wood due to two-step freeze- silicone oil treatments applied. We found that the contact angles of the treated wood were increase due to combined treatments, thus confirming a reduction in hydrophilicity degree of wood surface.

\section{Acknowledgements}

Some parts of this study were carried out in Bio-material Research Group Laboratory at the College of Material Engineering, Fujian Agriculture and Forestry University, China.The authors are grateful to Prof. Biao Huang.

\section{References}

Awoyemi L, Femi-Ola T,Aderibigbe E(2010) Pre-freezing as a pre-treatment for thermal modification of wood. Part 2: surface properties and termite resistance. Journal of the Indian Academy of Wood Science 7(1-2):19-24.

ASTM, American Society for Testing and Materials (1987) ASTM D 143-148. Standard Methods of Testing Small Clear Specimen of Timber. ASTM 143-83. Philadelphia, 48$105 \mathrm{p}$.

Cui W, Zhang N, Xu M, Cai L (2017) Combined effects of ZnO particle deposition and heat treatment on dimensional stability and mechanical properties of poplar wood. Scientific reports, 7(1):9961.

Hur J-Y, Kang H-Y(1997) Measurement of longitudinal liquid permeability using pressure bomb method. Journal of the Korean Wood Science and Technology25(3):66-74.

Ilic J(1995) Advantages of prefreezing for reducing shrinkage-related degrade in eucalypts: General considerations and review of the literature. Wood Science and Technology 29(4):277-285.

Lin B J, Colin B, Chen W H, Pétrissans A, Rousset P, Pétrissans M (2018) Thermal degradation and compositional changes of wood treated in a semi-industrial scale reactor in vacuum. Journal of analytical and applied pyrolysis130:8-18.

Missio A L, Mattos B D, de Cademartori P H, Gatto D (2016) Effects of two-step freezing-heat treatments on Japanese raisintree (Hovenia dulcis Thunb.) wood properties. Journal of Wood Chemistry and Technology36(1):16-26.

Missio A L, Mattos B D, de Cademartori P H, Pertuzzatti A, Conte B, Gatto D A (2015) Thermochemical and physical properties of two fast-growing eucalypt woods subjected to two-step freeze-heat treatments. Thermochimica Acta615:15-22.

Okon K E, Udoakpan U I (2018) Modification of the properties of wood via combination of treatments: Freeze treatment and silicone oil heat treatment part 1. Journal of Forestry, Environment and sustainable development 4(2):55-62.

Okon K E, Okon I E(2018) Modification of the properties of wood via combination of treatments: Freeze treatment and silicone oil heat treatment - Part 2. Emergent Life Sciences Research 4(2):51-57.

Okon K E, Lin F, Chen Y, Huang B (2017) Effect of silicone oil heat treatment on the chemical composition, cellulose crystalline structure and contact angle of Chinese parasol wood. Carbohydrate polymers164:179-185. 
Popescu M C, Froidevaux J, Navi P, Popescu, C M (2013) Structural modifications of Tilia cordata wood during heat treatment investigated by FT-IR and 2D IR correlation spectroscopy. Journal of Molecular Structure 1033:176-186.

Rostand M P, Dubois F, Sauvat N, Fournely E (2013) Strain analysis in dried green wood: Experimentation and modelling approaches. Engineering Fracture Mechanics 105:182-199.

Selamoglu N, Mucha J A, Ibbotson D E, Flamm D L (1989) Silicon oxide deposition from tetraethoxysilane in a radio frequency downstream reactor: Mechanisms and step coverage. Journal of Vacuum Science \& Technology B: Microelectronics Processing and Phenomena7(6):1345-1351.

Sik H, Choo K, Zakaria S, Ahmad S, Yusoff M, Chia C (2010) The influence of drying temperature on the hygroscopicity of rubberwood (Hevea Brasiliensis). Journal of Agricultural Science2(1): 48.

Tjeerdsma B F, Boonstra M, Pizzi A, Tekely P, Militz H (1998)Characterisation of thermally modified wood: molecular reasons for wood performance improvement. Holz als Roh-und Werkstoff 56(3):149.

Zheng A, Jiang L, Zhao Z, Huang Z, Zhao K, Wei G, Li H (2015) Impact of torrefaction on the chemical structure and catalytic fast pyrolysis behavior of hemicellulose, lignin, and cellulose. Energy and Fuels, 29(12): 8027-8034.

Biography 


\title{
Ionic-liquid based fire retardant for wood-based panels
}

\author{
Jussi Ruponen ${ }^{*}$ Jari Kukkonen2 \\ 1 Director, Customer Applications at Palonot Ltd. and Doctoral student at Aalto \\ University, Espoo, Finland* Corresponding author \\ jussi.ruponen@palonot.com \\ 2 Chief Technology Officer, Palonot Ltd., Espoo, Finland \\ jari.kukkonen@palonot.com
}

\begin{abstract}
An ionic-liquid based fire retardant "Palonot F1" was applied to manufacture fire-retardant treated LVL from Norway spruce (Picea abies). The main objective was to study, whether the globally most strict combustion performance requirements would be met by immersion treating the face veneers at green condition. According to the results, fire retardant treated spruce LVL had the performance of a quasi-non-combustible material (Q-NC) determined by the Building Standard Law of Japan. Additionally, Palonot F1 fire retardant reduced by ca. 39\% the charring rate of spruce LVL in comparison to the non-treated reference.
\end{abstract}

Key words: B-s1,d0, fire retardant, ionic liquid, quasi-non-combustible, wood-based panel

\section{Introduction}

The latest and forthcoming developments relating to the use of wood-based panels and to the regulations associated with construction, require that attention be paid to the available fireretardant technologies. Several established fire-retardant technologies provide B fire class (reaction to fire classification EN 13501-1) for various panels, e.g. plywood and LVL. However, the use of chemicals tends to be very expensive. Another negative feature of conventional technologies is that their chemical compositions contain inorganic phosphate salts, such as monoammonium phosphate (MAP), diammonium phosphate (DAP), or boron containing agents, such as borates, which are not environmentally acceptable or are not powerful enough to fulfil Bs1,d0 fire class at low retention levels. Also, wood items treated with fire retardants of the MAP and DAP type, are prone to physical and chemical deterioration if the treated wood panels absorb moisture.

A novel fire-retardant technology solution "Palonot F1" (F1), provides exceptional fire safety at a remarkably low retention level compared to conventional fire-retardant technologies. The fireretardant technology embodied in F1 is based on protic ionic liquid (ILs). F1 is composed of an aqueous solution of bisphosphonate acid, an alkanol amine, and optionally an alkaline agent. The solvent applied is water. F1 contains no substances of very high concern and is a sustainable and non-corrosive fire-retardant solution for wood-based panels and natural-fibre based products. F1 provides the highest $\mathrm{B}-\mathrm{s} 1, \mathrm{~d} 0$ fire retardancy according to EN 13501-1 whilst decreasing the time and effort needed for treatment and reducing the need for drying time and space. In the case of treating hot-pressed plywood after sanding, the panels can be stacked directly after the post- 
manufacture treatment, i.e. in the wet condition - as the penetration of the chemical continues within the stack. F1 meets the requirements for EU fire retardant durability standard (DRF INT

2) and, additionally, F1 treated products achieve emission classes M1 and E1 for building materials.

The urbanised area in Japan is divided into two fire protection districts, i.e. into districts of fire protection and quasi-fire protection. According to the Building Standard Law of Japan, a building with three stories or more must be fireproof within these two fire protection districts. The Japanese fire regulations are based on international standard fire tests including the cone calorimeter test ISO 5660-1. Nowadays, the Japanese Government promotes wooden structures and wooden interior decorations in public buildings as much as possible. Therefore, it is important to develop fireproof structural products such as fireproof LVL, preferably classified at least as a quasi-non-combustible material (Q-NC). The current technologies that base on crystalline salt lead to unsatisfactory changes within the wood product constitution due to excess use of chemicals. The changes include losses in mechanical properties weakening the possibilities of structural use. Additionally, it is desirable to lower the charring rate of LVL. So far, the best practice to secure the fire resistance in large wooden buildings, has been to cover the wood with non-combustible materials, e.g. gypsum boards and by excessive use of expensive sprinkler systems. Finally, the best available techniques for fire proofing pose a dilemma: The wooden buildings are unattractive to the investors, constructors and consumers - either the wooden buildings are very costly, difficult to maintain or the wood itself may be hidden from the bare eye.

F1 provides new possibilities to solve the dilemma. The load-bearing LVL could be overlaid with wooden veneers, impregnated or immersion treated with F1 fire retardant. Another approach would allow the face veneers, i.e. the outermost veneers, to be non-treated, if the LVL is laid up at the production so that the F1 treated veneers are directly next to the surface veneers. In other words, the F1 treated veneers would be placed as the second veneer layer from both the top and the bottom. These applications would enable us to construct fire resistant wooden buildings with real wooden surfaces. With this technology, a fire would not progress inside the load supporting parts, because of the surrounding fire-stop layers.

In order to be classified as a fireproof material in Japan, the heat release rate and the total heat release of a construction product must not exceed $200 \mathrm{~kW} / \mathrm{m}_{2}$ and $8 \mathrm{MJ} / \mathrm{m}_{2}$, respectively, in a cone calorimeter test (ISO 5660-1) at the heat exposure level of $50 \mathrm{~kW} / \mathrm{m} 2$ in horizontal orientation. The time of evaluation depends on the class pursued, being 20 minutes for noncombustible (NC) materials, 10 minutes for quasi-non-combustible (Q-NC) materials and 5 minutes for fire retardant $(\mathrm{FR})$ materials.

The objective of this study was to determine the combustion properties of F1 treated LVL from Norway spruce (Picea abies), according to the Building Standard Law of Japan.

\section{Materials \& Methods}

\section{Preparation of the specimens}


A veneer of Norway spruce (Picea abies), treated with F1, was applied on one surface of hotpressed LVL panels (Figure 1). The thickness of the veneer was $3 \mathrm{~mm}$. Diffusive impregnation was the method to treat green (never dried) veneers. The moisture content (MC) of the green veneers was approximately $100 \%$. Absorption of the impregnation solution in the green veneers was determined by weight percentage gain (WPG), which is a simple measure for chemical uptake in wood. Fire-retardant impregnated veneers were applied as the face veneer to commercially obtained and industrially manufactured LVL panels from Norway spruce (Picea abies). A commercial phenol formaldehyde film was used for adhesion. The lay-up was then hot pressed in a laboratory press under the following pressing parameters: press pressure $2.0 \mathrm{MPa}$, press temperature $130^{\circ} \mathrm{C}$, press time $10 \mathrm{~min}$.

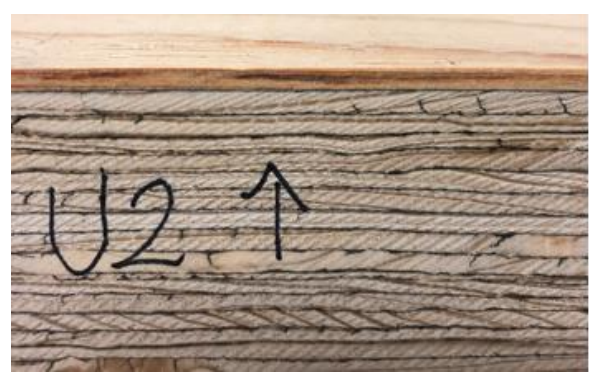

a) before fire test

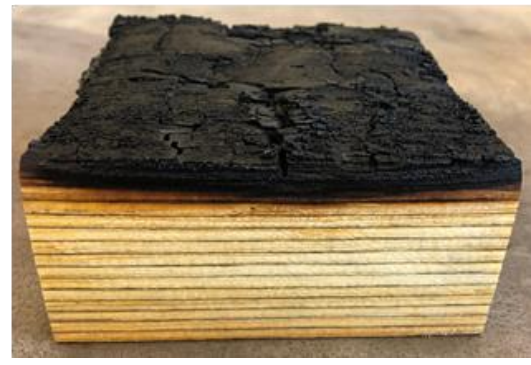

b) after fire test

Figure 1: $\quad$ LVL specimen with F1-treated surface veneer

\section{Testing the combustion performance}

The combustion performance of the hot-pressed and cooled LVL, was evaluated with a cone calorimeter (ISO 5660-1) using a heat flux of $50 \mathrm{~kW} / \mathrm{m} 2$. The test duration was 30 minutes. The cone calorimeter test is a fire test method to assess the contribution of the product tested to the rate of evolution of heat during its involvement in fire. The main parts of the apparatus are a cone-shaped radiant electrical heater with a temperature controller, a spark igniter, a weighing cell, a specimen holder, and an exhaust gas system. A picture of the cone calorimeter is presented in Figure 2.

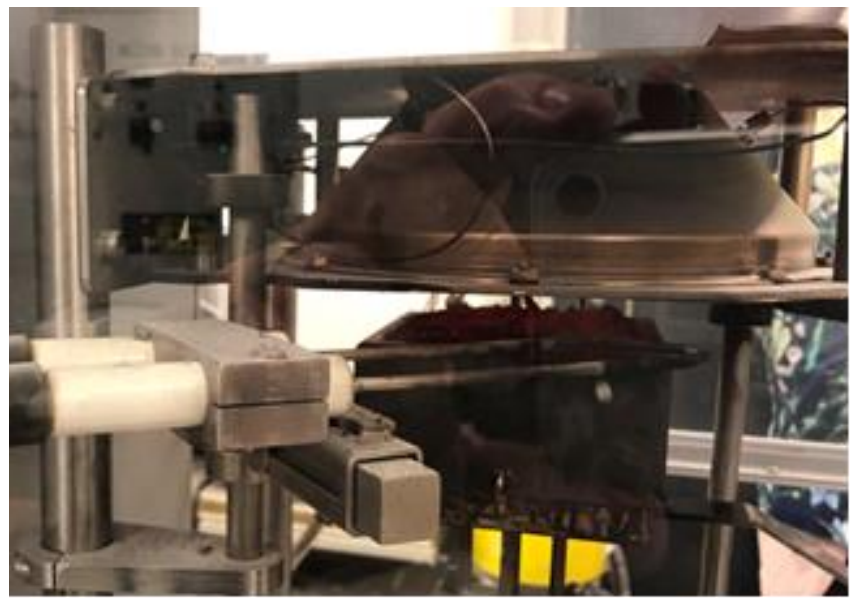

Figure 2: $\quad$ A picture of the cone calorimeter

The speed, at which the charring depth advances in the material, is called the charring rate and it is an essential parameter to depict the fire resistance of wooden structures. The charring rate 
allows the determination of the residual cross-section of the load-bearing wooden structure. After the fire tests, the specimens were cleaved to measure the total charring depth during the test. The charring rate was calculated by dividing the measured charring depth by the test time.

\section{Results and Discussion}

Regarding the final panel properties, the diffusive impregnation of green veneer with F1, is characterised by nil salting-out of the fire-retardant on the veneer surface and by its homogeneous distribution inside the veneer. According to the results, the fire retardancy of LVL was greatly improved by F1 treatment. In order to meet the Japanese fire requirements for building materials, which are said to be globally the strictest, the total heat released must be 8 $\mathrm{MJ} / \mathrm{m} 2$ or less, in 600 seconds for a quasi-non-combustible material, and in 1200 seconds for a non-combustible material. Spruce LVL overlaid with one F1 treated veneer (dry weight of 68.8 $\mathrm{kg} / \mathrm{m}_{3}$ ) exceeded $8 \mathrm{MJ} / \mathrm{m}_{2}$ in $1172 \mathrm{~s}$, which is depicted in Figure 3. Hence, the studied LVL performed as a quasi-non-combustible material (Q-NC) and almost like a non-combustible material (NC), according to the Building Standard Law of Japan. The margin to NC was not more than $28 \mathrm{~s}$. Additionally, the rate of heat release never reaches the threshold value of 200 $\mathrm{kW} / \mathrm{m} 2$ during the test, and hence the LVL in general fulfils the requirements for a construction product (Figure 4).

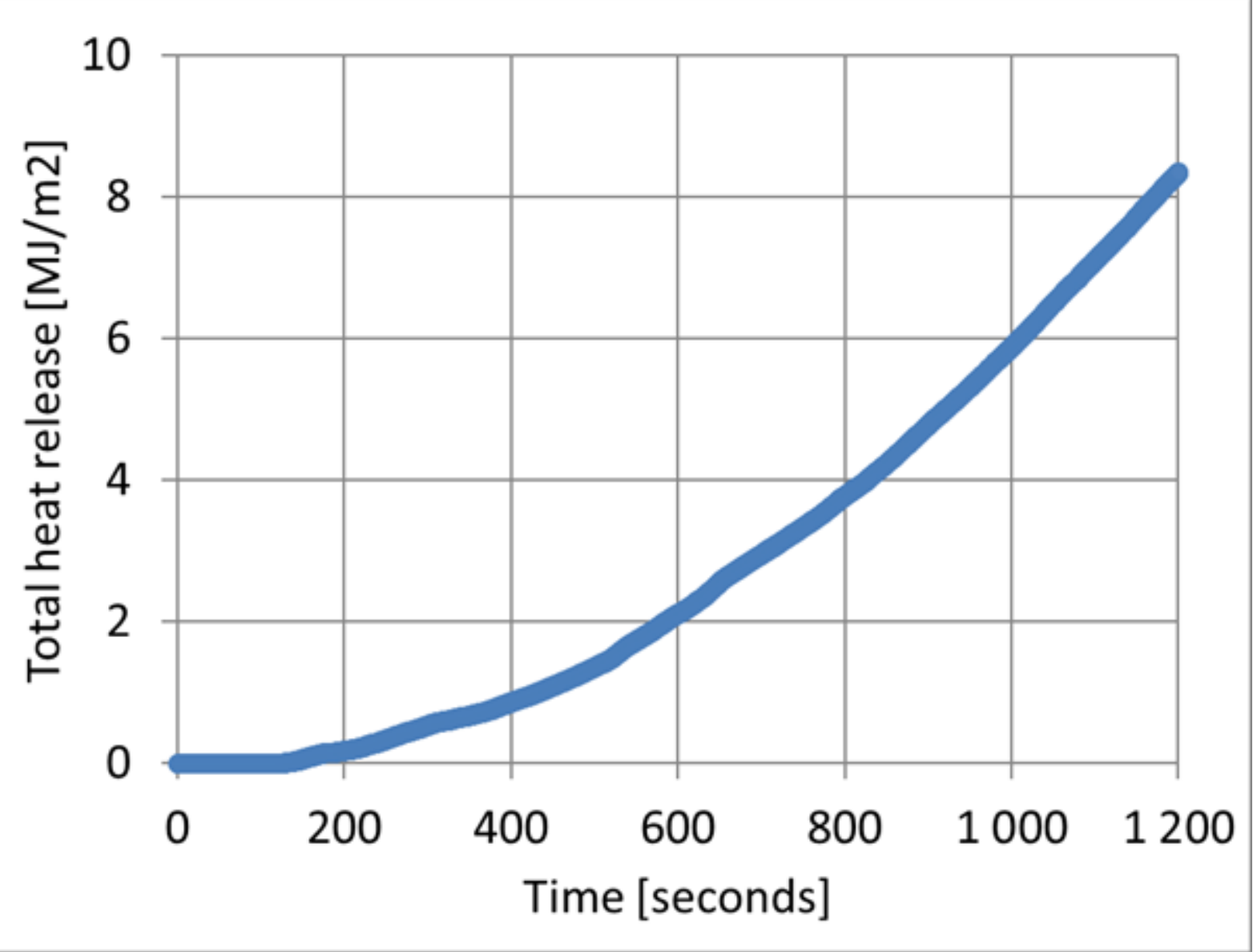

Figure 3: $\quad$ The total heat release according to ISO 5660 illustrated cumulatively. The determinative value of $8 \mathrm{MJ} / \mathrm{m} 2$ is reached after 1172 seconds. 


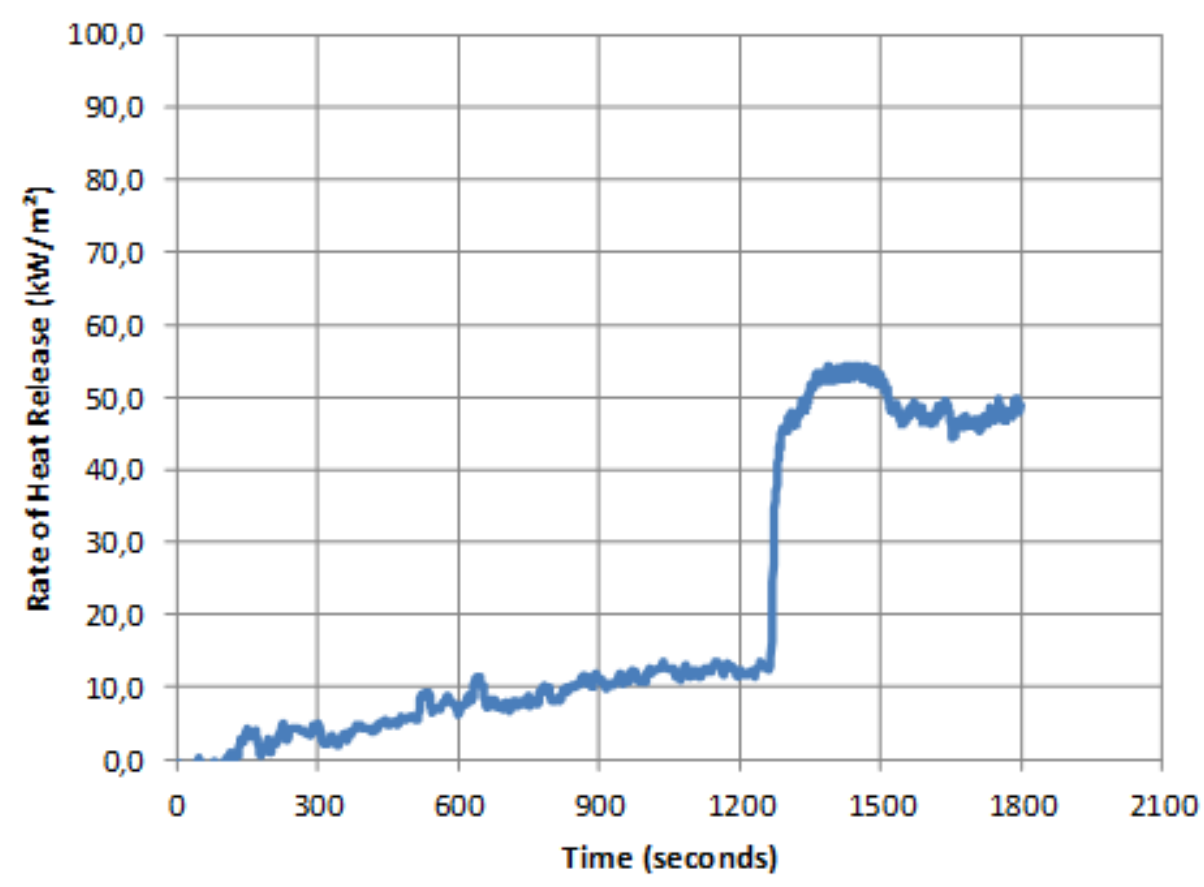

Figure 4: The heat release rate over the observation according to ISO 5660. The threshold value of $200 \mathrm{~kW} / \mathrm{m} 2$ is never reached.

Finally, the results indicate that F1 significantly reduces the charring rate of LVL in comparison to the non-treated LVL reference material. The charring rate of F1 treated LVL was reduced by ca. 39\% compared to that of non-treated LVL within the testing time of $30 \mathrm{~min}$ at a heat flux of $50 \mathrm{~kW} / \mathrm{m} 2$. The charring rate of F1 treated LVL was $0.48 \mathrm{~mm} / \mathrm{min}$ and the charring rate of original LVL was $0.79 \mathrm{~mm} / \mathrm{min}$. The observed charring rates of non-treated LVL are in good agreement with the previous research completed for spruce LVL (Hakkarainen, 2010) and massive spruce (Beikircher, Hartmann and Kögl, 2014).

\section{Summary and Conclusions}

An ionic-liquid based fire retardant "Palonot F1" was applied to manufacture fire-retardant treated LVL from Norway spruce (Picea abies). The main objective was to study, whether the globally most strict combustion performance requirements would be met by immersion treating the face veneers at green condition. Regarding the final panel properties, the diffusive impregnation of green Norway spruce veneer with F1, is characterised by nil salting-out of the fire-retardant on the veneer surface and by its homogeneous distribution inside the veneer. According to the results, the fire retardancy of LVL was greatly improved by F1 treatment: the fire retardant treated spruce LVL had the performance of a quasi-non-combustible material (QNC) determined by the Building Standard Law of Japan. Additionally, the margin to be classified as non-combustible material (NC) was not more than $28 \mathrm{~s}$. Such a minor margin could most 
probably be overcome by increasing the retention of the fire retardant within the veneers; in this experiment the chemical dry weight was $68.8 \mathrm{~kg} / \mathrm{m} 3$. Finally, Palonot F1 fire retardant reduced by ca. $39 \%$ the charring rate of spruce LVL in comparison to the non-treated reference. In industrial scale, this reduction within the charring rate would lead to optional advantages. On the one hand smaller dimensions and thus lower weights of the load-bearing structures could be enabled if current combustion performance is aimed at, and on the other hand indeed greater combustion performance is achieved if the current dimensions on load-bearing structures are maintained.

\section{Acknowledgements}

We would like to express our special thanks of gratitude to Kalle Kiviranta and Emmi Närhi from Savonia University of Applied Sciences for performing the combustion tests.

\section{References}

Beikircher W., Hartmann P. and Kögl J. (2014): Charring rate of intumescent fire protective coated Norway spruce (Picea abies L.). Proceedings of World Conference on Timber Engineering, WCTE 2014. Quebec City, Canada. Hakkarainen, T. (2010): Thin thermal barriers for wood based products to improve fire resistance. Research Report VTT-R-07061-09. available at https://www.vtt.fi/inf/julkaisut/muut/2009/VTT-R-07061-09.pdf Hasegama, T. (2013): Introduction to the Building Standard Law - Building regulation in Japan. Building Center of Japan, Tokyo, Japan. available at https://www.bcj.or.jp/upload/international/baseline/BSLIntroduction201307_e.pdf Yuko, S. (1992): Fire rating procedure in Japan. Proceedings of the Asia-Oceania Symposium on Fire Science \& Technology AOFST 1: 60-68 available at https://www.iafss.org/publications/aofst/1/60/view/aofst_1-60.pdf

Biography 


\title{
Proceedings of the 2020 Society of Wood Science and Technology International Convention
}

\section{Bioinspiration as a source for alternative wood modification, protection and functionalization}

\author{
Anna Sandak \\ anna.sandak@innorenew.eu \\ Jakub Sandak \\ jakub.sandak@innorenew.eu \\ InnoRenew CoE \& University of Primorska, Slovenia
}

\begin{abstract}
Living organisms use smart, optimized and elegant solutions to survive, thanks to continuous selection and mutation processes. Therefore, systems created in nature might be valuable sources of inspiration for development of new concepts, materials, and solutions in various fields (structural engineering, robotics, medicine, materials science). In the last years, possible benefits from denouements developed by nature have also become more interesting for sustainable materials design as well as wood protection and modification.

Recent advances in materials research have delivered several solutions for the construction sector. However, operational durability is still a limiting factor in many applications and environments. Wood is a versatile, natural and environmentally friendly material that has attracted attention as a material for sustainable building for many years. As a biological material, wood is sensitive to environmental conditions and microorganisms; therefore, wood products require protective measures to extend their service life in outdoor applications. This contribution will provide an overview of selected solutions that can be transferred from nature in order to develop an efficient protection system for wood in various applications.
\end{abstract}

Acknowledgment: The authors gratefully acknowledge the European Commission for funding the InnoRenew project [Grant Agreement \# 739574] under the Horizon 2020 Widespread-Teaming program and the Republic of Slovenia (investment funding of the Republic of Slovenia and the European Regional Development Fund).

Key words: biomimicry, bioinspiration, wood modification, wood protection

Biography 


\title{
Proceedings of the 2020 Society of Wood Science and Technology International Convention
}

\section{Hardness Determination in Surface-densified Wood: The Influence of the Hardness Test Method and the Density Profile}

\author{
Alexander Scharf, Luleå University of Technology, Sweden \\ alexander.scharf@Itu.se
}

\section{Abstract}

An increase in the density of low-density wood species can either be achieved by transverse compression under non-destructive conditions (densification) or by filling the lumens with polymerising chemicals. In surface densification - as opposed to bulk densification - only a thin layer beneath the wood surface is compressed. This approach consumes less resources and results in a lower overall weight of the product. The density profile of the product can be altered through the choice of material and process parameters, in order to achieve the intended product performance. The increase in density in the surface layer makes low-density wood species more suitable for applications like flooring, as the exposed surface will have a similar resistance to mechanical stresses as high-density hardwood species.

The resistance of a material to penetration of a harder test body is called hardness and is used as one of the main evaluation criteria for densified wood. It is well-known that the hardness of a wood surface correlates nearly linearly with its density, however, the test results are dependent on the used test method. Previous research has pointed out deficiencies of the commonly used Brinell hardness test method. When studying materials with an inhomogeneous density profile - such as surface-densified wood - a less dense core beneath a thin and dense surface layer will influence the Brinell hardness value with increasing penetration depth and test force. To achieve a hardness value for surface densified wood that reflects the product-in-use properties, e.g. resistance to indentations from users and wear resistance, it is necessary to improve the hardness test method for surface-densified wood.

Indenter geometries such as wedges and cylinders have been used for hardness testing of solid wood, but have not yet been tested for surface-densified wood. These tools provide a linear relationship between contact area and penetration depth which could prove beneficial for the hardness testing of surface-densified wood.

The objective of this project was to study how the hardness of surface-densified wood is influenced by the choice of the hardness test method and the density profile, as well as to investigate the influence of setrecovery on the former. Scots pine (Pinus sylvestris L.) specimens were surface-densified in a hot press with the process parameters (press temperature, press time, compression ratio and plasticisation with ionic liquids prior to densification) chosen to achieve density profiles that differ in the peak density, peak width and distance of the peak from the wood surface. The set-recovery was induced by three humid-dry cycles at $\mathrm{RH} 75 \%$. The hardness was tested according to the Brinell method, and with a $136^{\circ}$ wedge indenter. Correlations between hardness, process parameters and density profiles were evaluated by principal component analysis. The outcome of this study allows an improved comprehension of hardness in surface-densified wood, facilitating comparisons between and within studies.

Key words: Wood compression, densification, wedge hardness, set-recovery, ionic liquids

\section{Biography}




\title{
Proceedings of the 2020 Society of Wood Science and Technology International Convention
}

\section{Coupling THM treatments with phenol-based resin for reduced set-recovery}

\author{
Matthew Schwarzkopf 1 \\ matthew.schwarzkopf@innorenew.eu \\ Mike Burnard 1 \\ michael.burnard@innorenew.eu \\ Marica Mikuljan2 \\ marica.mikuljan@innorenew.eu \\ Andreja Kutnar1 \\ marica.mikuljan@innorenew.eu
}

\author{
1 InnoRenew CoE \& University of Primorska, Slovenia \\ 2InnoRenew CoE
}

\begin{abstract}
Wood modification techniques have been used to help valorise under-utilised wood materials and increase their performance with respect to durability, mechanical characteristics, and new forms and functions. One group of modifications are thermal-hydro-mechanical (THM) treatments. THM densification uses only heat, water, and mechanical force to compress and densify the wood material. This results in increased density, hardness, abrasion resistance, and some strength properties. During the THM densification process, wood is softened and compressed, resulting in densification without fracturing the cell walls. The main challenge associated with this type of densification is the fixation of the compressive deformation when the densified wood is exposed to moisture. The objective of this study was to couple a low-molecular weight phenol resin with THM treatments to reduce set-recovery in solid wood of some common wood species.

THM treatments were performed on poplar (Populus spp.), spruce (Picea abies), and beech (Fagus sylvatica). Prior to treatment, a low-molecular weight resin was impregnated into the wood structure. Densification results, mechanical characteristics (modulus of elasticity, rupture, and hardness), and setrecovery were assessed. All wood species were exposed to the same THM treatment. The mechanical performance of all specimens was largely dictated by their surface density as seen in the density profiles. Spruce specimens had high levels of set-recovery after the THM treatment, which is believed to have been caused by a combination of pit aspiration from kiln drying, limiting penetration of the resin. The THM treatment used in this study was successfully applied to poplar, spruce, and beech. The resin impregnation combined with THM treatment led to densified wood with improved mechanical properties. The improvements were the greatest in poplar, including the largest reduction in set-recovery, which was the objective of this study. When comparing mechanical properties to commercially available structural wood-composites the results from this study indicate that resin impregnated THM treated wood could be used in this application.
\end{abstract}

Biography 


\title{
Proceedings of the 2020 Society of Wood Science and Technology International Convention
}

\section{Wood Physics and Mechanics}

Chairs:

Ales Straze, University of Ljubljana, Slovenia

Mike Wolcott, Washington State University, USA

\section{$X$-ray computed tomography studies of moisture-content distribution in spruce boards exposed to liquid water}

\author{
José Couceiro \\ jose.couceiro@ltu.se \\ Dick Sandberg \\ dick.sandberg@ltu.se \\ Margot Sehlstedt-Persson \\ margot.sehlstedt-persson@ltu.se \\ Luleå University of Technology, Sweden
}

\section{Abstract}

The use of cross-laminated timber (CLT) as a construction material for high-rise timber buildings has increased in the recent years especially in Europe and North America; a trend that is expected to continue. The CLT-elements will often be finished with an impermeable layer, whether it is walls, floors and, especially, roof. In Sweden, often no weather protection is used during the construction of the building, allowing the wood to be exposed to liquid water and relaying on later atmospheric conditions to dry the timber prior to finishing. The Swedish building regulations require a maximum surface moisture content (MC) of $18 \%$ before assembly of the elements and a maximum surface MC of $16 \%$ before the wood is covered. This could drive to high levels of MC within the CLT while the surface is already dry, which is a highly possible scenario in the case of high buildings where sun and wind create good conditions for a fast surface drying. At the same time, the regulation requires control of MC to be made with an electrical pin-type MC-meter, which is problematic because its reliability lays in part on the device reaching a certain penetration into the wood. The measurement of surface MC could thus be erroneous and the risk for mould development would be high even if the regulations are strictly followed. If a CLT with a too high moisture level are covered with an impermeable surface layer, the moisture is trapped within the CLT and may cause microbiological degradation that could be problematic to correct later on. An update in the regulation requirements is recommended, but such update must be based on a proper understanding of how moisture can be distributed in CLT and other wood-based building material during outdoor construction.

This project aims to establish a method to study (1) the effect of liquid-water-exposure time on the MC distribution of Spruce timber boards, but that could potentially be used in other wood-based building materials as well, and (2) the drying process under emulated outdoor conditions. The focus is set on those elements that are laid horizontally or with a very low inclination, such as floors and roofs. Sections of methacrylate are glued to the internal side of $43 \times 200 \mathrm{~mm}$ planed spruce timber, allowing the wood to be exposed to standing water under a period of several days. CT images of different cross sections are taken periodically so that the evolution of MC profile can be monitored. The hypothesis is that the suction of liquid water will not be large and that it can dry quickly once the exposure to liquid 
Proceedings of the 2020 Society of Wood Science and Technology International Convention

water ends, but also that a MC gradient will develop beneath the surface which, under drying, may create regions of high MC that may be unnoticed by measuring with pin-type MC-meters.

\section{Biography}




\title{
Proceedings of the 2020 Society of Wood Science and Technology International Convention
}

\section{Understanding the Energy Dissipation Process on Hardwoods and its Dependence on the Anatomical Structures}

\author{
Júlio Amando de Barros1 \\ julioortizbarros@gmail.com \\ Gregório Ceccantini 1 \\ gregorio@usp.br \\ Victor Sibinelli \\ sibinelli95@gmail.com \\ Rodolfo Politano2 \\ rodolfo.politano@gmail.com
}

\author{
${ }_{1}$ University of Sao Paulo, Brazil \\ 2 Instituto de Pesquisas Energéticas e Nucleares
}

\begin{abstract}
In our previous work, presented as a poster on SWST 2018 conference at Nagoya, a trial of linking anatomical features and mechanical properties of Brazilian hardwoods was done. For that, a set of dynamic-mechanical analysis (DMA) was performed for 15 species of selected tropical woods. Besides that we measured several anatomic properties such as vessel diameter and vessel density, fiber wall thickness, rays density, and others. Formed our data set, a Principal Component Analysis was done in order to group dependent variables of both mechanical or anatomical origin. The great advance on the interpretation of wood mechanical behavior was the relation between energy storage and dissipation. The energy storage, being of elastic nature, is strongly related to wood density which is mainly guided by fiber cell wall thickness, as is shown on several works throughout the literature. The dissipation, quantified by the loss factor, on the other hand, is a difficult and not precise property to measure on usual mechanical test, but in a DMA this can be made with accuracy and its dependencies on frequency, time and temperature can be checked. Our main result was to relate the energy dissipation on hardwoods to the wood vessel density, in the same way that fibers wall are related to density and rigidity.

Now our work is based on the investigation of this finding; in other words we want to assess if the energy dissipation is mainly linked on vessels features. For that, the same experimental setup was used: the mechanical properties was measured by DMA and anatomical features by quantitative microscopy. Trying to vanish the influence of others anatomical parameters two hardwoods species was selected: peroba- rosa (Aspidosperma polyneuron) and jatobá (Hymenaea courbaril). They were chosen due to their similarity on fiber cell wall thickness, while being very different in vessel size and distribution. Aspidosperma polyneuron has a higher vessel density than Hymenaea courbaril but with smaller thickness in average. This produces for both a similar total vessel area, but different vessel wall-lumen ratio, once that small vessels creates proportionally less empty space.

After selecting the species, 15 samples of each one was prepared from 3 different individual, all of them were collected by the Plant Anatomy Laboratory research group and cataloged by the Xylarium SPFw. From each sample a small piece was cut for anatomical purpose, in such a way that for each of them both anatomical and mechanical properties were obtained. The loss factor dependences on
\end{abstract}


Proceedings of the 2020 Society of Wood Science and Technology International Convention

vessel density and thickness was then tested for: each individual by itself, all individual of the same species and at last comparing both species.

Biography 


\title{
Proceedings of the 2020 Society of Wood Science and Technology International Convention
}

\section{What Do We Know on Rosewoods Properties? A Wood Mechanics Update on the Endangered Pantropical Genus Dalbergia}

\author{
Iris Brémaud 1 \\ iris.bremaud@umontpellier.fr \\ Patrick Langbour2 \\ patrick.langbour@cirad.fr \\ 1 CNRS, Wood Team, LMGC, CNRS, Univ.Montpellier, France \\ 2 CIRAD, BioWooEB Reseach Unit, France
}

\begin{abstract}
Rosewoods are emblematic of "precious" tropical woods, with major cultural value in several high-end craftsmanship utilizations. Rosewoods are important both in the wood cultures of tropical regions where these trees grow, and in cultures of temperate regions where several species have been imported, sometimes for centuries. True Rosewoods belong to the pantropical genus Dalbergia (circa 250 species), and some species from botanically related genera are sometimes also included under the term Rosewoods. But uncontrolled demand has led to threats to these species. A dramatic, exponential increase in international traffic and over-exploitation for industrial-scale uses happened over the past decade. To safeguard these endangered species, CITES (Convention on International Trade in Endangered Species of Wild Fauna and Flora) listed the whole genus in 2017. Much scientific research is now being conducted on methods of wood identification to help enforcing the regulation of international trade. Yet, a fundamental question is not yet fully understood: what makes Rosewoods so particular?
\end{abstract}

Paradoxically, little scientific data is available on the material properties of these emblematic woods. Their rich appearance, with deep and variegated colors, is famous. Some literature reviews explore the chemical nature of their secondary metabolites, due to often important biological/pharmaceutical activities. Yet, data on their physical-mechanical wood properties are scarce. This presentation aims at providing an update on this topic, by combining an analytical review of literature data, and new experimental results. A focus is set on dynamic mechanical properties, given the importance of rosewoods in musical instrument making of diverse geo-cultural areas.

Results indicate that such data are currently available, in the literature, for only a dozen of species of Dalbergia (out of circa 250 species in the genus). A wide-scale exploration of the potential relation between botanical taxonomy and mechanical properties suggest that woods from Dalbergia genus exhibit singular characteristics as compared to biodiversity: most of these woods have abnormally low damping coefficient. This feature appears to be shared by closely botanically related genera (belonging to the Dalbergieae tribe). In a limited number of species (2 Dalbergia and 2 Pterocarpus), this feature is found to be due to particular heartwood extractives. A wide experimental campaign is being conducted to verify two main hypotheses: (i) would all species of Dalbergia genus (or even of Dalbergieae tribe) share atypical dynamic mechanical properties? (ii) would such a singular wood mechanical behavior of a botanical taxon express particular composition in secondary metabolites?

\section{Biography}




\title{
Proceedings of the 2020 Society of Wood Science and Technology International Convention
}

\section{Hardwood cutting forces at different speeds up to $80 \mathrm{~m} / \mathrm{s}$ for an evaluated real chip thickness}

\author{
Ondrej Dvoracek1 \\ o.dvoracek@wood-kplus.at \\ Stephan Frömel-Frybort 1 \\ s.frybort@wood-kplus.at \\ Daniel Lechowicz1 \\ d.lechowicz@wood-kplus.at \\ Thomas Krenke 1 \\ t.krenke@wood-kplus.at \\ Franz Haas2 \\ franz.haas@tugraz.at
}
1 Wood K plus - Competence Centre for Wood Composites and Wood Chemistry, Austria
2 Graz University of Technology, Austria

\begin{abstract}
Woodcutting is one of the key processes within the forest-based industry. For cutting force estimation, the piezo-electric force sensor is commonly used. These dynamometric systems use primarily circular cuts. Mechanisms taking place during an examination are very complex and hard to describe. Besides its anisotropy, the examination of woodcutting is additionally complicated by parameters like density and moisture content. Regarding changes in forest composition, the share of hardwood is increasing. Hence, there is an urgent need to understand disintegration processes, enabling knowledge-based optimisation measures of tools for hardwood disintegration. For basic investigations of disintegration processes a novel test device for analysis of linear cutting process has been developed. The device enables cutting examinations up to a velocity of $100 \mathrm{~m} / \mathrm{s}$. An innovative feature of the device is chip thickness evaluation. Accuracy of the chip dimension is measured by means of a laser sensor (LAM-F-20, WayCon, Germany) recording sample height before and after cutting, with a resolution up to $2 \mu \mathrm{m}$. The force in all directions and chip thickness were measured during cutting beech (Fagus sylvatica) with a single knife at speeds from $10 \mathrm{~m} / \mathrm{s}$ to $80 \mathrm{~m} / \mathrm{s}$. Before the tests, samples $(20 \times 50 \times 100 \mathrm{~mm})$ were stored at standard climatic conditions of $20^{\circ} \mathrm{C}$ and $65 \%$ of relative humidity until the equilibrium moisture content of approximately $12 \%$ is achieved. The results showed that investigated chip thicknesses $(0,05-0,6 \mathrm{~mm})$ varied of $+/-$ $15 \%$. The deviation is not commonly taken into consideration especially when the purchased system is utilized. Therefore, the method for data correction (based on the comparison of apparent and real chip thickness) was implemented. Due to this fact, the methodology serves more accurate results. Cutting forces always increased with growing chip thickness. Nevertheless, higher cutting speed does not mean a higher force. The results indicated that the force did not have linear progression and grew up when cutting velocity was both increased and decreased.
\end{abstract}

Biography 


\title{
Proceedings of the 2020 Society of Wood Science and Technology International Convention
}

\section{Advanced X-ray CT Scanning: a Versatile Research Tool for Analyzing Cores of Living Trees}

\author{
Tom De Mil \\ tom.demil@ugent.be \\ Joris Van Acker 1 \\ joris.vanacker@ugent.be \\ Hans Beeckman2 \\ hans.beeckman@africamuseum.be \\ Jan Van den Bulcke. \\ jan.vandenbulcke@ugent.be
}

\author{
1 UGCT - UGent-Woodlab, Department of Environment, Faculty of Bioscience \\ Engineering, Ghent University, Belgium \\ 2 Royal Museum for Central Africa, Belgium
}

\begin{abstract}
Density and wood anatomical tissue fractions are crucial variables in wood science. At UGent-Woodlab we have been working towards the use of X-ray Computed Tomography (CT) scanning to obtain large datasets of virtual tree cores. A toolchain was developed to scan tree cores with a resolution ranging from $60 \mu \mathrm{m}$ down to $4.5 \mu \mathrm{m}$. Assessing (i) density and (ii) tree ring growth simultaneously allows to map wood properties from pith to bark and to estimate how they vary depending on tree age and climate. When scanned at high resolution, not only wood density, but (iii) wood anatomical tissues become discernable and measurable. CT also represents a promising way to analyze (iv) grain angle variation from pith to bark, a timber property appreciated for esthetic reasons such as holographic effects (e.g. interlocked grain), but also causing undesirable effects on wood drying and processing. Additional scanning at a resolution of $0.8 \mu \mathrm{m}$ of a needle-sized sample scanned with a second X-ray CT system highlights the potential of cell-level scanning. We show how multi-scale scanning offers unprecedented potential for mapping wood properties without sample manipulation and with limited operator intervention. Custom-designed sample holders enable simultaneous scanning of multiple increment cores at resolutions sufficient for tree-ring analysis and densitometry, grain angle assessment. Single-core scanning enables the study of quantitative wood anatomy, thereby approaching the conventional thin-section approach. Furthermore, standardized X-ray CT volumes are ideal input imagery for automated pipelines with neural-based learning for wood property mapping and measurements of cellular parameters. Efforts are being made for an online platform, and machine learning techniques are being developed to treat such large datasets ( http://www.dendrochronomics.ugent.be/\#database).
\end{abstract}

\section{Biography}




\title{
A Sawmill Simulation Study of the Volume Yield Changes When Sawing With Thinner Kerfs
}

\author{
Magnus Fredriksson1*-Mikael Svensson2
}

\author{
1 Senior lecturer $(\mathrm{PhD})$, Luleå University of Technology, Skellefteå, Sweden \\ *Corresponding author \\ magnus.1.fredriksson@ltu.se
}

\author{
2 Process and Product Development Manager (MSc), LSAB, Långshyttan, Sweden \\ mikael.svensson@lsab.se
}

\begin{abstract}
Using thinner sawblades in sawmills has a potential for both increasing volume yield and decreasing energy usage in the sawing process; possible secondary effects of this are reduced outtake from forests or at least a better use of what is harvested, lower greenhouse gas emissions and higher productivity. How much the sawing kerf can be reduced depends on several factors, such as maintaining the stability of the sawblade, feeding accuracy and so on. This study deals with the possible volume yield increases when reducing the sawing kerf, based on different possible scenarios of which some are more realistic to achieve in the near future than others. The study is based on simulated sawing of 1464 Scots pine (Pinus sylvestris L.) and Norway spruce (Picea abies (L.) H. Karst.) logs. Tests were made for both circular sawblades as well as for band saws, deployed in a cant sawing process with a primary and a secondary saw. Both variable sawing patterns as well as fixed sawing patterns was investigated. In the first case, the choice of sawing pattern was optimized based on volume yield, while in the latter case, logs were presorted on top diameter into log classes that were each assigned a specific sawing pattern. The results show an increased yield of about 1.3 to 1.5 percent units per mm reduced sawblade thickness, and a maximum theoretical yield of $57-59 \%$ for a $0 \mathrm{~mm}$ saw kerf. The latter is of course not possible to achieve in practice, but it hints at the maximum potential of reducing the sawblade thickness. In the near future, it is expected that a kerf reduction of around $1 \mathrm{~mm}$ is possible. This would thus result in a possible yield increase of 1.3-1.5 percent units, with further increases depending on improvements in sawblade design, sawblade stabilization, improved materials, and machines that are more accurate. Possible future studies include quantification of secondary effects from the yield increase; effects that can help mitigate deforestation and climate change, with a retained level of production volumes.
\end{abstract}

Key words: Computer simulation, Picea abies, Pinus sylvestris, Sawing kerf, Sawing yield, Thinner sawblades

\section{Introduction}

In the sawmilling process, the aim is usually to produce as much valuable material as possible out of roundwood. The motivation for this is, among other things, that the cost of raw material in the forestry-wood value chain takes up a large part of the total costs (Lindholm 2006). Many 
times, this aim is expressed in terms of volume yield, i.e. maximizing the ratio of output volume to input volume. Due to the complex geometry of the raw material, this is a difficult problem and many different solutions have been proposed. For instance, the sawing pattern used is in most cases adapted to the geometry of the log in one way or another. Logs can be sorted into different classes based on their diameter, and assigned a fixed sawing pattern for that class. Alternatively, the position of the sawblades can be changed between each log based on a geometrical model of the log, which can be provided by various scanning systems. Even if fixed sawing patterns are used, the position of the log vis-à-vis the sawblades can be optimized for yield (Lundahl and Grönlund 2010, Fredriksson 2014). Scanning equipment can for instance be based on laser and camera equipment (Chiorescu and Grundberg 2001), X-ray (Grundberg 1999, Skog 2009) or Xray computed tomography (Giudiceandrea et al. 2011, Fredriksson et al. 2017). These scanners can be used both for log presorting and for sawing optimization (Skatter et al. 1998). If X-ray scanners are used, the internal quality of logs can also be taken into account.

Production planning optimization in a more general sense is also employed in most sawmills (Todoroki and Rönnqvist 2002, Zanjani et al. 2010, Alvarez and Vera 2014).

Other measures to improve volume yield include improving the stability of the mechanics in the sawing machines (Vuorilehto and Tulokas 2007), since this is a source of error when it comes to optimizing the sawing (Todoroki 2003, Berglund et al. 2013) and achieving correct dimensions of the sawn timber.

Another source of volume losses is drying; wood which is dried to a lower moisture content than desired shrinks more, thus reducing the output volume and therefore volume yield (Ekevad et al. 2011).

Board features can contribute to a lowered volume yield as well; if an undesired feature (defect) is present, it can in many cases be cut away in the edging or trimming process, resulting in a lower product volume. Such features can be either of a biological nature or created when transporting, handling, sawing or drying the wood (Broman and Fredriksson 2012). Finally, one source of material loss is the cutting itself. As the sawblade cuts into the wood, material is removed, normally in the form of sawdust. The thicker the sawblade, the larger volume removed. Efforts have therefore been made to reduce the sawing kerf (Steele et al. 1992, Steele and Araman 1996, Sun et al. 2000), which in turn can create other problems that need to be addressed such as reduced sawblade stiffness and stability (Orlowski 2003, Schajer and Mote 2007, Orlowski et al. 2007, Singhania et al. 2019).

To be able to assess whether further reductions of sawing kerf width is viable, from economical standpoints as well as environmental ones, knowledge of how a reduced sawing kerf affects the volume yield is needed. The effort spent on solutions for thinner kerfs need to be repaid as either economical gain, environmental benefits, or a combination of both. Therefore, a quantification of volume yield gain per millimeter reduced sawing kerf is valuable information.

The objective of this study was to investigate the effect of thinner sawing kerfs on volume yield, when sawing Scots pine (Pinus sylvestris L.) and Norway spruce (Picea abies (L.) H. Karst.) $\operatorname{logs}_{\mathrm{s}}$ in various sawmill production setups. The study was limited to conditions present in the Nordic countries, which affected both the choice of species as well as the chosen production setups.

\section{Materials \& Methods}


To study the effect of saw kerf size on volume yield, sawing simulation was used. Twelve different scenarios were studied, broken down as shown in Figure 1. Differentiation was made on sawing pattern adaptation; either using fixed sawing patterns for different log diameter classes or optimizing the sawing pattern individually for each log. Two different types of sawblades were also studied: circular saw blades or bandsaws. For the circular sawblades, two levels of sawing kerf width were chosen: $4.4 \mathrm{~mm}$ and $3.4 \mathrm{~mm}$. The levels were chosen as a result of discussions with tool manufacturers; the higher level representing a common saw kerf width today, and the lower level representing an estimate of what is possible to achieve given better material, better machinery and better control than is the case today. For the bandsaw case, four levels of saw kerf were studied: 2.9, 2.0, 1.5 and $0.8 \mathrm{~mm}$. Again, these levels were chosen together with tool manufacturers. The four levels for bandsaws represent, respectively: $2.9 \mathrm{~mm}$ representative of today's tools, $2.0 \mathrm{~mm}$ achievable with fairly small efforts and in a short timeframe, $1.5 \mathrm{~mm}$ achievable with considerable development to tools and processes, and finally $0.8 \mathrm{~mm}$ being seen as the limit of possible reduction of the sawing kerf.

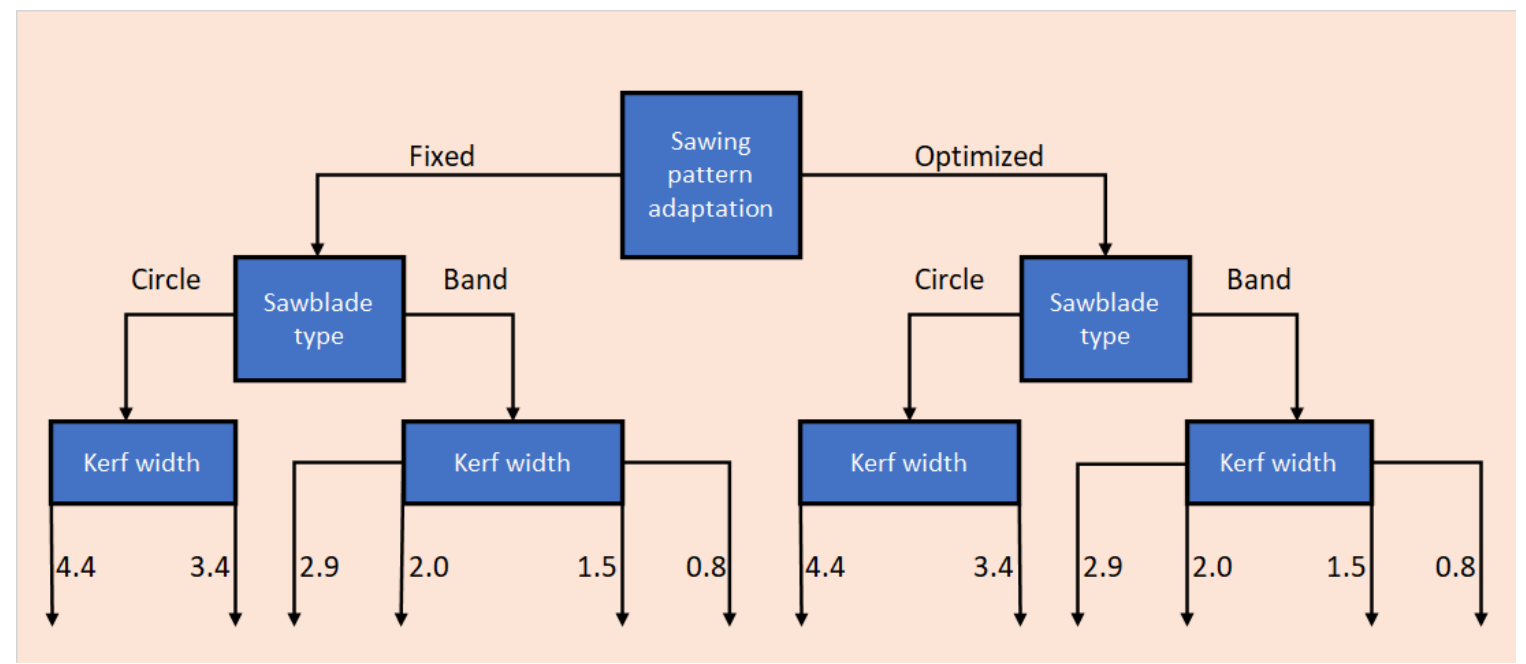

Figure 1. Breakdown of the sawing simulation scenarios studied. All measures are in mm.

\section{Roundwood Data}

The study was based on the Scots pine (Pinus sylvestris L.) and Norway spruce (Picea abies (L.) H. Karst.) logs of the Swedish Pine Stem Bank (Grönlund et al. 1995) and the European Spruce Stem Bank (Berggren et al. 2000). The stem bank trees, from well-documented sites at different locations in Europe, have been documented thoroughly regarding tree properties and silvicultural treatments. They were bucked into logs that were scanned with a medical computed tomography (CT) scanner (Siemens SOMATOM AR.T) to record internal as well as external properties. Adding to the stem bank data, 87 Scots pine logs from Nordmark (2005) were also used. Of these logs, one was excluded since it had a large crook and a small diameter, resulting in zero sawing yield in all cases. 714 Scots pine and 750 Norway spruce logs were thus used in this study, adding up to $1464 \operatorname{logs}$ in total. The same material was used in all the studied scenarios.

\section{Sawing Simulation}

Sawing simulation was performed using the simulation software Saw2003, developed by Nordmark (2005). The input was log models, based on the CT scanned logs of the stem banks. The log models were constructed by the outer shape description of the log. There is a possibility 
to use knot models describing the inner quality of the log, but this was not regarded in this study since the objective was to study the volume yield and not the quality of the sawn timber. The only quality aspect that was taken into account was wane, since the position of the board in the $\log$ and therefore the amount of wane will be affected by the sawing kerf, in a more predictable way than the quality due to knots. The wane rules are summarized in Table 1, and they follow the Nordic Timber Grading Rules where more details can be found (Anon. 1997). Boards were therefore graded into three quality classes, A, B or C, where A is the class with the strictest requirements. Only wane exceeding $3 \mathrm{~mm}$ was considered.

Table 1: Wane criteria for each quality grade. $t=$ thickness of the sawn timber. All measures are percentages of either length or thickness. If a measure is exceeded, the board cannot be graded as the corresponding quality grade.

\begin{tabular}{llll}
\hline Quality grade & A & B & C \\
\hline Length on each edge, $\mathrm{t}<=25 \mathrm{~mm}^{*}$ & 20 & 30 & 40 \\
Length on one edge, $\mathrm{t}<=25 \mathrm{~mm}^{*}$ & 30 & 40 & 50 \\
Length on each edge, $\mathrm{t}>25 \mathrm{~mm}^{*}$ & 10 & 20 & 30 \\
Length on one edge, $\mathrm{t}>25 \mathrm{~mm}^{*}$ & 20 & 30 & 40 \\
Depth, per edge** & 10 & 15 & 20 \\
Width on the outside edge, each edge** & 7 & 12 & 17 \\
\hline
\end{tabular}

*measured as percentage of timber length

**measured as percentage of timber thickness

Saw2003 models a sawmill that employs cant sawing with two sawing machines, with curve sawing in the second saw, edging and trimming. The latter two are value-optimized according to timber prices and grading criteria. An example of a log model used in Saw2003 is shown in Figure 2, with outer shape and knots.

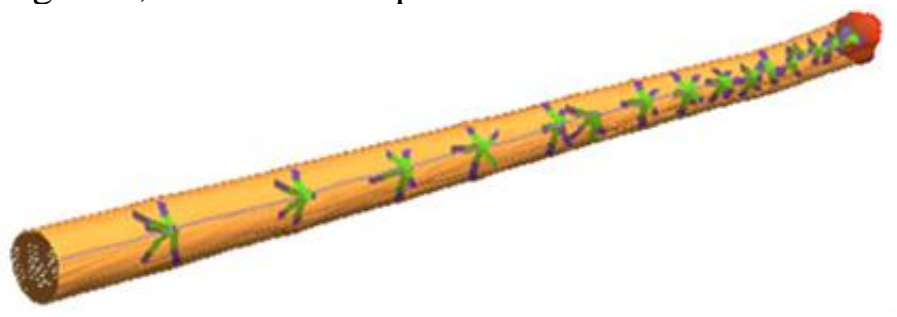

Figure 2. Example of log model used. The knots were disregarded in this study.

The sawing simulation results in virtual boards with information about knots, dimensions, quality, value and so forth. Saw 2003 has been used extensively in earlier research (Nordmark 2005, Moberg and Nordmark 2006, Lundahl and Grönlund 2010, Berglund et al. 2013, Fredriksson 2014).

\section{Settings Used for Simulations}

The corresponding sawing patterns for different diameters are presented in 
Table 2. They were used both for the case with fixed and optimized sawing patterns. For the fixed sawing patterns, the top diameter $10 \mathrm{~cm}$ from the log small end was used. In the case of optimized sawing patterns, all patterns were tested and the pattern resulting in the highest volume yield was chosen. Since Saw2003 employs value-optimized edging and trimming, the price relation between qualities affects the result. This is for instance shown by Berglund et al. (2013). The prices used in this study were 185, 160 and $100 € / \mathrm{m}_{3}$, for center boards of $\mathrm{A}$, B and C quality, respectively. For the sideboards, the prices were 300, 140 and $110 € / \mathrm{m} 3$, also for A, B and $\mathrm{C}$ quality. By-products were priced at $20 € / \mathrm{m} 3$. Only the wane of the boards affected the quality.

Sideboards were edged to widths of $75,100,115,125,127,150,175,200$ or $225 \mathrm{~mm}$, with a fixed thickness of 19 or $25 \mathrm{~mm}$ depending on the position in the sawing pattern. All boards were trimmed to module lengths of $1800+\mathrm{n} \times 300 \mathrm{~mm}$ modules, $\mathrm{n}$ being the number of length modules. The logs were curve sawn, so in the second saw the sawing kerf followed a seconddegree function that was fitted to the centreline of the cant. 
Table 2: Sawing patterns used in the study. The diameter limits were used when logs were sorted on diameter and assigned a fixed sawing pattern. Sorting was based on top diameter.

\begin{tabular}{lllll}
\hline $\begin{array}{l}\text { Lower diameter limit } \\
(\mathrm{mm})\end{array}$ & $\begin{array}{l}\text { Upper diameter limit } \\
(\mathrm{mm})\end{array}$ & No. of centerboards & $\begin{array}{l}\text { Width } \\
(\mathrm{mm})\end{array}$ & $\begin{array}{l}\text { Thickness } \\
(\mathrm{mm})\end{array}$ \\
\hline 0 & 129 & 2 & 75 & 38 \\
130 & 149 & 2 & 100 & 38 \\
150 & 169 & 2 & 100 & 50 \\
170 & 184 & 2 & 125 & 50 \\
185 & 194 & 2 & 125 & 63 \\
195 & 209 & 2 & 150 & 50 \\
210 & 219 & 2 & 150 & 63 \\
220 & 229 & 2 & 175 & 50 \\
230 & 249 & 2 & 175 & 63 \\
250 & 264 & 2 & 200 & 63 \\
265 & 284 & 2 & 200 & 75 \\
285 & 304 & 2 & 225 & 75 \\
305 & 324 & 4 & 200 & 50 \\
325 & 344 & 4 & 225 & 50 \\
345 & 384 & 4 & 200 & 63 \\
385 & 449 & 4 & 200 & 75 \\
\hline
\end{tabular}

For the green dimensions in the saw, a flat increase of all dimensions by $4 \%$ was used, e.g. a 125 $\mathrm{mm}$ nominal width was sawn as $130 \mathrm{~mm}$ to reflect drying shrinkage.

For the different scenarios, the corresponding kerf width was set for all sawblades in the first saw as well as the second saw.

The volume yield was finally calculated for each scenario as the total volume of sawn and dried timber divided by the total green volume of the logs, the latter using the full outer shape described by the log model.

\section{Fixed Sawing Patterns}

\section{Results and Discussion}

In the scenario with fixed sawing patterns, the volume yield for the circular sawblades was 51.1 $\%$ for a $4.4 \mathrm{~mm}$ sawing kerf, while it was $52.6 \%$ for a $3.4 \mathrm{~mm}$ kerf. This corresponds to a change of 1.5 percent units per mm. 
The volume yields for the bandsaw scenarios are presented in Figure 3.

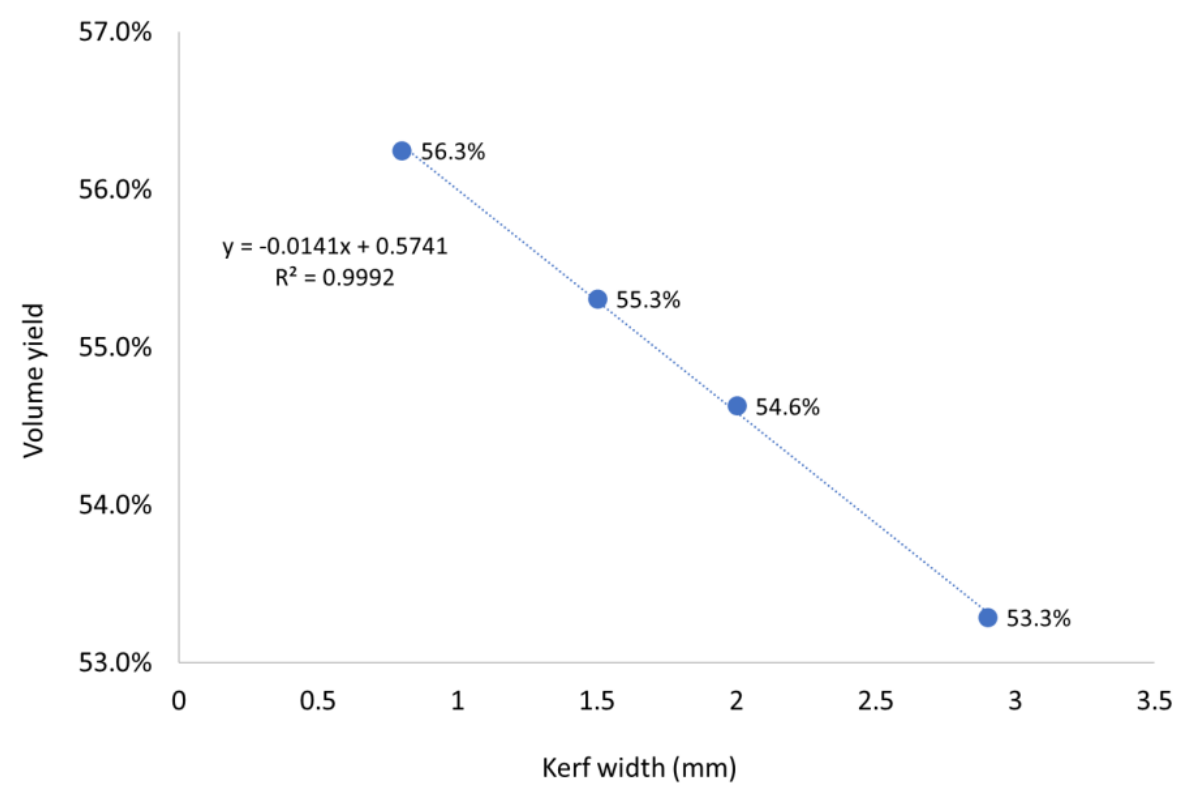

Figure 3. Volume yield as a function of sawing kerf width, when using fixed sawing patterns. A linear function has been fitted to the data points using least squares linear regression.

As can be seen, the function fitted to the data points will cross the y-axis at 57.41 percent volume yield, i.e. when the kerf width is zero. This can be seen as a theoretical maximum yield for this setup, when it comes to for instance raw material, sawing patterns, drying shrinkage etc.

Furthermore, the yield change is around 1.4 percent units per mm sawing kerf.

\section{Optimized Sawing Patterns}

For the scenario with optimal sawing patterns, the volume yield for the circular sawblades was $52.9 \%$ for a $4.4 \mathrm{~mm}$ sawing kerf, while it was $54.2 \%$ for a $3.4 \mathrm{~mm}$ kerf. This corresponds to a change of 1.3 percent units per mm. 
The volume yields for the bandsaw scenarios are presented in Figure 4.

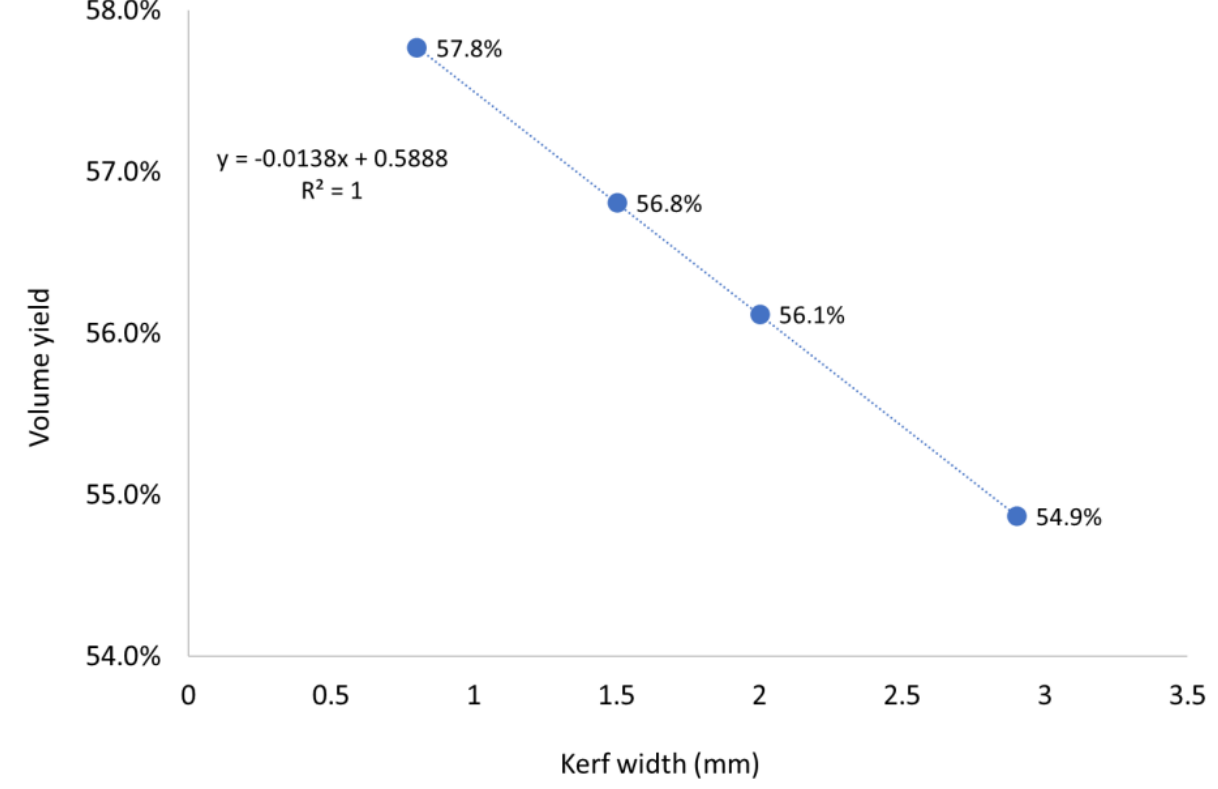

Figure 4. Volume yield as a function of sawing kerf width, when choosing an optimal sawing pattern for each log. A linear function has been fitted to the data points using least squares linear regression.

As can be seen, the function fitted to the data points will cross the $y$-axis at 58.88 percent volume yield, i.e. when the kerf width is zero. This is, in the same way as for the fixed sawing patterns, a theoretical maximum yield for this setup. Furthermore, the yield change is around 1.4 percent units per mm sawing kerf.

\section{Volume Yield per mm Sawing Kerf}

In Table 3 the different volume yield changes when changing the sawing kerf width are summarized. The change is fairly consistent, differing between 1.3 percent units per millimeter to 1.5 percent units per millimeter.

Table 3: Summary of the volume yield changes for the different studied cases, when changing the width of the sawing kerf.

\begin{tabular}{lll}
\hline Sawing patterns & Sawblades & $\begin{array}{l}\text { Volume yield change per mm } \\
\text { sawing kerf (percent units) }\end{array}$ \\
\hline Fixed & Circular & 1.5 \\
Fixed & Band & 1.4 \\
Optimized & Circular & 1.3 \\
Optimized & Band & 1.4 \\
\hline
\end{tabular}




\section{Difference Between Species}

A comparison between the two species, Scots pine and Norway spruce, can be seen in Table 4. The average yield was calculated as average sawn and dried volume divided by the green volume of the logs. Maximum and minimum values are calculated from the 12 different scenarios.

Table 4: Comparison between the two studied species.

\begin{tabular}{llll}
\hline Species & Average yield & Maximum yield & Minimum yield \\
\hline Scots pine & $53.6 \%$ & $56.9 \%$ & $50.0 \%$ \\
Norway spruce & $55.5 \%$ & $58.5 \%$ & $52.1 \%$ \\
\hline
\end{tabular}

The yield for different kerf widths is presented in Figure 5 and Figure 6, for the two studied species.

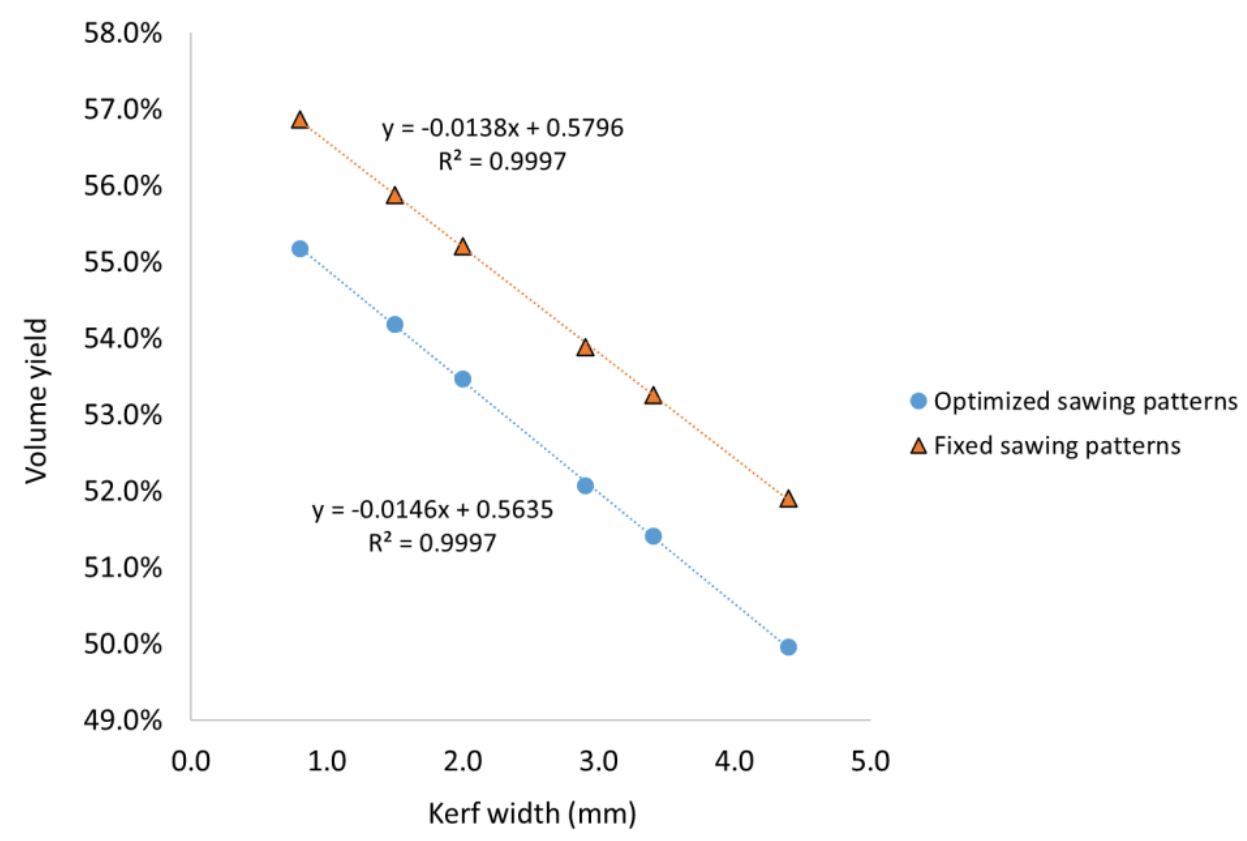

Figure 5. Volume yield as a function of sawing kerf width, for Scots pine. Linear functions have been fitted to the data points using least squares linear regression. 


\section{Proceedings of the 2020 Society of Wood Science and Technology International Convention}

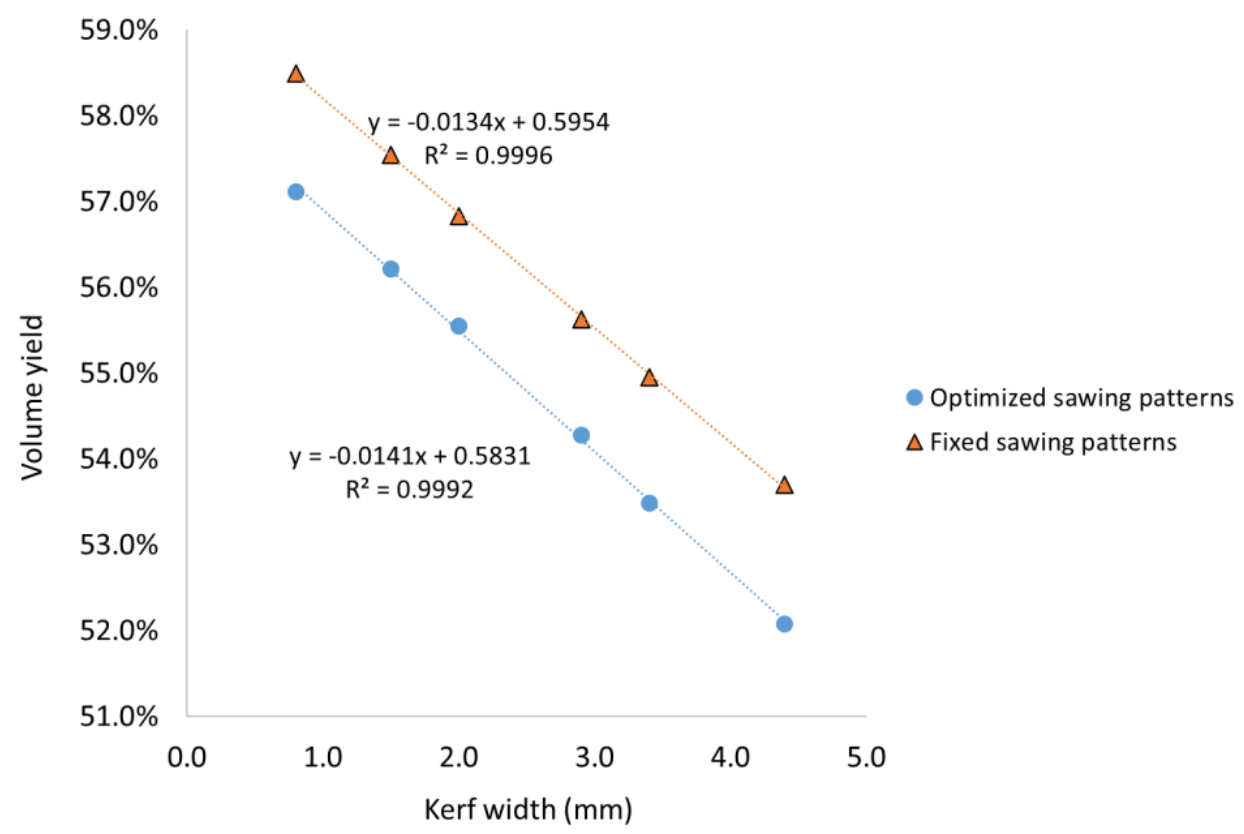

Figure 6. Volume yield as a function of sawing kerf width for Norway spruce. Linear functions have been fitted to the data points using least squares linear regression.

As can be seen in the figures, the change in yield depending on sawing kerf width is around 1.31.4 percent units per $\mathrm{mm}$ for both species.

\section{Discussion}

The results indicate a possible yield increase of 1.3-1.5 percent units per millimeter decreased sawing kerf.

Results achieved with simulation models will always differ from the real situation to some extent. In this study, all comparisons have been made using simulation data only, therefore reducing the effect of any discrepancies with the real systems. The log models used had a resolution which is lower than many commercial 3D scanning systems, with scans made every $40 \mathrm{~mm}$ in the lengthwise direction for the Pine Stem Bank and every $10 \mathrm{~mm}$ for the Spruce Stem Bank. This is also one of the reasons to avoid comparisons outside of the simulation environment.

In a practical situation, there will always be other factors affecting the volume yield, such the mechanical stability of machines, the consistency of the drying process, etc.

The study was also limited on conditions present in many Nordic sawmills. The results might therefore not be fully generalizable, depending both on the raw material and sawing practices. The exact source of the yield increase when sawing with thinner sawblades was not fully investigated in this study, but one can speculate that it could be several factors affecting the yield. The most obvious one is the fact that less material is turned into sawdust. This takes place between the boards, meaning that the position of boards is shifted somewhat towards the center of the log. The effect of this is that boards near the periphery, such as sideboards, can be made longer and wider. Furthermore, for the case of optimized sawing patterns, it is possible that a larger sawing pattern can be fitted to an individual log than was the case with thicker sawblades. The results are consistent between both different scenarios and different species, with the range of volume yield change being 1.3 to 1.5 percent units per mm kerf width. There are several 
potential benefits of this yield increase. First of all, it means a possibility to increase produced volumes for the same outtake from the forest, or vice versa maintain production while using less forest material. This is important since the competition for forest raw material will probably increase as a result of a shift towards a biobased society. Furthermore, the greenhouse gas emissions from production of timber would decrease since a large part of this is coming from the manufacturing of the material (Peñaloza et al. 2018). Another effect from thinner sawblades is a reduction of the needed power and therefore energy consumption in sawing machines (Wasielewski et al. 2012, Cristóvão et al. 2013).

In the near future, it is expected that a kerf reduction of around $1 \mathrm{~mm}$ is possible. This would thus result in a possible yield increase of 1.3-1.5 percent units, with further increases depending on improvements in sawblade design, sawblade stabilization, improved materials, and machines that are more accurate. Possible future studies include quantification of secondary effects from this yield increase such as reduction of emissions, increased profitability and so on.

\section{Summary and Conclusions}

The objective of this study was to investigate the effect of thinner sawing kerfs on volume yield. This was done through sawing simulation using the Swedish Pine Stem Bank and the European Spruce Stem Bank. The results show that a volume yield gain of just below 1.5 percent units is possible to achieve for each millimeter sawing kerf reduction, and this result seems to be quite consistent between different scenarios and species, being limited to the situation in the Nordic countries.

\section{Acknowledgements}

This study was financed with support from s Sweden's Innovation Agency (Vinnova) as a part of the strategic innovation program BioInnovation and the project "Swedish wood - Innovation potential for the bio-based society" (IPOS). 


\section{References}

Alvarez PP, Vera JR (2014) Application of robust optimization to the sawmill planning problem. Ann Oper Res 219(1): 457-475.

Anonymous (1997) Nordic Timber: Grading rules for pine (Pinus sylvestris) and spruce (Picea abies) sawn timber: Commercial grading based on evaluation of the four sides of sawn timber. Föreningen svenska sågverksmän (FSS), Sweden.

Berggren G, Grundberg S, Grönlund A, Oja J (2000) Improved spruce timber utilization (STUD). European shared cost research project within FAIR (DGXII/E2), contract no. FAIRCT96-1915. Final report sub-task A 1.2, database and non-destructive "glass-log" measurements. Technical Report. AB Trätek and Luleå University of Technology.

Berglund A, Broman O, Grönlund A, Fredriksson M (2013) Improved log rotation using information from a computed tomography scanner. Comput Electron Agric 90: 152-158.

Broman O, Fredriksson M (2012) Wood material features and technical defects that affect yield in a finger joint production process. Wood Mater Sci Eng 7(4): 167-175.

Chiorescu S, Grundberg S (2001) THE INFLUENCE OF MISSING BARK ON MEASUREMENTS PERFORMED WITH A 3D LOG SCANNER. For Prod J 51(9): 78-86.

Cristóvão L, Ekevad M, Grönlund A (2013) Industrial sawing of Pinus sylvestris L.: Power consumption. BioResources 8(4): 6044-6053.

Ekevad M, Lundgren N, Flodin J (2011) Drying shrinkage of sawn timber of Norway spruce (Picea abies): Industrial measurements and finite element simulations. Wood Mater Sci Eng 6(12): 41-48.

Fredriksson M (2014) Log sawing position optimization using computed tomography scanning. Wood Mater Sci Eng 9(2): 110-119.

Fredriksson M, Broman O, Sandberg D (2017) The Use of CT-Scanning Technology in Wood Value-Chain Research and in Wood Industry: A State of The Art. Pro Ligno 13(4): 533-539.

Giudiceandrea F, Ursella E, Vicario E (2011) A high speed CT scanner for the sawmill industry. In Proceedings of the 17th international non destructive testing and evaluation of wood symposium (pp. 14-16). Sopron, Hungary: University of West Hungary.

Grundberg S (1999) An X-ray LogScanner: a tool for control of the sawmill process. Doctoral dissertation, Luleå University of Technology, Sweden.

Grönlund A, Björklund L, Grundberg S, Berggren G (1995) Manual för furustambank (in Swedish). (English title: Manual for pine stem bank.) Technical Report 1995:19 Luleå University of Technology, Skellefteå, Sweden. 
Lindholm, G (2006) Sågverksbranschens kostnads- och intäktsstruktur - undersökning, analys och trender inom svensk sågverksnäring (in Swedish with English abstract). (English title: Cost and income structure of sawmills in Sweden.) Masters thesis no. 79, Swedish University of Agricultural Sciences.

Lundahl CG, Grönlund A (2010) Increased yield in sawmills by applying alternate rotation and lateral positioning. For Prod J 60(4): 331-338.

Moberg L, Nordmark U (2006) Predicting lumber volume and grade recovery for Scots pine stems using tree models and sawmill conversion simulation. For Prod J 56(4): 68-74.

Nordmark U (2005) Value recovery and production control in the forestry wood chain using simulation technique. Doctoral dissertation, Luleå University of Technology, Sweden.

Orlowski K (2003) Some approaches to the determination of saw blade stiffness. Drvna Industrija 54(4): 207-215.

Orlowski K, Sandak J, Tanaka C (2007) The critical rotational speed of circular saw: simple measurement method and its practical implementations. J Wood Sci 53(5): 388-393.

Peñaloza D, Erlandsson M, Pousette A (2018) Climate impacts from road bridges: Effects of introducing concrete carbonation and biogenic carbon storage in wood. Struct Infrastruct Eng 14(1): 56-67.

Schajer GS, Mote CD (2007) Analysis of optimal roll tensioning for circular saw stability. Wood and Fiber Sci 16(3): 323-338.

Singhania S, Kumar P, Gupta SK, Law M (2019) Influence of guides on critical speeds of circular saws. In Advances in Computational Methods in Manufacturing (pp. 519-530). Springer, Singapore.

Skatter S, Høibø OA, Gjerdum P (1998) Simulated yield in a sawmill using different measurement technologies. Holz Roh Werkst 56(4): 267-274.

Skog J (2009) Combining X-ray and 3D scanning of logs. Doctoral dissertation, Luleå University of Technology, Sweden.

Steele P, Wade MW, Bullard SH, Araman, PA (1992) Relative kerf and sawing variation values for some hardwood sawing machines. Faculty Publications, Stephen F. Austin University, Nacogdoches, Texas.

Steele PH, Araman PA (1996) Analyzing investments in thin-kerf saws. In Proceedings, 24th Annual Hardwood Symposium. pp. 55-60. 
Sun JC, Wang XG, Xi FJ (2000) Sliding mode active vibration control of circular saws. In Proceedings of the 2000. IEEE International Conference on Control Applications. Conference Proceedings (Cat. No. 00CH37162) (pp. 953-958). IEEE.

Todoroki C, Rönnqvist M (2002) Dynamic control of timber production at a sawmill with log sawing optimization. Scand J For Res 17(1): 79-89.

Todoroki C (2003) Accuracy considerations when optimally sawing pruned logs: internal defects and sawing precision. Nondestr Test Eval 19(1-2): 29-41.

Vuorilehto J, Tulokas T (2007) On log rotation precision. Forest Prod J 57(1/2): 91-96.

Wasielewski R, Orlowski K, Szyszkowski S (2012) Economical wood sawing with circular saw blades of a new design. Drvna industrija: Znanstveni časopis za pitanja drvne tehnologije 63(1): 27-32.

Zanjani MK, Ait-Kadi D, Nourelfath M (2010) Robust production planning in a manufacturing environment with random yield: A case in sawmill production planning. Eur J Oper Res 201(3): 882-891.

Biography 


\title{
Proceedings of the 2020 Society of Wood Science and Technology International Convention
}

\section{Mechanical Properties versus Structure of Oil Palm Wood (Elaeis guineensis JACQ.)}

\author{
Katja Fruehwald-Koenig \\ katja.fruehwald@th-owl.de \\ Ostwestfalen-Lippe University of Applied Sciences and Art, Germany
}

\section{Abstract}

Oil palms (Elaeis guineensis JACQ.) are mainly cultivated in large plantations for palm oil production to be used for food, chemicals, pharmaceuticals and bio-energy. Worldwide 25 million ha with 140 palms per ha and 25-30 years rotation provide almost 150 million $\mathrm{m}^{3}$ of trunks ( $>75 \%$ in Asia). After 25 years of age, the palms are felled and replaced due to declining oil production. Like fronds and leaves, the trunks remain on the plantation site for nutrient recycling which leads to increased insect and fungi populations. Many regions where oil palms grow currently suffer from a decline in timber harvested from their tropical forests. Recent research has explored the commercial uses of oil palm wood with the intension to partly substitute tropical timber species. In many cases, oil palm wood is good for panels (block-boards, flash doors, multi-layer solid wood panels) and construction timber. As density varies much within a palm trunk, grading of the lumber and knowledge of elasto-mechanical properties is an important issue.

Being monocotyledons, palms show distinct differences in the anatomical structure compared to common wood species. Only lateral and no radial growth of the stem means no growth rings, no wood rays, no knots. The wood consists of lengthwise oriented vascular bundles (VB) embedded in parenchymatous ground tissue. The vascular bundles are composed of vessels and sclerenchymatous fiber cells (fiber caps) with thick walls for structural stability; the density of the VB is high. The ground tissue consists of parenchyma cells, which are thin walled and contain lots of water and sugars. Their density is low and under load they easily buckle. Thus, from the structural mechanics point of view, if vascular bundles are considered as reinforcements (fibers) and ground tissue as matrix, oil palm wood can be seen as unidirectional long-fiber-reinforced bio-composite.

Within a research project, various elasto-mechanical properties of oil palm wood were determined on small-size test specimens with the assumption of orthotropic material behavior. Almost all elastomechanical properties correlate with density, which depends primarily on the age of the palm tree, the location within the trunk (cross section and height) and the size, number, and anatomical structure of vascular bundles. Shear strength and G-modulus in the three planes were tested using nondestructive testing methods (ultrasonic velocity of shear waves, natural frequency from flexural and torsional vibration) on one hand and static, destructive testing (Arcan test, shear test of wood specimen glued between two plywood plates acc. to EN 789, test on shear blocks acc. to DIN 52187, compression test, torsional test acc. to DIN 52190). The different test methods were examined with regard to their suitability for testing oil palm wood. Like for most long-fiber-reinforced composites, the Young's modulus and strength in tension parallel to the vascular bundles is high, highly dependent on the density and very much influenced by the properties of the vascular bundles. In contrast, shear strength, torsional modulus and G-modulus are low and very much influenced by the (low) properties of the parenchymatous ground tissue.

Biography 


\title{
Proceedings of the 2020 Society of Wood Science and Technology International Convention
}

\section{Color Change and Physical-Mechanical Properties of Four Furfurylated Fast-Growing Tropical Wood Species}

\author{
Yusuf Sudo Hadi 1 \\ yshadi@indo.net.id \\ Elis Nina Herliyana 1 \\ elisherliana@yahoo.com \\ Gustan Pari2 \\ gustanp@yahoo.com \\ Rohmah Pari2 \\ rohmahpari@gmail.com \\ Desy Mulyosari 1 \\ desy_m812@apps.ipb.ac.id \\ Imam Busyra Abdillah \\ ibusyra.a@gmail.com \\ 1 Bogor Agicultural University, Indonesia \\ 2 Forest Products Research and Development Centre, Indonesia
}

\begin{abstract}
Tropical plantation trees cut at young age produce timber that is dominated by sapwood and juvenile wood. Consequently, the timber has inferior quality in terms of physical and mechanical properties. Impregnation of the wood with furfuryl alcohol (FA) could improve its physical-mechanical properties. Specimens of jabon (Anthocephalus cadamba), sengon (Falcataria moluccana), mangium (Acacia mangium), and pine (Pinus merkusii) wood were impregnated with FA and tartaric acid as the chemical catalyst, and color change and physical-mechanical properties were evaluated. The densities of untreated jabon, sengon, mangium, and pine wood were $0.34,0.36,0.60$, and $0.72 \mathrm{~g} / \mathrm{cm} 3$, respectively. After FA impregnation, the weight percent gain of the wood reached $86.2 \%, 30.1 \%$, $19.1 \%$, and $15.2 \%$, respectively, and its color was darker than that of the untreated wood.

Furfurylated wood had better physical-mechanical properties than untreated wood in terms of moisture content (decreased 74\%), water absorption (decreased 82\%), anti-swell efficiency (69\%), anti-shrink efficiency (62\%), MOE (increased 14\%), and hardness (increased 44\%).

Keywords: plantation forest, sapwood, juvenile wood, furfurylated wood.
\end{abstract}

Biography 


\title{
Auto-ignition characteristics of wood
}

\author{
Preimesberger C.1-Rindler A.1 - Pfeifer C.2-Hansmann C.1*
}

1 Key Researcher PhD, Competence Centre for Wood Composites and Wood

Chemistry, Linz, Austria, * Corresponding author

c.hansmann@wood-kplus.at

2 Professor PhD, Institute for Chemical and Energy Engineering, University of

Natural Resources and Life Science (BOKU), Vienna, Austria

christoph.pfeifer@boku.ac.at

\begin{abstract}
The auto ignition (without external source) and fire behaviour of wood is very complex and depends on several factors that can influence the ignition behaviour of the material. Accordingly, it is difficult to apply generalizations regarding the behaviour of the material and supposed laws to different application scenarios. The investigations and test procedures as well as the results presented in basic wood science literature where obtained decades ago and differ considerably from one to another, which illustrates the complexity of the topic already mentioned. However, the generally accepted auto ignition point of wood $\left(330^{\circ} \mathrm{C}\right)$, only refers to the ignition of combustion gases and not exothermic behaviour of the material. Dealing with the term ignition regarding exothermic reactions, it must be differentiated between a glowing and a flaming mode, where the later represents the point where the gases ignite. Glowing without an auto ignition of gases also leads to a material combustion beyond $330{ }^{\circ} \mathrm{C}$, at a critical temperature, where an exothermic reaction, mass loss and light emission of wood starts needs to be defined as the glowing point. This glowing point not only depends on applied temperature in relation to time but also to the mass and volume of the treated sample. At this point, literature does not reveal specific values. Thus, tests on spruce cubes with side lengths of 5, 10, 15 and $20 \mathrm{~mm}$, comparable growth ring deviation and mass were performed. Samples were fitted with thermocouples at the surfaces and the center and exposed to isothermal conditions of $240{ }^{\circ} \mathrm{C}, 270{ }^{\circ} \mathrm{C}, 300{ }^{\circ} \mathrm{C}, 330{ }^{\circ} \mathrm{C}$ and $360{ }^{\circ} \mathrm{C}$. Already at this small volumetric variation of samples, different volume related behaviour could be determined concerning exothermal behaviour and combustion of samples. In addition, simultaneous thermal analysis (STA) was performed on the three main substances of wood (cellulose, hemicellulose and lignin) as well as different blends, <500 $\mu \mathrm{m}$ milled spruce and $0.56 \mathrm{~mm}$ thin spruce veneer discs. The tests were conducted under air atmosphere with varying air flows $(20,90$ and $180 \mathrm{ml} / \mathrm{min})$, heating rates $(10$ and $50 \mathrm{~K} / \mathrm{min})$ in a temperature range of 20$550{ }^{\circ} \mathrm{C}$ to enable a clear fitting of single wood constituents to entire thermogram of spruce wood. The achieved findings contribute to a better understanding of the ignition behaviour of wood and are relevant for future applications especially in the wood building sector.
\end{abstract}

Key words: auto ignition of wood, glowing point, simultaneous thermal analysis,

Biography 
Proceedings of the 2020 Society of Wood Science and Technology International Convention

\title{
Mechanical behavior of a painted wooden panel from the heritage subject to hygrothermal variations: role of the reinforcement
}

\author{
Delphine Jullien 1 \\ delphine.jullien@umontpellier.fr \\ Jean-Christophe Dupréz \\ jean.christophe.dupre@univ-poitiers.fr \\ Franck Hesser2 \\ franck.hesser@univ-poitiers.fr \\ Luca Uzielli3 \\ luca.uzielli@unifi.it \\ Lorenzo Riparbelli3 \\ lorenzo.riparbelli@unifi.it \\ Paola Mazzanti3 \\ paola.mazzanti@unifi.it \\ Cécilia Gauvin 4 \\ cecilia.gauvin@gmail.com \\ Joesph Gril5 \\ joseph.gril@cnrs.fr \\ Gilles Tournillon6 \\ g.tournillon@ateliertournillon.com \\ Philippe Hazael-Massieux7 \\ philippehazael-massieux@hotmail.fr \\ Danièle Amoroso7 \\ amorosowaldeis@gmail.com \\ Pierre Stepanoff 8 \\ p.stepanoff@montpellier3m.fr \\ Marina Bousvarous \\ m.bousvarou@montpellier3m.fr \\ 1 LMGC - University of Montpellier - CNRS, France \\ 2 Institut Pprime, University of Poitiers - CNRS, France \\ 3 DAGRI, University of Florence, Italy \\ 4 Cécilia Gauvin Consulting, Netherlands \\ 5 Institut Pascal, University of Clermont Auvergne, France \\ 6 ATELIER TOURNILLON, France \\ 7 Atelier AMOROSO WALDEIS, France \\ 8 Musée Fabre, France
}

\begin{abstract}
This collaborative work brings together the Musée Fabre, furniture and pictorial layer restorers as well as researchers from DAGRI (University of Florence), the PPRIME institute (University of Poitiers) and LMGC (University of Montpellier). The aim of this study is to characterize the mechanical behavior of a painted wooden panel from the heritage subject to controlled variations in the hygrothermal environment.

La Sainte Trinité couronnant la Vierge (16th century, anonymous) is a painted panel showing mechanical variations for many years, requiring the laying of facings in 1998 to prevent the paint layer from further tenting. It is made of four vertical thinned oak boards, assembled by horizontal and
\end{abstract}




\section{Proceedings of the 2020 Society of Wood Science and Technology International Convention}

vertical crossbars (reinforcement), probably glued and/or nailed onto them in the 19th c.a. A coating covered the whole backside of the panel. In 1963, the last conservation report suggested a drastic treatment consisting in an additional thinning of the panel and in dubbing the paint layer with another support. In 2017, conservators and curators decided to undertake a new conservation treatment. However, before any conservation act, a thorough study was decided, aiming to characterize the behavior of the panel and understand the occurrence of several new cracks.

These tests were carried out in a room of the museum open to the public. This imposed several constraints, such as the creation of a climatic enclosure and the installation of an adapted optical measurement device. The shape and the deformations of the panel are monitored by the stereo method followed by markers. Two pairs of cameras placed on either side of the panel allow tracking on both sides. Three deformometric devices make it possible to measure, by contact, local deformations and curvatures. Variations in water mass are obtained using a scale.

Variations in relative humidity of $+/-10 \%$ were carried out in stages of around two months. The position of the markers is measured every hour, which makes it possible to calculate the local movements of the panel in the three directions. The relief of the panel is concave with an amplitude of $16 \mathrm{~mm}$. The deformations are strongly influenced by the presence of the glued cross-beams, which can be seen as the result of an inappropriate intervention that strongly contributed to the separation and cracking of the boards, and to the damages of the paint layers.

The removal of these cross-beams has been operated by restorers, while local deformations and curvature have been registered by deformometric device, allowing to analyze the mechanical effect of cross-beams onto the panel. The four boards constituting the panel were glued again, and the behavior of the "new" panel subject to hygrothermal variations is characterized. As expected, the panel without cross-bars is much more reactive to the environment. The data obtained by the deformometric sensors are crossed with the optical measurements. Mechanical behavior is related to variations in the mass of water measured.

Keywords : painted wooden panel, cultural heritage, mechanical behavior, hygrothermal variations, image correlation, act of restoration

\section{Biography}




\title{
Proceedings of the 2020 Society of Wood Science and Technology International Convention
}

\section{Dynamic compensation of load cell response for cutting force measurements in wood machining}

\author{
Daniel Lechowicz \\ d.lechowicz@wood-kplus.at \\ Ondrej Dvoracek \\ o.dvoracek@wood-kplus.at \\ Stephan Frömel-Frybort \\ s.froemel-frybort@wood-kplus.at
}

\section{Wood K plus - Competence Centre for Wood Composites and Wood Chemistry}

\begin{abstract}
Piezoelectric dynamometers are widely used for cutting force measurements. However, the range of measurable frequencies of commercial dynamometers is not sufficient for machining of wood and wood-based materials. Although force measurements are conducted under dynamic conditions, current transducers are calibrated statically which subsequently can result in a distortion of the signal. As cutting forces prove to be a crucial parameter in the design of cutting tools and the supervision of machining processes, there is a growing demand for accurate and reliable methods for cutting force measurement. In this work, a filtering method of the acquired signal, increasing the bandwidth of the test rig, is proposed. The inverse filter has been applied to distorted cutting forces which was preceded by thorough examination of the rig by means of an impact hammer. To avoid accuracy loss, an average of ten impact tests was used. In order to go over the performance of the filtering method, a number of measurements of cutting forces were done using state-of-the-art pendulum-like test rig designed by Kompetenzzentrum Holz $\mathrm{GmbH}$. The assumption behind it was to avoid discontinuous nature of the rotary cutting process due to successive impacts of the cutting edge. Then, the original and transformed data were compared. Profound comparison of both signals implies that impacts of the cutting edge on the workpiece leading to dynamic excitation of the dynamometer affect the value of the cutting forces, which results in significant discrepancy between what is observed and real occurring cutting forces. Finally, several cutting tests were performed as the design of experiment included examination of the influence of different cutting speeds and chip thicknesses on cutting forces.
\end{abstract}

\section{Biography}




\title{
Proceedings of the 2020 Society of Wood Science and Technology International Convention
}

\section{Assessment of Energy-Saving by Using a Membrane-Based Thermal Energy Recovery System to Improve the Energy Efficiency of Kiln Drying Processes}

\author{
Ling Li 1 \\ ling.li@maine.edu \\ Nasim Alikhani 1 \\ nasim.alikhani@maine.edu \\ Jinwu Wang2 \\ jinwu.wang@usda.gov \\ Mehdi Tajvidi 1 \\ mehdi.tajvidi@maine.edu
}

\author{
1 School of Forest Resources, University of Maine, USA \\ 2 Forest Service, Forest Products Laboratory
}

\section{Abstract}

The moisture content (MC) of woody materials is usually very high. For instance, the MC of green wood varies from $60 \%$ to $80 \%$ and in some cases up to $120 \%$ (dry basis). Kiln drying is often used as the process to reduce the MC of lumber. Unlike the air-drying process, kiln drying is a very energy-intensive process, which consumes much energy to extract water from lumber which is subsequently to the atmosphere. The thermal energy loss from the venting of dry kilns takes up to $20 \%$ of total energy consumed by the whole drying operation because a considerably large thermal energy is stored in the moist exhaust air. Harvesting and reusing such waste thermal energy would improve the energy efficiency of the kiln drying process. We have examined the efficiency of moisture removal of a polydimethylsiloxane (PDMS) based membrane system by developing a lab-scale thermal energy recovery system. The results that were reported at the 2019 SWST Convention revealed that at least $50 \%$ of moisture vapor can be removed by the PDMS membrane system at the initial relatively humidity $(\mathrm{RH})$ in the range of $65 \%$ to $85 \%$, vacuum pressure of 26 inch $\mathrm{Hg}$, and airflow rate varying from 600 to $1000 \mathrm{ml} / \mathrm{min}$. In this follow-up study, the goal is to evaluate the energy-saving if a PDMS membranebased thermal energy recovery system is installed on a conventional heat-and-vent steam kiln. To calculate the energy consumption, a drying process was conducted using the small steam kiln with a capacity of $1500 \mathrm{bdft}$ at the School of Forest Resources of the University of Maine. The wood species was Eastern White Pine (Pinus strobus). The moisture contents of White Pine boards were measured at each drying step following the drying schedule. The total energy consumption included 1) heat required to raise the temperature of wood, air (in kiln and supplementary fresh air), and remaining bound water in wood; 2) heat required to remove free water and bound water; 3) heat loss through walls, roof, foundation, and door, etc.; and 4) heat loss stored in the exhaust air. The research findings showed that about $29 \%$ of energy-saving would be achieved if the moist, warm exhaust air were first dehydrated by passing through the PDMS membrane system and then redirected into the kiln.

Keywords: Energy-saving; Kiln drying processes; Membrane thermal energy recovery system; Waste thermal energy.

Biography 


\title{
Proceedings of the 2020 Society of Wood Science and Technology International Convention
}

\author{
The Steady-State Diffusion of Moisture in Southern Pine Lumber \\ Guizhou Wang \\ gwang16@ncsu.edu \\ Perry Peralta \\ perry_peralta@ncsu.edu \\ Phil Mitchell \\ pmitchel@ncsu.edu \\ Ilona Peszlen \\ ilona_peszlen@ncsu.edu
}

North Caroling State University, USA

\begin{abstract}
Moisture accumulation in a building envelope with cross-laminated timber (CLT) as wall component is an important consideration in the adoption of CLT in the construction industry. A comprehensive study was performed to investigate the hygroscopic behavior of CLT constructed out of southern pine lumber. This report details one aspect of the bigger study: moisture transport in southern pine wood below the fiber saturation point. Within this moisture content range, moisture transport in wood is governed by diffusional processes: bound water diffusion in cell walls and water vapor diffusion in the cell lumen. Although several approaches exist to model this process, the most common one is to use the Fickian diffusion law. A steady-state experiment using a diffusion cup was performed by exposing one face of a southern pine sample to $100 \%$ relative humidity and the other face to $65 \%$ relative humidity for 60 days. Thereafter, the sample was sliced to determine the moisture content distribution along the thickness direction. On average, a linear moisture content profile along the thickness direction was found. Therefore, it was concluded that the moisture conductivity coefficient is independent of moisture content. Simulations were also performed in COMSOL Multiphysics to verify the linear moisture content distribution. There was a strong agreement between experimental measurements and the simulation results, yielding a diffusion coefficient of $3 \times 10-6 \mathrm{~cm} / \mathrm{s}$. The simulation showed that steady-state condition is achieved within 60 days.

\section{Biography}




\title{
Review of Physical and Structural Properties of Oak Wood from Historical Constructions
}

\author{
Ales Straze \\ ales.straze@bf.uni-lj.si \\ Ervin Zveplan \\ ervinzvpln@gmail.com \\ Matjaz Dremelj \\ matjaz.dremel@gmail.com \\ Alen Belec \\ abelec06@gmail.com \\ Katarina Cufar \\ katarina.cufar@bf.uni-lj.si \\ Maks Merela \\ maks.merela@bf.uni-lj.si \\ Zeljko Gorisek \\ zeljko.gorisek@bf.uni-lj.si
}

\section{University of Ljubljana Biotechnical Faculty, Department of Wood Science and Technology, Ljubljana, Slovenia}

\section{Abstract}

We examined physical, mechanical and chemical properties of oak wood (Quercus sp.) felled 4 to 512 years ago. The wood originated from recently felled trees and from several historical constructions in Slovenia and was dendrochronologically dated. We made standardized samples and determined wood density, colour, dimensional stability and sorption properties. Mechanical properties were determined by static tests of hardness and shear strength, and dynamically by analysing ultrasound propagation in all anatomical directions. Structural and anatomical properties were studied with light microscopy techniques. Additionally, FTIR spectroscopy was used to determine the underlying basic chemical changes during wood service life.

The density of oak wood did not change during the service life; it was positively correlated with treering width and the proportion of latewood. Visual and CIELab analyses showed that the colour of heartwood became increasingly darker with age. The wood colour proved to depend on variable wood anatomy, with different proportions of vessels, tracheids, libriform fibres and rays. The percentage of hemicelluloses, determined by FTIR spectroscopy, decreased during the process of wood ageing. Slight degradation of cellulose during the ageing was additionally shown by using polarized light. The structural changes of historical oak wood influenced its physical properties. We confirmed lower hygroscopicity and higher dimensional stability of historic oak, especially in the tangential direction, as well as reduced transverse shrinkage anisotropy compared to recently felled wood. Stiffness and shear strength of oak wood has not changed during the service life. Regarding mechanical properties, the wood was weaker only in the case of transverse hardness. Besides ageing, also the location of wood during its service life and exposure to climate fluctuations seemed to influence the physical and structural properties of historical oak.

Keywords: wood, oak (Quercus sp.), ageing, physical properties, structural properties

\section{Biography}




\title{
Proceedings of the 2020 Society of Wood Science and Technology International Convention
}

\section{Bark and wood as raw materials for high performance insulations}

\author{
Oliver Vay \\ o.vay@wood-kplus.at \\ Maria Busquets Ferrer \\ m.busquetsferrer@wood-kplus.at \\ Christian Hansmann \\ c.hansmann@wood-kplus.at
}

Wood K plus - Competence Centre for Wood Composites and Wood Chemistry

\begin{abstract}
Thermal insulations play a central role for energy savings. For the raw materials environmental compatibility, recyclability, and renewability are important characteristics from the perspective of sustainability. Wood exhibits good insulation properties. Wood is sustainable, biodegradable, locally available and is an economically significant raw material for thermal insulation. Bark, that protects the wood in the living tree from environmental influences, also with regard to thermal loads, is another sustainable and abundant resource, quantitatively, however, not as important as wood. Bark is examined much less intensively and in detail than wood, among other things, due to technical challenges of examination.

In this study we show performance capability of aspen bark and wood for thermal insulation applications. Trapped air in a porous structure generates thermal resistance and conductivity is reduced by a lower density. Therefore, we applied a delignification process to estimate the potential of both materials. To determine the thermal conductivity on small samples, especially of modified bark or wood, we constructed a miniature heat flow meter. Reliability of the self-designed test tool respectively the measured thermal conductivities is demonstrated.

Anisotropic thermal properties were found for both raw materials. Thermal conductivity of bark (density $450 \mathrm{~kg} / \mathrm{m}^{3}$ ) was lower than of wood (density $310 \mathrm{~kg} / \mathrm{m}^{3}$ ). In radial direction as the direction the bark has to protect the tree from environmental influences thermal conductivity of $0.07 \mathrm{~W} / \mathrm{m} \cdot \mathrm{K}$ was evaluated while wood exhibits lowest thermal conductivity of $0.09 \mathrm{~W} / \mathrm{m} \cdot \mathrm{K}$ in tangential direction. By the chemical treatment, mass losses of approximately $45 \%$ for bark and $35 \%$ for wood has been obtained. This delignification yields about $20 \%$ to $35 \%$ improved thermal insulation properties, what makes bark and wood an even more interesting raw material for insulations.
\end{abstract}

\section{Biography}




\title{
Effects of latent heat exchange on water vapor sorption kinetics
}

\author{
Wim Willems \\ Research scientist, FirmoLin, Deurne, The Netherlands \\ w.willems@firmolin.eu
}

\begin{abstract}
The rate of moisture content (MC) change after a sudden relative humidity (RH) change reduces considerably at high RH. This effect has been partly understood by considering the viscoelastic rheology of the wood cell wall. The present contribution explains the significance of the latent heat exchange, associated with MC change, on the kinetics of water sorption at high RH. Model calculations show how this thermal rate-limiting effect can be experimentally disentangled from the simultaneous rheological effect.
\end{abstract}

Key words: Non-Fickian, moisture diffusion, coupled heat-moisture kinetics, thermally limited moisture transfer

\section{Introduction}

When wood is exposed to a humid atmosphere, it will obtain an equilibrium moisture content (EMC) that is mainly determined by the temperature and relative humidity $(\mathrm{RH})$. The complex dynamics of wood under variable environmental conditions is poorly understood, despite its scientific and technological significance. The steady-state moisture flow $j(\mathrm{~mol} \mathrm{~s}-1 \mathrm{~m}-2)$ across a thin wood specimen exposed to a constant moisture concentration gradient, $\nabla c(\mathrm{~mol} \mathrm{~m}-4)$, defines the preferred method to determine the moisture diffusion coefficient $D(\mathrm{~m} \mathrm{~s}-1)$ via $j=D \nabla c$. Unsteady-state moisture flow experiments using gravimetric methods are easier to perform and more accurate, however, much more difficult to analyze. The determination of $D$ from the recorded temporal weight changes after a stepwise change in RH can be in principle obtained from inverse modelling of Fick's diffusion equation $\partial c / \partial \mathrm{t}=\nabla \cdot(D \nabla c)$. Complexity arises in the wood domain from simultaneously interacting changes in temperature, moisture, wood polymer conformations and mechanical stresses (Thybring et al. 2019). In the ambient domain, the transient heat and moisture transfer to and from the wood surface are subject to physical limitations. Consequently, the determined $D$ for a given specimen is generally different between unsteady- and steady-state experiments (Wadsö 1994).

The most surprising difference between unsteady- and steady-state diffusion is the opposite sign of the large $\mathrm{RH}$-dependence of $D$, for which there is no generally accepted explanation. Current research on this subject is mainly devoted to understanding the wood rheological response during moisture uptake (Thybring et al 2019). Kelly and Hart (1970) investigated thermal effects on the 
moisture transfer rates in wood samples at high RH experimentally, concluding that the wood temperature changes associated with moisture content (MC) changes have a direct effect on the local $\mathrm{RH}$ at the wood surface, preventing the MC to reach the EMC belonging to the ambient RH. Willems (2017) applied this mechanism for thermally-limited moisture transfer (TLMT) in a simplified analytical model, showing that it preferentially retards the moisture kinetics at high RH. Thybring et al. (2019) correctly criticized the TLMT model on some of its simplifications, but their rejection of the TLMT mechanism was based on incorrect arguments. In the present contribution, the TLMT mechanism is alternatively and more fundamentally derived from the physics of moisture transfer in the ambient domain. This approach provides a better insight in the TLMT mechanism and how it essentially differs from earlier attempts (King and Cassie 1940; Armstrong et al. 1966; Crank 1975) to model thermal effects on the moisture transfer rate. For readability, the theory will be explained for moisture uptake only; it is equally applicable to drying.

\section{Theory}

Water vapor transfer in the ambient is driven by a gradient in the water vapor concentration, $c$ (mol m-3), which can be expressed in the water vapor pressure $p(\mathrm{~Pa})$ by using the ideal gas law: $c=p / R T$, where $R\left(=8.31 \mathrm{~J} \mathrm{~mol}_{-1} \mathrm{~K}-1\right)$ is the universal gas constant and $T(\mathrm{~K})$ the absolute temperature. $p$ can be written as the product of the saturated water vapor pressure $p_{\text {sat }}(T)$, which is a unique function of $T$, and the relative humidity $h(-)$. Denoting conditions in the ambient and at the wood surface with indices ' $\mathrm{a}$ ' and ' $\mathrm{s}$ ' respectively, the moisture flow $j=k m\left(c_{a}-c_{s}\right)$, where $k_{m}(\mathrm{~m} \mathrm{~s}-1)$ is a phenomenological water vapor transfer constant. The water vapor supply rate after a step change of $h_{a}$ from $h_{0} \rightarrow h_{1}$ is then expressed as:

$$
j=k_{m}\left(\frac{h_{1} p_{s a t}\left(T_{0}\right)}{R T_{0}}-\frac{a_{w}\left(u_{s}, T_{s}\right) p_{s a t}\left(T_{s}\right)}{R T_{s}}\right)
$$

where $a_{w}\left(u_{s}, T_{s}\right)=h_{s}$ is the water activity for the MC and temperature at the wood surface, which is the inverse of $u_{s}=u_{e q}\left(a_{w}, T_{s}\right)$, where $u_{e q}(h, T)$ is the moisture isotherm, expressing the EMC for a given $\mathrm{RH}$ and temperature. Initially, the $\mathrm{MC}$ is equilibrated at $h o$, hence, $a_{w}$ will gradually change from $h_{0}$ to $h_{1}$, whereas in the ambient, the change from $h_{0}$ to $h_{l}$ is immediate (stepwise).

$T_{s}$ inevitably becomes elevated above $T_{0}$ by the associated dissipation of heat from the adsorption of moisture in wood, having a self-limiting effect on the moisture supply rate (Eq.(1)). This is most evident after linearization of Equation (1) for small temperature differences, $\Delta T=\left(T_{s}-T_{0}\right)<<$ $T$, using the Clausius-Clapeyron equation, $d P_{s a t} / d T=P_{s a t} H_{0} / R T_{2}$, where $H_{0}\left(\mathrm{~J}_{\text {mol-1 }}\right)$ is the latent heat of water vapor at $T o$ :

$$
j \approx k_{m} \frac{p_{s a t}\left(T_{0}\right)}{R T_{0}}\left(h_{1}-a_{w}-\frac{a_{w} H_{0}}{R T_{0}^{2}} \Delta T\right)
$$

Under isothermal conditions $(\Delta T=0)$ or at very small $a_{w}, j$ is proportional to $\left(h_{1}-a_{w}\right)$, as expected. At finite $a_{w}$ there is a temperature difference $\Delta T$ where the flow is disrupted, despite the $\mathrm{RH}$ gradient: 


$$
(\Delta T)_{j=0}=\frac{R T_{0}^{2}}{H_{0}} \frac{h_{1}-a_{w}}{a_{w}}
$$

Equation (3) gives the maximum wood temperature elevation for moisture transfer, but it does not predict the actual $\Delta T$. The temporal behavior of $\Delta T$ is determined from the heat balance between the dissipation rate, associated with the moisture flow $j$, and the heat loss from wood to the ambient. Willems (2017) developed the simplest possible closed analytical model for the retrieval of $u(t)$ and $\Delta T(t)$ from the coupled heat and moisture flow balance with an incorporated TLMT mechanism. The wood specimen is regarded as infinitely thin, simplifying the heat and moisture diffusion equations to a system of exactly solvable simultaneous first-order rate equations:

$$
\begin{gathered}
\frac{d u}{d t}=\beta\left(u_{1}-u-\frac{h_{1} H_{0}}{R T_{0}^{2}} \Delta T\left(\frac{d u_{1}}{d h}\right)\right) \\
\frac{d \Delta T}{d t}=-\gamma \Delta T+\frac{H_{0}}{M c_{p}} \frac{d u}{d t}
\end{gathered}
$$

Equation (4) is the equivalent of Equation (2), translated to the moisture content $u$, where $d u 1 / d h$ is the slope of the moisture sorption isotherm at $h_{1} . \beta(\mathrm{s}-1)$ is an effective moisture uptake rate constant and $\gamma(\mathrm{s}-1)$ is an effective heat loss rate constant. The right-most term in Equation (5) gives the temperature change rate by the heat dissipation of moisture uptake, where $M(=0.018$ $\mathrm{kg} \mathrm{mol-1})$ is the molar mass of water and $c_{p}\left(\mathrm{~J} \mathrm{~kg}_{-1} \mathrm{~K}-1\right)$ is the effective specific heat capacity of wood. Under circumstances where the moisture kinetics are TLMT controlled, the step response from $u$ o to $u \imath$ becomes (Willems 2017):

$$
E=\frac{u-u_{0}}{u_{1}-u_{0}} \approx 1-\exp \frac{-\beta t}{\left(1+\frac{\beta}{\gamma} \frac{R}{M c_{p}}\left(\frac{H_{0}}{R T_{0}}\right)^{2} h_{1} \frac{d u_{1}}{d h}\right)}
$$

This provides an analytical expression for the TLMT response time constant $\tau(\mathrm{s})$ :

$$
\tau=\frac{1}{\beta}+\frac{1}{\gamma}\left(\frac{R}{M c_{p}}\left(\frac{H_{0}}{R T_{0}}\right)^{2} h_{1} \frac{d u_{1}}{d h}\right)
$$

\section{Results and Discussion}

The dynamic behavior of wood moisture becomes complex when there is interaction with heat, mechanical stresses and wood polymer rearrangements. The moisture uptake kinetics are dependent on the final RH level, the RH-step size towards this level and the hold time of the conditioning at the initial RH before the RH-step, as reviewed by Thybring et al. (2019). The TLMT theory singles-out the effect of heat exchange on the sorption kinetics, which certainly cannot explain all non-Fickian features of wood moisture kinetics. However, the TLMT 
mechanism seems to have a generic limiting effect on moisture changes at higher RH, which should be taken into account in the study of rheological effects on moisture dynamics.

Equation (3) expresses the $\Delta T$ condition, needed for the complete disruption of water vapor transfer in the ambient domain. It is a strong relationship, because it does neither explicitly depend on any wood property nor on any convective/diffusion parameter for moisture transfer in the ambient. It shows that near equilibrium $\left(a_{w} \rightarrow h_{1}\right)$ an ever smaller temperature deviation $(\Delta T)_{j=0}$ admits moisture transfer. Since moisture transfer is associated with heat dissipation, it is self-causing $\Delta T$. When this $\Delta T$ is nearing $(\Delta T)_{j=0}$, moisture transfer becomes thermally-limited. Under TLMT control, the moisture uptake rate is self-regulated to maximize $\Delta T$ as close as possible to $(\Delta T)_{j=0}$. A semi-empirical relation for the peak elevation can be obtained by substituting a suitable value (the average of $h_{0}$ and $h_{l}$ ) for $a_{w}$ in Equation (3), to find

$$
(\Delta T)_{\text {peak }} \approx \frac{R T_{0}^{2}}{H_{0}} \frac{h_{1}-h_{0}}{h_{1}+h_{0}}
$$

A verification of Equation (8) with experimental data of Christensen and Kelsey (1959) is shown in Figure 1.

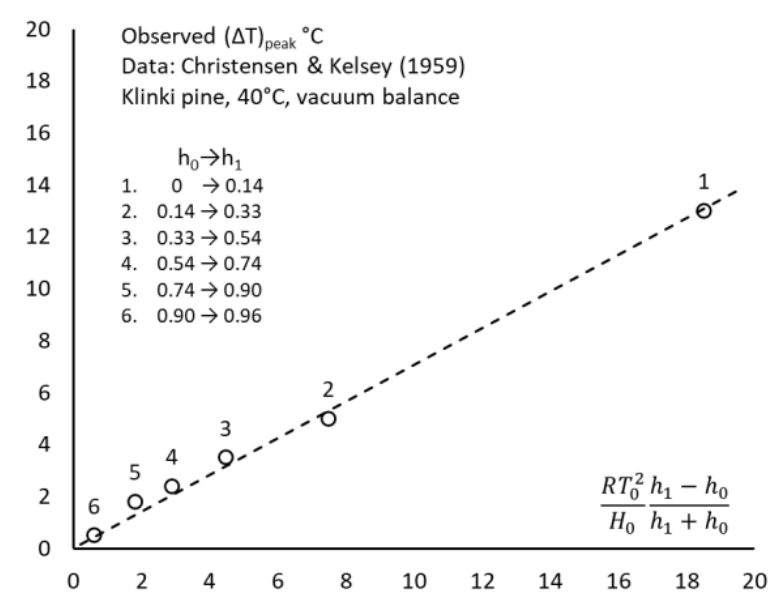

Figure 1. Verification of Equation (8) for the TLMT-predicted RH-trend of $(\Delta T)$ peak for various humidity steps $h o \rightarrow h_{l}$ (abscissa) versus the observed peak temperature (ordinate).

The observed $(\Delta T)$ peak are dependent on the heat transfer characteristics of the experiment, hence, Equation (8) is only an estimate (up to some factor) that cannot have general validity. However, it does confirm and explain the trend of $(\Delta T)$ peak in various RH-ranges.

In the view of previous authors (Christensen and Kelsey 1959, Thybring et al 2019), the very small peak temperature at high RH (Figure 1) would prove that there is no thermal effect on moisture kinetics. Without the moisture transfer considerations of Equation (2), there would indeed only be a $\Delta T$-effect on the moisture kinetics via a temperature coefficient of the EMC. This effect would then quickly disappear after the thermal peak has passed and lose significance at high $\mathrm{RH}$ where the thermal peak is small. However, the low peak temperatures at high RH are the consequence of the limited moisture transfer (and limited heat dissipation) at high RH. In case of TLMT, the temperature and moisture are completely entangled, meaning that none can 
change without the other. This is rigorously modeled in the simultaneous differential Equations (4) and (5) under the simplifying assumption of an infinitely thin specimen. The latter simplification enables an analytical treatment, resulting in a first-order response (Eqn. (6)).

The effect of heat exchange becomes evident, when it is eliminated by setting $H 0=0$ in Equation (6), yielding $E=1-\exp (-\beta t)$, i.e. $\tau=1 / \beta$. Comparing this result with Equation (7), TLMT causes an extra term, which is proportional to the factor $h_{l}\left(d u_{1} / d h\right)$ that strongly increases at high RH. Hence, the TLMT model is at least qualitatively capable to explain the opposite RH-trends in the apparent diffusion constant $D$ obtained from unsteady- versus steady-state experiments: $1 / \beta$ is related to $1 / D$ in the steady-state case without TLMT, which decreases with higher RH; the additional term in Equation (7) accounts for the unsteady-state case with TLMT, increasing with higher RH. This is illustrated in Figure 2 with dynamic vapor sorption (DVS) data on pine samples from Altgen et al. (2016), also used in the previous study (Willems 2017). The effective response time constant is now calculated from the maximum slopes $(d u / d t)_{\max }$ at each interval RH-step and moisture step size (Eqn. (9))

$$
\tau \stackrel{\text { def }}{=} \frac{u_{1}-u_{0}}{\left.\frac{d u}{d t}\right|_{\max }}
$$

This definition of the effective response time $\tau$, refers to the initial kinetics rather than the longterm kinetics. On the other hand, it has the advantage that in this early stage of the response, potentially interfering rheological effects are considered insignificant. The linear dependence of $\tau$ on the RH-dependent factor $h_{l}\left(d u_{l} / d h\right)$ (Eqn. (7)) is confirmed in the plot of Figure 2, giving strong support to the TLMT theory.

The slope in the linear regression of Figure 2 is inversely proportional to $\gamma$, the thermal loss rate constant. $\gamma$ is partly determined by the experimental design: a poorer heat conductivity to the ambient increases the slope, i.e. $\tau$ will depend stronger on RH. At low RH, $\tau$ appears to have an opposite RH-dependence, which effect is attributed to the RH-dependence of $\beta$ (steady state diffusion). This low RH-'tail' becomes pronounced in crosslink-modified wood (not shown). An expanded analytical TLMT model, incorporating typical slow dynamic relaxation components in wood, besides the main diffusion rate constant, is recently investigated (Willems 2020). The results from this study suggest that the TLMT retardation effect applies to every dynamic component in the moisture response, effectively time-stretching the entire response, independent of the detailed diffusion/relaxation rate distribution. This insight is expected to render a procedure to separate TLMT effects from the RH-dependent rheological effects. 


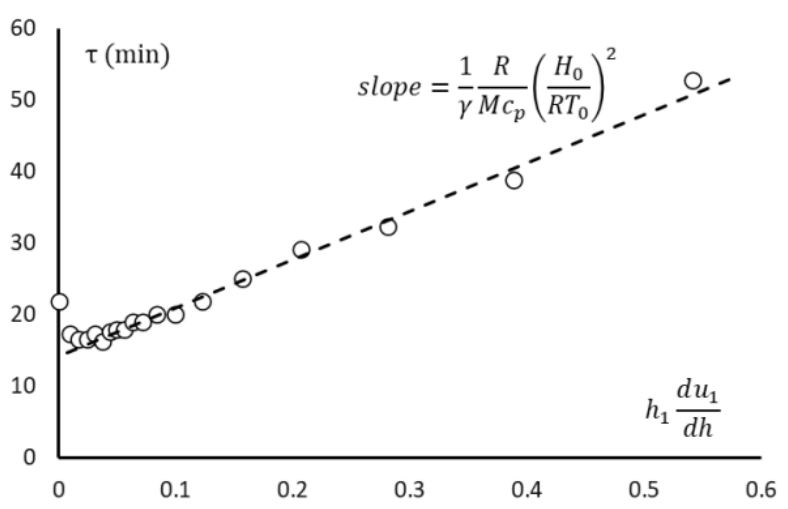

Figure 2. Plot of the experimental effective response time constant $\tau$ (Eqn. (9)) versus $h_{1}(d u 1 / d h)$, confirming TLMT behavior (Eqn. (7)). The broken line is a linear regression fit for the data points > 0.05 (abscissa).

\section{Summary and Conclusions}

Moisture transfer from the ambient source to the receiving wood surface imposes limits on the maximum allowed temperature elevation of the wood specimen. This mechanism is at the core of the TLMT model, explaining retarded moisture kinetics at high RH. Literature data confirm the TLMT-predicted RH-dependence of peak temperatures. The TLMT mechanism remains significant after the occurrence of the main thermal peak, as the maximum allowed temperature deviations for moisture transfer keep decreasing in time and moisture uptake is always associated heat dissipation. The distinctive linear relationship between the TLMT response time constant versus $h_{1}\left(d u_{1} / d h\right)$ was experimentally confirmed in the initial stages of the moisture response of pine wood, where potential other kinetic effects can be ignored.

In conclusion, the TLMT mechanism is embedded in the wood moisture dynamics in the higher RH-range. The retardation effect of TLMT must be removed from DVS data, to isolate rheological effects on moisture dynamics.

\section{References}

Armstrong AA, Wellons JD, Stannett V (1966) Temperature effects during the sorption and desorption of water vapor in high polymers. Part II. Films with special reference to ethyl cellulose. Macromol Chem Phys 95(1):78-91.

Altgen M, Hofmann T, Militz H (2016) Wood moisture content during the thermal modification process affects the improvement in hygroscopicity of Scots pine sapwood. Wood Sci Technol 50(6):1181-1195.

Christensen GN, Kelsey KE (1959) Die Sorption von Wasserdampf durch die chemischen Bestandteile des Holzes. Holz Roh Werkst 17(5):189-203.

Crank J (1975) The mathematics of diffusion. 2nd edition. Clarendon, Oxford.

Kelly MW, Hart AC (1970) Water vapor sorption rates by wood cell walls. Wood Fiber 1(4):270-282. 
King G, Cassie ABD (1940) Propagation of temperature changes through textiles in humid atmospheres. Part I. Rate of absorption of water vapour by wool fibres. Trans Faraday Soc 36:445-453.

Thybring EE, Glass SV, Zelinka SL (2019) Kinetics of water vapor sorption in wood cell walls: state of the art and research needs. Forests 10(8):704.

Wadsö L (1994) Unsteady-state water vapour adsorption in wood: An experimental study. Wood Fiber Sci 6(1):36-45.

Willems W (2017) Thermally limited wood moisture changes: relevance for dynamic vapour sorption experiments. Wood Sci Technol 51(4):751-770.

Willems W (2020) Heuristic study on the interaction between heat exchange and slow relaxation processes during wood moisture content changes. Submitted to Holzforschung.

Biography 


\title{
POSTER SESSION
}

\author{
Chair: Rupert Wimmer, BOKU, Austria
}

Student Posters:

\section{Understanding the Thermodiffusion Properties of Ionic Liquids in a Cellulosic Medium}

\author{
Júlio Amando de Barros \\ julioortizbarros@gmail.com \\ Kaline Goutinho \\ kaline@if.usp.br \\ University of Sao Paulo, Brazil
}

\begin{abstract}
Nowadays different forms of storage and production of clean energy are being researched and applied in a broad range of devices. One of the systems that is most often studied in this area is the aqueous solution of salts, which produces a huge quantity of free charged atoms. This can be used for production of electric potentials and thus is used in equipment such as supercapacitors and ionic thermopiles.

A crucial group of energetic mechanisms that uses ionic liquids can be made or have its properties consider enhanced by cellulose nano products. Our project intends to understand differences in the thermodiffusion properties of ions in the presence of natural and modified cellulose. For that, a complete set of Molecular Dynamics simulations was performed and a comprehensive analysis of the ion-cellulose solution dynamics was done. The software GROMACS was used together with GROMOS_54a6GLYCAM force field which is developed specifically for sugars.

The first step was to fully characterize the solute solvent interaction of cellulose in water, therefore simulations of a single cellobiose and a periodic fiber were executed on vacuum and water solution. Intra and intermolecular hydrogen bonds, and also the main conformation parameters, were analyzed.

Secondly the ions were included on the solutions, $\mathrm{Na}+$ and $\mathrm{Cl}$ - were chosen for that purpose. The interaction of them in an aqueous medium was analyzed for different temperatures and concentrations. The analyses were based in comparing the properties of both compounds (ions and cellulose) isolated and together.

At last, a modified cellulose fiber with propionic acid groups (used on the production of thermoelectric ionic papers) was formed and properly parameterized. The same set of simulations was again performed for fibers with different degrees of modification, the results were then compared with previous systems.

\section{Biography}


Proceedings of the 63rd International Convention of

Society of Wood Science and Technology

July 12-17, 2020 - Hoteli Bernardin, Portorož, Slovenia

Intra-Tree and Inter-Tree Variations in the Wood of Breadfruit (Artocarpus altilis, Parkinson Ex. F.A Zorn) Fosberg

Olusola Samuel Areo1

areo.os@frin.gov.ng

Ayodeji O. Omolez

omomole@yahoo.com

1Forestry Research Institute of Nigeria, Nigeria

2Department of Forest Production and Products, University of Ibadan, Nigeria

\section{Abstract}

Physico-mechanical properties variations in the tress breadfruit wood (Artocarpus artilis,Parkinson) grown in South-Western Nigeria were investigated in this study. Four matured trees (dbh class of $40-50 \mathrm{~cm}, 45-$ 55years of age) were randomly selected and sampled at stem height levels (10\%, 50\% and 90\%) and radial positions (corewood, innerwood and outerwood). Tested samples prepared were dried to about $12 \%$ moisture content before tests. Physical test (density, bending strength (MOR), modulus of elasticity (MOE) and maximum compression strength parallel to the grain (//MCS) shear strength and impact bending) were carried out in accordance with ASTM standards. Data collected were processed using a combination of descriptive and inferential statistics. The density ranged between $603 \mathrm{~kg} / \mathrm{m}_{3}$ to $571 \mathrm{~kg} / \mathrm{m}_{3}$ from the base to the top with a mean of $581 \mathrm{~kg} / \mathrm{m}_{3}$. The axial mean value for MOR obtained was $36.05 / \mathrm{mm} 2$ ranging from $42.07 \mathrm{~N} / \mathrm{mm}_{2}$ to $32.99 \mathrm{~N} / \mathrm{mm} 2$ while the radial values ranged was $35.71 \mathrm{~N} / \mathrm{mm} 2$ to $38.89 \mathrm{~N} / \mathrm{mm} 2$. The mean value for MOE is $3354.01 \mathrm{~N} / \mathrm{mm} 2$ ranging from $3992.97 \mathrm{~N} / \mathrm{mm} 2$ to $3145.18 \mathrm{~N} / \mathrm{mm} 2$ from the base to the top along the axial direction and radially, ranges from 3494.09 $\mathrm{N} / \mathrm{mm}_{2}$ to $3358.09 \mathrm{~N} / \mathrm{mm}_{2}$ from bark to bark. The mean value for //MCS is $20 \mathrm{Nmm}_{2}$ ranging from $23.05 \mathrm{~N} / \mathrm{mm}_{2}$ to $18.09 \mathrm{~N} / \mathrm{mm}_{2}$ along the tree height and across radial axes ranges from $20.74 \mathrm{~N} / \mathrm{mm} 2$ to $18.53 \mathrm{~N} / \mathrm{mm}_{2}$. The mean value for shear strength is $8.9 \mathrm{~N} / \mathrm{mm} 2$ ranging from $9.7 \mathrm{~N} / \mathrm{mm} 2$ to $8.5 \mathrm{~N} / \mathrm{mm}_{2}$ along the tree height and across radial axes ranges from $0.4 \mathrm{~m}$ to $0.3 \mathrm{~m}$ along the tree height and across radial axes ranges from $0.3 \mathrm{~m}$ to $0.3 \mathrm{~m}$. it was observed that the site factor did not significantly affects the pattern of variations in the wood properties but the intra-tree variations in the properties were pronounced across the radial axes in the individual tree while sampling height only affected the density significantly. It was observed that the correlation of density with the mechanical properties was slightly moderate. Breadfruit wood can be classified as moderate density with potentials as substitute species to industries with valuable hardwood timber. The significant differences found between the trees demonstrate the possibility of selection and improvement for increase wood quality. This study has therefore provided baseline information on the wood quality and utilization potential of Artocarpus altilis.

Keywords: Variations, Wood properties, Artocarpus, Mechanical properties, Wood density

Biography 
Proceedings of the 63rd International Convention of Society of Wood Science and Technology

July 12-17, 2020 - Hoteli Bernardin, Portoroz̆, Slovenia

Investigation on Thermo-Hydro Mechanical Treatments effects to densify Tasmanian planted and native timber species

See Paper Under Wood Modification and Preservation pg 324 
Proceedings of the 63rd International Convention of Society of Wood Science and Technology

July 12-17, 2020 - Hoteli Bernardin, Portorož, Slovenia

Characterization of Spruce Log Soaking Water and its Antifungal and Wood Preserving Properties

See Paper Under Wood Modification and Preservation pg 327 
Proceedings of the 63rd International Convention of

Society of Wood Science and Technology

July 12-17, 2020 - Hoteli Bernardin, Portoroz̆, Slovenia

Porous structures produced from different bark particles by mechanical foaming

See Paper Under Composites and Adhesives pg 183 
Proceedings of the 63rd International Convention of Society of Wood Science and Technology

July 12-17, 2020 - Hoteli Bernardin, Portorož, Slovenia

Hardwood cutting forces at different speeds up to $80 \mathrm{~m} / \mathrm{s}$ for an evaluated real chip thickness

See Paper Under Physics and Mechanics pg 362 
Proceedings of the 63rd International Convention of Society of Wood Science and Technology

July 12-17, 2020 - Hoteli Bernardin, Portorož, Slovenia

Simultaneous Chemical and Topographical Mapping of Wood Ultrastructures by Chemical Force Microscopy

See Paper Under Wood Chemistry and Cell Biology pg 257 
Proceedings of the 63rd International Convention of

Society of Wood Science and Technology

July 12-17, 2020 - Hoteli Bernardin, Portorož, Slovenia

The Importance of Cold Tack of Urea Formaldehyde in Plywood Production

Elfriede Hogger

See Paper Under Composites and Adhesives pg 197 
Proceedings of the 63rd International Convention of

Society of Wood Science and Technology

July 12-17, 2020 - Hoteli Bernardin, Portoroz̆, Slovenia

Sustainable development - international framework - overview and analysis in the context of forests and forest products with competitiveness and new opportunities

Annika Hyytia, Finland annika.hyytia@helsinki.fi

\begin{abstract}
The forest sector is in a remarkable role providing significant new sustainable opportunities globally. Innovations have an important role in the sustainable development, business and competitiveness. Quality is part of competitiveness. Quality is important for competitiveness. Customers' role is important.

This is a qualitative research based on literature. It is based on research articles and literature and organizational literature including several academic sources, for example Proquest, Academic Search Complete (EBSCO), Agris, CAB Abstracts, SCOPUS (Elsevier), Web of Science (ISI) and Google Scholar and Internet sites
\end{abstract}

Biography 
Proceedings of the 63rd International Convention of

Society of Wood Science and Technology

July 12-17, 2020 - Hoteli Bernardin, Portorož, Slovenia

Triboelectric Activation of Wood Surfaces by Mechanical Friction

\author{
Lena Maria Leiter 1 \\ lena.leiter@gmail.com \\ Raphaela Hellmayr 1 \\ raphaela.hellmayr@boku.ac.at \\ Roman Mynaz \\ roman.myna@boku.ac.at \\ Stephan Frömel-Frybort2 \\ s.froemel-frybort@wood-kplus.at \\ Rupert Wimmer 1 \\ rupert.wimmer@boku.ac.at
}

1 University of Natural Resources and Life Sciences Vienna, Austria

2 Wood K plus - Competence Centre for Wood Composites and Wood Chemistry

\begin{abstract}
Previous own research has shown that mechanical friction applied on wooden surfaces is creating electrical surface charges. In this research, triboelectric activation of wood surfaces by using a wood brushing machine is investigated. Wood samples from spruce, pine, fir, beech and oak have been processed with a TWINGO 300 B brushing machine. Afterwards the electrical surface charges were detected using a KEYENCE SK-H050 electrostatic sensor, in combination with an Ioniser Monitoring Unit (IMU). Machine settings such as feed speed and brush-pressure were varied to understand the effects on obtained surface charges. The interactions between wood species, wood density, wood moisture and surface roughness on the surface charge status are investigated. First data are showing that softwood is receiving an overall positive surface charge, while hardwoods have the tendency to be less but also positively charged. It is further investigated whether or not these differences can be explained by wood density differences, which are known to be directly connected to the obtained wood particle sizes while brushing. Another factor could be resin content, or the orientation of growth rings, i.e. vertical vs. flat-grain orientation.
\end{abstract}

\title{
Keywords
}

triboelectric surface charge, wood machining, brushing, electrical charge, spruce, pine, fir, beech, oak

Biography 


\title{
Structural, Chemical, and Multi-scale Mechanical Characterization of Waste Windmill Palm Fiber (trachycarpus fortunei)
}

\author{
Jing Li1, 2, Xuexia Zhang2, Jiawei Zhu2, Yan Yu2, Hankun Wang2*
}

1 Graduate student, Research Institute of Wood Industry, Chinese Academy of Forestry, Beijing, P.R. China.

lijing@icbr.ac.cn

(International center for bamboo and rattan)

${ }_{2}$ Graduate student, Graduate student, Associate Professor, Research Institute of

Bamboo \& Rattan Biomass and New Materials, International Center for Bamboo

and Rattan, Beijing, P.R. China. *Correspondening author

lijing@icbr.ac.cn, zhujw@icbr.ac.cn,wanghankun@icbr.ac.cn,

3 Associate Professor, Professor, College of Material Engineering, Fujian

Agriculture and Forestry University, Fuzhou, 350108, P.R. China

13121417614@163.com,yuyan9812@outlook.com

\begin{abstract}
This study investigated the structural, chemical, and multi-scale mechanical properties of windmill palm (trachycarpus fortunei) leaf sheath fiber, which were frequently wasted. Significant variation was observed in fiber diameter and cross-sectional morphology among different layers in a single leaf sheath, whereas the chemical composition, relative crystallinity index, and the microfibrillar angle (MFA) of palm fibers were almost the same among different layers. Windmill palm fibers had low cellulose contents (34.70-35.5\%), low relative crystallinity index (45.7-49.2\%), and high MFA (38.8-29.4 $)$, resulting in low strength and modulus, but high failure strain under tensile load. The tensile fracture surface of windmill palm fibers was assessed through SEM studies and its ductile fracture was confirmed, which can potentially enhance the toughness of composites when used as reinforcement material. Nanoindentation was carried out among different leaf sheath layers, and the results showed the modulus and hardness values of windmill palm fibers are in the same range as other plant fibers. The experimental results may help guide selection of suitable reinforcing fibers for use in composites in different applications.
\end{abstract}

Keywords: Windmill palm fiber; Fiber morphology; Mechanical properties; Nanoindentaion 


\section{Proceedings of the 63rd International Convention of \\ Society of Wood Science and Technology \\ July 12-17, 2020 - Hoteli Bernardin, Portorož, Slovenia \\ Introduction}

Over the last two decades, there has been a growing industrial interest in the development of lignocellulosic natural fibers as replacements for glass or other traditional reinforcement materials used in composites (Gurunathan et al., 2015). Natural fibers composites offer advantages of biodegradability, good accessibility, fast renewability, high specific properties, and low cost (Shinoj et al., 2011; Berges et al., 2016). However, a better understanding of the detailed morphology, structural, and mechanical properties of natural fibers is essential for evaluation of their potential as reinforcing materials in composites and optimization the service life performance of composites (Tran et al., 2015).

Windmill palm (Trachycarpus fortunei) is the most widely cultivated species at the latitudinal palm range margin, and distinguished by its large and fan-shaped leaves (Walther et al., 2010). Every year, a portion of the leaves of the palm dries out to form a mesh of coarse and brown leaf sheath fiber that clasps the tree trunk, making it appear to be wrapped in burlap (Gilman and Watson, 2015, Fig. 1a). The palm leaf sheath fiber is considered an abundant agricultural byproduct due to the necessary regular pruning process of the palm tree by removing loose mats to keep the tree attractive and safe. Currently, due to their high durability and strength characteristics, palm fibers are used to make a variety of by-products such as mattresses, sofas, marine ropes, sacks, and traditional raincoats (Zhai et al., 2013). However, these applications only utilize a small percentage of the total material produced, and the majority of the material is discarded directly as waste, causing serious environmental problems (Chen et al., 2015). The possible use of palm fibers for composite reinforcement may provide a strategy for the efficient utilization of these waste fibers.

Each palm leaf sheath is composed of a middle layer of coarse fibers which is sandwiched between two layers of fibers with smaller diameters. There have been only preliminary studies of palm leaf sheath fibers. Zhang et al., (2015) revealed a unique structure of palm fiber with subcylindrical shape containing abundant fiber cells in the cross section and Si-dots on the surface. Previously, the mechanical properties of palm fiber were mainly determined through monotonic tensile tests. Palm fiber exhibits excellent elongation properties, which is able to tolerate significantly higher stain than other natural fibers (Guo et al., 2014). Chen et al., (2017) investigated the influence of the chemical treatment of windmill palm fibers on its tensile properties, and found that alkalized fibers possessed higher tensile properties than untreated fibers. Nevertheless, none of these studies examined the potential variation in the physical and mechanical properties of palm fiber from different layers of the leaf sheath. Since there are three layers in each sheet of palm leaf sheath with some differences in terms of fiber morphology and tensile properties (Zhai et al., 2012), it is important to assess the properties of these individual layers for a more comprehensive evaluation of the use of palm fiber as composite reinforcement material.

To facilitate reliable use of palm fiber in composites, a detailed investigation was performed of the mechanical properties of windmill palm fibers, separated from the three layers of leaf sheath, in relationship to their chemical composition and structural properties. First, the mechanical properties of palm fibers were determined at two scales: tensile tests at the fiber scale and nanoindentation tests at the cell-wall scale. Next, microscopy (SEM) observation and X-ray diffraction were conducted to investigate morphology and structure (microfibrillar angle and 


\section{Proceedings of the 63rd International Convention of Society of Wood Science and Technology \\ July 12-17, 2020 - Hoteli Bernardin, Portorož, Slovenia}

relative degree of crystallinity), followed by chemical composition analysis. Finally, the results were considered in a detailed assessment of the relationships between the physical, chemical, and mechanical properties of the fiber.

\section{Sample preparation}

\section{Materials and methods}

Windmill palm tree trunk covered by leaf sheath was obtained from Anhui province, China (Fig. 1a). The leaf sheath fibers were mechanically separated from the petiole (Fig. 1b), and then washed with distilled water to remove impurities and dust and further air-dried to remove excessive water and moisture. Then, the cleaned leaf sheath was sorted into three layers,

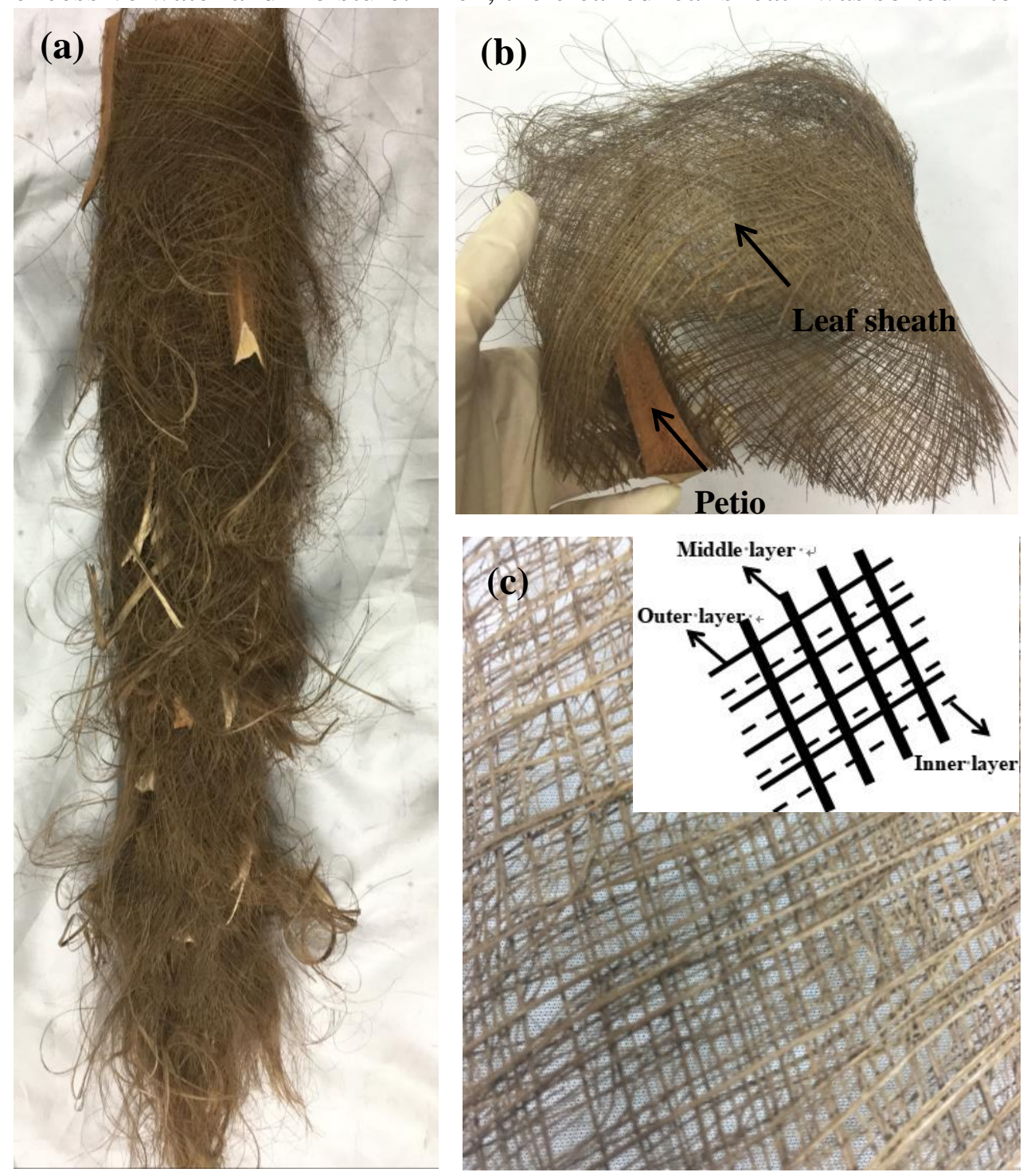

Figure 1 Photograph of (a) windmill palm tree covered with leaf sheath; (b) leaf sheath; (c) a small piece of leaf sheath showing the arrangements of different layers of fiber bundle, with inserted images showing the schematic view of fiber arrangement.

namely the outer, middle, and inner layers, according to their diameters and orientations (Fig. 1c). Comparison of sample preparation of different plant fibers was summarized in Table 1. 


\section{Proceedings of the 63rd International Convention of \\ Society of Wood Science and Technology \\ July 12-17, 2020 - Hoteli Bernardin, Portoroz̆, Slovenia}

Table 1 Fiber and elementary fiber sizes in different palm leaf sheath layers

\begin{tabular}{llllll}
\hline $\begin{array}{lllll}\text { Leaf sheath } \\
\text { layer }\end{array}$ & Fiber & & \multicolumn{3}{l}{ Elementary fiber } \\
\cline { 2 - 2 } \cline { 5 - 6 } $\begin{array}{llllll}\text { diameter } \\
(\mu \mathrm{m})\end{array}$ & & & Diameter $(\mu \mathrm{m})$ & $\begin{array}{l}\text { Length } \\
(\mu \mathrm{m})\end{array}$ & $\begin{array}{l}\text { Cell wall thickness } \\
(\mu \mathrm{m})\end{array}$ \\
\hline Inner layer & $230 \pm 37$ & & $12.1 \pm 1.9$ & $932 \pm 164$ & $2.2 \pm 0.3$ \\
Middle layer & $516 \pm 40$ & & $13.1 \pm 1.9$ & $1019 \pm 160$ & $1.7 \pm 0.3$ \\
Outer layer & $372 \pm 75$ & & $12.7 \pm 1.5$ & $989 \pm 178$ & $2.2 \pm 0.3$ \\
\hline
\end{tabular}

\section{Morphological and chemical analysis}

The longitudinal and transverse surface morphology of the palm fiber were investigated through scanning electron microscopy (SEM, XL30, FEI, USA) operating at 7kV. The tensile fracture surface of the palm fibers was also analyzed. Before SEM observation, the samples were sputtercoated with a thin layer of Pt using an Edwards Sputter Coater.

The diameter and length of each palm fiber and elementary fiber were measured with a digital biological microscope (XTS20G, Fukai LTD. China). In order to extract elementary fiber, palm fibers were chemically treated using a mixture solution of hydrogen peroxide and glacial acetic as described by Yu et al., (2011). For measurement of elementary fiber cell wall thickness, samples were embedded with Spurr resin and cut to obtain smooth transverse section for SEM observation.

The chemical composition ( $\alpha$-cellulose, hemicellulose, lignin, and ash content) of the palm fibers in different leaf sheath layers was analyzed in accordance with the Technical association of Pulp and Paper industry (TAPPI) standards, as described by Khalil et al., (2010).

\section{X-ray diffraction}

A Philips X-ray diffraction system (X'pert Pro, PANalytical B.V., Almelo, NL) was used to evaluate both the MFA and relative crystallinity index $(\mathrm{Cr} I)$ of palm fibers. Before measurement, palm fibers of the same layer were arranged closely to form a mat. Here, evaluation of the entire fiber was performed instead of examination of the powder samples that are commonly used in order to preserve the internal structure of the fibers (Marrot et al., 2013).

Using Euqation (1), MFA of the palm fibers was determined by application of the widely used 0.6T method (Stuart and Evans 1994):

$$
\text { MFA }=0.6 \times T
$$

where T-value was determined as half the width of the peak obtained in azimuthal distribution (Fig.1).

CrI was calculated as described by Segal et al., (1959), as follows:

$$
\operatorname{Cr} I=\frac{\left(I_{002}-I_{a m}\right)}{I_{002}}
$$




\section{Proceedings of the 63rd International Convention of \\ Society of Wood Science and Technology \\ July 12-17, 2020 - Hoteli Bernardin, Portorož, Slovenia}

where $I 002$ is the maximum intensity of the 002 peak at $2 \theta$ about $22^{\circ}$ and $I a m$ is the minimum intensity of diffraction of the amorphous materials at $2 \theta$ about $18^{\circ}$.

\section{Tensile tests}

Tensile tests were first conducted in a universal mechanical testing machine (Instron Microtester 5848 , USA) using a $500 \mathrm{~N}$ load cell. Before the tensile test, two palm fiber ends were glued with instant epoxy adhesive onto a piece of Poplar veneer to avoid any specimen sliding from the clamps. A gauge length of $50 \mathrm{~mm}$ was selected and elongation was recorded with a noncontacting video extensometer by tracking two small black speckles marked on the sample. For each layer of fibers, at least 30 fibers were tested. Tensile tests were conducted under an environment of $20^{\circ} \mathrm{C}$ and $30 \%$ relative humidity (RH). To calculate the tensile strength and modulus of palm fibers, the cross-sectional area of the samples was assessed with a digital microscope (XTS20G, Fukai LTD. China) and then measured with an image-processing software (Image-ProPlus 5.0, Media Cybernetics, USA).

\section{Nanoindentation testing}

For nanoindentation testing, palm fibers were embedded in Spurr resin and cured in a flat mold as previous described (Yu et al., 2011). After curing, the embedded samples were polished with a glass knife and a diamond knife to prepare a smooth surface exposing a transverse section. The nanoindentation experiments were performed using a Triboindenter (Hysitron Incorporation, USA) with a diamond Berkovich indenter (tip radius less than $100 \mathrm{~nm}$ ). The indentation procedure was performed under load control using a three-segment load ramp: reaching the peak load of $150 \mu \mathrm{N}$ within $6 \mathrm{~s}$, holding at the peak load for $6 \mathrm{~s}$, and then unloading within $3 \mathrm{~s}$. In total, 20-25 indentations were conducted for each layer of palm fibers. The elastic modulus and hardness were calculated from the experimental curves according to the method developed by Oliver and Pharr (1992).

\section{Fiber morphology}

\section{Results and discussion}

A windmill palm trunk is covered with a large amount of leaf sheath (Fig. 1a), and each leaf sheath can be easily separated into three layers of fibers due to the orderly arrangements (Fig. 1c). The fiber size differs in different layers of palm fibers (listed in Table 1): the middle layer contained the largest size of fibers $(516 \pm 40 \mu \mathrm{m})$, followed by the outer layer $(372 \pm 75 \mu \mathrm{m})$, and the inner layer $(230 \pm 37 \mu \mathrm{m})$. Also, morphological differences were detected by crosssectional SEM observation, as the fibers from the inner layer showed a homogeneous structure almost completely comprising numerous single elementary fiber (Fig. 2a), whereas the fibers from the middle and outer layers exhibited clear vessels and phloem tissue (conducting tissues) surrounded by elementary fibers (Fig. $2 b$ and c). This specific organization of fibers in different layers is likely related to their different functions, as the small fibers in the inner layer, which closely clasps the palm trunk, mainly play a structural role, and the large fibers in the outer and middle layers facilitate the transportation of nutrients through the conductive tissues. Unlike the observed variability of fiber diameters and morphology, the dimensions of elementary fiber were similar among the different layers, with average diameters ranging from 12.1 to $13.1 \mu \mathrm{m}$, and fiber length ranging from 930 to $1019 \mu \mathrm{m}$, and cell wall thickness ranging from 1.7 to $2.2 \mu \mathrm{m}$. A similar observation was reported by Zhai et al., (2012) previously. 


\section{Proceedings of the 63rd International Convention of \\ Society of Wood Science and Technology \\ July 12-17, 2020 - Hoteli Bernardin, Portorož, Slovenia}

There was similar surface morphology of palm fibers in different layers. For example, in a fiber sample from the outer layer, the fiber was sub-cylindrical in shape (Fig.3a) with a large number of wax and impurities on the rough surface (Fig.3b). In some cleaner areas, the surface was covered by arrays of protrusions (Fig.3c), identified as silica bodies embedding circular craters under higher magnification (Fig.3d) which had been confirmed through energy dispersive X-rays spectrometry (EDS) (D'Almeida et al., 2006). Similar features were also observed in other palm trees, such as piassava palm fibers (Nascimento et al., 2012), date palm fibers (Bourmaud et al., 2017), and sugar palm fibers (Rashid et al., 2016). The main function of these silica bodies is to protect the external surface of the fiber from pathogenic fungi and insects, but the presence of the silica may interfere with pulping and papermaking (Bourmaud et al., 2017). However, the silica bodies does not stick firmly onto the fiber and can be removed mechanically, leaving empty craters that may facilitate mechanical interlocking of the fiber and matrix due to the rougher surface (Shinoj et al., 211).

\section{Chemical composition and structural properties}

The chemical composition of windmill palm fibers in various leaf sheath layers is detailed in Table 2, and the composition of other palm family fibers and some commonly used fibers are presented for comparison. Like other natural fibers, analysis showed that the palm fibers were composed mainly of cellulose, hemicellulose, and lignin, with similar contents among the different layers of leaf sheath. The remarkable consistency of the composition was in contrast to the dramatic variations reported in fiber diameter and cross-sectional morphology.

Windmill palm has a relatively lower cellulose content (34.3-35.5\%) compared to other members of the palm family, such as oil palm (42.7-65.0\%, Shinoj et al., 2011), and sugar palm (43.844.5\% Huzaifah et al., 2017), but a level comparable with piassava palm (31.6\%, Nascimento et al., 2012). Compared with flax, jute, and sisal fibers (Guen et al., 2016), windmill palm fiber has a relative higher lignin content that is comparable to that of other palm family fibers, except oil palm. The high lignin content may contribute to its brown color and useful properties such as weather, fungal, and bacterial resistance (D'Almeida et al., 2006). 
Proceedings of the 63rd International Convention of Society of Wood Science and Technology

July 12-17, 2020 - Hoteli Bernardin, Portoroŭ, Slovenia
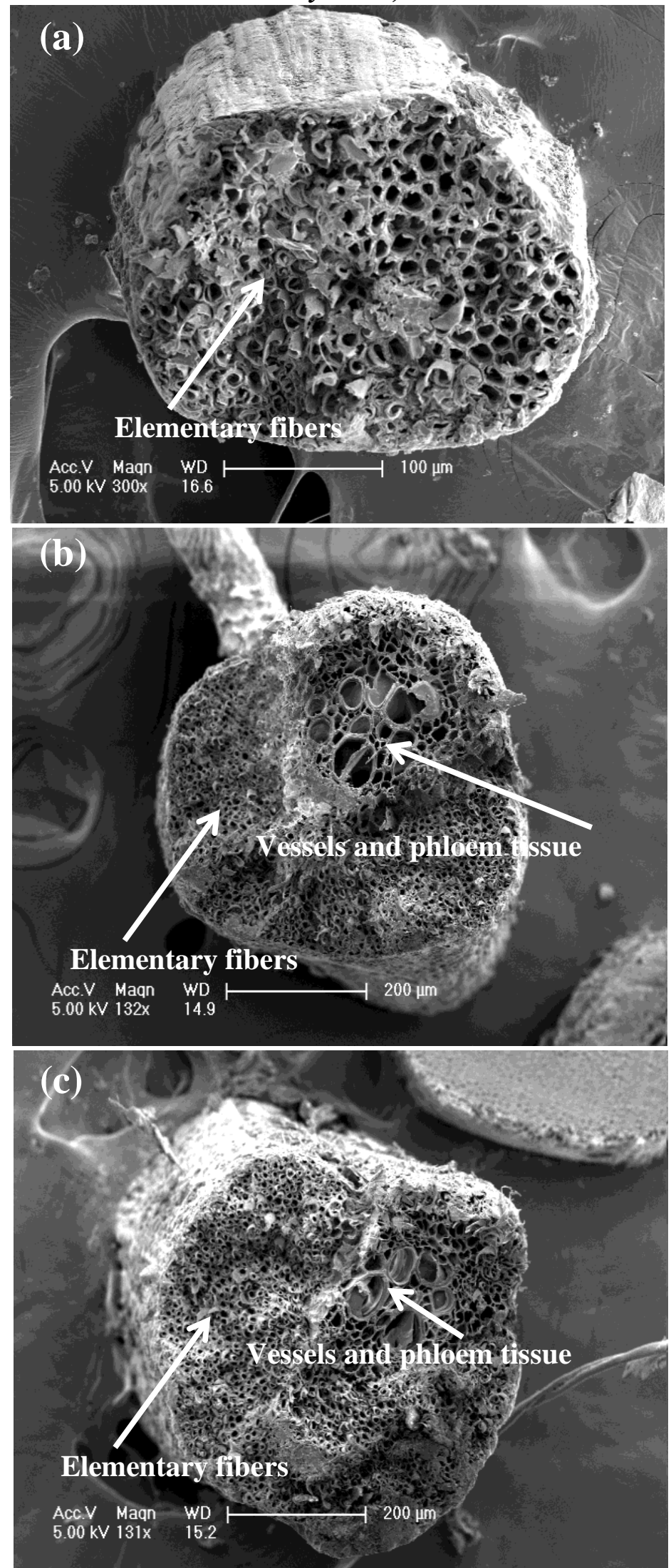

Figure 2 SEM images of palm fibers in different layers: (a) inner layer, (b) middle layers, (c) outer layer. 


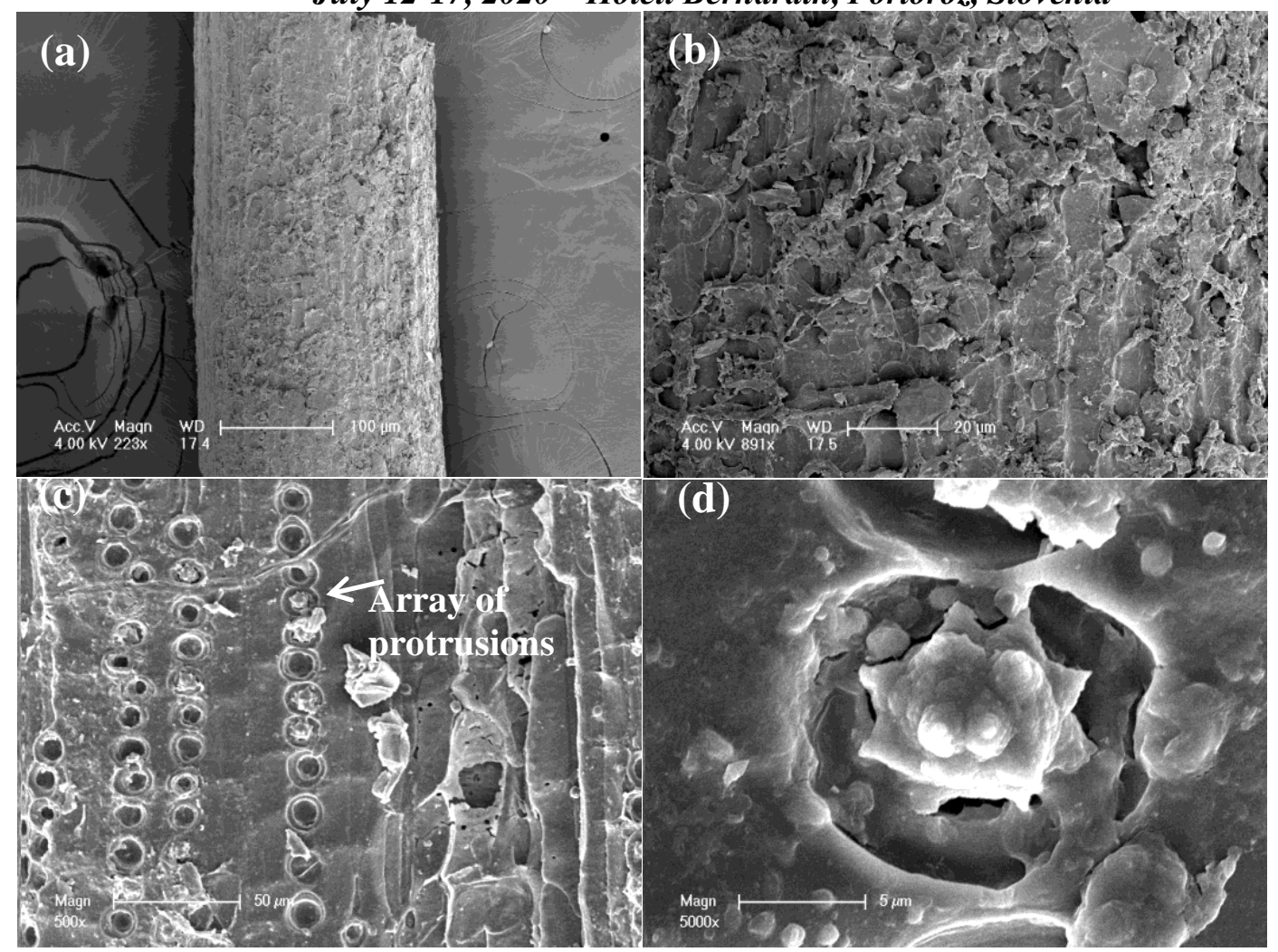

Figure 3 Surface morphological characterizations of palm fibers in outer layer: (a) sub-cylindrical shape, (b) waxy and course surface, (c) arrays of protrusions embedded with (d) silica.

The mircofibrillar angle (MFA), the spiral angle between the cellulose fibrils and the fiber axial, is considered an influential structural parameter that affects the axial mechanical properties of natural fibers ( $\mathrm{Yu}$ Y et al., 2014). The measured MFA values of palm fibers were in the range of $38.8 \pm 1.5^{\circ}$ for the inner layer to $39.4 \pm 1.0^{\circ}$ for the outer layer, which were very similar and Table 2 Comparison of properties of windmill palm fibers with other natural fibers reproducible values (Table 2). The relative crystallinity index (CrI) of windmill palm fibers was found to vary slightly for the different layers, with the highest in the middle layers $(49.2 \%)$, followed by the outer layers (46.7\%), and finally the inner layer (45.7\%). These results are similar to those reported by Zhai et al., (2012) and Zhang et al., (2015).

\section{Tensile properties}

The typical stress-strain curves of palm fibers obtained from each leaf sheath layer are presented in Fig. 4, and their tensile properties are listed in Table 2. The curves show that the palm fibers all exhibited linear elastic at low stress, and then yielding point at around $2 \%$ strain followed by plastic deformation until breakage, and similar results have been reported for piassava fiber (D'Almeida et al., 2006) and coir fiber (Tran et al., 2015). There were some evident differences in the mechanical properties of palm fibers among the different leaf sheath layers, as shown in Table 2. Some large variations in the tensile properties of palm fibers can be found in all three layers, which is often observed for natural fibers published by other 


\section{Proceedings of the 63rd International Convention of \\ Society of Wood Science and Technology}

July 12-17, 2020 - Hoteli Bernardin, Portoroz̆, Slovenia

Table 2 Comparison of properties of windmill palm fibers with other natural fibers

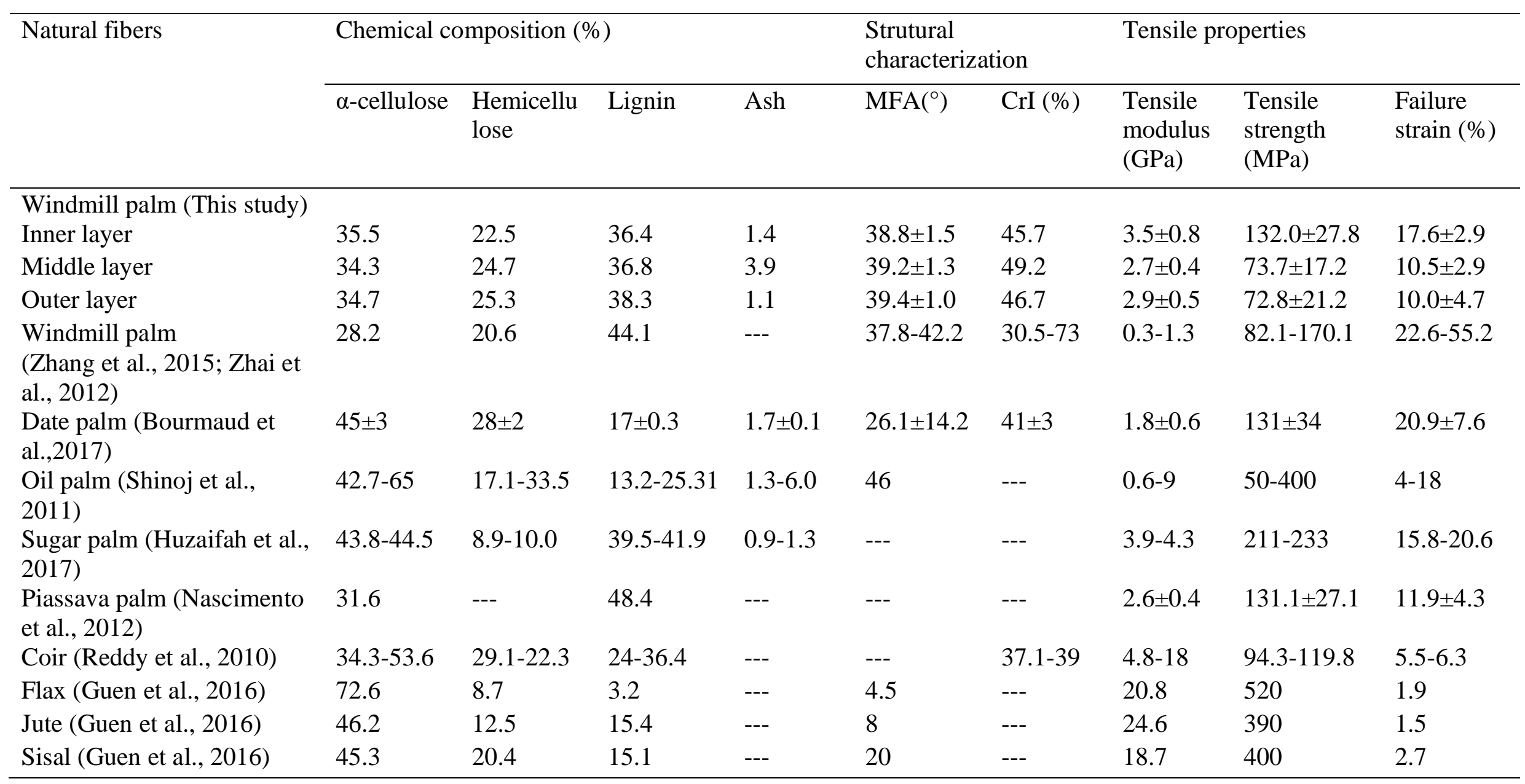



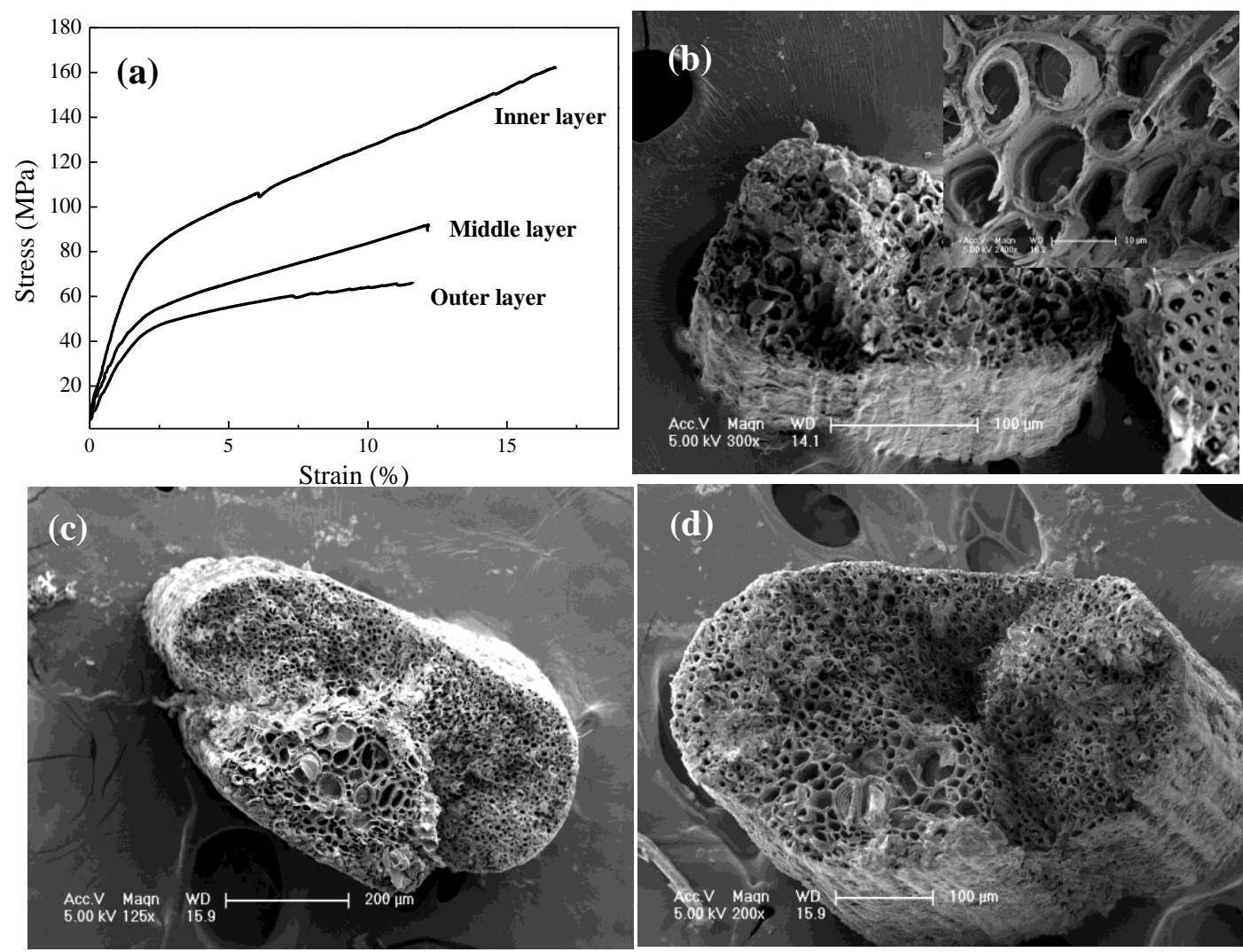

Figure 4 (a) Typical stress-strain curves of windmill palm fibers in different layers; fracture surface of fiber in (b) inner, (c) middle, and (d) outer layer of one windmill palm leaf sheath.

(Zhai et al., 2013; Bourmaud et al., 2017). In general, the average tensile modulus, stress, and failure strain of the fibers in the inner layer were much higher than those in fibers from the outer and middle layers. As the crystalline cellulose confers the stiffness and strength (around 135 Gpa, Kroon-Batenburg et al., 1986), the superior tensile properties of natural fibers have been attributed to the high cellulose content and crystallinity, and the comparatively low MFA (Djafari 2016). However, the cellulose content, CrI and MFA values were in similar ranges among different layers of windmill palm fibers (Table 2). Therefore, the differences in mechanical properties between layers may be more associated with the morphological parameters, as obvious variations in fiber morphology, particularly fiber diameter, were observed between different leaf sheath layers (Table 1). Fibers in the inner layers had the smallest diameter and exhibited superior mechanical properties among the three layers. Consistently, earlier studies showed significant correlations between mechanical properties and fiber diameter, and a decreased trend in mechanical properties was observed for increasing fiber diameters (Placet et al., 2012; Zhai et al., 2012). As assayed here, windmill palm fibers exhibited higher tensile modulus but lower failure strain compared with previously reported results (Zhai et al., 2012, and Zhang et al., 2015).

As shown in Table 2, windmill palm fibers exhibited significantly lower tensile modulus and strength compared with those of flax, jute, and sisal (Guen et al., 2016), but values that were much closer to that of other palm family fibers, such as date palm (Bourmaud et al., 2017) and especially piassava fiber (Nascimento et al., 2012). This is expected as windmill palm fibers have lower cellulose content (34.3-35.5\%), lower CrI (45.7-49.2\%), and higher MFA values 
(38.8-39. $\left.4^{\circ}\right)$. However, unlike these stiffer and stronger fibers that exhibit brittle failure at relatively low ultimate tensile strain (Table 2), windmill palm fibers showed ductile failure with a large failure strain of 10.0-17.6\% with dissipated strain energy. The ductile behavior of windmill palm fiber was related to its fracture mode, as shown in Fig. $4 b-d$. The failure of the fibers is caused by the fracture of the cell wall with delamination, as shown in the inset in Fig. 4b. Similar intercellular fracture has also been reported for other fibers with a low cellulose content and high MFA, such as coir and piassava fiber (Satyanarayana et al., 2018).

The use of windmill palm fibers as reinforcement material in composites is perhaps not an obvious choice due to its relatively lower tensile modulus and strength compared to other widely used fibers. However, although the addition of windmill palm fiber may not enhance the stiffness and strength of a composite, it can improve the toughness of the material due to its high failure strain. Additionally, waste windmill palm fiber can be incorporated with a strong-brittle fiber (such as jute or flax) into a polymer matrix to produce a hybrid composite, in which the palm fibers exhibit high failure strain which allows better stress transfer, and provides large diameter material to increase the effective fiber-matrix adhesion area (Gupta, et al., 2015). As mentioned above, the windmill palm fibers share strong similarities with coir and piassava fiber, and these two fibers have been successfully used as reinforcement materials (Reis et al., 2014; Yan et al., 2016), which strongly suggests that the windmill palm may be an excellent reinforcement material to improve the properties of composites.

\section{Nanoindentation testing}

Nanoindentation is a powerful tool to characterize mechanical properties on a very small scale (Jäger et al., 2011). The typical load-depth curves of the windmill palm fibers in different leaf sheath layer were determined and shown in Fig. 5a. Fibers in the inner layers reached a much lower maximum depth (ca. $96 \mathrm{~nm}$ ) compared to those from the middle and outer layers (ca. 145 $\mathrm{nm}$ ), however, the final depth of these fibers were similar (ca. $70 \mathrm{~nm}$ ) after the unloading process, which indicated different viscoelastic behavior among different layers. Fig. 5b-d exhibit the indented areas of the fiber cell wall in three layers, and only indents located in the cell (marked by red arrows) were considered acceptable.

The longitudinal elastic modulus and hardness of palm cell walls in three layers is shown in Table 3. Palm fibers in inner layers showed much higher value in elastic modulus (13.2 GPa) and hardness $(0.5 \mathrm{GPa})$ than that of palm fibers in the middle and outer layers. In general, the mechanical properties of the fiber cell wall are positively related to lignin content and negatively correlated with MFA values (Li et al., 2013). However, despite palm fiber in inner and outer layer exhibited no appreciable differences in chemical composition, MFA, CrI values (Table 2), as well as elementary fiber size and cell wall thickness values (Table 1), their nanoindentaion properties exhibited significant differences.

The diameter of fiber in inner layer was much smaller $(230 \mu \mathrm{m})$ that that of fiber in outer layer $(372 \mu \mathrm{m})$, which indicated that fiber diameter could be important contributors to the difference. Similar results have been observed for the two types of leaf sheath fiber identified 

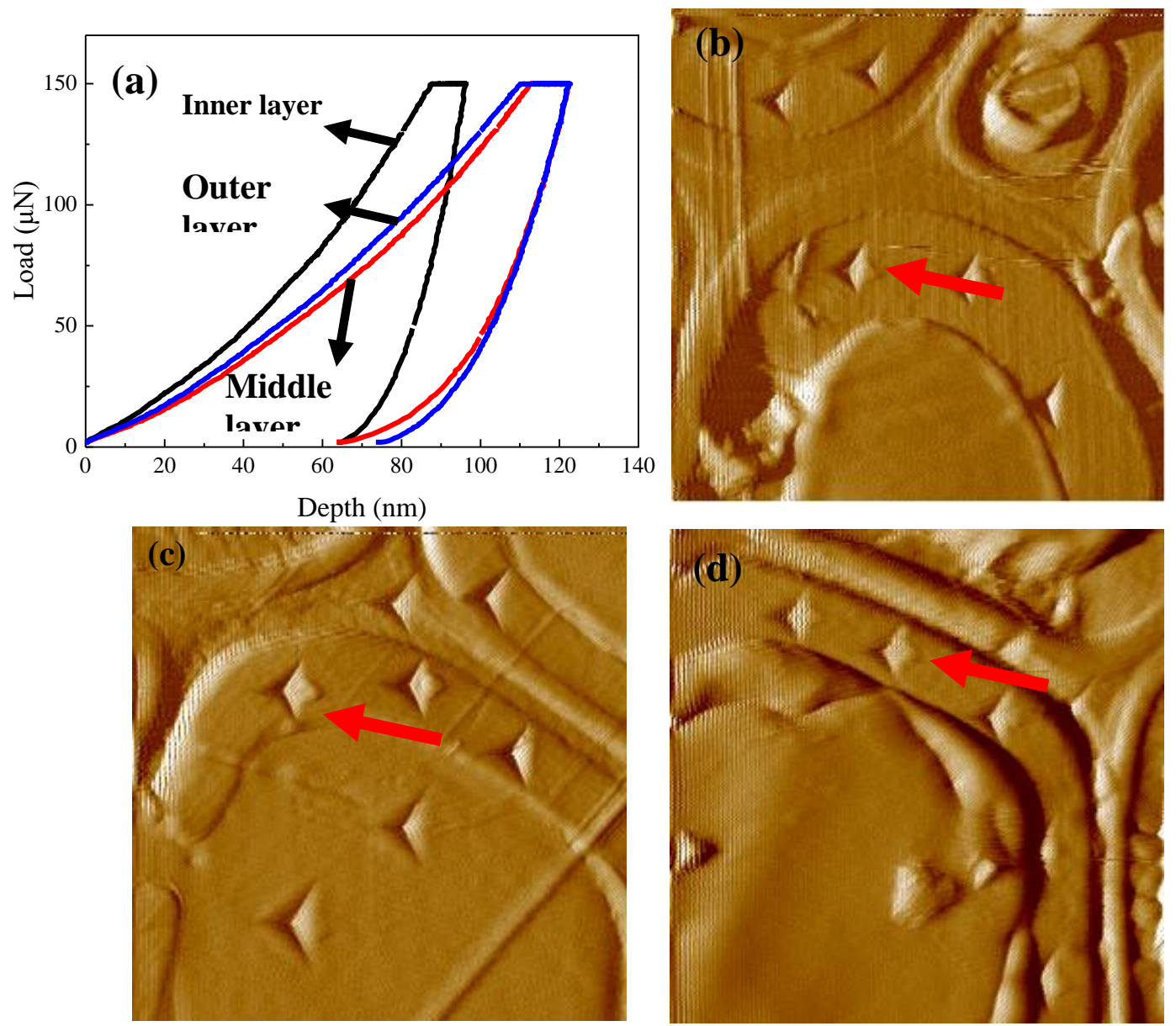

Figure 5 (a) Typical load-depth curves of nanoindentation tests in cell wall of windmill palm fibers in different layers; Residual indentations on cell wall of windmill palm fibers in (a) inner, (b) middle, (c) outer layer.

Table 3 Comparison of nanoindentation properties of windmill palm fiber with other natural fibers

\begin{tabular}{lll}
\hline Natural fibers & $\begin{array}{l}\text { Nanoindentation } \\
\text { modulus (GPa) }\end{array}$ & $\begin{array}{l}\text { Nanoindentation } \\
\text { hardness (GPa) }\end{array}$ \\
\hline Windmill palm(this study) & & \\
Inner layer & $13.2 \pm 1.3$ & $0.50 \pm 0.04$ \\
Middle layer & $8.9 \pm 0.8$ & $0.37 \pm 0.04$ \\
Outer layer & $8.5 \pm 0.9$ & $0.36 \pm 0.03$ \\
Windmill palm (Chen et al., 2017) & $7.6 \pm 4.0$ & $0.13 \pm 0.02$ \\
Date palm (Bourmaud et al., 2017) & $14.3-15.8$ & $0.47-0.53$ \\
Crops (Cotton stalk, Cassava stalk, Soybean Stalk, & $12.3-20.8$ & $0.41-0.85$ \\
Rice straw, hemp stalk) (Wu et al., 2010) & & \\
Hardwood (Poplar, Iroko, Alder birch, Manchurian & $16.9-24.6$ & $0.44-0.56$ \\
ash, Asian white birch, Red oak, White oak, & & \\
Monglian oak, Kwila, Keranji) (Wu et al., 2009) & & \\
Softwood (Loblolly pine, Spruce) (Wu et al., 2009) & $14.2-18$ & $0.34-0.53$ \\
\hline
\end{tabular}


in date palm, where small fiber bundles $(70-120 \mu \mathrm{m})$ exhibited superior nanoindentaion properties than large fiber bundles $(600-1200 \mu \mathrm{m})$, which might be related to their mechanical role in leaf sheath (Bourmaud et al., 2017). The nanoindentaion properties of windmill palm fiber were in the same range with those of crops and wood, and comparable to those of date palm (Bourmaud et al., 2017), as shown in Table 2. This may be partly explained by the remarkable high lignin content in the windmill palm fibers, which makes the fiber cell wall rigid.

\section{Conclusions}

The fiber morphology, chemical composition, physical, and multi-scale mechanical properties of windmill palm fibers in three leaf sheath layers were investigated in this study. The tensile and nanoindentation properties of fine fibers in the inner leaf sheath layer were highest among the three layers, which may reflect their mechanical role in leaf sheath. The palm fibers are not as strong and stiff, but exhibit a high elongation at break. The nanoindentation results revealed that the modulus and hardness of windmill palm fiber were comparable to those of wood and crops fibers. These results will help promoting the use of windmill palm fiber as a material from renewable resources with more high-value applications.

\section{Funding}

This work was supported by Basic Scientific Research Funds of International Center for Bamboo and Rattan (1632018017) and the 12th five years key technology R\&D program (2015BAD04B03).

\section{References}

Berges M, Léger R, Placet V, Person V, Corn S, Gabrion X, Rousseau J, Ramasso E, Lenny P, Fontaine $S$ (2016) Influence of moisture uptake on the static, cyclic and dynamic behaviour of unidirectional flax fibre-reinforced epoxy laminates. Compos Part A-Appl S 88:165-177

Bourmaud A, Dhakal H, Habrant A, Padovani J, Siniscalco D, Ramage MH, Beaugrand J, Shah DH (2017) Exploring the potential of waste leaf sheath date palm fibres for composite reinforcement through a structural and mechanical analysis. Compos Part A - Appl S 103:292-303

Chen C, Chen G, Li X, Guo H, Wang G (2017) The influence of chemical treatment on the mechanical properties of windmill palm fiber. Cellulose 24(4):1611-1620

Chen CJ, Zhang Y, Jia J, Wang M, Wang G (2015) Morphology research of windmill palm (trachycarpus fortunei) material. Kemija U Industriji 64(9-10):467-472

D’Almeida, JRM, Aquino RCMP, Monteiro SN (2006) Tensile mechanical properties, morphological aspects and chemical characterization of piassava (attalea funifera) fibers. Compos Part A - App S 37(9):1473-1479

Djafari SR (2016) Physical and mechanical properties of natural fibers. Advanced high strength fibre composites in construction

Gilman, E, Watson, D, 2015. Trachycarpus fortunei: windmill palm. Environmental Horticulture. ENH-802. UF/IFAS Extension Service, University of Florida

Guen MJL, Newman RH, Fernyhough A, Hill SJ, Staiger MP (2016) Correlations between the physiochemical characteristics of plant fibres and their mechanical properties. In: Fangueiro R, Rana S. (eds) Natural Fibres: Advances in Science and Technology Towards Industrial Applications. RILEM Bookseries, vol 12. Springer Dordrecht 
Guo M, Zhang TH, Chen BW, Cheng L (2014) Tensile strength analysis of palm leaf sheath fiber with weibull distribution. Compos. Part A - Appl S 62(17):45-51

Gupta MK, Srivastava RK (2016) Mechanical Properties of Hybrid Fibers-Reinforced Polymer Composite: A Review. J. Macromol. Sci. D - Reviews in Polymer Processing, 2016, 55(6): 17

Gurunathan T, Mohanty S, Nayak SK (2015) A review of the recent developments in biocomposites based on natural fibres and their application perspectives. Compos Part A Appl S. 77: 1-25

Huzaifah, MRM, Sapuan SM, Leman Z, Ishak MR (2017) Comparative study on chemical composition, physical, tensile, and thermal properties of sugar palm fiber (arenga pinnata) obtained from different geographical locations. Bioresources 12(4):9366-9382

Jäger A, Bader T, Hofstetter K, Eberhardsteiner J (2011) The relation between indentation modulus, microfibril angle, and elastic properties of wood cell walls. Compos Part A - Appl S 42(6):677-685

Khalil HPSA, Yusra AFI, Bhat AH, Jawaid M (2010) Cell wall ultrastructure, anatomy, lignin distribution, and chemical composition of malaysian cultivated kenaf fiber. Ind Crop Prod 31(1):113-121

Kroon-Batenburg LMJ, Kroon J, Northolt MG (1986) Chain modulus and intramolecular hydrogen bonding in native and regenerated cellulose fibres. Polym Commun 27(10):290292

Li X, Wang S, Du G, Wu Z, Meng Y (2013). Variation in physical and mechanical properties of hemp stalk fibers along height of stem. Ind Crop Prod 42:344-348

Marrot L, Lefeuvre A, Pontoire B, Bourmaud A, Baley C (2013) Analysis of the hemp fiber mechanical properties and their scattering (fedora 17). Ind Crop Prod 51(6):317-327

Nascimento DCO, Ferreira AS, Monteiro SN, Aquino RCMP, Kestur SG (2012) Studies on the characterization of piassava fibers and their epoxy composites. Compos Part A - Appl S 43(3):353-362

Oliver WC, Pharr GM, (1992) An improved technique for determininghardness and elastic modulus using load and displacement sensing indentation experiments. J Mater Res 7:156483

Placet V, Trivaudey F, Cisse O, Gucheret-Retel V, Boubakar ML (2012) Diameter dependence of the apparent tensile modulus of hemp fibres: a morphological, structural or ultrastructural effect? Compos Part A - Appl S 43:275-287

Rashid B, Leman Z, Jawaid M, Ghazali MJ, Ishak MR, (2016) Physicochemical and thermal properties of lignocellulosic fiber from sugar palm fibers: effect of treatment. Cellulose 23(5):2905-2916

Reddy KO, Reddy GS, Maheswari CU, Rajulu AV, Rao, KM (2010). Structural characterization of coconut tree leaf sheath fiber reinforcement. J Forestry Res 21(1):53-58

Reis JML, Motta EP (2014) Mechanical behavior of piassava fiber reinforced castor oil polymer mortars. Compos Struct 111(1):468-472

Satyanarayana KG, Flores-Sahagun, THS, Bowman P (2018) Lignocellulosic Materials of Brazil-Their Characterization and Applications in Polymer Composites and Art Works. In: Kalia S. (eds) Lignocellulosic Composite Materials. Springer Series on Polymer and Composite Materials. Springer, Cham

Segal L, Creely J, Martin A, Conrad C (1959) An empirical method for estimating the degree of crystallinity of native cellulose using the X-ray diffractometer. Text Res J 29(10):786 - 794. 
Shinoj S, Visvanathan R, Panigrahi S, Kochubabu M (2011) Oil palm fiber (opf) and its composites: a review. Ind Crop Prod 33(1): 7-22

Stuart SA, Evans R (1995) X-ray diffraction estimation of the microfibril angle variation in eucalypt wood. Appita J 48(3):197-200

Tran LQN, Minh TN, Fuentes CA, Chi TT, Vuure AWV, Verpoest I (2015) Investigation of microstructure and tensile properties of porous natural coir fibre for use in composite materials. Ind Crop Prod 65:437-445

Walther G, Gritti ES, Berger S, Hickler T, Tang Z, Sykes MT (2010) Palms tracking climate change. Global Ecol. Biogeogr. 16(6):801-809

Wu Y, Wang S, Zhou D, Xing C, Zhang Y (2009) Use of Nanoindentation and Silviscan to Determine the Mechanical Properties of 10 Hardwood Species. Wood Fiber Sci 41(1):64-73

Wu Y, Wang S, Zhou D, Xing C, Zhang Y, Cai Z (2010) Evaluation of elastic modulus and hardness of crop stalks cell walls by nano-indentation. Bioresour Technol 101(8):2867-2871

Yan L, Chouw N, Huang L, Kasal B, (2016) Effect of alkali treatment on microstructure and mechanical properties of coir fibres, coir fibre reinforced-polymer composites and reinforced-cementitious composites. Constr Build Mater 112:168-182

Yu Y, Tian G, Wang H, Fei B, Wang G (2011) Mechanical characterization of single bamboo fibers with nanoindentation and microtensile technique. Holzforschung 65(65):113-119

Yu Y, Wang H, Fang L, Tian G, Lin J (2014) Bamboo fibers for composite applications: a mechanical and morphological investigation. J Mater Sci 49(6):2559-2566

Zhai S, Li D, Pan B, Sugiyama J, Itoh T (2012) Tensile strength of windmill palm (trachycarpus fortunei) fiber bundles and its structural implications. J Mater Sci 47(2):949-959

Zhai S, Sugiyama J, Imai T, Horikawa Y (2013) Cell wall characterization of windmill palm (trachycarpus fortunei) fibers and its functional implications. IAWA J 34(1):20-33

Zhang T, Guo M, Cheng L, Li X (2015) Investigations on the structure and properties of palm leaf sheath fiber. Cellulose 22(2):1039-1051

Biography 
Proceedings of the 2020 Society of Wood Science and Technology International Convention

Differences between hygroscopicity limit and cell wall saturation investigated by LF-NMR on thermally-modified and lignin-removed Southern pine (Pinus spp.)

See Paper Under Early Stage Researchers pg 55 
Proceedings of the $\mathbf{2 0 2 0}$ Society of Wood Science and Technology International Convention

Preparation of Kenaf based nanobiocomposite as sustainable adsorbent for the removal of organic and inorganic and pathogenic contaminants

See Paper Under Wood in Health and Wellbeing pg 286 


\title{
Proceedings of the 2020 Society of Wood Science and Technology International Convention
}

\section{Bioinspired wood protection - evaluation of wood treated with biofinish}

\author{
Faksawat Poohphajai 1 \\ faksawat.poohphajai@innorenew.eu \\ Anna Sandak2 \\ anna.sandak@innorenew.eu \\ Lauri Rautkari3 \\ lauri.rautkari@aalto.fi \\ Michael Altgen 3 \\ michael.altgen@aalto.fi \\ Rene Herdiaz4 \\ rene.herdiaz@innorenew.eu
}

1InnoRenew CoE, Slovenia

2InnoRenew CoE \& University of Primorska, Slovenia

3Aalto University, School of Chemical Engineering, Department of Bioproducts and Biosystems, Finland 4 University of the Basque Country Chemical and environmental engineering department, Spain

\begin{abstract}
Wood is a versatile, natural and environmentally friendly material that has attracted attention for sustainable building for many years. As any biological material, wood is sensitive to environmental conditions and microorganisms; therefore, wood products require protective measures to extend their service life in outdoor applications. The typical wood protection systems are not always environmentally friendly and sustainable. The idea to utilize natural organisms, that are not deteriorating wood, but their presence inhibit growth of other decaying fungi was motivation for this investigation. Consequently, such approach for wood protection will contribute toward development of a new environmentally friendly and sustainable wood treatments and trigger the utilization and production of green materials in the wood industry.

This research is aiming to use biofilm that is built up by a yeast-like fungus, Aureobasidium pullulans, for wood protection. Biofinish is a fungal-based wood treatment with protective functionalities and self-repairing property. It has several advantages compare to the traditional wood coatings and chemical treatments due to its environmental friendliness, low maintenance cost and absence of harmful chemicals. The performance of wood protected with biofinish was characterized the at three different levels: macro, micro and molecular. This extensive evaluation will allow understanding, developing and optimizing an efficient biological protection system for wood in external applications.
\end{abstract}

Keywords: wood protection, biofinish, bioinspiration

Acknowledgements: The authors gratefully acknowledge the European Commission for funding the InnoRenew project (grant agreement \#739574 under the Horizon2020 Widespread-Teaming program) and the Republic of Slovenia (investment funding of the Republic of Slovenia and the European Union European Regional Development Fund). Special thanks to Xylotrade B.V. for providing Biofinish solution.

\section{Biography}


Proceedings of the $\mathbf{2 0 2 0}$ Society of Wood Science and Technology International Convention An ionic-liquid based fire retardant for wood-based panels See Paper Under Wood Modification and Preservation pg 348 
Proceedings of the $\mathbf{2 0 2 0}$ Society of Wood Science and Technology International Convention

ABES and DMA Cure Monitoring of Tannin Adhesive

See Paper Under Early Stage Researchers pg 67 
Proceedings of the $\mathbf{2 0 2 0}$ Society of Wood Science and Technology International Convention

Highly Anisotropic Wood-Based Composite with Layered Structure for Thermal and Electrical Conduction

See Paper Under Composites and Adhesives pg 240 
Proceedings of the $\mathbf{2 0 2 0}$ Society of Wood Science and Technology International Convention

Low Temperature Adhesive Bonding for Structural Wood Materials

See Paper Under Composites and Adhesives pg 241 


\title{
Proceedings of the 2020 Society of Wood Science and Technology International Convention
}

\section{The Vibrational Properties of Catalpa Ovata Wood for the Back Plate of the Guqin}

\author{
Yi-Hsuan Tsai \\ r06625034@ntu.edu.tw \\ Feng-Cheng Chang \\ fcchang@ntu.edu.tw \\ School of Forestry and Resource Conservation, National Taiwan University, Taiwan
}

\section{Abstract}

Wood of Chinese catalpa (Catalpa ovata) is the traditional material of the back plate of the guqin, which is the prominent musical instrument in ancient China. The guqin, a Chinese seven-string zither known for its long history, has been designed as solo instrument since antiquity, so it is characterized by the multiple personal style, which results in multifarious ways of making a guqin. In fact, there is a lack of scientific and systematic method of deciding materials, and instead, the guqin makers' experience and craftsmanship dominate the whole procedure. Thus, the aim of this research is using the nondestructive testing to measure the physical-mechanical properties of Chinese catalpa plates and trying to elaborate the correlation between the vibrational properties of Chinese catalpa and the guqin makers' principle of choosing materials. In this research, the physical-mechanical properties of Chinese catalpa plates, collected from an 80-year-old dismantled building and selected as the materials of guqins' back plates, were measured with the plate vibration method, and vibrational properties such as the speed of sound, the sound radiation coefficient, and the loss coefficient could be obtained. According to the results, the density of plate, which is the immediate parameter consulted by guqin makers, would affect the speed of sound in longitudinal direction positively and the sound radiation coefficient in transverse direction negatively, and comparing with the ratio of the sound radiation coefficient to the loss coefficient, the lower density plate has higher ratio, which means it can produce a loud sound when excited by a given force.

\section{Biography}




\title{
Effects of Wood Decay on Deformation Mechanism and Shear Performance of Screwed and Nailed Joints
}

\author{
Rintaro Ueda1*-Kei Sawata1 - Takanobu Sasaki 1 - Yosihisa Sasaki1 \\ ${ }_{1}$ Graduate Student, Senior Lecturer, Professor, Technical Staff, Graduate School \\ of Agriculture, Hokkaido University at Sapporo, Hokkaido, Japan \\ hokkai_arsenal@eis.hokudai.ac.jp,ksawata@for.agr.hokudai.ac.jp, \\ tak-sas@for.agr.hokudai.ac.jp
}

\begin{abstract}
Wood decay is an important cause of degradation of wooden construction for the severity of its damage to the structure. Common countermeasure is to reinforce the degraded wood members with reinforcing equipment using nails and screws. However, only a limited number of studies have focused on the difference between the performances of screwed and nailed joints with sound wood and those with decayed wood and hence the accumulated knowledge is insufficient. This study was aimed at investigating the performance of screwed and nailed joints with decayed wood. We conducted decay treatment on Sakhalin fir (Abies sachalinensis) specimens by exposing for more than 20 weeks to cultured flora of a brown-rot fungus, Fomitopsis palustris which is a standard test fungus in Japan. After the decay treatment, screws and nails were driven to the specimens and single shear tests were conducted on the screwed and nailed joints that were loaded parallel to the grain of the specimens. Observed failure modes of the specimens could be classified into 2 types with one plastic hinge formed in the fastener (Mode III) and two hinges (Mode IV) following European Yield Model. The dominant failure modes of the screwed joints were clearly different between the control (Mode IV) and decayed specimens (Mode III). This result could be attributed to the degradation of the bearing strength of the decayed main members and therefore, it is concluded that the deformation mechanism of the screwed joints were affected by decay. In the case of the nailed joints, only Mode IV of the failure mode was observed and the effect of decay on the deformation mechanism of the nailed joints was not confirmed.

As a result of significance tests for strength properties of the joints, it is considered that the maximum, yield, and ultimate shear resistance of the screwed joints and the maximum and ultimate shear resistance of the nailed joints were significantly degraded by decay. However, the difference between control and decayed specimens in the initial stiffness was not significant for either of screwed or nailed joints.
\end{abstract}

Key words: wood decay, brown rot, biodegradation, deterioration, fungi, nailed joint, screwed joint, shear resistance

\section{Introduction}


Wood decay caused by wood-rot fungus is well known as an important cause of degradation of wooden construction. When degradation occurred in wooden construction, the degraded member will be reinforced or partly replaced. As it might be difficult or costly to replace a wood member, reinforcing the structure with reinforcing equipment using screws and nails is more commonly accepted countermeasure.

Regarding wood decay, many researches have been conducted on causal fungus (Fukuda et al. 1980; Green and Highley 1997; Schmidt 2007), mechanism of decay (Mester T et al. 2004), and mechanical properties of decayed wood (Mori et al. 2013). These preceding studies have provided and prevailed the knowledge that properties of wood might be significantly degraded if attacked by wood-rot fungus and decayed. However, emphasis has long been put on prevention and control of wood decay. Regarding timber joints that the strength of structure largely depends on, the actual effect of decay on them have rarely been focused on so that only a limited number of researches have been conducted on nailed joints (Kent et al. 2005; Toda et al. 2010), screwed joints (Mori et al. 2015; Takanashi et al. 2018), and dowel-type joints (Sawata et al. 2008) in recent years and accumulated data is still insufficient.

Considered that effectiveness of reinforcing decayed wood member is unknown and that screwed and nailed joints are common and widely used, more data and knowledge for characteristics of screwed and nailed joints with decayed wood member is of necessity. Hence in this study, we conducted single shear tests on screwed and nailed joints with decayed wood member to investigate the effect of decay on the deformation mechanism and shear performance of them.

\section{Materials \& Methods}

\section{Specimens}

Figure 1 shows the outline of the specimens. The main members of the nailed and screwed joints were prepared from solid lumbers of Sakhalin fir (Abies sachalinensis). The dimensions of the main members of the screwed joints were $60 \mathrm{~mm}$ in width, $60 \mathrm{~mm}$ in thickness, and $300 \mathrm{~mm}$ in length and those for the nailed joints were $45 \mathrm{~mm}$ in width, $60 \mathrm{~mm}$ in thickness, and $300 \mathrm{~mm}$ in length. The number of the specimens for the screwed and nailed joints were 22 (10) and 25 (5), respectively (The figures in parentheses indicate the number of the control specimens included). Five out of nine control specimens for the screwed joints had a width of $45 \mathrm{~mm}$ instead of $60 \mathrm{~mm}$. The average wood density was $406 \mathrm{~kg} / \mathrm{m} 3$ (standard deviation $56.0 \mathrm{~kg} / \mathrm{m} 3$ ) and the average moisture content was $9.0 \%$ (standard deviation $1.87 \%$ ). These were measured from the sound part of the specimens after the shear tests.

The side members were steel plates with a thickness of $6.0 \mathrm{~mm}$. The main and side members were connected by a nail or screw right before the shear tests. Figure 2 shows the screw and nail used in this study. The screws used in this study were "TBA-65D" screws, having an outer thread diameter of $6.0 \mathrm{~mm}$ (of which the effective diameter was $4.5 \mathrm{~mm}$ ), core diameter of 4.0 $\mathrm{mm}$, and full length of $69 \mathrm{~mm}$ (of which the length with screw thread was $55 \mathrm{~mm}$ and the effective length was $65 \mathrm{~mm}$ ). "TBA-65D" screw was originally designed to be used with holddown hardware and made by Tanaka Co., Ltd., Ibaraki, Japan. "TBA-65D" screws were also used in the previous study of Takanashi et al. (2018). The nails were N125 nails with a diameter of $4.6 \mathrm{~mm}$ and full length of $125 \mathrm{~mm}$, and were cut into $69 \mathrm{~mm}$ in full length (of which the 
effective length was $65 \mathrm{~mm}$ ) so that they have almost the same effective diameter and length as "TBA-65D" screws.

【Screwed joints】

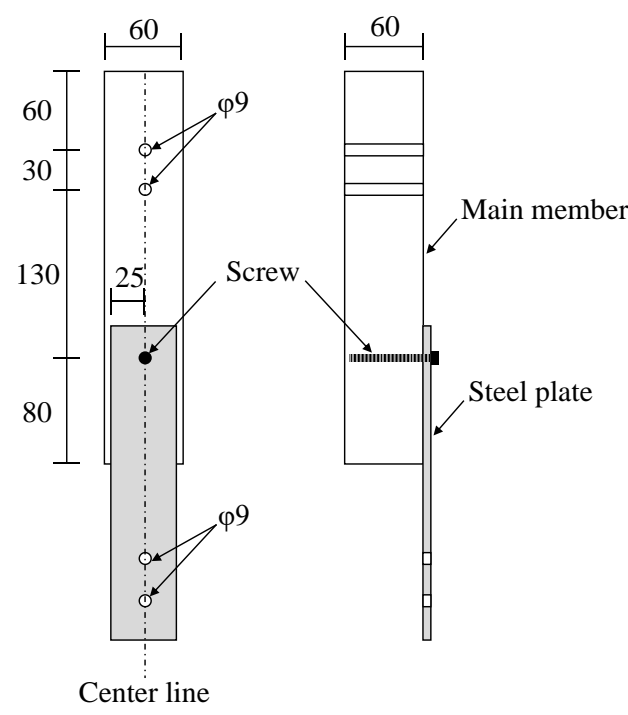

【Nailed joints】

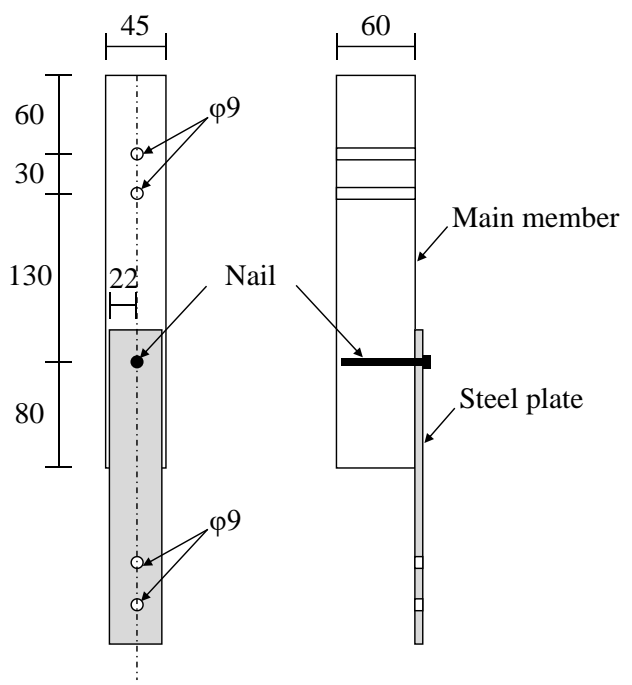

Center line

(Unit:mm)

Fig.1. Outline of the specimen.

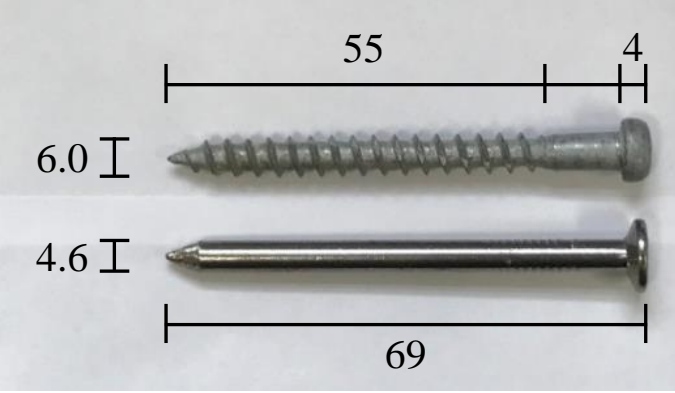

Fig.2. "TBA-65D” screw and shortened "N125" nail used in this study.

\section{Decay treatment}

The specimens were exposed to cultured flora of a brown-rot fungus, Fomitopsis palustris, which is a standard test fungus in Japan, for more than 20 weeks. Nutrient agar, floras of Fomitopsis palustris, and 17 small pieces (W16 x L 16 x H $8 \mathrm{~mm}$ ) of Sakhalin fir were filled in each one PP container having a width of $129 \mathrm{~mm}$, length of $89 \mathrm{~mm}$, and depth of $43 \mathrm{~mm}$ as shown in Figure 3. The containers were placed in a closed environment at $28^{\circ} \mathrm{C}$ and $75 \%$ relative humidity until the hyphae grew sufficiently. Subsequently, each container was attached to two specimens using stretch wrap so that the center of the container was coincided with the screwed or nailed point ( $80 \mathrm{~mm}$ away from the end) as shown in Figure 4 and the specimens were placed under a closed environment at $28^{\circ} \mathrm{C}$ and $75 \%$ relative humidity for more than 20 weeks. After the decay treatment period elapsed, the containers were detached from the specimens and the specimens were placed in room temperature and humidity for 2 weeks to be air-dried. 


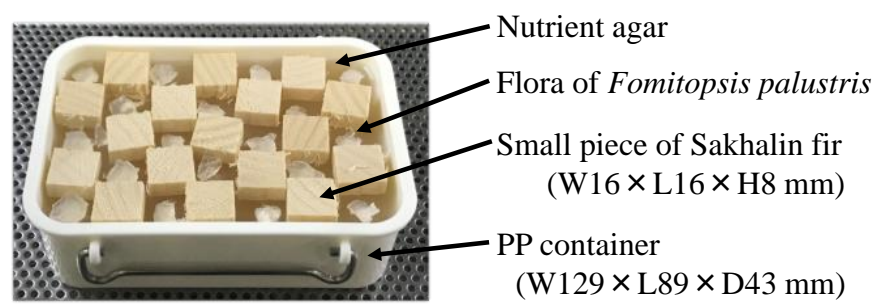

Fig.3. A rot fungus feeder unit.
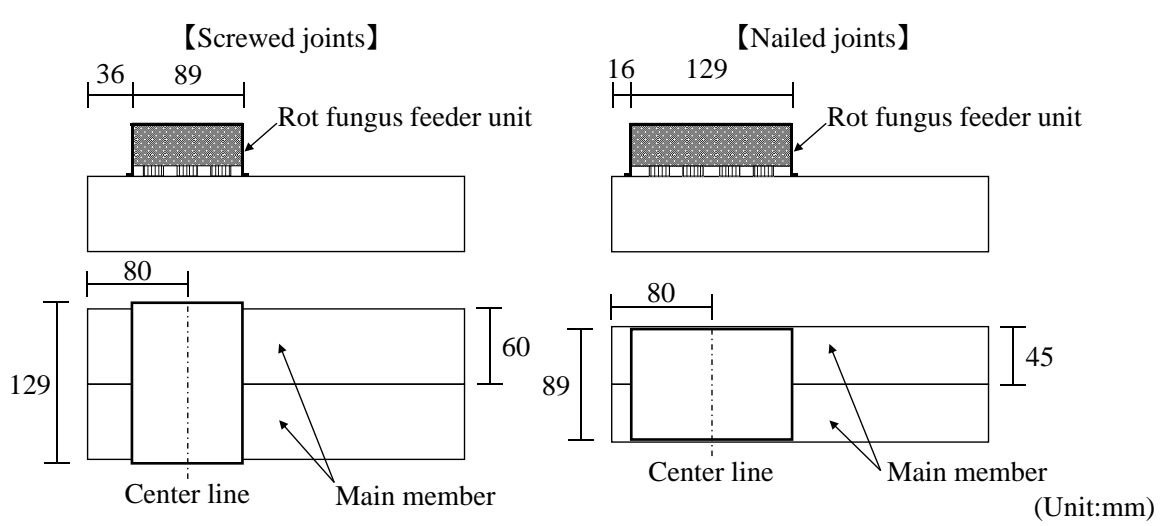

Fig.4. Outline of decay treatment using rot fungus feeder units.

Containers in which floras of wood rot fungus and small wood pieces were put on congealed nutrient agar are called "rot fungus feeder units." Decay treatment using rot fungus feeder units have been conducted in studies on nailed joints (Toda et al. 2010), multiple screwed joints (Takanashi et al. 2018), and column-sill joints (Toda et al. 2017), for this method is suited to conduct decay treatment on a specific and limited part of a wood member.

Decay-treated and air-dried specimens were connected to the steel plates by a screw or nail without predrilled hole, leaving slight gap to avoid initial friction between the main and side members. The end distance of the nailed and screwed joints were $80 \mathrm{~mm}$.

Test methods

Single shear tests were conducted on the nailed and screwed joints after the main and side member were fastened to the testing machine. The load was applied parallel to the grain for the main member. The relative slip was measured by two displacement transducers located on the two sides of the main member as shown in Figure 5. 
The relative slip on the centerline of the was calculated from the average of the two measured slips. The following slips indicate the relative slip on the centerline joints.

The load was applied to produce a relative slip of a certain slip level and subsequently reduced to $0 \mathrm{~mm}$. This loading procedure was repeated to produce and 8 times of the slip level and subsequently, the load was kept monotonically applied until the tests were terminated when the relative slip reached $\mathrm{mm}$ or fastener breakages occurred. The levels were determined from $1 / 2$ times of yield displacement obtained from the preliminary monotonic loading tests
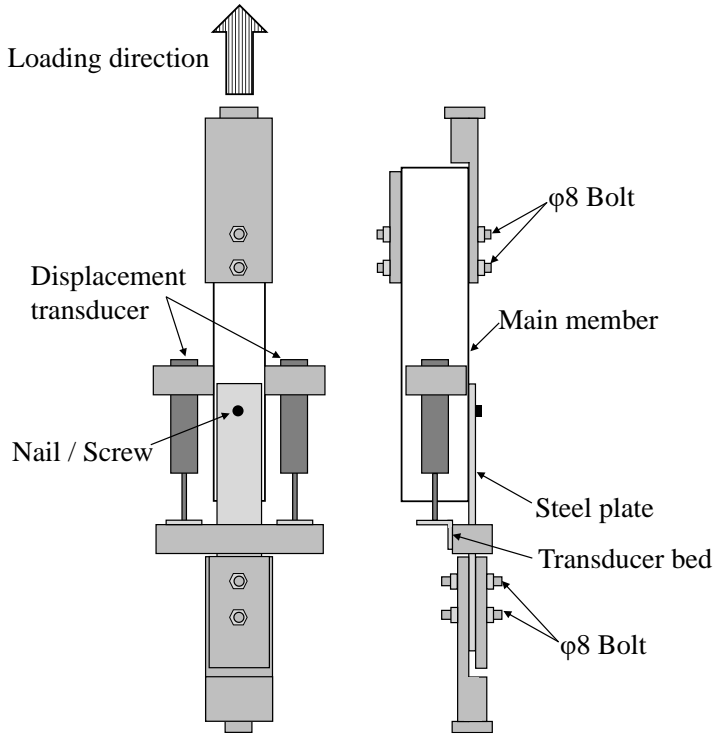

joints

of the

2,4 , at 30 slip the

Fig.5. Outline of the shear tests. conducted respectively on the screwed and nailed joints with un-decayed member, which were $0.5 \mathrm{~mm}$ for the nailed joints and $1.2 \mathrm{~mm}$ for the screwed joints.

After the shear tests, all the specimens were cleaved to observe the failure modes of the joints and determine the decay depth in the nailed or screwed point. The decay depth was obtained from the difference between the thickness of the main member and the length of the sound part. Afterwards, subsamples were cut from the decayed and sound part of the main members to determine the wood density and moisture content.

\section{Results and Discussion}

\section{Failure mode}

In the case of screwed joints, 8 out of 10 controls and 10 out of 12 decayed specimens failed, however, specimen failure due to main-member splitting was observed only in 1 control and the others were all due to fastener breakage. Whereas in the case of nailed joints, 3 out of 5 controls and 4 out of 20 decayed specimens failed and they were all due to splitting of the main member. Deformation of the nailed joints was accompanied by withdrawal of the nail in 3 out of 5 controls and 8 out of 20 decayed specimens.

Following EYM (European Yield Model), failure modes of the screwed and nailed joints could be classified into 2 types with one plastic hinge formed in the fastener (Mode III) and two hinges (Mode IV) by observing the deformed fastener (Architectural Institute of Japan 2006). Figure 6 shows the observed failure modes of the specimens. In the case of the screwed joints, 2 out of 10 controls and 9 out of 12 decayed specimens showed the failure of Mode III, whereas the others showed the failure of Mode IV and the dominant failure modes of the screwed joints were clearly different between the control (Mode IV) and decayed specimens (Mode III). This result could be attributed to the degradation of the bearing strength of the decayed main members as reported before. Therefore, it is inferred that the deformation mechanism of the screwed joints were affected by decay. Whereas in the case of the nailed joints, only Mode IV was observed and the effect of decay on the deformation mechanism of the nailed joints was not confirmed. 


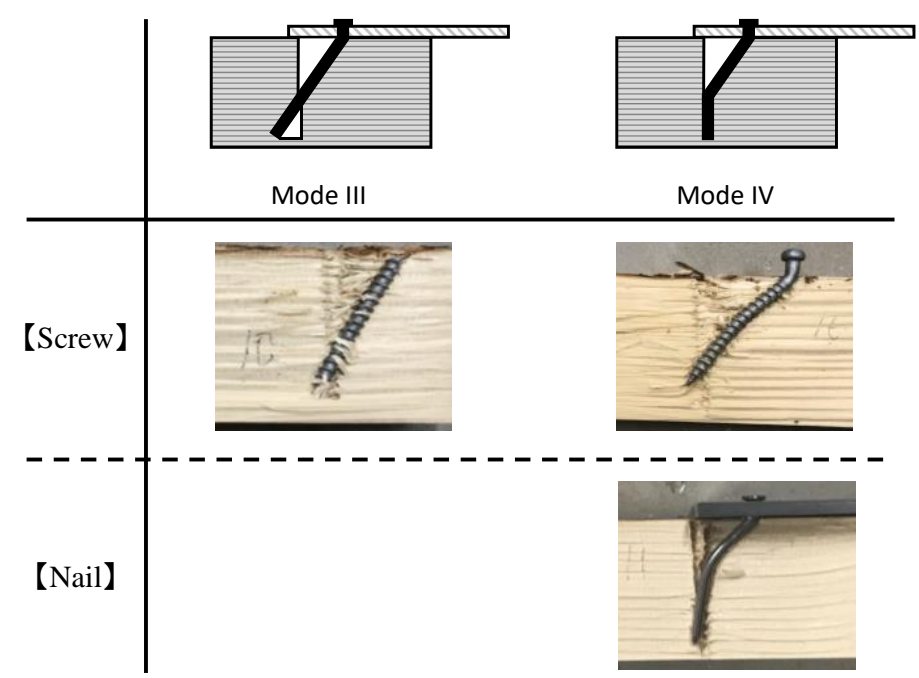

Fig.6. Observed failure modes of the specimens.

The shear performance of the joints

To evaluate the shear performance of the joints, the initial stiffness $\left(K_{\mathrm{s}}\right)$, maximum shear resistance $\left(P_{\max }\right)$, yield shear resistance $\left(P_{\mathrm{y}}\right)$, and ultimate shear resistance $\left(P_{\mathrm{u}}\right)$ were determined from the envelop load-slip curves as follows (Japan Housing and Wood Technology Center, 2017).

1. $P$ max was obtained from the maximum load. A straight line (line I in Fig. 7) was drawn as it passes through the 2 points on the curve corresponding to 10 and $40 \%$ of $P_{\max }$.

2. A straight line (line II in Fig. 7) was drawn as it passes through the 2 points corresponding to 40 and $90 \%$ of $P_{\max }$.

3. A straight line (line III in Fig. 7) was drawn as it has the same slope as line II and it is tangent to the curve.

4. The load and slip corresponding to the intersection of line I and III were obtained and defined as $P_{\mathrm{y}}$ and the yield slip, $D_{\mathrm{y}}$, respectively.

5. A straight line (line V in Fig. 7) was drawn as it passes through the origin and the coordinate

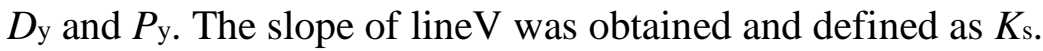

6. A straight line (line VI in Fig. 7) was drawn vertical to the horizontal axis from the point corresponding to $80 \%$ of $P_{\max }$ after the maximum load.

7. The area of the shape surrounded by the curve, horizontal axis, and line VI was calculated and defined as $S$.

8. A straight line (line VII in Fig. 7) was drawn parallel to the horizontal axis as the area of the shape surrounded by line V, line VI, line VII, and the horizontal axis is equal to $S$.

9. The load corresponding to the intersection of line V and VII was obtained and defined as $P_{\mathrm{u}}$. 


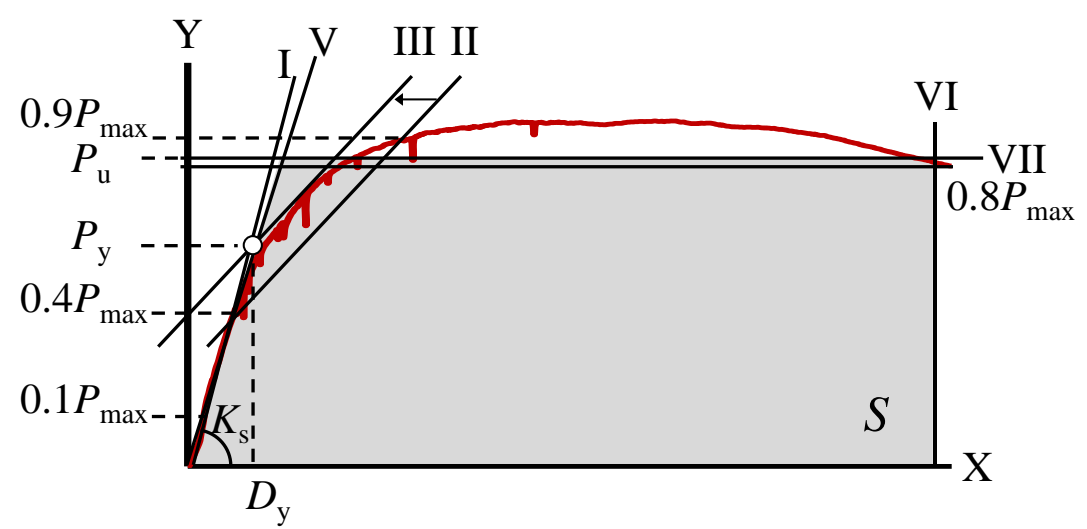

Fig.7. Method of evaluating shear performance of the joints. $K$, initial stiffness; $P_{\max }$, maximum shear resistance; $P_{\mathrm{y}}$, yield shear resistance; $D_{\mathrm{y}}$, yield displacement; $P_{\mathrm{u}}$, ultimate shear resistance.

The values of $K \mathrm{~s}, P_{\max }, P_{\mathrm{y}}$, and $P_{\mathrm{u}}$ are shown in Fig.8. Two control and one decayed specimens of screwed joints showed low rising of the load and could not be evaluated appropriately by this method, therefore they were excluded from succeeding evaluation. In the case of screwed joints, the difference between decayed and control specimens in $P_{\max }, P_{\mathrm{y}}$, and $P_{\mathrm{u}}$ were significant at the $5 \%$ level whereas that in $K_{\mathrm{s}}$ was not. Therefore, it is considered that the maximum, yield, and ultimate shear resistance of the screwed joints were significantly degraded by decay. In the case of nailed joints, the difference between decayed and control specimens in $P_{\max }$ and $P_{\mathrm{u}}$ were significant at the $5 \%$ level whereas those in $K_{\mathrm{s}}$ and $P_{\mathrm{y}}$ were not. Therefore, it is considered that the maximum and ultimate shear resistance of the nailed joints were significantly degraded by decay. In this study, the decayed specimens for nailed joints were considered to be in the stages of incipient decay as the decayed area were limited to the surface layer part. Therefore it is inferred that most part of the decayed specimens were almost sound, though, the effect of decay was reflected as degradation of $P_{\max }$ and $P_{\mathrm{u}}$. This result implies that a slight decay on joints can cause statistically significant degradation on its performance. By comparing the results of screwed and nailed joints, it is inferred that in the case of screwed joints, the effect of decay that appeared as the change in the deformation mechanism as described before was on the performance, reflected to $P_{\mathrm{y}}$ and therefore the difference in $P_{\mathrm{y}}$ was significant in contrast to the result of nailed joints.

Besides in this study, the effect of decay on the initial stiffness was not confirmed in either of the screwed or nailed joints and this result is coinciding with preceding studies for screwed joints (Takanashi et al. 2018) and nailed joints (Toda et al. 2010). It is inferred that the change in the deformation mechanism of joints caused by decay such that observed in the case of screwed joints appears after the yield point and therefore it was not reflected to $K$ s. 

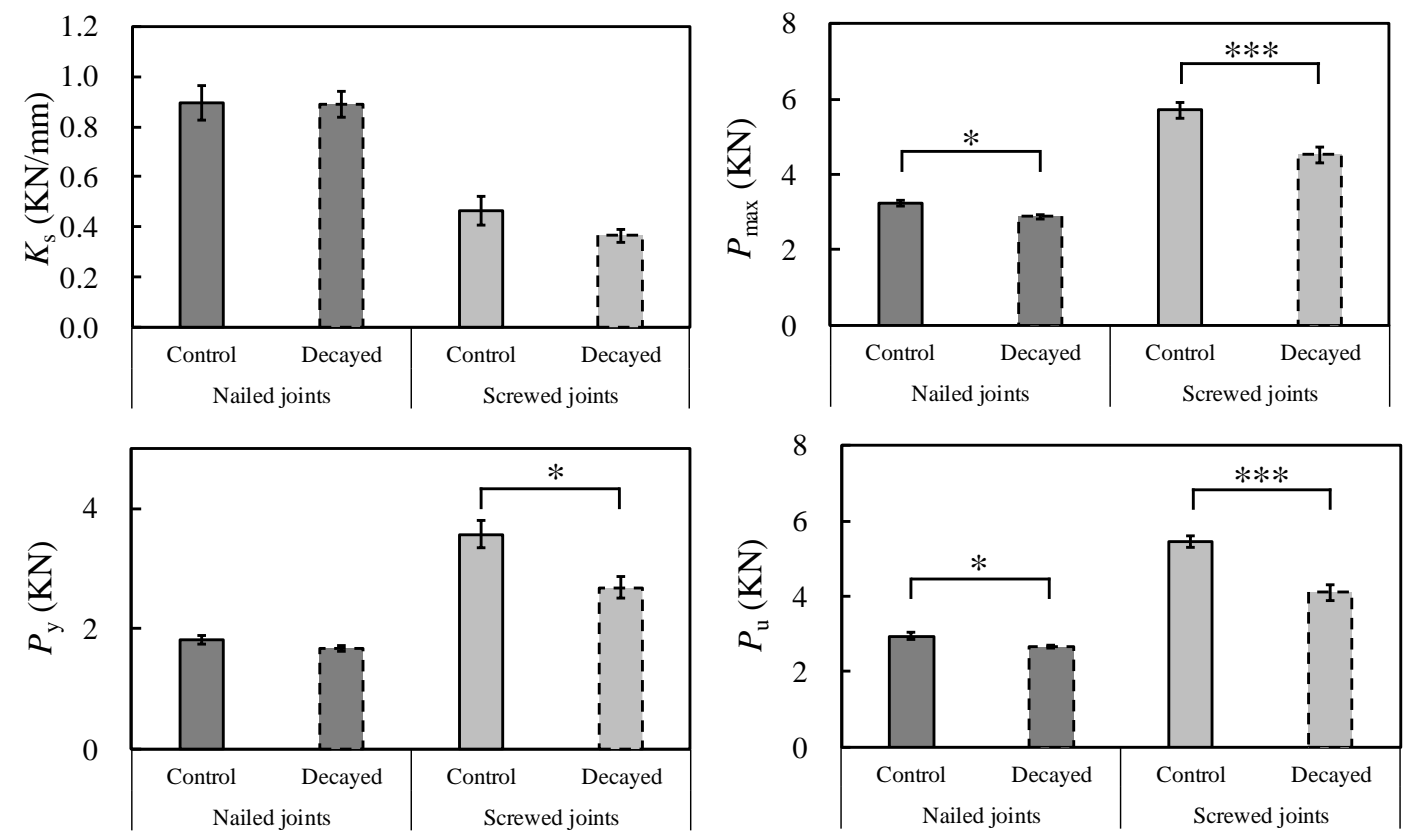

Fig.8. Values of $K_{\mathrm{s}}, P_{\max }, P_{\mathrm{y}}$, and $P_{\mathrm{u}}\left(^{*}=\right.$ significant at the $5 \%$ level, $* * *=$ significant at the $1 \%$ level).

\section{Summary and Conclusions}

Single shear tests were conducted on screwed and nailed joints with decayed main members of Sakhalin fir (Abies sachalinensis), and the degradation of shear performance of joints caused by decay was investigated. Following EYM, failure modes of the screwed and nailed joints could be classified into 2 types with one plastic hinge formed in the fastener (Mode III) and two hinges (Mode IV) by observing the deformed fastener. In the case of the screwed joints, both Mode III and IV were observed and the dominant failure modes of the screwed joints were clearly different between the control (Mode IV) and decayed specimens (Mode III). Degradation of shear performance of the screwed joints was confirmed in $P_{\max }, P_{\mathrm{y}}$, and $P_{\mathrm{u}}$ and degradation in $P_{\mathrm{y}}$ was considered to reflect the change in the dominant failure modes caused by decay. Whereas in the case of the nailed joints, only Mode IV was observed and the effect of decay on the deformation mechanism was not confirmed. Degradation of shear performance of the nailed joints was confirmed in $P_{\max }$ and $P_{\mathrm{u}}$. Degradation in $K_{\mathrm{s}}$ was not confirmed in either of screwed or nailed joints.

\section{Acknowledgements}

This work was supported by JSPS KAKENHI Grant Number 17K07870.

\section{References}

Fukuda K, Okayasu Y, Haraguchi R (1980) Influence of Temperature on Growth and Wooddecomposing Ability of Wood-rotting Fungi. Bulletin of the Experiment Forests, Tokyo University of Agriculture and Technology 17: 49-55. (in Japanese with English summary). 
Green IF, Highley TL (1997) Brown-rot wood-decay-insights gained from a low decay isolate of Postia placenta. Trends in Plant Pathology 1: 1-17.

Schmidt O (2007) Indoor wood-decay basidiomycetes: damage, causal fungi, physiology, identification and characterization, prevention and control. Mycol Progress 6: 261-279.

Mester T, Varela E, Tien M (2004) Wood Degradation by Brown-Rot and White-Rot Fungi. Genetics and Bio technology, The Mycota vol.2, Berlin, Germany.

Mori T, Yanase Y, Tanaka K, Kawano K, Noda Y, Mori M, Kurisaki H, Komatsu K (2013) Evaluation of Compression and Bending Strength Properties of Wood Damaged from BioDeterioration. Journal of the Society of Materials Science, Japan 62(4): 280-285. (in Japanese with English summary).

Kent SM, Leichti RJ, Rosowsky DV, Morrell JJ (2005) Effects of Decay on the Cyclic Properties of Nailed Connections. Journal of Materials in Civil Engineering 17(5): 579-585.

Toda M, Mori M, Ohashi Y, Hirai T (2010) Effects of Wood Decay on the Shear Performance of Nailed Timber Joint. Mokuzai Gakkaishi 56(1): 41-47. (in Japanese with English summary).

Mori T, Noda Y, Azuma T, Mori M, Toda M (2015) Evaluation of Single Shear Performance of Wood Screw Joint Driving into Compulsive Decayed Wood. Journal of Structural Engineering 61B: 237-241. (in Japanese with English summary).

Takanashi R, Toda M, Miyauchi T, Mori M, Mori T (2018) Shear Strength of Multi-screw Joints Connected to Decayed Lumber. Mokuzai Gakkaishi 64(3): 122-129. (in Japanese with English summary).

Sawata K, Sasaki T, Doi S, Iijima Y (2008) Effect of Decay on Shear Performance of Doweltype Timber Joints. Journal of Wood Science 54: 356-361.

Toda M, Takanashi R, Azuma T, Mori M (2017) Degradation of Strength of Column-sill Joints with Decay Treatment. Journal of the Forest Products Research Institute 545: 46-50. (in Japanese with English summary).

Architectural Institute of Japan (2006) Standard for Structural Design of Timber Structures. Maruzen-Yushodo Co., Ltd., Tokyo, Japan. pp. 26-71. (in Japanese).

Japan Housing and Wood Technology Center (2017) Mokuzou jikugumikouhou jyutaku no kyoyou ouryokudo sekkei 1: 300-301. (in Japanese).

Biography 
Proceedings of the 2020 Society of Wood Science and Technology International Convention

\title{
ADDING VALUE TO TIMBER COMPONENTS THROUGH CONSIDERATION OF DEMOLITION AND DISASSEMBLY
}

\author{
St. John Walsh \\ stjwalsh@gmail.com \\ University College Dublin, Ireland
}

\begin{abstract}
Consideration of the life cycle of timber products within the traditional construction sector in Ireland has been extremely limited to date. As a consequence, the majority of timber recovered following demolition is incinerated and therefore contributing to global warming.

Analysis of the current Irish housing stock has shown that it contains high volumes of quality timber components in good condition and of significant capital value. In making relatively minor adjustments to design, construction and demolition practices, opportunities exist to enable disassembly and reuse which would add value to forestry, timber components and completed constructions.
\end{abstract}

Biography 
Proceedings of the $\mathbf{2 0 2 0}$ Society of Wood Science and Technology International Convention

Preparation of Cellulose Acetate-Polyacrylonitrile Composite Nanofibers by Multi-fluid Mixing Electrospinning Method: Morphology, Wettability, and Mechanical Properties

See Paper Under Composites and Adhesives pg 254 


\title{
Analysis of VOC's and odor-active compounds from veneered particleboard coated with water-based lacquer
}

\author{
Qifan Wang 11*-Jun Shen 2* \\ 1 Ph.D. candidates, Northeast Forestry University, Harbin, Heilongjiang, China \\ wangqifan66@163.com \\ 2 Prof., Northeast Forestry University, Harbin, Heilongjiang, China* \\ Corresponding author \\ shenjunr@126.com
}

\begin{abstract}
To reduce the problem of volatile organic compounds (VOCs) and odor emissions from veneered particleboard coated with lacquer, this study focused on identifying odorant compounds and exploring the potential influence of environmental factors on VOCs and odor emissions. Veneered particleboard coated with water-based lacquer was studied via gas chromatography-mass spectroscopy/olfactometry, and, in total, 10 different odor types were identified, which were concentrated in 15 to $23 \mathrm{~min}$. The predominant odor impressions were fragrant, leather, and soybean paste, and the main odorant compounds identified were aromatics and alcohols. The total VOCs (TVOC) concentration and total odor intensity increased as the temperature increased, but these decreased as the ratio of relative humidity and the air exchange rate to the loading factor increased. The ratio of the air exchange rate to the loading factor had a greater impact on the VOCs released from the veneered particleboard than did either temperature or relative humidity, and, therefore, this ratio should be the primary factor considered during storage. The proportion of the odorant concentration to the TVOC concentration decreased with an increase in temperature and relative humidity, whereas the ratio of the air exchange rate to the loading factor had little effect. To accelerate the release of VOCs and odors from veneered particleboard coated with water-based lacquer before its use indoors and, thus, to reduce negative effects on humans, these conditions were found to be optimal: $40^{\circ} \mathrm{C}, 40 \% \mathrm{RH}$, and $1.0 \mathrm{~m} 3 \cdot \mathrm{h}-1 \cdot \mathrm{m}-2$ (ratio of air exchange rate to loading factor).
\end{abstract}

Key words: veneered particleboard coated with water-based lacquer, gas chromatography-mass spectrometry/olfactometry, volatile organic compounds, odorants, environmental factors

\section{Introduction}

Lacquer-covered, wood-based panels, widely used in interior decorating and furniture manufacturing, may cause indoor air pollution, odor issues, and lead to consumer complaints (Schraufnagel et al. 2018; Shen et al. 2018). Volatile organic compounds (VOCs) can produce worrisome odors that significantly affect people's emotional health (Aatamila et al. 2011) and even their physical health. 
The problem of VOCs emissions from veneered wood-based panels has been widely researched. Most studies have focused on the components, the testing methods, and the effects of environmental factors. Liu and Shen (2016) used a rapid test method to detect VOCs emissions from three-layer parquet and found that the VOCs comprised aromatic hydrocarbons and esters. The rapid test improved efficiency and reduced the costs associated with VOCs detection. Wal et al. (1997) found that environmental factors, such as temperature, relative humidity, and flow rate, affected the rate of VOCs release from different materials. A similar conclusion was drawn by Wang et al. (2017), who found that temperature had a greater effect on the release of VOCs from three-layer plywood than did relative humidity or the air exchange rate. Few reports, however, have focused on the odors from decorative panels or on the odors from solid wood. Díaz-Maroto et al. (2008) investigated the odor-active substances in American, French, Hungarian, and Russian oak (Quercus spp.) by gas chromatography-olfactometry (GC-O). They found that oak not only contained the typical compounds characteristic of oak's aroma but also other volatile compounds that smelled fruity. Similar GC-O studies were performed on poplar (Populus L. spp.), pine (Pinus L. spp.), and basswood (Tilia L. spp.) by Wang et al. (2017) and on incense-cedar [Calocedrus decurrens (Torr.) Florin] by Schreiner et al. (2017). Felix et al. (2013) reported that the degradation of a polymeric matrix produced a characteristic odor associated with aldehydes, ketones, and carboxylic acids, whereas the degradation of the lignocellulosic component released acetic acid, formaldehyde, formic acids, aldehydes, and other acids.

Despite the wide use of gas chromatography coupled with mass spectrometry (GC-MS) to identify VOCs and their concentrations (Dincer et al. 2006), the mammalian olfactory system is still the most sensitive and inclusive odor detector. VOCs may sometimes be present at concentrations that are below instrumental detection limits but are still detectable to people (Francesco et al. 2006). The coupling of GC-MS with olfactometry technology (GC-MS/O) was first proposed by Fuller et al. (1964) and was later improved by Acree et al. $(1976,1984)$ and Ullrich and Grosch (1987). Olfactometric techniques are used to identify odor-active compounds and to relate them to human perception (Davoli et al. 2003). Currently, there are various GC-MS/O detection methods (Brattoli et al. 2013): (1) the frequency of detection, (2) dilution to thresholds, and (3) direct intensity. Because of the accuracy and high sensitivity of GC-MS/O, it has been widely used in studies of food aromas and fragrances (Fur et al. 2003; Ferrari et al. 2004; D'Acampora et al. 2007). In recent years, researchers have begun to explore GC-MS/O applications in environmental (Bulliner et al. 2006), medical (Wagenstaller et al. 2013), and interior decorating (Knudsen et al.2007; Clausen et al. 2008; Burdack-Freitag et al. 2009) arenas.

Because the veneered particleboard coated with water-based lacquer commonly used in furniture production and interior decorating is widely known to release VOCs and odors (Zhu et al. 2015; Que et al. 2013; Wang et al. 2018), there has been increasing public concern. Therefore, to accelerate VOCs and odor emission from these materials after production, the most suitable environmental conditions for their storage should be explored. The purpose of this study was to identify the primary odorants and their sources associated with veneered particleboard coated with water-based lacquer and to investigate the influence of environmental factors.

\section{Materials \& Methods \\ Materials}


Particleboard samples used in the experiments were produced by Suofeiya Home Collection Co., Ltd. (Guangdong, China) (see Table 1 for detailed parameters). After samples were overlaid with Fraxinus mandshurica veneer $(0.25 \mathrm{~mm}$ thickness; urea formaldehyde resin and white latex, at a ratio of 6:4; coating amount, $100 \mathrm{~g} / \mathrm{m} 2$; hot pressing time, 3 minutes; hot pressing temperature, $100^{\circ} \mathrm{C}$ ), the water-based lacquer (Xinletian Brand) transparent sealer, sky blue barrier coat and distilled water) was applied by brushing twice with sealer and twice with barrier coat $(100 \mathrm{~g} / \mathrm{m} 2)$. The samples were cut into round pieces (60-mm diameter), with an exposed area of $5.65 \times 10_{-3}$ m2. The edges of the samples were wrapped with aluminum foil to prevent the release of compounds, and then they were stored in polytetrafluoroethylene (PTFE) bags and refrigerated until needed.

Table: 1 Detail parameters of the particleboard

\begin{tabular}{cc}
\hline Option & Parameters \\
\hline Tree species & $\begin{array}{c}\text { Eucalyptus robusta Smith } \\
\text { Guangdong, China }\end{array}$ \\
Place of origin & $12 \mathrm{~mm}$ \\
Thickness & $225^{\circ} \mathrm{C}$ \\
Hot-pressing temperature & $85 \mathrm{~s}$ \\
Hot-pressing time & $1.4 \mathrm{MPa}$ \\
Pressing pressure & $5.94 \%$ \\
MC & $0.64-0.65 \mathrm{~g} / \mathrm{cm} 3$ \\
Density & $180-220 \mathrm{~g} / \mathrm{m} 2$ \\
Adhesive & $1: 1.6$ \\
Adhesin content & $7.0-7.5$ \\
Adhesive pH & $55 \%-60 \%$ \\
Solid content of colloid & $0.35-0.4$ \\
Adhesive viscosity (Pa.s) & $55-60$ \\
Adhesive curing time (s) &
\end{tabular}

\section{Sample preparation}

VOCs (2 L) from veneered particleboard coated with water-based lacquer were adsorbed by a micro-chamber/thermal extractor (Tenax tube; Markes International, South Wales, UK), which could be adjusted from 0 to $250^{\circ} \mathrm{C}$. The cell volume was $1.35 \times 10_{-4} \mathrm{~m} 3$, and the loading rate (the ratios of the panel area to micro-chamber volume) was $41.85 \mathrm{~m} 2 \cdot \mathrm{m}-3$. The specific sampling process is shown below.

Before the experiment, the micro-chamber/thermal extractor was cleaned once with deionized water and once with methanol. The experimental period was 35 days. The samples were put in the micro-chamber extractor under the specific sampling condition shown in Table 2. The VOCs released from the samples were absorbed by Tenax TA tubes on days 1, 3, 7, 14, 21, 28, and 35 and then were identified using GC-MS/O. Purified, humidified air was supplied throughout the experiment. Four samples were made for an identity condition (three repetitions were performed for each measurement). The total number of specimens was 24. After sampling, the Tenax TA sampling tubes were wrapped in PTFE bags until needed.

Table 2: Experimental Scheme

\begin{tabular}{ccccc}
\hline $\begin{array}{c}\text { Experimental } \\
\text { Scheme }\end{array}$ & Research Direction & Temperature & Relative & Air Exchange \\
$\left({ }^{\circ} \mathrm{C}\right)$ & $\begin{array}{c}\text { Humidity } \\
(\%)\end{array}$ & \begin{tabular}{c} 
Rate to Loading \\
\hline
\end{tabular}
\end{tabular}


Proceedings of the 2020 Society of Wood Science and Technology International Convention

\begin{tabular}{ccccc}
\hline & & & & $\begin{array}{c}\text { Factor Ratio } \\
(\mathrm{m} 3 \cdot \mathrm{m}-2 \cdot \mathrm{h}-1)\end{array}$ \\
\hline A & Standard environment & 23 & 40 & 0.5 \\
B & Influence of the temperature & $23,30,40$ & 40 & 0.5 \\
C & Influence of the relative humidity & 23 & 40,60 & 0.5 \\
D & Influence of the ratio of air & 23 & 40 & $0.2,0.5,1.0$ \\
\hline
\end{tabular}

Temperature values are $\pm 1{ }^{\circ} \mathrm{C}$; Relative humidity values are $\pm 5 \%$; Air exchange rate to loading factor ratio values are $\pm 0.05 \mathrm{~m} 3 / \mathrm{m}_{2} \mathrm{~h}$

\section{Test setup of VOCs}

A unity thermal analysis desorption unit (Markes International) was used with nitrogen as the carrier gas and the following parameters: thermal desorption temperature, $280^{\circ} \mathrm{C}$; cold-trap adsorption temperature, $-15^{\circ} \mathrm{C}$; thermal analysis time, $10 \mathrm{~min}$; and injection time, $1 \mathrm{~min}$.

The DSQ II series quadrupole GC-MS unit came from Thermo Fisher Scientific (Schwerte, Germany). Chromatography was performed with a DB-5 quartz capillary column [30,000 m $($ length $) \times 0.26 \mathrm{~mm}$ (inner diameter) $\times 0.25 \mu \mathrm{m}$ (particle sizes); Agilent Technologies, Santa Clara, CA]. Helium was used as the carrier gas, with a constant velocity of $1.0 \mathrm{ml} \mathrm{min-1}$ by splitless injection. The chromatographic column was initially kept at $40^{\circ} \mathrm{C}$ for $2 \mathrm{~min}$; next, the temperature was increased to $50^{\circ} \mathrm{C}$ (in $2^{\circ} \mathrm{C} \mathrm{min}-1$ increments) and was held at that temperature for $4 \mathrm{~min}$. Finally, the temperature was increased to $250^{\circ} \mathrm{C}$ in $10^{\circ} \mathrm{C} \mathrm{min}-1$ increments and was held there for $8 \mathrm{~min}$, with the injection port temperature also at $250^{\circ} \mathrm{C}$. The following GC-MS conditions were used: ionization mode, electron ionization; ion energy, $70 \mathrm{eV}$; transmission line temperature, $270^{\circ} \mathrm{C}$; ion source temperature, $230^{\circ} \mathrm{C}$; and mass scan range, 50-650 atomic mass units.

Three duplicate tests were conducted for each sample for repeatability, and the results were based on the average value. Statistical analysis was used to estimate data. VOCs were identified by comparison with the MS spectra from the National Institute of Standard Technology (NIST) and Wiley (Hoboken, NJ) MS libraries, which matched degrees up to 800 or more. An internalstandard method was used in this experiment, with deuterium substituted for toluene at a concentration of $200 \mathrm{ng} \mu \mathrm{l}-1$, which added $2 \mu \mathrm{l}$. The internal-standard quantitative-analysis method used the following equation:

$$
M_{i}=A_{i} \times\left(\frac{M_{s}}{A_{s}}\right)
$$

where $M_{s}$ is the mass of the internal standard added to the calibration standard; $A i$ and $A_{s}$ are the peak areas of the products tested and the internal standard, respectively; and $M_{i}$ is the mass of the sample to which the internal standard is added.

\section{Identification and evaluation of odor}

GC-O technology was used in this experiment. The Sniffer 9100 Olfactory Detector came from Brechbühler AG (Echallens, Switzerland). The setup of the gas chromatograph equipped with an olfactometric detector is shown in Figure 1 (Plutowska et al. 2008). The transmission line temperature was $150^{\circ} \mathrm{C}$, and nitrogen was used as the carrier gas through a purge valve. Moist air was added to prevent dehydration of the nasal mucosa of the odor assessors. Direct intensity methods were chosen for analysis of the compounds. 


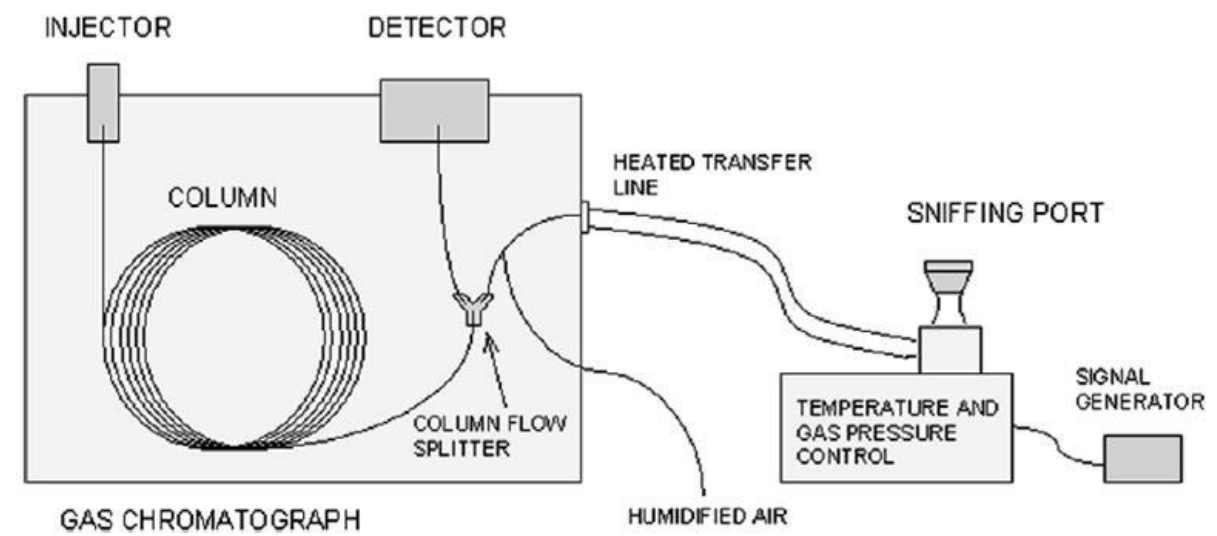

Figure 1. Scheme of the gas chromatograph equipped with an olfactometric detector (Plutowska et al. 2008).

Based on specific screening and training recommendations in "panel selection/training in the automotive industry: ISO12219-7", four assessors (between 20 and 30 years old, with no history of smoking and no olfactory organ disease) were chosen to form an odor-analysis evaluation group. The detailed process is shown in Figure 2. The deionized water, n-butanol solution (concentrations of $2 \mathrm{ml} / \mathrm{L}, 10 \mathrm{ml} / \mathrm{L}, 20 \mathrm{ml} / \mathrm{L}, 30 \mathrm{ml} / \mathrm{L}$ ), and $99.5 \%$ n-butanol solution were prepared and then were kept under these conditions: insulation from light, heat, and oxygen, $23^{\circ} \mathrm{C} \pm 2{ }^{\circ} \mathrm{C}$, relative humidity $40 \% \pm 10 \%$. The preparation time and concentration were labeled well. The solutions' storage lives were 3 days. One hour before the test, the six prepared solutions were put, separately, into six 1-L jars. The odor evaluation descriptions of the solutions (abovementioned) are shown in Table 3. For different grades of standard solution, the assessors were required to describe the odor characteristics correctly within 10 seconds; they were required to remember the distinctive characteristics after the first smelling. After five minutes, when the labels were hidden, they were required to distinguish the odor grade correctly within 10 seconds (with $>80 \%$ rate of correct answers); the assessors were required to correctly point out the error when the solution was mislabeled deliberately (with $>80 \%$ rate of correct answers).

Table 3. Odor evaluation description of n-butanol solution

\begin{tabular}{ccc}
\hline Classification of solutions & Grade & Odor evaluation and description \\
\hline deionized water, & 0 & No smell, no sense. \\
$2 \mathrm{ml} / \mathrm{L}$ & 1 & Perceptible, slight intensity \\
$10 \mathrm{ml} / \mathrm{L}$ & 2 & Perceptible, medium intensity, but no irritation. \\
$20 \mathrm{ml} / \mathrm{L}$ & 3 & Strong and irritant odor \\
$30 \mathrm{ml} / \mathrm{L}$ & 4 & Very strong and intensively irritant odor \\
$99.5 \%$ n-butanol solution & 5 & Unbearable odor \\
\hline
\end{tabular}




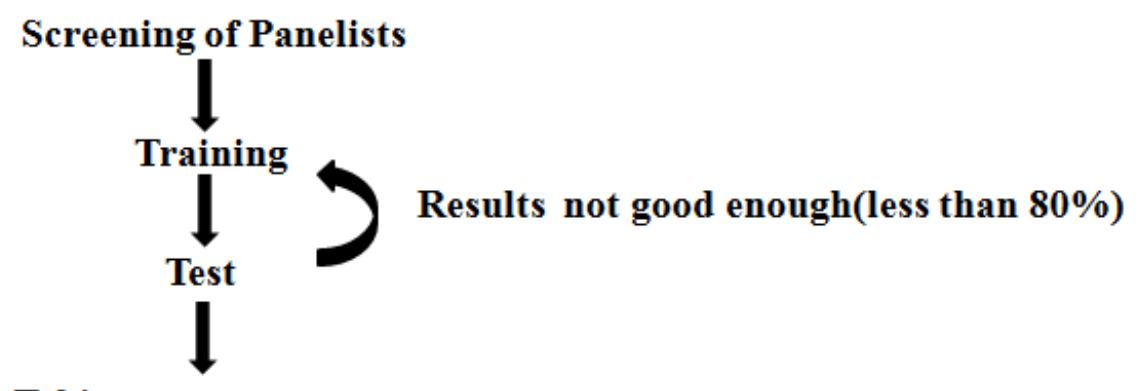

Taking part at measurements

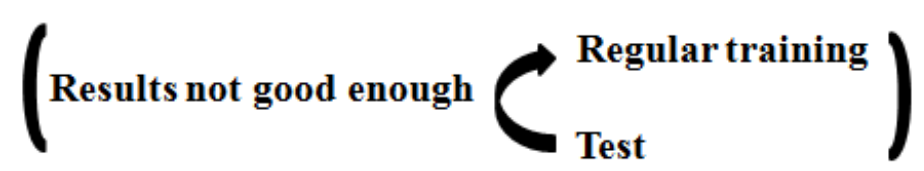

Figure 2. Sniffer detection process of GC-O.

The experimental environment was set to reference standard EN 13725-2003 (NSAI 2003). The room was well ventilated, and there were no peculiar smells within the room. The temperature was kept at $23^{\circ} \mathrm{C} \pm 2{ }^{\circ} \mathrm{C}$ throughout the entire experiment. Activities, such as eating, which might have an effect on indoor odors, were forbidden for $5 \mathrm{~h}$ before the experiment. During a GC run (described above), the human sensory-evaluation assessors recorded the odorants by characteristic and intensity value as well as retention time. The detection time for each sample lasted about 50 minutes. A six-point scale ranging from 0 to 5 was used for intensity judgment according to Japanese standards (Ministry of the Environment 1971): 0 = none, $1=$ very weak, 2 = weak, $3=$ moderate, $4=$ strong, and $5=$ very strong. The method of fingerprints span was used simultaneously to further verify the results. Experimental results were finally recorded when the same odor characteristics were described by at least two assessors. The intensity value was based on the average value from the different assessors. Compounds' refractive index value was calculated by the retention time of $n$-alkane (C6-C30) under the same conditions (van den Dool et al., 1963). Main aroma types and their total relative intensities were shown in the odor profile, based on the odor characteristics recorded by assessors, through the intensity identification and method of fingerprints span. The total relative intensities of each odor type were calculated by adding the intensities of different odorants together.

Results and Discussion Characterization of odor-active compounds

The odor-time intensity spectrum under scheme A (a standard environment) of particleboard coated with water-based lacquer tested by GC-MS/O is shown in Figure 3 (a), compared to the particleboard in Figure 3 (b). In total, 10 types of odors were identified from veneered particleboard coated with water-based lacquer. Most odors were detected in 15 to 23 min and reached a maximum odor intensity value at 17.22 min; odors from particleboard mainly were detected within 10 to $35 \mathrm{~min}$. Using the acute toxicity classification of compounds from the World Health Organization (WHO/IPCS 1996), the odor compound characteristics and relevant parameters of the veneered particleboard coated with water-based lacquer can be determined (Table 4). The key odor components of this material were primarily from aromatics, alcohols, and esters. Odorant components were also found in ethers. Alkane was not detected by odor, which was similar to the results found by Félix et al., who investigated the odor of wood-plastic 
composites and also found little influence of alkanes on the odor of the composites (Félix et al. 2013).

Table 4: Composition of odorant compounds of water paint coating particleboard

\begin{tabular}{|c|c|c|c|c|c|c|}
\hline Compounds & $\begin{array}{l}\text { Retention } \\
\text { index }\end{array}$ & $\begin{array}{c}\text { Mass } \\
\text { concentration } \\
(\mu \mathrm{g} \cdot \mathrm{m}-3)\end{array}$ & $\begin{array}{l}\text { Toxicity } \\
\text { classifica } \\
\text { tion }\end{array}$ & Odor character & $\begin{array}{l}\text { Odor } \\
\text { inten } \\
\text { sity }\end{array}$ & Possible sources \\
\hline \multicolumn{7}{|l|}{ Aromatics } \\
\hline Benzene & 640 & 9.08 & Low & Burnt & 1 & Particleboard \\
\hline Ethylbenzene & 848 & 209.75 & Low & Fragrant & 1 & Particleboard \\
\hline p-Xylene & 857 & 475.12 & Slight & Fragrant & 1.5 & Paint \\
\hline Styrene & 874 & 87.08 & Low & Cream & 3 & Particleboard \\
\hline 1,3-dimethyl-benzene & 878 & 183.84 & Low & Fragrant, honey & 2.25 & $\begin{array}{l}\text { Particleboard, spice } \\
\text { Plasticizer in }\end{array}$ \\
\hline $\begin{array}{c}\text { Dimethyl phthalate } \\
\text { Alcohols }\end{array}$ & 1462 & 146.23 & Slight & wormwood & 1 & waterborne lacquer \\
\hline $\begin{array}{c}\text { 2-butoxy-ethanol } \\
\text { 1-(2-methoxypropoxy)-2- } \\
\text { propanol }\end{array}$ & 998 & 1140.99 & Slight & $\begin{array}{c}\text { Leather, soybean } \\
\text { paste } \\
\text { Unpleasant } \\
\text { mixed smell }\end{array}$ & 3.5 & $\begin{array}{c}\text { Dye dispersant } \\
\text { Dispersant in } \\
\text { waterborne lacquer }\end{array}$ \\
\hline $\begin{array}{l}\text { 2-(2-butoxyethoxy)-Ethanol } \\
\text { Ether }\end{array}$ & 1169 & 3362.85 & Slight & Cucumber & 1 & Diluent of adhesive \\
\hline $\begin{array}{l}\text { Dipropylene glycol } \\
\text { monomethyl ether }\end{array}$ & 986 & 1851.48 & Slight & Alcohol & 1 & $\begin{array}{l}\text { Coupling agent and } \\
\text { active solvent in } \\
\text { waterborne lacquer }\end{array}$ \\
\hline
\end{tabular}

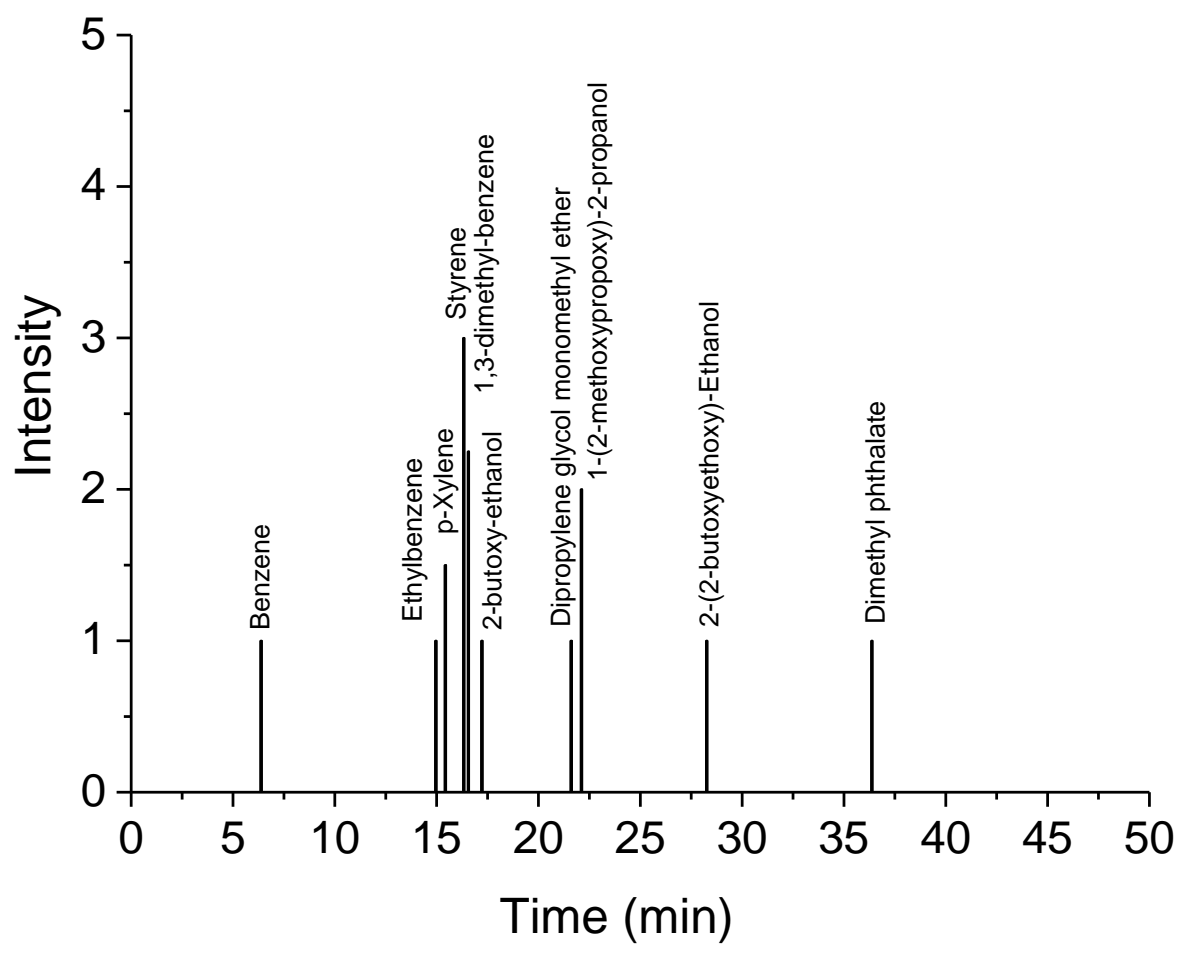


(a)

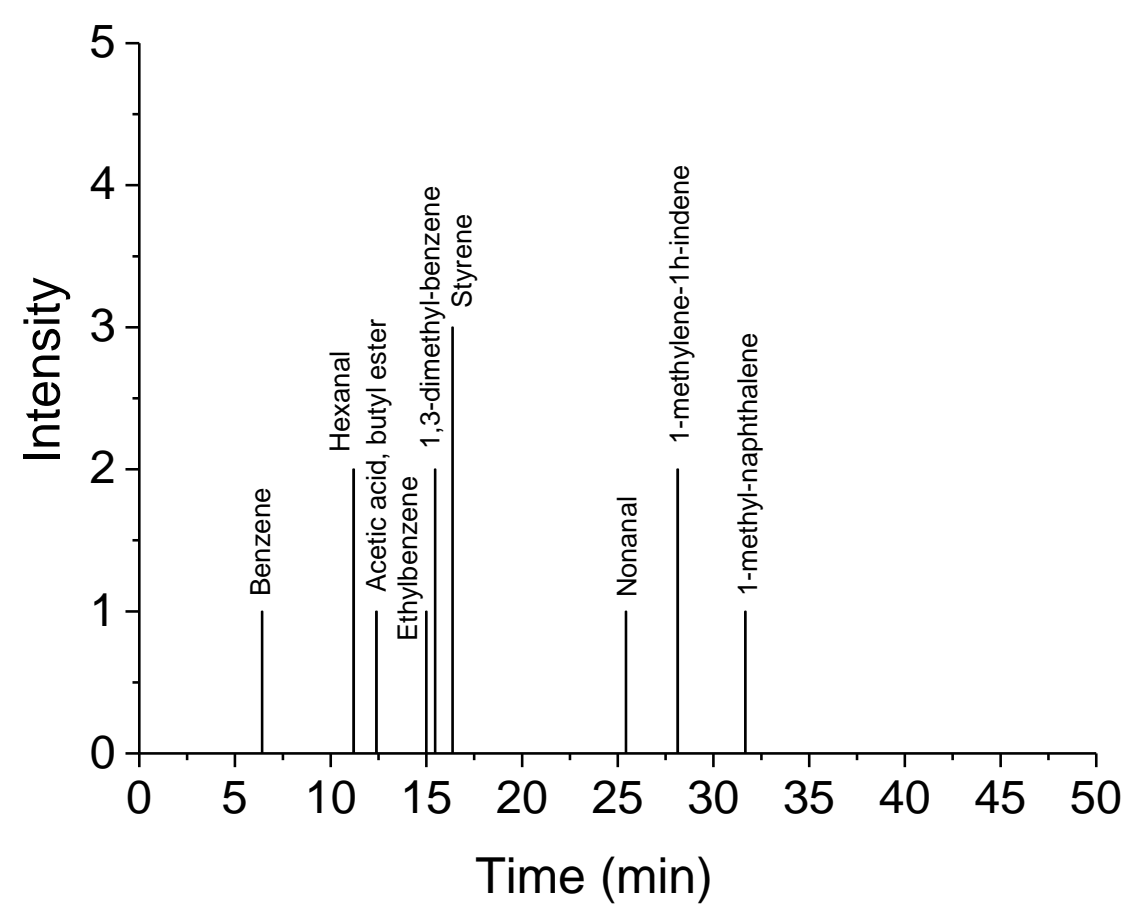

(b)

Figure 3. Gas chromatography (GC) total ion flow chart and odor-time intensity spectrum: (a) water paint coating particleboard, (b) particleboard.

Key odors were identified as potent smell contributors for the comparative analysis of mass spectral data, odor identification compare with relevant reference compounds, and parameters retention index (Xiao et al. 2016; Patcharee et al. 2011). Odor compound characteristics were identified as follows: ethylbenzene was reported as fragrant, similar to the aromatic odor reported by Larranaga et al. (2017); ethylbenzene has also been reported to have a pungent character (Infante et al. 2012). Benzene was found to have a burnt character, in contrast to the gasoline-like character reported by Sax (Félix. 1984) and the aromatic character reported by the U.S. National Institute for Occupational Safety and Health (NIOSH, 2010). Our testing found p-xylene to have a fragrant odor, similar to the aromatic odor reported by NIOSH and the sweet character described in the CAMEO Chemicals hazardous materials database. The styrene detected in this experiment had a cream characteristic, whereas its odor was described as gasoline-like and balsamic in Denk et al. (2017), aromatic in O'Neil (2013), and sweet, floral by NIOSH. Verschueren also found that, although pure styrene always has a sweet and pleasant character, it usually contains aldehydes that have a typical penetrating smell; and, thus, its character is sharp, sweet, and unpleasant (Verschueren. 2001). The dimethyl phthalate in this experiment was reported to have a wormwood character, whereas O'Neil reported a slight aromatic odor. 2-Butoxy-ethanol showed leather, soybean paste characteristics; this is somewhat similar to the slight rancid odor reported in Ashford (1994) and the sweet/ester odor, with a pleasant hedonic tone, reported in Verschueren (2001). In addition, dimethyl phthalate was also reported to have a mild ether-like odor (NIOSH) and a weak pleasant odor (Stoye, 2000). In this experiment, 2-(2-butoxyethoxy)-ethanol was reported to have a cucumber-like smell; other researchers found it to present a faint butyl odor 
(Lewis, 2007) and a mild ether odor (O'Neil, 2013). Research showed that variety of factors could influence differences of odor characteristics. According to van Gemert (2003), the odor characteristic is related not only to its concentration but also to the media in which it exists, which indicating in different concentrations and media, the same compound may show different odor characteristics. Also, the retention indices of the same compound may vary because different parameters are used for mass spectrometry. There are some problems to note about the odor identification results. Three compounds were detected by only a few reporters: 1,3-dimethylbenzene, 1-(2-methoxypropoxy)-2-propanol, and dipropylene glycol monomethyl ether. The subjective nature of smell could lead to differences in assessors' reports, and assessors might have difficulty detecting odorants present in low concentrations. Although assessor identifications were paired with accurate instrumental analysis that has a very low detection limit, it is possible that an odorant present at a concentration too low to be detected by GC-MS was diverted out along with identified compounds, leading to failure to identity the compound. To address the problem of subjective differences among assessors, pretraining must be thorough; also, multiple samples should be used. Among the compounds released from the particleboard covered with water-based paint, "benzene, ethylbenzene, $p$-xylene, styrene, acetic acid, butyl ester, 2-butoxy-ethanol, 2-(2butoxyethoxy)-ethanol, and dipropylene glycol monomethyl ether" are included in the list "VOCs from office furniture in greater than $10 \%$ of all products" from UL 2821 (2013), which merits attention. There was no direct correlation between the odor intensity and concentration of the different odorant compounds. However, the concentration can affect the odor intensity for certain types of compounds. Both et al. (2004) also found that odor intensity is logarithmically related to odorant concentration (Stevens' law or the power law).

The composition of odorous substances is complex, and different odors can interact. When the odorants are mixed, there are various ways in which the total odor intensity can be affected: in fusion, the total odor intensity is equal to the sum of odor intensity of the two compounds; in synergism, the total odor intensity is greater than the sum of odor intensity of the two compounds; in antagonism, the total odor intensity is less than the sum of odor intensity of the two compounds; and, for an unrelated effect, the total odor intensity is determined by one odorant. Considering the complex interaction among various odorant compounds, the effect of fusion on the total odor intensity was chosen for use in this experiment. Figure 4 shows profiles of the odor characteristics of veneered particleboard coated with water-based lacquer and possible odor sources. Fragrant was the dominant odor impression, with a rating of 4.75. Leather and soybean paste both have a rating of 3.5, followed by cream (3.0), honey (2.25), and unpleasant mixed smell (2.0). The attributes burnt (1.0), wormwood (1.0), cucumber (1.0), and alcohol (1.0) were rated with low intensities. Overall, the sample was evaluated as being generally comfortable, meaning that most people would feel comfortable in this environment (with the exception of allergic individuals). Particleboard (total intensity, 9.25) and paint (total intensity, 7.0) emissions were the primary sources of odor; spice and adhesive had intensities of 2.25 and 1 , respectively. 


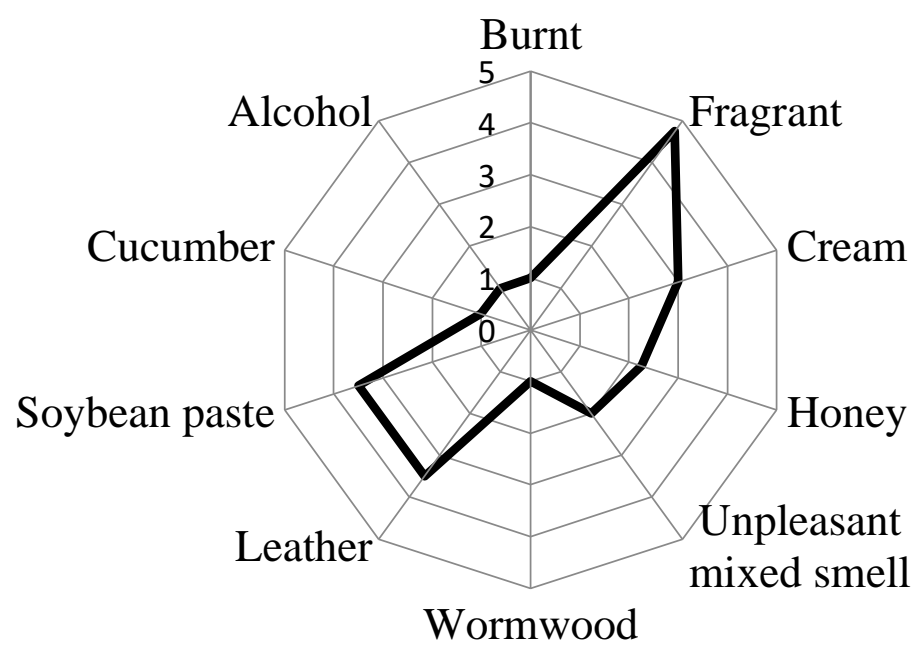

(a)

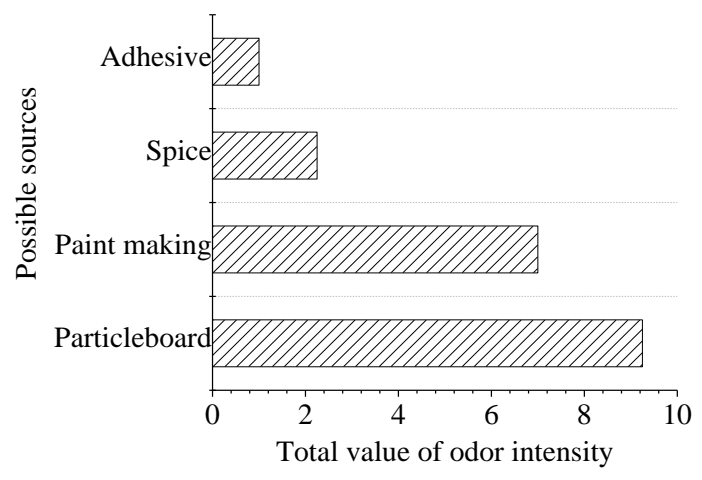

(b)

Figure 4. Odor and sources profile of water paint coating particleboard: (a) odor profile, (b) sources profile.

\section{Effect of environmental factors on VOCs and odor emissions}

Figure 5 shows the changes in TVOC concentration and total odor intensity under schemes B, $\mathrm{C}$, and D. Time is the most effective factor for eliminating VOCs from veneered particleboard coated with water-based lacquer; VOCs and odor gradually decreased with time, until a stable phase was reached. In the early stage, the TVOCs and total odor intensity reached their maximum values. According to the theory of mass transfer, the VOCs inside the particleboards continue to be released until the concentration difference disappears (Liu et al. 2017). However, the release rate and the time needed to reach equilibrium change as environmental factors vary. 


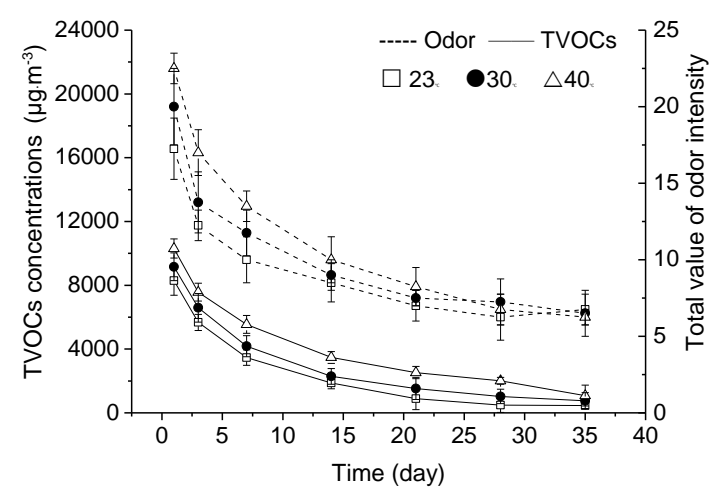

(a)

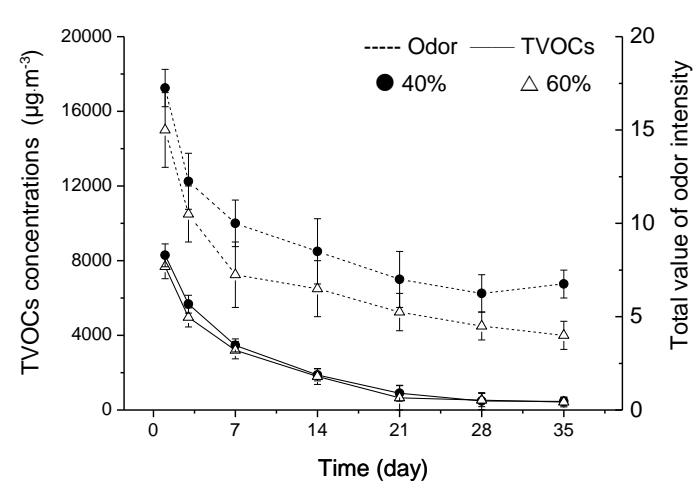

(b)

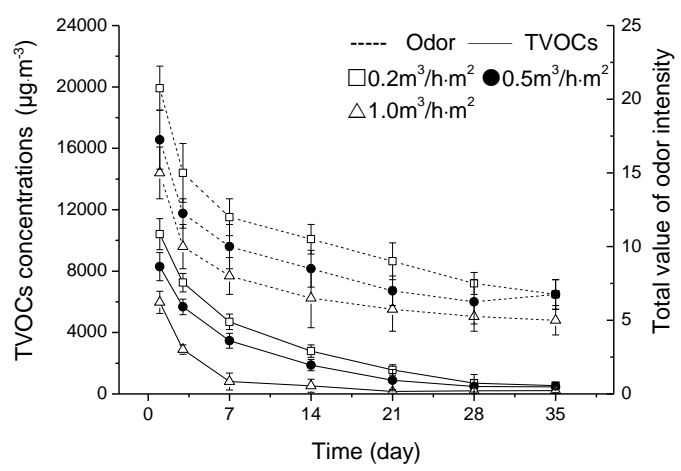

(c)

Figure 5. TVOCs concentration and total odor intensity of the water-based lacquer veneer particleboard at (a) different temperatures, (b) different relative humidity values, and (c) different air exchange rate to loading factor ratios.

The TVOCs and total value of the odor intensity from veneered particleboard coated with water-based lacquer increased when the temperature increased. At $23^{\circ} \mathrm{C}, 30^{\circ} \mathrm{C}$, and $40^{\circ} \mathrm{C}$, on the first day, the TVOCs from the veneered particleboard coated with water-based lacquer were, respectively, 8,290.26 $\mu \mathrm{g} \mathrm{m}-3,9,158.56 \mu \mathrm{g} \mathrm{m}-3$, and 10,305.63 $\mu \mathrm{g} \mathrm{m}-3$; the total values of odor intensity from the water-based coating were 17.25, 20, and 22.5, respectively (Figure 5a). As time passed, the distinctions between TVOCs and the total value of the odor intensity gradually diminished. At 23,30 , and $40^{\circ} \mathrm{C}$, from day 1 to day 35 , the average declines of the TVOCs were generally large, $94.39,91.47$, and $89.30 \%$, respectively, showing that time was a key factor for VOCs emissions. Increased temperature could somewhat promote the emissions of VOCs and odor. Temperature influences VOCs emissions through its effect on the diffusion coefficient (Li et al. 2013). With increased temperature, the mass transfer resistance decreases and promotes the release of the VOCs within the material; this may result in an increase in the mass transfer flux and the release coefficient, which could lead to an increase in the concentration of VOCs within an enclosure. An increase in temperature also promotes VOCs emissions because, when the temperature increases, material diffusion, desorption, evaporation, and chemical reactions are also increased, which can cause rapid and heavy TVOC emissions (Wang et al. 2017).

Figure $5 \mathrm{~b}$ shows the influence of relative humidity on TVOC concentration and total odor intensity under scheme $\mathrm{C}$. When relative humidity levels increased, the TVOCs and total value of 
the odor intensity from veneered particleboard coated with water-based lacquer decreased. From day 1 to day 21, the relative humidity had a greater effect on the emissions of VOCs and odors. The TVOC concentrations and the total value of odor intensity were lower at $60 \%$ than at $40 \%$ relative humidity. After 21 days, the effect of the relative humidity on the release of TVOCs of the veneered particleboard coated with water-based lacquer gradually weakened to the point that no statistically significant effect was found at different relative humidities. However, odor intensities were still affected by relative humidity. In water-based paint, the water is used as the solvent; so, when the relative humidity in the indoor environment increases, the evaporation rate decreases, resulting in increased residual VOCs concentration (Li 2008). Related research shows that higher relative humidity could promote release of VOCs from particleboard (Wang 2011); this can be explained by changes in the pore structure of the particleboard that are caused by the acceleration of hydrolysis, expansion of the pores in the drying layer, and hygroscopicity (Zhu et al. 2013). The results of this paper showed that the application of waterborne paint could prevent partial VOCs emissions from particleboard. Waterborne coatings are the main source of emissions and, thus, play a leading role in release characteristics.

As the ratio of the air exchange rate to the loading factor increased, the TVOCs and total value of the odor intensity from veneered particleboard coated with water-based lacquer decreased (Figure 5c). In general, when the air exchange rate to loading factor ratio decreased, the TVOC concentration increased and the time required for the TVOCs to reach equilibrium was shortened. The samples examined under lower ratios of air exchange to loading factor reached equilibrium sooner. Yu et al. (2006) and Yang et al. (2007) also found that increased ventilation reduced VOCs concentrations. Large amounts of fresh carrier gas can dilute VOCs emissions within the microcell extraction, which then enlarges the concentration gradient between the microcell extraction and particleboard panels, thereby promoting the release of VOCs and reducing their concentration. To accelerate the release of VOCs and odors before indoor use and to reach equilibrium in a shorter time, an environment with relatively higher temperature, lower humidity, and higher air exchange rate to loading factor ratio is suggested. The optimum storage condition for veneered particleboard coated with water-based lacquer after production was found to be $40^{\circ} \mathrm{C}, 40 \% \mathrm{RH}$, and 1.0 $\mathrm{m} 3 \cdot \mathrm{h}-1 \cdot \mathrm{m}-2$ (ratio of air exchange rate to loading factor).

\section{Effect of environmental factors on the components of VOCs and odor emissions in the equilibrium state}

Figure 6 shows the TVOC and odor component concentrations in the veneered particleboard coated with water-based lacquer under different environmental conditions in the equilibrium state. The TVOC and odor component concentrations in the stable phase changed with changes in single factors. The main odor components were found to be aromatics, alcohols, esters, and alkanes. The amounts of alcohols, esters, ethers, and aldehydes increased with increasing temperature and relative humidity; they decreased as the air exchange rate to loading factor ratio increased. The emissions of aromatics and alkanes decreased when the temperature, relative humidity, and the air exchange rate to loading factor ratio increased. When the relative humidity increased from $40 \%$ to $60 \%$, the TVOC concentrations of alcohols, aldehydes, ethers, and esters increased, respectively, 345.57\%, 33.80\%, 382.26\%, and 3.72\%. The concentrations of aromatics and alkanes were reduced by $57.66 \%$ and $44.03 \%$. 


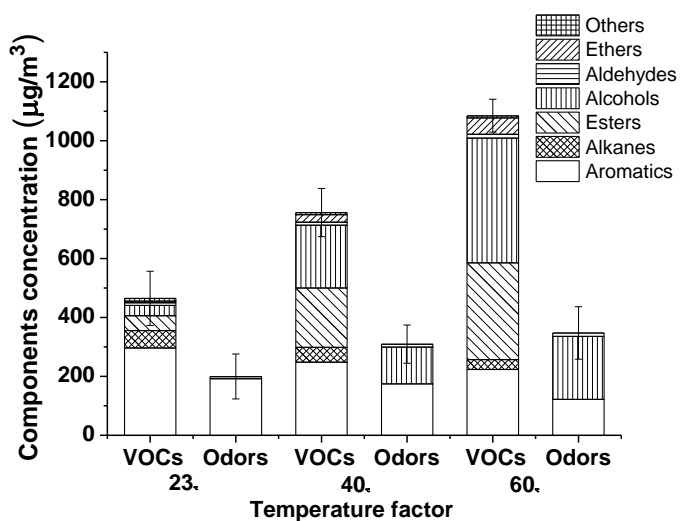

(a)

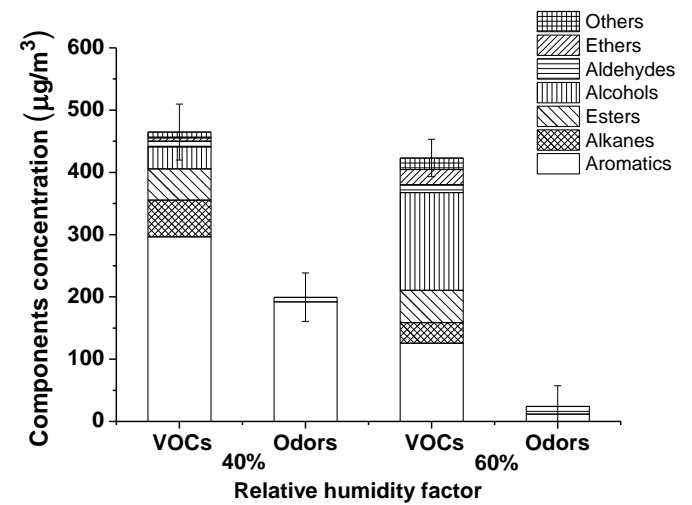

(b)

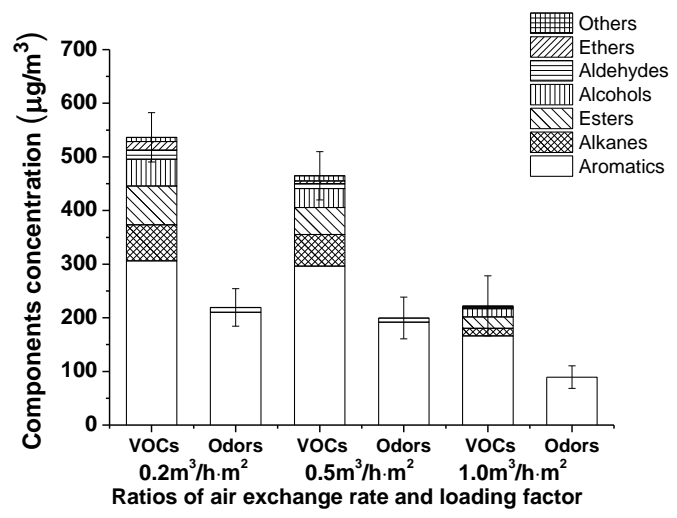

(c)

Figure 6. TVOCs and odor components concentrations from veneered particleboard coated with water-based lacquer under different conditions at an equilibrium state: (a) different temperatures; (b) different relative humidity values; and (c) different air exchange rate to loading factor ratios.

At $23{ }^{\circ} \mathrm{C}, 30{ }^{\circ} \mathrm{C}$, and $40{ }^{\circ} \mathrm{C}$, the proportion of the odor compound concentration to TVOC concentration was $42.94 \%, 40.96 \%$, and $32.03 \%$, respectively, whereas, at $40 \%$ and $60 \%$ relative humidity, the proportion was $42.94 \%$, and $5.77 \%$. The proportion was $40.89 \%, 42.94 \%$, and $40.17 \%$ when the air exchange rate to loading factor ratio was $0.2 \mathrm{~m}_{3} / \mathrm{m}_{2} \mathrm{~h}, 0.5 \mathrm{~m} 3 / \mathrm{m}_{2} \mathrm{~h}$, and 1.0 $\mathrm{m} 3 / \mathrm{m} 2 \mathrm{~h}$, respectively. The proportion of the odor substance concentration to TVOC concentration decreased with an increase in the temperature and relative humidity. The air exchange rate to loading factor ratio had little effect.

\section{Summary and Conclusions}

Problems associated with air pollution and odors from decorative wood-based panels have attracted increased public scrutiny. In this study, evaluation of veneered particleboard coated with water-based lacquer by GC-MS/O allowed key odorants to be identified and the effects of environmental factors on TVOC and odor emissions to be explored. These findings are important in controlling the quality of indoor air.

Based on this study, GC-MS/O can be successfully used to analyze and detect odors from wood-based panels and furniture materials. In total, 14 different odor types were identified from 
veneered particleboard coated with water-based lacquer; these were concentrated in 15 to 23 min and reached their maximum odor intensity at $17.22 \mathrm{~min}$. The predominant odor impressions were fragrant, leather, and soybean paste, and the main odorants were aromatics, alcohols, esters, and alkanes. The sample was evaluated as being generally comfortable, indicating that most people in a similar environment would feel comfortable (with the exception of allergic individuals). VOCs concentration and total odor intensity increased as the temperature increased but decreased as the ratio of relative humidity and the air exchange rate to the loading factor increased. Throughout the analysis, the ratio of the air exchange rate to the loading factor was shown to have a greater impact on the VOCs released from the veneered particleboard than either temperature or relative humidity, and, thus, this ratio should receive primary consideration during storage. In a state of equilibrium, the main odor components were aromatics, alcohols, esters, and alkanes. Alcohols and esters increased with increasing temperature and relative humidity and decreased as the ratio of the air exchange rate to loading factor increased; however, emissions of aromatics and alkanes decreased when the temperature, relative humidity, and the air exchange rate to loading factor ratio increased. To accelerate the release of VOCs and odors before indoor use and to reduce their effect on humans in a fixed period of time, the optimum storage condition after production for veneered particleboard coated with water-based lacquer was found to be $40^{\circ} \mathrm{C}, 40 \% \mathrm{RH}$, and $1.0 \mathrm{~m} 3 \cdot \mathrm{h}-1 \cdot \mathrm{m}-2$ (ratio of air exchange rate to loading factor).

The results of this study can be used to explore appropriate environmental conditions for the storage of veneered particleboard coated with a water-based lacquer after production to reduce the effect of VOCs and odors on humans. Meanwhile, this study is helpful to establish a database of decorative wood-based panels. However, note that the perception of odors is subjective and differed among assessors. At the same time, considering the complex interaction among different odors, there should be ongoing effort to improve the calculation of the total value of odor intensity. Further studies will focus on establishing the correlation between VOCs and odors from decorative wood-based panel and on exploring the method of evaluating total odor intensity.

\section{Acknowledgements}

The authors gratefully acknowledge the financial support of The National Key Research and Development Program of China (2016YFD0600706)

\section{References}

Acree TE, Butts RM, Nelson RR, Lee CY (1976) Sniffer to determine the odor of gas chromatographic effluents. Anal. Chem 48:1821-1822

Acree TE, Barnard J, Cunningham DG (1984) A procedure for the sensory analysis of gas chromatographic effluents. Food Chem 14:273-286

Ashford RD (1994) Ashford's Dictionary of Industrial Chemicals. London, England: Wavelength Publications Ltd p. 399

Aatamila M, Verkasalo PK, Korhonen MJ, Suominen AL,Hirvonen M.R, Viluksela MK, Nevalainen A (2011) Odour annoyance and physical symptoms among residents living near waste treatment centres. Environ. Res 111:164-170

Bulliner EA, Koziel JA, Cai L, Wright D (2006) Characterization of livestock odors using steel plates, solid-phase microextraction, and multidimensional gas chromatography-mass spectrometry-olfactometry. J. Air Waste Manag. Assoc 56:1391-1403 
Burdack-Freitag A, Mayer F, Breuer K (2009) Identification of odor-active organic sulfur compounds in gypsum products. Clean (Weinh) 37:459-465

Both R, Sucker K, Winneke G, Koch E (2004) Odor intensity and hedonic tone-important parameters to describe odor annoyance to residents? Water Sci. Technol 50:83-92

Brattoli M, Cisternino E, Dambruoso PR, Gennaro GD, Giungato P (2013) Gas chromatography analysis with olfactometric detection (GC-O) as a useful methodology for chemical characterization of odorous compounds. Sensors 13(12):16759-16800

Clausen PA, Knudsen HN, Larsen K, Kofoed-Sørensen V, Wolkoff P, Wilkins CK (2008) Use of thermal desorption gas chromatography-olfactometry/mass spectrometry for the comparison of identified and unidentified odor active compounds emitted from building products containing linseed oil. J. Chromatogr. A 1210:203-211

Denk P, Buettner A (2017) Sensory characterization and identification of odorous constituents in acrylic adhesives. Int. J. Adhes. Adhes 78, 182-188

Díaz-Maroto MC, Guchu E, Castro-Vázquez L, De Torres C, Pérez-Coello MS (2008) Aromaactive

compounds of American, French, Hungarian and Russian oak woods, studied by GC-MS and GC-O. Flavour Fragr. J 23: 93-98

D’Acampora Zellner B, Casilli A, Dugo P, Dugo G, Mondello L (2007) Odour fingerprint acquisition by means of comprehensive two-dimensional gas chromatography-olfactometry and comprehensive two-dimensional gas chromatography/mass spectrometry. J. Chromatogr. A 1141:279-286

Dincer F, Odabasi M, Muezzinoglu A (2006) Chemical characterization of odorous gases at a landfill site by gas chromatography-mass spectrometry. J. Chromatogr 1122:222-229

Davoli E, Gangai ML, Morselli L, Tonelli D (2003) Characterisation of odorants emissions from landfills by SPME and GC/MS. Chemosphere 51:357-368

Di Francesco F, Lazzerini B, Marcelloni F, Pioggia G (2001) An electronic nose for odor annoyance assessment. Atmos. Environ 35:1225-1234

Félix JS, Domeño C, Nerín C (2013) Characterization of wood plastic composites made from landfill-derived plastic and sawdust: Volatile compounds and olfactometric analysis. Waste Manag 33, 645-655

Ferrari G, Lablanquie O, Cantagrel R, Ledauphin J, Payot T, Fournier N (2004) Determination of key odorant compounds in freshly distilled cognac using GC-O, GC-MS, and sensory evaluation. J. Agric. Food Chem 52:5670-5676

Fur Y, Mercurio V, Moio L, Blanquet J, Meunier JM (2003) A new approach to examine the relationships between sensory and gas chromatography-olfactometry data using generalized procrustes analysis applied to six French Chardonnay wines. J. Agric. Food Chem 51:443452

Fuller GH, Stellencamp R, Tisserand GA (1964) The gas chromatograph with human sensor: perfumer model. Ann. N. Y. Acad. Sci 116:711-724

Greenguard Environmental Institute (2006) Standard Method for Measuring and Evaluating Chemical Emissions From Building Materials, Finishes and Furnishings Using Dynamic Environmental Chambers. GG Publications UL 2821-2013, Marietta, GA.

Infante PF, Bingham E (2012) Aromatic Hydrocarbons - Benzene and Other Alkylbenzenes. Patty's Toxicology. 6th ed. (1999-2016). New York, NY: John Wiley \& Sons, Inc. On-line Posting Date: Aug 17 


\section{Proceedings of the 2020 Society of Wood Science and Technology International Convention}

Knudsen HN, Clausen PA, Wilkins CK, Wolkoff P (2007) Sensory and chemical evaluation of odorous emissions from building products with and without linseed oil. Build. Environ 42:4059-4067

Li XH (2005) Study on the emission behavior of volatile organic compounds (VOCs) in the interior wall coating and paint. Dissertation, Lanzhou University (In Chinese)

Li S, Shen J, Jiang S (2013) Characteristics of VOC emissions from plywood in different environment factors. Sci. Silvae Sin 49:179-184 (In Chinese)

Larranaga MD, Lewis RJS, Lewis RA (2016) Hawley's Condensed Chemical Dictionary 16th Edition. John Wiley \& Sons, Inc. Hoboken, NJ p.576

Liu WJ, Shen J, Wang QF (2017) Design of DL-SW micro-cabin for rapid detection and analysis of VOCs from wood-based panels. J. Forestry Eng 4:40-45 (In Chinese)

Ministry of the Environment. (1971) Law No. 91: Offensive Odor Control Law. Government of Japan, Tokyo, Japan.

NSAI. National Standards Authority of Ireland (2003) Air Quality - Determination of Odour Mass Concentration by Dynamic Olfactometry. SN EN 13725-2003. NSAI, Dublin, Ireland.

NIOSH (2010) NIOSH Pocket Guide to Chemical Hazards. Department of Health \& Human Services, Centers for Disease Control \& Prevention. National Institute for Occupational Safety \& Health. DHHS (NIOSH) Publication No. 2010-168. Available from:http://www.cdc.gov/niosh/npg

O'Neil MJ (2013) The Merck Index-An Encyclopedia of Chemicals, Drugs, and Biologicals. Cambridge, UK: Royal Society of Chemistry p.592, 566, 1283

Pripdeevech P, Khummueng W, Park SK (2011) Identification of odor-active components of agarwood essential oils from Thailand by solid phase microextraction-GC/MS and GC-O. J. Essent. Oil Res 23, 46-53

Plutowska B, Wardencki W (2008) Application of gas chromatography-olfactometry (GC-O) in analysis and quality assessment of alcoholic beverages - A review. Food Chem 107:449-463

Que ZL, Wang FB, Li JZ, Furuno T (2013) Assessment on emission of volatile organic compounds and formaldehyde from building materials. Compos B Eng 49:36-42

Sax NI (1984) Dangerous Properties of Industrial Materials. 6th ed. New York, NY: Van Nostrand Reinhold p.152

Stoye D (2000) Ullmann's Encyclopedia of Industrial Chemistry. New York, NY: John Wiley \& Sons; Solvents. Online Posting Date: June 15, 2000

Schreiner L, Loos HM, Buettner A (2017) Identification of odorants in wood of Calocedrus decurrens

(Torr.) Florin by aroma extract dilution analysis and two-dimensional chromatography-mass spectrometry/olfactometry. Anal. Bioanal. Chem 409:3719-3729

Schraufnagel DE, Balmes J, Cowl CT, et al. (2018) Air Pollution and Non-Communicable Diseases: A Review by the Forum of International Respiratory Societies' Environmental Committee, Part 1: The damaging effects of air pollution. Chest 2018-Nov-09 (Epub 2018 Nov 09)

Shen J, Jiang LQ (2018) A review of research on VOCs release from wood-based panels. J. Forestry Eng 4:40-45 (In Chinese)

Ullrich F, Grosch W (1987) Identification of the most intense volatile flavor compounds formed during autoxidation of linoleic acid. Z. Lebensm. Unters. Forsch 184:277-282

van den Dool H, Kratz PD (1963) A generalization of the retention index system including linear temperature programmed gas-liquid partition chromatography. J. Chromatogr 11:463-470 
Verschueren K (2001) Handbook of Environmental Data on Organic Chemicals. Volumes 1-2. 4th ed. John Wiley \& Sons. New York, NY p.387, 1899

van Gemert LJ (2003) Compilations of odor threshold value in air, water and other media. Boelens Aroma Chemical Information Service

Wal JF, Hoogeveen AW, Wouda P (1997) The influence of temperature on the emission of volatile organic compounds from PVC flooring, carpet and paint. Indoor Air 7:215-221

Wang JX (2011) Study on impact of environmental factors on emission of VOC from wood-based panel. Dissertation, Northeast Forestry University (In Chinese)

Wagenstaller M, Buettner A (2013) Characterization of odorants in human urine using a combined chemo-analytical and human-sensory approach: A potential diagnostic strategy. Metabolomics 9:9-20

Wang QF, Shen J, Zhao Y, Liu WJ (2017) Influence of environmental factors to volatile organic compound emissions from plywood by a rapid detection method. For. Prod. J 67:120-125

Wang QF, Shao YL, Cao TY, Shen J (2017) Identification of key odor compounds from three kinds of wood species. In Proceedings of the 2017 International Conference on Environmental Science and Sustainable Energy (ESSE2017), Suzhou, China, 23-25 June 2017.

Wang QF, Shen J, Zhao Y, Liu WJ (2017) Influence of environmental factors to volatile organic compound emissions from plywood by a rapid detection method. For. Prod. J 67:120-125

Wang QF, Shen J, Shen XW, Du JH (2018) Volatile Organic Compounds and Odor Emissions from Alkyd Resin Enamel-coated Particleboard. BioResources 13(3): 6837-6849

Xiao Z, Fan B, Niu Y, Wu M, Liu J, Ma S (2016) Characterization of odor-active compounds of various Chrysanthemum essential oils by gas chromatography-olfactometry, gas chromatography-mass spectrometry and their correlation with sensory attributes. J. Chromatogr. B 1009-1010, 152-162

Yang JD, Zhang YR (2014) Air pollution pricing: analysis based on happiness. China World Econ 37:162-188 (In Chinese)

Yu YB, Zhang GQ, Yu DH (2006) External factors influencing contamination emissions from porous materials. Heat. Ventil. Air Cond 36:13-19 (In Chinese)

Zhu HO, Que ZL, Lu ZG (2013) Emission study of volatile, organic compounds released from bamboo flooring. China Wood Ind 27(3):13-17 (In Chinese)

Zhu XD, Liu Y, Shen J (2016) Volatile organic compounds (VOCs) emissions of wood-based panels coated with nanoparticles modified water based varnish. European journal of wood and wood products 74(4) 601-607

Biography 
Proceedings of the 2020 Society of Wood Science and Technology International Convention

Effect of lacquer decoration on VOCs and odor release from P.neurantha (Hemsl.) Gamble

See Paper Under Early Stage Researchers pg.79 
Regular Poster:

\title{
PROPERTIES OF PARTICLEBOARD MADE FROM RECYCLED POLYSTYRENE AND Cocos nucifera STEM PARTICLES
}

\author{
Babatunde Ajayi 1 \\ babatundeajayi2000@yahoo.com \\ Abiola Adeniran 1 \\ adeniranta@futa.edu.ng \\ Ayodeji Omolez \\ omoomole@yahoo.com \\ Omolola Akinlalus \\ unomololaregina@gmail.com
}

\author{
1 Federal University of Technology Akure, Nigeria \\ 2 University of Ibadan, Nigeria \\ 3 Rufus Giwa Polytechnic Owo, Nigeria
}

\section{Abstract}

The study investigates the use of Recycled Polystyrene (RP) in the production of particleboard. Boards of $6 \mathrm{~mm}$ thickness with dimension of $350 \mathrm{~mm} \times 350 \mathrm{~mm}$ were produced from mixture of Cocos nucifera stem particles and RP. The boards were made at varying mixing ratio of 1:1, 2:1, and 3:1 and board densities of $1000 \mathrm{~kg} / \mathrm{m}_{3} 1100 \mathrm{~kg} / \mathrm{m}_{3}$ and $1200 \mathrm{~kg} / \mathrm{m}_{3}$. Thickness swelling (TS), Water Absorption (WA), Modulus of Rupture, and Modulus of Elasticity of the boards were evaluated in accordance to ASTM D-1037 standard. Data obtained were subjected to analysis of variance (ANOVA) at $5 \%$ probability level. TS and WA decreases as the mixing ratio increases from 1:1 to $3: 1$ and board density increases from 1000 $\mathrm{kg} / \mathrm{m}_{3}$ to $1200 \mathrm{~kg} / \mathrm{m}_{3}$. Also, MOR and MOE of boards increase as the board density was increased from $1000 \mathrm{~kg} / \mathrm{m}_{3}$ to $1200 \mathrm{~kg} / \mathrm{m}_{3}$. However, MOR and MOE of boards initially increases as mixing ratio increases from 1:1 to 2:1 and later decreases with further increase in mixing ratio. The strongest and most dimensionally stable board was produced at board $1200 \mathrm{~kg} / \mathrm{m} 3$ and mixing ratio $2: 1$. This study proves that RP is a good substitute for formaldehyde based resin commonly used in particle boards industries.

Biography 
Heterospecific tree density and environmental factors affect Afzelia africana Sm. population structure in the Pendjari Biosphere Reserve, West Africa: Implications for Management and Restoration.

Justin A. Atanasso1, Sylvanus Mensah1, Akomian F. Azihou2, Bruno A. Djossa3, Romain Glèlè Kakaï1, Achille E. Assogbadjo2

Atanasso Akpovi Justin; Laboratoire de Biomathématiques et d'Estimations Forestières, Faculté des Sciences Agronomiques, Université d'Abomey-Calavi, atanassojustin@gmail.com

Mensah Sylvanus; Laboratoire de Biomathématiques et d'Estimations Forestières, Faculté des Sciences Agronomiques, Université d'AbomeyCalavi, sylvanus.m89@gmail.com Azihou Akomian; Laboratory of Applied Ecology, University of Abomey Calavi, sylvanus.m89@gmail.com

Djossa Bruno; Ecole de Foresterie et d'Ingénierie du Bois, Université Nationale d'Agriculture, Benin, djossabruno@gmail.com

Glèlè Kakaï Romain; Laboratoire de Biomathématiques et d'Estimations Forestières, Faculté des Sciences Agronomiques, Université d'AbomeyCalavi, gleleromain@gmail.com Assogbadjo Achille; Laboratory of Applied Ecology, University of Abomey-Calavi, assogbadjo@gmail.com

\begin{abstract}
.
Information on how abiotic and biotic factors affect species population structures and regeneration are critical for understanding plant growth in natural habitats. Here, we used data from three spatially distinct stands of A. africana in the Pendjari Biosphere Reserve in Benin, to determine how the species stands' structures respond to abiotic and biotic factors. A. africana stands' structures were studied using several parameters including basal area, tree height, density of successive diameter classes, and size class slope. We tested for individual effects of abiotic (mound density, soil type, terrain slope) and biotic (heterospecific tree density) factors on the species stands' structure. We also tested for similarity of species composition among studied A. africana stands. Results revealed a tree density structure with over-mature individuals, and size class distribution indicating a recruitment bottleneck at the juvenile stage (10-20 cm diameter), possibly due to mammal browsing, natural and artificial fires. Heterospecific tree density was positively associated with $A$. africana adult density, but negatively related to the species growth parameters (mean diameter, basal area and tree height). These results indicate some degrees of niche overlap between $A$. africana and coexisting species, but also partly reflect $A$. africana tolerance and adaptation to limited resources environment. Soil type significantly influenced both basal area and
\end{abstract}


regeneration density, greater values being observed on rock outcrop soils. Basal area was higher on steeper terrain slope, probably a result of species conservative strategies. These findings were discussed in line with management and restoration action needs in the Pendjari Biosphere Reserve. Keywords. Afzelia africana, importance value index; stand of Batia; stand of Bondjagou; stand of Bali; Pendjari Biosphere Reserve; Benin.

Biography 


\title{
Enhancing the fire resistance of cement-bonded particleboard made of Scots pine and poplar
}

\author{
Fatima Zohra Brahmia1 -Péter György Horváth2 -Tibor L. Alpar3* \\ ${ }_{1}$ PhD student, University of Sopron, Simonyi Károly Faculty of Engineering, Wood Sciences \\ and Applied Art, Institute of Wood Based Products and Technologies, Sopron, Hungary \\ fatima.zohra.brahmia@phd.uni-sopron.hu \\ 2 associate professor, University of Sopron, Simonyi Károly Faculty of Engineering, Wood \\ Sciences and Applied Art, Institute of Wood Based Products and Technologies, Sopron, Hungary \\ horvath.peter.gyorgy@uni-sopron.hu \\ 3 associate professor, Institution, City, State, Country * Corresponding author \\ alpar.tibor@uni-sopron.hu
}

\begin{abstract}
Cement bonded particleboard (CBPB) is well known as building material that has a growing market in central of Europe, requirements and regulations on both the global and national level forcing continuous developments. Over the years researchers focused on improving the hygroscopic and mechanical properties and shortening the manufacturing time of the CBPB but there was no improvement on its fire resistance. CBPB without any pre-treatment is a material within the B-s1, d0 classification of fire resistance. Using fire retardants could upgrade it to the classification $\mathrm{A}_{1}$ or $\mathrm{A}_{2}$ but the fire retardants should not affect the primary properties of CBPB. In this study, particles of Scots pine and poplar pre-treated with fire retardants (Borax, DAHP 150 $\mathrm{g} / 1$ and DSHP $77 \mathrm{~g} / \mathrm{l}$ ) were used for CBPB production. For the first time FR's pre-treatment was used for manufacture CBPB. Sodium silicate (SS) and Polydiallyldimethylammonium chloride+ montmorillonite (PDDA+MM) were used to increase the cement wood compatibility. In total 32 type of CBPB were prepared 8 of them were control with untreated particles. After 15 days from CBPB's curing, specimens were cut with the required dimensions for each test and Standard tests were made in order to investigate the effect of the FR's on the CBPB properties and if they meet the standard requirement. A non-combustibility test EN ISO 1182:2010 was made to determine whether the material will participate directly to fire expansion or not and if it upgraded to classification of a building products into classes A1 and A2. Results showed that fire retardants has influence on the mechanical properties of CBPB's. However, using 5\% of SS or $20 \%$ of (PDDA+MM) the boards can full fill the standard requirements. Only boards made of poplar particles pre-treated of DAHP $150 \mathrm{~g} / \mathrm{l}$ upgraded to A1 classification.
\end{abstract}

Key words: cement-bonded particleboard, fire retardant, Scots pine, poplar

\section{Introduction}

Over the years, building construction have improved from many aspects, starting with design to construction materials. This product has advantages of both concrete and wood. Its fire resistance 
is better than that of wood. It has a better tensile and bending strength than concrete, and it is also lighter. For cement-wood composites, it is reinforced by wood fibers, particles, flakes, and wood wool with different shapes and sizes (Ferraz et al., 2012). The most well-known cement bonded products are cement fiberboard, cement bonded particleboard (CBPB), wood-wool cement boards (WWCB), and building blocks (Vaickelionis and Vaickelioniene, 2006). Low density boards are used as thermal insulation (Frybort et al., 2008).

Cement wood composites (CWC) are building materials that have many influencing factors. The most important factor on CWC production is the compatibility between wood and cement. The wood species is the most important factor in cement-wood compatibility because not all species have the same kind and amount of extractives which are retarding the hydration of cement. Not only does the wood species have an effect, but the time of harvesting, age, and storing (Nasser et al., 2016) make a difference because these factors can influence the extractives within the wood (Alpar et al., 2011; Frybort et al., 2008; Wei et al., 2000). Pre-treatments for wood were used to decrease the extractives or cement inhibitors in many studies. The most used wood pre-treatments were hot and cold water, sodium hydroxide, calcium hydroxide, and alkaline hydrolysis. These pre-treatments can change the cement wood compatibility from non-compatible to suitable (Castro et al., 2014; Nasser et al., 2016; Nasser and Al-Mefarrej, 2011; Quiroga et al., 2016)

Mechanical properties and reduction of the curing time are the most important aspects that researchers are focused on. Usually mechanical properties are increased by using various additives like calcium chloride and sodium silicate (Alpar et al., 2011). To decrease the curing time of the CWC, carbon dioxide ( $\left.\mathrm{CO}_{2}\right)$ is used (Qi et al., 2010). It is not only used to reduce curing time, but also improves mechanical properties and water absorption as well (Wang et al., 2017).

A few research projects have examined the fire resistance of $\mathrm{CBPB}$, and they were mostly focused on proving that CBPB is non-combustible material or the effect of the additives on the thermal stability of the material (Saval et al., 2014; Yu et al., 2016). Nevertheless, the fire resistance of CBPB needs improvement especially that CBPB is a construction material and fire safety is important aspect in buildings. CBPB without any pre-treatment is a material within the B-s1, d0 classification of fire resistance (MSZ EN 13501-1:2007+ A1:2010) (Falco 2020). Using fire retardants as pre-treatments for wooden particles that be used in the CBPB could upgrade it to the $\mathrm{A}_{2}$ or $\mathrm{A}_{1}$ classification. However, the used fire retardants should not affect the primary properties like mechanical performance. In addition, the used fire retardants have to be eco-friendly, as to not harm people, and cheap as well because the CWC have to remain on budget. The known wood fire retardants that seem to have potential as pre-treatment agents are the phosphorus, boron compounds and polyethylene glycol.

The aim of this research is to increase the fire resistance of CBPB's made of poplar and Scots pine by using fire retardants pre-treatments for the used wood particles in the CBPB production. Since there was no previous researches on increasing fire resistance of CBPB with fire retardants pretreatments the used fire retardants were chosen carefully to be effective for fire retardation of poplar and Scots pine (Brahmia et al., 2020).

\section{Materials \& Methods}

A poplar hybrid (Populus cv. euroamericane 1214) and Scots pine (Pinus sylvestris) particles, Portland cement CEM I 42.5, and sodium silicate $\mathrm{SS}\left(\mathrm{Na}_{2} \mathrm{SiO}_{3}\right)$ were used as basic raw materials. 
Fire retardants: Borax $\left(\mathrm{Na}_{2} \mathrm{~B}_{4} \mathrm{O}_{7}\right)$, DSHP $\left(\mathrm{Na}_{2} \mathrm{HPO}_{4}\right)$, DAHP $\left(\left(\mathrm{NH}_{2}\right)_{4} \mathrm{HPO}_{4}\right)$. Alternate woodcement compatibilizers: montmorillonite (MM) (Na,Ca)0.33( $\left.\mathrm{Al}, \mathrm{Mg})_{2}\left(\mathrm{Si}_{4} \mathrm{O}_{10}\right)(\mathrm{OH})_{2} . \mathrm{nH}_{2} \mathrm{O}\right)$, Polydiallyldimethylammonium chloride (PDDA) $\left(\mathrm{C}_{8} \mathrm{H}_{16} \mathrm{NCl}\right) \mathrm{n}$. The fire retardants used were in powder form. They were dissolved in distilled water to become liquids. Chemicals were prepared with concentration of $150 \mathrm{~g} / \mathrm{l}$ for DAHP, $77 \mathrm{~g} / \mathrm{l}$ for DSHP and $25 \mathrm{~g} / \mathrm{l}$ for Borax under solubility temperature of $20^{\circ} \mathrm{C}$.

Particles of Sots pine and poplar were treated with fire retardants by spray gun in a drum blender. The initial moister content of wood particle was around $18 \%$. 1L of FR were sprayed for $3 \mathrm{~kg}$ of wood. CBPB were produced from treated Scots pine and poplar particles. The boards have three layers, the core layer with big particles and two surface layers with small particles. Sodium silicate was used as additive to increase the cement wood compatibility first with $2 \%$, then $5 \%$ of the cement weight. A mixture of PDDA and MM were used as well with different amount $0,2 \%$ and $20 \%$ of the cement weight. The used additives well known as bender for Scots pine and poplar with cement and as well good fire retardants. The following recipes (Table 1) manufactured all 32 CBPB's.

Table 1: CBPB recipe production.

\begin{tabular}{lllll}
\hline Recipe & R1 & R2 & R3 & R4 \\
\hline Wood & 1 & 1 & 1 & 1 \\
Cem & 2.6 & 2.6 & 2.6 & 2.6 \\
SS & 0.052 & 0.13 & 0 & 0 \\
PDDA & 0 & 0 & 0.001 & 0.1 \\
MM & 0 & 0 & 0.001 & 0.1 \\
CS & 0.52 & 0.52 & 0.52 & 0.52 \\
Total & 4.172 & 4.25 & 4.122 & 4.32 \\
\hline
\end{tabular}

Steel plate was covered by plastic in order the mixture do not stick. Wooden mould with dimension (400x400x200 mm) put above steel plate and the surface layer of the cement wood mixture was spread by hand after that the core layer then another surface layer. Then pressed with wooden cover by hand, the wooden mould was removed and steel spacers with thickness of $12 \mathrm{~mm}$ was put to ensure final thickness, another steel plate was put above the board and it was pressed with press machine under pressure of $7.9 \mathrm{MPa}$ for 24 hours in a Siempelkamp laboratory press.

\section{Mechanical properties}

After 15 days, all produced CBPB's were cut for tests to specimens with dimension of (50x250x12mm). Bending strength (Bending test) EN 310 was made Fig.1. 


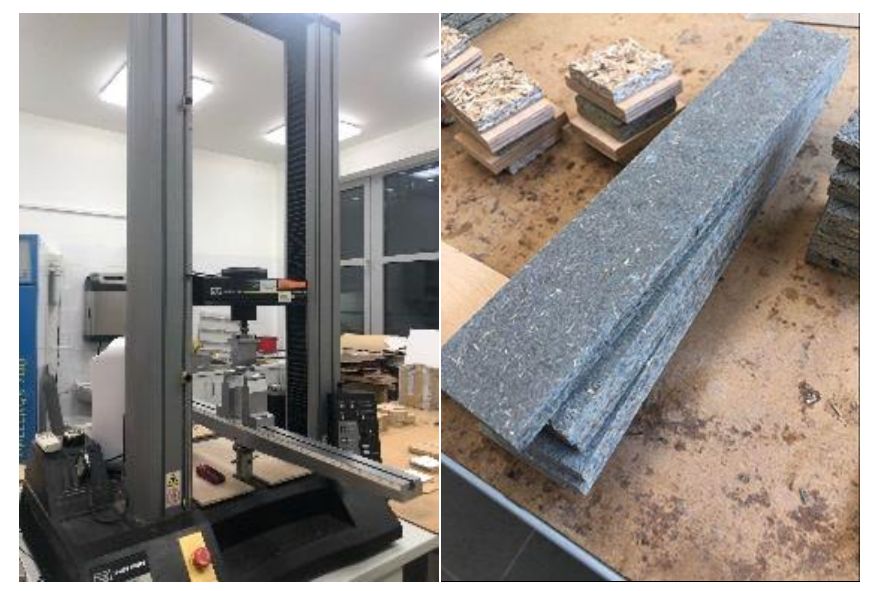

Fig.1: INSTRON IN5566 bending machine (a), specimens (b)

\section{Fire performance}

Specimens form CBPB's were taken in order to make Fire tests. The non-combustibility tests were made by a Wazau test apparatus corresponds to standard EN ISO 1182:2010. It was used to determine the classification of the CBPB specimens. EN ISO 1182 Non-combustibility test is one of the Euro class test standard. The Non-combustibility test is made to determine whether the material will participate directly to fire expansion and is relevant to classification of all building products into classes A1 and A2 (Table 2).

Table 2: Classes of reaction to fire performance for construction product EN ISO 13501-1:2007+A1:2010.

\begin{tabular}{|l|l|}
\hline Class & classification criteria \\
\hline $\mathrm{A} 1$ & $\Delta \mathrm{T} \leq 30^{\circ} \mathrm{C} ;$ and \\
& $\Delta \mathrm{m} \leq 50 \% ;$ and $\mathrm{tf}=($ i.e. no sustained flaming $)$ \\
\hline $\mathrm{A} 2$ & $\Delta \mathrm{T} \leq 50^{\circ} \mathrm{C} ;$ and $\Delta \mathrm{m} \leq 50 \% ;$ and $\mathrm{tf} \leq 20 \mathrm{~s}$ \\
\hline
\end{tabular}

\section{Results and Discussion}

\section{Mechanical properties}

According to Fig.2 and Fig.3 fire retardants has big influence on the bending and density of the produced CBPB's with both poplar and Scots pine. There is relation between density and MOR high density gives high MOR. In case of scots pine CBPB's made with SS has higher density than boards made with (PDDA+MM) while for poplar density of CBPB's made of SS and $(\mathrm{PDDA}+\mathrm{MM})$ has no difference in density.

For CBPB's made of Scots pine board made of untreated wood particles fulfilled the standard requirement with $\mathrm{MOR}=9,54 \mathrm{MPa}$ with using $2 \%$ of SS from cement weight. In other hand, board made with treated particle has lower MOR. Board made of particles treated with borax has 62,63\% lower MOR than the untreated one, while board made of particles treated with DSHP 77g/l has $25.37 \%$ lower MOR than the untreated for board with DAHP $150 \mathrm{~g} / \mathrm{l} \mathrm{MOR}$ drop with 53.52\% and 
none of them fulfilled the requirement. After adding 5\% of SS from cement weight, MOR dropped by $17.71 \%$ for the untreated board becoming $7.85 \mathrm{MPa}$ and standing out of the standard. While boards made of treated particles, it's MOR increased by $63.37 \%$ in case of board made of particles treated of borax, $39.20 \%$ in case of DSHP $7 \mathrm{~g} / \mathrm{l}$ and $49.67 \%$ in case of DAHP $150 \mathrm{~g} / \mathrm{l}$. With using $5 \%$ of SS boards made of particles treated with borax fulfilled the standard requirement by 10.22 MPa and DSHP 77g/l by 11.17 MPa but DAHP 150 almost reach standard it has MOR=8.81 $\mathrm{MPa}$ while standard requirement is $9 \mathrm{MPa}$ see Fig.2.(a).

For boards made of Scots pine particles with 0,2\% of (PDDA+MM), untreated board did not meet the requirement with $\mathrm{MOR}=5.66 \mathrm{MPa}$. Boards made of particles treated with DSHP $77 \mathrm{~g} / \mathrm{l}$ had $\mathrm{MOR}=5.99 \mathrm{MPa}$ which similar to untreated one. boards made of DAHP $150 \mathrm{~g} / \mathrm{l}$ pre-treated particles has lower MOR than the untreated with $54.62 \%$ while borax pretreatment prevent board from curing. By increasing the (PDDA+MM) to $20 \%$ control specimens MOR increased by $42.48 \%$, boards with DSHP $77 \mathrm{~g} / \mathrm{l}$ pretreatment increased with $42.59 \%$ and boards with DAHP150g/l pretreatment increased with $72.26 \%$ upgrading the boards to the standard requirements. However for borax pre-treatment even with $20 \%$ of (PDDA+MM) board cured but have low MOR 4.90 MPa see Fig.2.(b).

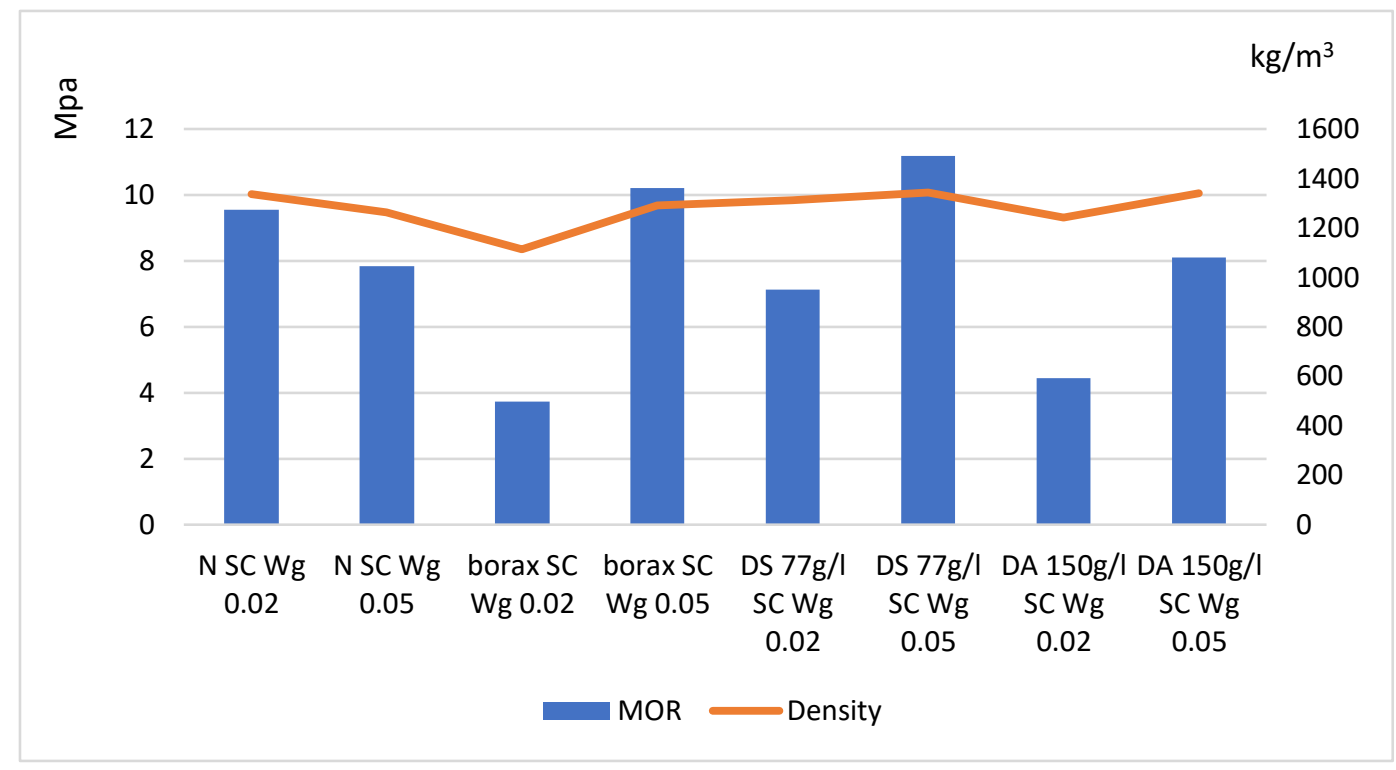

(a) 


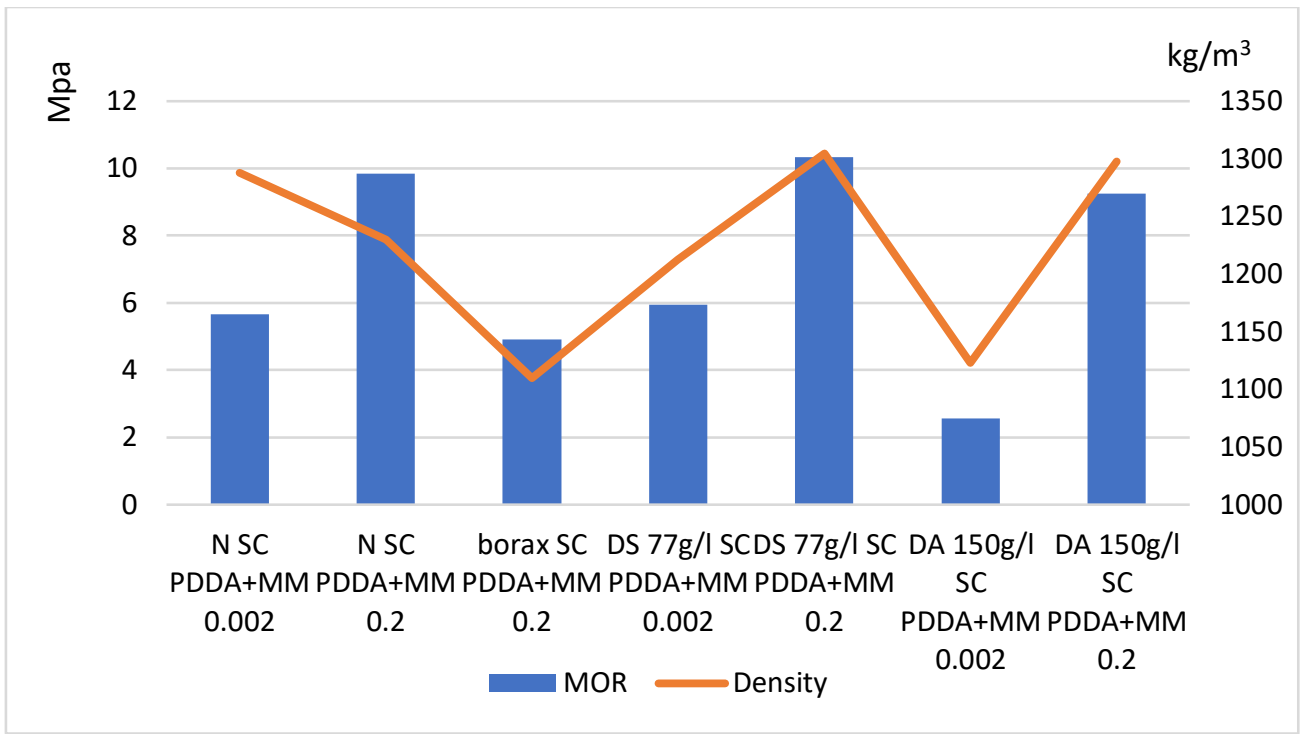

(b)

Fig.2: MOR and Density of CBPB made of Scots pine. (a) boards made with water glass additive, (b) boards made with PDDA+ montmorillonite additive

For boards made of poplar particles with $2 \%$ of SS, board made of untreated wood particles did not fulfilled the standard requirement with $\mathrm{MOR}=8.77 \mathrm{MPa}$. In addition, board made with treated particle has even lower MOR. Board made of particles treated with borax has $23.26 \%$ lower MOR than the untreated board, while board made of particles treated with DSHP $77 \mathrm{~g} / 1$ has $16.10 \%$ lower MOR than the untreated for board with DAHP $150 \mathrm{~g} / \mathrm{l}$ bending strength drop with $70.82 \%$. With comparing the poplar and scots pine results borax and DSHP $77 \mathrm{~g} / 1$ has small influence on the MOR of the CBPB's made of poplar than of Scots pine. After adding 5\% of SS from cement weight, MOR increased by $55.16 \%$ for the untreated board becoming $15.38 \mathrm{MPa}$ and fulfilling the standard requirement. Boards made of treated particles, it's MOR increased by $51.96 \%$ in case of board made of particles treated of borax, 35.92\% in case of DSHP $7 \mathrm{~g} / \mathrm{l}$ and $67.27 \%$ in case of DAHP $150 \mathrm{~g} / \mathrm{l}$. With using $5 \%$ of SS boards made of particles treated with borax fulfilled the standard requirement by $12.70 \mathrm{MPa}$ and DSHP $77 \mathrm{~g} / 1$ by $9.28 \mathrm{MPa}$ but DAHP 150 stand out of standard with 6.47 see Fig.3.(a).

For boards made of poplar particles with $0,2 \%$ of (PDDA+MM), untreated board did almost meet the standard requirement with $8.64 \mathrm{MPa}$. fire retardants pre-treatments decreased MOR of the CBPB's for borax it was decreased by $78.82 \%$, DSHP 77g/l it was decreased by 51.96 and $50.06 \%$ in case of DAHP $150 \mathrm{~g} / \mathrm{l}$. By increasing the (PDDA+MM) to $20 \%$ control specimens MOR increased by $49.01 \%$, boards with DSHP $77 \mathrm{~g} / 1$ pretreatment increased with $58.22 \%$ and boards with DAHP $150 \mathrm{~g} / \mathrm{l}$ pretreatment increased with $53.31 \%$ upgrading the boards to the standard requirements. However for borax pre-treatment even with $20 \%$ of (PDDA+MM) board cured but have low MOR 4.18 MPa see Fig.1.(b). 


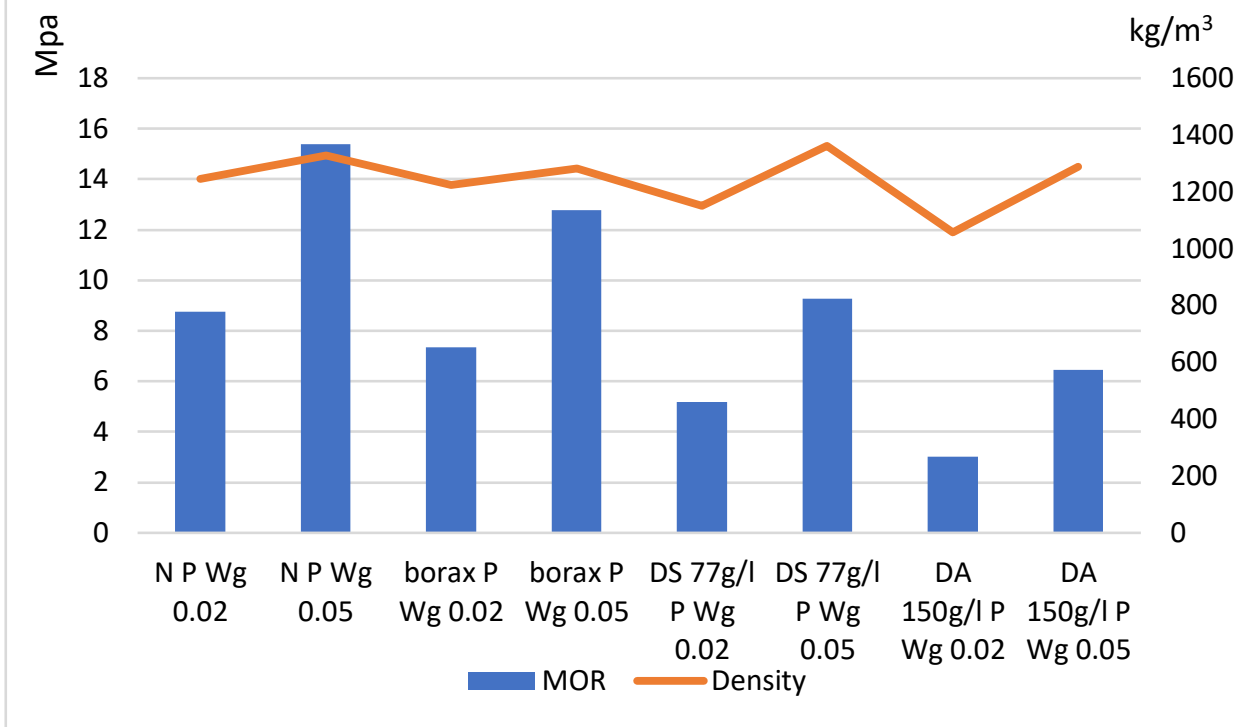

(a)

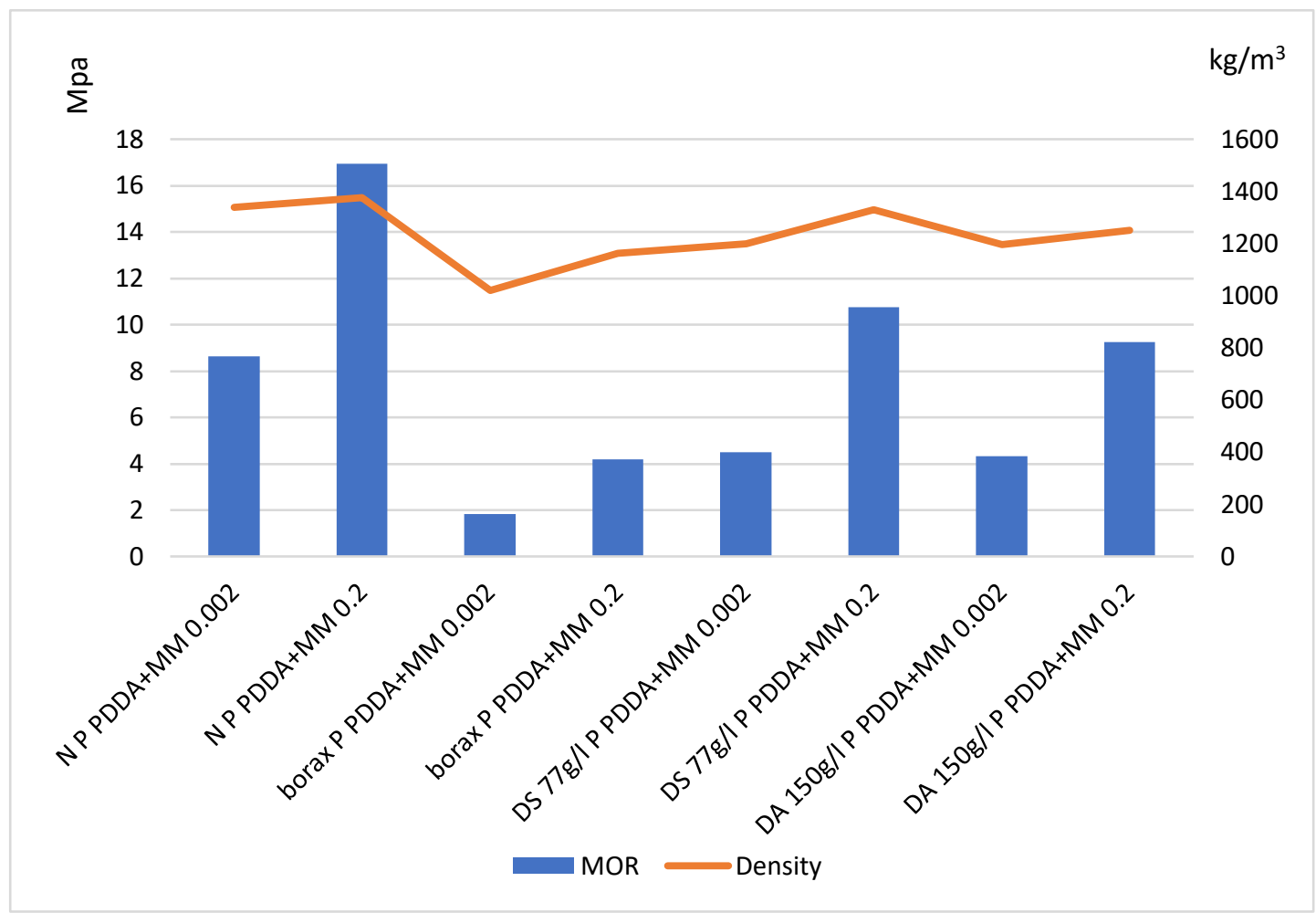

(b)

Fig.3: MOR and Density of CBPB made of poplar. (a) boards made with water glass additive, (b) boards made with PDDA+ montmorillonite additive

Fire performance 
Incombustibility test see Table 3 and Table 4, indicated that fire retardants has better performance on poplar than of Scots pine as it was expected when it was tested on solid wood (Brahmia et al., 2020). Fire retardant pre-treatments had no effect on fire performance of Scots pine except for DSHP $77 \mathrm{~g} / 1$, which reduced the $\Delta \mathrm{T}$ with $40.03 \%$ in case of CBPB with (PDDA+MM) additives (Table 3).

Table 3: Incombustibility test results of Scots pine samples

\begin{tabular}{cccccccccc}
\hline \multicolumn{1}{c}{ SS } & \multicolumn{10}{c}{ PDDA+MM } & & & DS & DA & DA \\
\cline { 2 - 10 } & untreated & borax & $77 \mathrm{~g} / 1$ & $150 \mathrm{~g} / 1$ & untreated & borax & $77 \mathrm{~g} / 1$ & $150 \mathrm{~g} / 1$ & $150 \mathrm{~g} / 1$ \\
\hline$\Delta \mathrm{T}\left(^{\circ}\right)$ & 58,32 & 51,08 & 47,8 & 49,28 & 57,23 & 48,94 & 34,32 & 58,32 & 51,08 \\
$\Delta \mathrm{m}(\mathrm{g})$ & 38,64 & 35,69 & 38,64 & 34,54 & 38,29 & 39,65 & 37,06 & 38,64 & 35,69 \\
$\mathrm{tf}(\mathrm{s})$ & 871,2 & 769 & 645 & 770 & 967 & 762 & 523 & 871,2 & 769 \\
\hline
\end{tabular}

For CBPB's made of poplar, fire retardants have an influence om fire performance. The $\Delta \mathrm{T}$ of CBPB made of DAHP $150 \mathrm{~g} / 1$ pre-treated particles and SS was reduced by $59.53 \%$ with $\Delta \mathrm{T}=$ $23.52^{\circ}, \Delta \mathrm{m}=34.54 \%$ which is lower than $50 \%$ of mass loss and no flaming upgrading the board to A1 class according to EN ISO 13501-1:2007+A1:2010 classification. CBPB's made of borax and DAHP $150 \mathrm{~g} / \mathrm{l}$ pre-treated poplar particles with (PDDA+MM) additives increased $\Delta \mathrm{T}$ with almost $48 \%$ but there was flaming during the test and was more than 20 s which did not fulfill the standard requirements. Since the interaction between SS and DAHP $150 \mathrm{~g} / \mathrm{l}$ prevent the flaming. Specimens with CBPB made of $150 \mathrm{~g} / \mathrm{l}$ pre-treatment and (PDDA+MM) additives was soaked into $\mathrm{SS}$ and let to dry for one week before test. After testing, it was found that $\Delta \mathrm{T}$ was reduced by $65.78 \%$ and there was no flaming, which upgrade the CBPB to A1 class. SS is well known as a wood fire retardants (Mahzabin et al., 2013; Medina and Schledjewski, 2009).

Table 4: Incombustibility test results of Poplar samples

\begin{tabular}{cccccccccc}
\hline \multicolumn{1}{l}{ SS } & \multicolumn{1}{c}{ PDDA+MM } & & & DA & DA \\
\cline { 2 - 10 } & untreated & borax & $77 \mathrm{~g} / 1$ & $150 \mathrm{~g} / 1$ & untreated & borax & DS $77 \mathrm{~g} / 1$ & $150 \mathrm{~g} / 1$ & $150 \mathrm{~g} / 1 *$ \\
\hline$\Delta \mathrm{T}\left(^{\circ}\right)$ & 58,12 & 54,46 & 47,36 & $\mathbf{2 3 , 5 2}$ & 57,52 & $\mathbf{3 0}$ & 39,94 & $\mathbf{2 9 , 3 6}$ & $\mathbf{1 9 , 6 8}$ \\
$\Delta \mathrm{m}(\mathrm{g})$ & 35,64 & 38 & 34,71 & 31,18 & 35,24 & 32,67 & 35,55 & 31,45 & 25,6 \\
$\mathrm{tf}(\mathrm{s})$ & 708 & 722 & 657 & $\mathbf{0}$ & 979 & 625 & 659 & 315 & $\mathbf{0}$ \\
\hline
\end{tabular}

Note: * samples soaked into SS let to dry 7 days before test

\section{Summary and Conclusions}

Over the years, many researchers have been developed CWC from mechanical properties, cement wood compatibility to shortening manufacturing time via pre-treatments. However, there was no researches on improving fire resistance of $\mathrm{CW}$ of CBPC. This paper studied the possibility of improving fire resistance of CBPB made of scots pine and poplar particles pre-treated with fire retardants. It was found that fire retardants have big influence on the MOR of the CBPB's but with using $5 \%$ of SS boards with scots pine or poplar particles pretreated with borax or DAHP $77 \mathrm{~g} / \mathrm{l}$ 
fulfill the standard requirements. In other hand, using 20\% of (PDDA+MM) for producing boards with particles of poplar or Scots pine pre-treated with DAHP $150 \mathrm{~g} / \mathrm{l}$ or DSHP $77 \mathrm{~g} / \mathrm{l}$ fulfill the standard requirements. Incombustibility test, showed that fire retardants did not have upgraded the CBPB made of Scots pine to A1 or A2 classifications but it has big effect on poplar DAHP $150 \mathrm{~g} / \mathrm{l}$ pre-treatment upgraded the CBPB made of poplar classification from B-ds 1,d0 to A1 according to EN ISO 13501-1:2007+A1:2010. Additives has influence on fire retardants performance SS improved fire performance of DAHP $150 \mathrm{~g} / \mathrm{l}$ as SS is considered as one of wood fire retardants itself.

\section{Acknowledgements}

This article was made in frame of the „EFOP-3.6.1-16-2016-00018 - Improving the role of research+development+innovation in the higher education through institutional developments assisting intelligent specialization in Sopron and Szombathely".

\section{References}

Alpar, T., Pavlekovics, A., Csoka, L., Horvath, L., 2011. Wood wool cement boards produced with nano minerals. Presented at the Proceedings 3rd Int. Scientific Conference on Hardwood Processing (ISCHP32011) I: Peer reviewed contributions, pp. 75-82.

Brahmia, F.Z., Alpár, T., Horváth, P.G., Csiha, C., 2020. Comparative analysis of wettability with fire retardants of Poplar (Populus cv. euramericana I214) and Scots pine (Pinus sylvestris). Surf. Interfaces 18, 100405. https://doi.org/10.1016/j.surfin.2019.100405

Castro, V., Araújo, R.D., Parchen, C., Iwakiri, S., 2014. Evaluation of pretreatment effects of Eucalyptus benthamii Maiden \& Cambage wood on the compatibility degree with Portland cement. Rev. Árvore 38, 935-942.

Falco "https://www.falco-woodindustry.com/Betonyp_epitolemez.html," Apr. 2020.

Ferraz, J.M., Del Menezzi, C.H.S., Souza, M.R., Okino, E.Y.A., Martins, S.A., 2012. Compatibility of Pretreated Coir Fibres ( Cocos nucifera L.) with Portland Cement to Produce Mineral Composites. Int. J. Polym. Sci. 2012, 1-7. https://doi.org/10.1155/2012/290571

Frybort, S., Mauritz, R., Teischinger, A., Müller, U., 2008. Cement bonded composites - A mechanical review. BioResources 3, 602-626. https://doi.org/10.15376/biores.3.2.602-626

Mahzabin, M.S., Hamid, R., Badaruzzaman, W.H.W., 2013. EVALUATION OF CHEMICALS INCORPORATED WOOD FIBRE CEMENT MATRIX PROPERTIES 8, 14.

Medina, L.A., Schledjewski, R., 2009. WATER GLASS AS HYDROPHOBIC AND FLAME RETARDANT ADDITIVE FOR NATURAL FIBER REINFORCED COMPOSITES 10.

"MSZ EN 13501-1:2007+A1:2010 (Fire classification of construction products and building elements. Part 1: Classification using data from reaction to fire tests)."

Nasser, R.A., Al-Mefarrej, H.A., 2011. Midribs of Date Palm as a Raw Material for Wood-Cement Composite Industry in Saudi Arabia 8.

Nasser, R.A., Salem, M.Z.M., Al-Mefarrej, H.A., Aref, I.M., 2016. Use of tree pruning wastes for manufacturing of wood reinforced cement composites. Cem. Concr. Compos. 72, 246-256. https://doi.org/10.1016/j.cemconcomp.2016.06.008

Qi, H., Cooper, P.A., Hooton, D., 2010. The investigation of basic processes of rapidly hardening wood-cement-water mixture with CO2. Eur. J. Wood Wood Prod. 68, 35-41. https://doi.org/10.1007/s00107-009-0351-z 
Quiroga, A., Marzocchi, V., Rintoul, I., 2016. Influence of wood treatments on mechanical properties of wood-cement composites and of Populus Euroamericana wood fibers. Compos. Part B Eng. 84, 25-32. https://doi.org/10.1016/j.compositesb.2015.08.069

Saval, J., Lapuente, R., Navarro, V., Tenza-Abril, A.J., 2014. Fire-resistance, physical, and mechanical characterization of particleboard containing Oceanic Posidonia waste. Mater. Constr. 64, 019.

Vaickelionis, G., Vaickelioniene, R., 2006. Cement hydration in the presence of wood extractives and pozzolan mineral additives. Ceram. Silik. 50, 115.

Wang, L., Chen, S.S., Tsang, D.C.W., Poon, C.-S., Dai, J.-G., 2017. CO 2 curing and fibre reinforcement for green recycling of contaminated wood into high-performance cement-bonded particleboards. J. CO2 Util. 18, 107-116. https://doi.org/10.1016/j.jcou.2017.01.018

Wei, Y.M., Guang Zhou, Y., Tomita, B., 2000. Hydration behavior of wood cement-based composite I: evaluation of wood species effects on compatibility and strength with ordinary portland cement. J. Wood Sci. 46, 296-302. https://doi.org/10.1007/BF00766220

Yu, Y., Hou, J., Dong, Z., Wang, C., Lu, F., Song, P., 2016. Evaluating the flammability performance of Portland cement-bonded particleboards with different cement-wood ratios using a cone calorimeter. J. Fire Sci. 34, 199-211.

Biography 


\title{
Promotion of Eucalyptus Hybrid Species as Utility Poles for Electricity Transmission: The Mechanical Strength Properties of Eucalyptus urograndis Grown in Ghana
}

Emmanuel Appiah-Kubi ${ }_{1}^{*}$ - Haruna Seidu2 - Francis Wilson Owusu2 - Ohene Addo3 ${ }_{1}$ Senior Lecturer, Department of Construction and Wood Technology, University of Education, Winneba, Kumasi Campus, Kumasi, Ghana *Corresponding author appiahkemma@gmail.com

${ }_{2}$ Principal Technologist, Principal Research Scientist, CSIR-Forestry Research Institute of Ghana, Fumesua-Kumasi, Ghana harryzeib@gmail.com,fwowusu3@yahoo.com

3Managing Director, Asuboa Wood Treatment Limited, P.O.Box JO 160, Juaso, Ghana

oheneohene@yahoo.com

\begin{abstract}
Electricity transmission is vital for the supply and distribution of energy for both domestic households and industrial usage. The most common wood species used as poles for electricity transmission in Ghana are Teak and Pines, which are unable to meet the demand for rural electrification programmes. Eucalyptus plantations have been set up in Ghana and are readily available. The suitability of the eucalyptus trees as an alternative to Teak and Pines for electricity transmission was assessed in this study. Five trees of four-year old eucalyptus hybrid species (Eucalyptus urophylla + Eucalyptus grandis = Eucalyptus urograndis $)$ were used for the study. The bending strength (Modulus of rupture, MOR and Modulus of elasticity, MOE) and Density were determined according to British Standard BS 373. Results were analyzed using Origin statistical software. The eucalyptus hybrid species recorded mean MOE and MOR values of 11,980 $\mathrm{N} / \mathrm{mm}_{2}$ and $89 \mathrm{~N} / \mathrm{mm}_{2}$ respectively. Sectional (longitudinal) comparison for all the trees investigated suggests uniform distribution of the strength properties along the height of the poles of Eucalyptus species. Strength properties (MOE and MOR) of Eucalyptus hybrid species from MIRO plantations in Ghana compares well with other eucalyptus species from other countries. Eucalyptus trees are therefore recommended for use as transmission poles in Ghana.
\end{abstract}

Keywords: Eucalyptus, utility poles, mechanical properties

\section{INTRODUCTION}


In Ghana, the most used species for electrification is Tectona grandis. Other species that complement teak include pines, afina, kusia and kusibiri. Ofori et al. (2008) assessed the suitability of plantation grown Kusia (Nauclea diderrichii Merill). The treatability of Kusia, as reported by Ofori et al. (2008) rendered it suitable for use as electricity transmission poles. Unfortunately, the volumes of these species have reduced drastically thereby posing challenges to the industry and the nation at large. Currently Pine poles are imported to supplement the growing demand for electricity transmission poles. Meanwhile some Eucalyptus species have been grown in plantations by individuals and companies in Ghana.

Eucalypts are known to possess high density and bending strength properties. Density ranges from $470 \mathrm{~kg} / \mathrm{m} 3$ to $980 \mathrm{~kg} / \mathrm{m} 3$. Modulus of elasticity ranges from $10500 \mathrm{~N} / \mathrm{mm} 2$ to $18220 \mathrm{~N} / \mathrm{mm} 2$. Eucalypts from natural forests tend to have higher densities than those from plantations. The physical and strength properties vary with age, genotype and planting site. However, growth rate appears not to influence physical and strength properties (Loulildi et al. 2012, Doran and Wongkaew 2008, Santos et al. 2004).

Loulidi et al. (2012) determined the physical and mechanical properties of a hybrid of E. grandis and E. camaldulensis in Morroco. Results from non-destructive tests conducted on specimens showed high bending strength properties - Modulus of elasticity (MOE) of $18219 \mathrm{~N} / \mathrm{mm} 2$ and a density of $470 \mathrm{~kg} / \mathrm{m} 3$. The parent species E. grandis and E. camaldulensis had Mean MOE of $14488 \mathrm{~N} / \mathrm{mm} 2$ and $18266 \mathrm{~N} / \mathrm{mm} 2$ respectively.

MIRO Forestry Limited has Eucalyptus plantation of about 5000 hectares in Ghana. The principal species grown by MIRO include E. pellita, E. Urophylla, E. grandis, E. camaldulensis and Corymbia citriodora. The trees of these species are less used by the furniture industry while the pole treatment industry has virtually no raw materials to work with. Meanwhile Eucalypts are being used in other countries as electricity transmission poles. Again, the government imports treated poles annually to undertake rural electrification projects. The use of Eucalypt species as poles is possible when their natural durability and others are known. There is therefore the need to study into the Eucalypts that are grown in Ghana to assess their potential for utilization as electrification poles. This study therefore aims at increasing the quantities of wood species available in Ghana to produce electricity transmission poles thereby supporting climate change mitigation, sustainable forest management and livelihood improvement. The specific objective is to determine the mechanical properties of plantation grown eucalyptus and their suitability as electricity transmission poles in Ghana.

\section{MATERIALS AND METHODS}

\section{Materials}

Five trees of four-year old eucalyptus hybrid species were extracted from the MIRO plantations in Agogo, Ashanti Region of Ghana for the laboratory tests. The trees extracted were given unique identification as follows: G1, H10, K1, W2, Z16. Each tree was sectioned into Butt (B), Middle 
(M) and Top (T) and transported to the Forestry Research Institute of Ghana's Wood Processing Workshop. The Logs were processed into $30 \mathrm{~mm}$ thick boards and stacked for air drying.

\section{Methods}

\section{Static Bending Test}

Static bending test was conducted to determine the Modulus of Elasticity (MOE) and Modulus of Rupture (MOR) of the trees. Sample preparations and tests were conducted based on the British Standards BS 373. According to the standard, specimen to be used in determining MOE and MOR should be free from knots, splits, decay with dimensions $20 \mathrm{~mm}$ x 20mm x 300mm.

Each tree was sectioned into Butt (B), Middle (M) and Top (T) with 20 specimens for each of the sections. The specimens were conditioned in a climate chamber (CLIMATUR) for $24 \mathrm{hrs}$ at $20{ }_{\circ} \mathrm{C}$ and $65 \%$ temperature and humidity respectively.

The tests were conducted using a Universal Testing Machine (Instron, model no. 4482). Results of test are stored in an output file by the Instron software.

Test results were extracted into Microsoft Excel format. The results were then transferred onto the Origin Lab software version 9.0 for analysis. The analysis was done comparing the means of the various sections within trees and that of tree-to-tree comparison. The results obtained are summarized in the tables below.

\section{Fibre Stress Determination}

Fibre stress, which is the longitudinal compressive or tensile stress in a member, such as a beam was estimated based on the 'characteristic' MOR strength value of the species. Traditionally, determination of strength properties is based on a combination of full-size pole test and small clear specimen test (Wolfe et al. 2001). Though strength properties are best determined on structural sized poles, small clear specimen test is employed where it is difficult to apply such an approach. MOR data on small clear specimens were used to determine the fibre stress. To obtain the fibre stress to be used for pole classification and dimensions, adjustment factors covering change from small clear bending strength to full-size pole strength, moisture content change due to drying of in-service poles, and pre-treatment conditioning effects, are applied on the 'characteristic' MOR strength value. The adjustment factors used were the factors adopted in the ANSI 05.1 standard (ANSI 1997). These were an $8 \%$ increase for the change from small clear bending strength to fullsize pole strength, a $16 \%$ increase for drying of in-service poles, and a $10 \%$ reduction in strength for kiln drying below $79^{\circ} \mathrm{C}$.

Thus, the designated fibre stress value that may be used for plantation-grown Eucalyptus was calculated using Equation 1:

Fibre stress = 'Characteristic' MOR x $1.08 \times 1.16$ x $0.90 \mathrm{~N} / \mathrm{mm} 2$

\section{RESULTS AND DISCUSSIONS}

Table 1: MOE/MOR at Moisture Content of 14\% determined for individual trees

Tree ID MOE (N/mm2) MOR (N/mm2)


Proceedings of the $\mathbf{2 0 2 0}$ Society of Wood Science and Technology International Convention

\begin{tabular}{lllll}
\hline & Mean & St. Dev. & Mean & St. Dev. \\
G1 & 12251 & 1787.44 & 97.28 & 13.50 \\
H10 & 11427 & 1120.71 & 81.15 & 8.61 \\
K1 & 12098 & 1513.58 & 87.93 & 7.80 \\
W2 & 13310 & 1279.21 & 94.48 & 8.15 \\
Z16 & 10818 & 1384.04 & 84.52 & 10.81 \\
Mean & $\mathbf{1 1 , 9 8 0}$ & $\mathbf{1 4 1 6 . 9 9}$ & $\mathbf{8 9 . 0 7}$ & $\mathbf{9 . 7 7}$ \\
\hline
\end{tabular}

Table 2: MOE/MOR at Moisture Content of 14\% determined for each section of each tree

\begin{tabular}{llllllll}
\hline $\begin{array}{l}\text { Tree } \\
\text { ID }\end{array}$ & \multicolumn{3}{c}{ MOE $(\mathbf{N} / \mathbf{m m})$} & \multicolumn{3}{c}{ MOR (N/mm2) } \\
\hline G1 & & BUTT & MID & TOP & BUTT & MID & TOP \\
& Mean & 11629 & 12477 & 12295 & 90.89 & 96.63 & 98.59 \\
& St. Dev. & 1884.77 & 1756.52 & 1632.59 & 18.30 & 13.42 & 14.24 \\
H10 & Mean & 11042 & 11633 & 11607 & 76.28 & 80.57 & 86.59 \\
& St. Dev. & 1355.34 & 822.12 & 1073.38 & 9.74 & 5.86 & \\
K1 & Mean & 12053 & 12290 & 11950 & 87.57 & 91.35 & 84.88 \\
& St. Dev. & 1688.42 & 1667.27 & 1191.28 & 6.51 & 8.48 & 7.26 \\
W2 & Mean & 13604 & 13171 & 13105 & 98.88 & 91.48 & 92.80 \\
& St. Dev. & 1220.83 & 1439.97 & 1255.36 & 7.18 & 6.92 & 8.59 \\
Z16 & Mean & 10565 & 10808 & 11079 & 77.37 & 85.43 & 90.78 \\
& St. Dev. & 1119.04 & 1906.96 & 959.35 & 8.70 & 10.05 & 9.50 \\
\hline
\end{tabular}

Table 3: Tukey Test on Section of all 5 trees combined

\begin{tabular}{|c|c|c|c|c|c|c|}
\hline \multirow{2}{*}{$\begin{array}{l}\text { Sectional } \\
\text { Comparison }\end{array}$} & \multicolumn{3}{|l|}{ MOE } & \multicolumn{3}{|l|}{ MOR } \\
\hline & $\begin{array}{l}\text { Sample } \\
\text { Size }\end{array}$ & Sig. & p-value & $\begin{array}{l}\text { Sample } \\
\text { Size }\end{array}$ & Sig. & p-value \\
\hline MID -BUTT & 200 & 0 & 0.36 & 200 & 0 & 0.26 \\
\hline
\end{tabular}


Proceedings of the $\mathbf{2 0 2 0}$ Society of Wood Science and Technology International Convention

\begin{tabular}{lllllll}
\hline TOP-BUTT & 200 & 0 & 0.56 & 200 & 0 & 0.06 \\
TOP-MID & 200 & 0 & 0.89 & 200 & 0 & 0.72 \\
\hline
\end{tabular}

*Sig. equals 1 indicates that the difference of the means is significant at 0.05 level

*Sig. equals 0 indicates that the difference of the means is not significant at the 0.05 level

Table 3 above indicates that the p-value of the one-way ANOVA is higher than 0.05 in all cases. This suggest that the MOE and MOR of the sections representing tree IDs G1, H10, K1, W2 and Z16 are not significantly different at $p<0.05$. This suggests the means of the section for the 5 trees are not significantly different. This is an indication that the mechanical strength of the Eucalyptus specie extracted from MIRO i.e. the MOE and MOR is uniformly distributed along the height of the trees.

Table 4: Tukey Test on Tree by tree comparison

\begin{tabular}{|c|c|c|c|c|c|c|}
\hline \multirow{2}{*}{$\begin{array}{l}\text { Section } \\
\text { ID }\end{array}$} & \multicolumn{3}{|l|}{ MOE } & \multicolumn{3}{|l|}{ MOR } \\
\hline & $\begin{array}{l}\text { Sample } \\
\text { Size }\end{array}$ & Sig.* & p-value & $\begin{array}{l}\text { Sample } \\
\text { Size }\end{array}$ & Sig.* & p-value \\
\hline H10-G1 & 120 & 1 & 0.011 & 120 & 1 & 0.000 \\
\hline K1-G1 & 120 & 0 & 0.996 & 120 & 1 & 0.001 \\
\hline K1-H10 & 120 & 1 & 0.032 & 120 & 1 & 0.004 \\
\hline W2-G1 & 120 & 1 & 0.001 & 120 & 0 & 0.933 \\
\hline W2-H10 & 120 & 1 & 0.000 & 120 & 1 & 0.000 \\
\hline W2-K1 & 120 & 1 & 0.003 & 120 & 1 & 0.003 \\
\hline Z16-G1 & 120 & 1 & 0.002 & 120 & 1 & 0.007 \\
\hline Z16-H10 & 120 & 0 & 0.534 & 120 & 0 & 0.273 \\
\hline Z16-K1 & 120 & 1 & 0.002 & 120 & 0 & 0.547 \\
\hline Z16-W2 & 120 & 1 & 0.000 & 120 & 1 & 0.004 \\
\hline
\end{tabular}

*Sig. equals 1 indicates that the difference of the means is significant at 0.05 level *Sig. equals 0 indicates that the difference of the means is not significant at the 0.05 level

Comparing tree by tree, the Tukey Test suggest that trees K1-G1 and Z16-H10 were not significantly different whereas the rest of the rest of the 8 pairs shows significant difference among their mean differences for the MOE. The MOR of W2-G1, Z16-H10 and Z16-K1 however, were not significantly different whilst the other pairs showed significant differences.

Table 5: Comparison of Eucalyptus hybrid from MIRO to other Eucalyptus species in other geographical locations.

\begin{tabular}{lllllll}
\hline Species & & $\begin{array}{l}\text { Age } \\
\text { (years) }\end{array}$ & $\begin{array}{l}\text { MOE } \\
(\mathbf{N m m - 2})\end{array}$ & $\begin{array}{l}\text { MOR } \\
(\mathbf{N m m - 2})\end{array}$ & $\begin{array}{l}\text { M.C. } \\
\text { \% }\end{array}$ & Year \\
\hline Eucalyptus hybrid & $\begin{array}{l}\text { Ghana } \\
\text { (MIRO) }\end{array}$ & 4 & 11980 & 89.15 & 12 & 2018 \\
& & & & & & \\
\hline
\end{tabular}


Proceedings of the $\mathbf{2 0 2 0}$ Society of Wood Science and Technology International Convention

\begin{tabular}{|c|c|c|c|c|c|c|}
\hline Eucalyptus umbra & Brazil & 28 & 14310 & 84.10 & 12 & $\begin{array}{l}\text { Marta et al, } \\
2018\end{array}$ \\
\hline Eucalyptus grandis & Uganda & - & 8207 & 33.90 & 12 & $\begin{array}{l}\text { Zziwa et al, } \\
2010\end{array}$ \\
\hline Eucalyptus marginata & Asia & - & 13000 & 111.70 & 12 & $\begin{array}{l}\text { David et al, } \\
1999\end{array}$ \\
\hline $\begin{array}{l}\text { Eucalyptus } \\
\text { clones }\end{array}$ & Argentina & 9 & 15491-19947 & 89-116 & 12 & $\begin{array}{l}\text { Acosta et al, } \\
2003\end{array}$ \\
\hline Eucalyptus genotypes & Argentina & $13-17$ & $13924-24015$ & $97-143$ & 12 & $\begin{array}{l}\text { Acosta et al, } \\
2003\end{array}$ \\
\hline
\end{tabular}

Table 5 above shows the MOEs and MORs of different species of eucalyptus around the world. Twenty-eight (28) year old trees of Eucalyptus umbra from Brazil have been established to have MOE of $14310 \mathrm{~N} / \mathrm{mm} 2$ and MOR of $84.10 \mathrm{~N} / \mathrm{mm} 2$. Eucalyptus grandis from Uganda has MOE of $8207 \mathrm{~N} / \mathrm{mm}_{2}$ and MOR of $33.90 \mathrm{~N} / \mathrm{mm} 2$. Eucalyptus marginata from Asia has MOE of 13000 $\mathrm{N} / \mathrm{mm} 2$ and $111.70 \mathrm{~N} / \mathrm{mm}_{2}$ for MOR. However, Eucalyptus hybrids clones and Eucalyptus genetotypes from Argentina have MOE and MOR values ranging from 13924 N/mm2 - 24015 $\mathrm{N} / \mathrm{mm}_{2}$ and $89 \mathrm{~N} / \mathrm{mm}_{2}-143 \mathrm{~N} / \mathrm{mm} 2$ respectively depending on the age. According to Acosta et al (2003), the strength properties increased with age from 13 years to 17 years for the Eucalyptus genotypes.

The 4-year-old Eucalyptus hybrid from MIRO Forestry Plantations recorded mean MOE and MOR values of $11980 \mathrm{~N} / \mathrm{mm} 2$ and $89.15 \mathrm{~N} / \mathrm{mm} 2$ respectively which were higher than Eucalyptus grandis and competes well with some other species from Brazil, Asia and Argentina.

\section{Fibre Stress}

The 'characteristic' MOR value is calculated using Equation 2 below:

$$
\text { MORP5\% }(\text { green })=\text { MORmean }-1.96 \sigma n-1
$$

MORP5\% $($ green $)=89.07-1.96(9.77)=69.92 \mathrm{~N} / \mathrm{mm} 2$

From the characteristic MOR value of $69.92 \mathrm{~N} / \mathrm{mm} 2$, the fibre stress is calculated unsing Equation 1:

Fibre stress = 'Characteristic' MOR x $1.08 \times 1.16 \times 0.90 \mathrm{~N} / \mathrm{mm} 2$

$=69.92 \times 1.08 \times 1.16 \times 0.90$

$=78.84 \mathrm{~N} / \mathrm{mm} 2$

The mean modulus of rupture (MOR) for small clear specimens of plantation-grown Eucalyptus was $89.07 \mathrm{~N} / \mathrm{mm}_{2}$ at a moisture content of $14 \%$, and after making allowances for the effects of the variability of wood, the 'characteristic' MOR obtained was $69.92 \mathrm{~N} / \mathrm{mm} 2$. Adjustment factors made on the 'characteristic' MOR to cover change from small clear bending strength to full-size pole strength, change in moisture content due to drying of in-service poles, and pre-treatment conditioning effects led to a designated fibre stress value of $78.84 \mathrm{~N} / \mathrm{mm} 2$. 


\section{CONCLUSIONS}

The longitudinal comparison of the individual trees suggests uniform distribution of strength (MOE/MOR) along the tree height from Bottom to the Top. Sectional (longitudinal comparison) for all the 5 trees equally suggests uniform distribution of the species of Eucalyptus extracted from MIRO plantations.

Inter tree comparison, however, suggests significant differences among their mean difference. Adjustment factors was made on the 'characteristic' MOR to cover change from small clear bending strength to full-size pole strength, has led to a designated fibre stress value of 78.84 $\mathrm{N} / \mathrm{mm} 2$. The strength properties of plantation-grown Eucalyptus species coupled with the estimated fibre stress render it suitable for use as poles for electric support lines.

\section{ACKNOWLEDGEMENTS}

We are grateful to MIRO Forestry Limited and Asuboa Wood Treatment Limited for providing funds for the study. Many thanks to the Director and staff of the Forestry Research Institute of Ghana (CSIR-FORIG) for the support in conducting the study at the Wood and Furniture Testing Centre at CSIR -FORIG.

\section{REFERENCES}

Acosta, M, Ciro, M, Lima, J (2015) Wood Technologies and Uses of Eucalyptus Wood from Fast Growing Plantations for Solid Products. Proceedings of the 51st International Convention of Society of Wood Science and Technology November 10-12, 2008 Concepción, CHILE. pp.6

ANSI (1997) ANSI 05.1 - American National Standard for wood poles - Specifications and dimensions. American National Standards Institute, Inc. New York, N.Y., USA. 28pp.

Doran, JC, Wongkaew, W (2008) Eucalyptus camaldulensis Dehnh. [Internet] Record from PROTA4U. Louppe, D., Oteng-Amoako, A.A. and Brink, M. (eds.) PROTA (Plant Resources of Tropical Africa), Wageningen, Netherlands. http://www.prota4u.org/search.asp. Accessed 6th October 2017.

Green, DW, Winandy, JE, Krestschmann, DE (1999) Mechanical properties of wood. Wood handbook- Wood as an Engineering Material. Gen. Tech. Rep. FPL-GTR-113. Madison, WI: U.S. Department of Agriculture, Forest Service, Forest Products Laboratory. 463 p.21

Loulidi, I, Famiri, A, Chergui, M, Elghorba, M (2012) The physical and mechanical properties of Eucalyptus hybrid E. camaldulensis $\mathrm{x}$ E. grandis: Comparison with its parental species. International Journal of Engineering and Science Vol. 1, Issue 1 (August 2012), pp. 01-07. ISSN: 2278-4721.

Marta, CJAN, Almeida, DH, Vasconcelos, JS, Almeida, TH, Araújo, VA, Christoforo, AL, Lahr, FAR (2018) Properties of Eucalyptus umbra Wood for Timber Structures. International Journal of 
Material Engineering. Scientific \& Academic Publishing, p-ISSN: 2166-5389 e-ISSN: 2166-5400. 2018; 8(1): 12-15.

Ofori, J, Annan, M, Amoako, KA (2008) Suitability of using plantation grown Nauclea diderrichii merill poles for electricity and telecommunication overhead support in Ghana-Part1: Sapwood width and dimension table. Ghana Journal of forestry, vol 23 and 24, p.1-14.

Santos, PET, Geraldi, IO, Garcia, JN (2004) Estimates of genetic parameters of wood traits for sawn timber production in Eucalyptus grandis. Genetics and Molecular Biology, 27, 4, 567-573. Wolfe, RW, Bodig, J, Lebow, PK (2001) Derivation of Nominal strength for Wood Utility poles. General Technical Report FPL-GTR-128. U.S. Department of Agriculture, Forest Service, Forest Products Laboratory, Madison, WI., USA. 11p.

Zziwa, A, Ziraba, YN, Awakali, JA (2010) Strength properties of selected Uganda Timbers. International Wood Products Journal. Vol 1, p.24

Biography 
Proceedings of the 2020 Society of Wood Science and Technology International Convention

\title{
Increasing Cold Tack of pMDI resin with Partial Soy Flour Substitution
}

\author{
Osei Asafu-Adjaye, Auburn University, USA \\ oaa0014@auburn.edu
}

\begin{abstract}
Polymeric diphenyl methane diisocyanate's (pMDI) high moisture tolerance, less resin application, shorter pressing time, and low curing temperature makes it one of the most important adhesives in the wood composite industry. However, pMDI is expensive and its utilization in particle board production is limited because resinated wood particles from pMDI have less tackiness leading to unstable pre-mats and subsequently loss of material. Partial substitution of pMDI with soy was investigated to improve the cold tack without compromising the panel properties. The tack of pMDI substituted soy formulations were measured with a modified ASTM technique (ASTM, 2017). The mechanical and physical properties of particle boards from the pMDI-soy system was assessed. Partial substitution of pMDI resin with soy flour increases the cold tack of the resin to the level achieved by urea formaldehyde resin. The substituted soy improved the panel properties. The tack can be fine-tuned by adjusting the amount of soy flour added.

The increase in tack is caused by the reaction of the isocyanate resin with the water contained in soy flour as well as with hydroxyl and other groups present in soy flour components. The higher cold tack should increase the stability of pre-mats, especially in particleboard manufacturing.
\end{abstract}

Biography 


\title{
Proceedings of the 2020 Society of Wood Science and Technology International Convention
}

\section{Adhesive Bonding of Planed and Sawn Jointed Sugar Maple Lumber: Bending Strength of Glued Joints}

\author{
Mohammadali Azadfar \\ azadfam@morrisville.edu \\ Benjamin Burns \\ burns236@morrisville.edu \\ Gifford Timian \\ timian039@morrisville.edu
}

State University of New York, College of Agriculture and Technology at Morrisville, NY, USA

\section{Abstract}

The sugar maple is one of the most important trees in the eastern United States and is the state tree of New York. Sugar maple is also known as hard maple and is the most frequently used species of maple for glue-jointed wood products. However, a surface quality suitable for the glue-jointing process is influenced by machining wood using circular table saw and jointer machines. The main objective of this study was to evaluate the strength of the glue lines in glued-jointed planed and sawn hard maple lumber. The pieces of wood were prepared by using a circular table saw and a jointer machine. First, the difference between the interaction with the wood glue on both the saw-cut and jointed substrates was observed. For example, using microscopic techniques, the results showed that more than $60 \%$ adhesive penetrated into the planed surface of hard maple after 10 minutes as compared with sawn maple with the same range of the moisture content. Then, the bending strength of maple lumber with a sawn edge and jointed edge glue joint was evaluated in accordance with the ASTM standard procedures. We present evidence that the breaking point of glue lines in the planed joints is considerably higher than sawn joints, indicating better adhesive bonding during the glue-jointing process.

\section{Biography}




\title{
The Influence of Oil Uptake on Moisture Excluding Efficiency in Thermally Treated Wood
}

\author{
Jan Baar1*-Petr Čermák2
}

1 Assistant Professor, Ph.D., Mendel University in Brno, Brno, Czech Republic

* Corresponding author

jan.baar@mendelu.cz

2 Assistant Professor, Ph.D., Mendel University in Brno, Brno, Czech Republic

petr.cermak.und@mendelu.cz.

\begin{abstract}
Thermal modification of wood is an environmentally friendly method for the improvement of wood water related properties - hygroscopicity reduction, dimensional stability and resistance against fungal degradation - which uses steam, nitrogen or oil as the heat transfer and oxygen excluding medium. High oil retention was proved during treatment in hot oil, especially when permeable wood species were used or the wood was kept to cool in oil bath. For comparison, hemp oil impregnated, and heat treated $\left(200^{\circ} \mathrm{C}\right)$ European beech wood samples were prepared, and the combined treatment was used as well. After the treatment, the samples were held in standard conditions and above the water level. The equilibrium moisture content was lower in all treatments compared to untreated beech and all treatments showed good moisture excluding efficiency, especially in short-term exposure. The combined treatment reduced the wood hygroscopicity the most with moisture excluding efficiency of $27 \%$ for saturated air. However, there are two issues which can influence the moisture content measurement in oil treated wood - increase in sample density/weight related to oil uptake after treatment and weight change caused by oxygen bonding during spontaneous drying process at the time of sample conditioning.
\end{abstract}

Key words: beech, moisture content, hemp oil, heat treatment, oxidation 


\section{Introduction}

Thermal modification of wood is an environmentally friendly method for improving wood moisture-related properties and the resistance against decay (Hill 2011). The process is based on use of a relatively high temperature $\left(160-260^{\circ} \mathrm{C}\right)$ in oxygen free environment resulting in the degradation of some of the cell wall components (Navi and Sandberg 2012). The most affected hemicelluloses undergo dehydration reactions associated with a decrease in hydroxyl (-OH) groups. The chemical and structural changes lead to reduction of wood equilibrium moisture content and improvement of dimensional stability and decay resistance (Allegretti et al. 2012, Welzbacher et al. 2008; Candelier et al. 2016).

The oxygen exclusion is achieved by different methods - heat treatment in steam, nitrogen atmosphere, or vegetable oil. The last mentioned acts not only as oxygen-excluding but also as heat-transfer medium (Sailer et al. 2000; Wang and Cooper 2005). Bal (2015) concluded that oil heat treatment is more efficient in water-related wood properties improvement in comparison with the hot air, due to the synergy effect of oils and heat, but marked an excessive oil uptake as a negative issue associated with this method. Thermal modification is usually closely linked with mass loss, which is considered as an indicator of treatment quality. However, oil heat treatment typically leads to weight increase due to oil uptake, which is very variable and depends on the period of heating, the final temperature, the permeability of wood species, sample cooling (in or outside a bath) or the sample size. For example, Jones et al. (2005) showed the indirect dependency of oil uptake on the longitudinal length of Sitka spruce samples. Karlsson et al. (2011) or Awoyemi et al. (2009) proved the effect of way of cooling on oil uptake, when significantly higher uptake was observed during cooling in oil bath. Many other authors stated variable mass increases ranging from units of percent up to $90 \%$, depending on wood species and the methodology used (Table 1). Generally, only the highest temperature for sufficiently long time caused mass loss of wood (e.g. $210^{\circ} \mathrm{C} / 6 \mathrm{~h}$; Dubey et al. 2012). If oil is used as protective agent itself, high retention and deep impregnation of oil into wood structure are required in order to provide long-term performance in outdoor conditions (Sailer and Rapp 2001), but these requirements lead to the unwanted weight increase at the same time. Further, as a result of high retention, scarcity of oxygen inside the wood prevents oxidation (i.e. polymerisation or drying of oil) thus forcing the liquid unpolymerised oil, which is not bonded to the main structural compounds in the wood cell wall, to exude from wood, especially when wood is heated during its use (Terziev and Panov 2010). 
Proceedings of the 2020 Society of Wood Science and Technology International Convention

Table 1: The overview of oil uptake during oil heat treatment process with related experiment parameters

\begin{tabular}{|c|c|c|c|c|c|c|}
\hline source & wood species & cooling & $\begin{array}{c}\text { temperature } \\
\left({ }^{\circ} \mathrm{C}\right)\end{array}$ & time $(\mathrm{h})$ & $\begin{array}{c}\text { length } \\
(\mathrm{mm})\end{array}$ & $\begin{array}{c}\text { WPG } \\
(\%)\end{array}$ \\
\hline Sailer et al. (2000) & Pinus sylvestris (SW) & in & $180,200,220$ & 4.5 & 10 & $45-70$ \\
\hline Lacić et al. (2014) & Alnus glutinosa & out & 180,200 & 6,10 & 300 & $4-9$ \\
\hline Bazyar (2012) & Populus tremula & out & $190,205,220$ & $4.5,6$ & 20 & $\sim 85$ \\
\hline $\begin{array}{l}\text { Wang and Cooper } \\
(2005)\end{array}$ & Picea glauca & - & 200,220 & 2,4 & 10 & $10-25$ \\
\hline $\begin{array}{l}\text { Karlsson et al. } \\
(2011)\end{array}$ & $\begin{array}{l}\text { Pinus sylvestris }(\mathrm{SW}) \\
\text { P. sylvestris }(\mathrm{HW}) \\
\text { P. tremula } \\
\text { Picea abies } \\
\text { P. sylvestris }(\mathrm{SW}) \\
\text { P. sylvestris }(\mathrm{HW}) \\
\text { P. tremula } \\
\text { Picea abies }\end{array}$ & out & $180,210,240$ & $0.5,1,2$ & 150 & $\begin{array}{l}75-98 \\
4-17 \\
48-88 \\
8-20 \\
-3-7 \\
-16-3 \\
-6-20 \\
-5-6 \\
\end{array}$ \\
\hline Spear et al. (2006) & $\begin{array}{l}\text { Pinus nigra } \\
\text { Picea abies } \\
\text { Pinus nigra } \\
\text { Picea abies }\end{array}$ & out & 180,200 & 3 & $\begin{array}{l}50 \\
120\end{array}$ & $\begin{array}{l}90-100 \\
\sim 12 \\
87-106 \\
\sim 7\end{array}$ \\
\hline Bal (2015) & Fagus orientalis & in & $160,190,220$ & 2 & 30 & $58-70$ \\
\hline $\begin{array}{l}\text { Awoyemi et al. } \\
(2009)^{*}\end{array}$ & $\begin{array}{l}\text { Pinus ponderosa } \\
\text { Picea mariana } \\
\text { Pinus ponderosa } \\
\text { Picea mariana }\end{array}$ & $\begin{array}{l}\text { in } \\
\text { out }\end{array}$ & 220 & 2 & 150 & $\begin{array}{l}\sim 90 \\
\sim 11 \\
\sim 9 \\
\sim 6 \\
\end{array}$ \\
\hline Dubey et al. (2012) & Pinus radiata & in & $160,180,210$ & $1,3,6$ & 300 & $-2-14$ \\
\hline
\end{tabular}

* oil uptake measured in $5 \mathrm{~mm}$ thick surface layer

The above-mentioned proves that the oil uptake is a variable parameter, but has always resulted in significantly higher weight/density of samples, which can distort results and influence the interpretation of moisture content of treated wood, since it is based on weight change calculation. Bal (2015) compared selected physical properties of hot oil and air treated beech wood and concluded that oil treated ones reached half values of the equilibrium moisture content compared to those air treated under the same conditions. Due to the oil uptake, the sample weight of the compared samples differed by about $60 \%$. Higher efficiency of oil heat treatment can be only apparent and similar amount of water can be absorbed under the same conditions. Therefore, the main objective of this study was to determine how the oil uptake influences the amount of absorbed water and moisture excluding efficiency and if the state of oil (polymerized vs. liquid) can affect the final performance of modified wood. 


\section{Materials \& Methods}

\section{Material}

European beech (Fagus sylvatica L.) wood samples, defect-free, with dimensions $20 \times 20 \times 300$ $\mathrm{mm} 3(\mathrm{R} \times \mathrm{T} \times \mathrm{L})$ was used during the treatment; the samples for hygroscopicity test were cut later from the ends of these samples. The samples were sorted into four groups with similar average dry density - $638 \mathrm{~kg} / \mathrm{m} 3$ - the reference (REF), hemp oil impregnated (OI), thermally modified (TM), and hemp oil impregnated and thermally modified (OI + TM).

\section{Impregnation and thermal modification}

The samples (OI, OI+TM) were vacuum (10 kPa) impregnated with natural hemp oil (O 1000, Hemp production $\mathrm{CZ}$ s.r.o.) for $2 \mathrm{~h}$ using a laboratory plant JHP1-0072. Weight percentage gain (WPG; \%) was expressed as a ratio of mass difference caused by the impregnation and the original specimen mass.

OI+TM and TM samples were further thermal modified using a small-scale laboratory heattreatment chamber (Katres spol. s r.o., CZ) at $200^{\circ} \mathrm{C}$ within steam environment. The whole process including heating and cooling phases took 6.5 hours, whereas the modification temperature $200^{\circ} \mathrm{C}$ was maintained for 3 hours. The modification degree was determined by mass loss (ML; \%), based on oven-dry $\left(103 \pm 2{ }^{\circ} \mathrm{C}\right.$ for $48 \mathrm{~h}$ ) mass before and after the thermal modification process divided by the original oven-dry mass.

\section{Wood hygroscopicity}

The samples $(20 \times 20 \times 45 \mathrm{~mm} 3 ; \mathrm{R} \times \mathrm{T} \times \mathrm{L})$ were oven dried $\left(103^{\circ} \mathrm{C}\right)$, cooled in desiccator and weighed at $0 \%$ moisture content (MC). A half of the specimens were exposed to standard conditions $\left(20^{\circ} \mathrm{C}, 65 \%\right)$, the rest were held above the water level $\left(20^{\circ} \mathrm{C}, \sim 100 \%\right)$. The water vapour absorption was controlled by regular weighing till wood moisture content reached steady state. The moisture excluding efficiency was calculated according to Equation (1):

$$
M E E=\left(\frac{m_{u}-m_{t}}{m_{u}}\right) \times 100(\%)
$$

where $\mathrm{mu}_{\mathrm{u}}$ is $\mathrm{MC}(\%)$ of the untreated specimens $(\%)$ and $\mathrm{mt}_{\mathrm{t}}$ is $\mathrm{MC}$ of the treated specimens (\%). Both of MC were determined according to Equation (2):

$$
m_{u} \text { or } m_{t}=\left(\frac{m_{w}-m_{0}}{m_{0}}\right) \times 100(\%)
$$

where $\mathrm{m}_{0}$ is sample oven dry weight before test $(\mathrm{g})$ and $\mathrm{m}_{\mathrm{w}}$ is the sample weight after exposition for a specific period $(\mathrm{g})$.

\section{Oil hygroscopicity}

Three vessels (diameter of $5 \mathrm{~cm}$ ) were filled with $1 \mathrm{~g}$ of hemp oil. Samples were dried for $45 \mathrm{~min}$ $\left(103^{\circ} \mathrm{C}\right)$ and weighed. Vessels with oil were held under conditions of $97 \%$ and $20^{\circ} \mathrm{C}$ (saturated solution of $\mathrm{K}_{2} \mathrm{SO}_{4}$ ) and were regularly weighed to determine the mass change.

\section{Results and Discussion}




\section{Wood impregnation and modification}

Wood thermal treatment is a modification process typically with ML, which is a sort of an indicator of this treatment quality. In our experiment, ML of beech wood was around $2.5 \%$ (Table 2, which is in agreement with Ferrari et al. (2013), who showed similar ML (3\%) of the same wood in thermo-vacuum process after $200^{\circ} \mathrm{C}$ and 3 hours of treatment. The ML of oil impregnated wood was significantly higher (16\%), which is mainly caused by unpolymerized oil exudation and its partial thermal degradation during treatment. We can assume mass loss of wood substance similar to non-impregnated wood and loss of about one half of present hemp oil (approx. $140 \mathrm{~kg} / \mathrm{m} 3$ ). The WPGs after oil impregnation are also presented in Table 2. Oil uptake led to density increase up to more than $1000 \mathrm{~kg} / \mathrm{m} 3$ in oil impregnated samples. Final density of impregnated and subsequently heat treated samples was lower due to a substantial oil loss.

Table 2: Samples oven dry density, mass loss after thermal treatment and weight percentage gain of oil (REF untreated, TM - thermal modified, OI - oil impregnated, OI+TM - combined treatment; coefficient of variation in

\begin{tabular}{lccc}
\multicolumn{4}{c}{ parenthesis $)$} \\
\hline REF & $\rho_{0}\left(\mathrm{~kg} / \mathrm{m}_{3}\right)$ & WPG $(\%)$ & ML $(\%)$ \\
TM & $673(4.0)$ & - & - \\
OI+TM & $667(3.2)$ & - & $2.5(20.0)$ \\
OI & $844(6.2)$ & $51.2(11.5)$ & $16.1(21.1)$ \\
& $1055(3.7)$ & $61.1(13.2)$ & -
\end{tabular}

\section{Moisture excluding efficiency (MEE)}

The average values of equilibrium moisture contents of individual groups are stated in Table 3. The untreated beech wood under standard conditions reached moisture content of nearly $12 \%$, all treatments resulted in reduced MC. The most significant reduction was achieved by the combined process, in both performed tests. The decline of the number of hydroxyl groups due to polysaccharides degradation leading to a lower number of available sorption sites for water is a generally known reason for lower EMC of heat treated wood (Hill 2006). On the contrary, oil is not able to penetrate the cell wall due to its molecule size and therefore cannot modify its chemical structure, it only influences the rate of the moistening process as a physical barrier retarding the moisture transport in wood.

Table 3: Equilibrium moisture content and sample weight change of untreated and treated wood under different conditions (REF - untreated, TM - thermal modified, OI - oil impregnated, OI+TM - combined treatment, coefficient of variation in parentheses)

\begin{tabular}{lrrrr}
\hline & \multicolumn{2}{c}{$\left(20^{\circ} \mathrm{C}, 65 \%\right)$} & \multicolumn{2}{c}{$\left(20^{\circ} \mathrm{C}, \sim 100 \%\right)$} \\
\hline & EMC $(\%)$ & $m_{\text {water }}(\mathrm{g})$ & $\mathrm{EMC}(\%)$ & \multicolumn{1}{c}{ m $_{\text {water }}(\mathrm{g})$} \\
\hline TM & $9.5(2.1)$ & $0.74(5.4)$ & $23.7(8.3)$ & $1.78(10.1)$ \\
OI & $9.7(3.1)$ & $1.17(4.3)$ & $22.3(6.1)$ & $2.57(7.8)$ \\
OI+TM & $7.9(2.5)$ & $0.81(6.2)$ & $19.9(7.0)$ & $2.04(10.8)$ \\
Ref & $11.5(2.6)$ & $0.93(6.5)$ & $27.4(1.5)$ & $2.21(2.7)$ \\
\hline
\end{tabular}

The MEEs of treated beech wood and their change during exposition to saturated air condition are shown in Figure 1. A positive, high value of MEE means that the treated wood absorbs less moisture than the untreated wood thus indicating an improvement in terms of reduction in the moisture uptake through the wood treatment. Results showed that all treatments are more effective in short-term expositions, where combined process reached almost $60 \%$ reduction in moisture content compared to untreated wood. Nevertheless, after longtime exposure the MEE gradually 
decreased as treated wood was drawing near the equilibrium state; this process was significantly slower than in untreated wood as can be seen in Figure 2.

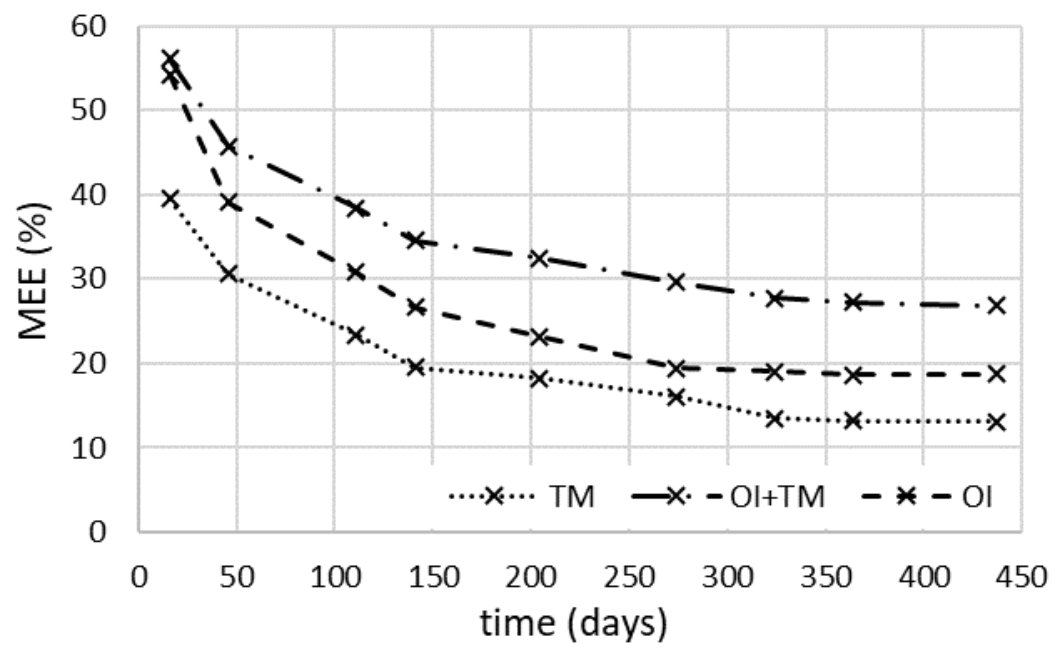

Figure 1. Moisture excluding efficiency of treated beech samples during exposition above water level (OI - oil impregnated, TM - thermally modified at $200{ }^{\circ} \mathrm{C}$, OI+TM - combined process)

Bazyar (2012), in line with results of other authors, stated that heat treatment in oil bath results in wood oil uptake usually higher than $20 \%$, whereas weight percentage gain is influenced by the sample size, wood species permeability or the cooling phase form. Bal (2015) compared the efficiency of heat treatment in hot air and oil and found out that all moisture related parameters are more significantly reduced in samples exposed to hot oil. For example, he reported $71.5 \%$ lower EMC for Oriental beech heat treated in hot oil at $220^{\circ} \mathrm{C}$ for 2 hours compared to untreated wood. At the same time, treated specimens weight increased by $64 \%$ due to oil uptake. From this point of view, our results are in accordance with general conclusions. Nevertheless, if we considered that oil heat treatment is connected with often substantial sample mass increase due to oil uptake, the value comparison can be misleading, because the counted moisture contents are related to the initial sample weight. In fact, the decrease in EMC can be just apparent due to the higher specimen weight caused by oil WPG. This fact often remained unmentioned or was not taken into consideration in former studies.

In our study, only heat treated wood showed a lower amount of water at the end of exposure in both expositions. The mass increase (expressed in $\mathrm{g}$ ) in the case of OI+TM specimens was comparable with the untreated ones. Oil impregnated specimens showed even a higher value, so we could conclude that even more water was absorbed by these samples during exposition. However, oil itself is not hygroscopic, so it could not be a cause of higher water absorption. There is another issue related to vegetable oils - drying process, when oils increased their mass due to oxidation - oxygen bonding. Tumosa and Mecklenburg (2003) showed that oxidation process is characterized by the initial steep weight increase later alternated with a gradual decrease due to loss of volatiles. The weight increase ranges between 8 and $12 \%$ depending on the type of drying (semi-drying) oil. In their study, the weight increase peak was reached between 10 to 30 days of exposure, but oxidation process can be slowed down by lack of oxygen in fully impregnated wood and/or high relative humidity of air. The mass increase of our hemp oil due to oxidation was not observed during the first 40 days in high humid conditions. The difference between reference and 
oil treated sample and analogically between heat treated and combined process treated samples is presumably related to oil oxidation, which occurs during conditioning of samples.

The above mentioned shows that measuring of EMC and related parameters in oil treated samples, especially with high oil loads, or even their comparison with other treatments efficiency can be incorrect and misleading.

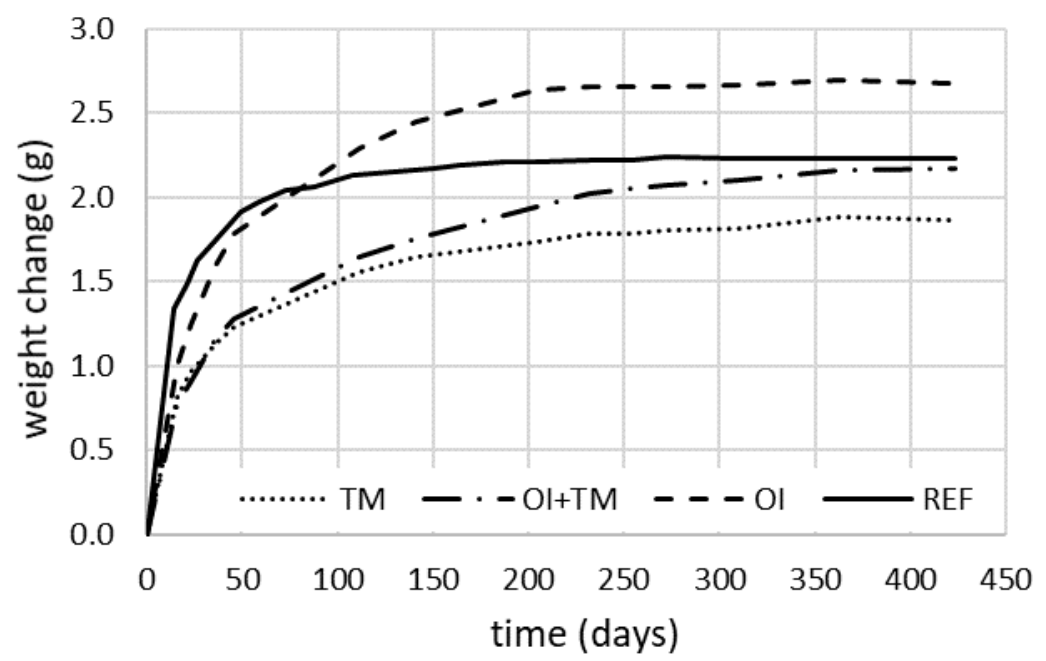

Figure 2. The sample weight change during exposition above water level (REF - untreated, OI - oil impregnated, $\mathrm{TM}$ - thermally modified at $200{ }^{\circ} \mathrm{C}$, OI+TM - combined process)

\section{Summary and Conclusions}

All used wood treatments led to lower equilibrium moisture content in comparison with reference samples in both environments - standard and fully saturated air. Moisture excluding efficiency was in short-term exposure between $40 \%$ (TM) and 55\% (OI); with an increasing time the MEE decreased. The absolute weight change after conditioning was higher in the samples containing oil. There are two issues which influence the interpretation of moisture content of oil treated wood - sample weight change due to oil uptake during impregnation and weight changes during samples conditioning due to oxygen uptake linked to oil drying process.

\section{Acknowledgements}

This work was financially supported by Grant Agency of the Czech Republic (GAČR), project no. 19-25171Y "Multi-scale Hygro-thermo-mechanical Behavior of Modified Wood-based Materials".

\section{References}


Allegretti O, Brunetti M, Cuccui I, Ferrari S, Nocetti M, Terziev N (2012) Thermo-vacuum modification of Spruce (Picea abies Karst.) and Fir (Abies alba Mill.) wood. BioResources 7:3656-3669.

Awoyemi L, Cooper PA, Ung TY (2009) In-treatment cooling during thermal modification of wood in soy oil medium: soy oil uptake, wettability, water uptake and swelling properties. European Journal of Wood and Wood Products 67:465-470.

Bazyar B (2012) Aspen decay \& oil heat treatment, BioResources 7:696-705

Ferrari S, Cuccui I, Allegretti O (2013) Thermo-vacuum modification of some European softwood and hardwood species treated at different conditions. BioResources 8:1100-1109.

Bal BC (2015) Physical properties of beech wood thermally modified in hot oil and in hot air at various temperatures. Maderas: Ciencia y Tecnología 17:789-798.

Candelier K, Thevenon FM, Petrissans A, Dumarcay S, Gerardin P, Petrissans M (2016) Control of wood thermal treatment and its effects on decay resistance: a review. Annals of Forest Science 73:571-583.

Dubey MK, Pang S, Walker J (2012) Oil uptake by wood during heat-treatment and post-treatment cooling, and effects on wood dimensional stability. European Journal of Wood and Wood Products 70:183-190.

Ferrari S, Cuccui I, Allegretti O (2013) Thermo-vacuum modification of some European softwood and hardwood species treated at different conditions. BioResources 8:1100-1109.

Hill CAS (2011) Wood modification: an update. BioResources 6:918-919.

Hill CAS (2006) Wood modification: Chemical, thermal and other processes. John Wiley \&Sons, Chichester

Jones D, Tjeerdsma BF, Spear M, Hill C (2005) Properties of wood following treatment with a modified hot oil. In: Militz H, Hill C (eds.) Wood modification: Processes, properties and commercialization. The second European conference on wood modification. Göttingen, Germany. Karlsson O, Sidorova E, Morén T (2011) Influence of heat transferring media on durability of thermally modified wood. BioResources 6:356-372.

Lacić R, Hasan M, Trajković J, Šefc B, Šafran B, Despot R (2014) Biological durability of oil heat treated alder wood. Drvna Industrija 65:143-150.

Navi P, Sandberg D (2012) Thermo hydro mechanical processing of wood. EPFL Press, Lausanne.

Sailer M, Rapp AO, Leithoff H, Peek RD (2000) Vergütung von Holz durch Anwendung einer Öl-Hitzebehandlung. Holz als Roh- und Werkstoff 58:15-22.

Sailer M, Rapp AO (2001) Use of Vegetable Oils for Wood Protection. In: Proc. of the COST Action E22 "Environmental Optimisation of Wood Protection", ISSN 0043-7719, pp. 1432-5225. Spear MJ, Hill CAS, Curling SF, Jones D, Hale MD (2006) Assessment of the envelope effect of three hot oil treatments: Resistance to decay by Coniophora puteana and Postia placenta. International Research Group on Wood Protection. Doc. No.: IRG/WP 06-40344.

Terziev N, Panov D (2011) Plant oils as "green" substances for wood protection. In: 4th international conference on environmentally-compatible forest products. Porto, Portugal, pp 143149.

Tumosa CS, Mecklenburg MF (2003) Weight changes on oxidation of drying and semi-drying oils. Collection Forum 18:116-123.

Wang JY, Cooper PA (2005) Effect of oil type, temperature and time on moisture properties of hot oil-treated wood. Holz als Roh- und Werkstoff 63:417-422. 
Proceedings of the 2020 Society of Wood Science and Technology International Convention

Welzbacher CR, Brischke C, Rapp OA (2007) Influence of treatment temperature and duration on selected biological, mechanical, physical and optical properties of thermally modified timber. Wood Material Science and Engineering 2:66-76.

Biography 


\title{
Proceedings of the 2020 Society of Wood Science and Technology International Convention
}

\section{Non-linear Material Model of Mechanical Behaviour of Oak Wood Exposed to Different Relative Humidity Conditions}

\author{
Martin Brabec \\ martin.brabec@mendelu.cz \\ Jaromir Milch \\ jaromir.milch@mendelu.cz \\ Jan Tippner \\ jan.tippner@mendelu.cz \\ Martin Sotner \\ xsotner@node.mendelu.cz \\ David Decky \\ david.decky@mendelu.cz \\ Petr Cermak \\ xcerma24@mendelu.cz
}

Department of Wood Science, Faculty of Forestry and Wood Technology, Mendel University in Brno, Czech Republic

\begin{abstract}
The mechanical performance of wooden structures or single timber elements is strongly influenced by ambient conditions. This should be taken into account when choosing a material for individual applications. Current assessment options offer more than experimental testing. A calibrated and experimentally verified numerical model capable to truly predict the reality is a very effective tool for the optimization of the material processing and utilization limits of products. This purpose requires the complete sets of material characteristics of wood with different equilibrium moisture content level. The literature overview proved that the relevant complete sets of material characteristics are rare but they can be collected from different studies. However such a collection process causes the inconsistency of material characteristics that makes such material models inaccurate and inapplicable in numerical modelling practise. Therefore, this study aims to reduce the lack of the calibrated material models of European oak (Quercus robur, L.) exposed to relative humidity range covering the common seasonal variability of ambient conditions. The elasto-plastic bi-linear material models include fully orthotropic elasticity and plasticity with non-linear isotropic hardening, where the compression-tension loading asymmetry in the plastic range (yield stresses and tangent moduli) is taken into account.

The mean relative errors (MRE) between the numerically predicted and experimentally measured mechanical behaviour of oak wood were minimized by the iterative calibration procedure, simultaneously for basic loading conditions such as compression, shear and bending. As the resulted MRE are lower than the natural variability in mechanical behaviour of wood (10-30\%) the predictive ability of the numerical models can be considered as excellent.
\end{abstract}

\section{Biography}


Proceedings of the 2020 Society of Wood Science and Technology International Convention

\author{
Building Your Social Media Presence \\ Candra Burns, Talking Forests, Germany \\ candra@talkingforests.com
}

\begin{abstract}
Candra Burns from Talking Forests will show you examples of how to build your social media presence in the oral presentation. In Instagram, she will show you how to research hashtags on Instagram and find the relevant ones, use the stories function on Instagram to create a buzz, how to follow hashtags and why, how to engage others with comments and questions. In Twitter, she will show you how to retweet other people's tweet, set up a 15 character tag/URL on this platform first, and research and use trending hashtags. In Facebook, she will show others how to create posts with links and photos and videos to share news about research. In LinkedIn, she will show others how to create a LinkedIn profile that will be your mobile resume.
\end{abstract}

Biography 


\title{
Development of technology for one-sided surface carbonization of wood
}

\author{
Petr Čermákl*-Jakub Döményl - Anna Oberle 1 - Dita Machová2 - Lucie \\ Zárybnická2 - Jakub Dohnal3-Veronika Vacenovská3
}

1 Department of Wood Science and Technology, Faculty of Forestry and Wood Technology, Mendel University in Brno, Czech Republic*xcerma24@mendelu.cz

2 Institute of Theoretical and Applied Mechanics of the Czech Academy of

Sciences, Department of Materials and Research, Centre of Excellence Telč, Czech

Republic

3 Brno University of technology, Faculty of Civil Engineering, Czech Republic

\begin{abstract}
One-sided surface charring of beech wood (Fagus sylvatica L.) was analyzed. Specimens were one-sided carbonized using contact heating system with a hot plate on the radial and tangential surface at various time-temperature regimes $\left(200 / 250 / 300 / 350\right.$ and $\left.400^{\circ} \mathrm{C}\right)$.

The degree of one-sided carbonization and its depth from modified surface was evaluated using temperature profiles, X-ray density profile and by spectrophotometric analysis of total carbohydrates at surface layers. An average total amount of carbohydrates of reference specimens was measured to be $0.75 \mathrm{mg} / \mathrm{g}$ of dry wood mass for specimens. Significant increase of soluble carbohydrates was found within surface layers of specimens carbonized at $400^{\circ} \mathrm{C}$ for 1 min and decreased with increasing distance from the heated surface. An average density $(680 \mathrm{~kg} \cdot \mathrm{m}-3)$ of reference specimens shows uniform density profile, while one-sided carbonized specimens tended to decrease according to time-temperature regime applied. It can be stated that one-sided carbonization affected wood properties to depth $2-4 \mathrm{~mm}$ from the surface, depending on used time-temperature regime. The very first results of current research project shows that beech wood also exhibits favorable results in terms of surface moisture related characteristics, but more detailed studies are needed to exploit potential of surface carbonization method for future use of beech wood. The process of wood surface carbonization can be optimized according to these results, regarding to desired material properties
\end{abstract}

Key words: contact heating; moisture behavior; surface modification; thermal degradation; wood carbonization; wood facades; wood charring; wood modification

\section{Introduction}

Due to environmental challenges that society is facing, material science and technology has been increasingly focusing on lignocellulose-based biopolymer materials such as wood. Wood is a lowcost, easy choice for outside façade of buildings. With proper care and maintenance, wooden façades are a lasting, low-impact option that are easy to recycle and dispose at the end of service life. However, wood is susceptible to weathering caused by UV-radiation, temperature and humidity changes. There has been a scientific effort to enhance wood to obtain materials that 
maintain their advantages over time and at the same time reduce their natural disadvantages such as variability, dimensional instability or biological decay (Rowell 2005; Kutnar and Muthu 2016). Wood modification allow reduction or even elimination of these disadvantages of wood and obtain better performance over the service life. Chemical, thermal and other treatments are commonly applied to wood resulting in permanent or temporary changes in wood properties (Militz 2000; Esteves and Pereira 2009; Hill 2011). Thermal treatment at elevated temperature has been considered as the most commercially successful and efficient way to decrease equilibrium moisture content (EMC) of wood and consequently improving its dimensional stability and biological resistance (Viitanen et al. 1994, Čermák et al. 2016). The main drawback of thermal treatment is low physical strength that prevents its use structural application (Syrjänen et al. 2000; Boonstra and Tjeerdsma 2006).

As an alternative to traditional thermal modification, wood could be modified only from the exposed surface(s), sparing time and costs and preserving the structural properties of wood (Gosselink et al. 2004; Kymäläinen et al. 2017 and 2018). One-sided surface charring has been traditionally utilized in Japan (Akizuki et al. 2001), where wood is burned with naked flame or a heated iron pad. So far, one-sided surface charring of beech wood at various time-temperature regimes using contact heating has not been scientifically investigated and knowledge about its performance is rather limited (Kymäläinen et al. 2017 and 2018, Čermák et al. 2020).

Beech wood is the most spread broadleaf species in forests of the Czech Republic. Its wood is a traditional material for wood-processing industry; however, potential of use is not fully utilized. In order to investigate the effect of one-sided carbonization on material properties of beech wood, several process parameters were tested and degree of carbonization analyzed. The results form a part of a project aiming to develop a new technique for beech wood modification with added value and improved performance.

\section{Materials \& Methods}

European beech (Fagus sylvatica L.) wood obtained from Czech forest enterprise was studied. Specimens of dimensions $50 \times 20 \times 350 \mathrm{~mm}$ were sorted into twenty-two groups with ten specimens in each group representing the orientation of carbonized surface, i.e. radial, tangential, and timetemperature regime (Tab. 1). Different time-temperature regimes were used in order to evaluate carbonization effect on the surface quality and its material properties.

Tab. 1: One-sided surface charring time-temperature regimes

\begin{tabular}{|c|c|c|c|c|}
\hline Temperature & Time 1 & Time 2 & \multicolumn{2}{c|}{ Annual ring orientation } \\
\hline Ref & - & - & $\mathrm{R}$ & $\mathrm{T}$ \\
\hline $200^{\circ} \mathrm{C}$ & $6 \mathrm{~min}$ & $20 \mathrm{~min}$ & $\mathrm{R}$ & $\mathrm{T}$ \\
\hline $250^{\circ} \mathrm{C}$ & $4 \mathrm{~min}$ & $6 \mathrm{~min}$ & $\mathrm{R}$ & $\mathrm{T}$ \\
\hline $300^{\circ} \mathrm{C}$ & $2 \mathrm{~min}$ & $4 \mathrm{~min}$ & $\mathrm{R}$ & $\mathrm{T}$ \\
\hline $350^{\circ} \mathrm{C}$ & $1 \mathrm{~min}$ & $2 \mathrm{~min}$ & $\mathrm{R}$ & $\mathrm{T}$ \\
\hline $400^{\circ} \mathrm{C}$ & $0,5 \mathrm{~min}$ & $1 \mathrm{~min}$ & $\mathrm{R}$ & $\mathrm{T}$ \\
\hline
\end{tabular}

Oven-dried specimens ( $0 \%$ MC) were one-sided carbonized using a laboratory hot plate (CERAN $33 \mathrm{SR} ; 450 \times 450 \mathrm{~mm})$ at atmospheric pressure on the radial $(\mathrm{R})$ and tangential $(\mathrm{T})$ surface. The degree of one-sided carbonization and its depth from modified surface was evaluated using temperature profiles, X-ray density profile and chemical analysis.

The temperature profile of one-sided surface carbonized specimens was continually measured for selected specimens using several $\mathrm{NiCr}-\mathrm{NiAl}$ thermocouples (type $\mathrm{K}$ ). In total, four measurements were used with the distance of 1,2,3 and $4 \mathrm{~mm}$ from the hot plate surface. The degree of thermal 
degradation of wood compounds was determined by the total carbohydrates at surface layers. Several thin layers of carbonized surface were prepared using microtome and grounded to obtain homogeneous mixture. The pre pared extract was used for subsequent spectrophotometric analysis of total carbohydrates. Furthermore, the reference along with the carbonized specimens of dimensions $50 \times 20 \times 50 \mathrm{~mm}$ were subjected to a density profile analysis. The conditioned specimens $\left(65 \% \mathrm{RH}\right.$ and $\left.20^{\circ} \mathrm{C}\right)$ were further measured using X-ray density profile analyzer (DPX300) with measuring step of $0.05 \mathrm{~mm}$.

\section{Results and Discussion}

First quantitative data from analytical technique providing results of total soluble carbohydrates for specimens carbonized at $400^{\circ} \mathrm{C}$ for $1 \mathrm{~min}$ and $200^{\circ} \mathrm{C}$ for $6 \mathrm{~min}$ (Fig. 1). According to this procedure the effective depth of carbonized surface can be evaluated. One-sided surface carbonization modifies the structure of wood cell wall polymers conferring new properties of the desire material. Thermal stability of the different polymers constitutive of wood differs according to the chemical structure. Hemicelluloses present a lower degree of polymerization and higher reactivity due to the amorphous structure, which are degraded first, followed by lignin and cellulose. The main results in Fig. 1 showed that the one-sided surface carbonization induced change in the soluble carbohydrates content of wood specimens. The most remarkable change was the quantitative increase of soluble sugars (including cellulose and glucose structural units of the hemicelluloses polymer), as a consequence of thermal degradation of wood compounds.

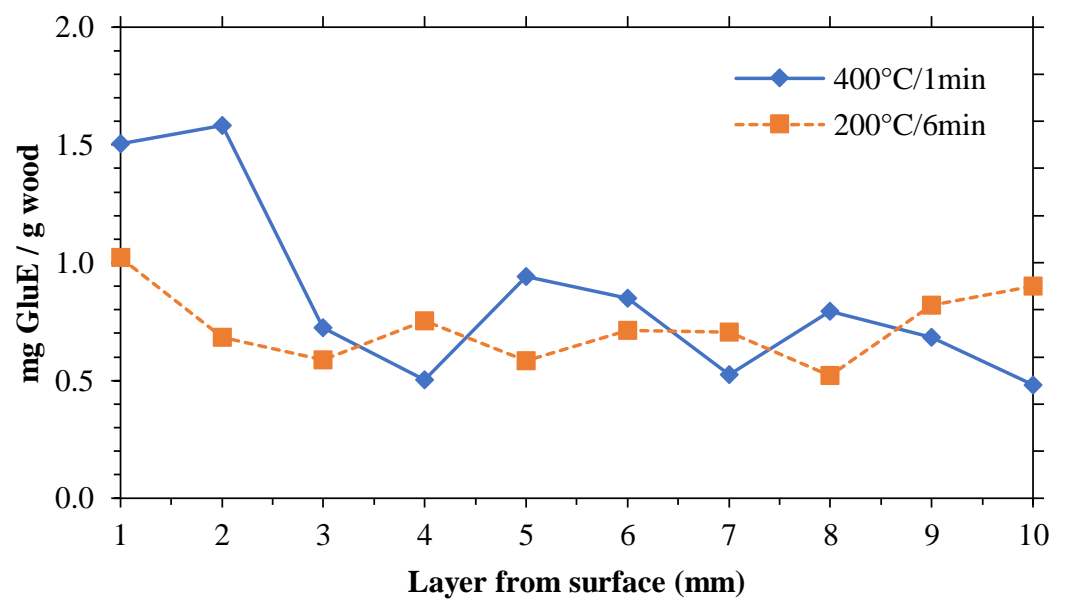

Fig. 1: Total amount of soluble carbohydrates $(\mathrm{mg} / \mathrm{g})$ within analyzed specimens $\left(400^{\circ} \mathrm{C} / 1 \mathrm{~min}\right.$ and $200^{\circ} \mathrm{C} / 6 \mathrm{~min}$ ) in various depth from charred surface

An average total amount of carbohydrates of reference specimens was measured to be $0.75 \mathrm{mg} / \mathrm{g}$ of dry wood mass for specimens. Due to the thermal degradation the sum of soluble carbohydrates increased significantly within surface layers of specimens carbonized at $400^{\circ} \mathrm{C}$ for 1 min and decreased with increasing distance from the heated surface. According to analyzed data, it can be assumed that one-sided carbonization at $400^{\circ} \mathrm{C}$ for $1 \mathrm{~min}$ affected material properties to minimum of $2-3 \mathrm{~mm}$ from the surface, while those at $200^{\circ} \mathrm{C}$ for 6 min only to maximum $1 \mathrm{~mm}$. This method can be further used for indication of depth affected by elevated temperature 


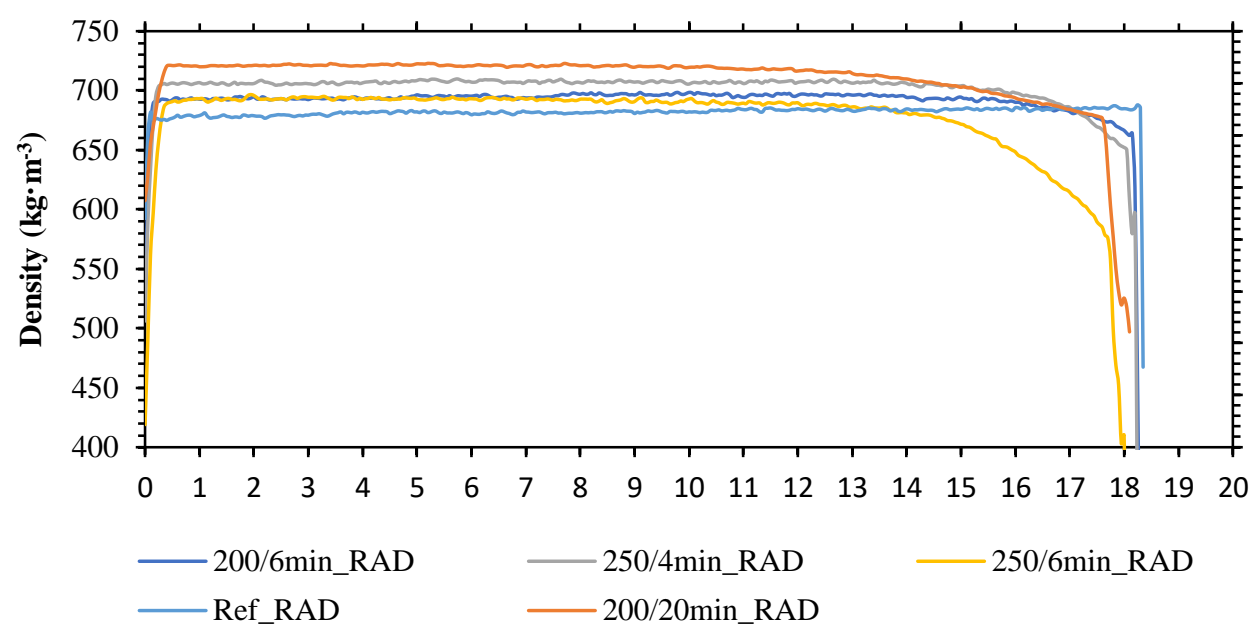

Fig. 2: Density profiles of reference and one-sided specimens carbonized at $200 / 250^{\circ} \mathrm{C}$

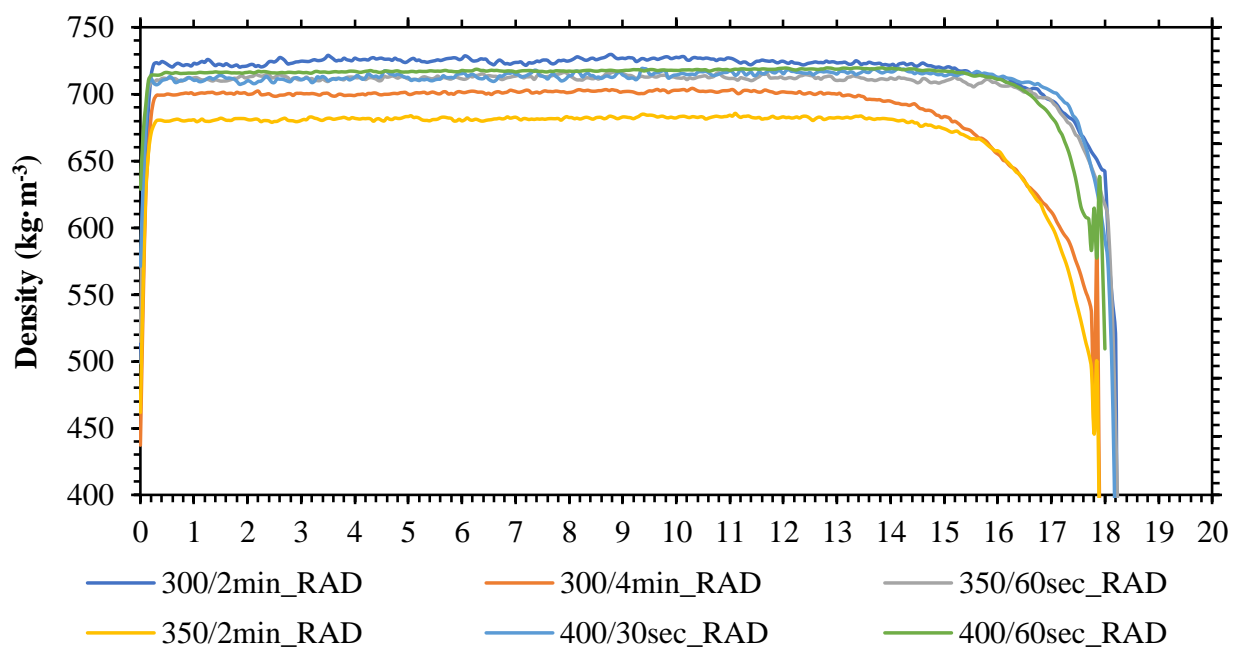

Fig. 3: Density profiles of specimens one-sided carbonized $300 / 350$ and $400^{\circ} \mathrm{C}$

Results of density profile measurements are shown in Fig. 2 and Fig. 3. Density profile represents density distribution over the cross section of tested specimens. An average density $(680 \mathrm{~kg} \cdot \mathrm{m}-3)$ of reference specimens shows uniform distribution, while one-sided carbonized specimens tended to decrease according to time-temperature regime applied. The process of wood surface carbonization can be optimized according to these results, regarding to desired material properties (color shade, moisture behavior, fire-resistance, etc.). According to the results it can be stated that one-sided surface carbonization decreased the surface density to minimum 2-4 $\mathrm{mm}$ from the surface, similarly as observed from spectrophotometric analysis.

\section{Summary and Conclusions}

The one-sided surface carbonization of beech wood (Fagus sylvatica L.) at various timetemperature regimes was studied. Chemical analysis provided total amount of soluble carbohydrates within various depth from carbonized surface. Significant increase of soluble carbohydrates as a result of thermal degradation of wood compounds, can be further used as tool for indication of depth affected by elevated temperature. These changes are closely related to 
severity of process (influence of duration) as well as specimen's annual rings orientation (influence of thermal conductivity). Furthermore, density profile measurements can be also used to evaluate degree of thermal degradation of surface layers. According to analyzed data, it can be assumed that applied one-sided carbonization affected material properties to minimum of $2-4 \mathrm{~mm}$ from the surface depending on time-temperature regime used.

Concluding from the very first results of current research project, beech wood also exhibits favorable results in terms of surface moisture related characteristics. Therefore, this might be suitable technique for one side exposed wood surfaces (wood cladding, wooden shingles) where wood-water interaction has a major importance, but also for those elements where stiffness of material is important (decking, wooden beams, etc.). Furthermore, more detailed studies dealing with moisture behavior, fire and decay resistance etc. of surface carbonization process are being undertaken.

\section{Acknowledgements}

This study was funded by Technology Agency of the Czech Republic (TAČR), project no. TJ02000072 "Development of technology for surface carbonization of wooden building elements: elimination of moisture and biodegradation effects".

\section{References}

Akizuki, M., Hasemi, Y., Yasui, N., Kinoshita, K., Yammamoto, K., Yoshida, M., Tamura, Y. and Takeda, M. (2001) Fire Safety Studies In The Restoration Of A Historic Wooden Townhouse In Kyoto - Fire Safety Experiments On Japanese Traditional Wood-Based Constructions. AOFST 5.

Boonstra, M., Tjeerdsma, B. (2006) Chemical analysis of heat treated softwoods. Holz RohWerkstoff 64(3):204-211.

Čermák, P., Dejmal, A., Paschová, Z., Kymäläinen, M., Dömény, J., Brabec, M., Hess, D., Rautkari, L. (2019) One-sided surface charring of beech wood. Journal of Materials Science 54:9497-9506.

Čermák, P., Vahtikari, K., Rautkari, L., Laine, K., Horáček, P., Baar, J. (2016) The effect of wetting cycles on moisture behaviour of thermally modified Scots pine (Pinus sylvestris L.) wood. Journal of Materials Science 51(3):1504-1511.

Esteves, B., Pereira, H. (2009) Wood modification by heat treatment: a review, BioResources 4(1):370-404.

Gosselink, R.J.A., Krosse, A.M.A., van der Putten, J.C., van der Kolk, J.C., de Klerk-Engels, B., van Dam, J.E.G. (2004) Wood preservation by low-temperature carbonisation. Industrial Crops and Products 19(1):3-12.

Hill, C. (2011) Wood modification: an update, BioResources 6(2):918-919.

Kutnar, A., Muthu, S.S. (2016) Environmental Impacts of Traditional and Innovative Forest-based Bioproducts. Springer, pp. 248.

Kymäläinen, M., Hautamäki, S., Lillqvist, K., Segerholm, K., Rautkari, L. (2017) Surface modification of solid wood by charring. Journal of Materials Science 52(10):6111-6119.

Kymäläinen, M., Turunen, H., Čermák, P., Hautamäki, S., Rautkari, L. (2018) Surface-related characteristics of surface charred spruce wood. Materials 11(11):2083-2097.

Militz, H. (2002) Thermal treatment of wood: European processes and their background. Stockholm, Inter. Res. Group on Wood Preservation, IRG/WP 14-40241. 20 p. 
Rowell, R.M. (2005) Handbook of wood chemistry and wood composites. Ed. R.M. Rowell. Florida: CRC Press, pp. 487.

Syrjänen, T., Jämsä, S., Viitaniemi, P. (2000) Heat treatment of wood in Finland. Proceedings of Seminar "Production and development of heat treated wood in Europe", Nov. 2000, Helsinki, Stockholm, Oslo.

Viitanen, H., Jämsä, S., Paajanen, L., Nurmi, A., Viitaniemi, P. (1994) The effect of heat treatment on the properties of spruce - a preliminary report. International Research group on Wood Preservation. Document No. IRG/WP 94-40032.

Biography 


\title{
Proceedings of the 2020 Society of Wood Science and Technology International Convention
}

\section{Surface free energy of ten tropical woods species and their acrylic and alkyd varnishes wettability}

\author{
Wayan Darmawan(1), Monica Br Ginting(2), Asih Gayatri(3), Rumanintya L. Putri(4), Dumasari(5), \\ Aulia Hasanusi(6) \\ (1)Prof., Faculty of Forestry, Bogor Agricultural University (IPB), Bogor (16680), Indonesia. \\ Phone +62-251-8621285, Fax. +62-251-8621256 \\ *(Corresponding author : e-mail : wayandar@indo.net.id; ORCID : 0000-0001-9603-2725) \\ (2) Research Assistance, Faculty of Forestry, Bogor Agricultural University (IPB), Indonesia. \\ (3) Research Assistance, Faculty of Mathematics and Natural Sciences, University of Indonesia, Indonesia \\ (4) Research Assistance, Universitas Islam Balitar, Blitar, Indonesia \\ (5) Research Assistance, Muhammadiyah University, Purwokerto, Indonesia \\ (6) Researcher, Center for Perhutani Research and Development, Cepu, Indonesia
}

Abstract

Surface properties of wood such as surface roughness, wettability and surface free energy (SFE) are important properties influencing further manufacturing process such as finishing or adhesive strength characteristics. The aim of this research was to determine surface properties such as surface roughness, SFE, and wettability of ten tropical woods and its effect to their bonding quality of varnishs. The woods tested in this study were fastgrowing teak, afrika, sungkai, mindi, merbau, durian, lamtoro, pulai, acacia and kempas. Wood surfaces were divided into unsanded and sanded using abrasive paper of 120 grits. SFE values were calculated based on the Rabel method. Wettability were measured by based on the contact angle between varnish liquids and wood surfaces using sessile drop method and $(\mathrm{S} / \mathrm{G})$ model was used to evaluate the wettability of the surface coatings on the wood. Bonding quality of varnishes was measured using cross-cut test based on the ASTM 3359-02 standard. The results show that unsanded kempas wood had the roughest surface with Ra value of $16.24 \mu \mathrm{m}$ and sanded lamtoro wood was the smoothest surface with Ra value of $6.86 \mu \mathrm{m}$. Unsanded afrika wood was the highest in SFE value of 53.61 $\mathrm{mJ} / \mathrm{m}^{2}$, and sanded fast-growing teak was the lowest in SFE values of $36.17 \mathrm{~mJ} / \mathrm{m}^{2}$. Sanded merbau woods was the lowest in $\mathrm{K}$ values of 0.022 for the water based acrylic varnish, and unsanded afrika wood were the highest in K values of 9.253 for the alkyd varnish. Afrika wood with the highest $K$ values (highest wettability) both for the acrylic and alkyd varnishes produced the highest bonding quality (grade 4 to 5). The oil-based alkyd varnish was more wettable and generated better bonding quality compared to the water-based acrylic varnish.

Keywords: acrylic and alkyd varnishs, bonding quality, surface free energy, surface roughness, wettability 


\section{Introduction}

Demand for wood as raw material in the level of log production continues to sustainably increase especially in the production of all categories of processed timber like sawnwood, plywood \& laminated veneer lumber, chipwood, veneer, and wood pulp. The Ministry of environment and forestry [1] reported that $\log$ production in 2017 reaches 30.61 million $\mathrm{m} 3$. In many other ways the use of wood as raw material still could not be replaced as it is relatively cheap, strong, environmentally friendly, and has an attractive appearance with the characteristic that could not be found in other materials.

Ten tropical wood species (fast-growing teak, afrika, sungkai, mindi, merbau, durian, lamtoro, pulai, acacia, and kempas) are widely used for multiple purposes. These woods are suitable for construction, furniture, paper, packing materials, panel wood, and et cetera. Merbau and kempas are high density wood species with high strength (class I-II) [2]. Durian, sungkai, acacia, afrika, mindi, and fast growing teak are medium density wood species with good strength (class II-III) [2]. Pulai and lamtoro are low density wood species with low strength (class IV-V) [2]. Some of the wood species can also be machined easily [3, 4]. There is abundant information about the physical or mechanical properties of these ten tropical woods but the information about the surface properties of these woods is still limited and not investigated yet. Surface properties of wood is one of the most important properties influencing further manufacturing process such as finishing or their adhesive strength characteristics. In order to complete the information for better utilization of the woods, the surface properties of the ten woods species need to be studied.

Application of coatings such as varnish and varnish on wood surfaces are commonly performed. The coatings protect wood surface and give a desired appearance. This coating aims to provide better aesthetic value to wood and also serve to cover up some of the weaknesses of wood in terms of colour and texture. The coating also protects wood from external conditions such as weather, temperature, air, sunlight or wood-damaging organisms [5].

According to Moita [6], the increase in surface roughness leads to the lower in the contact. Wood with a high surface roughness value has a low contact angle value because the varnish liquid spreads and seeps more quickly into the wood. One of the criteria that can be used to analyze the wetting behaviour of wood is the measurement of its contact angle. Contact angle values larger than $90^{\circ}$ indicate as a poor wetting characteristics of the varnishs liquid, in which it will be difficult for the varnishs liquid to wet a surface [6].

Wettability refers to how easily and efficiently a liquid spread over a solid surface [7]. The wettability can be characterized by some parameters such as contact angles, surface free energy, and adherence [8]. The amount of surface free energy (SFE) and surface tension affect also the value of wood wettability [9]. Both wettability and surface free energy are the important parameter to support information on interactions between wood surface and liquids (water, adhesives, and wood finishes) $[10,11,12,13]$. Wettability should be one of important indicator for evaluating the bonding between coatings and wood surface. Higher wettability provides better bonding quality of varnish [14]. Wettability can be determined by measuring the contact angle between liquid and surface. Many factor (such as surface tension phenomena, viscosity of liquids, wood aging, drying processing, and defects) influence penetration [10]. The purpose of this study was to investigate and to evaluate surface characteristics in term of surface roughness, SFE, and wettability for ten commercially Indonesian woods species. 


\section{Experimental}

\subsection{Sample Preparation}

Wood samples were prepared from ten species of wood, fast-growing teak (Tectona grandis), afrika (Maesopsis eminii), sungkai (Peronema canescens), mindi (Melia azedarach), merbau (Intsia bijuga), durian (Durio zibethinus), lamtoro (Leucaena leucocephala), pulai (Alstonia scholaris), acacia (Acacia mangium), and kempas (Koompassia malaccens). The lumbers were planed at their surfaces in planer. The planed lumbers were cut to produce samples for roughness measurement and wettability test. The surface roughness and wettability of wood samples were measured without sanding treatment. Wood specimens in dimension of $20 \mathrm{~cm} \times 12$ $\mathrm{cm} \times 2 \mathrm{~cm}$ (longitudinal x tangential x radial) were prepared by cutting the lumbers. The wood specimens were kept in an air-conditioned room with temperature of $23 \pm 2{ }^{\circ} \mathrm{C}$ and relative humidity of $80 \pm 5 \%$ for 2 weeks before roughness and wettability test. The room has been lighted and kept clean to retain the surface of wood samples in the same condition. Varnishes used for the wettability test were water-based acrylic and solvent-based alkyd. A mixture of alkyd varnish $(90 \%)$ and oil thinner (10\%) was prepared and stirred uniformly. Another mixture of acrylic varnish (90\%), and water (10\%) was also prepared. The viscosity of the alkyd and acrylic mixtures measured by viscometer was in the average of 0.2 and 1.5 poise respectively.

Surface roughness test

The measurement of surface roughness of wood specimens was performed perpendicularly to the fibre direction at five different positions on tangential surface of each sample using Mitutoyo type SJ-210 tester. The reason for measurement of roughness on the tangential surface was due to the decorative purposes. The tangential lumber has provided better decorative appearance compared to radial lumber, especially for furniture products coated with clear coats. The roughness measurement according to ISO 4287:1997 [15] was performed with a diamond tip radius of $5 \mu \mathrm{m}$, tracing length of $6 \mathrm{~mm}$, the cut off of $0.8 \mathrm{~mm}$ and speed of $0.5 \mathrm{~mm} / \mathrm{s}$. The value evaluated was the arithmetical mean roughness $(\mathrm{Ra})$.

\section{Contact angle measurement}

The dynamic contact angles of selected standard liquids (water, methanol, toluene, and glycerine) for measurement of SFE and of acrylic varnish for measurement of wettability were performed with video measuring system with a high-resolution CCD camera. During measurement, wood specimen was placed on the top of a table in front of the CCD video camera. The drop of selected standard liquids and the acrylic varnish with volume of $20 \mu 1$ were dropped by a syringe with a screw method to obtain the same droplets. The drop shapes on the wood surface were captured by the CCD camera and saved for the duration of $180 \mathrm{~s}$. Five droplets per sample was captured for each standard liquids and acrylic varnish for the measurements of contact angle. Each of the captured video images was cut to an individual image at intervals of $10 \mathrm{~s}$ for total duration of $180 \mathrm{~s}$. The Image-J 1.46 software with drop-snakes plugin analysis was used to measure the contact angle $(\theta)$ of the individual image of the drop. The contact angles of each droplet on the surface of wood specimen were measured both on the left side and the right side of the droplet and then the values were averaged. Total nineteen data points were taken for each recorded drop to obtain a curve of contact angle versus wetting time. The contact angle tests were conducted at the room with temperature of $23 \pm 2{ }^{\circ} \mathrm{C}$ and relative humidity of $80 \pm 5 \%$. 


\section{Determination of equilibrium contact angle and constant contact angle change rate}

A segmented regression model was used to determine the equilibrium contact angle $(\theta \mathrm{e})$ value. It is assumed that development of contact angle during wetting process can be described by two functions in a curve (Figure 1). The first function is a steep slope (quadratic) of the curve over the first second beginning of spreading and penetration, and the second function is a constant slope (plateau) for the later part of the curve (constant contact angle). The fitted regression model for the functions takes the form of quadratic model with plateau. The transition point between the two functions ( $t_{e}$ ) was directly obtained by using nonlinear least-squares procedures (PROC NLIN) in SAS STAT [16].

Figure 1. Deter

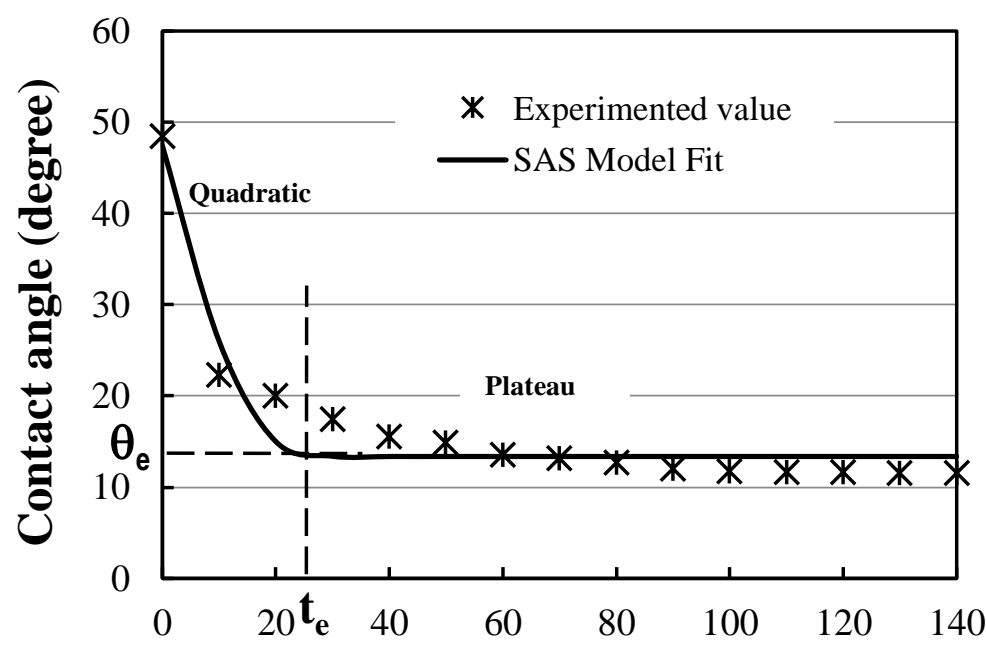

Contact c

contact angle as a

angle change ra

Wetting time (s)

ar time. The contact atively evaluate the wettability in this work. The equation of $\mathrm{S} / \mathrm{G}$ model can be expressed as follows:

$$
\theta=\frac{\theta \mathrm{i} \cdot \theta \mathrm{e}}{\theta \mathrm{i}+(\theta \mathrm{e}-\theta \mathrm{i}) \exp \left[K\left(\frac{\theta \mathrm{e}}{\theta \mathrm{e}-\theta \mathrm{i}}\right) t\right]}
$$

where $\theta$ is the contact angle at a certain time, $\theta \mathrm{i}$ is the initial contact angle, $\theta \mathrm{e}$ is equilibrium contact angle, $\mathrm{K}$ is the constant contact angle change rate and $\mathrm{t}$ is wetting time. A non-linier regression model was used to calculate $\mathrm{K}$ value using defined function to fit S/G equation by XLSTAT [18].

\section{Determination of SFE components}

Many methods have been used to calculate the SFE of wood. The two-liquid method is modified to be a multi-liquid method to determine the SFE value and its components are proposed by Rabel [19], using a regression line as in the equation 2:

$$
(1+\cos \theta e) \frac{\gamma_{l}}{\left(\gamma_{l}^{d}\right)^{1 / 2}}=\left(\gamma_{s}^{d}\right)^{1 / 2}+\left(\gamma_{s}^{p}\right)^{1 / 2}\left(\frac{\gamma_{l}^{p}}{\gamma_{l}^{d}}\right)^{1 / 2}
$$


where $\theta \mathrm{e}$ is equilibrium contact angle, $\gamma_{l}$ is the value of total surface tension, $\gamma_{l}^{d}$ is dispersive surface tension, $\gamma_{s}^{d}$ is dispersive component of SFE, $\gamma_{s}^{p}$ is polar component of SFE, and $\gamma_{l}^{p}$ is polar surface tension. The size of the equilibrium contact angle $(\theta \mathrm{e})$ of the standard liquid droplet (with known $\gamma \mathrm{l}$ ) on the surface of the woods samples is used for determining wood SFE $(\gamma \mathrm{s})$. In a linear regression line $(\mathrm{Y}=\mathrm{A}+\mathrm{BX})$, as $\mathrm{Y}=(1+\cos \theta \mathrm{e}) \frac{\gamma_{l}}{\left(\gamma_{l}^{d}\right)^{1 / 2}}, \mathrm{X}=\left(\frac{\gamma_{l}^{p}}{\gamma_{l}^{d}}\right)^{1 / 2}$, the slope $(\mathrm{B})$ will be $\left(\gamma_{s}^{p}\right)^{1 / 2}$ and the intercept (A) will be $\left(\gamma_{s}^{d}\right)^{1 / 2}$. The values of $\mathrm{X}$ and $\mathrm{Y}$ in this study were calculated by the four standard liquids as presented in Table 1. Meanwhile, the $\mathrm{Y}$ value was calculated from the measurement of contact angles of the standard liquids in Table 1 on each surface of woods specimens. The value of SFE should be $\mathrm{A}_{2}+\mathrm{B}_{2}=\left(\left(\gamma_{s}^{d}\right)^{1 / 2}\right)_{2}+\left(\left(\gamma_{s}^{p}\right)^{1 / 2}\right)_{2}$.

Table 1. The value of total surface tension, polar component of surface tension, dispersive component of surface tension for the standard liquids (in $\mathrm{mJ} / \mathrm{m} 2$ )

\begin{tabular}{lccc}
\hline Liquids & $\gamma l^{p}$ & $\gamma l^{d}$ & $\gamma l$ \\
\hline Water & 21.8 & 51.0 & 72.8 \\
Methanol 50\% & 12.9 & 22.7 & 35.6 \\
Toluene & 2.3 & 26.1 & 28.4 \\
Glycerin & 30.0 & 34.0 & 64.0 \\
\hline
\end{tabular}

Note: $\gamma l_{\mathrm{p}}$, polar component of surface tension; $\gamma l_{\mathrm{d}}$, dispersive component of surface tension; $\gamma \mathrm{l}$; the value of total surface tension.

\section{Coating application and bonding test}

The un-sanded and sanded wood samples were coated by the above mentioned varnish types for bonding quality evaluation. Two coats were applied on the wood surfaces to achieve a total application of $150 \mathrm{~g} / \mathrm{m} 2$ wet film and a dry film thickness of $60 \pm 5 \mu \mathrm{m}$. The required weight of each coat to achieve these spread rates was calculated based on the surface area of the samples. The varnishes were applied by brush on the front face and the back of the samples. Twenty-four hours drying time was allowed before the second coat was applied. When the second coat had dried, the coated samples were conditioned for one week in a clean room at approximately $25^{\circ} \mathrm{C}$ temperature and $75 \%$ relative humidity.

A cross-cut tape test method was applied to evaluate the resistance of the coating films to separation from wood surfaces [20]. A cross-cut pattern was made through the film with a sharp cutter head. Pressure-sensitive tape was applied over the cut. Tape was smoothed into place by using a pencil eraser over the area of the incisions. Tape was removed by pulling it off rapidly back over itself close to an angle of $180^{\circ}$. Adhesion was assessed on a 0 to 5 scale. The scale 5 is $0 \%$ area removed, and scale 0 is greater than $65 \%$ area removed. Five cross-cut patterns per sample were made for each varnish coating, two samples were used, and ten measurements of cross-cut were obtained. The scales of the adhesion were averaged.

\section{Results and discussion}

\section{Surface roughness}

Surface roughness is an important property in terms of surface quality, particularly in finishing treatments [21]. The result in Figure 2 shows that sanding contributed to a decrease in 
surface roughness values $(\mathrm{Ra})$ for all wood species. The result indicates that kempas had the roughest surface both for sanded and unsanded with $\mathrm{Ra}$ value of $11.06 \mu \mathrm{m}$ and $16.24 \mu \mathrm{m}$, respectively. Lamtoro had the smoothest surface after sanding with Ra value of $6.86 \mu \mathrm{m}$. Surface roughness of wood can be affected by some factors such as annual ring variation, density, cell structure, latewood/earlywood ratio and type of machining [22, 23].

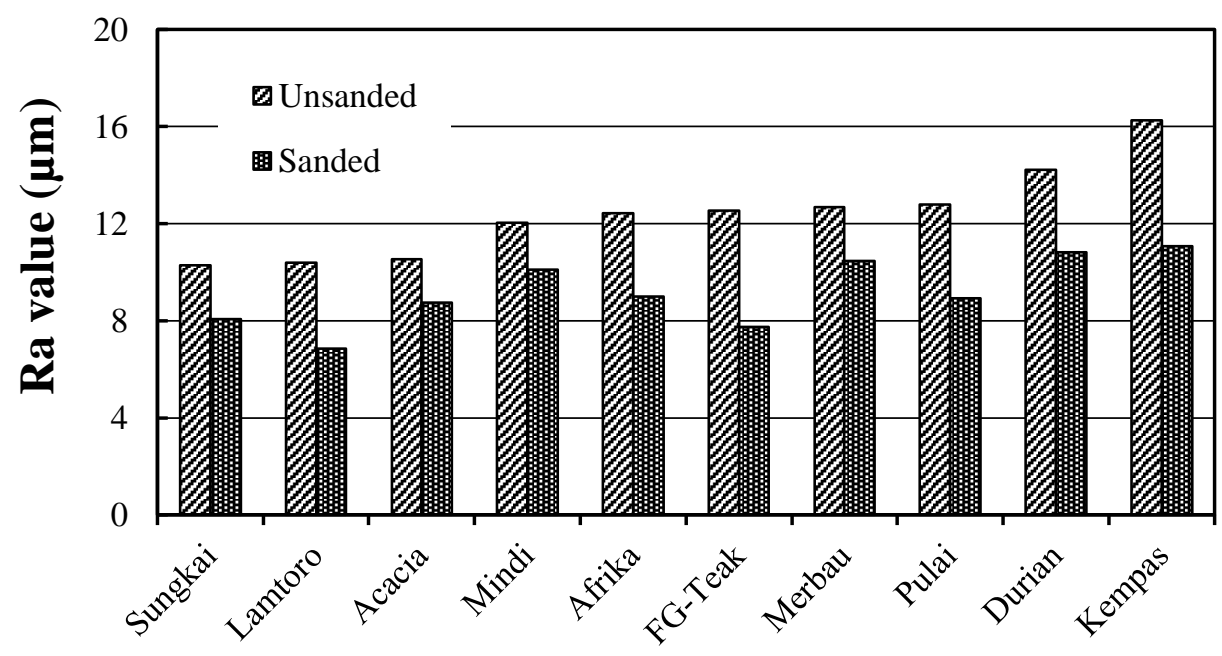

Wood Species

Figure 2. The values of surface roughness for the ten tropical wood species

It was reported that a higher surface roughness produces a higher surface hydrophilicity that tends to produce better wetting with lower of contacts angle [24]. The size of voids present in the wood may also influence surface roughness. Wood with large lumen and diameters would usually result in open grain after machining which lead to higher surface roughness [25]. Surface roughness of the woods tested in this work should be important in determining its SFE and wettability for the water-based acrylic and oil-based alkyd varnish.

\section{Surface Free Energy}

Equilibrium contact angle $(\theta \mathrm{e})$ was measured to calculate the SFE of the woods tested. The equilibrium contact angles were calculated using a segmented regression model and the results are shown in Table 2. Unsanded afrika wood had the lowest $\theta \mathrm{e}$ of $20.6^{\circ}$ and $25.2^{\circ}$ for water-based acrylic and solvent based alkyd varnishes, respectively and sanded lamtoro wood had the lowest $\theta$ e value of $6.1^{\circ}$ and $6.8^{\circ}$ for solvent based alkyd. Otherwise unsanded and sanded merbau woods were the highest in $\theta \mathrm{e}$ value of $39.8^{\circ}$ and $41.8^{\circ}$, respectively for the water-based acrylic varnish, and of $14.2^{\circ}$ and $15.9^{\circ}$, respectively for the solvent based alkyd varnish. The values of these $\theta \mathrm{e}$ showed the correlation with the surface roughness of the woods, in which a rougher wood surface tended to produce a lower $\theta$ e value. 
Table 2. The value of equilibrium contact angle for 10 tropical wood species

\begin{tabular}{lcccc}
\hline \multirow{2}{*}{ Wood } & \multicolumn{2}{c}{ Water-based acrylic paint } & \multicolumn{2}{c}{ Oil-based alkyd paint } \\
& $\theta \mathrm{e}($ Unsanded) & $\theta \mathrm{e}$ (Sanded) & $\theta \mathrm{e}$ (Unsanded) & $\theta \mathrm{e}$ (Sanded) \\
\hline Afrika & 20.6 & 25.2 & 6.1 & 7.1 \\
Acacia & 29.0 & 29.2 & 8.9 & 9.8 \\
Kempas & 26.9 & 28.2 & 9.7 & 12.7 \\
Lamtoro & 29.4 & 29.7 & 6.3 & 6.8 \\
Durian & 28.3 & 30.0 & 7.3 & 7.5 \\
Sungkai & 29.6 & 31.7 & 11.3 & 12.1 \\
Pulai & 31.7 & 31.8 & 8.2 & 10.1 \\
Mindi & 30.1 & 34.3 & 8.9 & 10.3 \\
FG-Teak & 33.7 & 37.9 & 10.8 & 11.4 \\
Merbau & 39.8 & 41.8 & 14.2 & 15.9 \\
\hline
\end{tabular}

The results in Table 2 show also that the $\theta$ e values of acrylic and alkyd varnishes for all wood surfaces were prominently different. The water-based acrylic varnish generated higher values of $\theta \mathrm{e}$. Its higher viscosity 1.5 poise compared to the solvent based alkyd varnish 0.3 poise could be the reason. The lower $\theta \mathrm{e}$ in solvent based alkyd varnish indicated the varnish liquid easier to spread and lead to beneficial substrate wetting and penetration in wood. The lower $\theta \mathrm{e}$ of the solvent based alkyd also indicates that it should create more intimate contact on the wood surface than the water-based acrylic.

Table 3 The value of total SFE and components for ten wood species (in $\mathrm{mJ} / \mathrm{m}_{2}$ )

\begin{tabular}{llccrrr}
\hline Wood & \multicolumn{3}{c}{ Unsanded } & \multicolumn{3}{c}{ Sanded } \\
\cline { 2 - 7 } & $\gamma_{s}{ }^{d}$ & \multicolumn{1}{c}{$\gamma_{s}{ }^{p}$} & \multicolumn{1}{c}{$\gamma_{s}$} & $\gamma_{s}{ }^{p}$ & $\gamma_{s}{ }^{p}$ & $\gamma_{s}$ \\
\hline FG-Teak & 23.60 & 15.00 & 38.60 & 26.55 & 9.62 & 36.17 \\
Merbau & 40.29 & 6.96 & 47.26 & 43.35 & 3.57 & 46.92 \\
Acacia & 41.69 & 7.31 & 49.00 & 36.60 & 7.16 & 43.76 \\
Sungkai & 42.16 & 7.64 & 49.80 & 35.52 & 7.85 & 43.37 \\
Pulai & 40.78 & 9.65 & 50.43 & 30.61 & 12.12 & 42.72 \\
Durian & 35.63 & 14.91 & 50.54 & 32.03 & 14.12 & 46.15 \\
Mindi & 35.53 & 15.52 & 51.05 & 27.91 & 17.69 & 45.60 \\
Lamtoro & 34.25 & 16.87 & 51.12 & 22.24 & 19.11 & 41.35 \\
Kempas & 46.49 & 6.85 & 53.34 & 41.46 & 7.10 & 48.55 \\
Afrika & 44.48 & 9.13 & 53.61 & 36.02 & 9.44 & 45.46 \\
\hline
\end{tabular}

Note: $\gamma_{s}^{p}$, polar component of SFE; $\gamma_{s}{ }^{d}$, dispersive component of SFE; $\gamma_{s}$, the value of total SFE

The SFE values of woods are shown in Table 3. The SFE decreased as the roughness of the woods decreased. It was also reported by Gindl et al. [26] that sanded surfaces of woods show smaller total surface free energies. Unsanded and sanded fast-growing teak had the lowest SFE values of $38.60 \mathrm{~mJ} / \mathrm{m}_{2}$ and $36.17 \mathrm{~mJ} / \mathrm{m} 2$, respectively. Unsanded afrika and sanded kempas woods were the highest in SFE values of $53.61 \mathrm{~mJ} / \mathrm{m} 2$ and of $45.46 \mathrm{~mJ} / \mathrm{m} 2$, respectively. The higher SFE 
value of the wood indicated the higher the energy on the surfaces of the wood to be used for breakdown the liquid to spread and penetrate on their surfaces. A rougher wood surface tended to produce a higher SFE. This could due to the contact area on the rougher surfaces higher than on smoother surfaces.

\section{Wettability}

$\mathrm{K}$ value is important for quantifying the wettability of varnish liquid on the surface of the wood. K-value of 0 indicates very poor wettability. $\mathrm{K}$ values of woods tested in this work are shown in Table 4. Unsanded and sanded merbau woods had the lowest $\mathrm{K}$ values of 0.027 and 0.022 , respectively for the water based acrylic varnish. The unsanded pulai and sanded sungkai had the lowest $\mathrm{K}$ value of 3.627 and for 3.485, respectively for the solvent based alkyd varnish. Otherwise unsanded and sanded afrika woods were the highest in K values of 0.055 and 0.051 , respectively for the acrylic varnish, and of 9.253 and 8.202, respectively for the alkyd varnish.

Table 4. K-values of water-based acrylic paint and oil-based alkyd paint for ten wood species

\begin{tabular}{lcccc}
\hline & \multicolumn{2}{c}{ Water-based acrylic paint } & \multicolumn{2}{c}{ Oil-based alkyd paint } \\
\cline { 2 - 5 } Wood & $\begin{array}{c}\text { K-value } \\
\text { (Unsanded) }\end{array}$ & $\begin{array}{c}\text { K-value } \\
\text { (Sanded) }\end{array}$ & $\begin{array}{c}\text { K-value } \\
\text { (Unsanded) }\end{array}$ & $\begin{array}{c}\text { K-value } \\
\text { (Sanded) }\end{array}$ \\
\hline Merbau & 0.027 & 0.022 & 5.600 & 4.249 \\
Lamtoro & 0.032 & 0.028 & 7.452 & 6.898 \\
Pulai & 0.033 & 0.029 & 4.506 & 3.627 \\
Kempas & 0.036 & 0.034 & 5.148 & 4.619 \\
Mindi & 0.037 & 0.034 & 7.447 & 6.310 \\
Acacia & 0.038 & 0.033 & 7.260 & 5.389 \\
FG-Teak & 0.038 & 0.032 & 5.730 & 5.038 \\
Durian & 0.041 & 0.035 & 6.637 & 6.531 \\
Sungkai & 0.052 & 0.038 & 5.557 & 3.485 \\
Afrika & 0.055 & 0.051 & 9.253 & 8.202 \\
\hline
\end{tabular}

The results in Table 4 show that the solvent based alkyd had larger $\mathrm{K}$ values compared to water-based acrylic because solvent based alkyd was lower in viscosity ( 0.3 poise) than waterbased acrylic varnish (1.5 poise). According to Gavrilovic-Grmusa et al. [27], wettability value decreases with increasing in viscosity of an adhesive. A lower in surface tension within the liquid could also result in a greater wettability. The solvent based alkyd varnish also had lower surface tension of $66.32(\mathrm{~mJ} / \mathrm{m} 2)$ compared to water based acrylic varnish of $80.52(\mathrm{~mJ} / \mathrm{m} 2)$. It also appears from the results in Tabel 4 that the unsanded wood samples had larger K value than sanded woods both for the acrylic and alkyd varnish. As noted in Darmawan et al. [14] that rougher surface of woods generates lower contact angle and ensuing better wettability. Shi and Gardner [17] reported that the greater K-values, the faster the time needed for the liquid to spread and penetrate on the wood surfaces. By considering the fact that the acrylic and alkyd in this study were prepared and applied at the manufacturer's recommended use, it can be concluded that the alkyd varnish produced better wettability than acrylic for all ten wood surfaces. 


\section{Bonding Quality}

Bonding quality of ten wood species are presented in Table 5. It is seen from Table 5 that bonding quality of unsanded woods was slightly better compared to sanded woods. Afrika and sungkai had the highest average of bonding quality compared to the others due to their high $\mathrm{K}$ values. Pulai and lamtoro had the lowest average of bonding quality due to their low $\mathrm{K}$ values.

Anatomical structure would be one of the major factors affecting the interaction between coating and wood material. Afrika wood had a porous structure that would result in better absorption and penetration of coating to its surface, then cause higher magnitude of interface which enhanced bonding quality characteristics. The results also indicate that sanding decreased bonding quality value. The increase in surface roughness will tend to the increase in bonding quality. It was also reported by Darmawan et al. [14] that when the surface becomes smoother, a coating lacks mechanical interlocking with the substrate, thus weakening the adhesion. A rough surface was proposed to enhance intrinsic adhesion by providing greater interfacial area. The coating liquid flowed and filled the wood pores, holes, crevices and microvoids to achieve strong bond between wood surface and coating material.

Table 5. Bonding quality of water-based acrylic paint and oil-based alkyd paint for ten wood species.

\begin{tabular}{lcccc}
\hline \multirow{2}{*}{ Wood } & \multicolumn{2}{c}{ Water-based acrylic Paint } & \multicolumn{2}{c}{ Oil-based alkyd Paint } \\
\cline { 2 - 5 } & Unsanded & Sanded & Unsanded & Sanded \\
\hline Afrika & 5B & 5B & 5B & 4B \\
Lamtoro & 4B & 3B & 3B & 3B \\
Durian & 3B & 3B & 5B & 4B \\
Acacia & 4B & 3B & 4B & 3B \\
Pulai & 3B & 3B & 3B & 3B \\
Mindi & 3B & 3B & 5B & 4B \\
FG-Teak & 5B & $4 \mathrm{~B}$ & 5B & 4B \\
Sungkai & 5B & 4B & 5B & 5B \\
Kempas & 3B & 2B & 5B & 2B \\
Merbau & 5B & 3B & 3B & 3B \\
\hline
\end{tabular}

The results in Table 5 show that alkyd varnish produced higher bonding quality than acrylic varnish for most of ten wood species. Better wettability of alkyd varnish (higher $\mathrm{K}$ values) contributed to better bonding quality. Sonmez et al. [28] noted that solvent based alkyd varnish completes its polymerization reaction on the wood surfaces which allow for chemical bonding on wood surfaces. Lower bonding quality of water-based acrylic varnish is considered because the water used as a solvent causes swelling of wood fibers and decrease penetration near the wood surfaces which lead to a weakening of the interface of wood and coating material [29].

\section{Conclusion}

Based on the findings in this work, the following general conclusions were drawn. Sanding with 120 grit number decreased the roughness of the wood surfaces. The equilibrium contact angles increase as the roughness of the planed surface of the woods decrease. The SFE values decrease as the equilibrium contact angles of the wood increase. The higher SFE values generate the higher K-values. The higher K-value indicates higher wettability and bonding quality of 
varnishes. Afrika wood has the greatest SFE and K values among the other wood species, and produces highest bonding quality. Solvent based alkyd varnish is more wettable and generates better bonding quality compared to the water-based acrylic varnish. The K-values of all woods tested in this work larger than 0 give an indication that the varnish liquids (acrylid and alkyd) can spread and penetrate on the surface of the woods tested. Improving the quality of especially fastgrowing wood from plantation by painting could be considered to spread their utilization for higher value wood products

\section{Acknowledgements}

The authors thank the Directorate for Research and Community Service of the Ministry of RISTEK-DIKTI of the Republic of Indonesia for the research grant

\section{References}

[1] Ministry of Environment and Forestry, The State of Indonesia's Forests 2018. Jakarta (ID): Ministry of Environment and Forestry, 2018.

[2] Martawijya A, Kartasujana I, Kadir K, Prawira S, Atlas Kayu Indonesia. Forest Products Research Institute, Bogor, 2005.

[3] W. Darmawan, I.S. Rahayu, C. Tanaka, R. Marchal, Chemical and Mechanical Wearing of High-Speed Steel and Tungsten Carbide Tools by Tropical Woods. Journal of Tropical Forest Science, 18 (2006) 166-172.

[4] W. Darmawan, D. Nandika, Y. Massijaya, A. Kabe, I. Rahayu, L. Denaud, B. Ozarska, Lathe Check Characteristics of Fast Growing Sengon Veneers and their Effect on LVL Glue-bond and Bending Strength. Journal of Materials Processing Technology, 215 (2015) 181-188. DOI: 10.1016/j.jmatprotec.2014.08.015.

[5] D. Crump, The Complete Guide to Wood Finishes. Australia (AUS): Simon and Shuster, 1993.

[6] Y. Yuan, T.R. Lee, Contact angle and wetting properties. Surface Science Techniques, 51 (2013) 3-34, http://dx.doi.org/10.1007/978-3-642-34243-1

[7] A. Baldan, Adhesion Phenomena in Bonded Joints. International Journal of Adhesion and Adhesives, 38 (2012) 95-116.

[8] M. Wålinder, Study of Lewis acid-base properties of wood by contact angle analysis. Holzforschung, 56 (2002) 363-371.

[9] I. Yuningsih, I.S. Rahayu, L. Dumasari, W. Darmawan, Wettability and adherence of acrylic varnishs on long and short rotation teaks. J Wood Mater Sci Eng. 2019. doi: 10.1080/17480272. 2019.1575903.

[10] Z. Qin, H. Chen, Q. Gao, S. Zhang, Wettability of Sanded and Aged Fast-growing Poplar Wood Surfaces: I Surface Free Energy. Bioresources 10 (2014) 1008-1023.

[11] M.E.P. Wålinder, D.J. Gardner, Acid-Base Characterization of Wood and Selected Thermoplastics. Journal of Adhesion Science and Technology, 16 (2002) 1625-1649.

[12] M. Gindl, A. Reiterer, G. Sinn, S.E. Stanzl-Tschegg, Effects of Surface Ageing on Wettability, Surface Chemistry, and Adhesion of Wood. Holz als Roh- und Werkstoff, 62 (2004) 273-280.

[13] J. Rathke, G. Sinn, Evaluating the Wettability of MUF Resins and pMDI on Two Different OSB Raw Materials. European Journal of Wood and Wood Products, 71 (2013) 335-342. 
[14] W. Darmawan, D. Nandika, E. Noviyanti, I. Alipraja, D. Lumongga, D.J. Gardner, P. Gerardin, Wettability and bonding quality of exterior coatings on jabon and sengon wood surfaces. J. Coat. Technol. Res., 15 (2017) 95-104

[15] International Standard (1997) Geometrical Product Specifications (GPS) Surface texture: Profile method, terms, definitions and surface texture parameters ISO 4287-1977. Geneva (Switzerland): International Organization for Standardization.

[16] SAS Institute, SAS STAT 9.1 User's Guide, 1st ed. SAS Institute Inc, Cary, NC, USA, 2004.

[17] S.Q. Shi, D.J. Gardner, Dynamic Adhesive Wettability of Wood. Wood and Fiber Sci., 33 (2001) 58-68

[18] XLSTAT Addinsoft, A Complete Statistical Add-In for Microsoft Excel. Addinsoft NY, USA, 2007.

[19] W. Rabel, Einige Aspekte der Benetzungstheorie and ihre Anwendung auf die Untersuchung und Veränderung der Oberflächeneigenschaften von Polymeren. Fabre und Lack, 77 (1971) 997-1006

[20] ASTM, “ASTM D 3359-97: Standard Test Methods for Measuring Adhesion by Tape Test." American Society for Testing and Materials, Philadelphia, 1997.

[21] U. Buyuksari, T. Akbulut, C. Guler, N. Ass, Wettability and surface roughness of natural and plantation grown narrow leaved ash (Fraximus angustifolia Vahl) wood. BioResources, 6 (2011) 4621-4730

[22] M.R.S. Amorim, P.G. Ribeiro, S.A. Martins, C.H.S.D. Menezzi, MR.Souza, Surface wettability and roughness of 11 amazonian tropical hardwoods. Floresta e Ambiente, 20 (2013) 99-109.

[23] M. Kilic, S. Hiziroglu, E. Burdurlu, Effect of machining on surface roughness of wood. Building and Environment. 41 (2005)1072-1078.

[24] C. Piao, J.E. Winandy, T.F. Shupe, From hydrophilicity to hydrophobicity: a critical review: part I wettability and surface behavior. Wood and Fiber Science, 42 (2010) 490510

[25] A. Syahirah, M.T. Paridah, H. Hamdan, U.M.K. Anwar, A.S. Nordahlia, S.H. Lee, Effect of anatomical characteristics and wood density on surface roughness and their relation to surface wettability of hardwood. Journal of Tropical Forest Science, 31(2019)269-277

[26] M. Gindl, G. Sinn, A. Reiterer, S. Tschegg, Wood surface energy and time dependence of wettability: a comparison of different wood surfaces using an acid-base approach. Holzforschung, 55 (2001) 433-440.

[27] I. Gavrilovic-Grmusa, M. Dunky, J. Miljkovic, M. Djiporovic, Influence of the viscosity of UF resins on the radial and tangential penetration into poplar wood and the shear strength of adhesive joints. Holzforschung, 66 (2012)849-856.

[28] A. Sonmez, M. Budakci, M Bayram, Effect of wood moisture content on adhesion of varnish coatings. Sci. Res. Essay, 4(2009)1432-1437

[29] M. Meijer, S. Haemers, W. Cobben, H. Militz, Surface energy determinations of wood: comparison of methods and wood species. Langmuir, 16 (2000)9352-9359.

Biography 


\title{
Bond Strength of Wood Adhesives: The Sensitivity of Standard Test Methods to Imperfections
}

\author{
Mohammad Derikvand ${ }^{*}$ - Gerhard Fink2 \\ 1 Postdoctoral Researcher, Department of Civil Engineering, Aalto University, \\ 02150 Espoo, Finland* Corresponding author \\ Mohammad.derikvand@aalto.fi \\ 2 Assistant Professor, Department of Civil Engineering, Aalto University, 02150 \\ Espoo, Finland \\ Gerhard.fink@aalto.fi
}

\begin{abstract}
The aim of this paper is to highlight some drawbacks and uncertainties related to possible imperfections associated with the use of key European and American standard test methods on shear strength measurement of wood adhesive bonds. For this purpose, a brief introduction is provided on adhesive bonding of wood materials and relevant failure modes under shear stress. Two standardized test methods for measuring the shear strength of wood adhesives are introduced, followed by a discussion around the drawbacks and imperfections related to the practical application of the two test methods. Finally, the research needs in this area are highlighted and some recommendations are made for addressing them in the future studies.
\end{abstract}

Key words: wood adhesives, bond strength, percentage of wood failure, bond line thickness, adhesive spread rate, growth ring orientation, imperfection.

\section{Introduction}


Adhesive is an integral element in the production of a variety of engineered wood products (EWPs) such as cross-laminated timber, glulam, and laminated veneer lumber. The bond strength evaluation of wood adhesives is part of daily activities in the quality control laboratory of many EWPs manufacturing companies. Most companies follow the testing instructions provided by national or international industry-accepted standard test methods. However, one of the challenges that has occasionally been highlighted by researchers is that most of the available standard methods are general and usually not relevant to all types of products (e.g., Sikora et al. 2016), even though many wood adhesives nowadays are produced to be used in a specific product or application. Accordingly, the selected test method may not necessarily be the most suitable method for the specific application, although it may fulfill the basic requirements. Parameters such as bond line thickness, adhesive spread rate, press pressure, and grain orientation, influence the bond strength of wood adhesives (Rowell 2012). The influencing parameters can vary within and between applications and products, which affects the reliability of a selected standard test method. In addition, some of the common standards are quite sensitive to minor technical errors in the sample preparation or testing (Karlsson and Wong 2004). Although for research purposes in a well-controlled laboratory environment the minor technical errors could be avoided, such imperfections are usually expected to happen in the industrial use. Therefore, it is important to properly evaluate the parameters that might influence the accuracy of bond strength measurement and the extent to which common standards are sensitive to these parameters.

In this paper, a brief discussion is presented on the fundamental of the bonding mechanism and failure of wood adhesives. This is followed by a review of various technical parameters and imperfections that might influence the accuracy and reliability of key European and American standard test methods on shear strength measurement of wood adhesive bonds. The gaps and research needs in this area are also discussed in order to evaluate the importance of the effects of such imperfections on the accuracy of the standard test methods in the future research.

\section{Adhesive bonding of wood materials}

Apart from its chemistry, the bonding performance of a wood adhesive is largely governed by its depth of penetration into the wood cells (Kamke and Lee 2007). Part of an adhesive applied between wood elements will penetrate the lumens of the wood cells through hydrodynamic flow and capillary action and a smaller amount will penetrate the wood cell-walls through diffusion (Kamke and Lee 2007, Gavrilović-Grmuša et al. 2016). A good bonding performance could be expected when the adhesive penetrates the wood cells to a sufficient degree. This will provide a good interaction and mechanical interlocking between the wood and the adhesive (Rowell 2012). Under similar conditions, the level of hydrodynamic flow and capillary action may vary between various wood species depending on their cellular structures. Due to this, the depth of penetration and therefore the bonding performance of a single adhesive will be generally influenced by the type of wood materials in addition to the viscosity of the adhesive itself. 


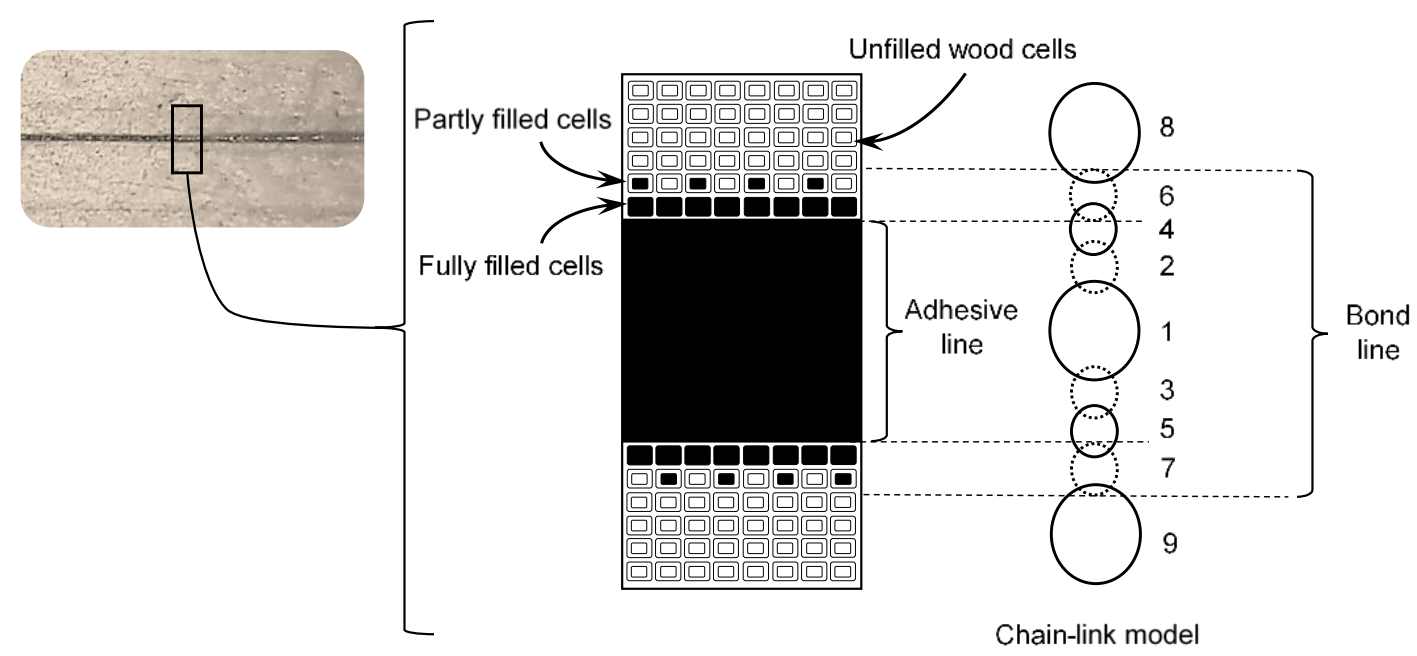

Figure 1. Illustration of the chain-link model in a wood-wood glued element.

This is usually addressed during the formulation of the adhesive and can be adjusted for different wood species and products. However, a uniform bonding performance will be challenging to achieve in manufacturing a product that is to be made of mixed wood species (Rowell 2012). A poor bonding performance in such products may result from the over-penetration of the adhesive into the more porous species or its under-penetration into the less porous one.

According to Marra (1992), the adhesive bond in wood materials can generally be modeled using a chain-link analogy comprised of five links (Fig. 1). Despite its detailed structure, the chain-link analogy is effective in describing and studying the bond performance of wood adhesives. As shown in Figure 1, Link 1 in the chain-link analogy is bulk adhesive; Links 2 and 3 are the adhesive interphase (or the adhesive boundary layer); Links 4 and 5 are the wood-adhesive interface; Links 6 and 7 are the interphase of the wood; and Links 8 and 9 are bulk wood (clear wood unaffected by the adhesive). According to this model, the bond is as strong as the weakest link in the chain.

The best-case scenario for a wood adhesive is when Links 8 or 9 are the weakest in the chain, resulting in pure wood failure. Most adhesives usually achieve this when tested in dry conditions. However, certain wood adhesives fail in the interphase region when tested in wet conditions (Frihart 2005). The interphase region is quite critical as it has to accommodate the possible swelling and shrinkage of the wood and volume reduction of the adhesive while it cures. Swelling and shrinkage strains in either components at service will also result in increased internal stresses that can negatively influence the bond performance in the interphase region (Frihart 2009). Due to this phenomenon, the performance of wood adhesives needs to be studied at various dry and wet states to mimic the actual conditions at service. 


\section{Proceedings of the 2020 Society of Wood Science and Technology International Convention}

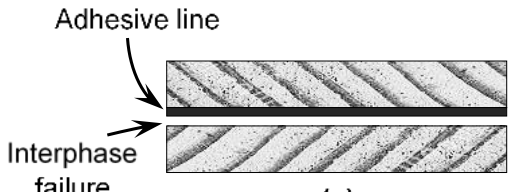

(a)

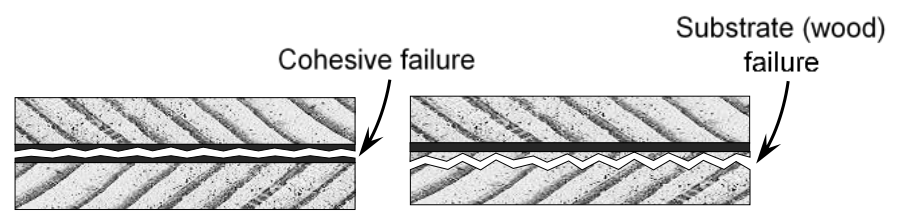

(b)

(c)

Figure 2. Three general macroscopic failure modes of wood adhesive bonds under shear force.

The chain-link analogy is quite detailed and therefore sometimes challenging to use especially for predicting failures in the bond line. This is because the induced stresses are usually not uniformly distributed across the bond line and therefore the failures do not always happen in only one single link in the chain (Hass 2012). Most standard test methods examine the bond performance of wood adhesives under shear loads, either in compression or in tension. Under shear stress, three macroscopic failure modes can be observed in general with the assumption of a uniform stress distribution: interphase failure, cohesive failure, and substrate or wood failure (Fig. 2).

a. Interphase failure refers to a type of shear failure that occurs within the interphase region of the bond line. Interphase failure occurs within Links 2 to 7 in the chain-link analogy. This includes failure in the adhesive interphase region (Links 2 and 3), interfacial failure (Links 4 and 5), and failure in the wood interphase region (Links 6 and 7). The interfacial failure (i.e., failure at the wood-adhesive interface) leaves clear wood on one surface and adhesive on the other. A true interfacial failure is not common for strong wood adhesive bonds but it can result from the poor adhesive penetration that may happen due to high density of wood, inadequate surface preparation, or high viscosity of the adhesive itself. Sometimes failure in the adhesive interphase region (Links 2 and 3) or the wood itself (Links 6 and 7) may be mistaken for the interfacial failure (Links 4 and 5). The differences are difficult to detect at the macroscopic level.

b. Cohesive failure is the pure shear failure of the bulk adhesive within Link 1. In wood materials, a cohesive failure may indicate that the shear strength of the adhesive line is less than that of the wood itself. This type of failure may also be observed when the adhesive line is too thick.

c. Substrate (wood) failure is characterized by the shear failure of the wood fibers within Links 8 and 9. This type of failure occurs when the shear strength of the bond line is higher than that of the wood.

In practice, other types of shear failure can also occur as a combination of the three general failure modes. Nevertheless, most standard test methods on shear strength measurement of wood adhesive bonds do not account for this effect and only require the percentage of wood failure to be assessed visually to the nearest $10 \%$. However, to properly understand the wood adhesive bonding mechanism, the relevant experiments are better to be associated with both macroscopic and microscopic evaluations of the failure modes of the bond line as well. 


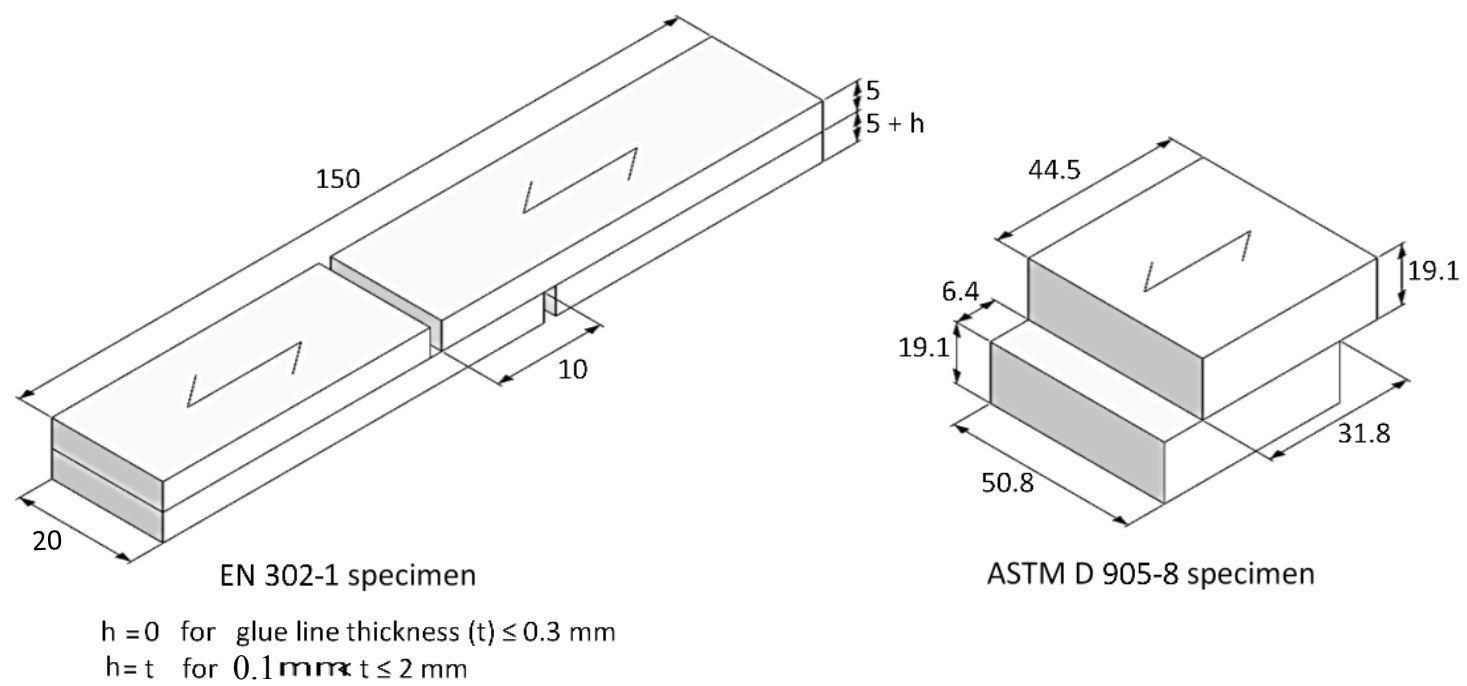

Figure 3. Configurations of EN 302-1 and ASTM D 905-8 specimens. Measurements in mm.

Key methods for shear strength measurement of wood adhesive bonds

Standard tests methods used for evaluating the bond strength of wood adhesives usually require the strength measurements to be taken under uniaxial shear stress parallel to the grain direction. In some standards, the shear stress is created by compressive loading and in some others by tensile loading. For each category, one of the most frequently used test methods is described in the following.

EN 302-1 (2013) is a European standard used for evaluating the shear strength of wood adhesives for load-bearing timber structures with close contact and thick glue lines. This standard provides guidance on measuring the shear strength of wood adhesives parallel to the grain direction. The shear stress must be induced on the adhesive line by tensile force. The test method has been developed for evaluating the shear strength of wood adhesives using different conditionings in both dry and wet states and under low and high temperatures. It is also suitable for assessing the compliance of one-component polyurethane adhesives, phenolic and aminoplastic adhesives, and emulsion polymerized isocyanate adhesives.

ASTM D 905-8 (2013) test method from the American Society for Testing and Materials is used to evaluate the shear strength of wood adhesive bonds by compressive loading. The bond area in this standard is quite larger than that in EN 302-1 (2013). ASTM D 905-8 (2013) test method is generally used to evaluate the shear strength of adhesive bonds in wood and similar materials. This test method is quite straightforward with respect to the necessity of following its specified conditions of specimen preparation, conditioning, and testing. The shear strength of the adhesive bond in this method is measured parallel to the grain direction. The configuration and dimensions of the EN 302-1 (2013) and ASTM D 905-8 specimens are shown in Figure 3.

\section{Imperfections of test specimens in practical use}

The application of the standard test methods in a well-controlled laboratory environment is not usually associated with major imperfections. However, in daily industrial use of standard test 
methods the likelihood of errors and imperfections is quite high. The imperfections could be related to the geometry, dimensions, but also mistakes/errors related to the general procedures for preparing and testing of the specimens. A few researchers have already raised the importance of this subject in the past as well. Karlsson and Wong (2004), for example, evaluated the sensitivity of the EN 302-1 and ASTM D-905 test methods to eccentric loading, amount of adhesive, and errors in cutting grooves and steps in the specimens. The experimental design of the study was not fully factorial and therefore the interaction effect of the test variables was not evaluated. However, they concluded that both test standards are sensitive to the intentional errors in the preparation and testing of the specimens. The results obtained were significantly affected even when there was only $\pm 0.5 \mathrm{~mm}$ error in the cutting depth of grooves and steps in the specimens.

In numerous studies in the past, the effects of growth ring orientation, press pressure, glue line thickness, and adhesive spread rate on the shear strength of wood adhesives in dry conditions were proved to be significant. However, there are uncertainties on how imperfection and inconsistency in such variables may influence the accuracy of the standard test methods. In EN 302-1 (2013), for example, it is assumed that a press pressure of $0.8 \pm 0.1 \mathrm{MPa}$ will result in a glue line thickness of $0.1 \mathrm{~mm}$ or less. This is quite general and may not necessarily result in the same glue line thickness, for example, in a low-viscosity adhesive compared to an expanding adhesive with a high viscosity.

The optimum spread rate of a wood adhesive is usually recommended by the manufacturer. The adhesives spread rate has conventionally been measured in many studies as the amount of adhesive that is initially applied on the adherents' surfaces. However, this method is clearly not reliable because it does not indicate how much adhesive will actually stay between the surfaces for bonding as a large amount of the adhesive initially applied will squeeze out under press pressure. This can lead to drawing incorrect conclusions from the results of bond strength measurement especially if the adhesive spread rate is one of the test variables. To overcome this drawback, the weight of the specimens before gluing and after clamping can be measured to estimate the amount of adhesive that is left for bonding (as in Santos et al. 2019). Measuring the exact bond line thickness and correlating it to the test results of individual specimens could be another solution. By measuring the bond line thickness, the volume of the adhesive applied in unit bond area could be estimated. The actual spread rate of the adhesive can then be estimated by multiplying the volume of the adhesive by its density at any stage even without knowing the weight of the specimens before gluing. A simple statistical correlation between the actual adhesive spread rate and the results obtained from the shear test of the bond line can then be used to adjust the results and improve the accuracy and repeatability of the experiments. For this purpose, clear guidelines must be provided on how the bond line thickness and adhesive volume can be rapidly and accurately estimated at the gluing or subsequent stages in practice. 


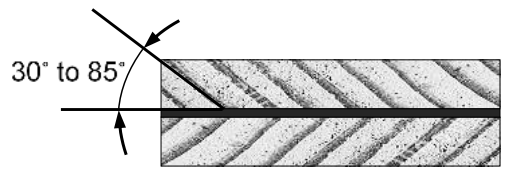

Standard cross-section with herringbone pattern

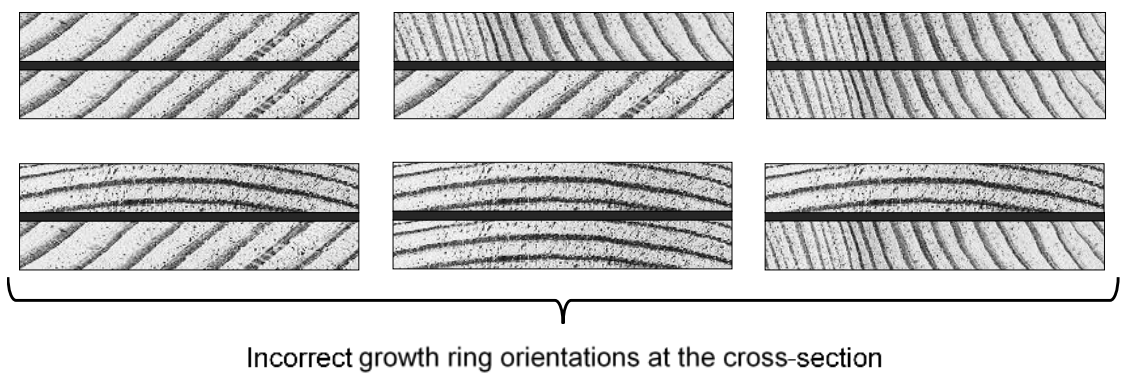

Figure 4. Some examples of incorrect growth ring orientations in EN 302-1 (2013) specimens.

The adhesive penetration depth on each side of a specimen is also likely to vary if the growth ring orientations of the adherents are different (see Figure 4 as an example). In such a case, the differences in the shear strength may not be significant for strong adhesive bonds tested in dry conditions, as most of the failure is likely to take place in the wood itself. However, cycles of wetting, boiling, and drying in the next stages of the test and increase in the test temperature required by standards can lead to increased internal stresses as a result of variable shrinkage and swelling of the specimens with different growth ring orientations. This can result in more decrease in the strength of Links 2 to 7 in the bond line of a specimen with small adhesive penetration depth. Therefore, the variation in the adhesive bond strength in the specimens with different growth ring orientations can become more notable. In such a situation, the accuracy and repeatability of a given test method will need to be addressed properly under various testing temperatures and moisture contents when exposed to such imperfections.

The subjects of growth ring orientation and fibre direction are especially important for evaluating the suitability of an adhesive that is going to be used in the production of certain types of EWPs with crossing layers - such as cross-laminated timber. In such products, the growth ring pattern and fibre direction in each layer vary significantly even within the same product type. However, the standard test methods described in this paper evaluate the shear strength of wood adhesives only in one direction-i.e., parallel to the grain. In numerous studies, researchers have been adopting their own test methods to evaluate the shear strength of adhesive bonds in products with crossing layers (e.g., Sikora et al. 2016). It is however still uncertain as to what extent the results of such tests may differ from those obtained from the available standard test methods on similar adhesives and wood species.

The existence of so many uncertainties in the basic application of the standard test methods indicates important research needs in this area. The future research should cover a range of objectives to properly understand the importance of the variables discussed in this paper and then propose reliable solutions to reduce the uncertainties associated with the imperfections and suitability of such standards for different products and applications. 


\section{Summary and Conclusions}

In this paper, a short introduction is provided on the bonding of wood materials, failure of adhesive bonds, and the key test methods used for measuring the shear strength of wood adhesives. For commonly used test methods, the uncertainties related to specimen fabrication and their influence are discussed and suggestions are made for addressing these drawbacks in the future research. Overall, it could be concluded that the standard test methods on the shear strength measurement of wood adhesives are quite general and come with important degrees of uncertainties that need to be addressed. It can be suggested to the future research to determine the importance of the influence of imperfections in specimen preparation and testing (both geometrical and technical aspects) on the reliability and accuracy of the standard test methods under various conditioning procedures. With the rapid development of EWPs, the need for establishing more detailed and reliable product-specific test methods is also paramount in evaluating the suitability of wood adhesives for different products and applications.

\section{References}

ASTM D 905-08 (2013) Standard test method for strength properties of adhesive bonds in shear by compression loading. American Society for Testing and Materials (ASTM) Annual Book of Standards. ASTM International, West Conshohoken.

EN 302-1 (2013) Adhesives for load-bearing timber structures - test methods - part 1: determination of longitudinal tensile shear strength. European Committee for Standardization, Brussels.

Frihart C.R (2005) Adhesive bonding and performance testing of bonded wood products. Journal of ASTM International 2(7): 1-12.

Frihart C.R (2009). Adhesive groups and how they relate to the durability of bonded wood. Journal of adhesion science and technology 23(4): 601-617.

Gavrilović-Grmuša I, Dunky M, Djiporović-Momčilović M, Popović M, \& Popović J (2016) Influence of pressure on the radial and tangential penetration of adhesive resin into poplar wood and on the shear strength of adhesive joints. BioResources 11(1): 2238-2255.

Hass P.F.S (2012) Penetration behavior of adhesives into solid wood and micromechanics of the bondline (Doctoral dissertation, ETH Zurich).

Kamke FA, Lee J.N (2007) Adhesive penetration in wood—a review. Wood and Fiber Science 39(2): 205-220.

Karlsson S, Wong M (2004) Experimental evaluation of the test methods EN 302-1 and ASTM D905 for wood-adhesive bonds. LTH Lund University Box, 118.

Marra A.A (1992) Technology of Wood Bonding: Principles in Practice; Van Nostrand Reinhold: New York, NY, USA.

Rowell R.M (2012) Handbook of wood chemistry and wood composites. 2nd edition. Boca Raton FL: CRC Press.

Santos P, Correia J.R, Godinho L, Dias A.M.P.G, Dias A (2019) Bonding quality assessment of crosslayered Maritime pine elements glued with one-component polyurethane adhesive. Construction and Building Materials 211: 571-582.

Sikora K.S, McPolin D.O, Harte A.M (2016) Shear strength and durability testing of adhesive bonds in cross-laminated timber. The Journal of Adhesion 92(7-9): 758-777.

Biography 


\title{
Proceedings of the 2020 Society of Wood Science and Technology International Convention
}

\section{Bagasse xylan nanocomposite films with high transparency, barrier properties and enhanced mechanical strength characteristics}

\author{
Seyedrahman Djafaripetroudy, Shahid Beheshti University, Iran \\ sr_jafari@sbu.ac.ir
}

\begin{abstract}
With growing awareness of environmental concerns, the biodegradable nature of hemicelluloses has made them an ideal choice in the development of sustainable solutions for bio-based packaging with the aim of reducing the overall carbon footprint of this industry. For this reason, xylans were used as important and abundant plant cell wall polysaccharides that can potentially be recovered in large quantities from agricultural residues such as bagasse. Here, bagasse xylan films (BXFs) were prepared with addition of sorbitol as a plasticizer and bagasse cellulose nanofibers (BCNs) as a strength enhancer through dispersion casting approach. Two different types of BCNs such as enzymatic pretreatment BCNFs and TEMPO-mediated oxidation BCNFs in different ratios were selected to strengthen the mechanical properties of the xylan neat films. Surface morphology, mechanical and barrier properties of the xylan films were comparatively measured. It was shown that the prepared xylan films possess high transparency and homogenous structure as revealed by FESEM. Mechanical testing explored that increasing of BCNs contents from 0 to $30 \%$ yielded consolidated xylan films with high tensile strength properties. Also, sorbitol addition generally provided less brittle xylan films. Owning to biodegradable properties, the prepared xylan films with appropriate mechanical strength and barrier properties are promising for potential applications in food packaging industries and can easily be replaced with synthetic petroleum-based ones.
\end{abstract}

Biography 


\title{
Experimental analysis of mass loss kinetics during heat treatment of wood
}

\author{
Jakub Dömény 1*-Dominik Hess 1 - Pavlína Suchomelová 1 - Petr Čermák 1
}

\author{
1 Department of Wood Science and Technology, Faculty of Forestry and Wood \\ Technology, Mendel University in Brno, Zemědělská 3, 613 00, Brno, Czech \\ Republic \\ * Corresponding author \\ Jakub.domeny@mendelu.cz.
}

\begin{abstract}
The mass loss kinetics during heat treatment of selected wood species was experimentally analyzed. European beech (Fagus sylvatica L.), English oak (Quercus robur L.), Norwegian spruce (Picea abies L. Karst.) and Scots pine (Pinus sylvestris L.) wood specimens were heat treated at $140^{\circ} \mathrm{C}, 160^{\circ} \mathrm{C}, 180^{\circ} \mathrm{C}, 200^{\circ} \mathrm{C}$ and $220^{\circ} \mathrm{C}$ for 1 to 6 hours using atmospheric pressure and superheated steam environment. The process intensity was determined by mass loss $\left(\mathrm{ML}_{\mathrm{L}}\right.$, based on oven-dry mass before and after the heat treatment. Furthermore, the equilibrium moisture content (EMC) was determined before and after heat treatment to analyze the effect of mass loss on the sorption properties. For the studied wood species, the ML was found to be less than $1-1.5 \%$ when temperature of $140^{\circ} \mathrm{C}$ and $160^{\circ} \mathrm{C}$ was applied. Differences between studied species were more significant at temperatures higher than $160^{\circ} \mathrm{C}$. At higher temperature $\left(220^{\circ} \mathrm{C}\right)$ a mass loss attained of $13.5 \%$ (beech), $18.8 \%$ (oak), 6.7\% (spruce) and 13.5\% (pine). The EMC was reduced after heat treatment within the range of $4-48 \%, 0.4-47 \%, 1-32 \%$ and $0.7-40 \%$ for beech, oak, spruce and pine, respectively. The reason for the decrease of the EMC is that less water is absorbed by the cell wall after the heat treatment as a result of chemical compounds degradation with a decrease of hydroxyl $(\mathrm{OH}-)$ groups. Further, the EMC correlates exponentially $\left(\mathrm{R}_{2}=0.91-0.95\right)$ with the decrease of specimens' mass depending on the used wood species and modification temperature applied. This study provides experimental mass loss results of various heat treated wood species and obtained data can be used for heat treatment process optimization as well as for the modeling and prediction of the mass loss and required material properties (EMC) for designed wooden products.
\end{abstract}

Key words: heat treatment, mass loss, equilibrium moisture content (EMC); wood modification

\section{Introduction}

Wood, as renewable material, plays an important role in our daily life as well as industry area. This material has a broad range of material properties for various applications. However, natural wood also has undesirable properties that might limit the range of feasible applications. 
Therefore, it has been a great scientific effort aimed at obtaining wood-based material that maintain its advantages over time and at the same time reduce its natural disadvantages such as natural variability, dimensional instability or biological degradability (Kutnar and Muthu 2016). Dimensional instability and biological degradability of wood are considered as a major disadvantages of wood. These particular properties are highly influenced by water presence. However, wood with inadequate material properties can be modified by various methods (Rowell 1983, Wepner and Militz 2005, Hill 2006). Wood modification methods can be applied in order to improve natural disadvantages by pre-swelling, i.e. bulking, or reducing the number of water attracting chemical groups, i.e. by chemical reaction or by thermal degradation of cell wall. Heat treatment for instance can be used as an efficient way to degrade some of the cell wall constituents accompanying with chemical changes resulting reduction in the number of hydroxyl groups of the hemicelluloses, as well as decreased accessibility of water molecules to cellulose hydroxyl groups due to the increase in cellulose crystallinity and cross-linking in lignin (Weiland and Guyonnet 2003; Hakkou et al. 2005; Boonstra and Tjeerdsma 2006). Heat treatment of wood has long been recognized as a potential method to improve the natural properties of the wood and has been one of the most successful methods of modification for many years. If the process is controlled carefully, the properties obtained following thermal modification can be tailored for further use of the wood in specific applications. One of the most important characteristics of thermally modified wood is a decrease in its equilibrium moisture content (EMC). Severity of the thermal modification process is commonly expressed as a mass loss (Candelier et al. 2016; Hill 2006). The mass loss as a consequence of the thermal degradation of wood is highly dependent on the initial wood characteristics such as wood species and its density as well as process parameters (Pierre at al. 2011). The mass loss is easy to be determined and it is assumed to be correlated with other material properties, such as equilibrium moisture content, swelling, decay resistance and mechanical properties (Nasir et al. 2018; Candelier et al. 2011; Mazela et al., 2003; Obataya et al., 2002). The knowledge about the mass loss kinetics of various wood species under different process parameters has therefore a high importance to optimize the heat treatment process, control the product quality and predict required material properties of heat treated wood. Therefore, the main motivation of this study was to analyze mass loss and equilibrium moisture content kinetics for selected softwood and hardwood species as a function of time and temperature.

\section{Materials \& Methods}

European beech (Fagus sylvatica L.), English oak (Quercus robur L.), Norwegian spruce (Picea abies L. Karst.) and Scots pine (Pinus sylvestris L.) were studied within present study. Wood specimens with dimensions $20 \times 20 \times 10 \mathrm{~mm} 3(R \times T \times L)$ were sorted into groups of ten for each species and treatment. The average oven-dry density of testing specimens was $0.69 \mathrm{~g} / \mathrm{cm} 3$ for beech, $0.67 \mathrm{~g} / \mathrm{cm}_{3}$ for oak, $0.52 \mathrm{~g} / \mathrm{cm}_{3}$ for spruce and $0.57 \mathrm{~g} / \mathrm{cm}_{3}$ for pine. The specimens were 
conditioned at $99 \%$ relative humidity $(\mathrm{RH})$ and $20{ }^{\circ} \mathrm{C}$ using the climate box and EMC at fiber saturation point (FSP) was determined according Eq. (1).

$E M C 99 \% R H(\%)=\left(m_{w}-m_{d}\right) / m_{d} \cdot 100$

where: $m_{w}$ is specimens' wet mass and $m_{d}$ is specimens' dry mass.

Afterwards, specimens were treated in laboratory thermal modification chamber using atmospheric pressure and superheated steam environment. Temperatures of $140^{\circ} \mathrm{C}, 160^{\circ} \mathrm{C}$, $180^{\circ} \mathrm{C}, 200^{\circ} \mathrm{C}$ and $220^{\circ} \mathrm{C}$ was applied for oven-dried specimens. The temperature was maintained for 1, 2, 3, 4, 5 and 6 hours. The mass loss $\left(\mathrm{ML}_{\mathrm{L}}\right)$ of thermally treated specimens was determined immediately after the end of the treatment process in order to evaluate the degree of the thermal modification. The ML was calculated according to Eq. (2).

$\operatorname{ML}(\%)=(m d u-m d m) / m d u \cdot 100$

where: $m d u$ is unmodified dry mass of the specimens and $m d m$ is modified dry mass.

Furthermore, thermally modified specimens were conditioned at $99 \% \mathrm{RH}$ and $20^{\circ} \mathrm{C}$, according the same procedure as previous modification, and equilibrium moisture content at FSP was determined according to Eq. (1) and values were compared to those at reference state.

\section{Results and Discussion}

The mass loss behavior of wood is considered as an indicator of the degree of modification achieved. As expected, the rising ML of specimens was observed as modification temperature level increased (Table 1). The influence of treatment temperature on the modification effect was significantly more pronounced than the influence of treatment time. Mass loss increased with the modification time and temperature and the same mass loss results could be obtained with different temperature, depending on the treatment time. According to the recorded data, it is evident that the thermal degradation reaction kinetics is strongly influenced by the nature of wood species. Hardwoods have been shown to be more sensitive to the thermal degradation than softwoods as demonstrated by the higher mass loss recorded for a same modification time and temperature.

Table 3. Mass loss results of selected wood species thermally modified at 140,160,180, 200 and $220^{\circ} \mathrm{C}$ (results represent the range from 1 hour to 6 hours of treatment)

\begin{tabular}{lccccc}
\hline MASS LOSS (\%) & \multicolumn{5}{c}{ Temperature } \\
& $\mathbf{1 4 0}^{\circ} \mathbf{C}$ & $\mathbf{1 6 0}^{\circ} \mathbf{C}$ & $\mathbf{1 8 0}^{\circ} \mathbf{C}$ & $\mathbf{2 0 0}^{\circ} \mathbf{C}$ & $\mathbf{2 2 0}^{\circ} \mathbf{C}$ \\
\hline \multirow{2}{*}{ Beech } & $0.13-0.46$ & $0.33-0.98$ & $1.01-1.99$ & $1.55-5.65$ & $4.41-13.49$ \\
& $(0.12)$ & $(0.04)$ & $(0.10)$ & $(0.23)$ & $(0.42)$ \\
Oak & $0.27-0.86$ & $0.78-1.79$ & $1.73-4.61$ & $5.04-12.23$ & $8.71-18.74$ \\
& $(0.10)$ & $(0.06)$ & $(0.25)$ & $(0.59)$ & $(0.54)$
\end{tabular}


Proceedings of the $\mathbf{2 0 2 0}$ Society of Wood Science and Technology International Convention

\begin{tabular}{lccccc} 
Spruce & $0.36-0.65$ & $0.59-0.87$ & $0.78-1.65$ & $2.35-5.98$ & $2.45-6.64$ \\
& $(0.15)$ & $(0.13)$ & $(0.13)$ & $(0.22)$ & $(0.19)$ \\
Pine & $0.57-1.69$ & $1.54-2.72$ & $2.55-5.46$ & $4.61-8.15$ & $8.42-13.45$ \\
& $(0.22)$ & $(0.33)$ & $(0.19)$ & $(0.62)$ & $(0.89)$ \\
\hline
\end{tabular}

* average standard deviation in parentheses

The ML was found to be less than $1-1.5 \%$ when temperature of $140^{\circ} \mathrm{C}$ and $160^{\circ} \mathrm{C}$ was applied. However, pine wood exhibits higher mass loss which may be explained by general richness in natural resins, containing volatile substances (Rowell et al. 2005). Differences between studied species were more significant at the temperatures above $160^{\circ} \mathrm{C}$. These differences may be explained by the quite similar reactions at the beginning of the thermo-degradation processes involving mainly removal of chemically bounded water and vaporization of volatile extractable compounds, while the nature of the wood species becomes more important in a second time due to the differences in chemical composition between softwoods and hardwoods. At the highest temperature $\left(220^{\circ} \mathrm{C}\right.$ ) a mass loss attained of $13.5 \%$ (beech), $18.8 \%$ (oak), $6.7 \%$ (spruce) and $13.5 \%$ (pine). Furthermore, the natural transition point between free and bound water, known as FSP, is defined as the theoretical condition of wood when its cell walls are fully saturated by water but no free water remains in the cell lumens (Skaar 1984). Equilibrium moisture content (EMC) at FSP was reduced after thermal modification within all applied treatments (Tab. 2). Depending on the temperature and time conditions used during the process, the EMC was reduced within the range of $4-48 \%, 0.4-47 \%, 1-32 \%$ and $0.7-40 \%$ for beech, oak, spruce and pine, respectively. Although no statistically significant effect was observed at $140^{\circ} \mathrm{C}$ for all studied wood species, the EMC of thermally modified wood exhibits a larger reduction with increasing temperature and time. The reason for the decrease of the EMC is that less water is absorbed by the cell wall after the thermal modification as a result of chemical compounds degradation with a decrease of hydroxyl (OH-) groups. The EMC reduction generally indicates an improvement in dimensional stability of analyzed wood species following thermal modification as reported by Altgen et al. (2018), Čermák et al. (2015), Rautkari and Hill (2014) and Biziks et al. (2014).

Table 4. Equilibrium moisture content results of selected wood species thermally modified at $140,160,180,200$ and $220^{\circ} \mathrm{C}$ (results represent the range from 1 hour to 6 hours of treatment)

\begin{tabular}{lcccccc}
\hline EMC (\%) & \multicolumn{5}{c}{ Temperature } \\
& Ref & $\mathbf{1 4 0}^{\circ} \mathbf{C}$ & $\mathbf{1 6 0}^{\circ} \mathbf{C}$ & $\mathbf{1 8 0}^{\circ} \mathbf{C}$ & $\mathbf{2 0 0}^{\circ} \mathbf{C}$ & $\mathbf{2 2 0}^{\circ} \mathbf{C}$ \\
\hline \multirow{2}{*}{ Beech } & 28.9 & $27.8-26.5$ & $26.9-25.4$ & $26.2-23.6$ & $24.2-18.7$ & $18.8-15.1$ \\
& $(1.8)$ & $(0.35)$ & $(0.47)$ & $(0.44)$ & $(0.54)$ & $(0.45)$ \\
\multirow{2}{*}{ Oak } & 24.7 & $24.6-23.9$ & $24.1-22.6$ & $22.2-19.7$ & $18.1-14.5$ & $15.6-13.1$ \\
& $(1.0)$ & $(0.29)$ & $(0.44)$ & $(0.20)$ & $(0.29)$ & $(0.16)$ \\
\multirow{2}{*}{ Spruce } & 27.1 & $26.8-26.2$ & $26.2-24.5$ & $25.3-22.9$ & $22.6-19.0$ & $21.8-18.4$ \\
& $(1.2)$ & $(0.34)$ & $(0.22)$ & $(0.38)$ & $(0.24)$ & $(0.28)$ \\
\multirow{2}{*}{ Pine } & 25.9 & $25.7-24.4$ & $25.6-23.4$ & $23.6-21.1$ & $21.3-18.5$ & $18.7-15.6$ \\
& $(1.1)$ & $(0.51)$ & $(0.48)$ & $(0.32)$ & $(0.34)$ & $(0.39)$ \\
\hline
\end{tabular}

* average standard deviation in parentheses

It is evident that the EMC correlates exponentially with the decrease of specimen's mass depending of used wood species and modification temperature applied (Fig. 1). However, the EMC seems to be almost stabilized beyond a limit value of approximately $10-12 \%$ of mass loss. This 
mass loss limit might indicate the completion of decomposition of hydroxyl groups accessible for water molecules, and therefore the EMC reduction is not further affected by the treatment time. Similar findings were reported earlier by Welzbacher et al. (2007), who stated that nearly unaffected EMC was observed above $10 \%$ of mass loss for spruce wood thermally modified at 180 $-240^{\circ} \mathrm{C}$.

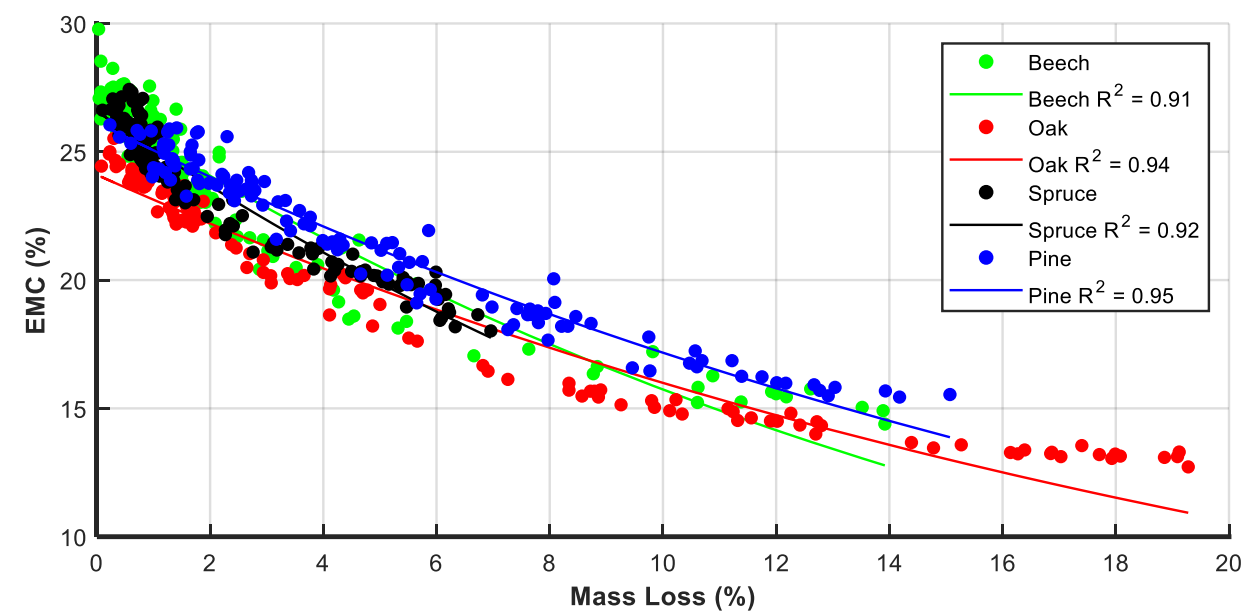

Figure 1. Exponential correlation between equilibrium moisture content (EMC) at $20^{\circ} \mathrm{C}$ and $99 \%$ relative humidity (RH) and mass loss of various thermally modified wood species

\section{Summary and Conclusions}

1. The mass loss kinetics is influenced by the nature of studied wood species.

2. No significant mass loss differences were found when low temperatures $\left(140^{\circ} \mathrm{C}\right.$ and $160^{\circ} \mathrm{C}$ ) were used. This was caused mainly due to removal of chemically bounded water and vaporization of volatile extractable compounds.

3. Pine wood exhibits higher mass loss which may be explained by general richness in natural resins.

4. The nature of the wood species becomes more important at higher temperature $\left(>160^{\circ} \mathrm{C}\right)$ due to the differences in thermal degradability between softwood and hardwood chemical compounds.

5. Equilibrium moisture content (EMC) was considerably reduced after the thermal modification depending on the temperature and time conditions used during the process.

6. EMC of thermally modified wood exhibits a larger reduction with increasing temperature and time. 


\section{Proceedings of the 2020 Society of Wood Science and Technology International Convention}

7. Those results can be used for the thermal modification process optimization and prediction of required mass loss as well as material properties (enhanced sorption behavior) for designed wooden products.

\section{Acknowledgements}

This study was funded by Grant Agency of the Czech Republic (GAČR), project no. 19-25171Y "Multi-scale Hygro-thermo-mechanical Behavior of Modified Wood-based Materials".

\section{References}

Altgen, M., Willems, W., Hosseinpourpia, R., Rautkari, L (2018) Hydroxyl accessibility and dimensional changes of Scots pine sapwood affected by alterations in the cell wall ultrastructure during heat-treatment. Polymer Degradation and Stability 152:244-252.

Biziks, V., Andersons, B., Sansonetti, E., Andersone, I., Militz, H., Grinins, J. (2014) One-stage thermo-hydro treatment (THT) of hardwoods: an analysis of form stability after five soakingdrying cycles. Holzforschung 69(5):563-571.

Boonstra, M., Tjeerdsma, B. (2006) Chemical analysis of heat treated softwoods. Holz RohWerkstoff 64(3):204-211.

Candelier, K., Chaouch, M., Dumarçay, S., Pétrissans, A., Pétrissans, M., Gérardin, P. (2011) Utilization of thermodesorption coupled to GC-MS to study stability of different wood species to thermodegradation. Journal of Analytical and Applied Pyrolysis 92(2):376-383.

Candelier, K., Thevenon, F. M., Petrissans, A., Dumarcay, S., Gerardin, P., Petrissans, M. (2016) Control of wood thermal treatment and its effects on decay resistance: a review. Annals of Forest Science 73(3):571-583.

Čermák, P., Rautkari, L., Horáček, P., Saake, B., Rademacher, P., Sablík, P. (2015) Analysis of dimensional stability of thermally modified wood affected by re-wetting cycles. BioResources 10(2):3242-3253.

Hakkou, M., Pétrissans, M., Zoulalian, A., Gérardin, P. (2005) Investigation of wood wettability changes during heat treatment on the basis of chemical analysis. Polymer Degradation and Stability 89(1):1-5.

Hill, C. (2006) Wood Modification - Chemical, Thermal and Other Processes. Wiley Series in Renewable Resources, p.239.

Kutnar, A., Muthu, S.S. (2016) Environmental impacts of traditional and innovative forest-based bioproducts. Springer, pp. 248.

Mazela, B., Zakrzewski, R., Grzeskowiak, W., Cofta, G., Bartkowiak, M. (2003) Preliminary research on the biological resistance of thermally modified wood. In: Proceedings of the 1 st European Conference on Wood Modification. Ghent University (RUG), pp. 113-120.

Nasir, V., Nourian, S., Avramidis, S., Cool, J. (2018) Prediction of physical and mechanical properties of thermally modified wood based on color change evaluated by means of "group method of data handling" (GMDH) neutral network. Holzforschung 73(4):381-392.

Obataya, E., Higashihara, T., Tomita, B. (2002) Hygroscopicity of heat treated wood III. Effect of steaming on the hygroscopicity of wood. Mokuzai Gakkaishi 48(5):358-355.

Pierre, F., Almeida, G., Brito, J. O., Perré, P. (2011) Influence of torrefaction on some chemical and energy properties of maritime pine and pedunculate oak. BioResources 6(2):1204-1218. 
Rautkari, L., Hill, C. (2014) Effect of initial moisture content on the anti-swelling efficiency of thermally modified Scots pine sapwood treated in a high-pressure reactor under saturated steam. Holzforschung 68(3):323-326.

Rowell, R.M. (1983) Chemical modification of wood. For. Prod. Abstracts 6:363-382. Rowell, R.M. (2005) Handbook of wood chemistry and wood composites. Ed. R.M. Rowell. Florida: CRC Press, p. 487.

Skaar, C. (1984) Wood-water relationships. In: The Chemistry of Solid Wood, American Chemical Society 207:127-174.

Weiland, J.J., Guyonnet, R. (2003) Study of chemical modification and fungi degradation of thermally modified wood using DRI FT spectroscopy. Holz als Roh-und Werkstoff 61(3):216220.

Welzbacher, C. R., Brischke, C., Rapp, O.A. (2007) Influence of treatment temperature and duration on selected biological, mechanical, physical and optical properties of thermally modified timber. Wood Material Science and Engineering 2(2):66-76.

Wepner, F., Militz, H. (2005) Fungal resistance, dimensional stability and accelerated weathering. performance of N-Methylol treated veneers of Fagus sylvatica, p. 169-177.

Biography 
Proceedings of the 2020 Society of Wood Science and Technology International Convention

\title{
Smart Thumper ${ }^{\mathrm{TM}}$, a Non Destructive Lumber Evaluation Phone Application
}

\author{
Frederico José Nistal França \\ fn90@msstate.edu \\ Songyi Han \\ sh2350@msstate.edu \\ R. Daniel Seale \\ rds9@msstate.edu \\ Mississippi State University, USA
}

\section{Abstract}

The objective of this research was to demonstrate the use of Smart Thumper in longitudinal and transverse vibration nondestructive techniques. The phone application uses its accelerometer and microphone to reach the natural frequency of 139 pieces of $2 \times 4(38.1 \times 88.9 \mathrm{~mm})$ and 135 pieces of $2 \times$ $8(38.1 \times 184.2 \mathrm{~mm})$ southern pine lumber. The phone application was compared to commercial transverse vibration equipment (Metriguard Model $340 \mathrm{E}$-Computer) and a longitudinal stress wave tool (Fibre-gen Hitman HM200). Lumber pieces were destructively tested following ASTM standards. A strong correlation was obtained between the transverse vibration and longitudinal stress wave modulus of elasticity (MOE) collected with Smart Thumper and the static bending results for both lumber sizes. Using the vibration mode (accelerometer), the $r_{2}$ was equal to 0.85 and 0.81 for $2 \times 4$ and $2 \times 8$ respectively). Evaluating lumber with the soundwave (microphone), the rawas equal to 0.78 and 0.89 for $2 \times 4$ and $2 \times 8$ respectively). The Smart Thumper results resemble the results obtained from both the E-Computer and the Hitman HM 200. Comparing Smart Thumper results with modulus of rupture (MOR) indicates that the results are consistent for both approaches and lumber sizes (accelerometer: $r_{2}=0.42$ and $r_{2}=0.38$ for $2 \times$ 4 and $2 \times 8$ respectively; microphone: $r_{2}=0.36$ and $r_{2}=0.35$ for $2 \times 4$ and $2 \times 8$ respectively). These results indicate a potential use of Smart Thumper to determine the modulus of elasticity (MOE) of structural lumber pieces and to expand the access of nondestructive techniques.

Biography 
Proceedings of the 2020 Society of Wood Science and Technology International Convention

\title{
Building a portable offline bark identification system through training a MobileNet-V2 by Knowledge Distilling and Network Pruning
}

\author{
Rado Gazo \\ gazo@purdue.edu \\ Fanyou Wu \\ wu1297@purdue.edu \\ Eva Haviarova \\ ehaviar@purdue.edu \\ Bedrich Benes \\ bbenes@purdue.edu \\ Purdue University, USA
}

\begin{abstract}
Automatic identification of tree species using images of tree bark can be useful for several forestryrelated tasks. Current well-performing bark identification systems rely heavily on real-time internet connection to access massive computing power. There are instances where such connections may be scarce in the forest. An off-line framework with acceptable performance on smart device may be a solution to this problem. In this research, we focus on training a light-weight neural network MobileNet-V2 with knowledge distilling and network pruning approach to obtain better model weights.

Biography
\end{abstract}




\title{
Proceedings of the 2020 Society of Wood Science and Technology International Convention
}

\section{Assessing success of sustainability curriculum development efforts: evidence from a US higher education institution.}

\author{
Rado Gazo1 \\ gazo@purdue.edu \\ ÇAĞATAY TAŞDEMİR2 \\ cagatay.tasdemir@btu.edu.tr
}

\section{${ }_{1}$ Purdue University, USA 2Bursa Technical University, Turkey}

\begin{abstract}
Sustainability issues are among priorities of global concerns and society expects universities to educate youth and help them reach a certain level of sustainability awareness. New regulations and laws on sustainability put pressure on businesses across all industries and force them to evolve into their more sustainable versions. There is a demand for additional (sustainability) qualifications in graduates when hiring new personnel. Many higher education institutions have started to develop and incorporate sustainability curriculums into their programs to respond to expectations of society and other stakeholders. However, whether these efforts achieve the desired outcomes is not well documented. This study was designed to present an example of a modern management techniquesbased inter-disciplinary sustainability curriculum and to provide evidence through pre- and posteducation assessment of students' perception of sustainability issues and modern management techniques to address them. A 3-credit 16 weeks long undergraduate level course that horizontally integrated sustainability into a secondary wood products engineering framework has been developed and taught at a U.S. higher education institution and then, success of developed sustainability curricula was measured with a 20-question survey. Results show that course content was successful at increasing sustainability awareness at both overall and individual sustainability pillar levels. At the end, $100 \%$ of students were able to develop complete understanding of various modern management techniques and stated that they felt confident to apply learnt skills to real life issues within their profession upon graduation.
\end{abstract}

Biography 


\title{
Proceedings of the 2020 Society of Wood Science and Technology International Convention
}

\author{
Circular Economy Principles for Furniture Industry \\ Eva Haviarova 1 \\ ehaviar@purdue.edu \\ Kendria Huff 1 \\ huff29@purdue.edu \\ Manja Kitek Kuzman2 \\ manja.kuzman@bf.uni-lj.si
}

\begin{abstract}
${ }_{1}$ Forestry and Natural Resources, Purdue University, USA 2 University of Ljubljana, Biotechnical Faculty, Department of Wood Science and Technology, Slovenia
\end{abstract}

\section{Abstract}

According to the Environmental Protection Agency, Americans throw out more than 12 million tons of furniture and furnishings each year. Europe generates just about the same amount (10 million). Because of complexity of furniture structure, only a small percentage of used furniture is recycled. Upholstered furniture is especially a problem. Rapid growth of furniture waste is linked to the fast population growth and unsustainable consumer practices. In the last decade, furniture became a commodity with low value, cost, and quality. Fast fashion trends are pushing the manufacturing of new stylish products quickly and cheaply and it is also true for the furniture industry and their products. To remedy this growing problem in furniture sector, there is a need to address each aspect of product life cycle. The framework of circular economy can produce alternative pathways that will reduce the end-of-life options that have negative impacts on the environment. Not only can alternative pathways be discovered, but products can also be produced in a way that initially prolongs their life span. There are furniture companies out there already incorporating circular economy principles: using recycled material, developing innovative products for easy recycling, and extending product lifespan by applying strength design. However, in general, we still have ways to go to implement true sustainability practices in the furniture production sector. This project is researching and benchmarking circular economy efforts in the furniture industry in the US and Europe and pointing out successful examples. The supporting policies and their synergies are also evaluated. Case studies will be presented and will determine whether these frameworks are viable and could be utilized.

\section{Biography}




\title{
Proceedings of the 2020 Society of Wood Science and Technology International Convention
}

\author{
Natural Insulating Material in the Form of Burning \\ Michaela Horvathova \\ michaela.horvathova@fbi.uniza.sk \\ Linda Makovicka \\ linda.makovicka@fbi.uniza.sk \\ University of Zilina, Slovakia
}

\begin{abstract}
The paper examines three types of natural insulation materials, such as fiberboard, hemp and straw, from the point of view of fire safety. Cellulose-based materials allow a wide range of applications when used for insulation and weatherproofing of buildings, in particular floors, roofs, ceilings, attics, sound barriers, etc. The use of these materials is increasing in ecological constructions as well as for weatherproofing wood-based structures. In terms of fire safety requirements, the question is: Which insulating material is the safest in terms of fire propagation? The article focuses on natural products used as external insulation systems which are covered by a facade plaster. Each type of insulation is briefly described in terms of its composition, use, and production process. We describe the process of preparation of samples as well as the testing and measurement procedures. Three tests were carried out for each type of material. For a more objective evaluation, results were averaged. The results of the cone calorimeter were used to obtain data for comparison. The aim is to clarify the behavior of the natural insulating material with regard to the heat release rate, ignition time, burning duration, and maximum heat release rate. These are the essential parameters for comparison. The values were compared to determine the safest material from the point of view of fire safety.
\end{abstract}

Key words: natural insulating material, cone calorimeter, heat release rate, straw, hemp, fiber board.

\section{Biography}




\title{
Proceedings of the 2020 Society of Wood Science and Technology International Convention
}

\author{
Low temperature potassium hydroxide pulping of straw \\ Md Sarwar Jahan \\ Pulp and Paper Research Division \\ Bangladesh Council of Scientific and Industrial Research \\ Bangladesh \\ sarwar2065@hotmail.com
}

\begin{abstract}
Conventional pulping processes require high pressure digester, which increased capital investment. In order to develop a simple technology with low capital investment; atmospheric pressure pulping process is our interest of this study.

The present research is focused on the pre-extraction of rice straw and wheat straw by potassium hydroxide $(\mathrm{KOH})$ at $90 \circ \mathrm{C}$ prior to pulping in order to remove silica and partial removal of lignin and hemicelluloses. Pre-extraction removed $76 \%$ and $73 \%$ lignin, $50.5 \%$ and $26.8 \%$ pentosan and $81 \%$ and $87 \%$ silica from the rice and wheat straw, respectively. Pre-extracted rice straw and wheat straw were subjected to $\mathrm{KOH}$ pulping by varying $\mathrm{KOH}$ charge $(6,8,10$ and $12 \%$ as $\mathrm{NaOH})$, time $(60,90$ and $120 \mathrm{~min}$ ) and temperature (70 and 90 。C). Pulp yield of $43.6 \%$ and $51.0 \%$ with kappa number 16.2 and 20.2, for rice straw and wheat straw, respectively, was obtained at the conditions of $12 \%$ alkali for 120 min of cooking at $90 \circ \mathrm{C}$. $\mathrm{KOH}$ rice straw and wheat straw pulp bleached to $76.8 \%$ and $80.1 \%$ brightness, respectively, by $D_{0} E p D_{1}$ bleaching sequences with $\mathrm{ClO}_{2}$ consumption of $25 \mathrm{kgClO} / \mathrm{ton}$ of pulp. The papermaking properties were inferior to that of corresponding pulps from higher temperature cooking. Dissolved silica, lignin and hemicelluloses were separated from the spent cooking liquor and potassium rich liquor was used for soil amendment.
\end{abstract}

Biography 


\title{
Proceedings of the 2020 Society of Wood Science and Technology International Convention
}

\section{OBJECTIVE AND SUBJECTIVE DETECTION OF WOOD DEFECTS}

\author{
Tomislav Seddlar \\ tsedlar@sumfak.hr \\ Branimir Jambreković \\ bjambreko@sumfak.hr \\ Filip Veselčić \\ fveselcic@sumfak.hr \\ Tomislav Siniković \\ tsinkovic@sumfak.hr \\ Faculty of Forestry, Croatia
}

\begin{abstract}
Modern wood processing requests access to wood with the aim of maximizing utilization of wood in qualitative and quantitative terms. One of the main obstacles to this objective is wood defects which are unavoidable flaws in tree growth and development of wood (knots, cracks, discoloration, etc.). The demand for cost-effective and rapid production with high economic utilization of raw materials led to the development of high-tech scanners that identify the surface of wood elements more effectively than the human eye. Information about identified errors from the scanned surface of wood elements is instantly received. This information proposed a model of cutting elements and associated classes with the aim of maximizing the qualitative or quantitative utilization. Considering that all wood defects from discoloration to cracks are computer programmed with an objective view, we are left to assume that the observers will not just look at a certain wood element as well as scanner. Their observation is subjective and a matter of the experience and perception of certain changes or anomalies on the wood elements. The aim of this study was to determine wood defects with industrial scanner as objective observation and detecting wood defects with human eye as a subjective perception of certain wood defects having regard that human eyes also have its own limits. Wood defects were investigated on wood elements from Slavonian oak (Quercus robur L.).

\section{Biography}


Proceedings of the 2020 Society of Wood Science and Technology International Convention

\author{
Dynamic Properties of Traditional Timber Building \\ Gi Young Jeong \\ Chonnam Naional University, Korea
}

\begin{abstract}
The goal of this study is to analyze the dynamic properties of traditional timber buildings in South Korea. To calibrate the ambient vibration test for traditional timber buildings, a timber frame building was constructed. The column composed of four columns in the front and two columns in the left and right. Hand-pushing excitation was applied to create the vibration of building in X-direction and Y-direction. Three different modal shapes of buildings were obtained in the experimental test. From the calibration of the methodologies, dynamic properties of three different traditional timber buildings in South Korea (Bulhoesa Daewoongjeon, Muwisa Geukrakjeon, Seonunsa Deawoongjeon) were investigated. Natural frequency of three buildings ranged from 1 to $3 \mathrm{~Hz}$. The highest natural frequency of $2.148 \mathrm{hz}$ of mode 1 was obtained from Muwisa Geukrakjeon and the lowest natural frequency of 1.367 of mode 1 was obtained from Bulhoesa Deawoong jeon was obtained.
\end{abstract}

\title{
Biography
}




\title{
Cellulose Nanofiber Effect on Bonding Strength of PUR and PVAc Glued Wood Joint in Shear Loading
}

\author{
Gourav Kamboj \\ kamboj@fld.czu.cz \\ Milan Gaff \\ gaff@fld.czu.cz \\ Anil Kumar Sethy \\ sethyanil@gmail.com \\ Rezaei Fatemeh \\ rezaei@fld.czu.cz
}

Czech University of Life Science, Prague, Czech Republic

\begin{abstract}
Adhesives play an important role in the wood industry and mechanical performance of wood adhesive bonds is of fundamental importance. Development of high performance material using nanoparticle or nanofiller has become a prominent area of research in academia as well as in industry. Cellulose nonofibers (CNF) have been reported to be relatively safe, even in its dry form and it is one of the most abundant material on the earth. High tensile strength and a Young's modulus make cellulose nanofibre one of the suitable reinforcing material for nanocomposites. In this study, cellulose nanofiber was added in PVAc (polyvinyl acetate) and PUR (Polyurethane) adhesive at various proportion $(0-3 \%$ based on weight). Lap joints were prepared using Beech (Fagus Silvatica) wood samples and glue shear strength was assessed. Addition of CNF showed significant effect on glue shear strength.
\end{abstract}

Biography 
Proceedings of the 2020 Society of Wood Science and Technology International Convention

\title{
Digital Solutions in Architecture and Timber Construction
}

\author{
Manja Kitek Kuzman 1 \\ manja.kuzman@bf.uni-lj.si \\ Eva Haviarova2 \\ ehaviar@purdue.edu
}

\author{
1 University of Ljubljana, Biotechnical Faculty, Department of Wood Science and \\ Technology, Slovenia \\ 2 Forestry and Natural Resources, Purdue University, USA
}

\begin{abstract}
An inspiration for the creation of innovative and interesting structures have always been nature with its flowing, organic forms, which have evolved for maximum optimization and efficiency. Organic architecture is based on studies of these nature-based forms, which as a rule, are almost never straight. The design and implementation of such flowing shapes is more complex than working with orthogonal shapes and requires a good spatial performance, knowledge of geometry and use of suitable design tools and techniques. Digitalization has facilitated the development of com $\neg$ plex geometric shapes and free-form shapes that were not mana geable before with simple design tools. Thanks to the broadened potential of computing, parametric design, and digital manufacturing, it is now possible to design structural elements and structures that deviate from orthogonal practices and form complex shapes. Architects and engineers consider the use of computers and computation techniques in planning and looking for solutions to a given design problem. They are provided with powerful analytical tools to create new designs, predict their behaviour, and formulate effective production stra $\rightarrow$ tegies. The materials that have been typically used are now combined with new engineered wood products (EWPs), which have the advantage of high load-bearing capacity, good dimensional stability, and flexibility in large dimensions. EWPs also offer greater design freedom for ambitious construc-tion and advanced manufacturing processes. The classic construction me $\neg$ thods are joined with a novel 3D printing technology, including 3D printing with wood filaments combined with PLA material. 3D printing already allow the creation of large and advance building structures. Digitalization solutions in architecture will be presented with examples of recently realized pro-jects and their involvement in different design stages. Examples of educational programs and student outputs dealing with digitalization processes will be also featured.
\end{abstract}

\section{Biography}




\title{
Proceedings of the 2020 Society of Wood Science and Technology International Convention
}

\section{Investigations of the Strength and Resistance of Glued Pine Wood from Tuchola Region}

\author{
Tomasz Krystofiak \\ tomkrys@up.poznan.pl \\ Barbara Lis \\ blis@up.poznan.pl \\ Radoslaw Mirski \\ radoslaw.mirski@up.poznan.pl
}

\section{Poznań University of Life Sciences, Department of Wood Based Materials, Poland}

\section{Abstract}

In the last years there has been a great interest in wooden construction. Glued laminated timber is used much more often in the construction of houses because of its broadly understood material savings. It can be observed a significant development in the field of adhesives for the production of large-size wooden elements for construction. So far widely used resorcinol-phenol-formaldehyde (RPF) adhesives are replaced for example by new generation of the melamine-urea-formaldehyde (MUF) resins.

For the wooden building construction elements pine wood is commonly used. Such wood specie has different properties depends on the area. Area around Tuchola city in Poland belongs to the regions where pine forest is growing.

For the experiments pine wood from Tuchola region and melamine-urea-formaldehyde resins (commercial product) were used. Samples prepared from bigger glued laminated timber and prepared in the laboratory conditions for the investigations were used. The glue mixtures have been prepared accordingly to the adhesive producer requirements (in relation 100:10 and 100:20 p.b.w. resin/hardener). Samples for the shearing strength and compression strength accordingly to the standards were prepared. The shearing strength by the loading speed $50 \mathrm{~mm} / \mathrm{min}$ was estimated, while compression strength by the loading speed $20 \mathrm{~mm} / \mathrm{min}$.

The strength and water- and thermo resistance of the glue-lines were carried out. The following tests were carried out: strength after 7 days of the conditioning time; strength after 96 hours in cold water (in wet state and after 7 days of the conditioning), strength after 6 hours of boiling water/2 hours cold water (in wet state and after 7 days of the conditioning) action; strength after 1 or 3 hours the temperature of 80 。C action. After strength measurements for each sample the WFP (wood failure coefficient) was estimated.

It was stated that tested connections with the good resistance were characterized. Results depends on the properties of wood. With the increasing of wood density higher WFP values were observed.

Keywords: pine wood, gluability, MUF resin, strength, resistance, Tuchola area, building construction element 
Proceedings of the $\mathbf{2 0 2 0}$ Society of Wood Science and Technology International Convention

Acknowledgement:

This research was funded by the National Centre for Research and Development, BIOSTRATEG3/ 344303/14/NCBR/2018.

Biography 
Proceedings of the $\mathbf{2 0 2 0}$ Society of Wood Science and Technology International Convention

\title{
Variations of earlywood vessel diameter of Quercus petraea Liebl according to tree size and altitude
}

\author{
Amelie Taupin 1 \\ amelie.taupin@inra.fr \\ Maryline Harroue 1 \\ maryline.harroue@inra.fr \\ Baptiste Kerfriden 1 \\ baptiste.kerfriden@inra.fr \\ Maxime LaCarin 1 \\ maxime.lacarin@inra.fr \\ Charline Mola 1 \\ charline.mola@inra.fr \\ Christophe Rose 1 \\ christophe.rose@inra.fr \\ Marie-Christine Trouy2 \\ marie-christine.trouy@univ-lorraine.fr \\ Jean-Michel Leban1 \\ jean-michel.leban@inra.fr
}

${ }_{1}$ INRA, France

2 Universite de Lorraine LERMAB-ENSTIB, Nancy, France

\section{Abstract}

This study reports on the variations of the sessile oak early wood vessels diameter along an altitudinal gradient, for different tree size classes. As the collected samples are increment cores extracted at breast height, we set up a new protocol of sample preparation in order to obtain anatomical images by the mean of one a Scanning Electron Microscope.

The mean diameters of the vessels have been measured with the software ImageJ@. The variations of this diameter are mainly explained by the variations of the tree sizes. The vessel diameter is increasing with the tree dimensions. None relationship between vessel diameter and altitude of the forest stands has been found until now. A high intra-tree variability is present and remains to be explained.

The proposed statistical model explains $27 \%$ of the total variance and can be used to simulate the mean diameter of early wood vessels for all the sessile oak trees from the national forest inventory database.

Key words: earlywood vessels diameter, sessile oak, SEM, tree height, altitude

References

Beeckman, H. (2016). WOOD ANATOMY and TRAIT-BASED ECOLOGY. IAWA Journal, 37(2), 127-151. https://doi.org/10.1163/22941932-20160127

Fonti, P., \& García-González, I. (2008). Earlywood vessel size of oak as a potential proxy for spring precipitation in mesic sites. Journal of Biogeography, 35(12), 2249-2257. https://doi.org/10.1111/j.13652699.2008.01961.x

Huber, F. (1993). Déterminisme de la surface des vaisseaux du bois des chênes indigènes (Quercus robur L, Quercus petraea Liebl). Effet individuel, effet de l'appareil foliaire, des conditions climatiques et 
Proceedings of the $\mathbf{2 0 2 0}$ Society of Wood Science and Technology International Convention

de l'âge de l'arbre. Annales Des Sciences Forestières, 50(5), 509-524.

https://doi.org/10.1051/forest:19930507

Leban, J. M., Hervé, J., Bontemps, J., Wurpillot, S., Dauffy, V., Morneau, F., ... Douzain, N. (2017). Le projet XyloDensMap. (December), 2-3. https://doi.org/10.13140/RG.2.2.10112.74244

Martínez-Cabrera, H. I., Jochen Schenk, H., Cevallos-Ferriz, S. R. S., \& Jones, C. S. (2011). Integration of vessel traits, wood density, and height in angiosperm shrubs and trees. American Journal of Botany, 98(5), 915-922. https://doi.org/10.3732/ajb.1000335

Preston, K. A., Cornwell, W. K., Denoyer, J. L., \& Preston, K. A. (1999). Preston 2006 Wood density and vessel traits as distinct correlates.pdf.

Rosell, J. A., Olson, M. E., \& Anfodillo, T. (2017). Scaling of Xylem Vessel Diameter with Plant Size:

Causes, Predictions, and Outstanding Questions. Current Forestry Reports, 3(1), 46-59.

https://doi.org/10.1007/s40725-017-0049-0

Scholz, A., Klepsch, M., Karimi, Z., \& Jansen, S. (2013). How to quantify conduits in wood? Frontiers in Plant Science, 4(MAR), 1-11. https://doi.org/10.3389/fpls.2013.00056

Biography 
Proceedings of the 2020 Society of Wood Science and Technology International Convention

\title{
Comparative study on moso bamboo shear strength in four test methods
}

\author{
Aiyue Huang \\ huangaiyue1124@163.com \\ Huanrong Liu \\ huanrongliu@126.com \\ Xiubiao Zhang \\ zhangxb@icbr.ac.cn \\ International Center for Bamboo and Rattan, China
}

\begin{abstract}
The materials shear strength are quite different in different test methods. Splitting is the main and fatal fracture to bamboo. In order to explore the splitting strength and behaviors of bamboo, shear strength of moso bamboo (Phyllostachys Pubescens) were tested in four methods, including three in shear-parallel-to-grain and one shear-perpendicular-to-grain in bending. Comparative analysis on shear strength and behaviors were conducted. Results indicated that shear strength of bamboo smaller specimen in shear-parallel-to-grain was highest, then shear strength in bending was second higher. The shear strength of shear-parallel-to-grain in tensile was lowest. There were sharp drops in load-displacement curves of shear-parallel-to-grain, which was different from the step by step failure mode in bending. And the interface shearing break was the main fracture characteristics in shearparallel-to-grain. However, the bending fracture and interface debonding were the main fracture characteristics in shear- perpendicular-to-grain in bending. The tests methods determined to the shearing loading and shearing strength and behaviors. And the structure and arrangement of components decided to the fracture behaviors and characteristics of bamboo.I

Biography
\end{abstract}


Proceedings of the 2020 Society of Wood Science and Technology International Convention

\title{
Development of Palm Oil-based Resins for Natural Fiber Composites
}

\author{
Wendi Liu \\ wdliu9054@163.com \\ Yuchao Wu \\ yc121708@163.com \\ Renhui Qiu \\ renhuiqiu@fafu.edu.cn
}

\section{Fujian Agriculture and Forestry University, China}

\begin{abstract}
The development of sustainable fiber-reinforced polymer composites using renewable materials has become a research hotspot. Palm oil-based fatty acid-ethyl acrylamide (POFA-EA) was synthesized from palm oil and a water soluable monomer, i.e., $N$-(2-hydroxyethyl)acrylamide (HEAA) under the condition of alkalinity. Isosorbide-methacrylate (IM) was synthesized from isosorbide and used as a comonomer for POFA-EA. The biobased resins were prepared from POFA-EA and IM at different weight ratios and then used as matrices for the preparation of natural fibers-reinforced composites. Bamboo and kenaf fibers were chosen as representatives for natural fibers. The properties of the resulting resins and composites were fully characterized. The results showed that POFA-EA and IM are well miscible, and the viscosity and curing temperature of the resulting POFA-EA/IM resins meet the requirement of composite processing. The flexural strength and modulus of the resins are 2.6-71.8 $\mathrm{MPa}$ and 2.6-71.8 GPa, respectively, depending on the weight ratio of POFA-EA to EA. The tensile strength, tensile modulus, flexural strength and flexural modulus of the composites are 27-92MPa, 2.2-3.0GPa, 28-74MPa and 5.3-8.6 GPa, respectively. This work provides a feasible way to develop renewable polymer composites.
\end{abstract}

\section{Biography}




\title{
Proceedings of the 2020 Society of Wood Science and Technology International Convention
}

\section{Anatomical features and growth ring width correlation of Catalpa bungei}

\author{
Yamei Liu \\ liuyamei3980@126.com \\ Shengquan Liu \\ liusq@ahau.edu.cn \\ Liang Zhou \\ mcyjs1@ahau.edu.cn \\ Min $\mathrm{Yu}$ \\ yuminwood@163.com
}

\section{Anhui Agricultural University, China}

\begin{abstract}
In this paper, anatomical characteristics and growth ring width of catalpa bungei plantation with six clones were analyzed, providing theoretical basis for plantation clonal optimization. 【Methods】: By means of optical micro-imaging and computer micro-imaging analysis system, the anatomical properties were determined and analyzed by segregation process and section method. 【Results and discussion】: (1) Near the pith areas (1 2 rings), the distribution type of vessels were diffuse; from 3 $\sim 9$ rings areas, the distribution type of vessels were semi-diffuse; from $10 \sim 13$ rings areas, the distribution type of vessels were ring. (2) From pith to bark direction: growth ring width and ratio of fiber wall thickness to lumen increased first and then decreased; fiber length increased first then keep stable; the ratio of fiber lumen to diameter decreased first and then increased; the vessel width keep stable first and then increased; the fiber double-wall thickness and fiber width did not vary distinctly. (3) In the same ring of six clones, the fiber length, double-wall thickness, the ratio of fiber wall thickness to lumen and vessel width in early wood were bigger than in late wood, the fiber width and ratio of fiber lumen to diameter in early wood were smaller than in late wood. (4) At the level of $\mathrm{P}=0.01$, the growth width were negatively correlated with the fiber length, the double-wall thickness and vessel width in early wood; the growth width was negatively correlated with fiber length, doublewall thickness and the ratio of fiber wall thickness to lumen in late wood, and the growth width was positively correlated with fiber width, the fiber lumen to diameter and vessel width in late wood.
\end{abstract}

\section{Biography}




\title{
Structural Reliability Analysis of Cross Laminated Timber Plates Subjected to Bending
}

\author{
Ramon Vilela ${ }^{1}-$ Nilson T. Mascia ${ }^{2 *}-$ Luciano F. Santos $^{3}$ \\ ${ }^{1}$ Doctorate candidate, School of Civil Engineering, Architecture and Urban Design, \\ State University of Campinas, Campinas, Brazil \\ ramonvilela@outlook.com \\ 2 Professor, School of Civil Engineering, Architecture and Urban Design, State \\ University of Campinas, Campinas, Brazil * Corresponding author \\ ntm@unicamp.br \\ ${ }^{3}$ Master's candidate, School of Civil Engineering, Architecture and Urban Design, \\ State University of Campinas, Campinas, Brazil \\ fsantos@hotmail.com
}

\begin{abstract}
Failure modes of Cross Laminated Timber (CLT) plates reach by an excess of tensile stress on finger joints, shear stress on transverse layer due to rolling shear effect and by natural vibration. The Probability of Failure (POF) of CLT plates can be estimated from the probability distribution of their ruptures and stiffnesses, as well as their correlation coefficients. In this context, the aim of this paper is to estimate the load capacity of Cross Laminated Timber plates from a specific probability of failure and the experimental results of mechanical and physical properties. For this purpose, CLT plates were manufactured with wood species of Pinus taeda L., from Brazilian reforestation plantations. Four-point bending tests were conducted to investigate the failure behavior of the CLT plates. Density and moisture content were obtained from small specimens extracted from these plates. Monte Carlo simulation was carried out to predict the probabilistic loads that produce the failure of CLT plates, considering the failure occasioned by natural vibration as well. Experimental and numerical results of the failure modes were compared and the maximum loads to an acceptable probability of failure of the several CLT lengths were estimated too.
\end{abstract}

Keywords: Timber structures, Cross Laminated Timber, Bending, Structural Reliability, Monte Carlo simulation. 


\section{Introduction}

Cross Laminated Timber (CLT) panel is an engineered wood product consisting of several layers of kiln-dried lumber boards arranged in crossed directions, bonded with structural adhesives, and pressed to form a solid, straight, rectangular panel. It is used primarily as a plate or wall structure. Residential, commercial, and industrial buildings have been composed of CLT panels as structural elements and/or fence walls around the world (Van De Kuilen et al. 2011).

Knowledge of failure prediction of CLT plates is necessary for structural design. The main modes of CLT failure in bending are reach by an excess of tensile stress on finger joints (Meethaworn and Srivaro 2017), shear stress on transverse ply due to rolling shear effect (Flores et al. 2016), and also natural vibration (Matilainen and Puttonen 2014). In general, excessive displacement is avoided by standards requirements to guarantee the user's sense of security (Associação Brasileira de Normas Técnicas 1997, Commité Européen de Normalization 2004).

Monte Carlo method is often applied to estimate the performance and the probability of de failure (POF) of structural components. For instance, Nogueira et al. (2012) presented a probabilistic method of reinforced concrete structures durability assessment via Monte Carlo simulations. Nigro et al. (2014) used the probabilistic approach to address the failure assessment of steel structures in fire. CLT compressive strength is predicted by Oh et al. (2015) employing the Monte Carlo simulation. Similarly, Ogawa et al. (2018) estimated the tensile strength distribution of CLT applying this method.

For predicting the CLT behavior used as a slab, its mechanical and physical variables and its probability distribution are needed, and the correlation coefficients of these variables too. These values can be obtained by experimental test results and summarized by statistical analysis.

The present study is part of a research project dealing with Cross Laminated Limber and concrete composite products, which has been developing in Brazil. The overall aim of the research project is to contribute with knowledge and methods to the rational modeling, analysis, design, and prediction of the strength of cross-laminated timber and concrete composite. This research involves public and private resources. The master's dissertation produced by Vilela (2020) is part of this research.

In light of this, the goal of the study is to estimate the load capacity of Cross Laminated Timber plates from a specific probability of failure and experimental results of mechanical tests, taking into account physical properties of wood.

\section{Materials \& Methods}

The Cross Laminated Timber plates were produced from wood species Pinus taeda L., from reforested plantations grown in Brazil, and manufactured by Crosslam Company. The layers of these plates were bonded with structural polyurethane adhesive. Thirty-two specimens were obtained from CLT plates to assess the density and moisture content, being sixteen of them were extracted from internal having the following approximate dimensions $40 \mathrm{~mm} \times 80 \mathrm{~mm} \times 60 \mathrm{~mm}$, while sixteen more were taken from external layers and had approximately the dimensions 40 $m \mathrm{~m} \times 40 \mathrm{~mm} \times 920 \mathrm{~mm}$. These CLT plates are manufactured by Crosslam, according to PRG 320:2019 (American National Standards Institute and The Engineered Wood Association 2019). 
Twenty-one specimens were experimental tested by the bending test. Seven specimens had lengths of $1.60 \mathrm{~m}$, seven of $2.08 \mathrm{~m}$, and others seven of $4.00 \mathrm{~m}$. All of them were set with 40L20T-40L-20L-40T thickness layers (in $m m$, L: longitudinal, T: transversal, $h=0.16 \mathrm{~m}$ ) and the width was $b=0.80 \mathrm{~m}$. Figure 1 shows the scheme used in the four-point bending experimental test, according to BS EN 16351:2015 (Commité Européen de Normalization 2015).

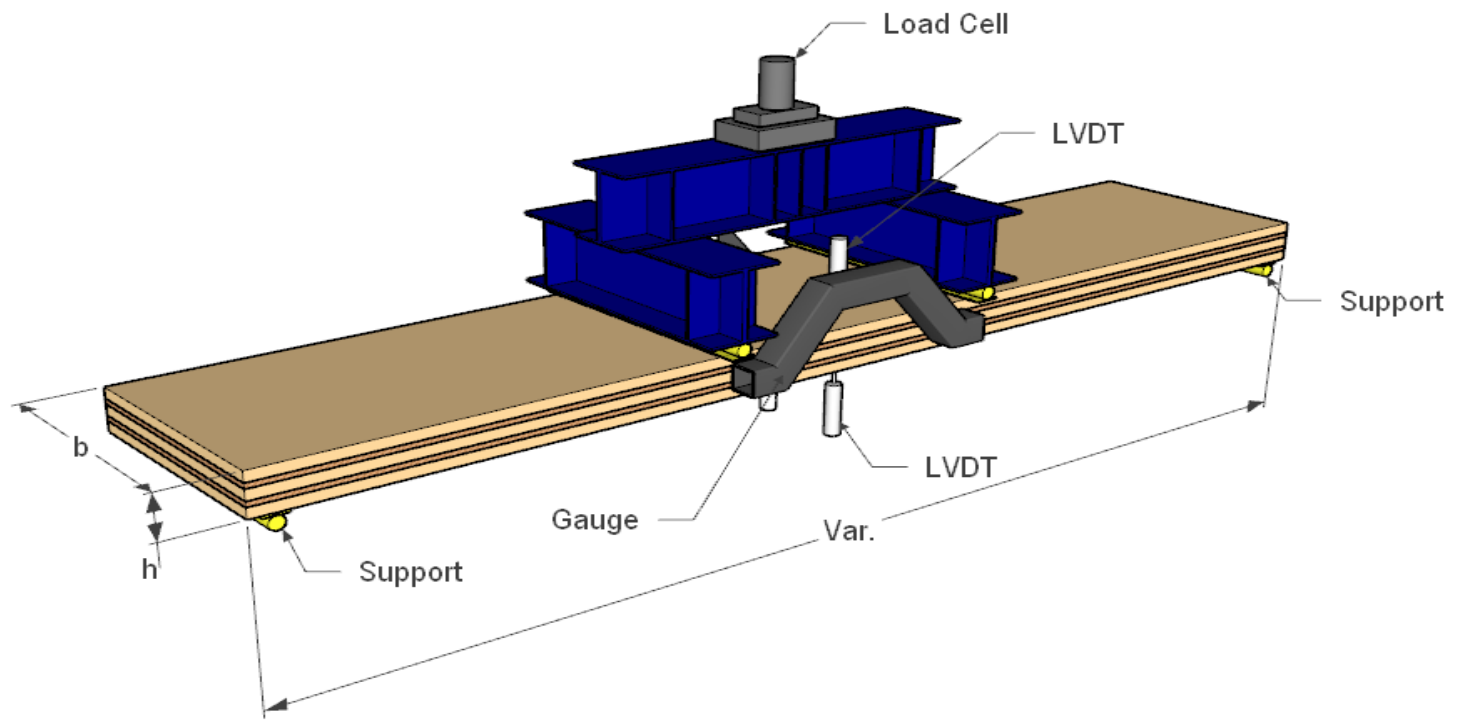

Figure 1. Bending test setup.

Two gauges, which were positioned at the midpoint of the plate to support the Linear Variable Differential Transformers (LVDT), provided the displacement measurements for the region subjected to pure bending. Apart from that, four LVDTs were placed to measure the total displacements. Thus, the bending stiffness (KCLT) and shear stiffness ( $S_{\text {CLT }}$ ) were calculated applying Equation (1) that is in accordance with Timoshenko Beam Theory (Timoshenko 1921), as follows:

$$
\delta_{1}=\frac{P a l_{1}^{2}}{16 K_{\mathrm{CLT}}} ; \quad \delta_{T}=\frac{P a}{48}\left(\frac{3 l^{2}-4 a^{2}}{K_{\mathrm{CLT}}}+\frac{24 \kappa}{S_{\mathrm{CLT}}}\right)
$$

where $\delta_{1}$ and $\delta_{\text {T }}$ are the local and total displacement, $P$ is the sum of applied load, $a$ is the distance between the load and its next support, $l_{1}$ is the length of the gauge, $K_{\text {CLT }}$ is the bending stiffness, $\kappa$ is the form factor, and $S_{\text {CLT }}$ is the shear stiffness.

The variables used in Monte Carlo simulation were the following, var1: Resistant Bending Moment $\left(M_{\mathrm{R}}\right)$, var2: Resistant Shear $\left(V_{\mathrm{R}}\right)$, var3: Bending Stiffness (KCLT), var4: Shear Stiffness (SCLT), var5: Density of external layers of CLT $(\rho 1)$, var6: Density of internal layers $(\rho 2)$, and var7: Moisture content $(U)$. The load variability was not considered, because the research goal was to obtain the load limit not the probability of failure.

Cholesky decomposition was applied via software Matlab ${ } 16$ to calculate the lognormal random data from the mean and standard deviation of the variables and correlation coefficients between them. Figure 2 exhibits the 106 generated data for each variable and the correlation coefficients. 
Proceedings of the $\mathbf{2 0 2 0}$ Society of Wood Science and Technology International Convention

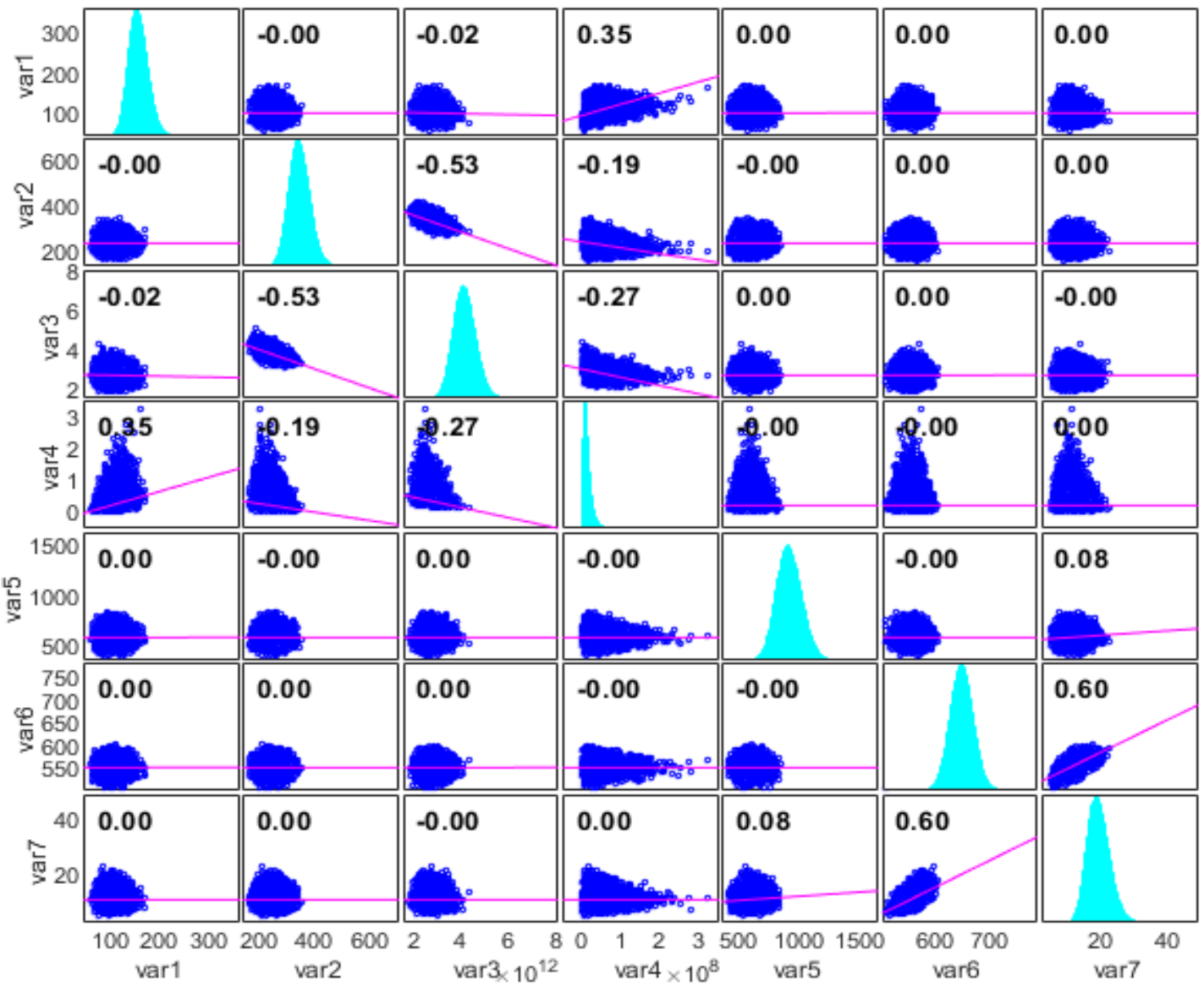

Figure 2. Correlation Matrix from CLT properties.

Equations (2), (3) and (4) estimated the maximum loads from bending, shear, and limit of displacement, respectively. In these equations, the continuous load from CLT self-weight is disregarded. Timoshenko Beam Theory (Timoshenko 1921) was considered in Equation (4).

$$
\begin{gathered}
q_{\mathrm{b}}=\frac{8 M_{\mathrm{R}}}{l^{2}}-p \\
q_{\mathrm{v}}=\frac{2 V_{\mathrm{R}}}{l}-p \\
q_{\mathrm{d}}=\left(\frac{5 l^{4}}{384 K_{\mathrm{CLT}}}+\frac{\kappa l^{2}}{8 S_{\mathrm{CLT}}}\right)^{-1}-p
\end{gathered}
$$

where $q_{\mathrm{b}}, q_{\mathrm{v}}$, and $q_{\mathrm{d}}$ are the loads obtained from bending, shear and displacement, respectively, $M_{\mathrm{R}}$ and $V_{\mathrm{R}}$ are the resistant bending moment and shear, respectively, $l$ is the length, and $p$ is the load from self-weight. 
The first natural frequency was estimated considering the CTL plate as a beam, according to Equation (5), (Thiel 2013).

$$
f_{n}=\frac{\omega_{n}}{2 \pi}=\frac{n^{2} \pi}{2 l^{2}} \sqrt{\frac{K_{\mathrm{CLT}}}{\rho A}}
$$

where $f_{\mathrm{n}}$ is the natural frequency $(\mathrm{Hz}), \omega_{\mathrm{n}}$ the angular frequency $(\mathrm{rad}), n$ the cardinal number of vibration mode, $l$ the beam length (m), $K$ is the bending stiffness (Pa.m4), $\rho$ is the density $\left(\mathrm{kg} / \mathrm{m}_{3}\right)$, and $A$ is the transverse area $\left(\mathrm{m}_{2}\right)$.

\section{Results and Discussion}

The maximum load necessary to produce failure for a specific length was estimated from the probability of failure equals POF $=10-5$. The CLT length was discretized in 100 several lengths until $8.00 \mathrm{~m}$.

In general, the load limits were obtained by the limit displacement (l/200). Thereafter, the rupture by shear governed the limit loads until about $1.5 \mathrm{~m}$. For greater lengths, the rupture by bending moment is responsible to limit the load. However, the first natural frequency limited the CLT length in $5.58 \mathrm{~m}$. The CLT length that produces a natural frequency $f_{\mathrm{n}}=8 \mathrm{~Hz}$ varied from 5.50 until $6.85 \mathrm{~m}$.

Figure 3 as follows shows these results.

The rolling shear effect caused the maximum load limit for small lengths, whereas the finger joint limited the design load in the same state. However, the maximum displacement governed the CLT design in this analysis. In addition, the length was limited by first natural frequency, which reduced approximately $1 \mathrm{~m}$ of the maximum length.

The procedure adopted to estimate the natural frequency was the behavior of the beam due to the width. For larger CLT panels, it is recommended considering the orthotropic plate behavior to calculate the natural frequency, like Zhou et al. (2017). 


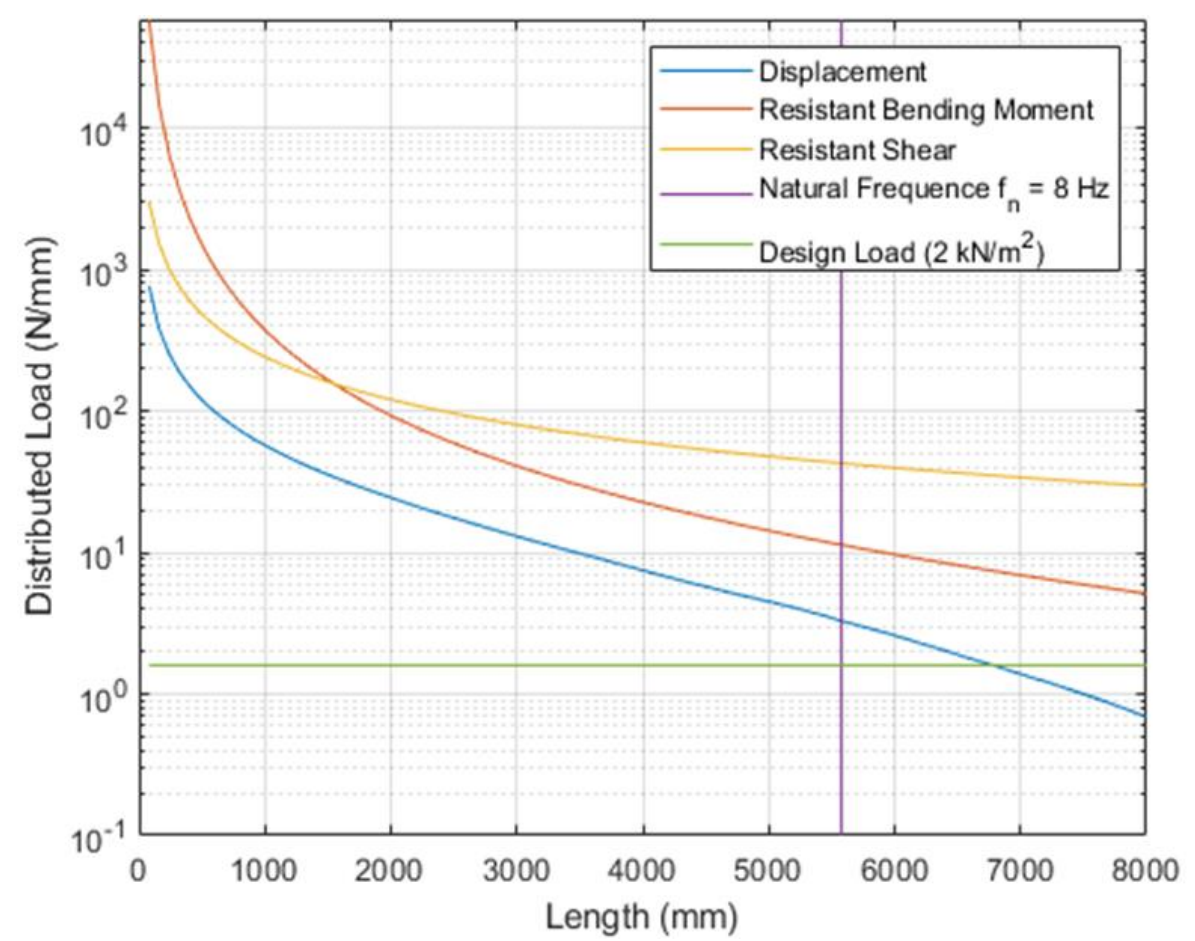

Figure 3. Correlation Matrix from CLT properties.

Comparing the values obtained by structural reliability procedure to the serviceability limit state procedure carried out by Vilela (2020), it can be observed that maximum load stabilized by displacement in the first procedure is more conservative, in general, than the serviceability limit state method. These results can be associated by weighting coefficients applied to limit the serviceability limit state responsible for improving the limit loads. On the other hand, the probability of failure for situations that do not lead to the ruin (failure) of the structure can be considered smaller, in the order of $\mathrm{POF} \cong 10-3$, which would cause the loading curve due to excessive displacement to increase (Almeida 2008).

Natural vibration by limiting the serviceability limit state restricts the CLT length in $5.99 \mathrm{~m}$, being this value is within the results obtained by the probabilistic method.

The bending and shear stiffnesses, and bending moment and shear resistance estimated by experimental procedures involve the global CLT behavior, which is composed by individual behavior and strength of each lamination (e.g., finger joints, rolling shear strength). The use of a full-size CLT bending test in several lengths is capable of representing the wood and laminations variables necessary to reliability structural analysis. Then, this procedure is an alternative to the semi probabilistic method (i.e., limits states) that uses characteristic values to estimate the wood and CLT properties.

\section{Summary and Conclusions}

This study deals with a probabilistic method to structural reliability analysis of Cross Laminated Timber elements subjected to bending from experimental results. Limit loads for several lengths were presented considering rolling shear and bending moment resistance, and CLT bending and shear stiffness. The length limit was estimated from the natural frequency in the first vibration mode (critical to loading walking people). 


\section{Proceedings of the 2020 Society of Wood Science and Technology International Convention}

Excessive displacement is the main mode of failure to analyze the CLT element in bending until $5.6 \mathrm{~m}$ length. Above this length the natural vibration governs the failure mode with a POF $=10-5$. Predicted maximum load from probabilistic displacement proved to be more conservative than the Limit State method.

The variability of wood is considerably large and should not be overlooked in the structural design of the CLT. The use of Monte Carlo Simulation to predict the limit loads according to the main failure modes of the CLT shown to be an alternative technique capable of estimating such loads for different failure probabilities according to each design criteria.

\section{Acknowledgements}

The authors would like to thank Crosslam Company (Suzano, SP, Brazil, http://crosslam.com.br) for providing materials, equipment, and financial support. Also, the Brazilian Coordination for the Improvement of Higher Education Personnel (CAPES) for the financial support to be carried out this research, and the School of Civil Engineering, Architecture and Urban Design, University of Campinas (UNICAMP), for the laboratory structure to perform the tests.

\section{References}

Almeida AF (2008) Projeto ótimo baseado em confiabilidade de pórticos planos de concreto armado (Optimal design based on reliability of flat reinforced concrete frames). Doctoral thesis. Pontifícia Universidade Católica do Rio de Janeiro, Rio de Janeiro, RJ: Brazil. 147 p. (In Portuguese).

American National Standards Institute, The Engineered Wood Association (2019) PGR 320: Standard for Performance-Rated Cross-Laminated Timber.

Associação Brasileira de Normas Técnicas (1997) NBR 7190: Projeto de Estruturas de Madeira (Design of wood structures). Rio de Janeiro, RJ: Brazil. (In Portuguese).

Commité Européen de Normalization (2004) Eurocode 5: Design of Timber Structure - Part 1-1: General - Common Rules and Rules for Buildings. Brussels, BBR: Belgium.

Commité Européen de Normalization (2015) BS EN 16351: Timber Structures - Cross Laminated Timber - Requirements. Brussels, BBR: Belgium.

Flores EIS, Saavedra K, Hinojosa J, Chandra Y, Das R (2016) Multi-scale modelling of rolling shear failure in cross-laminated timber structures by homogenisation and cohesive zone models. International Journal of Solids and Structures 81: 219-232. Matilainen J-P, Puttonen J (2014) Free vibration of CLT plates. Journal of Structural Mechanics 47(1): 17-33.

Meethaworn B, Srivaro S (2017) Structural Performance Evaluation of Finger-Jointed Rubberwood Manufactured by Factories in Thailand. 12(4): 9420-9426.

Nigro E, Bilotta A, Asprone D, Jalayer F, Prota A, Manfredi G (2014) Probabilistic approach for failure assessment of steel structures in fire by means of plastic limit analysis. Fire Safety Journal 68: 16-29.

Nogueira CG, Leonel ED, Coda HB (2012) Reliability algorithms applied to reinforced concrete structures durability assessment. Rev IBRACON Estrut Mater 5(4): 440-450.

Ogawa K, Ido H, Harada M, Nagao H, Kato H, Miyatake A (2018) Monte-Carlo Simulation Model for Predicting the Tensile Strength Distribution of Cross Laminated Timber. Journal of the Society of Materials Science, Japan 67(12): 1087-1093. 
Oh J-K, Lee J-J, Hong J-P (2015) Prediction of compressive strength of cross-laminated timber panel. J Wood Sci 61(1): 28-34.

Thiel A (2013) ULS and SLS design of CLT and its implementation in the CLTdesigner. In: European Conference on Cross Laminated Timber, Graz, ST: Austria.

Timoshenko SP (1921) On the correction for shear of the differential equation for transverse vibrations of prismatic bars. The London, Edinburgh, and Dublin Philosophical Magazine and Journal of Science 41(245): 744-746.

Van De Kuilen JWG, Ceccotti A, Xia Z, He M (2011) Very Tall Wooden Buildings with Cross Laminated Timber. Procedia Engineering 14: 1621-1628.

Vilela R (2020) Structural performance in bending of cross-laminated timber plates. Master's dissertation. State University of Campinas, Campinas, SP: Brazil.

Zhou J, Chui YH, Gong M, Hu L (2017) Comparative study on measurement of elastic constants of wood-based panels using modal testing: choice of boundary conditions and calculation methods. J Wood Sci 63(5): 523-538.

Biography 


\title{
Proceedings of the 2020 Society of Wood Science and Technology International Convention
}

\author{
Physical Properties of Particleboard Produced from Residues of Musa \\ paradisiaca pseudostem, Theobroma cacao and Ceiba pentandra \\ Prosper Mensah \\ CSIR-Forestry Research Institute of Ghana, Ghana \\ pmensah@csir-forig.org.gh
}

\begin{abstract}
This study determined the physical properties of particleboards manufactured from four agro-forest residues using cassava starch and urea formaldehyde as adhesives. The particle size of the agro-forest residues ranged from $0.5 \mathrm{~mm}$ and $1.5 \mathrm{~mm}$. About $2 \%$ of $\mathrm{NH}_{4} \mathrm{CL}$ was used as a hardener, based on the weight of the adhesive. The particleboards were made in accordance with ASTM D 1037-99. An industrial pressing machine was used to press the homogeneous single layer particleboards at a targeted density of $600 \mathrm{~kg} / \mathrm{m}_{3}$. The results indicated that the densities of the particleboards produced ranged from $421 \mathrm{~kg} / \mathrm{m}_{3}$ to $598 \mathrm{~kg} / \mathrm{m}_{3}$ whiles the moisture content was in the range of $10.75 \%$ to $11.88 \%$. The water absorption property of the composites boards ranged from $7.66 \%$ to $22.41 \%$ and $18.17 \%$ to $59.46 \%$ respectively for 2 -hour and 24 -hour immersions. Additionally, the thickness swelling of the particleboards produced range from of $3.38 \%$ to $5.03 \%$ and $9.37 \%$ to $21.49 \%$ for 2 hour and 24-hour immersion respectively. In accordance with ANSI A208.1.1999, EN 3122005 and result of other studies conducted using similar materials. The particleboards produced from the biomass materials using cassava starch and urea formaldehyde have adequate physical properties. The above notwithstanding comparatively for all the agro-forest materials used the water absorption and thickness swelling properties of the particleboards produced using urea formaldehyde was far better than that of cassava starch. Therefore it is recommended that further studies that combines cassava starch and urea formaldehyde as adhesives should be conducted.

Keywords; Cassava starch, Ceiba pentandra, Musa paradisiaca pseudostem, Particleboard, Theobroma cacao, Urea formaldehyde

Biography
\end{abstract}




\section{Characterization of Particleboard Produced from Residues of Musa paradisiaca pseudostem, Theobroma cacao pod, Theobroma cacao stem and Ceiba pentandra}

Stephen J. Mitchual1, Prosper Mensah2, Kwasi Frimpong-Mensah3, Emmanuel Appiah-Kubi4 1,4Department of Construction and Wood Technology Education, University of Education, Winneba, Kumasi Campus, P. O. Box 1277, Kumasi, Ghana ${ }_{2}$ CSIR-Forestry Research Institute of Ghana, P. O. Box UP 63, KNUST, Kumasi - Ghana 3Department of Wood Science and Technology, Kwame Nkrumah University of Science and Technology, Kumasi, Ghana

1Corresponding author: Email: stephenjobsonmitchual@gmail.com; Tel. +233203809967

$$
\text { Fax } 0322050039
$$

\section{Abstract}

This study investigated the possible use of four agro-forest residues generated in Ghana as an alternative raw material for particleboard manufacture using cassava starch and urea formaldehyde as adhesives. The particle size of the materials ranged from $0.5 \mathrm{~mm}$ to $1.5 \mathrm{~mm}$. An industrial pressing machine was used to press the homogeneous single layer particleboard. Physical and mechanical properties were determined in accordance with ASTM D 1037-06a and ASTM D 7519-11. The results indicate that the density of the particleboards produced ranged from 421 $\mathrm{kg} / \mathrm{m}_{3}$ to $598 \mathrm{~kg} / \mathrm{m}_{3}$. The water absorption property of the particleboards also ranged from $7.66 \%$ to $22.41 \%$ and $18.17 \%$ to $59.46 \%$ respectively for 2-hour and 24-hour immersions. Additionally, the thickness swelling of the particleboards ranged from of $3.38 \%$ to $5.03 \%$ and $9.37 \%$ to $21.49 \%$ for 2-hour and 24-hour immersions respectively. The study further indicated that the modulus of elasticity, modulus of rapture, internal bond strength and hardness of the particleboards produced for both cassava starch and urea formaldehyde were adequate. Comparatively, for all the agroforest materials used for this study, the physical and mechanical properties of the particleboards produced using urea formaldehyde as adhesive was better than those produced using cassava starch as adhesive. It could be concluded that the particleboards produced could be used for indoor applications or interior furnishings, under dry conditions. Additionally, it is recommended that further studies that combine cassava starch and urea formaldehyde as adhesives be conducted as well as studies on combining Musa paradisiaca pseudostem and Theobroma cacao pod in particleboard production.

Keywords: Agro-forest residue, Cassava starch, Particleboard, Physico-mechanical properties, Urea formaldehyde

\section{Introduction}


Particleboard, an engineered wood product, dates back to the early 20th Century. It was developed during the World War II to utilise inferior wood and wood waste when good quality wood was in short supply [1]. In the past, wood was the main raw material used for furniture and building applications, although the feasibility of non-wood alternatives has been investigated for many decades. Many factors including wood shortage as a result of the depletion of forest areas, environmental awareness and generation of large quantities of agro-forest residues which have disposal challenges have increased the need for the substitution of wood as a major raw material for the production of furniture and other wood products with particleboard. The demand for particleboard products has increased substantially throughout the world, representing $57 \%$ of the total consumption of wood-based panels, a percentage that is continuously growing at a rate of 2 $5 \%$ annually. As a result of this, about 28.4 million $\mathrm{m}_{3}$ of particleboards are produced in Europe each year mainly for furniture and building applications [2].

In recent times, most companies that produce particleboards have been substituting wood as a raw material with agricultural residues. This is because the volumes of timber harvested from the forest are being dramatically reduced and less timber is available. On the contrary with farming operations, residual fibres are annually renewed, often in sustainable volumes that could supply for composite panel production. In 2005, at least 30 industrial plants all over the world integrated the use of non-wood lignocellulosic aggregates in the production of particleboards [3]. Today, although the technical feasibility of non-wood particleboards is generally accepted, further research is needed to fully understand how the intrinsic properties of the raw materials can contribute to enhancing the overall performance of the engineered materials [4].

Agricultural residue, that is, residual fibre, is one of the major solid residues produced in the world. Typically, such residues like wheat and barley straw, rice straw and husks, sugar cane bagasse, plantain pseudostem and the pod, stem and husk of cocoa plant have little or no value. The management or disposal of these residues has become a questionable practice in many countries as they are often left to rot or burnt inefficiently in their loose form causing air pollution [5]. Besides, the burning of these residues is often detrimental to the soil and can cause health and related problems. The vast majority of examples of non-wood particleboard developments as indicated earlier is focused on the use of different kinds of natural fibres which comprise mainly agricultural residue. This is because the use of fibres makes an important contribution to the enhancement of the physical and mechanical properties of such boards through mechanical 
interlocking of particle [6]. Fibrous materials from crop plants are also preferred because of their availability and easy accessibility.

Musa paradisiaca pseudostem, a residue of plantain, is a lignocellulosic biomass material readily available on farmlands and in neighborhoods at no cost. Available data indicates that between 2000 and 2015, global production of plantain grew at a compound annual rate of 3.7 percent, reaching a record of 117.9 million tonnes in 2015, up from around 68.2 million tonnes in 2000 [7]. Ghana is the largest producer of plantain in West Africa and the third in Africa after Uganda and Rwanda [7]. It was estimated that at the end of the year 2016, about 7,184,842 tonnes of $M$. paradisiaca pseudostem residue was generated in Ghana [7]. This constitutes about 59\% of the total agricultural crop residues generated. M. paradisiaca pseudostem is one of the agricultural residues readily available in large quantities and has no special industrial application.

Another abundant agricultural waste generated in Ghana is the residue of Theobroma cacao (cocoa). Ghana is second to Cote d'Ivoire, producing about $20 \%$ of global cocoa production. Theobroma cacao prunings, pod, stem and shells are the main residue generated from cocoa production. T. cacao tree prunings and pods are normally left in the field as a kind of mulch while a small part may be used as domestic fuel. When T. cacao pod decays on farm lands, the composts emit methane into the atmosphere which also affects the degradation of the ozone layer 25 times that of carbon dioxide [8] and it is also a carrier of botanical diseases such as black pod rot. The wood from trees cut during re-planting ends up as domestic fuel or are used for the construction of mud houses in the farming communities.

Ceiba pentandra is a low-density species with density of about $409.22 \mathrm{~kg} / \mathrm{m} 3$ with acid-insoluble lignin and alpha-cellulose contents of $24.34 \%$ and $41.24 \%$ respectively [8]. It is noted to have long fibres. In a study conducted by Mitchual [9] which compared the fibre length of six (6) species for different particle sizes, C. pentandra was noted to have longer fibre length for each of the particle sizes. This characteristic makes it a suitable source of material for particleboard production.

Most of the previous studies conducted to explore alternative raw materials for production of particleboards have recognised agro-forest residues as potential source for its manufacture. For most of such studies, urea formaldehyde was used as adhesive. The emission of carcinogenic formaldehyde in the production and use of particleboards have generated a lot of discussions by researchers, some advocating for its substitution. Additionally, Rokiah et al. [10] noted that 
formaldehyde resins and other synthetic resins constitute waste disposal problem because they are non-biodegradable and also not recyclable. Thus, this study aimed at determining the physical and mechanical properties of particleboards produced from residues of Musa paradisiaca pseudostem, Theobroma cacao stem and pod, and Ceiba pentandra sawdust using cassava starch and urea formaldehyde as adhesives.

\section{Methodology}

\subsection{Materials and material preparation}

\subsubsection{Preparation of particles of biomass material}

Musa paradisiaca pseudostem, Theobroma cacao stem and pod, Ceiba pentandra sawdust, urea formaldehyde and cassava starch were used for the study. The plantain pseudostem was obtained from a farm land after harvesting. The water was extracted, and the fibres oven-dried before milling them into particles. Fig. 1 shows the stages of preparation of plantain pseudostem particles.

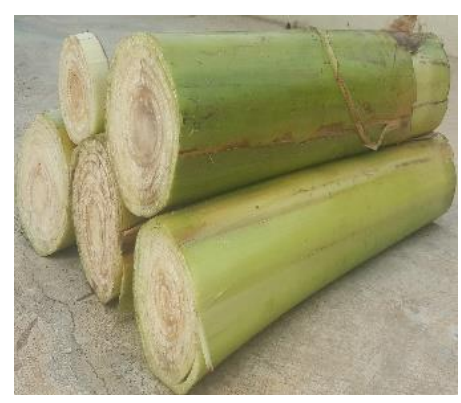

A. Fresh M. paradisiaca pseudostem
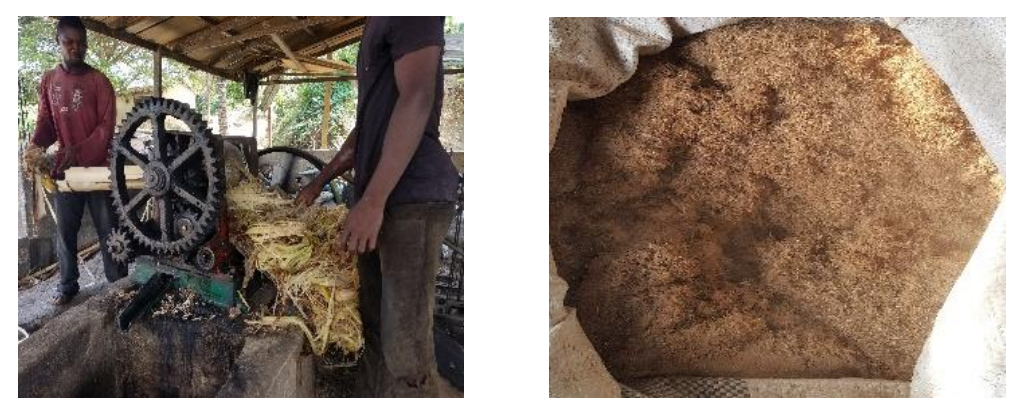

B. Water extraction from $M$. paradisiaca pseudostem
C. M. paradisiaca pseudostem particles

Fig. 1 Stages of processing of plantain pseudostem into particles

Figs. 2 and 3 show the stages of conversion of T. cacao stem and pod respectively into particles. Twenty-six (26) years old T. cacao trees were felled and then converted into sawdust by sawing. The fresh T. cacao pod as shown in Fig. 3A were first sun-dried and then crushed into particles using a hammer mill. Sawdust of $C$. pentandra was obtained from a timber processing company in Ghana. 


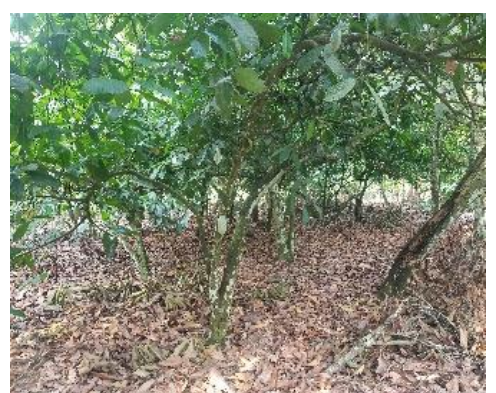

A. Cocoa plantation

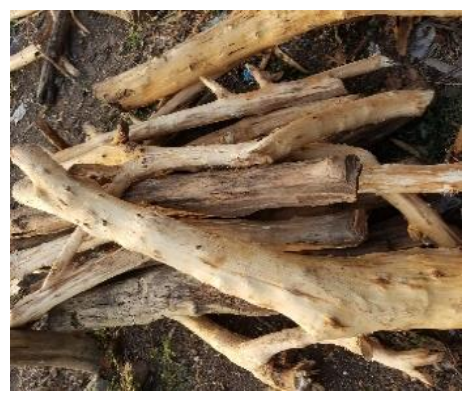

B. Cocoa stem

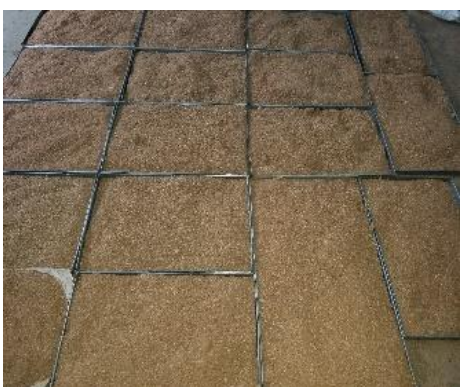

C. Cocoa stem particle

Fig. 2 Stages of processing of Theobroma cacao stem into particles

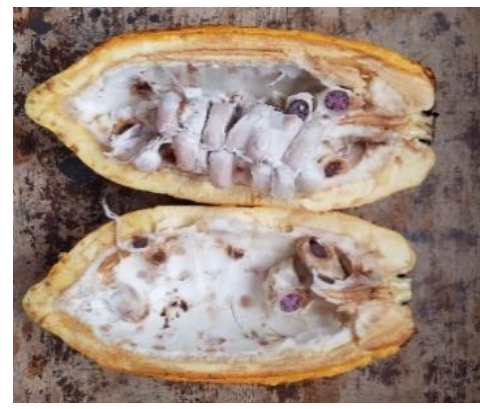

A. Fresh cocoa pod

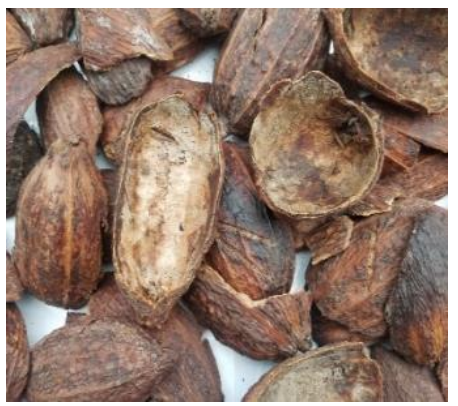

B. Dried cocoa pod

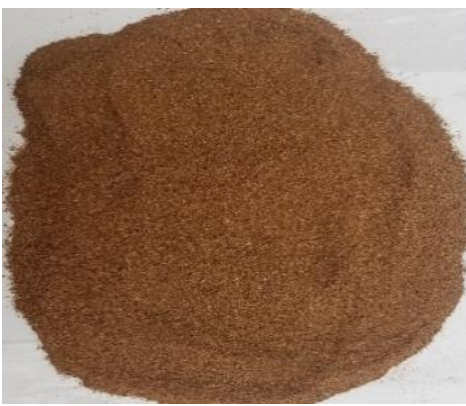

C. Cocoa pod particles

Fig. 3 Stages of processing of Theobroma cacao pod into particles

\subsubsection{Sieve analysis and grading of particles}

The particle size distribution of the agro-forest residues was determined in accordance with ASTM D 6913-17 [11]. Two hundred grammes of each of the agro-forest materials was placed in a set of sieves with sizes: $4.75 \mathrm{~mm}, 3.15 \mathrm{~mm}, 2.00 \mathrm{~mm}, 1.00 \mathrm{~mm}, 0.60 \mathrm{~mm}, 0.425 \mathrm{~mm}, 0.30 \mathrm{~mm}, 0.15$ $\mathrm{mm}$ and $0.063 \mathrm{~mm}$ and then mounted on automatic sieve shaker with serial number YGM15418/AZ/0260 and Model YGM15418. Shaking was done for 10 minutes. Thereafter, the weight of materials retained on each sieve was determined using an electronic balance. The percentages of materials retained on each sieve were computed and graphs of particle size distribution cumulative curves plotted.

\subsubsection{Urea formaldehyde}

Urea formaldehyde (UF) resin with a ratio of 1:1, of $65 \%$ solid content, specific gravity of 1.266 $\mathrm{g} / \mathrm{cm}^{3}$ at $30^{\circ} \mathrm{C}$, viscosity of $2.3 \mathrm{MPs}$ at $30^{\circ} \mathrm{C}, \mathrm{pH}$ of 7.5 and a gel time of 65 seconds at $100^{\circ} \mathrm{C}$ was used as the adhesive for making the particle board. 


\subsubsection{Preparation of cassava starch}

Fresh cassava tubers (Fig. 4) were obtained, washed, peeled and milled to obtain cassava dough. The dough was diluted with clean water to form a solution. Thereafter, the solution was strained with $1 \mathrm{~mm}$ wire mesh and allowed to stand for 24 hours to allow the starch to settle. The water was decanted to obtain the cassava starch. The starch was air-dried for ten days and ground to obtain powdered starch as shown in Fig. 5.

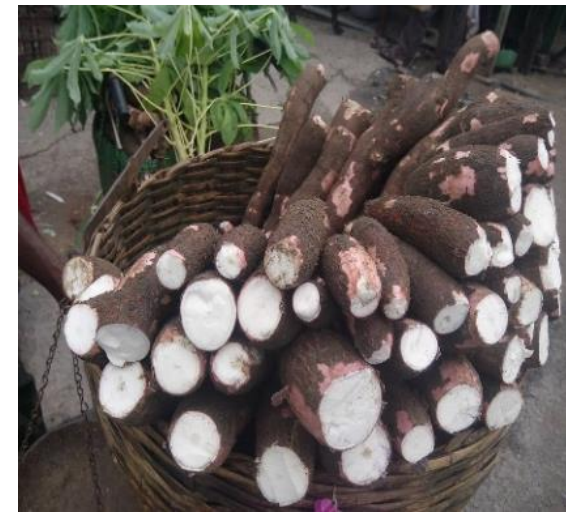

Fig. 4 Cassava tubers

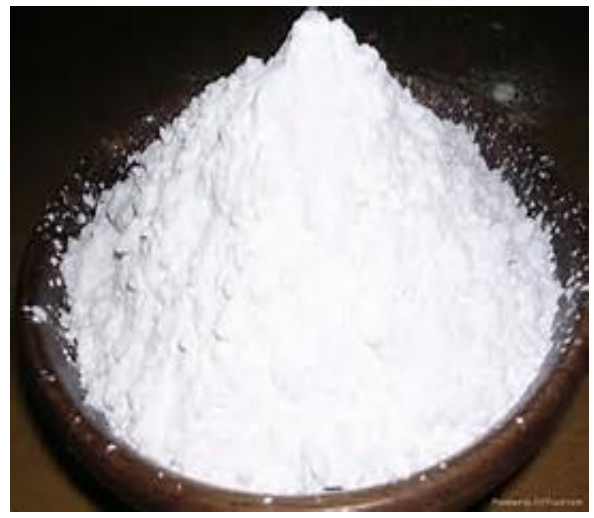

Fig. 5 Cassava starch

\subsection{Bulk density determination}

The bulk density of the loose biomass materials was determined in accordance with Hartmann et al. [12]. This was done by filling a 50-litre cylindrical container to the brim and weighing it. The volume of the cylinder was determined by measuring its height and internal diameter. The bulk density of the biomass materials was computed as shown in equation 1.

Where:

$$
\text { Bulk density }\left(\frac{k g}{m^{3}}\right)=\frac{M s p}{V c}
$$

Msp $=$ Mass of the biomass sample

$\mathrm{V}_{\mathrm{C}}=$ Volume of the cylindrical container

\subsection{Aspect ratio}

The particle width and length of one hundred and twenty particles of each specimen were measured with a digital LED compound light microscope of $10 \mathrm{x}$ magnification and analyzed with ImageJ 
1.51 Java 64-bit for determining the width and length. The aspect ratio was computed as shown in equation 2 .

$$
A R=\frac{P l}{P w}
$$

Where:

$\mathrm{AR}=$ Aspect ratio

$\mathrm{Pl}=$ Particle length

$\mathrm{Pw}=$ Particle width

\subsection{Particleboard manufacture}

The bulk density of the biomass materials were: $T$. cacao stem $=89.90 \mathrm{~kg} / \mathrm{m} 3$; Ceiba pentandra $=$ $94.41 \mathrm{~kg} / \mathrm{m}_{3}$; M. paradisiaca Pseudostem $=96.63 \mathrm{~kg} / \mathrm{m}_{3}$ and $T$. cacao pod $=323.96 \mathrm{~kg} / \mathrm{m} 3$. The materials were each dried to a moisture content of $4 \%$ and then thoroughly mixed with the adhesives. Ammonium chloride was added as a curing catalyst. The resinated particles were prepressed into an $80 \mathrm{~mm}$ single layer in $300 \mathrm{~mm}$ x $300 \mathrm{~mm}$ aluminium sheet mould. A $20 \mathrm{~mm}$ thick metal stopper was used to ensure that the boards produced had the same thickness. The mat was then pressed with the following conditions: Pressing temperature $170 \mathrm{o}$; ; pressing pressure 3.5 $\mathrm{MPa}$; pressing time 8 minutes; pressing closing rate 3 - $4 \mathrm{~mm} /$ minutes, target thickness $20 \mathrm{~mm}$; hardener 2\%; adhesive (UF and CS); and compacting time 15 minutes. The produced particleboards were then trimmed and conditioned in a climate controlled room having a temperature of $20 \pm 2{ }_{\circ} \mathrm{C}$ and a relative humidity of $62 \pm 2 \%$ for 6 days before they were sawn into various sizes for further studies.

\subsection{Moisture content}

The moisture content on oven-dry basis of the particleboards was determined in accordance with the ASTM D 1037 - 06a [13]. Five samples of each of the particleboards with dimensions $50 \mathrm{~mm}$ x $50 \mathrm{~mm}$ x $20 \mathrm{~mm}$ were placed in a laboratory oven at a temperature of $103 \pm 2{ }_{\mathrm{o}} \mathrm{C}$. Each sample was dried until the difference in mass between two successive weighings separated by an interval of two hours was $0.01 \mathrm{~g}$ or less. The moisture content of the specimen was then computed as shown in equation 3.

$$
\text { Moisture content }(\%) d b=\frac{M_{i}-M_{f}}{M_{f}} \times 100
$$

Where: 
$\mathrm{M}_{\mathrm{i}}=$ Initial mass $(\mathrm{g})$ of the test sample before drying

$\mathrm{M}_{\mathrm{f}}=$ Final oven-drying mass $(\mathrm{g})$ of the test sample

\subsection{Density}

The density of the particleboards produced was determined in accordance with ASTM D-1037 06a [13]. Specimen of dimensions $20 \mathrm{~mm}$ x $20 \mathrm{~mm}$ x $30 \mathrm{~mm}$ were prepared from the particleboards produced and kept in a desiccator. The oven-dried mass of the specimen was determined using an electronic balance. The dimensions of the specimen: length, breadth and height were determined using a digital veneer calliper. Density of each specimen was then computed using equation 4.

$$
\text { Density }\left(\frac{\mathrm{kg}}{\mathrm{m}^{3}}\right)=\frac{\text { Mass }}{\operatorname{LxW\times T}}
$$

Where:

$\mathrm{L}=$ Length of specimen

$\mathrm{W}=$ Width of specimen

$\mathrm{T}=$ Thickness of specimen

\subsection{Thickness swelling}

The thickness swelling property of the particleboard was determined in accordance with ASTM D1037 - 06a [13]. A test specimen with dimension $20 \mathrm{~mm}$ x $76 \mathrm{~mm}$ x $152 \mathrm{~mm}$ was soaked in pure water at room temperature $(27 \mathrm{oC})$ for 2 hours and 24 hours. The initial and the final thickness of the specimen after the period of submersion were determined with a digital veneer calliper. The thickness swelling for the 2-hour and 24-hour submersions was then computed using equation 5.

Where:

$$
\text { Thickness swelling rate }(\%)=\frac{T_{f}-T_{o}}{T_{o}} \times 100
$$

$T_{\mathrm{o}}=$ Initial thickness of test sample before soaking in distilled water

$\mathrm{T}_{\mathrm{f}}=$ Final thickness of test sample after soaking in water

\subsection{Water absorption}

The water absorption property of the particleboard was determined in accordance with ASTM D1037 - 06a [13]. A sample of dimension $20 \mathrm{~mm}$ x $76 \mathrm{~mm}$ x $152 \mathrm{~mm}$ was weighed and then submerged horizontally under $25 \mathrm{~mm}$ depth of pure water at room temperature $(27 \mathrm{oC})$ for 2-hour and 24-hour. For each of them, the excess water on the surface of the sample was removed with 
hand paper towel and was immediately weighed. The 2-hour and 24-hour water absorption properties were then computed using equation 6.

Where:

$$
\text { Water absorption rate after } 2 \text { hours }(\%)=\frac{W_{f}-W_{o}}{W_{o}} \times 100
$$

$\mathrm{W}_{\mathrm{o}}=$ Initial weight of test sample before soaking

$\mathrm{W}_{\mathrm{f}}=$ Final weight of test sample after soaking

\subsection{Modulus of elasticity (MOE) and modulus of rapture (MOR)}

The MOE and MOR of the particleboards were determined in accordance with the American Society for Testing and Materials standard methods ASTM D 1037-06a [13]. Specimen of size 20 $\mathrm{mm} \times 50 \mathrm{~mm} \times 250 \mathrm{~mm}$ were prepared from the particleboards produced. An Instron Universal Testing Machine (model Inspekt 50-1) operated with a load cell capacity of 50kN was used for the test. The loading rate applied to measure the bond strength was $4 \mathrm{~mm} / \mathrm{min}$.

\subsection{Internal Bond (IB)}

The test was conducted in accordance with ASTM D 7519-11 [14] and ASTM D 1037-06a [13]. Twenty four strips of particleboards $(152 \mathrm{~mm}$ x $305 \mathrm{~mm})$ with three replicates produced from each of the agro-forest residues using the two adhesives were subjected to the following exposure cycle: 16 hours of oven drying at a temperature of $70 \mathrm{oC}$, followed by a 3-hour soaking in water at a temperature of $20 \circ \mathrm{C}$. This was immediately followed by a 2-hour oven drying at a temperature of $70 \circ \mathrm{C}$, and immediately followed by a 3 -hour soaking in water at $20 \mathrm{oC}$. After the third exposure cycle, the boards were dried for 16 hours in an oven at a temperature of $70 \mathrm{oC}$. Finally, four specimen blocks of dimension $50 \mathrm{~mm}$ x $50 \mathrm{~mm}$ were cut from each of the strips. Tension perpendicular to surface (Internal Bond) test was conducted according to the test method of ASTM D 1037-06a [13]. The internal bond of each specimen was calculated using equation 7.

Where:

$$
\text { Internal bond strength }\left(\frac{N}{m^{2}}\right)=\frac{P m a x}{a b}
$$

$P \max =$ Maximum load $(\mathrm{N})$

$a=$ Width of the specimen (mm)

$b=$ Length of the specimen $(\mathrm{mm})$ 


\subsection{Hardness}

The hardness of the particleboards was determined in accordance with the American Society for Testing and Materials standard methods ASTM D 1037-06a [13]. To conduct the hardness test the particleboards were laminated to obtain the given thickness and subsequently cut into $25 \mathrm{~mm} \times 75$ $\mathrm{mm} \times 150 \mathrm{~mm}$, as specified by the standard. Janka ball test was used for determining the hardness of the particleboards using universal testing machine model 4482, operating with a load cell capacity of $100 \mathrm{kN}$.

\subsection{Ultra-structure analysis}

Samples of the particleboard of size $5 \mathrm{~mm}$ x $10 \mathrm{~mm}$ x $10 \mathrm{~mm}$ were investigated using scanning electron microscope (SEM). The specimens were coated with a thin film of gold and mounted on aluminum stub using carbon tape and then analyzed with Phenom ProX desktop SEM with EID at $15 \mathrm{kV}$ with a magnification range of $1300 \mathrm{x}$ to $1500 \mathrm{x}$.

\section{Results and discussion}

\subsection{Aspect ratio of agro-forest residues}

The result in Table 1 shows that $M$. paradisiaca pseudostem particles had the highest aspect ratio (135.03) followed by that of $T$. cacao stem (61.60) with $C$. pentandra (60.54) being the least. Previous studies have indicated that the mechanical properties of particleboards positively correlate with the aspect ratio (particle geometry) of the biomass materials. This is because of the greater surface area it provides in terms of contact between particles [15 and 16]. Furthermore, Gozdecki et al., [17] indicated that particles with a higher aspect ratio enhance stress transfer from the polymer matrix to the particles and ultimately improve the composite mechanical properties. Table 1: Aspect ratio of particle of the agro-forest residues

\begin{tabular}{lcccc}
\hline Agro-forest residue & Number of & \multicolumn{3}{c}{$0.5 \mathrm{~mm} \leq \mathrm{P}<1.5 \mathrm{~mm}$} \\
\cline { 3 - 5 } & samples & Aspect ratio & SD & Range \\
\hline C. Pentandra & 60 & 60.54 & 23.31 & $33.44-96.18$ \\
M. paradisiaca pseudostem & 60 & 135.03 & 33.48 & $111.89-204.35$ \\
T. Cacao Pod & 60 & Parenchymatous cells (No fibers present) \\
T. Cacao Stem & 60 & 61.60 & 22.64 & $33.69-96.14$ \\
\hline
\end{tabular}

Legend: $\mathrm{P}=$ Particle size; $\mathrm{SD}=$ Standard deviation 


\subsection{Particleboard density}

Density is a measure of the compactness of the individual particles in a board, and is dependent mainly on the density of the wood, the type of adhesive and the pressure applied during pressing [18]. The density of the particleboards (Table 2) with cassava starch as an adhesive ranged from $497 \mathrm{~kg} / \mathrm{m}_{3}$ to $598 \mathrm{~kg} / \mathrm{m}_{3}$ whilst that of urea formaldehyde ranged from $421 \mathrm{~kg} / \mathrm{m}_{3}$ to $557 \mathrm{~kg} / \mathrm{m} 3$. According to ANSI A208.1 [19], such particleboards could be graded as low density. Additionally, particleboards produced compares favorably with those produced from medium density wood. Besides, similar results were observed by Melo and Stangerlin [20] in a study to determine the physical and mechanical properties of particleboards manufactured from wood, bamboo and rice husk.

Table 2: Density of particleboard

\begin{tabular}{lcc}
\hline Biomass materials & \multicolumn{2}{c}{ Density $(\mathrm{kg} / \mathrm{m} 3)$} \\
\cline { 2 - 3 } & $100 \%$ Cassava starch & $100 \%$ Urea formaldehyde \\
\hline Ceiba pentandra & $536 \mathrm{a}(11.69)$ & $472 \mathrm{a}(67.86)$ \\
Musa paradisiaca pseudostem & $543 \mathrm{a}(32.25)$ & $493 \mathrm{a}(84.83)$ \\
Theobroma cacao pod & $598 \mathrm{~b}(34.31)$ & $557 \mathrm{~b}(30.90)$ \\
Theobroma cacao stem & $497 \mathrm{a}(26.24)$ & $421 \mathrm{a}(62.47)$ \\
\hline
\end{tabular}

Figures in columns with the same letters are not significantly different $(\mathrm{p}>0.05)$

The density of the particleboards produced from T. cacao pod for both cassava starch and urea formaldehyde was significantly higher than those produced from the other biomass materials. This could be due to the exceptionally high bulk density of its biomass raw material. Furthermore, the particleboards produced using cassava starch as adhesive had higher densities than their corresponding values for urea formaldehyde.

\subsection{Water absorption}

Understanding the water absorption property (WA) of particleboards is an important factor that needs to be evaluated in order to improve dimensional stability of composite [21]. Table 3 shows the water absorption property of particleboards for 2-hour and 24-hour immersion in water. The WA property of the particleboards manufactured from T. cacao pods was highest (worst) for the 2-hour immersion, having values of $22.41 \%$ and $14.98 \%$ respectively for cassava starch and urea formaldehyde adhesives. That of $M$. paradisiaca pseudostem was the least for the 2-hour immersion, having values of $9.86 \%$ and $7.77 \%$ respectively for cassava starch and urea 


\section{Proceedings of the 2020 Society of Wood Science and Technology International Convention}

formaldehyde adhesives. The higher WA property of $T$. cacao pod and $C$. pentandra particleboards could be due to the high content of silica and lower content of lignin present in these materials. Component such as silica interferes with the particles' adhesion and gluing processes [22, 23]. In all cases - 2-hour and 24-hour immersions - the particleboards produced using urea formaldehyde had lower (better) WA properties than their corresponding values for cassava starch. Cassava starch is hydrophilic, therefore, it tends to absorb more water, thus the bond formed between particles, particles-starch and starch-starch is easily broken [24, 25].

Table 3: Water absorption (\%) property of particleboards produced from agro-forest residue

\begin{tabular}{lrrll}
\hline \multirow{2}{*}{ Agro-forest residue } & \multicolumn{4}{c}{ Water absorption (\%) } \\
\cline { 2 - 5 } & \multicolumn{3}{c}{ 2-hour } & \multicolumn{3}{c}{ 24-hour } \\
\cline { 2 - 5 } & Cassava starch & UF & Cassava \\
starch & UF \\
\hline Ceiba pentandra & $19.15 \mathrm{c}(3.16)$ & $13.07 \mathrm{~b}(1.82)$ & $50.08 \mathrm{~d}(1.63)$ & $30.97 \mathrm{~b}(1.07)$ \\
Musa paradisiaca pseudostem & $9.86 \mathrm{a}(0.84)$ & $7.66 \mathrm{a}(1.49)$ & $23.79 \mathrm{a}(3.13)$ & $18.17 \mathrm{a}(1.58)$ \\
Theobroma cacao pod & $22.41 \mathrm{c}(1.21)$ & $14.98 \mathrm{~b}(1.57)$ & $59.46 \mathrm{~d}(1.04)$ & $43.80 \mathrm{c}(5.09)$ \\
Theobroma cacao stem & $12.65 \mathrm{~b}(1.83)$ & $8.10 \mathrm{a}(1.32)$ & $30.82 \mathrm{~b}(2.46)$ & $22.08_{\mathrm{a}}(1.64)$ \\
\hline
\end{tabular}

Figures with the same letters are not significantly different according to Tukey's multiple tests. $\mathrm{UF}=$ Urea formaldehyde

The WA property of the particleboards for the current study is similar to, or lower than those obtained by other researchers who used wood species and agro-forest residues for particleboard production. In a study on suitability of some fast-growing trees and date palm fronds for particleboard production using urea formaldehyde as an adhesive, Hegazy and Aref [34] indicated that the water absorption properties of boards produced ranged from 27.1-72.7\% for 2-hour water immersion and $38.4 \%-87 \%$ for 24 -hour water immersion. The manufactured particleboards could be suitable for producing cabinet, cladding and other interior fittings likely to be used in an environment which will minimize its exposure to moisture.

\subsection{Thickness swelling}

Thickness swelling is perhaps the most important factor when considering moisture effects on particleboards and it is affected by process variables such as the type of biomass raw material, particle geometry, board density, resin level, blending efficiency, and pressing conditions [27]. Using cassava starch as an adhesive, the thickness swelling of the particleboards as indicated in Table 4 ranged from $3.51 \%$ to $6.31 \%$ for 2 -hour immersion and $13.93 \%$ to $21.49 \%$ for 24 -hour immersion. Additionally, the thickness swelling of the particleboards with urea formaldehyde as 
an adhesive ranged from $3.38 \%$ to $4.75 \%$ for 2 -hour immersion and $9.37 \%$ to $16.17 \%$ for 24 -hour immersion. For both the 2-hour and 24-hour immersions, the thickness swelling of the particleboards with cassava starch as an adhesive was significantly higher (worse) than those produced using urea formaldehyde. This could be due to the higher hydrogen polymer chains of the cassava starch which resulted in higher absorption of water leading to higher thickness swelling [28].

Table 4: Thickness swelling of particleboards produced from agro-forest residue

\begin{tabular}{llllr}
\hline \multirow{2}{*}{ Agro-forest residue } & \multicolumn{4}{c}{ Thickness swelling (\%) } \\
\cline { 2 - 5 } & \multicolumn{3}{c}{ 2 Hours } & \multicolumn{2}{c}{ 24 Hours } \\
\cline { 2 - 5 } & Cassava starch & UF & Cassava starch & UF \\
\hline Ceiba pentandra & $5.03 \mathrm{~b}(1.04)$ & $3.91_{\mathrm{a}}(0.05)$ & $17.27_{\mathrm{c}}(2.23)$ & $13.22 \mathrm{~b}(2.62)$ \\
Musa paradisiaca pseudostem & $3.51_{\mathrm{a}}(0.31)$ & $3.38_{\mathrm{a}}(0.28)$ & $11.47_{\mathrm{a}}(4.52)$ & $9.37_{\mathrm{a}}(1.03)$ \\
Theobroma cacao pod & $6.31_{\mathrm{b}}(1.15)$ & $4.75_{\mathrm{a}}(0.77)$ & $21.49_{\mathrm{d}}(2.57)$ & $16.17_{\mathrm{c}}(1.14)$ \\
Theobroma cacao stem & $3.67_{\mathrm{a}}(1.34)$ & $3.61_{\mathrm{a}}(0.53)$ & $13.93 \mathrm{~b}(3.42)$ & $11.24 \mathrm{a}(2.11)$ \\
\hline
\end{tabular}

Figures with the same letters are not significantly different according to Tukey's multiple tests. $\mathrm{UF}=$ Urea formaldehyde

The result also indicated that for both 2-hour and 24-hour immersions, irrespective of the adhesive used, particleboards produced from $T$. cacao pod had a relatively higher thickness swelling whilst those produced from $M$. paradisiaca pseudostem showed minimum thickness swelling. The lower thickness swelling values of $M$. paradisiaca pseudostem particles could be due to its low bulk density $(96.63 \mathrm{~kg} / \mathrm{m} 3)$ which resulted in more compact boards, leading to better adhesion during hot pressing. Beside the high bulk density of $T$. cacao pod particles $(323.96 \mathrm{~kg} / \mathrm{m} 3)$ which could result in poor compaction, $T$. cacao pod contains a high amount of parenchyma tissues which could lead to greater affinity to absorb water [29, 30]. Kord et al. [31] indicated that the parenchyma tissues behaved like a sponge and is also more hygroscopic compared to other cells making it easier for the panels to absorb water.

The thickness swelling of all the particleboards produced could be considered adequate since they were lower than that indicated in ANSI A208.1 [19] and EN 312-2005 [32]. According to ANSI A208.1[19], particleboard for commercialization could have thickness swelling of up to $35 \%$ for 24-hour water immersion. Additionally, EN 312-2005 standards [32], indicated that particleboards should have a maximum thickness swelling of $8 \%$ and $15 \%$ for 2 -hour and 24 hour water immersions. 


\subsection{Modulus of elasticity}

The modulus of elasticity (MOE) obtained for the particleboards ranged from $1031 \mathrm{MPa}$ to 2413 MPa (Figure 6). The highest MOE was obtained for particleboards produced from M. paradisiaca pseudostem using urea formaldehyde as adhesive. The lowest MOE was obtained for particleboards produced from $T$. cacao pod using cassava starch as adhesive.

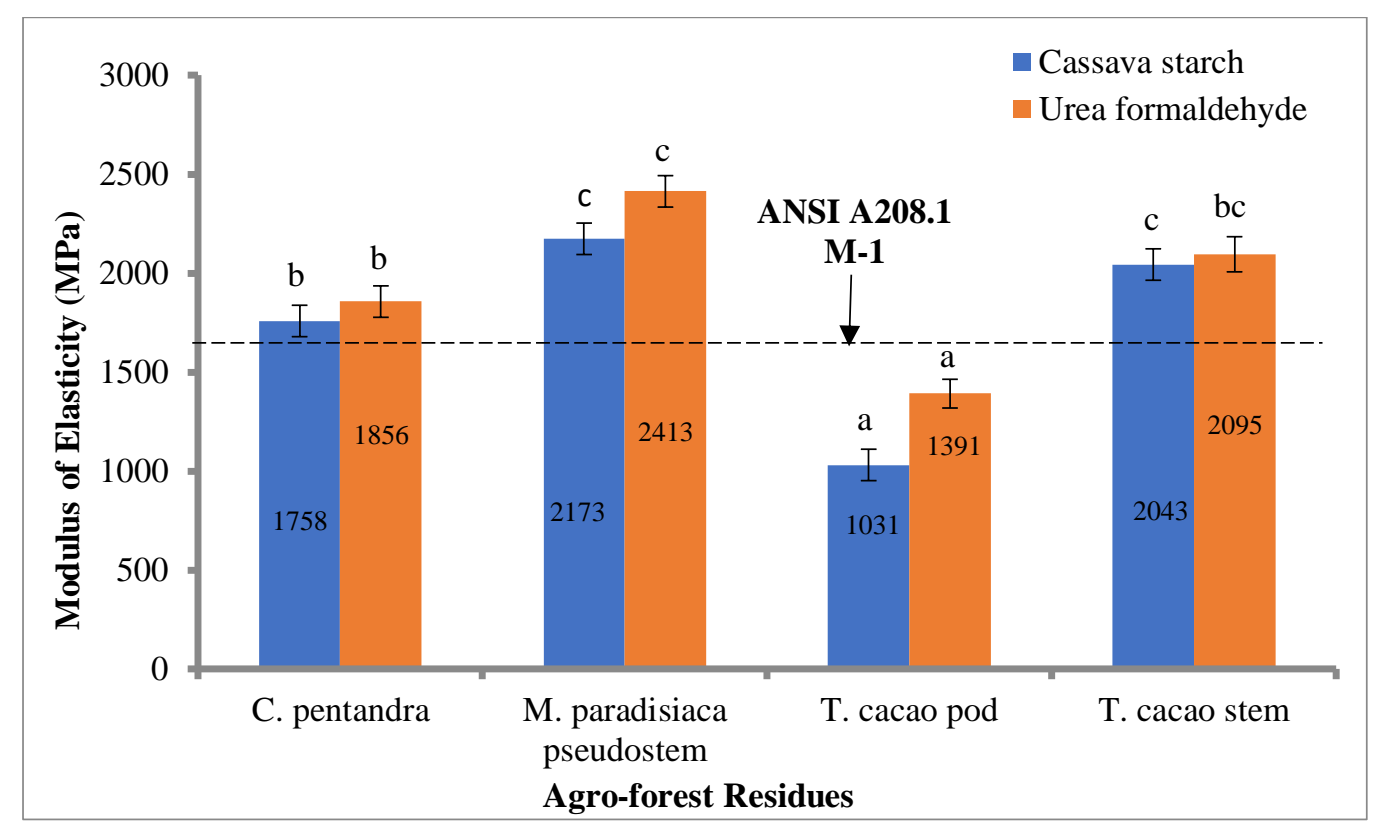

Fig 6: Modulus of elasticity of particleboards produced from agro-forest residues

NB: Bars with the same letter are not significantly different according to Turkey's multiple range tests

With the exception of particleboards produced from T. cacao pod, all the particleboards had higher MOE than the minimum value required for particleboards by the America National Standard Institute ANSI A208.1 [19] which is $1550 \mathrm{MPa}$ for general uses and furniture production.

The high MOE of the particleboards produced from $M$. paradisiaca pseudostem particles could be attributed to it comparatively high aspect ratio which was more than twice that of the other materials. Bax and Mussig [15] indicated that the mechanical properties of particleboards positively correlate with the aspect ratio (particle geometry) of the biomass materials used for its production. The result (Figure 6) also indicates that for the same agro-forest residue there was no significant difference between the MOE of the particleboards produced using cassava starch as adhesive and that of urea formaldehyde. This suggests that cassava starch could be used to substitute urea formaldehyde as an adhesive for producing particleboards.

\subsection{Modulus of rupture}


Modulus of rupture (MOR) is a measure of the maximum load-carrying capacity of a member in bending and is proportional to maximum moment borne by the specimen. The MOR of the particleboards ranged from 4.95 $\mathrm{MPa}$ (T. cacao pod) to $16.54 \mathrm{MPa}$ (M. paradisiaca pseudostem) as indicated in Figure 7. With the exception of particleboards produced from T. cacao pod using both cassava starch and urea formaldehyde adhesives all the particleboards produced had MOR higher than the minimum value indicated by ANSI A208.1 [19] for MOR required for interior fitments (including furniture) which is $10 \mathrm{MPa}$.

Similar results were also stated for particleboards made using under utilized raw material as well as agricultural waste and residues by Papadopoulos et al. [33], Tabarsa et al. [34], Azizi et al. [35], Khanjanzadeh et al. [36]. Similar to the result obtained for the MOE all the particleboards produced using urea formaldehyde as an adhesive had higher MOR than their corresponding values which used cassava starch.

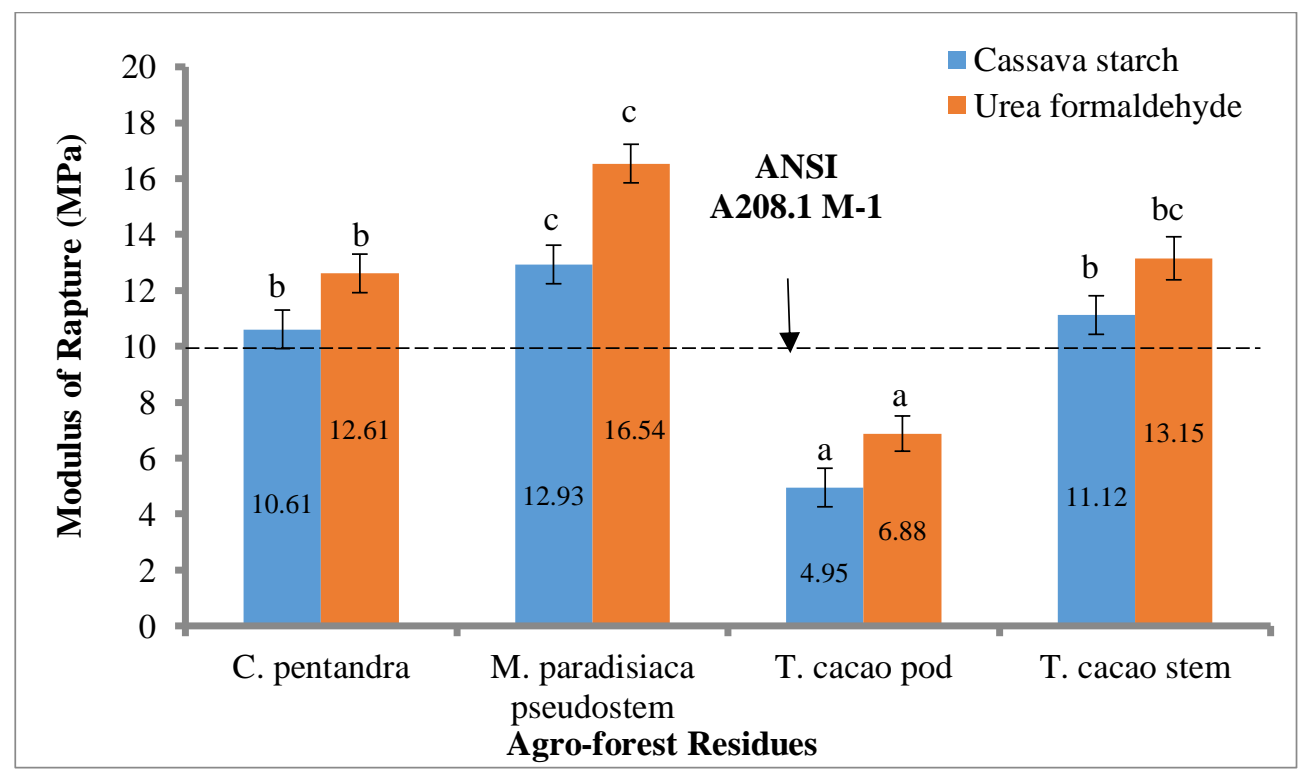

Fig. 7 Modulus of rupture of particleboards produced from agro-forest residues

NB: Bars with the same letter are not significantly different according to Turkey's multiple range tests

\subsection{Internal Bond Strength (IB)}

The internal bond strength of the particleboards using urea formaldehyde as adhesive were higher than those produced with cassava starch (Table 5). Musa paradisiaca boards had the highest IB of 


\section{Proceedings of the 2020 Society of Wood Science and Technology International Convention}

$1.14 \mathrm{~N} / \mathrm{mm} 2$ and $0.97 \mathrm{~N} / \mathrm{mm} 2$ for both UF and cassava starch adhesives respectively, and boards from Theobroma cacao pods had the lowest IB of $0.63 \mathrm{~N} / \mathrm{mm} 2$.

Table 5: Internal Bond strength (IB) of particleboards

\begin{tabular}{lcc}
\hline Agro-forest residue & \multicolumn{2}{c}{ Internal Bond (N/mm2) } \\
\cline { 2 - 3 } & $100 \%$ Cassava starch & $100 \%$ Urea formaldehyde \\
\hline Ceiba pentandra & $0.76 \mathrm{a}(0.09)$ & $0.83 \mathrm{a}(0.06)$ \\
Musa paradisiaca pseudostem & $0.97 \mathrm{~b}(0.05)$ & $1.14 \mathrm{~b}(0.03)$ \\
Theobroma cacao pod & $0.58 \mathrm{c}(0.03)$ & $0.63 \mathrm{c}(0.09)$ \\
Theobroma cacao stem & $0.70 \mathrm{a}(0.04)$ & $0.80 \mathrm{a}(0.07)$ \\
\hline
\end{tabular}

Figures with the same letters are not significantly different according to Tukey's multiple tests. $\mathrm{UF}=$ Urea formaldehyde

This corresponds with the results of the aspect ratio of the particles of the agro-forest residues where Musa paradisiaca pseudostem had the highest aspect ratio of 135.03 and Theobroma cacao pods having no fibres. The boards with higher MOR and MOE had higher IBs. The minimum value of internal bond required by ANSI A208.1 [19] is $0.5 \mathrm{~N} / \mathrm{mm} 2$ and according to EN 312 [32] is $0.40 \mathrm{~N} / \mathrm{mm}_{2}$ (for thickness of $6-13 \mathrm{~mm}$ ). Therefore, the particleboards made comply with the standards.

\subsection{Hardness}

Figure 8 shows the hardness of particleboards produced and it indicates that the highest value which was $8.78 \mathrm{kN}$ was obtained from $M$. paradisiaca pseudostem boards using urea formaldehyde as an adhesive. The least hardness, $2.49 \mathrm{kN}$, was obtained for particleboards produced from $T$. cacao pod using cassava starch as adhesive. 


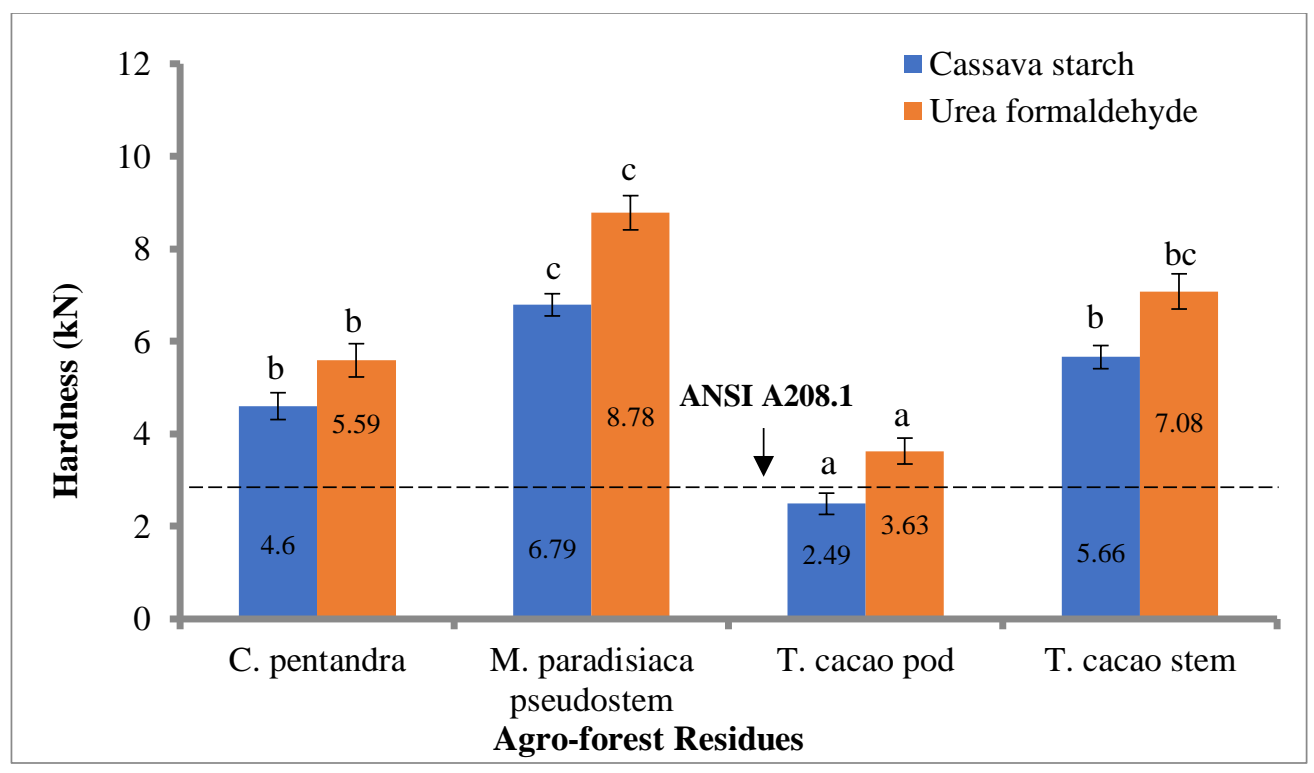

Fig 8 Hardness of particleboards produced from agro-forest residues

NB: Bars with the same letter are not significantly different according to Turkey's multiple range tests

The results indicate that except for the particleboards produced from $T$. cacao pods using cassava starch as adhesive, all the particleboards produced had hardness higher than the ANSI A208.1 standard [19] for general purpose usage which is $2.8 \mathrm{kN}$. Therefore, $M$. paradisiaca pseudostem, T. cacao stem and C. pentandra sawdust lcould be used to produce particleboards with adequate hardness for general purposes using cassava starch as adhesive. On the average, for the same agroforest material the particleboard produced using urea formaldehyde was harder compared to those produced using cassava starch.

\subsection{Scanning electron microscope (SEM) analysis of the manufactured particleboards}

The microstructural analysis of particleboards from T. cacao pod using cassava starch and UF urea formaldehyde revealed major micro pores and loosed particles (Fig 9g and 9h). It was observed that the particles were detached from the adhesives. The surface of the T. cacao pod particleboard was very rough indicating that the bonding between the particles and the adhesive was poor. This could be as a result of high bulk density and low aspect ratio of the biomass material [37 \& 38]. 


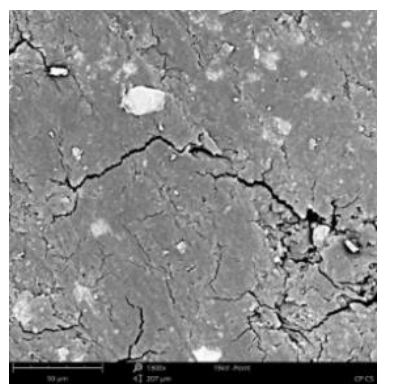

a: $\mathrm{CP}+\mathrm{CS}$

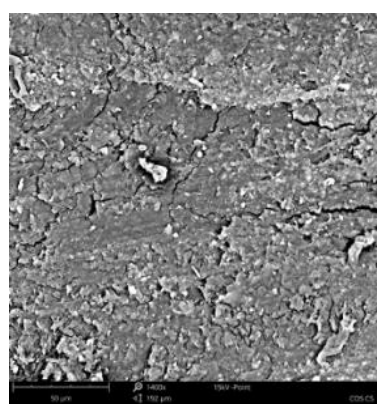

e: $\mathrm{TCS}+\mathrm{CS}$

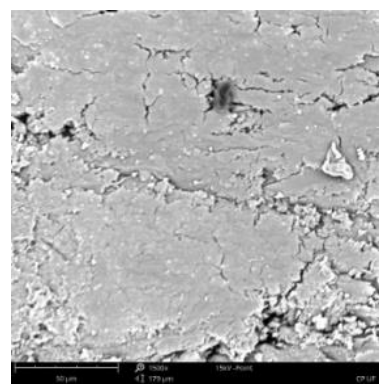

b: $\mathrm{CP}+\mathrm{UF}$

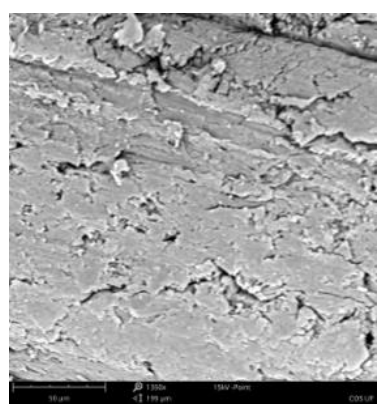

f: TCS + UF

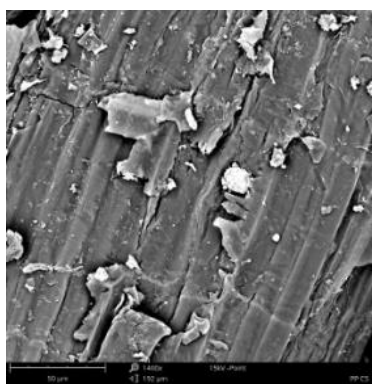

c: $\mathrm{MPP}+\mathrm{CS}$

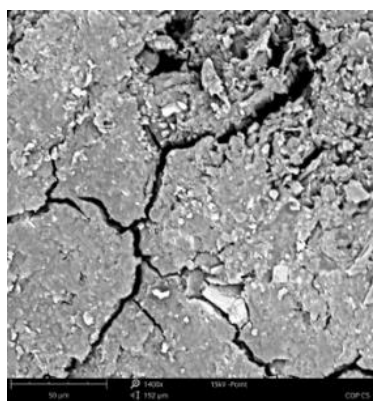

g: $\mathrm{TCP}+\mathrm{CS}$

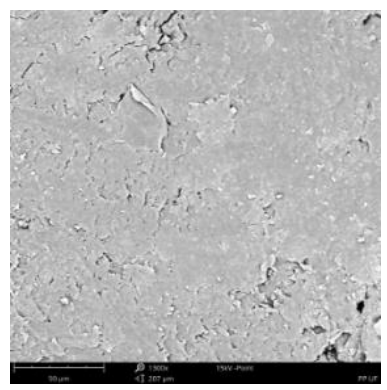

d: MPP + UF

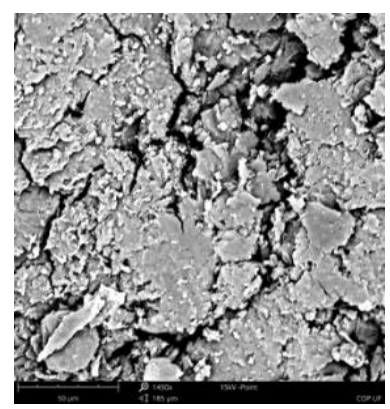

h: TCP + UF

Figure 9: Figures 9a to 9f show smooth surfaces indicating good compatibility between particles and adhesives. Figures $9 \mathrm{~g}$ and $9 \mathrm{~h}$ show discontinuity of particles and adhesives, thus detached particles from adhesives surfaces.

Legend: $\mathrm{CP}=$ Ceiba pentandra: $\mathrm{MPP}=$ Musa paradisiaca pseudostem: TCP $=$ Theobroma cacao pod: TCS $=$ Theobroma cacao stem: $\mathrm{CS}=$ Cassava starch: UF = Urea formaldehyde

On the contrary, specimen shown in figures $8 \mathrm{a}-8 \mathrm{f}$ indicated that the adhesives filled into the interparticle spaces of the particleboards. This therefore led to better agglomeration and compaction of the particles and adhesives. This good interfacial bonding between the adhesive and the particles would result in improved the mechanical strength [39].

\section{Conclusions}

This study investigated the physical and mechanical properties of particleboards produced from Theobroma cacao stem and pod, Musa paradisiaca pseudostem and Ceiba pentandra. The essence of this study was to investigate the suitability of the above mentioned agro-forest residues for making particleboards using cassava starch or urea formaldehyde as adhesive. It could be concluded from the study that with the exception of the particleboards produced from Theobroma cacao pod those produced from all the other three agro-forest residues had characteristics that could enable them to be classified as low density composite boards. The physical and mechanical properties of the particleboards produced from Theobroma cacao stem, Musa paradisiaca pseudostem and Ceiba pentandra had properties higher than that recommended by ANSI A208.1. Therefore, they could be used as a raw material for production of particleboards. Such composite 
boards produced could be utilized for indoor applications and for general purposes under dry condition such as furniture manufacturing. It is recommended that a further study that seeks to blend cassava starch and urea formaldehyde as adhesive to produce particleboards be considered. Additionally, it would be worthwhile considering a study that looks at the effect of blending Musa paradisiaca pseudostem and T. cacao pod on the physical and mechanical properties of particleboards produced.

\section{Acknowledgement}

The authors are grateful to the Wood Industry and Utilization Division of CSIR-FORIG for making their wood workshop and laboratory available for this study. We are also grateful to Mr Felix Boakye and Ms Linda Osei Bonsu of CSIR-Forestry Research Institute of Ghana for their support in the preparation of the samples for this study. Final appreciation goes to Ms. Dora Fianyo of the Department of Earth Science, University of Ghana, for her immense support during the SEM analysis.

\section{References}

1. Stark NM, Matuana LM, Clemons CM (2004) Effect of processing method on surface and weathering characteristics of wood-flour/HDPE composites. Journal of Applied Polymer Science 93(3):1021-1030.

2. Klímek P, Meinlschmidt P, Wimmer R, Plinke B, Schirp A (2016) Using sunflower (Helianthus annuus L.), topinambour (Helianthus tuberosus L.) and cup-plant (Silphium perfoliatum L.) stalks as alternative raw materials for particleboards. Industrial Crops and Products 92:157-164.

3. Bekas GA, Kaziolas DN, Zygomalasc I, Stavroulakis GE (2015) Life cycle analysis and optimization of a timber building. 7th International conference on sustainability in energy and buildings. Energy procedia 83:41-49. www.sciencedirect.com.

4. Tan BK, Ching YC, Poh SC, Abdullah LC, Gan SN (2015) A Review of Natural Fiber Reinforced Poly(Vinyl Alcohol) Based Composites: Application and Opportunity. Polymers 7: 2205-2222.

5. Maninder, Kathuria RS, Grover S (2012) Using agricultural residues as a biomass briquetting: An alternative source of energy. IOSR Journal of Electrical and Electronics Engineering 1(5), 1115.

6. Tumuluru JS, Wright CT, Kenny KL, Hess R (2011) A review on biomass densification technologies for energy application. U.S. Department of Energy. http://www.inl.aov. Accessed (2019)

7. Food and Agriculture Organization of the United Nations, F.A.O. (2017). FAO NEWS ARTICLE: Global wood production growth accelerates. Global production and trade of forest products. http://www.fao.org/forestry/statistics/80938/en/

8. GMI US EPA (2016) GMI US EPA (2016). Global methane initiative (GMI), global methane forum (GMF). United State Environmental Protection Agency. https://www.epa.gov/gmi 
9. Mitchual SJ (2013) Densification of sawdust of tropical hardwoods and maize cobs at room temperature using low compacting pressure without a binder. PhD Theses, School of Graduate Studies, Kwame Nkrumah University of Science and Technology, Kumasi, Ghana.

10. Rokiah H, Siti Hazneza AH, Othman S, Norli I, Mahamad Hakimi I, Hasnah MJ, Salmiah U (2009) Extractable formaldehyde from waste medium density fibreboard. Journal of Tropical Forest Science 21(1):25-33.

11. ASTM International (2017) Standard test methods for particle-size distribution of soils using sieve analysis. ASTM standard D6913/D6913M - 17.

12. Hartmann H, Böhm T, Daugbjerg Jensen P, Temmerman M, Rabier F, Jirjis R, Hersener JL, Rathbauer J (2004) Methods for bulk density determination of solid biofuels. In: Van Swaaij WPM, Fjällström T, Helm P, Grassi A (Hrsg.) 2nd world conference and technology exhibition on biomass for energy, industry and climate protection, Rome, 10-14 May 2004. Energy research Centre of the Netherlands ECN, Petten, 662-665.

13. ASTM International (1999) Standard test methods for evaluating properties of wood-base fiber and particle panel materials. ASTM standard D1037-06a, Philadelphia.

14. ASTM International (2011) Standard test methods for internal bond strength and thickness swell of cellulosic-based fiber and particle panels after repeated wetting. ASTM standard D7519:2011, West Conshohocken, USA.

15. Bax, B. and Mussig, J. (2008). Impact and tensile properties of PLA/cordenka and PLA/flax Composites. Compos Sci Technol, Vol. 68: 1601-1607.

16. Juliana, A. H., Paridah, M. T., Rahim, S. Nor Azowa, I. and Anwar, U. M. K. (2014). Effect of adhesion ad properties of kenaf (Hibiscus cannabinus L.) stem in particleboard performance. Journal of Adhesion Science Technology. 28(6): 546-60.

17. Gozdecki C, Zajchowski S, Kociszewski M, Wilckynski A, Mirowski M, (2011) Effect of wood particle size on mechanical properties of industrial wood particle-polyethylene composites. Polimery 56(5):375-380.

18. Vital BR, Lehmann WF, Boone RS (1974) How species and board densities affect properties of exotic hardwood particleboard. Forest Produsts Journal 12(24):37-45.

19. ANSI (1999) ANSI. Mat-formed wood particleboard: specification ANSI A 208.1.1993. Gaithersburg: National Particleboards Association.

20. Melo RR, Stangerlin DM (2014) Physical and mechanical particleboard manufactured from wood, bamboo and rice husk. Materials Research 17(3):682-686. httpI://dx.doi.org/10.1590/S1516-14392014005000052.

21. Wang W, Morrell JJ (2004) Water sorption characteristic of two wood/plastic composites. Forest Prod. Journal 54:209-212.

22. Calegari L, Haselein CR, Scaravelli TL, Santini EJ, Stangerlin DM, Gatto DA et al. Desempenho físico-mecânico de painéis fabricados com bambu (Bambusa vulgaris Schr.) em combinação com madeira. Cerne. 2007; 13(1):57-63.

23. Melo RR (2009) Physical-mechanical properties and decay resistance of wood and rice husk particleboard in different proportions (In Portuguese). Master's Thesis, Federal University of Santa Maria, Santa Maria, Brazil. 
24. Robyt J. (2008) Starch: Structure, Properties, Chemistry, and Enzymology. In: Fraser-Reid B.O., Tatsuta K., Thiem J. (eds) Glycoscience. Springer, Berlin, Heidelberg. DOI: 10.1007/978-3-540-30429-6_35.

25. Kushairi MS, Rokiah H, Othman S, Salim H, Wan Noor AWN, Norani AK, Nadiah J, Lily ZPA (2015) Evaluation of properties of starch-based adhesive and particleboard manufactured from them, Journal of Adhesion Science and Technology 29(4):319:336.

26. Hegazy SS, Aref IM (2011) Suitability of some fast-growing trees and date palm fronds for particleboard production. Forest Prod. J. 60(7/8):599-604.

27. Halligan AF (1970) A review of thickness swelling in particleboard. Wood Science and Technology 4(4):301-312.

28. Witono JR, Noordergraaf IW, Heeres HJ, Janssen LPMB (2014). Water absorption, retention and the swelling characteristics of cassava starch grafted with polyacrylic acid. Carbohydrate Polymers 103:325-332.

29. Ramle SF, Sulaiman O, Hashim R, Arai T, Kosugi A, Abe H, Mori Y (2012) Characterization of parenchyma and vascular. Lignocellulose Journal, 1(1):33-44.

30. Abdullah SK, Taj-Aldee SJ (2012) Extracellular enzymatic activity of aquatic and aeroaquatic condial fungi. Hydrobiologia 174: 217-223

31. Kord B, Zare H, Abdollah HA (2016) Evaluation of the mechanical and physical properties of particleboard manufactured from canola (Brassica napus) straws.

32. EN 312 (2005) Particleboards-specifications. European Committee for Standardization 312, Brussels-Belgium.

33. Papadopoulos AN, Hill CAS, Gkaravili A, Ntalos GA, Karastergiou SP (2004) Bamboo chips (Bambusa valgaris) as an alternative lignocellulosic raw material for particleboard manufacture. Holz als Roh-und Werkstoff 60:36-39.

34. Tabarsa T, Ashori A, Gholamzadeh M (2011) Evaluation of surface roughness and mechanical properties of particleboard panels made from bagasse. Composites: Part B 42:1330-1335. http://dx.doi.org/10.1016/j.compositesb.2010.12.018.

35. Azizi A (2011) Role of Microorganism in litter decomposition of Salix spp. MSc Dissertation. University of Agricultural Science and Technology of Kashmir.

36. Khanjanzadeh H, Bahmani AA, Rafighi A, Tabarsa T (2012). Utilization of bio-waste cotton (Gossypium hirsutum L.) stalks and underutilized paulownia (Paulownia fortunie) in wood-based composite particleboard. African Journal of Biotechnology 11(31):8045-8050.

37. Ogah, O. A. and Afiukwa, J. N. (2013). Characterization and comparison of mechanical behavior of agro fiber-filled high-density polyethylene bio-composites. Journal of Reinforced Plastics and Composite. Volume 33(1): 37-46.

38. Laskowska, A. and Mamiński, M. (2018). Properties of particleboard produced from postindustrial UF- and PF bonded plywood. European Journal of Wood and Wood Products, 76: 427435.

39. Han, G., Zhang, C., Zhang, D., Umenura, D. and Kawai, S. (1998). Upgrading of urea formaldehyde-bonded reed and wheat straw Particleboards using coupling agents, Journal of Wood Science 44, 282-286.

Biography 


\title{
Global CLT industry in 2020: Growth beyond the Alpine Region
}

\author{
Lech Muszynski ${ }^{1 *}$ - Pipiet Larasatie ${ }^{1}$ - Jose Erlin Martinez Guerrero ${ }^{1}$ \\ - Raquel Albee ${ }^{1}$ - Eric N. Hansen ${ }^{1}$ \\ ${ }^{1}$ Professor, Graduate Student, Graduate Student, Graduate Student, Professor \\ Oregon State University, Corvallis, OR, USA \\ * Corresponding author \\ lech.muszynski@oregonstate.edu,pipiet.larasatie@oregonstate.edu, \\ jose.querrero@oregonstate.edu, Raquel.albee@oregonstate.edu,eric.hansen@oregonstate.edu
}

\begin{abstract}
At the threshold of 2020, the cross-laminated timber (CLT) industry continues its incredible growth across the globe. The total output of the industry in 2020 is projected to reach 2 million cubic meters. The only continent where no new CLT plants come on line or are at least planned in 2020 is Antarctica. Although many new CLT lines were recently deployed outside of the Alpine region from where the industry evolved, Alpine countries still account for over $70 \%$ the output volume and nearly $62 \%$ of the annual per-shift capacity. And yet, after more than 25 years of CLT technology development, the industry still feels young and no less intriguing. The goal of this presentation is to provide updated insights into the global CLT industry structure, output potential, production profile, internal diversity, competitiveness, innovativeness, and perceived barriers to further expansion, including the unknown effects of the COVID-19 pandemic. The presentation is based on two global CLT industry surveys, 46 plant tours, and supplemental information from secondary sources. These results are intended to provide insights for potential entrants and stakeholders into the CLT manufacturing sector, including businesses along its extensive supply chain.
\end{abstract}

Key words: cross-laminated timber, CLT, manufacturing, global industry 


\section{Proceedings of the 2020 Society of Wood Science and Technology International Convention}

\section{Introduction}

Organic development of the global CLT industry over the last 25 years has produced substantial diversity in manufacturing processes, levels of automation, scales of operation, products and services options as well as in market strategies. The development has not followed typical commodity-oriented forest products industry models and it is difficult to provide an adequate precedent.

The purpose of this presentation is to provide an insight into the global CLT industry, its basic production characteristics, and business models. This publication is building on the first of its kind review of the global CLT industry published in 2017 (Muszynski et al. 2017).

Existing global CLT operations provide a living laboratory that provides understanding of both the current state-of-the-art as well as the trajectory and future development of the CLT industry. Especially important are insights for how newly emerging markets may develop.

\section{Methodology}

The second iteration of the global CLT industry survey presented in this paper has built on the experience of the first survey (Muszynski et al. 2017), with an improved methodology and a focus on the emerging CLT operations outside the Alpine cluster, and on dynamics in the industry's vital metrics.

Three major sources of information were considered: 1) an online survey launched in winter 2019 (Albee 2019); 2) targeted site tours of CLT manufacturing lines performed in the USA, Japan, Australia, China, New Zealand, France, Germany, Norway, Sweden, Finland, and Estonia; and 3) review of trade journals tracking the development of the CLT industry (mainly within the Alpine Europe and Czechia).

The online survey was sent to 66 active CLT and similar mass-timber panel (MTP) manufacturers, that is all that could be identified at that the beginning of 2019, of which 12 companies responded (response rate 18.2\%). In addition, 29 site tours targeting CLT and other MTP manufacturers, as well as MTP hardware manufacturers were completed in 24 months between winter 2017 and fall 2019. In both forms of communication, the item non-response is somewhat problematic with data in this study since not all respondents were willing to answer all questions in electronic surveys or in scripted interviews. Also, there are operations that we were unable to develop any reliable data about, beyond the fact that they exist.

Wherever possible, the data obtained from different sources were verified against each other. Overlaps and gaps in the coverage of these sources were carefully resolved using the "latest data point" approach, that is using the most recent reliable data from any of the three sources.

To ensure anonymity, information is presented in aggregate format and when discussing regional differences, the data is parsed by large regions defined in a way to avoid exposing information from a single manufacturer (Figure 4). One exception is the plant located in South Africa, which agreed to share related information openly (Smily 2019). 


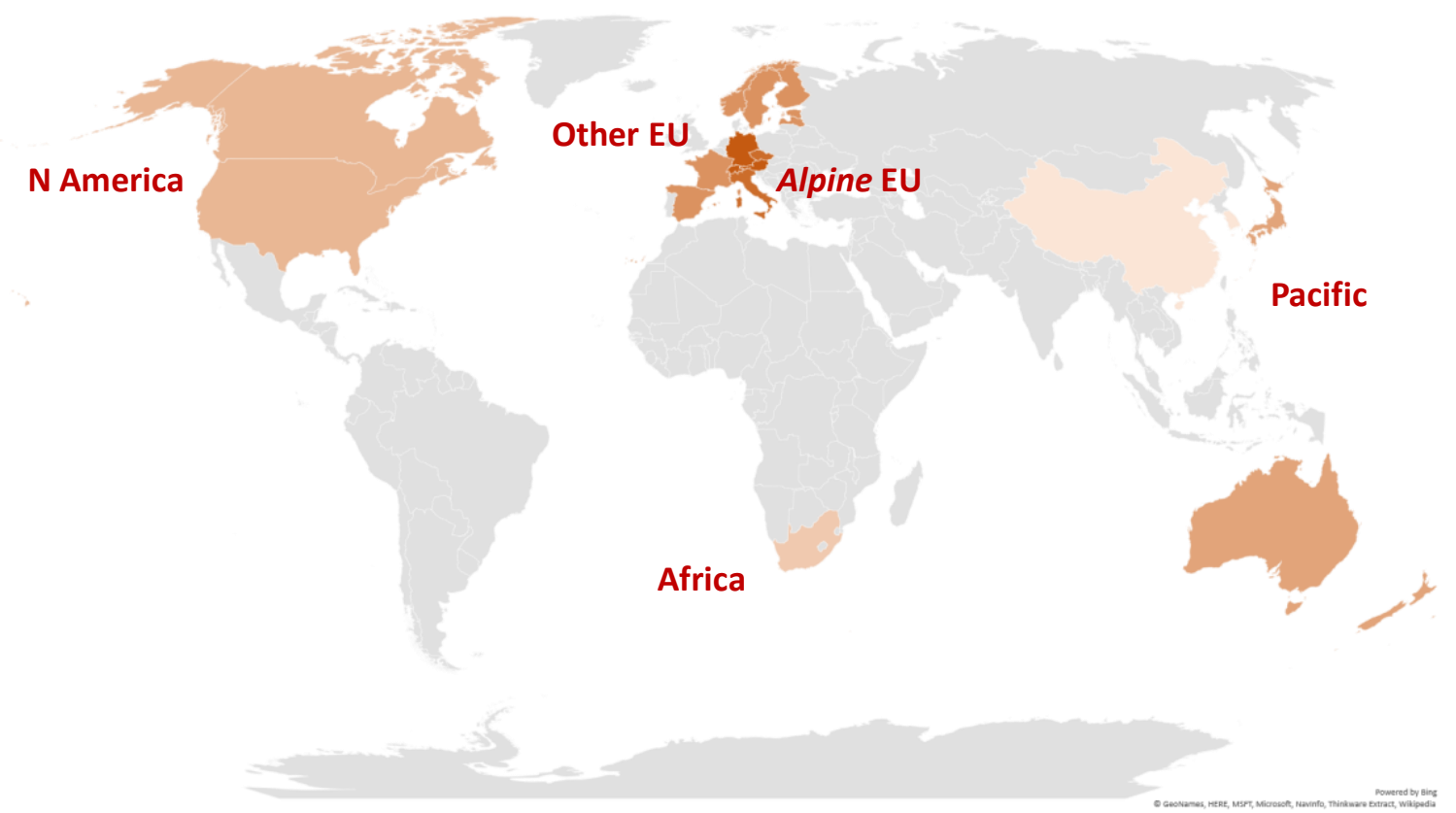

Figure 4: CLT producing regions.

One of the methodological difficulties in reporting the potential of a non-commodity, customproject driven industry is that the annual output is not necessarily the best tool for gauging its potential. For many metrics the annual per-shift capacity of production lines was selected as a more representative context than the total annual output.

\section{Major findings}

Ownership of the CLT plants varies from family enterprises to international holdings. Press types and sizes vary greatly (there is no size standard for CLT panels). Most CLT companies show some level of vertical integration within their complex value chains.

The scales of operation and the level of automation vary greatly. Annual volumes of production of CLT plants across the globe varied from less than $500 \mathrm{~m}^{3}$ to over $125,000 \mathrm{~m}^{3}$ (Figure $5 \mathrm{a}$ ), while the annual per-shift capacities varied from less than $500 \mathrm{~m}^{3}$ to $110,000 \mathrm{~m}^{3}$ (Figure $5 \mathrm{~b}$ ). However, over the past three years, an increasing number of new CLT plants opt for specialized off-the-shelf equipment solutions, characterized by high capacity, high level of automation and an option for full integration of entire lines. The comparison of these two graphs indicates that not all companies utilize their production capacity to the same degree. This particularly applies to a number of high capacity plants launched in 2019 but not reaching their full production potential in the start-up year.

The comparison of the graphs in Figure 5 indicates that not all companies utilize their production capacity to the same degree, which is consistent with the non-commodity character of the industry. In a particular sense, this is also true for a number of high capacity plants launched in 2019 but not reaching their full production potential in the start-up year. 


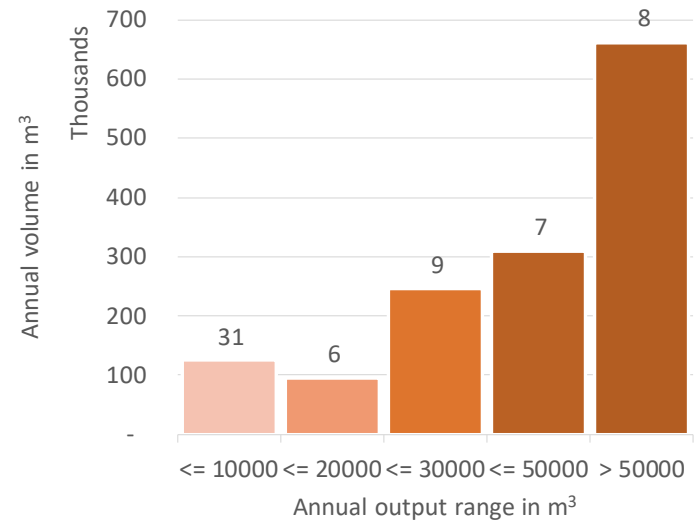

a)

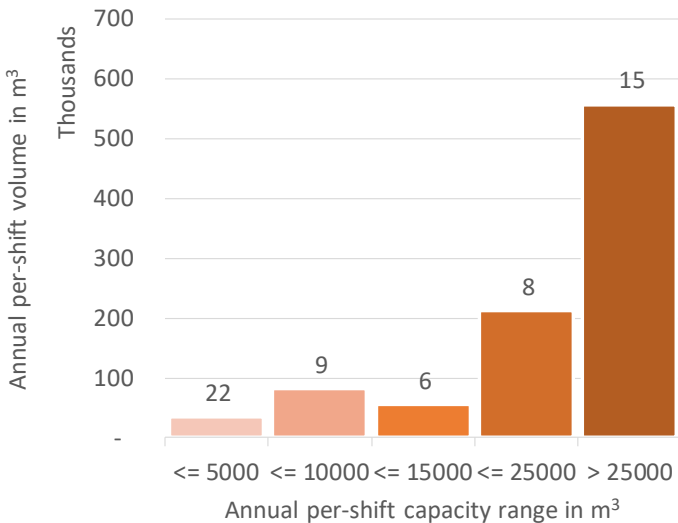

b)

Figure 5: Annual production volumes (a) and annual per-shift capacity (b) allocated to CLT lines representing a range of production capacity scale. Number of production lines in each category provided above the bars.

Currently, three out of four of all presses installed are fabricated by three specialized European manufacturers (Figure 6a). Nearly four out of five of all installed CNC centers we know about are fabricated by three leading European manufacturers (Figure 6b). As a result, many new production lines launched since 2017 are rather similar. That trend applies to the oldest and largest CLT companies in Alpine Europe as they upgrade their lines to meet demand.

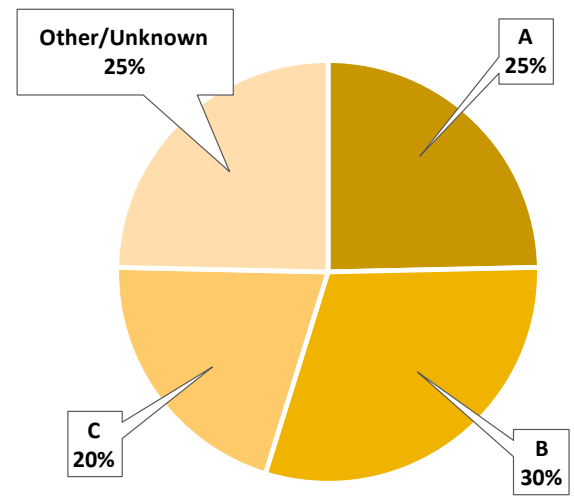

a)

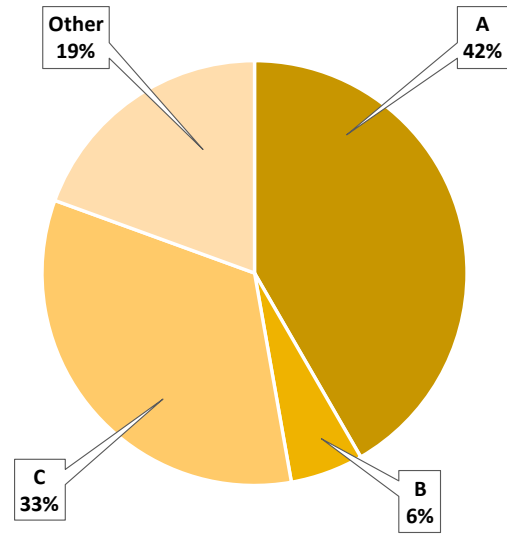

b)

Figure 6: Shares of known CLT lines equipped with presses (a) and CNC finishing centers (b) manufactured by three leading providers of respective equipment category.

Even as some companies operate more than one line under the same roof, few decide to build another plant in different location and even fewer build new production lines in foreign markets. This is true even for the major Alpine Region players that are very successful pursuing projects in foreign markets. An almost proverbial example is the activity of leading Austrian companies in the Australian market.

One interesting dynamic on the fringe of the CLT industry is the rise of complimentary "adhesive-free" cross-laminated panel products that use nails, wooden dowels and other alternative panel integration systems. In Europe, there are about 30 licensed manufacturers of 
nailed cross laminated panels marketed as MassivHolzMauer or MHM (MHM 2020) and no less than 10 lines producing panels bonded with wooden dowels (TechnoWood 2020).

Since the publication of the first global survey (Muszynski et al. 2017), substantial production capacity has been added outside the core Alpine region of Europe, including a new plant in South Africa, pilot plant in China, two short lived lines in Indonesia and feasibility studies conducted in Brazil and Chile. The only continent where no new CLT plants have come on line or at least planned in 2020 has been Antarctica.

In most countries outside the Alpine Region, growth of the CLT industry has been encouraged by the governments motivated by the desire to find a stable, economically viable outlet for substantial volumes of domestic lumber of lesser quality. The incentive programs used as a tool in these campaigns vary by country in terms of scale, specific form and duration, and not all are equally successful.

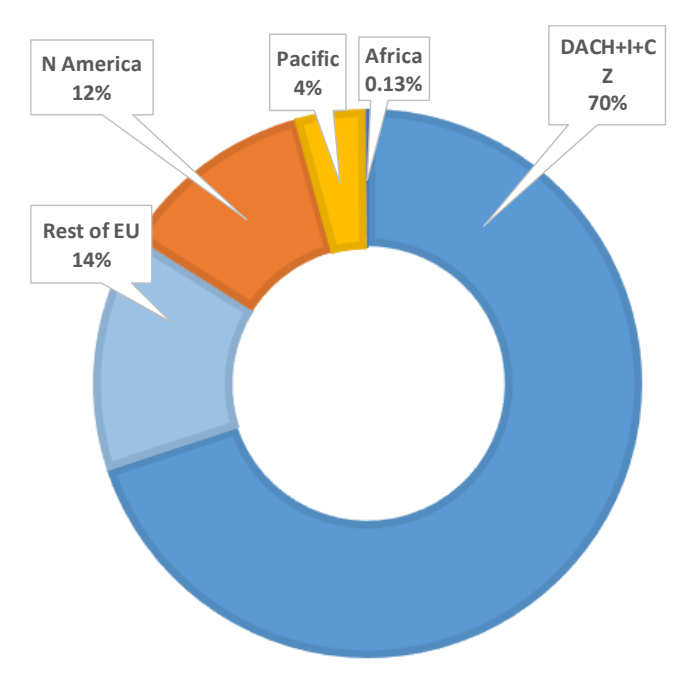

a)

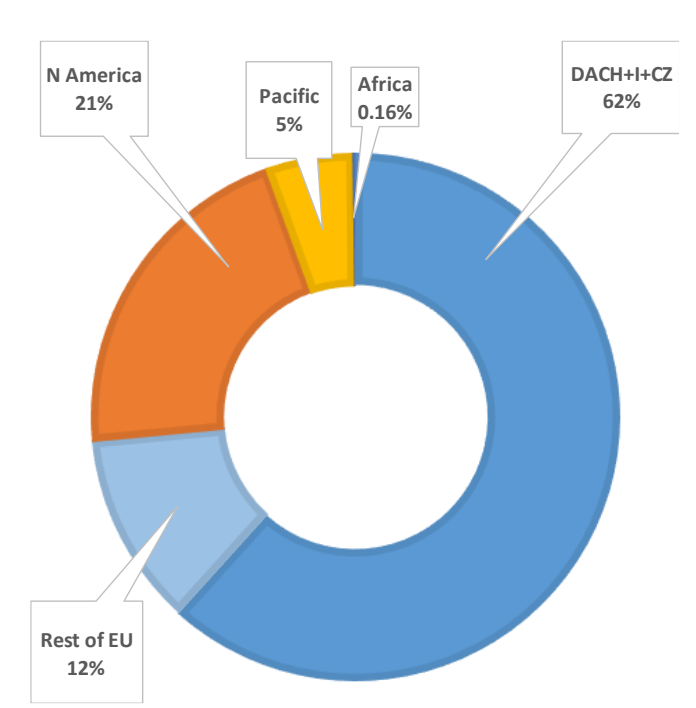

b)

Figure 7: Regional distribution of the total global CLT output volume (a) and per-shift capacity (b)....

Annual global output of CLT in 2019 that we can attribute to 60 specific production lines is about 1.44 million $\mathrm{m}^{3}$. The global annual per-shift capacity in 2019 based on 58 (two companies reported total output but not per-shift capacities) specific production lines is about 0.94 million $\mathrm{m}^{3}$. The Alpine region still accounts for over $70 \%$ the output volume (Jauk, 2019) and nearly $62 \%$ of the annual per-shift capacity (Figure 7). Considering known CLT operations for which the produced volumes/capacities are outdated or currently unavailable, the total 2019 output may be estimated at the level of 1.6-1.8 million $\mathrm{m}^{3}$. Further, considering the number of high-capacity plants that, by pre-pandemic standards, would likely reach full capacity in 2020, it, it is that by the end of 2020 the global annual output might reach 2.0-2.5 million $\mathrm{m}^{3}$.

Gauging the potential for the capacity of individual regions or countries to grow their CLT manufacturing market potential is notoriously difficult. This is because of substantial differences that exist between regions in terms of the strength of their economies, robustness of their construction markets, size and level of sophistication of their forest products industries, but also the density of population and myriad other factors that could be considered. Here we 


\section{Proceedings of the 2020 Society of Wood Science and Technology International Convention}

use a simple and manageable approach of creating estimates. However, a very rough estimate may be arrived at by using a set of substitute gross indicator metrics widely available for individual countries and possible to summarize for regions. For instance, while GDP per capita may be a readily available measure of a country's economic output that accounts for the size of its population, it must be combined with another metric indicative of that country's access to structural forest products and its ability to process them for meaningful estimates of CLT industry potential.

The metrics used in this study included the volume of softwood production (2018 data, FAO 2020), GDP (2018 data, World Bank 2020), population density (based on 2018 population and area data, FAO 2020), number of CLT lines, annual CLT output volume in 2019, and CLT per-shift production capacity all summarized by regions. All metrics except population density are expressed per capita. To facilitate an assessment of the potential of an individual country or region, One may view the metrics relative to that reference country or region. In the example presented in Figure 8, the relative metrics considered in this comparison are listed along the vertical axis, while the regions being compared are listed along the horizontal axis. Values of individual metrics are reflected by the area of the bubbles for a given metric and region. In this example, the reference country of interest is the United States of America. Accordingly, the size of the bubbles in the first column are the reference unit for other columns.

When metrics are compared visually via Figure 6, it is easy to see that there are no dramatic differences between the regions in terms of GDP or softwood production per capita. One somewhat differentiating metric is the population density, substantially higher for countries included in the Alpine region, which by Holzkurier standards include Austria, Czechia, Germany, Italy and Switzerland. But even with that distinction, this relatively small region outweighs all others in terms of number of installed CLT manufacturing lines (followed by the rest of CLT producing Europe and by the Pacific region) and has no equal in terms of the total annual CLT output volume or in per-shift production capacity. These gaps may be interpreted as an indirect indicator of the potential for regions that seem to be otherwise similar to the Alpine region in other gross metrics scaled per capita.

With due respect to the gross simplifications of this approach, it is possible to cautiously conclude that in order to match the level of saturation seen in the Alpine Europe, the US market should be able to support as many as 70 CLT production lines of various sizes (currently 5 ) and 16-fold increase of the production output volume from the level seen the threshold of 2020 (117 thousand $\mathrm{m}^{3}$ /year). These numbers may be scaled down to 40 production lines and $4 \mathrm{x}$ increase in production volumes if the CLT producing countries in other parts of Europe are considered as a model. 


\section{Proceedings of the 2020 Society of Wood Science and Technology International Convention}

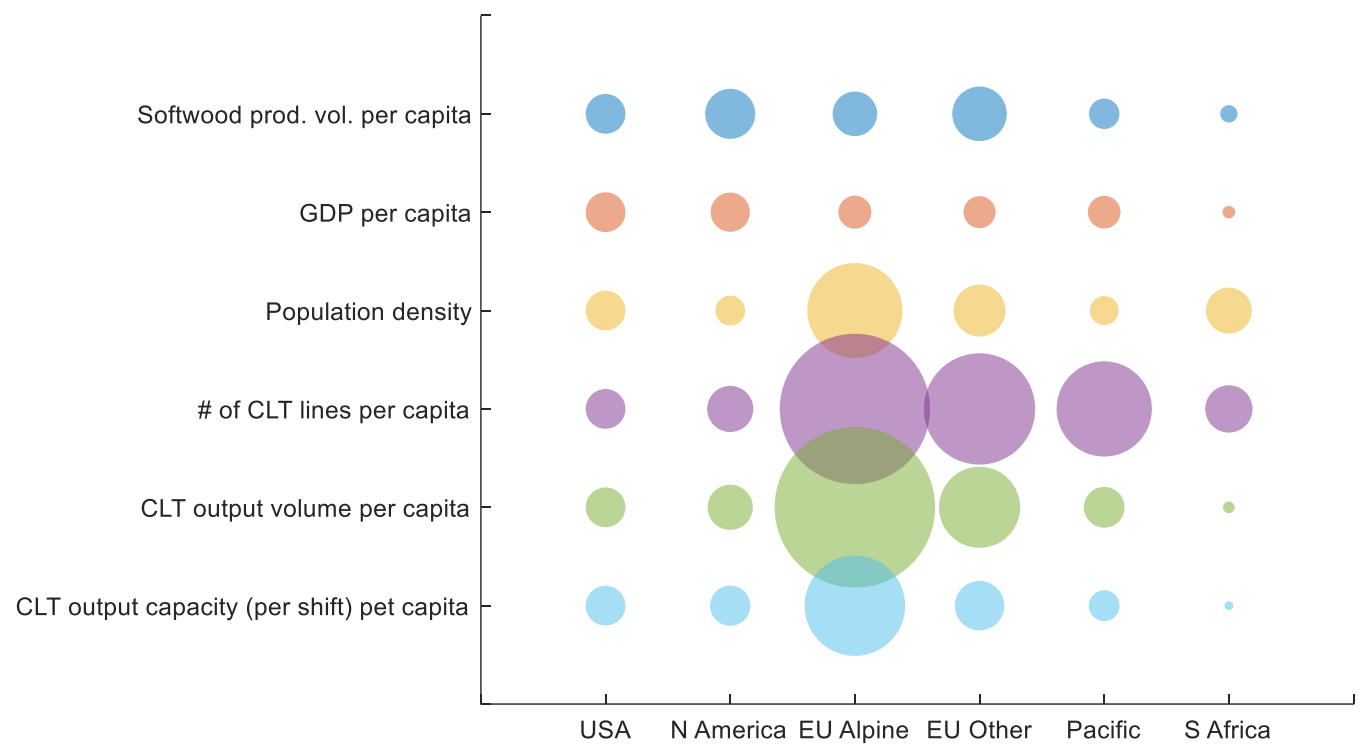

Figure 8: A comparison of selected socio-economic metrics scaled by population of CLT producing regions with per-capita CLT production in 2019 for each (combined sources).

Overall, at the threshold of 2020s the CLT industry continued its exponential growth across the globe. However, that upbeat picture could not possibly have predicted the pandemic triggering tectonic shifts in global economies.

The big question today is how does the pandemic impact the CLT industry as-we-speak and what are the perspectives of CLT players regarding the post-pandemic new normal.

The industry has a substantial degree of intrinsic flexibility and is oriented towards custommade products serving premium construction projects. Myriad questions arise from our current context:

What will be a winning strategy in the post-pandemic economy?

Will the industry's internal diversity provide sufficient resilience to weather the changes?

Will the high level of automation be an advantage in the post-pandemic new normal?

Will all elements of the complex supply chain of the industry be equally resilient?

How will the post-pandemic world affect the export prospects of CLT companies that typically export to overseas markets?

Will public enchantment/enthusiasm last?

Finally, with respect to governments, will utilization of low-value local species remain a priority? Will the industry be perceived as a dispensable luxury or a part of a solution for the new normal?

The anecdotal evidence based on brief unstructured conversations with the industry leaders in the US suggests that the CLT industry in the Pacific Northwest is navigating the pandemic 


\section{Proceedings of the 2020 Society of Wood Science and Technology International Convention}

relatively well. This sentiment is corroborated by the latest news from Alpine Europe (Jauk \& Guzely 2020).

\section{Summary and Conclusions}

Overall, at the threshold of 2020s the CLT industry continued its exponential growth across the globe. There has been substantial growth in the number of new, high capacity lines in regions outside Alpine Europe and an increase of production coming out of that region. After 25 years of development, the industry still feels very young and as exciting as ever. However, that upbeat picture is clouded by the pandemic triggering tectonic shifts in global economies and leaving us with more questions and unknowns than answers.

\section{Acknowledgements}

This project was funded by USDA ARS program. Additional support: Softwood Export Council, Linnaeus University, Estonian Forest and Wood Industries Association. The authors also acknowledge support of Dr. Chris Knowles (OSU), Ms. Tomoko Igarashi and and Mr. Yuichi Hayashi (American Softwoods, Japan), Ms. Jasmin Rainer and Mr. Günther Jauk (Holzkurier).

\section{References}

Albee R.R. (2019): Global Overview of the Cross-Laminated Timber Industry. MS thesis. Oregon State University, Corvallis, OR. 114 pp.

Albee R.R., L. Muszyński, E.N. Hansen, C.D. Knowles, P. Larasatie, J.E. Guerrero (2018): Recent developments in global cross-laminated timber (CLT) market. World Conference on Timber Engineering, Proceedings of the WCTE 2018, Seoul, Korea, August 20-24: 6 pp.

FAO (2020): Food and Agricultural Organization of the United Nations.

http://www.fao.org/faostat/en/\#data. Access date: 07/03/2020

Jauk G. (2019): Holzkurier (CLT special issue)

Jauk G. \& E. Guzely (2020: Corona is not going not stop CLT. Timber-Online, May/June, 2020. https://www.timber-online.net/wood products/2020/05/corona-is-not-going-not-stopclt.html. Accessed: 10/6/2020

MHM (2020): https://www.massivholzmauer.de/en/about-us/sales-offices/locations/mhmproducers.html. Accessed: 13/06/2020

Muszyński L., E. Hansen, B.M. S. Fernando, G. Schwarzman, J. Rainer (2017): Insights into the Global Cross-Laminated Timber Industry. BioProducts Business. 2(8): 77-92

Smily J. (2019): XLam ZA, personal contact. 28/10/2020

TechnoWood (2020): https://www.technowood.ch/downloads/technowood/tw-portfolio.pdf. Accessed 13/06/2020

World Bank (2020): https://data.worldbank.org/indicator/NY.GDP.MKTP.CD. Access date: $07 / 03 / 2020$

Biography 


\title{
Proceedings of the 2020 Society of Wood Science and Technology International Convention
}

\section{How Megaplatypus mutatus behaves inside a trunk? Studying its galleries via Computerized Axial Tomography and Digital Images Processing}

\author{
Andres Dolinko1 \\ adolinko@df.uba.ar \\ Yasmil Costales2 \\ yaia.costales@gmail.com \\ Cecilia Carmaran 1 \\ carmaran@bg.fcen.uba.ar \\ Esteban Ceriani Nakamurakare 1 \\ cerianinaka@gmail.com
}

${ }_{1}$ CONICET Researcher, DBBE-FCEyN, Universidad de Buenos Aires, Argentina ¿Undergraduate Thesis Student, Universidad Favoloro, Argentina

\section{Abstract}

Megaplatypus mutatus (syn. Platypus sulcatus), an ambrosia beetle native to South America, is one of the main forest pests in Argentina and an emergent foreign pest in Europe, representing a potential risk to forest and fruit plantations due to its low specificity. Special attention has been given to poplar plantations as a result of the high economic impact. This ambrosia beetle attacks vigorous hosts producing multiple attacks per tree, triggering a structural weakening and eventually causes the breakdown of the tree trunk; especially when weather conditions are unfavourable. Even though the relevance of understanding the microhabitat where this complex system develops, this is the first comprehensive study that characterizes the galleries of this forest pest analyzing the topology of tunnels, the implications in the wood structure and the reproduction of $M$. mutatus. In this context, two commercial plantations were sampled where we studied 28 attacked trees with a Philips-MX16-slice tomographer, generating $\approx 5200$ slides. A special computer algorithm that allows isolating the galleries from the rest of the image was specially developed. This allowed characterizing with high precision the geometry, dimensions and topological properties of the galleries in all the samples, as well as, a 3D visualization of the structure. The impacts of the obtained results in the frame of the pathogenic system are discussed.

Keywords: Computed Tomography, Digital image processing, 3D Visualization, Populus, Megaplatypus, Platypodinae, Ambrosia, Forest Pest.

Biography 


\title{
Proceedings of the 2020 Society of Wood Science and Technology International Convention
}

\section{Introducing the SWST Wood Technology Student Chapter at DISAFA, University of Torino, Italy}

\author{
Francesco Negro1 \\ francesco.negro@unito.it \\ Carlo Grignani 1 \\ carlo.grignani@unito.it \\ Eva Haviarova2 \\ ehaviar@purdue.edu \\ Victoria Herian 3 \\ vicki@swst.org \\ Roberto Zanuttini 1 \\ roberto.zanuttini@unito.it
}

1 DISAFA, University of Torino, Italy

2 Purdue University, USA

3 SWST, USA

\begin{abstract}
The Wood Technology Student Chapter (WTSC) was activated in December 2019 at the Department of Agricultural, Forest and Food Sciences (DISAFA), University of Torino, Italy, within the Education Program of the International Society of Wood Science and Technology(SWST). First SWST European Student Chapter, named WTSC-DISAFA, aims at broadening student perspectives and deepening their wood science and technology knowledge. This will be pursued in particular by: organizing activities such as seminars, experimental testing, visits etc.; exploring wood technology at national and international levels; highlighting the linkages between wood technology and other disciplines; encouraging relationship with other student associations.

The presentation provides an insight into the WTSC-DISAFA function and feedback from currently enrolled students. The presentation will also describe features of DISAFA and the wood technology education. The Student Chapter, its Constitution and the process that led to the Chapter formation are described. Students' interests and some of the current and future activities are also introduced. Sharing this experience, highlighting the main grounds on which is this new Student Chapter based, could motivate other wood products programs to create additional SWST student chapters.
\end{abstract}

Key words: DISAFA, Education, Student Chapter, SWST, Wood Technology

Biography 


\title{
Proceedings of the 2020 Society of Wood Science and Technology International Convention
}

\author{
Investigation of the damping behaviour of beech material \\ Gábor Németh \\ nemethg89@gmail.com \\ Endre Magoss \\ magoss.endre@uni-sopron.hu \\ Sándor Borza \\ borza.sandor@uni-sopron.hu \\ University of Sopron, Hungary
}

\begin{abstract}
Although there are numerous papers and studies regarding the topic, the dynamical aspects of wood physics still remain one of the lesser-studied subtopics of wood sciences. One of the particularly neglected areas of this subtopic is the measurement of the damping coefficient of different types of wood material subjected to transversal waves.

The main goal of this research is to present the driving influence factors of the structural damping coefficient (such as the thickness of the probe, the rigidity of the support and the amplitude of the vibration) through the example of the bending mode of beech cantilever beams. In order to achieve this, beech beams of various thickness values (ranging up to $25 \mathrm{~mm}$ ) have been used, with all of them subjected to free (bending) vibration of similar initial amplitude and boundary condition. By changing the starting amplitude and/or the strength of the end support, their effect on the damping coefficient are then directly measurable.
\end{abstract}

As a secondary target, using the aforementioned measurement method we would also like to determine whether or not it is possible to compare the damping coefficients due to transversal and longitudinal waves directly. Since those damping coefficients are well-known from various acoustic studies, this step requires no additional physical tests or experiments as it can be done as a straightforward comparison.

\section{Biography}




\title{
Proceedings of the 2020 Society of Wood Science and Technology International Convention
}

\section{Measuring the heat of interaction between lignocellulosic materials and}

\author{
water
}

Martin Nopens ${ }^{1}$, Lars Wadsö ${ }^{2, *}$, Christian Ortmann ${ }^{3}$, Michael Fröba ${ }^{4}$, and Andreas Krause ${ }^{1}$

1 Department of Wood Science and Technology, Universität Hamburg, 21031 Hamburg, Germany

$2 \quad$ Building Materials, Lund University, 22363 Lund, Sweden

3 TA Instruments, 65760 Eschborn, Germany

4 Institute of Inorganic and Applied Chemistry, Universität Hamburg, 20146 Hamburg, Germany

\begin{abstract}
Measuring the heat of interaction between lignocellulosic materials and water Wood properties are influenced by moisture content, and wood-water-interactions have therefore been studied for decades. Sorption of water on lignocellulosic materials leads to heat production (sorption enthalpy) which, together with sorption isotherms, can be used to characterize the sorption process.

Several explanations have been proposed to connect the sorption enthalpy with accessibility and amount of hydroxyl groups as well as with the number of sorbed water molecules in wood. Therefore reliable values for sorption enthalpy are needed. However, sorption enthalpies are non-trivial to measure. For the first time, sorption enthalpies are measured with four different methods on the same materials to be able to compare the methods' strengths and weaknesses. Isosteric heat, solution calorimetry, sorption calorimetry, and RH perfusion calorimetry have been applied to beech and scots pine wood. Advantages and disadvantages for all methods will be presented. As we noticed problems in comparing published enthalpy results for wood-water interaction, because different methods, definitions, and units have been used, we propose a sorption nomenclature.

Generally, the mixing enthalpy is a robust measure and therefore can be used to characterize the interaction between water and wood. The results for beech and pine were similar, and also agree with existing literature, but there is a significant scatter in the result. Especially investigations of sorption enthalpy using isosteric heat of sorption seems to be complicated and the results are highly influenced by both the isotherm raw data and the method of evaluation.

We do not recommend one methods over the other, as they can be used to elucidate different aspects of wood-water interactions. The four methods all have their advantages and disadvantages. Therefore we recommend using more than one method in parallel. However, the isosteric method - which is most commonly used due to availability of sorption isotherm data - should be used with caution.
\end{abstract}

\section{Keywords}

Sorption enthalpy, isosteric heat, solution calorimetry, sorption calorimetry, RH perfusion calorimetry, beech, pine, isotherms 
Proceedings of the $\mathbf{2 0 2 0}$ Society of Wood Science and Technology International Convention

\section{Literature}

Nopens, Martin; Wadsö, Lars; Ortmann, Christian; Fröba, Michael; Krause, Andreas (2019):

Measuring the Heat of Interaction between Lignocellulosic Materials and Water. In: Forests 10 (8), S. 674. DOI: 10.3390/f10080674.

Biography 


\title{
Proceedings of the 2020 Society of Wood Science and Technology International Convention
}

\section{Combined FTIR spectroscopy and rheology for investigating the influence of different wood extracts on adhesive curing}

\author{
Merve Özparpucu \\ oezparpucu@hfm.tum.de \\ Elisabeth Windeisen-Holzhauser \\ windeisen@hfm.tum.de \\ Klaus Richter \\ richter@hfm.tum.de \\ Technical University of Munich, School of Life Sciences Weihenstephan, Wood Research Munich, \\ Germany
}

\begin{abstract}
Adhesive bonding of wood plays a crucial role in the development of new advanced wood-based materials and composites. However, wood bonding is not a straightforward process as wood has inherently complex chemical and structural properties. In particular, wood extracts can accumulate at the surface and create a chemical boundary layer with different surface permeability, polarity, and wettability as well. Therefore, the interactions between the wood and adhesives are supposed to determine the quality of wood-adhesive bonds. In this study, interactions between the wood adhesives and extractable wood constituents were investigated systematically. The simultaneous examinations of the progress of chemical reactions and rheological properties of both pure adhesives (e.g. MUF, PUR, EPI and PRF) and adhesive-extract mixtures were performed using a real-time FTIR spectroscopy and in situ rheology. The results confirm significant influences of the extracts on the curing process of the adhesives, in particular for the extracts having a higher amount and acidity level such as chestnut extract $(\mathrm{pH}=3.8)$, and provide fundamental information on their chemical interaction.
\end{abstract}

\section{Biography}




\title{
Proceedings of the 2020 Society of Wood Science and Technology International Convention
}

\section{An anionic polyelectrolyte hybrid for wood-polyethylene composites with high strength and fire safety via self-assembly}

\author{
Mingzhu Pan, \\ mzpan@njfu.edu.cn \\ Nanjing Forestry University, China
}

\begin{abstract}
Wood-plastic composite (WPC), as a renewable and sustainable material, has received wide attention, but its inherent flammability greatly limits its broad application in residential construction and so on. In this work, to derive high-performance, high-function, and high-value-added WPC, an anionic polyelectrolyte hybrid was applied to simultaneously improve the flame retardancy and mechanical properties of woodpolyethylene composite. The anionic polyelectrolyte hybrid (APP-CNC) was constructed with ammonium polyphosphate (APP) and cellulose nanocrystals (CNC) by self-assembly with ionic and hydrogen bonding. The physical crosslinking network between APP-CNC hybrid and WPC enabled the whole materials possess both high load capacity and good deformation capacity synchronously. According to the digital image correlation (DIC), the strain transferred uniformly from HDPE molecular to wood fibers via the physical crosslinking network based on hydrogen bonding, and hence an increased high deformation region occurred and distributed uniformly in WPC/APP-CNC. Compared with neat WPC, a $42.69 \%$ increase in tensile strength and a $75.9 \%$ increase in Young' modulus of WPC/APP-9wt\%CNC were obtained. During pyrolysis, CNC promoted hybrid to pyrolyze ahead (T5\% of $298{ }^{\circ} \mathrm{C}$ ) and provided a carbon skeleton for char forming. Meanwhile, physical crosslinking network further caused a more compact char residue with a higher graphitization during combustion of WPC. With an incorporation of 20 wt\% APP-9wt\%CNC hybrid, WPC had a significant decrease in average heat release and total heat release of $62.6 \%$, and $23.8 \%$ respectively, compared with neat WPC. This work indicated that polyelectrolyte hybrid had a potential application prospect in preparation of high-performance, highfunction and high-value-added WPC.

Biography
\end{abstract}




\title{
Proceedings of the 2020 Society of Wood Science and Technology International Convention
}

\section{Dynamic behavior of phenol-formaldehyde modified wood under cyclic loading}

\author{
Jaka Gašper Pečnik1 \\ jaka.pecnik@innorenew.eu \\ Andreja Kutnar 1 \\ andreja.kutnar@innorenew.eu \\ Holger Militz2 \\ hmilitz@gwdg.de \\ Matthew Schwarzkopf 1 \\ matthew.schwarzkopf@innorenew.eu \\ Hannes Schwager2 \\ hannes.schwager@web.dev
}

1Innorenew CoE and University of Primorska, Slovenia ¿University of Göttingen, Germany

\begin{abstract}
Chemical modification of wood can increase the potential number of wood applications through improved performance, reduction of maintenance, and better durability. In this study, Scots pine (Pinus sylvestris L.) and European beech (Fagus sylvatica L.) were modified with a low molecular weight phenol formaldehyde (PF) resin. This study assessed the effect that this modification had on mechanical properties including fatigue strength, cyclic creep, and cyclic modulus of elasticity. Quasi-static, threepoint bending tests were conducted on a universal testing machine after modifing the wood samples. Reference and modified specimen groups ( $\mathrm{n}=25$ for each group) underwent cyclic fatigue testing resembling previously completed static testing. Our measure for fatigue strength was determined as complete value of $10_{6}$ pulsative loading repetitions using $10 \mathrm{~Hz}$ sinusoidal waveform. The upper stress limit was calculated based on an estimated value designated for individual specimens correlated from modulus of elasticity and modulus of rupture obtained under qausi-static test, while the lower stress level limit was close to 0 . The PF modified wood showed brittle material characteristics that were further correlated to a reduction in fatigue strength and change in cyclic creep behavior. Modification using PF increased the ratio of elastic-to-plastic deformation, which is the result of less pliable and more rigid matrix created from crosslinking PF resin and cell wall. Modification of both wood species decreased their fatigue strength. On the other hand, cyclic creep was found to be lower than for the reference groups. A decisive observation was found for a reduction in cyclic modulus that was negligible compared to the reference groups. This presentation will discuss the effect of modification on cyclic creep behavior and observations from cyclic modulus of elasticity that were found to have different behavior compared to normal untreated wood. Observed from static test, the ratio between total and plastic deformation was found to be significantly different from unmodified groups, which could be correlated to the dynamic behavior of the material. Modified wood did not show any signs of identified failure during the test, as the cyclic hysteresis loops typically did not show any reduction in stress-strain loading diagrams. Therefore, these findings are important for understanding of dynamic behavior of PF modified wood under cyclic loading in order to be used in high-demanding environments.

\section{Biography}


Proceedings of the $\mathbf{2 0 2 0}$ Society of Wood Science and Technology International Convention

The way of using logging waste in wood-based panels production

\author{
Olena Pinchevska \\ olenapinchevska@nubip.edu.ua \\ Olha Baranova \\ olhabaranovaa@gmail.com \\ Yuriy Lakyda \\ yuriy.lakyda@gmail.com
}

National University of Life and Environmental Sciences of Ukraine, Ukraine

\title{
Abstract
}

Every year in Ukraine, the issue of efficient and complete utilization of timber, including forest harvesting residues, is becoming increasingly acute. In 2018 alone, the amount of harvesting residues amounted to about 9 million $\mathrm{m}_{3}$, mainly accumulated in logging areas (tree tops, branches, decayed parts of trees, etc.) and subsequently incinerated. Among the harvesting residues, a considerable part is occupied by branches that are not used in the manufacture of wood-based panels and fuel briquettes due to its high bark content. It is suggested to use branches of poplar wood ( Populus ) for production of woodcomposite material. For this purpose, the wood component is not crushed as in the manufacture of known wood-composition material - chipboard, OSB, and are flattened.

\section{Biogrphy}




\title{
Proceedings of the 2020 Society of Wood Science and Technology International Convention
}

\section{Utilization of Juniper residues for strandboard manufacturing}

\author{
Tomas Pipiska \\ tpipiska@gmail.com \\ Scott Leavengood \\ scott.leavengood@oregonstate.edu \\ Fred Kamke \\ fred.kamke@oregonstate.edu
}

Oregon State University, USA

\section{Abstract}

Western juniper (Juniperus occidentalis) acreage in the Great Basin of the western United States has increased dramatically in the past century. In Oregon alone, western juniper woodlands have expanded from approximately 607,000 hectares ( 1.5 million acres) in 1930 to about 2.6 million hectares (6.5 million acres) today.

Juniper heartwood is resistant to fungi and insects and used for a variety of applications such as raisedbed gardens, gazebos, and decking as well as for interior uses like tables and cabinets. Juniper sawmills in Oregon, produce approximately 6,000 m3 (2000-2500 MBF) of lumber each year. Lumber production results in generation of residues like slabs, edgings, and trim ends. These residues are usually sold as firewood or burned by the sawmills.

The main purpose of this study is to explore utilization of juniper residues for value-added products. Slabs and edgings from the production of lumber usually contain bark. The first part of the research was focused on production of strands from slabs and edgings and the reduction of the bark on the strands during the manufacturing process. After that, we were focused on strandboard manufacturing from juniper strands and comparison of the physical and mechanical properties with other typical species for strandboard manufacturing.

Production of the strands with the comparable processes like in OSB mills showed the possibility of the manufacturing and reduction of the bark on the strands. The physical and mechanical properties of the juniper strandboards are comparable with other wood species.

\section{Biography}




\title{
Proceedings of the 2020 Society of Wood Science and Technology International Convention
}

\section{Surface Modification of Bamboo Fibers for Reinforcing Cement-based Composites}

\author{
Yang Ban \\ 582646914@qq.com \\ Wendi Liu \\ wdliu9054@163.com \\ Renhui Qiu \\ renhuiqiu@fafu.edu.cn
}

Fujian Agriculture and Forestry University, China

\begin{abstract}
The incorporation of fibers into cement-based materials can improve the toughness and reduce the shrinkage cracks of the materials. Bamboo fiber (BF) has good physical-mechanical properties such as high specific tensile strength and modulus. The replacement of traditional fibers with bamboo fibers in cement-based composites is of great significance in promoting green construction materials and sustainable development. However, bamboo fibers are hydrophilic and easily degraded by microorganisms. Surface modification of bamboo fiber would enhance interfacial adhesion between bamboo fiber and cement, and thus improve durability of bamboo fiber-reinforced cement composites. In this work, two coupling agents, i.e., Y-glycidyl ether oxypropyl trimethoxysilane (KH560) and isocyanatepropyltriethoxysilane (IPTS) were used to modify BFs, and then the modified fibers were used as reinforcements in cement-based composites. The resulting fiber-reinforced cement-based composites were evaluated in terms of flexural and compressive strength tests, cube compressive strength test, tensile strength tests, capillary water absorption test, chloride ion erosion test, dry shrinkage test, and freeze-thaw cycle test. The results showed that the modified BFs improved the flexural strength, splitting tensile strength, and tensile strength of the composites compared to the control composites using untreated BFs. The modified BF/cement composites had better aging resistance than the control. The modification of BFs with IPTS and KH560 decreased the degree of plastic shrinkage cracking and delayed the time of plastic shrinkage of the composites. Also, the modified BFs composites presented good anti-shrinkage capacity, impermeability and frost-resistance. FTIR, XPS and NMR analyses confirmed that the two silanes were bonded onto the fibers, which greatly improved the interfacial adhesion between BFs and cement.
\end{abstract}

\section{Biography}




\title{
Proceedings of the 2020 Society of Wood Science and Technology International Convention
}

\section{Mapping of moisture on wood surface with hyperspectral imaging}

\author{
Jakub Sandak1 \\ jakub.sandak@innorenew.eu \\ René Herrera Díazz \\ renealexander.herrera@ehu.es \\ Daniel Chuchalas \\ daniel.chuchala@pg.edu.pl \\ Faksawat Poohphajai4 \\ faksawat.poohphajai@innorenew.eu \\ Veerapandian Ponnuchamy4 \\ veerapandian.ponnuchamy@innorenew.eu \\ Nezka Sajincic4 \\ nezka.sajincic@innorenew.eu \\ Piotr Taube 5 \\ piotr.taube@sylvadrewno.com \\ Kazimierz Orlowski3 \\ korlowsk@pg.edu.pl \\ Anna Sandak 1 \\ anna.sandak@innorenew.eu
}

${ }_{1}$ InnoRenew CoE \& University of Primorska, Slovenia

2University of the Basque Country, Spain

3Gdańsk University of Technolog, Poland

4InnoRenew CoE

5SYLVA Sp. z o.o., Poland

\section{Abstract}

The water and wood relations influence greatly the technological processes of timber transformation as well as the performance of diverse products derived from wood. It is extremely important therefore to control moisture content at all stages of its use in order to assure optimal, functional and long-life service. There are several direct and indirect technical solutions enabling non-destructive assessment of the water present in wood, including electrical resistance, capacitance, microwave, attenuation or polarization of diverse electromagnetic radiations or variety of spectroscopic solutions, among the others. Especially use of the near-infrared spectroscopy was recently identified as highly suitable technique, combining ease of use, high sensitivity, and superior accuracy. Even if this technique enables rapid estimation of the wood moisture content (together with several other properties, such as density, chemical composition, mechanical strength or even cellulose crystallinity or extractives content), most of the available instruments are limited to off-line applications and measurement of a single point at each scan. As an alternative, the latest developments of hyperspectral imaging enable scanning of object surface with very high speed (up to several hundred spectral profiles per second) still assuring superior spatial and spectral resolution. The goal of this work was to compare the performance of three state-of-the-art hyperspectral imaging systems, covering different spectral bands. All cameras were produced by SPECIM (Oulu, Finland) and included FX10 (400-1000nm), FX17 (900-1700nm) and SWIR (1000-2500nm). Three sets of wood samples representing softwood (Norway spruce, Picea abies), ring-porous species (ash, Fraxinus sp.) and disuse-porous hardwood 


\section{Proceedings of the 2020 Society of Wood Science and Technology International Convention}

(beech, Fagus sylvatica) were conditioned in climatic chambers to predefined equilibrium moisture content. The relative humidity was varying from 0 to $100 \% \mathrm{RH}$ by controlling the partial pressure of the vapor over a selection of salt solutions. Conditioned wood samples were scanned simultaneously by three investigated cameras and resulting hyperspectral images were used for the development of chemometric models. Breeze software package (Predictera, Umea, Sweden) was implemented for image pre-processing (background correction with Principle Components Analysis) and moisture content prediction (Partial Least Square algorithm). The performance of all cameras was satisfactory and the moisture content root mean squared error of prediction varied from less than 1 to $4 \%$. A unique advantage of hyperspectral imaging system was a possibility for mapping of the moisture distribution over the surface of scanned samples. All tested cameras are suitable for practical application in the wood industry, including on-line wood quality control.

The authors gratefully acknowledge the European Commission for funding the InnoRenew project [Grant Agreement \# 739574] under the Horizon 2020 Widespread-Teaming program and the Republic of Slovenia (investment funding of the Republic of Slovenia and the European Regional Development Fund).

Part of this work was conducted during project Multi-spec (BI-IT/18-20-007) funded by ARRS.

\section{Biography}


Proceedings of the $\mathbf{2 0 2 0}$ Society of Wood Science and Technology International Convention

\title{
Reduction of Phenol Formaldehyde Resin Content in Dry Processed Fiberboards by Adding Hydrolyis Lignin
}

\author{
Ivo Valchev1 - Viktor Savov2* - Yvailo Yordanov1
}

1University of Chemical Technology and Metallurgy, 8 Kl. Ohridski blvd., 1756

Sofia, Bulgaria, ivoval@uctm.edu

\author{
${ }_{2}$ University of Forestry, $10 \mathrm{Kl}$. Ohridski blvd., 1797 Sofia, Bulgaria, \\ Corresponding author \\ victor_savov@ltu.bg
}

Production of dry-processed fibreboards is dominant and account more than $80 \%$ of the total production of this type of wood-based panels. A major challenge for the development of the technology for the production of dry-processed fibreboards is the reduction of formaldehyde emissions from the panels. This can be achieved by the reduction of the content of synthetic binders based on formaldehyde.

This report presents a study on the possibility of partial substitution of phenol-formaldehyde resin by technical, hydrolysis, lignin in the adhesive system for dry-processed fibreboards. Technical lignin is a residual product after diluted acid hydrolysis of wood to sugars and as such its cost is low. The investigations was carried out in laboratory conditions as total content of adhesives was $10 \%$ to absolutely dry fibers. The content of phenol-formaldehyde resin varied from 10 to $2 \%$ and respectively the content of hydrolysis lignin was from 0 to $8 \%$. The substitution of phenol formaldehyde resin with hydrolysis lignin was by step of $2 \%$.

It is obtained that the addition of hydrolysis lignin more than $6 \%$, leads to considerable difficulties in its homogeneous distribution in the fibreboards. This necessitates a decrease in the concentration of the lignin-phenol formaldehyde suspension. On the basis of the experimental studies, an analysis was made on the variation of the physical and mechanical properties of the fibreboards and on the minimum possible content of phenol-formaldehyde resin in adhesive system. The all produced dry-processed fibreboards meet the requirements of the relevant EN standards.

Key words: dry-processed fibreboards, phenol-formaldehyde resin, technical hydrolysis lignin 
The growing requirements to limitation of formaldehyde emissions from wood-based panels, in particular from dry-processed fibreboards, necessitate looking for solutions with full or partial substitution of binders now used with natural ones. Formaldehyde emissions from dry-processed fibreboards depend on a great number of factors (Corenberg, C. and Bertolloti, G. 2019), such as tree species, refining conditions, conditions of exploitation, boards age, etc. A main factor, however, remain the type and content of binder in wood (Carvalho, L. et al. 2012). Lignins play the role of natural binder in wood (Lu YC. et al. 2020). In recent years, a number of investigations on the possibility for use of lignin as binder in production of fibreboards were conducted (Mancera C. 2011; Nordström., E. et al. 2018, Ghaffar SH. and Fan, M. 2014). These investigations are mainly focused on production of boards with addition of residual lignin from enzymatic hydrolysis of biomass to sugars for bioethanol production, with such production being yet to enter the practice. A main shortcoming of technical lignin, to which the enzyme lignin belongs, is its water insolubility. This leads to inhomogeneous lignin distribution in boards and to prolongation of the press factor (Zhouh, X. et al. 2011, Tupciauskas, R. et al. 2017).

For our country, of interest is the use of industrial technical lignin that is a waste product from acid hydrolysis of wood to sugars. In old production landfills of hydrolysis factories in Bulgaria, significant amounts of this lignin that is also very low-priced are available (Petrin, S. et al. 2013). Our previous investigations show that, when introducing the hydrolysis dry lignin into wood-fibre pulp, the lignin becomes poorly active and performs more the role of a filler (Yotov et al. 2017 a). Better results are achieved when introducing the hydrolysis lignin in the form of suspension (Yotov et al. 2017 b). Similar regularities are also observed in other investigations, with the homogeneity of the fibres and lignin mixture seeming to be a problem, which should be investigated (Tupciauskas, R. et al. 2017). Other researchers successfully substitute phenol with technical lignin in phenol-formaldehyde resins that are used in production of wood-based panels (Cavadar A.D. et al 2008; Xiaodi, J. and Guo, M. 2018; Panga B. et al 2017). It has been established that these resins give better strength and mainly water-resistant indicators to the boards (Kumar, R. N. and Pizzi, A. 2019).

The aim of this study is to investigate the possibility of substitution of phenol-formaldehyde resin by industrial technical hydrolysis lignin and to analyze the effect of concentration of the adhesive system on the properties of dry-processed fibreboards.

In order to be investigated the possibility of partial replacement of the phenol-formaldehyde resin with hydrolysis lignin was used the experimental plan presented in Table 1.

Table 1: Experimental plan

\begin{tabular}{|c|c|c|}
\hline Series № & Phenol-formaldehyde resin content P, \% & Technical hydrolysis lignin content L, \% \\
\hline 1. & 10 & 0 \\
\hline 2. & 8 & 2 \\
\hline 3. & 6 & 4 \\
\hline 4. & 4 & 5 \\
\hline 5. & 2 & 8 \\
\hline
\end{tabular}

It was used industrial wood-fiber pulp, produced by the Asplund thermo-mechanical refining method. The pulp was provided by "Welde Bulgaria". The pulp was composed of $60 \%$ beech (Fagus Silvatica L.), 20\% Turkish oak (Quercus Cerris L.) and 20\% poplar (Populos alba L.). The 
moisture content of pulp was $11 \%$. Phenol-formaldehyde resin manufactured by "Dynea Romania" was used.

Technical hydrolysis lignin from the hydrolysis plant, which is not operated at present, was used in this investigation. The industrial technology process was based on the high temperature diluted sulphuric acid hydrolysis of sawdust and softwood and hardwood chips to sugars, which were further subjected to yeast fodder production. There are still about 200,000 tons of lignin in an industrial landfill.

Chemical analyses of technical hydrolysis lignin were determined according to the follow methods: cellulose (Kürschner, K. and Hoffer, A. 1929); lignin (TAPPI standard T 222 om-11), ash (TAPPI standard T 211 om-12) and Elemental Analyzer Euro EA 3000 is used for analysis of $\mathrm{C}, \mathrm{N}, \mathrm{S}$ and $\mathrm{H}$.

Respectively, the panels from the first to the fourth series were produced by introducing phenol formaldehyde resin and lignin at a concentration of 30\%. Due to the impossibility to import lignin, at a content above $6 \%$, at this concentration, the last series of panels was produced at an import concentration of $10 \%$. The blending of the pulp with the phenol-formaldehyde resin and the hydrolysis lignin was performed on a short retention blender at $850 \mathrm{rpm}$ with needle shaped paddles. The spraying of the binders was for $50 \mathrm{~s}$, followed by retention in the blender for $300 \mathrm{~s}$. For the hot-pressing was used laboratory press type PMS ST 100, Italy. The target density of the panels was 850 at $6 \mathrm{~mm}$ thickness of fibreboards. The press factor was $90 \mathrm{s.mm}-1$ and the temperature of hot-pressing was $200^{\circ} \mathrm{C}$.

The regime of hot-pressing was as follow: 1-st stage - duration of $80 \mathrm{~s}$ at specific pressure of 4 $\mathrm{MPa}$; 2-nd stage - duration of $80 \mathrm{~s}$ at specific pressure of $1.2 \mathrm{MPa}$; 3-rd stage - duration of $300 \mathrm{~s}$ at specific pressure of $0.8 \mathrm{MPa}$; and 4-th stage - duration of $80 \mathrm{~s}$ at specific pressure of

$\mathrm{MPa}$. Closing of the press was for $10 \mathrm{~s}$ and opening time was $30 \mathrm{~s}$.

The physical and mechanical properties of the panels were determined by testing of 8 test pieces by the methodology determined by the relevant EN standards (EN 310; EN 317; EN 319; EN 323). To be determined the mechanical properties of the panels was used Zwick/Roell Z010 universal testing machine.

\section{Results and Discussion}

Results of chemical analysis of the used technical hydrolysis lignin, presented in Table 2, show the presence of $25 \%$ of residual cellulose, which is characteristic of hydrolysis lignin produced after enzymatic or acid hydrolysis. This distinguishes them from the group of kraft, soda and organosolv technical lignin in which the carbohydrates content is minimal. The higher residual content of cellulose may exercise positive influence on the bonding of fibres in fibreboards production.

Table 2: Characteristics of the technical hydrolysis lignin from the diluted sulphuric acid hydrolysis plant

\begin{tabular}{|c|c|c|c|c|c|c|}
\hline Lignin, \% & Cellulose, \% & $\begin{array}{c}\text { Ash content, } \\
\%\end{array}$ & $\mathrm{C}, \%$ & $\mathrm{~S}, \%$ & $\mathrm{H}, \%$ & $\mathrm{~N}, \%$ \\
\hline 72.6 & 25.5 & 2.8 & 55.54 & 0.74 & 7.10 & 0.26 \\
\hline
\end{tabular}


The relatively low ash content and sulphur content also may be taken as an advantage of the used industrial hydrolysis lignin.

Upon production of fibreboards with participation of hydrolysis lignin, a main difficulty manifests itself in the introduction of lignin into the wood-fibre pulp. Although a hydrolysis lignin fraction with a size of 215-100 $\mu \mathrm{m}$ has been used, and the introduction into the pulp has been performed through a nozzle with a diameter of $1.5 \mathrm{~mm}$, as a result of the rapid sorption of the water by the lignin and, respectively, its swelling, at introduction concentration of $30 \%$ and lignin content of more than $6 \%$, its injection through a nozzle is impossible. This problem is solved with reduction of the suspension concentration to $10 \%$. This also becomes possible due to the relatively high hot pressing factor of 90 s.mm-1.

Results of determined density of dry processed fibreboards with various phenol formaldehyde resin and hydrolysis lignin content are presented in Table 3. As a whole, the density of the boards produced is relatively equal, very close to the set one, with deviation within the statistical error. The boards produced with $8 \%$ phenol-formaldehyde resin and $2 \%$ hydrolysis lignin makes an exception. As already mentioned, due to the impossibility for introduction of the significant amount of hydrolysis lignin at suspension concentration of $30 \%$, in the case of these boards, the hydrolysis lignin and the phenol-formaldehyde resin have been introduced at concentration of $10 \%$. This determines the density higher by $3.9 \%$ of the boards produced under these conditions in comparison with the set one.

Table 3: Density of dry-processed fibreboards at various content of phenol-formaldehyde resin and hydrolysis lignin

\begin{tabular}{|c|c|c|c|}
\hline $\begin{array}{c}\text { Series } \\
\text { № }\end{array}$ & $\begin{array}{c}\text { Content of phenol formaldehyde } \\
\text { resin } P, \%\end{array}$ & $\begin{array}{c}\text { Content of hydrolysis } \\
\text { lignin } L, \%\end{array}$ & $\begin{array}{c}\text { Density } \rho, \\
\text { kg.m-3 }\end{array}$ \\
\hline 1 & 10 & 0 & $858 \pm 7.72$ \\
\hline 2 & 8 & 2 & $851 \pm 9.36$ \\
\hline 3 & 6 & 4 & $848 \pm 9.80$ \\
\hline 4 & 4 & 6 & $847 \pm 10.73$ \\
\hline 5 & 2 & 8 & $883 \pm 11.63$ \\
\hline
\end{tabular}

Results presented in Figure 1 show that water absorption of boards produced deteriorates with increase of the substitution of phenol formaldehyde resin with hydrolysis lignin, with this change in series 4 being by $67 \%$. Of interest is series 5 characterized by $8 \%$ hydrolysis lignin and only $2 \%$ phenol-formaldehyde resin, but at suspension concentration of $10 \%$. In this case of these boards, water absorption is relatively improved, being by $28 \%$ only higher than the basic value. Explanation here may be sought in the more uniform distribution of the lignin introduced with lower concentration, as well as with the improved plasticization and, subsequently, lignin activation under the conditions of hot pressing, due to the increased water content of the press material and of the lignin itself. The lignin activation and the increased number of bonds with the fibrous elements may also explain the observed higher density of the boards produced. 
Proceedings of the $\mathbf{2 0 2 0}$ Society of Wood Science and Technology International Convention

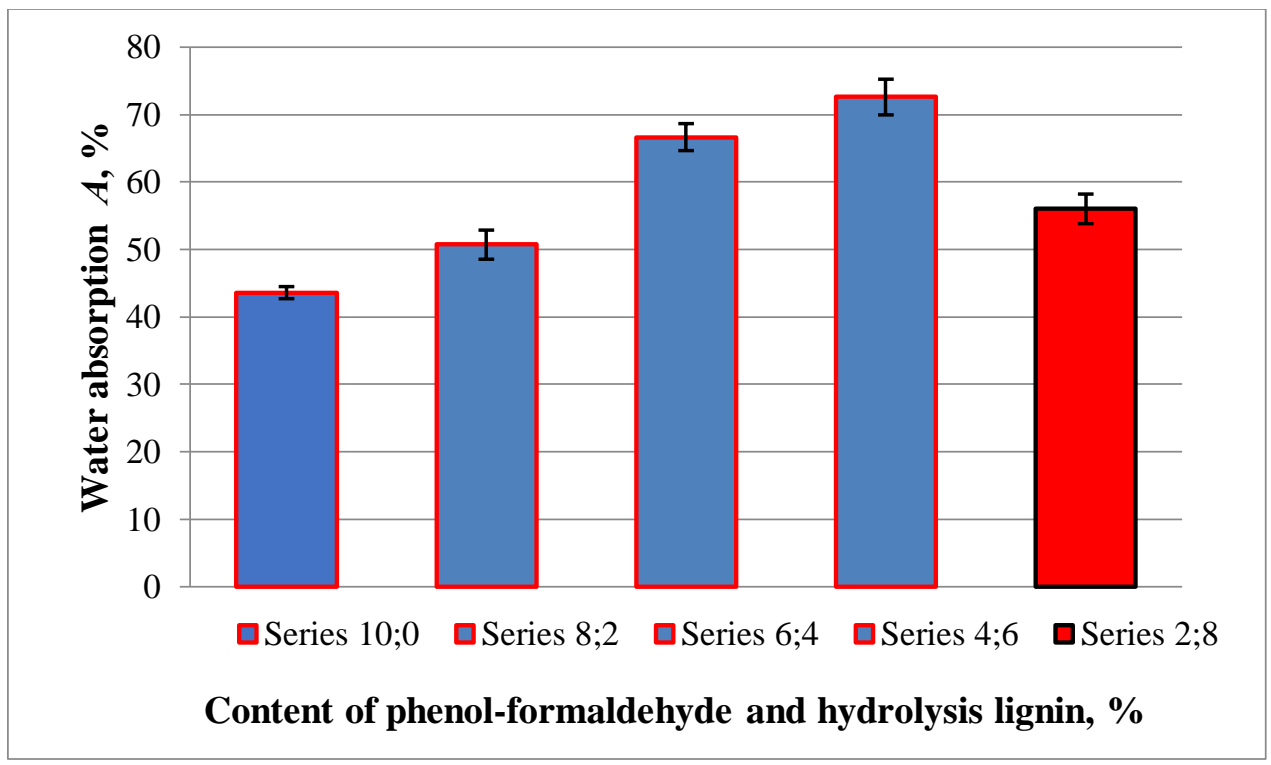

Figure 1. Water absorption of dry-processed fibreboards at various content of phenol-formaldehyde resin and hydrolysis lignin

Similar regularity is also observed with respect to the swelling in thickness of the boards (Fig. 2). Maximum deterioration of $56 \%$ is observed in the case of series 4 , whereas, again in the case of the boards of series 5 , characterized by $2 \%$ phenol-formaldehyde resin and $8 \%$ hydrolysis lignin, introduced at concentration of $10 \%$, relative improvement of this property is observed.

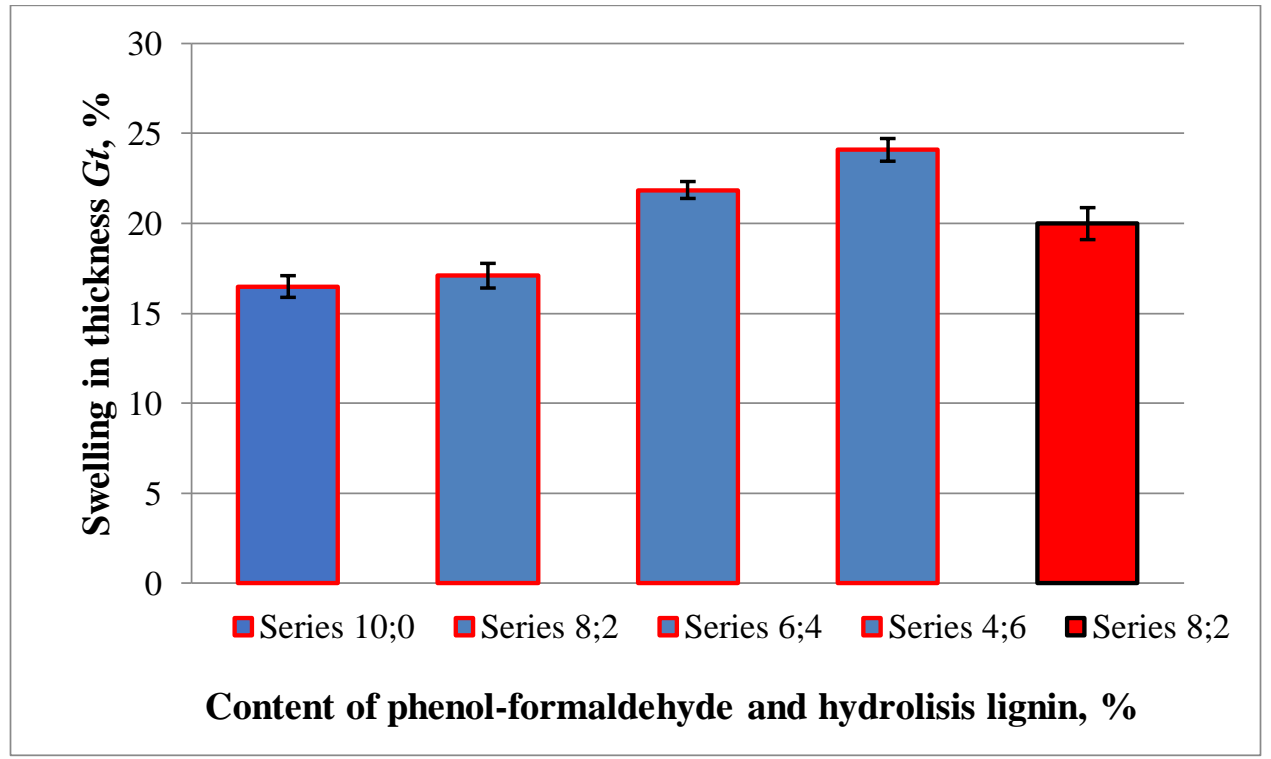

Figure 2. Swelling in thickness of dry-processed fibreboards at various content of phenol-formaldehyde resin and hydrolysis lignin

It must be noted that all produced boards meet the requirements with respect to this indicator of EN 622-5 for use in dry environment (swelling in thickness below 30\%). The boards with 
hydrolysis lignin content of up to $2 \%$ and phenol-formaldehyde resin content not less than $8 \%$ meet the requirement for use in dry environment (swelling in thickness below 18\%).

The bending strength of dry-processed fibreboards at various phenol-formaldehyde resin and hydrolysis lignin content is presented in Fig. 3. It has been established that this property decreases with increase of technical hydrolysis lignin content, with maximum deterioration of $31 \%$ being observed in the case of series 4.

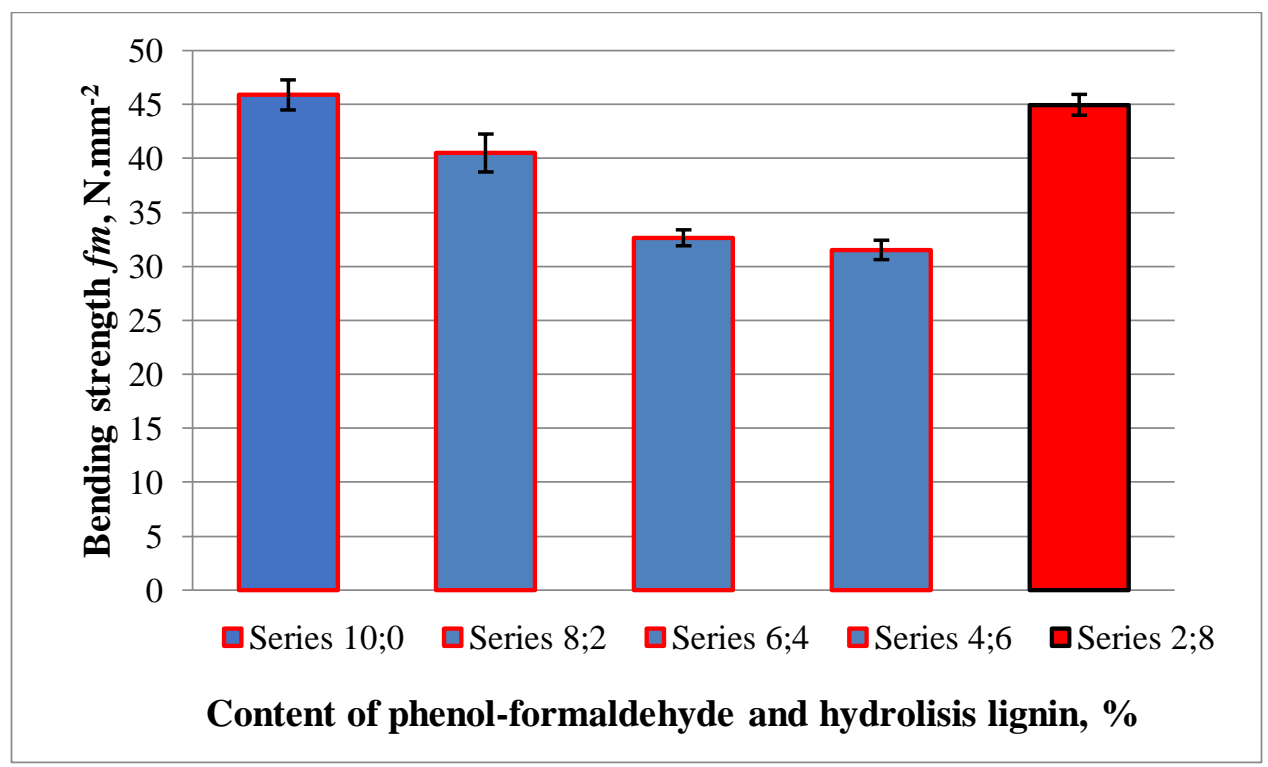

Figure 3. Bending strength of dry-processed fibreboards at various content of phenol-formaldehyde resin and hydrolysis lignin

Of interest again are the boards with $2 \%$ phenol-formaldehyde resin and $8 \%$ hydrolysis lignin, introduced into the wood-fibre mass at concentration of $10 \%$. In the case of this series, values of bending strength similar to those in the case of boards produced with phenol-formaldehyde resin only are recorded. This again confirms that, as a result of the more homogeneous distribution and increased water content, lignin activation and better bonding with the fibres are observed.

It must be noted that the boards of all series meet the requirements of EN 622-5 for bending strength for general-purpose boards for use in dry and in humid environment (bending strength above 30 N.mm-2). Except for the boards with $6 \%$ and $4 \%$ of phenol-formaldehyde resin content, all remaining boards meet the most rigorous requirements with respect to bending strength, viz. for bearing structures and use in humid environment (above 34 N.mm-2).

The modulus of elasticity of dry-processed fibreboards with various participation of phenolformaldehyde resin and hydrolysis lignin is presented in Fig. 4. Low decrease of this indicator in case of introduction of lignin into the series with $30 \%$ suspension concentration is observed. 


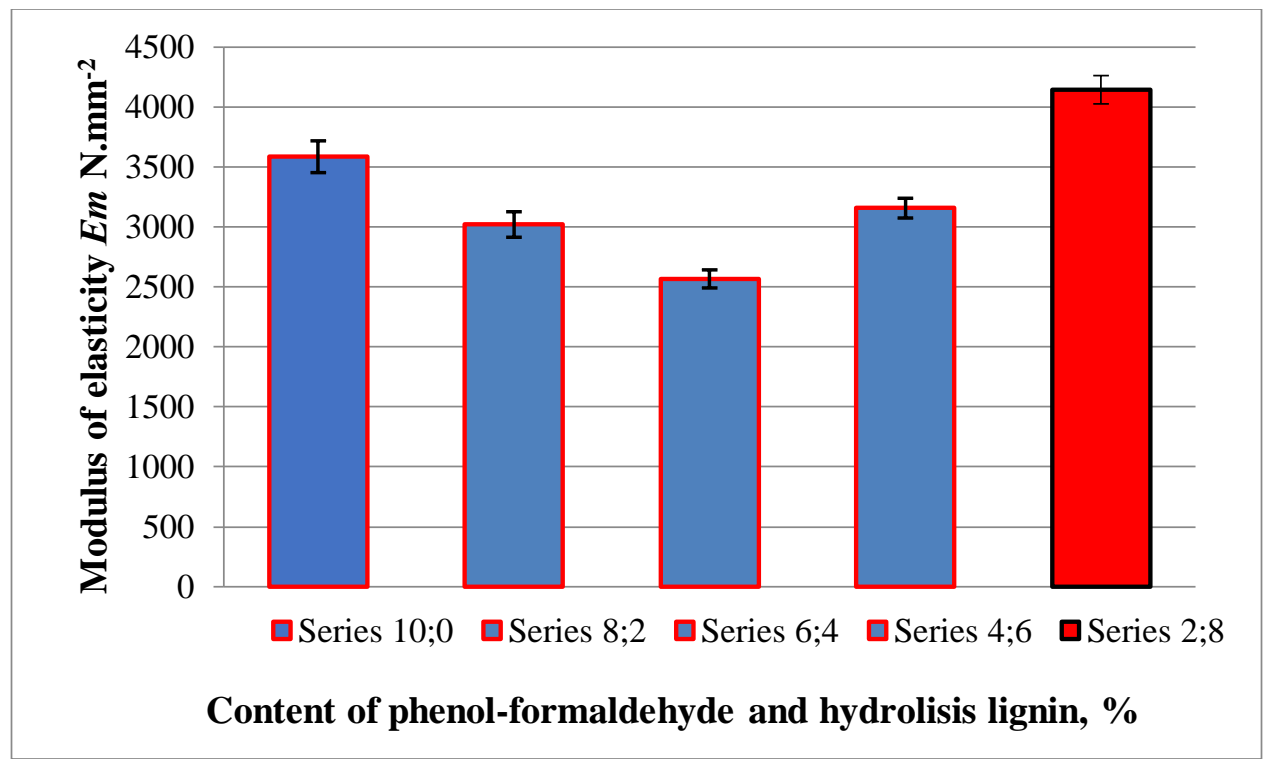

Figure 4. Modulus of elasticity of dry-processed fibreboards at various content of phenol-formaldehyde resin and hydrolysis lignin

The improvement in the value of the modulus of elasticity in series 5 , in the case of which the suspension concentration is $10 \%$, the hydrolysis lignin content is $8 \%$ and the phenol-formaldehyde resin content is $2 \%$, is clearly expressed. These boards have higher modulus of elasticity even in comparison with those of series 1 with $10 \%$ phenol-formaldehyde resin. The explanation may be again sought with the lignin activation and the higher flexibility (elasticity) that the lignin bonds give in comparison with those produced with synthetic resins. It is because of the increased elasticity due to the lignin bonds that wet-processed fibreboards, almost without participation of binders, have considerably bigger modulus of elasticity than dry process ones (with considerable participation of synthetic binders). Except for the board produced with $6 \%$ of phenolformaldehyde resin and 4\% of hydrolysis lignin, all remaining boards meet the most rigorous requirements to modulus of elasticity (above 3,000 N.mm-2) - for bearing structures and use in humid environment (EN 622-5).

Results for internal bond (IB) strength of dry-processed fibreboards with various participation of phenol-formaldehyde resin and hydrolysis lignin, presented in Fig. 5, show low decrease with increase of the introduced lignin amount. 


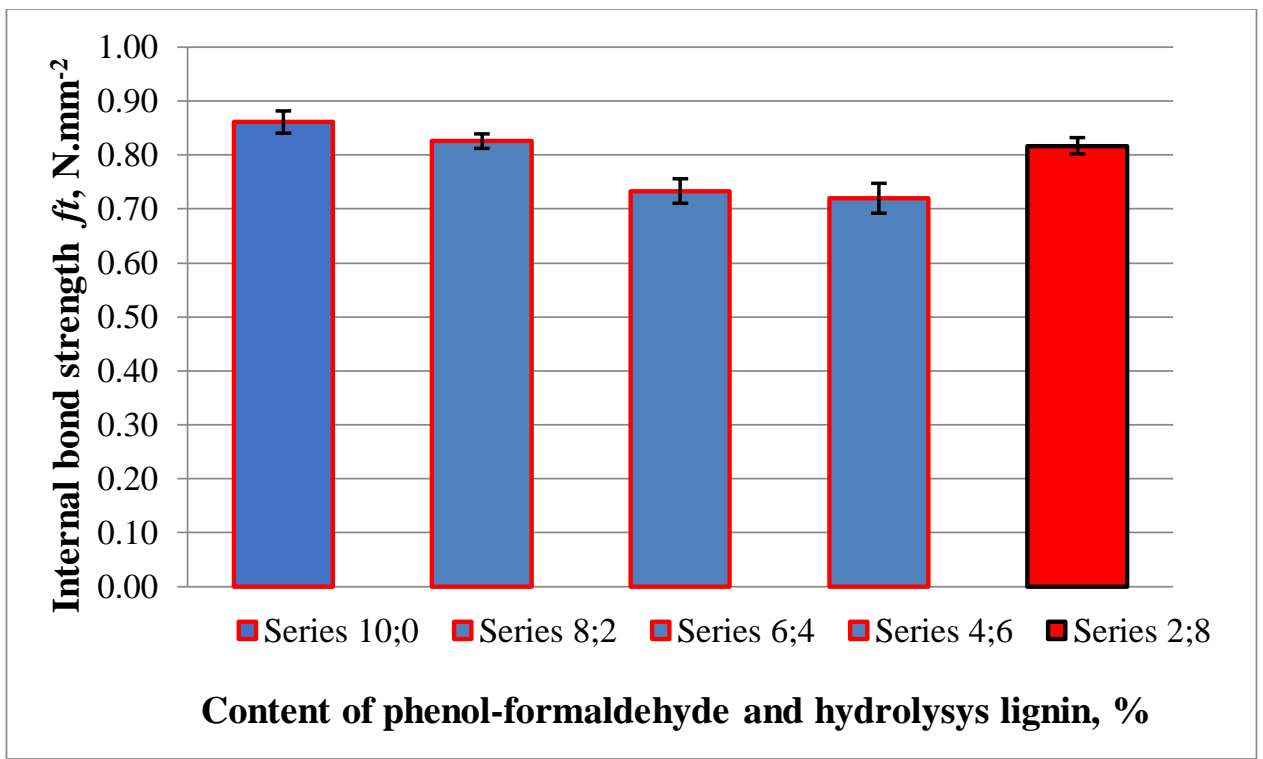

Figure 5. Internal bond strength of dry-processed fibreboards at various content of phenol-formaldehyde resin and hydrolysis lignin

The trend noted in the case of the previous investigated indicators, viz. towards improvement of the property values in the case of the boards produced at content of phenol-formaldehyde resin of $2 \%$ and content of hydrolysis lignin of $8 \%$, introduced at concentration of $10 \%$, is observed again. The IB strength in the case of this series is lower than the basic series 1 by less than $5 \%$. All boards produced meet the most rigorous requirements to the indicator, 0.7 N.mm-2, for fibreboards for bearing structures and use in humid environment.

\section{Summary and Conclusions}

The produced dry-processed fibreboards with adhesive system from phenol-formaldehyde resin and hydrolysis lignin meet the requirements of the relevant EN standards.

A main difficulty in the dry-processed fibreboards production with participation of hydrolysis lignin is the homogeneous introduction of lignin into the wood-fibre mass. Due to the rapid sorption of the water by the lignin and, respectively, its swelling, at concentration of $30 \%$ and lignin content of more than $6 \%$, its injection through a nozzle is impossible. This problem is solved with reduction of the suspension concentration to $10 \%$. This also becomes possible due to the relatively high hot pressing factor.

At concentration of phenol-formaldehyde resin and lignin of $30 \%$, with increase of the substitution of phenol-formaldehyde resin with hydrolysis lignin, deterioration in all properties of the boards is observed, except for a relative improvement of elasticity of boards having been established in case of a lignin content of more than $40 \%$ in the adhesive system.

The dilution of the adhesive suspension to $10 \%$, allows, at $80 \%$ substitution of the resin with lignin, to achieve properties higher than those obtained with use of phenol-formaldehyde resin only. The positive result may be explained with the more homogeneous distribution of the hydrolysis lignin, as well as with the lignin plasticization and activation as a result of the increased moisture content in the press material and in the lignin itself. Prolongation of the press factor is necessary in order to separate the gas-vapour mixtures from the press material.

\section{Acknowledgements}




\section{Proceedings of the 2020 Society of Wood Science and Technology International Convention}

This research was supported by the project № КП-06-KОСТ/1 "Study of the potential of lignin raw materials in Bulgaria and development of technologies for their modification and effective application in industry" funded by Bulgarian National Science Fund.

Carvalho, L., Magalhães., F., João, F. Formaldehyde Emissions from Wood-Based Panels -Testing Methods and Industrial Perspectives. 2012, p. 44. researchgate.net/publication/236273710.

Cavdar A. D., Kalaycioglu, H., Hiziroglu, S. Some of the properties of oriented strandboard manufactured using kraft lignin phenolic resin. Journal of materials processing technology 202, 2008, pp. 559-563.

EN 310:1999 Wood-based panels - Determination of modulus of elasticity in bending and of bending strength.

EN 317:1998 Particleboards and fibreboards - Determination of swelling in thickness after immersion in water.

EN 319:2002 Particleboards and fibreboards - Determination of tensile strength perpendicular to the plane of the board

EN 323:2001 Wood-based panels - Determination of density.

EN 622-5:2010 Fibreboards - Specifications - Part 5: Requirements for dry process boards.

Ghaffar SH, Mizi Fan. Lignin in straw and its applications as an adhesive. International Journal of Adhesives;48, 2014, pp. 92-101.

Yotov, N., Savov, V, Valchev, I, Stoiko Petrin, St., Karatotev, V. Study on possibility for utilization of technical, hydrolysis, lignin, in composition of medium density fiberboard. Innovation in woodworking industry and engineering design. Vol VI 2, 2017 a, pp. 69-74. ISSN 1314-6149.

Yotov, N., Valchev, I., Petrin, St., Savov, V. Lignosulphonate and waste technical hydrolysis lignin as adhesives for eco-friendly fiberboard. Bulgarian Chemical Comunications, Volume 49, Special Issue L, 2017 b, pp. 92 - 97. ISSN 0324-1130.

Korenberg, C. and Bertolotti, G. Emissions from MDF: Governing Factors and Mitigation Strategies. Studies in Conservation. Routledge, Taylor \& Francis Group, 2019, ISSN: 0039-3630. DOI 10.1080/00393630.2019.1565153

Kumar, R. N., Pizzi, A. (2019) Phenol-Formaldehyde Resins. In book: Adhesives for Wood and Lignocellulosic Materials. DOI: 10.1002/9781119605584.ch31.

Kürschner, K. and Hoffer, A. Techn. Chem. Papier und Zellstoff Fabr., 26, 1929, p.125.

Lu YC., Lu Y., Fan X. Structure and Characteristics of Lignin. In: Sharma S., Kumar A. (eds)

Lignin. Springer Series on Polymer and Composite Materials. Springer, Cham, 2020.

Mancera $\mathrm{C}$. The effect of lignin as a natural adhesive on physic-mechanical properties of Vitis vinifera Fiberboards. Bioresources. Volume 6, number 3, 2011, pp. 2851-2850.

Nordström., E., Demircan, D. Fogelström, L., Khabbaz, F. Malmström, E. Green binders for wood adhesives. Interhopen Books. 2018, p.71. dx.doi.org/10.5772/intechopen.72072.

Petrin, St.; Valchev, I., Nenkova, S., Radoykova, T. Utilization of waste hydrolysis lignin from the Razlog area. University of Chemical Technology and Metallurgy, Sofia, 2013.

Tupciauskas, R, Gravitis, J., Abolins J, Veveris, A., Andzs,M, Liitia, T, Tarja Tamminen, T Utilization of lignin powder for manufacturing self-binding HDF. Holzforschung 71(7-8), 2017, pp. 555-561. DOI 10.1515/hf-2016-0180.

Xiaodi, J and Guo, M. Preparation and properties of a chitosan-lignin wood adhesive. International Journal of Adhesion and Adhesives 82, 2018, pp. 8-13. 
Zouh, X., Tan, L., Zhang, W., Chenlong, Lv., Zheng, F., Zhang, R., Du, G., Tang., B., Liu, Xu Enzymatic hydrolysis lignin derived from corn stoves as an instant binder from bio-composites: effect of fiber moisture content and pressing temperature on board's properties. Bio-resources 6 (1), 2011, pp. 253-264.

Panga, B., Yanga, S., Fanga, W., Yuana, T., Argyropoulos, Dimitris S., Suna R. Structureproperty relationships for technical lignins for the production of lignin-phenol-formaldehyde resins, Industrial Crops and Products, Vol. 108, 1 December 2017, pp. 316-326.

Biography 


\title{
Proceedings of the 2020 Society of Wood Science and Technology International Convention
}

\section{Life cycle assessment of the new InnoRenew CoE research building - hot spots and the effects of methodological differences on the results for a wooden frame building}

\author{
Erwin M. Schau 1 \\ erwin.schau@innorenew.eu \\ Eva Prelovšek Niemelä \\ eva.prelovsek@innorenew.eu \\ Urban Kavka2 \\ urbankavka1@gmail.com \\ Andreja Kutnar2 \\ andreja.kutnar@innorenew.eu
}

1InnoRenew CoE, Slovenia

2InnoRenew CoE and University of Primorska, Slovenia

\section{Abstract}

The construction industry accounts for around $15 \%$ of all greenhouse gas emissions. During their use phase, buildings use $40 \%$ of the total energy consumption, which contributes significantly to air pollution and other environmental impacts. Energy consumption during the use phase is predicted to decrease as efficient buildings, like zero and near zero energy buildings, become more common. However, climate change and other environmental problems from the production or raw materials, construction and end of life remain serious concerns that need to be solved urgently.

Life cycle assessment (LCA) and the EU-recommended Environmental Footprint (EF) are well known and accepted tools to measure a comprehensive set of environmental impacts throughout a product's life cycle. In this contribution, we assess the InnoRenew CoE building being constructed in Izola, Slovenia. This is the largest wooden frame building in the republic and will host offices and laboratories for $50+$ researchers on a total area of $8200 \mathrm{~m} 2$. We show the environmental hot spots and how different methodological choices in the LCA modelling and life cycle impact assessment phase influence the results. We also show how the results could be used to develop a reference model for other nonresidential buildings suitable for architects and designers to improve the life cycle environmental impacts of wooden buildings.

Keywords: Life cycle assessment (LCA), non-residential buildings, wood frame, Product Environmental Footprint (PEF)

Acknowledgement The author(s) gratefully acknowledge(s) the European Commission for funding InnoRenew CoE (grant agreement \#739574) under the H2020 Widespread-Teaming programme and Republic of Slovenia (investment funding of the Republic of Slovenia and the European Union's European Regional Development Fund).

\section{Biography}


Proceedings of the $\mathbf{2 0 2 0}$ Society of Wood Science and Technology International Convention

\author{
Adhesives Based on Lignin, Tannin and Liquefied Wood \\ Milan Sernek \\ milan.sernek@bf.uni-lj.si \\ Jaša Saražin \\ jasa.sarazin@bf.uni-lj.si \\ University of Ljubljana, Biotechnical Faculty, Slovenia
}

\begin{abstract}
Wood industry is significant consumer of adhesives. The largest amount of adhesives is consumed in wood based-composites, where mainly aminoplastic adhesives (urea- and melamine- formaldehyde), phenolic adhesives (phenol- and resorcinol-formaldehyde) or isocyanate adhesives are used. Majority of these wood adhesives are on formaldehyde basis, which makes them harmful to health and environment. Nowadays, there are many efforts placed on development of new bio-based adhesives, which could at least partially substitute the formaldehyde adhesives. The proposed solutions of this paper are focused on different adhesive formulations based on lignin, tannin and liquefied wood. Main disadvantage of these adhesives are lower strength and durability properties and higher consumption of energy for curing.
\end{abstract}

\title{
Biography
}




\title{
Proceedings of the 2020 Society of Wood Science and Technology International Convention
}

\section{Structural joints of furniture made of cardboard and plywood}

\author{
Lukáš Fictum \\ qqfictum@node.mendelu.cz \\ Alena Sobotkova \\ alenasobotkova@gmail.com \\ Milan Šimek \\ milan.simek@mendelu.cz
}

\section{Mendel University in Brno, Czech Republic}

\section{Abstract}

The article describes and explains current trends in cardboard and plywood furniture that is produced by a combination of laser technology and a plotter. The main material is a cardboard sheet made of recyclable raw materials. The aim is to re-utilize raw materials that end up in waste and have no further use today, once they serve as packaging material. Cardboard boards are sandwiches that have sufficient strength and rigidity if properly oriented on the product and for specific applications, such as starting furniture for young families or new businesses, they can save both raw materials and costs.

Our project deals with the development of the technology for processing furniture made on the basis of corrugated and coated cardboard and plywood. It is expected that the furniture will be primarily intended for final assembly by the customer, based on the Ready-to-Assemble (RTA) principle.

This is an experimental project using cardboard as the main construction material. Cardboard furniture as a theme that recurs repeatedly with the requirements for recyclability of consumer furniture has been elaborated by students, designers and architects many times during the last half century (Alvarado, Davies, Jacobs, Gehry, Guiomar). However, cutting cardboard furniture always entails considerable wear of the cutting tools, which is further increased if the panels are composed of multiple layers of cardboard or paperboard glued to each other.

Testing of material behavior and experimenting with shape possibilities will result in design and prototype of chair intended for interior, working chair. The prototype will be subsequently tested in the furniture testing room according to the european standards.

In order to lighten and strengthen the whole structure, the structure will be conceived as combined with the supporting part of the structure consisting of plywood, seat part and decorative backrest of cut, engraved cardboard. The following structural joints are considered to be used in project: insertion, bending, grooving, eventually tenon and mortise or dowel. For the production of furniture samples and joint testing a new combined universal CNC machine will be used (laser, plotter).

Keywords: cardboard furniture, laser cutting, plotter

ASHBY, M. F. Materials and the environment: eco-informed material choice. 2nd ed. Boston: Elsevier/Butterworth-Heinemann, c2013. ISBN 9780123859716

BARBERO, S. - COZZO, B. Ecodesign. Potsdam: Tandem, 2012. 349 s. ISBN 978-3-8331-6308-1. JIVKOV, Vassil; STRENGTH PROPERTIES OF NEW LIGHTWEIGHT PANELS FOR FURNITURE AND INTERIORS, Conference: 23rd International Scientific Conference on Wood is Good - with Knowledge and Technology to a Competitive Forestry and Wood Technology Sector Location: Zagreb, CROATIA Date: OCT 12, 201, ISBN: 978-953-292-026-0 
Proceedings of the 2020 Society of Wood Science and Technology International Convention

HOLMAN, Will. Guerilla furniture design: how to build lean, modern furniture with salvaged materials. North Adams, MA: Storey Publishing, 2015. ISBN 978-1612123035.

ŠIMEK, M. -- KOŘENÝ, A. -- SEBERA, V. -- TIPPNER, J. -- DLAUHÝ, Z. Development of Ready-toAssemble Furniture Constructions. In BARNES, H M. -- HERIAN, V L. 57th SWST International

convention. 7th Wood structure and properties conference. 6th European hardwood conference. 1. vyd. Monona: Society of Wood Science and Technology, 2014, s. 837--846. ISBN 978-0-9817876-4-0.

Biography 
Proceedings of the 2020 Society of Wood Science and Technology International Convention

\title{
Paper and plastic waste composite boards for furniture
}

\author{
Alena Sobotkova \\ alenasobotkova@gmail.com \\ Milan Šimek \\ milan.simek@mendelu.cz \\ Lukáš Fictum \\ qqfictum@node.mendelu.cz
}

Mendel University in Brno, Czech Republic

\section{Abstract}

This article focuses on the use of wastepaper and plastic material which is used for creating composite material - paper-plastic boards. The idea of using cardboard as a material for furniture is valuable because of its sustainability. There is a lot of wastepaper which would no longer have other use. There are companies which are using cardboard for $100 \%$ sustainable furniture. The paper which is used is packaging material or other cardboard taken from recycling companies. Second material which works as a binder for paper boards is re-used plastic material from a company production. Different types of postfactory a postconsumer plastic is used for creating the boards.

The goal of this project is to create boards which are made with high temperature and pressed by single opening hydraulic press. After the pressing the boards are climatized and their physical and mechanical properties are tested and compared with industrially manufactured boards and with another composite boards made from waste material. The testing is done according to the European standards. The most important tests for the use as furniture parts are bending strength and modulus of elasticity, internal bond, screw withdrawal resistance, swelling in thickness and water absorption.

After the testing and comparison with other materials, the results are used for design of furniture which is used in interior. Mostly the material can be used as a desk for table or storage furniture.

Biography 


\title{
Proceedings of the 2020 Society of Wood Science and Technology International Convention
}

\section{Attracting children to wood science and renewable material professions}

\author{
Vesna Starman 1 \\ vesna.starman@innorenew.eu \\ Črt Tavzes 1 \\ crt.tavzes@innorenew.eu \\ Eva Prelovšek Niemelä 1 \\ eva.prelovsek@innorenew.eu \\ Marica Mikuljan 1 \\ marica.mikuljan@innorenew.eu \\ Jaka Gašper Pečnik1 \\ jaka.pecnik@innorenew.eu \\ Nastja Podrekar2 \\ nastja.podrekar@innorenew.eu
}

1InnoRenew CoE, Slovenia

2InnoRenew CoE and University of Primorska, Slovenia

\section{Abstract}

A decreasing trend of interest for wood science professions has been observed in the field. Early engagement with the field may help develop interest later in life, when young people are choosing career paths. Therefore, we are performing workshops for elementary school students to introduce the field at an early age. In 2019, we performed several different workshops where children from elementary schools were able to experiment with wood and other natural materials. Wood was presented to them from microscopic to macroscopic levels. They learned about different wood species and engineered wood products and their properties. Furthermore, children were able to experiment with their hands. In order to present to them which professions can be directly and indirectly connected to wood, they met kinesiologists, architects, wood engineers, chemists, and biologists that are working as researchers at the InnoRenew CoE, a renewable materials research centre in Slovenia.

In this presentation, the main lessons learned will be presented along with further needs in early education that will lead to attracting new generations of workers, researchers, and enthusiasts to the sector.

Biography 


\title{
Proceedings of the 2020 Society of Wood Science and Technology International Convention
}

\section{Effect of Moderate Thermal Treatment on Properties of Resonance Spruce for Piano Soundboard}

\author{
Jan Tippner \\ Jakub Dömény \\ Petr Zatloukal \\ Pavlina Suchomelova \\ Department of Wood Science and Technology \\ Faculuty of Forestry and Wood Technology \\ Mendel University in Brno, Czech Republic
}

\begin{abstract}
Thermal modifications of wood could provide perspective way to reduce negative effect of moisture on musical instruments. Resonance spruce (Picea abies L. Karst) used for soundboards is characterized by high sound velocity in longitudinal direction, low internal friction and high specific dynamic modulus of elasticity. The moderate thermal treatment with steam protection can maintain original acoustic properties with significant influence on equilibrium moisture content (EMC) and dimension stability. To test the effect of thermal treatment the 3 groups of specimens $(44 \mathrm{~mm} \times 450 \mathrm{~mm} \times 12 \mathrm{~mm})$ of resonance wood selected from piano soundboards manufacturing have been prepared (un-treated, $180^{\circ} \mathrm{C}, 200^{\circ} \mathrm{C}$ ) and conditioned in $20^{\circ} \mathrm{C}$ and relative humidity steps of $40 \%, 60 \%$ and $80 \%$. The relative weight loss $4.7 \%$ and $7 \%$ was achieved by modifications at $180^{\circ} \mathrm{C}$ and $200^{\circ} \mathrm{C}$ respectively. EMC, longitudinal and bending dynamic modulus of elasticity, logaritmic decrement of damping and acoustic conversion efficiency (ACE) were evaluated in every step of conditioning. The decreasing of EMC by both thermal treatment is significant, the specimen modified at $180^{\circ} \mathrm{C}$ showed about $36 \%$ lower EMC at $60 \%$ relative humidity, the treatment by $200^{\circ} \mathrm{C}$ brought about $42 \%$ decreasing of EMC. Both treatments significantly affected EMC but the effect on acoustic properties was not statistically significant, however, the changes for $200^{\circ} \mathrm{C}$ treated group were more perceptible. Acoustic properties were compared at every step of conditioning too. Dynamic moduli and ACE decreased with higher EMC and the damping increased for control group and both modified groups.
\end{abstract}

Biography 


\title{
Proceedings of the 2020 Society of Wood Science and Technology International Convention
}

\section{Effect of cutting parameters on dust emission and surface roughness during helical planing sucupira wood}

\author{
Roger Hernández1 \\ roger.hernandez@sbf.ulaval.ca \\ Bruno Ugulino2 \\ bruna.ugulino@fpinnovations.ca \\ José Tarcisio Limaз \\ jtlima@ufla.br
}

1Laval University, Canada

2 FPInnovations, Canada

3 Universidade Federal de Lavras, Brazil

\section{Abstract}

Dust produced during the usual operations of wood machining may not be totally captured by the devices integrated to machinery, and be dispersed in the workshops. Thus, the decrease of dust emissions during wood machining is of great interest. The machining parameters can influence the chip thickness and resulting dust emission and surface quality of wood. The purpose of this study was to evaluate the effect of cutting parameters on the airborne dust emission $(0.1$ to $15 \mu \mathrm{m})$ and surface roughness produced by helical planing sucupira wood (Diplotropis sp.). Four feed speeds that produced four average chip thicknesses $(0,10 \mathrm{~mm}$ to $0.22 \mathrm{~mm})$ were studied at $8 \%$ and $12 \%$ moisture content $(\mathrm{MC})$ of wood. The results showed that dust emission decreased as chip thickness increased. Dust emission was higher at $12 \% \mathrm{MC}$ than at $8 \% \mathrm{MC}$ but for thicker chips $(>0.14 \mathrm{~mm}$ ). For thinner chips, dust emitted was similar for the two studied moisture contents. Furthermore, higher values of chip thickness produced higher surface

roughness. The best planing condition was obtained when using $8 \%$ moisture content and $16 \mathrm{~m} / \mathrm{min}$ feed speed. This condition was the fastest feed speed allowable to obtain the best surface quality while minimizing dust production

Biography 


\title{
Proceedings of the 2020 Society of Wood Science and Technology International Convention
}

\section{Effects of Radial Growth Rate on Wood Quality Parameters of Superior Teakwood from Muna Island, Indonesia}

\author{
Imam Wahyudi \\ imyudarw16@yahoo.com \\ Alvin Muhamad Savero \\ alvin.savero@yahoo.uk \\ IPB University, Indonesia
}

\section{Abstract}

Supply shortage of best quality teakwood as raw material for wooden furniture industry in Indonesia is a major problem. Under this condition, several fast-growing Tectona grandisseedlings had been developed and planted including the superior teak from Muna Island. Feasibility of using the superior Muna teakwood for material production was studied. Samples of $T$. grandis were collected from one area of man-made forest in Kampung Baru Region, Muna Sub-district, Southeast Sulawesi Province, Indonesia. Various wood qualities were measured and related to the radial growth rate. Radial growth rate did not significantly affect the longitudinal released strain of the surface growth stresses, wood color, wood grain, wood density, specific gravity, and dimensional stability. However, it affected wood figure and texture. Higher radial growth rate tends to promote more distinct wood figure, higher density, smoother wood texture, and lower absolute values of the released strain. Smaller diameter trees tend to produce longer fiber length and higher portion of tension wood. In general, the superior Muna teakwood produced from bigger and medium diameter trees are suitable as raw material for wooden furniture manufacturing.

Keywords: fiber length, growth stress, Tectona grandis, tension wood, wood density

Biography 


\title{
Proceedings of the 2020 Society of Wood Science and Technology International Convention
}

\section{Modeling of Thermal Performance of Cellulose Insulation Imbedded with Phase Change Material}

\author{
Xun Wang \\ xunwang@my.unt.edu \\ Sheldon Shi \\ sheldon.shi@unt.edu \\ Weihuan Zhao \\ weihuan.zhao@unt.edu \\ Liping Cai \\ liping.cai@unt.edu \\ University of North Texas, USA
}

\begin{abstract}
Over the past decades, the phase change materials (PCM) have become one of the main topics of energy efficiency enhancement due to its latent heat storage capability. Imbedding PCM into the building walls has been an effective method to reduce the energy consumption and enhance the feeling comfort in the building. In this paper, the idea of improving the thermal insulation performance and energy efficiency of building applications with using PCM/cellulose composites has been investigated. The PCM composites were prepared by filling and sealing the PCM into a veneerhoneycomb sandwich structure with several different thicknesses and sizes of the honeycomb midlayer. By testing and comparing the thermal performances (heat flux) of PCM composite wall and standard drywall at the same conditions, it can be concluded that the PCM composite can significantly increase the wall thermal insulation performance and reduce the energy consumption effectively. An effective R-value is developed for the PCM/cellulose composite insulation, which is comparable to the $\mathrm{R}$-value of the regular insulation materials. The thermal insulation performance model of PCM/cellulose composites are generated by using the thermal insulation data form these tests.
\end{abstract}

\section{Biography}




\title{
Segmentation of Knot Defects on Coniferous Lumber Surface Using Deep Neural Network
}

$$
\begin{gathered}
\text { Hwanmyeong } \mathrm{YEO}^{1^{*}-H y u n b i n} \mathrm{KIM}^{2}-\mathrm{Hy} \text { wnwoo } \mathrm{CHUNG}^{3} \text {-Sang-Yun } \mathrm{YANG}^{4}- \\
\text { Yonggun PARK }- \text { JongGyu CHOI}{ }^{6} \text {-Un Taek Hwang }
\end{gathered}
$$

${ }^{1}$ Professor, Department of Forest Sciences and Research Institute of Agriculture and Life Sciences, College of Agriculture and Life Sciences, Seoul National University, Seoul, Republic of Korea

* Corresponding author hyeo@snu.ac.kr

2 Ph.D. Student, Department of Forest Sciences, College of Agriculture and Life Sciences, Seoul National University, Seoul, Republic of Korea youursea@snu.ac.kr

${ }^{3}$ Ph.D. Student, Department of Forest Sciences, College of Agriculture and Life Sciences, Seoul National University, Seoul, Republic of Korea boltzman1223@gmail.com

${ }^{4}$ Senior Researcher, Department of Forest Sciences and Research Institute of Agriculture and Life Sciences, College of Agriculture and Life Sciences, Seoul National University, Seoul, Republic of Korea sly1357@snu.ac.kr

${ }^{5}$ Research Assist Professor, Department of Forest Sciences and Research Institute of Agriculture and Life Sciences, College of Agriculture and Life Sciences, Seoul National University, Seoul, Republic of Korea gunny007@snu.ac.kr

${ }^{6}$ Undergraduate Student, Department of Forest Sciences, College of Agriculture and Life Sciences, Seoul National University, Seoul, Republic of Korea chlwhdrb722@snu.ac.kr

${ }^{7}$ Undergraduate Student, Department of Forest Sciences, College of Agriculture and Life Sciences, Seoul National University, Seoul, Republic of Korea alex0801@snu.ac.kr

\begin{abstract}
For using wood practically, it is necessary to objectively and speedily detect and assess their defects such as wood knots. Visual lumber grading or defect classification by human eye may result in differences due to subjective decisions. Deep learning technology, which has recently been increasingly used in computer vision for image analysis and pattern recognition due to its high accuracy and speed, was studied to detect and segment surface knots of lumber in this study. 938 wood images were obtained from larch, red pine, Korean pine, cedar, cypress, D- fir, and radiata pine. 1172 Images of four kinds (Decayed, Encased, Sound, Spike) of knot were
\end{abstract}




\section{Proceedings of the 2020 Society of Wood Science and Technology International Convention}

extracted from the wood images. With dataset on type and location of the knots, learning algorithm was proceeded. The dataset was split into training and test sets for validation with the ratio of 4:1. Mask R-CNN (Regions with Convolutional Neural Network) model was performed using ResNet101 to learn knot segmentation based on Feature Pyramid Network. The Feature Pyramid Network is a method for improving resolution to a compressed feature map by adding a low-resolution feature map image and a high-resolution image using interaction of the topdown pathway and bottom-up pathway. The reduction in computation speed due to resolution correction was compensated by applying the residual network. Feature Pyramid Network, whose strides were 4, 8, 16, 32 and 64, was used as a structure for image pre-processing. Region Proposal Network, whose anchors were 32, 64, 128, 256 and 512, was applied to the technique for detecting and partitioning knots. Mask R-CNN model used in this study shows high performance in image segmentation of wood surface knots, even some wooden patterns were detected as a knot. Overfitting occurred after 202nd epoch of learning, at that time, minimum loss of the model was $0.35 \%$. Also, even there was a large difference in the number of images by knot types, the model does not show a drastic bias regardless of the difference in the number of images. It is expected that the knots can be segmented with higher accuracy by further massive training of various types.

Key words: Deep-learning, Convolutional Neural Network, Knot detection, Knot classification

Biography 


\title{
Classification of Heat Treatment Degree of Wood Components Using Near-infrared Spectroscopy
}

\author{
Yonggun PARK ${ }^{1}$, Sang-Yun YANG ${ }^{2}$, Hyunbin $K I M^{3}$, Hwanmyeong YEO ${ }^{*}$ \\ ${ }^{1}$ Research Assist Professor, Department of Forest Sciences and Research Institute \\ of Agriculture and Life Sciences, College of Agriculture and Life Sciences, Seoul \\ National University, Seoul, Republic of Korea \\ gunny007@snu.ac.kr \\ ${ }^{2}$ Senior Researcher, Department of Forest Sciences and Research Institute of \\ Agriculture and Life Sciences, College of Agriculture and Life Sciences, Seoul \\ National University, Seoul, Republic of Korea \\ sly1357@snu.ac.kr \\ ${ }^{3}$ Ph.D. Student, Department of Forest Sciences, College of Agriculture and Life \\ Sciences, Seoul National University, Seoul, Republic of Korea \\ youursea@snu.ac.kr \\ ${ }^{4}$ Professor, Department of Forest Sciences and Research Institute of Agriculture \\ and Life Sciences, College of Agriculture and Life Sciences, Seoul National \\ University, Seoul, Republic of Korea \\ *Corresponding author: hyeo@snu.ac.kr
}

\begin{abstract}
This study was carried out to classify heat treatment degree of wood components using nearinfrared (NIR) spectroscopy. NIR reflectance spectra were acquired from the larch wood (Larix kaempferi) which was heat-treated at the various temperatures and time conditions ( 7 temperature conditions at $10^{\circ} \mathrm{C}$ intervals between 160 and $220^{\circ} \mathrm{C}$ and 12 temperature conditions at 1-hour intervals between 1 and 12 hours). The changes in the NIR spectral shape of heattreated larch wood were found at 1216, 1580, 1785, $2134 \mathrm{~nm}$ wavelength bands, which correlated with cellulose, hemicellulose and lignin. The acquired raw spectra were mathpreprocessed by 3-point moving average and standard normal variate (SNV) in sequence to improve the accuracy of analysis by removing the noise of spectra. A hierarchical clustering analysis (HCA) using preprocessed NIR spectra resulted in three distinct clusters (A: $220^{\circ} \mathrm{C} 7-12$

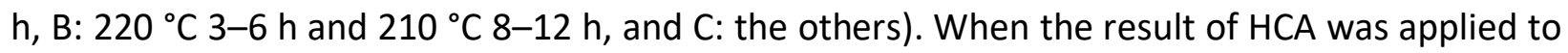
principal component analysis (PCA), A principal component score plot of the NIR spectra was well grouped by the grouping result, and the first principle component (PC1) reflected the cluster analysis grouping well. A partial least squares discriminant analysis (PLS-DA) was performed to develop the discriminant regression model of the three heat treatment degrees. The determination coefficient $\left(R^{2}\right)$ and root mean square error of validation (RMSEV) were over 0.9
\end{abstract}


Proceedings of the 2020 Society of Wood Science and Technology International Convention

and under 0.2 , respectively. From the result of this study, NIR spectroscopy is considered to be a good candidate to routinely measure the degree of heat treatment for wood components.

Key words: Heat treatment degree, Near-infrared spectroscopy, Principal component analysis, Hierarchical clustering analysis

Biography 


\title{
Enhancing Particleboard Panels' Performance Properties by Nanocellulose and Boric Acid Reinforcement
}

\author{
Mert Yildirim ${ }^{1 *}-$ Zeki Candan $^{1}$ \\ ${ }^{1}$ Department of Forest Products Engineering, Faculty of Forestry, \\ Istanbul University-Cerrahpasa, 34473, Istanbul, Turkey \\ * Corresponding author: yildirimmert1993@gmail.com \\ zekic@istanbul.edu.tr
}

\begin{abstract}
The major goal of this study was to develop nanocellulose (NC) and boric acid (BA) reinforced particleboard panels with enhanced physical and mechanical properties. Urea-formaldehyde (UF) resin used to produce particleboard panels was reinforced with NC at loading level of $0 \%$, $1 \%, 3 \%$, BA at loading level of $0 \%, 1 \%, 3 \%$ and $\% 5$. To obtain physical properties density, thickness swelling (TS), and water absorption (WA) tests were performed while modulus of rupture (MOR), modulus of elasticity (MOE), and internal bonding strength (IB) tests were carried out to acquire mechanical performance properties of the particleboard panels. The findings obtained in this scientific study revealed that NC and BA reinforcement significantly affected the physical and mechanical performance properties of the particleboard panels. It was determined that the dimensional stability of the particleboard panels improved by all the NC and BA used in this study. It was determined that using $1 \% \mathrm{NC}$ and $5 \% \mathrm{BA}$ in the particleboard panels had the best results in the WA analysis. It was also determined that using 3\% NC and 3\% BA in the particleboard panels had the best results in the MOR, MOE, and IB tests. It was concluded that the physical and mechanical performance properties of the particleboard panels could be enhanced by using proper NC and BC loading levels. In addition, NC and BA reinforcement technique could be used to develop novel furniture components and interior design materials.
\end{abstract}

Keywords: Nanocellulose, Boric acid, Nanoscience, Nanotechnology, Particleboard, Performance properties, Wood-based composite panels, Furniture components

Biography 


\title{
Development of Low Formaldehyde-Emitting Furniture Components by Nanocellulose and Boric Acid Reinforcement
}

\author{
Mert Yildirim ${ }^{1 *}-$ Zeki Candan ${ }^{1}-$ Oktay Gonultas $^{2}$ \\ ${ }^{1}$ Department of Forest Products Engineering, Faculty of Forestry, \\ Istanbul University-Cerrahpasa, 34473, Istanbul, Turkey \\ *Corresponding author: yildirimmert1993@gmail.com \\ zekic@istanbul.edu.tr \\ ${ }^{2}$ Department of Forest Products Engineering, Faculty of Forestry, \\ Bursa Technical University, 16310, Bursa, Turkey \\ oktay.gonultas@btu.edu.tr
}

\begin{abstract}
Formaldehyde emission from wood-based composite panels such as plywood, particleboard, medium-density fiberboard, oriented strandboard, laminated veneer lumber, etc. is of great importance since it could affect human health. The major raw material of furniture production is particleboard panel. It is also used for interior design and architectural applications. Developing low formaldehyde-emitting particleboard panels as an environmentally friendly material by nanotechnology application was objected in this work. Urea-formaldehyde adhesive used to produce particleboard panels was reinforced with various loading levels of nanocellulose and boric acid. Formaldehyde emission analysis was carried out according to EN ISO 9397-1997. The findings showed that the formaldehyde emission of the urea-formaldehyde adhesive improved by all the nanocellulose and boric acid used in this study. It is determined that boric acid has no significant effect on free formaldehyde, while increasing the amount of nanocellulose slightly decreases it. By using nanocellulose reinforcement, it is possible to produce low formaldehydeemitting particleboard panels so that environmentally friendly furniture could be manufactured.
\end{abstract}

Keywords: Nanocellulose, Boric acid, Formaldehyde emission, Wood-based composite panels, Particleboard, Furniture components

Introduction 


\section{Proceedings of the 2020 Society of Wood Science and Technology International Convention}

Thanks to its unique properties, particleboard panel is one of the most important products of furniture production. Particleboard panel is wood-based composite panels manufactured under pressure and heat from particles of wood and/or other lignocellulosic material in particle form with the addition of an adhesive. Particleboard panel is the most used wood-based composite panels in furniture production and interior decoration. Other wood-based composite products include medium-density fiberboard, plywood, oriented strandboard, laminated veneer lumber.

Urea-formaldehyde adhesive is the most common synthetic resin adhesive used in particleboard panel because of its advantages, such as low cost, good adhesion, high curing rate, which make it plays an effective role in the manufacturing of the wood-based composite panels (Dunky et al. 2002; Candan et al. 2015). Despite their advantages, there are also some disadvantages of UF adhesive. Their strength against humidity is low particularly in high temperatures. Therefore, wood-based composite panels that have been produced by urea-formaldehyde adhesive is suitable for use in closed areas. Moreover, the biggest problem is exposure to formaldehyde emission that is emitted from wood-based composite products (Gao et al. 2018).

The formaldehyde emissions of wood-based composite panels due to their formaldehyde-based resin content are a disadvantage in many applications. Formaldehyde emissions are very important issue to consider for particleboard panels that will be used in furniture and decoration. Formaldehyde emissions are a toxic gas known to be carcinogenic by many health organizations in the world (Candan et al. 2014; National Cancer Institute 2012; Roffael 2006; Salthammer et al. 2010).

In the past, many studies have been made to decrease the free formaldehyde content of ureaformaldehyde adhesive and the formaldehyde emission of its bonded products (Candan et al. 2013; Wang et al. 2013). Boron compounds have been used in the protection of wood-based composite panels for quite a long time (Grexa et al. 1999). The use of nanotechnology in the production of particleboard panel is of critical importance to overcome the formaldehyde emission problem (Candan 2012; Candan 2014; Ciraci 2005; Jones et al. 2005; Roughley 2005). It has been revealed that the addition of nanocellulose may have beneficial effects on the properties of resin. The addition of nanocellulose decreased the formaldehyde emission values of wood-based composite panels (Candan et al. 2014; Zhang et al. 2011).

The aim of this work was to investigate the effect of the addition of nanocellulose and boric acid to urea-formaldehyde adhesive on the properties of particleboard panels formaldehyde emission.

\section{Materials \& Methods}

\section{Materials}


Urea-formaldehyde adhesive, and hardener were supplied by Kastamonu Integrated Wood Industry and Trade Inc., located in Gebze, Turkey. UF resin (E1 grade) with solid content of 50 wt\% was used in the production of particleboard panels. Liquid ammonium sulfate $\left(\mathrm{NH}_{4}\right)_{2} \mathrm{SO}_{4}$ with solid content of 20 wt\% was added to the UF resin as a catalyst. Nanocellulose and boric acid were used to modify urea-formaldehyde adhesive.

\section{Methods}

Urea-formaldehyde (UF) adhesive used to produce particleboard panels was reinforced with NC at loading level of $0 \%, 1 \%, 3 \%, \mathrm{BA}$ at loading level of $0 \%, 1 \%, 3 \%$ and $\% 5$. As a catalyst, liquid ammonium sulfate was incorporated into the urea-formaldehyde adhesive.

\section{Formaldehyde emission analysis}

Formaldehyde emission analysis was carried out according to EN ISO 9397-1997. The free formaldehyde was determined by an oximation reaction with hydroxylamine hydrochloride. The formed hydrochloride acid from this reaction has been determined by potentiometric titration using sodium hydroxide solution. Samples were taken from the reaction mixture and poured into a beaker. Then, they were dissolved by $50 \mathrm{ml}$ of a mixture using a magnetic stirrer. The solution was adjusted to $\mathrm{pH} 3.5$ with $0.1 \mathrm{M} \mathrm{HCl}$. Twenty-five milliliters of hydroxylamine hydrochloride solution was stirred for $10 \mathrm{~min}$. The sample was then back-titer to $\mathrm{pH} 3.5$ with $0.1 \mathrm{M} \mathrm{NaOH}$.

\section{Results and Discussion}

The formaldehyde emission values of the particleboard panels are shown in Figure 1.

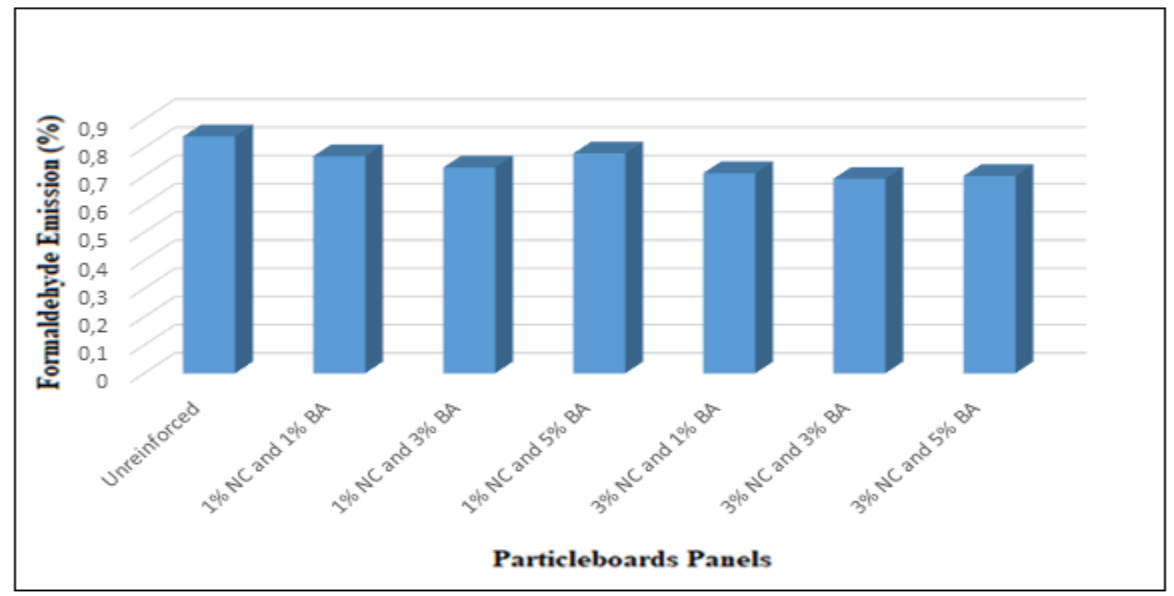

Fig. 1. Formaldehyde emission results of the nanocellulose and boric acid reinforced particleboard panels.

The results of this study revealed that all of the nanocellulose (NC) and boric acid (BA) reinforced particleboard panels had lower formaldehyde emission values than the unreinforced particleboard panels. The particleboard panels reinforced with 3\% NC and 3\% BA had the lowest 


\section{Proceedings of the 2020 Society of Wood Science and Technology International Convention}

formaldehyde emission values. The maximum decrease in formaldehyde emissions of the particleboard panels was $22 \%$. Figure 3 also indicates that boric acid has no significant effect on free formaldehyde, while decreased with increasing nanocellulose loading level.

\section{Summary and Conclusions}

Formaldehyde emissions from particleboard panels are of great importance because of their negative impact on human health. The nanocellulose significantly affected the formaldehyde emission values of the particleboard panels. Increasing the amount of nanocellulose used in this study could significantly reduce the free formaldehyde content of urea-formaldehyde adhesive and the formaldehyde emission of particleboard panels. It was determined that using $3 \%$ nanocellulose (NC) and 3\% boric acid (BA) in the particleboard panels had the best results in the formaldehyde emission. The use of nanocellulose and boric acid reinforcement on thermosetting resins can help develop novel particleboard panels that are environmentally friendly.

\section{Acknowledgments}

The authors would like to thank Istanbul University-Cerrahpasa Research Fund for its financial support in this project (Project No: 31076). The authors thank Istanbul University Research Fund (Project No: 4806, Project No: 19515, Project No: 31014, Project No: 43150 and Project No: 49525). The authors would like to express their appreciation for the assistance provided by Kastamonu Integrated Wood Industry and Trade Inc., located in Gebze, Turkey. The authors also would like to thank TUBA Turkish Academy of Sciences for its support.

\section{References}

Candan, Z., (2012) Nanoparticles use in manufacture of wood-based sandwich panels and laminate flooring and its effects on technological properties, Ph.D. Thesis, 289 pp., Istanbul University, Istanbul, Turkey.

Candan, Z., Akbulut, T. (2013). Developing environmentally friendly wood composite panels by nanotechnology. BioResources 8(3): $3590-3598$.

Candan, Z., Gonultas, O., Akbulut, T. (2013). Nanocellulose reinforced adhesives for wood composites. COST FP1205, December 3 -4, SWEDEN.

Candan, Z. (2014). Environmentally friendly wood composites by nanocellulose. COST FP1205, October $15-16$, SPAIN.

Candan, Z., Akbulut, T. (2014). Nano-engineered plywood panels: Performance properties. Composites Part B: Engineering 64, 2014, 155 - 161.

Candan, Z., Akbulut, T. (2014). Low formaldehyde-emitting wood composites by nanotechnology. 57th Society of Wood Science and Technology International Convention, June 23 - 27, Zvolen, SLOVAKIA. 
Candan, Z., Akbulut, T. (2015). Physical and mechanical properties of nanoreinforced particleboard composites. Maderas. Ciencia y tecnología 17(2): 319 - 334.

Ciraci, S. (2005). "Science and technology at one of a billionth of a meter," Science and Technique, Tubitak, Ankara, Turkey.

DIN EN ISO 9397., (1997). Determination of free formaldehyde content by hydroxylamine hydrochloride method.

Dunky, M., and Pizzi, A. (2002). Wood adhesives. In Adhesion Science and Engineering - 2. Surfaces, Chemistry and Applications. Amsterdam, The Netherlands, 1039-1104.

Gao, Q.; Liu, C.; Luo, J.; Li, X.; Chen, L.; Wang, W.; Li, J., (2018). Effects of resin open time and melamine addition on cold pre-pressing performance of urea-formaldehyde resin. Eur. J. Wood Prod., 76: 1253-1261.

Grexa, O.; Horvathova, E.; Besinova, O.; Lehocky, P., (1999). Flame retardant treated plywood. Polym. Degrad Stabil., 64: 529-533.

Jones, P., Wegner, T., Atella, R., Beecher, J., Caron, R., Catchmark, J., Deng, Y., Glasser, W., Gray, D., Haigler, C., Joyce, M., Kohlman, J., Koukoulas, A., Lancaster, P., Perine, L., Rodriguez, A., Ragauskas, A., and Zhu, J. (2005). "Nanotechnology for the forest products industry - Vision and technology roadmap," Report Based on Nanotechnology for the Forest Products Industry Workshop, Landsdowne, Virginia, USA, October 17-19, 2004, TAPPI Press, Atlanta, GA, USA.

National Cancer Institute (2012). "Formaldehyde and cancer risk," http://www.cancer.gov/cancertopics/factsheet/Risk/formaldehyde.

Roughley, D. J. (2005). "Nanotechnology: Implications for the wood products industry. Final Report," Forintek Canada Corporation, North Vancouver, Canada, 73.

Roffael, E. (2006). "Volatile organic compounds and formaldehyde in nature, wood and woodbased panels," Holz als Roh- und Werkstoff 64(2), 144-149.

Salthammer, T., Mentese, S., and Marutzky, R. (2010). "Formaldehyde in the indoor environment," Chem. Rev. 110(4), 2536-2572.

Wang X.M., Li J.Z., Zhang J.Z., Gao Q. (2013). Technics and Properties of Plywood Manufacture with Modified Urea-formaldehyde Resin. Adv. Mater. Res., 602:743-746.

Zhang H, Zhang J, Shong S, Wu G, Pu J. (2011). Modified nanocrystalline cellulose from two kinds of modifiers used for improving formaldehyde emission and bonding strength of ureaformaldehyde resin adhesive. BioResources 6(4), 4430 - 4438.

Biography 


\title{
Proceedings of the 2020 Society of Wood Science and Technology International Convention
}

\section{Improving the Mould and Blue-Stain Resistance of Bamboo through Acidic Hydrolysis}

\author{
Zixuan Yu \\ Department of Biomaterials, International Center for Bamboo and Rattan, China
}

\begin{abstract}
Bamboo is much easier to be attacked by fungus compared to wood, resulting in shorter service life and higher loss in storage and transportation. It has been long accepted that the high content of starch and sugars in bamboo is mainly responsible for its low mould resistance. In this paper, acetic acid, propionic acid, oxalic acid and hydrochloric acid were adopted to hydrothermally hydrolyze the starch in bamboo, with the aims to investigate their respective effect on the mould and blue-stain resistance of bamboo. The glucose yields, weight loss and color changes of solid bamboo caused by the different acidic hydrolysis were also compared. The results indicated that weak acidic hydrolysis was capable of improving the fungus growth rating to 1 or 2 from previous 3 (for the mould Aspergillus niger) and 4 (for the blue-stain fungus Botryoplodia theobromae) resistance. The surface color of bamboo was only slightly influenced by the four different acid treatments with the highest overall color change value $\left(\Delta \mathrm{E}^{*}\right)$ only 6.83 for the hydrochloric acid treatment. The results in this study demonstrate acidic treatment can effectively remove the starch grains in bamboo but only result in limited improvement in fungus resistance. Therefore, the origins of the low mould and blue-stain resistance of bamboo cannot be solely attributed to the existence of starch particles. Other possible mechanism like the content of soluble carbohydrates (glucose, fructose, sucrose) should be further explored.
\end{abstract}

Biography 


\title{
Proceedings of the 2020 Society of Wood Science and Technology International Convention
}

\section{Physical and mechanical properties of flatten bamboo panel and bonding performance in different bonding surface}

\author{
Xiubiao Zhang \\ zhangxb@icbr.ac.cn \\ Huanrong Liu \\ liuhuanrong@icbr.ac.cn
}

\section{International Center for Bamboo and Rattan, China}

\begin{abstract}
Based on the latest no crack bamboo culm flattening technique, the density and shrinkage rate, the static flexural strength and modulus, compressive strength, tensile strength and shear strength parallel to the grain of flattened bamboo was studied, the phenolic resin was used to explore the shear strength and impregnation stripping length of flattened bamboo with different bonding interfaces (outer layer- outer layer, outer layer- inner layer, inner layer - inner layer), the result shows that the density of the flattened bamboo show a slight increase for the process of culm flattening is a compressed and densified process, especially in outer layer; The drying shrinkage rate is generally shown as tangential drying shrinkage rate $>$ radial drying shrinkage rate $>$ longitudinal drying shrinkage rate, the tangential drying shrinkage rate in the outer layer is greater than that in the inner layer, the longitudinal drying shrinkage rate in the inner layer is greater than that in the outer layer. The static bending strength and elastic modulus, the tensile strength, the compressive strength and the shear strength parallel to the grain basically retain the original mechanical properties of the bamboo. When bonding at different interfaces, the interlayer shear strength was shown as : outer layer - outer layer > outer layer - inner layer > inner layer - inner layer, however, in the impregnation stripping test, the peeling length of outer layer - inner layer is smaller than that in outer layer - outer layer and inner layer - inner layer. Based on the test results, the size stability of the flattened bamboo was poor, which is the focus of the future study.
\end{abstract}

\section{Biography}




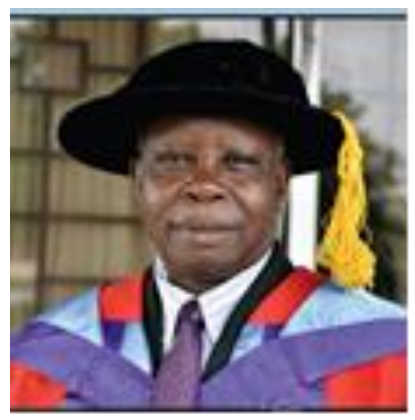

\section{Ajayi, Babatunde}

\section{Expertise: Wood Products, Wood Science and Bio-resources Technology}

Biography:

Professor Babatunde Ajayi was born on 25th August, 1955 in Ijan Ekiti, Nigeria. He obtained his HND in General Forestry at the Federal College of Forestry, Ibadan, PGD in Timber and Material Technology at High-Wycombe, UK in 1986, MSc in Forest Industries Technology at the University College of North Wales Bangor, UK in 1990 and $\mathrm{PhD}$ in Wood Science and Bio-Composites Technology from the Federal University of Technology, Akure, Nigeria, in 2000. He assumed the status of a Professor in 2010 and has served as the HOD of Forestry and Wood Technology Dept., FUTA, Nigeria between 2012 and 2015. He has also supervised many students at PhD, M.Agric.Tech, and B.Agric.Tech, as well as co-supervised postgraduate students from other Departments in the University.

Prof. Ajayi has served as external examiner to undergraduate and postgraduate students in some universities. He has published more than 70 papers in reputable local and international journals and presented papers at more than 33 conferences and professional meetings in North America, South America, Europe, Asia, Australia, Africa etc. His research focus is on the use of conventional biomaterials (Wood) and non-conventional bio-materials from agricultural wastes, common weeds, waste paper and other wastes prevalent in Nigeria and world environment to produce value-added panel products using Portland cement, pozzolan, virgin plastic (HPDE), recycled plastic (LPDE), and car battery case (CBC) as binders, by the application of simple, innovative and adaptable technologies in the manufacturing processes. In 2011, he received a Merit Award as the best innovative researcher for Local Raw Materials Content, R\&D from the Raw Materials Research and Development Council of the Federal Ministry of Science and Technology at the TECHNO-EXPO 2011 in Abuja, Nigeria.

Prof Ajayi, has presented his research findings at various places globally including: Vancouver, Canada in 2004; Grand Rapids, Michigan USA, 2004; Brisbane, Australia 2005; Brazil, Sao Paulo, 2006, Pirassununga and Lavras 2007; Taipei, Taiwan 2007; Madrid, Spain 2008; St LOUIS, Missouri, 2008; Aalborg Denmark in 2010; Brazil, Pirassununga 2010; Madison, Wisconsin 2010; Seoul, Korea, 2010; Cairo, Egypt 2010; Portland, Oregon 2011; Washington, DC 2012; Canberra, Australia in 2012; Austin, Texas 2013; Portugal, 2014; Atlanta, Georgia 2015; Jackson, Wyoming 2015; Vietnam in 2015; Portugal 2016; Cape Town, South Africa, 2018. He is a senior expert on Climate Change and Environment to CTA and is currently serving as chairman or member of various committees in the university. He is the chairman of the Anti-Corruption and Transparency Unit (ACTU) under the Independent Corrupt Practices and Other Related Offences Commission (ICPC). 


\section{Akinyele, Adejoke}

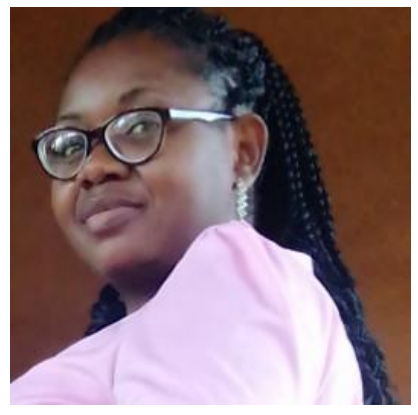

\section{Expertise:Tree Improvement and Silviculture}

\section{Biography - Adejoke Akinyele}

Dr Adejoke Olukemi Akinyele is a Senior Lecturer in the Department of Forest Production and Products, University of Ibadan, Nigeria. She served as the Sub-Dean Undergraduate (Forestry) in the old Faculty of Agriculture and Forestry, University of Ibadan from 2012- 2016. She is currently the Sub-Dean Postgraduate for the Faculty of Renewable Natural Resources, University of Ibadan.

She became a Commonwealth Academic fellow in School of Environment, Natural Resources and Geography, Bangor University, Wales, United Kingdom in 2016. She is a CIPSEM fellow under the UNEP/UNESCO/BMU fellowship at Technische Universitat, Germany in 2013. She is a recipient of the Netherlands Fellowship Programme, Wageningen International, The Netherlands in 2012 and 2010. She is an alumnus of BioVision, The World life Sciences Forum, Scientific Foundation of Lyon and French Academy of Sciences. She is also a member of the United States Alumni group through the Norman E. Borlaug International Agricultural Science and Technology Fellowship Program. She was a visiting scientist in the School of Forestry and Conservation, University of Florida, Gainesville, USA in 2009. She won the Federal Government of Nigeria Postgraduate Award as well as Basorun M.K.O. Abiola Research Fellowship for Postgraduate students in 2002. She also won the African Network for Agroforestry Education (ANAFE), Kenya, part fellowship award for Master's Degree Students in 2000. Dr Akinyele is a member Nigerian Young Academy, Forestry Association of Nigeria, full Member of the Organization for Women in Science for the Developing World (OWSD) and an associate member of Competence Platform for Bioenergy in Arid and Semi-Arid Ecosystems of Africa (COMPETE). She is also a member of Society for Conservation Biology (SCB), International Union of Forestry Research Organisations (IUFRO), African Forest Forum (AFF), Society for American Foresters as well as Commonwealth Forestry Association.

She has successfully supervised students at both undergraduate and postgraduate levels. She has several peer reviewed journal articles, chapters of books and conference proceedings to her credit. 


\section{Alpar, Tibor}

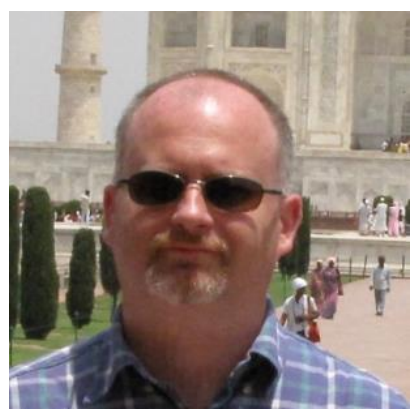

Expertise: Cement-bonded wood products, recycling of wood based products, liquefaction of wood, WPC, reducing formaldehyde emission, bio-composites

Name: Alpár Tibor L., PhD.

Date and place of birth: 1969. 10. 31.

Knowledge of languages: English, German

Education: MSc. of wood sciences, 1994

BSc. of information technology engineer, 2004

Scientific degrees: PhD. 2000

Affiliation: Institute of Wood-based Products and Technologies, Simonyi Károly Faculty of Engineering, Wood Sciences and Applied Arts, University of West Hungary

Present status: associate professor

Work experience:

1997-2000 University of Sopron, Faculty of Wood Sciences, Department of Wood Composites, researcher 1998-2001 independent advisor of Falco Rt.

2000-2003 University of West Hungary, Faculty of Wood Sciences, Department of Wood Composites, senior researcher

2001-2003 STA (Science and Technology Agency) fellowship of Japanese government at Forestry and Forest Products Research Institute (Tsukuba), Wood Composites Laboratory

2003- University of West Hungary, Faculty of Wood Sciences, Department of Wood Composites, associate professor

2003-2004 head of Center of Higher Education at University of West Hungary, Faculty of Wood Sciences

2004- head of FAIMEI Material and Product Testing Laboratory

2004- MC member of COST E31 - Management of recovered wood

2008-2010 vice dean at Faculty of Wood Sciences, University of West Hungary

2011-2013 director of NRRC Natural Resources Research Center, University of West Hungary

2013-2017 dean of Simonyi Károly Facultiy of Engineering, Wood Sciences and Applied Art

2018- Vice Rector for Research and International Relations, University of Sopron

Major research fields were/are: 
Proceedings of the 2020 Society of Wood Science and Technology International Convention

cement-bonded wood products, recycling of wood based products, liquefaction of wood, WPC, reducing formaldehyde emission, bio-composites. 


\section{Armando de Barros, Julio}

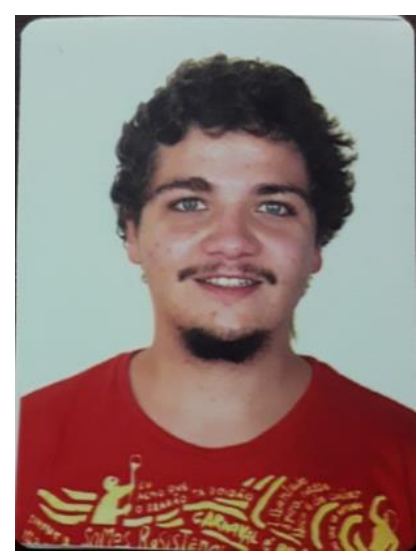

Expertise: Physical properties of wood and its components, energy dissipation dependence on wood anatomy, molecular dynamics view of cellulose-ions interactions for green energetic devices

\section{Biography - Júlio Amando de Barros}

I am a Master's student on Physics at the University of São

Paulo - Brazil. Interested on the many applications of cellulose for nanotechnologies, I am now working on a theoretical approach for understanding the interactions between ions and modified cellulose for green energy purposes. Our methodology is based on computational simulations, from ab initio calculations to molecular dynamics systems.

For more information please look for me! 
Proceedings of the 2020 Society of Wood Science and Technology International Convention

\section{Antwi, Kwaku}

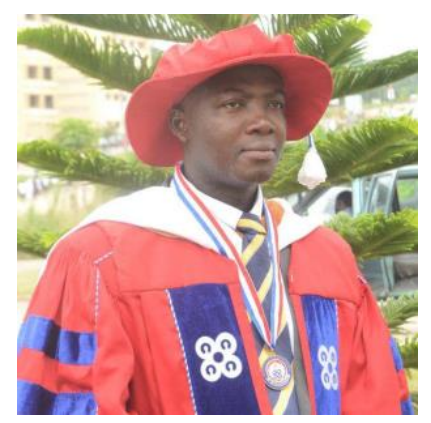

Expertise: Wood Science and Technology

Biography - Kwaku Antwi

Dr Kwaku Antwi is a Ghanaian based lecturer and researcher. He holds Bachelors, Masters and PhD in Wood Science and Technology 


\section{Appiah-Kubi, Emmanuel}

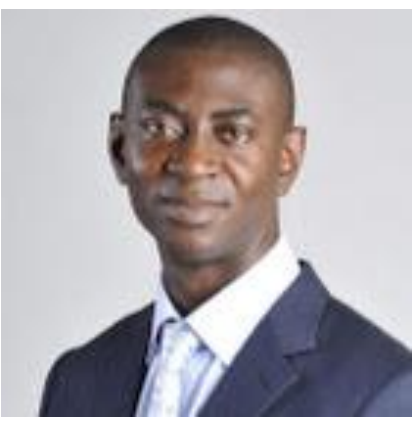

Expertise: Civil engineering with expertise in Wood and Structural Engineering Efficient processing of wood, the design and supervision of construction of timber structures, concrete and reinforced concrete and steel structures Efficient processing and utilization of wood, bamboo and other bio-materials

\section{Biography - Emmanuel Appiah-Kubi}

Emmanuel Appiah-Kubi is a Senior Lecturer at the Department of Construction and Wood Technology Education (University of Education, Winneba), Kumasi Campus, Kumasi, Ghana. I was a Research Scientist at CSIR-Forestry Research Institute of Ghana (CSIR-FORIG), Kumasi, between 2010 and 2018. I was a Demonstrator/Teaching and Research Assistant at the Civil Engineering Department, KNUST after BSc study between 2005 and 2009.

I had my BSC, MPhil and PhD Degrees in Civil Engineering from the Kwame Nkrumah University of Science and Technology (KNUST), Kumasi, and has had a lot of international internships and research stays in European institutions. I had an internship at the School of Architecture, Wood and Civil Engineering, Bern University of Applied Sciences (BFH), Biel, Switzerland during my MPhil study where I worked with colleague Swiss students for my project work. I also had a 6-month research stay at the Georg-August University of Goettingen, Germany as a doctoral research student with sponsorship from the German Academic Exchange Services (DAAD), where I conducted part of my PhD research. I am a member of the Ghana Institution of Engineering (GhIE) i.e. a registered Professional Civil Engineer, with expertise in Structural Engineering. I have also had a lot of experience in the wood industry in Ghana through processing of wood and bamboo and the construction of wooden and bamboo structures. I conduct research into the technological properties of wood, bamboo and other wood-based materials for efficient utilization. My research work has helped to promote and enhanced the use of lesser-used wood species in Ghana through efficient processing methods and techniques. I have helped to establish and also manages the Wood and Furniture Testing Laboratory at CSIR-FORIG. I am currently a member of the International Bamboo and Rattan Organization (INBAR) Task Force for Structural uses of Bamboo, and also a member of the International Standardization Organization (ISO) Technical Committee ISO/TC 165 -Timber Structures. 


\section{Areo, Olusola Samuel}

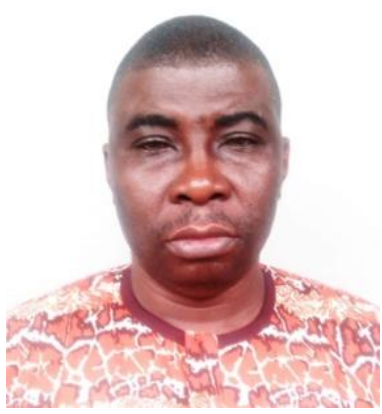

Expertise: Forest Products, Wood and Fiber Science

Biography - Olusola Samuel Areo

I am a Principal Research Scientist and Head of the Wood Processing Section in the Institute responsible to, Formulate and execute research and collaborate with other scientists both within and outside the Institute in developing appropriate technologies for value addition of wood species. I also engage in capacity building of subordinate staff and students from tertiary Institutions through departmental and Institution seminar series. I disseminate research findings through the extension service unit of the Institute and publications in academic Journals and Conference Proceedings.

Participation at this congress will subject my presentation to constructive criticism, comments and suggestions that would assist me to make improvement on the work and by extension to other projects. I will also listen and learn from participants' presentation on related subject and interest in the area of wood science and sustainable forest product utilisation, which will further equip me with new methodologies that I can adapt and apply to my research activities. It will assist to broaden my horizon, improve on my research skill and effectively improve my productivity in my Institute, Nigeria and Africa. 


\section{Arnič, Domen}

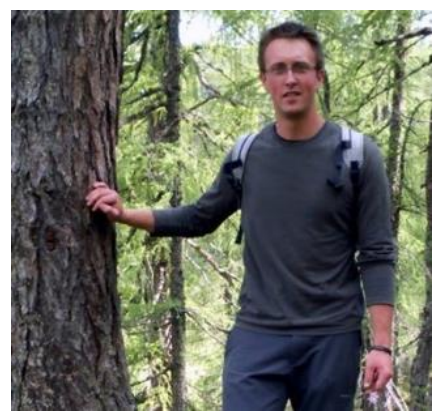

Expertise: Wood properties, Forest-based bioeconomy, Wood anatomy

Biography - Domen Arnič

After a master's degree in "Forestry and Renewable Forest Resources" at the Biotechnical Faculty, University of Ljubljana (Slovenia), I am now continuing with postgraduate education at the same university at the field of Economics of natural resources. The topic of my Ph.D. is related to the impact of climate change on productivity and properties of beech (Fagus sylvatica) and Norway spruce (Picea abies) wood and availability of wood (wood biomass) for Slovenian forest-based bioeconomy. Currently, I am employed as a young researcher at the Slovenian Forest institute. 


\section{Asafu-Adjaye, Osei}

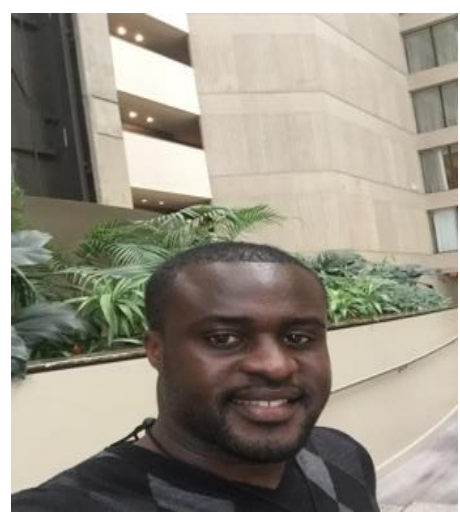

Expertise: Wood Composite and Adhesive Development

Biography - Osei Asafu-Adjaye

Osei is a PhD candidate interested in wood based adhesives, wood composites, Mass timber and CLT. He holds a MSc in Polymer and Fiber Engineering, MPhil in Wood Technology and BSc in Wood Science and Technology. 


\section{Aslam, Sidra}

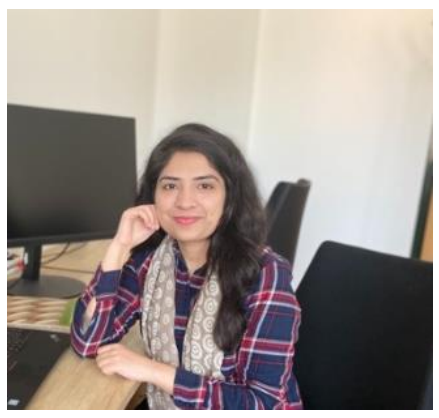

Expertise: Security and Privacy in Blockchain chain technology

Biography - Sidra Aslam

Sidra Aslam has completed a Master of Science in

Computer Science (MSCS) from COMSATS Institute of

Information Technology Islamabad, Pakistan in January

2017. She was awarded the best research paper shield from

National Software Engineering Conference (NSEC), IEEE

in December 2015. She is pursuing her Ph.D. at the University of Primorska Slovenia. She is associated with a research team;

working on the wood supply chain, Ontology-based

Semantics, and privacy at the ICT group. Her research interest includes Information

security and privacy, Knowledge-Based Systems, and Semantic web

Technologies. 


\section{Azadfar, Mohammadali}

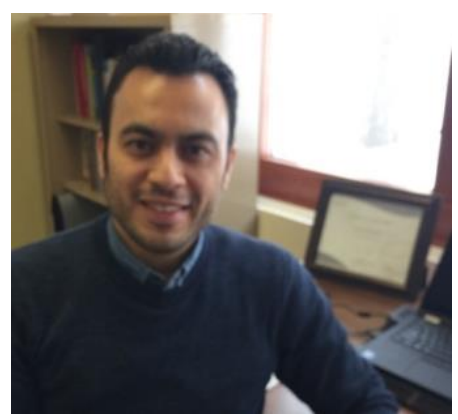

Expertise: Mechanics and chemistry of wood and wood composites; conversion of lignocellulosic biomass into value-added products; industrial extension/outreach in forest products

\section{Biography - Mohammadali Azadfar}

Mohammadali Azadfar is an assistant professor of environmental \& renewable resources in the SUNY Morrisville School of Agriculture, Business \& Technology. Prior to joining Morrisville in 2019, he was a postdoctoral research associate in the Composite Materials and Engineering Center at Washington State University (Pullman, Wash.). He received his Ph.D. in bioenergy and bioproducts engineering from the Department of Biological Systems Engineering at Washington State University in 2016 and completed his M.S. and B.S. in natural resources engineering - wood science and technology in Tehran, Iran.

Technical Interests

Mechanics and

chemistry of wood and wood composites; conversion of lignocellulosic biomass into value-added products; industrial extension/outreach in forest products.

Teaching Interests composites; wood chemistry; secondary wood processing; wood drying and preservation; wood glues, laminating and finishes; lumber manufacturing and grading; furniture design construction. 
Proceedings of the 2020 Society of Wood Science and Technology International Convention

\section{Baar, Jan}

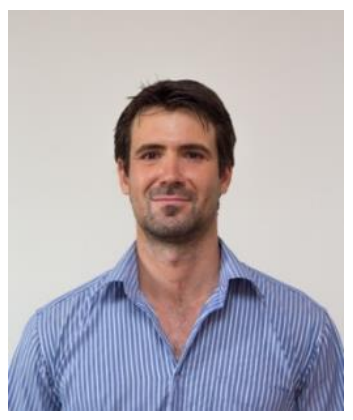

Expertise: Wood degradation, weathering, wood structure

Biography - Jan Baar

Jan Baar is assistant professor of Wood science at Mendel University in

Brno, he joined the department in 2012. His research interest includes

wood preservation, wood extractives influence on wood properties and wood discoloration. 


\section{Balasso, Michelle}

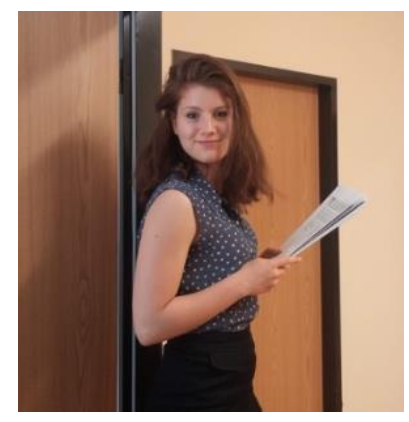

Expertise: Forestry, wood sciences

Biography - Michelle Balasso

Michelle is a PhD candidate and researcher at the University of Tasmania, Australia, within the Australian Research Council funded Centre for Forest Value, working across the wood production chain of plantation timber. She holds a BSc in Forest and Environmental Technologies and an MSc in Forest Science and has been a Research Assistant at the Forest Ecology and Remote Sensing Department at the University of Goettinghen, in Germany. She is a passionate researcher with a soft spot for forestry, while being very involved in the wood production industry and collaborating with the major forestry companies in Tasmania. Originally from the Dolomites in Italy, she is a trail runner, nature-lover with a strong bond with wild and alpine environments. She's been traveling to several countries, developing a strong network in the forest, ecology, and wood production sectors, presenting her research at remarkable international conferences. She is involved with several projects and is frequently busy in public speaking events bringing her traveling and woman-in forestry experience, as well as forestry and wood quality expertise. 
Proceedings of the 2020 Society of Wood Science and Technology International Convention

\section{Baranova, Olha}

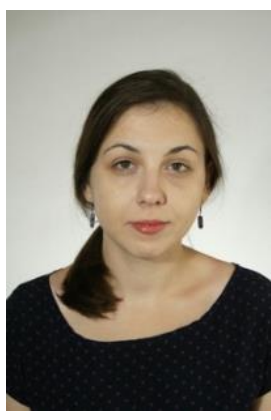

Expertise: Wood-based materials, non-destructive testing of wood-based materials, powder coating

Biography - Olha Baranova

Senior Lecturer of Department of Technology and Design of Wood Products University of Life and Environmental Sciences of Ukraine.

Scientific interests- technology of protective and decorative coatings, and non-destructive testing of wood. 


\section{Barbero-Lpez, Aitor}

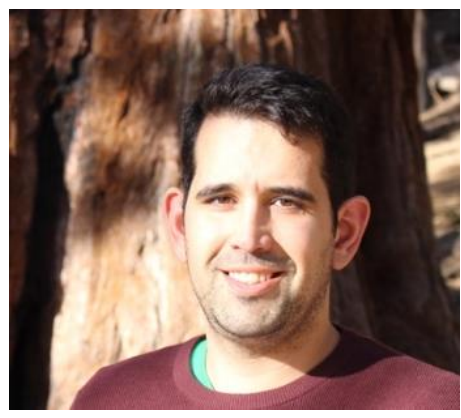

Expertise: Wood Preservation

Biography - Aitor Barbero-López

Aitor is an Early Stage Researcher in the University of Eastern Finland. His aim is to identify bio-based antifungal chemicals in forestry side-streams, which can be used for wood preservation.

Before starting his DSc, Aitor worked in the Finnish Forest Research institute of Finland, and he studied an MSc in Wood Materials Science. His research interests are wood preservation, wood modification and wood decay. Due to his background, he also has interest in plant and tree ecophysiology and mycorrhizae. 
Proceedings of the $\mathbf{2 0 2 0}$ Society of Wood Science and Technology International Convention

\section{Barcic, Andreja Pirc}

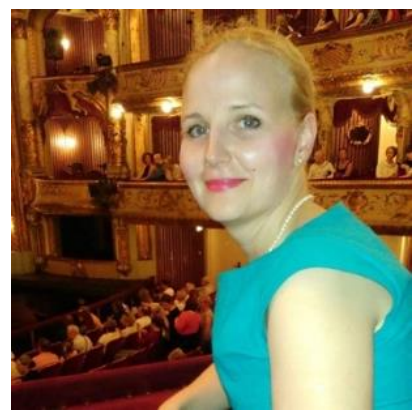

Expertise: Business Innovation, marketing and trade in wood based industry, business planning and calculations

Biography: Non available 


\section{Bartuska, Birger}

Expertise: Wood technology, manufacturing and digitalization in the wood industry

Biography - Birger Bartuska

Birger Bartuska is a junior researcher at the competence center Wood K plus area wood materials technologies.

After finishing his masters in wood technology and mangaement at the university of applied life sciences in Vienna on the topic of hemp fiber reinforced thermoplastic composites he is doing his phd in the field of digitalisation and new production technologies in the wood industry. 


\section{Beranič, Tina}

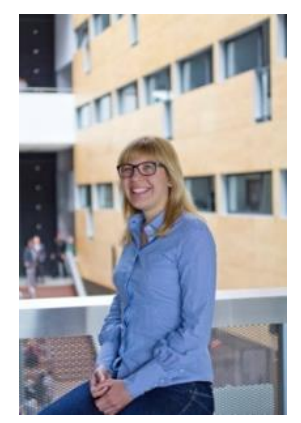

Expertise: Digitalization, software engineering

Biography - Tina Beranič

Tina Beranič received a PhD degree in computer science and informatics from the University of Maribor in 2018. She is a Teaching Assistant and a Researcher at the Faculty of Electrical Engineering and Computer Science, University of Maribor. Her research interests are in the area of software quality, especially the domain of software metrics and software metrics thresholds. She is also working in the digitalization domain, researching the application of digital tools and digital transformation. 


\section{Böger, Thomas}

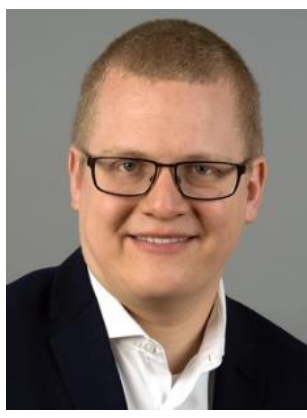

Expertise: Adhesives and Laboratory Managment

Biography - Thomas Böger

Since 2018 Thomas Böger is a researcher at the Technical University of Munich in the research group of wood based materials. His field of research is adhesives for solid wood applications. He studied Wood Engineering (B.Eng.) and Timber Technology (M.Sc.) in Germany and Switzerland. After his studies he worked several years as a test and application engineer for adhesive producers with applications in the wood- and microelectronic-industry. 
Proceedings of the 2020 Society of Wood Science and Technology International Convention

\section{Brabec, Martin}

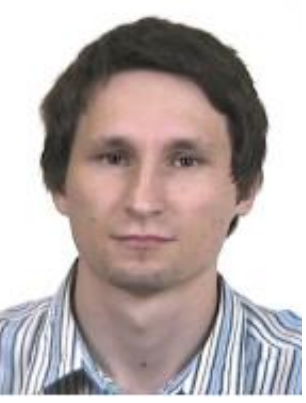

Expertise: Wood mechanics, Digital Image Correlation, Material characterization

Biography - Martin Brabec

An investigation of mechanical behaviour of wood and live trees by menas of full-field optical technique based on digital image correlation (DIC). 


\section{Brémaud, Iris}

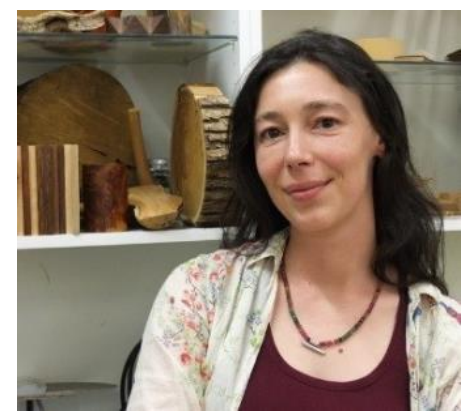

Expertise: Wood physics in the scope of diverse connections: between artisanal and scientific knowledge on wood; between the complexity of physical behaviour and the botanical diversity of wood; between biological and cultural diversity; the relationship between humans and wood in instrument making and in traditional crafts

Biography - Iris Brémaud

Iris Brémaud is researcher at CNRS - French National Centre of Scientific Research - in the "Wood Team" of Laboratory of Mechanics and Civil Engineering in Montpellier. She followed an initial University training in plant biology, while starting to learn guitar and lute making. From 2000 she specialised her work on wood material (with a focus on wood for instrument making) through her MSc in Wood Science and $\mathrm{PhD}$ in Mechanics. Her doctoral thesis (2006) was on "Diversity of woods used or usable in musical instruments making". She subsequently continued research on wood diversity and wood physics, focusing on cross-cultural views of wooden instruments and on the structure-chemistry-properties relationships in wood mechanics, as a Post-Doc researcher in Japan, then in Nancy (France), then in Switzerland. In 2013 she was recruited as permanent CNRS research fellow. In 2014 she founded the International Symposium "Wood Science and Craftsmanship". In 2016 she obtained the degree of Habilitation to Supervise Research with a thesis entitled "Towards and ethno-bio-mechanical vision of wood".

Her current research in CNRS Montpellier aims at a systemic approach to wood behaviour, diversity and cultural uses, by relating fundamental wood physics/mechanics to botanical origin and to "hand knowledge" of wood craftsmen. There is still a focus on musical instruments making but the research now extends to several woodworking trade specialities. Recent works, often in collaboration with artisans, involve early stage researchers and national or international collaborations. 


\section{Bruno, Maria Roberta}

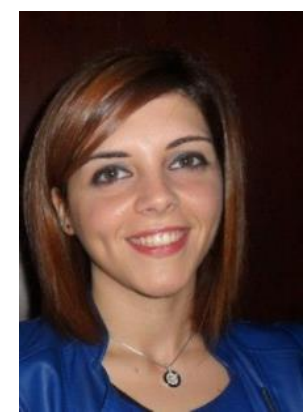

Expertise: Analysis from chemical-biological point of view agricultural waste in order to create new eco-sustainable industrial products

\section{Biography - Maria roberta Bruno}

Maria Roberta Bruno graduated in 2012 and continues to carry out activities related to the world of agriculture and environmental protection, initially as a field technician in companies organic following both the technical and the administrative part. Subsequently plays activities in the field of experimental research in the CREA research center in Metaponto (MT), where it analyzes various eco-sustainable agricultural systems. She currently carries out research at the University of Basilicata analyzing from a chemical-biological point of view agricultural waste in order to create new eco-sustainable industrial products. 


\section{Burnard, Michael}

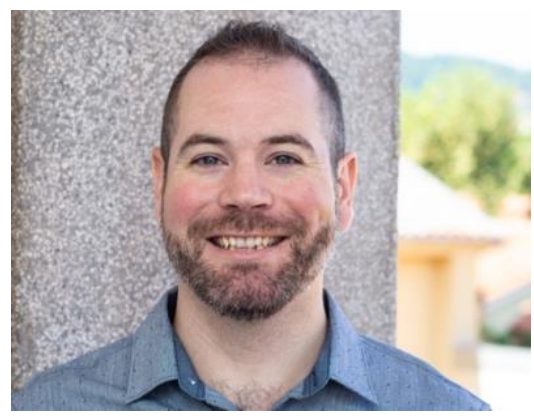

Expertise: Human health in the built environment; Sustainability of wood construction; Wood composites, wood quality, wood value chains; Data Science

Biography - Michael Burnard

Dr. Michael (Mike) Burnard was born in the United States of America but moved to Slovenia in 2013 to complete his $\mathrm{PhD}$. Mike is now an assistant professor at the University of Primorska where he is the coordinator of the Data Science Masters programme and, performs research, teaches, and mentors students. He is also the deputy director of the InnoRenew CoE, a research organisation founded in 2017 following successful funding from the H2020 Widespread-Teaming programme. His research interests are focused on enhancing human health and using wood in the built environment as well as advancing sustainability through intelligent use of renewable resources, particularly in buildings. Mike also works in many other areas including business management, innovation, data science, and ICT. 


\section{Burns, Candra}

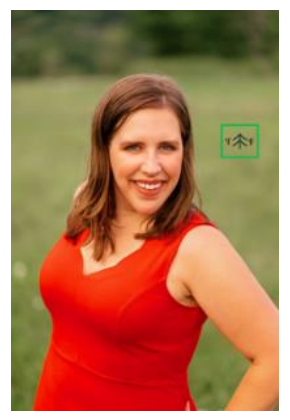

Expertise: International Social Media Consultant in the Forest and Wood sector

\section{Biography - Candra Burns}

Candra Burns built her foundation by volunteering in her local community as a child. She started applying for scholarships and grants in high school to go to college because she was raised low-income and first generation. Candra took advantage of the support programs on both of her college campuses. Within five years, she earned 25 scholarships and grants claiming her a debt-free education.

Since 2015, she has been the social media communications chair for Washington State Society of American Foresters and holds that chair while she lives in Germany with her Air Force husband. She realized her passion for media marketing through these efforts which gave her the ideas to start Talking Forests, a social media based communication business in 2016.

Candra's business wishes to help others have a voice and build an online presence. Her inspiration comes from the people who gave her hope and the people who give her hope for the future. These are the generous people who work every day to grow and help each other equally.

In 2018, she gave a refreshing social media speech at the International Forest Business Conference in Poland, documented the \#forestproud conference in Atlanta, and taught military spouses how to use social media at a regional conference with her "Building the Future with Social Media" speech at the American's Working Around the Globe Conference at Ramstein Air Base.

In 2019, she taught social media seminar classes in Edelweiss Resort at the American's Working Around the Globe Annual Conference to inspire spouses with "A Future with Social Media" and "LinkedIn 101" to show them how to leverage social media to achieve any goal they have.

She was a speaker in the fall of 2019 at the Society of Wood Science and Technology's International Convention in Yosemite National Park and to the Society of American Forester's National Conference in Kentucky. She holds two associates degrees from Grays Harbor College and a Bachelor of Science from The Evergreen State College. She is a proud military spouse with the ability to work from anywhere in the world. 
Proceedings of the 2020 Society of Wood Science and Technology International Convention

\section{Cahyono, Tekat Dwi}

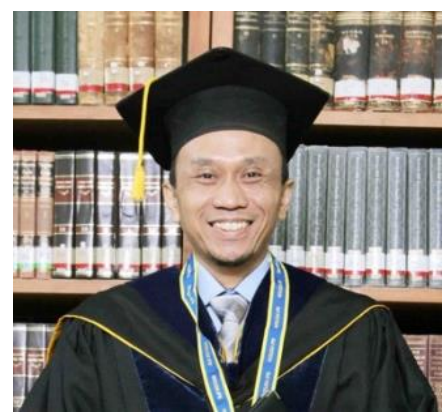

Expertise: Wood bio-composites; Wood modification;Wood preservation

Biography - Tekat Dwi Cahyono

I was born in Malang, Indonesia, 1st July 1975. I graduate from Bogor Agricultural University (Doctoral Program) at 2015. I am a lecturer at University of Darussalam Ambon, one of the private college in Ambon, Indonesia. I have research team and our research interest are basic properties and wood modified. 


\section{Carrero, Tulio}

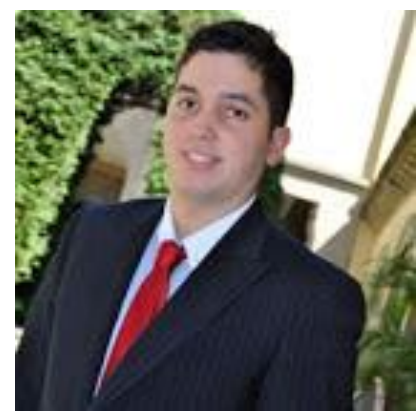

Expertise: Civil Engineering

Biography - Tulio Carrero

Tulio E. Carrero R. BIODATA.

Tulio Enrique Carrero Roa received his BS in Venezuela from the Universidad de Los Andes in 2015 and MS degree from the Universidad Católica Andrés Bello in 2018. Nowadays, he is Ph.D. Candidate from the Pontificia Universidad Católica de Chile "PUC" in 2017-2021. His tutors are Pablo Guindos and Hernan Santa Maria. He won the Conicyt Scholarship in 2017. He is a Civil Engineer Professional with proven capabilities and knowledge in technical areas of civil engineering such as structural engineering, geotechnical, soil, sanitation, hydrology, hydraulics, roads, surveying, pavements as well as personnel management, control and project management. He had work in VEPICA Company, included in the 100 best tops of engineering companies of the world. He specializes in the design and construction of Timber Structures. He is working on a Fondecyt Program about Cross-Laminated "CLT" Wood structures.

Next, I will indicate the different works in which I have worked:

- Conference Korea-2018: Carrero T, Ureta-Céspedes F, Cabrera T, Cárcamo S, Santa María H, Guindos P. (2018). "Global analysis of light-framed timber construction detailing and its performance during major contemporary earthquakes,” 2018 World Conference on Earthquake Engineering, Seoul, Corea, August 20232018.

- Patent: Aprobado el concurso DTD-UC, revisión del documento final de patente con el nombre: Muro Estructural compuesto del Tipo Marco-Plataforma de CLT.

- Conference CLEM-2019: . Carrero T, Montaño J, Santa María H, Guindos P (2019) “Comportamiento cíclico de conexiones híbridas de 1sl, hormigón y acero con clt”. 2019 4to congreso Latinoamericano de Estructuras de Madera, Montevideo, Uruguay, Noviembre 18-20 2019. 


\section{Cermak, Petr}

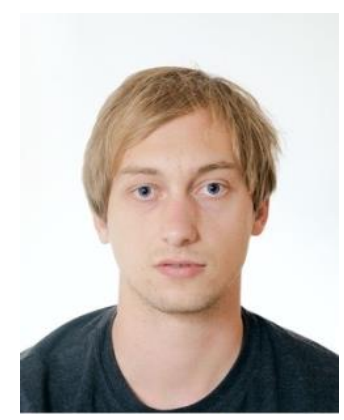

Expertise: Wood Modification, Thermal Modification, Wood Charring, Process Development

Biography - Petr Cermak

Petr Čermák is academic staff - researcher at Department of Wood Science and Technology (Faculty of Forestry and Wood Technology, Mendel University in Brno). He got his Ph.D. at Mendel University in Brno. Since 2014 was as a postdoctoral researcher granted at the same university. He is focused on material engeneering of natural lignocellulose materials with special focus on wood. His scientific interests lie mainly in area of wood modification, hygro-thermo mechanical treatment of wood, wood-water interaction, wood welding and material properties testing. His expertise was gained not only at MEDELU, but also during short/long term visits at foreign institutions in Finland (Aalto University), Germany (Eberswalde University of Sustainable Development, Gottingen University), Hungary (University of Sopron) and others. He is as a project leader/member active in participation in the national and international research projects (GAČR, TAČR, OPVK, IraSME, CZ/DE bilateral project(s), etc.) and publishing of his research in high-quality peer-review journals and presenting at international conferences. 


\section{Chen, Nairong}

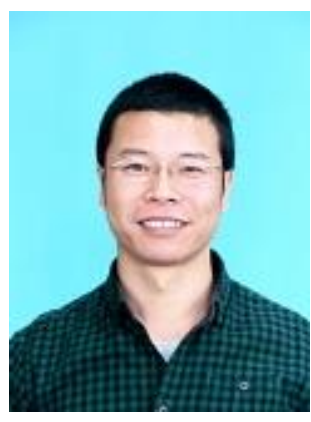

Expertise: Wood adhesives

Biography - Nairong Chen

My research interests in green materials, particularly in bio-based resins, wood based composites, and bio-based porous materials. Recent projects have examined the properties of soy-based adhesives developed for interior wood composites. Other studies have investigated the room temperature curing formaldehyde-free adhesives for construction engineering, and those for protecting environment and human beings. In my research field of bio-based adhesives and wood products, I have a good profile with 37 peer review journal publications and 14 patents, and was awarded "2016 Excellent Youth Science of Fujian Province, China". I have been the project manager and collaborator of several NSFC projects on my research areas.

Fujian Agriculture and Forestry University (FAFU) is jointly sponsored by the Ministry of Agriculture, State Forestry Administration, and Fujian Provincial Government. The university has been rated " $\mathrm{A}$ " in terms of undergraduate teaching by the Ministry of Education. FAFU currently owns 75 provincial and national innovative platforms, and ranks second among the country's provincial agricultural and forestry universities with its highquality faculty, social services, and researches. FAFU altogether some 672 research findings have received provincial or national scientific and technological awards, 28 of which are entitled to China's top three research awards. 


\section{Couceiro, José}

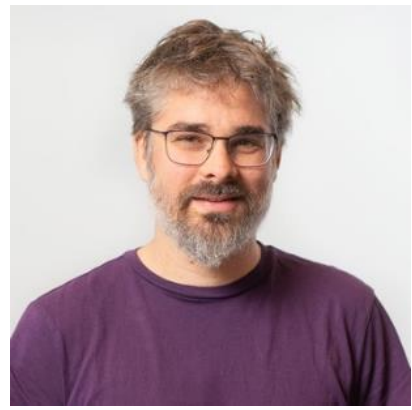

Expertise: Wood drying and computed tomography

Biography - José Couceiro

José Couceiro finished his Forestry Engineering bachelor in the University of Vigo, Spain, in 2009 and moved to Sweden to enrole on a master progam in Wood Technology in Luleå University of Technology in Skellefteå. He later became a PhD student and defended his thesis on september 2019, focusing on the use of computed tomography to study moisture distribution in wood. Now he is Associate Senior Lecturer in the division of wood science and engineering. 


\section{Cristini, Valentino}

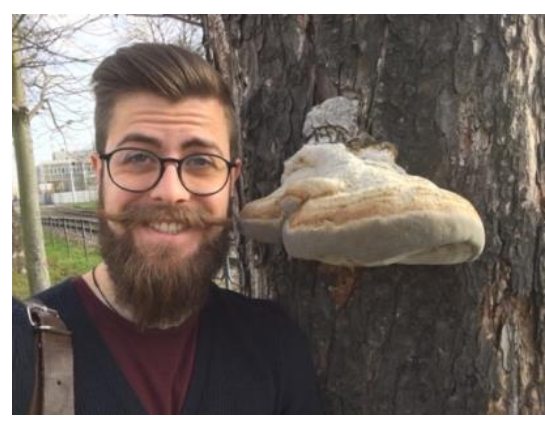

Expertise: Biodegradation of wood, wood decay fungi, arboriculture, tree biomechanics

Biography - Valentino Cristini

Born and grown up in northern Italy, in 2012 moved to the Czech Republic and attended university study of arboriculture and forestry at Mendel University in Brno. From 2012 to 2019 worked as an arborist within the fields of tree assessment, biomechanics, and phytopathology. Since 2019 I'm a Ph.D. student at the Department of Wood Science and Technology of Mendel University in Brno. My main field is the biological deterioration of wood in standing trees and its material properties. 
Dahle, Sebastian

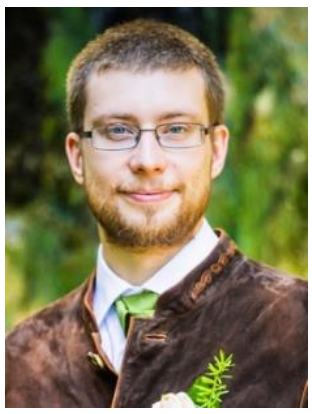

Expertise: Physics, Surface Science, Plasma Technology, Wood Science and Technology

Biography - Sebastian Dahle

\section{PERSONAL INFORMATION}

Sebastian Dahle

$+38613203618+4915154206509$

sebastian.dahle@bf.uni-lj.si

www.sebastiandahle.de

Skype sebastian.dahle

\section{WORK EXPERIENCE}

01/09/2018-Present

Marie Curie fellowship

University of Ljubljana, Slovenia

01/07/2013-31/08/2018

Postdoctoral research fellow

Clausthal University of Technology, Germany

- Conducting research

- Leading research projects

- Supervising a team of up to 8 co-workers

01/03/2010-30/06/2013

Research fellow

Clausthal University of Technology, Clausthal-Zellerfeld (Germany)

\section{EDUCATION AND TRAINING}

01/10/2017-26/03/2018

Assist. Prof. (Slovenian: docent)

University of Ljubljana, Slovenia

Habilitation in Wood Science and Technology

01/03/2010-22/03/2013

Dr. rer. nat. (doctor of natural sciences) EQF level 8

Clausthal University of Technology, Germany

01/10/2005-22/02/2010

Dipl.-Phys (diploma in physics) EQF level 7 
Proceedings of the 2020 Society of Wood Science and Technology International Convention

Clausthal University of Technology Germany

Physics and Physical Technology 


\section{Darmawan, Wayan}

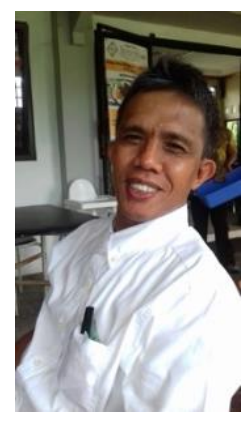

Expertise: Wood Science and Technology, Wood Machining, Wood Surface Coating, Wood Modification

\section{Biography - Wayan Darmawan}

Wayan Darmawan is a full professor at the Department of Forest Products, Faculty of Forestry, Bogor Agricultural University (IPB) since 2012. He received his doctorate at the University of Shimane, Japan in 2000. He continued his post-doctoral study at the Ecole Nasionale Superior de Art et Metier, France in 2002-2003. He was an Erasmus Mundus visiting professor fellow at Dresden University, Germany in 2009. He had been serving as Director of the Forest Products Department in 2010-2014. He concentrates his research work in the domains of wood machining, wood quality improvement by surface coating. He has been a member of the SWST since 2012. 


\section{De Arana-Fernández, Marina}

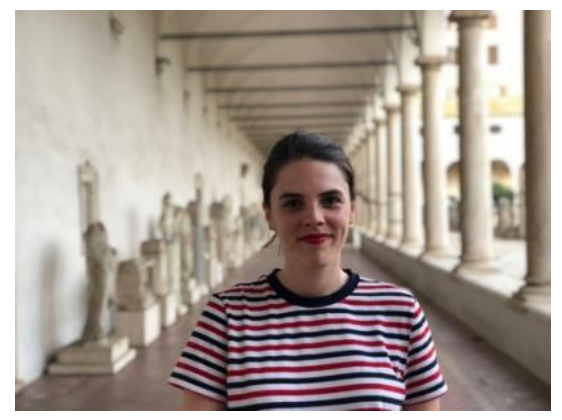

Expertise: Architecture, forestry, construction, cultural heritage

Biography - Marina de Arana-Fernández

2010 - 2016. Degree in Architecture by Universidad Politécnica de Madrid

2016 - 2017. Master in Architecture by Universidad Politécnica de Madrid

2017 - 2018. Architect in Geneva, Switzerland

2018 - 2019. Master in Rehabilitation of Cultural Heritage by Università degli Studi RomaTre

2019. Stage as an Architect in Parco Archeologico di Pompei, Italy

2019 - present. PhD in Wood and Cork Technology Research Group by Universidad Politécnica de Madrid

2020 - present. Researcher Associate in Timber Construction Research Group of the Universidad Politécnica de Madrid, Spain. Topic: Reuse and recycle of timber from demolition in structural products and design for the deconstruction in the future (InFutUReWood European project). 


\section{De Mil, Tom}

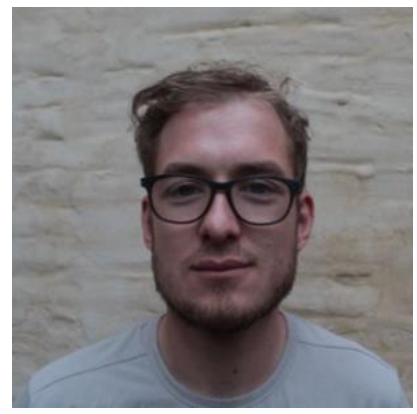

Expertise: Wood anatomy, Wood technology, X-ray Computed Tomography, dendrochronology

Biography - Tom De Mil

Tom De Mil obtained his PhD in 2017 at UGent-Woodlab in close collaboration with the Royal Museum for Central Africa. With fieldwork in the Democratic Republic of the Congo, his main focus was on X-ray CT scanning of tree cores from tropical forests. He made a field-to-desktop toolchain that allows to perform tree ring analysis and microdensitometry. In his current FWO project he uses this toolchain to analyze rings of the oldest trees in the world: ancient bristlecone pine.

He has made several contributions in peer-reviewed scientific journals (as author and co-author) and presented his progress on conferences, by means of oral and poster presentations 


\section{Derikvand, Mohammad}

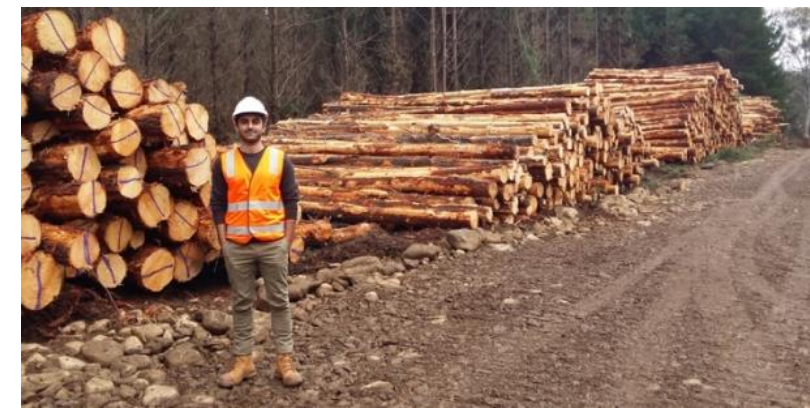

Expertise: Wood science and engineering

\section{Biography - Mohammad Derikvand}

Mohammad Derikvand is a postdoctoral researcher from Department of Civil Engineering at Aalto University, Finland. Mohammad does research in a range of different topics related to Wood Science and Engineering. He has been involved in wood-related research activities for more than 12 years and has teaching experience in three different countries. Mohammad's most recent research activities are focused on the shear performance of timberconcrete composite connections and evaluation of the accuracy of various test methods for bond strength measurement of wood adhesives. 
Proceedings of the $\mathbf{2 0 2 0}$ Society of Wood Science and Technology International Convention

\section{Devallance, David}

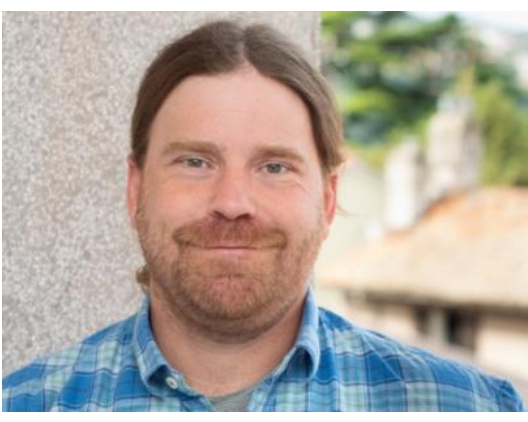

Expertise: Renewable Composite Materials

Biography - David Devallance

David is the research group leader in Renewable Materials Composites at the InnoRenew CoE. He received a

Bachelor of Science in wood products processing and manufacturing from the Pennsylvania State University and his Master of Science and PhD in wood science from Oregon State University. 
Proceedings of the $\mathbf{2 0 2 0}$ Society of Wood Science and Technology International Convention

\section{Díaz, René Herrera}

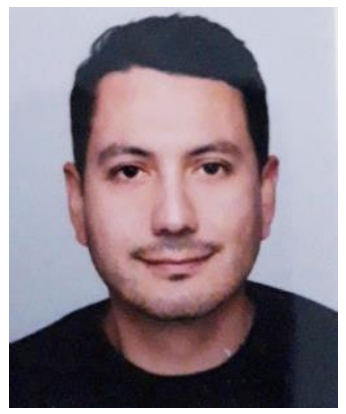

Expertise: Wood treatments, non-destructive techniques, wood protection, analytical techniques

Biography - René Herrera Díaz

MSc and Ph.D. in Renewable Materials Engineering from the University of the Basque Country (Spain). Currently, I'm a Postdoctoral researcher funded by the Basque Government at the Innorenew COE research center (Slovenia), where I work on wood modification methods, characterization techniques and valorization of wood products. 


\section{Djafaripetroudy, Seyedrahman}

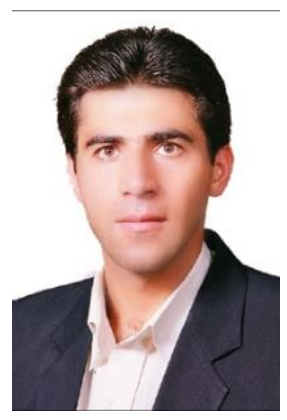

Expertise: Cellulose nanotechnology and Biorefinery

Biography - Seyedrahman Djafaripetroudy

I have be working as an Assistant Professor at Biorefinery engineering department at SBU in IRAN. Here we are focusing on the production of cellulose nanomaterials from different agro-based residues such as Bagasse, Wheat and Rice straw for varying industrial application such as paper and board, novel biocomposites. Working on the extraction of hemicelluloses from the mentioned lignocellulosic materials for packaging application will be our future endeavor. 


\section{Dolezal, Franz}

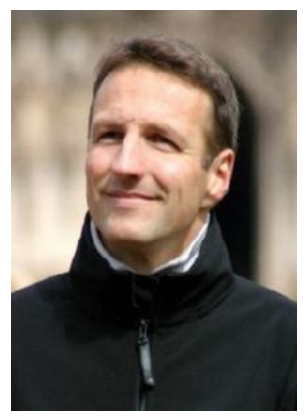

Expertise: Building acoustics and sound insulation, Sustainability of building products and buildings

\section{Biography - Franz Dolezal}

Master studies of architecture at TU Vienna and RWTH Aachen with emphasis on building physics. Doctoral studies at TU Vienna, civil engineering, with building physical subject (flanking transmission in solid wood structures).

Professional experience in building physics, consulting engineer for sustainability and energy conservation and research in building acoustics and sustainability of building products. Since 2017 at IBO in charge for research projects on building acoustics and Life Cycle Assessment of building products.

Member of several national and European standardisation committees and building LCA related boards. 


\section{Dömény, Jakub}

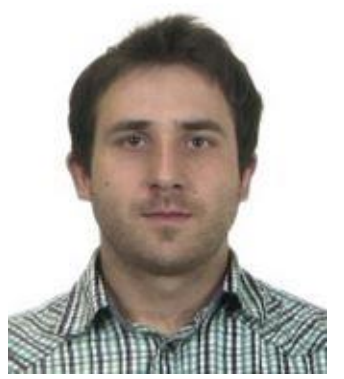

Expertise: Wood modification and improvements of material properties of solid wood, microwave treatment applications, acceleration of chemical reactions by microwave heating, microwave plasticization and microwave drying

\section{Biography - Jakub Dömény}

Dr. Jakub Dömény is academic staff - researcher from Mendel University in Brno, Faculty of Forestry and Wood Technology, Department of Wood Science. His expertise lies in field of wood modification and improvements of material properties of solid wood. He is mainly focused on microwave treatment applications, especially acceleration of chemical reactions by microwave heating, microwave plasticization and microwave drying. He is lecturer of various courses, mainly wood modification, physical and mechanical properties of wood, wood drying and development of new wood-based materials. 


\section{Dupleix, Anna}

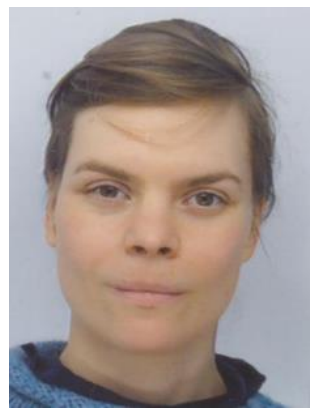

Expertise: Wood sciences, social sciences

Biography - anna dupleix

I began my research career by studying the impact of the physical-mechanical properties of wood on its mechanical machining (peeling process) and its use in civil engineering. After a year of agricultural training to acquire technical skills in beekeeping and a post-doctoral project at the University of Aalto (Finland) on the energy contribution of wood use inside human housing, I began to wonder about the influence of the wood material used to build hives on the health of bee colonies, which are now under threat. The first results of an interdisciplinary approach that brings together anthropology, wood science and ecology to confront traditional knowledge with scientific knowledge reveal habitat properties that can affect living organisms, bees and their parasites, which we then experiment in the laboratory at the level of individuals and colonies. In particular, instrumental devices under development demonstrate the repellent effect of volatile compounds in chestnut wood on the bee parasitic mite, varroa destructor, and quantify the influence of the thermal and radiative properties of the wood and the environment on the internal climate. 


\section{Dvoracek, Ondrej}

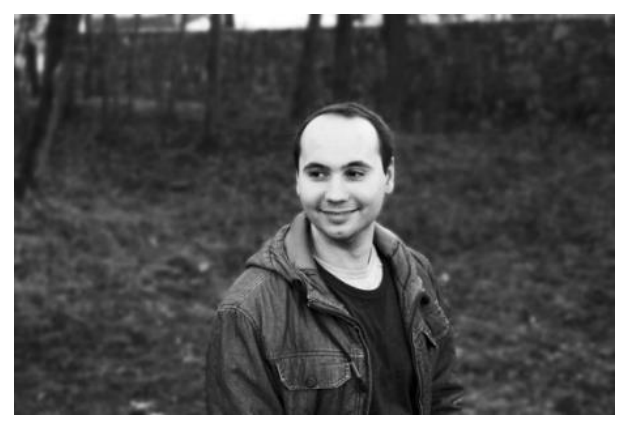

Expertise: Data analysis, Wood disintegration, Machine prototyping

Biography - Ondrej Dvoracek

Ondrej Dvoracek works as a Junior Researcher in the Team Mechanical Disintegration of Competence Centre for Wood Composites and Wood Chemistry, Austria. He received his Bachelor's and Master's degrees from the Brno University of Technology in Mechanical Engineering Design. He is a doctoral candidate at the Technical University of Graz in the Institute of Production Engineering. He also worked as a research worker focused on studying smart magnetorheological fluids used in damping systems, university lector of 3D modelling and developer of long-time prosthetic feet fatigue testing machines. His current research interests include mechanical processes taking place during high-speed cutting of hardwood. He is developing a device which enables to study it. 


\section{Effah, Bernard}

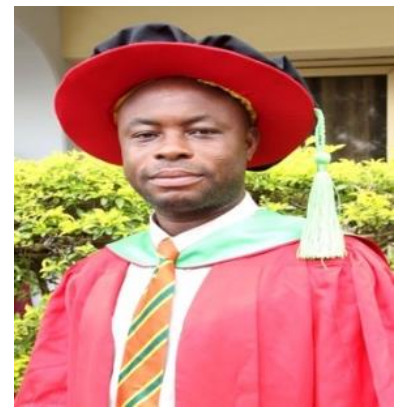

Expertise: Wood Product Science, Composite Materials Microscopy and Spectroscopy (AFM), Materials Characterisation, Engineered wood, Bioenergy (Biomass)

Biography - Bernard Effah

Dr. Effah is a Senior Lecturer at Kumasi Technical University in Ghana. He holds a $\mathbf{P h D}$ in Wood Product Science from Stellenbosch University, South Africa. He also holds the following: Galileo Master Certificate in Renewable Energy (Biomass) from the European Energy Centre (UK); MSc. Wood Science from the Kwame Nkrumah University of Science and Technology - Ghana and MA. in Educational Leadership from the University of Education, Winneba - Ghana. Dr. Effah's research interest are; Composite Materials, Microplastics, Microscopy \& Spectroscopy (AFM), Materials Characterisation, and Biomass. Dr. Effah is an external examiner for some Universities and a reviewer for some Journals. 


\section{Espinoza, Omar}

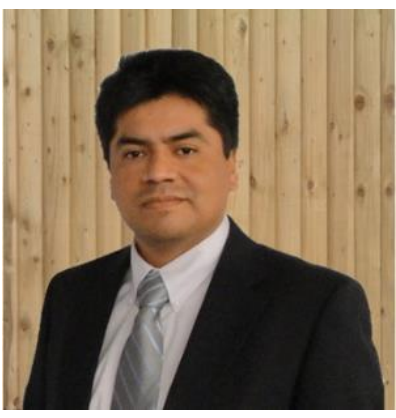

Expertise: Marketing and Management of Forest Products

\section{Biography - OMAR ESPINOZA}

Omar Espinoza is Associate Professor at University of Minnesota's Department of Bioproducts and Biosystems Engineering, and chairs the Forest Products Management Development Institute. He is Director of Undergraduate Studies for the Sustainable Systems Management (SSM) major. He worked in managerial positions in the forest products industry for seven years. Omar's educational background include a BS in Industrial Engineering, an MBA, and MS and PhD degrees in Wood Science \& Forest Products. His research is focused on marketing and management of innovative wood products. 
Proceedings of the $\mathbf{2 0 2 0}$ Society of Wood Science and Technology International Convention

\section{Fang, Changhua}

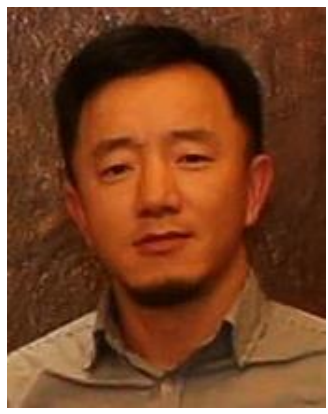

Expertise: Wood/Bamboo modification

Biography - Changhua Fang

Present: Professor at International Centre for Bamboo and Rattan, China

2007-2011: Postdoctoral Fellow at the Wood Research Center, Laval University, Quebec, Canada

2003-2007: Ph.D in Wood Science and Technology, University of Montpellier II, France 


\section{Ferrer, Maria Busquets}

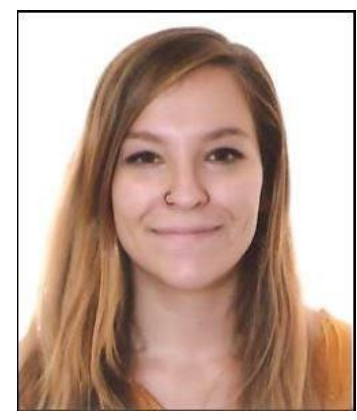

Expertise: Material science and engineering

Biography - Maria Busquets Ferrer

Maria Busquets Ferrer works as a Junior Researcher in the Team Smart Wood Natural Materials of Competence Centre for Wood Composites and Wood Chemistry in Austria, while finishing her doctoral studies in the University of Natural Resources and Life Sciences in Vienna. Previously, she completed her bachelor's and master's degree in Carlos III University of Madrid, in the topic of material science and engineering.

Her research is focus on porous materials made from natural resources. 


\section{França, Frederico José Nistal}

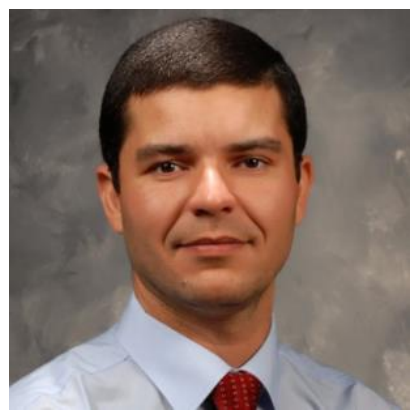

Expertise: Nondestructive tests, physics and mechanics of wood

\section{Biography - Frederico José Nistall França}

Frederico José Nistal França is an Assistant Research Professor at Mississippi State University, USA. Originally from Brazil, he holds a PhD degree in Sustainable Bioproducts from Mississippi State University (2017), a Master degree in Forest Science (2014) and a Wood Industry Engineering degree (2012) from the Federal University of Espírito Santo, Brazil. His areas of interest are: physical and mechanical properties of wood, nondestructive evaluation of wood (NDT). Currently, he is conducting the hardwood basic properties project in agreement with Stairways Manufacture Association and the USDA Forest Products Laboratory.

In 2016, Dr. França won the Graduate Student Research Award from College of Forest Resources and Wildlife Research Center. The research was predicting the modulus of elasticity (MOE) and modulus of rupture (MOR) of southern yellow pine based on NDT and visual grading. In 2015, Dr. França was chose to represent Mississippi State University at the Schweighofer Students Workshop in Vienna, Austria, where students in wood science field from had a change to be part of young researchers group to exchange ideas on technology and innovation in the wood industry. In 2013 and 2016 Fred did internships at the Forest Product Laboratory, Madison, WI USA, where he received a Certificate of Appreciation from USDA Forest Service (2013) for his research contribution to the USDA Forest Product Laboratory. 


\section{Fredriksson, Magnus}

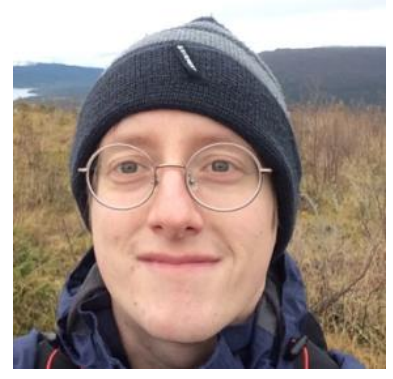

Expertise: CT-scanning, Process control, Sawing optimization, Sawing simulation, Sawmill technology, X-ray scanning

Biography - Magnus Fredriksson

Present employment:

2018- Senior project manager, RemaSawco AB (50\%).

2020- Senior lecturer, Luleå university of technology (LTU), Division of Wood Science and Engineering.

Previous academic employment:

2017-2020 Associate senior lecturer, Luleå university of technology, Division of Wood Science and Engineering.

2014-2016 Researcher, Luleå university of technology, Division of Wood Science and Engineering.

Additional information:

2018- Leave of absence $50 \%$ from LTU to work at RemaSawco AB.

2016 Visiting Postdoctoral Fellow at the University of British Columbia (UBC), Vancouver, British Columbia, Canada.

2010-2014 PhD student, Luleå university of technology, Division of Wood Science and Engineering.

2012-2014 Local representative in Skellefteå for the PhD student association, Luleå University of Technology. 2013 Five weeks as guest student at Forstliche Versuchs- und Forschungsanstalt Baden- Württemberg (FVA), Freiburg, Germany.

2009 MSc in Mechanical Engineering, Linköping University, Sweden. 
Proceedings of the 2020 Society of Wood Science and Technology International Convention

\section{Frias, Mariana}

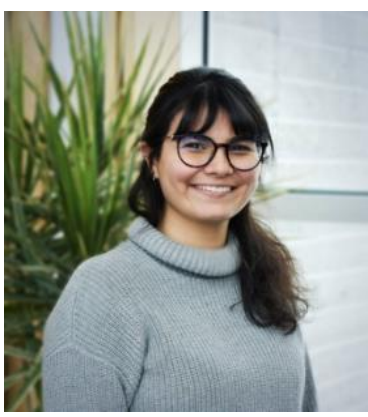

Expertise: Wood science, chemical and mechanical engineering

Biography - Mariana Frias

Mariana Frias is a M.Sc. candidate at Laval University in Canada, where she studies the parameters involved in the process of wood impregnation under the program of Wood Sciences. 
Fruehwald-Koenig, Katja

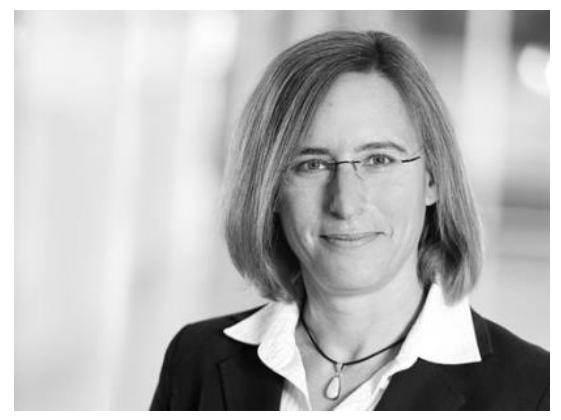

Expertise: Wood Technology; Products for Timber Engineering; Properties of Wood, Wood and Natural Fibre Based Products; Production of Wood Based Composites; Utilization of Hardwoods; Utilization of Oil Palm Lumber

\section{Biography - Katja Fruehwald-Koenig}

1999 Graduation (Diploma) in Wood Science and Technology at the University of Hamburg, Germany

1999-2002 Head of the research group wood technology at JOANNEUM RESEARCH Forschungsgesellschaft mbH, HOLZ.DESIGN.INSTITUT, Judenburg, Austria (applied R\&D, consultancy)

2002-2005 Graz University of Technology, Austria (2002-2003 Delegated as scientific officer to Umwelt- und Innovationszentrum Judenburg GmbH, Zeltweg, Austria, duties: technology transfer, consultancy in timber and timber engineering; 2003-2005 Senior researcher (teaching and R\&D) at the Institute for Timber Engineering and Wood Technology)

since 2005 Tenure Professor for Products and Production in Timber Engineering at Ostwestfalen-Lippe University of Applied Sciences and Arts, Lemgo, Germany, Department for Production Engineering and Wood Technology, Study Courses Wood Technology (Bachelor + Master Program in German), Production Engineering and Management (Master Program in English), Production Engineering and Management (Master Program in German) Head of the Laboratory for Timber Engineering: Products and Production Since 2014 several R\&D projects on properties and utilization of oil palm wood 
Proceedings of the 2020 Society of Wood Science and Technology International Convention

\section{$\mathbf{F u}, \mathbf{Y u}$}

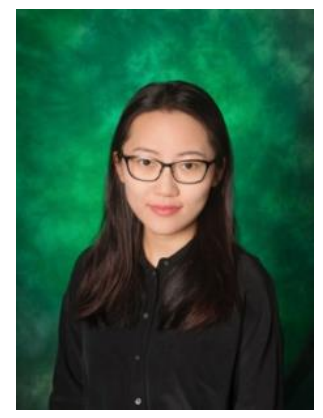

Expertise: Material Biodegradation

Biography - Yu Fu

$\mathrm{Yu}$ Fu is a Ph.D. candidate in the Department of Mechanical and Energy Engineering at the University of North Texas. Her research currently focuses on the biodegradation of natural fiber and plant-based adhesives. Yu received her bachelor's degree from the Northeast Forestry University in China where she majored in Wood Science and Engineering. 


\title{
Gallardo, Alberto Quintana
}

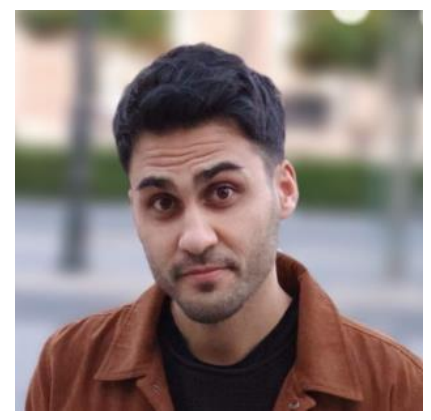

Expertise: Sustainable Building Construction, Life Cycle Assessment, Building Acoustics

\author{
Biography - Alberto Quintana Gallardo
}

Alberto was born in Valencia, Spain. He obtained a bachelor's degree in Technical Architecture in 2014. After that, he decided to study a master's degree in Acoustic Engineering. It was during that period when he started to be interested in research. As its master's final dissertation, he programed and performed a FDTD simulation of sound diffusers based on sonic crystals. After publishing and presenting those results in the Spanish National Congress on Acoustics (Tecniacústica), he was offered a position as a research assistant. The position implied working on the Life Cycle Assessment of sustainable building materials and to characterize their acoustic properties. Over the last four years he has been working on different materials such as, bio-epoxy composites, sheep wool, wooden-framed rice straw panels and clay concrete. He is currently working on a project to boost the valorization of the rice straw generated in Valencia and projects to boost the use of wood in the Spanish building sector. 


\section{Gardner, Douglas}

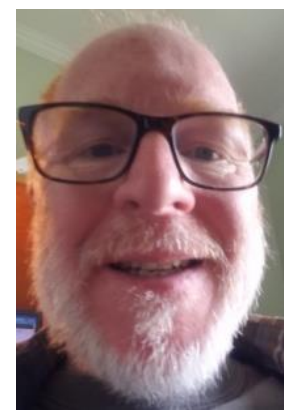

Expertise: Wood Science and Technology

Biography - Doug Gardner

Douglas J. Gardner is Professor and Program Leader of Forest Operations, Bioproducts \& Bioenergy in the School of Forest Resources at the University of Maine. He is also member of the Advanced Structures and Composites Center and Forest Bioproducts Research Institute. Gardner's research, teaching, and service activities focus on polymer and interfacial science aspects of wood-polymer composite materials. He is also involved in research in the areas of adhesion and surface science, cellulose nanocomposites, extruded wood plastic composites, and additive manufacturing. He has co-authored over 230 technical publications and 140 research presentations, and 5 patents. Gardner is a Fellow and Past-President of the Society of Wood Science and Technology (SWST). He is also a member of the American Chemical Society, Forest Products Society, and Society of Plastic Engineers. Doug serves on the editorial advisory board of Reviews of Adhesion and Adhesives. He has been recognized for his work by receiving the 1992 Cahn Award, and the 2004-2005, 2011-2012 and 2018-2019 G. Peirce and Florence Pitts Weber Outstanding Researcher in Forest Resources Award, the 2007 Director's Outstanding Faculty Award at the AEWC Center, University of Maine, 2008 Forest Products Society L. J. Markwardt Wood Engineering Award and the SWST 2010 2nd Place, 2012 3rd Place, 2013 Honorable Mention, and 2017 1st Place George Marra Award of Excellence. He was awarded the SWST Distinguished Service Award in 2014 and the SWST Distinguished Educator Award in 2018. He appeared in Strathmore's Who's Who 2007-2008. In December 2005 he was a visiting lecturer at Beijing Forestry University, and in June 2006 was a visiting lecturer at BOKU, Vienna, Austria and in March 2015 was a visiting lecturer at the Slovak Technical University in Zvolen, Slovakia. He was recognized as an Honorary Member of the Union of Wood Processing Manufacturers of the Slovak Republic in 2000.

Doug has a BS degree in Forestry (1980) and Certificate of Advanced Study in Pulp and Paper Management (1981) from the University of Maine, and a PhD degree from Mississippi State University (1985). 


\section{Gavric, Igor}

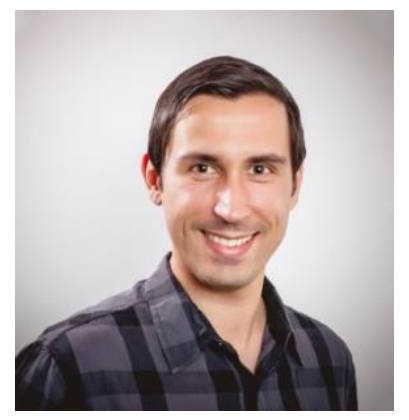

Expertise: Civil engineering, timber engineering, seismic engineering, structural engineering, cross-laminated timber, mass timber, timber connections

Biography - Igor Gavric

Dr. Igor Gavric is a researcher in the Sustainable Building with Renewable Materials research group at the InnoRenew $\mathrm{CoE}$ and an assistant at the Faculty of Mathematics, Natural Sciences and Information Technologies, University of Primorska. He graduated in Civil Engineering at the Faculty of Civil and Geodetic Engineering, University of Ljubljana in 2009. In 2013 he earned his PhD degree in Civil Engineering from the University of Trieste, Italy, in collaboration with the Trees and Timber Institute of Italian National Research Council (CNR IVALSA) in Trento. His PhD research focused on experimental testing and analytical modelling of seismic behaviour of cross-laminated timber (CLT) buildings. During his doctorate programme he was a visiting researcher at FPInnovations, Vancouver, Canada, and at the University of Canterbury, New Zealand and actively participated in COST action FP1004. After completing his PhD, he worked on postdoctoral research projects with University of Sassari, Italy and as a researcher at FPInnovations in Vancouver, Canada. He also has 5 years of experience in structural design practice, construction of timber buildings, and in R\&D national and EU projects that he gained at CBD d.o.o. and at the development center Intech-les. His main research interests are on advanced timber and hybrid structural systems, tall timber buildings, seismic behaviour and design methods of cross-laminated timber (CLT) buildings, and cyclic behaviour of timber building wall systems and connections. Dr. Gavric is a member of CEN/TC250/SC8/WG3 working group Eurocode 8: Earthquake resistance design of structures - Timber structures. 


\section{Gazo, Rado}

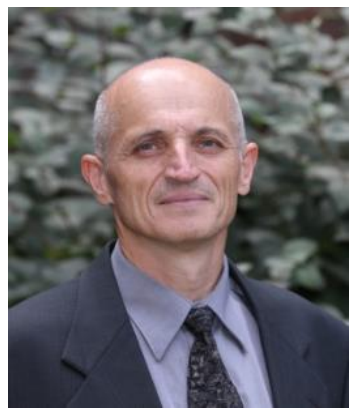

Expertise: Wood Products Processing

Biography - Rado Gazo

Rado Gazo, PhD is a professor of Forestry and Natural Resources in the Department of Forestry and Natural

Resources Wood Research Laboratory at Purdue University. He authored or co-authored 63 successful proposals for grants and contracts, totaling $\$ 6.5$ million (attributable to him), with over $\$ 5.5$ million of that related to evaluating tree, log and lumber quality using CT, laser and image scanning research and development. He has published 40 refereed research journal articles, 5 teaching articles, 6 book chapters, 50 refereed proceeding articles and 175 other publications. He has given more than 115 invited and 210 other presentations to research an industry groups. He also teaches several classes including Properties of Wood, Secondary Wood Products Manufacturing and Furniture Design for CNC.

Rado is an active member of his professional societies. He served for many years as a chair of the Ohio Valley Section and board of director of the Forest Products Society and the Society of Wood Science and Technology. He currently serves as a board director of Ohio Valey Lumber Drying Association.

Before attending graduate school, Rado worked in a sawmill and a furniture company. He received his M.S. in 1989 from the Technical University in Zvolen, Slovakia and his Ph.D. in 1994 from Mississippi State University. Before joining Purdue University, Rado worked as a researcher at the Louisiana Forest Products Laboratory and as a visiting scientist at the New Zealand Forest Research Institute.

Rado has worked with over 100 companies, often in consulting capacity. His research focuses on the application of industrial engineering and operation research techniques to problems in primary and secondary wood products manufacturing industries. In this field, he was the first to develop a flow simulation program that models processing of wood in a furniture company. Companies using his program were able to increase significantly their raw material utilization and process effectiveness. His continuing efforts in this area have brought him international recognition that includes invited papers, a paid visiting research scientist position in New Zealand and a grant from Canadian government/industry research institution, among others.

Since 2004, working closely with Indiana primary and secondary industry, Indiana Hardwood Lumbermen's Association and others, Dr. Gazo helped to formulate a strategy for research on advanced wood products manufacturing. This strategy has now been adopted by then newly created Indiana State Department of Agriculture and was actively supported by Purdue University's Center for Advanced Manufacturing. In the framework of these efforts, Dr. Gazo refocused a major portion of his research activities on the development of CT scanning of logs and lumber, and establishment of a Hardwood Scanning Center. He organized a consortium of Indiana hardwood lumber and veneer manufacturers and other state and national institutions to fund this new area of research. In 2012, this effort has successfully brought the industry first-ever commercially available industrial-grade CT scanner and 
Proceedings of the 2020 Society of Wood Science and Technology International Convention

related optimization software, and in 2018, the industry first-ever successful automated hardwood lumber grading system. 
Proceedings of the 2020 Society of Wood Science and Technology International Convention

\section{Georgiades, Maria}

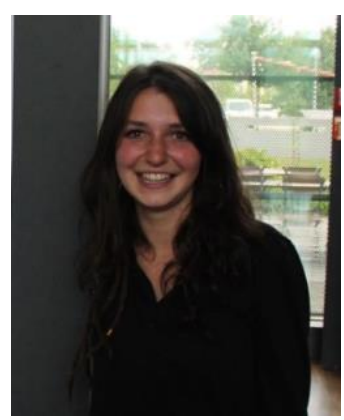

Expertise: Wood Technology and Management

Biography - Maria Georgiades

Maria Georgiades is a starting master student in Wood Technology and Management at the University of Natural Resources and Life Sciences in Vienna, where she did her Bachelor Degree in Wood and Fibre Technology. For her bachelor thesis she had a project on climbing holds made from epoxy and different bio-based materials. Then she started a part-time job at the Institute of Wood Technology and Renewable Materials in a research project dealing with wood dust. 


\section{Guebitz, Georg}

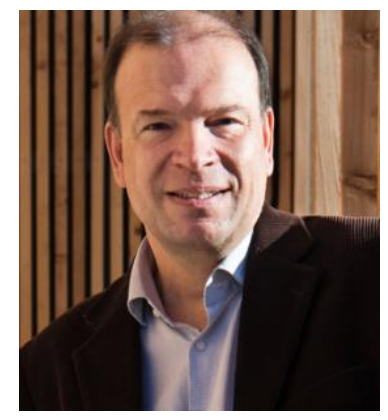

Expertise: Enzyme Technology

Biography - Georg Guebitz

Prof. Dr. Georg M. Guebitz obtained his PhD in Biotechnology from TU-Graz in 1996. As an Erwin-Schroedinger Fellow, he investigated enzymatic processes for lignocellulose processing at University of British Columbia, Canada from 1996 - 98. Since 2013, he holds a full professorship at University of Natural Resources and Life Sciences, Vienna and is the head of the Department of Agrobiotechnology and of the Institute of Environmental Biotechnology with focus on biotechnical functionalisation and processing of materials. He has participated in 30 European projects related to polymer processing and coordinated 9 out of which. In parallel, he cooperated with industry and research centres such as ACIB. Gübitz has published more than 350 scientific papers in peer reviewed journals, he holds 16 patents and has edited various books. 


\section{Gusenbauer, Claudia}

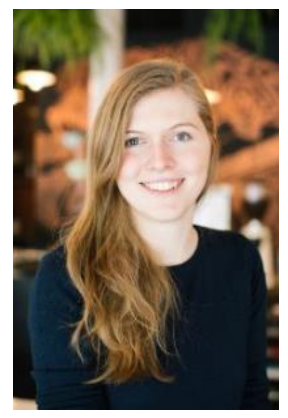

Expertise: Wood characterization, atomic force microscopy, chemical force microscopy, wood functionalization, wood cell wall science

\section{Biography - Claudia Gusenbauer}

Claudia Gusenbauer is currently working as a doctoral student at the Institute of Wood Technology and Renewable Materials, BOKU - University of Natural Resources and Life Sciences. In her thesis, she focusses on novel, high resolution characterization techniques. The core of her experimental work is Atomic Force Microscopy (AFM), a method which revealed astonishing insights into lignocellulosic materials. With the further development of this method together with complementary approaches such as Raman and Infrared Microscopy, she intends to support the optimization of wood modification procedures. From May to July 2019, she was working at Lehigh University, PA, USA, at the Department of Chemistry at a Scanning Probe Microscopy research lab, in which she learned functionalization procedures and optimized measurement set-ups.

During her master's program wood technology and management (BOKU), she studied for one semester at the Swedish University of Agricultural Sciences (SLU) in Uppsala, Sweden. In her master thesis, which was awarded with the Klaus-Fischer Innovation Award and BOKU Talent Award, she was developing new insulation materials. At the research institute Wood K plus and in the innovation team of Weitzer Parkett, an Austrian wood flooring producer, she gained work experience in the fields of wood adhesive systems, standards and regulations which are relevant in the field of wood science and technology. 
Proceedings of the 2020 Society of Wood Science and Technology International Convention

\section{Hadi, Yusuf Sudo}

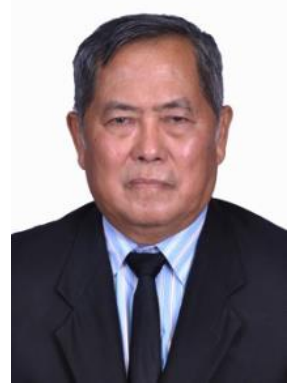

Expertise: Wood bio-composites; Wood modification;Wood preservation

Biography - Yusuf Sudo Hadi

Head of Biocomposites Division. 


\section{Hansmann, Christian}

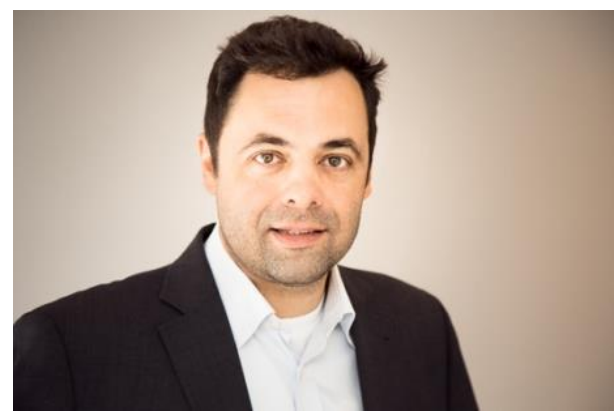

Expertise: Wood modification and functionalization, Natural building materials

Biography - Christian Hansmann

Christian Hansmann finished his PhD at BOKU and Wood K plus in 2004 on the topic of "Chemical modification of solid wood". After that he started working as a Senior Researcher at the competence center. Now he is Key Researcher, Teamleader of the team Smart Wood and Natural Materials and Area Manager of the area Wood Materials Technologies. His main research focus is besides fundamental research into wood modification on the development of functionalised all new biobased materials. 


\section{Haviarova, Eva}

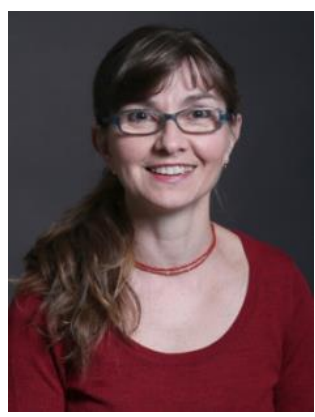

Expertise: Sustainable Wood Products Design

Biography - Eva Haviarova

Dr. Eva Haviarova is an associate professor of Wood Products Engineering and Strength Design in The Department of Forestry and Natural Resources, Purdue University. She is responsible for teaching of World Forest and Society, Global Sustainability Issues, and several Wood Products Development courses. She is conducting research in areas of Strength Design, Sustainable Product Development, Value Added for Hardwoods, Design and Development of Low-Cost Furniture for Underprivileged, Design of Light Timber Frames, Global Sustainability Issues, and advanced Wood ID. She has published over 50 peer-reviewed publications and delivered over 200 professional presentations. Through her outreach activities, she is working mainly with the forest products industry. She is active member of several professional associations and currently serves as the President of the Society of Wood Science and Technology. 
Proceedings of the $\mathbf{2 0 2 0}$ Society of Wood Science and Technology International Convention

\section{Heim, Lucie}

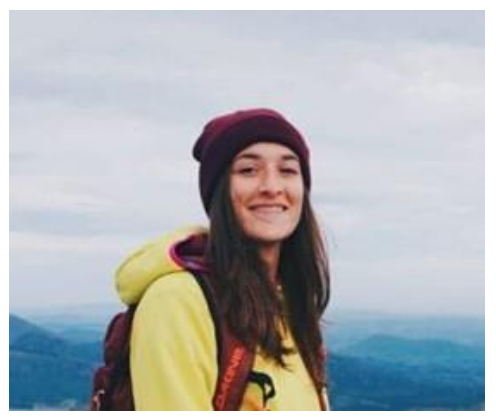

Expertise: Agroforestry, wood development

Biography - Lucie HEIM

I am a french PhD student. My thesis entitled "Understanding the mechanisms of xylogenesis and the physiology of poplars, black locust and walnut trees in agroforestry for a valorization in the wood sectors" just started in January, 2020. Three laboratories are involved : LaBoMaP (ENSAM), UMR PIAF (INRAE) and UR BioWooEb (Cirad). 


\section{Hellmayr, Raphaela}

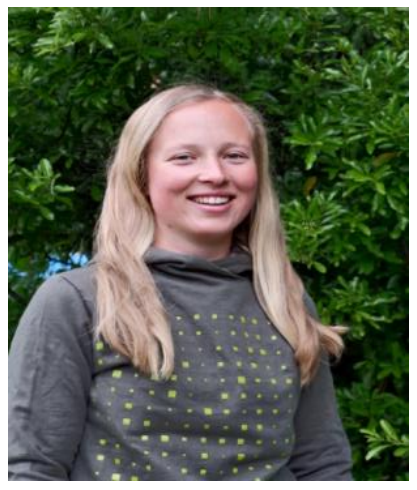

Expertise: Cradle to cradle in wood technology

Biography - Raphaela Hellmayr

Raphaela Hellmayr is a PhD student at the University of Natural Resources and Life Sciences in Vienna at the Institut of Wood Technology and Natural Materials. She holds a Masters Degree in Wood Technology and Management obtained at the University of Natural Resources and Life Sciences, Vienna. She obtained a Bachelors degree in Forest Products Technology \& Timber Construction at the Salzburg University of Applied Sciences (Campus Kuchl, Austria). During her studies she did extensive internships, such as at Stellenbosch University (South Africa), or at the Swiss Federal Institute of Technology in Zuerich. Her research is about novel bio-based adhesives and applications as well as on specific aspects in wood-processing. 


\section{Hellmeister, Marilia}

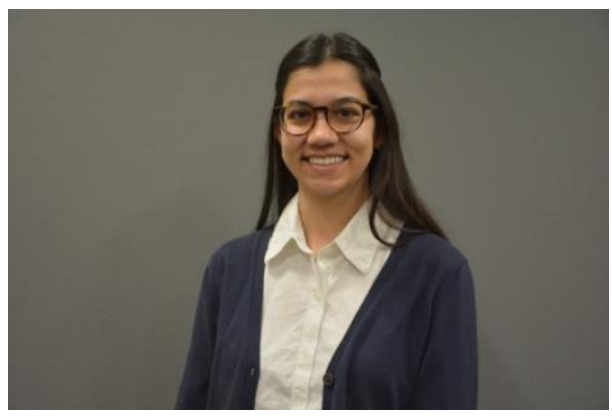

Expertise: Wood Science, Mass Timber, Sustainability, Life Cycle Assessment

Biography - Marilia Hellmeister

Master's student at the University of Maine - School of Forest Resources. Research interests in the area of Mass

Timber, Carbon emissions, Life Cycle Assessment and environmental impacts. Forest Engineer graduated from Sao Paulo State University, Brazil. Studied abroad at the University of Kentucky (2013-2014) and completed a summer internship at the Forest Products Laboratory (FPL-USDA) in the sector anatomy of wood. Experience in Wood Frame Structures, Forest Logistics and wood certification. 
Proceedings of the 2020 Society of Wood Science and Technology International Convention

\section{Hess, Dominik}

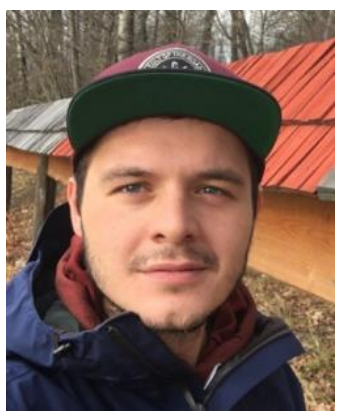

Expertise: Physical properties of wood, modification of wood

Biography - Dominik Hess

Dominik Hess is a Ph.D. student and young researcher from Mendel University in Brno, Faculty of Forestry and

Wood Technology, Department of Wood Science and Technology. He is mainly focused on wood modification and physical properties of wood. 


\section{Hogger, Elfriede}

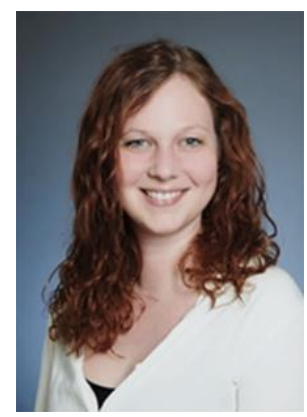

Expertise: Research on existing adhesive systems, Method development and analysis of adhesives

Biography - Elfriede Hogger

Elfriede Hogger is currently working as a Junior Researcher and PhD student at Wood K plus, Kompetenzzentrum Holz GmbH.

Education:

-2010-2013 Bachelor studies: Forest Products Technology and Timber Construction, FH Salzburg Kuchl

-2013-2015 Master studies: Forest Products Technology and Management, FH Salzburg Kuchl

- 2015-current PhD studies: Wood technology and renewable materials, University of Natural Resources and Applied Life Sciences, BOKU, Vienna

Focus:

- Research on existing adhesive systems

- Method development and analysis of adhesives 
Proceedings of the 2020 Society of Wood Science and Technology International Convention

\section{Hong, Seung Hyun}

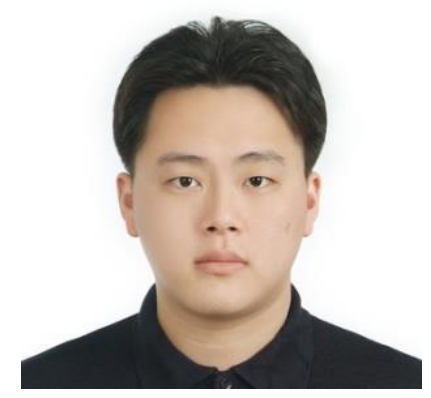

Expertise: Wood science and engineering, CLT, Fire test

Biography - Seung Hyun Claas

na 
Proceedings of the $\mathbf{2 0 2 0}$ Society of Wood Science and Technology International Convention

\section{Horváthová M, Michaela}

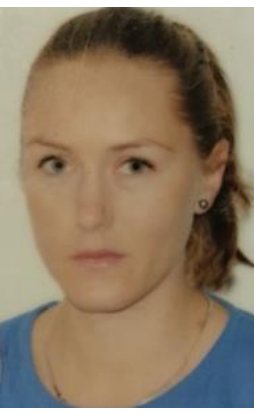

Expertise: Fire engeneering, testing materials on wood and bio based

Biography - Michaela Horvathova

none 
Proceedings of the 2020 Society of Wood Science and Technology International Convention

\section{Hyytiä, Annika}

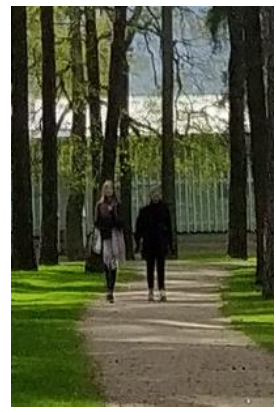

Expertise: Sustainable development internationally in forests and forest products

Biography - Annika Hyytiå

Annika Rantala (Hyytiä)

Student, Faculty of Biological and Environmental Sciences

Doctoral Student, Forest Economics and Marketing, "Sustainable development - International framework -

Overview and analysis in the context of forests and forest products", Department of Forest Sciences, University of Helsinki, Finland 


\section{Jahan, Md Sarwar}

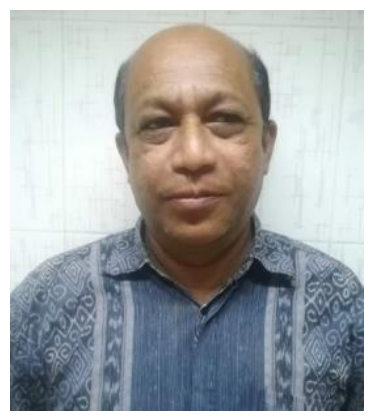

Expertise: Pulping, Biorefinery and Wood Chemistry

Biography - Md Sarwar Jahan

After completing M.Sc in Applied Chemistry, Dr. Jahan joined in BCSIR Labs in 1992 and started his carrier on pulp and paper. He received PhD degree, completed postdoctoral research on wood and pulping chemistry. Dr.

Jahan was a Visiting Scholar at the University of New Brunswick. So far I have published more than 160 research articles in different international journals. His main focus of research is to utilize lignocelluloses in producing pulp, chemicals and biomaterials. 


\section{Jakob, Matthias}

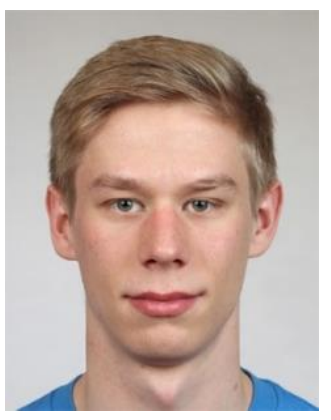

Expertise: Wood modification, Wood densification

Biography - Matthias Jakob

Matthias Jakob is currently working as a doctoral candidate at the Institute of Wood Technology and Renewable Materials, BOKU - University of Natural Resources and Life Sciences, Vienna.

After a school education in cooking, he is today more often cooking wood veneers than vegetables, to get the best out of wood. His research topic focusses on the modification of wood to enhance its mechanical and physical properties and to make it more competitive to metals and well-established polymer composites. The main idea of his work is to increase the wood's density by transversal compression to exploit the well-known density-strength relationship of wood. To avoid damages during densification, he reduces the cell wall rigidity by a partially delignification of wood.

Matthias Jakob holds a bachelor degree in "Environment and Bio-Resources Management" and a master degree in "Material and Energetic Exploitation of Renewable Raw Materials". During these highly interdisciplinary programs, he found his passion in wood and natural fibers sciences. True to the motto "Try to use wood in a material way, at the end you can still burn it.", he is today focusing more on the material- than on the energetic exploitation. 


\section{Jambrkovic, Branimir}

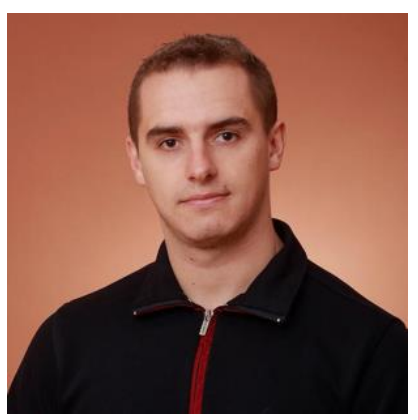

Expertise: Additive Manufacturing (Fused Deposition Modeling), Bio-based composites (Wood filaments), 4D printingRaman spectroscopy, Forest Products Technology, CNC Technology

\section{Biography - Branimir Jambreković}

Branimir Jambreković was born on December 10, 1991, in Bjelovar. He finished elementary school in Nova Rača and high school of mathematics in Bjelovar. In 2010, he enrolled at the Faculty of Forestry, University of Zagreb, where he graduated in 2015 and earned a master's degree in wood technology. He has been employed since May 16, 2016, at the Faculty of Forestry as an assistant at the Institute of Wood Science, where he enrolled in the postgraduate doctoral study the same year. On the Institute of Wood Science, he is entrusted with the implementation of exercises from the teaching courses Technical properties of wood 1, Technical properties of wood 2, Physical properties of wood, Mechanical properties of wood, Investigation of physical and mechanical properties of wood, Special products of wood, Technological properties of wood. 


\section{Jullien, Delphine}

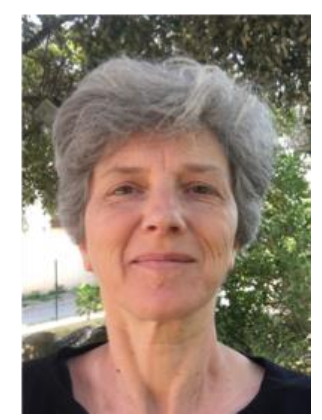

Expertise: Analysis of the hygromechanical behavior of wood for the conservation of painted panels from cultural heritage, Characterization of the physical properties of tropical wood used in clarinets, Tree biomechanics: growth stresses and wind effect, Material constituting the hives: interaction between wood and health of bee colonies

Biography - delphine jullien

PhD 1995 (University of Montpellier),

assistant-professor 1998- (University of Montpellier),

head of Wood team of LMGC (University of Montpellier) 2017-.

Research in wood mechanics, especially tree biomechanics: growth stresses assessment and modelling in trees, relation with tree morphology; application to conservation of wooden objects from cultural heritage: monitoring of in situ microclimate and deformations of painted panels, use of image correlation, hygroscopic behaviour of wood, mechanical simulation of restoration acts or artwork manipulations in close collaboration with restorers; and more recently interaction between the beehive material and the honey-bee colonies: influence of wood specie on bees health. 
Proceedings of the $\mathbf{2 0 2 0}$ Society of Wood Science and Technology International Convention

Justin, Atanasso Akpovi 


\section{Kain, Stefan}

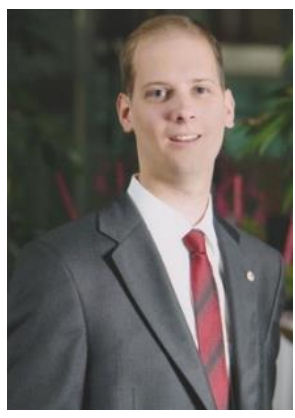

Expertise: Additive Manufacturing (Fused Deposition Modeling), Bio-based composites (Wood filaments), 4D printingRaman spectroscopy, Forest Products Technology, CNC Technology

Biography - Stefan Kain

DI Stefan Kain, BSc completed his master's degree in 2016 (degree program: wood technology and wood management) at the University of Applied Sciences Salzburg. In the same year he started working as a junior researcher at the University of Applied Sciences Salzburg (Campus Kuchl) and was entrusted with the research project "TFP Hybrid Materials", which was successfully completed in December 2019.

Since January 2020, he has been working as a junior researcher for the "SCSM - Salzburg Center for Smart Materials" project, in which he deals with the processing and characterization of biogenic materials for Fused Deposition Modeling (3D printing). In addition, Stefan Kain is working on his doctorate at the University of Salzburg (NAWI) under the supervision of Prof. Alexander Petutschnigg (University of Applied Sciences Salzburg) and Prof. Maurizio Musso (University of Salzburg). 


\section{Kamgoj, Gourav}

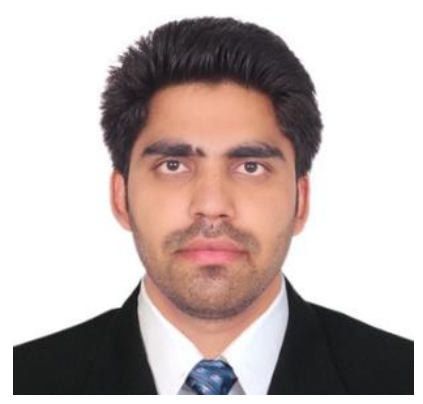

Expertise: Wood Science and Technology

Biography - Gourav Kamboj

Gourav Kamboj

- Education:

2009 - 2012 Graduate in Physics, Chemistry and Mathematics. Kurukshetra University Kurukshetra-India.

2012 - 2014 Masters in Wood Science and Technology. Forest research Institute (Dehradun)-India.

Since 2017 Doctoral degree program in Wood Processing and Technology in Czech University of Life SciencePrague

- Other knowledge -foreign languages, passing special courses, etc:

English. Hindi.

- Employment and work experience - including student stays:

2014 -2015 -quality inspector of furniture in C.L. Gupta Export Pvt. Ltd. India.

2015 - 2018 -quality executive in Fab India overseas Pvt. Ltd. 


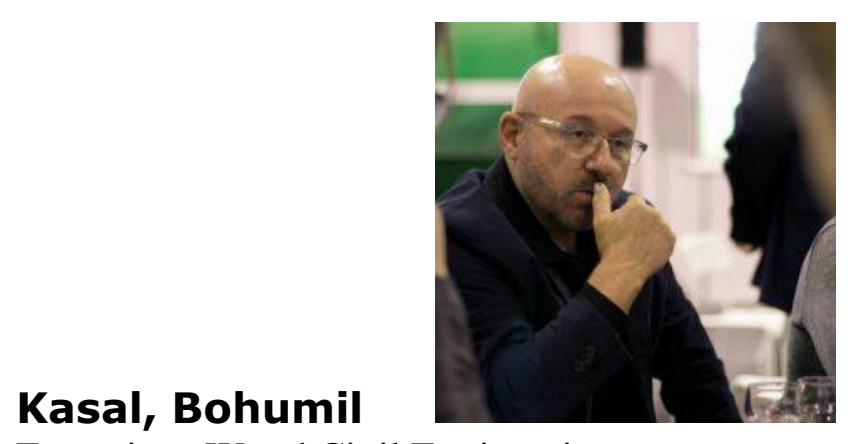

Expertise: Wood Civil Engineering

Dr. Bohumil Kasal graduated in 1980 from the Technical University Zvolen in Slovakia with the engineering degree (Ing.) in Wood Technology. Between 1980 and 1987 he worked at the State Wood Research Laboratory in Bratislava, Department of Physics as a Research Engineer. Between 1987 and 1989, Dr. Kasal worked at the area of wood composites at Virginia Polytechnic Institute and State University in Blacksburg, USA and received a MS degree in Sustainable Biomaterials. He then moved to Oregon State University (1989-1992) where he worked as a Research Associate and received a MS degree in Civil and Environmental Engineering (Structures) and PhD degree in Renewable Materials with minors in Applied Mathematics and Structural Engineering. In 1992 he worked at Alpine Engineered Products, Inc. in Pompano Beach, Florida as a Research and Development Engineer. Since 1992, Dr. Kasal was an Assistant Professor, Associate Professor and Professor at the North Carolina State University in Raleigh, NC at the Department of Wood and Paper Science. He also held a faculty position at the department of Civil and Environmental Engineering. At NC State, Dr. Kasal's work focused on engineering applications of wood, relations between genetic markers and wood properties, and methods for the in-situ evaluation of timber. Dr. Kasal's work in historic timber evaluation was presented by the US National Science Foundation in its budget request to the Congress of the United States in 2005 as one the examples of a successful international research. Dr. Kasal's research on light-frame wood structures under natural hazard loads was discussed in various media networks such as ABC, NBC or NBC International, and in 2001-2002, Dr. Kasal was a Senior Fulbright Scholar and Visiting Professor in Dresden, Germany. During that time, he led an EU research project on seismic performance of timber frames that was featured by the EU as an example of a successful team research.

In 2005, Dr. Kasal was named the Bernard and Henrietta Hankin Chair of Residential Building Construction at the Pennsylvania State University at University Park, PA - a prestigious endowed chair position. He was also appointed a Professor of Architectural Engineering and a Professor of Civil and Environmental Engineering, and directed the Pennsylvania Housing Research Center. At Penn State, Dr. Kasal conducted research on low-rise buildings subjected to wind loads and directed international research on timber structures under seismic loading and composite wood structures. He taught courses in wood mechanics, wood composites and the design of timber structures. Dr. Kasal held honorary appointments at the University of Bristol, UK and University of New Brunswick, Canada, adjunct Professorship at the North Carolina State University, USA and he is a Professor at the Czech Technical University in Prague, Czech Republic and Professor at the University of Primorska, Slovenia.

In 2010, Dr. Kasal was selected to be the Director of the Fraunhofer Institute for Wood Research, WilhelmKlauditz-Institute WKI. At the same time, he was appointed as a Professor of Organic and Wood-based Construction Materials at the Technical University of Braunschweig.

Kasal is a member of the American Academy of Mechanics, American Society of Experimental Mechanics, Society of Wood Science and Technology and a number of other professional societies and editorial boards and has authored over 200 publications. He is also accredited as a professional engineer in the area of diagnostics and building evaluation. In 2011 he was elected a Fellow of the International Academy of Wood Science and in 2017 a Member of the American Society of Civil Engineers. 


\section{Kibleur, Pierre}

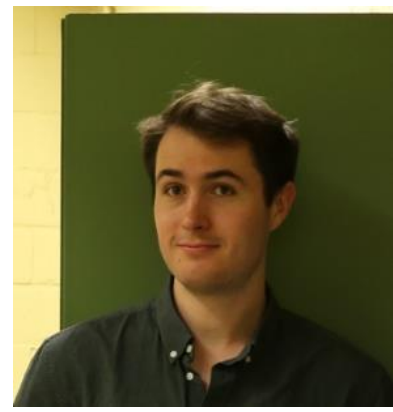

Expertise: Wood-based panels, X-ray micro-tomography, Image processing

Biography - Pierre Kibleur

Pierre Kibleur obtained his master's degree in Computational Science and Engineering from EPFL (Ecole Polytechnique Federale de Lausanne), in 2018. His current research at Ghent University revolves around the dynamic behavior of wood-based panels, particularly swelling due to water absorption. 


\section{Koc, Kucuk Huseyin}

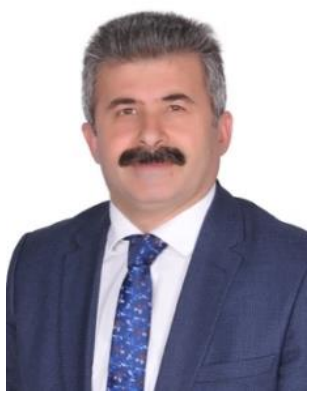

Expertise: Industrial management, furniture, quality improvement applications

\section{Biography - Kucuk Huseyin KOC}

He is a faculty member at Istanbul University-Cerrahpasa Faculty of Forestry, Department of Forest Industry

Engineering. His work focuses on forest industry, furniture, industrial management and quality. He has around 140 publications in the study area. 16 of these publications have been published in international refereed journals. 25 of the publications are papers presented at international scientific meetings and their full text is published. 75 of them are articles published in national refereed journals. 40 of the publications are in the form of papers presented at national scientific meetings and published in full text. He has also published two books, a common national patent that has been approved, and several ongoing and completed projects. 


\section{Kolajo, Tolulope}

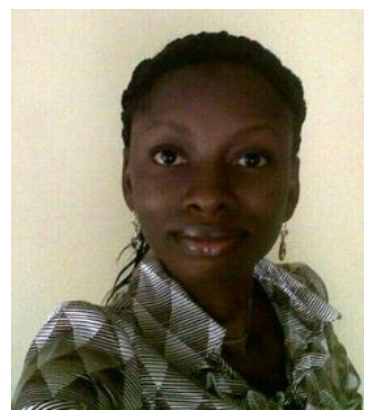

Expertise: Pulp and Paper technology, Biocomposites, Biomass processing

Biography - Tolulope Kolajo

\section{Bio-sketch on Tolulope Eunice KOLAJO}

I am a young faculty member who has just obtained a Ph.D. and given a teaching position at the Department of Wood Products Engineering, Faculty of technology, University of Ibadan, Nigeria. A thorough, meticulous and excellence driven person with special interest in teaching and research. My research has been focused on the indigenous plants in pulp and papermaking as well as conversion of agricultural and forest wastes to renewable energy resources.

Among other researches, I have designed and constructed a chemical reactor that operates on low temperature (published in International Journal of Engineering Research and Technology (IJERT). ISSN: 2278-0181.Vol. 5 Issue 01, January-2016. Pg. 217-219) for delignification of non-woody biomass into cellulose pulp laps for the paper industry and bio-refineries. The reactor was constructed using locally sourced materials and technology and can be easily operated, repaired and maintained, providing more earnings from maize production as well as job opportunities for the teeming unemployed youths. I have conducted a study to obtain the optimum chemical pretreatment schedule for the maize stalk biomass, produced and characterized bio-ethanol from maize stalks. I have presented some research findings on some indigenous plants that have been found suitable for papermaking as well as biosynthesis in some local conferences (35th and 39th Annual Conference of the Forestry Association of Nigeria, 3rd Biennial National Conference of the Forest and Forest Products Society). My research focus is the use of other agricultural wastes: coconut husks, banana and plantain stalks, cassava peels, sugarcane bagasse which are abundantly cultivated in Nigeria into renewable energy resources to maximize output from farming and forest operations, and domesticating the machines and processes.

An opportunity to attend the SWST 2020 Convention will provide the requisite exposure, learning new techniques in bio-energy conversion and storage, learning new information, finding solutions to problems. 


\section{Kovacevic, Marko}

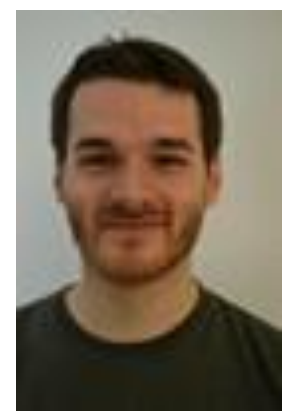

Expertise: VOC emission from wood and wood-based materials; process optimization regarding VOC-emission

\section{Biography - Marko Kovacevic}

Marko Kovačević is a junior researcher at Kompetenzzentrum Holz (Wood K Plus), a research institute in the area wood and wood-related resources located in Austria. Since 2018 Marko's main research topics have been VOCemission from wood and wood-based products, as well as VOC-emission reduction by modifying production process parameters. He is a PhD-Student at University of Renewable Materials and Life Sciences (BOKU) and is currently enrolled in a Micromasters program in Data Analytics at Georgia Institute of Technology (Georgia Tech). Marko graduated from University of Belgrade with a diploma degree in wood science and from University of Renewable Materials and Life Sciences (BOKU) with a master's degree in wood technology and management. 
Proceedings of the 2020 Society of Wood Science and Technology International Convention

\section{Krajnc, Luka}

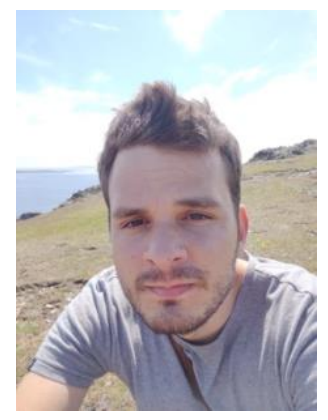

Expertise: Forestry, wood, mechanical properties, silviculture, non-destructive evaluation

Biography - Luka Krajne

Luka Krajnc, $\mathrm{PhD}$, is a forestry researcher studying what affects mechanical and physical properties of wood and how to manipulate them in the forest. He specialises in using non- and semi-destructive methods for assessing mechanical and physical properties of wood at various stages, from standing trees to wood products. 


\section{Krystofiak, Tomasz}

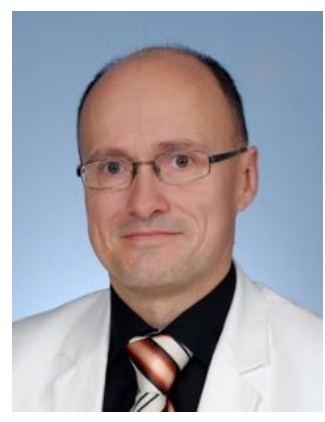

Expertise: Proecological adhesives and lacquer products, Glue-lines and lacquer coatings, Wood modification, Wettability and surface phenomena, Wood based materials

\section{Biography - Tomasz Krystofiak}

Tomasz Krystofiak - Dr habil. eng.; He works in the Department of Wood Based Materials, Laboratory of Gluing and Finishing of Surfaces on Poznan University of Life Sciences (Poland). In 2002 he finished PhD. work. He is interested in proecological adhesives and lacquer products, properties of the glue-lines and coatings, wettability and adhesion processes, activation and modification of the different surfaces. Member of Management Committee in the COST Action CA15216. 


\section{Kuzman, Manja Kitek}

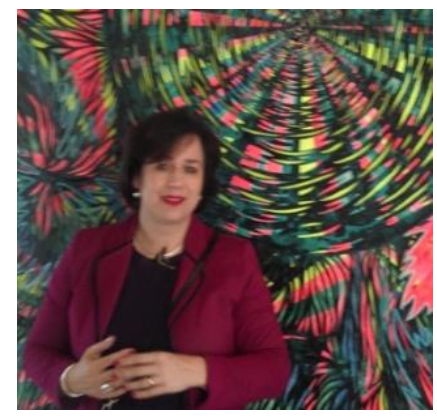

Expertise: Developing wood construction, innovative use of wood, sustainable wood products and product design, energy-efficient timber construction, building modernization with prefabricated components and architects' perception of engineer wood product, 3D-printing design and healthy living environment with wood

\section{Biography - Manja Kitek Kuzman}

Dr. Manja Kitek Kuzman is an associate professor of architecture at the Biotechnical Faculty, Department of Wood Science and Technology, University of Ljubljana. She is responsible for teaching of construction and design, innovations and sustainable wood architecture. Her research and teaching interests revolve around developing wood construction, innovative use of wood, sustainable wood products and product design. Her current research interests include comparison of wood constructions in US and Europe and architects' perception of engineer wood product, 3D-printing design and healthy living environment with wood. 


\section{Larasatie, Pipiet}

Expertise: competitive marketing and business management strategies of forest products industries, including business development of engineered wood products, public perceptions of wooden multi storey building (Tall Wood Buildings), digitalization in business, and gender diversity in the forest sector workforce and higher education

\section{Biography - Pipiet Larasatie \\ Interdisciplinary scholar and social scientist studying competitive marketing and business management strategies of forest products innovation, including business development of engineered wood products (Cross Laminated Timber/CLT), public perceptions of wooden multi-storey building (Tall Wood Buildings), and gender diversity in the forest sector workforce and higher education.}

For more information about her research, please visit www.competitive-forest.com 
Proceedings of the 2020 Society of Wood Science and Technology International Convention

Leban, Jean-Michel

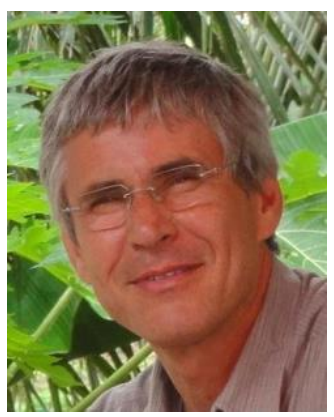

Expertise: Wood Science

Biography - Jean-Michel LEBAN

Jean-Michel Leban is Research Director, EFPA, INRA, Champenoux, France.

He is Editor in chieffor Annals of Forest Science

He was Professor, Director of the School of Wood Science (ENSTIB), Lorraine University

Research area, linking Growth and Yield and Wood Properties models, microdensitomtry 


\section{Lechowic, Daniel}

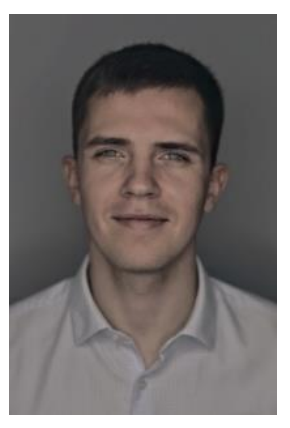

Expertise: Machining processes of wood and wood-based products and smart manufacturing solutions for the wood industry

Biography - Daniel Lechowicz

Daniel Lechowicz studied Wood Technology at Poznań University of Life Sciences and majored in Mechanical Wood Technology. He is a Junior Researcher in Competence Centre for Wood Composites and Wood Chemistry in Tulln, Austria. As a member of the Mechanical Disintegration Team, his current research interests include machining processes of wood and wood-based products and smart manufacturing solutions for the wood industry. 


\section{Leiter, Lena Maria}

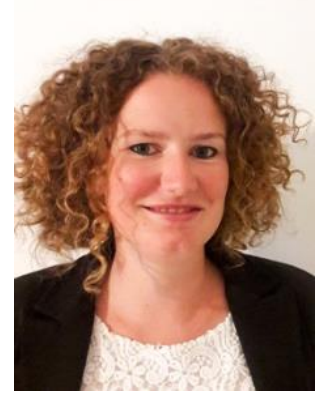

Expertise: Wood Technology and Management, Material and Energetic Exploitation of Renewable Raw Materials

\section{Biography - Lena Maria Leiter}

I am about to graduate in the two master degrees "Wood Technology and Management" and "Material and Energetic Exploitation of Renewable Raw Materials (NAWARO)" at the University of Natural Resources and Life Sciences, Vienna. Last year I did a 6 month student exchange via ERASMUS at the Ghent University (Belgium) as part of my studies.

I have a great passion for working with wood, especially as a renewable raw- and building material. During my school time at a high school with a focus on forestry I had the opportunity to work in several forestry companies, which extended my knowledge of the business aspects of working with the material. During my studies, I concentrated on the processing of wood and thus expanded my experience with wood as a material.

At my high school I practiced my communicative skills as a pupil representative and at the University I continued as an elected student representative for forestry and wood industry. It was not only my job to help students, but also to keep an active communication with the lecturers. Thus, I also became a member of the "academic study commission for the development and improvement of the related curricula (forestry, timber industry, natural dangers and wild life)".

Through this work I had the opportunity to participate in the "Student workshop at schweighofer Prize 2017". In 2019 I was part of a team that participated in the "Evergreen Innovation Camp Hackathon". 


\section{Li, Jing}

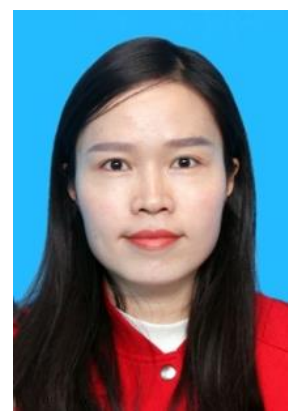

Expertise: Structure and mechanical characterization of biomass materials

Biography - jing li

Personal biography

Jing Li, Chinese citizen, Female, Born on August 15, 1985. Devoted to scientific research on the structure and function of biomass materials. Mainly engaged in the studies on the macroscopic and microscopic morphological structure characterization of wood/bamboo, mechanical properties testing and its environmental factors etc;

Introduced the artificial intelligence deep learning algorithms into the field of bamboo structure research, and solved the key technical problems of automatic detection, positioning, counting and measurement of related morphological parameters for different types of vascular bundles; Developed "Rapid Analysis of Section Structure of Functionally Graded Material " software.

\section{Education}

09/2019 - present Ph. D. Candidate in Wood Science and Technology. Chinese Academy of Forestry, China. 09/2017 - 06/2019 Master of Science in Wood Science and Technology. International Center for Bamboo and Rattan, China.

09/2003 - 06/2007 Bachelor of Management. Central South University of Forestry and Technology, China. 
Proceedings of the 2020 Society of Wood Science and Technology International Convention

\section{Li, Jingyu}

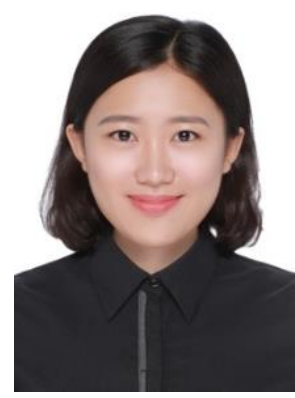

Expertise: Wood physics

Biography - Jingyu Li

Doctor candidate from Beijing Forestry University. Interested in wood-water study. 
Proceedings of the 2020 Society of Wood Science and Technology International Convention

\section{Li, Ling}

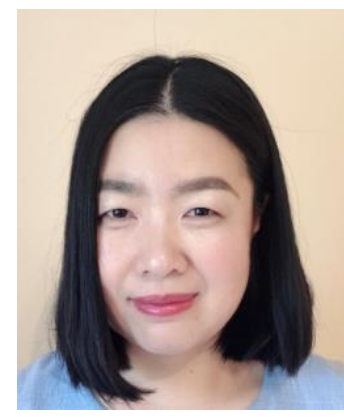

Expertise: Wood physics, wood pellets, biomass, bioenergy

Biography - Ling Li

Dr. Ling Li is an assistant professor of sustainable bioenergy systems at the School of Forest Resources of the University of Maine. 
Proceedings of the 2020 Society of Wood Science and Technology International Convention

\section{Li, Shujun}

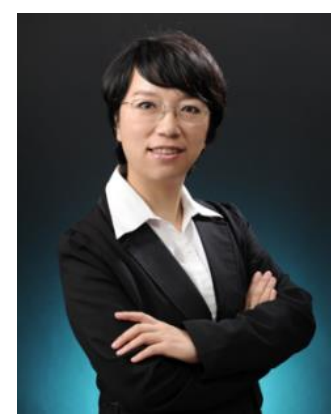

Expertise: Wood Protection, Wood Chemistry

Biography - Shujun Li

Shujun Li got her Ph.D. in 2001 at Northeast Forestry University, China, majored in Wood Science and Technology, Since September 1, 2007, she has worked for more than 12 years as a full professor at College of Material Science and Engineering, Northeast Forestry University. She visited Oregon State University twice, in the group of Prof. Jeff Morrell. 


\section{Liang, Daxin}

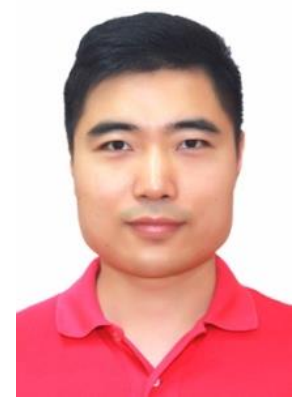

Expertise: Cellulose; biomass composites; water treatment; adsorption

Biography - Daxin Liang

Dr. Daxin Liang is an Associate Professor in College of Materials Science and Engineering, Northeast Forestry University. Dr. Daxin Liang has published numerous SCI indexed papers on the subject of thermoelectrics, biomass composites, and nanomaterials. He is a recognized expert in materials science, giving many invited papers at international meetings around the world. His work published in Nano Letters (Flexible Nanocrystal-Coated Glass Fibers for High-Performance Thermoelectric Energy Harvesting, Nano Letters, 2012, 12, 2140) attracted global interest, and was reported by over 10 international media such as Science Daily and C\&EN. 


\section{Lipovac, Dean}

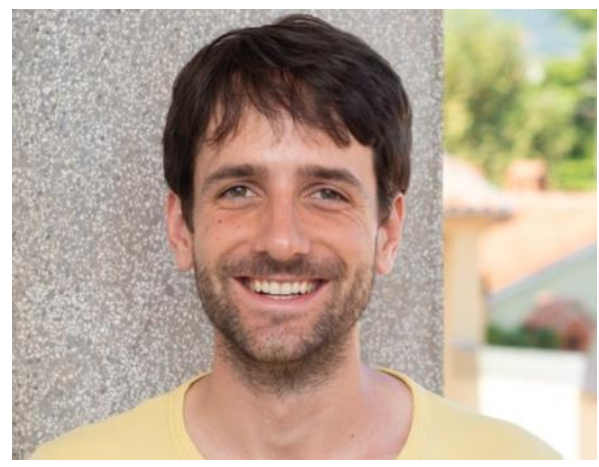

Expertise: Mental health in the built environment

Biography - Dean Lipovac

Dean Lipovac completed a master's degree in applied psychology at the Faculty of Mathematics, Natural Sciences and Information Technologies, University of Primorska (UP), in Koper, Slovenia and is currently a PhD student. He is an assistant researcher at the InnoRenew CoE and Andrej Marušič Institute (UP). His main research interest is the connection between the built environment and human mental health. His work is focused on researching how different materials used in indoor design influence physiological, emotional, and cognitive indicators of well-being. 


\section{Liu, Huanrong}

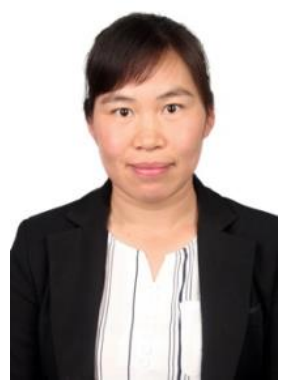

Expertise: Bamboo based engineering material, especially in the manufacture process, testing, utilities, and pruduct in structure and furniture

\section{Biography - Huanrong Liu}

Huanrong Liu, PhD. , Assistant researcher of International Center for bamboo and rattan. Her main research: Bamboo engineering composites.

Bamboo is rich in China, She mainly work on bamboo-based composite, including the reasonable and scientific designing, manufacturing, and performance-evaluating (static performance and impact and fatigue performance), in order to explore sufficient utilization of bamboo engineering composites in area of building, bridge, boat, and so on. 


\section{Liu, Wendi}

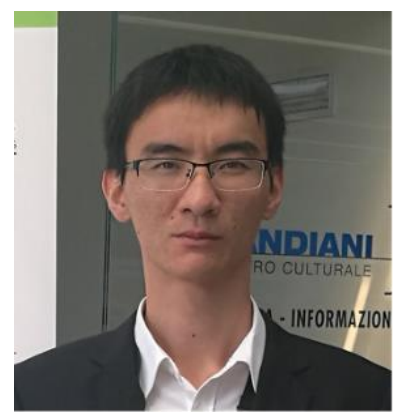

Expertise: Natural fibers-reinforced composites; Polymer composites

Biography - wendi liu

Dr. Wendi Liu is a researcher at College of Transportation and Civil Engineering, Fujian Agriculture and Forestry University (FAFU), China. He obtained two Ph.D. degrees in Forestry Engineering from FAFU in 2016 and Integrated Systems Science from Akita Prefectural University, Japan in 2019. He had a visiting experience in Civil Engineering at Brunel University, UK from January 2015 to November 2017.

Dr. Liu has more than 7 years experience in the research of natural fibers reinforced polymer composites. He has authored more than 20 papers in the leading wood science and composites science journals including Cellulose, Holzforschung, Wood Science and Technology, Composites Science and Technology, Composites Part A, ACS Sustainable Chemistry and Engineering, etc. His research interests include surface modification of natural fibers, development of biobased thermosets from vegetable oils, as well as strengthening and toughening of poly(lactic acid)-based blends and composites. 


\section{Liu, Yamei}

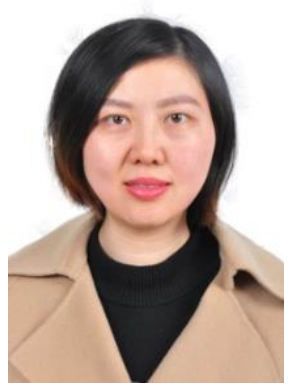

Expertise: Wood anatomy, Biomass materials

\section{Biography - Yamei Liu}

I come from School of Forestry\&Landscape Architecture, Anhui Agricultural University, I teach undergraduates in it, and I also do research on wood science and technology. My research fields are the qualities and uses of wood, and biomass composite materials. I graduated with a $\mathrm{PhD}$ in 2010 and been a teacher up to now. I also worked as a student counselor from 2015 to 2019. I have presided and participated in more than 10 scientific research projects, such as National natural science foundation of China, The National Key Research and Development Plan of China, and so on. Since 2007, I have had about ten papers published in different journals, including Ann. For. Sci.

Nowadays, I have finished two main projects, one is focus on the formation of reaction wood, the other is on the wood quality properties in fast-growing plantations. 


\section{Liu, Yuansong}

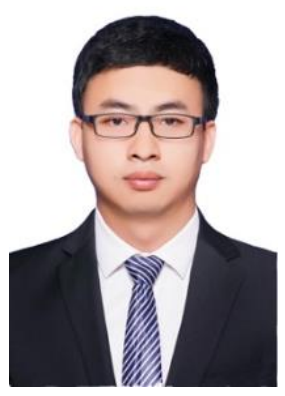

Expertise: Wood science and technology

Biography - Yuansong Liu

Liu yuansong, male, born in ganzhou city, jiangxi province, China,1993-12-08, is currently studying in the school of materials science and technology, Beijing forestry university. The bachelor's degree was completed in Inner Mongolia agricultural university, and master's degree was completed in nanjing forestry university. The research interests include wood composites and biological modification of wood, and he has published relevant papers in related journals, such as Composite structures, Dyes and pigments, European Journal of Wood and Wood Products. 


\section{Llana, Daniel}

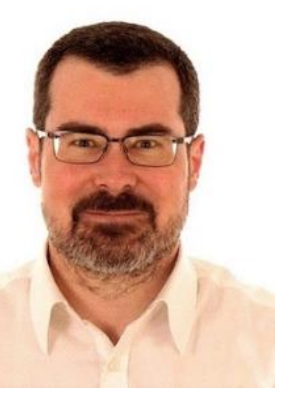

Expertise: Non-destructive testing for grading new timber and evaluation of existing structures, Reuse and recycling of recovered wood, Standardization

Biography - Daniel F. Llana

Dr. Daniel F. Llana

2007. Bachelor of Engineering (Agronomy) by Universidad de León, Spain.

2010. M.Sc.Eng. (Rural Construction) by Universidad Politécnica de Madrid, Spain.

2016. Ph.D. by Universidad Politécnica de Madrid, Spain. Topic: Non-destructive techniques applied to structural grading of timber in new and rehabilitation works.

2016-2017. Post-doc at the Universidad Politécnica de Madrid, Spain. Topic: Assessment of existing timber structures by NDT techniques.

2017-2020. Post-doc in the Timber Engineering Research Group of the National University of Ireland Galway, Ireland. Main topics: Engineered Wood Products, Recycling of timber from demolition and Hardwood forest.

2020-present. Post-doc in the Timber Construction Research Group of the Universidad Politécnica de Madrid,

Spain. Topic: Reuse and recycle of timber from demolition in structural products and design for the deconstruction in the future (InFutUReWood European project).

Main research areas:

Non-destructive testing applied to the grading of structural timber

Assessment of existing timber structures

Reuse and recycle of timber from demolition in mass timber products

Standardization 
Proceedings of the $\mathbf{2 0 2 0}$ Society of Wood Science and Technology International Convention

\section{Loh, Yueh Feng}

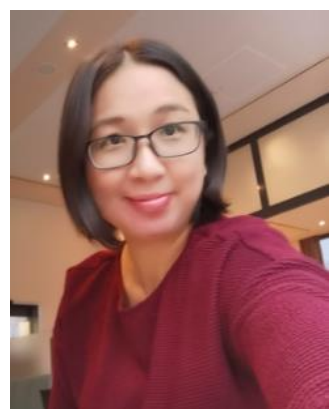

Expertise: Wood Science and Technology, Oil palm trunk plywood, Biocomposite

Biography - Yueh Feng Loh

$\mathrm{n} / \mathrm{a}$ 
Proceedings of the 2020 Society of Wood Science and Technology International Convention

\section{Ma, Xinxin}

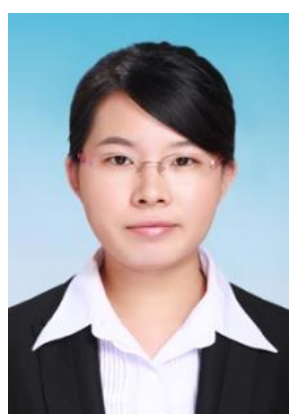

Expertise: Wood and bamboo science and technology

Biography - Xinxin Ma

Xinxin Ma obtained Ph.D at China Academy of Forestry and served as an associate professor at International center for bamboo and rattan. She engaged in mechanical property of bamboo materials, including creep and fatigue property of bamboo scrimber and other bamboo-based materials. 


\section{Mandal, Sujata}

Expertise: Development of sustainable Nanocomposites for pollution control, energy harvesting/conversion/storage, and biomedical applications; Use of sustainable and low-cost methods for water purification and wastewater management; Optimization of energy efficiency in the area of water purification, wastewater management, and sustainable building

\section{Biography - Sujata Mandal}

Sujata Mandal is a doctoral candidate and a teaching fellow in the Mechanical and Energy Engineering department at the University of North Texas. Sujata earned dual master's degrees in Physics (from Kumaun University in India) and in Sustainable Energy Systems from State University of New York at Cortland. Sujata graduated from her masters in sustainable energy systems with a strong GPA of 3.6, and she maintains an outstanding GPA of 3.96 in the program. Prior to joining the University of North Texas, she served as full time visiting faculty of physics in SUNY Onondaga and an adjunct in the department of chemistry at SUNY Cortland. She received the second prize in the 3MT thesis competition and received a graduate student research award from the University of North Texas. Also, while in India, Sujata served as Head of High School Activities between 2011 and 2014 for the Sehwag International School and served as Department Chair for Science and Mathematics for the Vidya Sanskar International School and Ashok Hall, India 2006-2010. She was also appointed as Management Representative for ISO 9001 -Quality Management Policy and ISO -14401-Environment Management Policy. Sujata attended the International Water Conference at the University of Oklahoma (US) and presented her research work in Sep 2019. 


\section{Marrot, Laetitia}

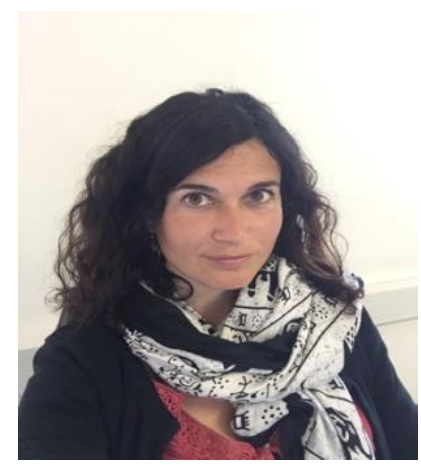

Expertise: Composites, textile, lignocellulosic materials, bio-carbon

Biography - Laetitia Marrot

Dr. Laetitia Marrot is a researcher in the Renewable Materials Composites Group at the InnoRenew CoE. She earned her PhD in Materials Science in 2014 from the University of South Brittany, France and then worked as a postdoctoral researcher at the University of Grenoble Alpes, France in the Laboratory of Pulp and Paper Science.

Her research has focused on sustainable composites reinforced by natural fibers, mechanical and physico-chemical properties of natural fibers, adhesion between natural fibers and polymer matrices at several scales of observation, and optimization of mechanical properties of complex cellulosic products.

At the InnoRenew CoE, she is working on the development of new applications for hemp and wood by products in the Slovenian industry. 


\section{Mascia, Nilson}

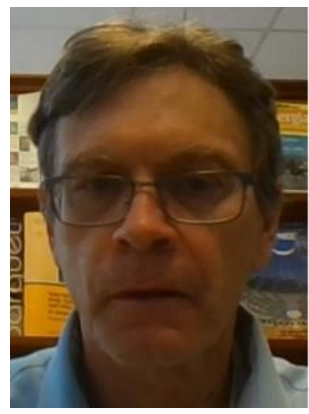

Expertise: Wood mechanics, Wood structures, Strength of materials

Biography - Nilson Mascia

- Post Doctorates

CNR (Consiglio Nazionale delle Ricerche)

- Ivalsa (Istituto per Valorizzazione del Legno e delle Specie Arboree)

- Florence-Italy,2015-2016

Forest Products Laboratory-Madison-Wi-USA ,2015

State University of Wisconsin-Madison, USA, 1998

- Full Professor State University of Campinas, 2011

- Associate Professor in Strength of Materials

State University of Campinas, 1997

- Doctoral Degree in Structural Engineering

State University of São Paulo, 1991

- Master Degree in Structural Engineering

State University of São Paulo, 1985

- Civil Engineer

State University of São Paulo, 1981 


\section{Mensah, Prosper}

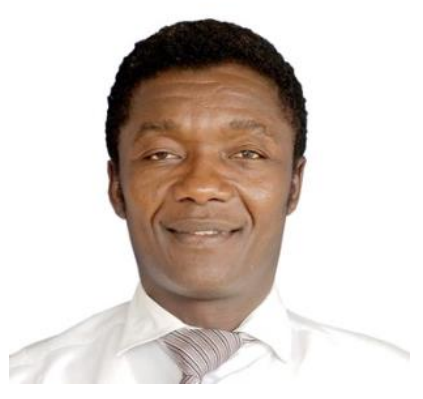

Expertise: Determine durability, mechanical and physical properties of wood-based and nonwood-based composite; non-timber forest products (NTFP); industrial utilization of biomass; sawmilling of wood species, furniture manufacture and testing and utilization of small diameter trees; Teaching and Training; Facilities management, remodeling of buildings, fixing and maintenance

\section{Biography - Prosper Mensah}

Prosper Mensah is a Principal Technologist in the Wood Industry and Utilization Division of CSIR- Forestry Research Institute of Ghana. The Institute is mandated among others to 1. Conduct high quality user-focused forestry research that generates scientific knowledge and appropriate technologies. 2. Disseminate forestry related information for the improvement of the social, economic and environmental well-being of the Ghanaian people. 3. To enhance the sustainable development, conservation and efficient utilisation of Ghana's forest resources. 4. To foster stronger linkages through collaborative research across disciplines among its scientists, stakeholders and external Institutions.

My filed of interests are to determination of durability, mechanical and physical strength properties of wood, woodbased and non-wood-based composite products for efficient utilization. Conduct research into non-timber forest products (NTFP) such as Theobroma cacao stem and Bambusa as alternative to wood to reduce the overexploitation of timber in Ghana. Research into the industrial utilization of available biomass (Musa paradisiaca pseudostem, Theobroma cacao pod, sawdust and other Agro forest residues) for the production of particleboards to build ecological and green houses and also for affordable furniture and housing in Ghana, sawmilling of wood species, furniture manufacture and testing, teaching and training and facilities management, remodeling of buildings, fix and maintenance

My Professional Background

2017 - 2020: PhD, Wood Science and Technology, University of Education, Winneba-Kumasi Campus 2006 - 2009: M.Phil. Wood Science and Technology, University of Education, Winneba-Kumasi Campus 2003-2007: B. Ed Technology Education (First Class). University of Education, Kumasi Campus. 1996-2000: Professional Teacher Certificate 'A', Post-Secondary (with 2 distinctions) College of Education, Komenda

Research Project

1. Characterization of particleboards manufactured from four agro-forest residues - comparative between cassava starch and urea formaldehyde.

2. Anatomical and Chemical mix influencing the characterization and utilization of Theobroma cacao stem wood 
Proceedings of the 2020 Society of Wood Science and Technology International Convention

3. Effect of moisture content and preservatives on discoloration of oil palm lumber.

I am current a part-time lecturer in the department of construction and wood in the University of Education Winneba-Kumasi campus and also Lectures on the same University IDeL program at Ejisuman in Kumasi. I have successfully supervise sixteen undergraduate student.

Prosper Mensah is active member in International Society of Wood Science and Technology - Wisconsin (2019 to date), Ghana Science Association (2019 to date) and CSIR-FORIG Research Staff Association (2019 to date). 


\section{Mitchual, Stephen}

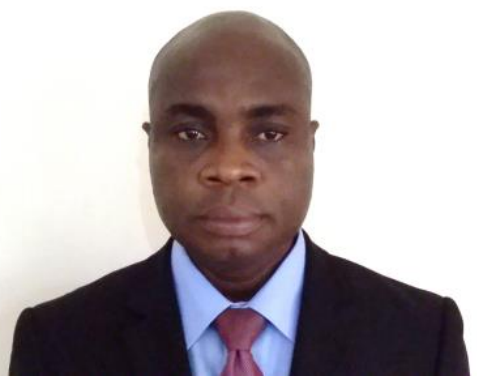

Expertise: Wood Biomass Energy and Wood Composite Materials

\section{Biography - Stephen Mitchual}

Stephen Jobson Mitchual is an Associate Professor in Wood Science and Technology at the University of Education, Winneba, Ghana. He holds MSc and PhD degrees in Wood Science and Technology from the Kwame Nkrumah University of Science and Technology in Ghana. Currently, he is the Dean of the Faculty of Technical Education. He teaches courses in Wood Science and Technology and other related disciplines at both undergraduate and postgraduate levels. Over the years, he has extensively conducted research in the area of wood biomass-energy, wood composite, sawmilling and sawmill safety and has published several scientific research articles in reputable international journals. He co-authored the following scientific research papers: Physico-chemical characteristics and market potential of sawdust charcoal briquettes; Effect of species, particle size and compacting pressure on relaxed density and compressive strength of fuel briquettes; and Briquettes from combination of maize cobs and Ceiba pentandra at room temperature and low compacting pressure without a binder which have been cited widely in reputable international journals. Additionally, he has attended and presented his research works at various international conferences. He is a member of the Society of Wood Science and Technology in the United State of America. 


\section{Muilu-Mäkelä, Riina}

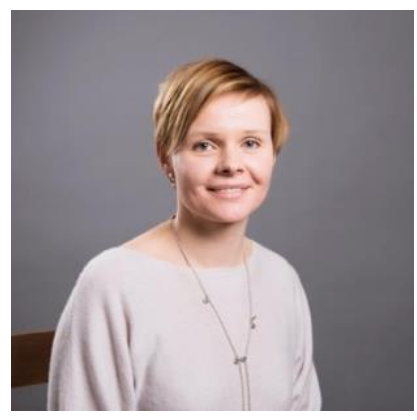

Expertise: Plant molecular biology, Wood science

\section{Biography - Riina Muilu-Mäkelä}

Riina Muilu-Mäkelä has over 15 years of experience in plant and wood science. Originally, she is a molecular biologist and graduated as a doctor from the University of Oulu in 2015. In her PhD work she investigated abiotic stress responses of Scots pine seedlings on transcription and metabolite levels and more specifically focused on polyamine metabolism. She has been involved in several international research projects and worked formerly in University of Oulu and in Finnish Forest Institute. She got the permanent position in Natural Resources Institue Finland at the beginning of 2017 and since then she has been a leader of two multidisciplinary projects where the health and well-being effects of wood materials have been investigated. Riina has been talking about the health effective properties of wood in different events and has given some interviews to magazines about this popular subject. Her first state of the art study was written in 2014 about the health benefits of wood in indoor use. 


\section{Musah, Munkaila}

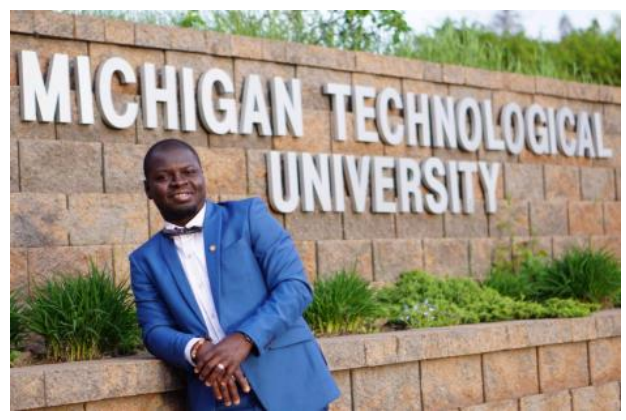

Expertise: Forest biomaterials; Wood properties, quality and modifications; Mass timber (cross laminated timber)

\section{Biography - Munkaila Musah}

Munkaila Musah is a PhD Candidate at the College of forest Resource and Environmental Science, Michigan Technological University with research focus on the bonding properties, engineering performance and life cycle analysis of cross laminated mix species from the Great Lakes region. The primary goal of His research highlights the bonding performance of wood adhesive composite for load bearing capacities aimed at sustainable wood utilization efficiency, marketing and application of wood in the construction industry. 


\section{Muszynski, Lech}

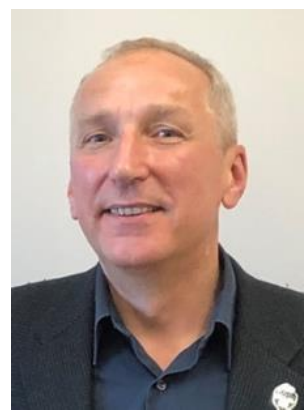

Expertise: Wood-based composites, cross-laminated timber (CLT), mass-timber panel (MTP) manufacturing; properties

\footnotetext{
Biography - Lech Muszynski

Dr. Lech Muszyński is a Professor in the Department of Wood Science and Engineering at the Oregon State University. A native of Poland, he received his M.S. in Wood Technology and Ph.D. in Forestry and Wood Technology from the Agricultural University of Poznań (now the University of Life Sciences in Poznań). In 19982004 he worked in the Advanced Engineered Wood Composites Center at the University of Maine. His research area includes mechanical performance of solid wood, advanced wood-based composites, with stress on interface performance, bonding, durability, fire resistance, damage assessment, and hygro-mechanical behavior. Since 2010 one of the focus areas of his research has been the cross laminated timber (CLT) technology. Dr. Muszyński has toured CLT manufacturing plants, construction sites, CLT-focused research centers, and CLT-related businesses across the globe.
} 
Proceedings of the 2020 Society of Wood Science and Technology International Convention

Myronycheva, Olena

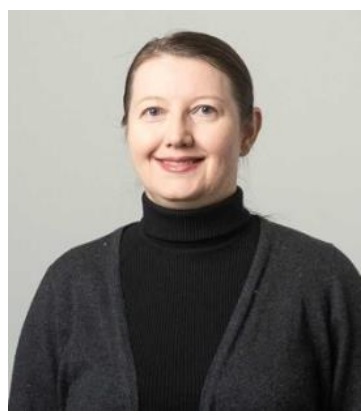

Expertise: Biodegradation

Biography - Olena Myronycheva

PhD student Wood Science and Engineering 


\section{Nakamurakare, Esteban Ceriani}

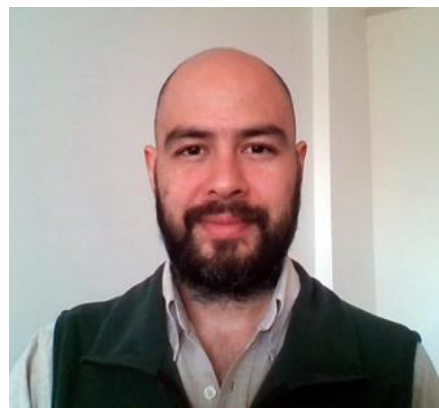

Expertise: Entomology, Mycology, Forest Pest Management, Ambrosia Beetles, Pheromones

Biography - Esteban Ceriani Nakamurakare

My research interests focus on studying the interactions between tree-pathogens and host plant, i.e. tree-pathogens being fungus/insects or combination of both. As an undergraduate student I followed the specialization in entomology, this formation aided me as a $\mathrm{PhD}$ candidate providing both conceptual knowledge and laboratory skills at the time of studying a multitrophic interaction between beetle-plant-fungi $(\mathrm{PhD}$ thesis on the most important forest pest of Populus in Argentina, being an "ambrosia interaction"). During my academic career, I also learned and applied multiple microbial methodologies of isolation, culturing and fungal identifications techniques. Additionally, I gained invaluable field experience as I was responsible for more than ten collection-trips amongst different commercial plantations of Populus spp. in Argentina. Nowadays, as a CONICET-Researcher (early stage) I have solid skills in bioinformatics, computed tomography analyses and molecular biology. 
Proceedings of the 2020 Society of Wood Science and Technology International Convention

\section{Negro, Francesco}

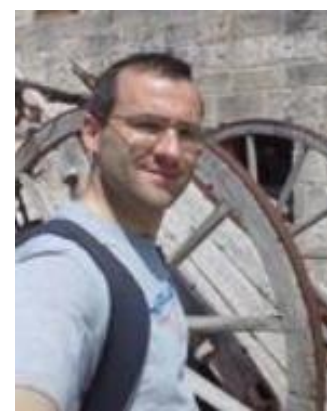

Expertise: Wood technology; development of innovative wood-based products; grading of structural timber; sustainability of wood-based products

Biography - Francesco Negro

Francesco Negro is Research fellow in Wood Technology at DISAFA, University of Torino, Italy. He mainly deals with the development of innovative wood-based products, Regulations in the wood sector and sustainability of wood and derived products. 


\section{Németh, Gábor}

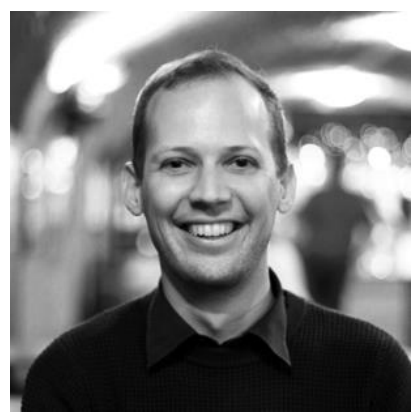

Expertise: Finite Element Analysis and the study of the dynamic behaviour of wood material

Biography - Gábor Németh

Gábor Németh is a full-time simulation engineer at Magna International Inc. and a PhD candidate at the University of Sopron, Hungary, under the supervision of Dr. Endre Magoss and Dr. Sándor Borza.

Given his background in automotive engineering, his main area of research is the dynamic behaviour of wood material, more precisely the damping effect of different species under free or forced vibration. Since this topic is considered a fairly neglected subtopic of wood physics, he chose it as a convenient topic for his PhD research as well. Given the fact that he works with numerical calculations on a daily basis, his research often incorporates FEM simulations in order to validate his physical measurements and to help with the interpretation of the obtained data. 


\section{Neyses, Benedikt}

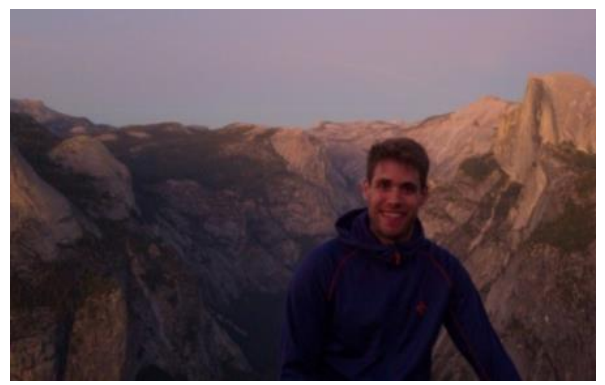

Expertise: Wood modification, Wood densification-(Ionic liquids)

Biography - Benedilkt Neyses

- $\quad$ Born and raised in Germany.

- B.Eng. in Mechanical Engineering at FH Aachen University, Germany.

- $\quad$ Moved to Skellefteå, Sweden in 2013.

- $\quad$ M.Sc. in Wood Technology at Luleå University of Technology.

- $\quad$ PhD at Luleå University of Technology, Graduation in October 2019.

- Currently Assistant professor in the Wood Science and Engineering Division at Luleå University of Technology.

- Climbing and being in nature are my main hobbies. 


\section{Niemelä, Aarne}

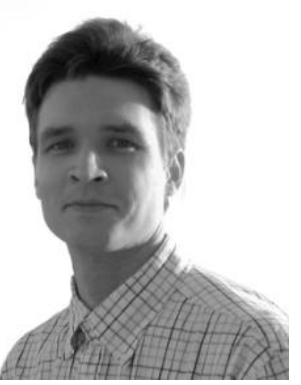

Expertise: Mass Timber and Sustainable Architecture

Biography - Aarne Niemelä

Aarne is architect MSc and assistant researcher at the InnoRenew CoE. He obtained a master's degree in architecture and urban planning at Aalto University, after studies at its predecessor, Helsinki University of Technology, and Technische Universität Berlin. At InnoRenew, his main activity during the last two years has been the architectural design of the new Research center, which is currently under construction at Izola, Slovenia.

He was born in Turku, Finland and has over 15 years of experience on architectural planning in the fields of residential, educational, cultural and commercial buildings as well as broader urban development concepts. Together with Eva Prelovsek Niemelä and various colleagues, he has been awarded in several architectural competitions (e.g. Europan). Defining the borders between private, semi-private and public spaces is one of his key points of interest in architecture, along with the shifts between small and large scales. Currently, he is involved with the opportunities of renewable materials and their potential to bring benign influence on the whole of built environment and its users. 


\section{Niemelä, Eva Prelovsek}

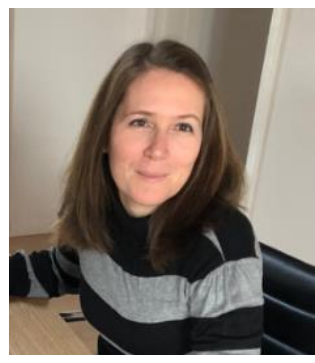

Expertise: Mass Timber and Sustainable Architecture

\section{Biography - Eva Prelovšek Niemelå}

Eva Prelovšek Niemelä is a researcher at the InnoRenew CoE, an architect and authorized designer architect for buildings in Slovenia. Her main research interest is in using timber in architecture and interior design. Her current work is based on the implementation of Slovenia's biggest wooden building - InnoRenew CoE institute's building, its monitoring during construction and after completion to predict ageing of wood in correlation to weather conditions, micro-climatic circumstances and design of details.

She finished her education in the field of architecture at the Technical University in Vienna and at the Academy of Fine arts in Vienna in 2002. In 2006 she finished her master studies at the Faculty of Architecture, University of Ljubljana. Since 2005 she has been working in her architectural studio Atelje Prelovšek. She set up many expositions in the National Gallery in Ljubljana and in other galleries in Slovenia and abroad. She conducted many new buildings and renewals.

Between the years 2008 and 2017 she also regularly wrote articles in architectural magazines and, as a curator and moderator, co-organized the Month of Design (Mesec oblikovanja) and the Architectural Conferences within the City of Design in Ljubljana. In the years 2015-2017 she was the chief editor of the architectural magazine HIŠE. 
Proceedings of the $\mathbf{2 0 2 0}$ Society of Wood Science and Technology International Convention

\section{Nop, Patrik}

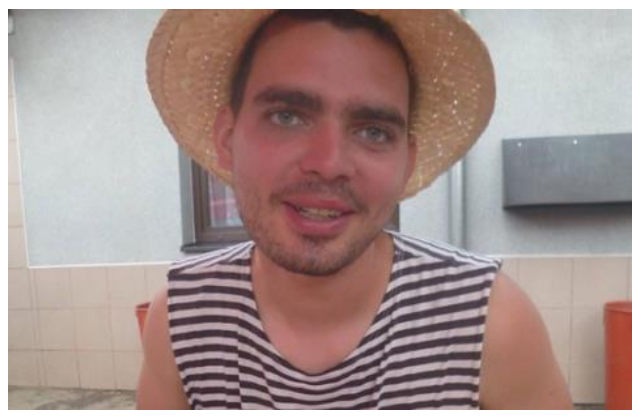

Expertise: Acoustics of wood

Biography - Patrik Nop

Non-available 


\section{Nopens, Martin}

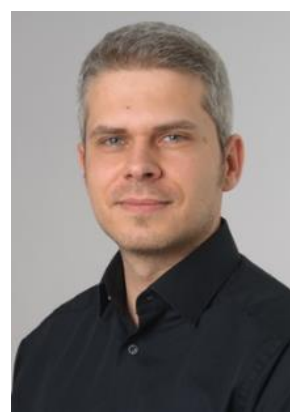

Expertise: Wood-Water-Interactions, Timber Construction

Biography - Martin Nopens

Since April 2016 I am working as research associate in the Institute for wood science (Universität Hamburg) within the workgroup of Prof. Dr. Andreas Krause. Between 2010 and 2016 I studied wood science and technology (B. Sc. as well as M. Sc.) at the Institute for wood science. In my early days I did an Apprenticeship as cabinetmaker (20002003), as well as an Advanced training master carpenter (2006-2007) and worked from 2003 to 2010 as cabinet maker at different places. 
Proceedings of the 2020 Society of Wood Science and Technology International Convention

Nüssel, Luca

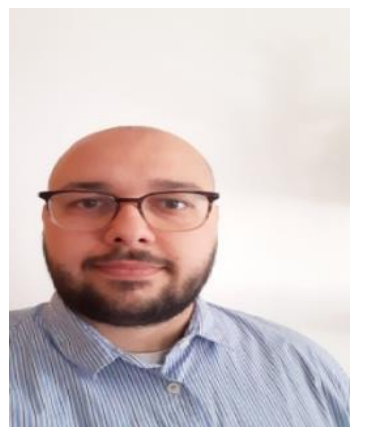

Expertise: Triboelectric charging of wood dusts

Biography - Luca Nuissel

Luca Nüssel is a Master student at the University of Natural Resources and Life Sciences Vienna. He is attending the master programme Wood Technology and Management while he holds a bachelor degree in wood and fiber technology. Luca is currently working at the Institute of Wood Technology and Natural Materials on the topics of sawdust reduction and triboelectrical charging of sawdust. 


\section{Oporto. Gloria}

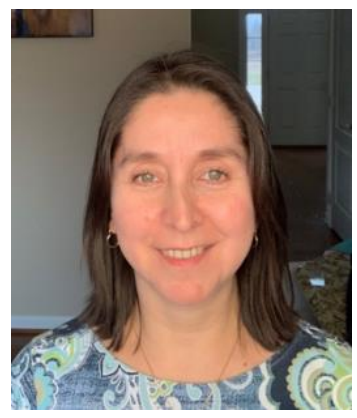

Expertise: Biomaterials and composites from lignocellulosic sources

Biography - Gloria Oporto

Dr. Gloria S. Oporto is a faculty member in the School of Natural Resources at West Virginia University (WVU). She completed her B.Sc. in Chemical Engineering at the University of Concepción, Chile, and continued working at the University of Concepcion as a Research Engineer in areas that included wood chemistry, wood-based composites, and energy from woody biomass. She received her Doctor of Philosophy degree in Forest Resources and her certificate in Advanced Engineered Wood Composites from the University of Maine in December, 2009. Dr. Oporto has been working at WVU since June, 2010 and she was promoted to Associate Professor in 2016 in the Wood Science and Technology Program. Her main interests are focused in nanomaterials and its application in advanced composites, and biomaterials from lignocellulosic sources. 


\section{Oudjehane, Azzeddine}

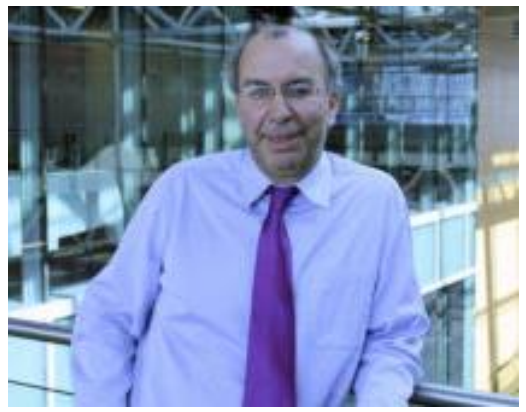

Expertise: Construction project management, Green building, Sustainability and resilience in Construction, Mass timber design and construction

Biography - Azzeddine Oudjehane

Dr. Azzeddine Oudjehane has over 30 years of experience leading multi-disciplinary projects in R\&D, business innovation and market development working with various stakeholders from academia, government and industry. Azzeddine holds graduate degrees in both Applied Science and Business Administration.

In 2012, Azzeddine joined the first undergraduate BSc in Construction Project Management in Canada at SAIT. Azzeddine strives through teaching excellence to train the next generation of construction project managers in Alberta and Canada, while developing scholarly applied research that meets the needs of the Alberta industries.

With over 100 publications and presentations at international conferences, Dr. Oudjehane serves in various journal review committees and has chaired sessions at conferences. In the past year, he gave several presentations and keynotes on the role of innovation for sustainable construction practices. Azzeddine currently serves as the Vice Chair of the Leadership Board for the AB Chapter of CaGBC. He is also the treasurer and secretary of the Board of Directors for Value Analysis Canada. Azzeddine is currently leading several applied research projects demonstrating the feasibility and value of sustainable and innovation practices in construction. These include sustainable mass timber design and construction as well as innovation integrating artificial intelligence and unmanned systems in construction project management. 


\section{Özparpucu, Merve}

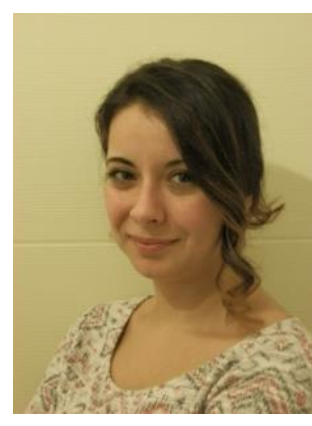

Expertise: Wood materials science

Biography - Merve Özparpucu

Merve Özparpucu is a material scientist who obtained her Ph.D. degree in ETH Zurich in Wood Materials Science Group in 2018. During her Ph.D., she analyzed genetically modified wood micro-mechanically, chemically and structurally for understanding the mechanical function of the lignin in the wood cell walls. After her Ph.D., she became a postdoc researcher at the Technical University of Munich, Chair of wood science. Her current focus lies on investigating the interactions between the chemical components of wood and wood adhesives which plays a crucial role in the development of new advanced wood-based materials and composites. 
Proceedings of the $\mathbf{2 0 2 0}$ Society of Wood Science and Technology International Convention

\section{Pan, Mingzhu}

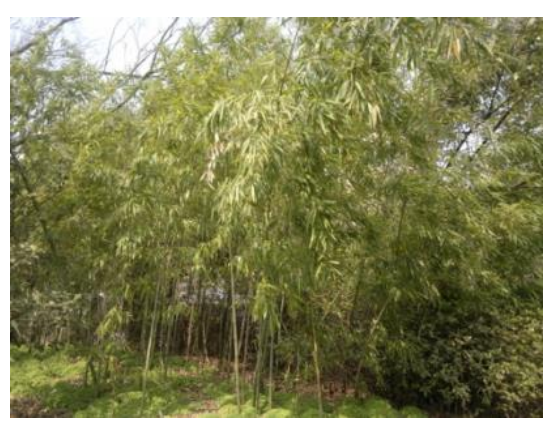

Expertise: Wood functional composites

Biography - Mingzhu Pan

Chunxiang Ding, Mingzhu Pan*, He Chen, Shuai Zhang, Changtong Mei*

College of Materials Science and Engineering, Nanjing Forestry University, Nanjing 210037, China 
Proceedings of the 2020 Society of Wood Science and Technology International Convention

\section{Panwar, Rajat}

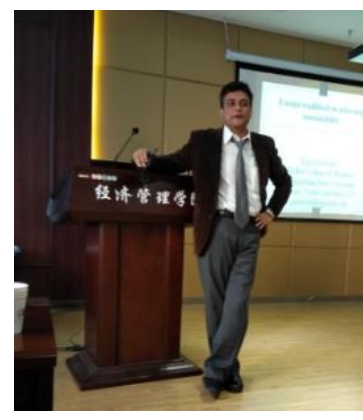

Expertise: Bioeconomy, corporate sustainability and corporate responsibility

Biography - Rajat Panwar

To be added. 
Proceedings of the 2020 Society of Wood Science and Technology International Convention

\section{Pecnik, Jaka Gasper}

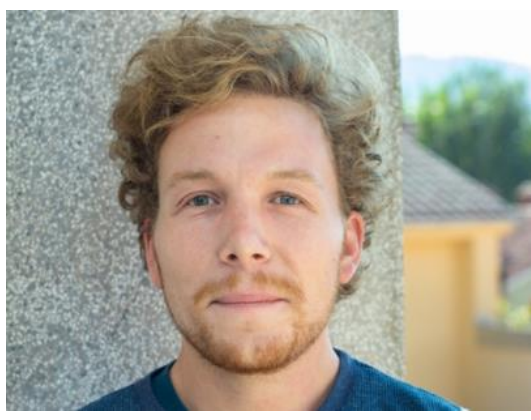

Expertise: Wood mechanics, wood adhesive interface, bio-based composite

Biography - Jaka Gašper Pečnik

Jaka Gašper Pečnik, is assistant researcher at Innorenew Coe and Institute Andrej Marušič at the University of

Primorska. He is in charge of mechanical laboratory testing, focusing on static and dynamical properties of the solid wood, wood-based composites, adhesive bonds and fracture of wood. He is a second year PhD student at the Faculty of Management of the University of Primorska. 


\section{Peszlen, Ilona}

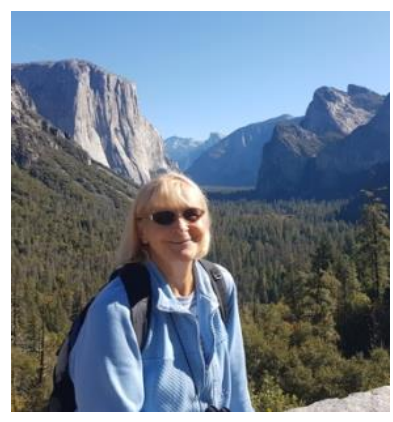

Expertise: Wood Science

\section{Biography - ILONA PESZLEN}

Ilona Peszlen is an Associate Professor at the Department of Forest Biomaterials, North Carolina University.

Previously, she was a faculty member at the Department of Forestry, Iowa State University and at the Institute of Wood Sciences, University of West Hungary. She teaches wood property related courses. Her research emphasis is on juvenile and reaction wood, effects of environment on wood properties, genetic improvement of wood quality, and on properties and utilization of plantation wood.

Ilona received her B.S. in Wood Technology (1978), her M.S. in Wood Engineering (1979) from the University of Sopron, and her M.S. in Higher Education (1984) from the University of Gödöllö, Hungary. She was the recipient of a Fulbright Scholarship and completed her Ph.D. in Wood Science \& Forest Products (1993) at the Virginia Polytechnic Institute and State University, Blacksburg, Virginia. She did post-doctoral research at the North Carolina State University, Raleigh and at the University of Canterbury, Christchurch, New Zealand. 
Proceedings of the 2020 Society of Wood Science and Technology International Convention

\section{Pinchevska, Olena}

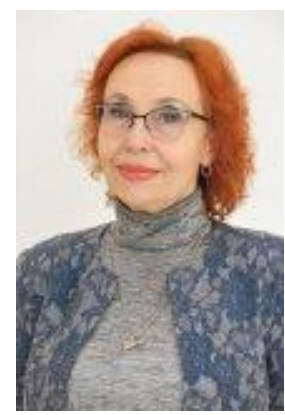

Expertise: Wood drying, wood-based materials

Biography - Olena Pinchevska

Head of the Department of Technology and Design of Wood Products in National University of Life and environmental Sciences of Ukraine. Scientific interests- wood drying ans science of wood. 
Proceedings of the 2020 Society of Wood Science and Technology International Convention

\section{Pipiska, Tomas}

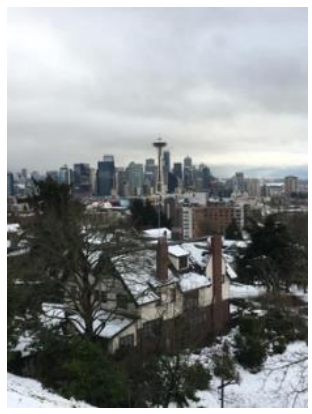

Expertise: Wood-based composites, plywood, OSB, particleboard

Biography - Tomas Pipiska

The author is focused on the wood composites and bonding of the hardwood species 


\section{Poohphajai, Faksawat}

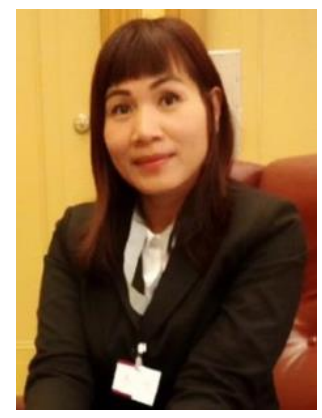

Expertise: Wood Modification, Biomaterials for wood coating

Biography - Faksawat Poohphajai

Faksawat Poohphajai is an assistant researcher in the Wood Modification group at the InnoRenew CoE, Slovenia and PhD student at Aalto University, Finland. She graduated with a Bachelor of Science in Forestry (Forest Products) from Kasetsart University, Thailand, in 1996 and worked as a forest officer for the Royal Forest Department, Thailand, for 15 years. In 2018, she completed a Master of Science in Wood Technology from Luleå University of Technology, Sweden. Her PhD research topic is "Evaluation of Biofilm for wood protection". The overall objective of the study is to evaluate the interaction of biofilm that is built up by Aureobasidium pullulans with wood materials and its mode of actions in protecting the wood substrate against environmental conditions. 


\section{Qiu, Renhui}

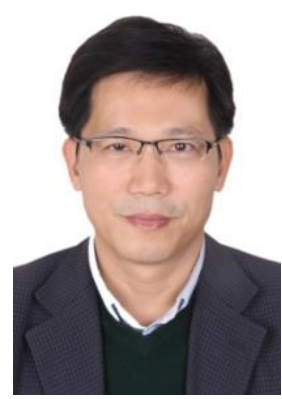

Expertise: Wood plastic composites; Biocomposites; Biobased resins; Green building materials

Biography - Renhui Qiu

Prof. Renhui Qiu received his Ph. D. degree from the Northeast Forestry University, China. He is currently a professor and the dean of College of Material Engineering, Fujian Agriculture and Forestry University, China. Prof. Qiu is leading a research group on natural fibers-reinforced polymer composites, natural fibers-reinforced asphalt/cement concrete materials, pervious concrete, and biobased polymer and composites, in which more than 10 granted projects have been conducted and finished. Prof. Qiu has more than 70 peer-reviewed articles published in ACS Sustainable Chemistry \& Engineering, Cellulose, Holzforschung, Wood Science and Technology, Composite Science and Technology, etc. 
Proceedings of the $\mathbf{2 0 2 0}$ Society of Wood Science and Technology International Convention

\section{Quesada, Henry}

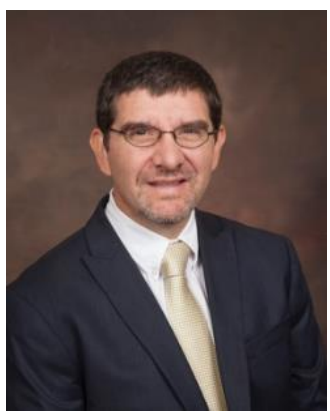

Expertise: Industrial Engineering

Biography - Henry Quesada

Dr. Quesada has been a faculty member of the Department of Sustainable Biomaterials since 2008. He works in the areas of marketing, process improvement and supply chain management applied to wood products. 
Proceedings of the $\mathbf{2 0 2 0}$ Society of Wood Science and Technology International Convention

\section{Reichel, Vicky}

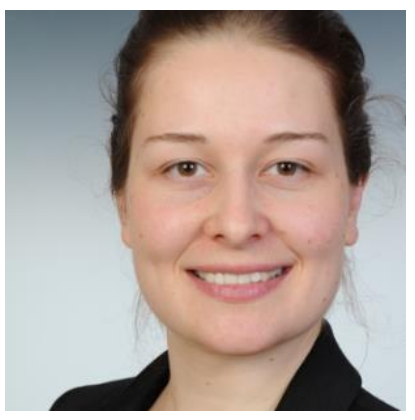

Expertise: Hybrid lightweight construction and integrated manufacturing - cutting processes for multi material components

Biography - Vicky Reichel

- Holding a M. Sc. in Automotive Engineering

- Ph. D. Student since 2017 at Institute of Machine Tools and Production Technology at the department "manufacturing of hybrid components" working at Open Hybrid LabFactory

- Research Focus: Cutting techniques for hybrid components 


\section{Ruponen, Jussi}

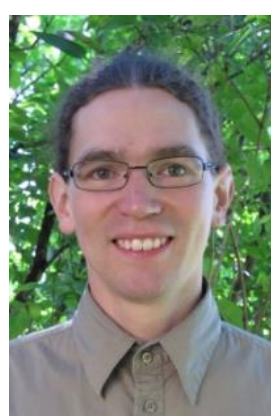

Expertise: Fire safety, Wood products technology, Wood material technology

Biography - Jussi Ruponen

Director, Customer Applications (Dec 2019 - Present)

Product Manager (Feb 2019 - Dec 2019)

Palonot Oy operates a business of a fire-retardation solution provider and a fire-retardant supplier.

I am responsible for global B2B customer management and acquisition. My responsibilities include broad

technological customer support, with demanding application development. Additionally, my expertise is employed within various $R \& D$ projects.

Graduate student researcher and part-time lecturer at Aalto University (Sep 2009 - Present) 


\section{Sandak, Anna}

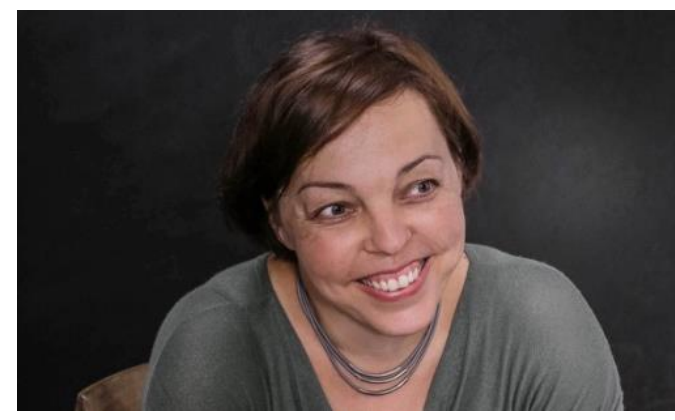

Expertise: Wood modification

\section{Biography - Anna Sandak}

Anna is the research group leader in Wood Modification at the InnoRenew CoE.

Since 2016 she is an assistant professor and research associate at the Faculty of Mathematics, Natural Science and Information Technology at the University of Primorska. She was previously employed at Trees and Timber Institute of Italian National Research Council, where she coordinated the Laboratory of Surface Characterization.

She has PhD in Wood Science and M.Sc. in Biology. Anna is a member of Italian Society for Near Infrared Spectroscopy, International Committee for Near Infrared Spectroscopy, International Research Group on Wood Protection, International Society for Plant Spectroscopy and Network of Early-Career Sustainable Scientist \& Engineers and in 2012 she was nominated as IUFRO Officeholder, deputy of division 5.03.05 - Biological resistance of wood. She also actively contributes to several COST actions, including FP1006, FP1101, FP1303, FP1407, FP1405, TU1403, CA 15216 and CA16226.

Her research activities include multi-aspect characterization of lignocellulosic materials, non-destructive testing, evaluation of degradation level of wood and wood-based products and application of different spectroscopic techniques for the characterization of bio-based materials. Anna is analyzing the multi-scale relationship and performance of modified and functionalized bio-based materials and implementing them as new architectural elements. Her passion is to search for biomimetic solutions for the design of new materials and to promote knowledge-based use of bio-inspired materials in modern sustainable buildings 


\section{Sandak, Jakub}

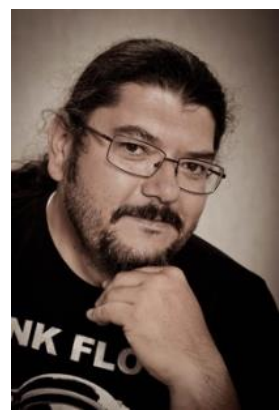

Expertise: Wood science and technology

Biography - Jakulb Sandak

Jakub, "Kuba", has a Doctor of Philosophy in Agricultural Sciences from Tottori University (Japan), a master of Science in Natural Resources Process Engineering from Shimane University (Japan), an engineer of Wood Science and Technology from University of Life Sciences in Poznan (Poland). He is a third-generation carpenter, currently a researcher at InnoRenew Centre of Excellence, assistant professor and research associate at the Faculty of Mathematics, Natural Science and Information Technology at the University of Primorska. 
Proceedings of the $\mathbf{2 0 2 0}$ Society of Wood Science and Technology International Convention

\section{Saražin, Jaša}

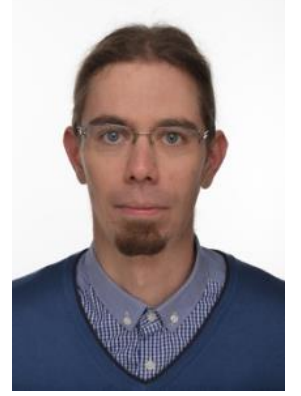

Expertise: Bio-based wood adhesives, bonding wood with metal and curing characterisation of adhesives

Biography - Jaša Saražin

Jaša Saražin is a doctoral student at University of Ljubljana, Biotechnical faculty, scientific area Wood and Biocomposites. His research work is focused on bio-based wood adhesives, bonding wood with metal and curing characterisation of adhesives. 
Proceedings of the $\mathbf{2 0 2 0}$ Society of Wood Science and Technology International Convention

\section{Savov, Viktor}

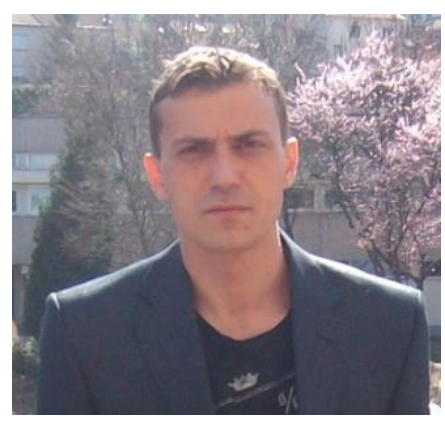

Expertise: Technology of Wood-Based Panels; Technology of Fibreboards

Biography - Viktor Savov

Associate Professor at University of Forestry - Sofia, Bulgaria

Department of Mechanical Wood Technology

Subject taught - Technology of Materials from Wood Fibres 
Proceedings of the $\mathbf{2 0 2 0}$ Society of Wood Science and Technology International Convention

\section{Scharf, Alexander}

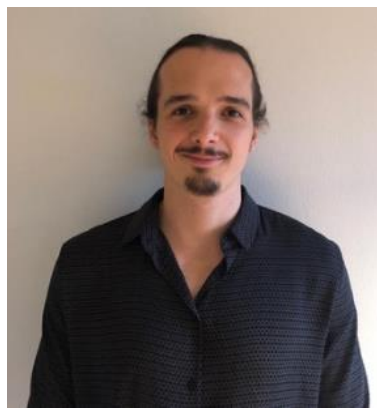

Expertise: Thermo-mechanical wood densification and hardness testing

Biography - Alexander Scharf

Alexander Scharf is a PhD student in Wood Science and Technology at Luleå University of Technology.

Research topic: Surface densification of wood. 


\section{Schau, Erwin M.}

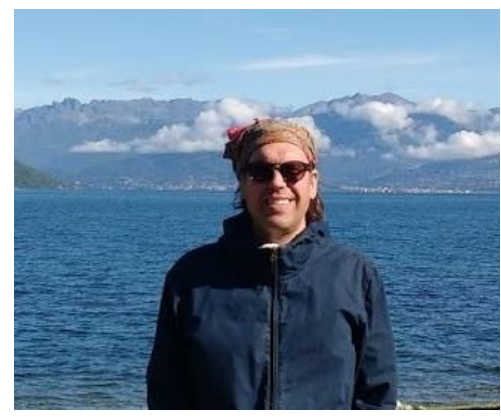

Expertise: Research, with a focus on the life cycle assessment (LCA) methods for bio-based product system

\section{Biography - Erwin M. Schau}

Dr. Erwin M. Schau is a researcher at the InnoRenew CoE where his activities are to conduct science and research, including life cycle assessment (LCA).

He holds a PhD degree from the Norwegian University of Science and Technology (NTNU), Faculty of Social Sciences and Technology Management and a Master's degree from the Department of Industrial Economy and Technology Management within the Industrial Ecology program at NTNU.

Since 1996 he has been involved in research on the environmental impact of biobased systems and has more than 15 years of experience from different research companies, international institutions, and universities in life cycle sustainability assessment of feed, food, and fibre products like food products, paper and wood products (e.g. bamboo bicycles), but also on automotive products and transport systems. His main focus has been on energy use and climate change, applying and developing the LCA of products for the biobased industry. From 2013 to 2018 Dr. Erwin M. Schau performed research and development for the European Commission's Joint Research Center (Italy) on the European Union recommended life cycle assessment method - the Environmental Footprint (EF), where he led the pilot projects developing Product Environmental Footprint Category Rules (PEFCR) for the fields of intermediate paper and olive oil. The life cycles in these projects start with the raw material and seedlings production and finish with the end of life, like waste handling (e.g. incineration) or recycling. 
Proceedings of the $\mathbf{2 0 2 0}$ Society of Wood Science and Technology International Convention

\section{Schmid, Thomas}

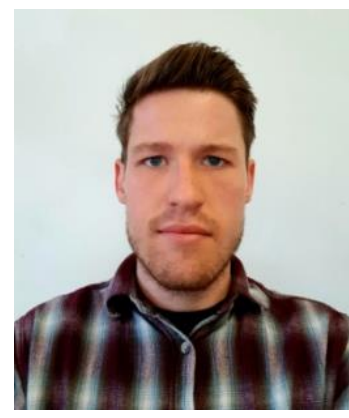

Expertise: Wood adhesives, Wood-based panels, Wood plastic composites

Biography - Thomas Schmid

Thomas Schmid is 25 years old. After studying wood technology at Rosenheim Technical University of Applied Sciences hes currently employed at the universitys laboratory for wood adhesives and wood based panels. His research is based on the topic of woodfiber enhanced plastic materials and wood-plastic composites. 


\section{Schmidt, Evan}

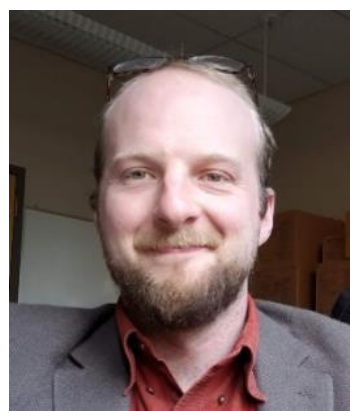

Expertise: Mass Timber research and construction

Biography - Evan Schmidt

With a diverse background in Design and Wood Science, Evan manages outreach and education activities at TallWood Design Institute. Evan received his M.S. in Wood Science at Oregon State University, where his research focused on hygrothermal performance of cross laminated timber during construction and in service. Prior to attending OSU he studied architecture and worked as an independent contractor providing landscape design service and drafting and permitting services for residential construction. 


\section{Schuh, Mathias}

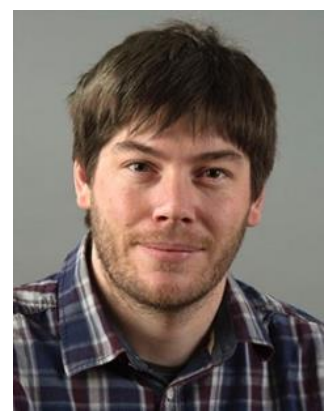

Expertise: Engineered wood, adhesives, wood composites

Biography - Mathias Schuh

Since 12/2018: Research Associate and PHD-Student at the Chair of Wood Science, Wood Research Munich, Technical University of Munich

2018: Master's thesis at the Institut für Holztechnologie Dresden (IHD), Department of Materials 2016 - 2018: Master program Wood Science and Technology, Technische Universität Dresden 2012 - 2017: Bachelor program Forest Sciences, Technische Universität Dresden 


\section{Schwarzkopf, Matthew}

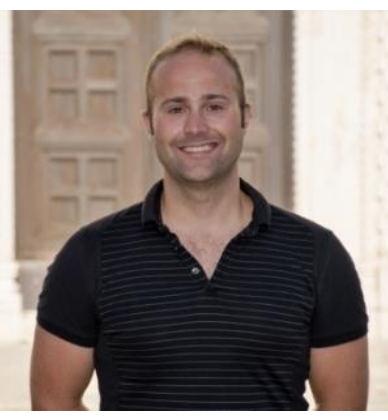

Expertise: Utilization of agricultural/industrial residues for value added wood-based products

Biography - Matthew Schwarzkopf

Dr. Matthew Schwarzkopf is a Researcher at the InnoRenew Centre of Excellence and an Assistant Professor at the University of Primorska. He earned his Ph.D. in 2014 from Oregon State University, USA with a dual major in Wood Science and Materials Science.

His research interests include micro-mechanical testing of the wood-adhesive/polymer interphase, optical measurement techniques, wood-plastic composites, low-grade woody biomass utilization, and measurement of micro-scale local surface properties of wood.

He is currently involved in a variety of international projects including a Horizon 2020 project, ProEnrich, promoting the utilization of agricultural residuals.

Matthew holds a MS in Wood Science from Oregon State University (Oregon, USA 2009) and a BS in Forestry from Iowa State University (Iowa, USA 2007). 


\section{Sebera, Vaclav}

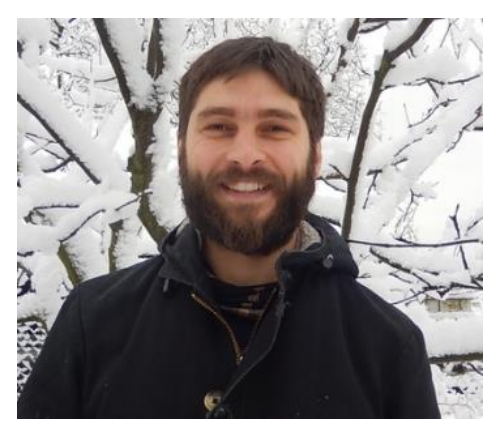

Expertise: Wood and composite mechanics, finite element analysis, tree biomechanics, material science, wood technology

\section{Biography - Vaclav Sebera}

Dr. Václav Sebera is a researcher at the InnoRenew CoE. He is focusing on mechanics of wood and wood-based composites at various levels of observation. Within this field, he employs optical techniques based on Digital Image Correlation (DIC) and numerical approaches utilizing Finite Element Method (FEM). He further focuses on tree biomechanics investigating stability of trees and works on the development of inspection techniques. In 2009 he received a Fulbright scholarship for a research project at Oregon State University (USA). Four years later he earned his Ph.D. at Mendel University in Brno (Czech Republic) where he was employed as Research assistant since then. He also works as a external lecturer at the University of Applied Sciences in Rosenheim (Germany). 


\section{Seidu, Haruna}

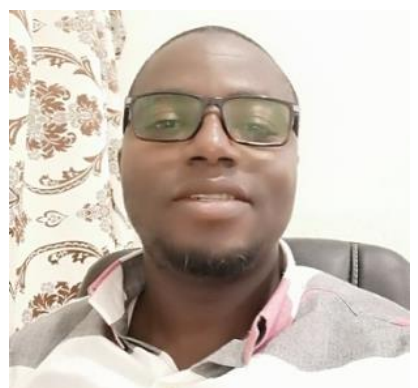

Expertise: Mechanical Properties of Wood, Furniture Testing, Wood Utilization, Information Technology

\section{Biography - Haruna Seidu}

Haruna Seidu is a Principal Technologist at the CSIR-Forestry Research Institute of Ghana. He was employed to the institute in 2013 as a technical officer in charge of mechanical property determination of wood. He was upgraded to the position of a Principal Technologist in 2018 after acquiring a masters degree in Information Technology from the Open University of Malaysia. In 2016, He was sponsored to Bern Institute of Applied Science to by the UNDP to be trained in ISO 17025 protocols. He has attended several conferences organised by UNIDO locally. Currently, He is in charge of testing of wood, wood based panels and Furniture using European Standards at the Wood and Furniture Testing Centre located in the Institute. He am currently engaged in everal research activities including the determination of Eucalyptus properties to augment the dwindling teak.He is also involve in the standardization of wood product by the Ghana Standard Authorithy.

Between 2002 and 2012, he was a Senior High school at the Asare Bediako Senior High School in the Ashanti Region near Obuasi where he taught integrated science and Information Technology. This was after he completed Tamale Technical University, where he pursued and graduated with HND Agricultural Engineering in completed in 2001. To boost my Teaching carrier, he persued professional teaching program at the University of Education Winneba and graduated in 2010. 


\section{Sernek, Milan}

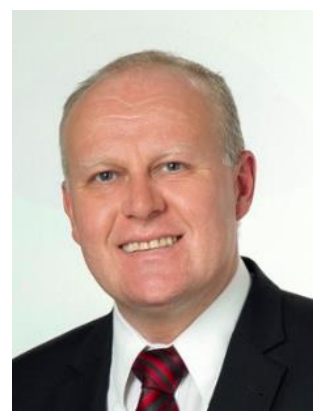

Expertise: Wood adhesives, adhesive bond performance, bonding of modified wood and properties of wood-based composites

\section{Biography - Milan Sernek}

Milan Šernek earned a doctoral degree at Virginia Polytechnic Institute and State University, USA.

Currently, he is full professor and head of the Department of Wood Science and Technology,

Biotechnical faculty, University of Ljubljana, Slovenia. He teaches courses about adhesives and wood

bonding, wood-based composites and designing of technological processes. His research work is focused on the wood adhesives, adhesive bond performance, bonding of modified wood and properties of woodbased composites. 


\section{Sethy, Anil Kumar}

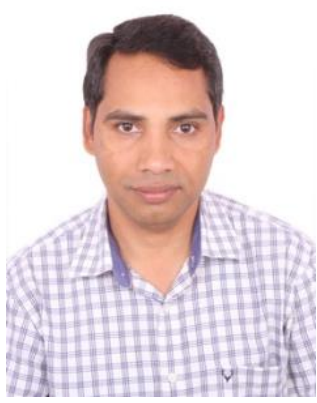

Expertise: Wood Science and Technology

Biography - Anil Kumar Sethy

Academic:

- $\quad \mathrm{PhD}$ (Wood Science): The University of Melbourne, Australia - 2011

- MSc (Wood Science and Technology): Forest Research Institute-Deemed University, Dehradun, India- 2001

\section{Research Career:}

- Researcher- Czech University of Life Science, Prague, Czech Republic- (May 2019 - continuing - By availing study leave from IWST, Bangalore, India)

- Scientist- Institute of Wood Science and Technology, Bangalore, India ( since April 2003)

Research interest: Wood composite, Wood modification and Wood quality assessment.

\section{Publication:}

- 20 papers in peer reviewed scientific journals

- 16 papers/posters in national and international conferences

Scholarships obtained:

- $\quad$ MIRS and MIFRS from the University of Melbourne to pursue PhD.

- SF Pond Trust travelling scholarship to present a paper in the 41st IRG-2010, held in France.

- Go8 Australia-Germany Joint Research co-operation scheme funding for exchange visit to the University of Gottingen, Germany. 


\section{Shang, Lili}

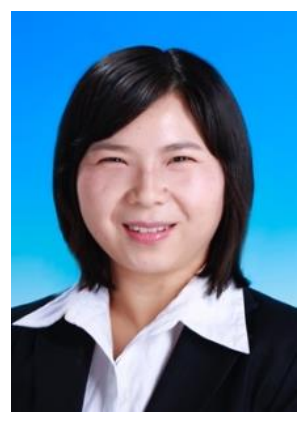

Expertise: Basic properties and functional modification of bamboo and wood materials, Rattan based new carbon materials

\section{Biography - Lili Shang}

Ms. Lili SHANG was graduated in 2017 with postdoctor majoring in wood science and technology at Chinese Academy of Forestry Sciences. She has been working in International Center for Bamboo and Rattan (ICBR) as a research scientist since 2017. Now, she mainly studies in the properties and modification of rattan. 


\section{Sichamba, Kennedy}

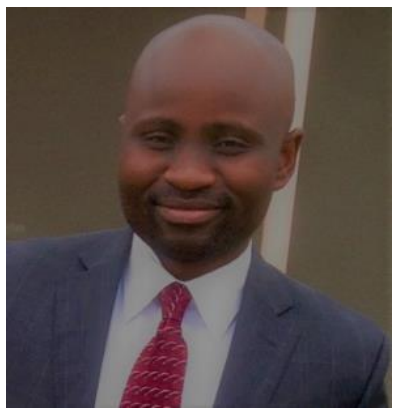

Expertise: Utilisation of Wood and Non wood plant materials for paper making and Bio-energy production

\section{Biography - Kennedy Sichamba}

Mr. Kennedy Sichamba obtained his Master of Science degree in Wood Science and Engineering from Oregon State University, USA, in 2012, and is currently a lecturer at Copperbelt University in Zambia. His masters degree research focused on utilizing western juniper harvesting residues (foliage and twigs) for oil extraction and biofuels production. His current work involves teaching Pulp and Paper Technology to undergraduates, as well as supervising their research projects in the field. He is so very passionate about utilizing non-wood plant materials for pulp and paper, bioenergy production, and other chemical products. 


\section{Sobotkova, Alena}

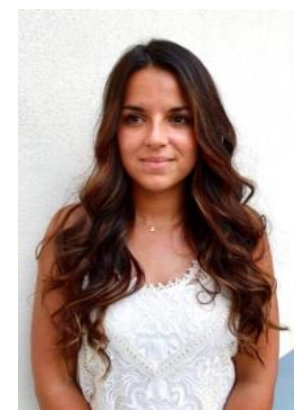

Expertise: Furniture, furntiure design and technology, material engineering

\section{Biography - Alena Sobotkova}

$\mathrm{PhD}$ student of furniture design and Technology at Mendel University in Brno. Currently in the third year working on my thesis with the topic of Sustainability in furniture design. I have previous experience of teaching at Louisiane State University for one year as part of PhD study at MENDELU. I did also three month internship at Salzburg University of Applied Sciences. I have working experience in the field of furniture, interior and graphic design. 


\section{Solt, Pia}

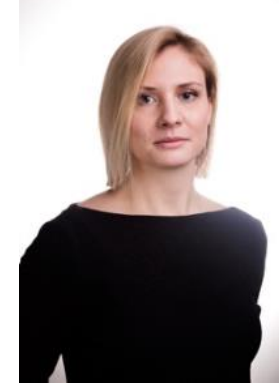

Expertise: Wood adhesives

Biography - Pia Solt

\section{EDUCATION:}

Apr. 15 - Jun. 19: Doctor of wood technology and renewable materials

University of Natural Resouces and Life Science, Vienna (BOKU)

- PhD Thesis: Alternative Adhesive Systems for Wood Panel Application - Bio-based and Formaldehyde-free Adhesives

- Summa cum laude

Sep. 12 - Sep. 14: Master of Wood technology and economy University of applied sciences, Salzburg

- Master Thesis: Development and investigation of a high density panel based on chemical tanned leather shavings (Wet Blue) and wood fibres

- Passed with distinction

Sep. 09 - Jul. 12: Bachelor of Wood technology and timber construction University of applied sciences, Salzburg

- Bachelor Thesis: Valorisation of pulp and paper waste water: Lignin polymer

\section{PROFESSIONAL EXPERIANCE:}

Jul. 19 - now: Senior scientist

Wood K plus - Kompetenzzentrum Holz GmbH ,Tulln, AT

Feb. 15 - Jun. 19: Junior Researcher \& PhD student

Wood K plus - Kompetenzzentrum Holz GmbH ,Tulln, AT

Oct. 15 - now: Lector "Technologie des Holzes" 
Proceedings of the 2020 Society of Wood Science and Technology International Convention

University of Natural Resources and Life Science, Vienna, AT

Dec. 12 - Feb. 15: Junior Researcher

University of applied sciences, Salzburg, AT 


\section{Solt-Rindler, Axel}

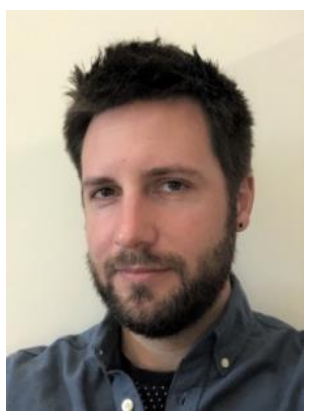

Expertise: Novel wood/non-wood combinations (inorganic and organic materials); all-new biobased functionalized materials; ignition and burning behavior of bio-based materials; development of multi-layered panel materials; nanoindentation, dynamic mechanical testing, quasi-static mechanical testing; thermal conductivity and thermal degradation of wood-based materials; light and scatter electron microscopy

Biography - Axel Solt-Rindler

Education

Feb.2015 - Jun.2019 Universität der Bodenkultur Wien

Doctoral studies of Natural Resources and Life Sciences (with distinction)

- $\mathrm{PhD}$ Topic: The Significance of bond region micromechanics on the moisture related dimensional stability of thin wooden multi-layered panels

(Prof. Dr. Johannes Konnerth)

Sep.2009 - Sep.2014 Fachhochschule Salzburg

Master in Forest Products Technology \& Management (with distinction)

- Master Topic: Development and investigation of a high density panel based on synthetic tanned leather shavings (wet white) and wood fibres (Prof. Dr. Marius C. Barbu)

Bachelor in Forest Products Technology (with merit)

- Bachelor Topic 1: Investigation of the property change and strength of fibreboards produced of natural and synthetic resins under different temperature conditions (Dr. Thomas Schnabel)

- Bachelor Topic 2: Investigation of the properties of bark in relation to its use as a blow-in insulation (Dr. Stefan Hinterreiter)

Business

Jun.2019 - now Kompetenzzentrum Holz GmbH Tulln, Austria

Senior Researcher 
Proceedings of the 2020 Society of Wood Science and Technology International Convention

Feb.2015 - Jun.2019 Kompetenzzentrum Holz GmbH Tulln, Austria

Research Associate

Apr.2013 - Jan.2015 Fachhochschule Salzburg Kuchl, Austria

Junior Researcher 


\section{Starman, Vesna}

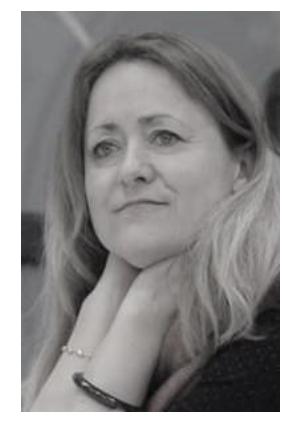

Expertise: Educational science, breaking gender stereotypes in relation to career choice and gender, how to involve all age groups in wood science

Biography - Vesna Starman

Vesna is an assistant researcher at the InnoRenew CoE.

As a Master of Science in the area of social pedagogical science, she is most likely to face challenges that include behavioural and emotional problems. She also writes articles on these subjects and conducts lectures for the professional and general public.

She teaches pedagogy at the preschool education programme at the high school SŠ Izola.

At the InnoRenew $\mathrm{CoE}$ she focuses primarily on breaking gender stereotypes in relation to career choice and gender, and she is researching how to involve all age groups in wood science. 


\section{Straze, Ales}

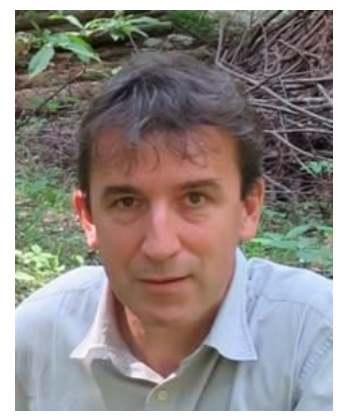

Expertise: Wood physics, wood mechanics, wood drying, hydrothermal treatment of wood, NDT characterization of bio-based materials, acoustics of wood and lignocellulosic composites

Biography - Ales Straze

Born

July 16th, 1971, Celje, Slovenia

\section{Studium / Education}

1997 Graduation, Wood Science and Technology, Biotechnical Faculty, University of Ljubljana 2000 Master of Science, Wood Science and Technology, Biotechnical Faculty, University of Ljubljana 2010 Ph. D. Wood Science, Biotechnical Faculty, University of Ljubljana

\section{Work positions}

1997 - Junior researcher at Biotechnical Faculty, University of Ljubljana

2000 - Assistant researcher at Biotechnical Faculty, University of Ljubljana

2011 - Assistant Professor of Wood Science, University of Ljubljana

2016 - Associate Professor of Wood Science, University of Ljubljana

\section{Expertise}

Wood physics, wood mechanics, wood drying, hydrothermal treatment of wood, NDT characterization of bio-based materials, acoustics of wood and lignocellulosic composites

Work, research, lecturing abroad

2007 STSM at Chalmers University of Technology, Göteborg

2011 STSM at Bern University of Applied Sciences, Biel, Switzerland

2012 STSM at CNR-IVALSA - Italian Trees and Timber Institute, Trento, Italy

2015 Invited lecturer at Kazakh National Agrarian University, Faculty of Forestry, Almaty, Kazakhstan 2015, 2016 Invited lecturer at Mendel University in Brno, Czech Republic

2017 Invited lecturer at FHS Salzburg-Kuchl, Austria

2018 Invited lecturer at Kazakh National Agrarian University, Faculty of Forestry, Almaty, Kazakhstan 2019 invited lecturer at University of Zagreb, Faculty of Forestry, Zagreb, Croatia

Projects (selection; member of the research team)

V4-1419 Rational use of hardwoods with a focus on beech wood, 1.7.2014-30.6.2017

P4-0015 Wood and lignocellulosic composites, 1.1.1999-31.12.2019

L4-7163 Rational use of wood in the context of sustainable forest management, 1.9.2005-31.8.2008

L4-7367 Optimisation of algorithm of drying process in respect of optimal physical and chemical properties of wood, 1.9.2005 - 31.08.2008

APPLAUSE, Allient Plant Species (1.9.2017 - 1.9.2020) 


\section{Suchomelova, Pavlina}

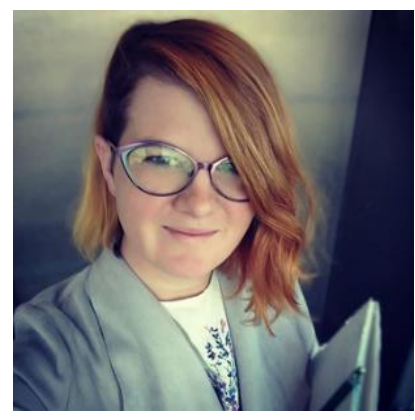

Expertise: Numerical simulations of wood behavior, Physical and mechanical properties of wood, Moisture transport and thermal transfer in wood, Wood mechanics

Biography - Pavlina Suchomelova

Author is Ph.D. student and young researcher at the Dep. of Wood Science and Technology of Mendel University in Brno. She is focused on the numerical simulations of wood and wood-based materials physical and mechanical behavior. 


\section{Sun, Hao}

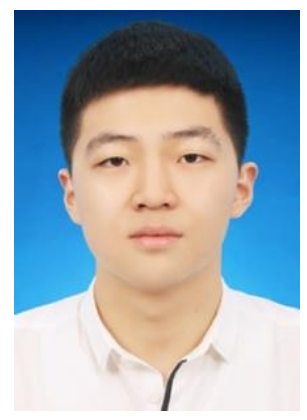

Expertise: Wood Science and Technology

Biography - Hao Sun

Hao Sun, Ph.D candidate, major in wood science and engineering. He graduated from Northeast Forestry University majoring wood science and technology in 2018 with a bachelor's degree in engineering.

Research area: Improvement the mechanical properties and dimensional stability of rubber wood through thermal modification and impregnation of latex; Preparation and characterization of wood-based composites 


\section{Tellnes, Lars G.F.}

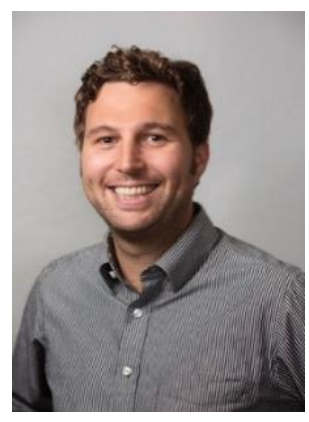

Expertise: Life cycle assessment (LCA), environmental Product declarations (EPD), industrial ecology, wood products and buildings

\section{Biography - Lars G. F. Tellnes}

Lars Tellnes is a reasearcher within sustianable innovations focusing on Wood Products and Construction industry. He has a master in industrial ecology and has previously worked at the Norwegian Institute of Wood Technology. For the last Three years, he has been Affiliated at Ostfold Research which soon will change name to Norwegian Institute of Sustainability Research. Besides Research, he is also teaching life cycle assessment at the Norwegian University of Life Sciences. Tellnes is a specialist withing life cycle assessment and environmental Product declarations of Wood Products and have been working With a large number of industrial Companies. Internationally he has spread his experiences With several Networks such as International Research Group on Wood Protection, COST actions and sustainable built environment Conference series. 


\section{Tran, Anita}

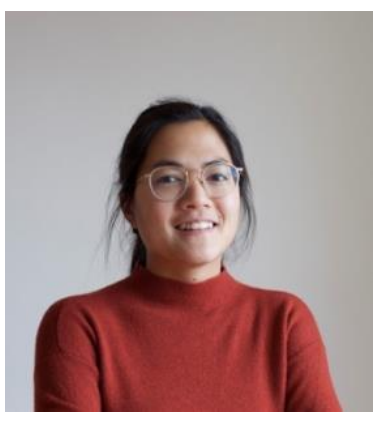

Expertise: Wood adhesion, adhesive bonding, cold temperature cure/hardening, nanoindentation Biography - Anita Tran

Anita Tran is working as doctoral candidate at the Institute of Wood Technology and Renewable Materials at the University of Natural Resources and Life Sciences (BOKU) Vienna. Coming from a broad interdisciplinary background, her main fields of interests are renewable resources in real life applications and material testing. Therefore, she is currently working on low temperature curing of wood adhesives aiming for more energy efficiency in industrial processes. This involves diverse testing methods such as nanoindentation and rheology to generate fundamental knowledge on cold bonding mechanisms.

She holds a bachelor degree in International Business Communication and a master double degree in Renewable Resources from Technical University of Munich and BOKU. During her master thesis at BOKU she focused on producing porous wood materials to substitute conventional foams for which she received the Science Rotary Award Tulln. 
Proceedings of the 2020 Society of Wood Science and Technology International Convention

\section{Tsai, Yi-Hsuan}

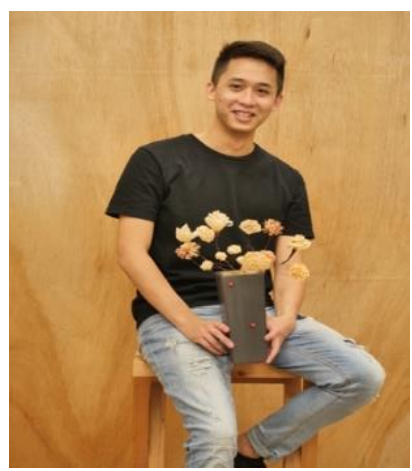

Expertise: Biology of materials, analysis of the traditional materials of the guqin, the Chinese seven-string zither

\section{Biography - Yi-Hsuan Tsai}

Yi-Hsuan Tsai is a graduate student in the School of Forestry and Resource Conservation, National Taiwan University. He majors in biology materials, and his research topic is the analysis of the traditional materials of the guqin, the Chinese seven-string zither. 


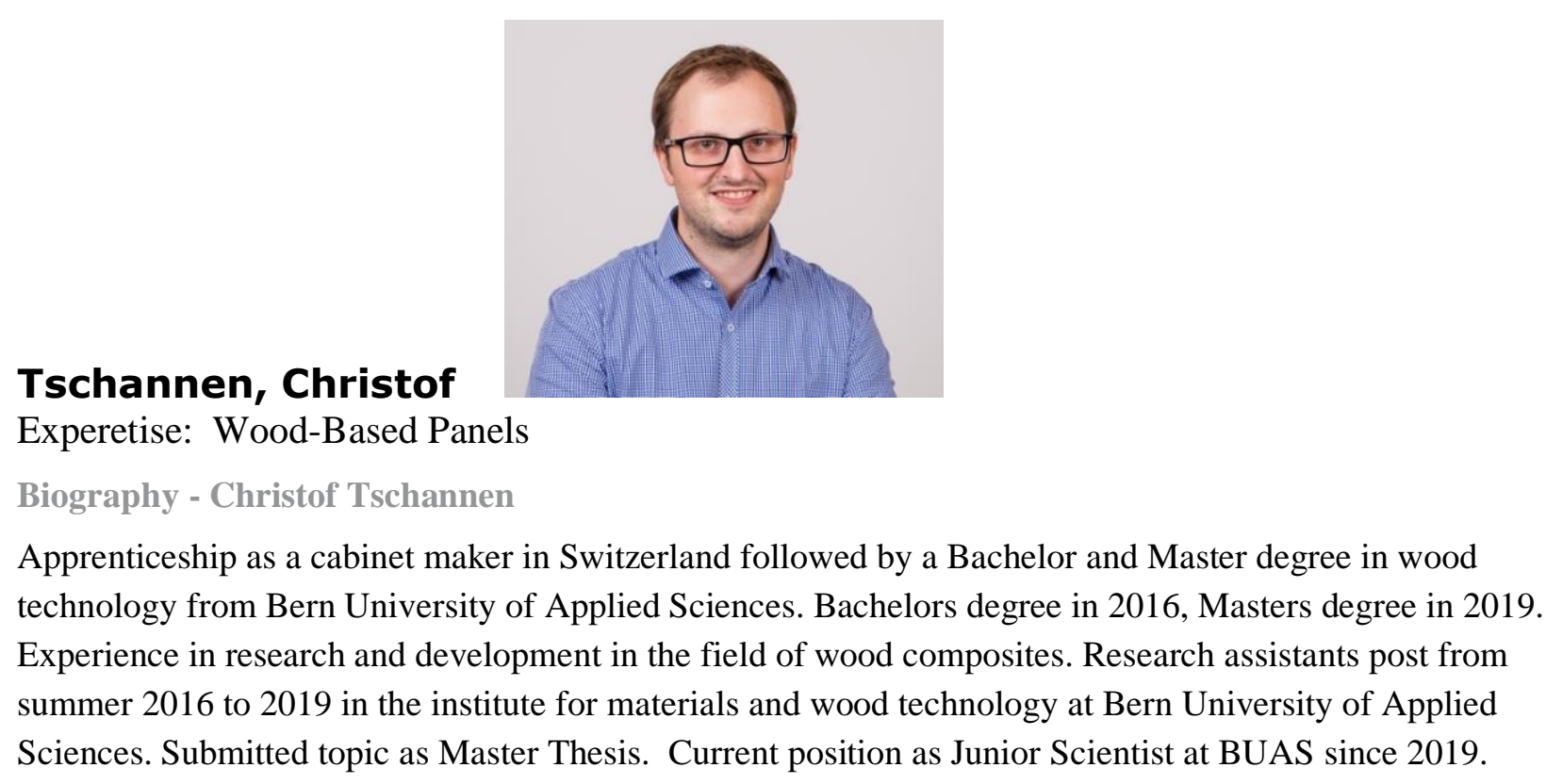


Proceedings of the $\mathbf{2 0 2 0}$ Society of Wood Science and Technology International Convention

\section{Ueda, Rintato}

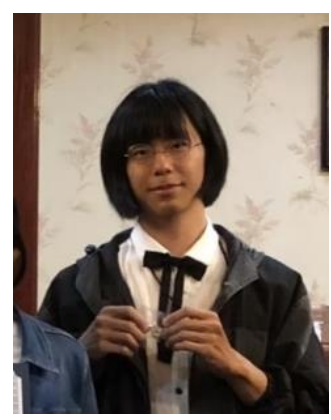

Expertise: Timber Engineering, Wood Preservation

Biography - Rintato Ueda

A PhD student, belonging to Graduate School of Agriculture, Hokkaido University. 
Proceedings of the 2020 Society of Wood Science and Technology International Convention

\section{Ugulino, Bruna}

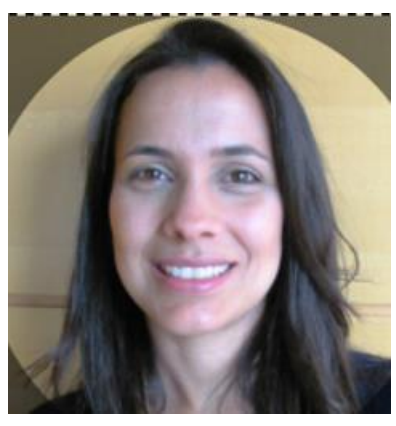

Expertise: Wood Products Manufacturing

Biography - bruna Ugulino

Bruna Ugulino works as Researcher at the Primary Wood Products Manufacturing, Smart Manufacturing Department of FPInovations, at QUebec City. 


\section{Vay, Oliver}

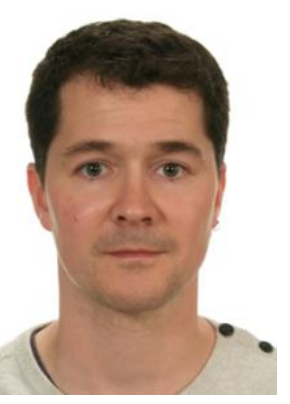

Expertise: Physical characterization of wood and natural materials, engineering of materials like wooden floorings and thermal insulations

Biography - Oliver Vay

Oliver Vay works as a Senior Researcher in the Team Smart Wood Natural Materials of Competence Centre for Wood Composites and Wood Chemistry, Austria. He received his diploma degree from University of Hamburg and his PhD degree from University of Natural Resources and Applied Life Sciences, Vienna.

His research areas include physical characterization of wood and natural materials, engineering of materials and thermal insulations. He also worked as a research worker focused on developing wooden floorings. 


\section{Vojáčková, Barbora}

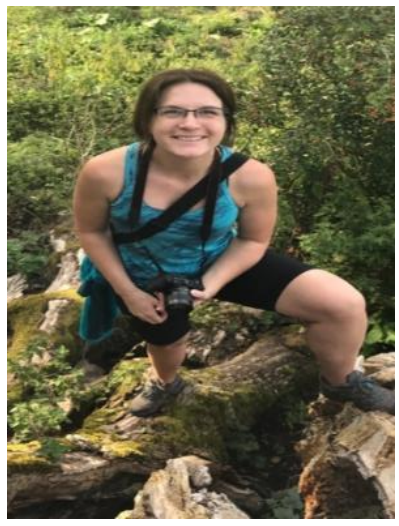

Expertise: Tree biomechanics, arboriculture, numerical simulation

Biography - Barbora Vojáčková

2015 - 2019 (not finished) PhD Forest Phytology, PhD Thesis: Branch Mechanical Response to Static Loading.

Research: Involvement in the national projects (2020 - now) Tree Dynamics: Understanding of Mechanical Response to Loading; (2014 - 2017) Non-invasive Technology system for the tree stability measurement and safety evaluation and European project (2016 - 2019) Veteran Tree Management Skills Certification.

Work: 2008 - now Working in arboriculture with specialisation to tree risk assessment; 2011 now Working on Department of Wood Science and Technology, Faculty of Forestry and Wood Technology, Mendel University in Brno.

Previous study: College of Landscape Architecture, BSc Arboriculture, MSc Forest Engineering. 
Proceedings of the $\mathbf{2 0 2 0}$ Society of Wood Science and Technology International Convention

Wahyude, Imam

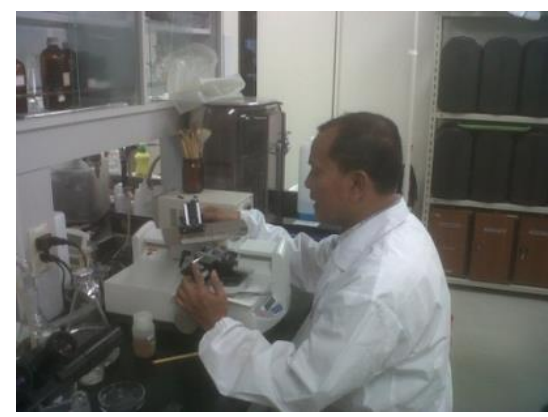

Expertise: WOOD STRUCTURE AND IDENTIFICATION; WOOD QUALITY

Biography - Imam Wahyudi

1986: Graduated from IPB University, Indonesia. Majoring in Forest Products Technology (S1)

1990: Graduated from from IPB University, Indonesia. Majoring in Wood Science and Technology (S2)

2000: Graduated from from Nagoya University, Japan. Majoring in Wood and Bio-material Physics (S3)

1987 to present: Lecturer at Faculty of Forestry IPB University, Indonesia

2007 to present: Head of Wood Quality Laboratory, Faculty of Forestry IPB University, Indonesia 


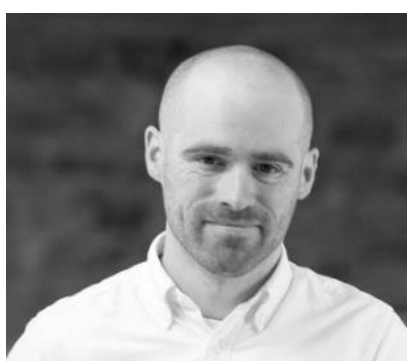

\section{Walsh, St John}

Expertise: Architecture

\section{Biography - St John Walsh}

St John established Alder Architects in 2018 having gained over 10 years experience working with award winning architecture practices in Ireland and the UK on a range of projects from small scale domestic commissions to large public and commercial buildings.

While working with Donaghy \& Dimond Architects in Dublin, he was project architect on both Inchicore National School \& the Gate Lodge extension in Rathfarnham, respectively awarded RIAI Awards for Best Educational Building \& Domestic Extension in 2015. With AY Architects, he was project architect on Eleanor Palmer Science Lab, built for Eleanor Palmer Primary School in Camden, which has been awarded a RIBA London Award for 2019. He has also worked with Scott Tallon Walker \& BDP architects on award-winning large scale commercial \& residential projects.

Having studied in Dublin and Copenhagen, St. John graduated from UCD in 2010 with a first class honours degree and continues to be involved in academia. Currently in the role of design studio tutor at the UCD School of Architecture, he has previously acted as a visiting critic at UCL's Bartlett School of Architecture and studio mentor at the Royal College of Art London. 


\section{Wang, Dong}

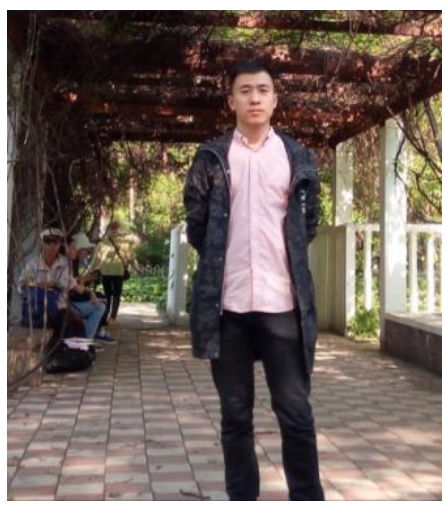

Expertise: Electrospun functional nanocomposites

Biography - Dong Wang

My name is Dong Wang and I am a PhD student at Northeast Forestry University (School of Material Science and Engineering ) of China under the supervision of Prof. Guangping Han.

Research Area: High-Performance Supercapacitors Based on Lignin-based Nanofibers by Electrospinning; Preparation and Properties of Electrospun Cellulose Nanocrystal reinforced Composite Nanofibers. 
Proceedings of the 2020 Society of Wood Science and Technology International Convention

\section{Wang, Qifan}

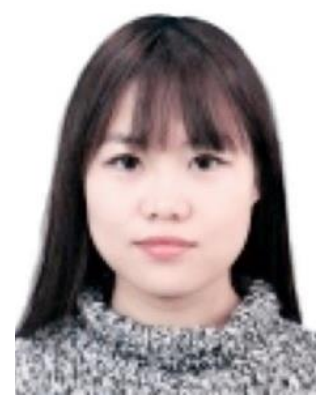

Expertise: VOCs and odor emission from wood-based panel

Biography - Qifan Wang

Qifan Wang, Ph.D. candidates, College of Material Science and Engineering, Northeast Forestry University, Harbin, China. Main research direction: Volatile Organic Compounds 
Proceedings of the 2020 Society of Wood Science and Technology International Convention

\section{Wang, Xun}

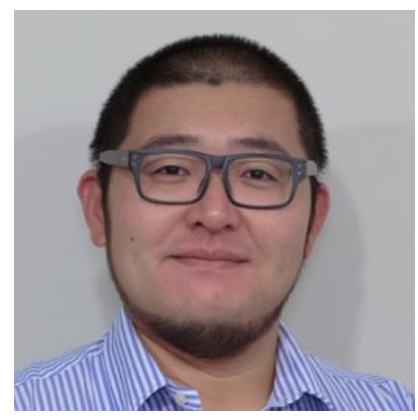

Expertise: Phase Change Materials

Biography - Xun Wang

Xun Wang is a Ph.D. candidate at University of North Texas, the United States. His research focuses on identifying thermal performance of phase change material composite involved in building applications. The identification may improve the thermal insulation of building and reduce the energy consumption. 
Proceedings of the 2020 Society of Wood Science and Technology International Convention

\section{Wanschuua, Regina}

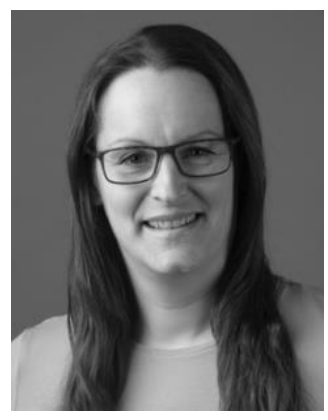

Expertise: Wood extractives

Biography - Regina Wanschura

Degree in Forest Science as Dipl-Ing. 2007

2007-2009 StoraEnso Wood-Supply in Munich (Unterschleißheim)

Since 2010 Co-worker at the TUM School of Life Sciences Weihenstephan, Chair of Wood Science, Munich, Germany 


\section{Willems, Wim}

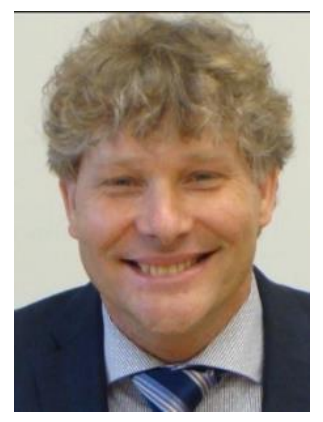

Expertise: Wood physics, wood modification

\section{Biography - Wim Willems}

Wim Willems (1964), obained a BSc degree in Process Control engineering in 1985 and his MSc degree in Applied Physics in 1990 at Eindhoven Technical University in the Netherlands. After 4 years of industrial research and development, he got involved in his family-owned company in the wood industry, gaining expertise in hardwood drying. In 2003, he invented a new type of thermal wood modification technology using pressurized unsaturated steam, which led to the foundation of a new company,

FirmoLin, in 2008, in which he is still working, responsible for the research and development activities. He earned his $\mathrm{PhD}$ degree summa cum laude on thermal wood modification in the Wood Biology and Wood Products group of Göttingen in Germany in 2015.

He currently shares time between his supporting activities in process equipment engineering and quality control of thermally modified timber for FirmoLin on the one hand and as an independent researcher on the other hand, working on the subject of wood modification, with emphasis on the aspects of woodmoisture interaction and wood durability. 
Proceedings of the $\mathbf{2 0 2 0}$ Society of Wood Science and Technology International Convention

\section{Winter, Armin}

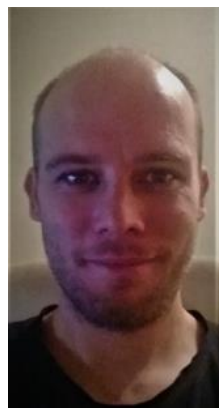

Expertise: Natural Materials Science, Cellulose Science

Biography - Armin Winter

na 


\section{Yang, Shumin}

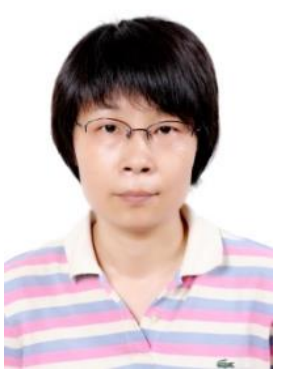

Expertise: Wood anatomy and characteristics, Non-destructive testing

Biography - shumin yang

Dr. Shumin YANG was graduated in 2003 with PhD majoring in wood science and technology at Tottori University, Japan. She has been working in International Center for Bamboo and Rattan (ICBR) as a research scientist since 2010 and was promoted to associate professor in 2012. Now, she mainly launches studies in the following areas: A. Anatomical characteristics of cell wall of plants, B. Non-destructive Technology for wood and bamboo based on X-ray imaging. She has chaired or participated in over 10 national and provincial level projects and has published two books (including co-authored works) and over 40 publications papers. Currently, she is a member of Bamboo and rattan resources and utilization Branch under Chinese Society of Forestry (CSF), also a member of biomass materials Branch under CSF. 
Proceedings of the 2020 Society of Wood Science and Technology International Convention

\section{Yeh, Chin-Hao}

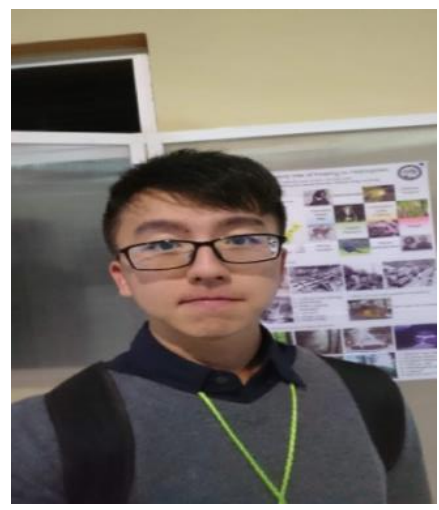

Expertise: Biomaterial Structural Design

\section{Biography - Chin-Hao Yeh}

I am Chin-Hao Yeh, and I come from Taiwan. I study at National Chung Hsing University, and my major is forestry, I am now in Biomaterial Structural Design Lab, and my thesis is about nature fiber composites. 
Proceedings of the 2020 Society of Wood Science and Technology International Convention

Yeo, Hwanmyeong

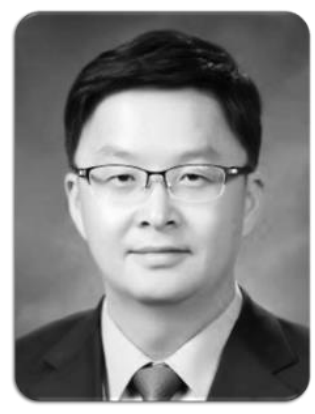

Expertise: Wood Physics, Wood Drying, Heat and Mass Transfer

Biography - Hwanmyeong YEO

Professor, Environmental Materials Science Major, Department of Forest Sciences, Seoul National University 


\section{Yildirim, Mert}

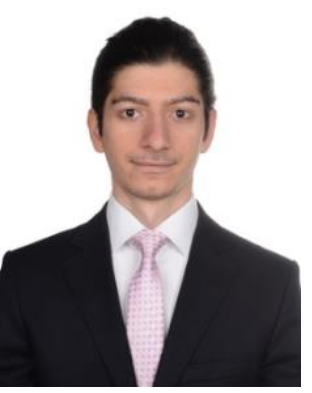

Expertise: Nanotechnology, composite materials and biomaterials

\section{Biography - Mert Yildirim}

Mert YILDIRIM is a Ph.D. student in the Department of Forest Industrial Engineering at Istanbul University-Cerrahpasa. He received his M.Sc. (2019) degree in Forest Industrial Engineering and MBA (2019) degree in Master of Business Administration at Istanbul University. During his graduate studies, he won various prizes in national competitions and worked on their TUBITAK projects. His research interests include nanotechnology, composites and biomaterials. 


\section{Zeng, Bin}

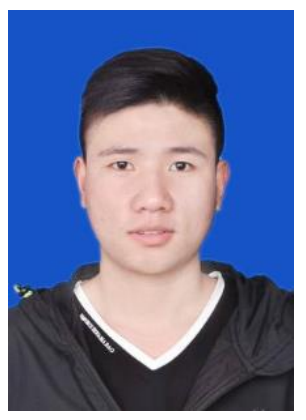

Expertise: Wood science and technology

\section{Biography - Bin Zeng}

My name is bin Zeng, 24 years old, I am studying for a master's degree at Northeast Forestry University. my research area focus on volatile organic compounds (VOCs) emission of wood-based panels and solid wood.

During the postgraduate period, I am actively involved in various scientific research projects, such as Participated in "The National Key Research and Development Program of China (2016YFD0600706-2)" 《Study on VOCs Release Law, Limitation and Odor Detection Technology of Decorated Wood-based Home Materials》---Responsible for experiment, data statistics and analysis; Participated in "Project of National Natural Science Foundation of China (grant no. 31971582)". 《Study on the Expression of Wood Odor Characteristic Map and the Formation Mechanism of Odor》---Mainly assisted in the improvement and debugging of domestic volatile organic compounds (VOC) sampling equipment, collected and analyzed VOC from different materials; Participated in "Independent Innovation Fund for Doctoral Students".

I study hard with excellent results and outstanding achievements in scientific research, Apply my professional knowledge to practice and publish 3 papers:

Analysis of odorants in wood of Cinnamomum burmanni (Nees et T.Nees) Blume with different moisture content. Scientia Silvae Sinicae. (First author / Chinese Core Journal) (In Chinese)

Effects of temperature on volatile organic compounds and odor emissions of PVC-overlaid MDF. Wood Research . (Third Author/SCI)

Study on VOCs and Odor Release of Painted Veneered Particleboard. Scientia Silvae Sinicae. (Third author / Chinese Core Journal) (In Chinese).

In order to study the research results of other scholars in related fields, understand the future research trends, and improve their research capabilities and insights, I hope to have the opportunity to participate in this major conference. 
Proceedings of the $\mathbf{2 0 2 0}$ Society of Wood Science and Technology International Convention

\section{Zhang, Xiubiao}

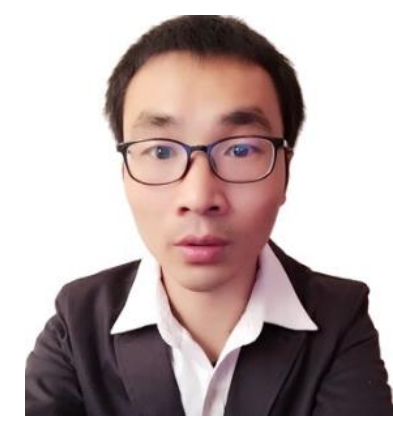

Expertise: Wood and bamboo science and technology

Biography - Xiubiao Zhang

Xiubiao Zhang, PhD., Assistant researcher of International Center for bamboo and rattan. Research fields: Bamboo-based / wood-based engineering composites, including the scientific designing, manufacturing and performance-evaluating. 


\section{Žigon, Jure}

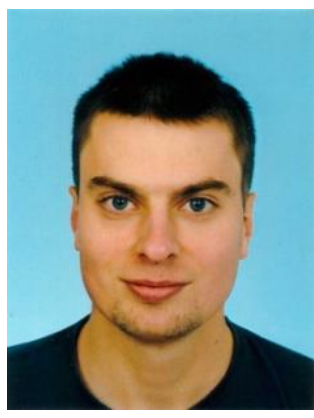

Expertise: Wood Science and Technology, focus on surface treatment technologies

Biography - Jure Žigon

ŽIGON, Jure, PETRIČ, Marko, DAHLE, Sebastian. Dielectric barrier discharge (DBD) plasma pretreatment of lignocellulosic materials in air at atmospheric pressure for their improved wettability : a literature review. Holzforschung : International Journal of the Biology, Chemistry, Physics and Technology of Wood, ISSN 0018-3830. 2018, vol. 72, iss. 11: 979-991

ŽIGON, Jure, PETRIČ, Marko, DAHLE, Sebastian. Wettability of wood surfaces with waterborne acrylic lacquer stains adjusted by DBD plasma in air at atmospheric pressure : predavanje na 11th International Symposium on Contact Angle, Wettability and Adhesion, 13 - 15 June 2018, New Jersey, USA.

ŽIGON, Jure, PETRIČ, Marko, DAHLE, Sebastian. Artificially aged spruce and beech wood surfaces reactivated using FE-DBD atmospheric plasma. Holzforschung : International Journal of the Biology, Chemistry, Physics and Technology of Wood, ISSN 0018-3830. Tiskana izdaja, 2019, vol. 73, iss. 12: 1069-1081. 


\section{Zlámal, Jan}

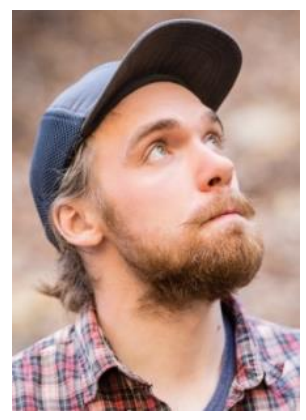

Expertise: Non-destructive testing of wood, wood science, non-destructive evaluation of wood in forest

Biography - Jan Zlámal

Jan Zlámal is Ph, D. student at the Department of wood science and Technogy of Mendel University in Brno. He joined the Mendel University in 2014 where Graduated from Wood Technology and Timber Management study program with master degree.

During his university studies, he focused on the topic of moon-wood and the influence of the logging period on the timber quality. Furthermore he worked on topic of prediction of spruce timber properties based on non-destructive in-situ testing. His Ph, D. studies began in 2019 and are primarily focused on the possibilities of estimating the properties of wood by non-destructive and semi-destructive testing methods. 
2020 Co-Organizer and Host of Online Convention InnoRenew COE and University of Primorska
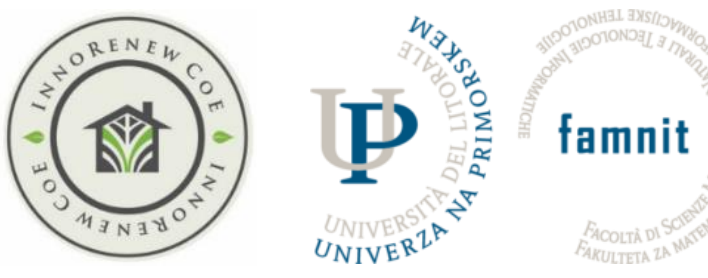

2020 List of Participating Sponsors

Silver Sponsor

W-WestVirginiaUniversity.

\section{Copper Sponsor}

NC STATE UNIVERSITY

Forest Biomaterials

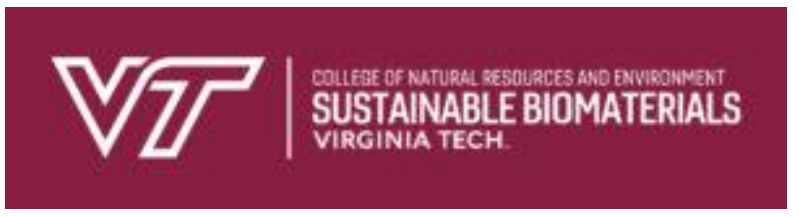




\section{WOOD SCIENGE AND TECHNOLOGY}

\section{Applying Science, Technology, and Engineering to U.S. Forest Products Industry}



Students in this program are prepared for the challenges of an ever-changing bioenergy, renewable materials and sustainable construction industry career.

A nationally recognized program and accredited by the Society of Wood Science and Technology, our curriculum will provide you with the key skill sets necessary to work in the U.S. forest products industry - including the lumber industry, engineered wood composites, biorefining, bioenergy, renewable materials and sustainable construction.

Tailor this major to your interests by focusing on one of these areas:

- Forest Utilization

- Sustainable Low-Rise Residential Construction

- Wood Processing

The major also requires a professional internship, which connects students with industry before they graduate.

\section{GET CONNECTED}

CONTACT US

davisinfo@mail.wvu.edu

SCHEDULE A VISIT

304-293-3489

tour.wvu.edu 


\section{OREGON STATE UNIVERSITY}

\section{WOOD \\ SCIENCE \\ GRADUATE DEGREE}

Earn your master's or Ph.D. degree in wood science from Oregon State University!

We offer a graduate education fully engaged in the dynamism and diversity of this rapidly evolving global field.

For additional information, please email our Graduate Program Coordinator at: WOODSCIENCE@OREGONSTATE.EDU

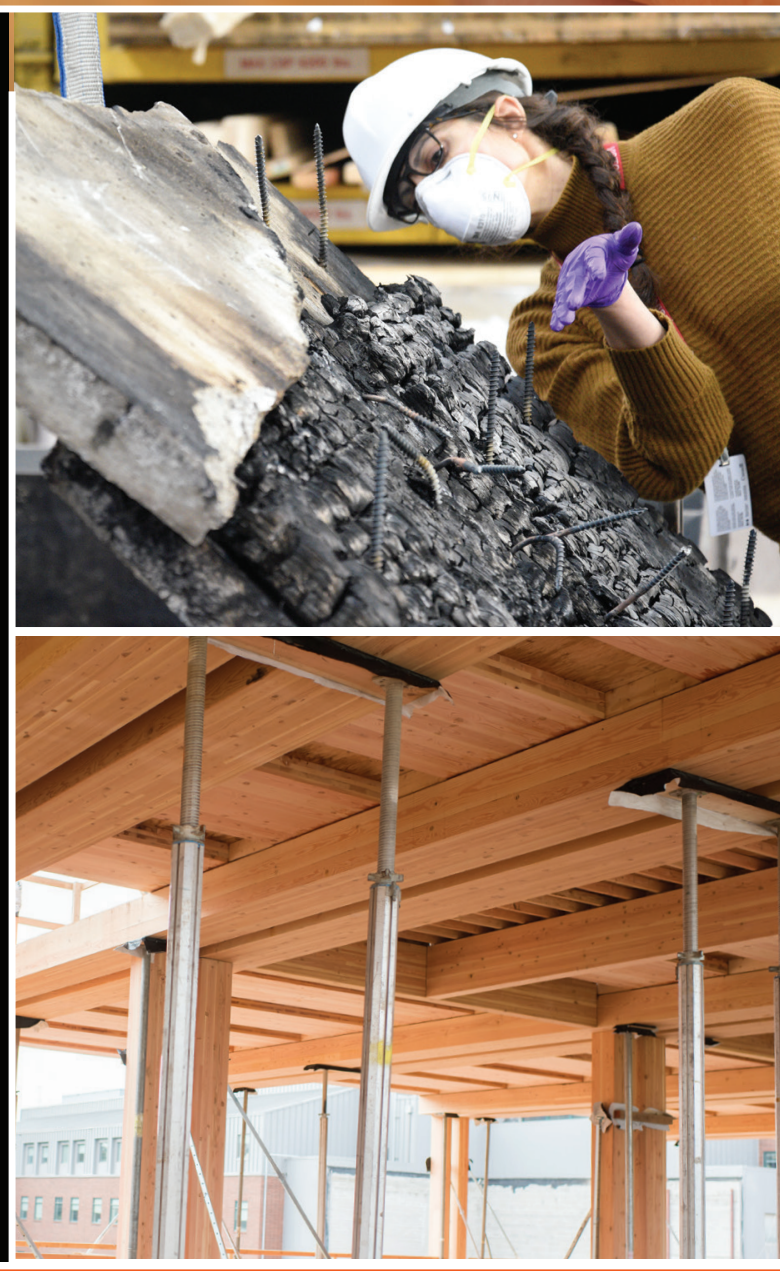




\section{Department of Sustainable Biomaterials}

Applying Science, Technology, Engineering, and Business to America's Sustainable Natural Resources
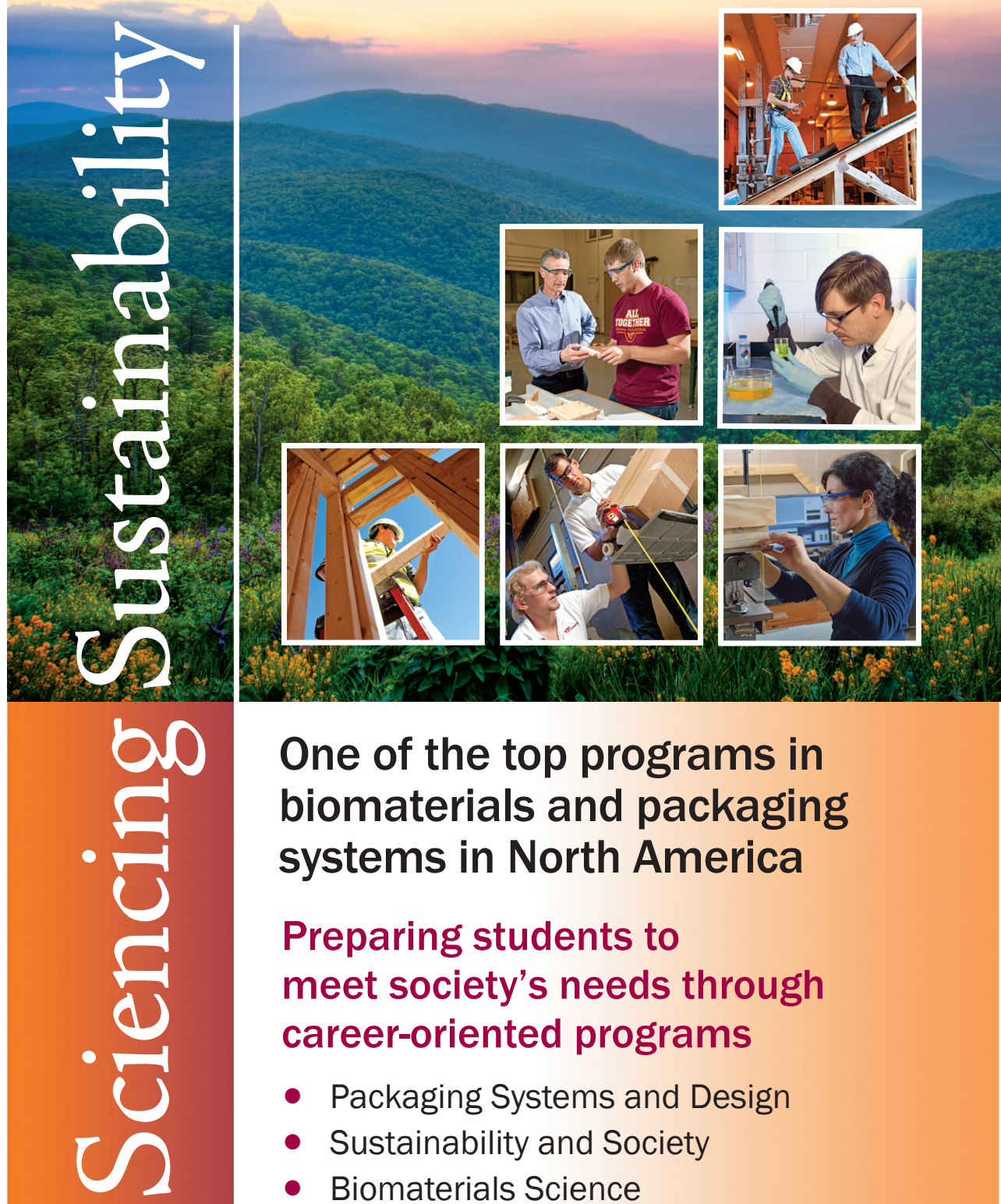

One of the top programs in biomaterials and packaging systems in North America

Preparing students to meet society's needs through career-oriented programs

- Packaging Systems and Design

- Sustainability and Society

- Biomaterials Science

- Forest Products Business

- Green Residential Construction

Learn more at sbio.vt edu or stop by Cheatham Hall Room 230. 


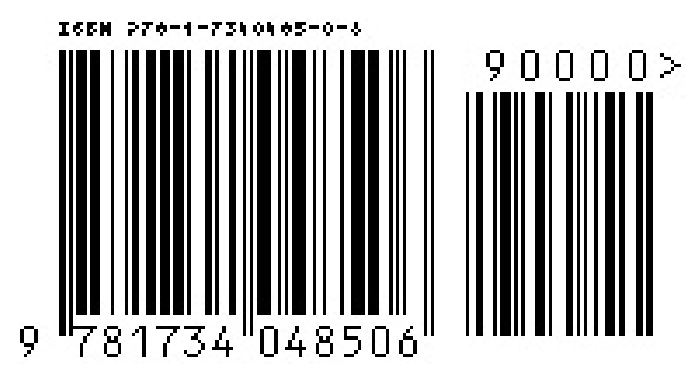

